\title{
Wind and Seismic Effects
}

Proceedings of the 23rd Joint Meeting

NIST SP 820

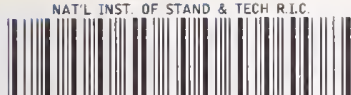

All103 7lO604
NIST

PUBLICATIONS
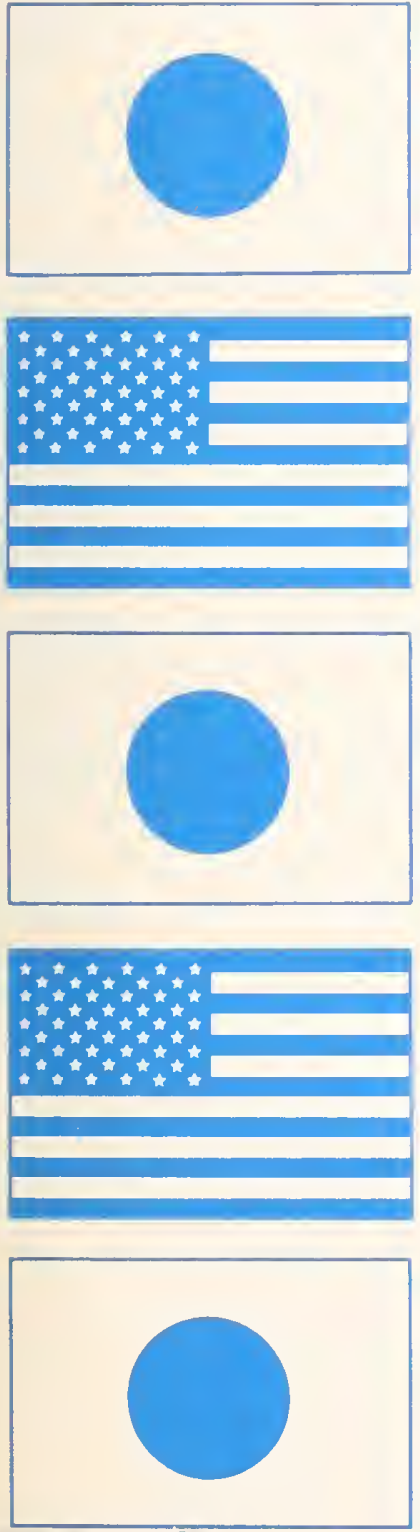

$-Q C$

100

.057

\#820

MENT OF COMMERCE

tte of Standards and Technology

1991

C. 2
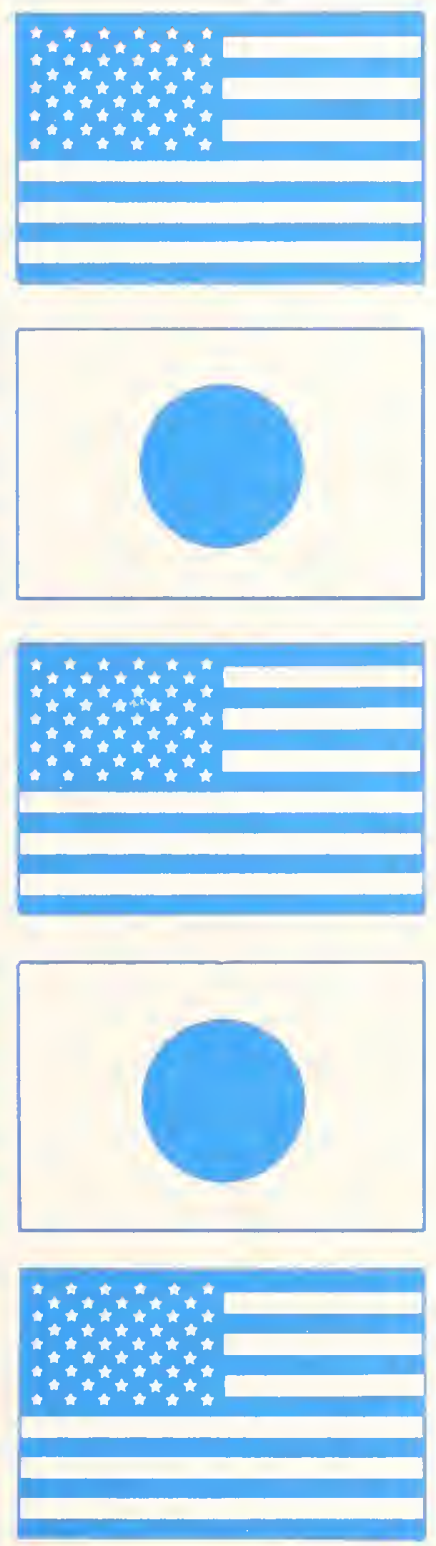
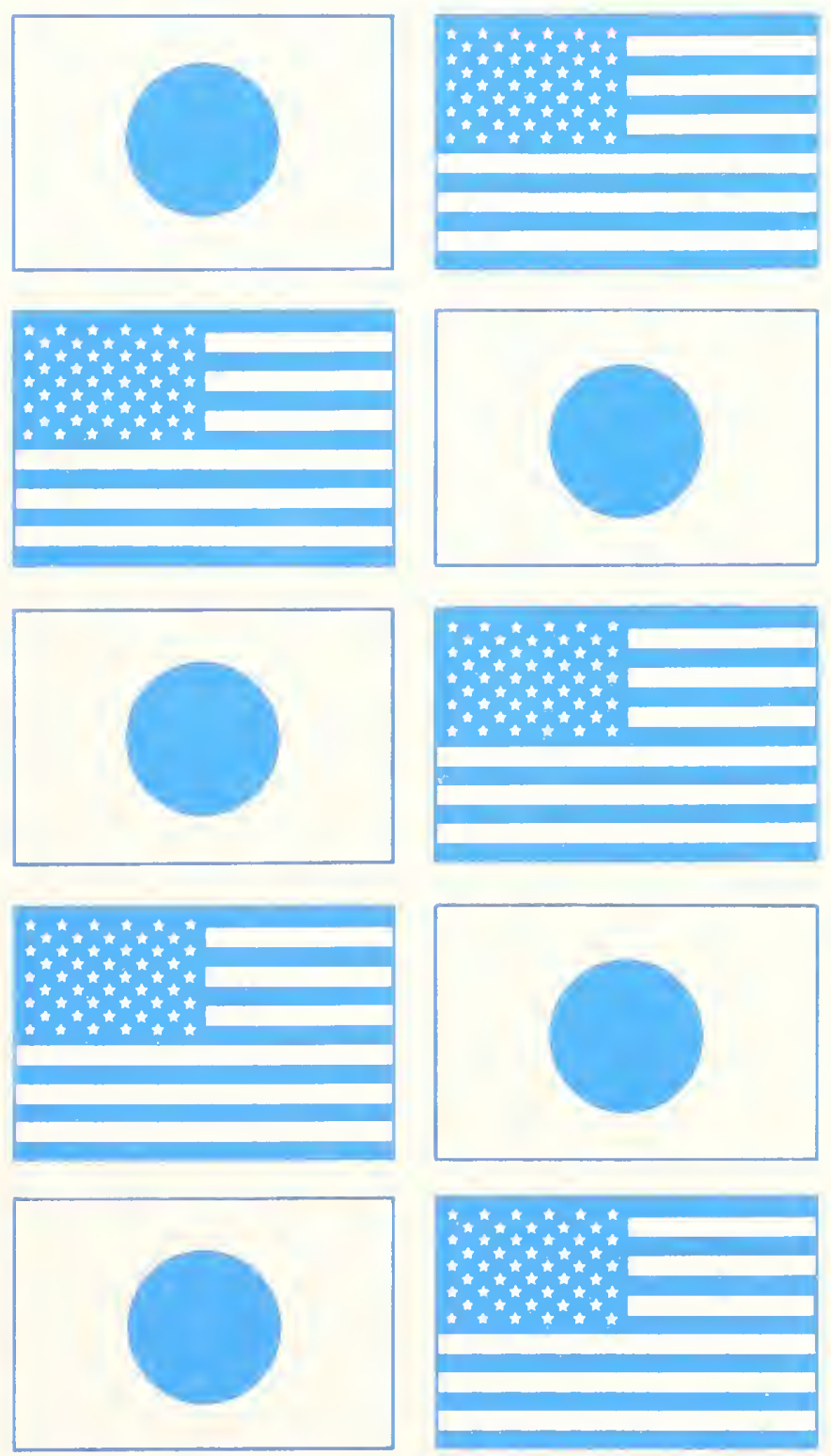


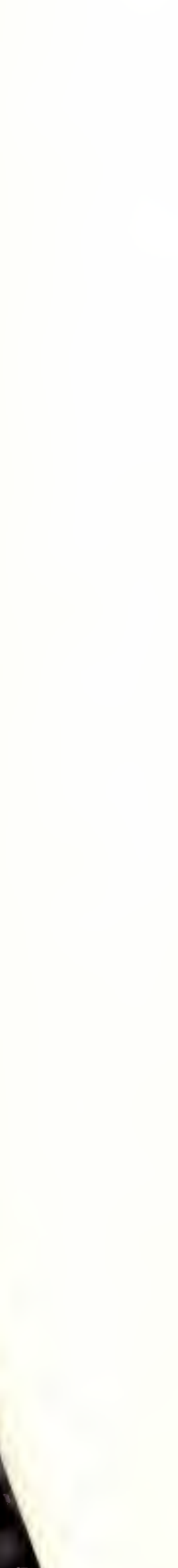




\section{Wind and Seismic Effects}

NIST SP 820

PROCEEDINGS OF

THE 23RD JOINT

MEETING OF

THE U.S.-JAPAN

COOPERATIVE PROGRAM

IN NATURAL RESOURCES

PANEL ON WIND AND

SEISMIC EFFECTS

Issued September 1991

Noel J. Raufaste, EDITOR

Building and Fire Research Laboratory National Institute of Standards and Technology

Gaithersburg, MD 20899

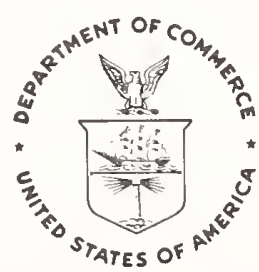

U.S. DEPARTMENT OF COMMERCE Robert A. Mosbacher, Secretary 
National Institute of Standards and Technology Special Publication 820 Natl. Inst. Stand. Technol. Spec. Publ. 820, 636 pages (Sept. 1991) CODEN: NSPUE2 WASHINGTON: 1991 


\section{PREFACE}

\section{BACKGROUND}

Responding to the need for improved engineering and scientific practices through exchange of technical data and information, research personnel, and research equipment, the United States and JAPAN in 1961 created the U.S.-JAPAN Cooperative Science Program. Three collateral programs comprise the Cooperative Science Program. The U.S.-JAPAN Cooperative Program in Natural Resources (UJNR), one of the three, was created in January 1964. The objective of UJNR is to exchange information on research results and exchange scientists and engineers in the area of natural resources for the benefit of both countries. UJNR is composed of 17 Panels each responsible for specific technical subjects.

The Panel on Wind and Seismic Effects was established in 1969. Seventeen U.S. and six Japanese agencies participate with representatives of private sector organizations, to develop and exchange technologies aimed at reducing damages from high winds, earthquakes, storm surge, and tsunamis. This work is produced through collaboration between U.S. and Japanese member researchers working in 11 task committees. Each committee focuses on specific technical issues, e.g., earthquake strong motion data. The Panel provides the vehicle to exchange technical data and information on design and construction of civil engineering lifelines, buildings, and water front structures, and to exchange high wind and seismic measurement records. Annual meetings alternate between JAPAN and the U.S. (odd numbered years in JAPAN; even numbered years in the U.S.). These one-week technical meetings provide the forum to discuss ongoing research and research results; one-week technical study tours follow the meetings.

The National Institute of Standards and Technology (NIST) provides the U.S.-side chairman and secretariat. The Public Works Research Institute (PWRI), JAPAN, provides the JAPAN Side chairman and secretariat.

Cooperative research is performed through formal Panel Programs. In 1981 cooperative research in Large-Scale Testing was started under the auspices of the Panel. Also in 1981, joint research on Reinforced Concrete Structures was initiated. Full-scale testing was performed at the Building Research Institute (BRI), one of the six Japanese member organizations, with supporting tests in JAPAN and in the U.S. Two years later a joint research program on Steel Structures was initiated. Full-scale testing again was led by BRI with supporting tests in the U.S. and JAPAN. The U.S.-JAPAN coordinated program for Masonry Building Research was started in 1985. A U.S.-JAPAN coordinated program on Precast Seismic Structural Systems was initiated in 1991.

Task Committee meetings, exchanges of data and information through technical presentations at annual Panel meetings, exchanges of guest researchers, visits to respective research laboratories and informal interactions between Panel meetings, joint workshops and seminars, and joint cooperative research programs all contribute to the development and effective delivery of knowledge that has influenced design and construction practices in both countries. 
Direct communication between counterpart country organizations is the cornerstone of the Panel. Effective information exchanges and exchanges of personnel and equipment have strengthened domestic programs of both countries. There are opportunities for experts in various technical fields to get to know their foreign counterparts, conduct informal exchanges, bring their respective views to the frontiers of knowledge, and advance knowledge of their specialties.

The Panel's results have supported improvements in practices in both countries. They have:

1. created and exchanged digitized earthquake records for use as the basis of research for Japanese and U.S. geotechnics and structures;

2. produced data that advanced U.S. design and construction of bridge columns;

3. produced large-scale testing data that advanced seismic design standards for buildings;

4. created a database comparing Japanese and U.S. standard penetration tests to improve seismic design criteria for soil liquefaction;

5. created databases on storm surge and shore line interaction and on tsunamis and tsunami warning systems for use by designers to verify mathematical models of tsunamis and storm surge.

\section{HIGHLIGHTS OF THE 23rd JOINT PANEL MEETING}

The 23rd annual U.S.-JAPAN Joint Panel meeting was held at the Public Works Research Institute, Tsukuba, JAPAN, during 14-17 May 1991. Eighteen U.S. members participated-13 from Federal agencies and 5 from universities. Forty-two papers were authored--22 by U.S. members and 17 by Japanese. Thirty-one papers were presented orally. The papers were organized into seven themes: Wind Engineering; Earthquake Engineering; Storm Surge and Tsunamis; Performance of Nonstructural Systems; U.S.-JAPAN Cooperative Research Program; International Decade for Natural Disaster Reduction; Summaries of the Task Committee Workshops conducted during the past year; and Reports (oral presentation only).

Some highlights of the meeting include:

- Vice Minister, Dr. MITANAI, Ministry of Construction (MOC) recognized the importance of the work of the Panel. The panel activities was reported at the 13th Plenary Meeting of the U.S.-JAPAN Cooperative Program in Natural Resources (UJNR) held on 10 May 1991, Tokyo, where progress of the Program's 17 Panels was discussed. 
- A Press Briefing was held during the Panel's Opening Session to celebrate NIST's gift to PWRI of a cutting from its Sir Isaac Newton Apple Tree. The ceremony was covered by the national and local press.

- Useful information was gained about JAPAN's public works projects and civil engineering research and their application of research into practice:

- discussion on new technologies to reduce building damages from earthquakes e.g., response control systems; PWRI is leading a 2 year base isolation program working with 30 private organizations and leading a 5 year effort in active control also working with 30 private organizations;

- $\quad$ better understanding of Japan's building structural code requirements and regulations;

- $\quad$ predicting liquefaction potential using geomorphological mapping;

- discussion on investigation of the 16 July 1990 Philippine Earthquake by the Japanese team;

- The Panel developed a catalogue, State-of-Art and Recent Trend on Engineering Technology for Reducing Wind and Earthquake Effects containing title, keywords, and author index of over 1200 Panel papers published during its 23 year life. Over 1000 copies will be distributed to developing countries in support of the International Decade for Natural Disaster Reduction (IDNDR).

- An 11-Panel Task Committee was established on Wind and Earthquake Engineering for Offshore and Coastal Facilities.

- Six of the Panel's 11 Task Committee workshops are scheduled to be held during the coming year.

- A Press Briefing concluded the technical sessions with national coverage of the Panel's activities.

\section{TECHNICAL SITE VISITS}

Following the Joint Technical Meeting, the Panel members participated in a conference on the International Decade for Natural Disaster Reduction (IDNDR) and visited construction projects, disaster areas, and laboratories. These visits occurred during 18-23 May. Highlights include:

IDNDR one-day symposium, "A Focus on Disaster Prevention 100 years After the Nobi Earthquake" was held in Gifu City north of Nagoya in recognition of their disastrous 
earthquake of November 1891. Six presentations were made: three from the U.S.-side Panel (Hurricane Hugo, Loma Prieta Earthquake, and U.S Federal Agency Programs in Disaster Countermeasures) and three from the JAPAN-side Panel (Nobi Earthquake, Effective Communication to Local Population During A Disaster, and Disaster Preparedness in Gifu). The Japanese organizers will publish a proceedings of the conference in Fall 1991. This event received extensive press coverage.

The Japanese Government Headquarters for IDNDR under the Prime Minister's Office took the lead in developing a basic policy for the promotion of IDNDR in JAPAN. The MOC is charged with carrying out the policy because its administration is involved in reducing the effects of natural disasters. The Panel on Wind and Seismic Effects, with MOC and other Japanese government agencies, supported the idea to hold the IDNDR symposium to enhance public interest and understanding in natural disaster prevention.

The Building Research Institute (BRI), MOC, described their research being conducted at its several laboratories. At the Building Element Laboratory, tests on the seismic resistance of beam-column connections of glued laminated timber construction were reviewed. A fullscale test of base isolation and other methods of improving seismic resistance were demonstrated at the Field Test Site. At the Large Structural Test Laboratory, tests on viscously damped shear walls were demonstrated in their four-story steel frame building, and earlier tests conducted in the laboratory as part of the U.S.-JAPAN Collaborative Program were discussed. The Structural Test Laboratory was visited where various tests on high strength concrete materials and members were being conducted.

The Kumagaigumi Company Institute of Construction Technology (KICT), described their Structural Dynamic Testing Laboratory, the Ocean Hydraulic Laboratory, and the Environmental Testing Laboratory. For the first, tests on a visco-elastic damped shear wall were demonstrated and a videotape described the development of seismic response control systems and other research involving earthquake resistance of tall buildings. In the second laboratory two open channels and a test basin were observed. Their $40 \mathrm{~m} \times 20 \mathrm{~m} \times 1.5 \mathrm{~m}$ (131 x $66 \times 5 \mathrm{ft}$ ) deep basin is nearing completion and will be able to individually control wave generation in each of its two open channel $0.5 \mathrm{~m}(1.6 \mathrm{ft})$ wide basins and to model tidal conditions and coastal currents. In the Environmental Laboratory's super-clean room, protocol measurement methods are developed for electronic components.

The Public Works Research Institute (PWRI), MOC, described its Structural Engineering Laboratory's $26.4 \mathrm{MN}$ (6 million lb) universal testing machine and specimens of deep steel beams and columns that had been tested. At the Vibration Laboratory the problem of liquefaction was discussed with a vivid model demonstration. At the Earthquake Engineering Laboratory base isolation of bridges was the prime subject. Various types of bridge bearings were shown and a videotape described their use. PWRI's Boundary Layer Wind Tunnel is the largest in the world. Its test section is $41 \mathrm{~m} \mathrm{x} 4 \mathrm{~m} \mathrm{x} 30 \mathrm{~m}(135 \times 13 \times 98 \mathrm{ft})$. The laboratory was built to test a 1:100 scale model of the $4 \mathrm{~km}$ Akashi-Kaikyo suspension bridge. The Honsho-Shikoku Bridge Authority paid for the construction of this facility. A variety of models of other major bridges will be tested in this facility during the coming 10 years. 
Tokyo Metropolitan Disaster Prevention Center (MDPC), is located in the new Tokyo Metropolitan Government City Hall, Shinjuku-ku, Tokyo. The 55-story building is $243 \mathrm{~m}$ (797 ft) high and $44 \mathrm{~m}(144 \mathrm{ft})$ wide. MDPC has centralized its command and control for disaster response and relief operations. MDPC occupies three floors. Its mainframe computer is isolated from the building by base isolators. MDPC provides the command and control for the Tokyo metropolitan area. Disaster information is analyzed for damage assessment and prediction of severity. Their map information system provides for two-way communication to analyze the severity of the event and to communicate to the 64 disaster relief centers within Tokyo. Construction of the City Hall was completed in April 1991 costing 180 billion yen ( $\$ 1.3$ billion). The MDPC facility cost 18 billion yen ( $\$ 130$ million).

Chubu High Speed Surface Transportation (CHSST) Corporation, Nagoya, manages this experimental magnetic levitation, two-passenger car train -- a candidate mass transportation system. CHSST's objectives are to produce a low-noise and vibration and hydrocarbon free propulsion system. The passenger car testing on their $1.5 \mathrm{~km}$ test track commenced in May 1991 and will continue through May 1993. CHSST estimates the cost per km for the twin rail system will be $\$ 7.4$ million.

Toyota Motor Corporation and Toyota Home, Toyota, is located near Nagoya. Included in this visit was a review of some advanced automotive systems development, a tour of one automotive production plant, and discussion about Toyota's residential home subsidiary -Toyota Home. Toyota claims $5 \%$ of its automotive sales are returned to perform R\&D. A greater amount of research soon will be performed in their Belgium and U.S. laboratories. Toyota's prefabricated home business is based on its automotive technology. About $85 \%$ of the home is fabricated at Toyota's plant; 3-8 weeks are required to construct the home onsite (subject of weather conditions).

Second Nunobiki Road Tunnel, Kobe, is a $3 \mathrm{~km}$ 90-degree curved tunnel under construction to reduce traffic congestion which has increased since the completion of the first tunnel in 1969. Construction started in 1989 with expected completion in March 1993. The tunnel is cut from rock having compressive strength of $1000-2000 \mathrm{~kg} / \mathrm{cm}^{2}$. The slot drilling method is used for a $300 \mathrm{~m}$ (984 ft) section adjacent to the bullet train and the existing

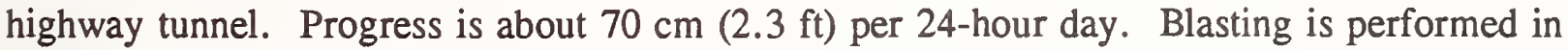
the remaining $2.7 \mathrm{~km}(1.7 \mathrm{mi})$ tunnel. The cost of the tunnel is projected at $\$ 32$ million. The tunnel is being constructed by the Kobe City Public Corporation.

Akashi-Kaikyo Bridge, Kobe, is a $4 \mathrm{~km}$ (2.5 mi), 3-span, 2-hinged truss suspension bridge with center span of $1,990 \mathrm{~m}(6,529 \mathrm{ft})$; each end span is $960 \mathrm{~m}(3,150 \mathrm{ft})$. It will be the world's longest bridge when completed in 1998. The bridge under construction by the Honshu-Shikoku Bridge Authority will connect Awaji Island to Honshu Island crossing the 4 $\mathrm{km}(2.5 \mathrm{mi})$ Akashi Straits. This bridge is part of the overall major Honshu-Shikoku highway project to connect Honshu Island and Shioku Island by automobiles and trains. There are three major bridge crossings; this one is the eastern-most crossing. The central crossing was the first completed link, occurring two years ago. 
About 200,000 tons of steel will be used in the superstructure and about 1.42 million $\mathrm{m}^{3}$ of concrete will be used for the cable anchorage substructure. The anchorage superstructure on the Honshu side was excavated using construction equipment to control tolerances within about $15 \mathrm{~cm}$ (6 in). The two tower caissons are $85 \mathrm{~m}$ (279 ft) in diameter and $64 \mathrm{~m} \mathrm{(210} \mathrm{ft)}$ deep. They were towed to the site and sunk by filling its outer lining with water and then the center with $525,000 \mathrm{~m}^{3}$ of concrete.

The bridge is designed to survive an earthquake of $8.5 \mathrm{M}$ and 10 minute average wind velocity of $46 \mathrm{~m} / \mathrm{s}$. The main towers will rise $300 \mathrm{~m}(985 \mathrm{ft})$ above sea level. The bridge cables are about $1.1 \mathrm{~m}(3.6 \mathrm{ft})$ in diameter, consisting of 37,000 steel wires $5 \mathrm{~mm}$ in diameter.

The cost of the bridge is $\$ 3$ billion. Nineteen corporations are working on the superstructure; five corporations are working on the towers.

Higashi-Kobe Bridge, Kobe, is a 3-span continuous cable-stayed bridge under construction by the Hashin Expressway Public Corporation (HERP). The bridge is part of the Bayside Route that connects Osaka and Kobe. Its center span is $485 \mathrm{~m}(1,591 \mathrm{ft})$ and end spans of $200 \mathrm{~m}(656 \mathrm{ft})$ each. Based on center span length, this $885 \mathrm{~m}(2,904 \mathrm{ft})$ bridge is the world's longest cable-stayed bridge.

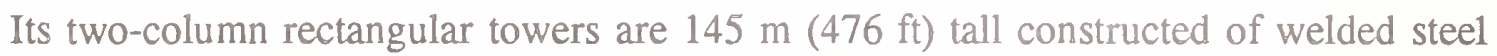
sections. A square notch cutout was made at each tower corner to reduce wind-induced vibration from vortex shedding which can damage the structure as demonstrated by wind tunnel model testing. Wind tunnel model tests indicated a need to dampen the tower from wind-induced vibration during construction. Mass-tuned oil dampers were installed at computed heights of the tower during construction and moved upward during its erection. Twelve cable stays are attached to each tower in a harp pattern. The harp pattern cable configuration was selected because it reduces the compressive vertical forces and bending moments (about a horizontal axis perpendicular to the longitudinal axis of the bridge) on each bridge tower column as compared to the fan pattern commonly used. The approximately 125 $\mathrm{mm}(5 \mathrm{in})$ diameter cables are covered with a $20 \mathrm{~mm}(0.8 \mathrm{in})$ thick polyethylene tube for corrosion protection. These covers are designed with ribs parallel to the cable axis to reduce the probability of wind and rain induced vibrations. Each of the 96 cables consists of 241 to $3017 \mathrm{~mm}$ diameter wires. The towers are fabricated on a $35 \mathrm{~m} \times 32 \mathrm{~m} \mathrm{x} 26.5 \mathrm{~m}(115 \mathrm{x}$ 105 x $87 \mathrm{ft}$ ) deep pneumatic concrete caisson.

The bridge has two decks each for three lanes of traffic. The lower bridge deck is $36.5 \mathrm{~m}$

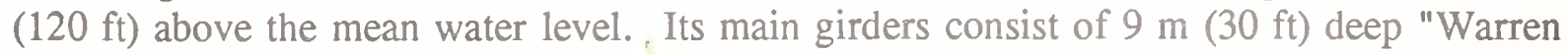
Trusses." The corresponding dimensions of the boxed section diagonals are $1.0 \times 0.7 \mathrm{~m}(3.3$ $x 2.3 \mathrm{ft}$ ). The vertical downward force component at the intersection of the truss diagonals on the top deck at the bridge is balanced by the tensile force from the cable connecting the top deck of the bridge and the tower. The main girders and their tower supports at the tops of the caisson are pin-supported in the longitudinal direction to lengthen the fundamental period of the bridge to $4.4 \mathrm{sec}$. Mass tuned oil-dampers are installed at each end of the bridge to reduce longitudinal displacements from earthquake ground motions. 
Construction started in 1989 with completion scheduled for 1993. Total cost for the project is projected at 34 billion yen ( $\$ 250$ million).

Port Island, is a man-made island in Kobe Harbor constructed from fill material excavated from mountains $25 \mathrm{~km}$ north of Kobe and transported to the harbor by conveyors passing through a tunnel cut in the mountain. The 436 ha (1077 acres) island was constructed during 1966 through 1981. Various social and cultural facilities are being constructed on the center of the island. The residential buildings on the island have a planned population of 16,000. There are five container cargo berths on each side of the island. The island is currently being extended to double its size. Also, an airport for Kobe is planned as a separate island further into the bay as a new Port Island extension. The construction cost of Port Island is 558 billion yen ( $\$ 4.1$ billion). Kobe City and the Ministry of Transport have construction responsibilities for the island.

Rokko Island, is adjacent to Port Island. It too, is man-made constructed from rocks excavated from the nearby Rokko Mountains. The island has an area of 580 ha (1432 acres) and container and liner cargo berths surround its perimeter with a residential area in the center of the island. It has a planned population of about 30,000. Its construction began in 1972 and is expected to be completed in 1993. Kobe City and the Ministry of Transport are responsible for its construction. The estimated construction cost is 1,240 billion yen $\mathbf{( \$ 9 . 1}$ billion).

Kansai International Airport, a man-made island located in the southeast part of Osaka Bay about $4 \mathrm{~km}(2.5 \mathrm{mi})$ off the coast of Osaka, has been under construction since 1987. Completion is expected in the summer of 1994. This site was selected to minimize noise pollution from large numbers of aircraft required to serve this region. The existing Osaka International Airport is seriously restricted in operation because of noise. It will be the first fully developed off-shore airport and the first around-the-clock airport ever constructed in Japan.

The airport is a rectangular island $4.4 \mathrm{~km} \mathrm{x} 1.25 \mathrm{~km}(2.7 \times 0.8 \mathrm{mi})$ covering an area of 511 ha (1262 acres). Fill materials, imported by ship from mountains on the nearby mainland and from island sites is crushed near the source, delivered to push barges on the sea coast by belt conveyors and barged to the reclamation site. Poor strata under the island requires

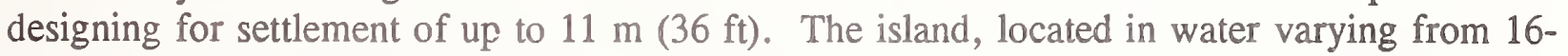
$19 \mathrm{~m}(52$ to $62 \mathrm{ft})$ in depth, requires over 180 million $\mathrm{m}^{3}$ ( 235 million $\left.\mathrm{yd}^{3}\right)$ of fill material. To design against liquefaction from potential seismic events and to control future settlement, sand drain piles each $40 \mathrm{~cm}(1.3 \mathrm{ft})$ in diameter spaced $2.5 \mathrm{~m}(8.2 \mathrm{ft})$ apart are driven into the alluvial clay layer. Over $11 \mathrm{~km}(6.8 \mathrm{mi})$ of sea walls form the periphery of the island.

The access bridge connecting the island to the mainland is a single truss construction except near the ends where spans are steel-box girders. Spans vary in length up to $150 \mathrm{~m} \mathrm{(492 \textrm {ft } )}$ at the navigation lanes. The bridge has six lanes for autos and a two-rail system designed for $120 \mathrm{~km} / \mathrm{hr}(75 \mathrm{mph})$ trains 


\begin{abstract}
This publication is the proceedings of the 23rd Joint Meeting of the U.S.-Japan Panel on Wind and Seismic Effects. The meeting was held at the Public Works Research Institute, Tsukuba, Japan, during May 14-17, 1991. The proceedings include the program, list of members, panel resolutions, task committee reports, and 42 technical papers.

The papers were presented under seven themes: (I) - Wind Engineering, (II) - Earthquake Engineering, (III) - Storm Surge and Tsunamis, (IV) - Joint Cooperative Research Program, (V) - Performance of Nonstructural Systems, (VI) - International Decade for Natural Disaster Reduction, and (VII) - Summaries of Task Committee Workshop Reports (oral presentations only).
\end{abstract}

KEYWORDS: accelerograph; bridges; buildings; concrete; design criteria; disasters; disaster reduction; earthquakes; geotechnical engineering; ground failures; lifelines; liquefaction; masonry; repair and retrofit; risk assessment; seismic; soils; standards; storm surge; structural engineering; tsunamis; and wind loads. 


\section{CONTENTS}

PAGE

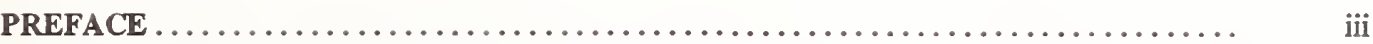

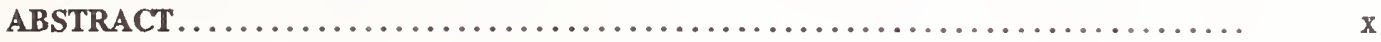

AGENDA FOR 23nd JOINT UJNR MEETING ......................... xvii

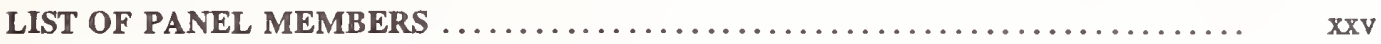

LIST OF TASK COMMITTEE MEMBERS ........................... xLi

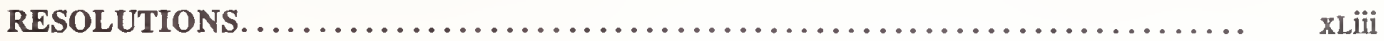

THEME I: Wind Engineering

Probabilistic Performance Goals for Wind and Tornado Design ................ 3 James R. Hill, James R. McDonald, and Robert C. Murray

Analysis of Tornado in Mobara City on December 11, 1990 ................. 15

H. Niino, T. Fujitani, T. Murota, N. Yamaguchi, and H. Okada

Hurricane Hugo in Perspective .................................. 29 Peter R. Sparks

THEME II: Earthquake Engineering

The Worldwide Earthquake Risk Management (WWERM) Program............. S. T. Algermissen, Paul. R. Krumpe, and Walter W. Hays

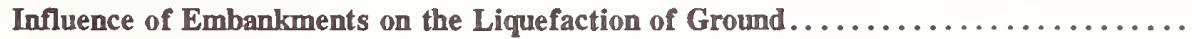
Yasuyuki Koga, Jun-ichi Koseki, Takao Shimazu, and Osamu Matsuo

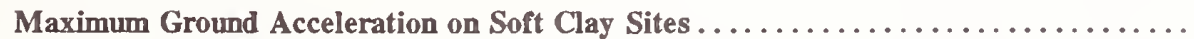
Tingley $\mathbf{K}$. Lew

Broadband Strong-Motion Seismic Observation Network

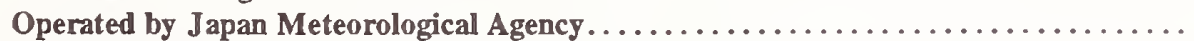
Masahiro Yamamoto, Iwao Sasakawa, Akira Nagai, Takeshi Kakishita, Akihiko Wakayama, Koichi Uhira, and Masaaki Seino

Seafloor Seismic Network Offshore Southern California................... Charles E. Smith 


\section{CONTENTS}

PAGE

Distribution of Liquefaction in the Saitama Plain

by the 1923 Kanto Earthquake and Geomorphological Maps

Tadao Dohi and Takekazu Akagiri

Damage to Civil Engineering Facilities From the

July 1990 Philippine Earthquake . . . . . . . . . . . . . . . . . . . . . . . .

Yasushi Sasaki and Michio Okahara

Recorded Structural Response During the M7.1

Loma Prieta Earthquake,

A. Gerald Brady

Monotonic and Cyclic Loading Tests of Rockfill Materials...................

Norihisa Matsumoto, Nario Yasuda, Masahiko Ohkubo, and Ryo-ichi Yoshioka

Full-Scale Structural Applications of Active Control Systems

T. T. Soong, A. M. Reinhorn, and M. Shinozuka

Base-Isolated Buildings and Seismic Safety Evaluation

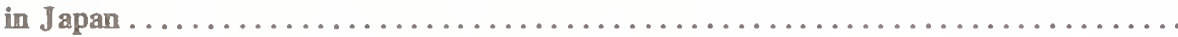

Yoshikazu Kitagawa and Mitsumasa Midorikawa

Dynamic Modeling of Soil-Structure Systems for Control

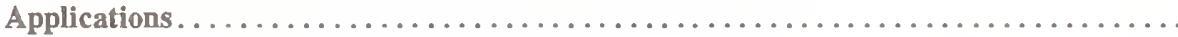

H. A. Smith and R. I. Borja

Current Research Efforts in Japan for Passive and Active

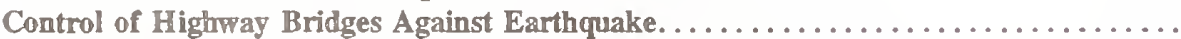

Kazuhiko Kawashima, Kinji Hasegawa, Shigeki Unjoh,

Hiroyuki Nagashima, and Hideyuki Shimizu

Status of U.S. Research on Structural Control Systems

S. C. Liu, H. J. Lagorio, and K. P. Chong

Vibration of Large-Scale Shaking Table Foundation ......................

Chikahiro Minowa, Nobuyuki Ogawa, Tadashi Mikoshiba,

Keiichi Ohtani, and Norio Oyagi

Safety and Economic Benefits Realized From Upgrading

the Lawrence Berkeley Laboratory . . . . . . . . . . . . . . . . . . . . . . . . .

Donald G. Eagling and James R. Hill

Structural Regulations of Buildings and Development of

Technology in Japan.

Yuji Ohashi and Hiroyuki Yamanouchi 


\section{CONTENTS}

PAGE

Seismic Hazard Assessment of Liquefaction Potential

at Mormon Island Auxiliary Dam, California, USA . .

David W. Sykora, Joseph P. Koester, and Mary E. Hynes

System Identification of Spirally Reinforced Circular Bridge

Columns Subjected to Cyclic Lateral Loading ...

William C. Stone and Andrew W. Taylor

Simplified Procedure for Inspecting Earthquake Resistant

Potential of Highway Bridges Against Soil Liquefaction ....................

Ken-ichi Tokida, Jiro Fukui, and Hideo Matsumoto

Evaluation and Repair of Major Water Resources Structures

for Improved Safety and Seismic Stability William Roper

Shaking Table Tests for Hydrodynamic Pressure Acting on Double Cylindrical Caisson Type Breakwater in

the Deep Sea

Tatsuo Uwabe, Makoto Osada, and Setsuo Noda

THEME III: Storm Surge and Tsunamis

Subaerial and Submarine Landslide Generated Tsunamis .

James F. Lander, Patricia A. Lockridge, and Herbert Meyers

A Study on the Effect of Tsunami Breakwater

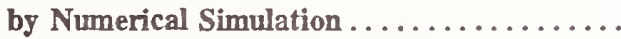

Chiaki Goto and Katsutoshi Tanimoto

THEME IV: Joint Cooperative Research Program

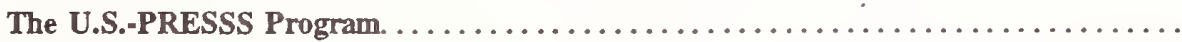
M. J. Nigel Priestley

U.S.J Japan Cooperative Research Program

Precast Seismic Structural System......

Shin Okamoto, Shinsuke Nakata, Takashi Kaminosono,

Hitoshi Shiohara, and Mizuo Inukai 


\section{CONTENTS}

PAGE

THEME V: Performance of Nonstructural Systems

Current Efforts to Improve the Performance of Nonstructural

Systems Based on Experience From the Loma Prieta Earthquake..............

Robert Reitherman

Stateof-the-Art Report on Seismic Design of Building Equipment

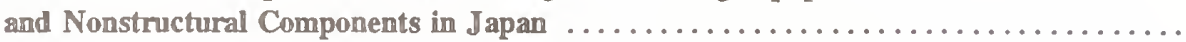

Masaya Hirosawa, Hatsukazu Mizuno, and Mitsumasa Midorikawa

THEME VI: International Decade for Natural Disaster Reduction

Damages and Lessons From the Loma Prieta Earthquake* Stephen A. Mahin

Damages and Lessons Learned From Hurricane Hugo* Peter R. Sparks

United States Federal Agency Programs in Disaster

Countermeasures* Paul F. Krumpe and Kenneth F. Sullivan

Manuscripts Authored for Panel Meeting but Not Presented Orally

Boundary Layer Wind Tunnel Study on Full

Aeroelastic Long Span Bridge Model...........................

Koichi Yokoyama, Tomoki Kanazaki, and Masahiko Yasuda

Comparison of Responses of a Select Number of Buildings to the 10/17/1989 Loma Prieta (Califomia) Earthquake

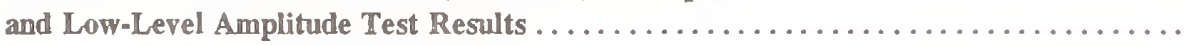
M. Celebi, L. T. Phan, and R. D. Marshall

Evaluation of Penetration Resistance for Liquifaction

Assessment at Jackson Lake Dam ..

Jeffrey A. Farrar and Nario Yasuda

Torsional Resistance of Multi-Column Foundation

Yukitake Shioi, Michio Okahara, Jiro Fukui, and Syoji Takagi

*U.S. papers presented at the IDNDR Seminar in Gifu City, Japan on May 20, 1991. 


\section{CONTENTS}

PAGE

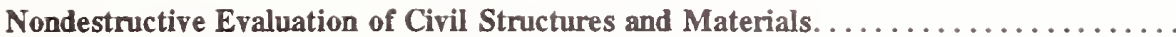

Ken P. Chong and John B. Scalzi

NSF Supported Research in Concrete Structures

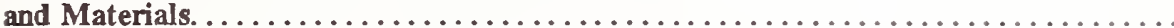

Ken P. Chong, Shih-Chi Liu, and Henry J. Lagorio

Development of Water Level and Wave Height

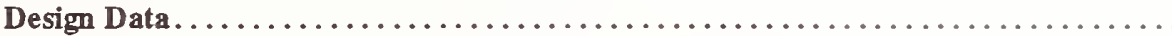
Martin C. Miller, William E. Roper, Leon E. Borgman, and Joannes J. Westerink

U.S. Coordinated Program for Masonry Building

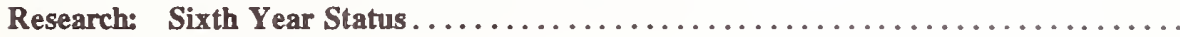
James L. Noland

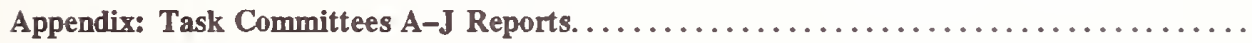


Tuesday, May 14, 1991 - 10:30-12:00

Conference Hall (8th Floor), Public Works Research Institute

Call to order by Dr. Takashi Iijima, Secretary-General, Japan Panel, Director of Planning and Research Administration Department, Public Works Research Institute

Remarks by Dr. Hiroshi Mitani, Vice-Minister of Construction for Engineering-Affairs, Ministry of Construction

Remarks by Dr. Edward M. Malloy, Counsellor for scientific and Technological Affairs, Embassy of the United states of America

Remarks by Dr. Tetsuhisa Shirakawa, Director, International Affairs Division, Science and Technology Promotion Bureau, Science and Technology Agency

Remarks by Dr. Toshio Iwasaki, Chairman, Japan Panel, DirectorGeneral, Public Works Research Institute, Ministry of Construction

Remarks by Dr. H.S. Lew, Chairman (Acting Chairman), U.S. Panel, Chief Structures Division, Building and Fire Research Laboratory, National Institute of Standards and Technology, Department of commerce

Introduction of Japan Members by Japan Panel Chairman and U.S. Members by U.S. Panel Chairman

Election of Joint Meeting Chairman

Adoption of Agenda

Closure by Dr. Takashi Iijima

Adjourn

Commemorative Planting

Group Photograph

Lunch - 12:00-13:00 (Hosted by the Geographical Survey Institute)

Technical session - 13:00-14:20 (International Conference Room 8F) * speaker

Session 1 - Theme I - WIND ENGINEERING

Chairman: T. Iwasaki 
13:00-13:20 Probabilistic Performance Goals for Wind and Tornado Design

13:20-13:40 Analysis of Tornado in Mobara City on December 11, 1990

H. Niino*, T. Fujitani, T. Murota, N. Yamaguchi, H. Okada

13:40-14:00 Hurricane Hugo in Perspective

Peter R. Sparks*

14:00-14:20 Discussion

$14: 20-14: 30 \quad$ Break

Task Committee Meetings - 14:30-17:00

C--Repair and Retrofit of Existing Structures (Meeting Room 531)

D--Evaluation of Performance of Structures (Meeting Room 531)

E--Ground Motion and Seismic Design Forces (Meeting Room 532)

H--Soil Behavior and Stability During Earthquakes (Meeting Room 627)

J--Wind and Earthquake Engineering for Transportation systems (Meeting Room 628)

Preliminary Meeting

K--Wind and Earthquake Engineering for offshore and Coastal Structures (Meeting Room 629)

Adjourn

Reception (Hosted by Vice-Minister for Engineering-Affairs of the Ministry of Construction)

Wednesday, May 15

Technical session - 9:00-12:00

Session 2 - Theme II - EARTHQUARE ENGINEERING

Chairman: H.S. Lew

$$
\begin{aligned}
\text { 9:00- 9:20 } & \text { The Worldwide Earthquake Risk Management (WWERM) } \\
& \text { Program } \\
& \text { S.T. Algermissen*, Paul R. Krumpe, Walter W. Hays } \\
\text { 9:20- 9:40 } & \text { Influence of Embankments on the Liquefaction of } \\
& \text { Ground } \\
& \text { Y. Koga*, J. Koseki, T. Shimazu, O. Matsuo } \\
\text { Maximum Ground Acceleration on Soft Clay Sites } & \text { Tingley K. Lew* }
\end{aligned}
$$


$10: 00-10: 20 \quad$ Discussion

$10: 20-10: 40 \quad$ Break

Session 3 - Theme II - EARTHQUARE ENGINEERING

Chairman: H.S. Lew

10:40-11:00 Broadband Strong-Motion Seismic Observation Network operated by Japan Meteorological Agency

M. Yamamoto*, I. Sasakawa, A. Nagai, T. Kakishita, A. Wakayama, K. Uhira, M. Seino

11:00-11:20 Seafloor Seismic Network offshore Southern California

Charles E. Smith*

11:20-11:40 Distribution of Liquefaction in the saitama Plain by the 1923 Kanto Earthquake and Geomorphological Maps

T. Dohi, T. Akagiri

$11: 40-12: 00 \quad$ Discussion

Lunch - 12:00-13:00 (Hosted by the Port and Harbour Research Institute and the Meteorological Research Institute)

Technical session - 13:00-15:20

Session 4 - Theme II - EARTHOUARE ENGINEERING

Chairman: T. Iwasaki

13:00-13:20 Damage to Civil Engineering Facilities from the July 1990 Philippine Earthquake

Y. Sasaki*, M. Okahara

13:20-13:40 Recorded Structural Response During the M7.1 Loma Prieta Earthquake Comments

A. Gerald Brady*

13:40-14:00 Monotonic and Cyclic Loading Tests of Rockfill Materials
N. Matsumoto, N. Yasuda*, M. Ohkubo, R. Yoshioka

$14: 00-14: 20 \quad$ Discussion

Session 5 - Reports of Workshops

Chairman: T. Iwasaki

14:20-14:30 $\quad$ (H) Workshop on Remedial Treatment of Potentially Liquefiable soils K. Tokida*

$14: 30-14: 40$

(I) 2nd Tsunami Workshop $\mathrm{J}$. Lander*

$14: 40-14: 50$

(J) lst Workshop on Seismic Retrofit of Bridges K. Kawashima* 
$14: 50-15: 00$

(J) 7 th Bridge workshop

M. Fujiwara*

$15: 00-15: 20 \quad$ Discussion

$15: 20-15: 30 \quad$ Break

Task Committee Meetings - 15:30-17:00

A--Strong-Motion Instrumentation Arrays and Data (Meeting Room 531)

B--Large-Scale Testing Program (Meeting Room 532)

G--Passive, Active, and Hybrid Control systems (Meeting Room 627)

F--Disaster Prevention Methods for Lifeline systems (Meeting Room 628)

I--Storm Surge and Tsunamis (Meeting Room 629)

Adjourn

Thursday, May 16

Technical session - 9:00-12:00

Session 6 - Theme II - EARTHQUARE ENGINEERING

Chairman: H.S. Lew

9:00- 9:20 Full-Scale Structural Applications of Active Control systems

T.T. Soong, A.M. Reinhorn, M. Shinozuka*

9:20-9:40 Base-Isolated Buildings and Seismic safety Evaluation in Japan

Y. Kitagawa*, M. Midorikawa

9:40-10:00 Dynamic Modeling of Soil-structure systems for Control Applications

H.A. Smith*, R.I. Borja

$10: 00-10: 20 \quad$ Discussion

$10: 20-1040 \quad$ Break

Session 7 - Theme II - EARTHQUARE ENGINEERING

Chairman: H.S. Lew

10:40-11:00 Current Research Efforts in Japan for Passive and Active Control of Highway Bridges Against Earthquake

K. Kawashima*, K. Hasegawa, S. Unjoh, H. Nagashima,

H. Shimizu 
$11: 00-11: 20$

Status of U.S. Research on Structural Control Systems

$11: 20-11: 40$

S.C. Liu*, H.J. Lagorio, K.P. Chong

Vibration of Large-Scale Shaking Table Foundation C. Minowa*, N. Ogawa, T. Mikoshiba, K. Ohtani, N. Oyagi

$11: 40-12: 00 \quad$ Discussion

Lunch - 12:00-13:00 (Hosted by Building Research Institute)

Technical Session - 13:00-17:00

Session 8 - Theme III - STORM SURGE AND TSUNAMIS

Chairman: T. Iwasaki

13:00-13:20 Subaerial and Submarine Landslide Generated Tsunamis

13:20-13:40 A Study on the Effect of Tsunami Breakwater by Numerical Simulation

c. Goto*, K. Tanimoto

$13: 40-13: 55$ Discussion

Session 9 - Theme IV - U.S.-JAPAN JOINT COOPERATIVE RESEARCH PROGRAM

Chairmar: T. Iwasaki

13:55-14:15 The U.S.-PRESSS Program

M.J. Nigel Priestley (H.S. Lew*)

14:15-14:35 U.S.-Japan Cooperative Research Program Precast Seismic structural system

S. Okamoto, S. Nakata*, T. Kaminosono, H. Shiohara, M. Inukai

$14: 35-14: 50 \quad$ Discussion

$14: 50-15: 10 \quad$ Break

\section{Session 10 - Theme II - EARTHQUARE ENGINEERING}

Chairman: T. Iwasaki

15:10-15:30 Safety and Economic Benefits Realized from Upgrading the Lawrence Berkeley Laboratory

Donald Eagling*, James R. Hill

Structural Regulations of Buildings and Development of Technology in Japan

Y. Ohashi*, H. Yamanouchi 
$15: 50-16: 10$

$16: 10-16: 30$

$16: 30-17: 00$
Seismic Hazard Assessment of Liquefaction Potential at Mormon Island Auxiliary Dam, CA, U.S.A.

David W. Sykora, Joseph P. Koester, Mary E. Hynes (Gus Franklin*)

System Identification of Spirally Reinforced Circular Bridge Columns subjected to Cyclic Lateral Loading

W.C. Stone, A.W. Taylor (H.S. Lew*)

Adjourn

Dinner (Hosted by Director General of Public Works Research Institute)

Friday, May 17

Technical Session - 9:00-12:00

Session 11 - Theme II - EARTHQUARE ENGINEERING

9:00- 9:20 Simplified Procedure for Inspecting Earthquake Resistant Potential of Highway Bridge Against Soil Liquefaction

K. Tokida*, J. Fukui, H. Matsumoto

9:20- 9:40 Evaluation and Repair of Major Water Resources Structures for Improved safety and seismic Stability

William Roper*

9:40-10:00 Shaking Table Tests for Hydrodynamic Pressure Acting on Double Cylindrical Caisson Type Breakwater in the Deep sea

T. Uwabe*, M. Osada, S. Noda

$10: 00-10: 20 \quad$ Discussion

$10: 20-10: 40 \quad$ Break

SEssion 12 - Theme $\mathrm{V}$ - PERFORMANCE OF NONSTRUCTURAL SYSTEMS

Chairman: H.S. Lew

10:40-11:00 Current Efforts to Improve the Performance of Nonstructural Systems Based on Experience from the Loma Prieta Earthquake

Robert Reitherman (Stephen Mahin*)

11:00-11:20 State-of-the-Art Report on Seismic Design of Building Equipment and Nonstructural components in Japan

M. Hirosawa*, H. Mizuno, M. Midorikawa

$11: 20-11: 40 \quad$ Discussion 
Lunch - 11:40 - 12:40 (Hosted by the National Research Institute for Earth Science and Disaster Prevention)

Reports on Activities Related to IDNDR - 12:40-13:00

Chairman: T. Iwasaki

Reports of Task Committees - 13:00-15:00

A--Strong-Motion Instrumentation Arrays and Data

B--Large-Scale Testing Programs

C--Repair and Retrofit of Existing Structures

D--Evaluation of Performance of Structures

E--Ground Motion and Seismic Design Forces

F--Disaster Prevention Methods for Lifeline Systems

G--Passive, Active, and Hybrid Control Systems

H--Soil Behavior and Stability During Earthquakes

I--Storm Surge and Tsunamis

J--Wind and Earthquake Engineering for Transportation Systems

$15: 00-15: 20$ Break

Adoption of Final Resolutions 15:20-16:10

Chairman: T. Iwasaki

$16: 10-16: 20$ Break

Closing Session 16:20-16:40

Call to order by Dr. Takashi Iijima, Secretary-General, Japan Panel, Director, Planning and Research Administration Department, Public Works Research Institute

Closing Remarks by Dr. H.S. Lew, Chairman (Acting Chairman), U.S. Panel, Chief, Structures Division, Building and Fire Research Laboratory, National Institute of Standards and Technology, Department of Commerce

Closing Remarks by Dr. Toshio Iwasaki, Chairman, Japan Panel, Director-General, Public Works Research Institute

Closure by Dr. Takashi Iijima

Press Conference 16:50-17:20 (Conference Hall - 8F) 


UNITED STATES-SIDE PANEL ON WIND AND SEISMIC EFFECTS MEMBERSHIP LIST
1991

Dr. Richard N. Wright

Chairman

Director, Building and Fire Research Laboratory National Institute of Standards and Technology U.S. Department of Commerce

Gaithersburg, MD 20899

$301.975 .5900 \quad$ FTS $879.5900 \quad$ FAX 301.975 .4032

Mr. Noel J. Raufaste

Secretary-General

Head, Cooperative Research Programs

Building and Fire Research Laboratory

National Institute of Standards and Technology

U.S. Department of Commerce

Gaithersburg, MD 20899

301.975 .5904 FTS $879.5904 \quad$ FAX 301.975 .4032

Dr. S. T. Algermissen

Research Geophysicist

Hazard and Risk Assessment Group

MS 966, POB 25046

Denver Federal Center

Geological Survey

U.S. Department of the Interior

Denver, co 80225

303.236 .1611 FTS 776.1611 FAX 303.236 .0618

Dr. Celso S. Barrientos

Supervisory Physical Scientist

INESDIS-E/RA28

Suitland Professional Center, Room 315

National Oceanic and Atmospheric Administration

U.S. Department of Commerce

5001 Silver Hill Road

Suitland, MD 20746

$301.763 .4178 \quad$ FAX 301.420 .1883

Dr. Eddie N. Bernard

Director, Pacific Marine Environmental Laboratory

National Oceanic and Atmospheric Administration

U.S. Department of Commerce

7600 Sand Point Way, NE

BIN C15700/Building 3

Seattle, WA 98115-0070

$206.526 .6239 \quad$ FTS $392.6800 \quad$ FAX 206.526 .6815 
Dr. Roger D. Borcherdt

Branch of Engineering Seismology and Geology

Geological survey

U.S. Department of the Interior

345 Middlefield Road, MS 977

Menlo Park, CA 94025

415.329 .5619 FTS $459.5619 \quad$ FAX 415.329 .5163

Dr. A. Gerald Brady

Research Civil Engineer

Branch of Engineering Seismology and Geology

Geological survey

U.S. Department of the Interior

345 Middlefield Road, MS 977

Menlo Park, CA 94025

415.329 .5664 FTS $459.5664 \quad$ FAX 415.329 .5163

Mr. H. Lee Butler

Chief, Research Division

Coastal Engineering Research Center

U.S. Army Engineer Waterways Experiment station

Office CEWES-CR

P.O. Box 631

Vicksburg, MS 39180-0631

601.634 .2405 FTS 542.2405 FAX 601.634.4314

Dr. Ken P. Chong

Program Director, structures and Building systems

Directorate of Engineering

National Science Foundation

1800 G Street, N.W., Room 1108

Washington, DC 20550

$202.357 .9542 \quad$ FAX 202.357.7636

Mr. James D. Cooper

Deputy Chief, Structures Division, HNR-10

Federal Highway Administration

U.S. Department of Transportation

6300 Georgetown Pike

McLean, VA 22101

703.285 .2447 FAX 703.285 .2379

Mr. Robert D. Dikkers

Assistant Chief, Structures Division

Building and Fire Research Laboratory

National Institute of Standards and Technology

U.S. Department of Commerce

Gaithersburg, MD 20899

301.975 .5863 FTS 879.5863 FAX 301.975 .4032 
Dr. A. G. Franklin

Chief, Earthquake Engineering \& Geophysics Division

CEWES-GH Geotechnical Laboratory

U.S. Army Engineer Waterways Experiment station

3909 Halls Ferry Road

Vicksburg, MS 39180-3909

$601.634 .2658 \quad$ FTS $542.2658 \quad$ FAX 601.634 .3139

Mr. G. Robert Fuller

Acting Director, Manufactured Housing and Construction

Standards Division

Room 9152 HSMM

U.S. Department of Housing and Urban Development

Washington, DC 20410-8000

202.708 .2210 FAX 202.708.0299

Mr. James H. Gates

Caltrans - Structures

P. O. Box 942874

Sacramento, CA 94274

916.445.1439 FAX 916.445.0574

Mr. Peter E. Gurvin

Director, Building Design and Engineering Division

Foreign Building Operations

Building SA-6, Room 335

U.S. Department of state

Washington, DC 20520

703.875 .6117 FAX 703.875.6204

Dr. Walter W. Hays

Deputy for Research Applications

Office of Earthquake, Volcanoes and Engineering

905 National Center

Geological survey

U.S. Department of the Interior

Reston, VA 22092

703.648 .6711 FTS 959.6717 FAX 703.648 .6717

Mr. James R. Hill

Manager, Natural Hazards Mitigation Programs Office of Safety, Health and Quality Assurance U.S. Department of Energy

Washington, DC 20585

$301.353 .4508 \quad$ FAX 301.353.5285

Mr. Larry C. Hultengren

Senior Structural Engineer

Office of Civil/structural Engineering

Foreign Building Operations

U.S. Department of State

Washington, DC 20520

$703.875 .6194 \quad$ FAX 703.875.6204 
Dr. William B. Joyner

Geophysicist

Branch of Ground Motion \& Faulting

Geological Survey

U.S. Department of the Interior

345 Middlefield Road, MS 977

Menlo Park, CA 94025

415.329 .5640 FTS 459.5640 FAX 415.329 .5163

Mr. Roger M. Kenneally

Structural Engineer

Structural and Seismic Engineering Branch

Seismic Section

Office of Nuclear Regulatory Research

U.S. Nuclear Regulatory Commission

Washington, DC 20555

301.492 .3893 FAX 301.443.7836

Mr. Richard W. Kramer

Technical Review Staff, D-3210

Bureau of Reclamation

U. S. Department of the Interior

P.O. Box 25007

Denver, CO 80225

303.236 .8539 FTS 776.8539 FAX 202.647.5269

Mr. Paul F. Krumpe

Physical Scientist

Office of U.S. Foreign Disaster Assistance

Agency for International Development

U.S. Department of state

Washington, DC 20523

202.647 .9758 FAX 202.647.5269

Dr. Henry J. Lagorio

Program Director, Architectural and Mechanical systems

Division of Biological and Critical systems

National Science Foundation

1800 G Street, N.W.

Washington, DC 20550

202.357 .9780 FAX 202.357.9803

Dr. H.S. Lew

Chief, Structures Division

Building and Fire Research Laboratory

National Institute of Standards and Technology

U.S. Department of Commerce

Gaithersburg, MD 20899

301.975 .6061 FTS 879.6061 FAX 301.975 .4032 
Mr. Tingley K. Lew

Research Structural Engineer

Structures Division, Code L51, Bldg. 560, Rm. 278B

Naval Civil Engineering Laboratory

Port Hueneme, CA 93043

$805.982 .1234 \quad$ FAX 805.982 .1418

Dr. Shih-Chi Liu

Program Director, Structural systems

Division of Biological and Critical systems

National Science Foundation

1800 G Street, N.W., Room 1132

Washington, DC 20550

$202.357 .9780 \quad$ FAX 202.357.7636

Mr. Robert B. MacDonald

Manager, Geology Branch

Engineering and Research, code D-3610 A

Bureau of Reclamation

U.S. Department of the Interior

Building 67, Denver Federal Center

Denver, CO 80225

303.236 .6904 FTS $776.8643 \quad$ FAX 303.236 .6763

Dr. Wayne N. Marchant

Chief, Research and Laboratory Services Division

P. O. Box 25007, Denver Federal Center

Code D-3700

Bureau of Reclamation

U.S. Department of the Interior

Denver, CO 80225

303.236 .5983 FTS $776.5983 \quad$ FAX 303.236 .7664

Dr. Francis G. McLean

Chief, Geotechnical Engineering and Embankment Dams Branch

P.O. Box 25007

Bureau of Reclamation

U.S. Department of the Interior

Denver, co 80225

303.236 .3854 FTS $776.3854 \quad$ FAX 303.236 .6763

Mr. Herbert Meyers

Chief, Earth Geophysics

National Geophysical Data Center

National Oceanic and Atmospheric Administration

U.S. Department of Commerce

325 Broadway

Boulder, CO 80303-3328

303.497 .6521 FTS $320.6521 \quad$ FAX 303.497 .6513 
Mr. Howard D. Nickerson

Earthquake Engineering and Weapons Specialist

Naval Facilities Engineering Command

Hoffman Building \#2, Room 12S63, Code 04B2

200 stovall street

Alexandria, VA 22332

$703.325 .0044 \quad$ FAX 703.325.1916

Dr. William E. Roper

Assistant Director

Research and Development (Civil Works)

U.S. Army Corps of Engineers

20 Massachusetts Avenue, N.W

Washington, DC 20314-1000

$202.272 .0257 \quad$ FAX 202.272.0907

Dr. Erwin L. Schaffer

Assistant Director, Wood Products Research

Forest Products Laboratory

Forest Service

U.S. Department of Agriculture

One Gifford Pinchot Drive

Madison, WI 53705-2398

608.264 .5672 FTS $364.5672 \quad$ FAX 608.231 .9592

Mr. Charles E. Smith

Research Program Manager

offshore Minerals Management

Technology Assessment and Research Branch

Minerals Management Service

U.S. Department of the Interior

381 Elden Street, MS 4800

Herndon, VA 22070-4817

703.787 .1559 FAX 703.787.1010

Dr. T. T. Soong

Samuel P. Capen Professor

Department of Civil Engineering

National Center for Earthquake Engineering Research

State University of New York at Buffalo

212 Ketter $\mathrm{Hall}$

Buffalo, NY 14260

716.636 .2469 FAX 716.636 .3733

Mr. Kenneth F. Sullivan

Lifelines Project Manager

Earthquakes and Natural Hazards Division

Federal Emergency Management Agency

Washington, DC 20472

202.646 .2889 FAX 202.646.3104 
Mr. Edward F. Younger

Director, Structural Engineering Service Code 088C1

Office of Facilities

Department of Veterans Affairs

810 Vermont Avenue, N.W.

Washington, DC 20420

$202.233 .2864 \quad$ FTS $373.2864 \quad$ FAX 202.233.7854 


\section{ALTERNATE MEMBERS}

Dr. Clifford J.Astill

Program Director

Division of Fundamental Research for Critical Engineering Systems

National Science Foundation

1800 G Street, N.W.

Washington, DC 20550

$202.357 .9500 \quad$ FAX 202.357.9803

Dr. Mehmet K. Celebi

Research Civil Engineer

Branch of Engineering Seismology and Geology

Geological Survey

U.S. Department of the Interior

345 Middlefield Road, MS 977

Menlo Park, CA 94025

415.329 .5623 FTS $459.5623 \quad$ FAX 415.329 .5163

Mr. Michael Changery

Chief, Global Analysis Branch

National Climatic Data Center

National Oceanic and Atmospheric Administration

U. S. Department of Commerce

Federal Building

Ashville, NC 28801

704.259.0765 FTS 672.0765 FAX 704.259.0246

Mr. C.Y. Chen

Senior Civil/Geotechnical Engineer

Foreign Building operations

$\mathrm{A} / \mathrm{FBO} / \mathrm{PE} / \mathrm{CSB}, \mathrm{SA}-6, \mathrm{Rm}$. 327

Washington, DC 20520

$703.875 .6207 \quad$ FAX 703.875 .6204

Mr. Vincent P. Chiarito

Research Structural Engineer

structural Mechanics Division

Structures Laboratory

U.S. Army Engineer Waterways Experiment Station

3909 Halls Ferry Road

Vicksburg, MS 39108-6199

601.634 .2714 FAX 601.634.2309

Dr. James F. Costello

Senior Structural Engineer

Structural and Seismic Engineering Branch

Structural section

Office of Nuclear Regulatory Research

U.S. Nuclear Regulatory Commission

Mail stop $007 \mathrm{NL}$

Washington, DC 20555

$301.492 .3818 \quad$ FAX 301.492.3696 
Mr. Lucian G. Guthrie

Structural Engineer

Office of Chief of Engineers

HQUSACE (CEEC-ED)

U.S. Department of the Army

20 Massachusetts Avenue, N.W.

Washington, DC 20314-1000

202.272 .8673 FAX 202.272.1485

Dr. James R. Houston

Chief, Coastal Engineering Research Center

US Army Engineer Waterways Experiment station

P.O. Box 631

Vicksburg, MS 39180-0631

$601.634 .2000 \quad$ FAX 601.634 .2655

Mr. James Iander

Geophysicist

Cooperative Institute for Research in

Environmental sciences

University of Colorado

Campus Box 449, Room 152 RL3

3100 Marine street

Boulder, co 80309

303.497 .6446 FTS $320.6446 \quad$ FAX $303-497.6513$

Mr. Robert R. Ledzian

Senior Staff Assistant for Research

Office of Liaison - Engineering Research, Code 3020

Bureau of Reclamation

U.S. Department of the Interior

18 th \& C Streets, N.W.

Washington, DC 20240

202.208 .3432 FAX 202.208.6252

Mr. Ronald J. Morony

Director, Innovative Technology and Special

Projects Division

office of Policy Development and Research

U.S. Department of Housing and Urban Development

Washington, DC 20410-6000

$202.755 .0640 \quad$ FAX 202.755.0299

Dr. J. Eleonora Sabadell

Director, Natural and Manmade Hazards Mitigation Program

Directorate of Engineering

National Science Foundation

1800 G street, N.W.

Washington, DC 20550

$202.357 .9780 \quad$ FAX 202.357.9803 
Dr. John B. Scalzi

Program Director, structures and Building systems National Science Foundation

1800 G Street, N.W.

Washington, DC 20550

202.357 .9542 FAX 202.357.7636 
Dr. Toshio Iwasaki

Chairman

Director-General

Public Works Research Institute

Ministry of Construction

1, Asahi, Tsukuba-shi,

Ibaraki-ken 305

Tel. 0298-64-2211

Dr. Takashi Iijima

Secretary-General

Director, Planning and Research Administration Department

Public Works Research Institute

Ministry of Construction

1, Asahi, Tsukuba-shi,

Ibaraki-ken 305

Tel. 0298-64-2211

Mr. Tadao Dohi

Head, Geographic Department

Geographical Survey Institute

Ministry of Construction

1, Kitazato, Tsukuba-shi

Ibaraki-ken 305

Tel. 0298-64-1111

Mr. Tokunosuke Fujitani

Chief, The Second Research Laboratory

Applied Meteorology Research Division

Meteorological Research Institute

Japan Meteorological Agency

1-1 Nagamine, Tsukuba-shi,

Ibaraki-ken 305

Tel. 0298-51-7111

Mr. Kazuhiro Nishikawa

Head, Bridge Division

Structure and Bridge Department

Public Works Research Institute

Ministry of Construction

1, Asahi, Tsukuba-shi,

Ibaraki-ken 305

Tel. 0298-64-2211 
Dr. Masaya Hirosawa

Deputy Director General

Building Research Institute

Ministry of Construction

1, Tatehara, Tsukuba-shi,

Ibaraki-ken 305

Tel. 0298-64-2151

Dr. Kazuhiko Kawashima *

Head, Earthquake Engineering Division

Earthquake Disaster Prevention Department

Public Works Research Institute

Ministry of Construction

1, Asahi, Tsukuba-shi,

Ibaraki-ken 305

Tel. 0298-64-2211

Dr. Yoshikazu Kitagawa

Director

Testing and Evaluation Department

Building Research Institute

1, Tatehara, Tsukuba-shi,

Ibaraki-ken 305

Tel. 0298-64-2151

Mr. Yasuyuki Koga

Head, Soil Dynamics Division

Construction Method and Equipment Department

Public Works Research Institute

Ministry of Construction

1, Asahi, Tsukuba-shi,

Ibaraki-ken 305

Tel. 0298-64-2211

Mr. Tadahiko Fujisawa

Head, Fill Type Dam Division

Dam Department

Public Works Research Institute

1, Asahi, Tsukuba-shi,

Ibaraki-ken 305

Tel. 0298-64-2211

Mr. Tatsuo Murota

Director, Structural Engineering Department

Building Research Institute

Ministry of Construction

1, Tatehara, Tsukuba-shi,

Ibaraki-ken 305

Tel. 0298-64-2151 
Dr. Shinsuke Nakata

Head, structural Division

International Institute of Seismology and Earthquake Engineering

Building Research Institute

Ministry of Construction

1, Tatehara, Tsukuba-shi,

Ibaraki-ken 305

Tel. 0298-64-2151

Dr. Setsuo Noda

Director, Structural Engineering Division

Port and Harbour Research Institute

Ministry of Transport

3-1-1, Nagase, Yokosuka,

Kanagawa-ken 239

Tel. 0468-41-5410

Mr. Keiichi Ohtani

Head, Earthquake Disaster Prevention Laboratory

National Research Institute for Earth Science and

Disaster Prevention

Science and Technology Agency

3-1, Tennodai, Tsukuba-shi,

Ibaraki-ken 305

Tel. 0298-51-1611

Mr. Shin ohtsuka

Head, Typhoon Research Division

Meteorological Research Institute

Japan Meteorological Agency

1-1, Nagamine, Tsukuba-shi

Ibaraki-ken 305

Tel. 0298-51-7111

Mr. Michio Okahara

Head, Foundation Engineering Division

structure and Bridge Department

Public Works Research Institute

Ministry of Construction

1, Asahi, Tsukuba-shi

Ibaraki-ken 305

Tel. 0298-64-2211

Dr. Shin Okamoto

Director, International Institute of seismology and Earthquake Engineering

Building Research Institute

Ministry of Construction

1, Tatehata, Tsukuba-shi,

Ibaraki-ken 305

Tel. 0298-64-2151 
Dr. Norio Oyagi

Director, Third Research Division

National Research Institute for Earth Science

and Disaster Prevention

Science and Technology Agency

3-1, Tennodai, Tukuba-shi,

Ibaraki-ken 305

Tel. 0298-51-1611

Dr. Yasushi Sasaki

Director, Earthquake Disaster Prevention Department Public Works Research Institute

Ministry of Construction

1, Asahi, Tsukuba-shi,

Ibaraki-ken 305

Tel. 0298-64-2211

Dr. Masaaki Seino

Head, Seismology and Volcanology Research Division

Meteorological Research Institute

Japan Meteorological Agency

1-1, Nagamine, Tsukuba-shi

Ibaraki-ken 305

Tel. 0298-51-7111

Mr. Minoru Fujiwara

Director, structure and Bridge Department

Public Works Research Institute

Ministry of Construction

1, Asahi, Tsukuba-shi,

Ibaraki-ken 305

Tel. 0298-64-2211

Dr. Katsutoshi Tanimoto

Director, Hydraulic Engineering Division

Port and Harbour Research Institute

Ministry of Transport

3-1-1, Nagase, Yokosuka,

Kanagawa-ken 239

Tel. 0468-41-5410

Mr. Ken-ichi Tokida

Head, Ground Vibration Division

Earthquake Disaster Prevention Department

Public Works Research Institute

Ministry of Construction

1, Asahi, Tsukuba-shi,

Ibaraki-ken 305

Tel. 0298-64-2211 
Dr. Takaaki Uda

Head, Coastal Engineering Division

River Department

Public Works Research Institute

Ministry of Construction

1, Asahi, Tsukuba-shi,

Ibaraki-ken 305

Tel. 0298-64-2211

Dr. Tatsuo Uwabe

Chief, Disaster Prevention Laboratory

Structural Engineering Division

Port and Harbour Research Institute

Ministry of Transport

3-1-1, Nagase, Yokosuka-shi

Kanagawa-ken 239

Tel. 0468-44-5030

Dr. Hiroyuki Yamanouchi

Head, Structural Dynamics Division

Structural Engineering Department

Building Research Institute

Ministry of Construction

1, Tatehara, Tsukuba-shi,

Ibaraki-ken 305

Tel. 0298-64-2151

Dr. Yutaka Yamazaki

Associate Director for Composite Structures Research

Structural Engineering Department

Building Research Institute

Ministry of Construction

1, Tatehara, Tsukuba-shi,

Ibaraki-ken 305

Tel. 0298-64-2151

Mr. Koichi Yokoyama *

Head, Structure Division

Structure and Bridge Department

Public Works Research Institute

Ministry of Construction

1, Asahi, Tsukuba-shi,

Ibaraki-ken 305

Tel. 0298-64-2211

* Secretary 
IIST OF TASK COMMITTEE MEMBERS 1991

Task Committee

A. Strong-Motion Instrumentation Arrays and Data

US side
A.G. Brady*
M.K. Celebi
A.F. Franklin
W.B. Joyner
R.B. MacDonald
F.G. Mclean
H. Meyers

B. Large-Scale Testing Programs

C. Repair and Retrofit of Existing Structures

\section{Evaluation of structural Performance}

E. Ground Motion and Seismic Design Forces Programs
K.P. Chong*

G.E. Freeland

H.J. Lagorio

H.S. Lew

R.J. Morony

D.H. Oh

J.B. Scalzi

G.R. Fuller*

S.A. Asar

M.K. Celebi

J.B. Scalzi
H.S. Lew*

C.E. Smith

Japanese Side

S. Noda*

S. Hattori

M. Ichikawa

Y. Ishiyama

K. Ohtani

Y. Sasaki

H. Yamanouchi

K. Ohtani*

Y. Koga

S. Noda

S. Okamoto

K. Yokoyama

H. Yamanouchi

M. Hirosawa*

T. Iwasaki

S. Okamoto

H. Shinohara

S. Okamoto*

T. Hanafusa

K. Masamura

T. Murota

M. Okahara

H. Shinohara

H. Yamanouchi

K. Yokoyama

S.T. Algermissen*

C.S. Barrientos

A.G. Brady

G.R. Fuller

P.F. Krumpe
K. Kawashima*

S. Hattori

T. Iwasaki

M. Nagaoka

Y. Sugimura

T. Uwabe 
Task Committee-continued

F. Disaster Prevention Methods for Lifeline systems

G. Passive, Active, and Hybrid Control systems

H. Soil Behavior and Stability During Earthquakes

I. Storm Surge and Tsunamis

J. Wind and Earthquake

Engineering for

Transportation systems
US Side

R.D. Dikkers*

M.K. Celebi

J.D. Cooper

P.F. Krumpe

T. Liu

J.B. Scalzi

J.S. Spencer

K.F. Sullivan

S. Wu

S.C. Liu*

C. Biglow

L.C. Hultengren

A. Iin

T.T. Soong

K.F. Sullivan
A.G. Franklin*
C.Y. Chen
F.G. McLean
C.E. Smith

H. Meyers*

C.J. Astill

C.S. Barrientos

E.N. Bernard

L. Butler

C.F. Jelesnianski

P.F. Krumpe

J. Lander

W.E. Roper

J.D. Cooper*

A.G. Franklin

J.H. Gates

J.B. Scalzi
Japanese Side

Y. Sasaki*

K. Kawashima

T. Murota

S. Noda

K. Ohtani

M. Shinozuka

T. Uwabe

Y. Kitagawa*

K. Tokida*

Y. Koga

N. Matsumoto

M. Okahara

Y. Sugimura

H. Tsuchida

T. Uda*

M. Ichikawa

K. Kurashige

K. Masamura

M. Okada

N. Oyagi

H. Takahashi

K. Tanimoto

S. Saeki*

M. Fujiwara

T. Iwasaki

K. Kawashima

M. Okahara

Y. Sasaki

K. Yokoyama

*Chairman 


\section{RESOLUTIONS}

RESOLUTIONS OF THE TWENTY-THIRD JOINT MEETING

U.S.-JAPAN PANEL ON WIND AND SEISMIC EFFECTS (UJNR)

Public Works Research Institute

Ministry of Construction

1, Asahi, Tsukuba-shi, Ibaraki 305

May $14-17,1991$

The following resolutions are hereby adopted:

1. The Twenty-third Joint Panel Meeting provided an opportunity to exchange valuable technical information which was beneficial to both countries. In view of the importance of cooperative programs on the subject of wind and seismic effects, the continuation of Joint Panel Meetings is considered essential.

2. The following activities have been conducted since the Twenty-second Joint Meeting:

a. Guest researchers from both countries performed joint research that advanced the state of earthquake engineering.

b. Technical documents, research reports, and proceedings of workshops were exchanged.

c. The Japanese MOC documents on base isolation systems for buildings were translated into English by the U.S.-side Panel. They were reviewed by both sides and approved for publication and dissemination by NIST and NTIS.

d. Five workshops were held:

a) 2nd Tsunami Workshop, Task Committee (I), at Honolulu, Hawaii, Nov. 5-7, 1990.

b) 1st Meeting of Joint Technical Coordinating Committee on Precast Seismic Structural Systems, Task Committee (B), at San Diego, CA, Nov. 29-Dec. 1,1990 .

c) Ist Workshop on Seismic Retrofit of Bridges, Task Committee (J), at Tsukuba, Dec.17-22, 1990.

d) Workshop on Remedial Treatment of Potentially Liquefiable Soils, Task Committee (H), at Tsukuba, Jan. 22-25, 1991.

e) 7th Bridge Workshop, Task Committee (J), at Tsukuba, May 8-11, 1991. 
3. A two day seminar where Panel members participated was held in Charleston, South Carolina during the Panel's study tours on May 21 - 22, 1990 on the subject of lessons learned from Hurricane Hugo and repair and retrofit of historic buildings. The seminar was hosted by the Charleston Historic Foundation and The Citadel.

4. The Panel will continue to seek methods to contribute to the International Decade of Natural Disaster Reduction (IDNDR) such as exchanging Proceedings of joint Panel Meetings and Task Committee Workshops with their respective Country's National Committees of IDNDR. The Panel compiled a bibliography of papers presented at the past 23 Joint Panel meetings and $\mathrm{T} / \mathrm{C}$ workshops, and will disseminate to various countries suffering from strong winds and earthquakes.

5. The Panel recognizes the importance of research on improving the design and construction of offshore and coastal facilities. The Panel approves the establishment of a new Task Committee ( $\mathrm{T} / \mathrm{C}$ " $\mathrm{K}$ ") on Wind and Earthquake Engineering for Offshore and Coastal Facilities. Its Mission Statement will be developed and discussed at the respective country's domestic meetings.

6. The Panel recognizes the importance of the work by both sides in the US-Japan Joint Research Program on Precast Seismic Structural Systems (PRESSS).

7. The Panel accepts each Task Committee's report developed during the Twenty-third Joint Meeting. Each report presents objectives, scope of work, accomplishments, future plans, information exchange, impacts and barriers.

8. The Panel endorses the following proposed Task Committee workshops during the coming year.

a. Task Committee (A) plans a workshop on Strong Motion Record Processing for Long Periods during the spring of 1992.

b. Task Committee (B) proposes holding a workshop to develop a joint research program on Composite, Mixed, and Hybrid Structures during the spring of 1992.

c. Task Committee (B) will conduct its 2nd meeting of the Joint Technical Coordinating Committee on Precast Seismic Structural Systems (PRESSS) in Japan, Oct 30-Nov. 1, 1991.

d. The Committee ( $E$ ) has scheduled a workshop on Hazard/Risk Assessment and Design Earthquake Loading in Tsukuba, Japan during 28-29 May 1991. 
e. Task Committee (F) has scheduled the Fourth Workshop on Earthquake Disaster Prevention for Lifeline Systems during August 19-21, 1991 in Los Angeles.

f. Task Committee ( $G$ ) has scheduled a workshop on the Design of Bridge Base Isolation at the National Center for Earthquake Engineering Research during September 1-5, 1991.

g. Task Committee (J) will hold its Eighth Bridge Workshop, scheduled in the U.S. just prior to the 24th UJNR Joint Meeting.

Scheduling for the workshops and planning meeting shall be performed by the U.S. and Japan chairmen of the respective Task Committee with concurrence of the Joint Panel chairmen. Results of each activity shall be presented at the next Joint Panel Meeting.

9. The Panel recognizes the importance of continued exchange of personnel, technical information, research results, and recorded data that lead to mitigating losses from strong winds and earthquakes. The Panel also recognizes the importance of using available large-scale testing facilities in both countries. Thus, these activities should continue to be strengthened and expanded and, as appropriate, share Task Committee activities at other meetings that have technical interests in the Task Committee activities. To facilitate these exchanges, the Panel will provide official endorsement.

10. The Twenty-Fourth Joint Meeting of the UJNR Panel on Wind and Seismic Effects will be held at NIST, Gaithersburg MD, U.S.A., May 1992. Specific dates, program, and itinerary will be proposed by the U.S. Panel with concurrence of the Japan Panel. 


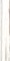




\section{Wind Engineering}




\title{
Probabilistic Performance Goals for Wind and Tornado Design
}

by

\author{
James R. Hill* \\ James R. McDonald** \\ Robert C. Murray***
}

\section{ABSTRACT}

Department of Energy, (DOE), facilities across the United States, use wind and tornado design and evaluation criteria based on probabilistic performance goals. In addition, other programs such as Advanced Light Water Reactors, New Production Reactors, and Individual Plant Examinations for External Events for commercial nuclear power plants utilize design and evaluation criteria based on probabilistic performance goals. The use of probabilistic performance goals is a departure from design practice for commercial nuclear power plants which have traditionally been designed utilizing a deterministic specification of wind and tornado loading combined with deterministic response evaluation methods and permissible behavior limits. Approaches which utilize probabilistic wind and tornado hazard curves for specification of loading and deterministic response evaluation methods and permissible behavior limits are discussed in this paper. Through the use of such design/evaluation approaches, it may be demonstrated that there is high likelihood that probabilistic performance goals can be achieved.

\section{INTRODUCTION}

Use of deterministic design and evaluation criteria to meet probabilistic performance goals is the approach used by DOE facilities across the United States as given in UCRL15910, "Design and Evaluation Guidelines for Department of Energy Facilities Subjected to Natural Phenomena Hazards." An overview of the approach is presented in this paper. References 1-14 provide related background material.

UCRL-15910 wind and tornado provisions use deterministic evaluation criteria with the hazard annual probability of exceedance specified to get design/evaluation wind speeds. The evaluation of response and structure or equipment capacities are performed using deterministic methods which are familiar to engineers. Wind speeds are developed from probabilistic hazard curves are used to meet performance goals for various building occupancies.

\section{PERFORMANCE GOALS}

Performance goals may be expressed in terms of annual probability of exceedance of some level of damage. Levels of damage can include that damage beyond which occupants are endangered, beyond which hazardous materials cannot be confined, beyond which a facility cannot safely shutdown, or beyond which a facility cannot continue its mission. The performance goal for the safety of Advanced Light Water Reactors is on the order of $1 \times 10^{-5}$ annual probability of exceedance for external events induced core damage. Performance goals upon which design/evaluation guidelines are based for DOE facilities in UCRL-15910, are presented in Table 1.

For each performance goal there are separate wind and tornado design and evaluation criteria. DOE management categorize facilities or individual structures, systems, or components depending on the cost, mission importance, or hazard to people or the

\footnotetext{
* U. S. Department of Energy, Office of Safety

Appraisals, Washington, D.C., 20585

** Texas Tech University

Lubbock, Texas 79409
}

***Lawrence Livermore National Laboratory

Livermore, CA 94550 
environment. For UCRL-15910, a DOE natural phenomena hazards panel selected reasonable and achievable performance goals, bounded by current practice.

- For ordinary facilities, the performance goals are consistent with design according to conventional building code provisions.

- For high hazard facilities, the performance goals are comparable to performance reached by nuclear power plants as measured by probabilistic risk assessments (PRAs).

\section{PERFORMANCE GOAL ACHIEVEMENT}

Structure/equipment performance is a function of: (1) the likelihood of hazard occurrence and (2) the strength of the structure or equipment item. Therefore, design and evaluation criteria have been developed to attain performance goals by: (1) specification of hazard probability for definition of wind and tornado loadings and (2) specification of response evaluation methods, acceptance criteria, and design detailing requirements with controlled levels of conservatism. Acceptable performance can only be reached by consistent specification of all design or evaluation criteria elements as shown below:

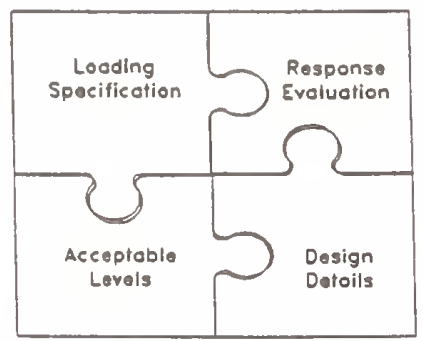

UCRL-15910 wind and tornado design and evaluation guidelines contain the following provisions:

\section{Lateral Force Provisions}

Damage Control Provisions

Detailing Provisions
Quality Assurance and Peer Review Provisions

Wind/tornado performance depends on the level of the hazard and on conservatism in the response evaluation and acceptance criteria. For example, a performance goal of $1 \times 10^{-4}$ can be achieved either by: (1) a conservative evaluation/acceptance approach for a more frequent hazard probability, such as $1 \times 10^{-3}$ or by: (2) a median centered evaluation/acceptance approach coupled with a less frequent $1 \times 10^{-4}$ hazard probability. UCRL-15910 uses the former approach because conservative evaluation/acceptance approaches are well established, extensively documented, and commonly practiced.

\section{DESIGN AND EVALUATION CRITERIA FOR WIND LOAD}

A uniform approach to wind load determination that is applicable to the design of new facilities and the evaluation of existing ones has been developed for DOE. A uniform treatment of wind loads is recommended to accommodate extreme, hurricane, and tornado winds. Buildings or facilities are first assigned appropriate usage categories. Criteria are recommended such that the performance goals for each category can be achieved. Procedures according to ASCE 7-88 (formerly ANSI A58.1) are recommended for determining wind loads produced by straight, hurricane, and tornado winds. The extreme wind/tornado hazard models developed for DOE sites were used to establish site-specific criteria for each of some 25 DOE sites.

The performance goals established for General Use and Important or Low Hazard usage categories are met by conventional building codes or standards. These criteria do not account for the possibility of tornado winds, because wind speeds associated with extreme winds typically are greater than those for tornadoes at exceedance probabilities greater than approximately $1 \times 10^{-4}$. For this reason, tornado design criteria are specified only for buildings and facilities in Moderate and High Hazard categories, where hazard 
exceedance probabilities are less than $1 \times 10^{-4}$.

The traditional approach for establishing tornado design criteria is to select extremely low exceedance probabilities. For example, the exceedance probability for design of commercial nuclear power plants is $1 \times 10^{-7}$. There are reasons for departing from this traditional approach. The low exceedance value for commercial nuclear power plants was established circa 1960 when very little was known about tornadoes from an engineering perspective. Much has been learned about tornadoes since that time. Use of a low hazard probability is inconsistent with the practice relating to other natural hazards, such as earthquakes. There are many uncertainties in tornado hazard probability assessment, but they are not significantly greater than the uncertainties in earthquake probability assessment. The strongest argument against using low probability criteria is that a relatively short period of record (37 years) must be extrapolated to extremely small exceedance probabilities. For these reasons, an alternative approach was used in the UCRL-15910 guidelines.

\subsection{Establishment of Wind and Tornado Hazard Annual Probabilities}

The rationale for establishing tornado criteria is described below. Figure 1 shows the tornado and straight wind hazard curves for two DOE sites (SLAC and ORNL). The wind speed at the intersection of the tornado and straight wind curves is defined for purposes of this discussion as the transition wind speed. An exceedance probability is associated with each transition wind speed. If the exceedance probability of the transition wind speed is less than $1 \times 10^{-5}$ per year, tornadoes are not a viable threat to the site, because straight wind speeds are higher than tornadoes for a given return period. Thus, from Figure 1, tornadoes need not be considered at SLAC, but should be considered at ORNL.

Best-estimate wind speeds were developed for each DOE site, along with the transition wind speed. Those sites with transition wind speed exceedance probabilities greater than $10^{-5}$ should be designed for tornadoes; others should be designed for extreme winds or hurricanes.

The tornado wind speed is obtained by selecting the wind speed associated with an exceedance probability of $2 \times 10^{-5}$ per year. The value of $2 \times 10^{-5}$ is the largest one that can be used and still represent a point on the tornado hazard curve. For example, the tornado wind speed for the ORNL is 130 $\mathrm{mph}$ (peak gust at $10 \mathrm{~m}$ ).

A comparison of the slopes of the tornado hazard curves for the DOE sites reveals that the slopes are essentially the same even though the transition wind speeds are different. The criteria required to meet the performance goals of Moderate and High Hazard facilities can be met by using multipliers that are equivalent to an importance factor in the ASCE 7-88 design procedure. The multipliers are specified in lieu of two different exceedance probabilities for Moderate and High Hazard facilities. The value of the importance factor is selected to achieve lower probability of tornado damage for High Hazard facilities compared to Moderate Hazard facilities. The importance factors are then chosen to meet the performance goals.

In general, design criteria for each usage category include:

1. Annual hazard exceedance probability.

2. Importance factor.

3. Wind generated missile parameters for Moderate and High Hazard facilities.

4. Tornado parameters for Moderate and High Hazard facilities, if applicable.

The criteria are formulated in such a way that a uniform approach for determining design wind loads, per ASCE 7-88, can also be used for extreme, hurricane, and tornado winds.

In order to apply the ASCE 7-88 procedure, tornado gust wind speeds must be converted to fastest-mile. Appropriate gust response factors and velocity pressure exposure 
coefficients are utilized in the process of determining wind loads. Appropriate exposure categories also are considered in the wind load calculations. Open terrain (Exposure C) should always be assumed for tornado winds, regardless of the actual terrain conditions.

\subsection{CRITERIA FOR DESIGN OF FACILITIES}

The criteria presented herein are consistent with the performance goals described earlier. Buildings or facilities in each category have a different role and represent different levels of hazard to people and the environment. In addition, the degree of wind hazard varies geographically. Facilities in the same usage category, but at different geographical locations, will have different criteria specified to achieve the same performance goal.

The minimum wind design criteria for each of the four usage categories are summarized in Table 2. The recommended basic wind speeds for extreme wind, hurricanes, and tornadoes are contained in Table 3. All wind speeds are fastest-mile. Minimum recommended basic wind speeds are noted in the table.

\subsubsection{General Use Facilities}

The performance goals for General Use facilities are consistent with objectives of ASCE 7-88 Building Class I, Ordinary Structures. The wind-force resisting structural system should not collapse under design load. Survival without collapse implies that occupants should be able o find an area of relative safety inside the building. Breach of the building envelope is acceptable, since confinement is not essential. Flow of air through the building and water damage are acceptable. Severe damage, including total loss, is acceptable, so long as the structure does not collapse.

The ASCE 7-88 standard calls for the basic wind speed to be based on an exceedance probability of 0.02 per year. The importance factor for this class of building is 1.0. For those sites within 100 miles of the Gulf of Mexico or Atlantic coastlines, a slightly higher importance factor is recommended to account for hurricanes.

Terrain surrounding the facilities should be classified as Exposure B, C, or D, as appropriate. Gust response factors and velocity pressure exposure factors should be used according to rules of the ASCE 7-88 procedures.

Wind pressures are calculated on the walls and roofs of enclosed buildings by appropriate pressure coefficients specified in the ASCE 7-88 standard. Openings, either of necessity or created by wind forces or missiles, result in internal pressures that can increase wind forces on components and cladding. The worst cases of combined internal and external pressures should be considered, as required by the standard.

Structures in the General Use category may be designed by either allowable stress design (ASD) or strength design (SD) as appropriate for the material used in construction. Except when applicable codes provide otherwise, plausible load combinations shall be considered to determine the most unfavorable effect on the building, foundation, or structural member being considered. When using ASD methods, allowable stresses appropriate for the building material shall be used with the following combinations that involve wind:

(a) $\mathrm{DL}+\mathrm{W}$

(b) $0.75(\mathrm{DL}+\mathrm{W}+\mathrm{LL})$

where

$$
\begin{aligned}
& \mathrm{DL}=\text { dead load } \\
& \mathrm{LL}=\text { live load } \\
& \mathrm{W}=\text { wind load }
\end{aligned}
$$

When using SD methods, the following load combinations that involve wind are recommended:

(a) $U=0.9 \mathrm{DL}+1.3 \mathrm{~W}$

(b) $\mathrm{U}=1.2 \mathrm{DL}+0.5 \mathrm{LL}+1.3 \mathrm{~W}$

The SD method requires that the strength provided be greater than or equal to the strength required to carry the factored loads. 
Appropriate strength reduction factors must be applied to the nominal strength of the material being used.

\subsubsection{Important or Low Hazard Facilities}

Important or Low Hazard facilities are equivalent to essential facilities (Class II), as defined in ASCE 7-88. The structure's main wind-force resisting structural systems shall not collapse at design wind speeds. Complete integrity of the building envelope is not required because no significant quantities of toxic or radioactive materials are present. However, breach of the building envelope may not be acceptable if wind or water interfere with the facility function. If loss of facility function is caused by water damage to sensitive equipment, collapsed interior partitions, or excessive damage to HVAC ducts and equipment, then loss of cladding and missile perforation at the design wind speeds must be prevented.

An annual wind speed exceedance probability of 0.02 is specified, but the importance factor for important or Low Hazard category structures is 1.07. For those sites located within 100 miles of the Gulf of Mexico or Atlantic coastlines, a slightly higher importance factor is used to account for hurricane winds.

Once the design wind speeds are established and the importance factors applied, the determination of wind loads on Important or Low Hazard category structures is identical to that described for General Use category structures. Facilities in this category may be designed by ASD or SD methods, as appropriate, for the construction material. The load combinations described for General Use structures are the same for Important or Low Hazard structures. However, greater attention should be paid to connections and anchorages for main members and components, such that the integrity of the structure is maintained.

\subsubsection{Moderate Hazard Facilities}

The performance goal for Moderate Hazard facilities requires more rigorous criteria than is provided by standards or model building codes. For some DOE sites, tornadoes must be considered.

\section{Extreme Winds and Hurricanes}

For those sites where tornadoes are not a viable threat, the recommended basic wind speed is based on an annual exceedance probability of $1 \times 10^{-3}$. The importance factor is 1.0. For those sites located within 100 miles of the Gulf of Mexico or Atlantic coastlines, a slightly higher importance factor is specified to account for hurricanes.

Once the basic wind speeds are established and the importance factors applied, determination of Moderate Hazard category wind loads is identical to that described for the General Use category. Facilities in this category may be designed by ASD or SD methods, as appropriate, for the material being used in construction. Plausible load combinations shall be considered to determine the most unfavorable effect on the building, foundation, or structural member being considered. When using ASD, allowable stresses appropriate for the building material shall be used with the following wind load combinations:
(a) $\mathrm{U}=0.9(\mathrm{DL}+\mathrm{W})$
(b) $U=0.67(D L+W+L L)$

The SD load combinations recommended for the Moderate Hazard category are:
(a) $\mathrm{U}=\mathrm{DL}+1.3 \mathrm{~W}$
(b) $U=1.1 \mathrm{DL}+0.5 \mathrm{LL}+1.2 \mathrm{~W}$

Greater attention should be paid to connections and anchorages for main members and components, such that the integrity of the structure is maintained.

A minimum missile criteria is specified to account for objects or debris that could be picked up by extreme winds, hurricane winds, or weak tornadoes. A 2X4-in. timber plank weighing $15 \mathrm{lbs}$. is the specified missile. Its impact speed is $50 \mathrm{mph}$ at a maximum height of $30 \mathrm{ft}$ above ground level. The missile will break glass; it will perforate 
sheet metal siding, wood siding up to $3 / 4$ in. thick, or form board. The missile could pass through a window or a weak exterior wall and cause personal injury or damage to interior contents of a building. The specified missile will not perforate unreinforced concrete masonry or brick veneer walls or other more substantial walls.

\section{Tornadoes}

For those sites requiring design for tornadoes, the criteria are based on sitespecific studies. The basic wind speed is associated with an annual hazard probability of exceedance of $2 \times 10^{-5}$. The wind speed obtained from the tornado hazard model is converted to fastest-mile. The importance factor for the Moderate Hazard category is 1.0 .

With the wind speed converted to fastest-mile wind and an importance factor of 1.0 , equations in the ASCE standard should be used to obtain design wind pressures on the structure. Exposure Category $\mathrm{C}$ should always be used with tornado winds regardless of the actual terrain roughness. The velocity pressure exposure coefficient and the gust response factor are obtained from appropriate tables in the ASCE standard. External pressure coefficients are used to obtain tornado wind pressures on various surfaces of the structure. A distinction is made between the main windforce resisting system and components and cladding.

If the building is not specifically sealed to maintain an internal negative pressure for confinement of hazardous materials, or, if openings greater than one square foot per 1000 cubic foot of volume are present, or, if openings of this size can be created by missile perforation, then the effects of internal pressure should be considered according to ASCE procedures. On the other hand, if the building is sealed, then atmospheric pressure change (APC) pressures associated with the tornado should be considered.

APC pressure is half its maximum value at the radius of maximum wind speed in a tornado. Thus, critical tornado loading will be one-half maximum APC pressure plus maximum tornado wind pressure. A loading condition of APC alone can occur on the roof of a buried tank or sand filter, if the roof is exposed at the ground surface. APC pressure always acts outward. The effect of rate of pressure change on ventilation systems should be analyzed to assure that it does not interrupt function or processes carried out in the facility. Procedures and computer codes are available for such analyses.

Plausible load combinations shall be considered to determine the most unfavorable effect on the building, foundation, or structural member being considered. When using ASD methods, allowable stresses appropriate for the building materials shall be used with the following load combinations that involve wind.

(a) $\mathrm{U}=0.75\left(\mathrm{DL}+\mathrm{W}_{\mathrm{t}}\right)$

(b) $\mathrm{U}=0.625\left(\mathrm{DL}+\mathrm{W}_{\mathrm{t}}+\mathrm{LL}\right)$

The SD load combinations recommended for the Moderate Hazard category are:

(a) $\mathrm{U}=\mathrm{DL}+\mathrm{W}_{\mathrm{t}}$

(b) $\mathrm{U}=\mathrm{DL}+\mathrm{LL}+\mathrm{W}_{\mathrm{t}}$

where

$\mathrm{W}_{\mathrm{t}}=$ tornado loading, including APC, as appropriate.

Two missiles are specified as minimum criteria for this usage category. The 2X4-in. timber plank weighing $15 \mathrm{lbs}$. is assumed to travel in a horizontal direction at a speed up to $100 \mathrm{mph}$. The horizontal speed is effective up to a height of $150 \mathrm{ft}$ above ground level. If carried to a great height by the tornado winds, the timber plank could achieve a terminal vertical speed of $70 \mathrm{mph}$ in falling to the ground. The horizontal and vertical speeds are assumed to be uncoupled and they should not be combined. The missile will perforate most conventional wall and roof cladding except reinforced masonry or concrete. The cells of concrete masonry 
walls must be filled with grout to prevent perforation by the timber missile. The second missile is a 3-in. diameter standard steel pipe, which weighs 75 lbs. It can achieve a horizontal impact speed of $50 \mathrm{mph}$ and a vertical speed of $35 \mathrm{mph}$. Its horizontal speed could be effective to heights of $75 \mathrm{ft}$ above ground level. The missile will perforate conventional metal siding, sandwich panels, wood and metal decking on roofs, and gypsum panels. In addition, it will perforate unreinforced concrete masonry and brick veneer walls, reinforced concrete masonry walls less than 8 in. thick, and reinforced concrete walls less than 6 in. thick. Although wind pressure, APC, and missile impact loads can act simultaneously in a tornado, the missile impact loads can be treated independently for design and evaluation purposes.

\subsubsection{High Hazard Facilities}

The performance goal can be achieved for this category if the main wind-force resisting members do not collapse, structural components do not fail, and the building envelope is not breached at the design wind loads. Loss of cladding, broken windows, collapsed doors, or significant missile perforations must be prevented. Strong air flow through the building or water damage cannot be tolerated.

\section{Extreme Winds and Hurricanes}

For those sites that do not require specific design for tornado resistance, the recommended basic wind speed is based on an annual hazard exceedance probability of $1 \times 10^{-4}$. The importance factor is 1.0 . The wind speed is fastest-mile at an anemometer height of 10 meters above ground level.

Once the basic wind speeds are established and the importance factors applied, determination of High Hazard facility wind loads is identical to that described for the General Use category. Facilities in this category may be designed by ASD or SD methods, as appropriate, for the material being used in construction. Recommended wind load combinations are the same as for
Moderate Hazard facilities. Greater attention should be paid to connections and anchorages for main members and components, such that the integrity of the structure is maintained.

The missile criteria is the same as for the Moderate Hazard category, except that the maximum height achieved by the missile is $50 \mathrm{ft}$, instead of $30 \mathrm{ft}$.

\section{Tornadoes}

For those sites requiring design for tornado resistance, the criteria is based on sitespecific studies. The recommended basic wind speed is associated with an annual hazard probability of exceedance of $2 \times 10^{-5}$ (the same as the Moderate Hazard category). The wind speed obtained from the tornado hazard model is converted to fastest-mile. The importance factor for the High Hazard category is 1.35 .

With the wind speed expressed as fastestmile and an importance factor of 1.35 , equations should be used to obtain design wind pressures on the structure. Exposure Category $\mathrm{C}$ should always be used with tornado winds regardless of actual terrain roughness. The velocity pressure exposure coefficient and the gust response factor are obtained from appropriate tables in the ASCE standard. External pressure coefficients are used to obtain tornado wind pressures on various surfaces of the structure. A distinction is made between the main windforce resisting system and components and cladding in determining wind pressures.

If the building is sealed to confine hazardous materials, the wind and APC load combinations specified for the Moderate Hazard usage category also should be used for this category. The effects of rate of pressure change on ventilating systems should be analyzed. Recommended tornado wind load combinations for Moderate Hazard facilities also apply to High Hazard facilities.

Three missiles are specified as minimum criteria for this usage category. The $2 \times 4$-in. timber plank weighs $15 \mathrm{lbs}$. and is assumed to travel in a horizontal direction at speeds up 
to $150 \mathrm{mph}$. The horizontal missile is effective to a maximum height of $200 \mathrm{ft}$ above ground level. If carried to a great height by the tornado winds, it could achieve a terminal speed in the vertical direction of $100 \mathrm{mph}$. The horizontal and vertical speeds are uncoupled and should not be combined. The missile will perforate most conventional wall and roof cladding except reinforced masonry and concrete. Each cell of the concrete masonry shall contain a $1 / 2$-in.diameter rebar and be grouted to prevent perforation by the missile. The second missile is a 3-in.-diameter standard steel pipe, which weighs 75 lbs. It can achieve a horizontal impact speed of $75 \mathrm{mph}$ and a vertical speed of $50 \mathrm{mph}$. The horizontal speed could be effective at heights up to 100 $\mathrm{ft}$ above ground level. This missile will perforate unreinforced concrete masonry and brick veneer walls, reinforced concrete masonry walls less than 12 in. thick, and reinforced concrete walls less than 8 in. thick. The third missile is a 3000-lb automobile that is assumed to roll and tumble on the ground and achieve an impact speed of $25 \mathrm{mph}$. Impact of an automobile can cause excessive structural response to columns, walls, and frames. Impact analyses should be performed to determine specific effects. Collapse of columns, walls, or frames may lead to further progressive collapse.

\section{SUMMARY AND CONCLUSIONS}

UCRL-15910 is an example of deterministic design/evaluation criteria developed to achieve probabilistic performance goals. UCRL-15910 also covers seismic and flood as well as wind and tornado criteria as discussed in this paper. The criteria developed is consistent with the consensus standard ASCE 7-88. Conservatism is specified which is sufficient to achieve the performance goals. This conservatism increases from general use to high hazard usage category.

The UCRL-15910 wind/tornado design and evaluation guidelines follow the philosophy of: (1) gradual reduction in hazard annual exceedance probability; and (2) gradual increase in conservatism of evaluation procedure as one goes from a General Use to a High Hazard facility. Four separate sets of design/evaluation criteria have been presented in UCRL-15910, each with a different performance goal. In all these criteria, loading is selected from hazard curves on a probabilistic basis but response evaluation methods and acceptable behavior limits are deterministic approaches with which design engineers are familiar.

\section{REFERENCES}

1. Advanced Light Water Reactor Requirements Document, Volume 1, ALWR Policy and Summary of TopTier Requirements, Final Draft for Review, 1990, Electric Power Research Institute, Palo Alto, California.

2. Individual Plant Examination of External Events (IPEEE) for Severe Accident Vulnerabilities - 10CFR 50.54 (f), (Generic Letter No. 88-20 - Supplement 4, Draft for Comment), 1990, U.S. Nuclear Regulatory Commission.

3. Kennedy, R.P., S.A. Short, J.R. McDonald, M.W. McCann, R.C. Murray, and J.R. Hill, June 1990, Design and Evaluation Guidelines For Department of Energy Facilities Subjected to Natural Phenomena Hazards, Lawrence Livermore National Laboratory Report UCRL$15910,1990$.

4. Regulatory Guide 1.76, U.S. Nuclear Regulatory Commission.

5. Safety Analysis Reports for Nuclear Power Plants, LWR Edition, 1989, NUREG-0800, U.S. Nuclear Regulatory Commission.

6. Uniform Building Code, 1988 Edition, International Conference of Building Officials, Whittier, California. 
7. Coats, D.W. and R.C. Murray, Natural Phenomena Hazards Modeling Project: Extreme Wind/Tornado Hazard Models for Department of Energy sites, Report UCRL-53526 Rev. 1, Lawrence Livermore National Laboratory, Livermore, California, 1985.

8. McDonald, J.R., Structural Details for Wind Design, Lawrence Livermore National Laboratory, Report UCRL-21131, 1988.

9. U.S. Department of Energy, General Design Criteria, DOE or Dev 6430.1A, Washington, D.C., 1989.

10. Minimum Design Loads for Building and Other Structures, ASCE 7-88 (formerly ANSI A58.1), American Society of Civil Engineers, July 1990.

11. Evaluation of External Hazards to Nuclear Power Plants in the United States, NUREG/CR-5042, UCID21223, Lawrence Livermore National Laboratory, Livermore, California, 1988.

12. McDonald, J.R., Extreme winds and Tornadoes: An Overview, Lawrence Livermore National Laboratory, Report UCRL-15745, 1985.

13. McDonald, J.R., Extreme Winds and Tornadoes: Design and Evaluation of Buildings and Structures, Lawrence Livermore National Laboratory, Report UCRL$15747,1985$.

14. ANS 2.3, Standard for Estimating Tornado and Extreme Wind Characteristics at Nuclear Power Plant Sites, ANSI Standard published by the American Nuclear Society, La Grange Park, Illinois, 1983. 


\section{Table 1. Performance Goals for Each Usage Category}

\begin{tabular}{|c|l|l|}
\hline $\begin{array}{c}\text { Usage } \\
\text { Category }\end{array}$ & \multicolumn{1}{|c|}{$\begin{array}{c}\text { Performance Goal } \\
\text { Description }\end{array}$} & $\begin{array}{c}\text { Performance Goal Median } \\
\text { Annual Probability } \\
\text { of Exceedance }\end{array}$ \\
\hline $\begin{array}{c}\text { General } \\
\text { Use }\end{array}$ & Maintain Occupant Safety & $\begin{array}{c}-10.3 \text { of the onset of major component'll damage } \\
\text { to the extent that occupants are endangered }\end{array}$ \\
\hline $\begin{array}{c}\text { Important or } \\
\text { Low Hazard }\end{array}$ & $\begin{array}{l}\text { Occupant Safety, Continued Operation } \\
\text { with Minimal Interpuption }\end{array}$ & $\begin{array}{l}-5 \times 10-4 \text { of component damage to the extent that } \\
\text { the component cannot perform its function }\end{array}$ \\
\hline $\begin{array}{c}\text { Moderate } \\
\text { Hazard }\end{array}$ & $\begin{array}{l}\text { Occupant Safety, Continued Function, } \\
\text { Hazard Confinement }\end{array}$ & $\begin{array}{l}-10.4 \text { of component damage to the extent that the } \\
\text { component cannot perform its function }\end{array}$ \\
\hline $\begin{array}{c}\text { High } \\
\text { Hazard }\end{array}$ & $\begin{array}{l}\text { Occupant Safety, Continued Function, } \\
\text { Very High Confidence of Hazard Con- } \\
\text { finement }\end{array}$ & $\begin{array}{l}-10.5 \text { of component damage to the extent that the } \\
\text { component cannot perform its function }\end{array}$ \\
\hline $\begin{array}{c}\text { Reactor } \\
\text { Facilities }\end{array}$ & Beyond the scope of UCRL-15910 \\
\hline
\end{tabular}

11. Component refers to structure, equipment, or distribution system.

\section{Table 2. Summary of Minimum Wind Design Criteria}

\begin{tabular}{|c|c|c|c|c|c|}
\hline & Building Category & General Use & $\begin{array}{l}\text { Important or } \\
\text { Low Hazard }\end{array}$ & Moderate Hazard & High Hazard \\
\hline \multirow{3}{*}{$\begin{array}{l}W \\
\text { i } \\
n \\
d\end{array}$} & $\begin{array}{l}\text { Annual Probability } \\
\text { of Excoedance }\end{array}$ & $2 \times 10^{-2}$ & $2 \times 10^{-2}$ & $1 \times 10^{-3}$ & $1 \times 10^{-4}$ \\
\hline & $\begin{array}{l}\text { Importance } \\
\text { Factor }\end{array}$ & 1.0 & 1.07 & 1.0 & 1.0 \\
\hline & Missile Criteria & & & $\begin{array}{l}2 \times 4 \text { timber plank15 lb @ } \\
50 \mathrm{mph} \text { (horiz.): max. } \\
\text { height } 30 \mathrm{ft} .\end{array}$ & $\begin{array}{l}2 \times 4 \text { timber plank } 15 \text { lb @ } \\
50 \text { mph (horiz.); max. } \\
\text { height } 50 \mathrm{ft} \text {. }\end{array}$ \\
\hline \multirow[b]{4}{*}{$\begin{array}{l}T \\
0 \\
r \\
n \\
a \\
d \\
0\end{array}$} & $\begin{array}{l}\text { Annual Hazard } \\
\text { Probability } \\
\text { of Exceedance }\end{array}$ & & & $2 \times 10^{-5}$ & $2 \times 10^{-5}$ \\
\hline & Importance Factor & & & $1=1.0$ & $I=1.35$ \\
\hline & APC & & & 40 psi@ 20 pst/sec & 125 psf@ 50 pst/sec \\
\hline & Missile Criteria & & & $\begin{array}{l}2 \times 4 \text { timber plank } 15 \mathrm{lb} @ \\
100 \text { mph (horiz.); max. } \\
\text { height } 150 \mathrm{ft} ; 70 \text { mph (vert.) } \\
3 \text { in. dia. std. steel pipe, } 75 \\
\text { lb @ } 50 \text { mph (horiz.); max. } \\
\text { height } 75 \mathrm{ft}, 35 \text { mph (vert.) }\end{array}$ & $\begin{array}{l}2 \times 4 \text { timber plank } 15 \mathrm{lb} @ \\
150 \text { mph (horiz.), max, } \\
\text { height } 200 \mathrm{ft} ; 100 \mathrm{mph} \\
\text { (vert.) } \\
3 \text { in. dia. std. steel pipe, } 75 \\
\text { lb @ } 75 \text { mph (horiz.); max. } \\
\text { height } 100 \mathrm{ft}, 50 \text { mph (vert.) } \\
3,000 \mathrm{lb} \text { automobile @ } 25 \\
\text { mph, rolls and tumbles }\end{array}$ \\
\hline
\end{tabular}


Table 3. Recommended Basic Wind Speeds for DOE Sites

\begin{tabular}{|c|c|c|c|c|c|c|}
\hline \multirow{3}{*}{ Building Category } & \multicolumn{6}{|c|}{ Fastest-Mile Wind Speeds at $10 \mathrm{~m}$ Height } \\
\hline & \multirow{2}{*}{$\begin{array}{c}\text { General } \\
\text { Use }\end{array}$} & \multirow{2}{*}{$\begin{array}{l}\text { Important } \\
\text { or Low } \\
\text { Hazard } \\
\text { Wind }\end{array}$} & \multicolumn{2}{|c|}{ Moderate Hazard } & \multicolumn{2}{|c|}{ High Hazard } \\
\hline & & & Wind & Tornado & Wind & Tornado \\
\hline DOE PROJECT SITES & $2 \times 10^{-2}$ & $2 \times 10^{-2}$ & $1 \times 10^{-3}$ & $2 \times 10^{-5}$ & $1 \times 10^{-4}$ & $2 \times 10^{-5}$ \\
\hline Bendix Plant, MO & 72 & 72 & - & 144 & - & 144 \\
\hline $\begin{array}{l}\text { Los Alamos National Scientific } \\
\text { Laboratory, NM }\end{array}$ & 77 & 77 & 93 & - & 107 & - \\
\hline Mound Laboratory, OH & 73 & 73 & $\cdots$ & 136 & - & 136 \\
\hline Pantex Plant, TX & 78 & 78 & - & 132 & - & 132 \\
\hline Rocky Flats Plant, CO & 109 & 109 & 138 & (3) & 161 & (3) \\
\hline $\begin{array}{l}\text { Sandia National Laboratories, } \\
\text { Albuquerque, NM }\end{array}$ & 78 & 78 & 93 & - & 107 & -- \\
\hline $\begin{array}{l}\text { Sandia National Laboratories, } \\
\text { Livermore, CA }\end{array}$ & 72 & 72 & 96 & -- & 113 & - \\
\hline Pinellas Plant, FL & 93 & 93 & 130 & - & 150 & - \\
\hline Argonne National Laboratory--East, IL & $70(1)$ & $70(1)$ & $\cdots$ & 142 & - & 142 \\
\hline Argonne National Laboratory--West, ID & $70(1)$ & $70(1)$ & 83 & 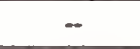 & 95 & - \\
\hline Brookhaven National Laboratory, NY & $70(1)$ & $70(1)$ & - & $95(2)$ & - & $95(2)$ \\
\hline Princeton Plasma Physics Laboratory, NJ & $70(1)$ & $70(1)$ & - & 103 & - & 103 \\
\hline Idaho National Engineering Laboratory & $70(1)$ & $70(1)$ & 84 & -- & 95 & - \\
\hline Feed Materials Production Center, OH & $70(1)$ & $70(1)$ & - & 139 & - & 139 \\
\hline $\begin{array}{l}\text { Oak Ridge National Laboratory, } \mathrm{X}-10, \mathrm{~K}-25 \text {, } \\
\text { and } \mathrm{Y}-12, \mathrm{TN}\end{array}$ & $70(1)$ & $70(1)$ & - & 113 & - & 113 \\
\hline Paducah Gaseous Diffusion Plant, KY & $70(1)$ & $70(1)$ & - & 144 & - & 144 \\
\hline Portsmouth Gaseous Diffusion Plant, OH & $70(1)$ & $70(1)$ & - & 110 & - & 110 \\
\hline Nevada Test Site, NV & 72 & 72 & 87 & - & 100 & - \\
\hline Hanford Project Site, WA & $70(1)$ & $70(1)$ & $80(1)$ & - & $90(1)$ & $\cdots$ \\
\hline Lawrence Berkeley Laboratory, CA & 72 & 72 & 95 & - & 111 & - \\
\hline $\begin{array}{l}\text { Lawrence Livermore National } \\
\text { Laboratory, CA }\end{array}$ & 72 & 72 & 96 & - & 113 & - \\
\hline $\begin{array}{l}\text { Lawrence Livermore National } \\
\text { Laboratory, Site } 300 \text {, CA }\end{array}$ & 80 & 80 & 104 & - & 125 & - \\
\hline $\begin{array}{l}\text { Energy Technology and Engineering } \\
\text { Center, CA }\end{array}$ & $70(1)$ & $70(1)$ & - & $95(2)$ & - & $95(2)$ \\
\hline Stanford Linear Accelerator Center, CA & 72 & 72 & 95 & - & 112 & - \\
\hline Savannah River Plant, SC & 78 & 78 & - & 137 & - & 137 \\
\hline
\end{tabular}

\section{NOTES:}

(1) Minimum extreme wind speed.

(2) Minimum tornado speed.

(3) Athough extreme winds govern at Rocky Flats, it is recommended that facilities be designed for the tornado missile criteria. APC need not be considered. 


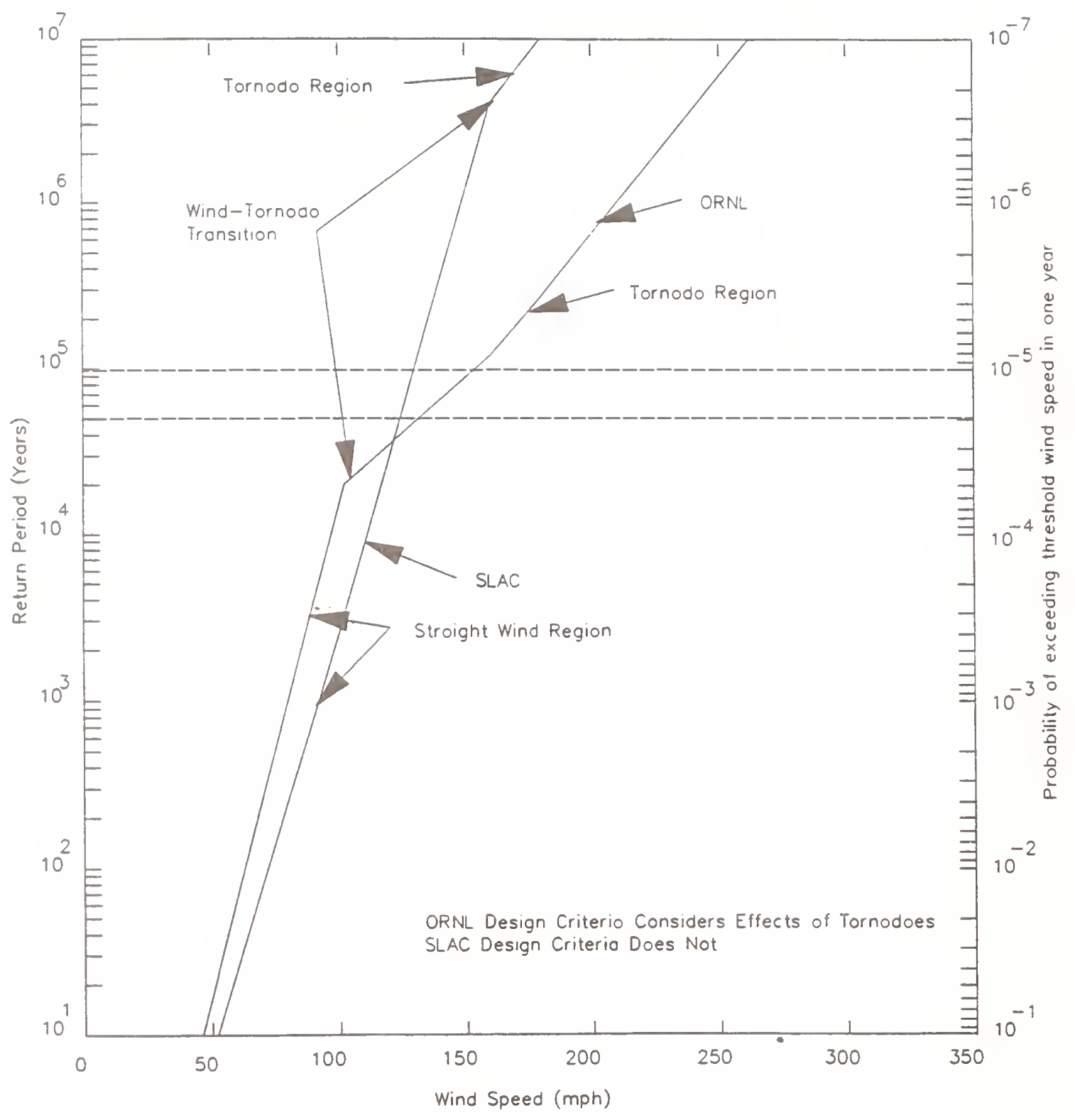

Figure 1. Straight Wind and Tornado Regions of Wind Hazard Curves 


\section{Analysis of Tornado in Mobara City on December 11, 1990}

\section{H Niino ${ }^{1}, \mathrm{~T}$ Fujitani ${ }^{2}, \mathrm{~T}$ Murota $^{3}, \mathrm{~N}$ Yamaguchi ${ }^{3}$ and H Okada ${ }^{3}$}

\section{ABSTRACT}

On the evening of December 11, 1990, a tornado hit the Mobara City in the central part of the Boso Peninsula, about $55 \mathrm{~km}$ southeast of Tokyo. The tornado produced one of the severest damages in the Japanese records. One person died, 73 persons were injured, 82 houses completely destroyed, 161 houses partially destroyed and 1504 houses damaged. The characteristics of the tornado as revealed from damage survey are reported.

KEYWORDS :tornado, damage survey, estimated wind speed, translational speed.

\section{INTRODUCTION}

In Japan there have been enough records of strong winds associated with typhoons and extratropical cyclones to establish wind resistant design codes based on their statistical properties. Since tornadoes occur less frequently over narrow areas and last rather shortly, however, only sparse data which directly record strong winds associated with them exist. Accordingly, damage survey has been one of the effective means to study characteristics of tornadoes; in fact, their general characteristics such as dimensions, translational velocity and maximum wind, have been reasonably estimated through damage surveys.

Though the immediate damage due to tornadoes may be confined to a small area, the probability that such a damage will lead to the secondary damage to much wider area seems to be increasing as the urban functions become sophisticated and complex. Constructions which may be liable to this probability include nuclear power plants, chemical factories, bullet trains and ultralong-span bridges. Thus, it seems necessary to establish wind resistant design codes which consider strong winds due to tornadoes as soon as possible. It seems also necessary to establish a warning system similar to the tornado warning in the United States.

Since tornadoes are less frequent phenomena, it is important to accumulate data on their characteristics before any statistical analysis is done. Whenever a tornado occurs, it is an urgent task to make a quick damage survey and collect every detum related to the tornado.

On the evening of December 11, 1990, a tornado hit the Mobara City which is located in the center of the Boso Peninsula, $55 \mathrm{~km}$ southeast of Tokyo and produced one of the severest damage in the Japanese record. One person died, 73 persons were injured, 82 houses completely destroyed, 161 houses partially destroyed and 1504 houses damaged. Scientists of Meteorological Research Institute(MRI) and Building Research Institute(BRI) started a detailed investigation on the tornado on December 12 . In the following, the characteristics of Japanese tornadoes are introduced briefly, and then the characteristics of the Mobara Tornado as revealed from the damage survey are reported.

1 Physical Meteorology Division, Meteorological Research Institute.

2 Applied Meteorology Division, Meteorological Research Institute.

3 The Third Division, Building Research Institute. 
2. CHARACTERISTICS OF JAPANESE TORNADOES

The characteristics of Japanese tornadoes described in this chapter are extracted from an excellent technical report by Mitsu$\mathrm{ta}^{1}$ ) who summarized the statistics on the tornadoes in Japan from 1961 to 1982:

1)The number of tornadoes during 22 years is 396. This gives an average number of 18 per year, which is much smaller than 771 per year in the United States ${ }^{2}$.

2)There is a distinct regional difference in the occurence of tornadoes. The Pacific side of the Japan Island experiences more tornadoes than the Japan Sea side does. Among 43 prefectures, the Kagoshima Prefecture, the southest prefecture of the Kyushu Island, experiences tornadoes most frequently (37 tornadoes during 22 years). The number density per $10^{4} \mathrm{~km}^{2}$ per year is maximum for the Okinawa Prefecture, the southest prefecture of Japan, and is 6.3. This number is larger than that for the Oklahoma State in the United States.

3)Tornadoes occur most frequently in September, and next in August. These two months account about 38 percent of the total occurence of tornadoes. March has tornadoes least frequently. September and August are the months when the Japan Islands are hit by typhoons most frequently. Since tornadoes are often accompanied with typhoons, this may explain the reason why these two months have such frequent occurence of tornadoes.

4)About three fourths of tornadoes move toward directions between east and north. Only few estimations for the translational speed of tornadoes exist. They give the average value of about $10 \mathrm{~m} / \mathrm{s}(36 \mathrm{~km} / \mathrm{h})$.

$5)$ On average twenty eight houses are totally destroyed, 0.5 persons are killed and 20.6 persons are injured per year.

6) No wind record at the radius of maximum wind exists. Wind speeds of more than $60 \mathrm{~m} / \mathrm{s}$ at Hachijou Island in 1964 and more than $80 \mathrm{~m} / \mathrm{s}$ at Tokyo in 1978 have been recorded near tornado paths. Wind speed of more than $100 \mathrm{~m} / \mathrm{s}$ have been estimated from a damage to a construction in Toyohashi City in 1969.

\section{MOBARA TORNADO \\ 3.1. Meteorological conditions}

From 1800 to 1930JST on the evening of December 11, 1990, damages due to heavy winds were observed at Mobara, Futtsu, Kimitsu, Kamogawa, Choshi Cities and Maruyama Town in the Chiba Prefecture and hails over much wider region. Among the cities, the Mobara City in the central part of the Boso Peninsula experienced the severest damage which has been concluded to be due to a tornado because of the following reasons:

1)A funnel cloud was recorded on a video film which was taken from $1 \mathrm{~km}$ distance. The video shows anti-clockwise rotation of the funnel cloud.

2)The wind directions estimated from damage survey at more than 60 locations show the existence of a convergent flow associated with a cyclonic vortex.

3)A sudden pressure drop of about $9 \mathrm{hPa}$ was recorded at the Chosei High School near the damage path (Sect.3.1.2). A number of habitants in the damage path reported symptoms such as singing in the ears and nosebleeding which seem to be caused by a sudden and large pressure drop.

It is not possible to tell if all the damages due to the heavy winds in the Chiba Prefecture were caused by tornadoes, since we have not made a damage survey over the cities except for the Mobara City. It is noted, however, that a funnel cloud was eyewitnessed in the Kamogawa City.

\subsubsection{Synoptic condition}


An extratropical cyclone of $1004 \mathrm{hPa}$ was located in the east of the Korea Peninsula at 0900JST in the morning of December 11. It moved eastward while developing and reached the Noto Peninsula at 1500. A cold front extended southeastward from the center of the cyclone. Another cyclone was generated on the cold front near the boundary between the Aichi and Miye Prefectures at about 1500 and moved eastward along the south coast of the Honshu Island while developing. It reached the boundary between the Shizuoka and Kanagawa Prefectures at 1800 , then the boundary between the Tokyo and Saitama Prefectures at 2100.

Figure 2 shows the surface weather map at 1800 , about 1 hour prior to the tornadogenesis. The cyclone is located at the west part of the Kanto Plain. The cold front is extending toward the Izu Peninsula. According to the Tokyo Radar of the Japan Meteorological Agency (JMA), a group of cumulonimbuses were located about $150 \mathrm{~km}$ east of the cold front. Two strong cells were located at the south edge of the cumulonimbuses. These two cells moved northeastward and generated the heavy winds and tornadoes in the Chiba Prefecture. Thus, the Mobara Tornado was generated in the warm sector of the extratropical cyclone. The results of the analysis of the mesoscale features which led to the tornadogenesis are described by Niino et al. ${ }^{3)}$.

\subsubsection{Meteorological records}

No meteorological records were obtained in the damage path of the tornado. However, several records were found near the path. These records* will be described in the following briefly. The analysis of these records is still in progress and its results will be reported elsewhere ${ }^{4)}$.

1)Wind speed and direction

Maximum wind speed of $30.8 \mathrm{~m} / \mathrm{s}$ was recorded at 1910 by an anemometer in the farm field of the Mobara Agricultural High School (at the height of $10 \mathrm{~m}$ at Point D) located about $900 \mathrm{~m}$ east of the tornado path. The wind direction was SE before 1850, then changed to $\mathrm{N} \sim \mathrm{E}$, and was $\mathrm{SE}$ right before the tornado cut the electric power supply. The anemometer at the Mobara Transforming Station of the Tokyo Electric Power Company(Point F), about $700 \mathrm{~m}$ east of the path, recorded the maximum speed of $29.5 \mathrm{~m} / \mathrm{s}$ at about 1920 . The variation of the wind direction at Point $\mathrm{F}$ is quite similar to that at Point D. The wind direction before 1840 was ESE, then showed large fluctuations, and was SE when the maximum speed was observed. The anemometer of the Environmental Division, the Chiba Prefecture, at Point B showed that the wind direction right before the electricity was stopped was NE. The wind directions at these three points are consistent with the cycloninc rotation of the tornado as revealed from the video image.

2)Pressure

Pressure records were obtained at Point $\mathrm{C}, \mathrm{D}$ and $\mathrm{E}$ in Fig. 3. A sudden pressure drop of about $9 \mathrm{hPa}$ was recorded at about 1900 at the Chosei High School (Point C), about $400 \mathrm{~m}$ east of the path. This pressure drop is considered to be due to the tornado itself. At the Mobara Agricultural High School (Point D), where the wind data were recorded, a pressure drop of $2 \mathrm{hPa}$ was recorded at about 1900 , and at the Fujimi Junior High School(Point E), about $2000 \mathrm{~m}$ west of the path, a drop of $2.5 \mathrm{hPa}$ was recorded. These pressure drops are considered to be due to a mesocyclone which spawned the tornado.

* The time described in section 3.1. will be based on the time recorded on barographs, anemograph and others. Since no caribration of the time was done, the description of time will involve some ambiguity. 


\subsection{Summary of the damage}

The damages due to the Mobara Tornado were summarized by the Mobara City on January 17, 1991, and is as follows:

1)Damage to human : 1 fatality and 73 injuries.

2)Damage to houses : 82 houses completely destroyed, 161 houses partially destroyed and 1,504 houses damaged.

3)Sum of damage in Japanese currency : 3,700 million yen.

The damages to lifelines summarized by the Fire Fighting and Disaster Prevention Section, the Chiba Prefecture, on December 17, 1990, are:

1)Stoppage of electric power: 13,000 houses. 2)Interruption of telephone: 1,000 circuits.

These damages were one of the severest caused by a tornado in Japan after the World War II and the Disaster Relief Act retroactive to December 11 was invoked to the Mobara City at 1700 on December 12.

\subsection{Damage distribution}

Figure 3 shows the distribution of damages to houses based on the data provided by the Mobara City. Solid circles show completely destroyed houses, solid triangles partially destroyed houses and open circles damaged houses. As will be described in Section 3.4.1., it has been found that the tornado moved northeastward. The first damage started near the intersection, where the old Route 128 meets Route 409, at Midori-Machi in the south part of the City. The width of the damage path increases northward along the JR Sotobo Line. The damage path includes the area around the JR Shin-Mobara Station and extends to the Ko-bayashi Area in the north part of the City. The length of the damage path is about $6.5 \mathrm{~km}$ and its average width is about $500 \mathrm{~m}$ ( The maximum width is $1200 \mathrm{~m}$ ).

Most of the severe damages to houses are concentrated in the Takashi Area in the center of the City. Figure 4 shows the damages in the Takashi Area photographed from a helicopter of the Kyodo-Tsushin Company on the morning of December 12. If the distribution of the damages near the Mobara City Gymnasium north of the Takashi Area is examined more carefully, one notices that the distribution has an eastward protuberance of about $500 \mathrm{~m}$. It is also noteworthy that several houses in the east part of the protuburence were totally destroyed or severely damaged.

\subsection{Characteristics of the tornado}

In the following the characteristics of the tornado as revealed from the damage survey are described.

\subsubsection{Tornado path}

Figure 5 shows the spatial distribution of wind directions obtained from the damage survey on December 12 . The wind directions were estimated from the directions to which road signs, poles, trees and crops on farms were leaning or fell down. It is seen that the wind directions on the east side of the dashed lines are S SE and those on the west side $W \sim N E$. Thus, the wind direction changes markedly across the dashed lines, which are essentially convergence lines. These lines are located in the northwest side of the heavily damaged area in Fig. 3. These facts show that the center of the tornado vortex moved along the dashed lines and the tornado had a cyclonic rotation in accordance with the analysis of the video image and wind records.

The tornado moved straightforwardly north-northeastward from Midori-Machi, where the first damage was noted, to the Mobara City Gymnasium. The tornado path derived from the distributions of wind directions and damages, however, becomes obscure near the Gymnasium. The path becomes evident again near the Route 128 in 
the north of the Gymnasium and extends north-northeastward. The tornado crossed the JR Sotobo Line right south of the ShinMobara Station and moved further straightforward to the Kobayashi Area.

It is noted that the tornado path seems to jump near the Gymnasium in addition to the eastward protuburence of the damage distribution. Two possible reasons may be considered: Firstly, the Gymansium whose dimensions are $77 \mathrm{~m}$ in width, $94 \mathrm{~m}$ in length and $21 \mathrm{~m}$ in height, could have blocked the inflow near the surface to the tornado vortex. This may have resulted in the generation of two vortices both in the east and northwest sides of the Gymnasium. Secondly, either the intensification of the circulation of the mesocyclone or the increase of surface roughness may have led to the change of the structure of the tornado vortex. Laboratory experiments ${ }^{5}$ ) show that in either case a thin laminar vortex can be transformed into a thick turbulent vortex or multiple vortices. In any case, it is evident that some structural change of the tornado vortex occured in the middle of its path. Further investigation concerning the cause of the structural change is currently in progress.

\subsubsection{Translational velocity}

The principle for estimating the translational velocity of the tornado is remarkably simple: One would only need to know the times at which two different places first experienced damage due to the tornado. In practice, however, to obtain accurate estimates for the times is extremely difficult. In the previous studies, the times have been estimated within an accuracy of 1 minute at least. In the present study, we have analyzed the time data recorded by a single computer at a control center of a security company. The computer records the times and places at which alarm signals due to damages to houses or stoppage of power supply are given. The accuracy of the time data is 1 second.

In addition to the accurate estimates described above, another estimate was made. The latter was based on the eyewitness evidence provided by a habitant and her 'playback' simulation in addition to the time data of stoppage of electric power supply.

1) Estimation based on the data of the security company

The earliest alarm signal, which notified a stoppage of electric power supply came from the Hayano Area in the south part of the Mobara City at 2 seconds before 1913. Three signals which notified direct damages to buildings and houses came from the Takashi Area in the center of the City at 01,07 and 10 seconds after 1915. The distances between the point in the Hayano Area and the three points in the Takashi Area are about $2000 \mathrm{~m}$. Accurate distances and the time differences give the estimate for the translational speed of $14.8,16.5$ and $17.8 \mathrm{~m} / \mathrm{s}$ whose average is $16.3 \mathrm{~m} / \mathrm{s}$.

2)Estimation based on the time of stoppage of electric power supply and eyewitness evidence provided by the habitant

The data of the security company gave estimates for the translational velocity in the southern half of the tornado path. Since electric power supply was stopped when the tornado hit the center of the City and cut the high voltage electricity cable $(6.6 \mathrm{kV})$, the time data of the security company were not available for the northern half of the path. The time for the stoppage of power supply was recorded by the Tokyo Electric Power Company and is between 1915 and 1916.

According to a habitant near the JR Shin-Mobara Station, severe wind due to the tornado occured after the stoppage of electric power supply. She experienced the stoppage of power supply on the first floor. 
She watched outside through windows and then went upstairs to find a flashlamp. The severe wind started when she found the flashlamp. A 'playback' simulation by herself gave a time interval of 90 100 seconds between the stoppage of power supply and the severe wind. The distance of $1600 \mathrm{~m}$ between the high tension cable and her house together with the time interval give an estimate for the translational velocity of $16.2 \sim 18.0 \mathrm{~m} / \mathrm{s}$.

The estimates for the translational velocity derived from two different method agree reasonably well and it may be concluded that the tornado moved north-northeastward at the speed of $16 \mathrm{~m} / \mathrm{s}$. The translational velocity of the tornado is considered to be closely related to the movement of the mesocyclone which spawns the tornado. The translational velocity of the mesocyclone obtained by the single Doppler radar at Meteorological Research Institute was $14.9 \mathrm{~m} / \mathrm{s}^{3}$ ) which again agrees well with that of the tornado.

\subsubsection{Estimation of maximum wind speed}

For the purpose of disaster prevention, it is very important to accumulate enough data on maxumum winds of tornadoes. Though direct measurements of the maximum wind due to the Mobara Tornado do not exist, estimates of maximum wind were made based on damages to constructions. It was assumed that the constructions were damaged by the pressure forces due to winds which were steady and uniform in the vertical direction. It is noted that the estimated wind speeds are additions of rotational winds and translational velocity of the tornado vortex. Most of the constructions used for the estimation of the wind speed are located near the ground. Therefore, it should be remembered that the estimated wind speeds are affected by local conditions such as a presence of buildings near the constructions. The estimated wind speeds as well as the types of the constructions used for the estimations are shown in Table 1. The locations of the constructions together with the estimated wind directions are indicated by arrows in Fig. 6. The largest wind speed was derived from a distortion of a road sign and is $78 \mathrm{~m} / \mathrm{s}$. Thus, it can be concluded that the Fujita scale of the Mobara Tornado is at least F3.

\section{SUMMARY}

The characteristics of the tornado which hit the Mobara City, the Chiba Prefecture, on the evening of December 11, 1990, were studied based on the damage survey and meteorological records. The following results were obtained:

1) The tornado was generated in the warm sector of a extratropical cyclone.

2) The tornado produced one of the severest damage in the Japanese record: 1 person died, 73 persons were injured, 82 houses completely destroyed, 161 partially destroyed and 1504 damaged.

3) The damage path is $6.5 \mathrm{~km}$ in length and $500 \sim 600 \mathrm{~m}$ in average width. The maximum width is $1200 \mathrm{~m}$.

4)The analysis of the damage distribution and the tornado path indicates that some structural change of the tornado vortex occured at the middle of its path.

5) The analysis of the times at which the initial damages ocurred at several buildings or houses gave a translational speed of the tornado of $16 \mathrm{~m} / \mathrm{s}$.

6) The maximum wind speed estimated from damages to constructions was $78 \mathrm{~m} / \mathrm{s}$; the Fujita scale of the Mobara Tornado is at least F3. 


\section{ACKNOWLEDGEMENT}

The authors express their hearty thanks to the habitants of the Mobara City who answered their questionnaire in the intervals of rehabilitation work, and to the Prefectural Office of Chiba, the City Office of Mobara, the Observatories of the Japan Meteorological Agency, the Mobara Agricultural High School, the Chosei High School, The Fujimi Junior High School, the Tokyo Electric Power Company and the information media who provided with various forms of data concerning the tornado. They are also grateful to Messrs. Hisao Ohno, Hiroshi Nirasawa, Osamu Suzuki, Nobuyuki Kinoshita and Dr. Izuru Takayabu, Meteorological Reserach Institute(MRI), and Mr. Hisashi Nagamatsu, Building Research Institute(BRI), who made the damage survey in corporation with them. The present investigation was made as a part of the Cooperative Project entitled "An Investigation on the Characteristics of the Air Flows Associated with the Tornado in the Mobara City" between MRI and BRI.

\section{REFERENCES}

1)Mitsuta, Y.(Ed.), 1983: Studies on Wind Disasters Caused by Tatsumaki(Tornadoes and Waterspout) and Severe Local Storms in Japan, (in Japanese with English Abstract), Final Report of the Special Research Project for Natural Disaster Sponsored by the Ministry of Education, 124pp. 2)Fergusson, E.W., F.P. Ostby and P.W. Leftwich, Jr., 1989: The Tornado Season of 1986, Mon. Wea. Rev., 117, 221-230.

3) Niino, H., O. Suzuki, T. Fujitani, H. Nirasawa, H. Ohno, I.Takayabu, N. Kinoshita, T.Murota and N.Yamaguchi, 1991: An Observational Study of the Mobara Tornado, Proceedings of the Third Tornado Symposium, Norman, Okalahoma, April 2-5, 1991( to appear).

4)Niino, H., T. Fujitani, Y. Yamaguchi and T.Murota,1991: On the Characteristics of the Mobara Tornado, December 11, 1990., (in Japanese), J. Japan Soc. Wind Eng., (to be sumitted).

5)Church, C.R., J.T.Snow, G.L.Baker and E.M.Agee, 1979: Characteristics of Tornadolike Vortices as a Function of Swirl Ratio: A Laboratory Investigation, J.Atmos. Sci., 36, 1755-1776. 


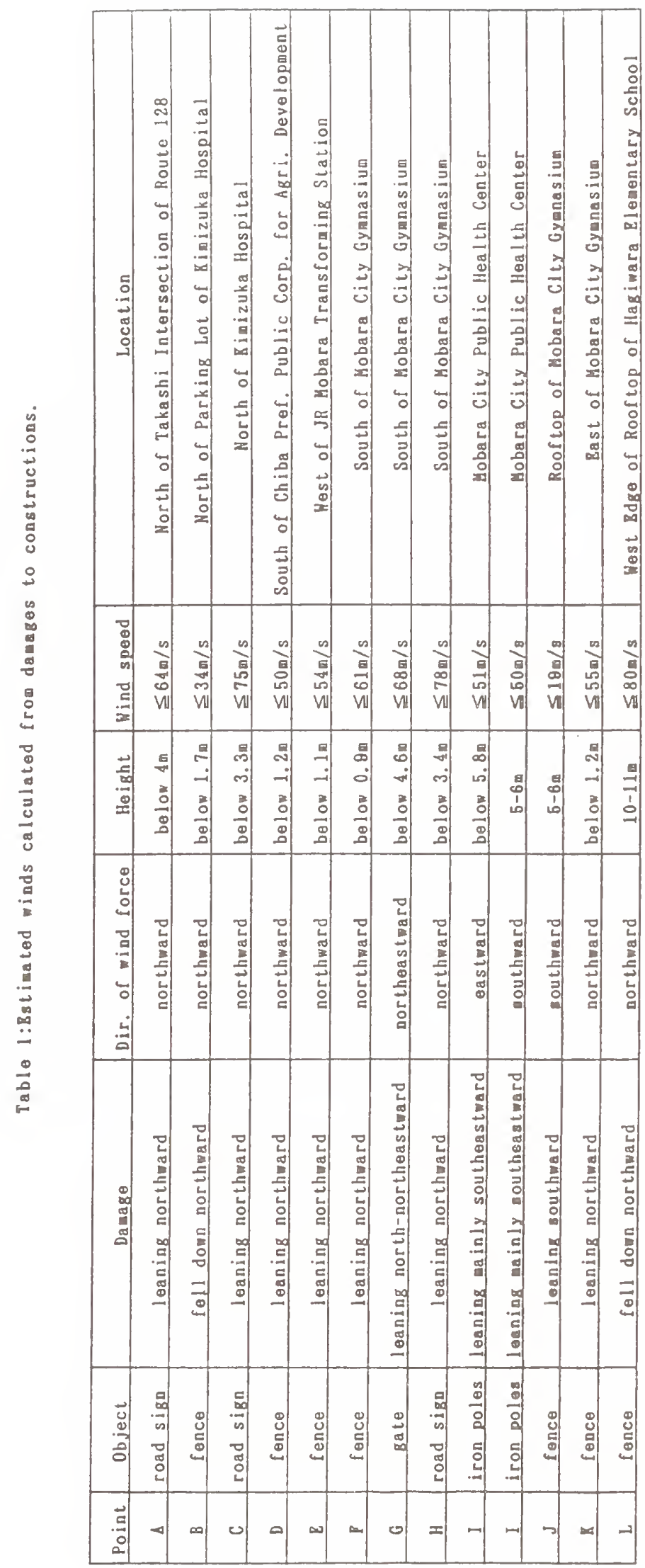




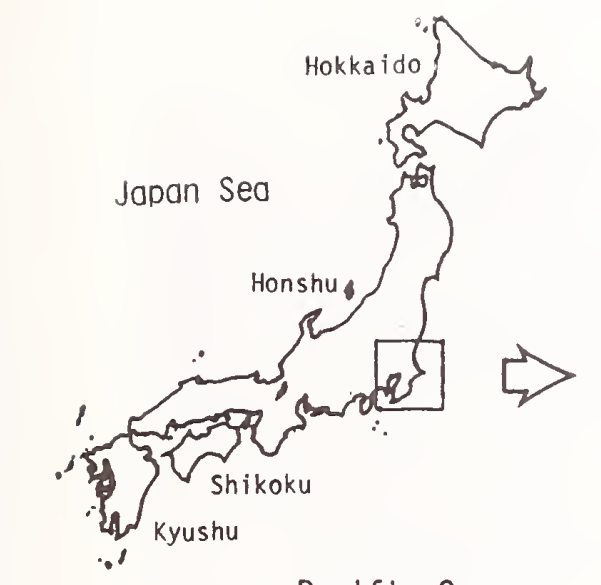

Paclfic Ocean

- Okinawa

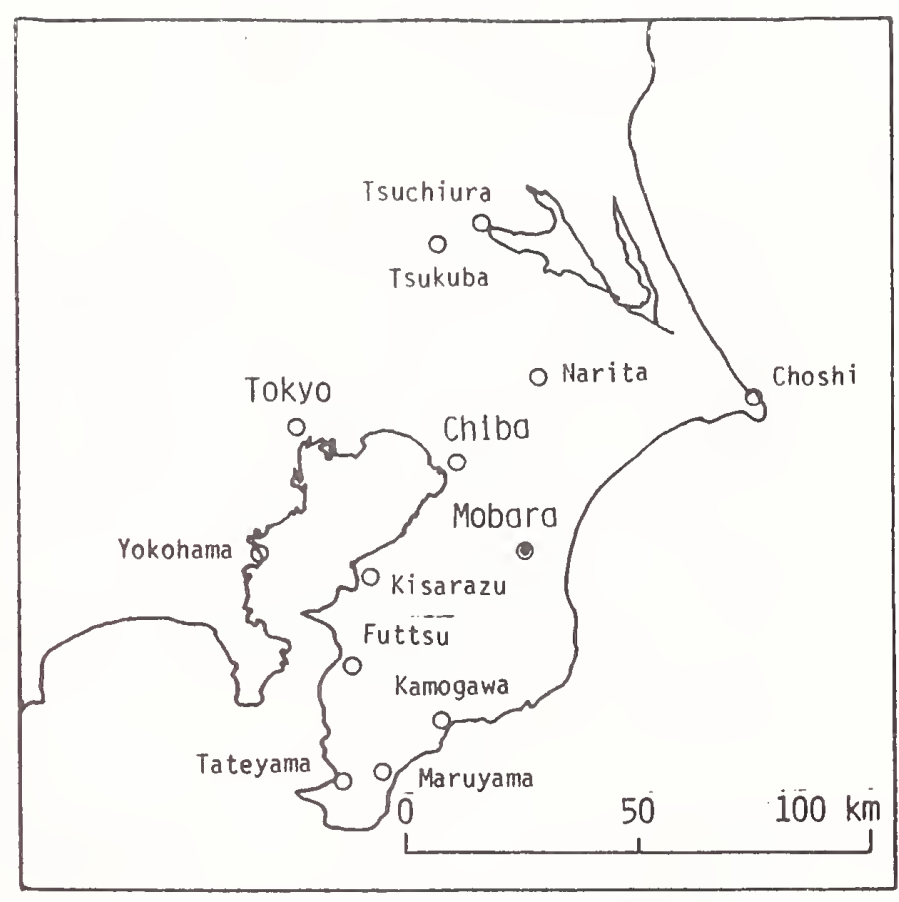

Pig. 1: Locations of cities in the Chiba Prefecture.

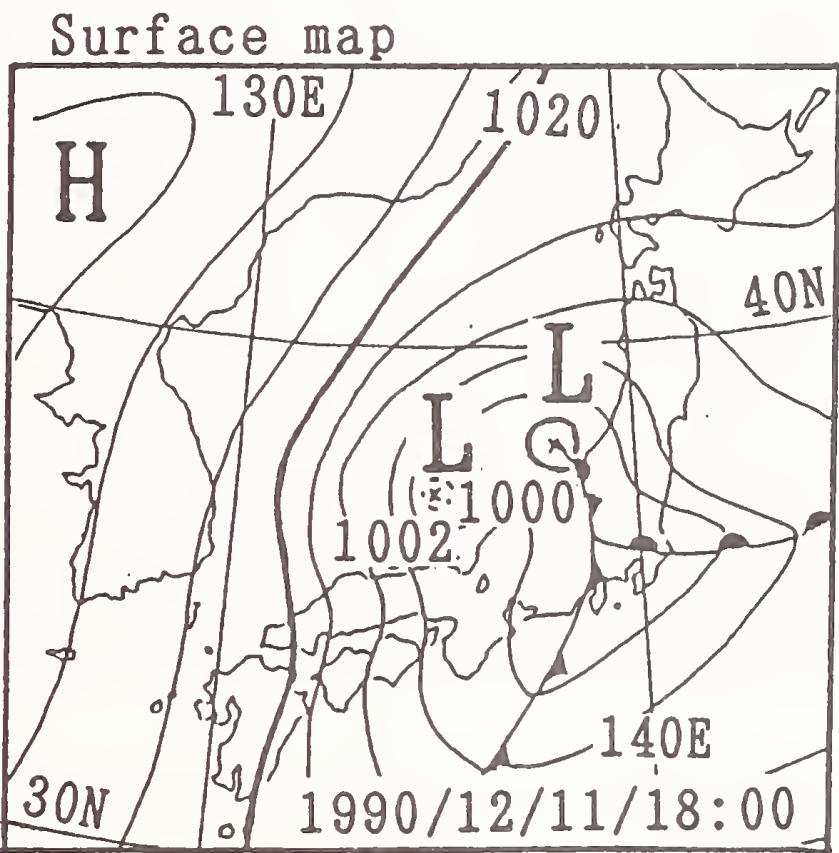

Pig. 2: Surface weather map at 1800JST on December 11, 1990. 


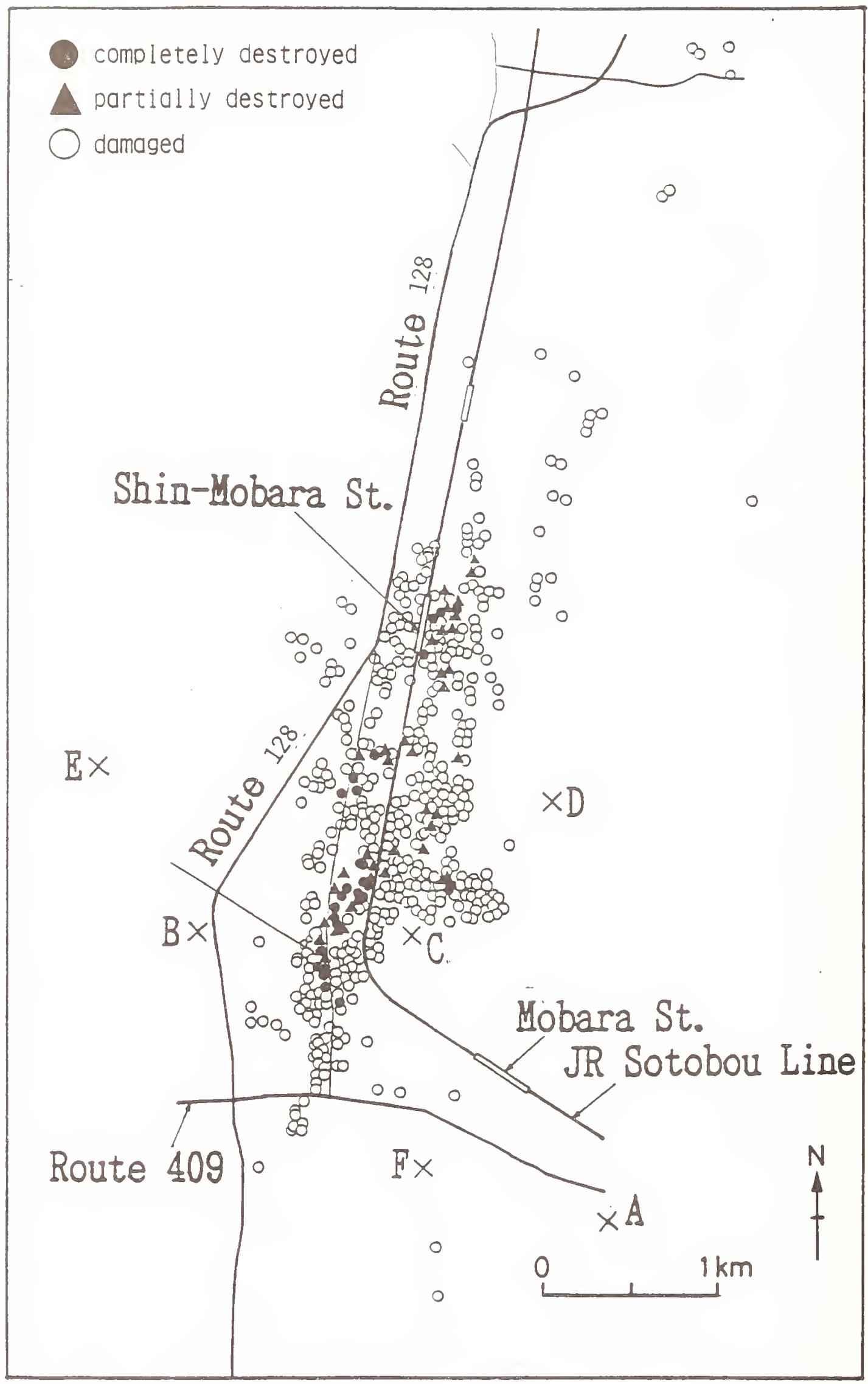

Pig. 3:Damage distribution in the Mobara City. 


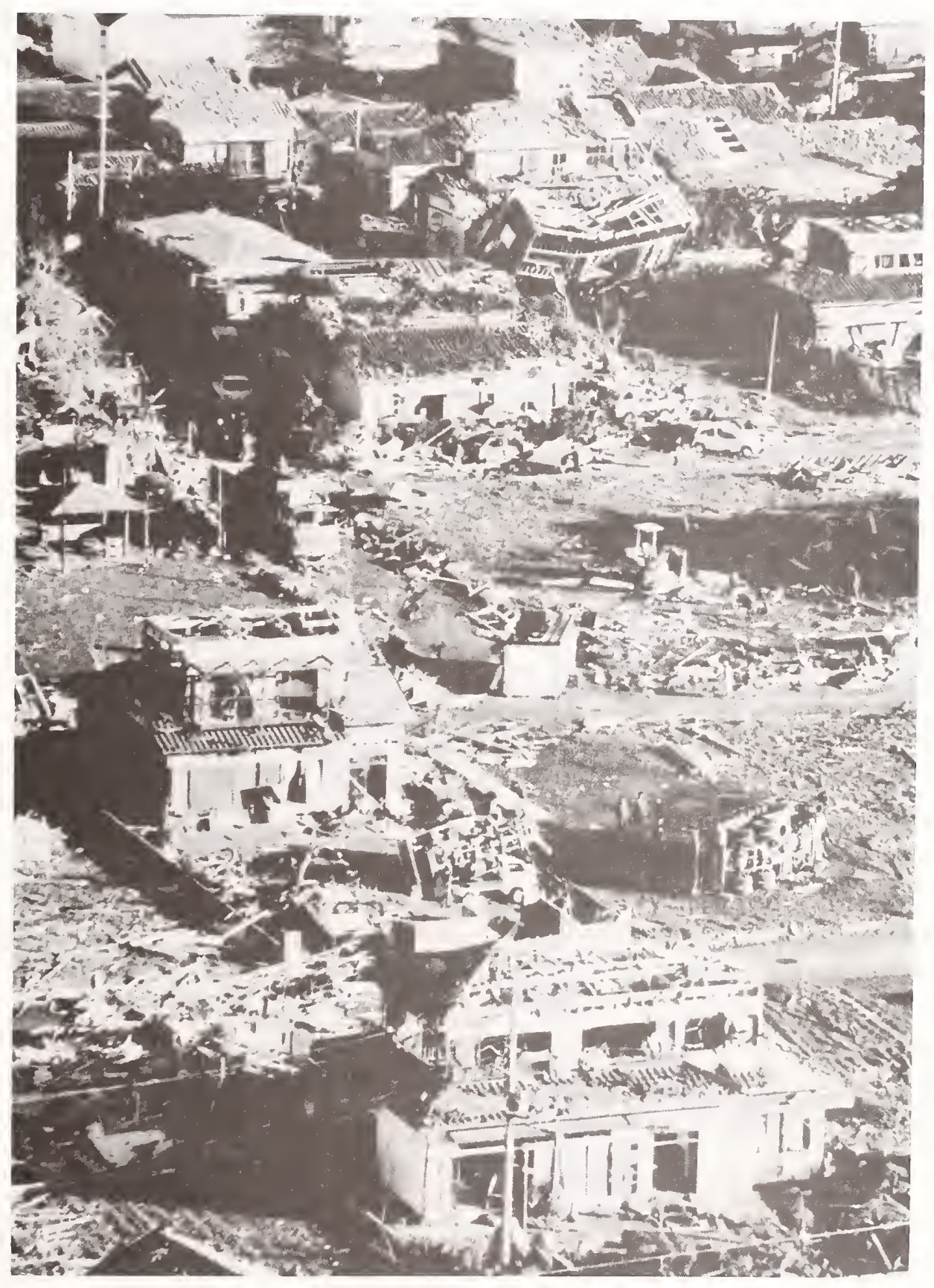

Pig. 4:Aerial Photograph of the damaged aroa (the Takashi Area of the Mobara City)(Courtesy of Kyodo-Tsushin Company). 




Pig. 5:Distribution of estimated wind directions and the tornado path. 


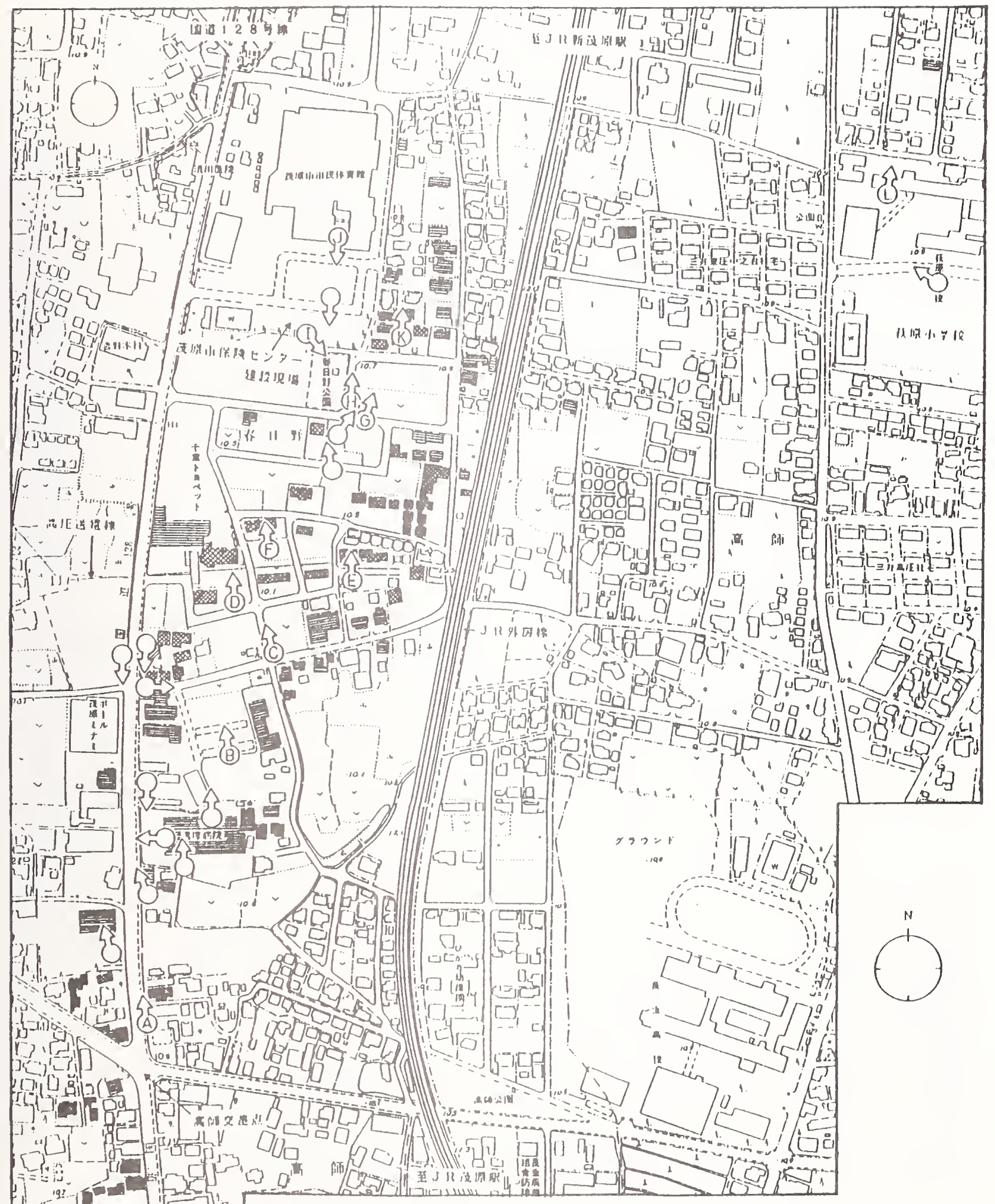

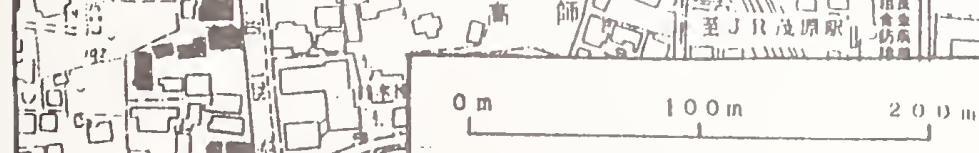

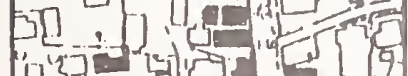
1] (1) E.
Pig. 6:Distribution of damagos to housos in tho Takashi Aroa togother with locations of tho constructions usod for ostimating tho wind spond. Tho diroctions to which tho constructions woro loaning and foll down aro shown by arross. and the charaters in the arrows donoto the typo of constructions describod in Tablo 1. 国 shows compintoly hostroyod houso anil partially destroyed houso. 


\section{Hurricane Hugo in Perspective}

by

Peter R. Sparks*

\section{ABSTRACT}

Wind and surge conditions in Hurricane Hugo are reviewed and their relationship to the extent and nature of damage is discussed. It is shown that in areas where the gust wind speed exceeded $50 \mathrm{~m} / \mathrm{s}$, $10 \%-20 \%$ of the buildings were destroyed or seriously damaged. At $40 \mathrm{~m} / \mathrm{s}$ the figure was about $6 \%$ and at $30 \mathrm{~m} / \mathrm{s}$ only $1 \%$ were seriously damaged. Surge damage, although locally severe, only accounted for about $10 \%$ of the overall damage.

In general damage was related to the local conditions not to the relative severity. Thus the wind damage in Charleston, where the wind conditions had a recurrence interval of 50 years, was similar to that in Sumter where the same wind speed had a recurrence interval of more than 200 years. It is suggested that this was due to the fact that more than $95 \%$ of structural systems and 99\% of building enclosures had been selected without direct reference to design wind conditions which had been based on appropriate recurrence intervals. For recently constructed buildings design flood levels did have a bearing on the structural form.

Certain types of buildings and components performed very poorly, primarily mobile homes, unreinforced masonry buildings, older single family dwellings close to the ocean and some newer ones with masonry foundations, most roofing materials and some wall cladding components.

The severe disruption of the electricity supply system, beginning when the wind reached about $30 \mathrm{~m} / \mathrm{s}$, and its effect on the community is discussed and contrasted with the much better performance of the telephone system.

It is concluded that the extensive damage resulted in general not from unprecidented wind and surge conditions, but from the failure to use available knowledge on wind and surge effects in the selection of building and utility systems.

KEYWORDS: buildings; damage; Hurricane Hugo; storm tides; tropical cyclones; utilities.

\section{INTRODUCTION}

By the time Hurricane Hugo crossed the coast of South Carolina just after midnight on September 22,1989 , it had already caused over $\$ 2$ billion worth of damage in the Caribbean. In its passage through the states of North and South Carolina it caused further damage estimated to be nearly $\$ 7$ billion, making it the most expensive storm in the United States history.

* Department of Civil Engineering, Clemson University, Clemson, SC 29634-0911 
At landfall Hugo had a central pressure of $934 \mathrm{mb}$ and an eye about $50 \mathrm{~km}$ in diameter. Winds circulated in a counterclockwise direction about the eye, but the high forward speed produced a highly asymmetric wind field, increasing speeds to the right of the track and reducing them to the left. The highest winds and worst storm surge occurred where the northeastern part of the eye-wall crossed the coast about $35 \mathrm{~km}$ northeast of the city of Charleston at Bulls Bay. The high forward speed $(13 \mathrm{~m} / \mathrm{s}-18 \mathrm{~m} / \mathrm{s})$ and a track almost normal to the coast resulted in very unusual wind conditions in the interior of South Carolina and the western part of North Carolina.

\section{WIND CONDITIONS}

A number of anemometers measured wind conditions during the passage of Hugo. Unfortunately only one of these did so under standard meteorological conditions and no anemometers survived in the area of highest winds.

Figure 1 shows the probable maximum gust wind speeds at a height of $10 \mathrm{~m}$ in the most exposed locations, based on corrected observations in Charleston, Myrtle Beach, Beaufort, Sumter, Camden, Florence, Charlotte, and Hickory plus the use of a theoretical wind field model.

\section{STORM TIDES}

Continuous records of water level were obtained near the Customs House in Charleston and at Winyah Bay near Georgetown. Additional still water levels were obtained by surveys of tide marks along the coast.

In the Charleston area tides ranged from $3 \mathrm{~m}$ above mean sea level in Charleston Harbor to $4.5 \mathrm{~m}$ at the north end of the Isle of Palms. At the south end of Bulls Bay the tide reached $6 \mathrm{~m}$ and at the north end of the bay, in the fishing village of McLellanville, it was $4.2 \mathrm{~m}$ to $4.8 \mathrm{~m}$. In the resort areas along the northern coast, including Myrtle Beach, tides were $3 \mathrm{~m}$ to $4 \mathrm{~m}$ above mean sea level. The normal tidal range is less than $2 \mathrm{~m}$ and much of the occupied land is only $2.5 \mathrm{~m}$ to $4 \mathrm{~m}$ above mean sea level.

In the areas that experienced the eye of the storm, Charleston, Folly Beach, Sullivans Island and the Isle of Palms, the offshore winds before the eye held the surge back until the winds dropped as the eye passed. The water level then rose rapidly, remained up while the trailing eyewall passed and then dropped as the winds subsided.

To the northeast of the eye the surge rose more steadily, reaching its peak at about the time of the highest winds. The surge began to drop as the winds diminished and moved around to the south.

To the southwest of the eye the offshore winds suppressed the surge and little flooding was experienced.

\section{SEVERITY OF THE STORM}

Based on its central pressure, Hugo was the 10th most intense storm to strike the United States this century, being about the same strength as the 1926 storm 
in Miami and Hurricane Hazel which struck the Carolinas in 1954. The hurricane produced the highest storm tide recorded on the Atlantic coast this century, but a similar tide was recorded at Savannah Beach near the South Carolina-Georgia border in 1893 and higher tides might have been experienced in the Charleston area in the storm of 1752. However, in the southern part of Bulls Bay the tide was a very rare event which would be expected to be exceeded on average only once in over 500 years. In McLellanville the mean recurrence interval was about 300 years and at the northern end of the Isle of Palms about 200 years. On Sullivans Island, in Charleston, and along most of the northern coast the mean recurrence interval was approximately 100 years and about 80 years at Folly Beach.

In the Charleston area the winds had a mean recurrence interval of about 50 years, but similar conditions had not been experienced since 1911. They had however also been experienced in 1893 , since records began in 1879 . Based on the description of damage, the wind conditions in Hugo were almost certainly exceeded in 1752 and possibly in a number of other storms in the 300 year history of the city.

In the Bulls Bay area the wind conditions probably had a mean recurrence interval of about 100 years, possibly as high as 200 years. It was about 60 years in McLellanville and less than 20 years in the Myrtle Beach area.

The combination of an intense storm and high forward motion produced rare wind conditions in the interior of South Carolina and in the Charlotte area of North Carolina. At Sumter, $150 \mathrm{~km}$ from the coast, the mean recurrence interval was probably between 200 and 300 years. The very gusty wind conditions in Charlotte, $300 \mathrm{~km}$ from the point of landfall, may have had a recurrence interval more than 100 years.

\section{BUILDING PERFORMANCE}

Since the early 1960s engineers have recommended that buildings and other structures be designed for conditions with a mean recurrence interval of 50 to 100 years. Well designed structures usually incorporate factors of safety, so serious structural damage should not be expected in conditions with a mean recurrence interval less than 500-1000 years. Such conditions existed only for surge action in Bulls Bay and probably did not exist anywhere for wind action. Nevertheless the damage was widespread. The extent of damage appeared to be related to the local conditions, not the relative severity of those conditions, nor was damage confined to buildings constructed before appropriate design criteria were available. In retrospect this was not surprising.

Most of the damage occurred in South Carolina where the building stock consists of approximately $75 \%$ wood-framed single-family dwellings, $15 \%$ mobile homes, and about $10 \%$ other types of buildings. These other types, however comprise about $35 \%$ of the value of construction. 
Single-family dwellings are usually constructed on traditional lines, sometimes influenced by prescriptive building code requirements. These requirements generally do not adequately reflect the need to resist wind and water effects.

Since 1976 mobile homes have been constructed to Federal Government standards. The wind loading requirements in these are much lower than those generally set for conventional construction and reflect a very poor understanding of wind effects on buildings.

In South Carolina buildings over $450 \mathrm{~m}^{2}$ or three or more stories in height must be designed by a registered architect or engineer. Even these buildings often contain components selected on the basis of empirical design procedures and product data which do not adequately consider the effects of wind (or surge).

Under these circumstances it is unlikely that, of all of the buildings affected by Hurricane Hugo, more than 5\% had structural systems designed to resist appropriate wind and surge loads. Probably less than $1 \%$ of the buildings had roofing and cladding systems specifically designed for appropriate wind conditions. Design wind speeds based on recurrence intervals therefore had very little bearing on the wind resistance of most buildings.

Design flood levels had more of a bearing on coastal construction because the availability of insurance through the government-run
National Flood Insurance Program was tied to satisfying floor elevation requirements based on the 100 year flood level. Unfortunately the flood maps were not very accurate and buildings were often constructed without consideration of the forces generated by the storm surge and the associated wind loads.

Table 1 gives the insured losses for buildings and their contents. The number of insurance claims for each type of building is in almost exactly the same proportion as its relative contribution to the building stock and the amount of damage is in the same proportion as its relative value. Although the flood damage was widely reported and many buildings were destroyed, flood losses were only about $10 \%$ of the total property losses and accounted for only $4 \%$ of the insurance claims.

Table 2 gives the Red Cross estimate of the number of housing units damaged. This was made shortly after the storm, subsequently insurance claims were made on nearly 3 times as many properties as were initially observed to be damaged. Ultimately claims were made on $30 \%$ of buildings in South Carolina but only $3 \%$ were seriously damaged or destroyed. The vast majority of damage was due to relatively minor wind damage followed by extensive rain damage.

The distribution of damage was closely related to gust wind speeds, the proportion of mobile homes, and, for surge damage, proximity to the ocean. In some rural areas where $20 \%-30 \%$ of the population 
lives in mobile homes, $70 \%-80 \%$ of the buildings completely destroyed were of that type.

On the islands near Charleston and on the shores of Bulls Bay, nearly all buildings experienced some wind or surge damage and in some coastal communities nearly $50 \%$ of the ocean-front buildings were completely destroyed.

In counties where the wind gusted to more than $50 \mathrm{~m} / \mathrm{s}$, at least $80 \%$ of the buildings experienced some damage and 10\%-20\% were destroyed or experienced extensive damage. Damage rates diminished as the wind speed dropped. At $40 \mathrm{~m} / \mathrm{s}$ about $6 \%$ of buildings were destroyed or seriously damaged. At $30 \mathrm{~m} / \mathrm{s}$ less than $1 \%$ received significant damage.

Certain types of buildings and some building components performed poorly. As mentioned earlier mobile homes had a high damage rate, but so did single-story unreinforced-masonry buildings, older pre-engineered metal buildings, older single-family dwellings close to the ocean and some newer ones using masonry foundations, mostly roofing materials and some wall cladding elements. The poor resistance of many of these buildings could be traced to poor building code requirements and inappropriate design and construction practices.

\section{PERFORMANCE OF UTILITIES}

The electric utility companies had constructed transmission and distribution systems which were very vulnerable to wind damage. The decision to use wood poles for high voltage transmission systems and overhead local distribution systems was probably made on economic grounds. Although interruption of power supply is common in the region in severe thunderstorms and had been experienced in earlier hurricanes, the extreme vulnerability of the system had not been appreciated by the utility companies nor their customers. It had certainly not been appreciated that loss of electric power for an extended period of time would have such an effect on the basic essentials of life - the ability to obtain food and water and the provision of wastewater facilities.

Approximately 1.5 million people, living in areas where the wind speed exceeded $30 \mathrm{~m} / \mathrm{s}$, lost electric power. The utility companies made tremendous efforts to restore power, but the extent of the damage was so great that in many cases the system could not be repaired, but had to be rebuilt, usually to the previously existing standards. Eight days after the storm only $23 \%$ of the customers in the Charleston area had power and in some rural areas it was two to three weeks before power was restored.

The telephone companies had attempted to reduce the vulnerability of their systems by burying cables. In most areas there was very little interruption of telephone service. Other forms of communication, including television and radio broadcasts and even two way radio communications of emergency services, were seriously affected by 
loss of electric power and the collapse of transmission towers.

\section{CONCLUSIONS AND LESSONS LEARNED}

Hurricane Hugo taught South Carolina and the nation some very expensive lessons. The potential for disaster had been recognized but the political and economic systems made it difficult to remedy the situation. It is worth examining what went wrong.

The state had chosen a laissez-faire system of building control. The power to adopt and the responsibility for enforcement of building codes had been delegated to local jurisdictions. This resulted in considerable variation in the quality of control, from some of the best in the country to no control at all.

The model building code adopted showed a very poor understanding of the wind and surge effects on structures and permitted forms of construction in wood and masonry which were inconsistent with the loading requirements. Lacking proper deemed-to-comply documents, the performance requirements of the code were unenforceable for non-engineered structures. Using the permitted forms of construction in the code led to structural systems unsuitable for a hurricane, tornado, and earthquake prone area such as South Carolina.

In poor rural areas mobile homes were the only affordable form of housing for many people. These homes were built to inadequate standards and when delivered to site were often not properly anchored.

Despite the fact that cladding failures can pose a threat to public safety and even compromise the structural integrity of a building, cladding systems had been specified by those without adequate training in structural design. The professional licensing laws had permitted this.

In recent years owners had often been unwilling to pay for adequate professional inspection during construction. The quality of construction had suffered. Compounded by poor building code requirements, the use of inappropriate design professionals and inadequate material testing standards, this had led to cladding systems and, in some cases, structural systems with very low wind resistance.

The insurance industry had been willing to insure property with little regard for its wind resistance. Premiums were often based on the building's fire resistance. Thus there was little or no incentive for the owner to improve wind resistance in order to meet insurance requirements.

The electric utility companies had been permitted to construct transmission and distribution systems which were very vulnerable to damage by a hurricane. The public was unaware of how fragile the system was or how dependent they were on a continuous supply of electricity.

Finally, there was the lack of experience. For 30 years prior to 
Hugo, during which time the hurricane-prone areas of the state expanded rapidly, no major hurricanes hit the South Carolina coast.

From an engineering standpoint the dominating lesson is clear and the solution is straightforward. Design and construction practices must reflect the loads which are known to occur in conditions with reasonable recurrence intervals. The prospects for achieving this and correcting past mistakes are not good.

The building stock changes slowly and the fragmented building control system in the United States is ill-equipped to impose improved construction standards. Based on the success of the National Flood Insurance Program, the best prospect for improved construction is by insurance industry action. That industry certainly learned its lesson in Hugo when it paid out the equivalent of all property insurance premiums collected in South Carolina in the last 5 years.

Not all lessons learned were concerned with what went wrong. Properly designed buildings performed well and the telephone service was a fine example of what can be achieved with good planning. Perhaps the most valuable lesson learned was that modern technology can be used very effectively to monitor storms and warn coastal residents of impending danger.

In 1893 a storm of similar strength to Hugo drowned 1000-2000 people in South Carolina. Prior to Hugo's landfall over 250,000 people were evacuated from the coastal area. Only a handful of people were killed, none by drowning in their homes. It is a poor reflection on the construction industry that many evacuees returned to buildings that were in considerably worse condition than their counterparts after the 1893 storm.

\section{ACKNOWLEDGEMENTS}

This study of the effects of Hurricane Hugo was made possible by grants from the National Science Foundation, South Carolina Sea Grant Consortium, South Commission on Higher Education, the Federal Emergency Management Agency and Clemson University. This support is gratefully acknowledged. 
Table 1. Insured Damage to Buildings and Contents in South Carolina

Number of Claims

Total Amount

(\$ million)

Wind

Conventional dwellings $\quad 287456$ (74\%) 1423 (55\%)

Mobile homes

$57808(15 \%)$

$172(7 \%)$

Commercial property

$41282(11 \%)$

$997(38 \%)$

Total wind damage

386546

2592

Flood

All types

15739

320

Table 2. Number of Dwelling Units Destroyed or Damaged in South Carolina

\begin{tabular}{lrrrr}
\hline & Destroyed & $\begin{array}{r}\text { Major } \\
\text { Damage }\end{array}$ & $\begin{array}{r}\text { Minor }{ }^{*} \\
\text { Damage }\end{array}$ & Total \\
\hline Single family dwellings & 3783 & 18146 & 57698 & 79627 \\
Apartments & 313 & 2647 & 8948 & 11908 \\
Mobile homes & 5200 & 5976 & 9063 & 20239 \\
Total & 9296 & 26769 & 75709 & 111774 \\
& & & & \\
\hline
\end{tabular}

* Externally observable damage only, excludes damage to outbuildings, fences, decks, porches etc. 


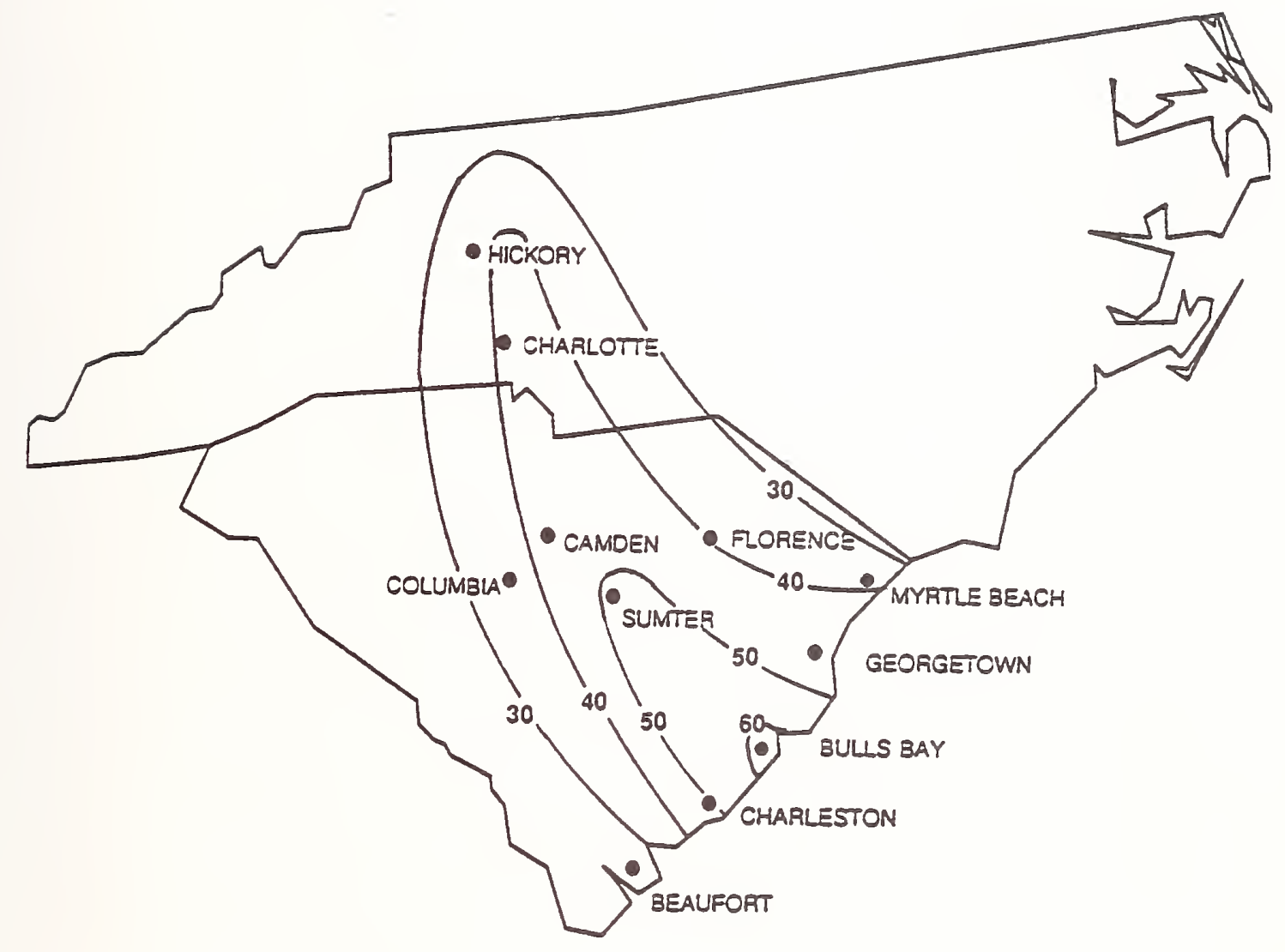

Figure 1. Probable Maximum Gust Wind Speeds (m/s) 


\section{Theme II}

\section{Earthquake Engineering}




\section{ABSTRACT}

The Worldwide Earthquake Risk Management (WWERM) Program was initiated as a cooperative effort of the Agency for International Development (AID), U.S. Office of Foreign Disaster Assistance (OFDA), and the U.S. Geological Survey in late 1989. The initial objective of the program is to develop an action plan and conduct a twoyear pilot program to demonstrate the utility, importance, feasibility, and need for uniform global earthquake hazard mapping and risk assessment/management. Three areas have been selected for the pilot studies: chile, Indonesia, and Morocco. The WWERM program is a project of the International Decade for Natural Disaster Reduction (IDNDR) .

KEYWORDS :

international; risk

Earthquake; hazard;

\section{INTRODUCTION}

The Worldwide Earthquake Risk Management (WWERM) Program was developed as an outgrowth of an Executive Briefing on "Strategic Planning to Reduce Economic Impacts of Earthquake Hazards throughout the World" held at the National Academy of Sciences, Washington, D.C., on March 8 and 9, 1988 (Williams and Hays, 1988). This Executive Briefing established the need for a more quantitative evaluation of the potential for earthquake disasters and for the assessment of the economic impact and casualty loss potential of such disasters. In addition, the need to assess the longrange economic losses associated with destructive earthquakes was also outlined.

\section{OBJECTIVES OF THE PROGRAM}

The initial objectives of the program have been to develop an action plan and conduct a two-year pilot program in each of three geographic regions to demonstrate the utility, importance, feasibility, and need for uniform global earthquake hazard mapping and risk assessment/management, in preparation for and as a program linked to the Decade for Natural Disaster Reduction.

The three geographic regions are Morocco, Chile, and Indonesia. The principal objective in these three areas is to demonstrate the feasibility and utility of defining the earthquake hazard through the development of probabilistic ground-motion maps and the estimation of future earthquake economic losses in selected pilot studies. The demonstration of the feasibility of these types of studies will lead to a broader program that will form the basis for risk management, lifesaving preparedness planning, and the development of mitigation strategies.

Additional goals are to develop a five-year implementation plan with OFDA and to obtain financial commitments (co-funding) from USAID missions, host governments, international organizations, and the private sector. These kinds of commitments will support the worldwide scope of the WWERM program and allow it to be fully integrated into and be a major contribution to the International Decade of Natural Hazard Reduction.

\section{RATIONALE FOR THE PROGRAM}

Earthquake risk management (the reduction of both the economic and life loss resulting from earthquakes) requires the following: (1) The quantitative assessment of the hazard; and (2) the evaluation of the risk (loss) in terms of the expected hazard. No efficient plan for earthquake risk management is possible unless it is based on an assessment of both the spatial and temporal nature and magnitude of the hazard and risk. As an example, large earthquake ground motion in the Atacama Desert of Northern chile represents a real and considerable earthquake hazard but negligible risk since structures and population at risk are very minimal. Conversely, moderate earthquake ground motion in santiago, the capital, would result in significant economic loss and casualties.

The examples cited are obvious, but on a global scale the evaluation of expected earthquake losses is a difficult scientific and technical problem of considerable subtlety. The evaluation of the magnitude and spatial distribution of expected losses is, however, an essential prelude to successful risk management because it: (1) allows the always inadequate resources for disaster mitigation to be applied to areas of catastrophe potential on a rational basis; and (2) identifies areas of catastrophe potential that may not be easily recognized because of the combination of unusual ground motion (and related geological hazards, such as landsliding and liquefaction) with large exposures of poorly reinforced structures with high occupancy.

${ }^{1}$ U.S. Geological Survey, Denver Federal Center, Box 25046, MS 966, Denver, co 80225

${ }^{2} U . S$. Office of Foreign Disaster Assistance, 2201 C Street, N.W., Room 1261A, Washington, D.C. 20523

${ }^{3}$ U.S. Geological Survey, National Center, MS 905, 12201 Sunrise Valley Drive, Reston, VA 22092 
Obvious examples are the Mexico City disaster of 1985 and the 1970 earthquake in Peru (which killed approximately 60,000 people).

This project represents a pioneering international effort to quantitatively evaluate earthquake hazard and risk and, therefore, to provide an improved technical base for risk management.

\section{PROGRESS}

\subsection{Indonesia}

Visits were made to Jakarta and Bandung in June 1990 by S. T. Algermissen (Project Chief), Paul C. Thenhaus (Geologist), and E. V. Leyendecker (Engineer). Through the interest and encouragement of OFDA and AIDIndonesia, the visit and meetings culminated in a project proposal to AID-Indonesia outlining a project design for earthquake risk management training in Indonesia. Recommendations in this proposal are for a collaborative hazard and risk assessment of the Gorontalo area in sulawesi Province, Indonesia, involving two future training trips by USGS staff followed by a technical workshop upon project completion that would document hazard evaluation methods, products, and uses in mitigating the earthquake hazard and risk. Post-workshop project evaluation is also included. Additional funding for the expanded program in Indonesia was supplied both by OFDA and AID-Indonesia.

The area selected for the case history is the City of Gorontalo in Sulawesi. The city of Gorontalo and the surrounding area in sulawesi have several advantages as a pilot study area in Indonesia: (1) The area is highly seismic (Figure 1): (2) a damaging earthquake occurred near there on April 18, 1990 and damage data are available for the earthquake; and (3) data are available in the Gorontalo area. The surficial geology is an important factor in altering the levels of ground motion and, consequently, an important element in estimating future damage.

Earthquake damage and geological data for Gorontalo and the surrounding area will be obtained from scientists at the Geological Research and Development Center at Bandung. These damage data will aid USGS in developing vulnerability (loss to structures as a function of ground shakingl relationships for Gorontalo. The Geological Survey is developing a probability ground shaking and earthquake loss model for the case history area.

In summary, sufficient data are available for the Gorontalo area such that it provides an excellent location for the demonstration of seismic hazard and risk (loss) assessment. The steps in the hazard and risk study are:

(1) Development of a probabilistic model for the computation of the expected earthquake ground motion in sulawesi (specifically the Gorontalo area). This model is developed from an analysis of the earthquake catalog, seismotectonic maps and seismic wave attenuation data developed under the OFDA-USGS-SEASEE program. The effects of local surficial geology on ground shaking in the Gorontalo area will also be incorporated into the model.

(2) Compute the expected ground motion in the study area for periods of time of interest of, for example, 10, 50, and 250 years. For example, the expected ground motion in a 50-year period is used in seismic design provisions of model building codes in the United States. These maps are routinely prepared by the U.S. Geological Survey (see, for example, Algermissen and others, 1990).

(3) Use the ground-motion maps in (2) above to calculate the expected future earthquake losses in the Gorontalo area for various time period of interest.

\section{2 chile}

A visit to Santiago, Chile, was made by S. T. Algermissen in late June 1990 to discuss the WWERM Project with possible chilean collaborators. The development of suitable earthquake hazard evaluations (probabilistic ground-motion maps) is somewhat eased in chile because a concurrent project is underway in chile (an AID-OFDAUSGS cooperative project) to provide a hazard evaluation. Thus, the emphasis in discussions in chile has been on the selection of a suitable area for risk (earthquake loss) assessment.

Considerable data on earthquake losses and vulnerability exist in central chile as a result of the studies of Dr. Joaquin Monge of the University of Chile, of the damage resulting from the large, $M_{3}=7.8$ central chile earthquake of 1985. The area chosen for the pilot study of hazard and risk assessment in chile is the community of Maipú (Figure 2). In the 19th century, Maipú was an agricultural community, but it is now largely a residential area in the southwestern part of the greater santiago metropolitan complex. Nearly all of the information necessary for a seismic risk study is already available: (1) An accurate population count; (2) the spatial distribution of structures with regard to construction type: and (3) data on damage from past earthquakes. Considerable additional information is available on damage resulting from the 1985 earthquake, nature of the surficial geologic materials, etc. An example of the housing data available for Maipú is shown in Table 1.

A technical workshop on the project, with co-sponsorship by the United Nations Disaster Relief Organization (UNDRO) is planned for Santiago, Chile, in October 1991.

\subsection{Morocco}

Morocco is a highly seismic country that has experienced many damaging earthquakes (Figure 3). A cooperative program of 
seismic hazard and risk assessment is being planned through Dr. Oriss Ben Sari, Director of the Center for Technical and Scientific Research (CTSR) in Rabat. CTSR will supply data on the distribution of population, classes of buildings, and the nature of the surficial geology in the study area. CTSR already has an active seismological network research program and a 22-station seismological network. They have nearly completed a seismotectonic map of the entire count ry.

\section{SUMMARY}

The oreliminary phase of the WWERM program is proceeding on schedule. It is hoped that the scope of the project can be expanded sufficiently to provide meaningful comparative measures worldwide, such that these comparisons provide an improved quantitative basis for earthquake disaster management and contribute substantially to the International Decade for Natural Disaster Reduction.

\section{REFERENCES}

(1) Algermissen, S.T., Perkins, D.M., Thenhaus, P.C., Hanson, S.L., and Bender, B.L., 1990, Probabilistic Earthquake Acceleration and Velocity Maps for the United states and puerto Rico, U.S. Geological survey Misc. Field studies Map, $\mathrm{MF}-2120$.

(2) Williams, Mary E. and Hays, Walter W. (1988) Strategic Planning to Reduce Economic Impacts of Earthquake Hazards throughout the World, Proceedings of the Executive Briefing, National Academy of Sciences, Washington, D.C., March 8-9, 1988, U.S. Geological Survey, Open-File Report 88-361, 149 pps and Appendices. 


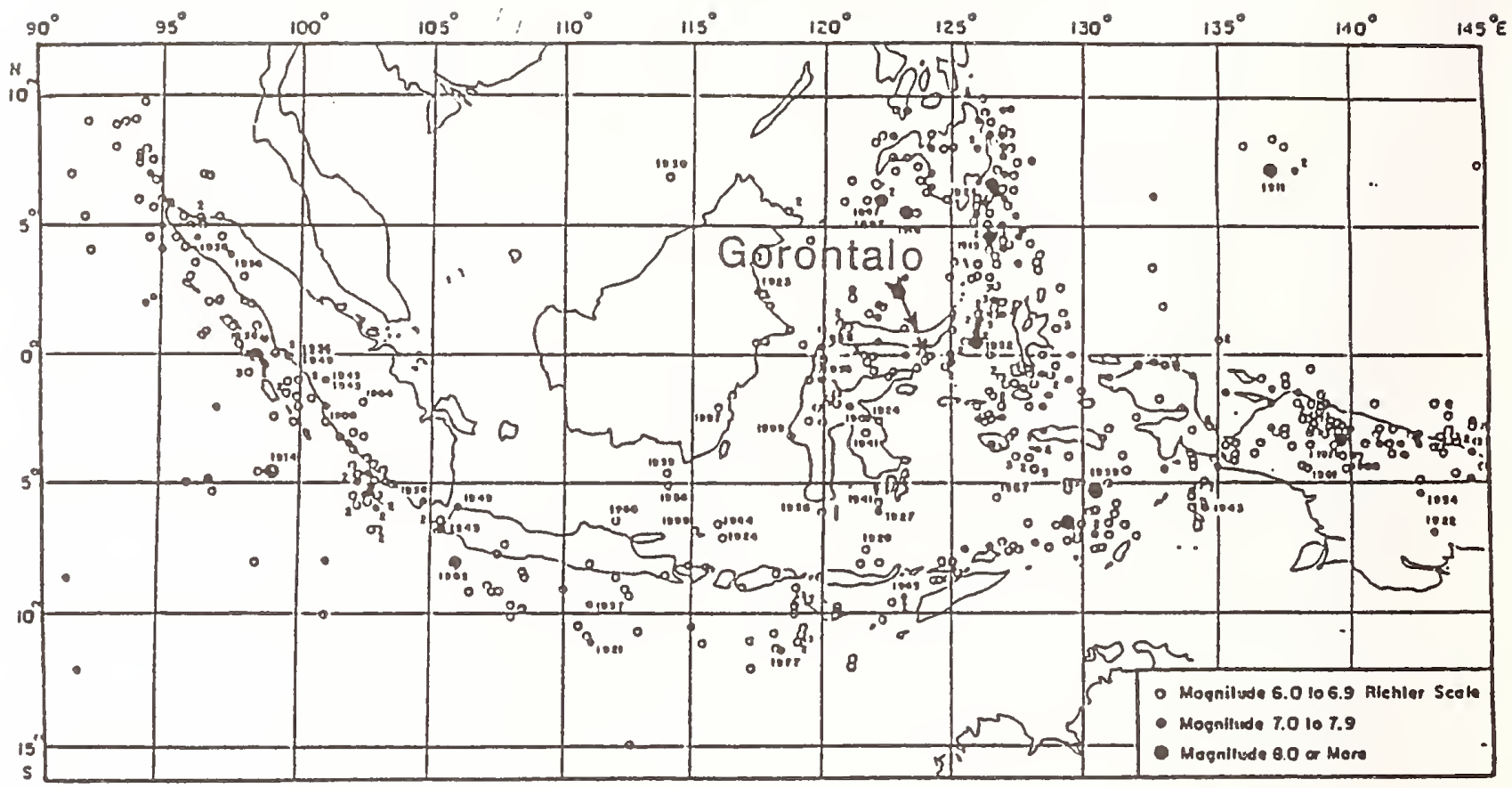

Figure 1. Seismicity of Indonesia showing the major shallow earthquakes 1897-1984 and the 1ocation of the selected study area. Note the high rate of seismicity in the Gorontalo area.

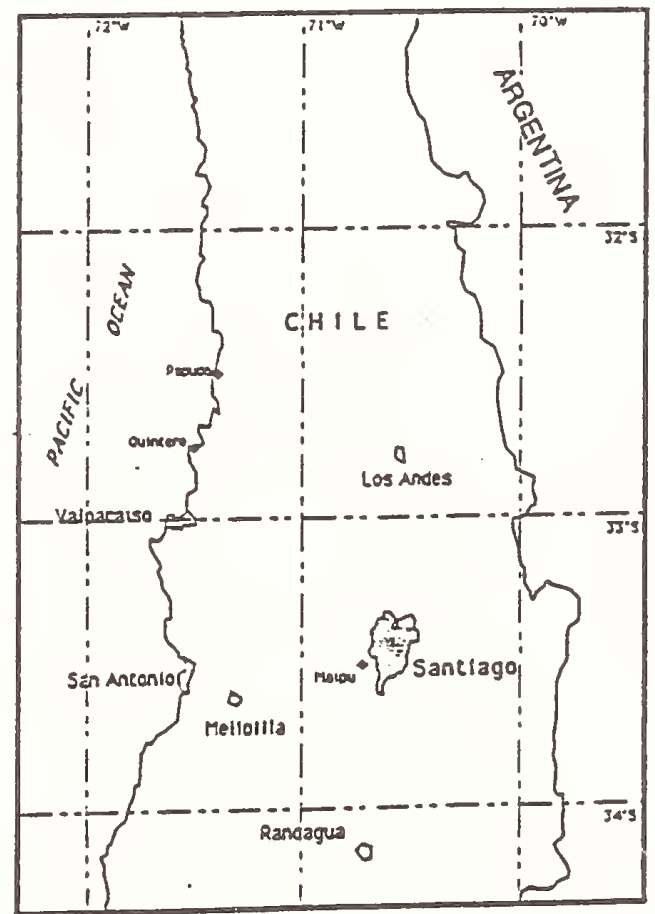

Figure 2. Location map showing the project area in Chile (Maipú) 


\begin{tabular}{|c|c|c|c|c|}
\hline \multirow{3}{*}{$\begin{array}{l}\text { TIPO DE } \\
\text { VIVIENDA }\end{array}$} & \multicolumn{4}{|c|}{ COMUNA } \\
\hline & \multicolumn{3}{|c|}{ MAIPU } & CERRILLOS \\
\hline & UABANO & RURAL & TOTAL & URBANO (TOTAL) \\
\hline \multirow{8}{*}{$\begin{array}{l}\text { Particular: } \\
\text { casa } \\
\text { departamento } \\
\text { mejora,emergencia } \\
\text { viv. de conventillo } \\
\text { callampa } \\
\text { rancho,ruca o choza } \\
\text { móvil } \\
\text { otro tipo }\end{array}$} & 24.042 & 1.291 & 25.333 & 13.822 \\
\hline & 20.693 & 1.219 & 21.912 & 10.095 \\
\hline & 1.343 & - & 1.343 & 1.296 \\
\hline & $\begin{array}{r}1.882 \\
103\end{array}$ & . & $\begin{array}{r}1.882 \\
103\end{array}$ & $\begin{array}{c}2.056 \\
332\end{array}$ \\
\hline & 6 & $=$ & 6 & 18 \\
\hline & 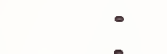 & 63 & 63 & - \\
\hline & 15 & $\begin{array}{l}1 \\
8\end{array}$ & $\begin{array}{r}1 \\
23\end{array}$ & $\begin{array}{c}6 \\
19\end{array}$ \\
\hline & & & & 16 \\
\hline \multirow{5}{*}{$\begin{array}{l}\text { Colectlva: } \\
\text { residencial, pensión } \\
\text { hotel, motel, posada } \\
\text { institución } \\
\text { otro tipo }\end{array}$} & 25 & 4 & 29 & \\
\hline & $\cdot$ & - & - & - \\
\hline & - & - & - & - \\
\hline & 15 & 3 & 18 & 14 \\
\hline & 10 & 1 & 11 & 2 \\
\hline TOTAL & 24.067 & 1.295 & 25.362 & 13.838 \\
\hline
\end{tabular}

Table 1. Distribution of buildings by construction type in the communities of Maipú and Cerrillos in the metropolitan area of Santiago, Chile

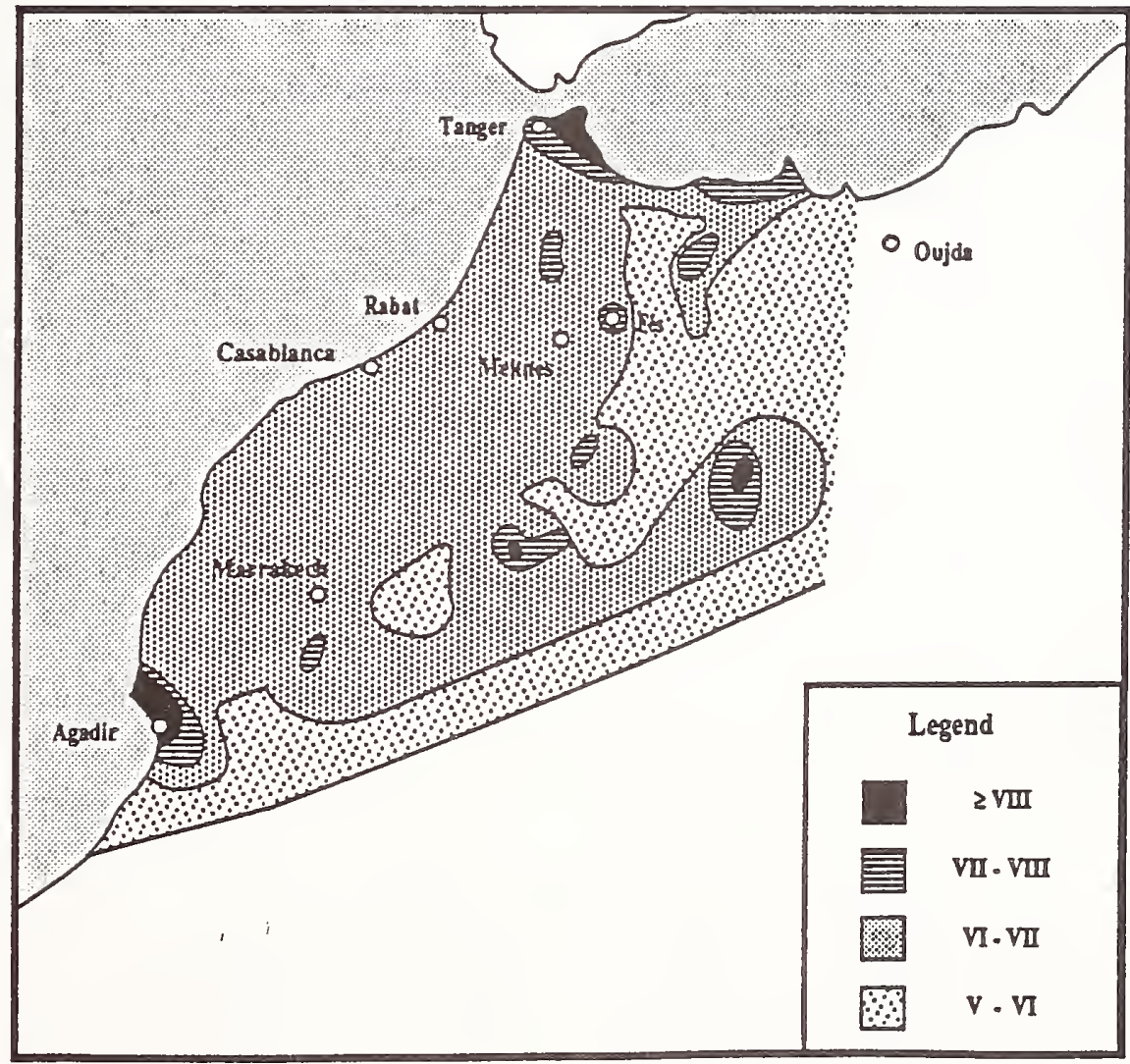

Figure 3. Maximum Modified Hercalli intensity map of Morocco for the period 1901-1980 



\section{Influence of Embankments on the Liquefaction of Ground}

BY

Yasuyuki Roga', Jun-ichi Roseki ${ }^{2}$, Takao Shimazu ${ }^{3}$ and Osamu Matsuo ${ }^{4}$

ABSTRACT

Of the influence of the embankments on the liquefaction of sand deposit the characteristics of the excess pore water pressure are examined through the results of shaking table tests of model embankment on a liquefiable ground. Emphasis is laid on the maximum pore pressure and the relationship between liquefaction resistance factor and pore pressure generation in the free field and below the embankment.

REY WORDS: Liquefaction, Embankment, Model shaking table test

\section{INTRODUCTION}

It has been well known since the Niigata earthquake that the liquefaction of ground might cause large damages to many kinds of structures. As a consequence of many studies on liquefaction several methodologies to assess the liquefaction potential have been developed and some of them have already been adopted in technical codes. However, most of them are only applicable to predict the behaviour of level free field ignoring the effect of structures to the ground. And the effect of the structure on the liquefaction of ground is not yet clarified.

We sometimes confront a situation to evaluate the stability of the embankment on liquefiable ground during earthquakes. In that case the liquefaction potential or the excess pore water pressures of the ground near embankments are needed for the stability analyses. The aim of this paper is to distinguish their characteristics in the free field and the ground below the embankment based on model tests.

\section{RELATED PREVIOUS STUDIES}

\subsection{Liquefaction characteristics of the level} ground

There have already been substantial knowledge about liquefaction of level ground. In order to represent the stability of the ground against liquefaction, the liquefaction resistance factor $F_{L}$ is defined as below(1),

$F_{L}=\frac{R}{L}$

in which $\mathrm{R}$ is the dynamic shear resistance ratio, $L$ is the shear stress ratio during earthquakes.

Seed et al. formulates the excess pore pressure in the ground(see Fig.1)(2):

$\frac{u_{\sigma}}{\sigma \rho_{0}}=\frac{2}{\pi} \sin ^{-1}\left(\frac{N}{N_{L}}\right)^{1 / 2 \alpha}$

in which $u_{0}=$ excess pore pressure generated by cyclic loading, $\sigma^{\prime} \circ=$ initial effective confining stress, $N_{L}=$ number of cycles required to cause liquefaction under uniform stress conditions, $\mathrm{N}=$ number of loading cycles, $\alpha=$ experimental constant.

In Japan the excess pore pressure due to earthquakes is often formulated by use of $F_{L}$ in Eq. (1) based on the following assumption.

Assumption: the dynamic shear resistance ratio $\mathrm{R}$ and the number of loading cycles $\mathrm{N}$ are in a linear relationship when both are represented in logarithmic scale, that is,

$\mathrm{R}=\mathrm{a} \mathrm{N}{ }^{\mathrm{b}}$

in which a, b = experimental constant.

If the shear stress ratio during earthquakes $L$, whose number of cycles to cause liquefaction is $\mathrm{N}_{L}$, is applied by $\mathrm{N}$ cycles(Fig.2), it follows from Eq. (3)

$\mathrm{L}=\mathrm{a} \mathrm{N}_{\mathrm{L}}{ }^{\mathrm{b}}$

Combining Eqs. (3) and (4) leads to

$F_{L}=\frac{R}{L}=\left(\frac{N}{N_{L}}\right)^{0}$

${ }^{1}$ Head, Soil Dynamics Division, Construction Equipment and Method Department, Public Works Research Institute, Ministry of Construction, Japan.

?Researcher, ditto.

${ }^{3}$ Assistant, ditto.

${ }^{4}$ Assistant Director, Economic Cooperation Bureau, Ministry of Foreign Affairs, Japan. Formerly, Senior Researcher, Soil Dynamics Division, Construction Equipment and Method Department, Public Works Research Institute, Ministry of Construction, Japan. 
This equation is rewritten as

$\frac{N}{N_{L}}=F_{L}{ }^{1}>0$

Substituting this into Eq. (2) leads to the following relationship between the excess pore pressure and the liquefaction resistance factor $F_{L}$ :

$\frac{\mathrm{u}_{\mathrm{O}}}{\sigma^{\prime} \mathrm{o}} \sim \frac{\mathrm{N}}{\mathrm{N}_{\mathrm{L}}}=\mathrm{F}_{\mathrm{L}}{ }^{1 / \mathrm{b}}$

Take the technical guideline for designing of common utility $\operatorname{duct}(3)$ for instance, the equation

$\frac{\mathrm{u}_{\mathrm{O}}}{\sigma^{\prime} \mathrm{O}}=\mathrm{F}_{\mathrm{L}}^{-7}$

is proposed.

2.2 Evaluation method of the influence of an embankment on the ground liquefaction and the stability of the embankment

The effects of the embankments on liquefiable grounds are;1)increase of the overburden pressure, 2) increase of the irertia force, 3)additional initial shear stress, 4) spatial difference of lateral confining condition.

Stability analysis methods of the embankments on liquefiable grounds during earthquakes are; 1) slip surface analysis method, 2) local safety factor method through FEM, 3) permanent deformation analysis method through FEM. Of these the method 1) is mainly adopted in technical codes in Japan. The resistance of the ground for the stability analysis might be expressed either in terms of total stress on the basis of accumulated strain due to cyclic loading or in terms of effective stress through excess pore pressure caused by cyclic loading. The latter formulation is frequently used in Japanese technical codes(4).

Fig. 3 shows a typical procedure in Japan for the stability analysis of the embankments on liquefiable grounds.

The equation below is often used for the stability analysis of an embankment shown in Fig.4(4):

$\mathrm{F}_{\mathrm{s}}=\frac{\sum\left\{\mathrm{c}^{\prime} \cdot 1+\left(\mathrm{W}-\mathrm{u}_{\mathrm{o}} \cdot \mathrm{b}-\mathrm{u}_{\mathrm{e}} \cdot \mathrm{b}\right) \cdot \cos \alpha \cdot \tan \phi^{\prime}\right\}}{\sum\left(\mathrm{W} \cdot \sin \alpha+\mathrm{k}_{\mathrm{h}} \cdot \mathrm{W} \cdot \mathrm{h} / \mathrm{R}\right)}$

in which $c^{\prime}, \phi^{\prime}=$ cohesion and shear resistance angle of soil,

$W=$ total weight of a slice,

1 = length of the arc of a slice bottom,

$\mathrm{b}=$ width of a slice, $u_{0}=$ pore pressure in ordinary condition,

$u_{e}=$ excess pore presure caused by earthquake loading,

$k_{n}=$ design seismic coefficient,

$R=$ radius of a slip circle,

$h=$ height of the center of slip circle from the center of gravity of a slice (see Fig.5)

The excess pore pressure $u_{\ominus}$ is calculated from $\mathrm{Eq} .(5)$. That is, a horizontal overburden is assumed for the soil below the embankment ignoring its shape effect, then the liquefaction resistance factor $F_{L}$ is calculated to estimate the excess pore pressure in the ground.

\subsection{Liquefaction potential from cyclic loading tests in the laboratory \\ The characteristics of sands have been} examined by cyclic triaxial tests or cyclic torsion shear tests. The liquefaction characteristics of level ground has been simulated by isotropically consolidated undrained cyclic loading of triaxial specimens since the beginning of the study of liquefaction(5). When cyclic torsional shear tests are conducted, isotropically or anisotropically consolidated specimens are applied undrained cyclic torsional loading under the condition of confined axial displacement (6). When the ground near structures or the soil in a slope is concerned, cyclic axial loading is given to anisotropically consolidated triaxial specimens $(7,8)$. When cyclic torsional shear tests are conducted, undrained cyclic torsional shear is applied after some initial torsional shear is given to isotropically or anisotropically consolidated specimens. In one case the axial displacement is confined during cyclic loading (9) while in another the axial displacement is not confined with constant confining stresses(10). Such different loading methods and displacement confining conditions give different progressive deformation and pore pressure generation of soils. As one of the examples, Finn et al. formulated the pore pressure generation under undrained cyclic loading of anisotropically consolidated triaxial specimens as follows(Fig.6)(8):

$\frac{u_{\circ \searrow}}{\sigma_{\Xi \circ}}=\frac{1}{2}+\frac{1}{\pi} \cdot \sin ^{-1}\left[\left(\frac{N}{N_{\odot \circ}}\right)^{1 / \alpha}-1\right]$

in which $u_{c y}=$ pore pressure, $\sigma_{30}=$ lateral confining stress, $N=$ number of cycles, $N_{50}=$ number of cycles to develope a pore pressure equal to $50 \%$ of the confining stress $\sigma 3_{0}, \alpha=$ parameter depending on the consolidation ratio $\mathrm{K}_{0}=\sigma_{10} / \sigma_{30}$. 
2.4 Liquefaction characteristics in the ground near a structure from model shaking table tests

Yoshimi and Tokimatsu performed shaking table tests of rigid structures on sand layers and observed the change of pore pressure near a structure and settlement behaviour(Fig.7)(11).

The writers conducted shaking table tests of embankments on liquefiable grounds, which exhibited different behaviour of pore pressures in the free field and below the embankment (Figs.8,9)(12).

\section{EXPERIMENTAL INVESTIGATION}

\subsection{Outline}

The difference of the pore pressure in the free field and below an embankment was precisely examined from model shaking table test results. Investigated were shaking table tests on the model shown in Fig.10. The spatial distribution of pore pressure was first examined and then the acceleration and pore pressure time history were analyzed on the basis of the cumulative damage theory to obtain the relationships between the liquefaction resistance factor $F_{L}$ and the pore pressure ratio $\mathrm{r}_{\mathrm{u}}$.

\subsection{Outline of model tests}

Three test cases are analyzed in this paper. Model embankments were placed on saturated sand layers as shown in $\mathrm{Fig.10}$. The relative densities of the ground were $73-79 \%$. Sinusoidal excitation with different frequencies were applied as shown in Table 1. In respective test cases the magnitude of the excitation was increased stepwise, however, only the first cases that the liquefaction of the ground first occurred were analyzed.

\subsection{Method of data arrangement and calculation}

Fig.ll shows the procedure of the data arrangement and calculation.

1) Calculation of pore pressure ratio

The time history of pore pressure ratio is calculated from time history of the pore pressure by dividing by the effective overburden pressure $\sigma_{v o}$ '. The pressure $\sigma_{\text {vo }}$ can be calculated from Eq. (9) one dimensionally by use of the unit weight of the model and the depth of pore pressure gauges. However, as the installed depth of the gauges might have some error it was estimated from the record of pore pressure when liquefaction surely occurred as shown in Fig. 12 .

$\sigma_{\vee 0}{ }^{\prime}=\gamma^{\prime} \cdot z+\gamma_{t} \cdot H$

in which $\gamma^{\prime}=$ effective unit weight, $z=$ depth from the ground surface, $\gamma_{t}=$ total unit weight, $\mathrm{H}=$ height of embankment.
2) Arrangement of the distribution of excess pore pressure ratio $\mathrm{ru}$

The distribution of the pore pressure ratio $r u$ was arranged at every specified time.

3) Calculation of dynamic shear stress ratio $\tau_{\text {o }} / \sigma_{\text {vo' }}$

The dynamic shear stress ratio $\tau_{\mathrm{d}} / \sigma_{\text {vo' }}$ was calculated from Eq.(10) (see Fig.13).

$\frac{\tau_{\mathrm{d}}}{\sigma_{\mathrm{vo}}},=\frac{1}{\sigma_{v 0}}, \sum_{i} \frac{\gamma \mathrm{i} \cdot \mathrm{hi}}{\mathrm{g}} \cdot \mathrm{Ai}$

in which $\sigma_{v o}{ }^{\prime}=$ initial effective overburden pressure, $\mathrm{A} i=$ response acceleration at the $i-t h$ layer, $\mathrm{h} i=$ thickness of the $i$-th layer, $\quad \gamma i=$ unit weight of the $i$-th layer, $g=$ acceleration of gravity.

4) Calculation of the number of cycles required to cause liquefaction

The number of cycles when the pore pressure ratio $\mathrm{r}_{\mathrm{u}}=\mathrm{l}$ is counted for every pore pressure gauge in the free field.

5) Assumption of the liquefaction resistance curve

The shape of the liquefaction resistance curve, which is required to apply the cumulative damage theory, was assumed to be given by Eq.(11). This curve was determined referring to the liquefaction resistance curve of Toyoura sand obtained from cyclic torsion shear tests as shown in Fig. 14.

$$
\begin{aligned}
& \tau_{\mathrm{a}} / \sigma_{\mathrm{mo}} \geqq 0.3 ; \\
& \tau_{\mathrm{a}} / \sigma_{\mathrm{mo}}-0.3=-1.25 \log \left(\mathrm{N}_{\mathrm{c}} / \mathrm{N}^{\prime}\right) \\
& \tau_{\mathrm{d}} / \sigma_{\mathrm{mo}}<0.3 ; \\
& \tau_{\mathrm{a}} / \sigma_{\mathrm{mo}}-0.3=-0.11 \log \left(\mathrm{N}_{\mathrm{c}} / \mathrm{N}^{\prime}\right)
\end{aligned}
$$

Eq.(11) can be written as

$$
\mathrm{N}_{\mathrm{c}} / \mathrm{N}^{\prime}=\mathrm{f}\left(\tau_{\mathrm{a}} / \sigma_{\mathrm{mo}}{ }^{\prime}\right)
$$

in which $f=$ equation to give the relation between cyclic stress ratio and normalized number of cycles, $\mathrm{N}_{\mathrm{c}}=$ number of cycles to cause liquefaction when uniform cyclic stress ratio ‘d $/ \sigma_{\mathrm{mo}}$ ' is applied, $\mathrm{N}^{\prime}=$ parameter to locate the liquefaction resistance curve, $\sigma_{\text {mo }}{ }^{\prime}=$ effective mean stress, which is calclated assuming $\mathrm{KO}=0.5$.

6) Evaluation of liquefaction resistance curve The parameter $N^{\prime}$ was evaluated from the following procedure.

In order to apply the cumulative damage theory to an irregular train of shear stress ratio, it is divided into every half cycle then the cumulative damage up to the $i$-th half cycle is given by the equation below, 
$\mathrm{D}=\sum_{\mathrm{i}} \frac{0.5}{\left(\mathrm{~N}_{\mathrm{C}}\right) \mathrm{i}}$

in which $\left(\mathrm{N}_{\mathrm{C}}\right) \mathrm{i}=$ number of cycles to cause liquefaction when the i-th half cycle stresis ratio ( $\left.\tau_{\mathrm{a}} / \sigma_{\text {mo' }}\right) i$ is repeatedly applied.

Substituting Eq.(12) into Eq.(13) leads to the equation below.

$$
D=\frac{1}{N^{\prime}} \cdot \sum_{i} \frac{0.5}{f\left\{\left(\tau_{\mathrm{a}} / \sigma_{\mathrm{mo}}\right)_{1}\right\}}
$$

A value of $\mathrm{D}>1.0$ indicates a liquefied condition and $\mathrm{D}<1.0$ a non-liquefied condition, therefore following equations are obtained for respective conditions.

Liquefaction condition:

$$
N^{\prime} \leqq \sum_{i} \frac{0.5}{f\left\{\left(\tau_{\mathrm{d}} / \sigma_{\mathrm{mo}}\right)_{i}\right\}}
$$

Non-liquefaction condition:

$$
N^{\prime}>\sum_{i} \frac{0.5}{f\left\{\left(\tau_{d} / \sigma_{\text {mo }}\right)_{i}\right\}}
$$

Substituting the shear stress ratios up to the cycles to liquefaction, which was obtained in 4), into Eq.(15) and the shear stress ratios up to one half cycle before the above cycles to liquefaction into Eq.(16), we can estimate the possible range of the parameter $N$ ' which locates the liquefaction resistance curve. A possible range of $\mathrm{N}^{\prime}$ is estimated by conducting the same procedures for every pore pressure gauge, the average $\mathrm{N}^{\prime}$ of the ground can be evaluated.

7) Calculation of equivalent cyclic shear stress ratio $\mathrm{L}$

When the parameter $N^{\prime}$ to locate the liquefaction resistance curve is obtained, the cumulative damage $D$ up to the $i$-th half cycles is computed from the above Eq.(14). Then the equivalent cyclic shear stress ratio $L$ is determined as the amplitude of uniform cyclic shear stress ratios of 20 cycles to give the same cumulative damage.

The relationship between the cumulative damage $D$ due to the shear stress ratios up to the $i$-th half cycles and the number of cycles $N_{L}$ to cause liquefaction is given by

$\mathrm{D}=\sum_{1}^{40} \frac{0.5}{N_{L}}=20 / \mathrm{N}_{L}$

Thus

$N_{L}=20 / D$

The equivalent shear stress ratio $\mathrm{L}$ corresponding to $\mathrm{N}_{\mathrm{L}}$ is computed by the following equations obtained from Eq.(11)

$$
\begin{aligned}
& N_{L} \leqq N^{\prime} ; \\
& L=0.3-1.25\left(\log N_{L}-\log N^{2}\right) \\
& N_{L}>N^{\prime} ; \\
& L=0.3-0.11\left(\log N_{L}-\log N^{\prime}\right)
\end{aligned}
$$

8) Evaluation of dynamic shear resistance ratio $R$

Substituting $\mathrm{N}_{\mathrm{L}}=20$ into Eq.(19), the dynamic shear resistance ratio $\mathrm{R}$ to cause liquefaction in 20 cycles is computed.

9) Computation of liquefaction resistance factor $\mathrm{F}_{\mathrm{L}}$

The liquefaction resistance factor $F_{L}$ is computed for every half cycle using the equivalent shear stress ratio $\mathrm{L}$ derived in 7 ) and the dynamic shear resistance $\mathrm{R}$ derived in 8) by

$F_{L}=\frac{R}{L}$

Note that $R$ and $L$ are both determined for uniform 20 cycles.

10) Arrangement of the relationship of liquefaction resistance factor $F_{L}$ and excess pore pressure ratio $\mathrm{r}_{\mathrm{u}}$

The relationship between the liquefaction resistance factor $F_{L}$ and the excess pore pressure ratio $r_{u}$ is arranged for every pore pressure data.

\subsection{Results and discussion}

Fig. 15 shows examples of time histories of the dynamic shear stress ratio $\tau_{\text {al }} \sigma_{\text {vo', , the }}$ equivalent shear stress ratio $\mathrm{L}$, the liquefaction resistance factor $F_{L}$, the pore pressure ratio $r_{u}$ of the variables described above at 4 typical locations. The parameter $N^{\prime}$ was assumed 18 because it was estimated about 18 for all cases from Eqs.(15) (16). The reference liquefaction curve is determined by substituting $N^{\prime}=18$ into Eq.(11). Fig.16 shows the distribution of excess pore pressure ratio $r_{u}$ at the 5-th cycle of excitation and right after the excitation. It is shown in all the cases that the excess pore pressure ratio $r_{u}$ builds up faster in the free field than below the embankment although the shape of distribution is a little different respectively. The liquefaction resistance factor $F_{L}$ is larger below the embankment than in the free field because of the overburden effect of embankment. It is also shown that while the excess pore pressure ratio $r_{u}$ in the free field builds up to 1 , the excess pore pressure does not below the embankment. The 
buildup is smaller below the crest than below the slope and the increase of pore pressure ratio $r_{u}$ is smaller in the shallower portion of the ground than in the deeper portion. This can be attributed to the different lateral confining conditions in the ground due to the embankment that a complete liquefaction does not occur below the embankment while it does in the free field.

Fig.17 shows the relationship between the liquefaction resistance factor $F_{L}$ and the excess pore pressure ratio $\mathrm{ru}$. Such relationships are obtained by combining the time histories of $\mathrm{ru}$ and $F_{L}$ in Fig.15. Figs.17 a)d)g) shows the result in the free field, Figs.17 b)e)h) that below the crest and Figs.17 c)f)i) that below the slope toe. The following can be seen from these figures.

1) The pore pressure ratios $r$ u are distributed in the range from $\mathrm{F}_{L}{ }^{-2}$ to $\mathrm{F}_{L}{ }^{-7}$. The influence of the installed depth of pore pressure gauge could not be seen.

2) Below the crest of the embankment the pore pressure ratio showed a smaller tendency than those in the free field against the same $F_{L}$. The pore pressure ratio did not reach unity even when $F_{L}$ becomes below 1. Regarding to the effect of the installed depth of gauges, the pore pressure ratio exhibits lower value at the deeper location.

3) The pore pressure ratio below the slope toe was less than that in the free field against the same $F_{L}$. However, it exceeded one when $F_{L}$ reached one. This can be reduced to that the overburden pressure was calculated one-dimensionally.

4) The effect of the excitation frequency on the relation between $F_{L}$ and $r_{u}$ was small in the free field and below the embankment.

\section{CONCLUSION}

1) The liquefaction resistance factor $F_{L}$ is larger and the increase of the pore pressure is slower below the embankment than in the free field because of the overburden effect of embankment.

2) The pore pressure ratio below the embankment does not develope up to 1 while that in the free field can develope up to 1 .

3) The pore pressure ratio below the embankment is smaller than that in the free field when compared with the same $F_{L}$. Below the embankment the pore pressure ratio is smaller than 1 even when $F_{L}$ is less than 1.

4)When the stability of an embankment on a liquefiable deposit is considered the stability factor is estimated genarally smaller if the pore pressure below the embankment is computed only by use of the relationship between $F_{L}$ and $r_{u}$ for the free field.

\section{REFARENCES}

1. Tatsuoka,F。 et a1.(1980): Standard Penetration Tests and Soil Liquefaction, Soils \& Foundations, Vol.20, No.4, pp.95-111.

2. Seed,H.B. et al.(1976): Pore-Pressure Changes During Soil Liquefaction, Jour.of Geotech. Eng. Div., ASCE, Vol.102, No.GT4, pp.323-346.

3. Japan Road Association(1986): Technical Guideline for Designing of Common Utility Duct(in Japanese), pp.65-66.

4. Japan Road Association(1986): Technical Guideline for Highway Earthwork Countermeasures for Soft Ground(in Japanese), pp.81-88, pp. 280-291.

5. Seed,H.B. and Lee,K.L.(1966): Liquefaction of Saturated Sands During Cyclic Loading, Jour.of Soil Mech. and Foundations Div., Proc. of ASCE, Vol.92, No.SM6, pp.105-134.

6. Ishihara, K. and Yasuda,S.(1975): Sand Liquefaction of Sand Deposits During Earthquake, Soils \& Foundations, Vol.17, No.3, pp.1-17.

7. Lee, K.L. and Seed,H.B. (1967): Dynamic Strength of Anisotropiccally Consolidated Sand, Jour. of Soil Mech. and Foundation Div., ASCE, Vol.93, No.5, pp.169-190.

8. Finn,W.D.L. et al.(1978): Cyclic Pore Pressures under Anisotropic Conditions, Earthquake Engineering and Soil Dynamics, Proc. of ASCE Geotech. Eng. Div. Specialty Conf., Vol.1, pp.457-470.

9. Tatsuoka,F. et al.(1982): Cyclic Undrained Stress-Strain Behavior of Dense Sands by Torsional Simple Shear Test, Soils \& Foundations, Vol.22, No.2, pp.55-70.

10. Watanabe,N. et al.(1991): Permanent Deformation Characteristics under Static and Cyclic Shear stress Loading(in Japanese), 26th Annual Meeting of Japanese Society of Soil Mech. \& Foundations Eng.

11.Yoshimi,Y. and Tokimatsu,K.(1977): Settlement of Buildings on Saturated Sand During Earthquakes, Soils \& Foundations, Vol.17, No.1, pp. 24-38.

12.Koga,Y. and Matsuo,O.(1990): Shaking Table Tests of Embankments Resting on Liquefiable Ground, Soils \& Foundations, Vol.30, No.4, pp.162-174.

13.Shimazu,T. et al.(1991): Characteristics of Pore Water Pressure in the Foundation of Embankment during Earthquakes(in Japanese), 26th Annual Meeting of Japanese Society of Soil Mech. \& Foundations Eng. 
Table 1 Analyzed Test Cases

\begin{tabular}{|c|c|c|c|c|c|}
\hline \multirow{2}{*}{ Case } & \multicolumn{4}{|c|}{ Excitation Condition } & Excitation \\
\cline { 2 - 5 } & Wave form & Frequency & Duration & No.of Cycles & Acceleration \\
\hline 1 & Sinusoidal & $2.5 \mathrm{~Hz}$ & $8 \mathrm{sec}$ & 20 & $190 \mathrm{gal}$ \\
\hline 2 & Sinusoidal & $10.0 \mathrm{~Hz}$ & $2 \mathrm{sec}$ & 20 & $315 \mathrm{gal}$ \\
\hline 3 & Sinusoidal & $5.0 \mathrm{~Hz}$ & $4 \mathrm{sec}$ & 20 & $208 \mathrm{gal}$ \\
\hline
\end{tabular}

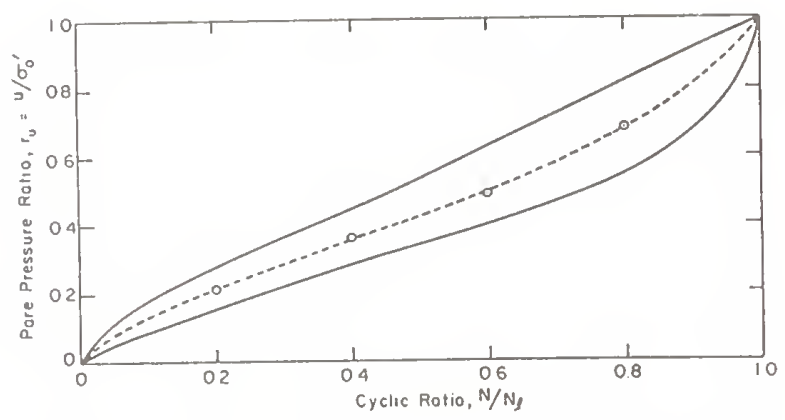

Fig.1 Rate of Pore -Water Pressure Buildup in Cyclic Simple Shear Tests (2)

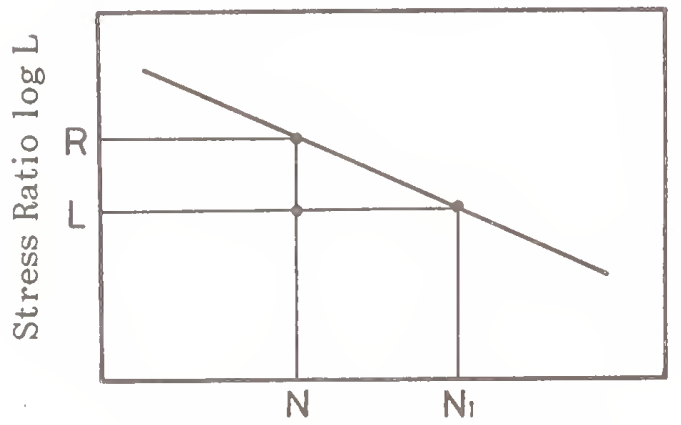

Number of Cycles $\log \mathrm{N}$

Fig.2 Relation between Stress Ratio and Number of Cycles

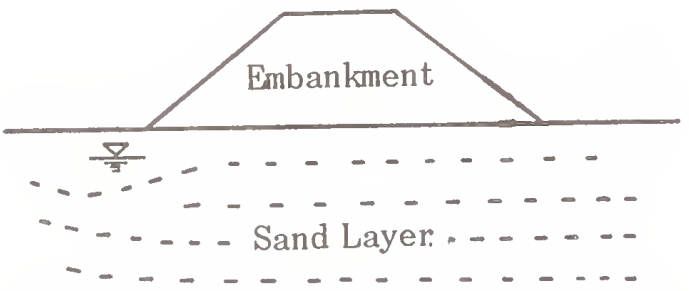

Fig.4 Embankment on Liquefiable Ground

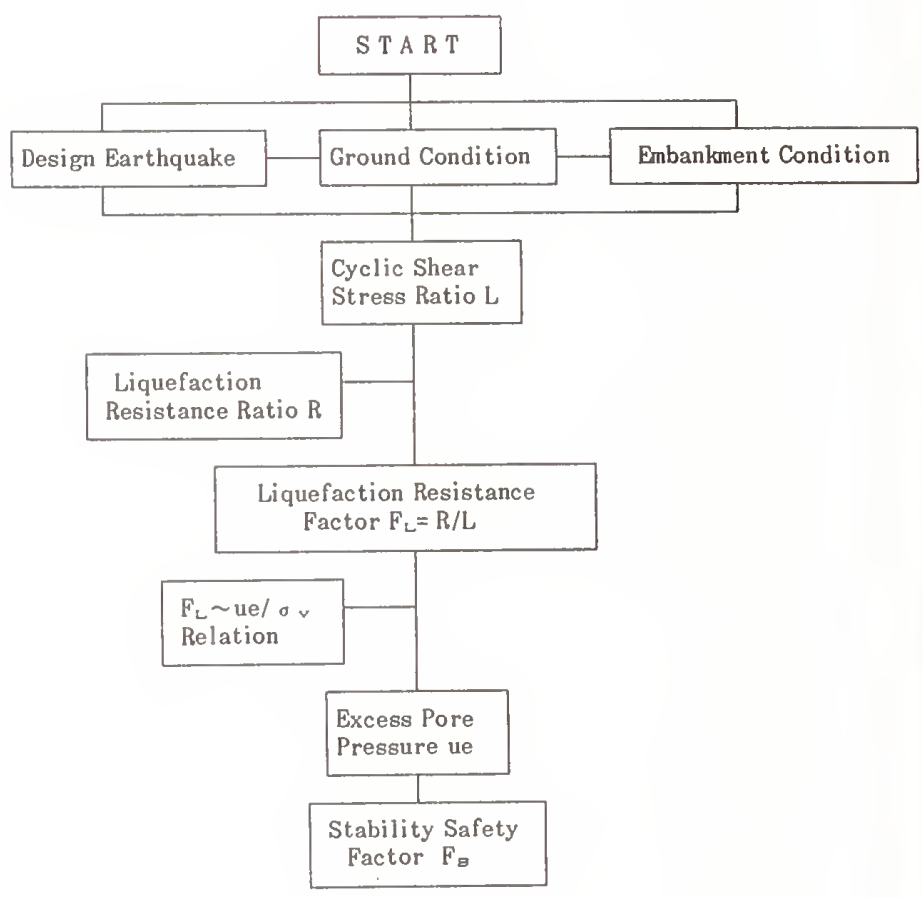

Fig.3 Procedure for Stability Analysis of Embankments on Liquefiable Ground

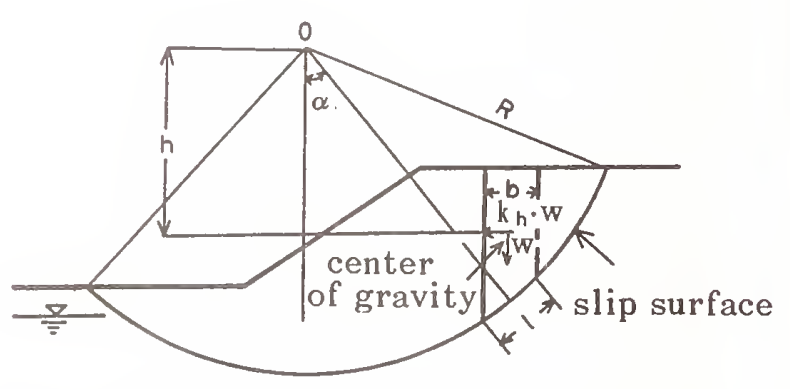

Fig.5 Stability Calculation by Slice Method 


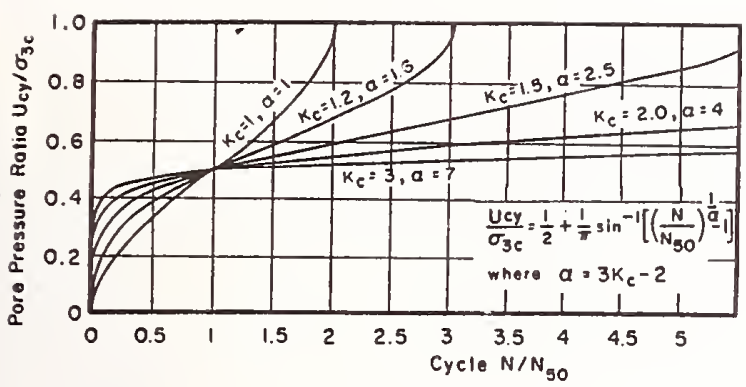

Fig.6 Normalized Curves from Pore Pressure

Build-up Equation (8)

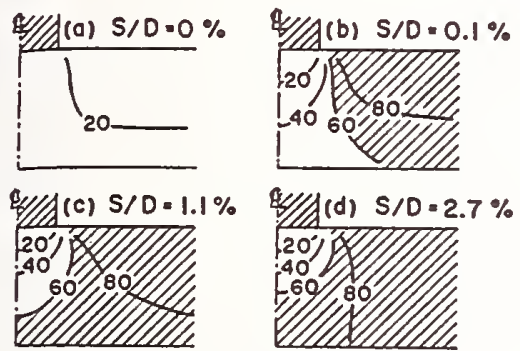

$\mathrm{S}=$ set $t$ lement of structure

$D=$ depth of sand deposit

Fig.7 Contours of Maximum Pore Pressure Buildup Ratio, u $/ \sigma_{z \square}(\%)$ for Test A 20 (1I)
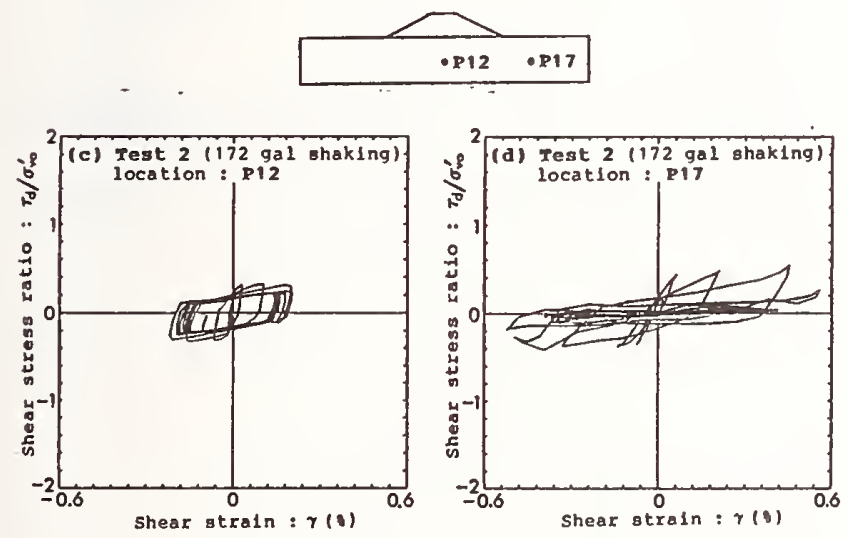

Fig.9 Shear Stress-Strain Relationships in the Models (12)

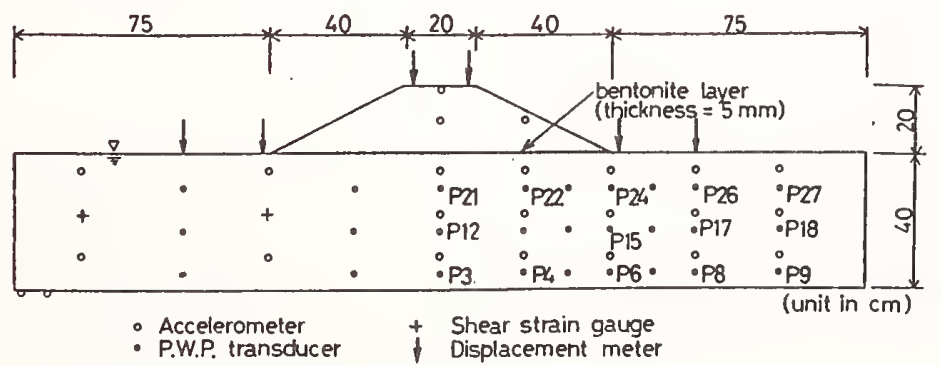

Fig.10 Analyzed Model Embankments 


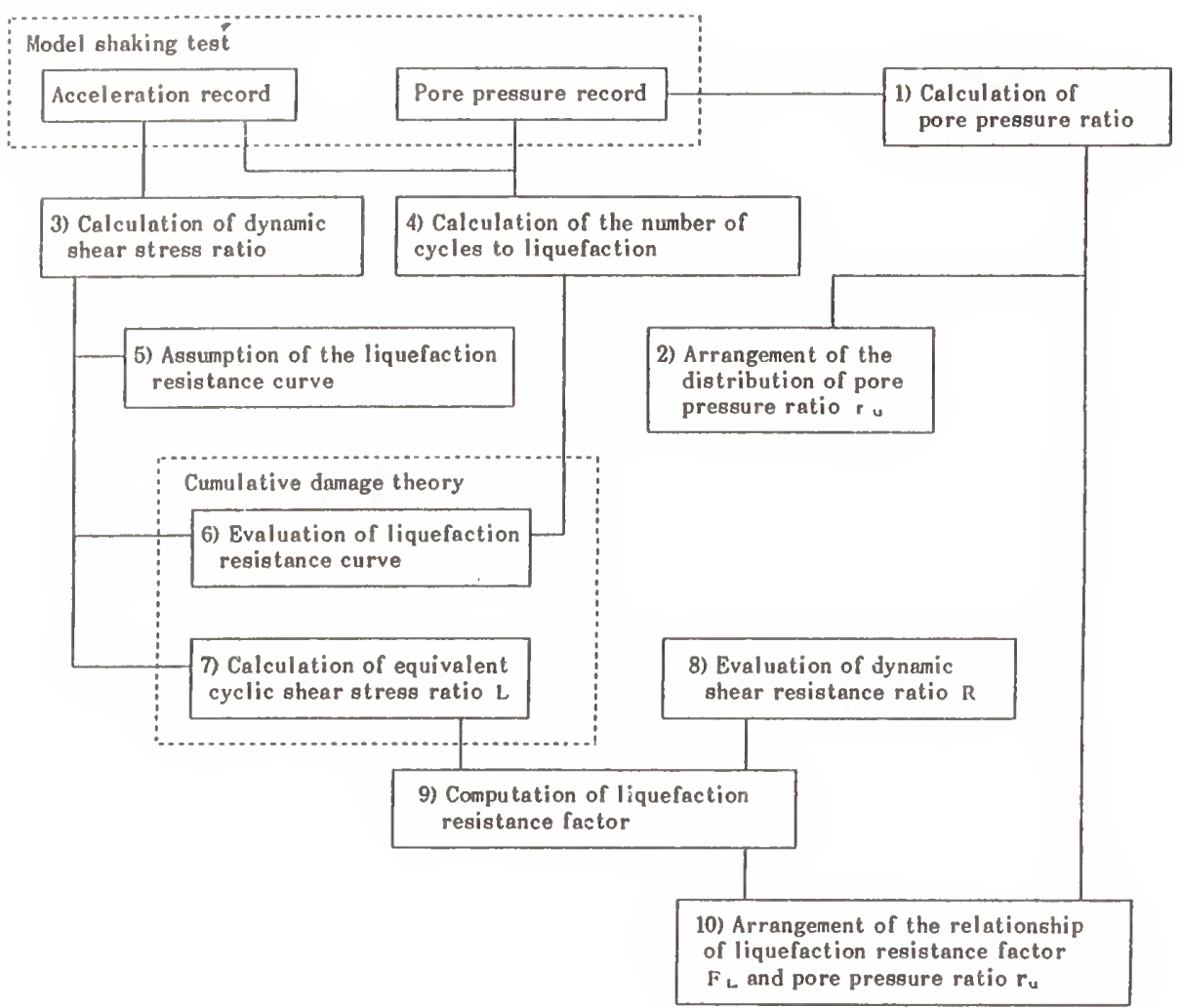

Fig.11 Procedure of Data Arrangement and Calculation

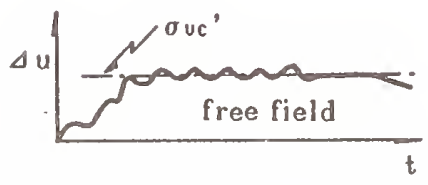

Fig. 12 Estimation of the Effective Overburden Pressure from Pore Pressure Record

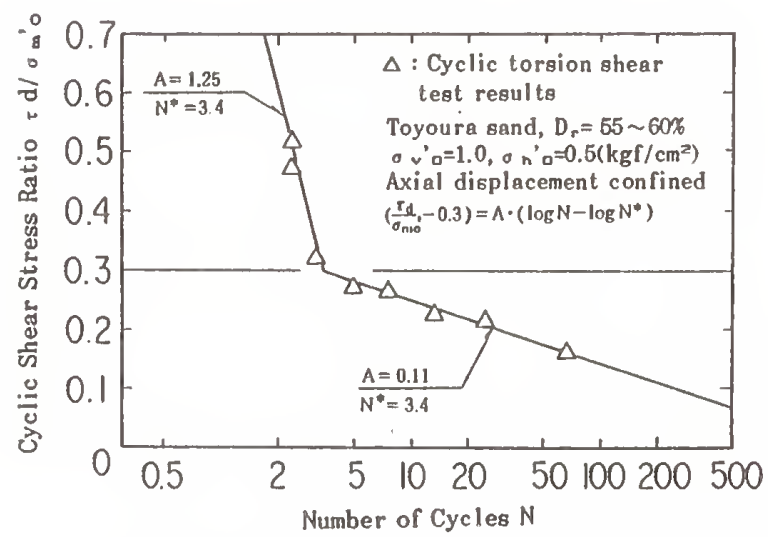

Fig.14 Reference Liquefaction Resistance Curve from Cyclic Torsion Shear Test of Toyoura Sand

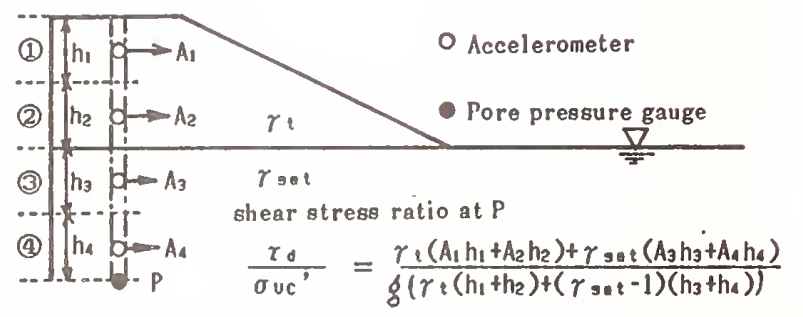

Fig.13 Calculation of Dynamic Shear Stress Ratio 


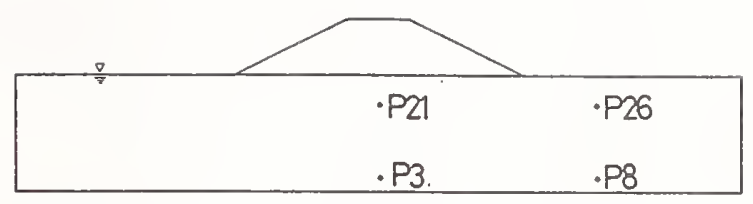

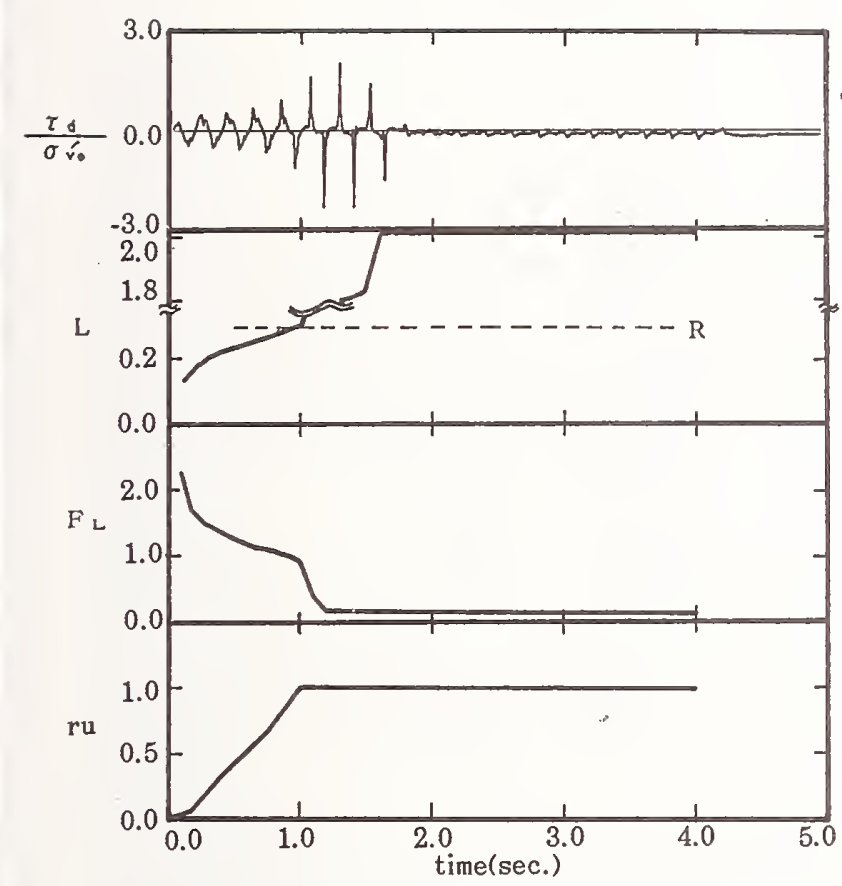

a) Free field( Case 3, P26)

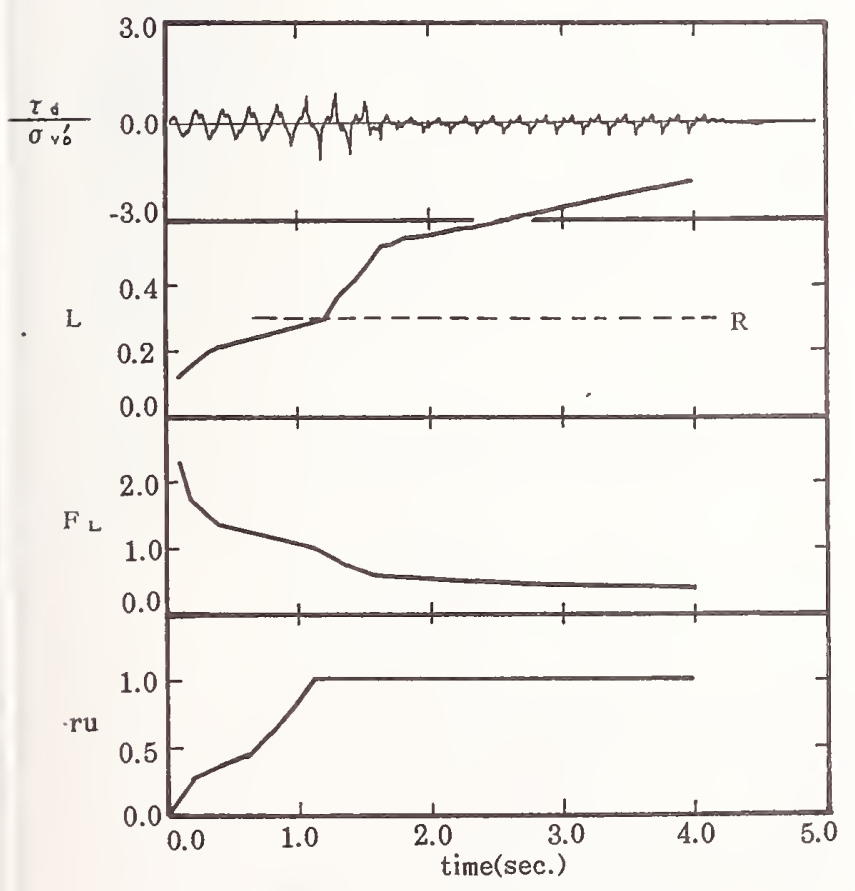

b) Free field( Case 3, P8)

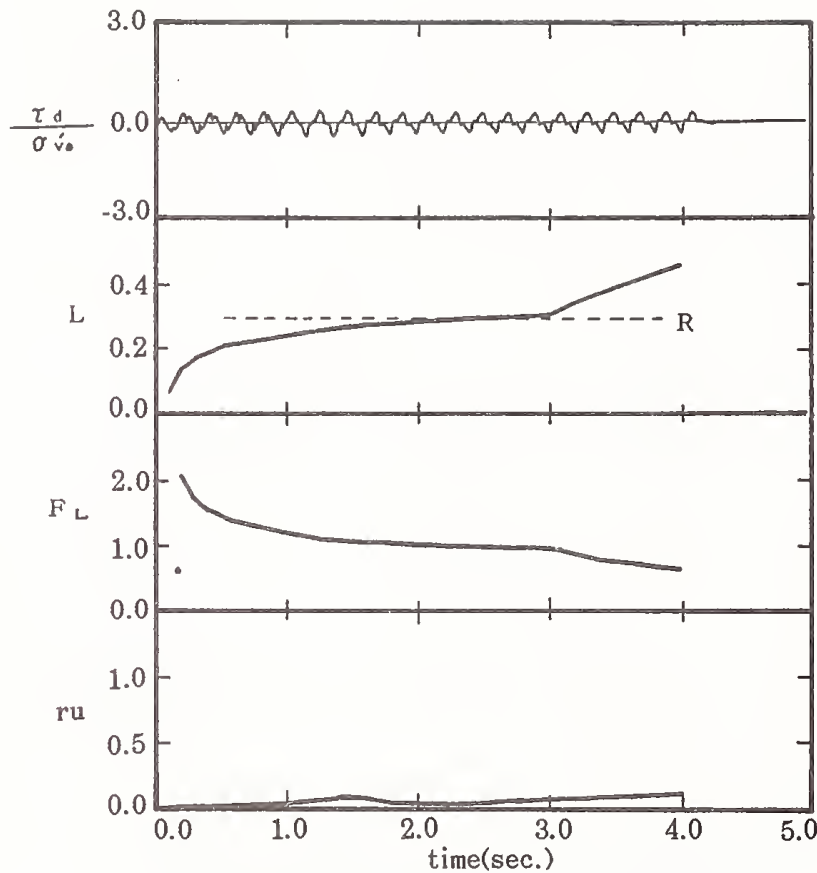

c) Below the embankment( Case3, P21)

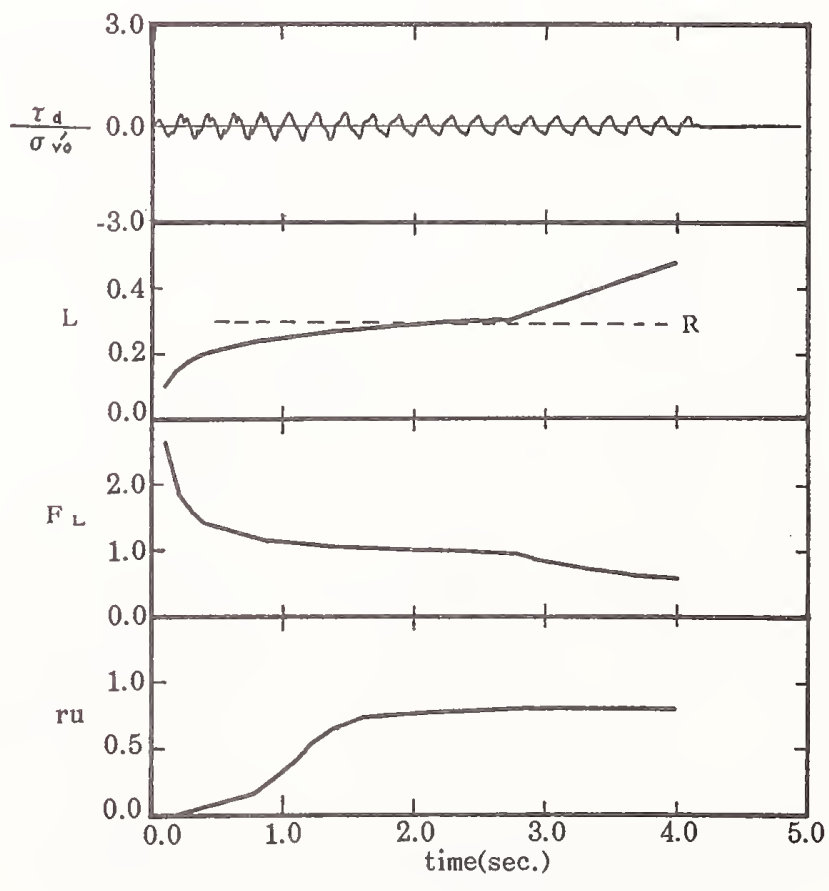

d) Below the embankment( Case3, P3)

Fig.15 Time Histories of $\tau_{\text {a }} / \sigma$ vó, L, FL, ru 
a) Case 1
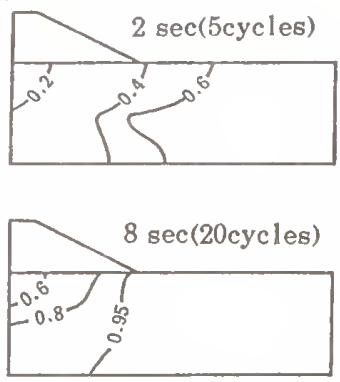

b) Case 2
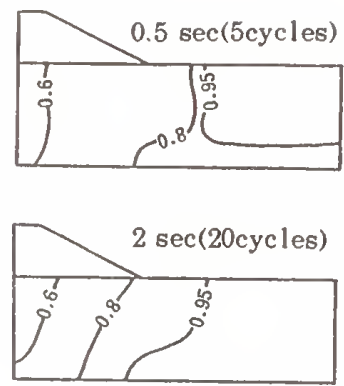

c) Case 3
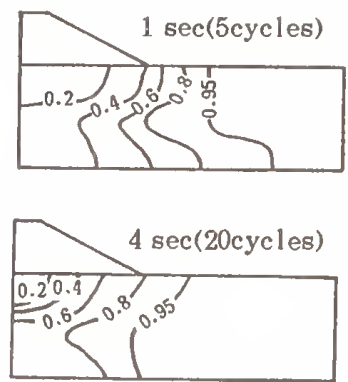

Fig.16 Distribution of Excess Pore Pressure Ratio

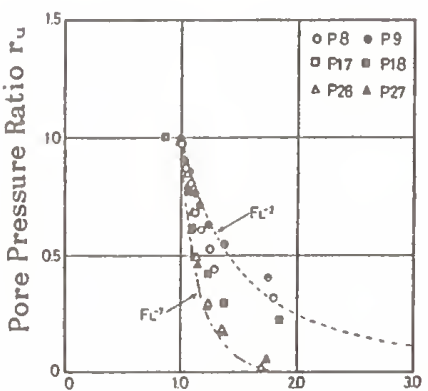

Liquefaction Resistance Factor $F_{2}$

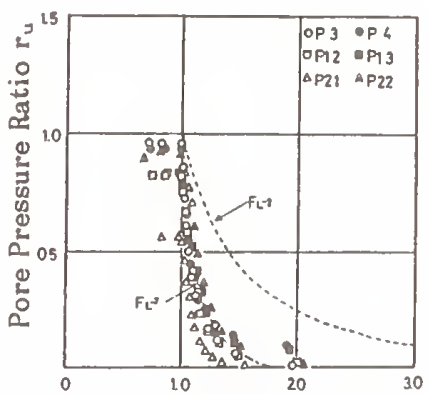

a) Casel Free field
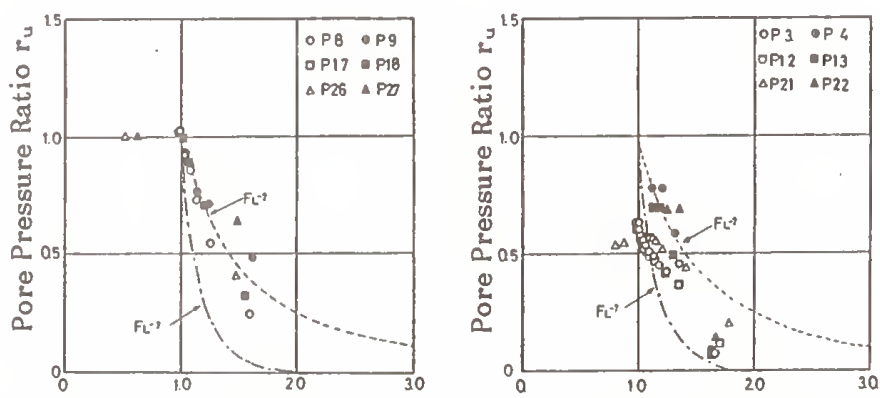

b) Case1 Below the crest

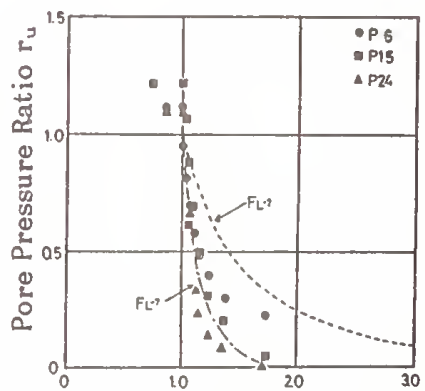

d) Case2 Free field
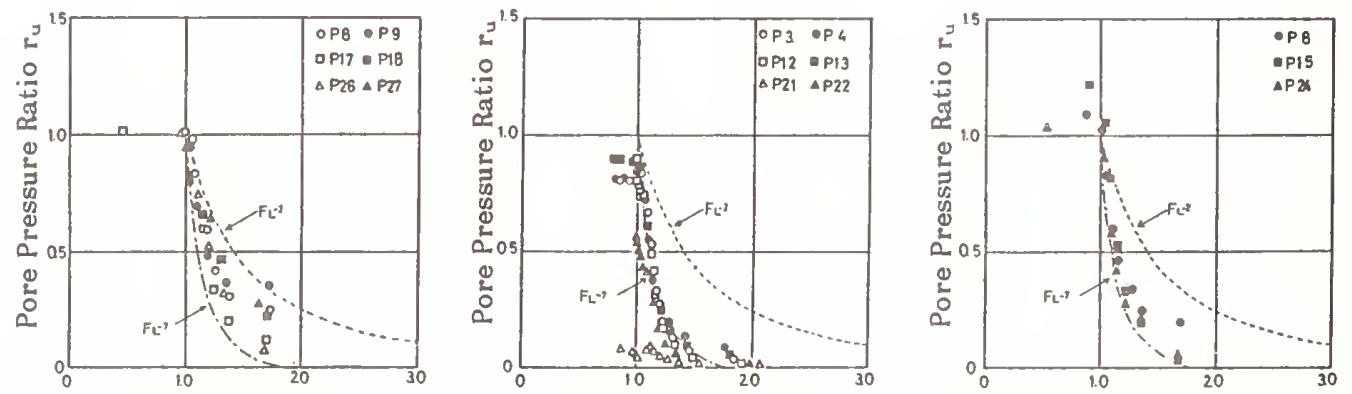

Liquefaction Resistance Factor $F_{L}$ Liquefaction Resistance Factor $F_{L}$ Liquefaction Resistance Factor $F_{L}$ g) Case3 Free field

h) Case3 Below the crest

i) Case 3 Below the slope toe

Fig.17 Relationship between Liquefaction Resistance Factor $F_{L}$ and Excess Pore Pressure Ratio $\mathrm{r}_{u}$ 


\title{
Maximum Ground Acceleration on Soft Clay Sites
}

\author{
by
}

Tingley K. Lew ${ }^{1}$

\section{ABSTRACT}

During the 7.1 magnitude 1989 Loma Prieta northern California earthquake, relatively large horizontal maximum ground accelerations (MGAs) were recorded on soft clay (young San Francisco Bay mud) sites. Some of these MGAs were as much as three to four times larger than those recorded nearby on rock about the same distance from the fault rupture. These large MGAs were primarily caused by resonance between the surface clay deposits and the dominant frequency components of the incident waves. An equation is presented for determining the upperbound MGA on soft clay sites. The upperbound MGA on soft clay sites is controlled by the soft clay shear strength $\left(\tau_{\text {ult }}\right)$, density, and layer thickness. The theoretical results were compared with the Loma Prieta earthquake MGA data from young San Francisco Bay mud sites. With a couple of exceptions, the $\tau_{\text {ut }}=$ $1,000 \mathrm{psf}(47.9 \mathrm{kPa})$ theoretical curve defines the upperbound MGA data for soft clay sites in the Loma Prieta earthquake.

The equation presented can be used to compute the upperbound MGA on a soft clay site from the soft clay density, shear strength, and layer thickness including that of the surficial fill. For sites where only the soft clay layer thickness is known, the approximate upperbound site MGA can be determined from the MGA versus layer thickness curve presented for $\tau_{\text {utt }}=1,000 \mathrm{psf}(47.9 \mathrm{kPa})$.

KEYWORDS: Earthquake; shear strength; layer thickness; maximum ground acceleration; soft clay; strongmotion; young bay mud.

\subsection{INTRODUCTION}

The expected earthquake ground motions at a site are needed for the design of new facilities and the estimation of potential earthquake damage in natural disaster preparedness planning. One of the major parameters used in the design of new facilities and the prediction of potential earthquake damage to existing facilities is the horizontal maximum ground acceleration (MGA). Generally, the frequency content of the earthquake ground motion is considered indirectly by specifying the shapes of the design spectra. Duration of the ground motion is considered implicitly in the design of new facilities by the indirect specifications of ductility requirements (e.g., the $R_{w}$ values and structural detailing requirements in the 1990 Recommended Lateral Force Requirement by the Structural Engineers Association of California). In the estimation of potential earthquake damage to existing facilities, the assumed available ductility is based on the structural detailing of the facility, past earthquake performance of similar types of construction, and engineering judgment.

The MGA, duration, and frequency content of earthquake ground motion at a site depend on the source mechanism, path of the incident waves, and the local soil conditions at the site. Generally, we do not know the source mechanism nor the path of the incident waves from the source to the site for future earthquakes relative to a given site. We can only estimate the effects that the local soil conditions may have on the incident waves.

The accelerations of the incident earthquake waves at the bedrock of a site can be greatly amplified by resonance of the site soil deposits. Resonance occurs when the characteristic shear wave periods of the surface soil strata are near one of the dominant periods of the incident waves (Ref 1 through 5). Thus, structural damage at the site is intensified. Even greater earthquake damage occurs if the fundamental period of the structure is near one of the characteristic shear wave periods for the site. Double resonance of the site and structure relative to the dominant periods of incident earthquake waves occurs under such a condition. This phenomenon was demonstrated by the structural damage at Mexico City about $300 \mathrm{~km}$ from the epicenter in the 1985 Mexico earthquake (Ref 6).

The aim of this paper is to develop an analytical relationship for determining the upper bound horizontal ground acceleration on soft clay sites.

\footnotetext{
${ }^{1}$ Naval Civil Engineering Laboratory

Port Hueneme, CA 93043
} 
Currently, the design MGA for a site is estimated from empirical attenuation relationships derived mainly from recorded strong-motion data in the western United States. Definitive soil condition data (e.g., depth of the soil layers, soil type, shear strength, and shear wave velocities) are not available for most of the strong-motion recording sites in the United States. Hence, the attenuation relationships generally differentiate only between soil and rock $(\operatorname{Ref} 7$ ). In addition, the majority of the strong-motion data used to develop the attenuation relationships comes from earthquakes and recording sites in southern California. Most of these recording sites are located in deep alluvium, generally much thicker than those in the San Francisco Bay area. On deep alluvium sites, amplification of the incident waves traveling up to the surface would be offset by the attenuation if the sediment section were relatively thick. The lack of adequate strong-motion data from soft clay sites prevents the establishment of a separate, statistically significant data set for analysis.

The heaviest damaged areas in the 1906 San Francisco earthquake are on sites with soft clay soil (young bay mud, YBM) (Ref 8), Figure 1. During the 7.1 magnitude 1989 Loma Prieta northern California earthquake, many strong-motion records were obtained from soft clay sites as well as stiff soil and rock sites in the San Francisco Bay area (Ref 9 and 10$)$. A plot of the MGA verses the closest distance to fault rupture is shown in Figure 2. ${ }^{3}$ The median and 84 percentile curves using Campbell's attenuation equation (Ref 11) is given for reference. Each data point shown in the figure is the average of the MGA in the two orthogonal horizontal directions. With a few exceptions, most of the data for stiff soil and rock sites are within the median plus one standard deviation $(\sigma)$ curve. By contrast, most of the data for soft soil sites are above the (median $+\sigma$ ) curve, with some of them apparently larger than (median $+2 \sigma$ ). There appears to be an upper limit for MGA in soft soil sites of about $0.3 \mathrm{~g}$, at least for this earthquake. It is apparent that the incident waves at soft clay sites (YBM) were greatly amplified by the relatively soft clay layers near the surface. For example, the recorded MGA on soft clay at the Naval Station Activity (NSA) Treasure Island is $0.16 \mathrm{~g}$. The corresponding recorded MGA component on rock at nearby Yerba Buena Island is only $0.06 \mathrm{~g}$. Thus, the apparent amplification factor by the soft clay layer at NSA Treasure Island is 2.67. At some other soft clay sites, the dynamic amplification factor relative to adjacent rock sites is as large as about 4.0. Dynamic amplification factors between 4 and 8 are determined from low level aftershock recordings for soft clay sites in the Loma Prieta earthquake.

\subsection{PROPERTIES OF YOUNG SAN FRANCISCO BAY MUD}

The San Francisco Bay is bounded primarily by marshlands, alluvial deposits, and the coastal ranges. The major geological units in the San Francisco Bay are shown in Figure 1. These units are classified as bedrock, alluvium, and YBM, Reference 8 .

1. Bed rock consists of standstone, siltstone, and greenstone of the Franciscan formation. Bedrock at YBM sites is generally located at between about 200 and 600 feet $(61.0$ and $182.9 \mathrm{~m}$ ) below the surface.

2. Alluvium consists of late Quatenary $(10,000 \mathrm{yr}$ to 3 my b.p.) flood plain deposits of silt and clay, inter layered with alluvial fans and stream bed deposits of sand and gravel.

3. Young bay mud consists of Holocene age $(10,000$ yr b.p.) sediments, soft, water-saturated, organic-rich silts and clays, occasionally interlayered with sand deposits. These sediments are derived from suspended materials brought into San Francisco Bay by rivers draining the Central Valley and streams draining the Southern Bay area. Typical YBM properties are shown in Table 1. The thicknesses of YBM vary between zero and 120 feet $(36.6 \mathrm{~m})$ for the sites shown. YBM densities vary between 90.5 and 113 pcf $\left(1,450\right.$ and $\left.1,810 \mathrm{~kg} / \mathrm{m}^{3}\right)$ with a mean of $101.7 \mathrm{pcf}$ $\left(1,629 \mathrm{~kg} / \mathrm{m}^{3}\right)$ and coefficient variation of 0.053 . Their shear strengths vary between 100 and 1,500 psf (4.79 and $71.8 \mathrm{kPa})$ with a mean of $583 \mathrm{psf}(27.9 \mathrm{kPa})$ and $\sigma$ of $230 \mathrm{psf}(11.0 \mathrm{kPa})$. The water contents of YBM vary between 35 and $120 \%$, with the majority being greater than $50 \%$.

Seed and Sun (Ref 12 ) reported that the shear modulus of YBM decreases with increasing shear strain, Figure 3. By contrast, the damping ratio of YBM increases with shear strain. The rate of shear modulus reduction with increasing strain for YBM is sig-

\footnotetext{
${ }^{2} \mathrm{~A}$ summary of the attenuation relationships commonly used in the U.S. is presented in this reference. ${ }^{3}$ For emphasis, no attempt was made in the figure to differentiate the data from the U.S. Geological Survey (USGS) and the Califormia Strong Motion Instrumentation Program (CSMIP).
} 
nificantly less than that for typical sands, but is generally in good agreement with other clays. The damping characteristics are well within the range for typical clays, Figure 3.

Seed and Sun presented a summary of the shear wave velocity profiles of YBM at six San Francisco Bay shore sites measured by various investigators, Figure 4. The former reported that the shear wave velocity is essentially constant, $250 \mathrm{fps}(76.2 \mathrm{~m} / \mathrm{s})$, for the upper 30 feet $(9.1 \mathrm{~m})$. Thereafter, the velocity appears to increase gradually to about $500 \mathrm{fps}(152.4 \mathrm{~m} /$ s) at 60 feet depth. However, we noted that the shear wave velocity at some sites may remain constant to depths of 60 feet or greater (e.g., the San Mateo site shown in Figure 4). Although no shear wave velocity profile is currently available for the NSA Treasure Island strong-motion recording site, the standard penetration values for the YBM at the site remain near zero for depths of between 45 and 100 feet (13.7 and $30.5 \mathrm{~m})$ as for the upper 20 feet $(6.1 \mathrm{~m})$ of sandy hydraulic fill over 15 feet $(4.6 \mathrm{~m})$ of loose sandy fill. This suggests that the shear wave velocity is relatively low to the 100 -foot depth.

Young Bay mud tends to flow laterally toward the direction of minimum potential energy when not confined during earthquake ground shaking (e.g., into sloughs, channels, or excavations). Although YBM does not liquefy during earthquakes, thin, clean, discontinuous, loose sand layers within the YBM generally have a high potential for liquefaction. Water saturated, loose silty sand and/or sandy fill on top of the YBM also have a relatively high potential for liquefaction during earthquakes. ${ }^{4}$ Differential settlement, one of the major causes of structural and underground utility damage in earthquakes, generally accompanies soil lateral flow or spreading, liquefaction, and/or vibratory compaction.

\subsection{THEORY}

Based on the strong-motion data available before the 1989 Loma Prieta earthquake, seismologists tended to find good agreement between site specific dynamic amplification factors determined from weak $\left(10^{-9}\right.$ to $\left.10^{-3} \mathrm{~g}\right)$ and strong $(0.04-0.20 \mathrm{~g})$ motion, Reference 13. Accordingly, the maximum ground acceleration for a soft clay sites on the San Francisco Bay shore can be determined by modifying the site rock acceleration by the site dynamic amplification factor (DAF). For example, the estimated rock MGA at the Naval Air Station (NAS) Alameda from a 7.0 magnitude about $7.5 \mathrm{~km}$ east of the site on the Hayward fault is $0.35 \mathrm{~g}$. The DAF for the sites from the Loma Prieta earthquake is 3.25. The DAF was estimated from the $0.26 \mathrm{~g}$ MGA recorded at the sites with 15 feet $(4.6 \mathrm{~m})$ of medium dense sand fill over 28 feet $(8.5 \mathrm{~m})$ of YBM and the $0.08 \mathrm{~g} \mathrm{MGA}$ recorded on rock or rock-like material at the Strawberry Canyon, Berkeley station about the same distance from the nearest ruptured surface. Hence, the MGA at NAS Alameda would be $1.14 \mathrm{~g}$ from a 7.0 magnitude earthquake on the Hayward fault. Physically, this is not probable because at the relative low shear strength of the YBM, Table 1.

In engineering mechanics, the strength of a given material defines the conditions that produce failure. Failure takes place when a material is subjected to a certain stress state, usually called strength. Failure of the material occurs by fracture or yielding (plastic flow). In the fracture mode, the material disintegrates at certain stresses or strains. In the yielding mode, the material strain increases by relatively large amounts at constant stress or with relatively small stress increments. Soft clay fails in the yielding/ plastic flow mode whereby relatively large strain increases accompanies each stress increment.

By definition then, no known material is able to transmit stresses that are greater than its inherent strength. The incident earthquake horizontal shear waves at the site bedrock generally propagates vertically, or nearly so, upward to the surface. When these shear waves encounter the soft clay layer, the relatively low shear strength of the layer limits the amplitudes (accelerations) of the waves consistent with its shear strength. Thus, the shear strength of the soft clay limits the maximum acceleration that can be transmitted to the ground surface. When the accelerations of these waves exceed the shear strength of the soft clay, the clay yields and, thereby, limits the stress transmitted to its yield strength. In addition, energy is dissipated by the soft clay layer as it yields. This further limits the stress amplitudes of subsequent waves transmitted to the ground surface.

\footnotetext{
${ }^{4}$ Liquefaction potential for saturated, loose sandy fills can be mitigated by ground improvement techniques, such as vibrafloation, compaction piles, and gravel columns. Such tecloniques appear to have successfully prevented liquefaction in localized areas on NSA Treasure Island during the Loma Prieta earthquake.
} 
The approach used in the following theoretical development is similar to that used by Seed and Idriss (Ref 14) in their development of a simplified procedure for determining soil liquefaction.

First we assume that the soft clay layer (column) of thickness, $\mathrm{h}$, behaves as a rigid body with maximum acceleration $\mathrm{a}_{\max }$ on top, and maximum rigid body shear stress $\left(\tau_{\max }\right)_{r}$ on the bottom as shown in Figure 5a. The layer thickness, h, may include thin interlayers of sand and a relatively thick layer of loose silty sand and/or fill on the surface. It is assumed that these layers do not have a significant effect on the overall dynamic response of the soft clay layer as a whole. The maximum shear stress at depth $\mathrm{h}$ for the rigid soil column:

$$
\tau_{\max r}=\gamma h \frac{9 \max }{g}
$$

$$
\text { where } \begin{aligned}
\gamma & =\text { wet unit weight of soft clay }\left(\mathrm{FL}^{-3}\right) \\
\mathrm{h} & =\text { soft clay layer thickness }(\mathrm{L}) \\
\mathrm{a}_{\max } & =\text { maximum ground acceleration }\left(\mathrm{FT}^{-2}\right) \\
\mathrm{g} & =\text { gravitational constant }\left(\mathrm{FT}^{-2}\right)
\end{aligned}
$$

Because the soft clay column is deformable, the actual shear stress at depth $\mathrm{h}$ increases at a decreasing rate with depth as shown in Figure 5b. We account for this by modifying $\left(\tau_{\max }\right)_{r}$ by a reduction factor $r_{d}$, Figure 5c:

$$
\left({ }^{\tau_{\max }}\right)_{\mathrm{d}}=\mathrm{r}_{\mathrm{d}} \cdot(\mathrm{Tmax})_{\mathrm{r}}
$$

The reduction factors used in this study are given in Table 2. These values correspond to the average values given by Seed and Idriss (Ref 14). By substituting Equation (2) into Equation (1), we get

$$
\tau_{\max d}=\gamma \mathrm{h} \frac{\mathrm{q}_{\max }}{\mathrm{g}} \mathrm{r}_{\mathrm{d}}
$$

Furthermore, we define

$$
\text { MGA }=\frac{\mathrm{a}_{\max }}{\mathrm{g}}
$$

and

$$
\tau_{\text {ult }}=\left(\tau_{\max }\right)^{\prime} d
$$

where $\mathrm{MGA}=$ maximum ground acceleration in $g$ units

$$
\tau_{\text {ut }} \quad=\text { shear strength of soft clay }
$$

By substituting Equations (4) and (5) into Equation (3) and solving for MGA, we get

$$
\mathrm{MGA}=\frac{\tau_{\mathrm{ult}}}{\mathrm{r}_{\mathrm{d}} \gamma \mathrm{h}}
$$

Thus, the upperbound maximum ground acceleration on a soft clay site is a function of the soft clay shear strength and an inverse function of the soft clay density and thickness.

According to the unit weights and shear strengths given in Table 1 for the young San Francisco Bay mud, it is judged that the following values are representative:

$$
\begin{aligned}
& \gamma=100 \mathrm{pcf}\left(1,602 \mathrm{~kg} / \mathrm{m}^{3}\right) \\
& \tau_{\text {ut }}=300-1,000 \mathrm{psf}(14.4-47.9 \mathrm{kPa})
\end{aligned}
$$

The above values were substituted into Equation (6) for soft clay layer thicknesses between 10 and 100 feet $(3.05$ and $30.5 \mathrm{~m})$. The MGAs for shear strengths of 300,600 , and $1,000 \mathrm{psf}(14.4,28.7$, and $47.9 \mathrm{kPa})$ are plotted in Figure 6. From the curves in the figure, it is apparent that MGA on soft clay sites increases with the soft clay shear strength. For a given shear strength, the site MGA decreases with increasing layer thickness due to the increase in soil inertia force with layer thickness. The site MGA decreases rapidly with increasing layer thickness for thicknesses between 10 and 40 feet ( 3.05 and $12.2 \mathrm{~m}$ ). For layer thickness greater than 40 feet $(12.2 \mathrm{~m})$, the site MGA is relatively insensitive to increases in layer thickness. The increase in inertia force with layer thickness in this thickness range offsets the reduction in shear stress in the soil column.

\subsection{COMPARISON WITH EARTHQUAKE DATA}

The theoretical results are compared with the maximum ground acceleration data from young San Francisco Bay mud sites in the 1989 Loma Prieta earth- 
quake in Figure 7. Data points for sites with known soft clay layer thickness are represented by the solid symbols in the figure. Because we have the soft clay layer thicknesses for only 14 of the 20 young San Francisco Bay mud sites shown on Tables 3 and 4, the approximate thicknesses for the other sites were computed from the dominant site periods estimated from the strong-motion records by using the following equation.

$$
\mathrm{h}=\mathrm{T}\left(\frac{\mathrm{R} \mathrm{V}_{\mathrm{s}}}{4}\right)
$$

$$
\begin{aligned}
& \text { where } \mathrm{h}=\text { layer thickness }(\mathrm{L}) \\
& \mathrm{T}=\text { fundamental shear wave velocity }(\mathrm{T}) \\
& \mathrm{V}_{\mathrm{s}}=\text { shear wave velocity at small } \\
& \text { strains }\left(\mathrm{LT}^{-1}\right) \\
& \mathrm{R}=\text { reduction factor to account for the } \\
& \text { decrease in } \mathrm{V}_{3} \text { with increasing } \\
& \text { shear strain }{ }^{5}
\end{aligned}
$$

For simplicity, $\mathrm{V}_{\mathrm{s}}=250 \mathrm{fps}(76.2 \mathrm{~m} / \mathrm{s})$ and $\mathrm{R}=0.67$ were used for all the other sites. For sites with two distinct dominant periods, the computed layer thicknesses for the two periods were summed to obtain the total soft clay layer thickness.

If the proposed theory is valid, all the data points should be below the MGA curve corresponding to the upperbound shear strength of the soft clay (YBM). With a couple of exceptions, all the data points are below the curve for $\tau_{\text {ult }}=1,000 \mathrm{psf}(47.9 \mathrm{kPa})$, Figure 7. The choosing of $\tau_{\text {ult }}=1,000$ psf was fortuitous. However, the trend of the data definitely follows the asymptotic portion of the curves. The grouping of the data between the $300 \mathrm{psf}$ and $1,000 \mathrm{psf}$ curves for soil thicknesses between about 10 and 100 feet $(1.98$ and $19.8 \mathrm{~m}$ ) suggests that the dynamic shear strength at the YBM sites is generally between 300 and 1,000 psf ( 9.66 and $47.9 \mathrm{kPa})$.

As a further check on the validity of the theory developed, the estimated ground acceleration near St. Michaels Church, Charleston during the 1886 Charleston, South Carolina earthquake (Ref 15 ) is plotted in Figure 7. The soft clay layer thickness near the site is about 52 feet $(15.8 \mathrm{~m})$, Reference 16 . The earthquake had an estimated magnitude between 6.5 and 7.0 with its epicenter about 15 miles $(24 \mathrm{~km})$ northwest of Charleston. The site MGA was estimated by conventional probabilistic structural and dynamic analysis of the Church with a known level of damage. The site MGA estimate was based on the assumption that all the damage to the Church was caused by the main shock. There were many smaller magnitude aftershocks following the main shock. However, the relative contribution of these aftershocks to the overall damage of the Church is unknown. Thus, the resulting estimate is considered an upperbound value by Elton and Marciano (Ref 15). The estimated mean MGA is $0.33 \mathrm{~g}$ with a coefficient of variation (COV) of 0.24 . In Figure 7, the range of probable MGAs at the site is represented by the vertical bar (between 0.17 and $0.33 \mathrm{~g}$ ). We judged that the most probable MGA at the site is about $0.25 \mathrm{~g}$, the solid symbol. The 1886 Charleston, SC earthquake data follows the general trend of the MGA data recorded in young San Francisco Bay mud sites during the 1989 Loma Prieta earthquake.

\subsection{CONCLUSIONS}

Based on theory presented and the comparison between the theoretical results with strong-motion MGA data from young San Francisco Bay mud (soft clay) sites in the 1989 Loma Prieta earthquake, the following conclusions are drawn:

1. The upperbound MGA on soft clay sites is controlled by the soft clay shear strength $\left(\tau_{\text {ull }}\right)$, density, and thickness.

2. With a couple of exceptions, the $\tau_{\text {ut }}=$ $1,000 \mathrm{psf}(47.9 \mathrm{pKa})$ theoretical curve defines the upperbound the MGA data for soft clay sites in the Loma Prieta earthquake.

3. The trend of the Loma Prieta earthquake data follows the trend of the theoretical curves.

4. The equation presented can be used to compute the upperbound MGA on a soft clay site from the soft clay density, shear strength, and layer thickness including that of the surficial fill.

5. For sites where only the soft clay layer thickness is known, the approximate upperbound site MGA can be determined from the MGA versus soft

$5 \mathrm{~V}_{\mathrm{s}}=\sqrt{\mathrm{G} / \rho}$, where $\mathrm{G}=$ shear modulus and $\rho=$ mass density. See Figure 3 for reduction of $G$ with increasing shearing strain. 
clay layer thickness curve for $\tau_{\text {ut }}=1,000 \mathrm{psf}(47.9 \mathrm{kPa})$ in Figure 6.

\subsection{RECOMMENDATIONS}

The MGA data from 20 strong-motion recording stations in the Loma Prieta earthquake were used in the comparison with the theoretical results. The soft clay layer thicknesses are known for only 14 sites. The approximate layer thicknesses for the other six sites were estimated from the dominant periods in the strong-motion accelerograms for the sites. It is recommended that the soil layer thicknesses and soil properties, such as shear strength, shear wave velocities, and densities be determined for all the soft clay strong-motion recording sites where they are not available. Comparison of the theory presented with recorded MGAs on soft clay sites from other earthquakes is also recommended and encouraged.

\subsection{ACKNOWLEDGMENTS}

The continual support by Mr. H. Nickerson (NAVFAC Code 042B) and Mr. J. Cecilio (NAVFAC Chief Engineer) is appreciated. Mr. D. M. Boore (USGS geophysicist) and Mr. R. B. Darragh (CSMIP, seismologist) provided the author with the soil thickness data for the USGS and CSMIP soft clay recording sites, respectively.

This paper was sponsored by the Naval Facilities Engineering Command.

\subsection{REFERENCES}

1. H.B. Seed and I.M. Idriss. "Analysis of Ground Motions at Union Bay, Seattle During Earthquake and Distant Nuclear Blasts." Bulletin of the Seismological Society of America, 60:1, 125-136, Feb 1970.

2. R.D. Brocherdt. "Effects of Local Geology on Ground Motion Near San Francisco Bay." Bulletin of the Seismological Society of America, 60:1, 2961, Feb 1970.

3. W.B. Joyner, R.E. Warrick, and A.A. Oliver, III. "Analysis of Seismograms From a Downhole Array in Sediments Near San Francisco Bay." Bulletin of the Seismological Society of America, 6:3, 937-958, 1976.
4. S.H. Seale and R.J. Archuleta. "Site Amplification and Attenuation of Strong Ground Motions." Bulletin of the Seismological Society of America, 76:6, 1673-1699, 1989.

5. M.D. Trifunac. "How to Model Amplification of Strong Earthquake Motions by Local Soil and Geological Site Conditions." Earthquake Engineering and Structural Dynamics, No. 19, 833-846, 1990.

6. E. Rosenblueth. "The Mexican Earthquake: A First Hand Report," American Society of Civil Engineers, Civil Engineering, 56:1, 38-40, 1986.

7. W.B. Joyner and D.M. Boore. "Measurement, Characterization, and Prediction of Strong Ground Motion" in Earthquake Engineering and Soil Dynamics II - Recent Advances in Ground Motion Evaluation. Geotechnical Special Publication No. 20, American Society of Civil Engineers, 43-102, 1988.

8. R.D. Borcherdt, W.B. Joyner, R.E. Warrick, and J.F. Gibbs. "Response of Local Geological Units to Ground Shaking." U.S. Geological Survey Professional Paper 941-A, edited by R.D. Borcherdt, A52A67, 1975.

9. R. Maley, A. Acosta, F. Ellis, E. Etheredge, L. Foote, D. Johnson, R. Porcella, M. Salsman, and J. Switzer. "U.S. Geological Survey Strong- Motion Records From Northern California (Loma Prieta) Earthquake of October 17, 1989." U.S. Geological Survey Open File Report 89-568, Menlo Park, CA, $85 \mathrm{pp}, 1989$.

10. A. Shakal, M. Huang, M. Richle, C. Ventura, T. Cao, R. Sherburne, M. Savage, R. Darragh, and C. Peterson. "CSMIP Strong-Motion Records From the Santa Cruz Mountain (Loma Prieta) California, Earthquake of 17 October 1989." California Division of Mines and Geology Report OSMS 89-06, Sacramento, CA, $195 \mathrm{pp}, 1989$.

11. K.W. Campbell. "Near-Source Attenuation of Peak Horizontal Acceleration." Bulletin of the Seismological Society of America, 71:6, 2039 - 2070, 1981.

12. H.B. Seed and J.I. Sun. "Implications of Site Effects in the Mexico City Earthquake of Sept. 19, 1985 for Earthquake Resistant Design Criteria in the San Francisco Bay Area of California." Report No. UCB/EERC - 89/03, Earthquake Engineering Re- 
search Center, University of California, Berkeley, CA, Mar 1989.

13. K. Aki. "Local Site Effects on Strong Ground Motion" in Earthquake Engineering and Soil Dynamics II - Recent Advanced in Ground Motion Evaluation. Geotechnical Special Publication No. 20, American Society of Civil Engineers, New York, NY, 103-155, 1988.

14. H.B. Seed and I.M. Idriss. "Ground Motion and Liquefaction During Earthquakes." Earthquake Engineering Research Institute, El Cerrito, CA, 1982.
15. D.J. Elton and E.A. Marciano, "Ground Acceleration Near St. Michael's Church During the 1886 Charleston, S.C. Earthquake." Earthquake Spectra, 6:1, 81-103, 1990.

16. D.J. Elton and J.R. Martin. "Dynamic Site Periods in Charleston, S.C." Earthquake Spectra, 5:4, 703-734, 1989. 


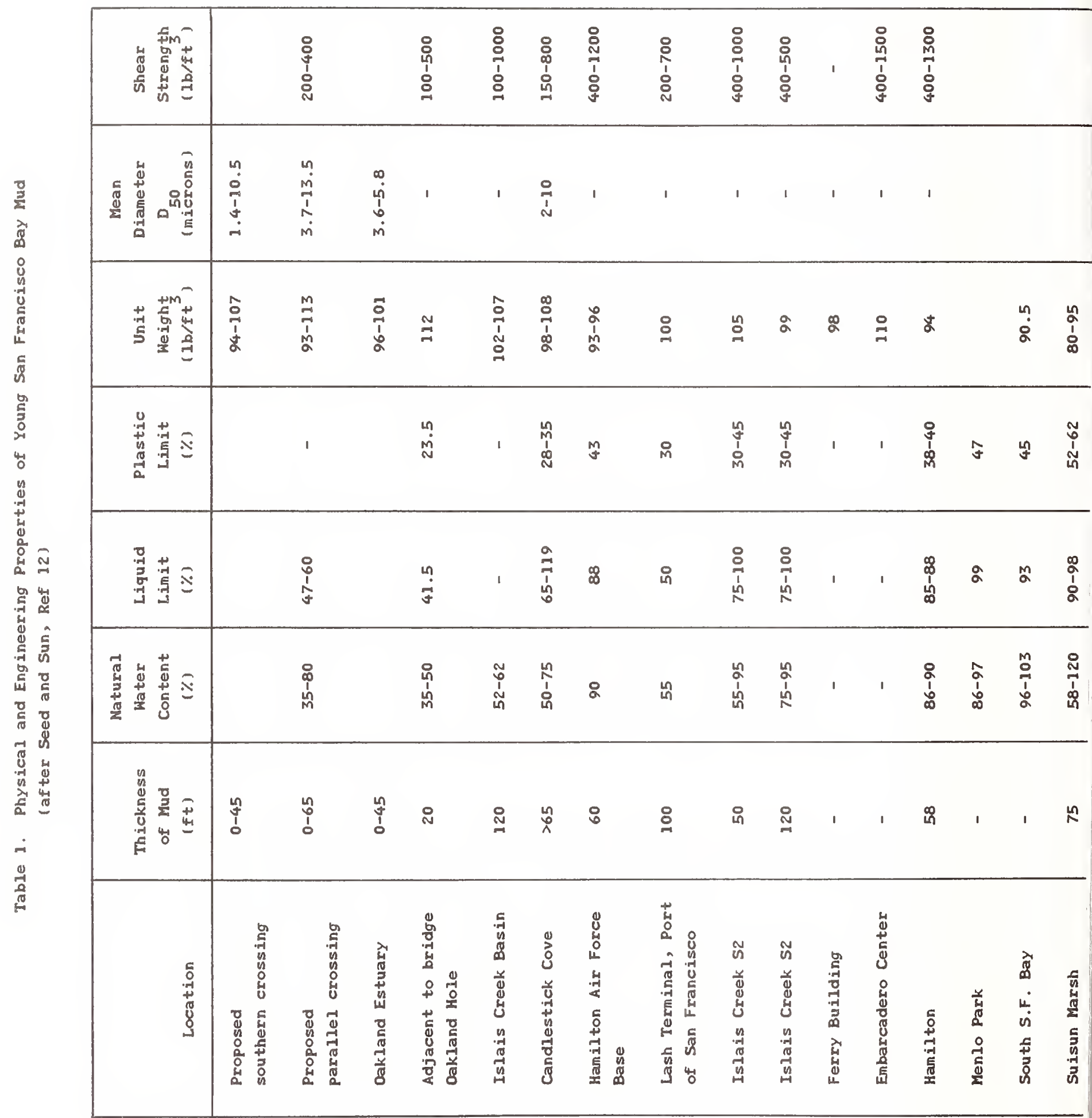


Table 2. Maximun Shear Stress Reduction Factor for

Deformable Body Relative to Rigid Body, $r_{d}$.

\begin{tabular}{|r|c|}
\hline $\begin{array}{c}\text { Depth } h \\
\text { (ft) }\end{array}$ & $r_{d}=\frac{\left(\tau_{\text {max }}\right)^{d}}{\left(\tau_{\max }\right)^{r}}$ \\
\hline 0 & 1.00 \\
5 & 0.99 \\
10 & 0.98 \\
15 & 0.97 \\
20 & 0.96 \\
30 & 0.92 \\
40 & 0.85 \\
50 & 0.75 \\
60 & 0.68 \\
70 & 0.61 \\
80 & 0.55 \\
90 & 0.53 \\
100 & 0.50 \\
\hline
\end{tabular}




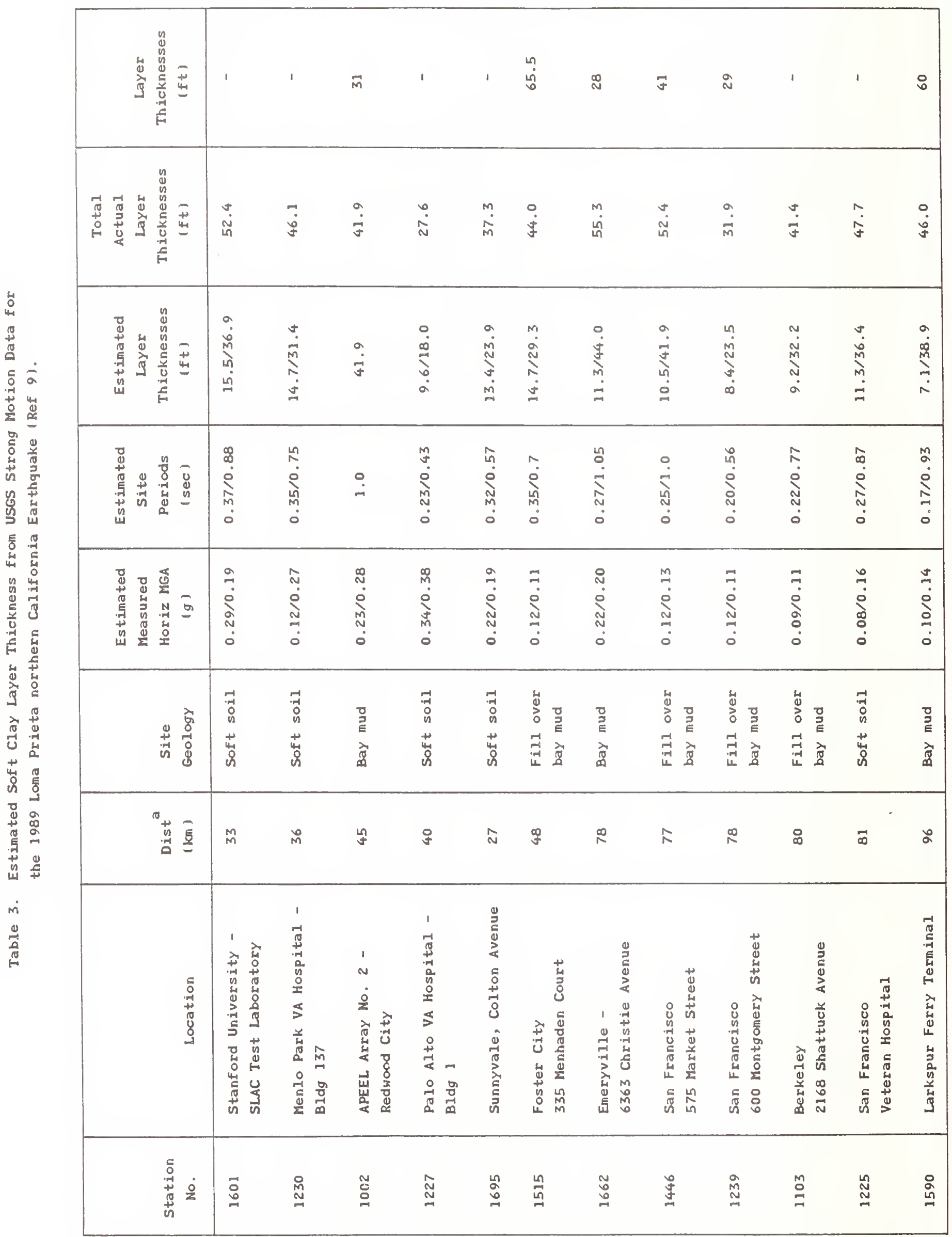




\begin{tabular}{|c|c|c|c|c|c|c|c|c|}
\hline 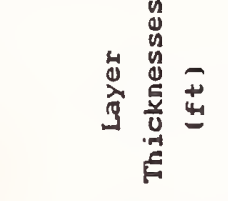 & $\hat{n}$ & $\stackrel{M}{\sim}$ & $\cong$ & 尺ิ & $\stackrel{n}{\wedge}$ & $\stackrel{\circ}{\circ}$ & 음 & $\stackrel{M}{\mathfrak{v}}$ \\
\hline 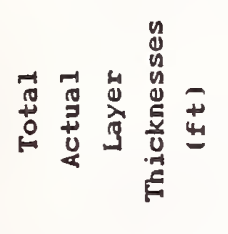 & $\stackrel{n}{n}$ & $\stackrel{\infty}{a}$ & $\underset{m}{\infty}$ & $\begin{array}{l}\text { Ũ } \\
\text { ஸे }\end{array}$ & $\begin{array}{l}0 \\
\dot{m} \\
\stackrel{n}{n}\end{array}$ & m. & 这 & $\stackrel{\circ}{\stackrel{f}{\sigma}}$ \\
\hline 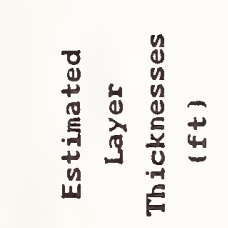 & 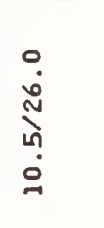 & 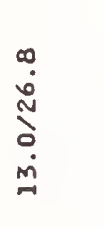 & $\begin{array}{l}\stackrel{N}{N} \\
\stackrel{N}{0} \\
\stackrel{N}{N}\end{array}$ & $\begin{array}{l}\stackrel{a}{\dot{5}} \\
\text { wे } \\
\stackrel{0}{0}\end{array}$ & $\begin{array}{l}\stackrel{0}{0} \\
\dot{g} \\
0 \\
\dot{m}\end{array}$ & $\stackrel{m}{\hat{0}}$ & 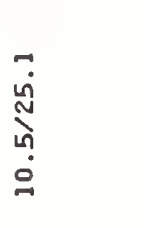 & $\begin{array}{l}\stackrel{n}{\infty} \\
\stackrel{n}{n} \\
\ddot{n}\end{array}$ \\
\hline 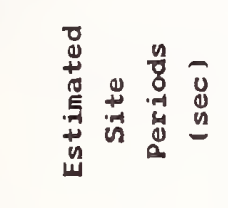 & 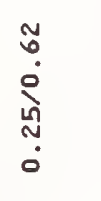 & \begin{tabular}{l}
\multirow{2}{0}{} \\
$\dot{0}$ \\
$\dot{0}$ \\
$m$ \\
$\dot{0}$
\end{tabular} & $\begin{array}{l}\text { Ln } \\
\dot{0} \\
0 \\
0 \\
\dot{m} \\
0\end{array}$ & 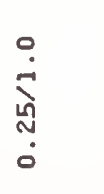 & $\begin{array}{l}a \\
\dot{0} \\
\dot{m} \\
\dot{m} \\
\dot{0}\end{array}$ & $\stackrel{\stackrel{n}{N}}{i}$ & $\begin{array}{l}\stackrel{0}{0} \\
\dot{0} \\
\text { ஸे } \\
\dot{0}\end{array}$ & $\begin{array}{l}\infty \\
0 \\
0 \\
0 \\
0 \\
\dot{p} \\
\dot{0}\end{array}$ \\
\hline 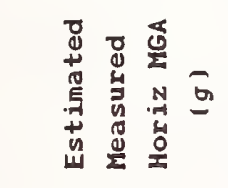 & $\begin{array}{l}\stackrel{2}{\grave{0}} \\
\stackrel{0}{0} \\
\stackrel{i}{0} \\
\dot{0}\end{array}$ & $\begin{array}{l}\stackrel{ \pm}{N} \\
\dot{0} \\
\stackrel{m}{m} \\
\dot{0}\end{array}$ & 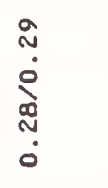 & $\begin{array}{l}\vec{N} \\
\vdots \\
\vdots \\
\stackrel{0}{0}\end{array}$ & $\begin{array}{l} \pm \\
\vdots \\
\vdots \\
\vdots \\
0\end{array}$ & $\begin{array}{l}\stackrel{0}{0} \\
\vdots \\
\ddot{0}\end{array}$ & $\begin{array}{l}7 \\
\dot{0} \\
\stackrel{0}{0}\end{array}$ & $\begin{array}{l}\stackrel{2}{0} \\
\dot{0} \\
\stackrel{0}{0} \\
0 \\
0\end{array}$ \\
\hline 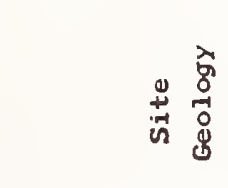 & 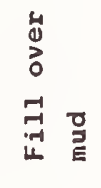 & 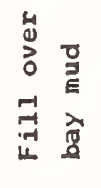 & 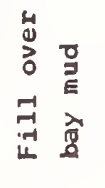 & 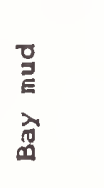 & 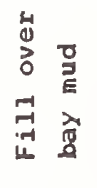 & 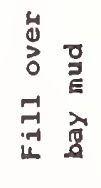 & 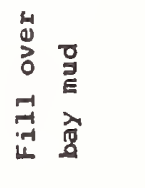 & 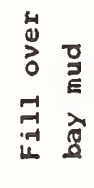 \\
\hline 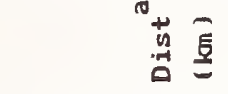 & 寸 & 8 & $\stackrel{2}{\wedge}$ & $\tilde{m}$ & 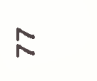 & $\hat{\imath}$ & $\stackrel{i}{i}$ & $\stackrel{n}{\kappa}$ \\
\hline $\begin{array}{l}5 \\
.7 \\
+7 \\
8 \\
8 \\
3\end{array}$ & 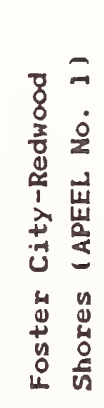 & 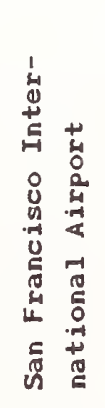 & 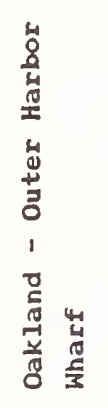 & 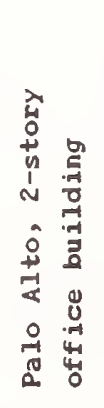 & 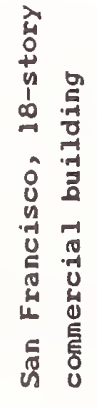 & 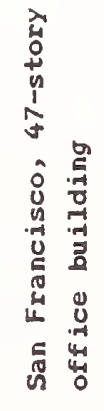 & 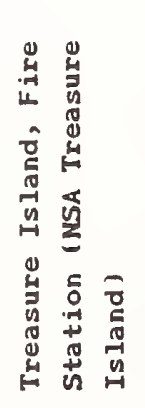 & 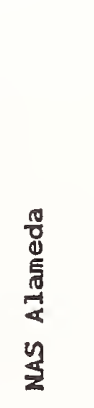 \\
\hline 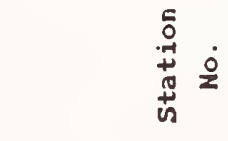 & 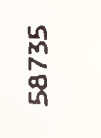 & $\begin{array}{l}\stackrel{M}{N} \\
\underset{0}{N} \\
\text { H. }\end{array}$ & 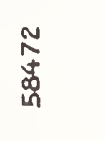 & 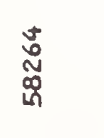 & $\begin{array}{l}\text { 品 } \\
\text { 品 }\end{array}$ & 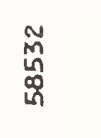 & 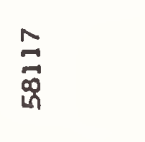 & 崫 \\
\hline
\end{tabular}

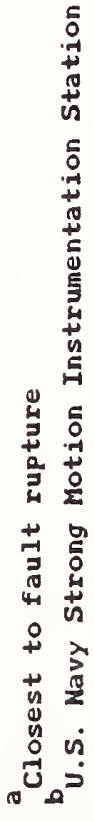




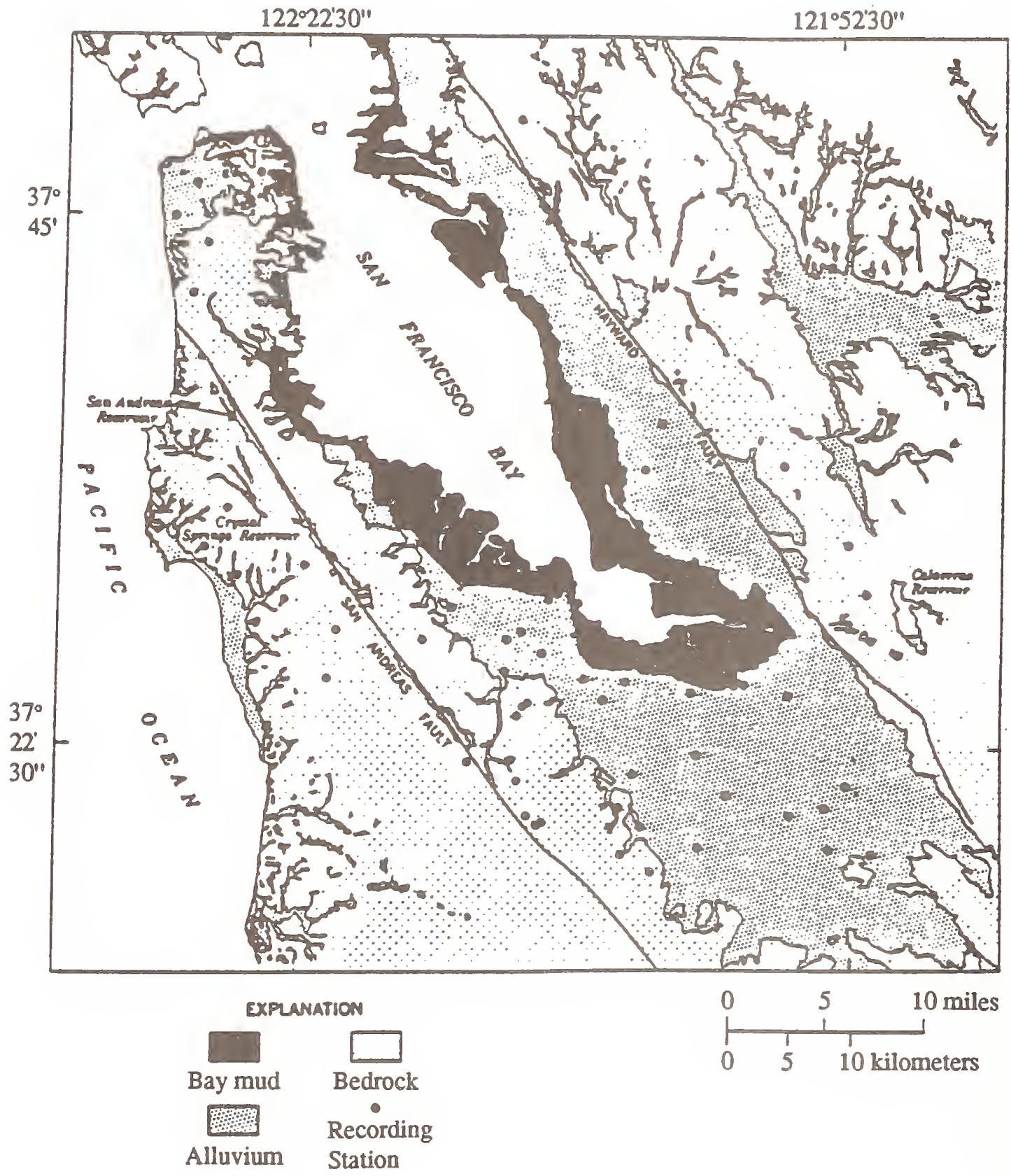

Figure 1. Geological conditions in the vicinity of San Francisco Bay (after Brocherdt, et al., Ref 8). 


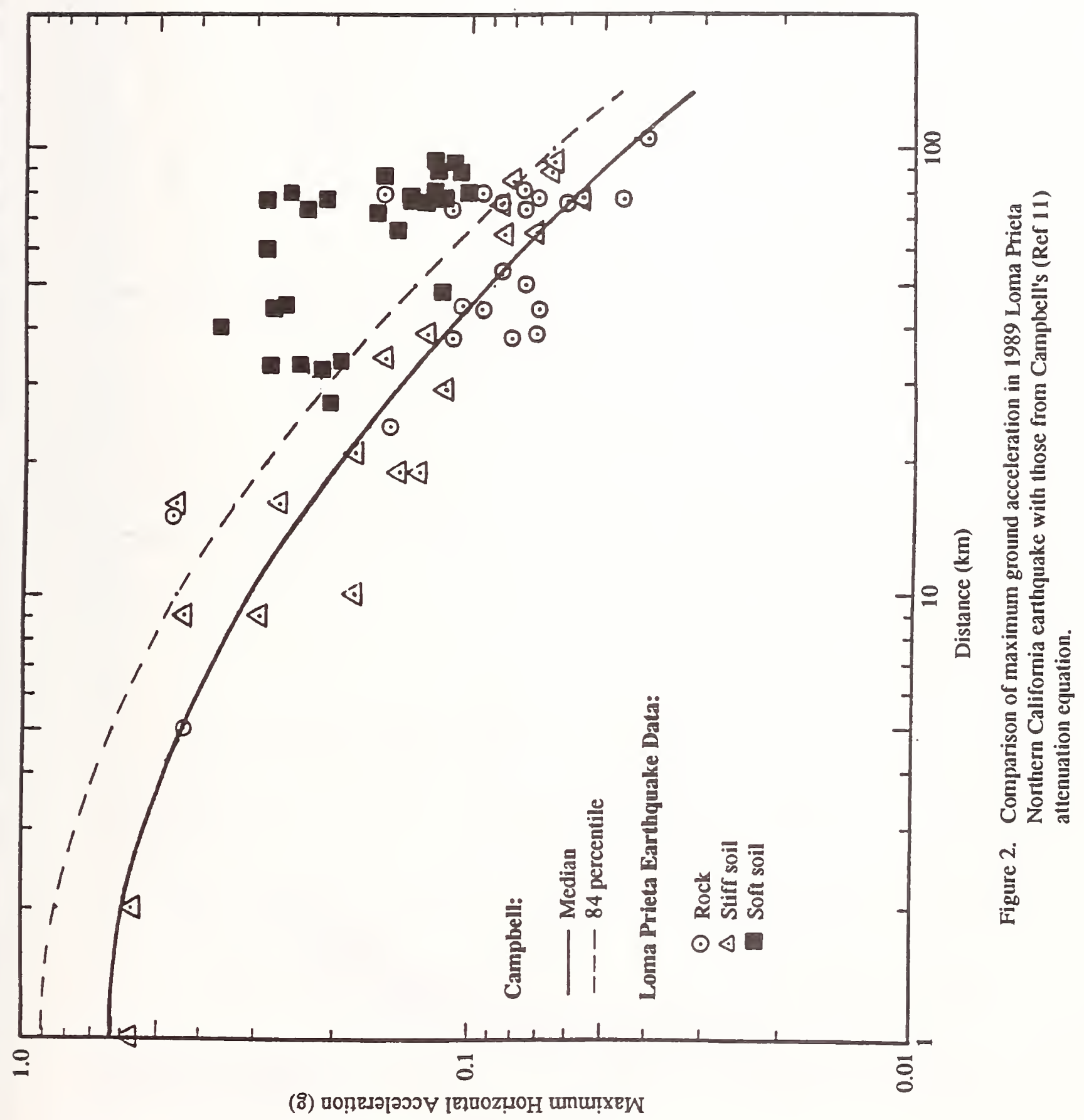



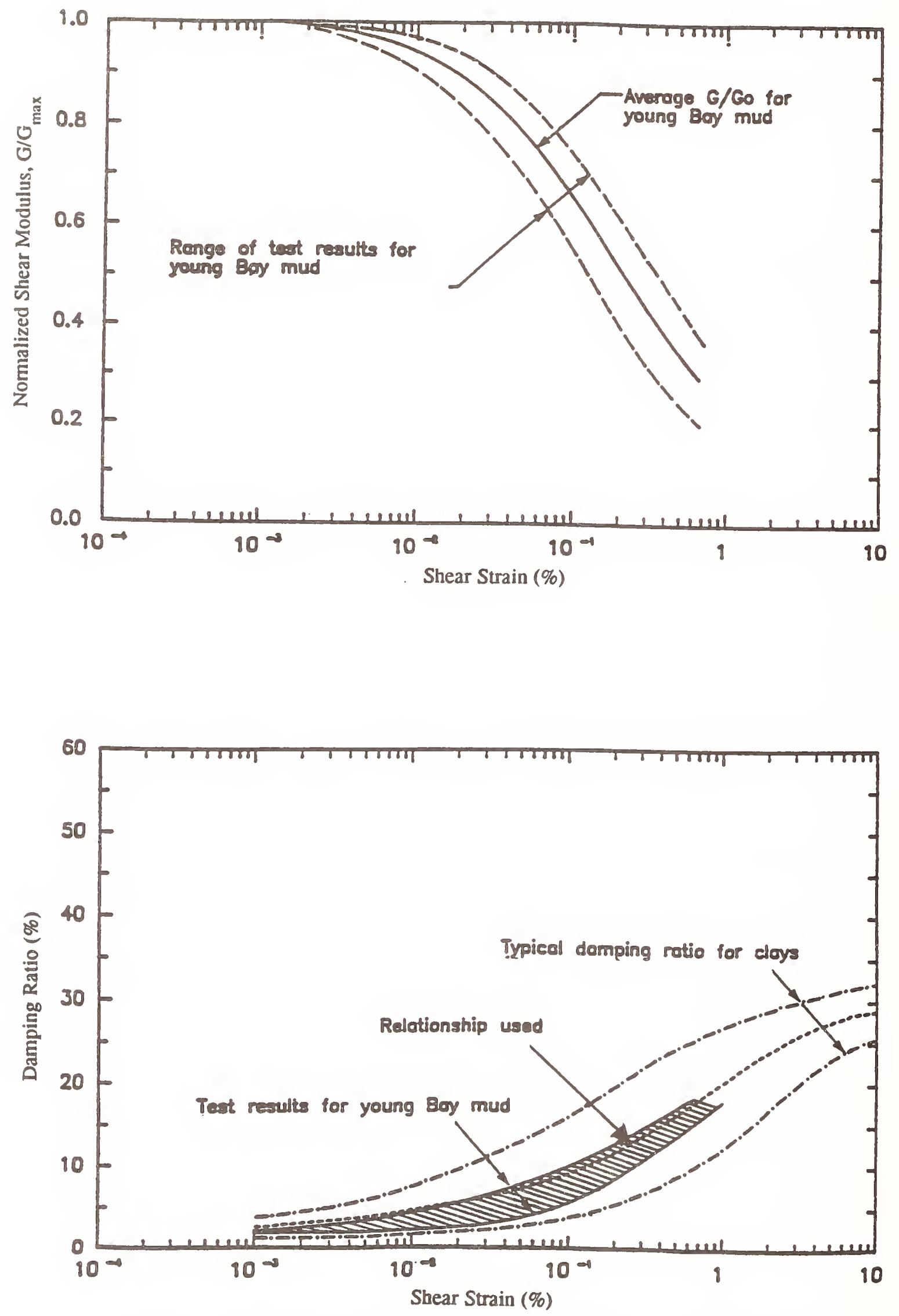

Figure 3. Variation of normalized shear modulus and damping ratio with shear strain for you San Francisco Bay mud (after Seed and Sun, Ref 12). 


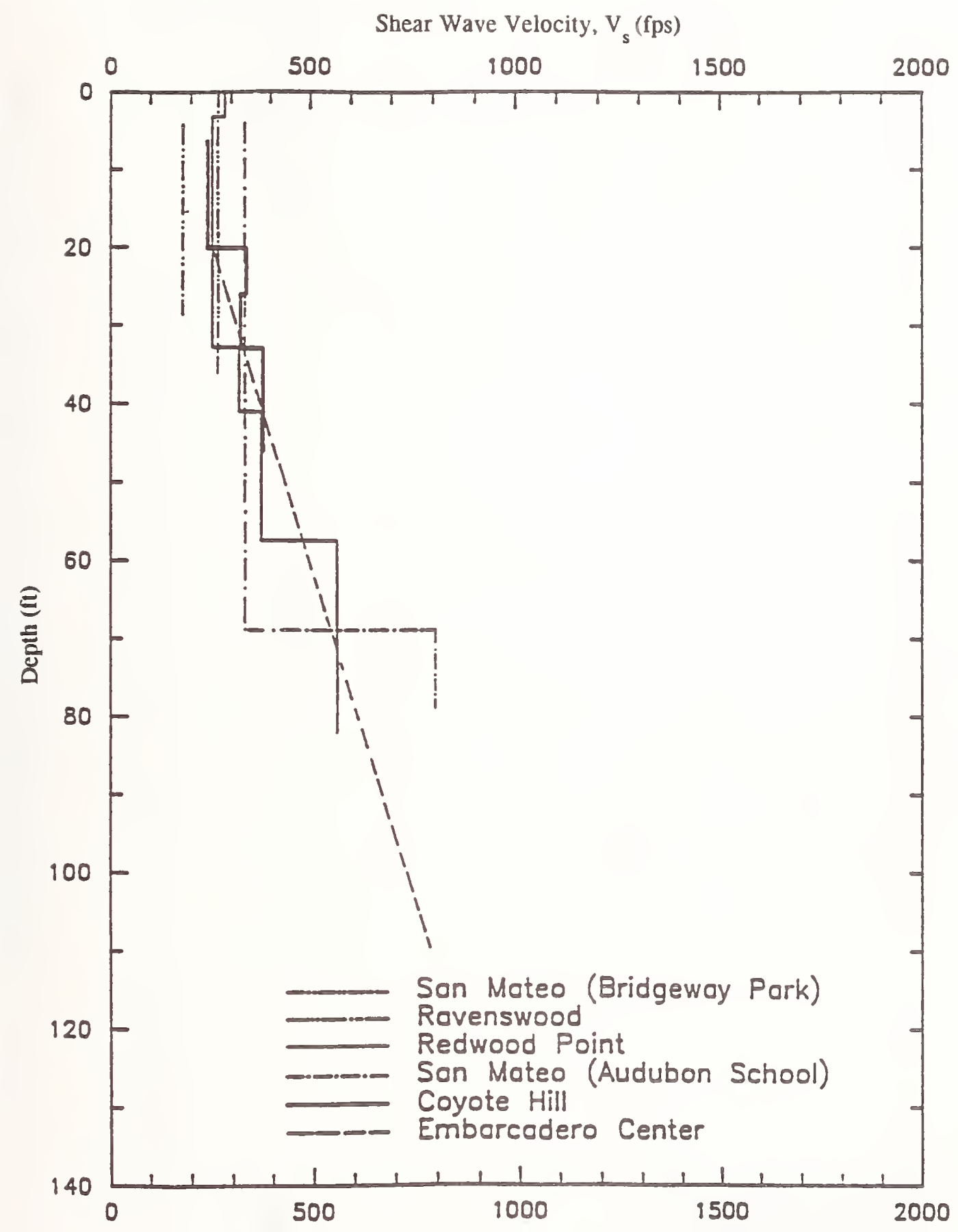

Figure 4. Measured shear wave velocity profiles for six young bay mude sites on the San Francisco Bay shore (after Seed and Sun, Ref 12). 

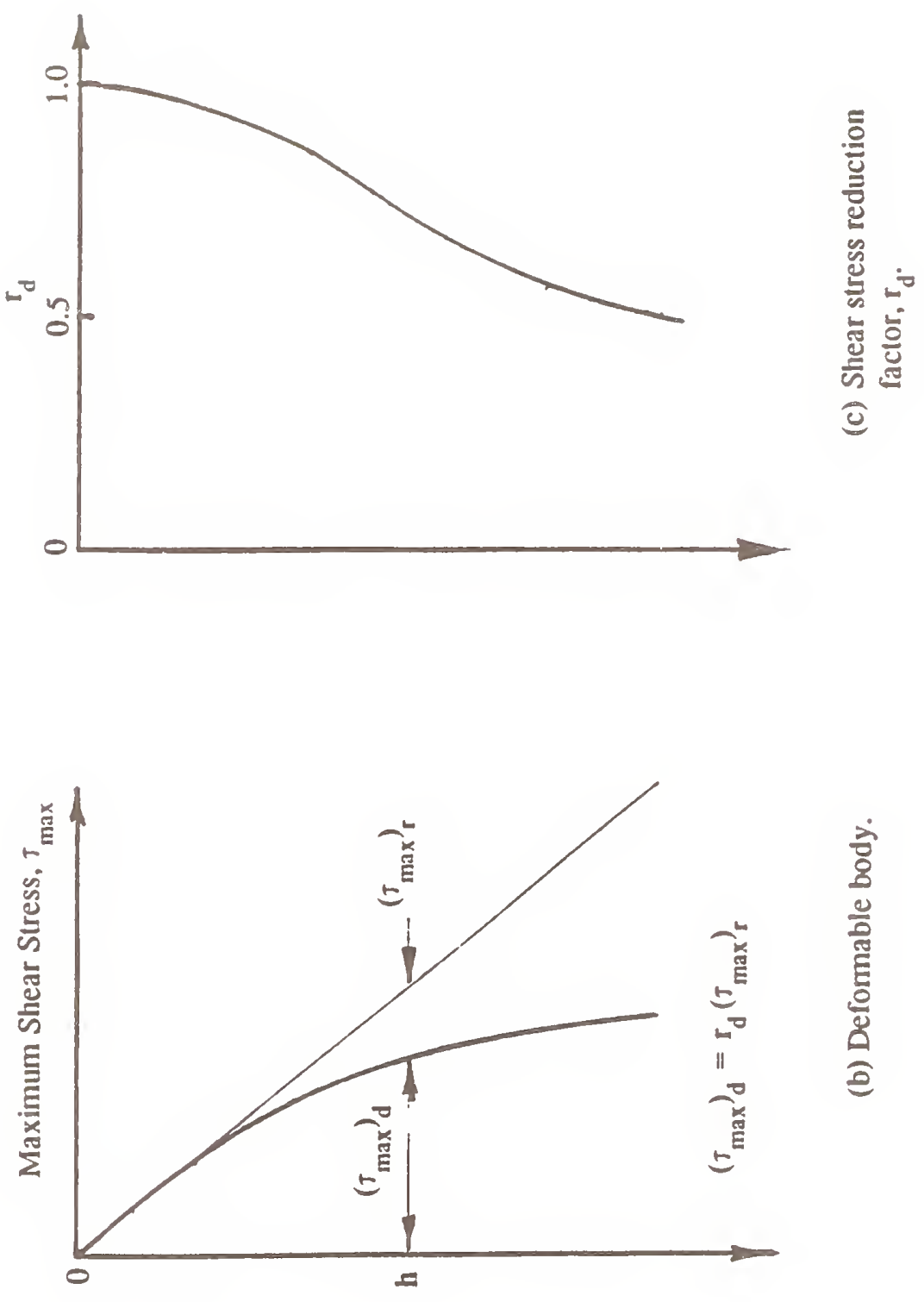

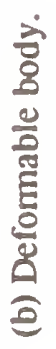

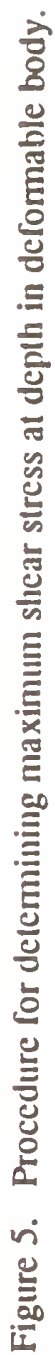

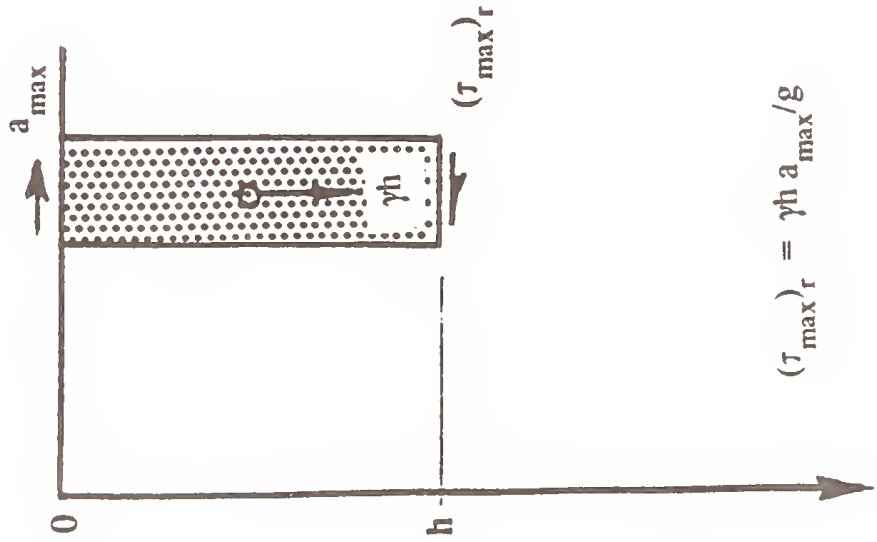

प1dวa 


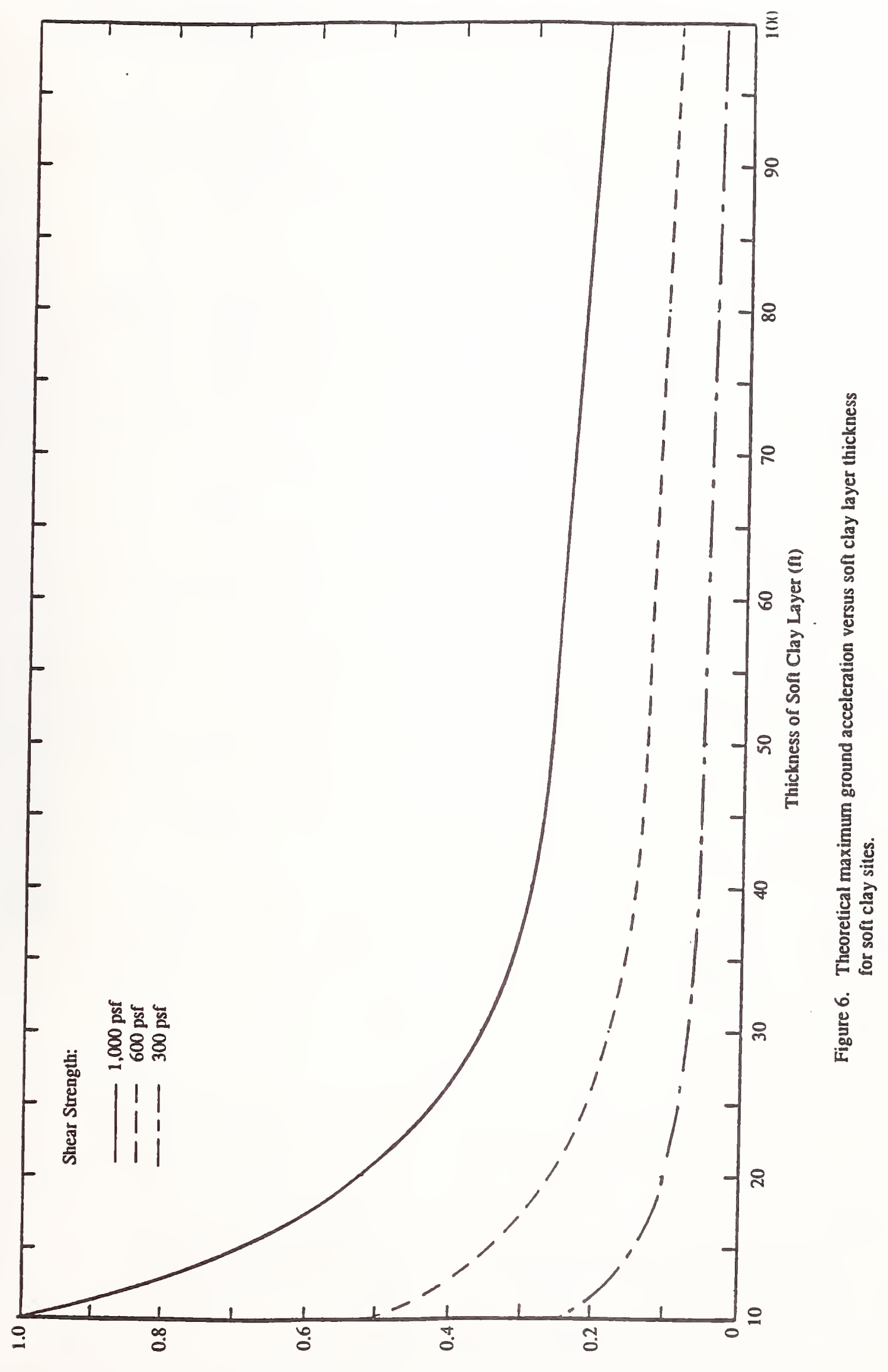

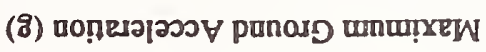




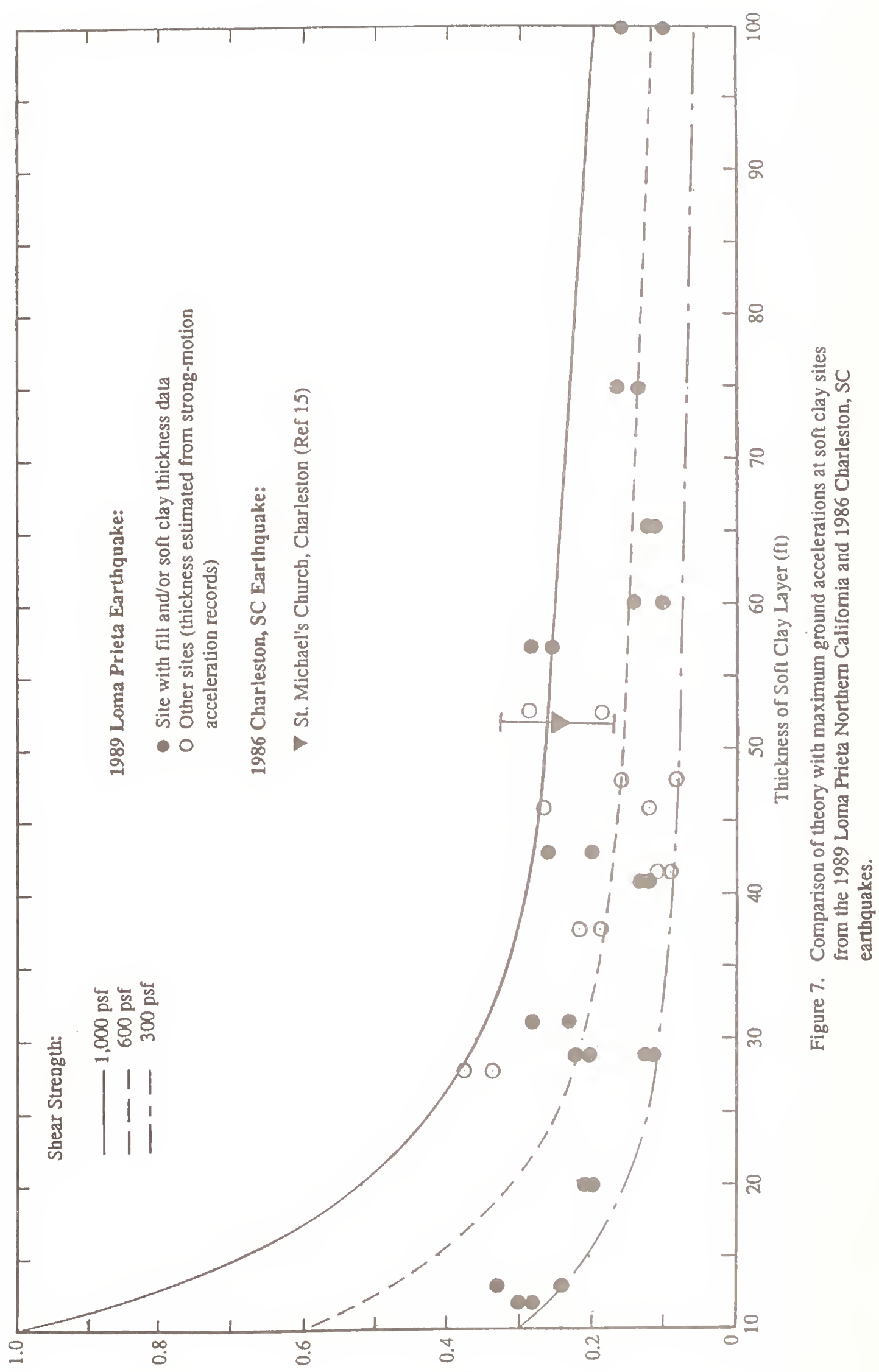

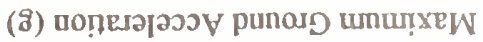




\title{
Broadband Strong-Motion Seismic Observation Network Operated by Japan Meteorological Agency
}

\section{operated by Japan Meteorological Agency}

\author{
Masahiro Yamamoto ", Iwao Sasakawa ${ }^{2}$, Akira Nagai ${ }^{3}$, Takeshi Kakishita \\ Akihiko Wakayama , Koichi Uhira , Masaaki Seino ${ }^{7}$
}

\section{SUMMARY}

The JMA has deployed a strong motion seismic observation network of newly developed seismometers, the digital 87 type electromagnetic strong motion seismographs, installed in 74 stations in Oct. 1989.

The seismometer has an electromagnetic force feedback which operates over the frequency band 0.005 to $10 \mathrm{~Hz}$ and the dynamic range 0.03 to $980 \mathrm{gal}$.

The analysis of data from two earthquakes with mag. nitude 7.1 and 6.5 is presented in this paper. From the latter earthquake, strong motion seismogram at near field (epicentral distance: $13.3 \mathrm{~km}$ ) was obtained without clip (max. $a=330$ gal, max. $v=27$ kine and max. $d=9.4 \mathrm{~cm}$ ). The focal process analysis based on the new seismographs is also presented.

For the data obtained in the frequency band less than $0.05 \mathrm{~Hz}$, however, the computed displacement seismograph becomes noisy due to the limitation of minimum resolution to $30 \mathrm{mgal}$.

KEY WORDS: Electromagnetic Strong Motion seismograph(ESM), Earthquake of near E off NE Japan in 1989. Earthquake of near Izu-Oshima Is. in 1990 , Source process

\section{FOREWORD}

Since 1950, the mechanical type analogue strong motion seismographs(MSM) have been operated at 114 stations for the local large earthquake observation by JMA. The MSM has a defect that, in frequency band less than $0.2 \mathrm{~Hz}$, frequency is proportional to displacement and the instrument is mechanically clipped only at $3 \mathrm{~cm}$ of displacement. JMA has a responsibility for the quick tsunami warning service. Therefore, it is very important to observe the large amplitude and low frequency seismic waves from tsunamigenic earhquakes. The me- chanical strong motion seismograph has a limitation for that purpose. Therefore, the Meteorological Research Institute (MRI) of JMA had developed a new prototype strong motion seismometer in $1983^{\text {') }}$. JMA has started an operation of it in Oct. 1989.

In this paper, we first describe oulline of the new strong motion seismometer and then the station distribution. Subsequently, the merits and some remaining problems will also be presented based on the result of wave form analysis from two earthquakes which occurred in E off NE Japan (M: 7.1) and near Izu-Oshima Is. (M: 6.5).

\section{AN OUTLINE OF THE ELECTROMAGNETIC STRONG MOTION SEISMOGRAPH (ESM) AND THE STATION DISTRIBUTION}

JMA, in cooperation with MRI, has started the operation of the ESM at 74 out of 114 seismic stations in OCT, 1989. This seismograph operates over the frequency band 0.005 to $10 \mathrm{~Hz}$ and dynamic range 0.03 to 980 gal as shown in Fig. 1.

As compared with the MSM as shown in the same Fig. 1, the ESM has the broadband in frequency and high dynamic range.

The ESM is composed of the measurement (MP) and the processing (PP) parts as shown in Fig. 2. The feed-

\footnotetext{
1 Deputy Head, Seismology and Volcanology Division, Japan Meteorological Agency

2 Senior Technical Staff. Seismology and Volcanology Division, Japan Meteorological Agency

3 Technical Staff, Sejsmology and Volcanology Division, Japan Mereorological Agency

4 Technical Suff, Seismology and Volcanology Division, Japan Meteorological Agency

5 Research Suff, Seismology and Voicanology Research Division, Melcorological Research Institule

6 Research Staff, Seismology and Volcanology Research Division, Meteorolog. ical Researth Institute

7 Chief, Seimology and Voleanology Research Division, Meteorological Research Irscitute
} 
back operates over the frequency band 0 to $400 \mathrm{~Hz}$ and dynamic range $1 \mathrm{mgal}$ to $1000 \mathrm{gal}$. In order to minimize the noise, three 16 bits ADC are implemented with oversampling design, for each of the three components.

Digitized 50 samples/s in MP are transmitted to PP. The same data are also telemetered to relevant regional Tsunami warning centers and also stored on floppy disk as accelerogram at each station. The distribution of the 74 stations that are equipped with the ESM is shown in Fig. 3.

\section{WAVE FORM COMPARISON BETWEEN MSM} AND ESM

For monitoring the proper operation of the ESM, two seismograms from the $E S M$ and the $M S M$ recorded at the same station are compared. The ESM seismogram is filtered with the filter that has the same characteristics as the MSM.

The earthquakes which are used for the comparison are as follows.

Fig. 4 shows the seismic activities which occurred in E off NE Japan during the period of Oct. 27 เo Nov. 10, 1989. The main shock took place on Nov. 2 with a magnitude of 7.1 accompanying a tsunami (max. height is 92 $\mathrm{cm}$ from peak to trough). The epicentral distribution (magnitude 4.0 or more) and the cross section along A-B line are shown in Fig. 4.1 and Fig. 4.2, respectively. The focal mechanism of main shock shows a reverse type fault reflecting the E-W compressional stress field as shown in Fig. $4.3^{2)}$.

Fig. 5 shows the seismic activities near Izu-Oshima Is. which include an earthquake of magnitude 6.5 (the main shock) on Feb. 20, 1990. Some disasters such as road collapse and small Tsunami (peak to trough is 32 $\mathrm{cm}$ ) were reported.

Epicentral distribution of the main and after shocks (magnitude 2.5 and more) is shown in Fig. 5.1. The focal mechanism of the main shock shows a strike slip fault reflecting the NW-SE compressional stress field). They are projected on two vertical planes in Fig. 5.3\%

Two seismograms, from each of the two seismographs (MSM and ESM) are shown in Fig. 6 from these two earthquakes. Left and right seismograms correspond to the MSM and the ESM respectively.

Fig. 6.1 is the seismograms recorded at Hachinohe (HAC in Fig. 3. epicentral distance of $150 \mathrm{~km}$ ) from the earthquake of $E$ off NE Japan (M: 7.1). Fig 6.2 is the seismograms recorded at Oshima (epicentral distance of $13 \mathrm{~km}$ ) and Tokyo (epicentral distance of $113 \mathrm{~km}$ ).

Note that the polarities of EW and UD components are reverse between $M S M$ and $E S M$.

The seismogram of ESM at Oshima recorded the event satisfactorily, on the other hand, that of MSM is saturated.

\section{SPECTRAL ANALYSIS}

Three seismograms recorded at Hachinohe from the E off NE Japan is shown in Fig. 7.1 after filtering with bandwidth of 0.01 to $10 \mathrm{~Hz}$ for acceleration and 0.05 to $10 \mathrm{~Hz}$ for velocity and displacement.

The maximum traced amplitude on this record becomes about three times as large as the record taken by the MSM.

Acceleration spectrum density for EW component of the period $20 \mathrm{sec}$. before and after maximum amplitude is shown on the left of Fig. 7.2.

Noise spectrum density with the minimum digitized resolution of $30 \mathrm{mgal}$ is estimated about $0.1 \mathrm{~cm} / \mathrm{sec}$ at $0.05 \mathrm{~Hz}$ and $0.2 \mathrm{~cm} / \mathrm{sec}$ at $0.025 \mathrm{~Hz}$. The noise might overshadow the signal in the frequency range less than 0.0 $25 \mathrm{~Hz}$.

Displacement spectrum density after the low cut filtering at $0.05 \mathrm{~Hz}$ is shown on the right of Fig. 7.2.

Three seismogram records at Oshima from the Izu Oshima Is (M: 6.5) is shown in Fig. 8.1 after filtering with bandwidth of 0.01 to $10 \mathrm{~Hz}$ for acceleration and 0.05 to $10 \mathrm{~Hz}$ for velocity and displacement as with Fig. 7.1. Recorded maximum acceleration, velocity and displacement are $330 \mathrm{gal}, 27$ kine and $9.4 \mathrm{~cm}$, respectively.

Acceleration spectrum density for NS component of the period $20 \mathrm{sec}$ before and after maximum amplitude is shown on the left of Fig. 8.2.

In this case also, some considerations may become necessary with regard to the noise level for the records 
obtained in the low frequency range less than $0.025 \mathrm{~Hz}$.

Displacement spectrum density after the low cut filtering at $0.05 \mathrm{~Hz}$ is shown on the right of Fig. 7.2.

From these two aralyses, it becomes clear that an appropriate filter needs to be chosen in case of the wave analysis in low frequency range.

\section{AN OUTLINE OF THE SOURCE PROCESS OF 1990 NEAR IZU-OSHIMA EARTHQUAKE}

The source process of the near Izu-Oshima earthquake in 1990 was studied with ESM displacement data obtained at Oshima(OSH), Ajiro(AJI), Irozaki(NGT) and Mishima(MIS), whose locations were shown in Fig5.1. These data were filtered for removing frequency components higher than $0.3 \mathrm{~Hz}$ in order to reduce the ambiguity due to inhomogeneous crustal structure near the surface. Synthetic seismograms were calculated with the velocity structure model of Yoshii et al. (1985) ${ }^{\text {s) }}$.

The non-linear inversion method proposed by Takeo (1987) ${ }^{6)}$ was adopted to deduce the dislocation distribution and rupture propagation on the assumed fault plane.

In the present study, the main-shock fault was estimated from the after shock distribution to be $20 \mathrm{~km}$ long and $12 \mathrm{~km}$ wide (from the depth of $1.5 \mathrm{~km}$ to $13.5 \mathrm{~km}$ ) with strike of $\mathrm{N} 352^{\circ}$ and dip on $76^{\circ}$. The fault plane was divided into 15 sections and double couple source was arranged at the center of each section. The source process of the earthquake was assumed to be expressed by an integration of double couple sources having the same source time function.

The synthetic seismograms calculated with the final solution were compared with the observed seismograms as shown in Fig. 9.1. In this case, only pure strike slip was taken into consideration. Rapture propagation and seismic moment distribution over the fault are shown in Figs. 9.2 and 9.3, respectively. They suggest that the rapture front propagated at the speed of 2$3 \mathrm{~km} / \mathrm{sec}$ from north to south and the total seismic moment of $5 \times 10^{17} \mathrm{Nm}$, most of which was released at the central part of the fault. These results show that major dislocation took place in the central part of the fault with time delay of a few seconds afuer the onset of rapture and dislocation was small at shallower portion of the fault.

\section{References}

1) Seismology and Volcanology Research Division,MRI: Strong-Motion Seismograph model 83 for the Japan Meteorological Agency Network, Techn. Rep. MRI, 7,130p, 1983

2) Sendai District Meteorological Observatory, JMA: Seismic Activity in the Region far E off Sanriku (Oct.27-Nov.18,1989), Rep.Coordinat. Committee Earthq.Predict., 44, pp38-43, 1990

3) Earthquake Prediction Information Division JMA: On the Earthquake (M6.5) near the Izu-Oshima Island, February 20,1990, Rep.Coordinat. Committee Earthq.Predict., 44, pp147-152,1990

4) Ishikawa,Y., K.Matsumura, H.Yokoyama, and H.Matsumoto: SEIS-PC .. its outline .., Geological Data Processing, 10, pp 19-34, 1985

5) Yosii,T., S.Asano, S.Kubota, Y.Sasaki, H.Okada, T.Masuda, T.Moriya, and H.Murakami: Crustal Structure in Izu Peninsula, Central Japan, As Derived from Explosion Seismic Observations. 2.Ito-Matsuzaki Profile, J.Phys.Earth, 33, pp435-452, 1985

๑) Takeo, M.: An Inversion Method to Analyze the Rupture Processes of Earthquakes Using Near-Field Seismograms, Bull. Seism. Sos. Am., 77, pp490-513, 1987 


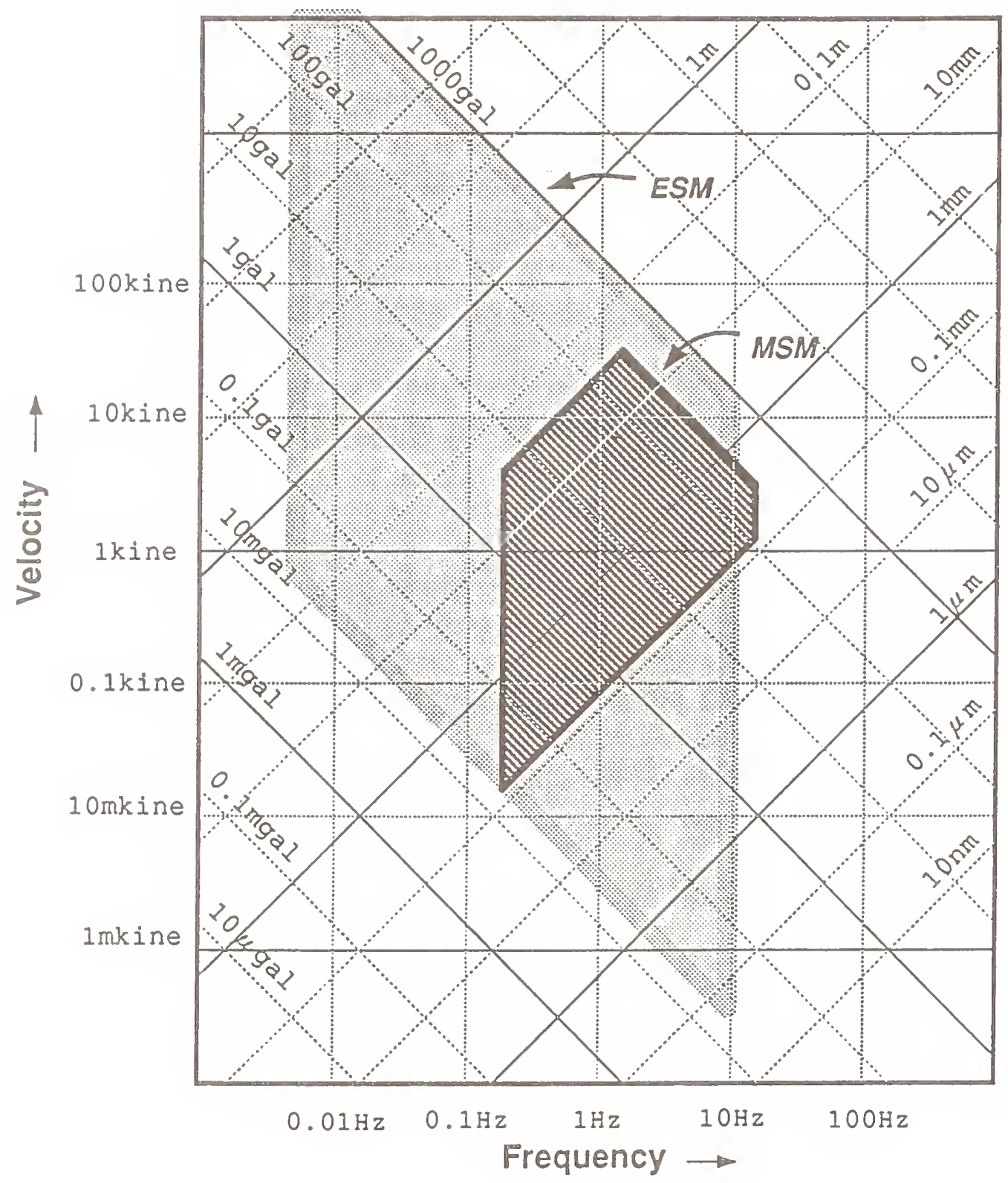

Fig. 1 Observatinal Domains in frequency and dynamic ranges of Mechanical Strong Motion seismograph (MSM) and Elecromagnetic Strong Motion seismograh(ESM). 

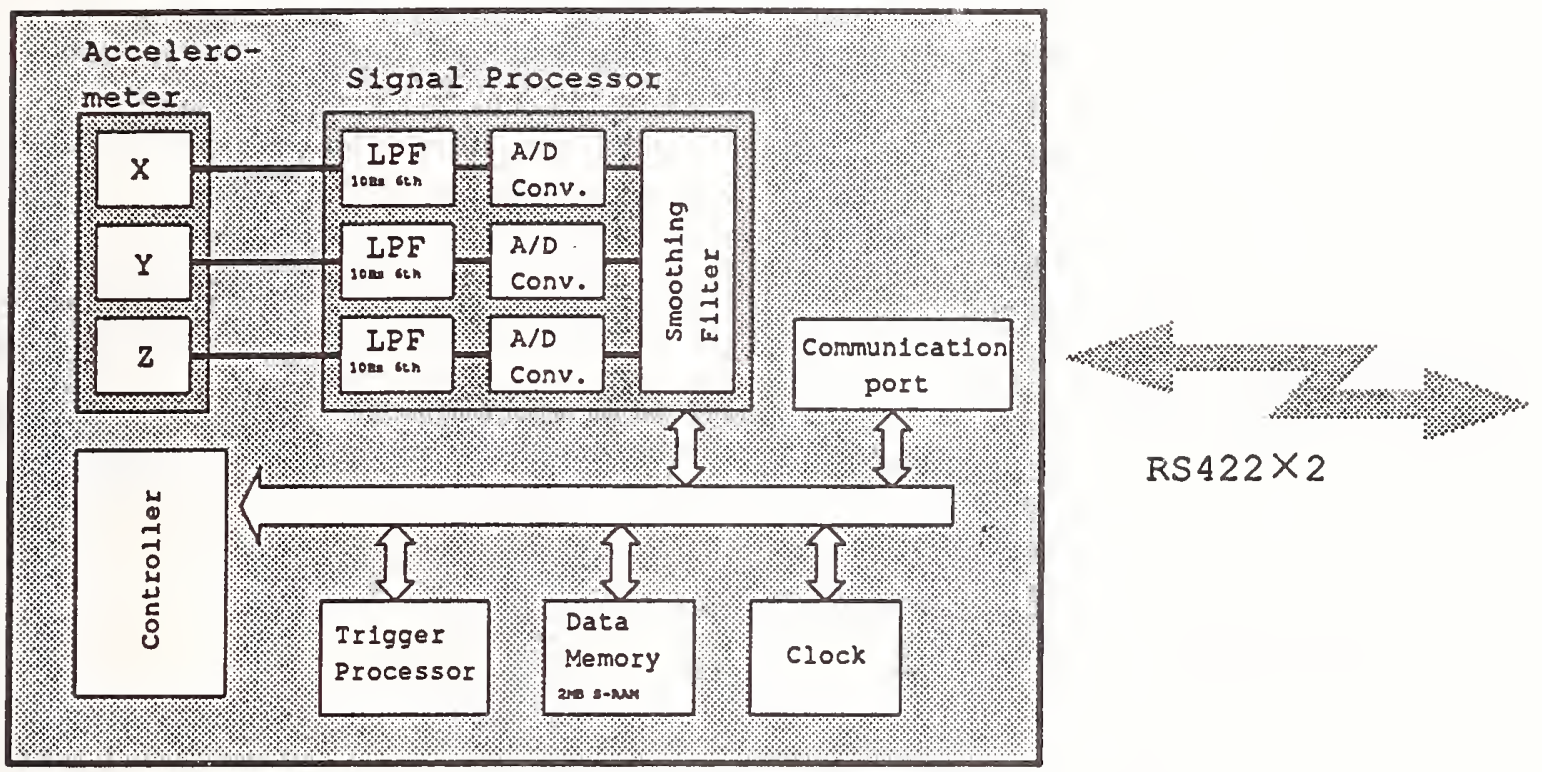

RS $422 \times 2$

\section{Measurement part}

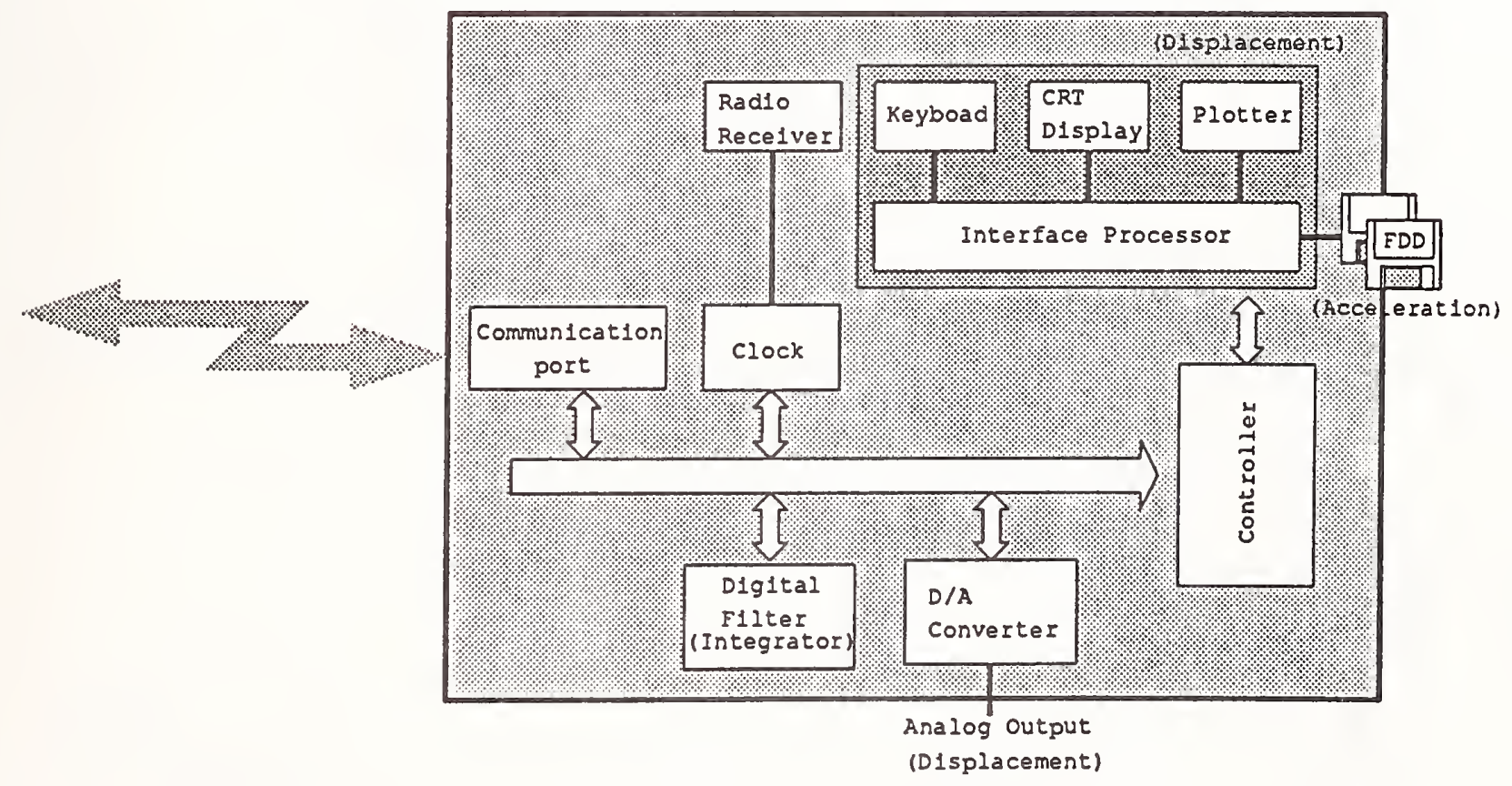

Processing part

Fig. 2 Block diagram of ESM. 


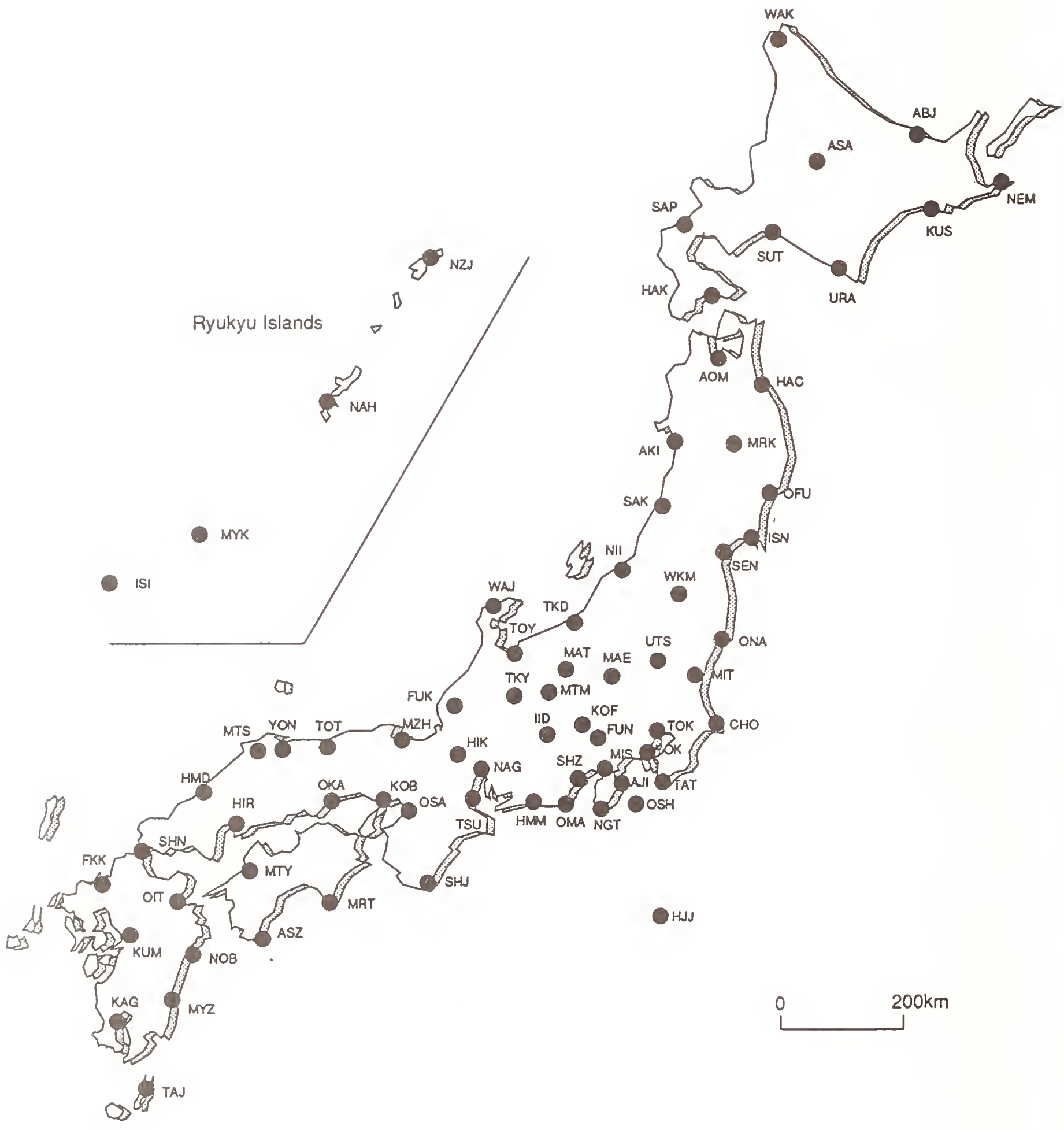

Fig. 3 Locations of the 74 ESM stations in Apr. 1991. 


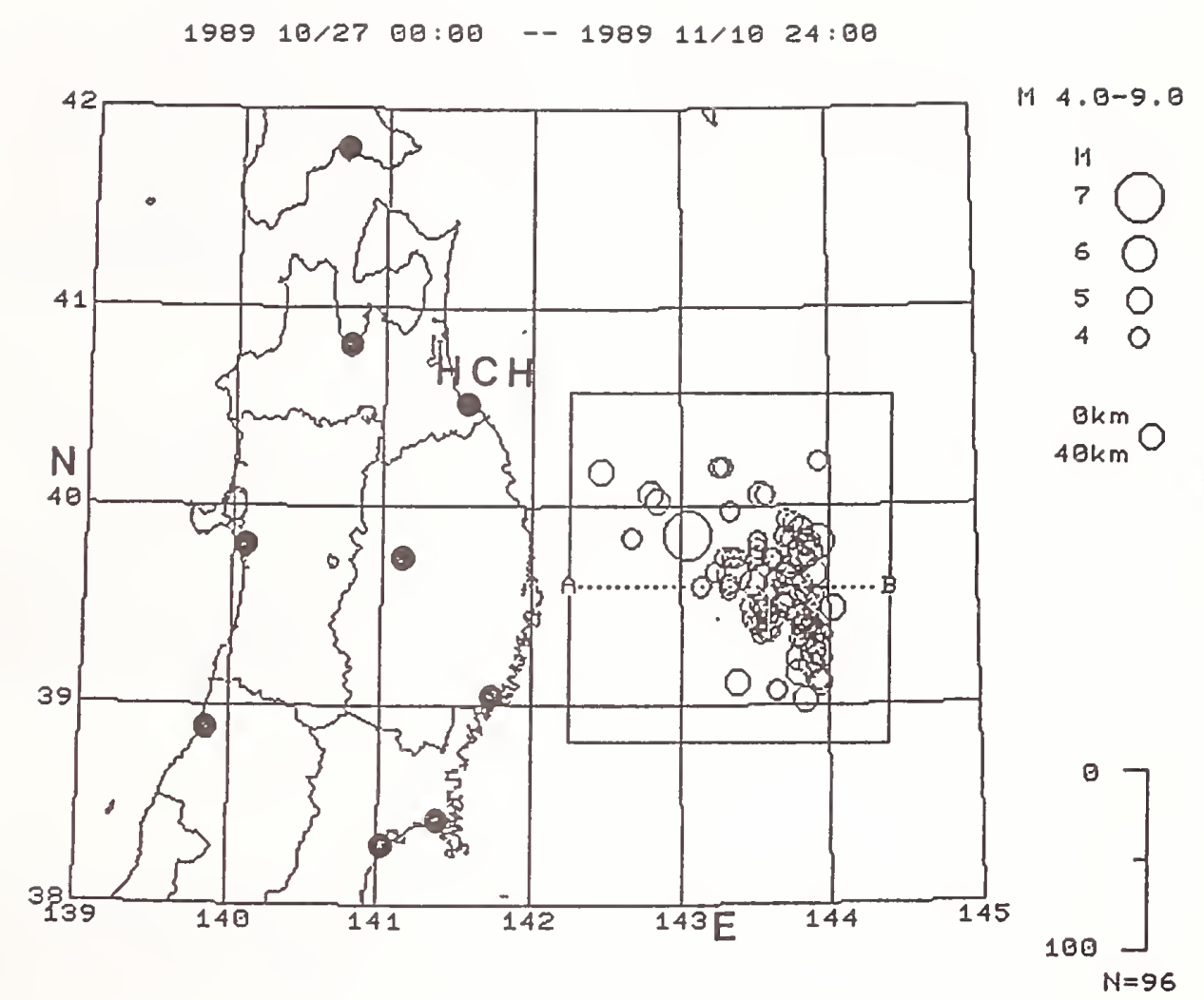

Fig. $4-1$

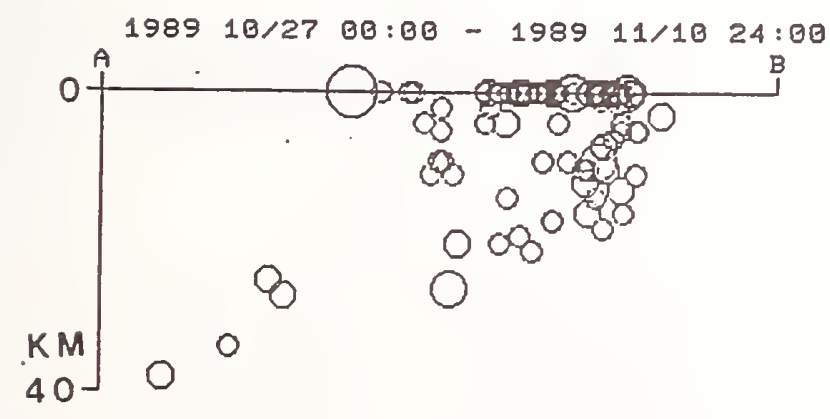

$X: Y=1: 2$

Fig. 4-2

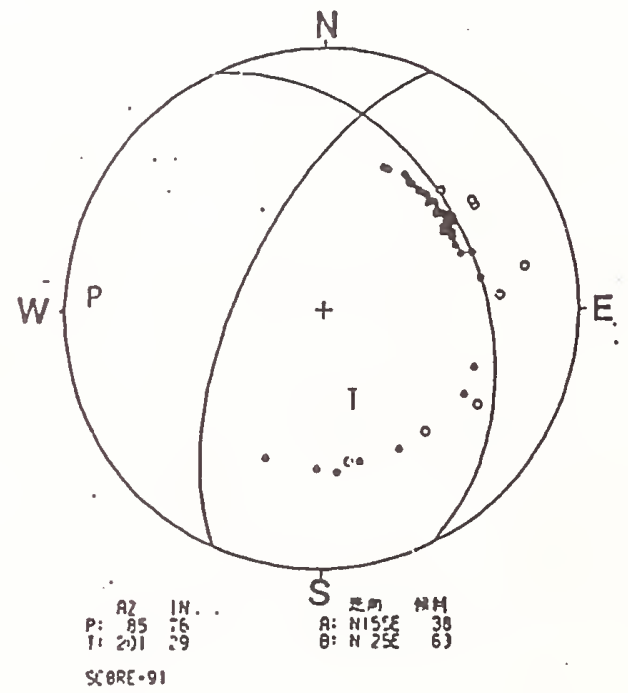

Fig. $4-3$

Fig. 4 Outline on the earthquake of E off NE Japan (M: 7.1) in 1989.

Fig. 4.1 Epicentral distribution. Solid circles show the location of the ESM.

$\mathrm{HCH}$ is used for the analysis in this report.

Fig. 4-2 Focal distribution projected on cross section A-B in Fig. 4-1.

Fig. 4-3 Focal mechanism solution plotted on the upper hemisphere.

Solid and open circles show the compressional and dilatational first motion respectivery. 


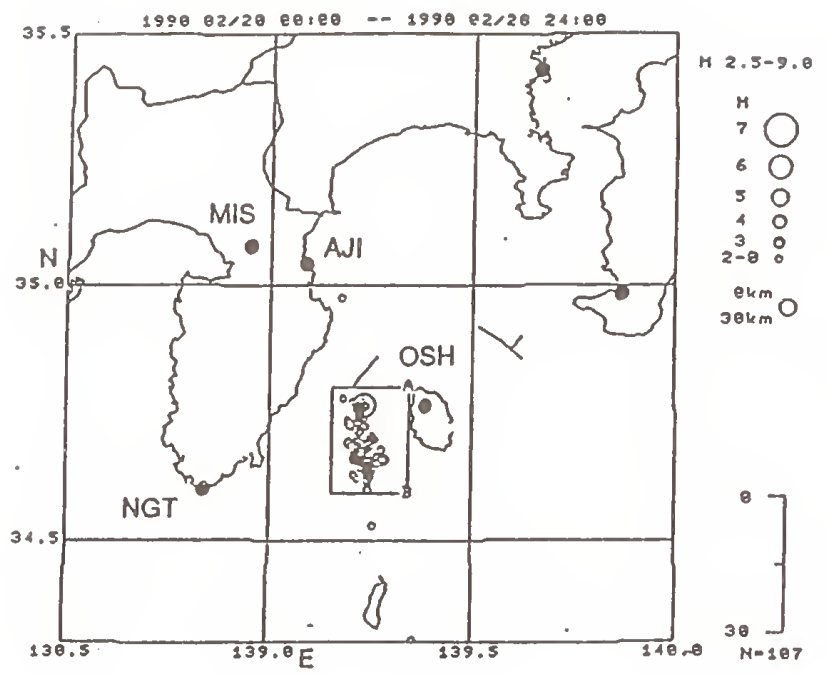

Fig. 5-1

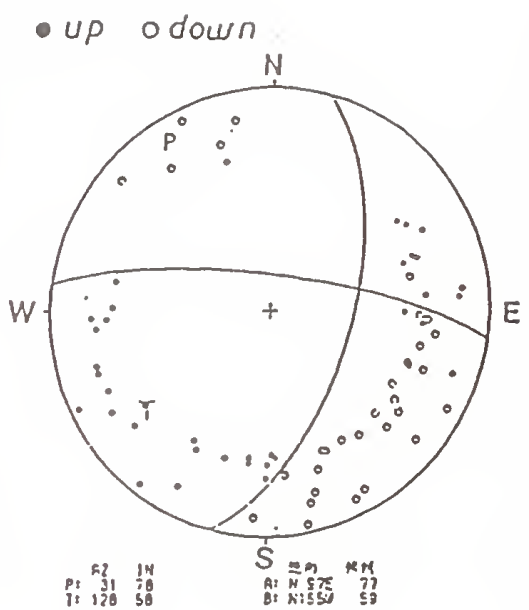

Fig. 5-2

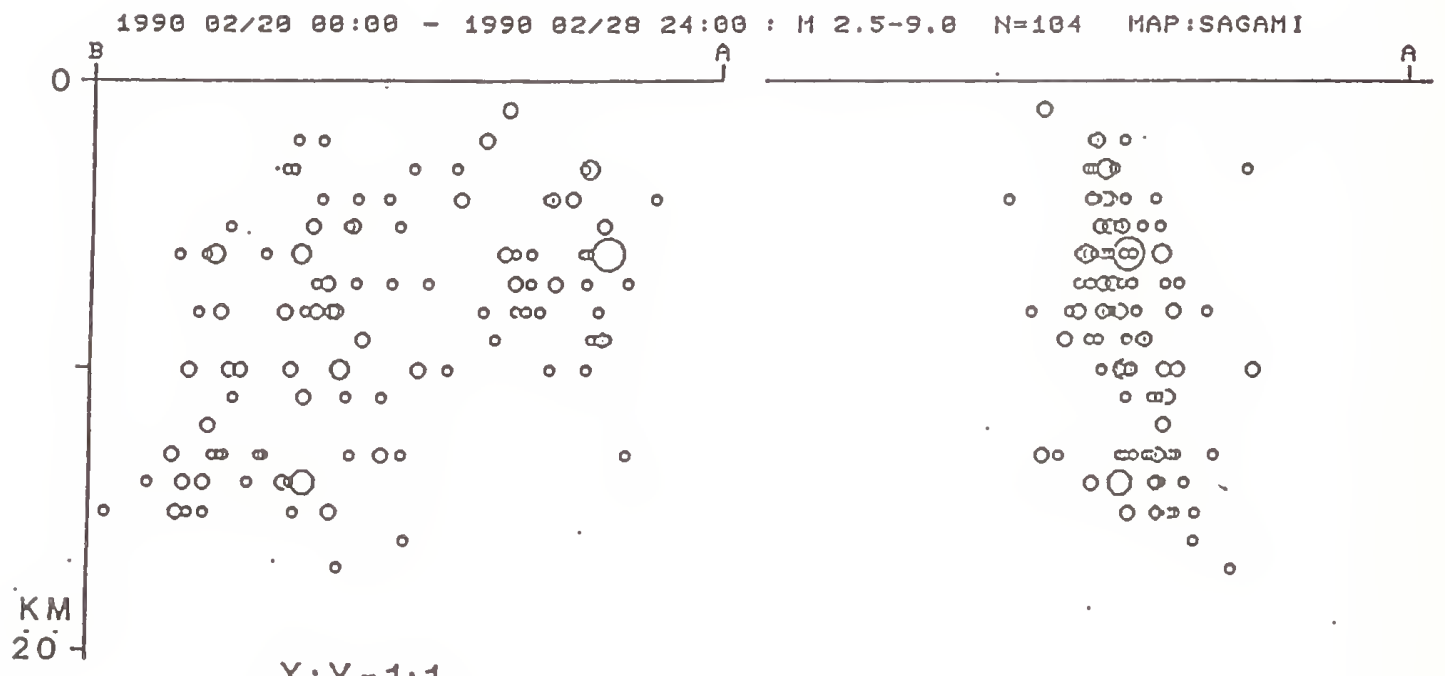

$X: Y=1: 1$

Fig. 5 Outline on the earthquake of near Izu-Oshima Is. (M: 6.5) in 1990.

Fig. 5-1 Epicentral distribution. Solid circles show the location of ESM. OSH is the Oshima station used in this siudy.

Fig. 5-2 Focal mechanism solution.

Fig. 5-3 Focal distribution projected on cross sections A - B (left) in Fig. 5-1 and the direction perpendicular to it(right) . 


\section{HACHINOHE}
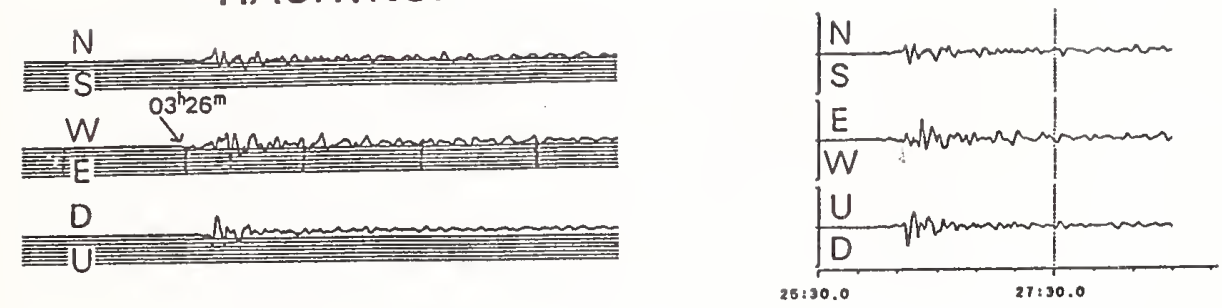

Fig. 6-1
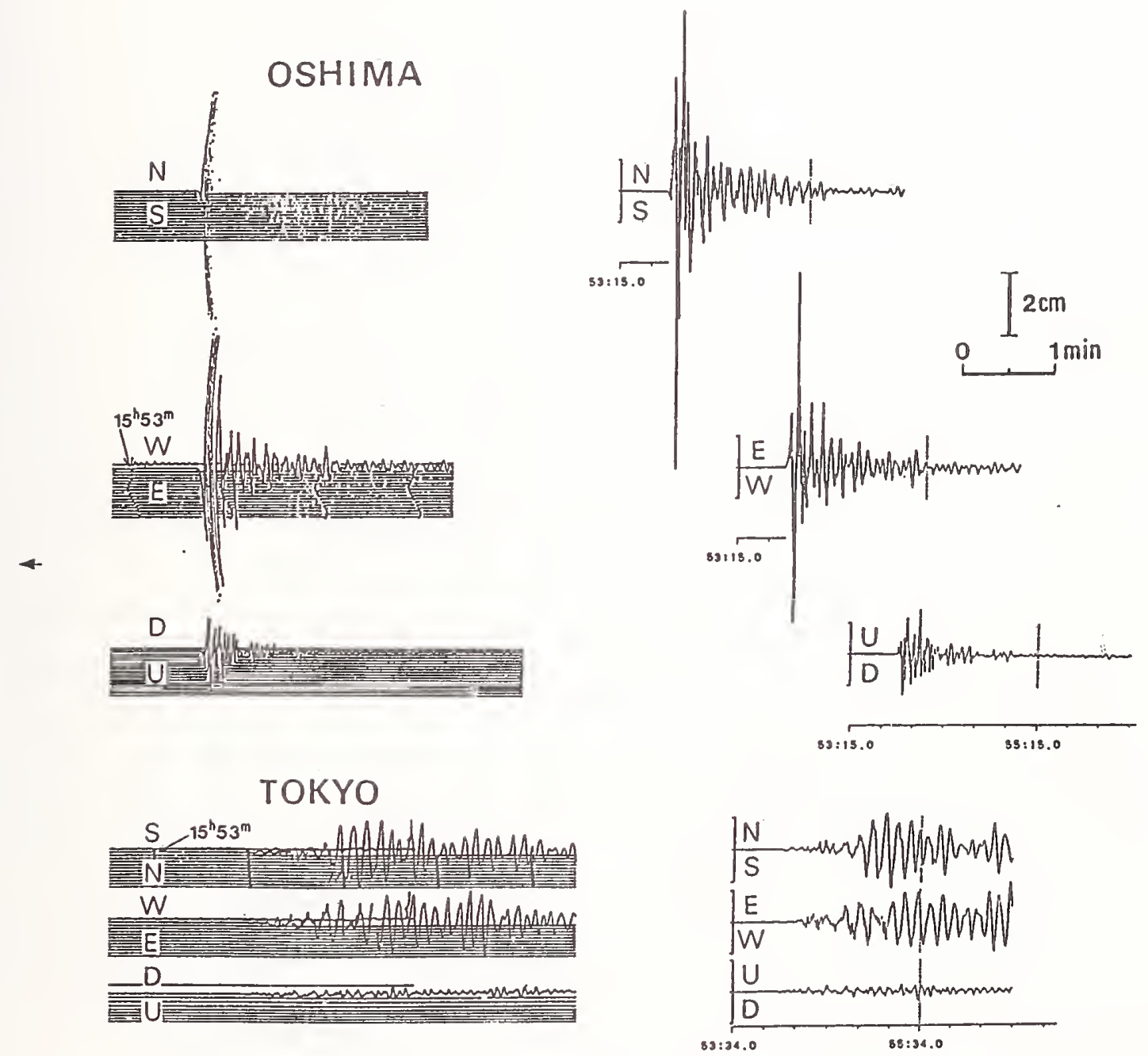

Fig. 6-2

Fig. 6 Comparisons of seismograms. MSM (left) and ESM (right). ESM's seismogram is filtered out in orded to be the same MSM's characters.

Fig. 6-1 Seismograms of HAC from the earthquake of E off NE Japan in 1989.

Fig. 6-2 Seismograms of Oshima and Tokyo from the earthquake of near lzu-Oshima is. in 1990. 

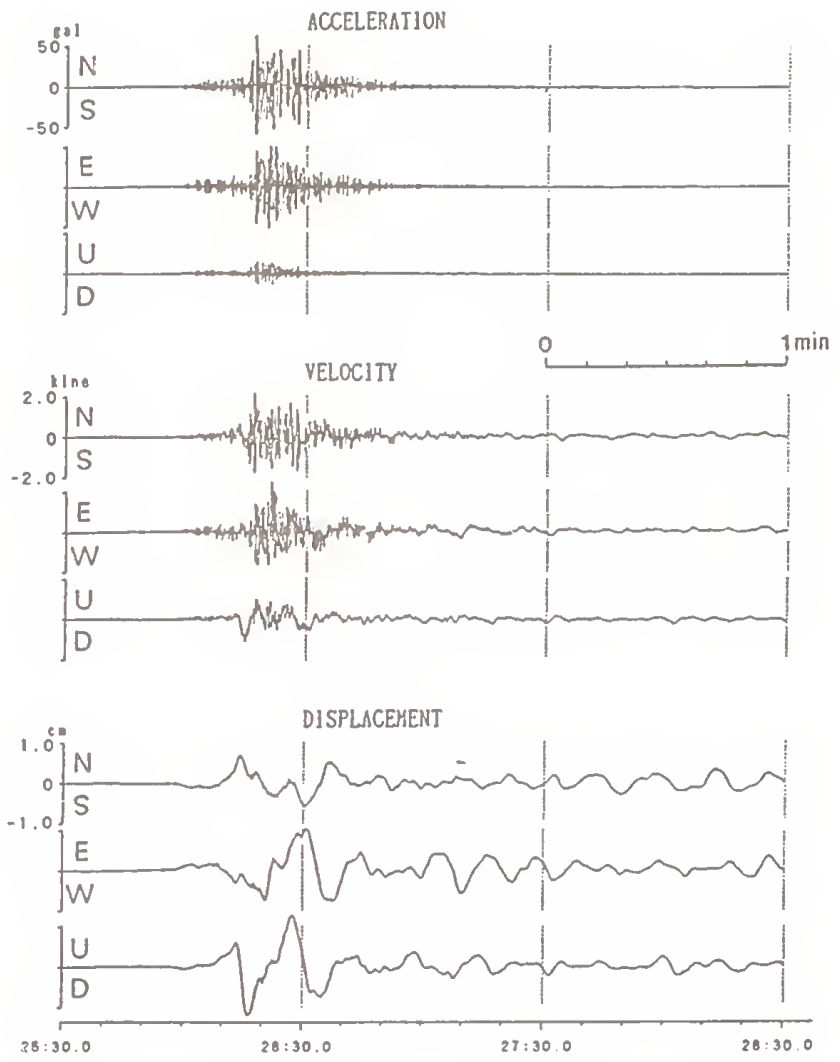

Fig. $7-1$

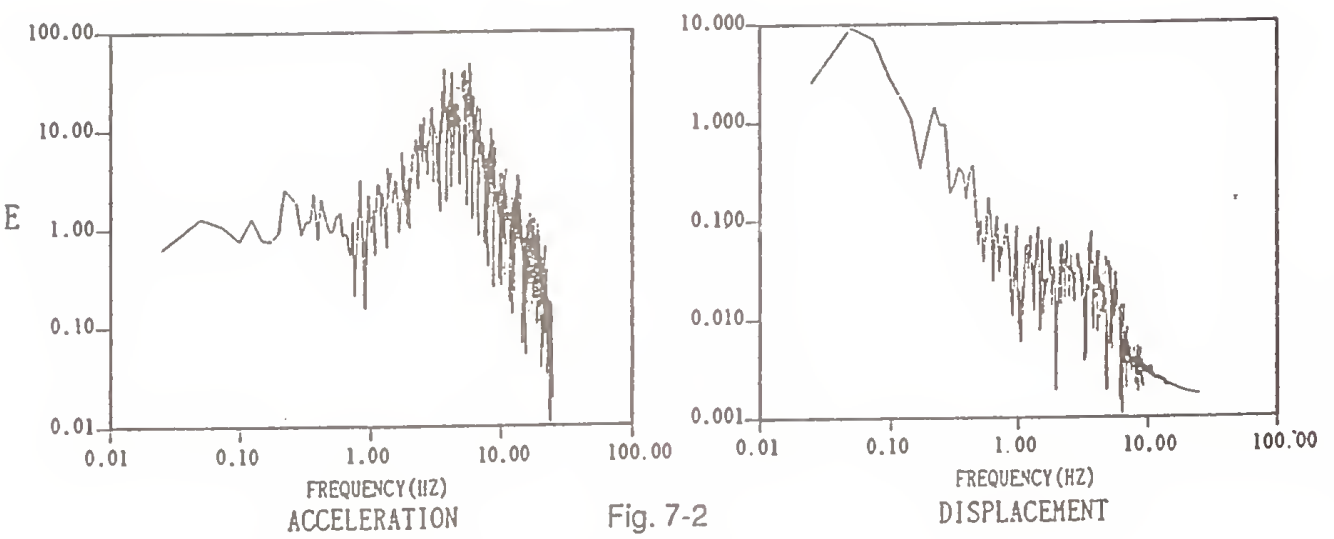

Fig. 7 Seismograms at HAC and spectrum analysis.

Fig. 7-1 Seismograms of acceleration, velocity and displacement.

Fig. 7-2 Spectrum density of acceleration and displacement from the EW component at HAC.

Fig. 7 Seismograms at HAC and spectrum analysis.

Fig. 7.1 Seismograms of acceleration, velocity and displacement.

Fig. 7-2 Spectrum density of acceleration and displacement from the EW component at HAC. 

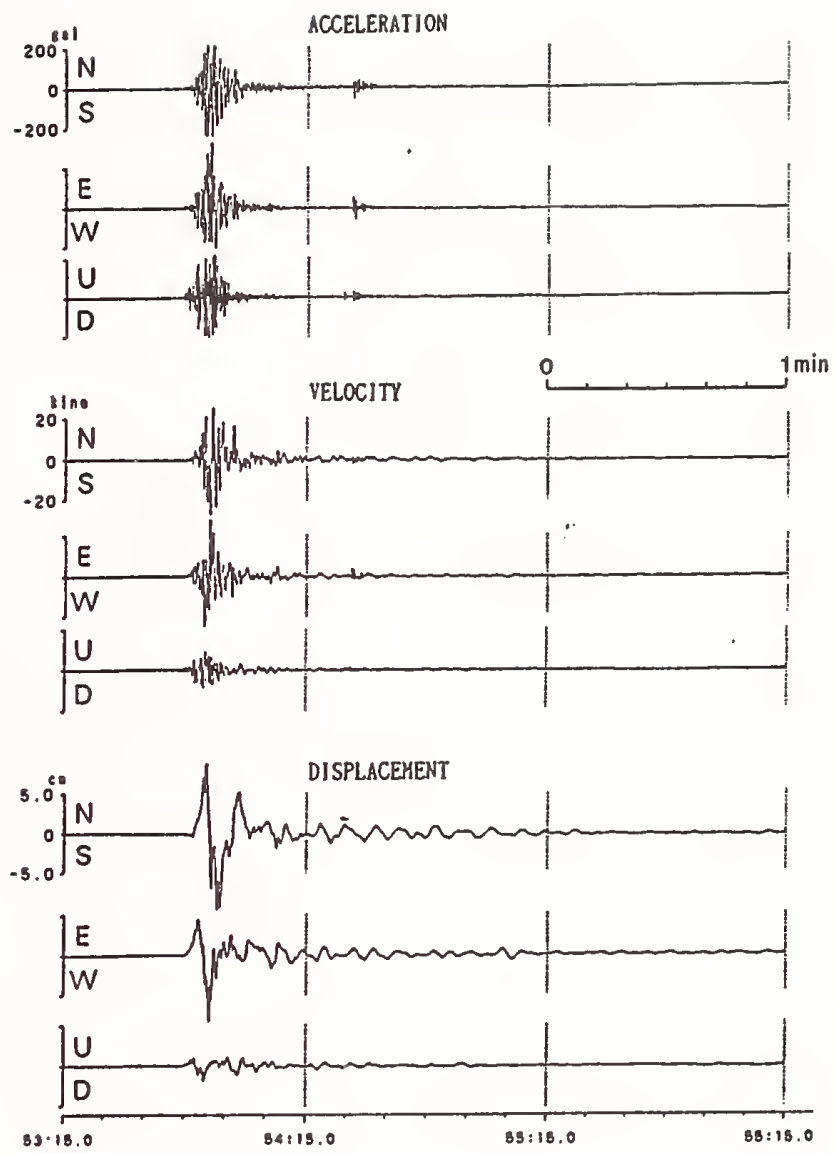

Fig. 8-1
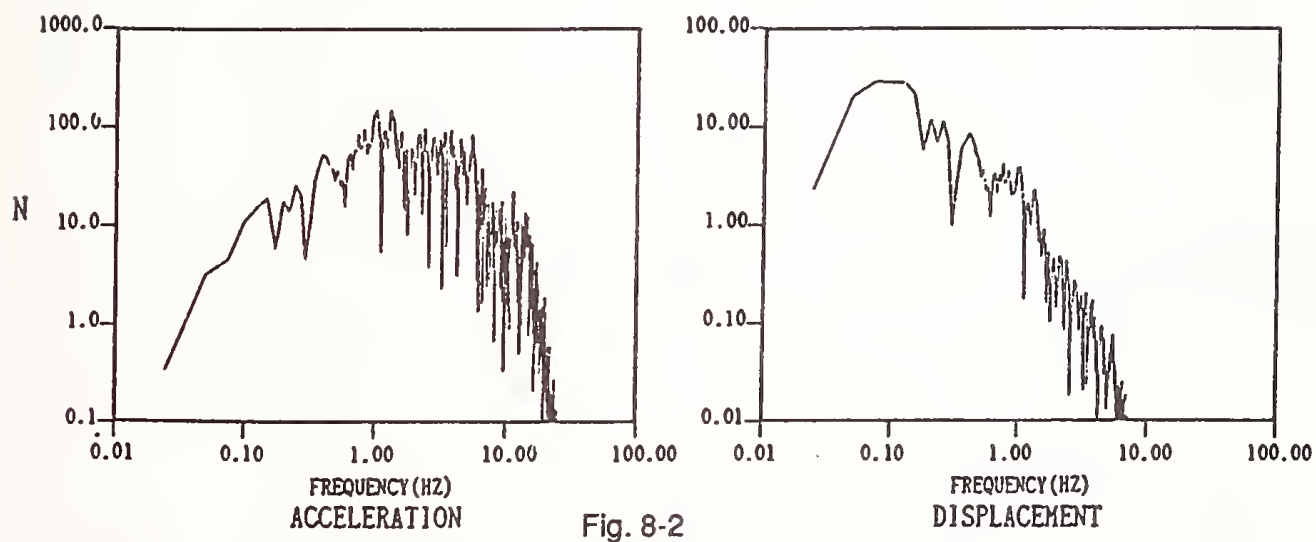

Fig. 8 Seismograms at $\mathrm{OSH}$ and spectrum analysis.

Fig. 8-1 Seismograms of acceleration, velocity and displacement.

Fig. 8-2 Spectrum density of acceleration and displacement from the NS component at Oshima. 

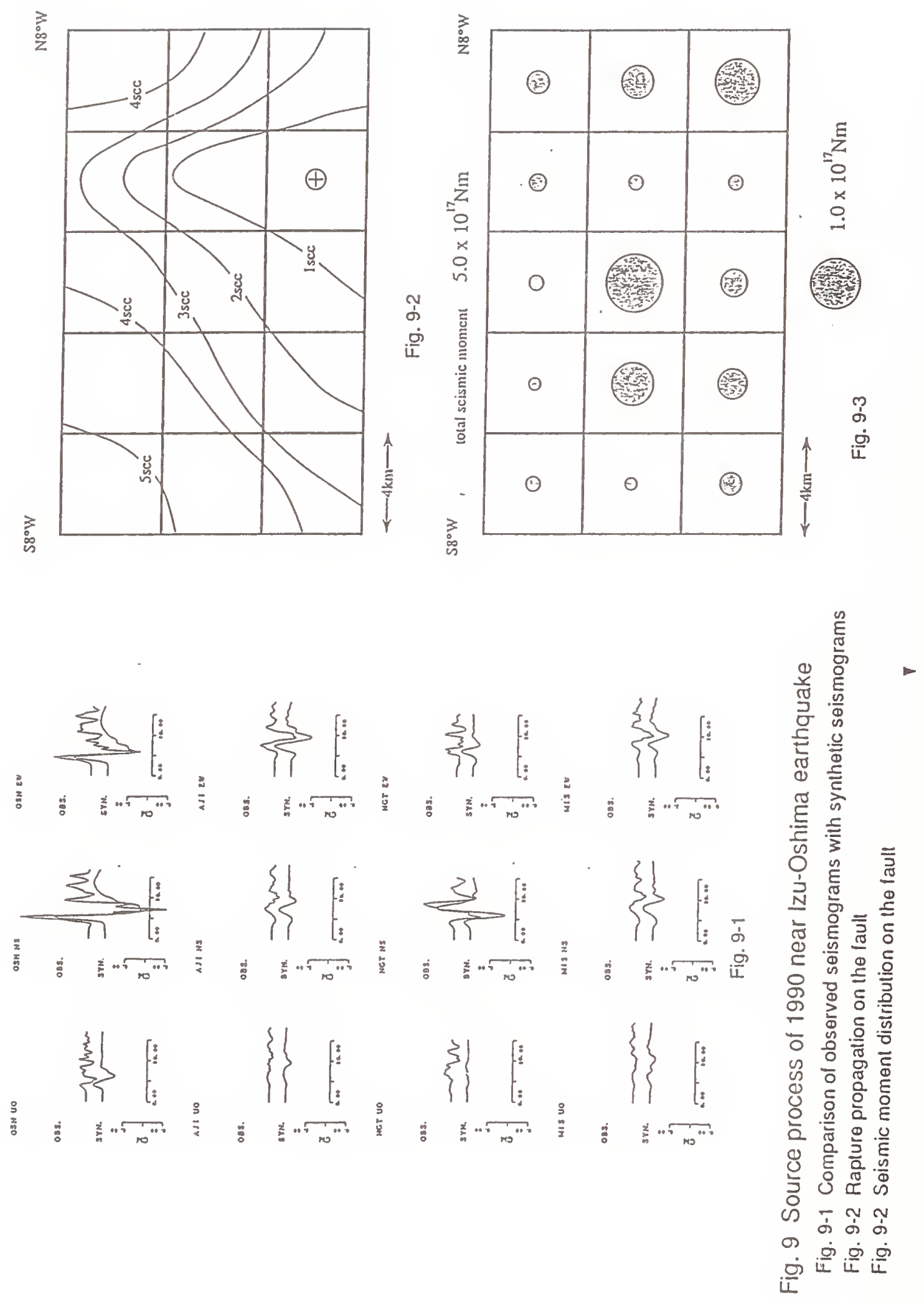


\section{ABSTRACT}

Designing offshore facilities to resist earthquakes pose perplexities that differ from those problems encountered in designing similar facilities for other environmental loads, such as winds, waves, currents, and ice floes. Normal operational loads occur frequently over the lifetime of a structure, and therefore, design information can be accumulated quickly. Because of this, design codes and other standards of practice have evolved fairly rapidly to address these normal types of loads. In contrast, earthquakes are rare events and data on the response of seafloor sediments to earthquake-induced ground motions are scarce, thereby introducing significant uncertainty for analyzing seismic-hazard aspects of offshore operations. To reduce this uncertainty, a research program has been undertaken by the Minerals Management Service, jointly with industry, to develop and deploy instrumentation to measure seafloor seismic motions and to gather data to assess the effects of large seismic events predicted for the future. The primary objectives of this paper are to present an overview of the Seafloor Earthquake Measurement System (SEMS) Program and to describe the installation of a SEMS network offshore southem Califomia.

KEYWORDS: Earthquake hazards, offshore platforms, offshore structures, seafloor seismic response, seismic design criteria.

\section{INTRODUCTION}

Both Govemment and industry recognize the need to acquire design and verification informa- tion on seismic activity offshore, particularly at locations of current or future oil and gas operations. Industry needs seismic data to design facilities that are structurally adequate and cost effective, and the Federal Govemment requires the information to fulfill its regulatory responsibilities to ensure safe, pollution-free operations. The necessity for the data by each group may at first seem diverse; however, on further examination the needs are found to be compatible and complementary.

Design criteria developed by the oil and gas industry for offshore structures, as presented in the American Petroleum Institute Recommended Practice 2A (API, 1989), are well established and sound, provided that adequate information about the environment is available to make the necessary engineering decisions. Climatic and oceanographic information for most offshore areas is available or can be obtained from military, commercial, or private entities that have conducted activities in those areas for decades. The data, although more complete for some regions than others, nevertheless provide some guidance for offshore engineering.

Even in the most seismic areas of the world, the occurrences of very strong ground motions at a given site is a rare event. In fact, the infrequency of recorded strong seismic motions has tended to foster a passive attitude toward the design of

\footnotetext{
* Research Program Manager

Technology Assessment and Research Branch

Minerals Management Service

Herndon, Virginia 22070-4817
} 
offshore structures. Seismic data are not convenient by-products of other activities that have aided in the collection of climatic and oceanographic information. Therefore, an independent, concerted, and sustained effort must be taken to obtain and quantify earthquake data for use by engineers.

\section{OFFSHORE EARTHQUAKES}

In the design of offshore facilities, the need for offshore seismic data to complement earthquake data obtained from onshore locations has been well documented (Reece, Ryerson, and McNeil, 1981, NAS, 1976, Henyey et al., 1979). In the United States, much of the effort has focused on the areas offshore southem Califomia and, to a lesser extent, offshore Alaska. Subjects of major importance relate to area seismicity, soil response, energy transfer between the sediment and platform foundation, overall platform response, and the consequence to operations resulting from the response (Smith, 1990). In the past, estimates of anticipated earthquake ground motions for offshore structures were made totally from onshore records because of the lack of reliable long-term measurements offshore.

Although certain design lasks are common to both onshore and offshore structures, offshore facilities involve many differences that make these tasks unique and are the subject of much interest to engineers. These differences include, for example, the following aspects: a) attenuation factors may be different in saturated seafloor soils, especially if the soils are soft and/or gassy; b) wave reflection by the water column may alter site-specific wave forms; c) offshore structures are often much larger than onshore facilities and have their mass concentrated at the very top of the structure; d) the presence of water changes the characteristics of earthquake ground motions and introduces new forces that result from the added mass effects of the water, e) earthquakes may cause mud slides that can travel very long distances on the seafloor and exert large loads against structures and pipelines; f) earthquakes may give rise to seaquakes, which involve the propagation of "P" waves through the water column and which can result in damage to floating facilities. Fi- mally, the location of offshore epicenters may have some uncertainty associated with them because the seismographic nets from which they were determined are sited shoreward of an offshore event (Reece, Ryerson, and McNeil, 1981, Poulos, 1988).

To eliminate many of the uncertainties associated with offshore earthquake ground motions, the Minerals Management Service (MMS), jointly with the oil and gas industry, is sponsoring the installation of a seismic monitoring network offshore southern California. The purpose of this program is to obtain high quality seafloor seismic data and correlate that information with measured and predicted platform response data. Scientific and engineering analyses of the various forms and magnitudes of quakes will be conducted and compared with onshore data with a view to extrapolating the data to larger events which are required for design purposes.

\section{RESPONSE METHODOLOGY}

The validity of a methodology used for predicting the response of offshore structures to earthquakes is central to the design of those structures. In this context, validity refers to the ability of the methodology to accurately calculate the true platform response. However, it may not be possible to totally verify the validity of the methodology over the complete range of parameters of interest. Validity issues can be partially resolved through empirical approaches wherein actual field measurements are compared with calculated responses. This approach is illustrated in figure 1. The figure highlights bifurcation of the analytical domain into calculated versus measured response. With this approach, an earthquake can be measured with land-based instruments. Then these measurements can be used as input to a soil response model which, in turm, calculates the soil response in the vicinity of a seafloor instrumentation system. The calculated soil response can then be compared with the measured response to determine the validity of the calculation for that specific earthquake. If there is disagreement between the calculated and measured response, instrumentation performance and/or model validity is questionable. Similar compar- 
isons can, in principle, be made between calculated and measured response to study the validity of other elements of the composite evaluative methodology.

Although there is an extensive seismographic network onshore in southem California, the coverage offshore has been neglected. The knowledge of the uncertainties that exist in using onshore seismic data for the design of offshore facilities, the imporance of the southem California area for future energy needs, and the high probability of future large earthquakes in that area contributed to the decision to develop accurate and reliable seafloor monitoring instruments. These instruments are being installed to form an offshore network to gather data to supplement onshore information. To close the data loop, offshore structures located near the monitoring sites have been instrumented to obtain structural response information for comparison with predicted values.

\section{SEMS SEAFLOOR INSTRUMENTATION}

In 1977, MMS (then the Conservation Division of the U.S. Geological Survey), the Department of Energy, and several major oil companies contracted with Sandia National Laboratories for the development of the Seafloor Earthquake Measurement Systems (SEMS). The objective was to develop a totally self-contained unit that could be installed at remote locations and that would allow the retrieval of data at any time during the operational lifetime of the system. The principle design considerations for the SEMS unit were that it have low power consumption, a broad range sensing capability, an efficient use of data storage, and simplicity of installation and data retrieval. From 1979 to 1980, four prototype units (referred to as SEMS I) were placed in the Santa Barbara channel (Ryerson, 1981). These initial prototype units only had an operational life of less than 1 year. However, the preliminary data and analyses showed that there may, as postulated, be fundamental differences between onshore and offshore ground motions during seismic events (Reece, Ryerson, and McNeil, 1981).
In 1985, a second generation prototype system, known as SEMS II, was developed. The project was conducted as a joint effort with Shell Oil Company, and the unit was installed in 240 feet $(72 \mathrm{~m})$ of water 10 miles $(16 \mathrm{~km})$ offshore Long Beach, near Shell's platforms Elly and Ellen in the Beta Field. The SEMS II unit had improved operating specifications and was designed to have a system life of 4 years. The system recorded two significant earthquakes during the month of July 1986. The first event, known as the Palm Springs Earthquake $(M=6.0)$, occurred on July 8 and had an epicentral distance of 91 miles $(145 \mathrm{~km})$ from the SEMS monitoring site. The second event, the Oceanside Earthquake $(M=5.8)$, occurred on July 13 and had an epicentral distance of 46 miles $(74 \mathrm{~km})$. An analysis of the data from these two earthquakes indicated that the seabed responded comparably to onshore areas in terms of its vibrational frequency but with a significant decrease in vertical sediment motion as recorded by onshore instrumentation (Sleefe and Engi, 1987).

Both the SEMS I and SEMS II units used a detection algorithm based on the arrival of the vertical component of the earthquake signal. Because of this technique, the units suffered from a high false-trigger rate-as many as 1,000 per month. The excessive triggering rate, as well as other software problems, resulted in the SEMS II unit being removed after a 2 1/2-year service life.

Based on experience gained with the first two prototypes and using new component and battery technology, a more sensitive and reliable system, dubbed SEMS III, was developed. The SEMS III, like its predecessors, was designed to operate as an autonomous unit. It consists of a seafloor electronics package called the Data Gathering Subsystem (DAGS) and a shipboard interrogation unit. The DAGS connects to a seismic probe embedded approximately 8 feet $(2.4 \mathrm{~m})$ in the seafloor, and it records and stores seismic signals and transfers digital data on command to a shipboard receiver using underwater acoustic telemetry. The surface system, referred to as the Buoy Repeater System, consists of acoustic transmitting and receiving components and a user-friendly computer. The computer is used for retrieving and analyzing 
data from the DAGS and altering operating parameters. The operational concept is shown as SEMS Unit No. 1 in figure 2.

The increased sensitivity of the system results from its new microprocessor software, which includes an improved multiaxis detection algorithm (Sleefe, 1990). The microprocessor continuously monitors accelerometer signals and stores data when seafloor motions reach a predetermined value. The triaxially configured accelerometer package (seismic probe) allows it to detect movement in three directions to overcome a major disadvantage of previous prototypes. The previous systems were designed and built before it was realized that the predominate seafloor response would be in the horizontal direction. In addition, the SEMS III unit provides improved lower noise electronics and lower power consumption to accommodate an 8-year life system.

\section{OFFSHORE SEISMIC NETWORK}

In July 1989, a SEMS III unit was installed in the Beta Field in 210 feet $(64 \mathrm{~m})$ of water. This effort was accomplished with the cooperation of Shell Oil Company. The unit was placed near the previous location of the SEMS II prototype as shown in figure 3. This system was designed to operate as shown in the diagram referred to as SEMS Unit No. 1 in figure 2. The major difference in the installation procedure for the SEMS III unit, as compared to previous systems, was that the seismic probe (accelerometer package) was emplaced by means of a vibrocoring drill that vibrated the probe into the seafloor sediment. The soil coupling between the probe and sediment is greatly improved by embedding the probe at least 8 feet $(2.4 \mathrm{~m})$ below the mud line. A complete detail of the development and installation of the Long Beach unit is given by Sleefe (1990).

Initial results from the Long Beach SEMS unit have been very encouraging. The unit has accurately triggered on several small local earthquakes and has provided detailed data for study. Table 1 provides a listing of earthquakes and aftershocks recorded during the first 4 months of 1990.

Figure 4 shows the location of these earthquakes relative to some of the known major faults. It is clear that the SEMS III unit has the capability to detect and record earthquakes occurring both onshore as well as offshore. The quality of the data is very good as demonstrated by the recording of the Upland Califomia earthquake of February $28,1990(M=5.5)$, as shown in figure 5. A preliminary analysis of the data recorded thus far confirms the early findings of a reduction in the vertical seismic response. A statistical analysis has shown that offshore peak vertical accelerations are nearly an order of magnitude weaker than the corresponding onshore measurements (Sleefe, 1990).

Because of the success of the SEMS III unit at the Long Beach site, two additional units were planned to form an offshore data-gathering network. This network will provide engineers with data necessary to verify, and if required, modify existing response models used in the design of offshore facilities.

The second unit in the network was installed offshore Point Pedemales near UNOCAL's platform Irene as shown in figure 6. As a joint project with UNOCAL, the unit was placed at a water depth of 240 feet $(74 \mathrm{~m})$ and was located some 500 feet $(150 \mathrm{~m})$ from the base of the steel jacket. Unlike the Long Beach unit, the Point Pedernales instrument is not completely autonomous, but is hard-wired to the platform as shown in figure 2. The DAGS was located on the deck of the platform. The accelerometer probe was emplaced by using a vibrocorer drill in the same manner as with the Long Beach unit. This second unit was connected to the DAGS by running a weighted cable along the seafloor and through a specially designed riser to the platform deck. The major advantage for using the unit in this way is that the DAGS could be connected directly to a telephone modem and therefore, interrogated at any time. Also, since the unit is powered from the platform and, if necessary, with standby batteries, the system will have a greater extended life span. 
The platform is also instrumented with a series of accelerometers to measure its seismic response. Data taken at the base of the platform (where the response is influenced by the soilstructure interaction) and at the platform deck can be compared with the "free-field" response measured by the SEMS probe. Analy sis of measured data from these three locations, especially after a moderately large earthquake, will improve knowledge of the way energy is transferred from the seafloor sediments, through the piles, and into the platform.

To complete the offshore network, future plans call for the installation of a third SEMS unit offshore Ventura in the spring of 1991. It is proposed to locate the unit near UNOCAL's platform Gilda in 205 feet $(62 \mathrm{~m})$ of water as shown in figure 7. It will be hard-wired to the platform in the same manner as the Point Pedernales unit. However, the exact type of system to be used has not been decided at this time. Consideration is being given to making the unit totally autonomous and placing it at a deeper water site, 600 - to 800 -foot (180 to $240 \mathrm{~m}$ ) water depths.

With the installation of the third SEMS unit, an offshore array will be formed that will be capable of recording all significant earthquakes affecting southern California. Figure 8 is a composite for the location of the units, and the locus of circles shown indicates the sensitivity of the units to earthquakes of a given magnitude. This illustration shows a high probability that a small to medium earthquake will be recorded by at least one or two units, and larger events by possibly all three. The acquisition of additional seismic data, as well as the monitoring of sediment responses at multiple seafloor sites, will provide a useful framework to assess current design methodologies. With this information, which may take several years to obtain and analyze, engineering efforts can be improved to ensure a safe design within economic reason.

\section{CONCLUSION}

Seismic activity poses a potential hazard for offshore structures in terms of ground accelera- tions, rupturing along fault planes and triggering of large mud slides. Currently, design methods for offshore structures are based on premises that ignore differences between the responses of onshore and offshore sediments. However, preliminary analyses of seismic response data taken from seafloor instruments have indicated several interesting discrepancies. Because of the environmental sensitivity of offshore oil and gas operations, issues relating to seafloor response, as well as platform response, need to be more fully investigated, both experimentally and analytically. To this end, a reliable and sensitive SEMS unit has been developed to measure and collect seismic seafloor responses. These units are being deployed to form an offshore network to gather data for comparison with onshore results and to verify current design procedures. Data of this nature will greatly enhance the ability to understand the response of, and to develop design guidelines for, offshore structures located in seismically active areas.

\section{REFERENCES}

API 1989. API Recommended Practice 2A(RP2A), Recommended Practice for Planoing Designing and Constructing Eixed Offshore Platforms, 18 th Edition, American Petroleum Institute, Washington, D.C.

Henyey, TL., Teng, T.I., McRaney, J.K., and Manov, D.V. 1979. A seafloor seismic monitoring network around an offshore oil field platform and recording of the August 13, 1978, Santa Barbara earthquake, OTC 3613, Proceed ings. 11th Annual Offshore Technology Conference, Houston, Texas.

NAS 1976. Seafloor Engineering: National Needs and Research Requirements, National Academy of Sciences, Washington, D.C.

Poulos, H.G. 1988. Marine Geotechnics, Unwin Hyman Ltd., London, England.

Reece, E.W., Ryerson, D.E. and, McNeil, R.L. 1981. Long-term measurements of ground mo- 
tions offshore, Proceedings. Intemational Conference on Recent Adyances in Geotechnical Earthquake Engineering and Soil Dynamics, University of Missouri-Rolla, Rolla, Missouri.

Ryerson, D.E. 1981. Seafloor Earthquake Measurement Systems. Volumes I II. and III, Repor No. SAND 81-1810, Sandia National Laboratories, Albuquerque, New Mexico.

Sleefe, G.E. 1990. The long-term measurement of strong-motion earthquakes offshore southern California, OTC 6336, Proceedings, 22nd Annual Offshore Technology Conference, Houston, Texas.

Sleefe, G.E. and Engi, D. 1987. Seafloor response for two southern California earthquakes, Proceedings, 1987 Society for Experimental Mechanics Spring Conference on Experimental Mechanics, Houston, Texas.

Smith, C.E. 1990. Seismic design considerations for offshore oil and gas structures, Proceedings of the 21st Joint Meeting of the U.S.JJapan Cooperative Program in Natural Resources-Panel on Wind and Seismic Effects, NIST SP776, National Institute of Standards and Technology, Gaithersburg, Maryland. 
Date Location

Magnitude (M) Distance (km)

Jan. 17, 1990

Gardena

3.3

35

Peb. 28, 1990

Upland

5.5

74

Peb. 28, 1990

Upland

4.8

74

Mar. 10, 1990

Offshore Newport Beach

2.6

11

Apr. 4, 1990

offshore Oceanside

4.0

73

Apr. 17, 1990

Upland

4.6

70

Table 1. Earthquakes recorded by the Long Beach SEMS unit

\section{OFFSHORE PLATFORM RESPONSE TO EARTHQUAKES}

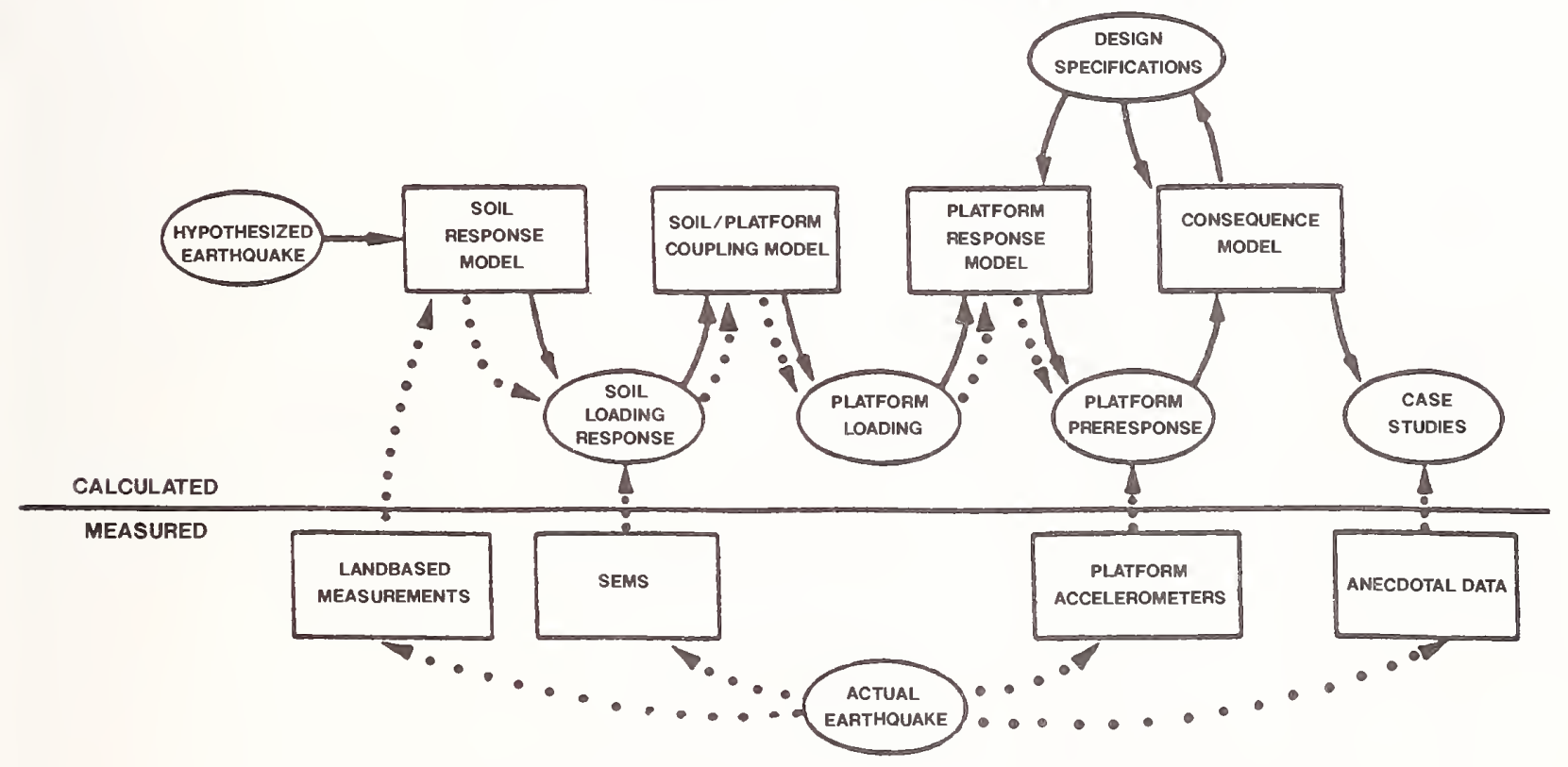

Figure 1. Methodological basis for offshore platform design 


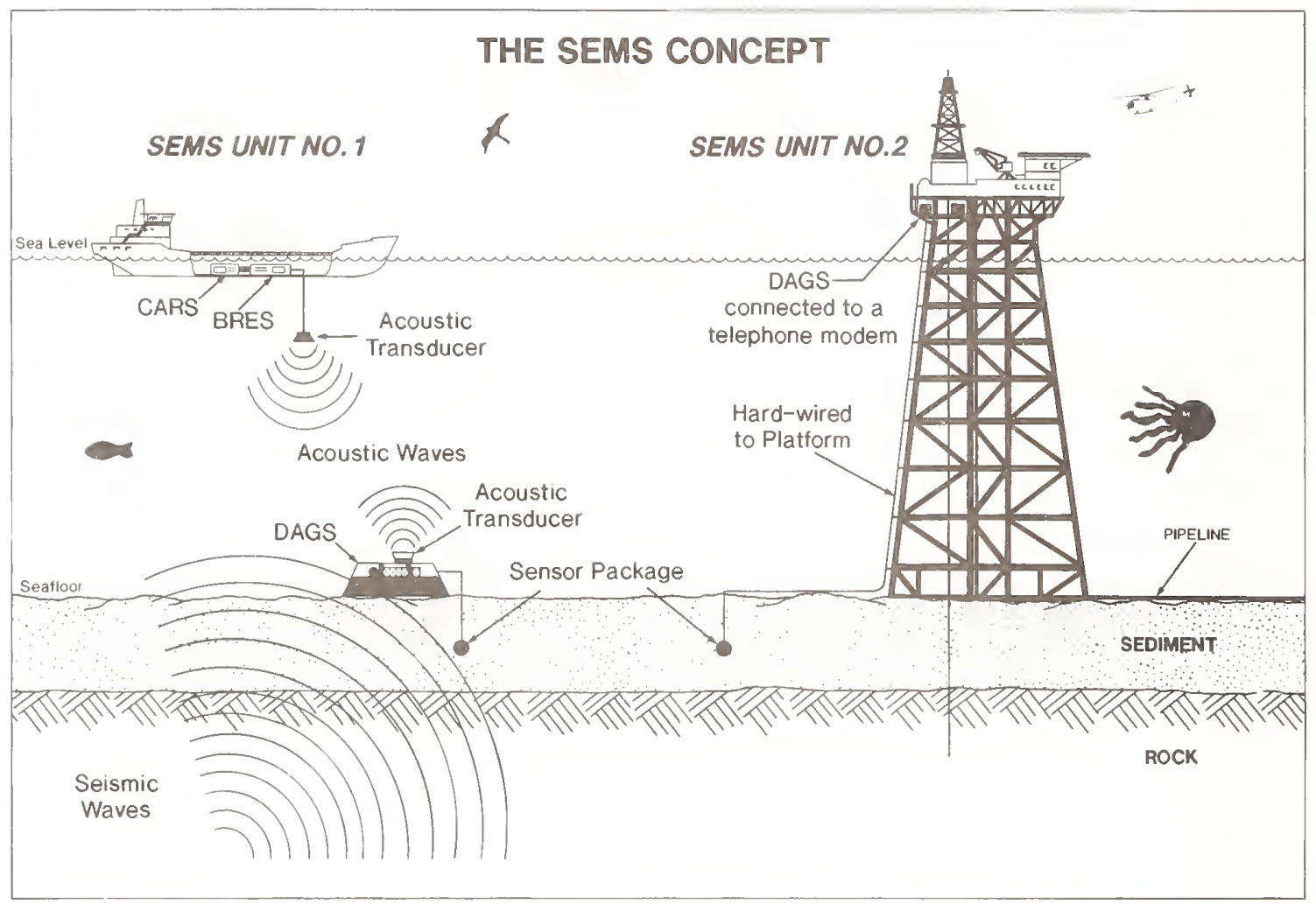

Figure 2. SEMS installation concepts

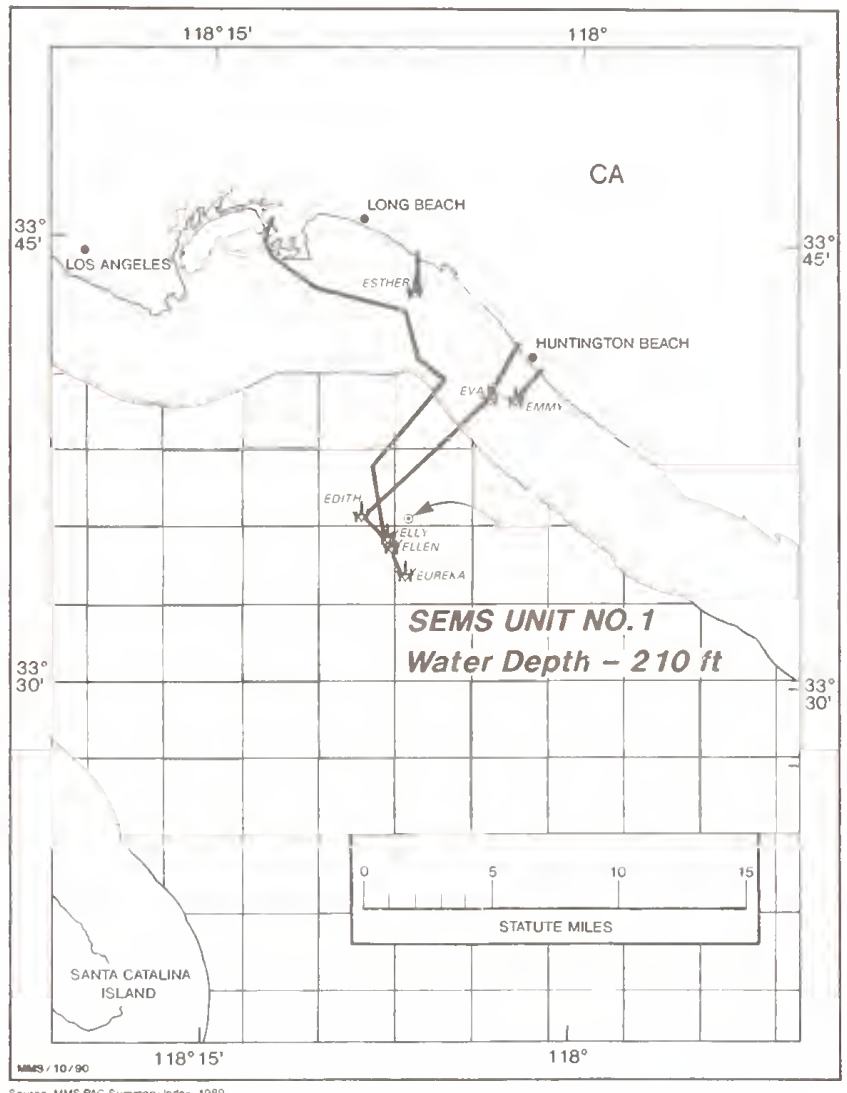

Figure 3. Location of the Long Beach SEMS unit 


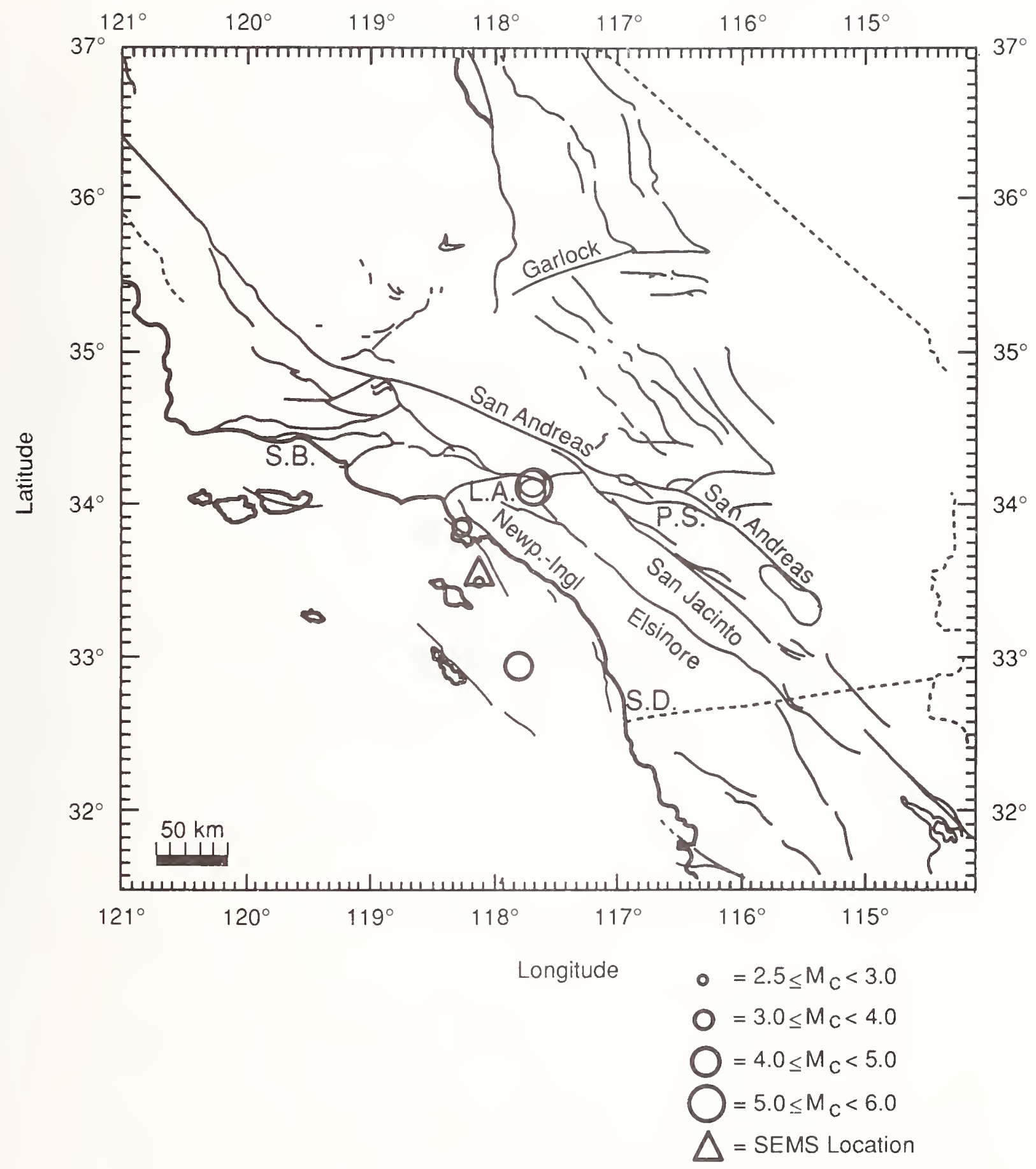

Figure 4. Significant earthquakes recorded by the SEMS III unit 


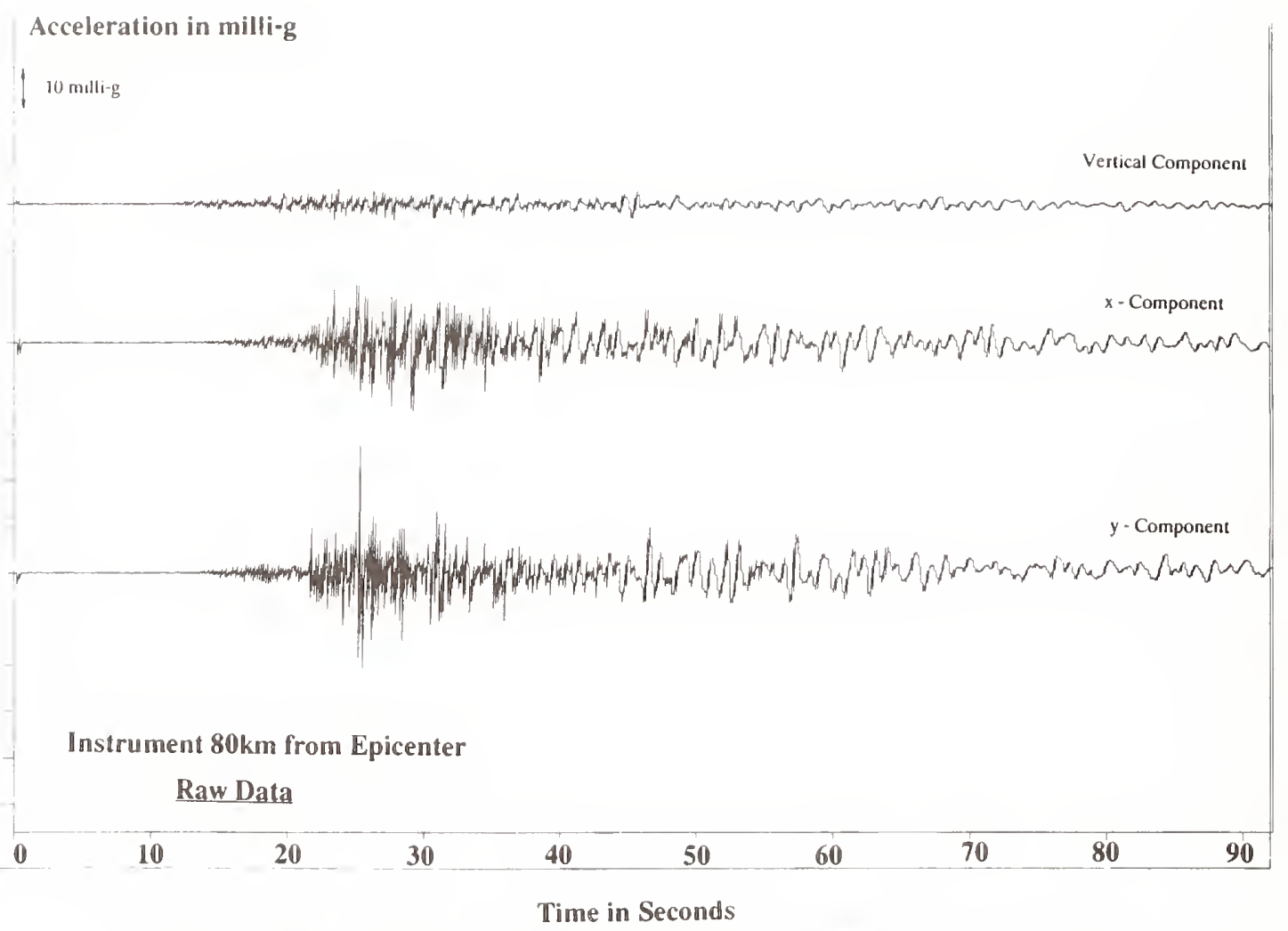

Figure 5. SEMS recording of Upland, California, earthquake $(2 / 28 / 90, M=5.5)$

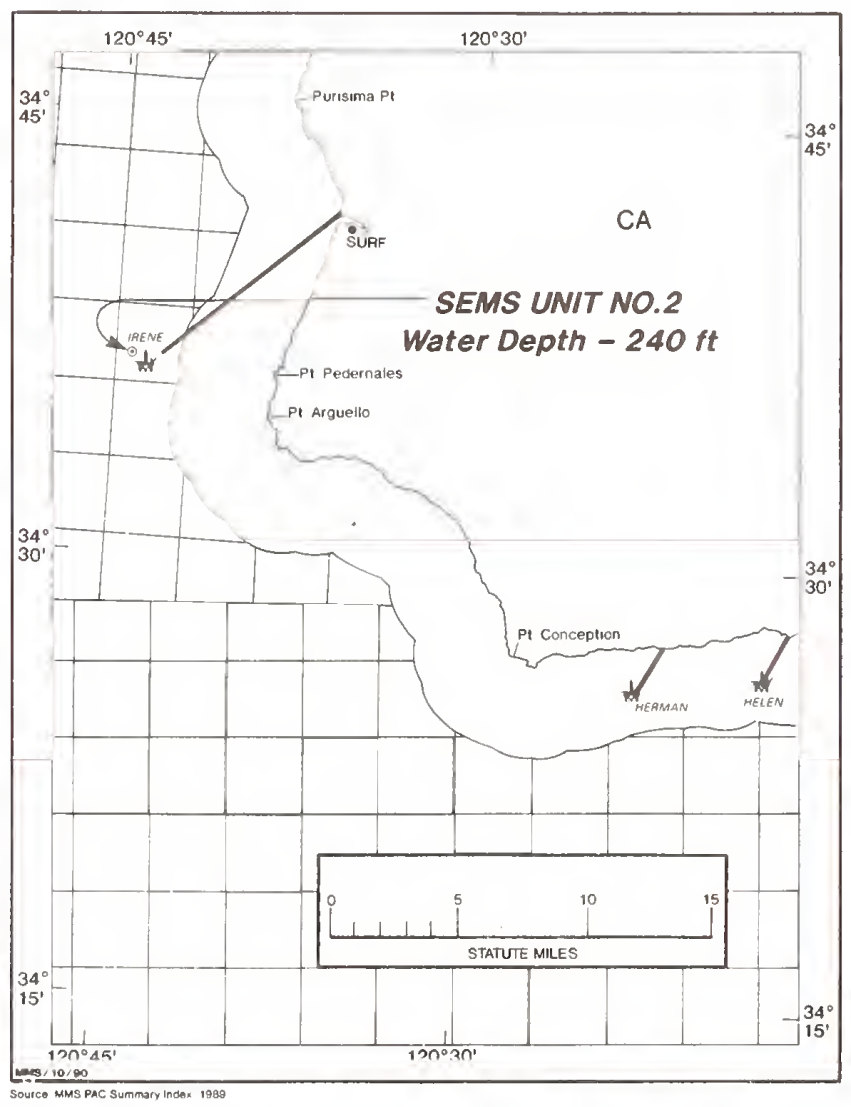

Figure 6. Location of the Point Pedernales SEMS unit 


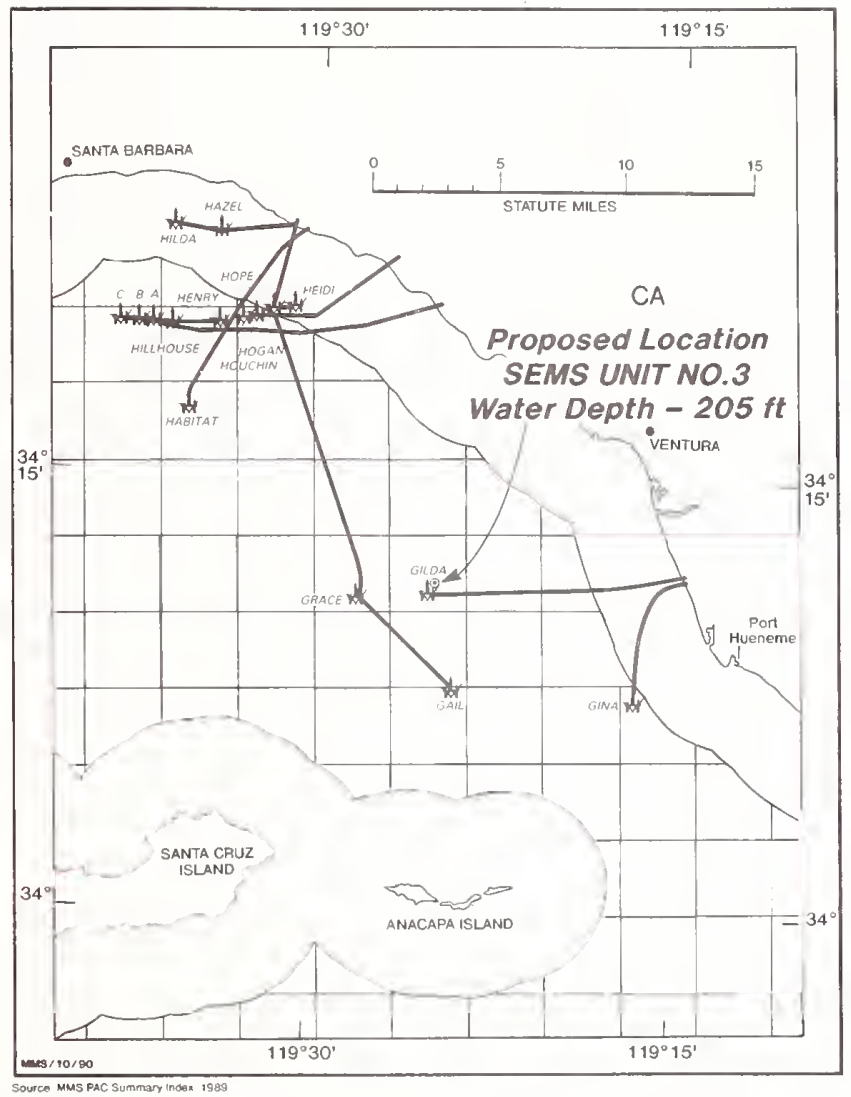

Figure 7. Proposed location of the Ventura SEMS unit

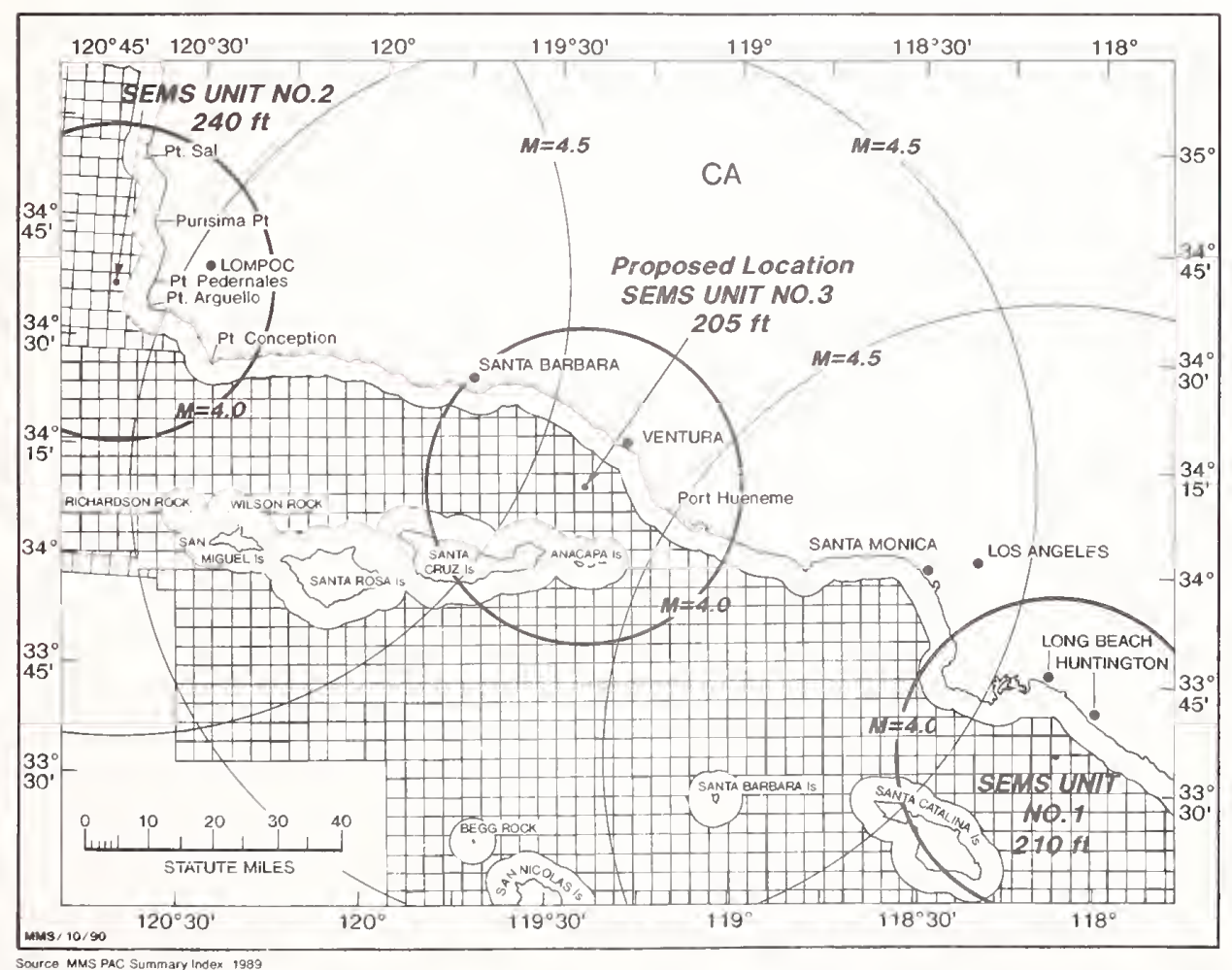

Figure 8. SEMS offshore data-gathering network 



\section{Distribution of Liquefaction in the Saitama Plain by the 1923 Kanto Earthquake and Geomorphological Maps}

\section{Tadao DOHI', Takekazu AKAGIRI ${ }^{2}$}

Abstract

The 1923 Kanto earthquake caused intensive damages in the Kanto district including Tokyo. It caused geomorphological accidents, which were collapses, slides and cracks in many places in the Kanto district. And so many cracks were caused in the Saitama lowland in the center of the Kanto plain. Many houses were destroyed and agricultural land had been collapsed.

The authors researched the aspects of geomorphological acciderits and how to use existing geomorphological maps for prediction of liquefaction potential. And they concluded that the reports described very precisely and correctly the aspects of geomorphological accidents and that the cracks and others were typical liquefaction. And it became clear that existing geomorphological maps are also available for prediction of liquefaction potential.

Keywords:Liquefaction peotential. The 1923 Kanto earthquake, Natural levee, Land condition map series Liquefaction

\section{Introduction}

The Kanto earthquake, one of the big earthquake, caused intensive damages in the Kanto district including Tokyo in 1923. This earthquake caused geomorphological accidents. which were collapses, slides and cracks in many places in the Kanto district. Among them, so many cracks were caused in many places in the Saitama lowland in the central part of the Kanto plain. And many houses were destroyed and agricultural land had been collapsed.

Geomorphological mapping is available to predict liquefaction potential, but it is not clear how to use existing geomorphological maps compiled by GSI, National Land Agency and other organizations.

The authors tried to clarify the aspects of geomorphological accidents, especially liquefaction and how to use existing geomorphological maps for prediction of liquefaction potential.

\section{Method}

They considered to clarify the aspects of geomorphological accidents caused by the earthquake, especially on cracks, eruption of sand and water based on interview, fieldcheck, land condition maps and reports of the ear thquake.

The interview with farmers was done with information of past landscapes using former topographic maps. He selected farmers who were older than 80 years old in good health, and who had lived there continuously and could remember the aspects very clearly.

1: Director, Geographical Department. Geographcal Survey Institute. Ministry of Construction 2 :Head, Second Geographical Division. dit to 
They compared with results of field survey, interview, land condition maps and the reports, and considered liquefaction potential and how to use existing geomorphological maps.

\section{The 1923 Kanto Earthquake}

The hypocenter of the earthquake was $35.1^{\circ} \mathrm{N}, 139.5^{\circ} \mathrm{E}$ in the Sagami bay. The maximum amplitude in Tokyo was $14-20 \mathrm{~cm}$, and the magnitude was M7. 9. Finally, decease and missing 142,000 , complete and partial destruction of houses 254,000 . destruction by fire 447,000. Geomorphological accidents, which are collapses, slides, cracks, upheaval of ground and so on, were caused in many places in the Kanto district. The ground raised up about $2 \mathrm{~m}$ in the Boso peninsula and part of Kanagawa prefecture. Tokyo and its surroundings subsided. Sea floor of the Sagami bay raised in the north and subsided in the south part. Tsunami hit the coastal area of the Kanto district about $12 \mathrm{~m}$ high at Atami.

\section{Source map}

There are many reports and maps showing aspects of the earthquake damages which are building damage, geomorphological accidents, tsunami. vibration of the earthquake and so on, especially, in the reports by the Shinsai Yobo Chousakai and Geological Survey. The reports and maps are the most useful for us to follow geomorphological accidents. In the map. distribution of cracks is shown. The aspects were drawn on the topographic map on the scale of $1: 50,000$ by GSI at that time and reduced scale into $1: 100,000$. According to the map, long and many cracks were caused in villages facing rivers from north to south.
3-1. Aspects at Hanada in Koshigawa town

According to the report, the outline is shown as in the followings in this area. In Hanada, many cracks were caused from east to west in dry and paddy fields. They were about $900 \mathrm{~m}$ long, $2 \mathrm{~m}$ to $9 \mathrm{~m}$ wide. Much water squirted with sand. Sand deposited on the ground surface $15 \mathrm{~cm}$ thick and much sand flowed down into the former river course thick. Large scales of crack were $900 \mathrm{~m}$ long, $60 \mathrm{~cm}$ wide and $1 \mathrm{~m}$ deep. And ground surface waved by sand deposits and many belt like collaspes. Small cracks were $20 \mathrm{~m}$ long, $1 \mathrm{~m}$ wide, $1 \mathrm{~m}$ deep on the dry fields in many places.... Sand came out from the bottom of the well $3 \mathrm{~m}$ deep. (Geological Survey:1924).

Interviewing with old peoples, it was made sure that the results of interview were the same as the report by GS(1924) and that much sand flowed horizontally. And boiled sand was coarse sand with greyey blue, And it came from the layer under ground water level. Sand layer of the dry fields moved and flowed into the paddy fields in the former river course to fill it about 3 feet thick. It took many days to take of $f$ sand by many farmers.

In the dry fields, where sand erupted out, product of crops was very poor for 20 to 25 years since the earthquake and kinds of crops to grow well were limited to a few kinds.

3-2. Nakasone in Yoshikawa town

Cracks, sand boils were seen in Nakasone. Nakasone is located on a belt like landform, facing the river, where is $1 \mathrm{~m}$ to $1.5 \mathrm{~m}$ higher than the delta surface, and where the Nakagawa river flows down from north to south. 
And the river runs in the west and villages are located in the east on the same landform. Three linear cracks were caused along the village with erupted sand. Each of them continues about $1 \mathrm{~km}$ long north to south intermittently. But, the width of cracks were only $15 \mathrm{~cm}$.

3-3. Kawafuji in Yoshikawa town

The site is located at the point where the Furutone river meanders and point bars are formed by flooding water. A few long cracks were distributed continuously from the southern area. In addition to these long cracks, seven or eight cracks with several hundreds of meters long were caused in parallel to the point bars in the slip off slope. The aspects of damage were also very intensive with cracks, erupted sand and water in dry fields. And it is clear that liquefaction was caused very intesnsively in this area.

3-4. Kawakubo in Kasukabe town

Kawakubo is located along the Furutone river and well developed natural levees and riverine dunes. According to the document, the outline is shown in the followings.

In housing area and dry fields near the Furutone river, cracks were caused intensively with erupting water, sand, black clay, decayed tree-tips and pumice gravels. Water erupted out and reached about one foot from the ground level and inundated the surroundings about $15 \mathrm{~cm}$ deep. House floors were submerged and sand deposited 4 inches thick. Also irrigation canal was buried with sand.

Live fence in the Mr. ISHIKAWA Kizo's yard ras moved partially by the earthquake as showing the figure. This is a typical case of horizontal movement by liquefaction. The length of the movement was about $72 \mathrm{~m}$ long and moved $1.5 \mathrm{~m}$ toward east. And the live fence was changed from straight line into curved arc-like form. In Moto-shinjuku, hens' egg size gravels erupted out with much water from the aquifer in gravel layer $3 \mathrm{~m}$ deep. Thus, it is clear that horizontal movement by liquefaction was caused in Kawakubo.

\section{3-5. Liquef action}

As mentioned above, based on field survey of landforms and interview, it was made sure that cracks and eruption of water and sand were caused. These phenomena were typical liquefaction. And these were seen in many places very clearly which were Kawakubo, Hanada and Kawafuji at least based on our survey and documents.

4. Geomorphological maps for applied purposes (Land condition map series)

Land condition map series is one of thematic maps published by GSI showing geomorphological classification, distribution of ground level and facilities rlating to natural hazards onto one sheet map With document at another side. Geomorphological classification is a method to classify ground surface into landform units based on geomorphological process, form, material and time when the landform was formed.

At the beginning of the classification work, the whole area is classified into large geomorphological units which are mountainous area, hilly-and-tablel and and lowland. The large classification unit is classified into smaller landform units. Small units are, for example, river terrace, fan, delta, coastal dune, 
artificially changed landforms and so on. Detailed units are natural levee, former river course, back marsh and so many microlandforms in the lowl and.

Fluvial proces transports much material to the lower basin, deposits material and have formed various kinds of landforms in the plain. Natural levee is a landform which river floods formed, it consists of fine sand and silty material, and slightly higher than the surrounding. Watching the cross section of natural levee, it looks like a lens located onto the delta surface. Usually the surface of natural levee is rather dry and is used as dry fields and villages are distributed on it. Riverine dunes are formed by aelion process on natural levee.

An undercut slope is the site where river water runs at the bank of the outside of the meander course and steep cliffs are easily formed, and erosion is intensive. And slip of $f$ slope is another side, that is, the inside of the meander. Point bar is formed there, which is a waving sandy land form.

In Kawafuji and Hanada, the inside of meander consists point bar. Sandy material deposits very thin in parallel. The slip off slope slightly waves gently.

\section{Former edition of topographic maps}

GSI supplies xerox copies of former editions of topographic maps to the public to know pas landscapes. These maps are out of print and each one copy is kept by GSI.

Topographic maps were used as base maps of the crack distribution map. The maps are classified into former edition of topographic maps in the present. And we caught general aspects of the surroundings of the study area around 1923 using former maps. It is about 70 years since the earthquake. And landscapes changed remarkably. For the reason former edition maps are indispensable to understand content of the interview correctly. While, former editions of topographic maps give much historical information which is difficult to know using aerial photographs.

In Nakasone, thin natural levee is formed. Cracks were caused in its eastern fringe. But, the size of the present natural levee is larger than the one around the 1923 earthquake, because the it had been banked up using abandoned soil supplied by the excavation of river course. It is 1 to $1.5 \mathrm{~m}$ higher than the original one. And another side of natural levee facing delta surface was also banked 2 feet or 3 feet for housing spot by spot.

Thus, based on former edition of topographic maps, reports, interview and field survey, it became clear that the original natural levees are usually smaller than the present ones shown in the land condition maps.

6. Characteristics of liquefied sites shown by geomorphological maps

Many cracks and eruption of sand and water were seen in the study area. Based on the research, it was made sure that most of these phenomena were liquefaction. These were caused on the natural levees and point bars and the edge of well developed sandy landforms. The distribution coincided with past cases which other researchers reported. But, various long cracks were caused in undercut slopes in addition to slip off slopes. Naturally, in banked landforms. Natural levees cover saturated soft ground.

Liquefaction can be caused the 
most easily in the fringe of natural levees with banked sites and sandy land forms.

In the classification of natural levees based on aerial photo-interpretation for the land condition map series, boundaries of the natural levees are shown using the most outer fringe lines of natural levees including sandy banked parts.

Natural levees with banked parts were interpreted together as natural levees. The fringe of the natural levee consists of the same material as the original natural levees in many cases and it is difficult to distinguish original ones and banked zone, if there is nobodey who knows the landscapes before construction.

Geomorphological map series (land condition map series by GSI) has been established for prediction of flooding more than thirty years ago based on the experience of I sewan typhoon which hit Japan in 1958 and killed more than 5,000 peoples. And. the map also can be available to predict liquefaction potential because both flooding and liquefaction potential depend on the distribution of micro-landforms in the lowland. Naturally, it is necessary to know the difference of characteristics between flooding and liquefaction.

\section{Conclusions}

(1) Many reports on the 1923 Kanto earthquake show various cracks and squirt of water and sand. The authors followed the contents based on interview with old farmers selectively in the study area. As a result, the contents of the reports are correctly and precised ly described on earthquake damages. It became clear that cracks with water were typical liquefaction based on literature and field check. Liquefaction was caused in broad area with sand boils, collapses, horizontal movement of sand with water.

(2) In the study area, liquefied sites were distributed in the fringing zone of riverine dunes, dry and paddy fields in low natural levees and $d r y$ fields in slip off slope. Sandy micro-landforms are very thin and look like a weak cover on the saturated soft delta surface.

(3) In many places, present natural levees are the results which were banked up using abandoned soil by the excavation of the channel around 1923 earthquake onto the original natural levees. There are many small landform units which are difficult to interpret using aerial photographs because of partial artificial change.

(4) Existing geomorphological maps (land condition maps) are also available for prediction of liquefaction potential in addition to specialists work. It is necessary to read the maps tracing the inner boundaries of natural levees. It is natural that artificially changed landforms are easily liquefied.

\section{References}

Geological Survey Institute(1824): Kanto Jishin Chousa Houkoku Vol.1 (The Report of Field Survey on the Kanto-Earthquake Damage) (GS1924)

Geographical Survey Institute (1917): Topographical Map of KASUKABE on the scale of $1: 50,000$

Geographical Survey Institute (1972): Land Condi tion Map, Noda on the scale of $1: 25,000$

Ministry of Consturuction (1976): $1: 25,000$ Simplified Geomorphological Map Series of the Kanto Dis$\mathrm{trict}$

Shinsai Yobo Chousakai (1925): Shinsai Yobo Chousakai Houkoku Vol.100. (The Report of the office for Prevention of Earthquake Damage 1925) 
㽞域地震激東関
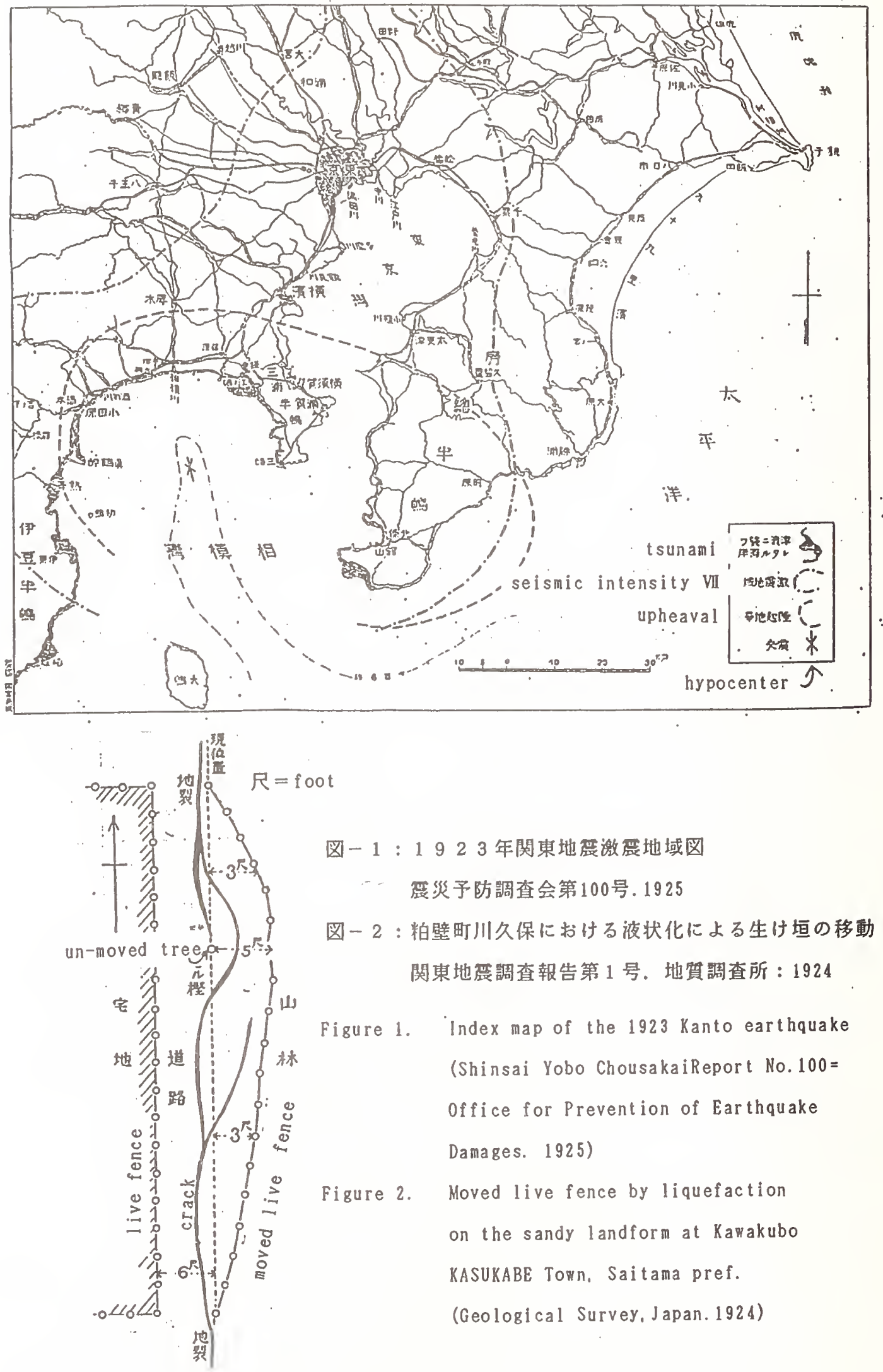

装災予防調查会第100号. 1925

関東地覆調查報告第 1 号。地筫調查所: 1924

Index map of the 1923 Kanto earthquake

Shinsai Yobo ChousakaiReport No.100=

Office for Prevention of Earthquake

Damages. 1925)

Moved live fence by liquefaction

on the sandy landform at Kayakubo

KASUKABE Torn, Saitama pref.

(Geological Survey, Japan. 1924) 

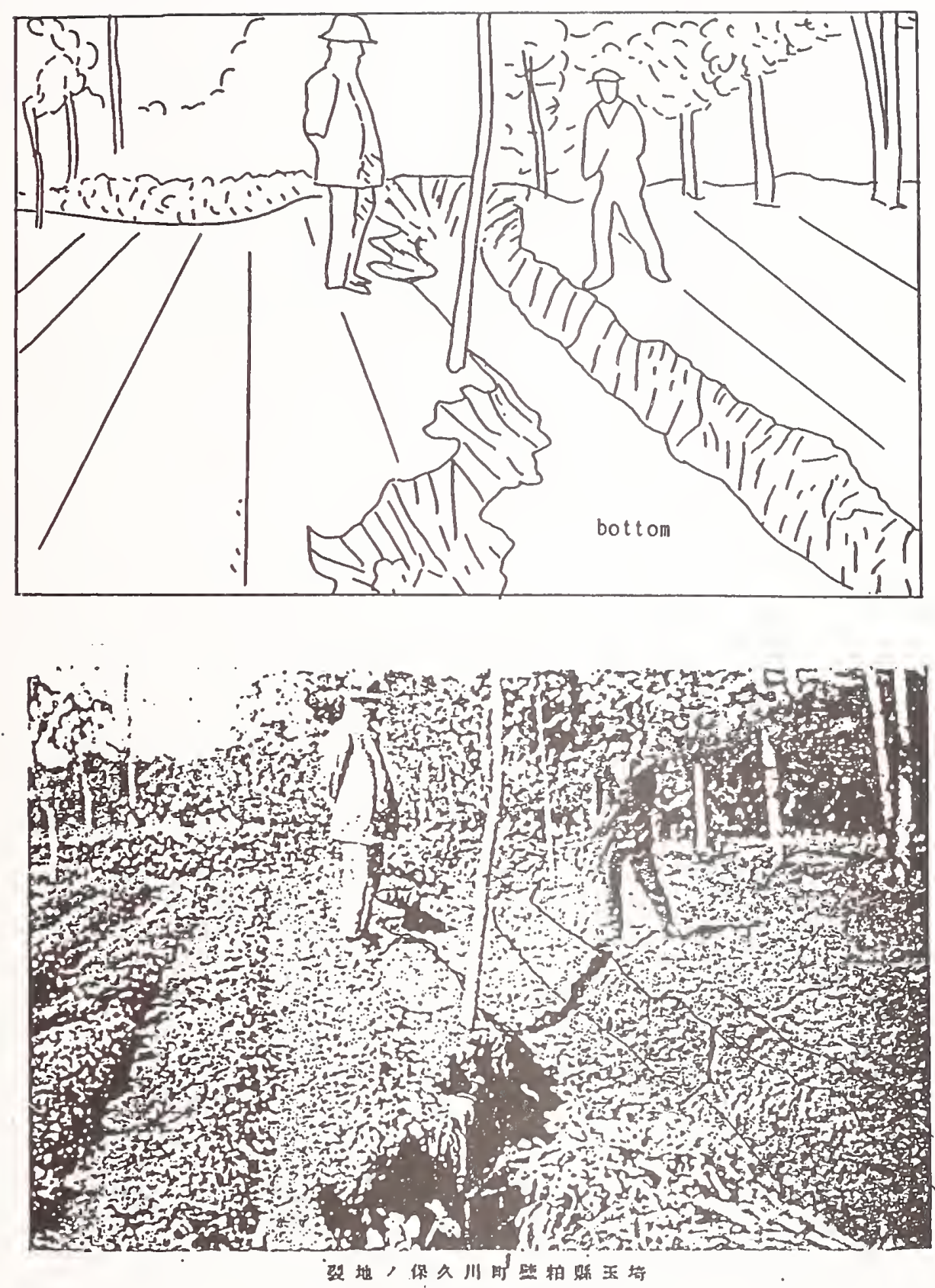

Figure 3. A crack at Kawakubo

Geological Survey Institute(1924)

図一：粕壁町川久保における地裂

图一 2 に同し 


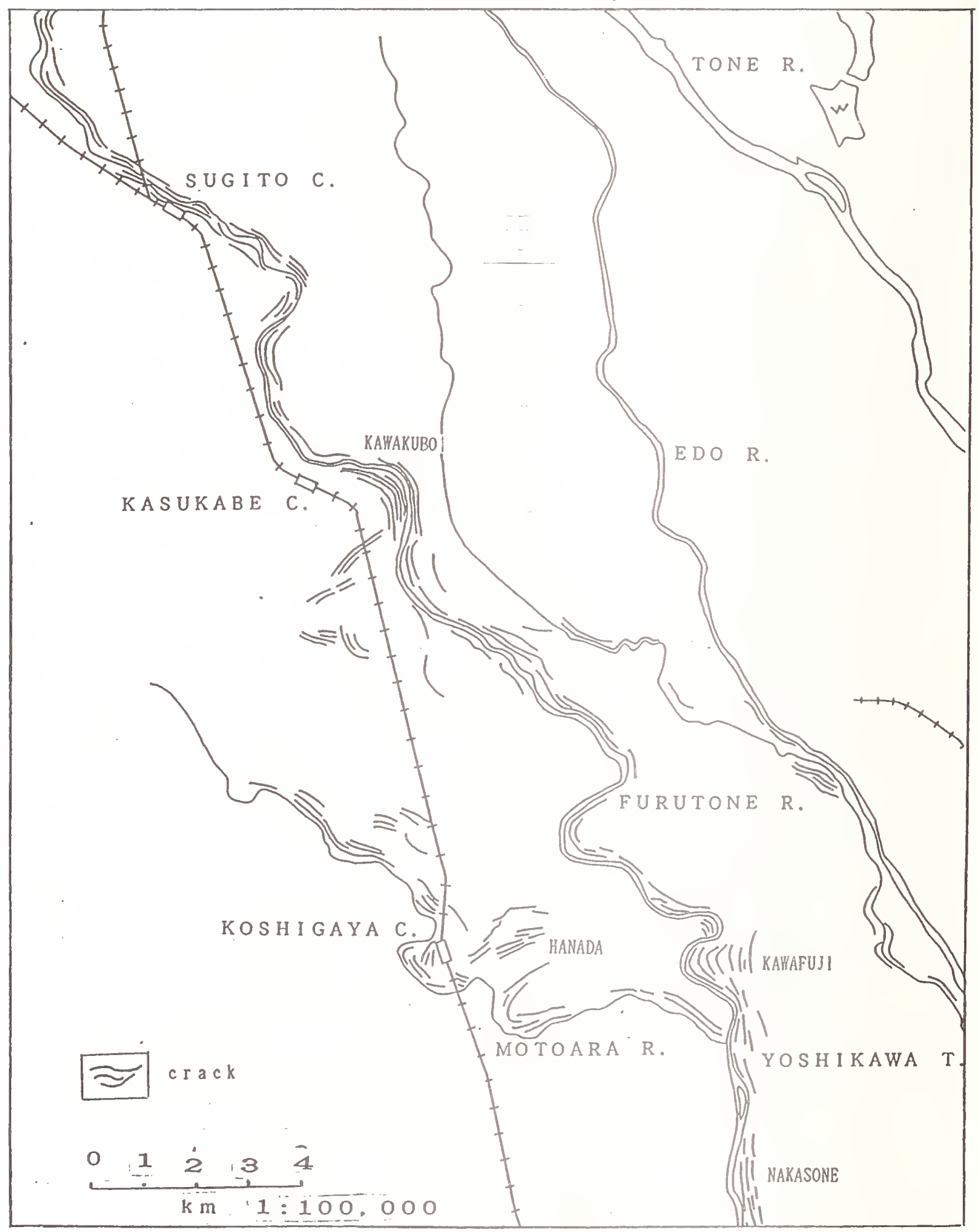

Figure 4. Distribution map of Cracks in the lowland in the southern area of Saitama pref.

Geological Survey Institute(1924) 図-4“埼玉県南部低地にお゙ける地裂の分布

因一 2 に同じ。原典加ら要部拔青編集 


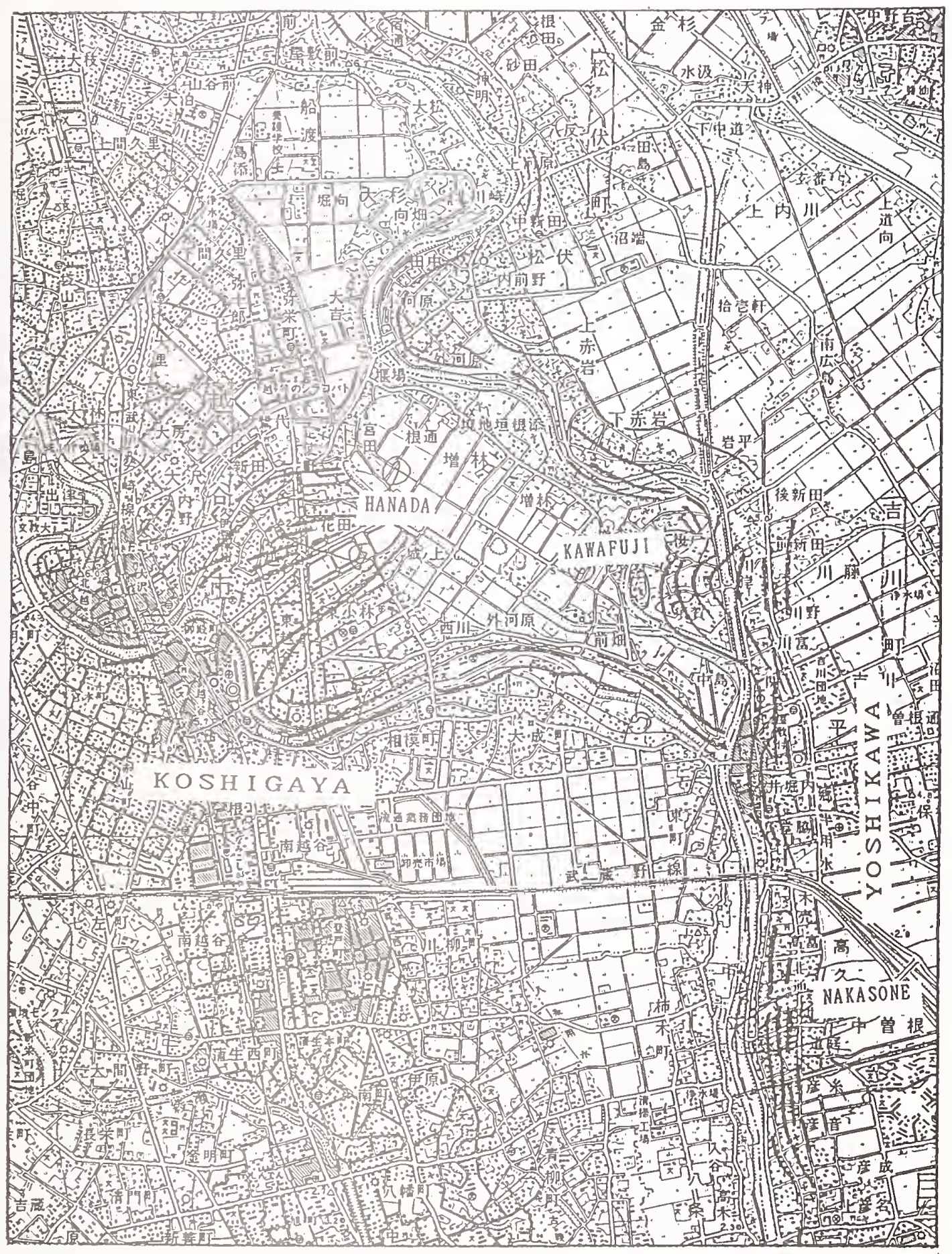

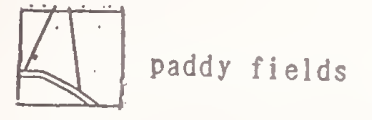

urbanized area

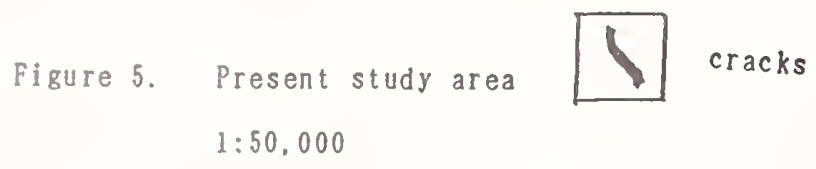

図-5:現在の対象地域の主部

国土地理院1:50.000地形図:1986. 


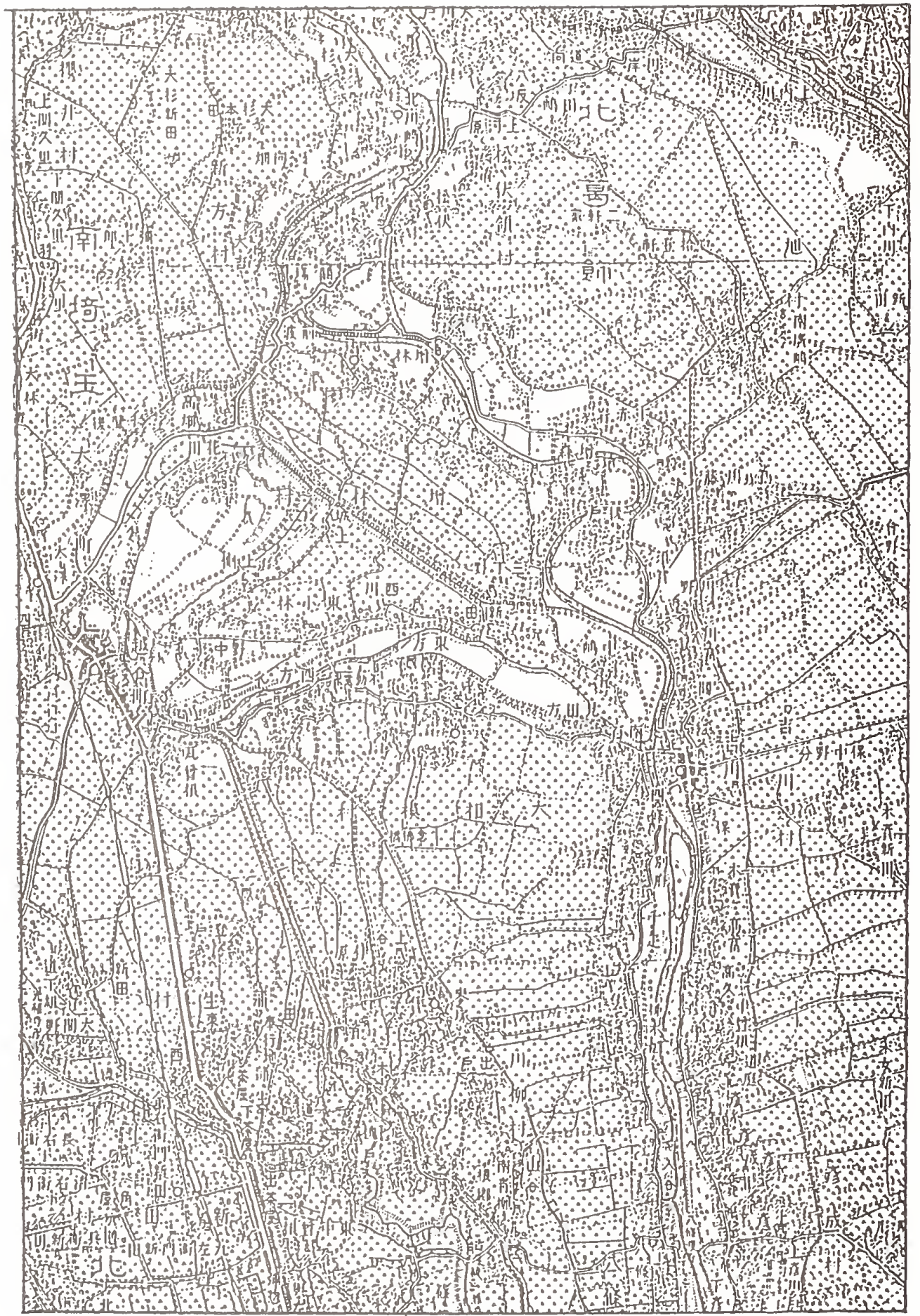

Figure 6. Topographical map around 1923

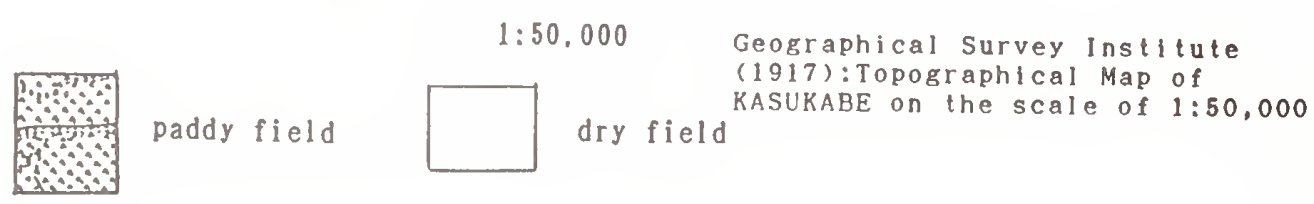





Figure 7. Land condition map

(1972): Land Condition Map. Noda on

$(1: 25,000$ color $) \times 0.7$ 
YasushI SASAKI ${ }^{* 2}$ and MIchIO OKAHARA $* 2$

\begin{abstract}
[ABSTRACT]
A major earthquake occurred in the Phlllpplnes on July 16, 1990. The northern part of the Luzon Island suffered from serlous damages. The Japanese Government dispatched the Technical Expert Team of the Japan Disaster Rellef Team to provide guldance and advice on emergency restoration and post-earthquake measures and "Report of Expert Team of Japan Disaster Rellef Team on the Earthquake in Phillppines of July 16, 1990" was finally complled by the Team.

Thls paper summarlzes this report and Includes the data obtalned by subsequent survey. Furthermore, damaged plle foundation of Magsaysay bridge is analyzed to evaluate the lateral resistance of plle foundations and the selsmic force.
\end{abstract}

\section{[KEYWORDS ]}

Ear thquake; LIquefaction; Damage; Road slde-slopes; Bridge; Plle; Rlver faclllty; Dam.

\section{Introduction}

An earthquake of Magnitude 7.8 on Rlchter scale hit the central part of Luzon Island at around 16:26 (local time) on July 16, 1990.

The eplcenter of thls earthquake was reported to be some $130 \mathrm{~km}$ from Manlla In the north north east direction and was located about $40 \mathrm{~km}$ from Cabanatuan In the north east direction.

Considering the severlty of the earthquake damage In the Phlllppines, the Japanese Government dispatched the Japan Disaster Rellef ( JDR ) Team ( consisting of Medical team, Rescue team and a Technical Expert team) In response to the demand from the Phllippines Government.

The Medical team of 2 medical doctors, 4 nurses, and 3 coordinators was dispatched to the Phllipplnes on the day after the earthquake, and returned to Japan on July 24 after cooperating in activities at hospltals In Bagulo clty. The Rescue team of 11 fire flghters, 11 pollce officers, and 4 coordinators was dispatched on July 18 and came back on July 26 after carrying out cooperatlve work in Bagulo.

Following to these dispatches, the Japanese Government also declded to dispatch the Technlcal Expert team of 4 clvil engineers, 2 bullding engineers, 1 geologlst, and 1 coordinator. The Technical
Expert team departed from Japan on July 29, two weeks after the event, and came back to Japan on August 7 after staylng in the Phlllppines for 10 days. The team complled thelr findings and recommendations gained from thelr fleld reconnalssance of the damaged sites Into a preliminary report, and made a brlefing of the report to the englneers of the Phlllppines government before they left from Manlla.

The Technical Expert team members drafted the final report soon after their return to Japan. The final report of 360 pages, whlch is written In English, contalns a detalled description about the types and distribution of damage, the urgent temporary repalr methods of the damaged Infrastructures, and also the mld- and long-term rehabllitation works and countermeasures against further disasters.

In order to hold the lecturing seminar on the report on March 7,1991 , the Japanese government agaln dispatched three experts Including one of the authors of this paper to the Phllipplnes. These experts agaln vislted the severely damaged Bagulo and Dagupan areas for two days before the seminar.

This paper summarles the final report of the JDR Technlcal Expert team and mentions brlefly the current status of the rehabllitation works of the damaged clvil engineering structures. The damage and repalr works of the bullding structures are to be written in a separate paper.

\section{Outline of the earthquake characterlstics} and the damage

Selsmic Activity in Phlllppine

The Republlc of the Phllippines and Japan are sltuated in the Circum-Paclfic Selsmlc zone. Both countries suffer from Intense selsmlc activity and have experlenced severe damage due to a large number of destructive earthquakes.

The earthquakes in the Phlllppines are classlfled into (1) earthquakes caused by subduction of plates at such deep sea

- 1 Director, Earthquake DIsaster Prevention Department, P.W.R.I., MInIstry of Construction

- 2 Head, Foundation Englneering Division, Structure and Brldge Department, P.W.R.I., Min Istry of Construction 
trenches as the Phlllpplne urench, the East Luzon trench and the Manlla trench, and (2) earthquakes caused by dislocation of active faults such as the Phllipplne Fault.

These trenches and the major actlve faults are shown in Figure-2.1.

Notable destructive earthquakes in recent years are shown in Table 2.1. The earthquake damage in Mindanao is mostly caused by tsunamis. The Ragay Earthquake of magnitude 7.0 In southern Luzon In 1973 had accompanled left-lateral strlke-sllp displacement as much as $3.2 \mathrm{~m}$ on the ground surface ( Allen, 1975).

Large earthquakes of magnitude greater than 6.8 have occurred repeatedly along the Phllppine fault, even in 20th century.

Figure-2.2 shows the epicenters of these earthquakes along the Phlllppine fault and the lengths of thelr causative faults estimated from the earthquake magnitudes. As shown in this figure, a destructive earthquake has not occurred in the central part of Luzon Lsland, where the earthquake of July 16, 1990 took place, since 19th century. The shaded areas in this figure are the selsmlc gap along the Phllppine fault ( Nakata et.al).

Although the Phllipplnes has very hlgh selsmic activity and experlenced many destructlve earthquakes repeatedly In the past, only 15 selsmic observation stations are operated by the Philipplne Institute of Volcanology and Selsmology (PHIVOLCS).

Furthermore, data from these observation stations are not yet centrallzed enough to gain sufflcient accuracy for the determination of the location of eplcenters.

Strong motion observation, which is indispensable for developing seismic design codes for structures, is not belng carrled out sufficlently. Five strong motion accelerometers had been installed in the Phillppines but none of them was in operation at the time of the earthquake because there was a lack of recording paper. Consequently, no strong motlon record was obtalned for thls earthquake.

The Earthquake and the Distribution of Selsmic Intensity

The parameters of thls event are as follows:

Time and Date; 16:26, July 16, 1990 ( Local time)

Magnitude; 7.8 in Rlchter scale ( by USGS)

Epicenter: $15.658^{\circ} \mathrm{N}, 121.227^{\circ} \mathrm{E}$ ( by USGS)

Focal Depth; 25km (by USGS)

The distribution of seismic Intensity in Ross1-Forrel scale is reported by PHIVOLCS as shown In Figure-2.3.

\section{The Causatlve Fault}

The eplcenter of this earthquake is located on the Phllipplne fault, and some $120 \mathrm{~km}$ long segment of this fault is consldered to be broken by thls event. The maximum lateral gap whlch appeared on the ground surface was about 5 meters.

The northernmost tip of the fault movement is confirmed to be at Cayapa vlllage near Imugan in a mountalnous area, which is east of Bagulo, and the southernmost was around Bantug. The eplcenter was located one third of the broken fault length from the southernmost point.

An eplcenter is the orlgin of the fault breakage, thus it is considered that the earthquake shaking was caused by the fault rupturing $80 \mathrm{~km}$ northwards and $40 \mathrm{~km}$ southwards along the Philippine fault.

The fault movement traced along the fault is shown in Figure-2.4 (Nakata et.al).

\section{Outline of Damage}

This earthquake is firstly characterlzed by a wide varlety of damage over a wide area.

The damage by this earthquake is mostly distributed in a trlangular area surrounded by Bagulo, Dagupan and San Jose. This area Is in the north west side of the fault.

The second characteristic is that there was little damage near the eplcenter while the damage in areas far from the eplcenter. such as Bagulo and Dagupan was more serlous. The third characterlstic showed that the damage can be classifled into two categorles; 1) structural damage by strong ground shaking, 2) geotechnical damage.

of these two types damage, 2) geotechnical damage includes both a) settlement of bulldings, collapse of bridges, and the damage to pavement due to the soll liquefactlon, and b) damage to roads in mountalnous areas due to road-side slope fallures.

The largest number of casualtles and Infured were reported in Bagulo City in Benguet Province. Most were caused by the collapse of medlum size to hlgh rise bulldings such as hotels. Also, collapse and fire which occurred simultaneously at the Export Product Area caused a large loss of llves. A large number of passengers on a bus passing on the Kennon Road were trapped in landslides and reported to be dead.

Nuevavizcaya Provlnce Is located In the east of Benguet Province where numerous landslides occurred on steep slopes in mountalnous reglons.

Most of the casualtles In Cabanatuan city were caused by the collapse of the 
Chrlstian College. Collapse of a bullding in the publlc market was also reported. Although this city was close to the epicenter. other damage was not substantlal.

In the cltles along the Lingayen Gulf, including Dagupan clty, severe damage took place due to soll llquefaction. In Dagupan City, the ground surface sunk about 1 to $1.5 \mathrm{~m}$ over a wide area, and a large number of bulldings settled and/or inclined.

Danaged brldges were found over a wlde area. From the 39 bridges examined during the fleld reconnalssance by the JDR Technical Expert team, 28 bridges were evaluated to be damaged from a vlew point of load bearing capacity in the following ways; a) Fallen bridges-6 (Including 1 temporary bridge), b) Serlously damaged-6, c) Partlally damaged-8, and d) Slightly damaged-8.

In addition, fallure to embankments near bridge approaches were commonly observed even though thelr strength were not affected.

Damage to roads was observed at many places, especlally on the Japan Phllipplnes Frlendshlp Highway which is the main route In the northern part of Luzon island, as well as on the Kennon Road, the Marcos Highway and the Nagullian Road to Bagulo. Among these roads only the Nagulllan road was made passable for one way trafflc after the earthquake. Others were left closed even though intense restoration work was in progress at the time of reconnalssance, resulting in serlous obstacles to dally llfe as well as to rescue and restoration activitles. The earthquake occurred in the ralny season, so there was a high possibllity of secondary disasters, such as slope fallures, even after the immedlate restoration work had been done.

RIver facllitles were damaged over a long distance, especlally in the Agno RIver system, and sinking, cracking and breakage of levees, and damage to parapet and revetment structures was observed. Although there was little damage along the Panpanga river, severe damage to the levee was observed on the west slde of Mt. Arayat.

The damage to dams was also serlous. Cracking, sinking and sliding at top of the embankments were observed at the Anbuklao Dam and Binga Dam In the Agno River System, and the Pantabangan Dam and the Masiway Dam of the Panpanga RIver System.

\section{Restoration Works}

According to the final report by the
Philippine government, the damage statistles are as follows: casualties 1,642; Infured 1,495; missing 178; totally collapsed houses 16,467; partly collapsed houses 26.646; total amount of damage to Infrastructures 14 blllion pesos (about 70 blllion yen, about 500 million dollars) (Ikeda).

By referring to the report by the JDR Technlcal Expert team, the report by the Aslan Development Bank and the report by the World Bank, the Phlllppine government is executing the restoration works in the following levels:

Level I : urgent restoration for recovering the function ( temporary bridges, detour construction).

Level II ; restoration for recovering the pre-earthquake functions ( repair and retrof(t), to be completed in two years.

Level III ; restoration Including strengthening against future possible blg earthquakes, to be completed in more than two years.

\section{Soll llquefaction}

Damage of a wide varlety of structures due to soll llquefaction was observed over a wide area, especially in the coast area along the Lingayen gulf.

Fallure of river levees, collapse of bridge substructures and resulting falling off of glrders, settlement of hlghway embankments, tilting and settlement of bulldings, lifting up of burled water supply plpes, and floating up of burled tanks at gasolene stations were seen.

Much of the typlcal damage was observed In Dagupan clty. Dagupan clty with a population of 110 thousand people runs along the both sides of the Pantal river. Many relnforced concrete bulldings were damaged by tilting and sinking without having major structural fallures. Road embankments, even though whlch were as low as $1.5-2 \mathrm{~m}$, settled at several sites and fallures of pavements were observed near Dagupan. The Magsaysay bridge, which is a key means of connecting the parts of the city on elther side of the Pantal river, falled. The girders fell down because the abutment moved laterally when llquefaction Induced lateral spreading of the ground.

In southern part of the clty, where many low rise dwelling houses are located, 1.5-2 $m$ of settlement of the ground surface took place which caused difficulty with dralnage.

F1gures-3.1 and 3.2 show the damaged area of Dagupan city. The area shown consists of thick alluvium deposits having loose sand layers and silty sand layers up to 7-10 m below the ground surface. The anclent 
river channels are shown in Figure-3.2. The area where damage to structures was heavy is located on the old river channel, and Inside the area surrounded by winding course of existing river.

The Department of Public Works and Highways (DPWH) of the Phillppine government conducted standard penetration tests at many sites around Dagupan city in order to investigate the soll conditions of the damaged area after the earthquake. An example of that SPT results is shown on Figure-5.5. The SPT method conducted in the Phillppines seems to be sllghtly different from that in Japan as they do not use bentonlte suspenslon to protect the bore hole, the rope to pull up the drop welght is controlled by drum. The measured blow count number needs to be modified to account for the energy transmitted.

The maximum ground acceleration was estlmated to be around 200 gals from the empirical attenuation formula in Japan. The liquefaction potentlal assessed by the method in Japan Illghway Speclflcation utllizing the estimated ground motion and the measured blow count is also shown in Figure-5.5. From this Figure, it is consldered that the layers up to around 7-10 meters below the ground surface may be liquefled.

At the time of the lecturing seminar in March, 1991, they were Intensely conducting restoring work of the damaged dralnage system and streets In Dagupan clty, and of the Magsaysay bridge.

The damaged Magsaysay bridge was a seven span slmply supported bridge resting on plle-bent foundations. The foundation type of the new bridge was a cast-in-place large diameter plle foundation. The existing old plles are obstacles for constructing the new cast-1n-place plles, so the old plles for plers p-4 and p-5 were pulled out from the ground. The plles for pler p-5 were cracked and falled in bending at around 10 meter below the ground surface, and the upper portion of the plles were bent'towards the river side. From the depth of the cracks on these plles, the thickness of the llquefled layer was estimated to be around 10 meter below the ground surface. The plles for p-5 were constructed in single row whereas the plles for $\mathrm{p}-4$ were constructed in three rows, all of whlch were undamaged.

\section{Damage to Road-Side Slopes}

Status of Damage to the Japan Phlllppine Frlendship Highway

Damage to the Japan Phllippine Frlendshlp Highway by the earthquake was serlous. covering a $76 \mathrm{~km}$ section whlch runs through mountalnous sectlon between San Jose (kms 160) and Arltao (kms 236).

Fig. 4.1 shows an outline of the damaged section. In the Bayombong district ( $\mathrm{km} \mathrm{265)}$ north of Aritao a few cracks occurred on the road shoulders only, whlle on the road between San Jose and Aritao, the trafflc was shut down due to slope fallure of the road.

Since large-sized fault displacements were produced along the Highway in the nelghborhood of Digdig (kms 183) it is thought that the strong shaking of the earthquake motion was centered around the mountalnous areas.

According to investigation by a hellcopter, in addition to slope fallure along the Japan Phlllppine Frlendship Highway, slope fallure on surrounding mountainsides was observed; the scope of this slope fallure spreads to Bagulo and its surroundings.

The most prominent feature of the earthquake damage along the Highway was that a great number of continuous slope fallures occurred not only on the artiflclally cut slopes but also on the natural slopes. However, the slope fallures all had shallow surface sliding.

These districts have the reglonal characterlstics that there are few trees on the surface of the mountains and no slope protection measures are used. Surface layer of slope which is weathered due to the heavy rains and the high tropical temperatures and barely balance against the static force of ralnwater erosion was easlly slid when subjected to strong vibrations.

It may be noted that the annual rainfall In Santa Fe (kms 215) on the north side of Dalton Pass (kms 208, 1000 meters above sea level) and San Jose to the south of the Pass from 1976 to 1984 is that, 1500 to $3400 \mathrm{~mm} \mathrm{in}$ Santa Fe and 1700 to $3200 \mathrm{~mm}$ in San Jose. Sometimes these districts are hit by heavy ralns accompanyed by the progress of typhoons.

Since the Highway runs along the fault topography with a NW-SE direction branching off from the Phlllpplne fault, the geological features there are disturbed and changed in quallty by its influence.

The geology is composed of the following: the basement is granlte and dlorite of the Mesozolc era, Cretaceous perlod; dlabase and andesite of the Paleogene perlod to Neogene perlod: and sandstone, mudstone and limestone of the Neogene. The basement rock is covered by terrace gravel of Dllivium perlod in Quarternary, alluvlum sand, gravel and clay of Quarternary 
perlod; then the surface geology is composed of talus sediment and the present riverbed sand and gravel.

The basement rock is in an unstable state having clayey seams caused by fault activity. Furthermore, since the granite malniy distributed in the Santa $\mathrm{Fe}$ nelghborhood is decomposed and so unstable that it can easlly cause the slope fallures.

Slope fallure hardly occurred where there were slopes composed of hard rock, low slopes (less than $10 \mathrm{~m}$ ) and gentle grade natural slopes. Furthermore, compared with the many slope fallures, there was little damage to the structures, such as stone masonry retalning walls and gablons whlch reinforce the lower parts of slope faces.

One of the features of the disaster is that damage was hardly observed on the structures with a base rigldly connected with the sound natural ground.

Some pavements were damaged. Cracks were caused by settlement of the embankment shoulders, there was damage from falling stones caused by the earthquake motion and thrusting up of pavement slabs due to fault displacement. At the places where faults cross the road, the whole road surface slid laterally (about $2 \mathrm{~m}$, to the axls line) and the pavement slabs were badly damaged. However, It was not enough to stop the trafflc.

In addition to the damage to the road Itself due to the afore-mentloned collapse of slops, there were outflows of huge amounts of muddy sands whlch caused a large amount of damage from flowing mud and drifting wood in the low-lying areas (rlvers) of the region.

Table 4.1 shows the types and distribution of damage along the Highway from visual observation. The number of the places with slope fallure reached more than 200 and totalled about $12 \mathrm{~km}$ of the HIghway. Most of the slope fallures occurred continuously along the direction of the road.

Status of Damage to The Three Maln Routes to Bagulo

Though the Nagulllan Road could be passed through, some sectlons stlll had only one passable lane because of the large quantity of collapsed earth and sand from the falled slopes and the settlement of road surfaces on banked sectlons after the earthquake. In the areas of $\mathrm{KM} 267+700$ and $K M 261+000$, collapsed earth and rocks of more than $5,000 \mathrm{~m}^{3}$ remained. The total amount of collapseod earth and rock was estimaed to exceed $50,000 \mathrm{~m}^{3}$.
It was difficult to remove this large quantity of collapsed earth, rocks and huge fallen rocks, and addining to this difficulty rehabllitation work was prevented by rainfall.

The section between KM272+000 and KM 277+500 of the Marcos Highway was closed untll September 1990 because it took a long time to remove the collapsed soll. Although the features of the damage due to slope collapse on the Marcos Highway were simllar to those on the Naugillan Road, the scale of the slope fallures was much larger than that on the Nagullian Road. The obstacles whlch cover the Inaccessible sectlons exceeded $164,000 \mathrm{~m}^{3}$.

The Kennon Road, one of the three main routes leading to Bagulo clty, was the most extremely damaged (FIg.4.2).

The damage to the Kennon Road differs from the Marcos Highway, In the point that the large quantlty of debris from the slopes along the road included huge fallen rocks.

The classiflcation of slope fallures in Kennon Road Is shown in Table 4.2.

The mountaln slopes on both sides of the Buedo river falled during the shaking and supplled a large quantity of debrls which ralsed the bed of the Buedo rlver. When the rehabllitation plan for Kennon Road is formulated, the partial realignment of the road must be considered in sections beginning with the locations where the former road is susceptlble to be flooded due to the ralsed river bed.

On every route, even when the accumulated earth was removed was susceptible to newly-fallen debrls and further erosion of the shoulders whlch may further damage to the functions of the roads due to the heavy rain. Therefore, measures to provide sufflclent dralnage facllitles are necessary.

\section{Damage to bridges}

1) Status of Damage to Brldges and Damage Analys 1s

Damaged brldges ranged so widely from Manlla to the northern part of Luzon Island that a fleld survey on all of them in a limited perlod was hardly possible. Therefore, the team declded on a survey pollcy which would cover as many sites as posslble and check on bridges heavily damaged.

In fact, fleld surveys on a total of 30 brldges were made. The team also checked nine damaged bridges on the Japan Phillppine Frlendshlp Highway by hearings from the local englneer as well as by looking at photographs which had been taken in previous surveys. 
According to the DPWH damage survey results as of Aug. 1990, the surveys had not been conducted yet on 25 bridges. However. these apparently did not Include bridges with serlous damage, such as fallen brldge. FIg. 5.1 shows the locatlons of damaged bridges, 79 bridges, Including the additional results of subsequent inspection.

Bridge damages extended to large area of Luzon Island, Including many brldges partlcularly on the Japan Phllippine Frlendshlp HIghway and the Manlla-North Road. These are trunk roads linking the northern part of Luzon Island to Manlla.

on the Manlla-North Road IInkIng Manila and San Fernando via Tarlac and on roads in Its vicinitles, the Carmen, Calvo and Tabora Bridges fell and the Aringay Brldge was serlously damaged.

In Dagupan Clty and 1 ts suburbs where heavy damage was caused by llquefaction, the Magsaysay Brldge fell and the Embarcadero and Rabon Bridges were heavlly damaged.

On the Japan Phlllpine Frlendshlp Hlghway, the Manlcla Bridge fell and the Sicsican Bridge was in danger of falling. As for the Puncan II Bridge, no abnormalltly was discovered in 1 ts structure but it seemed that it could have been damaged by the oncoming large quantity of driftwood.

Table 5.1 shows data, status of damage and damage sketches concerning major damaged brldges .

Damage characteristics Include falling of of the superstructure due to pler Inclination caused by the llquefaction of ground, damage of the glrder ends, shoes, and brldge seats caused by inertlal force. damage of the abutment plles, footings, and girder ends caused by earth pressure and Inertlal force, damages of the plle heads in plie bent plers, settlement of plers, and settlement of approaches.

of these damage types, severe damage by llquefaction, damage to plle bent abutments and plers and damage to shoes and brldge seats were remarkable.

Mention must first be made of the fact that the horlzontal bearing force of damaged bridges in general was small because thelr foundations generally had Insufficlent setting depth (presumed to be about $10 \mathrm{~m}$, at most). The single-row plle form (one row in the direction at right angles to the bridge axis) was common (plle bent) and the commonly used plles were made of wood or RC. Thelr shoes were relatively simple structures and did not have a sufficient number of anchor bolts. The bridge seat on which the shoes rested was narrow so that there was a danger of bridge fall or easy sllp-out of the shoe in the event of a large displacement of the substructure. Also, shear fracture was llable to occur in the bearing edge at the pler top and in the girder end.

The degree of damage had to be judged In order to carry out emergency rehabllitation. The team decided upon assessing the of damage degree for Individual bridges in accordance with Manual for Repalr Methods of CIvil Engineering Structures Damaged by Earthquakes (Minlstry of Construction, March 1986). The bridges of major damage levels, $D$ and $E$ were shown In Flg. 5.1. The degrees of damage concerning bearing capacity were declded according to the following flve ranks:
A: No damage ........ There is no known abnormallty concerning bearlng capacity.
B: Minor damage .... There is no posslbllity of Immedlate decline of bearing capacity.
C: Medlum damage .. The damage may lower the bearing capacity, but if It does not worsen from aftershocks, live load, etc., the brldge can be used tentatively for the trafflc.
D: Major damage ... The damage serlously affects the bearing capacity and may result critlcal consequences, such as a bridge fall.
E: Bridge fall ..... The case of a fallen bridge

In deciding upon degree of damage concerning bearing capacity, it is most Important to determine whether or not a brldge fall wlll eventually occur. Here, bridges with the posslbllitles of a fall due to llve loads, aftershocks, etc. are classlfled as belng in the $D$ rank. As a whole, these bridges must be totally closed to trafflc.

\section{2) Selsmic Design for Bridges}

According to the recent "Design Guldelines Criterla and Standards by DPWH 1989 (hereafter referred to as the Guldeline), aseismic design is to be applied to civil englneerlng structures such as dams, tanks, and bridges. Detalled procedures and methods of selsmlc deslgn are not shown in this Guidline.

Detalled information on bridges is glven in the "Natlonal Structural Code of the Phlllpplnes, Vol.II, Bridges by the Assoclation of Structural Engineers of the 
Phlllppines, 1987" (hereafter referred to as the Code). This paragraph describes the selsmlc design of brldges.

\section{History of Selsmlc Design for Bridges}

The selsmic design of bridges before 1972 was not clear.

Selsmic design was performed on the basis of the guldellne Issued in 1972. It was speclfled that $10 \%$ of the dead load must be considered as the minimum seismlc effect.

According to the guldellne (1972), It was speclfled that the actual selsmlc design is to be performed on the basls of "Earthquake Engineering for the ILZGAN-BUTAN ROAD in the Island of MIndanao-Phlllppines by the Aslan Development Bank" Issued in 1972.

From 1989, It was speclfled that $10 \%$ (dead load $+1 / 2$ llve load) is to be considered as the design earthquake force in the Guldeline above which was revised from the 1972 guldellne.

Actual selsmic design was done on the basis of the aforementioned code issued in 1987.

Selsmlc Deslgn Method for Bridges (as per the Code in 1987)

Selsmic design for those areas expecting earthquake occurrence is to be done by considering the relation to active faults of the construction sites, response characteristics of the ground and the bridges, etc.

Both the equivalent statlc load method (selsmic intensity method) and the response spectrum method are shown in the code as the practical calculation methods. The former is specifled as follows:

For almost equal underground layer rigidity, design earthquake force (EQ) is calculated using the following equation.

$$
E Q=C \cdot F \cdot W
$$

Where, $F$ = Compensation factor for each structure (1.0: single column type plers, 0.8: RIgId-frame plers) $W=$ Dead load

$C=A$ combined response factor whlch Is greater than 0.1

Value $C$ is obtalned using the maximum acceleration (A) of the foundation, thickness of alluvinm layer to baserock, and the natural perlod ( $\mathrm{T}$ ) of structures.

If the aforementloned data (maximum acceleration of foundation, etc.) are unknown, the following equation can be used to calculate EQ.

$$
E Q=0.10(W+L / 2)
$$

Where, $W=$ Dead load, and $L=$ Live load,

The calculation for complicated structures is to be made by the response spectrum method.

Load for the stopper of glrder ends at movable shoes, is as follows:

$\mathrm{EQ}=0.25 \times \mathrm{DL}$ - (shearing force generated on a pler due to earthquake force).

Where, $D L=$ Reaction force on the superstructure to be consldered for design

However, there seems to be some uncertainty for the practical application of the above guldellne.

3) Calculation of Lateral Resistance of Plle Foundations and The Selsmic Force for Magsaysay Bridge

Fig. 5.3 and 5.4 show the fallen old Magsaysay Brldge and the newly planned Magsaysay Bridge respectlvely.

Calculations were executed in order to estimate earthquake force which actually acted, the level of llquefaction and lateral resistances of plle foundations.

Since there is a shortage of preclse data on plle foundations, plle cross section, and soll propertles, estimated data were used in the calculations.

Conditions and Methods of Calculations.

(1) The soll conditions and models shown in F1g. 5.5 were used for the calculation. The soll parameters were obtalned at the site away from the bridge, because the soll condition was unknown at the bridge site.

Both models for plers P4 and P5 are assumed to have the same soll condition. The calculation models shown in Fig.5.5 used the survey results obtalned after the earthquake.

(2) The horlzontal ground reaction coefficlents are assumed to be from $\mathrm{KH}=1.0$ to $10.0 \mathrm{Kgf} / \mathrm{cm} 3(\mathrm{Kh}=10 \mathrm{kgf} / \mathrm{cm} 3$ is equivalent to SPT $N$ value of 10 ). Calculations were also carrled out assuming outstanding plles saused by liquefaction occurrence.

(3) The ultimate bending moment capacities of plles were obtalned assuming RC plles with $40 \mathrm{~cm} \times 40 \mathrm{~cm}$ cross section and 3 types of relnforcing steels.

(4) Maximum bending moments (Mm) of a plle and the displacements $(\delta \mathrm{T})$ at the pler tops were obtalned and lllustrated when earthquake force (Ho) was applled. The selsmlc Intensity $\mathrm{Kh}$ was defined as the ratlo of horlzontal force to dead load.

Results of Calculation 
(1) Regarding to the pier P5, results of calculation are lllustrated In FIg. 5.6. It can be concluded that the plles would be broken if seismic force equivalent to more than $\mathrm{Kh}=0.1$ acted even wlthout the occurrence of liquefaction. The actual plles were falled in bending due to liquefaction.

(2) Piles for the pler P4 would be broken if deep range of ground were llquefled. There was little damage to the actual piles as mentloned In the prevlous chapter.

6. Damage to rivers and dams 1) Damage to Rivers

At the Agno river system in Flg.6.1, the team observed damaged river facllitles on a wide scale. Cracks at the crests of the levees and settlement and sliding of the levees were marked and some of them had collapsed. Furthermore, cracks and collapsing were observed at the parapet and revetment structurs.

There were few damaged sltes at the Pampanga rlver system, however, a collapse of the levee near Mt. Arayat was partlcularly notable.

No significant damage was seen at the gates, which seemed to be operated smoothly.

- The sltuation of the damage at the Agno river site was as follows.

The Tarlac RIver; A Branch of The Agno RIver (Panigul SIte)

Large cracks occurred at the crowns of levee of $5-6 \mathrm{~m}$ in helght, and sllding occurred as shown In Flg.6.2. The materlal of the levee was malnly composed of fine sands. Some places were temporarlly rehabllitated with sand-bag plling.

The revetments, made of plain concrete using boulders, were dameged by sliding with the collapse of levees In such a way that the foundations were lald directly on the natural ground. Although these revetments were badly damaged, the revetments, in whlch foot protection on the river frontage had been conducted by the placing of boulders, suffered llttle or no damage.

The Agno River (VIllasls to Bayambang
Sltes)

Many cracks were observed at the crests of levees of 5 to $6 \mathrm{~m}$ helght. Some levees sank about $1 \mathrm{~m}$ as a whole, or, some of the levees slld and collapsed. Sllding occurred towards the direction in which the ground helght, inside or outside of the dike, was relatlvely lower. The maln materlal of the levees seemed to be silt.
The Agno River (Bayambang to Urblztondo $\underline{\text { Sites) }}$

Several oblique cracks on the crowns of levees of about $5 \mathrm{~m}$ in helght, and big collapses caused by sliding were observed.

According to a housewife who saw the collapse at its actual location, serious horlzontal shaking occurred, cracks opened, and then the earth dikes slid (Fig.6.3b).

Both sides of the earth dikes were marsh and the ground conditions were very bad.

\section{2) Damage to Dams}

The team Investigated the following dams; the Ambuklao Dam and the Blnga Dam of the Agno rlver system, and the Pantabangan Dam complex (composed of the Pantabangan Dam, the Aya Dam and the Maslway Dam) and the Angat Dam of the Panpanga river system. All the dams except for the Masiway Dam were embankment dams.

Cracking and settlement of the crests of the dams and shallow sllding on the slopes of the dams were observed mostly in the Ambukulao Dam (FIg. 6.4), the BInga Dam (FIg. 6.5) and the MasIway Dam.

Since all the dams had become old and malntenance on them seemed to be insufficlent, a lot of damage was also observed whlch was unrelated to the earthquake.

\section{Conclusion}

As described prevlously in Chapter 2, the characteristic features of the seismic damage this time are: 1) that the damage was spread over a wlde range, 2) that the types of damage suffered were dlverse and 3) that about $5 \mathrm{~m}$ lateral dislocation along the Phillpplne pault appeared on the ground surface over a long distance (conflrmed at least approx. $120 \mathrm{~km}$ ). The maln affected area was roughly within a trlanglar area with one side approx. 50-60km connecting Bagulo, Dagupan and San Jose, wlth damage found scattered to Cabanatuan CIty and colonles along the Japan Phllipplne Friendship Highway.

The types of damage are roughly divided Into 2 types 1.e. 1) collapse of structures by shaking and 2) ground fallure. The ground fallure included: a) sinking and tilting of buildings and damage to Infrastructures such as bridges, due to soll llquefaction as well as damage to pavements and b) damage to roads by land slldes centered around in the mountainous area.

In the "Report of Expert Team of Japan Disaster Rellef Team on the Earthquake In Philipplnes of July 16,1990 " the technical recommendations, such as items deslred to 
be urgently acted on, items for whlch quick action is desired to be taken and 1tems for whlch actions should desirably be taken over the long time perlod have been made based on fleld reconnaissance.

Among these 1tems, Items to be acted on urgently for clvil englneering structures are brlefly cited here. Analysis of damaged plle foundation for Magsaysay Bridge is also mentloned here.

Items DesIred to Be Urgently Acted on

(1)Dlagnosis, repair and relnforcement of brldges suffering from the disaster

Trunk roads connecting the northern part of Luzon to Manila Include 2 routes 1.e., the Japan Phlllppine Frlendshlp Highway and the Manlla North Road. In the former, some Impassable zones stlll remain due to the existence of a large quantity of debris, In the latter, because the Carmen Brldge collapsed, a bypass through Lingayen has been provided.

Many bridges suffered from the dlsaster along the Manlla North Road, whlch is left as only one road, including this bypass road, connecting the northern reglon of Luzon to Manlla and Its perlpheral roads.

There are even some of these bridges whlch are susceptible to the progressive status of damage under the load of trafflc of heavy vehlcles. Considering this road's Importance as a trunk road, It goes without saying that the diagnosis on the degree of damage and repalr and relnforcement of damaged bridges are necessary for the rapld recovery of transportation means.

As a result of fleld surveys on 39 brldges at this time, 12 bridges were found to have suffered hlgh degrees of damage, including 6 bridges which fell down. Practical proposals on Immedlate countermeasures and a full-scale recovery plan were offered in the tentative report for 10 of these bridges.

of the remaining bridges suffering from the disaster which were not dlagnosed this time because of time restrictions, diagnosis should be conducted soon.

(2) Setting of urgency bypasses and erection of emergency temporarlly erected bridges

The diagnosis, repair and reinforcement descrlbed in the prevlous Item are one set of countermeasures to be urgently taken, but substantial time will be required before thelr completion. As a stop-gap measure to be taken in the meantime, setting urgency bypasses and erecting emergency temporary bridges are necessary.

Such actlons have already been taken to some degree, and it looks as if emergency recovery has become efflclent to some extent, but further treatment of the whole range of damaged roads and of all damaged bridges will be necessary.

(3)Measures for prevention of drifting of bridges., etc., by flowing sediment and logs

At the Puncan II Bridge on the Japan Phllppine Frlendshlp Ilghway, danger of the bridge belng set adrift by running sediment and logs was observed.

At the Carmen, Calvo, Manlcla and Magsaysay Bridges whlch fell down, glrders whlch fell down have been left as they are, lmpeding the passage of flowing water during floods. Some measure to remove them qulckly needs to be taken.

(4) Early opening of 3 routes to Bagulo

Among the 3 main routes to Bagulo, only the Nagulllan Road has been opened.

However, along thls route, substantlal lengths of road are left where only one-way trafflc is avallable because of large scale collapses and potential disasters resulting from rain fall. It should be an urgent priority to hasten the opening of the Marcos Highway.

The remalning ' 2 routes, which have relatively short impassable sections, can be quickly repalred providing at least 2 routes which lead to Bagulo.

For this purpose, larger numbers of heavy duty machines for removal of collapsed sediment should be provided.

In the opened road, it is desired to keep watching and to control traffic volume to prevent a secondary disaster from occurring.

(5)Emergency recovery of river embankments and dams

Early execution of emergency recovery of the damaged parts of levees and dams which suffered from the disaster is necessary. This is because the ralny season has set in. Furthermore, after the season is over, full-scale permanent recovery work needs to be done.

(6) Study for acquirlng baslc data for future recovery plans

In proceeding with the above-descrlbed countermeasures, records on the planned processes and methods of thelr execution, etc., should be left, such that they wlll serve not only as mere records of recovery of this time's disaster but as data for reference in planning countermeasures for the future.

Analysis of The Damaged Bridge of
Magsaysay
From analysis of the plle foundations of
fallen Magsaysay Brldge, it is clearly seen
that there is no conslderation of
liquefaction in design and that the selsmic
intensity is considered to be at most $10 \%$. In


conclusion the horlzontal bearing capacity of a plle foundation is insufficlent to cope with liquefaction. Furthermore the plle bent foundation Itself is very flexible, therefore, it can be sald the bridges are susceptible to fall during a strong earthquake.

\section{Acknowledgement}

This paper is prepared mainly based on "Report of Expert Team of Japan DIsaster Rellef Team on the Earthquake In Phlllppines of July 16, 1990", which was authored by the Technical Expert team of seven members headed by Prof. T. Okada of Tokyo Unlversity with lots of assistance and support provided by the DPWH, DOTC, NHA, Armed Forces of the Phllippines, PHILvocs, local authorlties of the Phllippines Government, the Japanese consulting firms, and JICA experts. The manuscrlpt of this paper was typed by Mr. S.Takagl of the Foundation DIvision, PWRI and English was revlewed by Dr. G.McRay of Earthquake Englneerlng DIvislon, PWR!.

The authors greatly appreclate these contributions given by all individuals above.

\section{Reference}

1) Allen,C.R.: Geological criterla for evaluating selsmiclty. Geol.Soc.Amer.Bull. vol.86, ppl04l 1057, 1975

2) DPWH : Designing Materlals(Magsaysay Br.etc)

3) JICA : Report of Expert Team of Japan Disaster Rellef Team (JDR) on the Earthquake in Phlllppines of July 16, 1990.

4) A.ShImazu, Y.Sasakl and M.Okahara : Reconnalssance Report on the Phllippines Earthquake of July 16, 1990, Civil Englneering Journal, VoL.32-10, 1990.

5) T.Nakata, et al. : Earthquake Fault of 1990 Phillppines, Journal of Geology, 99-5. 1990.

6) Y.Sasak1 : Recnnalsance Report on the Phlllppines Earthquake of July 16, 1990, Tsuchl-to-klso, 38-11, Nov: 1990.

7) M.Okahara and M.Mitanl : Study Report on Damages by the Phlllppines' Earthquakes, Journal of Foundation Eng., 18-12, Dec.1990.

8) T.Ikeda : Earthquake of Luzon Island and Alds of Restoration. Monthly Journal of Construction, Jan.1991.

9) Y.Sasakl : Characteristics of Disaster by Recent Overseas Earthquakes, Technlcal Memorandum of PWRI, VOL. 2928, Feb.1991.

10) Nlppon Koel : Kennon Road Disaster Prevention Project Final Report, Feb.1991. 
Table 2.1 Destructive Earthquakes and their impacts in the Philippines

\begin{tabular}{|c|c|c|c|c|c|}
\hline DATE & EPICENTER & INTENSITY & MAGNITUDE & CASUALTY & INJURED \\
\hline $\begin{array}{l}01 \mathrm{Jul} . \\
1954\end{array}$ & $\begin{array}{l}\text { Bacon, } \\
\text { Sorsogon }\end{array}$ & VII & 8.3 & 13 & 101 \\
\hline $\begin{array}{l}01 \text { Apr. } \\
1955\end{array}$ & $\begin{array}{l}\text { Lanao, } \\
\text { Mindanao }\end{array}$ & VII & 7.5 & 291 & 713 \\
\hline $\begin{array}{l}02 \text { Aug. } \\
1968\end{array}$ & $\begin{array}{l}\text { Casiguran, } \\
\text { Aurora }\end{array}$ & VII & 7.3 & 270 & 600 \\
\hline $\begin{array}{l}07 \text { Apr. } \\
1970\end{array}$ & $\begin{array}{l}\text { Baler, } \\
\text { Quezon }\end{array}$ & VII & 7.3 & 15 & 200 \\
\hline $\begin{array}{l}17 \text { Aug. } \\
1976\end{array}$ & $\begin{array}{l}\text { Moro Gulf, } \\
\text { Mindanao }\end{array}$ & VII & 7.9 & 3,739 & 8,000 \\
\hline
\end{tabular}




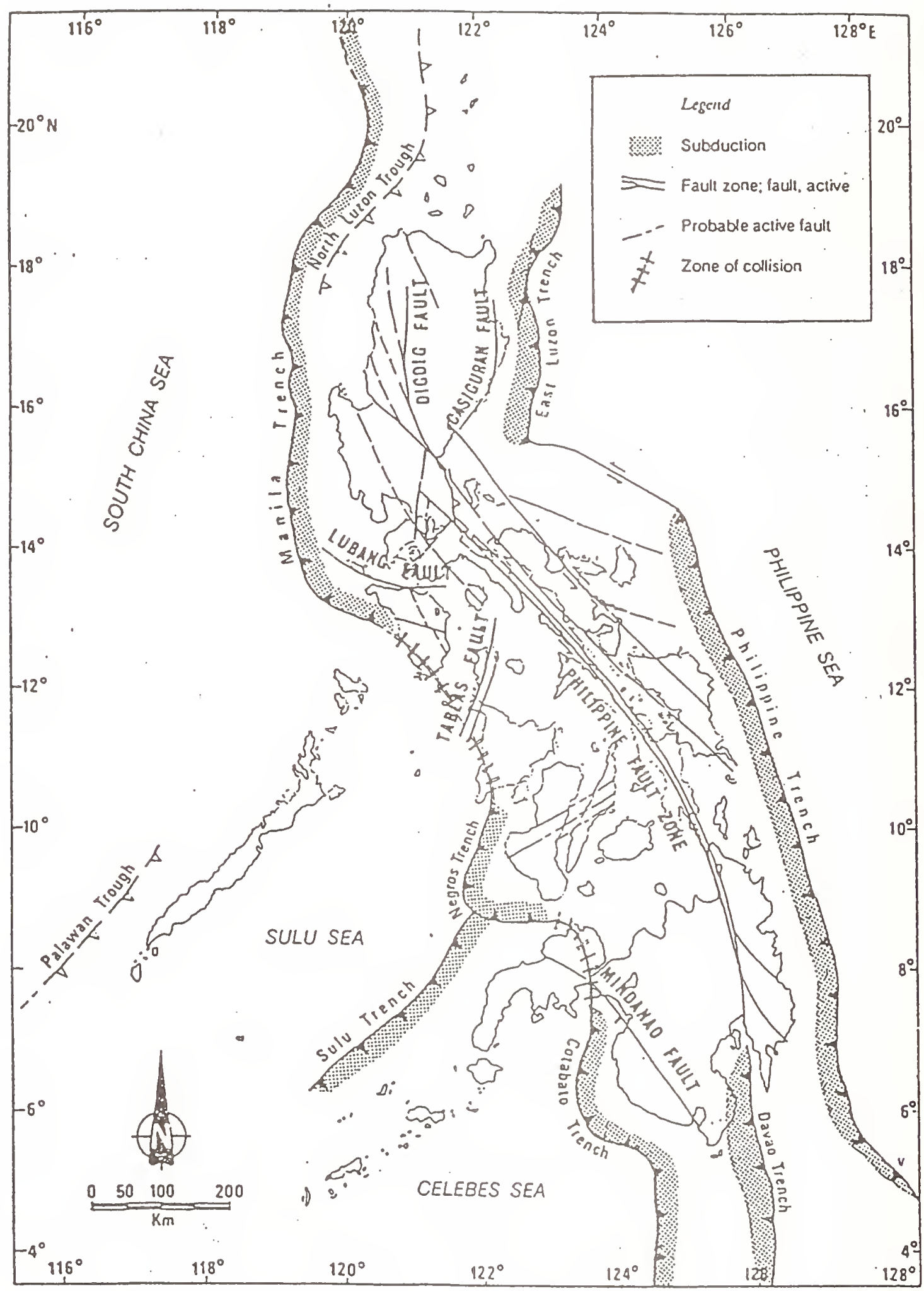

Fig. 2.1 Trenches and Major Active Faults in the Philippines and its surroundings 


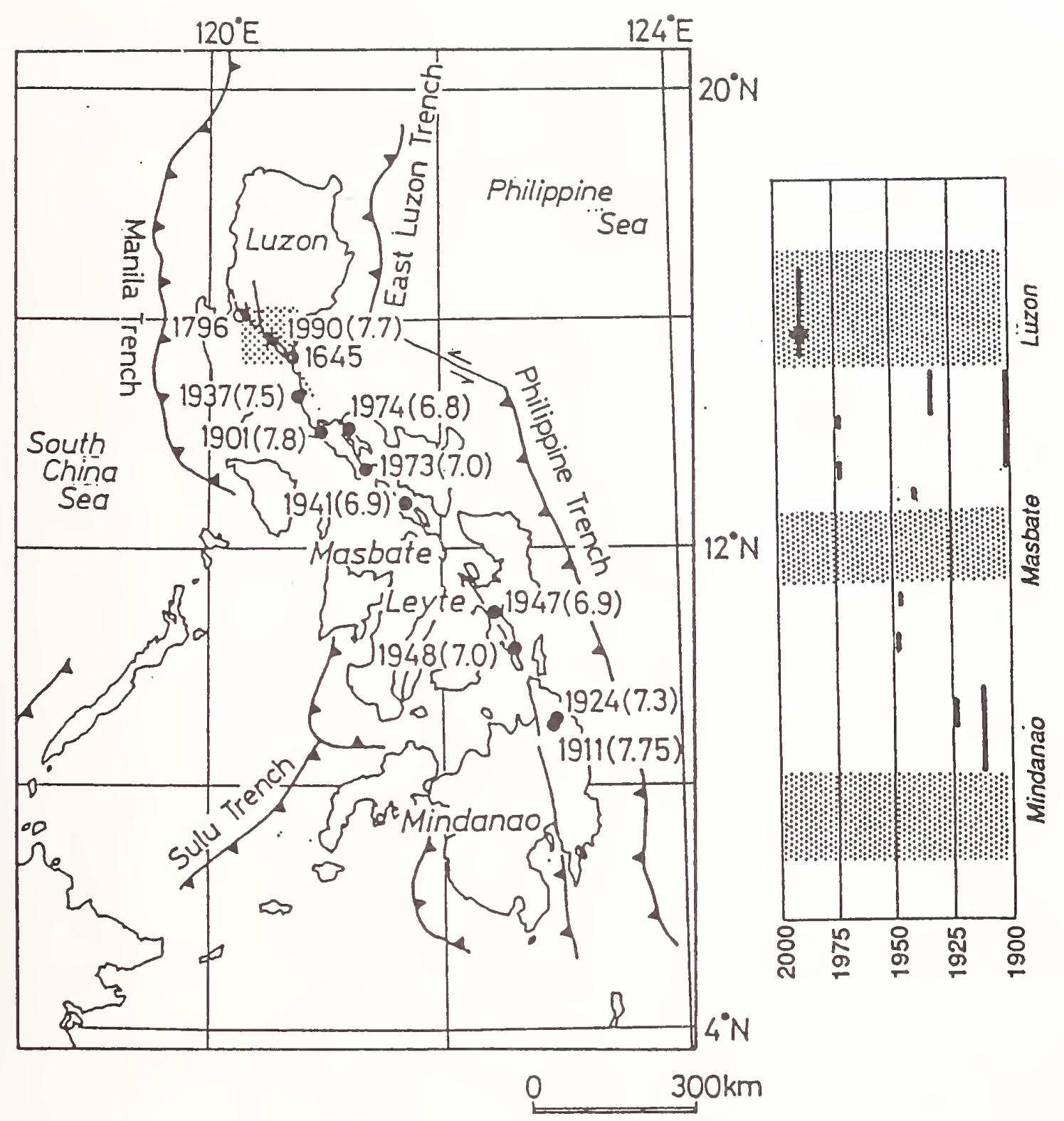

Fig. 2. 2 Major Earthquakes along the Philippine Fault and Seismic Gaps along the Fault (After Nakata et.al) 


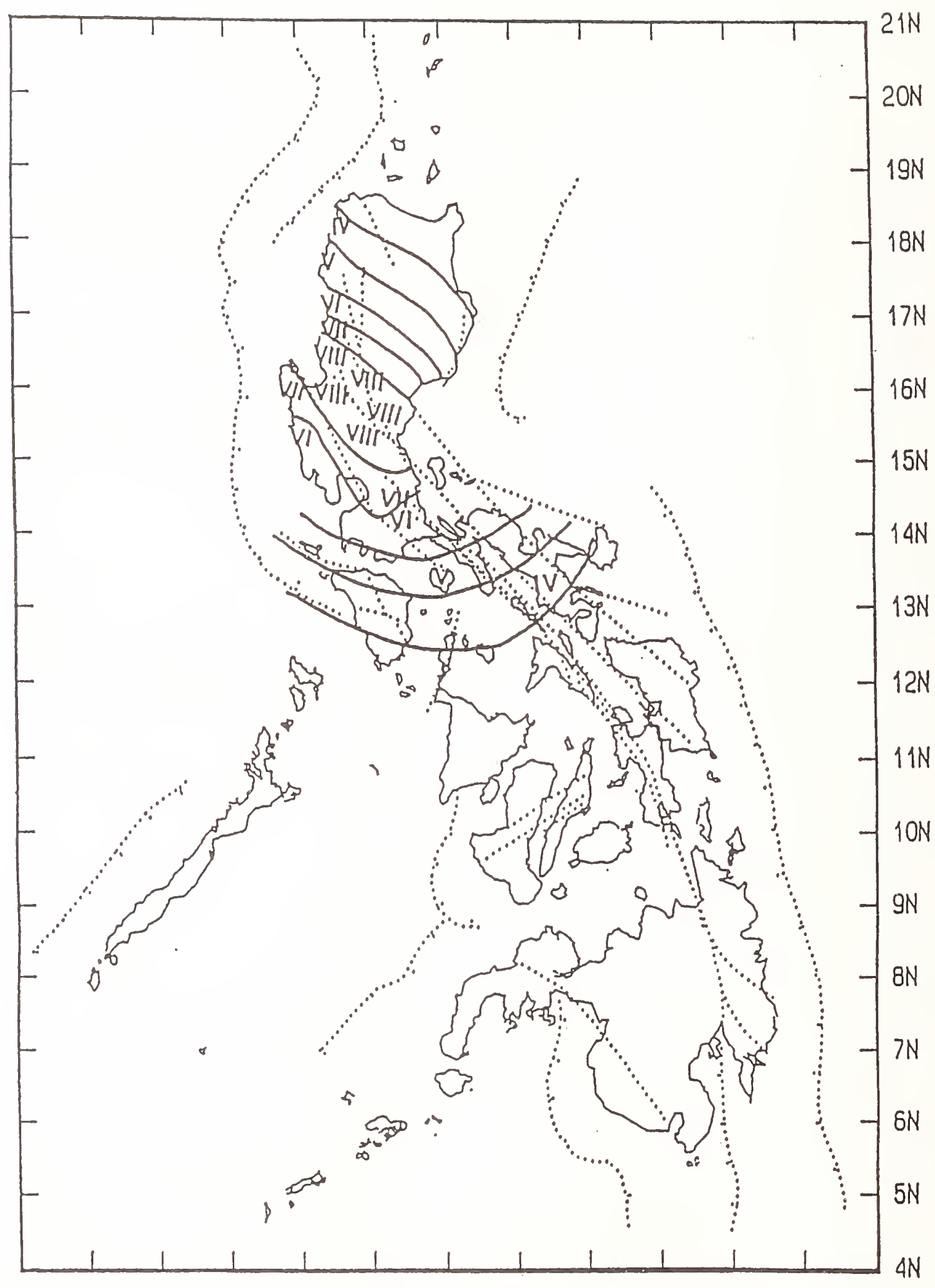

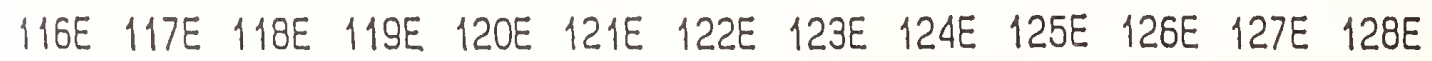

Fig. 2. 3 Seismic Intensity Distribution 


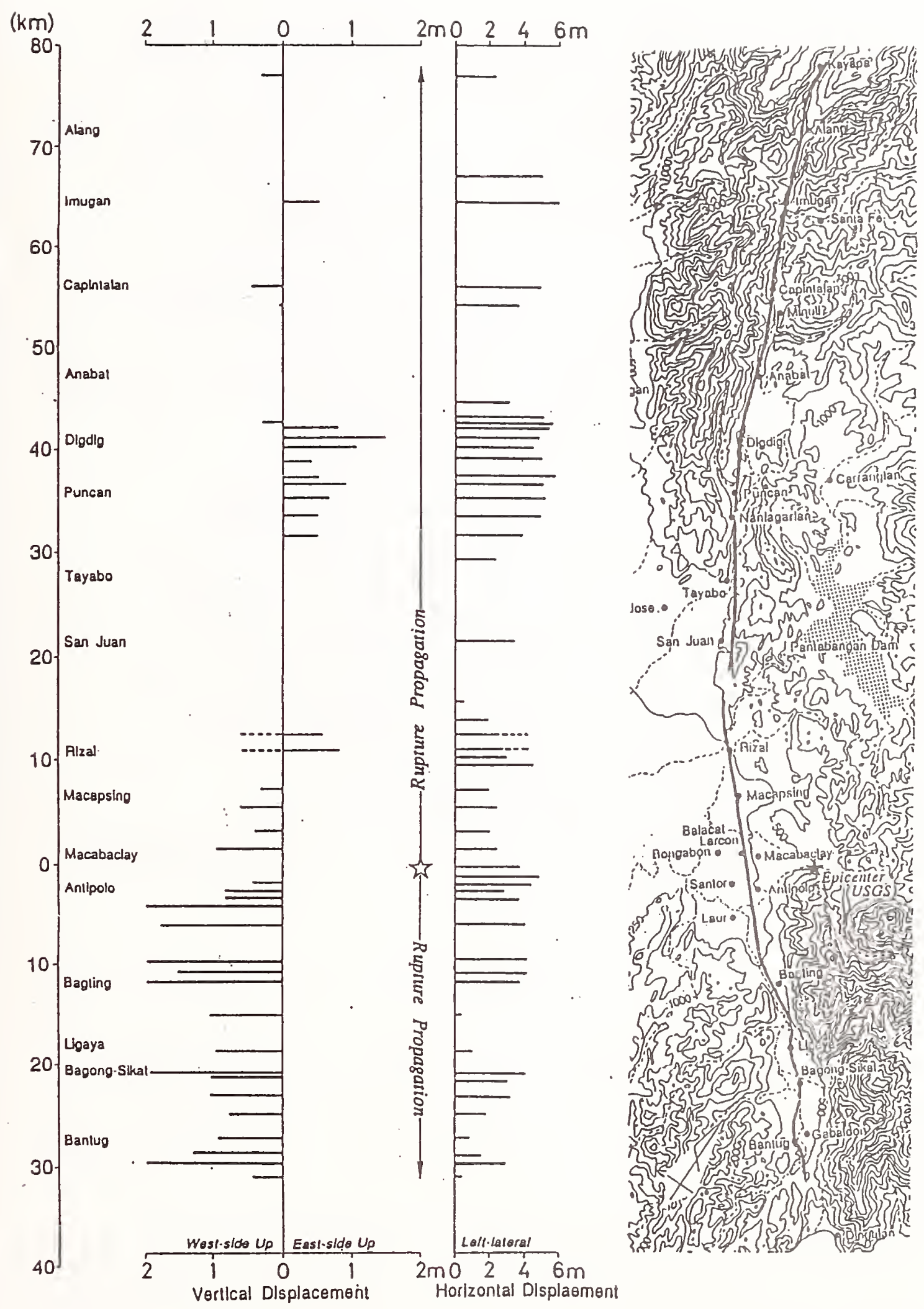

Fig. 2.4 Displacements along the Fault Caused

by the 1991 July Earthquake 


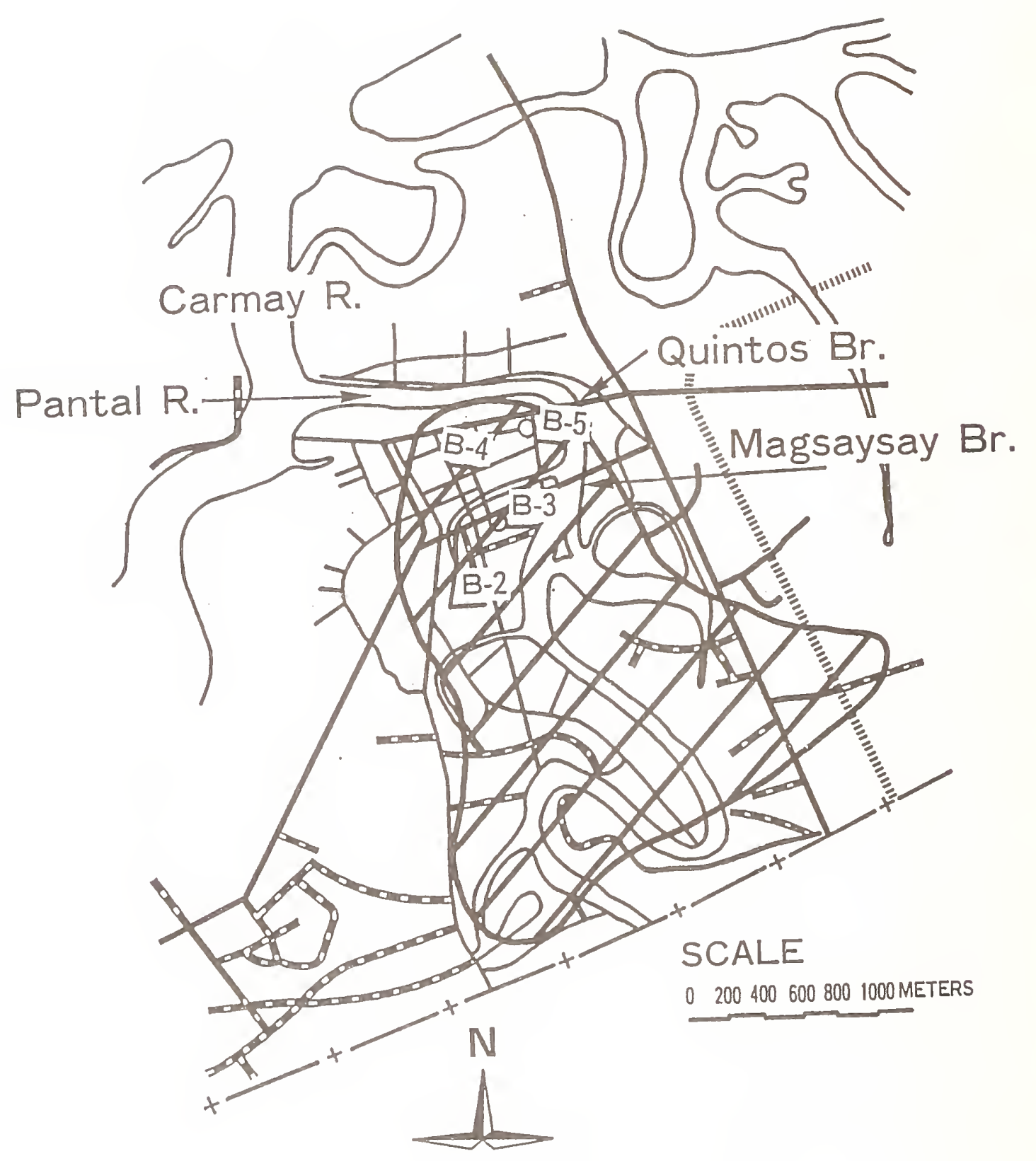

Fig. 3.1 Damaged Area of Dagupan City due to Liquefaction 


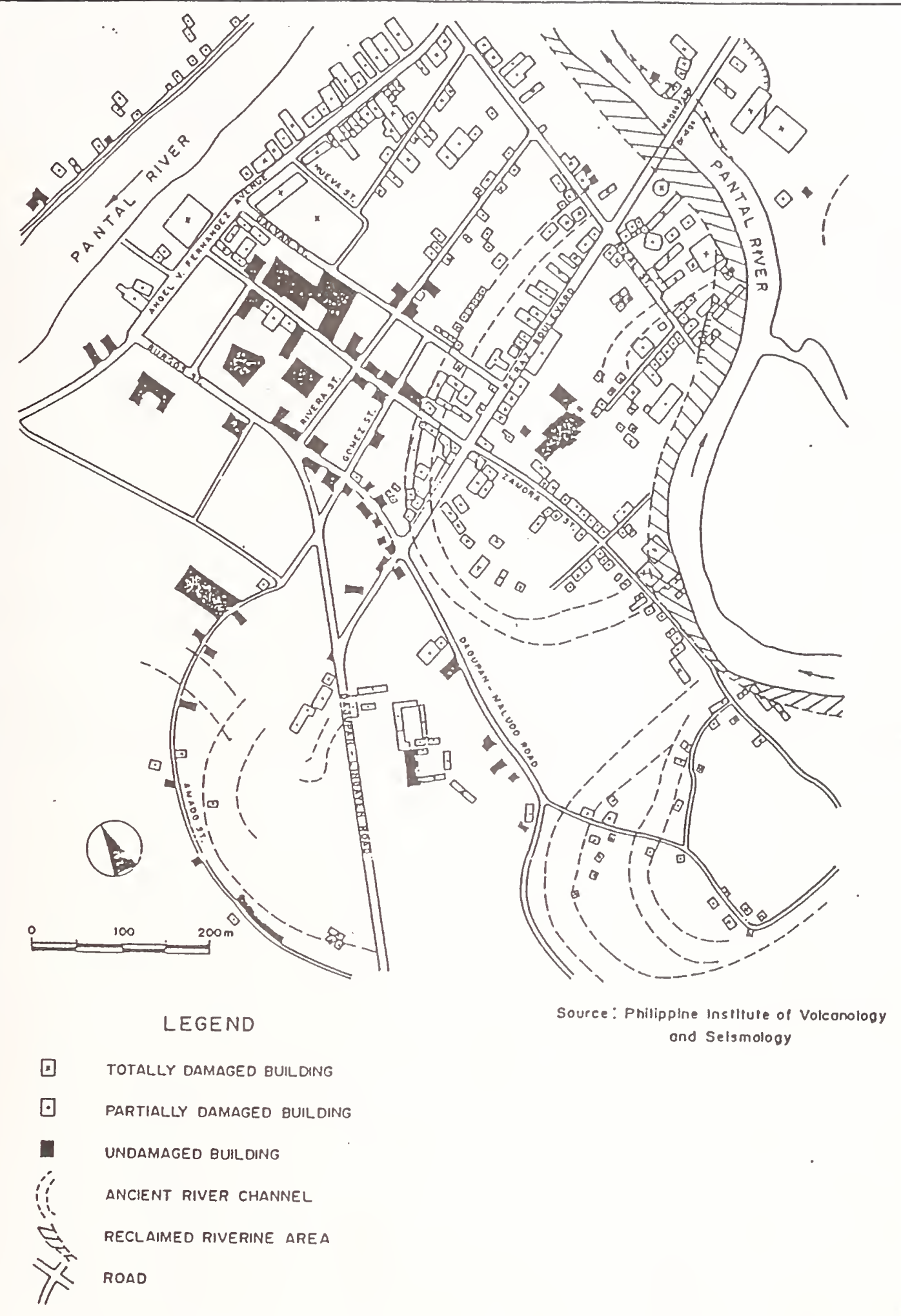

Fig. 3. 2 Affected Buildings in Central Area of Dagupan City 
Table 4.1 Outline of Damage (Number of Damaged Places)

\begin{tabular}{|c|c|c|c|c|c|c|c|c|}
\hline \multirow[t]{2}{*}{ Saction } & \multicolumn{3}{|c|}{ Cut slope } & \multicolumn{2}{|c|}{ Bank slope } & \multicolumn{2}{|c|}{ Pavement } & \multirow[t]{2}{*}{ - Others } \\
\hline & Large & Med. & Small & $\operatorname{Lag} g \theta$ & Small & $\begin{array}{l}\text { Theust } \\
\text { up }\end{array}$ & Paults & \\
\hline$\left\{\begin{array}{l}\operatorname{Rms} 160 \text { (San Jose) } \\
\text { to } \operatorname{Rms} 183 \text { (DIgdIg) }\end{array}\right.$ & 36 & $10^{\circ}$ & 10 & 3 & 6 & 12 & 9 & $\begin{array}{l}\text { Yud flow } \\
\text { Accumulation of } \\
\text { deifting wood }\end{array}$ \\
\hline $\begin{array}{l}\text { Rms } 183(D \perp g d 1 g) \\
\text { to } \operatorname{Rms~} 200\end{array}$ & 51 & 9 & 2 & 3 & 5 & 8 & 2 & $\begin{array}{l}\text { Mud flow } \\
\text { Drifting wood }\end{array}$ \\
\hline $\begin{array}{l}\text { Rms } 200 \\
\text { to Kms } 208 \text { (Dalton) }\end{array}$ & 30 & 34 & 15 & 5 & 21 & 3 & 2 & . \\
\hline $\begin{array}{l}\operatorname{Rms} 208 \text { (Dalton) } \\
\text { to } \operatorname{Rms} 215 \text { (Sta. Be) }\end{array}$ & 18 & 7 & 37 & 3 & 6 & 2 & & \\
\hline $\begin{array}{l}\text { Xms } 215 \text { (Sta. Pe) } \\
\text { to } \operatorname{Rms} 236 \text { (Arttao) }\end{array}$ & 11 & & 11 & 1 & 12 & & & - \\
\hline Total & 28 & $\begin{array}{l}60 \\
1 \mathrm{plac}\end{array}$ & 75 & $\begin{array}{l}15 \\
65\end{array}$ & $\begin{array}{r}50 \\
2 \cos s\end{array}$ & 26 & 13 & \\
\hline
\end{tabular}

Note: Cut slope; Large: more than $30 \mathrm{~m}$ of slope height Medium: 15 to $30 \mathrm{~m}$ Small: less than $15 \mathrm{~m}$

Bank slope; Large: collapse from the boundary of the cut-bank Small: shoulder settlement 

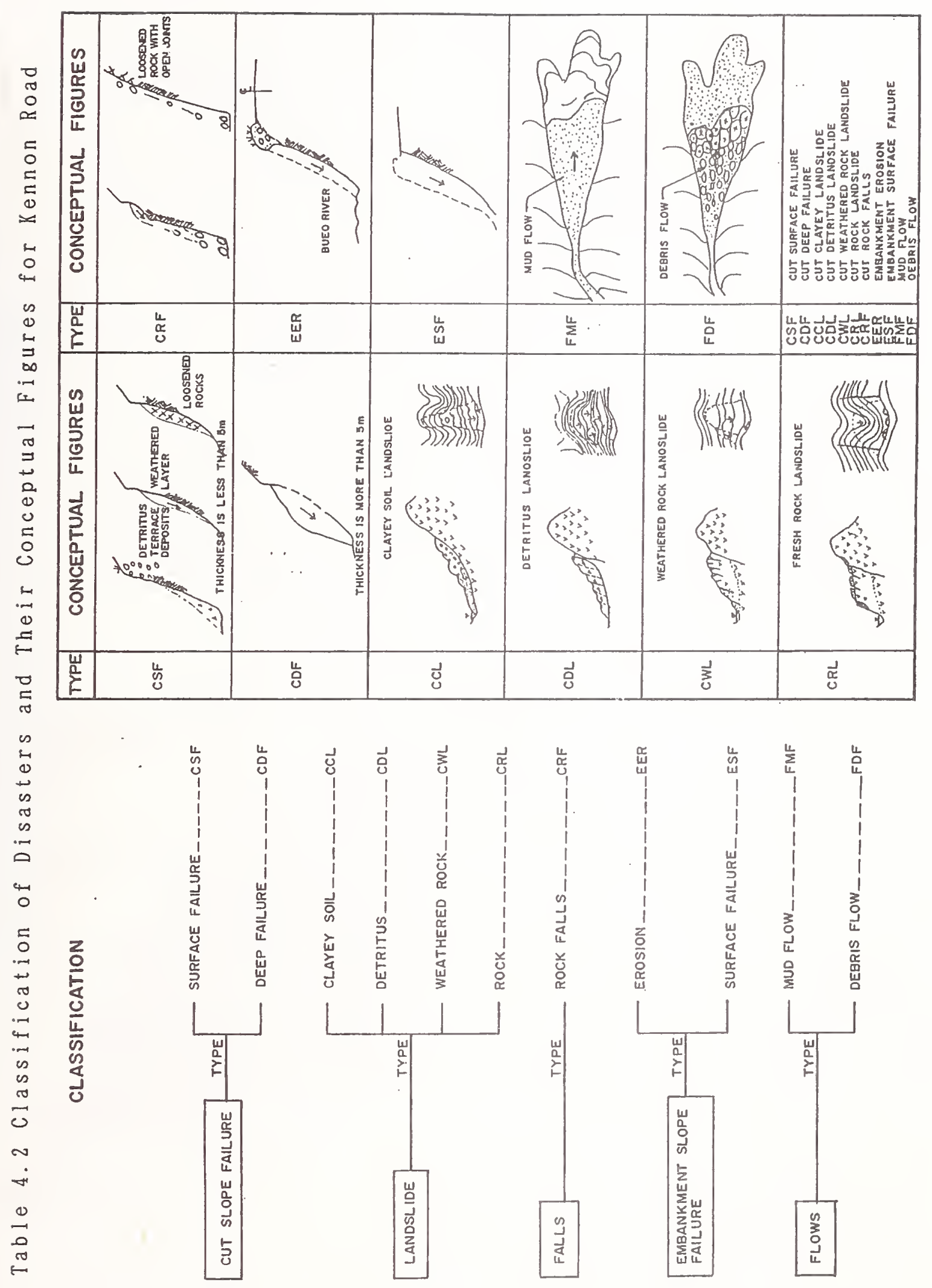

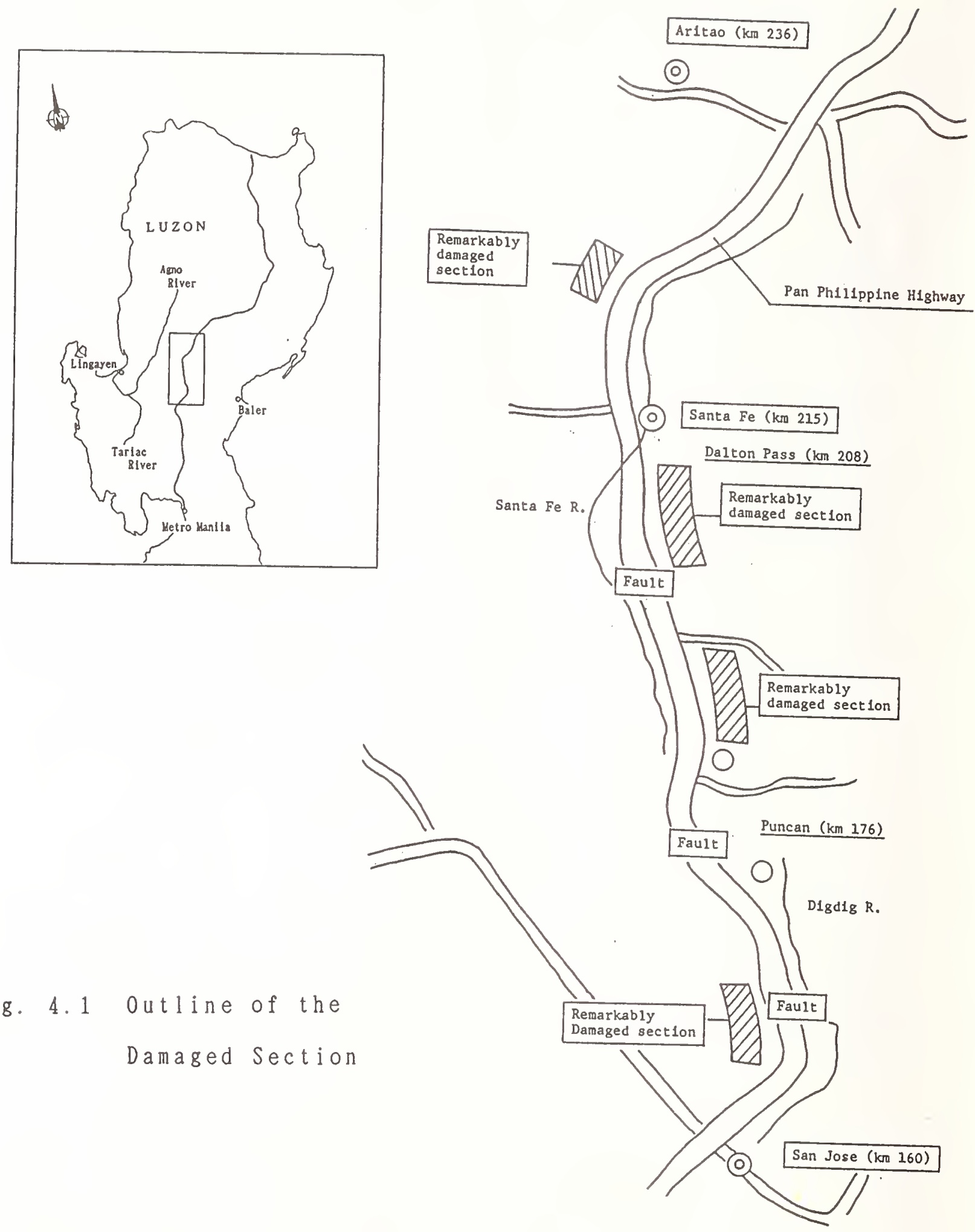

Fig. 4.1 outline of the

Damaged Section 


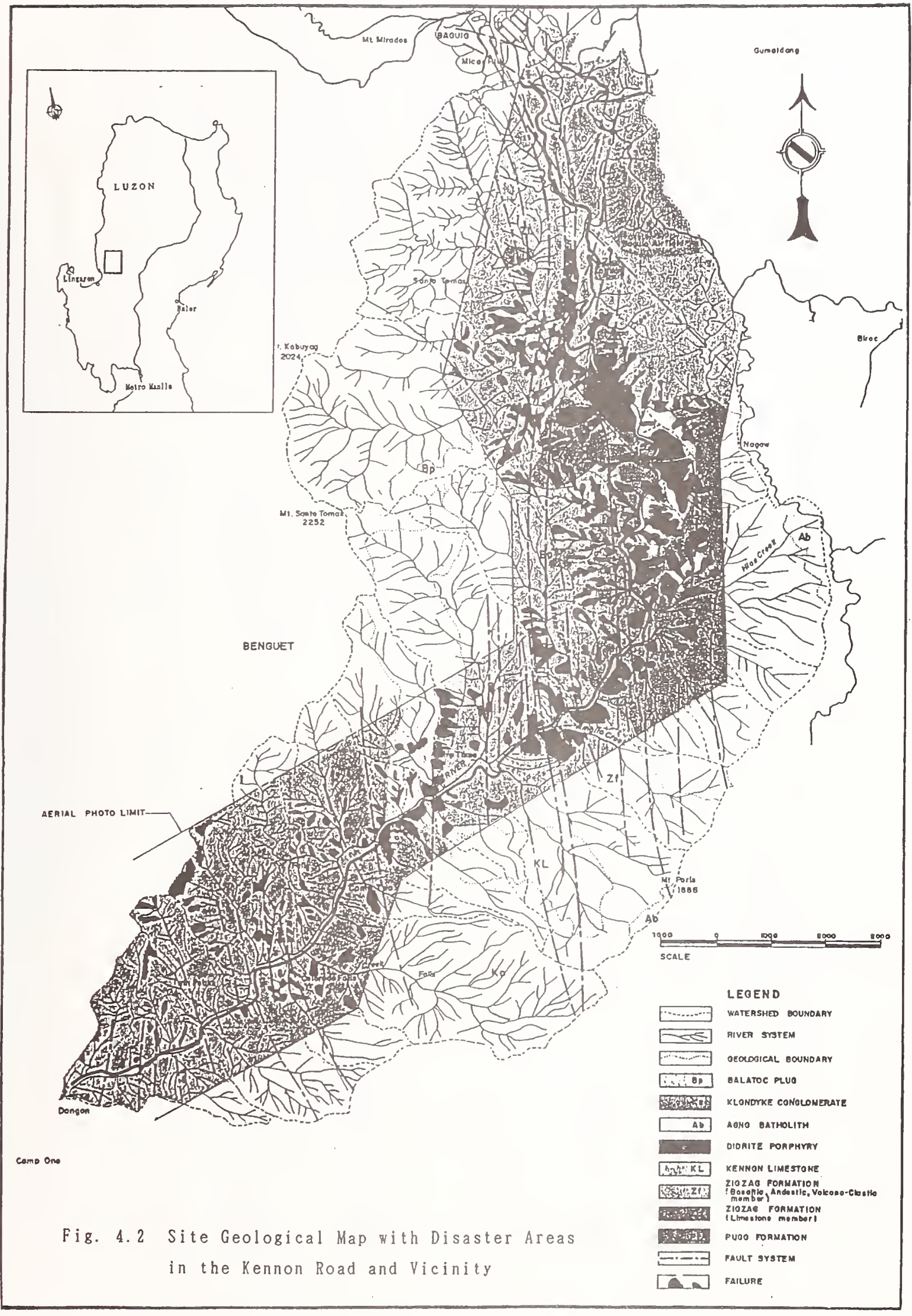




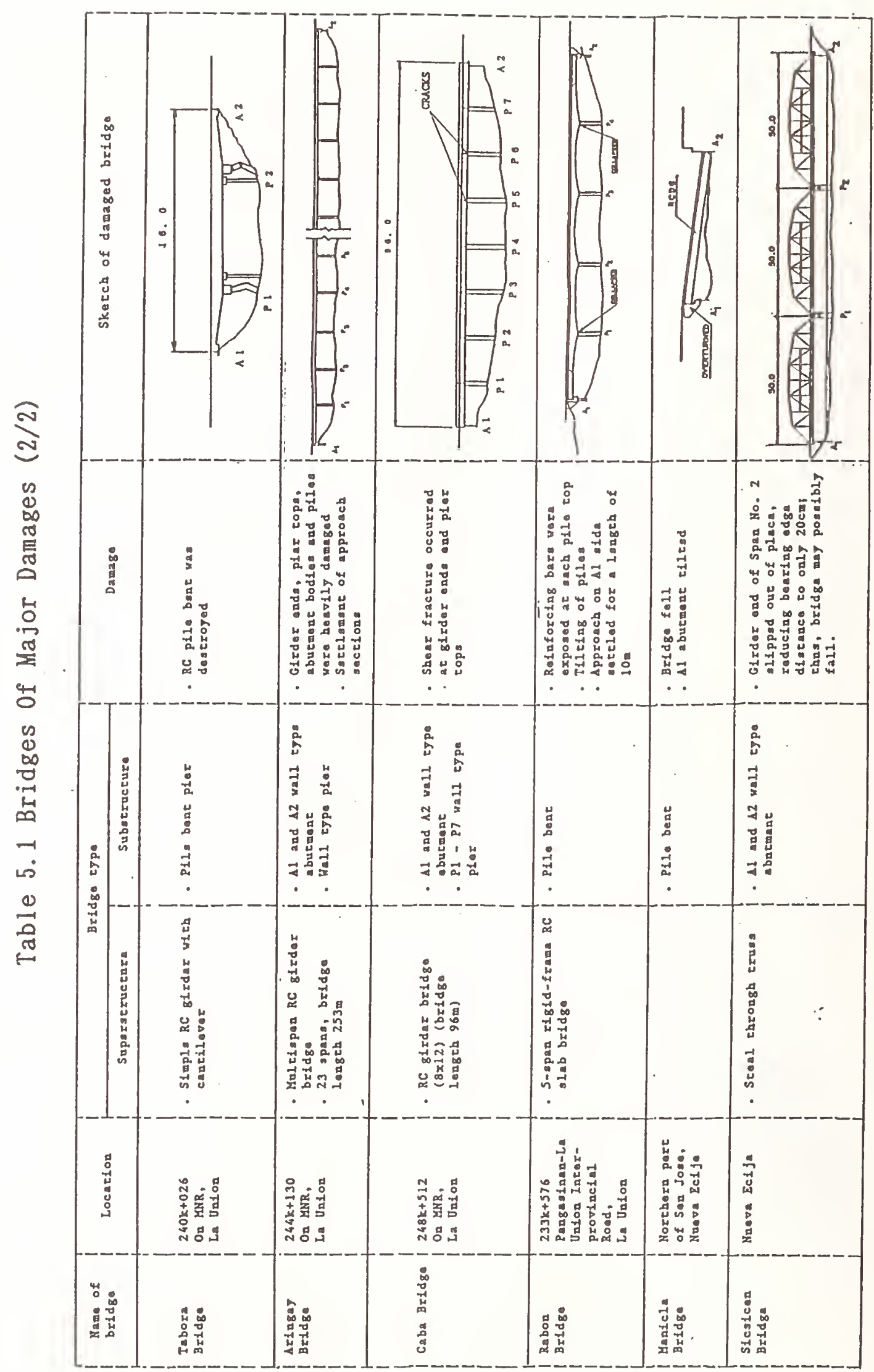




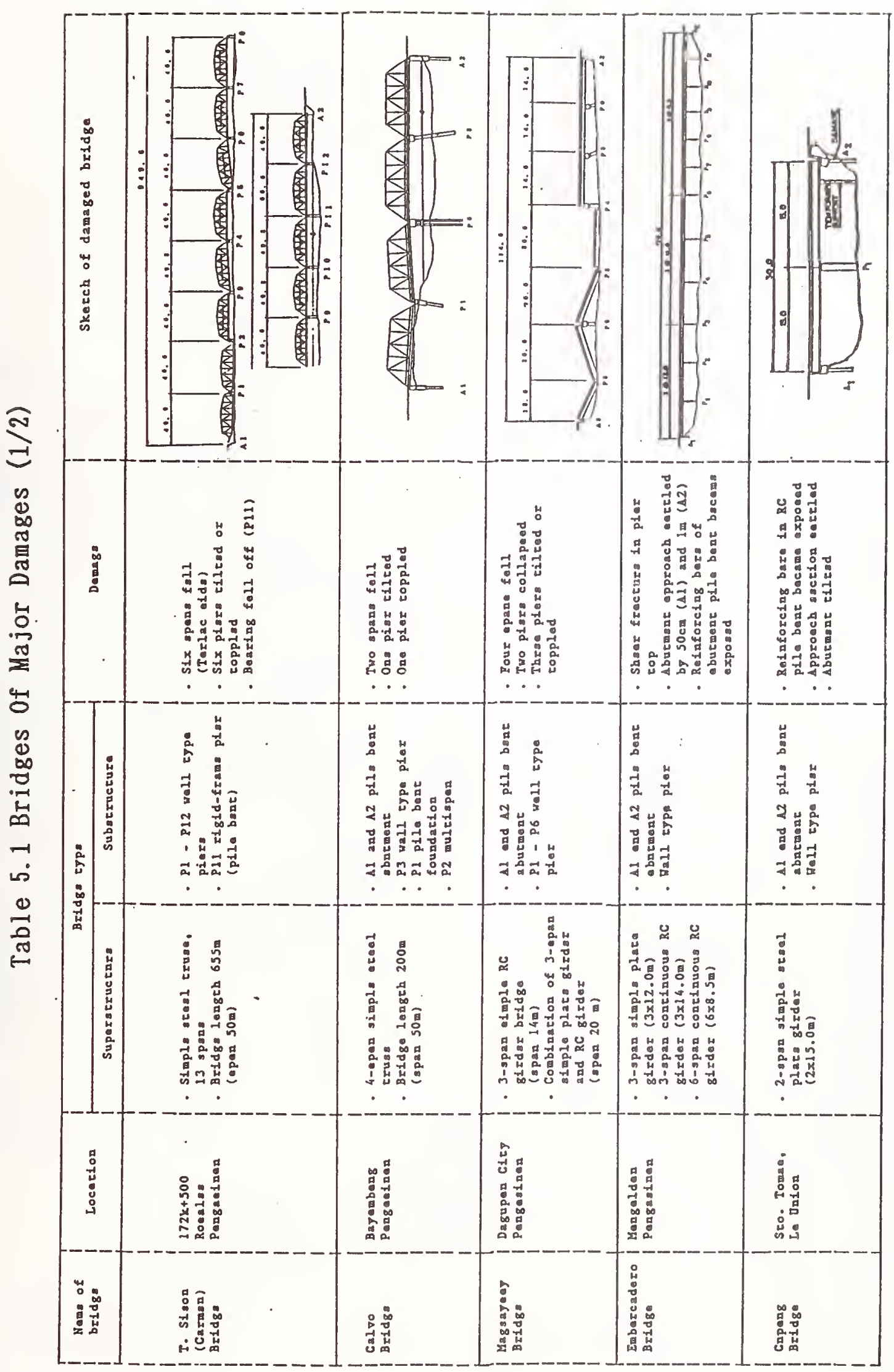




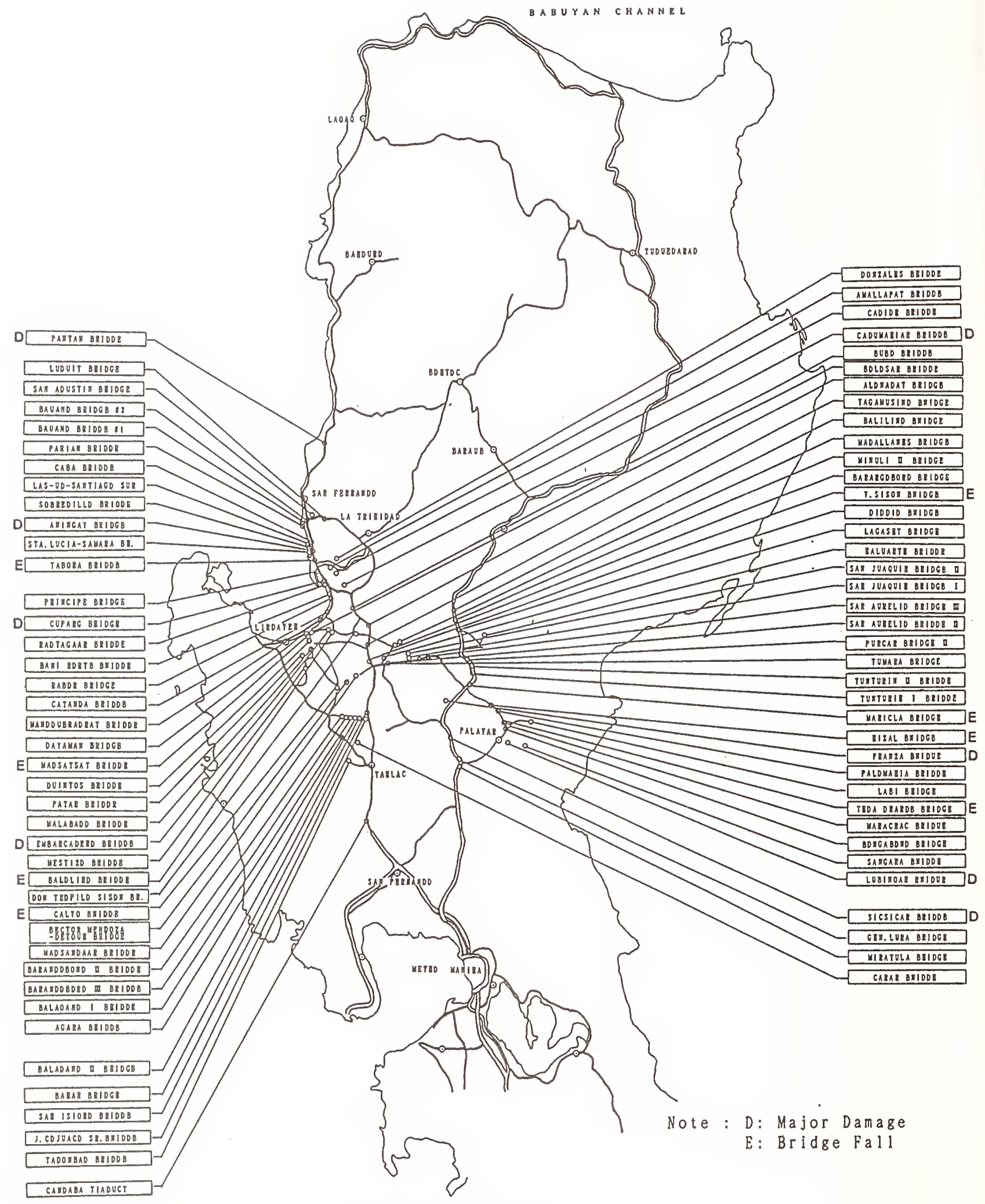

Fig. 5. 1 Location of Damaged Bridges 

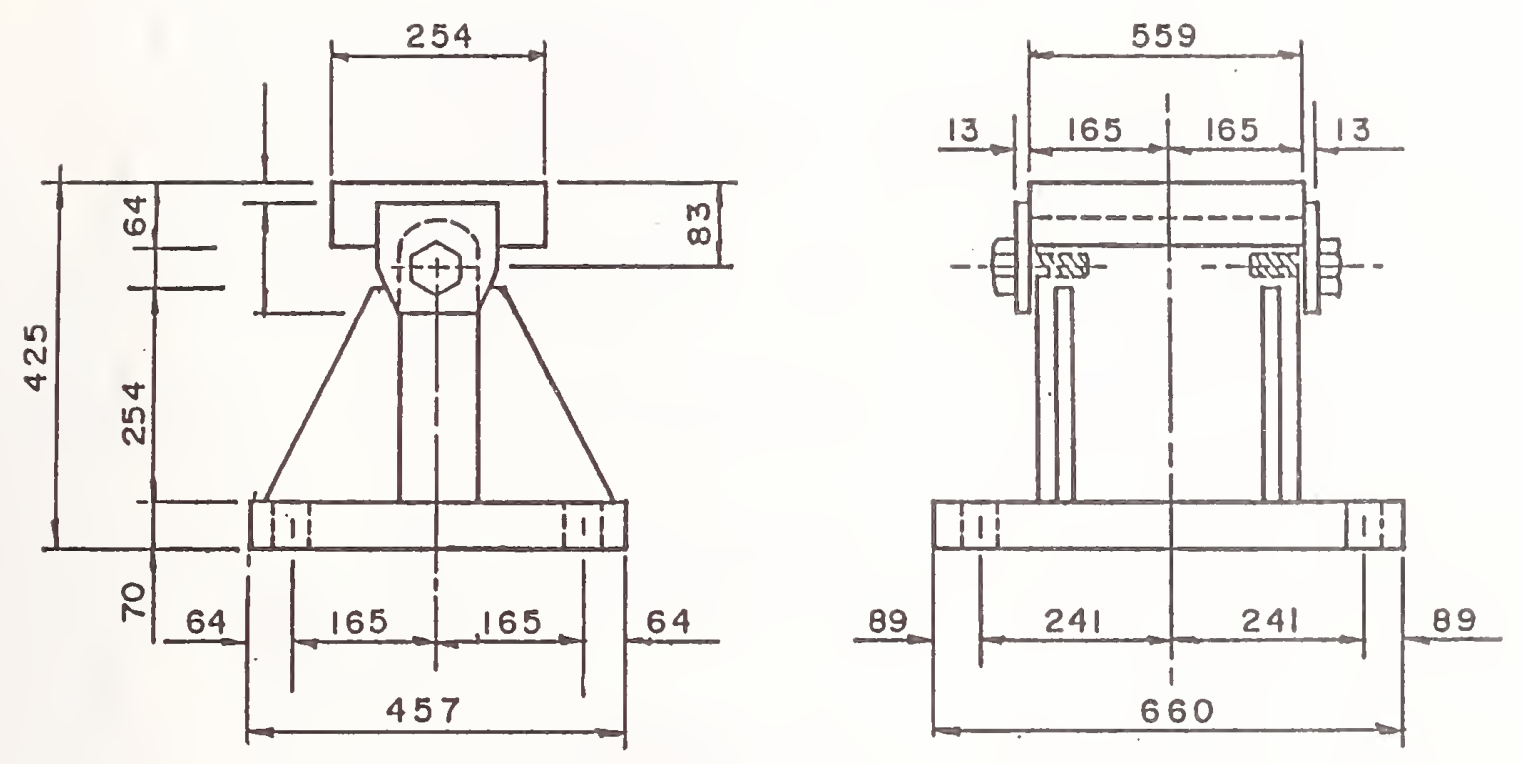

(a) Fixd Bearing
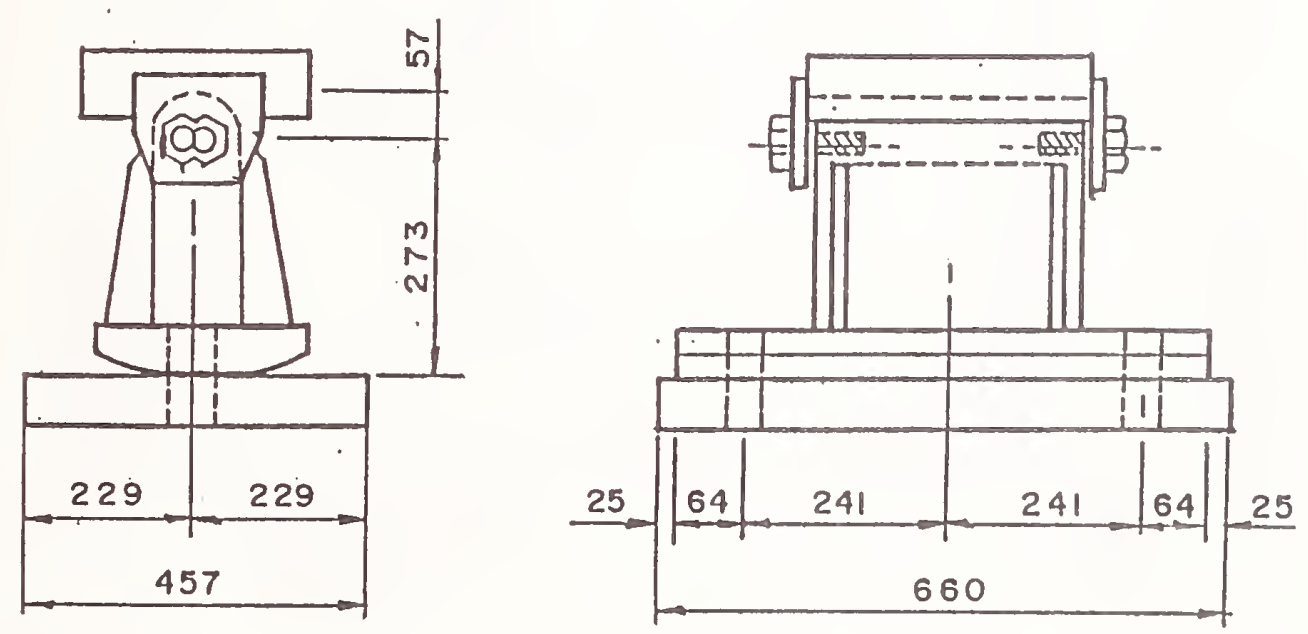

(b) Movable Bearing

F i g. 5. 2 B e a r i n g D e $t$ a i 1 s 


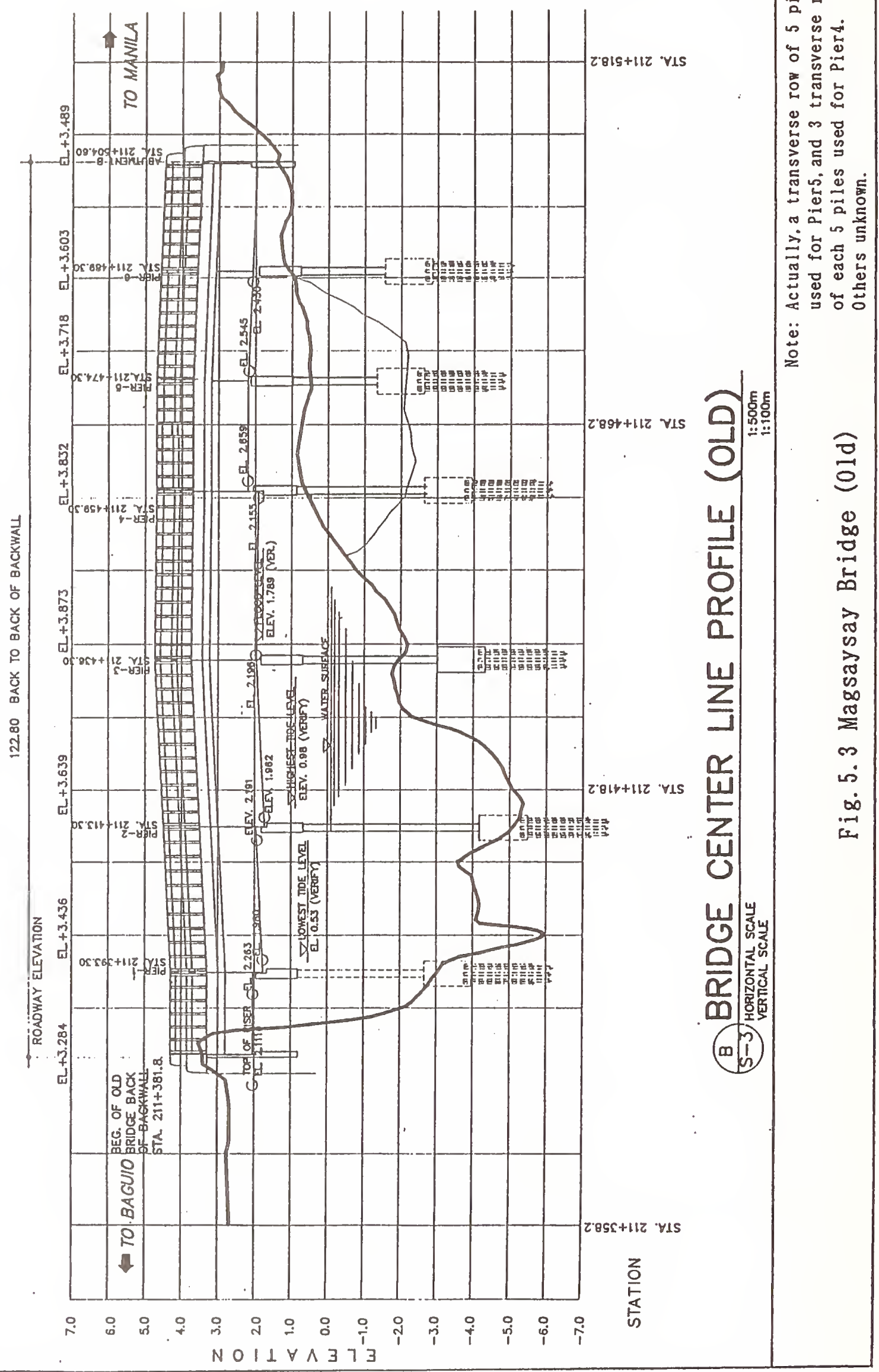




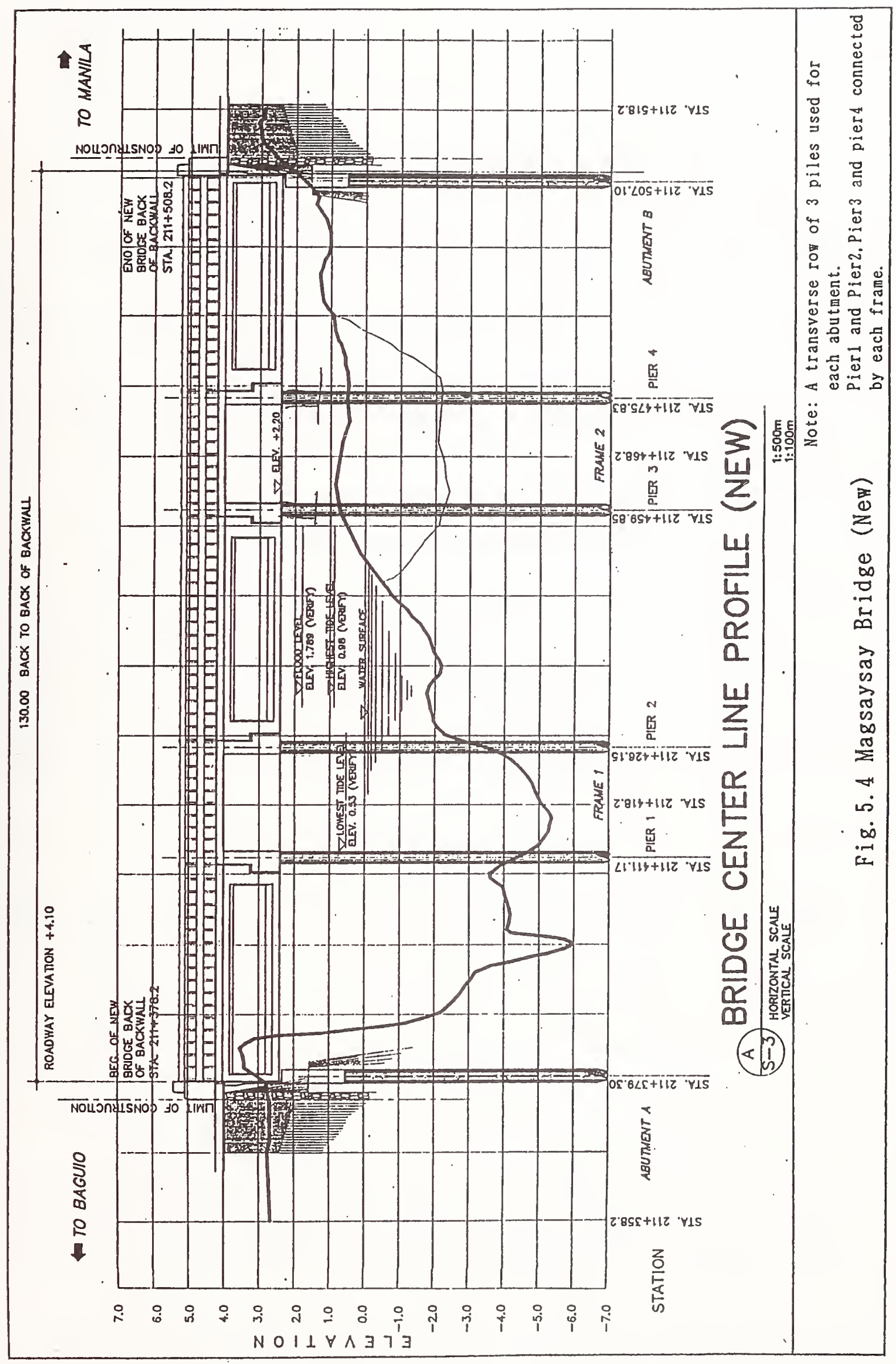




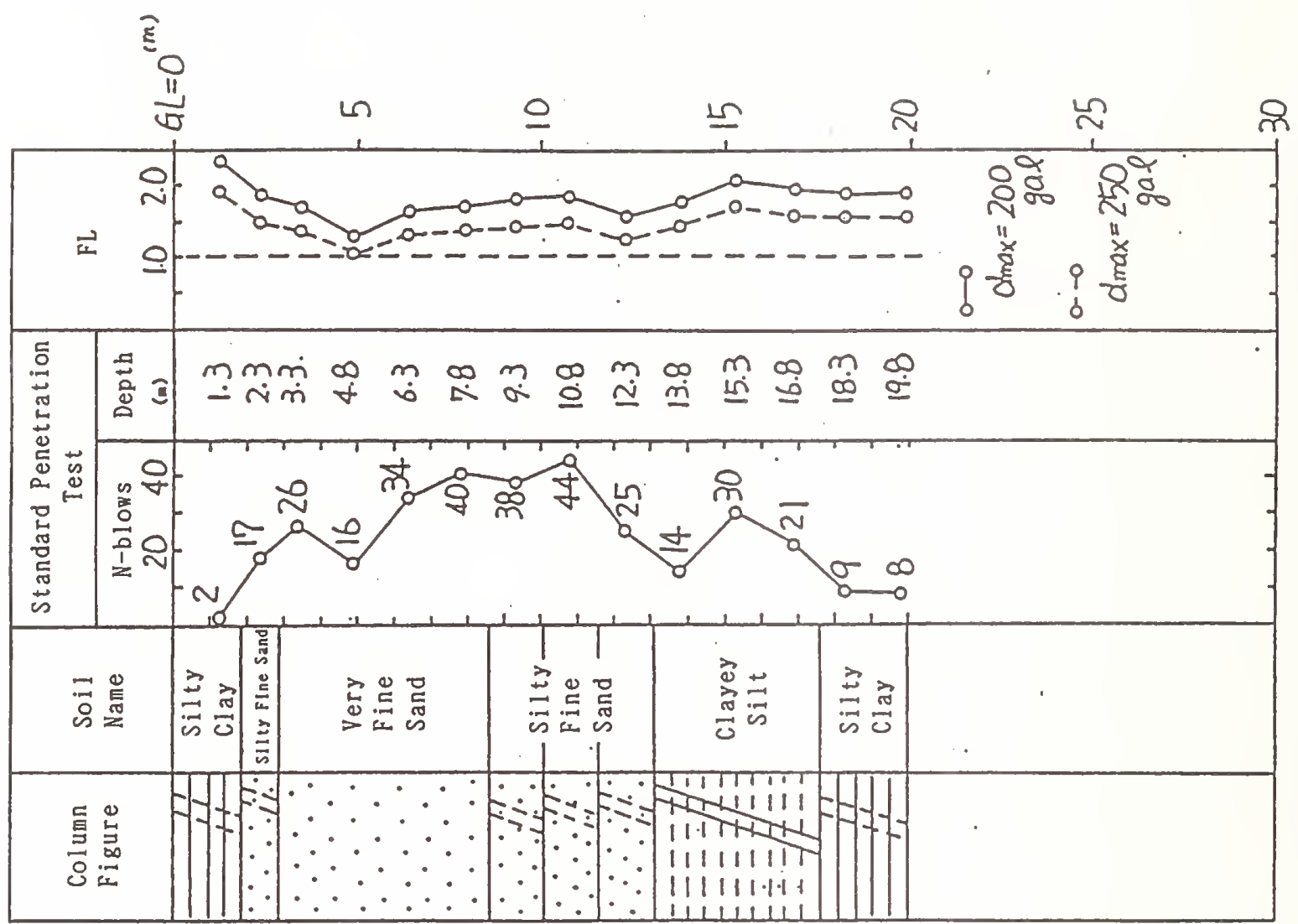

(a)

(a)

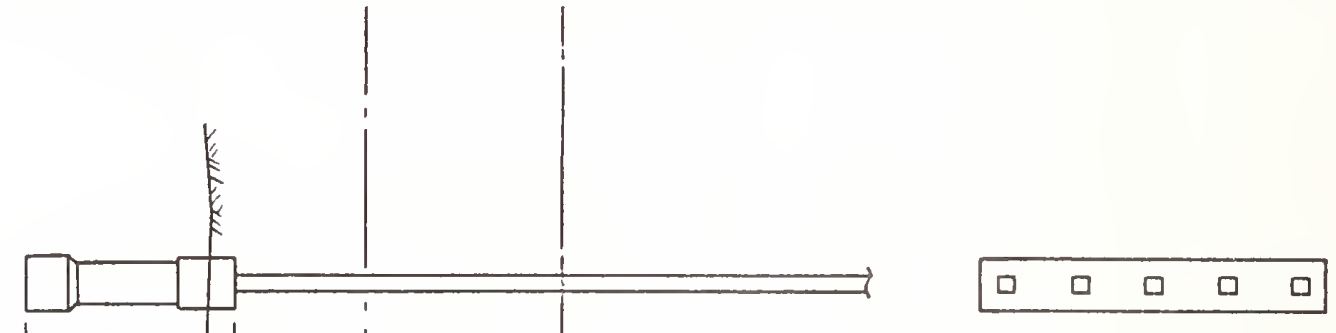

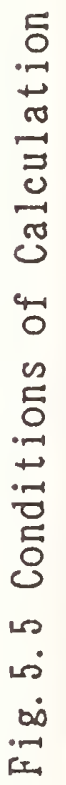




\section{P i e r 5}
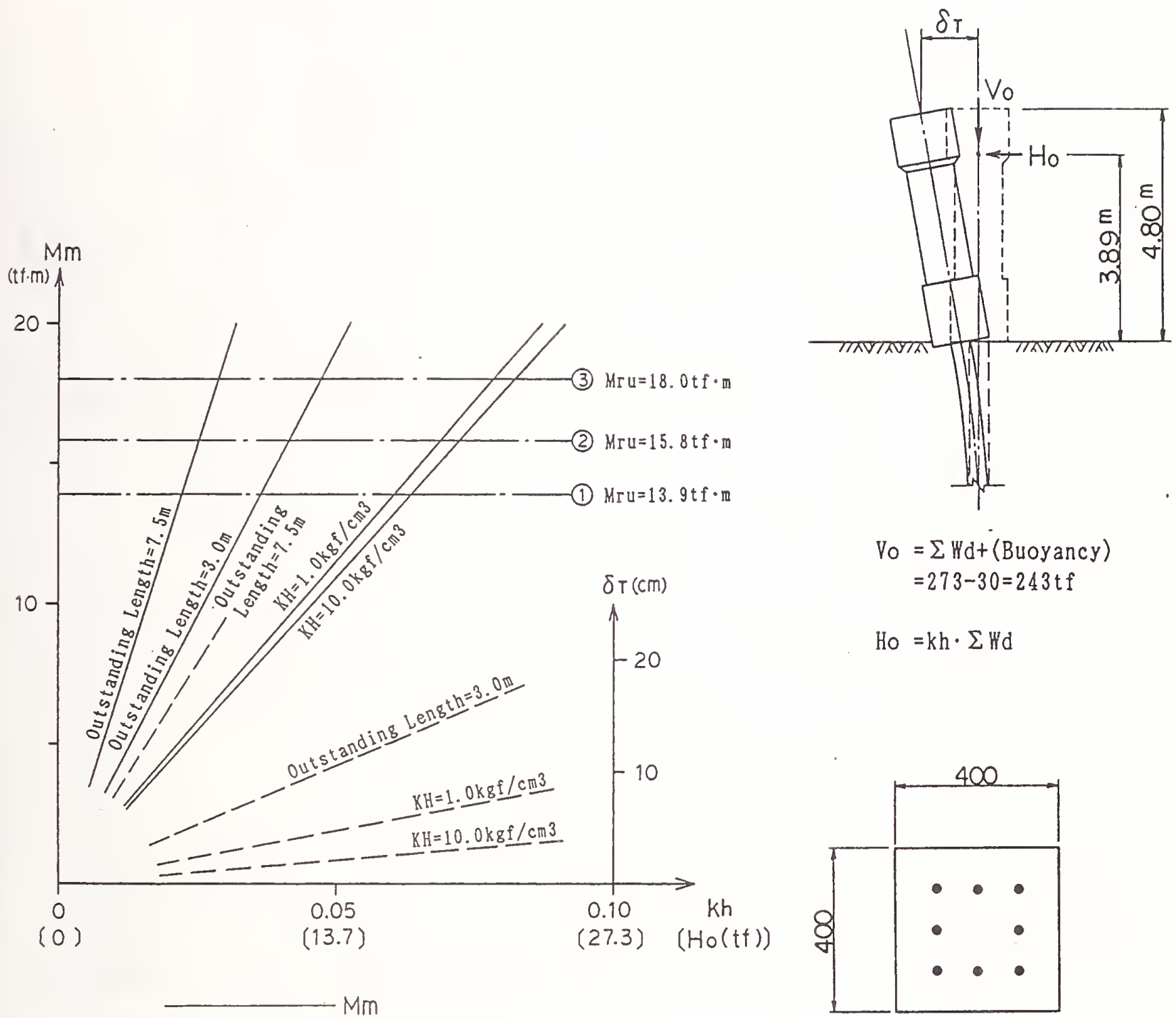

Assumed Pile Section

kh : Seismic Intensity Equivalent

to Horizontal Force Due to Earthquake

$\mathrm{Mm}$; Calculated Maximum Bending

Moment of a Pile

Mru;Ultimate Bending Moment Capacity

of a Pile Determined by Pile Section

$\delta T ; C a l c u l a t e d$ Displacement at the Pier Top

Calculation Cases of Reinforcing Steels

$\mathrm{KH}$;Assumed Lateral Ground Constant

(1) $8 * D 19=22.9 \mathrm{~cm} 2$

(2) $8 * \mathrm{D} 22=31.0 \mathrm{~cm} 2$

(3) $8 * D 25=40.5 \mathrm{~cm} 2$

Fig. 5.6 Relationship between the Lateral Resistance of a Pile and Effect of Seismic Force in Case of Pier 5 


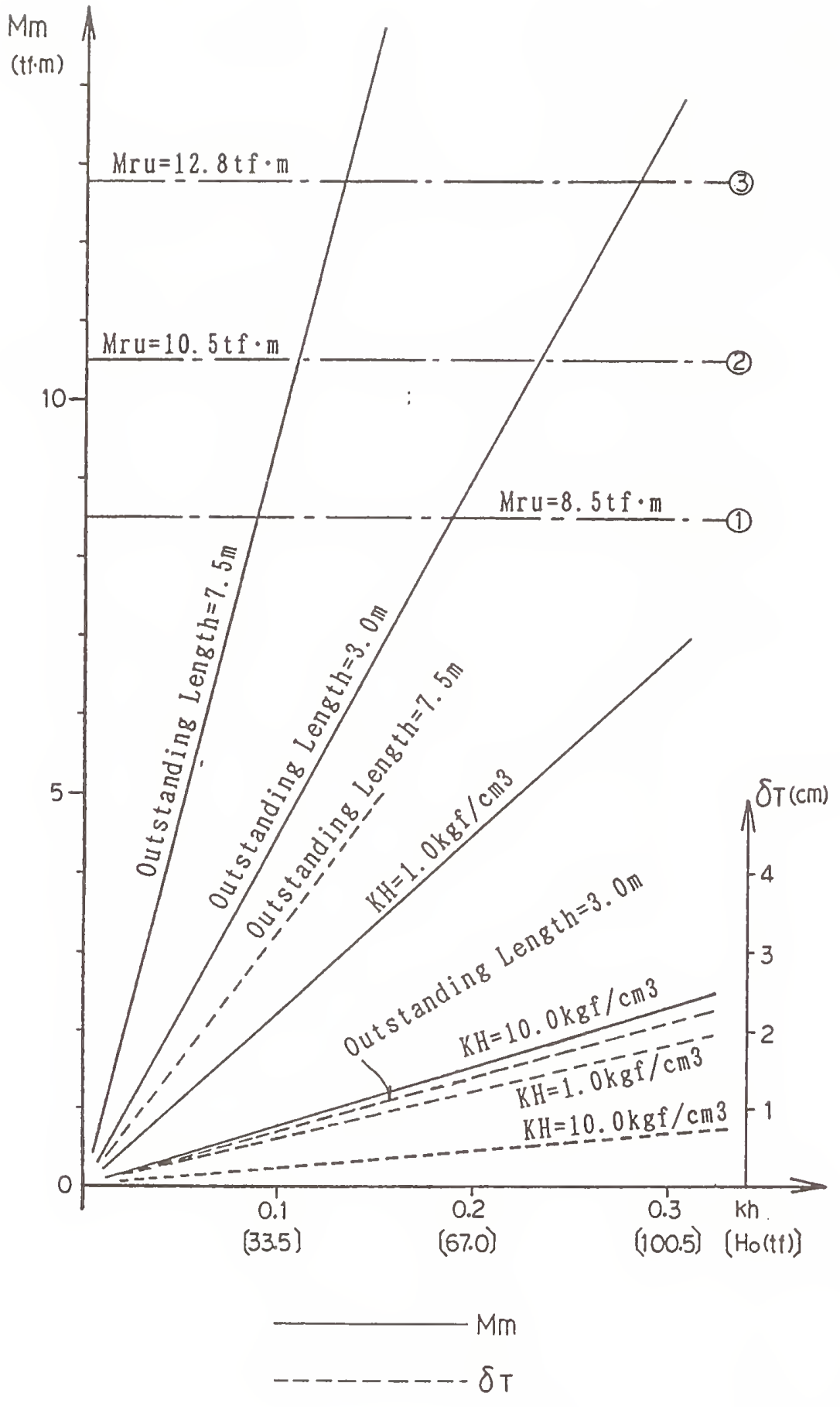

kh ; Seismic Intensity Equivalent

to Horizontal Force Due to Earthquake

Mm ; Calculated Maximum Bending

Moment of a Pile

Mru;Ultimate Bending Moment Capacity

of a Pile Determined by Pile Section

$\delta T$ :Calculated Displacement at the Pier Top

KH ; Assumed Lateral Ground Constant

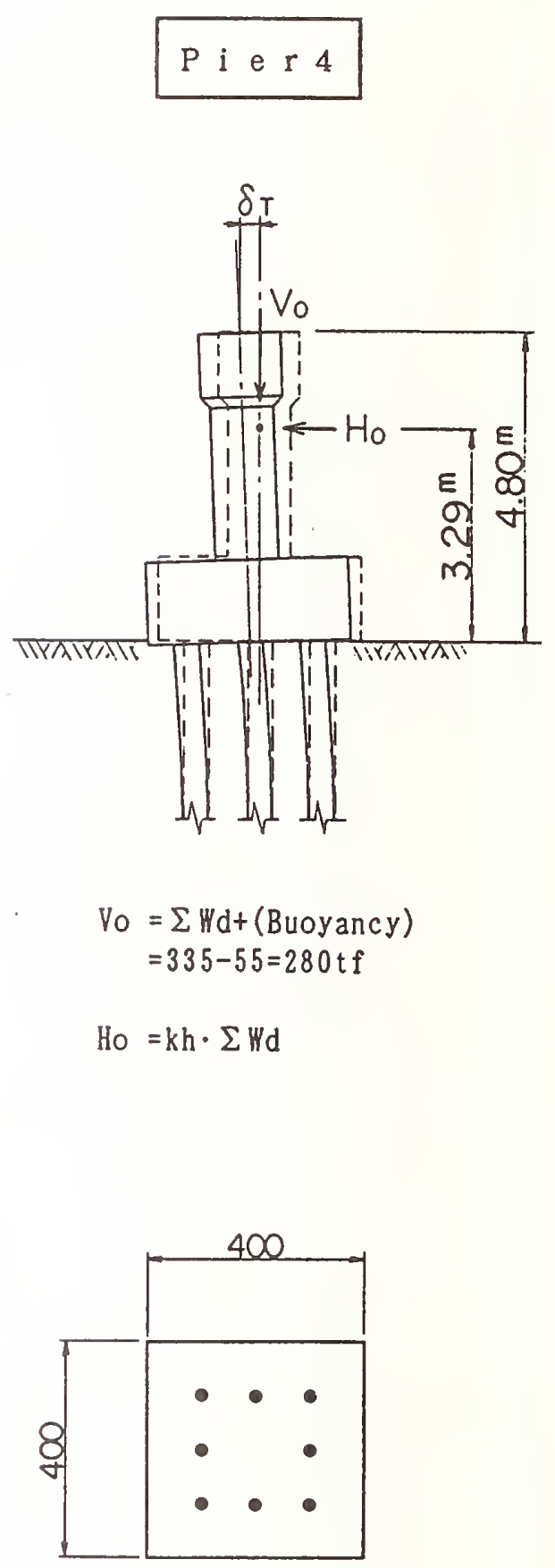

Assumed Pile Section
Calculation Cases of Reinforcing Steels

(1) $8 * 019=22 \cdot 9 \mathrm{~cm} 2$

(2) $8 * D 22=31.0 \mathrm{~cm} 2$

(3) $8 * D 25=40.5 \mathrm{~cm} 2$

Fig. 5.7 Relationship between the Lateral Resistance of a Pile and Effect of Seismic Force in Case of Pier 4 


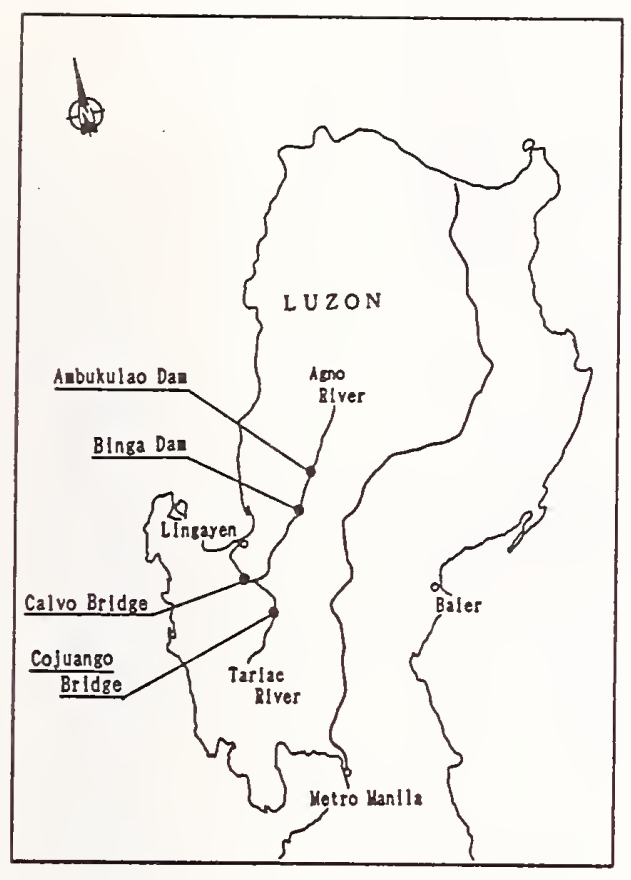

Fig. 6.1 Location of Damages to Rivers and Dams

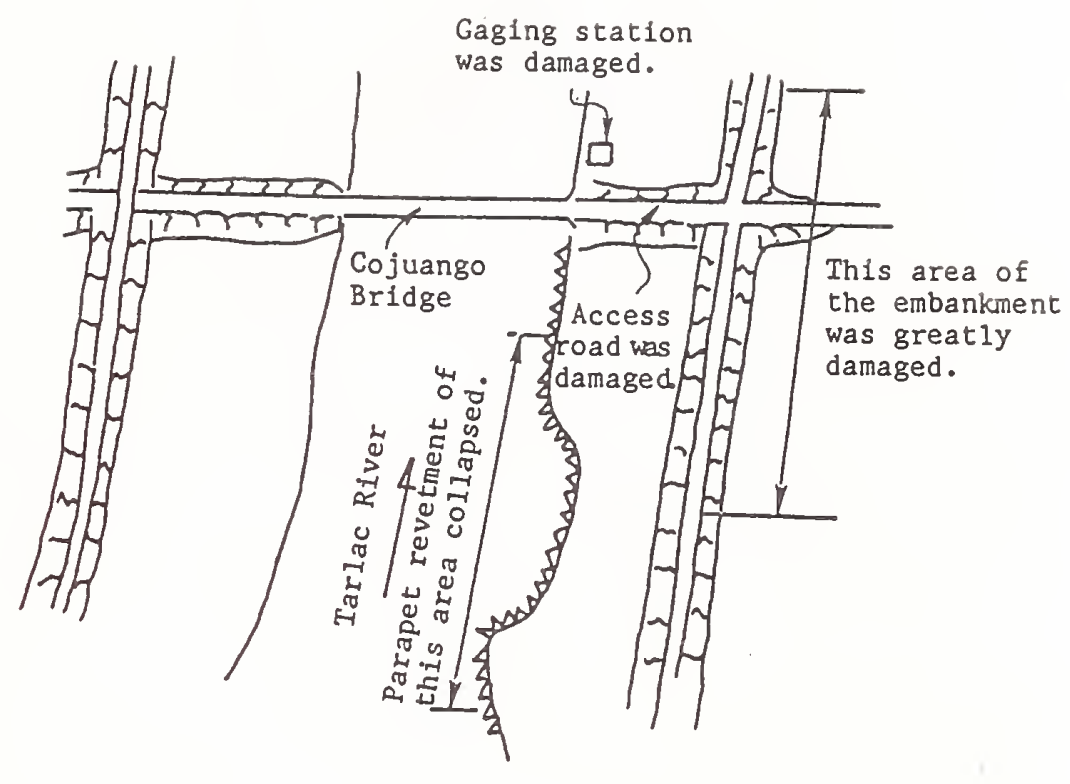

Fig. 6.2 Damaged Site of Tarlac River

Agno River (low flow channel located far away)

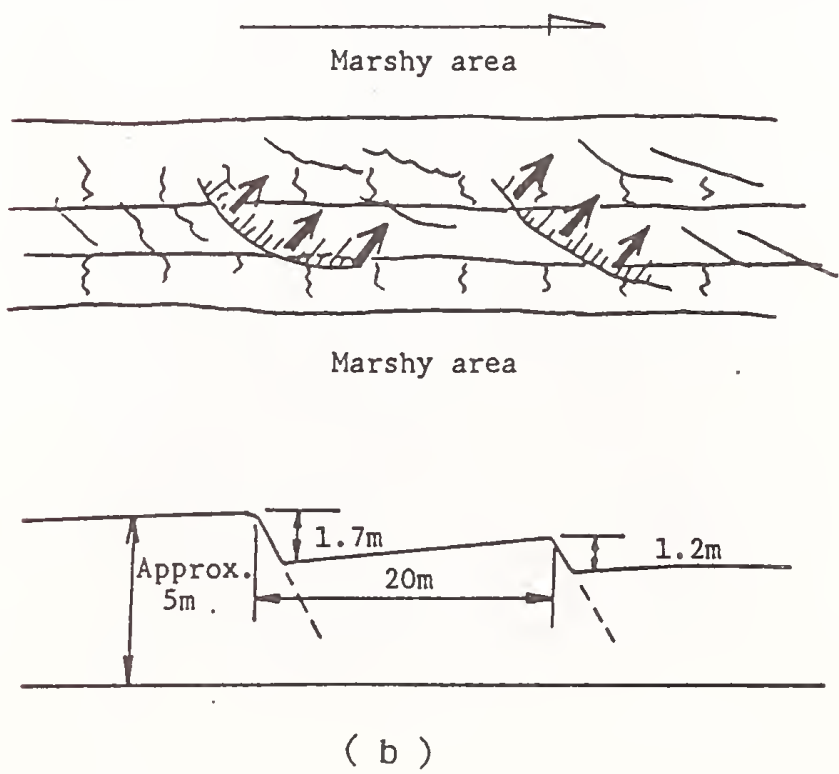

Fig. 6.3 Damaged Sites of Agno River 

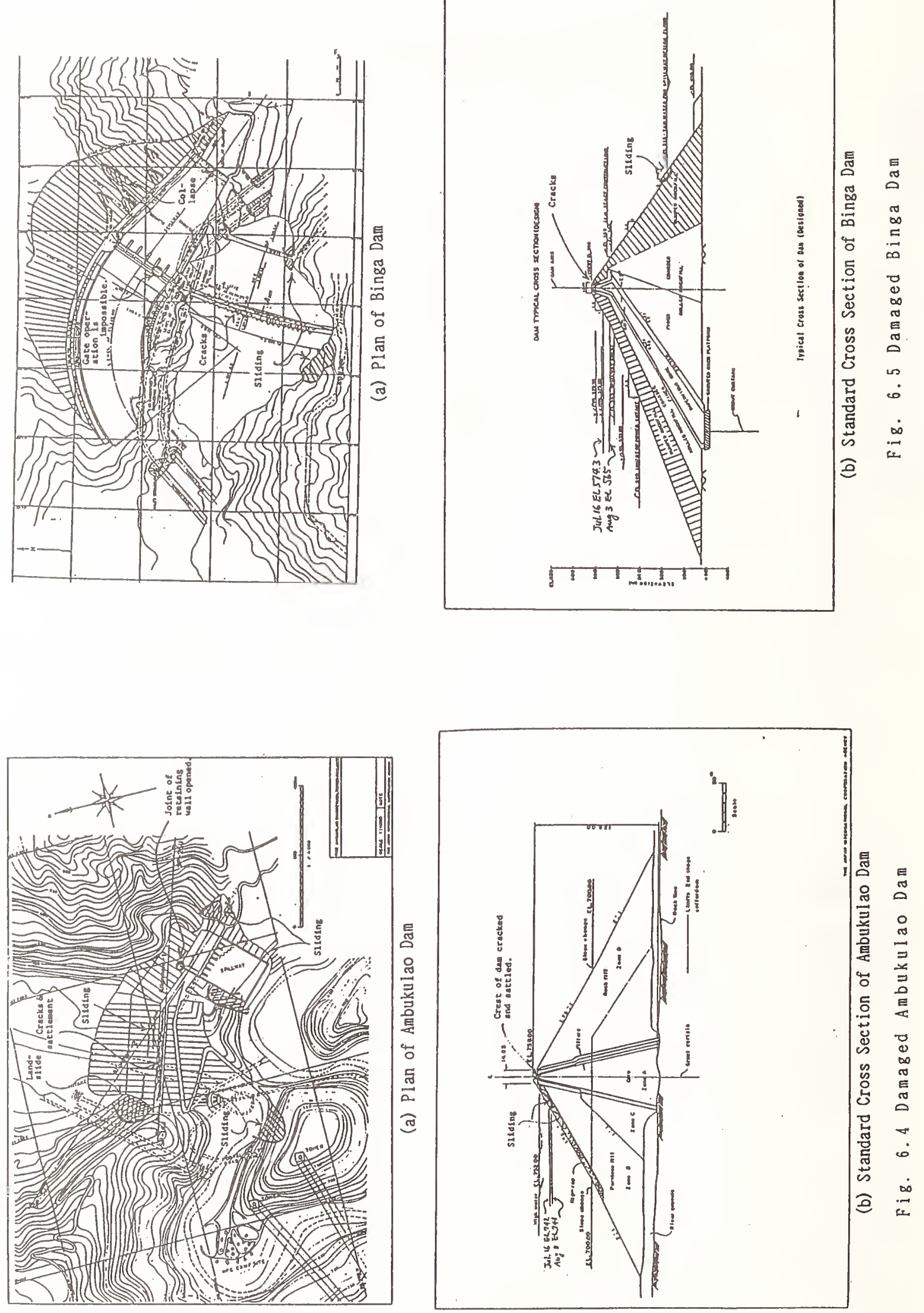


\title{
Recorded Structural Response During the M7.1 \\ Loma Prieta Earthquake
}

\author{
by \\ A. Gerald Brady*
}

\section{ABSTRACT}

The recording of structural response during strong-motion earthquakes has been a goal of the structural engineering profession since the $30^{\prime} \mathrm{s}$, in the profession's quest to understand how buildings behave and to design against collapse. The Loma Prieta earthquake provided an unmatched collection of records, although few instrumented structures were even close to collapse. Near-collapses or structurally damaging motion will be recorded at a much slower rate than the engineering profession desires and funding programs will need to address this question.

KEYWORDS: collapse, instrumentation, response, strong-motion, structures.

\section{INTRODUCTION}

The Loma Prieta earthquake provided strong-motion accelerograms from 137 ground and structural stations throughout the epicentral area, the San Erancisco Bay Area and surrounding areas. The largest networks are those of the California Strong-Motion Instrumentation Program, CSMIP, lof the Division of Mines and Geology, CDMG, of the Department of Conservation), and the US Geological Survey, USGS. Several structures instrumented by private organizations add to the total. The data from CDMG and USGS are made readily available as soon as processing is completed (CSMIP staff, 1989; Brady and Mork, 1990), and much research on structural behavior has already been initiated. A seminar was held by CSMIP on 30 May, 1991, where short presentations were made by researchers having already spent a year on funded research on Loma Prieta data (CSMIP staff, 1991). A further year of funding, with grants of up to $\$ 25,000$, was launched in May, 1991 .
As of this writing, May-June, 1991, data are available from 47 structural stations: 37 multi-story buildings, four dams, three bridges, a gymnasium, an elevated rail and a wharf. Some instrumentation dates from times when only a limited amount of data was satisfactory (three of the multistory buildings and one dam), but $94 \%$ of the structural stations recording Loma Prieta have extensive instrumentation, with between 10 and 30 channels designed and placed to help solve specific problems related to the structure, in all or part. Structural stations cover a wide range of epicentral distance, from a four-story Watsonville building at 18 $\mathrm{km}$ and Anderson Dam at $27 \mathrm{~km}$, to a 13-story Berkeley building at $99 \mathrm{~km}$ and a 3-story Richmond building at $112 \mathrm{~km}$, although beyond an epicentral distance of $100 \mathrm{~km}$, ground level accelerations at structural sites do not exceed $0.10 \mathrm{~g}$. Azimuthal coverage is restricted to approximately 180 degrees, since the San Andreas fault lies close to the Pacific ocean. The prominent centers for these structures are the urban areas of san Francisco, Oakland and San Jose, and nearby locations. However, the remainder of the northeastern side of the fault is uniformly covered.

\section{INSTRUMENTATION GOALS.}

Structural instrumentation reflects a longheld desire to understand how structures behave during earthquakes, particularly during damaging motion. Recorded weak motion, defined for the purposes of this paper as a level of motion for which the structure remains primarily elastic and undamaged, is useful for the interpretation of a specific structure's design and the relationship between

\footnotetext{
* U.S. Geological Survey
} Menlo Park, CA94025 
design concepts and actual elastic dynamic behavior. Recorded strong motion, on the other hand, concentrates attention on damage and poorly understood dynamics and can, if called for, provide evidence that building codes need improving. It is the intelligent analysis of recordings from strong damaging motion that will decrease the seismic hazard in the years ahead, as well as the much more frequently occurring visual inspection and subsequent interpretation of damaged structures.

As structures have become more complex, architecturally and geometrically, so has our interest heightened in their behavior during strong motion. More sensors have clearly become necessary as structure size increases. However, until every joint is monitored for displacement and rotation, a clearly impossible task, missing structural dynamic properties will be needed from estimates, calculations and assumptions, in order to provide the motion at non-instrumented points. Graphical representations of structural dynamic response use joint motions that are recorded, together with estimated values for all other points.

The more obvious structural parameters that affect dynamic behavior during strong damaging motion, and would have to be incorporated in the analysis of strong-motion recordings, include:

a. The force-displacement relationship, perhaps as simple as elastoplastic.

b. Joint detailing, the reinforcing steel's containment of concrete, and the ability to maintain integrity.

c. The ductility ratio able to be achieved.

d. Behavior under repeated excursions into the nonlinear regime (see, for example, Perez and Brady, 1984).

These considerations complicate enormously the analysis of structural strong-motion recordings, although not from the Loma Prieta earthquake because none of the instrumented buildings were damaged.

\section{SYSTEM IDENTIEICATION.}

The goals of system identification routines include the identification of basic vibrational patterns in the response of a structure to an earthquake input, from which the total vibrational behavior can be built up. The extent of the participation of the basic patterns, or modes, can change with time as the earthquake input progresses (see, for example, Safak, 1988). Taking into account the incomplete instrumentation that is lamented on earlier, any mode shapes associated with system identification might well be reliable at instrumented points, but unreliable at all others. In spite of this, much useful information is obtained on frequencies, damping, participation factors, mode shapes of basic vibrational patterns, and the variations of each of these with time, from system identification investigations. It is clear that the usefulness of the information is Iimited by the same concerns expounded above, namely, incomplete instrumentation, unknown nonlinearities, and assumptions, however subtle, on the way structures behave during strong damaging earthquake motion. A few records from earthquakes other than Loma Prieta have been recovered from structures suffering structural damage from earthquake shaking, and fewer still from structures with extensive instrumentation. These records offer the real opportunity of correlating earthquake input, nonlinear structural motion, and documented damage. The structural engineering community and the building code writers need more of these research results.

\section{VERTICAL MOTION}

A specific area where an understanding of earthquakes, structures, and their relationship appears to be less than adequate is in the analysis of vertical structural motion. Although designing for vertical loads is basic, the dynamics associated with measured vertical motion adds a dimension of difficulty. Differing vertical motion at two different locations at the same level (for ex- 
ample, basement level), implies either the rocking of the structure on its foundation as in the rolling of a ship at sea, or the vertical motion of columns that remain vertical as in the stepping of stilts. Without the measurement of joint rotations, we cannot distinguish between these two possibilities, because there can be an arbitrary amount of the second, the stilt-stepping, without any addition to the horizontal structural motion. How much, then, of the recorded vertical motion is rocking?

\section{PERIOD LENGTHENING DURING STRONG MOTION}

Records from an extensively instrumented structure generally permit the calculation of natural periods and lowest modes of vibration even from original analog records, should this be the recording medium. As the excitation continues, or as it builds in intensity, the stiffness of individual components decreases, due to infinitesimal cracks, and, the mass remaining constant, the modal periods consequently lengthen. Under stronger excitation still, structural members weaken from cracks, initially infinitesimal, but becoming damaging given sufficiently high excitation levels. This is accompanied by further period lengthening. This behavior is not yet sufficiently documented nor, consequently, able to be estimated. Its presence in the strong-motion records of a structure provides a quantitative measure of the decrease in stiffness, but no details of its occurrence.

\section{DESIGN CONSIDERATIONS}

The successful design of structures for seismic effects, apart from following the relevant building codes, is dependent on the ability to understand how a completed structure will respond to a future earthquake, how this response builds, and how the behavior changes from the expected norm with the lowering strength of critical sections. This task will slowly become easier as the response of specific structures to weak motion is measured. All instrumented structures in the Loma Prieta area reached at least this stage. Further success will follow the recording of response of structures to strong motion at non-linear levels (a small fraction of Loma Prieta structures). Less common still, we await correlations made between damage to a structure and its recorded motion during the damaging experience. Post-earthquake reconnaissance of damaged structures, an endeavor that precedes recorded motion by many hundreds of years, retains its position as a fundamental provider of experience, namely, the partially documented detailed dynamic response of structures. Documentation can only be considered partial because there need not be a one-toone correspondence between the timevarying dynamics of a structure and the observable damage after an earthquake.

The goal of reducing the earthquake hazard in structures yet to be designed and built relies in part on understanding the dynamics of existing structures. Even though a structure's behavior during a specific strong-motion earthquake might be well documented, there is very little data to suggest that the same dynamic behavior will be evident during the next. To the author's knowledge there is in fact no such example. Insofar as the next earthquake to cause structural damage to a specific structure is not going to be a duplicate of one that already has done so, it is likely that specific instances of dynamics-damage pairs will remain part of a very slowly growing and consequently little-used database. This statement might well be used as an argument for increasing the number of thoroughly instrumented structures in high seismicity areas, but the best that can be hoped is that the time scale for useful data be reduced from hundreds of years to perhaps scores. In any case, the time is much further into the future than funding programs can usually envisage.

The structural engineering community and particularly that segment of it that is responsible for changes to building codes cannot wait for a database of pairings of measured dynamics and inspected damage. There exists a risk in attempting to consider changes to a code on the basis of a specific dynamics-damage trend in 
that no such trend can yet be considered reliable. Changes to codes are slow to appear for this reason. It is clear that the tightening or loosening of some seismic code requirements, at the expense of those remaining unchanged, might possibly be associated with not fully understanding the complete structural dynamics phenomenon. The detailed faulting mechanism and wave propagation characteristics of all future damaging earthquakes are surely not yet sufficiently understood to be of specific use to the structural engineering profession in its efforts to reduce seismic hazard.

7. BAD GROUND, AMPLIEICATION, AND RESONANT FREQUENCIES

One of the interesting research efforts in the San Francisco Bay Area after the M7.1 1989 Loma Prieta earthquake has been the identification of areas of soft soil able to amplify vertically-travelling shear waves on their passage up from underlying bedrock. Horizontal ground oscillations from these waves are generally considered the principal cause of damage to residential areas in San Francisco, to the Bay Bridge, and to the Cypress Street Viaduct (Hanks and Brady, 1991). In addition to identifying the existence of soft soil of sufficient depth, questions are raised as to why some of these areas did result in significant amplification, with resulting damage to structures thereon, while others, even much closer to the epicenter, did not. One of the obvious contributing factors is that each soft soil area has its own set of resonant frequencies appropriate to large, nonlinear, damaging motion, at which amplification is certain. Outside these frequencies, and how far outside is dependent on the damping in the soil at large, nonlinear, damaging motions, there is little amplification. At the rock/soil interface, or more accurately, at all interfaces between high shear wave velocity media, and low, an amplification must occur, independent of frequency, because of energy considerations. If the resonant amplifications are dominant at a specific site, then this site will suffer large, damaging motions only if the resonant frequencies and the input frequencies of the earthquake coincide, and if the input amplitudes are sufficiently high.

Although surface waves will have played a part in the ground motion throughout the Bay Area, they did not apparently contribute to any of the damaging motion in the San Francisco area.

Shear waves emanate from a rupturing fault as slip proceeds. One prominent propagation path is in the direction transverse to the rupture, with particle motion parallel to the rupture, driven by the slip on the fault. Along the direction of rupture, both ahead and behind, transverse shear waves travel, with transverse particle motion, in sympathy with the relaxation of the transverse restoring forces. The frequencies of these waves, and all other associated body waves, are entirely dependent on the detailed travel history of the rupture. This detail is not known, and cannot be measured, but efforts at estimating it are made from strong-motion records written at the surface in the epicentral and adjacent areas. There exists no way of estimating the predominant frequencies or their possible range for large damaging earthquakes. Representations of estimated rupture detail indicate, in general, nonuniform rupturing and variable rupture speeds. For any large earthquake, even a repeat earthquake on the same section of fault, generated frequencies are clearly arbitrary. The highest and lowest frequencies measured on strong-motion instruments on rock in the epicentral area of large earthquakes are each affected by signal-to-noise limitations, but are of the order of 50 and $0.05 \mathrm{~Hz}$, respectively. Fourier spectra or response spectra of such records confirm the apparent arbitrariness of prominent frequencies between these bounds.

\section{CONCLUSIONS}

The structural engineering profession is wise to limit its treatment of the seismic component of codes to a general one. For example, in light of the above paragraphs, there is no justification at present, nor in the 
forseeable future, for treating any soft soil in high seismicity regions differently from other soft soil. Although the understanding of the seismological and geophysical aspects of the most recent multiple-recorded earthquake (in the present case, Loma Prieta) has grown considerably in recent years, the ability to predict the effects of the next remain in question. There are not enough data, and there have not yet been enough earthquakes, for the situation to be any different.

\section{REFERENCES}

1. CSMIP staff, 1989, "Plots of the processed data for the interim set of 14 records from the Santa Cruz Mountains (Loma Prieta) earthquake of October 17, 1989." Office of StrongMotion Studies Report, CDMG, Sacramento, Calif., and subsequent reports and tapes.

2. Brady, A.G., and P.N. Mork, 1990, "Loma Prieta, California, earthquake, october 18 (GMT), 1989; processed strong-motion records, vol 1," U.S. Geological Survey Open File Report 90-247, and subsequent tapes.

3. CSMIP staff, 1991, "SMIP91 seminar on seismological and engineering applications of recent strong-motion data; preprints," Calif. Dept. of Conservation, CDMG; Sacramento,

Calif.

4. Perez, V. and A. G. Brady, 1984, "Reversing cyclic elastic demands on structures during earthquakes and application to ductility requirements," EERI Earthquake Spectra, 1, 1, p. 7-32.

5. Safak, E., 1988, "Analysis of recordings in structural engineering: adaptive filtering, prediction and control," US Geological Survey Open File Report 88-647.

6. Hanks, T. C. and A. G. Brady, 1991, "The Loma Prieta earthquake, ground motion, and damage in Oakland, Treasure Island, and San Francisco," Bull. Seis. Soc. Am., in press. 
Norihisa MATSUMOTO*1, Nario YASUDA*2, Masahiko OHKUBO*3, Ryo-ichi YOSHIOKA*4

\section{ABSTRACT}

In this paper the static and dynamic strengths of rock materials of rockfill dam body are investigated through monotonic and cyclic loading tests.

Keyword: Rockfill materials, large-scale triaxial test, cyclic loading, monotonic loading

\section{Introduction}

In an undrained cyclic loading test on saturated loose sands under laboratory conditions, the sand tend to flow losing its original structure. resulting in liquefaction. In contrast, dense sands don't tend to behave this way and shows the condition of cyclic mobility. Although this happens, due to the cyclic loading the pore water pressure increases causing cumulative strain magnification. Therefore, the dynamic strength can be established from the number of cycles and resulting strain. The static strength can be simply obtained from a monotonic loading test.

From this, it seems that monotonic and cyclic loading tests are not mutually exclusive but actually relate to each other.

This report is concerned with the monotonic and cyclic test result for well compacted rockfill materials. The paper aims at illustrating the definition of shear strength by the laboratory testing, and presents the effect of cyclic numbers, prescribed strain, relative density, initial confining stress, initial shear stress and the testing method for dynamic strength, and the overall relationship between static and dynamic strength.

\section{Spocimen Preparation and Test Procedure}

The materials used in this study were transported from a quarry site for the Sagurigawa Dam. The rock material consists of very hard and high quality gabbro.

A rigid specimen of $30-\mathrm{cm}$ in diameter and $60-\mathrm{cm}$ in height was utilized for the cyclic triaxial test. $A$ hollow cylindrical specimen was an $80-\mathrm{cm}$ in outer diameter, a 40-cm in inner diameter and a height of $80-\mathrm{cm}$ was used for the cyclic torsional shear test. These specimens are shown in Fig.1. The physical properties of the test materials are given in Table 1.

The grain size distribution curve for the test materials is illustrated in Fig.2. The maximum particle size of specimen is $63.5 \mathrm{~mm}$. which is less than $1 / 5$ of the diameter of the specimen used for the monotonic loading tests. The uniformity coefficient of the rock material was set 30 in order to minimize the effect of the system compliance. In this figure, the gradation curve for the rockfill materials of the Oroville Dam (with which Banerjee etal.'12 conducted cyclic loading tests with undrained condition) is also plotted. The gradation curve for the Oroville Dam materials had the maximum particle size of $50.8 \mathrm{~mm}$ (which is slightly small when compared with $63.5 \mathrm{~mm}$ for the maximum particle size of our specimens) is almost the same as that for this study. Banerjee et al. used a $10 \%$ reduction in the cyclic strength ratio as correction factor for the membrane compliance of the undrained cyclic triaxial test, for materials with a diameter of $9.5 \mathrm{~mm}$ at $D_{50}(50 \%$ diameter of soil particle). Therefore, for the purpose of this study, the $10 \%$ reduction in the cyclic strength ratio is to be repeated.

The materials were placed in six layers, with each layer compacted by $33 \mathrm{kgf}$ weight electric vibratory rammer. Finally, the specimens with $85 \%$ and $95 \%$ of relative density were prepared.

The procedures for cyclic testing is given as follows.

1) A confining pressure of $0.2 \mathrm{kgf} / \mathrm{cm}^{2}$ was applied to the specimen $(30-\mathrm{cm}$ in diameter and $60-\mathrm{cm}$ high) and subsequently the vacuum pressure inside the specimens was released.

2) Carbon dioxide $\left(\mathrm{CO}_{2}\right)$ was supplied under pressure of $0.05 \mathrm{kgf} / \mathrm{cm}^{2}$ to the

*1 Dr. Eng. Chief, Filldam Division, P.W.R.I., Ministry of Construction, Tsukuba City, Japan (Presently Japan Dam engineering (enter)

*2 Senior Research Eng., ditto

*3 Eng., ditto

*4 Visiting Research Eng., ditto

(Presently Shimz Corp.) 
specimen for a 24 hours period, in order to fill any air void completely with $\mathrm{CO}_{2}, \mathrm{CO}_{2}$ was used because it is much easier to dissolve in water than air and a higher degree of saturation for the specimens can be accomplished.

3) After replacing the air with $\mathrm{CO}_{2}$, 70 liters of de-aired water was supplied to the sample for a 24 hours period.

4) The degree of saturation of the specimen was then investigated by Skempton's B-value method and testing was carried out if the specimen had a $B$-value of more than 0.96 .

5) A 1,000 cc burette was used for measuring the volume change in the sample during an average 45 minute consolidation. Cyclic loading tests were started once the rate of volume change in specimen became less than $0.05 \%$ per minute.

A cyclic undrained test was carried out under load-controlled condition of $0.1 \mathrm{~Hz}$. The specimen was subjected to a back pressure of $2.0 \mathrm{kgf} / \mathrm{cm}^{2}$.

The digitized test results were recorded on a personal computer using a low-pass filter of $1.0 \mathrm{~Hz}$ and were subsequently plotted.

\section{Dynamic strength}

$\tau$ ap is defined as the cyclic strength achieved during cyclic loading test, where $\tau_{\text {a }}$ is the cyclic stress when the shear strain reaches $\varepsilon_{p p}$ at fallure after $N_{p}$ cycles. Generally, $\tau_{d p}$ is effected by the vertical effective stress $\sigma^{\prime} v o$, horizontal effective stress $\sigma^{\prime}$ no of the field, cyclic number $N$ and the initial shear stress $\tau_{s}$. The shear strength is expressed as merely $\tau_{\text {dp }}$ or $\left(\tau_{s}+\tau_{d p}\right)$ which is the sum of $\tau_{\text {s }}$ and $\tau_{\text {dp }}$, and the shear strength ratio is obtained by dividing both shear strength values by $\sigma^{\prime} v$. These points are used in the following discussion.

In the case of the triaxial tests, shear stress ratio is expressed by the following equations:

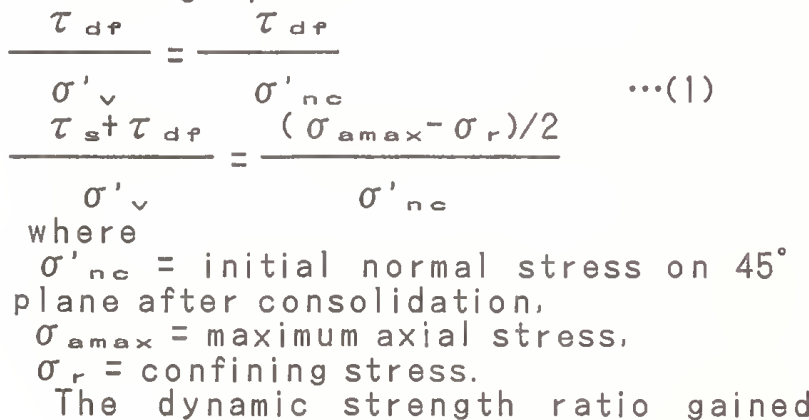

from the triaxial test has to be corrected since tests in the laboratory are not representative of the in-situ considering the the rotation of the axes of principal stresses, horizontal stress and plane-strain state etc.

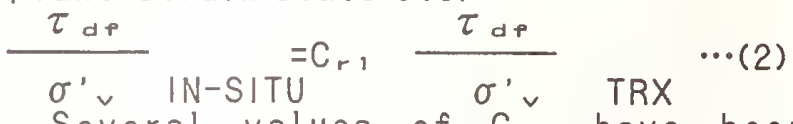

Several values of $C_{r}$ have been reported by previous researchers according to $K_{0}(=\sigma$ sol $\sigma$ ici the principal stress ratio during a consolidation) as shown in Table 2.

On the other hand, the cyclic shear stress $\tau_{d}$ is added with the initial shear stress $\tau_{s}$ for torsional simple shear tests. $\tau_{\text {de }}$ is defined as the shear strength achieved during cyclic torsional shear test for a $\tau_{\text {a }}$ of $a$ cyclic stress when the shear strain reaches a certain value, which is established as the axial strain $\varepsilon_{p}$ or shear strain $\gamma_{p p}$ at failure, after $N_{p}$ loading cycles. Hereinafter, the strength is expressed by a dimensionless stress ratio $\tau_{d e} / \sigma^{\prime} v$ or $\left(\tau_{d p}+\tau_{s}\right) / \sigma^{\prime} v$ as the case of the triaxial test. A correction factor $\mathrm{C}_{r}$ shown in the following equation is required to compare the in-situ stress ratio with the laboratory stress ratio. This is because the plane-strain condition is not completely satisfied unless the radial confining stress is controlled so as to maintain the areal strain at zero.

$$
\frac{\tau_{d p}}{\sigma^{\prime}{ }_{\text {IN-SITU }}}=C_{r z} \frac{\tau_{d p}}{\sigma^{\prime}{ }_{\text {Can be said that }} C_{r 2} \text { is }}
$$
approximately 1.0 .

\section{Test results}

In this report, the strain regulating dynamic strength in the cyclic loading test is defined as single amplitude, which is half of the double amplitude for isotropic consolidation, and the peak strain which remains in compressed direction for anisotropic consolidation.

The dynamic strength ratio is expressed by the following equation.

$$
\frac{\tau_{d}+\tau_{s}}{P_{c}}
$$

where, $\tau_{d}=$ cyclic shear stress, $\tau_{s}=$ initial shear stress. $P_{c}=i n i t i a l$ effective

mean principal stress.

Fig.3 illustrates the relationship 
between the dynamic strength ratio and the number of cycles. Each curve shows the dynamic strength ratio when the axial strain reaches $0.5,1.0,2.5$ and $5.0 \%$ respectively. The dynamic strength ratio for the anisotropically consolidated condition is 2 to 3 times as large as that of the isotropically consolidated one. The dynamic strength decreases according to the increase in the number of cycles or the decrease of prescribed strain. The curve of the dynamic strength ratio for the anisotropically consolidated condition has an inclination to close at the boundary line of stress reversal

$\left(\left(\tau_{d}+\tau_{s}\right) / P_{0}=0.75\right)$. Fig.4 shows the relationship between $P_{c}$ and the dynamic strength ratio, which is obtained from the curves for 20 cycles with $1 \%$ of axial strain for the specimens at $85 \%$ and $95 \%$ of relative density. The dynamic strength ratio for the specimen at $95 \%$ of relative density under both isotropically and anisotropically consolidated condition is $1.5 \sim 2.0$ times larger than that at $85 \%$ of relative density. The dynamic strength ratio depends upon the confining stress and increases according to the decrease in $P_{c}$. Yunoki, et al ${ }^{6}$ reported the same tendency as in the results for dense sands.

Fig.5 indicates the relationship between the dynamic strength ratio and the relative density. The increase in the dynamic strength ratio at each level of shear strain is equal for the isotropically consolidated specimens. In the case of unisotropically consolidated samples, the increase in dynamic strength ratio is remarkably reaching $2.5 \%$ of the axial strain.

The relationship between the dynamic strength ratio and principal stress ratio during consolidation is indicated in Fig.6. The dynamic strength ratio has a tendency to increase accompanying the increase in the principal stress ratio as described by Yasuda, et al. 72

Fig.7 shows curves of the dynamic strength ratio for the torsional shear test under isotropic consolidation. which coincides with that of the triaxial test. This corresponds to about a value of 1.0 for $C_{r 1}$ for a value of 1.0 for $K_{0}$ in Table 2. The shear strain $\gamma$ in the cyclic torsional test is compared with axial strain $\varepsilon_{\text {o }}$ in the cyclic triaxial test and Poisson's ratio $\nu$ which is 0.5 for undrained tests.

$$
\gamma=(1+\nu) \cdot \varepsilon_{a}
$$

Yamashita, et al. ${ }^{8}$ reported that the result of the torsional simple shear test on dense sands is greater than that for the triaxial test on the sample prepared using the air-pluviation method. On the other hand, Ochi, et al. ${ }^{9}$ claimed that the relationship between the result of the triaxial test to that of the torsional shear test, is dependant upon differences in the sample preparation method and relative density.

Fig.8 shows the comparison between the undrained dynamic strength, and the drained and undrained static strengths for rockfill materials. The dynamic strength is the value recruited at 20 cycles and $2.5 \%$ of the axial strain. Incidentally, the static strength is defined as the peak stress within $15 \%$ of the axial strain. It is recognized that the undrained dynamic strength with an anisotropic consolidation is larger than the drained static strength at a normal stress of less than $5.0 \mathrm{kgf} / \mathrm{cm}^{2}$. However, $2.5 \%$ of the peak strain and 20 cycles have been adopted, and these values are not appropriate for application as the dynamic failure for filldams. These have been adopted in this report because of the limitation in the loading capacity of the triaxial testing equipment used here. Therefore, the dynamic strength at larger axial strain is expected to increase.

\section{Conclusion}

The following points were concluded after carrying out a series of monotonic and cyclic loading tests, using well compacted rockfill materials.

(1) In the undrained cyclic loading test, the pore water pressure rises and the strain increases according to the increase in cyclic frequency. The dynamic strength obtained depends on the cyclic frequency, reference strain, relative density, initial confining stress, initial shear stress and testing method. The overall tendency in this study coincides with that expected for a dense sand.

(2) The dynamic strength in cyclic torsional shear is almost the same as that for the cyclic triaxial test with the isotropic consolidation.

(3) The dynamic strength for the anisotropic consolidation was greater than the drained static strength at a 
normal stress of less than $5.0 \mathrm{kgf} / \mathrm{cm}^{2}$.

\section{References}

1) N.G.Banerjee, H.B.Seed, C.K.Chan,

rCyclic Behavior of Dense CoarseGrained Materials in Relation to the Seismic Stability of DamsJ, UCB/EERC$79 / 13,1979$.

2) W.D.L, Finn, J.J.Emery, Y.P.Gupta,

IA Shaking Table Study of the Liquefaction of Saturated Sands during Earthquakes」, Proc. Third European Symposium on Earthquake Engineoring, 1970.

3) H.B.Seed and W.H.Peacock, rTest Procedures for Measuring Soil Liquefaction Characteristics J. Proc. of ASCE, SM8, Vol.97, 1971.

4) G.Castro, rLiquefaction and Cyclic Mobility of saturated Sands」. Proc. of ASCE, Vol.101, No.GT6, 1975.

5) Ishihara,K. and Li, S-I., Liquefaction of Saturated Sand in Triaxial Torsion Shear Test」, Soils and Foundations, Vol.12, No.3, pp.19 39, 1972.

6) Yunoki, Y. et al., rEffect of Confining Pressure on Cyclic Triaxial Test Results of Dense SandJ. The 17th Japan National Conference on Soil Mechanics and Foundation Engineering. pp.1649-1652, 1982, (in Japanese)

7) Yasuda,M. et al., rCyclic Undrained Deformation-Strength Characteristics of Akashi Undisturbed Gravity Samples in Large-Scale Triaxial Tests」. The 24 th Japan National Conference on Soil Mechanics and Foundation Engineering, pp.817-820, 1989, (in Japanese)

8) Yamashita, S., et al., rCyclic Undrained Triaxial and Torsional Shear Strength of Sand with Consideration of Membrane Penetrations. The 22 th Japan National Conference on Soil Mechanics and Foundation Engineering, pp.777-780. 1987. (in Japanese)

9) Ochi, K. et al., rComparison of Shear Strength Between Triaxial and Torsional Shear Tests National Conference on Soil Mechanics and Foundation Engineering, pp.583-586, 1984. (in Japanese) 
Table-1 Physical Properties of Materials

\begin{tabular}{|ll|l|}
\hline Spefific gravity & $G_{s}$ & 2.933 \\
\hline Water content & $W$ & $0.54(\%)$ Air-dry \\
\hline Maximum void ratio & $\mathrm{e}_{\max }$ & 0.569 \\
\hline Minimum void ratio & $\mathrm{e}_{\mathrm{m} \mathbf{m}}$ & 0.142 \\
\hline Maximum grain size & $\mathrm{d}_{\mathrm{max}}$ & $63.5 \mathrm{~mm}$ \\
\hline Coefficient of uniformity & $\mathrm{U}_{\mathrm{c}}$ & 30 \\
\hline Dry density of specimen & $r_{\mathrm{d}}$ & $2.46 .2 .53 \mathrm{gf} / \mathrm{cm}^{3}$ \\
\hline
\end{tabular}

Table-2 $C_{r}$ of Previous Researchers

\begin{tabular}{|l|l|c|c|}
\hline & E quations & $C_{r_{1}}$ for $K_{0}=0.4$ & $C_{r_{1}}$ for $K_{0}=1.0$ \\
\hline Finn, et a 1. $\left.{ }^{2}\right)$ & $C_{r_{1}}=\left(1+K_{0}\right) / 2$ & 0.70 & 1.0 \\
\hline Seed and Peacock & Varies & $0.55 \sim 0.72$ & 1.0 \\
\hline Castro & $C_{r_{1}}=2\left(1+2 K_{0}\right) / 3 \sqrt{ } 3$ & 0.69 & 1.15 \\
\hline Ishihara and $L i^{5)}$ & $C_{r_{1}}=\left(1+2 k_{0}\right) / 3$ & 0.60 & 1.0 \\
\hline
\end{tabular}




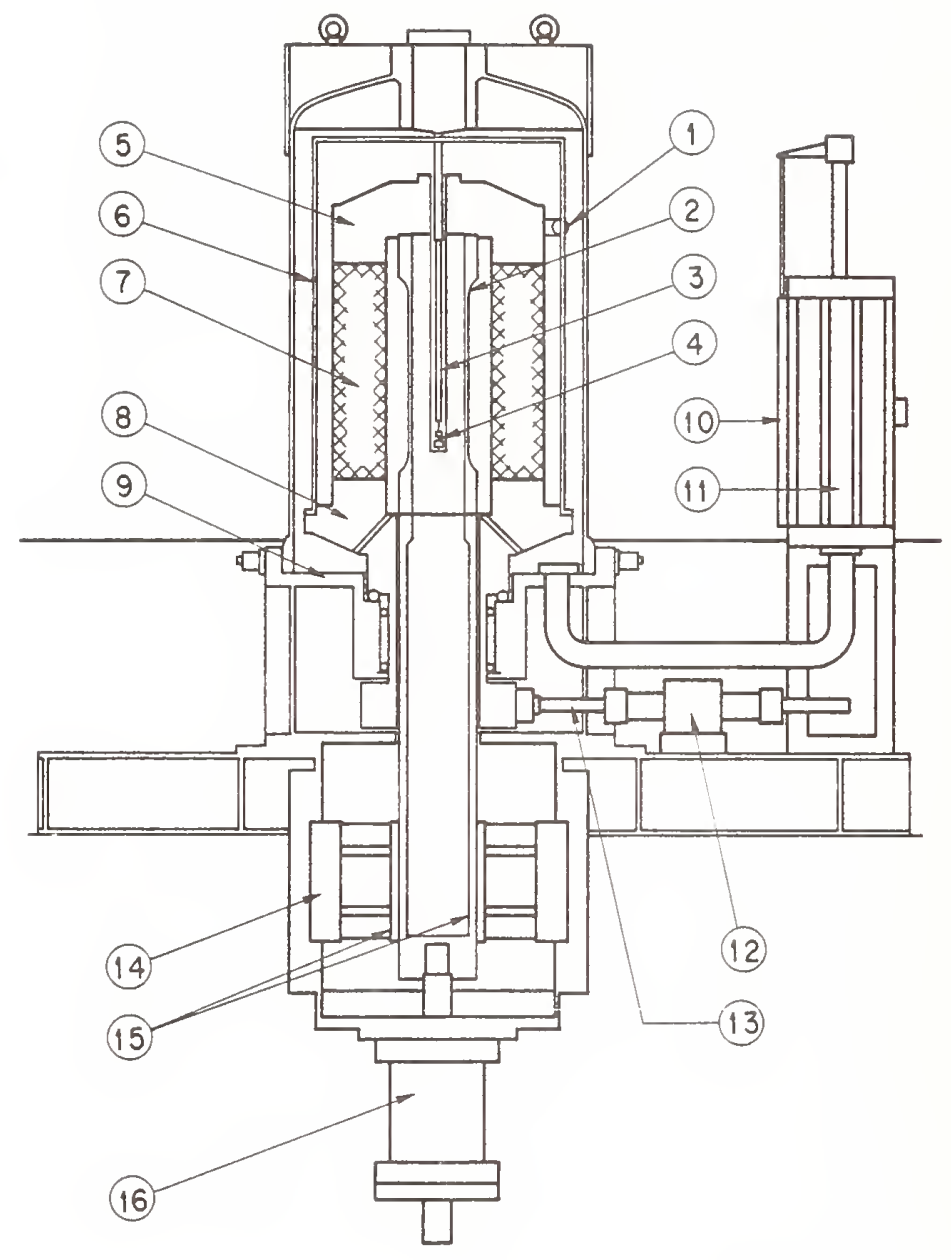

(1) GAP SENSER

(2) AXIAL LOAD AND TORGUE PICKUP

(3) DISPLACEMENT TRANSDUCER

(4) ROTARY DEGREE PICKUP

(5) CAP

(6) MEASUREMENT FRAME

(7) HALLOW CYLINDRICAI SPECIMEN $(\$ 80-40 \mathrm{~cm} \times \mathrm{H} 80 \mathrm{~cm})$

(8) PEDESTAL

(9) CELL BOTTOM

(10) OUTER VOLUME CHENGE PICKUP

(II) CELL PRESSURE EQUIMENT

(12) TORQUE LOADING EQUIPMENT

(13) TOROUE ARM

(14) TORQUE REACTION

(15) LOADING AND REACTION ROD

(16) AXIAL LOADING EQUIPMENT

Fig. 1 Large-Scale Cyclic Torsional Shear Apparatus 


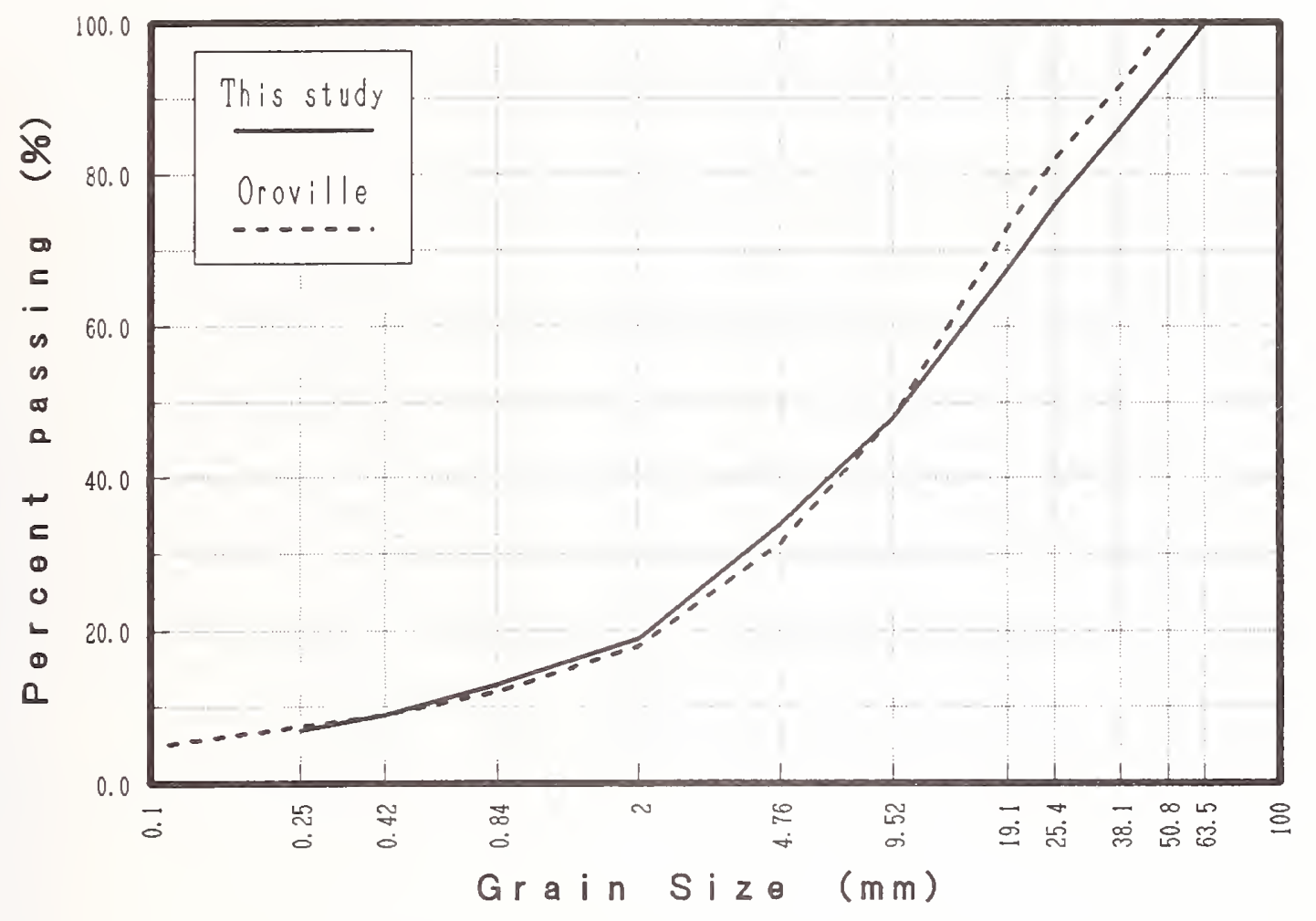

Fig. 2 Grain size distribution curve

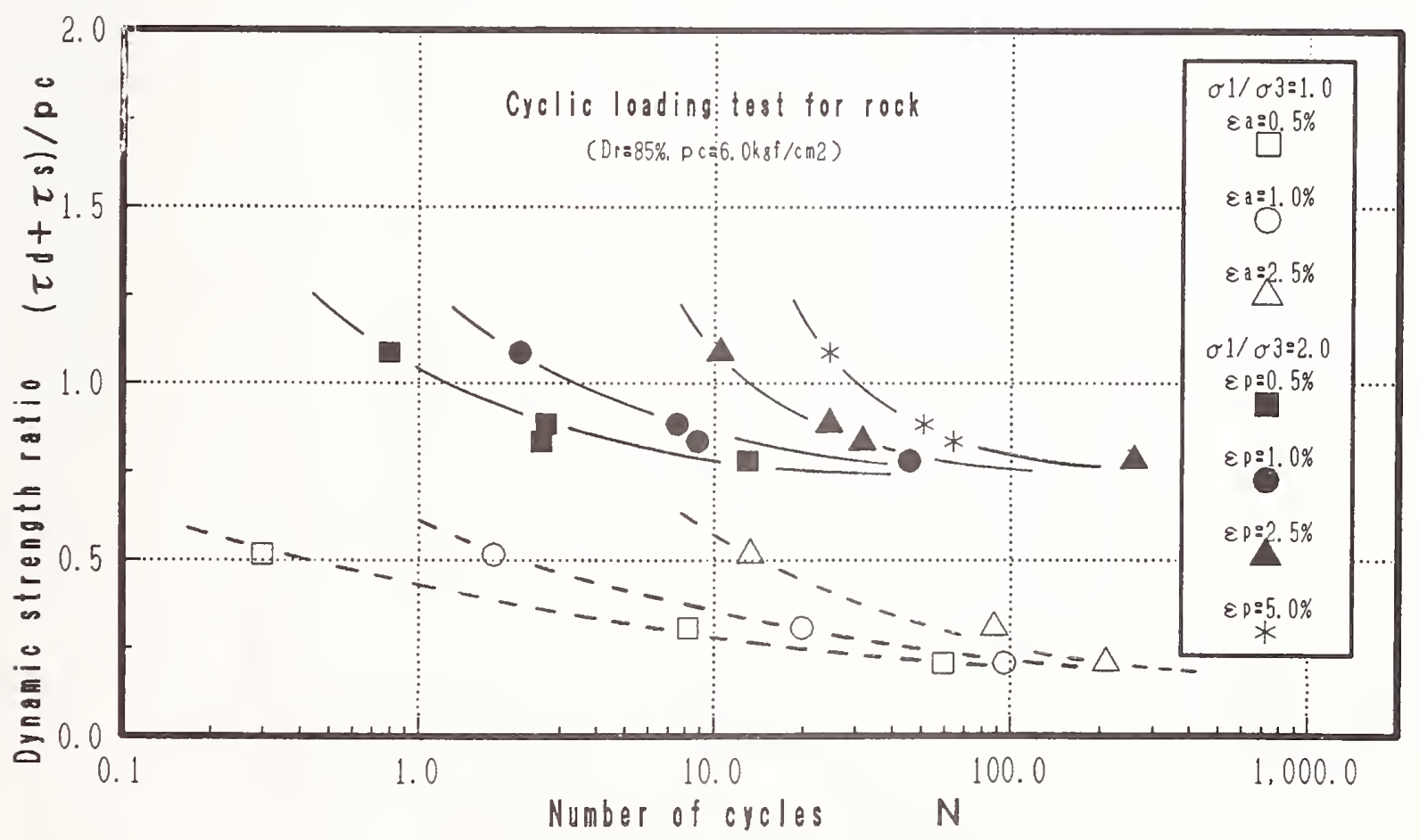

Fig. 3 The relationship between dynamic strength ratio and number of cycles causing various values of axial strain 


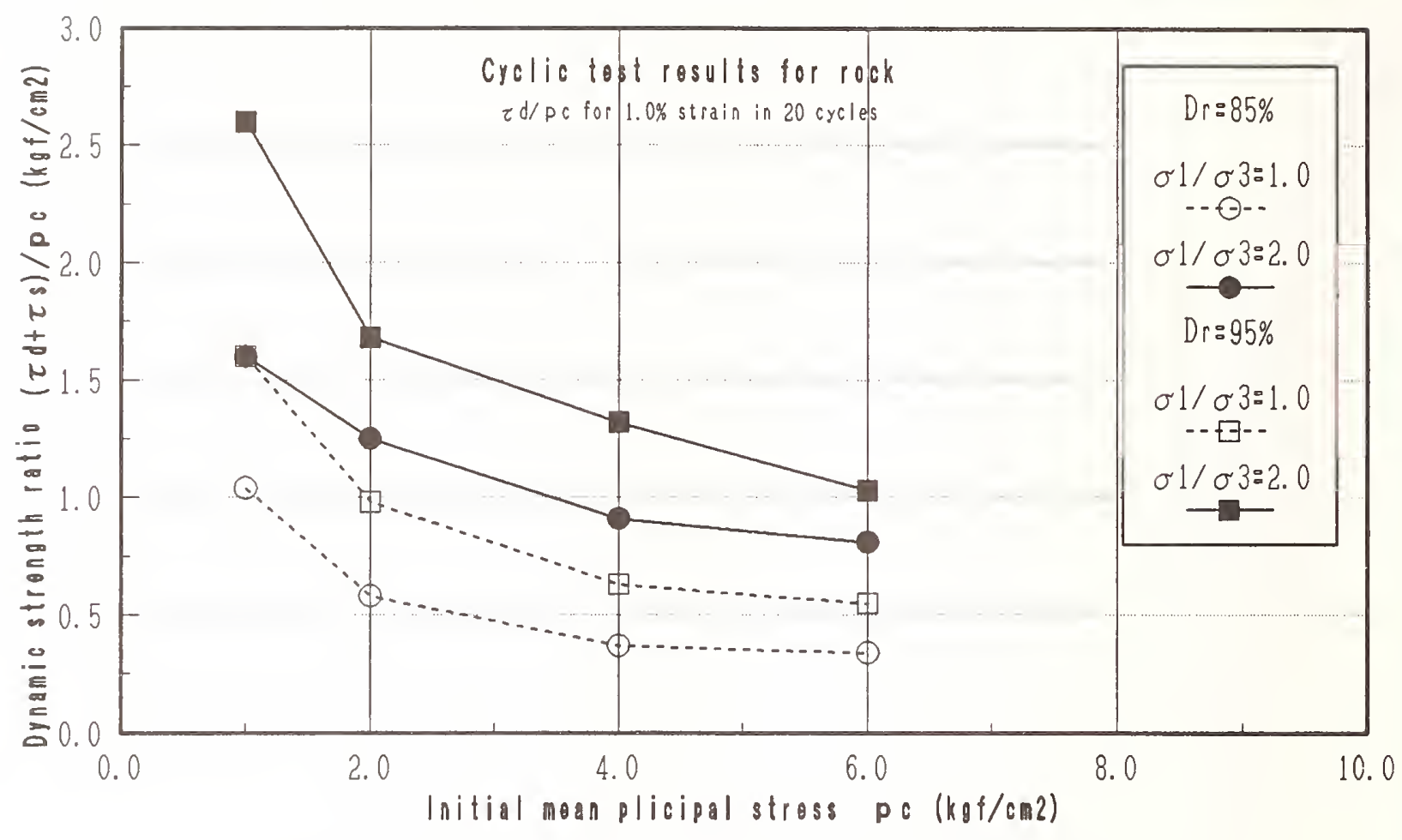

Fig. 4 The relationship between dynamic strength ratio and initial mean principal stress causing $1 \%$ of axial strain at 20 cycles

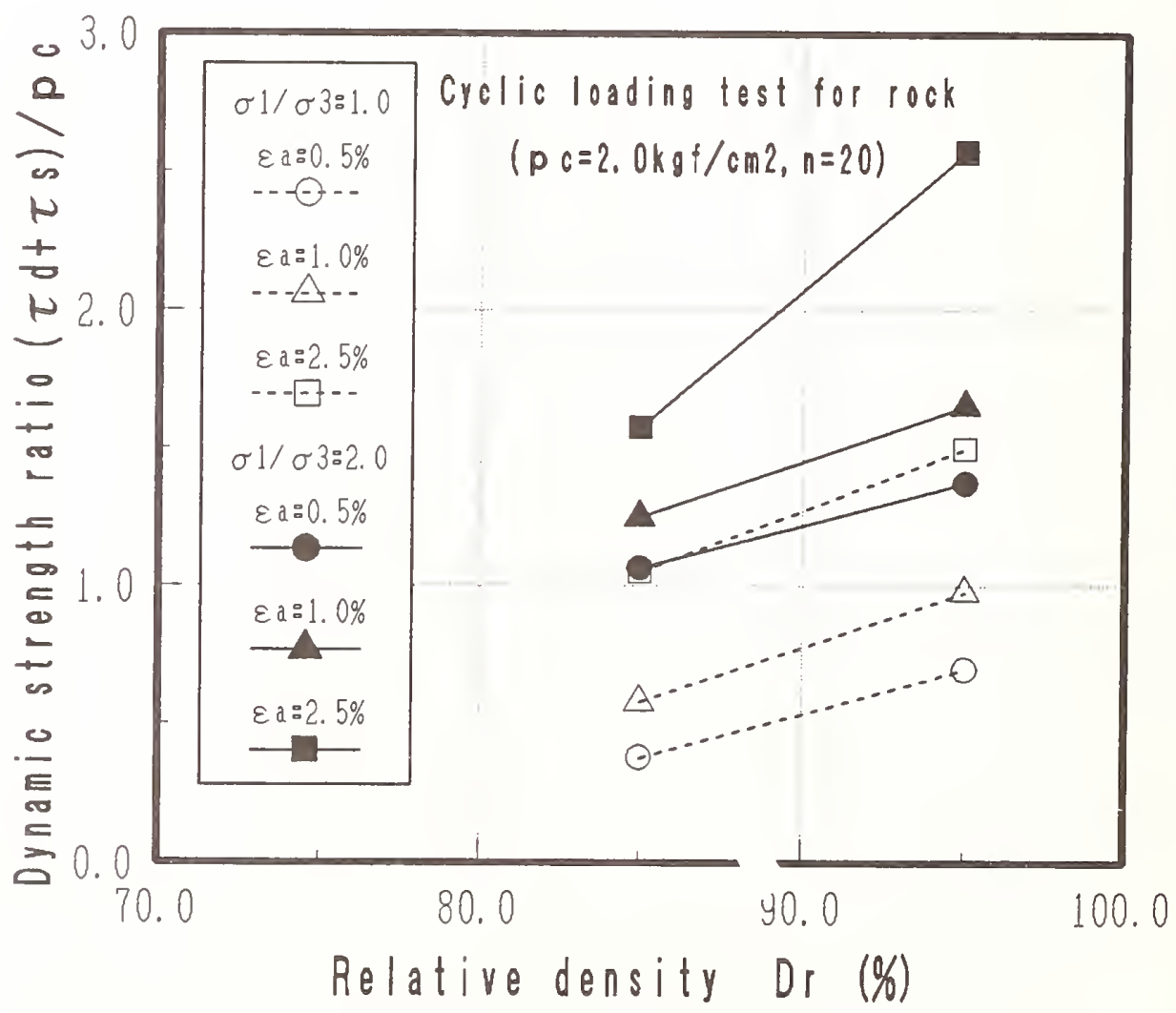

Fig. 5 The relationship between dynamic strength ratio and relative density 


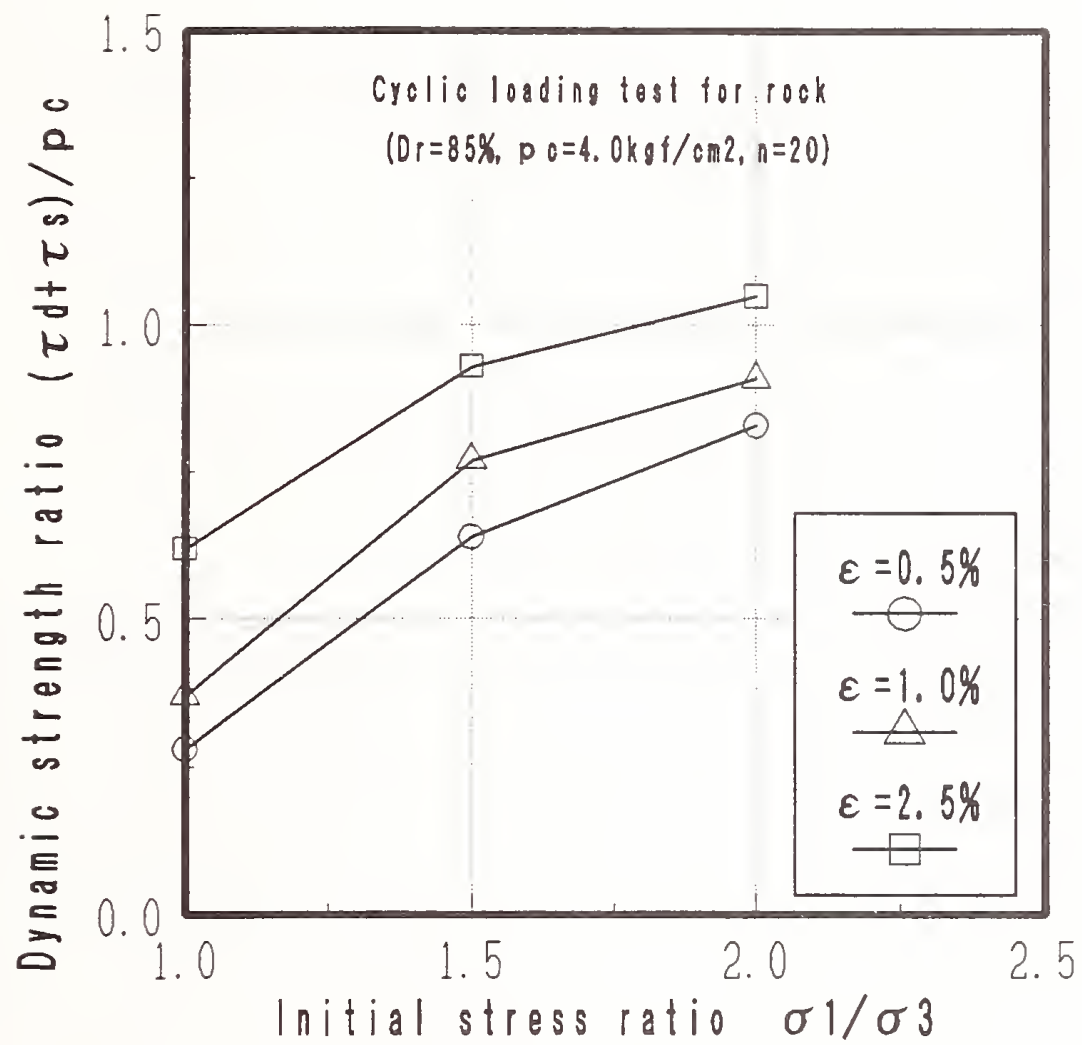

Fig. 6 The relationship between dynamic strength ratio and initial stress ratio causing various values of axial strain

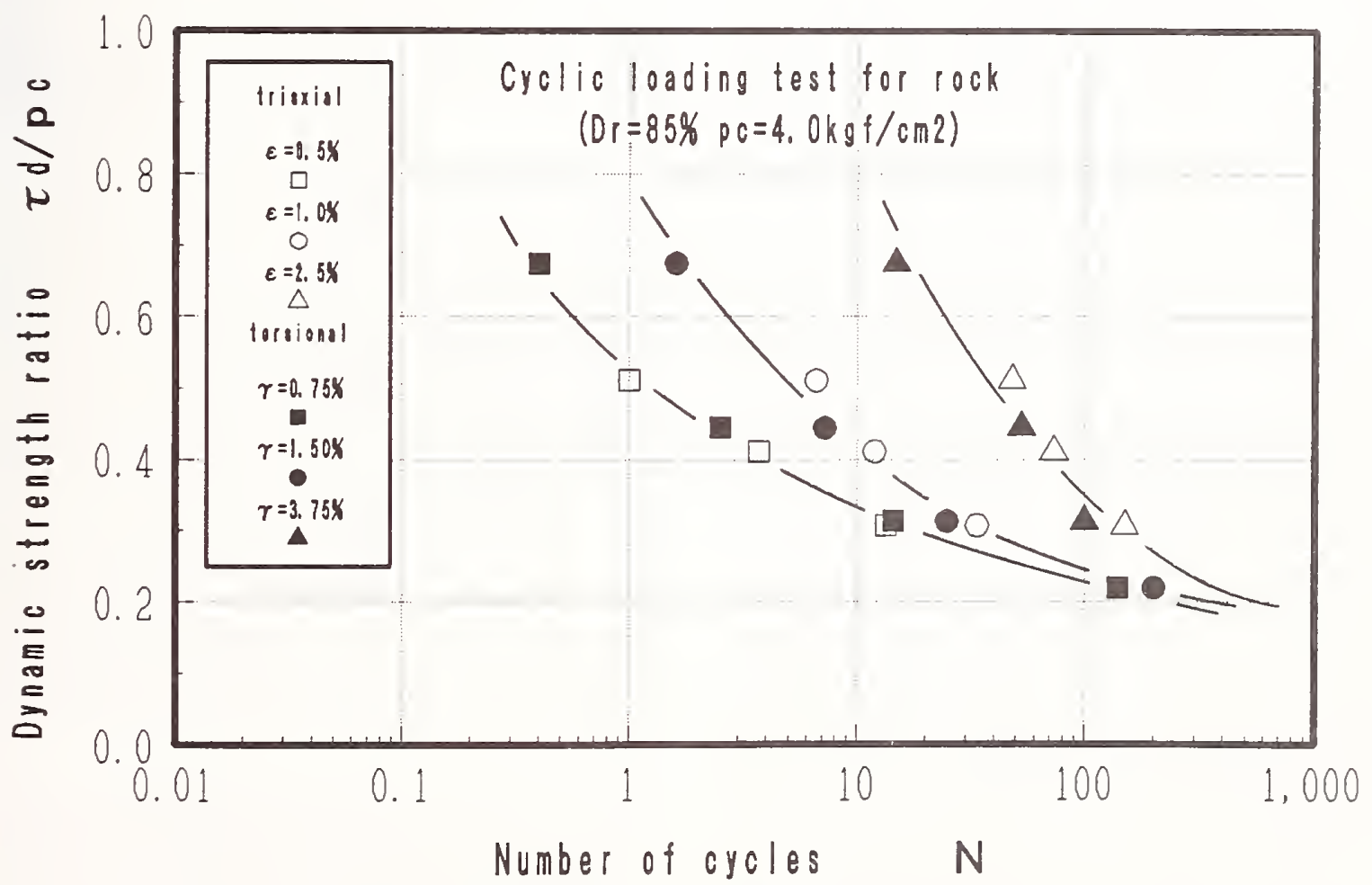

Fig. 7 The relationship between dynamic strength ratio and number of cycles in cyclic triaxial and torsional shear tests 


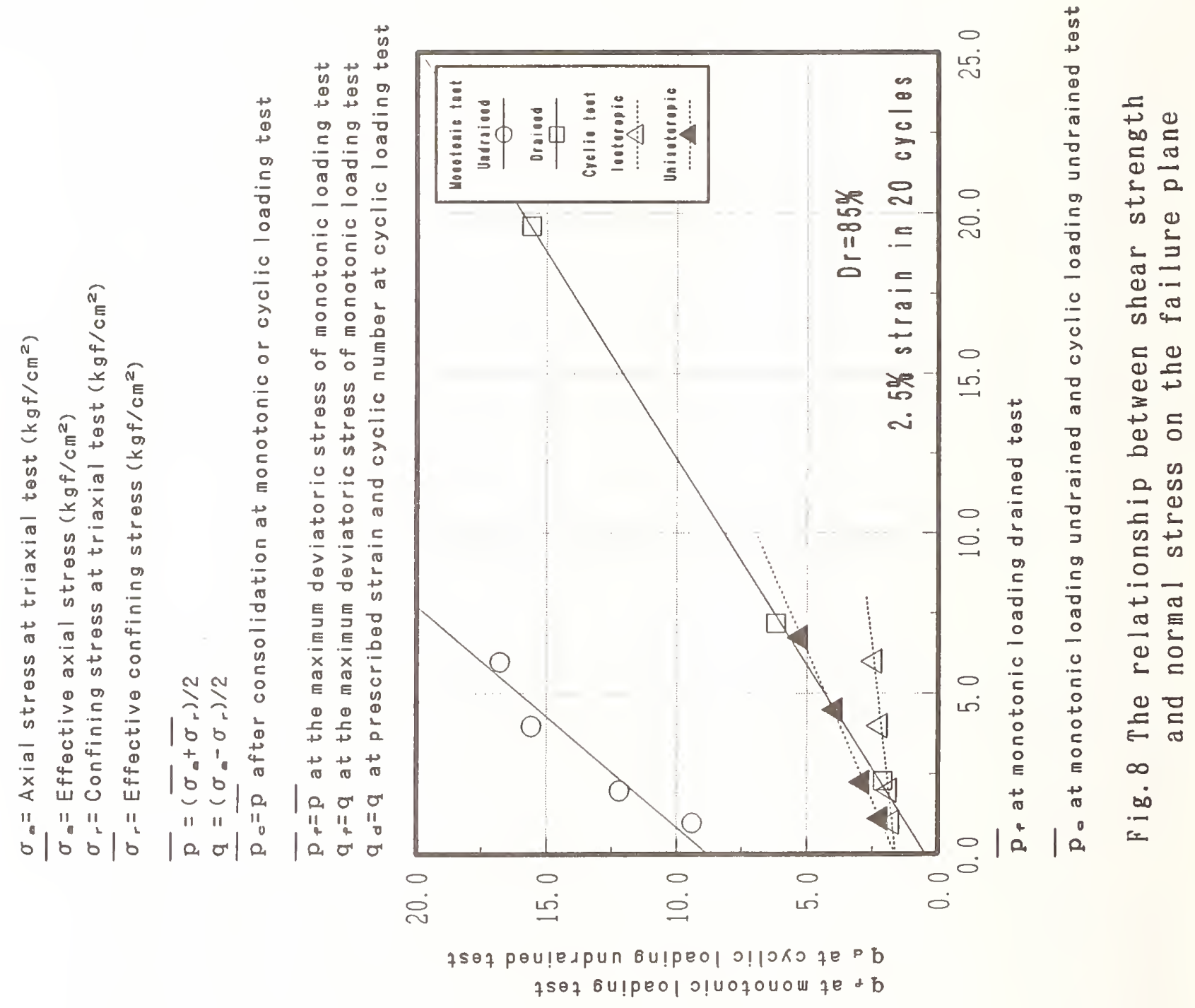




\begin{abstract}
An active bracing system has been designed, fabricated, and installed in a full-scale dedicated test structure for structural response control under seismic loads. Presented in this paper are the design of the active system, control algorithm development, and simulated as well as preliminary test results. Detailed design and analysis of the active system are carried out with respect to hardware development, control force constraints, and power and energy requirements. It is shown that a full-scale efficient active structural control system can be developed within limits of current technology. Simulation and test results provide information on performance bounds that can be expected of active systems in structural control under seismic loads and under constraints imposed by practical considerations.
\end{abstract}

KEYWORDS: structural safety; active control; earthquake engineering.

\section{INTRODUCTION}

The possible use of active control systems as a means of structural protection against environmental loads, such as wind and earthquakes, has received considerable attention in recent years. It has now reached the stage where active systems have been installed in full-scale structures (Kobori, 1990; Soong, 1990). As an example, an active mass driver system was recently installed atop of the eleven-story Kyobashi Seiwa Building in Tokyo. This system, designed primarily for comfort control of building occupants, has performed well under several hurricanes and moderate earthquakes encountered since installation.

Another active mass damper system was recently installed in a dedicated full-scale 600-ton test structure on the grounds of the Takenaka Research Laboratory. It has also performed well during a recent moderate earthquake. In addition, a fullscale active bracing system has been installed in the same structure for performance evaluation purposes. The advantage of having the performance of two active systems evaluated using the same structure is obvious. In addition to providing the same base parameters for performance comparisons, this arrangement allows the calibration of both systems by using one of the systems as motion inducer and the other as motion controller. Even without actual environmental disturbances, much of the performance characteristics of these systems can be assessed.

To provide a focus, this paper addresses design, fabrication, and performance issues related to the development of the active bracing system. These discussions provide a realistic assessment of the potential benefit which can be derived from an active system on the one hand, and system design and capability requirements on the other.

\section{TEST STRUCTURE AND ACTIVE BRACING SYSTEM}

\subsection{Test Structure}

As mentioned above, a dedicated full-scale structure was erected for performance verification of two active structural control systems, i.e., an active mass damper and an active bracing system. Located in Tokyo, Japan, the structure is a symmetric two-bay six-story building as shown in Fig. 1. It was constructed of rigidly connected steel frames of box columns and W-shape beams with reinforced concrete slabs at each of the floors. Weighing 600 metric tons, the structure was designed as a relatively flexible structure with a fundamental period of $1.0 \mathrm{sec}$ in the strong direction and $1.5 \mathrm{sec}$ in the weak direction in order to simulate a typical high-rise building. It is assumed that the floor slabs are rigid in their planes and the structure does not twist; accordingly, the

* National Center for Earthquake Engineering Research and Department of Civil Engineering, State University of New York at Buffalo, Buffalo, NY 14260 
space structure was modeled as a fixed-base plane frame with three degrees of freedom (horizontal, vertical and rotation) at each joint in the eigenvalue analysis. The stiffness of the concrete slabs was taken into account by considering rigid zones at ends of the members in analytical modeling. The spectral properties of the structure obtained analytically as well as experimentally are compared in Table 1, showing that their differences are within $3 \%$ for all modes.

\subsection{Active Bracing System (ABS)}

As shown in Fig. 1, the biaxial active bracing system consists of a pair of hydraulic actuators in each of the principal directions with the diagonal braces connected to the first floor. The actuators, monitored by two hydraulic servovalve controllers with auxiliary hydraulic accumulators, are capable of generating $685 \mathrm{kN}$ of control force in each direction.

Velocity sensors are attached to the base, the first, the third and the sixth floors and an accelerometer is placed at the base. Measurements derived from these sensing devices serve as the feedback state variables in either of the two proposed control algorithms. The PC-Limited 286 microcomputer facilitated with $A / D$ and $D / A$ boards is used for on-line computation. The control logic is implemented on an $80286-24 \mathrm{MHz}$ processor and an 80287-10 MHz co-processor.

\subsection{Design Earthquakes}

For design purposes, the peak velocity of the design earthquakes was taken to be $10 \mathrm{~cm} / \mathrm{sec}$ based on local seismic records of the past seven years $($ maximum $=9.5 \mathrm{~cm} / \mathrm{sec}$ ). Accordingly, the scaled (32\%) El Centro earthquake with 98 $\mathrm{cm} / \sec ^{2}(0.1 \mathrm{~g})$ peak acceleration was determined as the design earthquake which corresponds to the criterion of $10 \mathrm{~cm} / \mathrm{sec}$ maximum velocity. Response analyses were also carried out using a series of recorded earthquake time histories to verify the adequacy of the design specifications.

\subsection{Control Algorithms}

The real-time computations in the microcomputer were based on a reduced order model (ROM) active control algorithm. Two basic algorithms based on the classical closed-loop linear optimal control law (Reinhorn, Soong et al, 1989) were designed for this investigation: (a) three-velocity feedback which uses only velocities measured at three critical floors in the structure (Soong, Reinhorn, et al, 1991) and (b) velocity feedback with observer which accounts for full dimensional state feedback with aid of a state estimator (Soong, Reinhorn et al, 1991).

Both algorithms were modified to include the compensation of delays in the force application with respect to the measured signal. The time delays are a result of phase shifts in instruments, conditioners, time required for on-line computation and time required for the actuator to respond. A phase type compensation was employed in connection with compensation of a parallel time delay in computations and actuators. All compensations were based on field measured performances of the control components (Reinhorn, Soong, et al, 1989).

\subsection{Simulated Results}

Simulations using several design earthquakes produced satisfactory results as shown in Table 2. The maximum power required during an earthquake reaches $20 \mathrm{kw}$ for most earthquakes except for Hachinohe earthquake where $50 \mathrm{kw}$ are required. The total energy consumption during an earthquake of one minute will be of the order of 0.3 $\mathrm{kwh}$ to $0.9 \mathrm{kwh}$ which can be delivered from passive electrical power sources. Additional power should be considered for the continuous operation of changing electrical and hydraulic equipment.

A typical structural response of the full-scale system is shown in Figures 2. The performance is shown for the top floor of the structure where both displacements and accelerations are reduced. As a result, the base shear is also substantially reduced. The required resources to produce such performance are shown in Figure 3 (for the strong direction of the structure for both actuators operating in this direction). The large forces are required for short period of times associated with several power peaks and a rapid initial energy demand.

\section{DESIGN OF ACTIVE BRACING SYSTEM (ABS)}

The primary parameters upon which the detail system design is based are the control force, the actuator displacement and the actuator velocity, 
which are related to the determination of the actuator capacity, the cylinder stroke, and the flow rate requirement of the hydraulic servovalve. In addition, the total flow of the hydraulic fluid required during a seismic event is the basis of sizing the hydraulic supply system. During the operating period of the active system, the hydraulic servo-controller supplies a constant flow of oil regardless of the actual requirement. When the demand of oil is more than what is supplied, the accumulator will pressure a subsidiary flow to the actuator cylinder; inversely, when supply is more than demand, excess oil will be discharged into the accumulator, thus no additional pumping is necessary during the short period of earthquake excitation. For economic reasons, the pumping rate of the controller is determined to be the average flow rate estimated over the time history of the cumulative flow such that the accumulator volume is minimized. These design parameters were established in accordance with the simulated results of resource demands required for a desired structural performance under the design earthquake as discussed below.

\subsection{Preliminaries}

The maximum control force and the specification of the hydraulic actuators were determined based upon the experimental study of a 1:4 scaled model. The fundamental frequency of the 1:4 scaled model was about $2.5 \mathrm{~Hz}$ and the time scale of the ground motions used in the tests was a reduction by a factor of $1 / 2$ of the prototype, which made the model dynamically similar to the fullscale structure having a fundamental frequency of approximately $1 \mathrm{~Hz}$ and subjected to the design earthquake. Therefore, the expected maximum control force of the full-scale system can be estimated to be proportional to the dimensions of the structure and the intensity of the ground motion.

The maximum control force normalized with respect to the weight of the structure was $9.5 \%$ for the 1:4 scaled model associated with a $40 \%$ reduction in relative displacement under the $25 \%$ El Centro earthquake with an appropriate change in time scale. It was assumed in the scaling of the active system that, for the same degree of reduction in response, the force to weight ratio remained the same for the full-scale structure if it is subjected to earthquakes of the same intensity as used in the scaled model tests. Accordingly, the expected maximum control force for the full-scale model weighing 600 metric tons was estimated to be about $712 \mathrm{kN}$ under $32 \%$ El Centro earthquake. Based on these estimates and the available manufactured units, two 35-ton hydraulic actuators were chosen in each direction. In other words, the active system can provide $685 \mathrm{kN}$ maximum control force uniaxially.

\subsection{Analysis and Design}

Having determined the specification of the hydraulic actuators, further analysis of the control system can be performed based on the associated parameters. A stiffness of the diagonal brace (including the actuator) of $61.3 \mathrm{kN} / \mathrm{mm}$ was assumed in the simulation in order to estimate the actuator displacement and velocity. Changes in the structural eigenproperties due to implementation of additional braces are insignificant, therefore the influence of bracing on the structural dynamics was neglected in the analysis. The flow rate requirement of the actuator or the hydraulic servovalve was in turn calculated from the piston area of the cylinder and the actuator velocity based on a first-order approximation. Analytical simulations were performed only in the strong direction for design purposes and the same design specifications were used in the other direction.

\subsubsection{Design of Passive Power Resource}

The required flow rate of the hydraulic cylinders can be determined approximately in terms of the piston area and the actuator velocity. Figure 4 illustrates the cumulative flow accumulated during an earthquake, which is obtained by integrating the time history of the flow rate. The slope of this curve represents the instantaneous flow rate required to achieve the control goal. It is observed from interpreting the slope of the curve that system demand is the highest between 2 and 5 seconds and less so over the rest of the time history, a property apparently resulted from the nonstationary nature of the earthquake motion and the control effect contributed in the previous time period. The linear curve represents the cumulative volume of a constant flow which is obtained by minimizing the difference between the demand and supply of oil using the least-square criterion. The largest difference between the cumulative flow and the average flow indicates the minimum volume of the hydraulic accumulator to be considered in design. 


\subsection{Specification}

\subsubsection{Braces}

The design of the braces is based on the maximum control force and the anticipated stiffness with the assurance that buckling will not occur under actuator actions. Circular steel tubes were used as bracing members with the following specifications: length $=360.5 \mathrm{~cm}$, diameter $=165.2$ $\mathrm{mm}$, thickness $=4.5 \mathrm{~mm}$ and strength $=564 \mathrm{kN}$.

\subsubsection{Hydraulic Actuators}

Four units of PARKER, heavy duty hydraulic cylinder series $2 \mathrm{H}$ - style TC (NFPA style Mx2) were selected as controllers with the following specifications: length $=73.5 \mathrm{~cm}$, piston diameter $=152.4 \mathrm{~mm}$, rod diameter $=63.5 \mathrm{~mm}$, stroke $=$ $\pm 5 \mathrm{~cm}$, and average capacity $=344 \mathrm{kN}$.

The average capacity of the actuator is calculated from the working pressure $(3,000 \mathrm{psi})$ of the hydraulic oil and the average piston area, i.e., average of the piston area on one side and the same area minus the rod area on the opposite side of the piston. The capacity can be improved by increasing working pressure of the hydraulic oil.

\subsubsection{Hydraulic Servovalve Manifold}

A pair of hydraulic actuators is monitored by a unit of servovalve controllers in each direction. Hydraulic accumulators are provided to regulate oil supply without additional pumping during earthquake motions (within $1 \mathrm{~min}$. in general). Only $1 / 3$ of the accumulator volume contains hydraulic oil, the rest is filled with nitrogen. The mechanical system gains substantial pressure with only a slight volume change of the nitrogen. A margin was added in sizing the accumulator, in addition to the calculated quantity shown in Table 2 , to account for energy loss due to pressure drop and error due to the first-order approximation, respectively.

Two units of MTS model 252.2x servovalves with flow rating of $15 \mathrm{gpm}(55 \mathrm{lpm})$ at $1000 \mathrm{psi}$ pressure drop were used accompanied with two five-gal. pressure accumulators and two two-gal. return accumulators.

\subsection{Verification}

From the analytical data shown in Table 2, it was found that the design was appropriate for almost all earthquake records used except for the case of Hachinohe earthquake. In that case, it requires a maximum control force of $696.5 \mathrm{kN}$ which is far beyond the design capacity of the system if the same control strategy is to be used. Investigation was made by restricting the output control force within the design capacity of the actuator while using the same feedback gains. Results show less reduction of structural response (about 30\% in displacement and 47\% otherwise) when the control force is restricted to $333 \mathrm{kN}$ per actuator whereas stability of the mechanical system is preserved.

This situation should also be taken into account in the on-line control practice due to erratic nature of earthquake ground motions.

\section{EXPERIMENTAL PERFORMANCE OF CONTROL SYSTEMS}

Recently, the construction was completed and initial tests were performed on the site. The tests included three stages: (a) control of microtremor excitation due to traffic and wind; (b) control of free vibration of the structure after excitation produced by the use of the active mass damper as a force exciter; and (c) control of forced vibration using the active mass damper exciter. Typical test results are presented herein as an illustration of the system performance.

Figure 5(a) shows the uncontrolled structural response in both directions. The decayed rate of the uncontrolled response is very slow because the system is only slightly damped (1\% in the strong direction and $0.5 \%$ in the weak direction). Figure 5(b) shows the build-up of the structural vibration and then the influence of control applied at the peak of excitation. The increase in damping is evident, showing, for example, an increase from $0.5 \%$ to $3.5 \%$ in the weak direction. The influence of control during forced vibration is shown in Fig. 5(c). The response builds up in the transient stage and reaches its steady state, which is evidently smaller than the previous tendency as shown in Fig. 5(b). 


\section{CONCLUSIONS}

Presented in this paper are design, simulation and performance of a full-scale active bracing system which was recently installed in a full-scale test structure. All components of the system were selected from currently available hardware and the power and energy resources required for this structural application were found to be within limits of current technology.

Analytical simulation and initial structural tests indicate that the system can produce significant structural response reduction. While more widespread applications of active structural control systems must await more extensive analytical and experimental verification, results obtained to date have been very encouraging and more full-scale demonstrations are expected to confirm these findings.

\section{ACKNOWLEDGEMENT}

This work was supported in part by the National Center for Earthquake Engineering Research under Grant Nos. NCEER-89-2201 and NCEER-902201. The authors are indebted to MTS Systems Corporation, Takenaka Corporation and Kayaba Industry Co., Ltd. for their technical assistance, consultation and financial support.

\section{REFERENCES}

1. Kobori, T. (1990), "State-of-the-art of Active Control Research in Japan," Proc. National Workshop on Structural Control, Los Angeles, CA.

2. Reinhom, A.M. and Soong T.T., et al. (1989), "1:4 Scale Model Studies of Active Tendon Systems and Active Mass Dampers for Aseismic Protection," Report NCEER-89-0026, National Center for Earthquake Engineering Research, Buffalo, NY.

3. Soong, T.T. (1990), "State-of-the-art of Active Control Research in the U.S.," Proc. National Workshop on Structural Control, Los Angeles, CA.

4. Soong, T.T. (1990), Active Structural Control: Theory and Practice, Longman, London and Wiley, NY.
5. Soong, T.T. and Reinhorn, A.M., et al. (1991), "Full-scale Implementation of Active Control, I. Design and Simulation," ASCE J. Structural Engineering (in press).
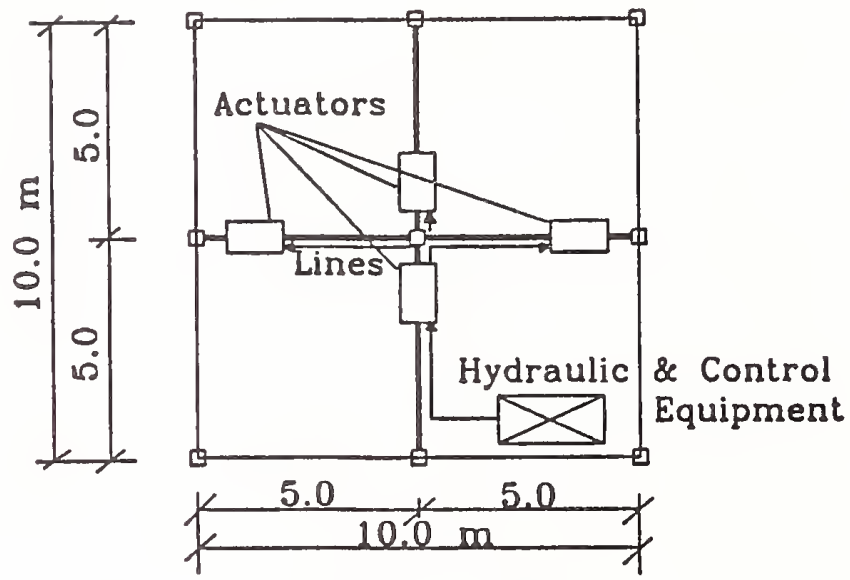

(a) Top View

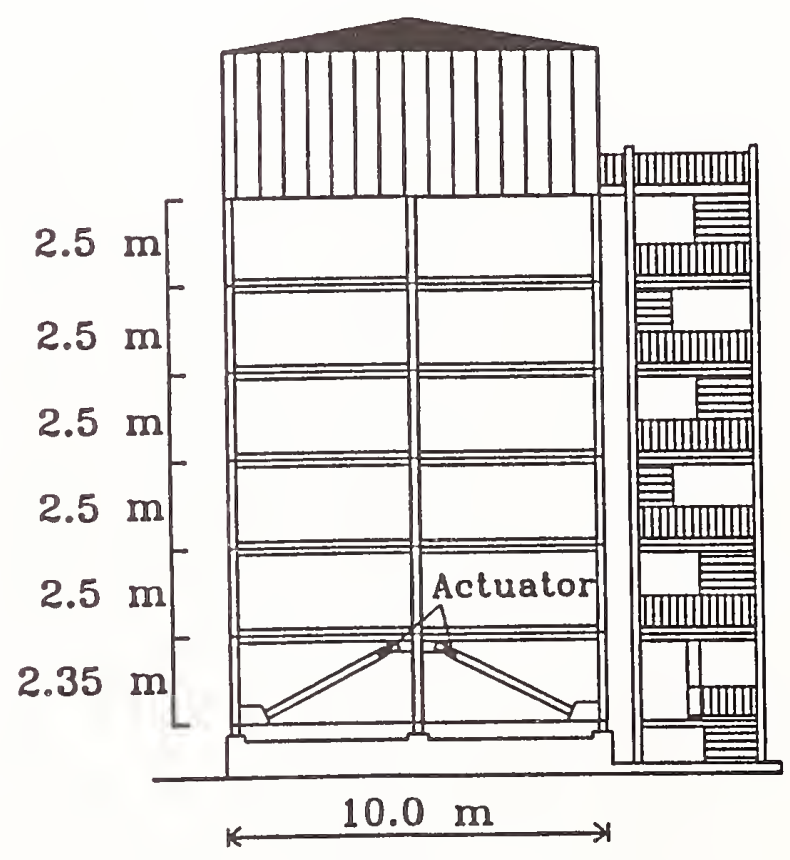

(b) Front View

Figure 1. Test Structure and Active Bracing System 
Table 1. Modal Frequencies of Test Structure

\begin{tabular}{|c|c|c|c|c|}
\hline \multirow{2}{*}{ Mode } & \multicolumn{2}{|c|}{ X-direction } & \multicolumn{2}{c|}{ Y-direction } \\
\cline { 2 - 5 } & $\begin{array}{c}\text { Record } \\
(\mathrm{Hz})\end{array}$ & $\begin{array}{c}\text { Analysis } \\
(\mathrm{Hz})\end{array}$ & $\begin{array}{c}\text { Record } \\
(\mathrm{Hz})\end{array}$ & $\begin{array}{c}\text { Analysis } \\
(\mathrm{Hz})\end{array}$ \\
\hline 1 & 0.900 & 0.922 & 0.650 & 0.643 \\
\hline 2 & 2.700 & 2.703 & 1.800 & 1.750 \\
\hline 3 & 4.650 & 4.737 & 2.975 & 2.918 \\
\hline 4 & 6.850 & 6.973 & 4.125 & 4.117 \\
\hline 5 & 9.400 & 9.481 & 5.425 & 5.511 \\
\hline 6 & 12.75 & 13.03 & 7.250 & 7.623 \\
\hline
\end{tabular}

Table 2. Summary of Response Analysis Under Design Earthquakes

\begin{tabular}{|c|c|c|c|c|c|c|c|c|c|c|c|c|}
\hline \multirow[b]{2}{*}{ Earthquakes } & \multirow[b]{2}{*}{$\begin{array}{l}\text { Scale } \\
\text { factor }\end{array}$} & & \multicolumn{3}{|c|}{ Performance indices } & \multicolumn{7}{|c|}{ Resource requirement / Actuator } \\
\hline & & & $\begin{array}{l}\text { Top fl. } \\
\text { disp. } \\
(\mathrm{cm})\end{array}$ & $\begin{array}{l}\text { Top fl. } \\
\text { acc. } \\
(\mathrm{g})\end{array}$ & $\begin{array}{l}\text { Base } \\
\text { sliear } \\
(\mathrm{kN})\end{array}$ & $\begin{array}{l}\text { Control } \\
\text { force } \\
(\mathrm{kN})\end{array}$ & $\begin{array}{l}\text { Actuator } \\
\text { disp. } \\
\text { (cm) }\end{array}$ & $\begin{array}{c}\text { Max. } \\
\text { flow } \\
\text { rate } \\
\text { (gpm) }\end{array}$ & $\begin{array}{l}\text { Ave. } \\
\text { flow } \\
\text { rate } \\
\text { (gpm) }\end{array}$ & $\begin{array}{l}\text { Vol.ofa } \\
\text { ccum. } \\
\text { (gal.) }\end{array}$ & $\begin{array}{c}\text { Total } \\
\text { volume } \\
\text { of oil } \\
\text { (gal.) }\end{array}$ & $\begin{array}{c}\text { Power } \\
(\mathrm{kW})\end{array}$ \\
\hline El Centro & 0.32 & $\begin{array}{c}\text { Unctrl } \\
\text { Cirl } \\
\text { Red. }(\%) \\
\end{array}$ & $\begin{array}{l}7.98 \\
4.66 \\
41.6 \\
\end{array}$ & $\begin{array}{l}0.37 \\
0.23 \\
36.5 \\
\end{array}$ & $\begin{array}{c}1018.3 \\
618.0 \\
39.5 \\
\end{array}$ & 313.9 & 0.51 & 19.72 & 2.7 & 0.11 & $\begin{array}{c}0.74 \\
\text { in } 20 \mathrm{~s} \\
\end{array}$ & $20: 02$ \\
\hline Miyagioki & 0.68 & $\begin{array}{c}\text { Unctrl } \\
\text { Ctrl } \\
\text { Red. }(\%) \\
\end{array}$ & $\begin{array}{l}5.30 \\
3.27 \\
36.4 \\
\end{array}$ & $\begin{array}{l}0.43 \\
0.21 \\
50.7 \\
\end{array}$ & $\begin{array}{l}847.6 \\
547.4 \\
35.8 \\
\end{array}$ & 245.3 & 0.40 & 15.24 & 2.0 & 0.12 & $\begin{array}{c}0.71 \\
\text { in } 30 \mathrm{~s}\end{array}$ & 16.08 \\
\hline $\begin{array}{l}\text { Mexico } \\
\text { (N90W) }\end{array}$ & 0.65 & $\begin{array}{c}\text { Unctrl } \\
\text { Ctrl } \\
\text { Red. }(\%) \\
\end{array}$ & $\begin{array}{r}9.70 \\
5.80 \\
40.2 \\
\end{array}$ & $\begin{array}{l}0.32 \\
0.18 \\
44.2 \\
\end{array}$ & $\begin{array}{l}1347.9 \\
877.0 \\
35.0 \\
\end{array}$ & 255.1 & 0.41 & 6.21 & 1.2 & 0.18 & in $\begin{array}{l}1.33 \\
100 \mathrm{~s}\end{array}$ & 5.65 \\
\hline $\begin{array}{l}\text { Mexico } \\
(\mathrm{S} O 0 \mathrm{E})\end{array}$ & 1.115 & $\begin{array}{c}\text { Unctrl } \\
\text { Ctrl } \\
\text { Red. }(\%) \\
\end{array}$ & $\begin{array}{l}9.95 \\
6.99 \\
29.8 \\
\end{array}$ & $\begin{array}{l}0.34 \\
0.24 \\
30.4 \\
\end{array}$ & $\begin{array}{c}1389.1 \\
1000.6 \\
28.2 \\
\end{array}$ & 323.7 & 0.53 & 9.36 & 1.5 & 0.34 & in 2.13 & 10.77 \\
\hline $\begin{array}{c}\text { Pacomia Dam } \\
(\mathrm{S} 16 \mathrm{E})\end{array}$ & 0.095 & $\begin{array}{c}\text { Unctrl } \\
\text { Ctrl } \\
\text { Red. }(\%) \\
\end{array}$ & $\begin{array}{l}5.58 \\
3.90 \\
30.1 \\
\end{array}$ & $\begin{array}{l}0.35 \\
0.17 \\
50.7 \\
\end{array}$ & $\begin{array}{l}741.6 \\
500.3 \\
32.7 \\
\end{array}$ & 255.1 & 0.42 & 10.94 & 2.0 & 0.06 & $\begin{array}{l}0.47 \\
\text { in } 20 \mathrm{~s} \\
\end{array}$ & 10.06 \\
\hline $\begin{array}{l}\text { Pacomia Dam } \\
\text { (S74W) }\end{array}$ & 0.104 & $\begin{array}{c}\text { Unctrl } \\
\text { Ctrl } \\
\text { Red. }(\%) \\
\end{array}$ & $\begin{array}{l}4.14 \\
2.68 \\
35.1 \\
\end{array}$ & $\begin{array}{l}0.30 \\
0.14 \\
52.6 \\
\end{array}$ & $\begin{array}{r}606.3 \\
406.1 \\
33.0 \\
\end{array}$ & 176.6 & 0.29 & 9.35 & 2.0 & 0.055 & $\begin{array}{l}0.44 \\
\text { in } 20 \mathrm{~s} \\
\end{array}$ & 4.88 \\
\hline $\begin{array}{c}\text { Taft } \\
(\mathrm{N} 21 \mathrm{E})\end{array}$ & 0.715 & $\begin{array}{c}\text { Unctrl } \\
\text { Ctrl } \\
\text { Red. }(\%) \\
\end{array}$ & $\begin{array}{l}7.64 \\
4.36 \\
42.9 \\
\end{array}$ & $\begin{array}{l}0.63 \\
0.30 \\
53.3 \\
\end{array}$ & $\begin{array}{c}1083.0 \\
535.6 \\
50.5 \\
\end{array}$ & 333.5 & 0.54 & 18.29 & 3.0 & 0.12 & $\begin{array}{r}0.96 \\
\text { in } 20 \mathrm{~s} \\
\end{array}$ & 21.48 \\
\hline Tokyo & 1.48 & $\begin{array}{c}\text { Unctrl } \\
\text { Ctrl } \\
\text { Red. }(\%) \\
\end{array}$ & $\begin{array}{l}4.85 \\
3.73 \\
23.2 \\
\end{array}$ & $\begin{array}{l}0.33 \\
0.26 \\
21.1 \\
\end{array}$ & $\begin{array}{l}623.9 \\
406.1 \\
34.6 \\
\end{array}$ & 333.5 & 0.54 & 12.63 & 2.7 & 0.07 & $\begin{array}{l}0.37 \\
\text { in } 10 \mathrm{~s} \\
\end{array}$ & 21.60 \\
\hline Hachinohe & 0.60 & $\begin{array}{c}\text { Unctrl } \\
\text { Ctrl } \\
\text { Red. }(\%) \\
\end{array}$ & $\begin{array}{l}17.93 \\
9.48 \\
47.1 \\
\end{array}$ & $\begin{array}{l}0.79 \\
0.41 \\
48.6 \\
\end{array}$ & $\begin{array}{c}2731.1 \\
1471.5 \\
46.0 \\
\end{array}$ & 696.5 & 1.13 & 26.74 & 6.0 & 0.17 & $\begin{array}{l}1.51 \\
\text { in } 20 \mathrm{~s} \\
\end{array}$ & 59.02 \\
\hline $\begin{array}{l}\text { Hachinohe } \\
\text { (limited Cirl } \\
\text { force) }\end{array}$ & 0.60 & $\begin{array}{c}\text { Unctrl } \\
\text { Ctrl } \\
\text { Red. }(\%) \\
\end{array}$ & $\begin{array}{l}17.93 \\
12.65 \\
29.4 \\
\end{array}$ & $\begin{array}{l}0.79 \\
0.69 \\
12.5 \\
\end{array}$ & $\begin{array}{c}2731.1 \\
1660.8 \\
39.2 \\
\end{array}$ & 333.5 & 0.54 & 31.04 & 4.0 & 0.17 & in $20 \mathrm{~s}$ & 55.54 \\
\hline
\end{tabular}



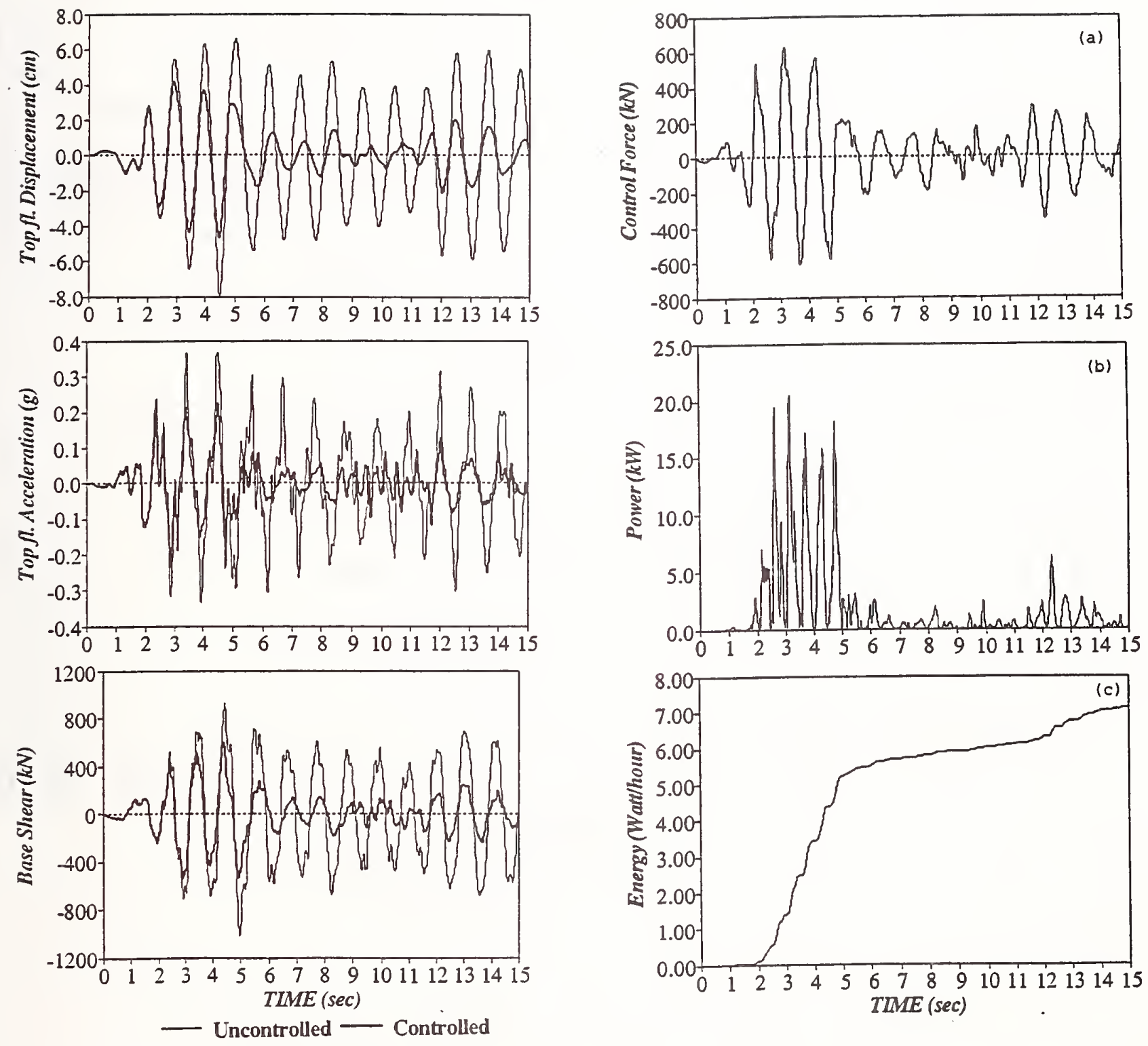

Figure 2. Structural Response Under 32\% El Centro Earthquake

Figure 3. Control Requirements Under 32\% El Centro Earthquake 


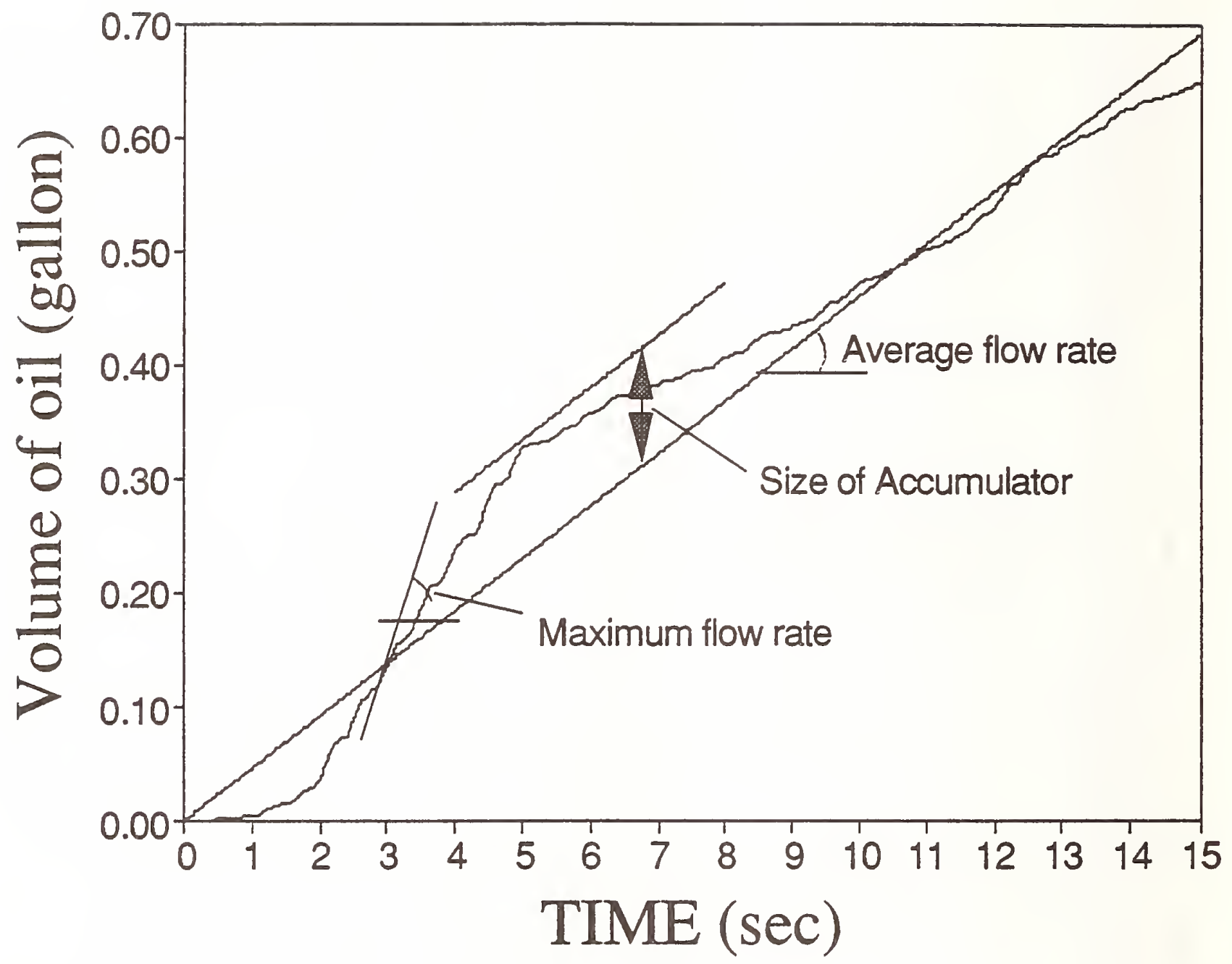

Figure 4. Cumulative Oil Flow During 32\% El Centro Earthquake 

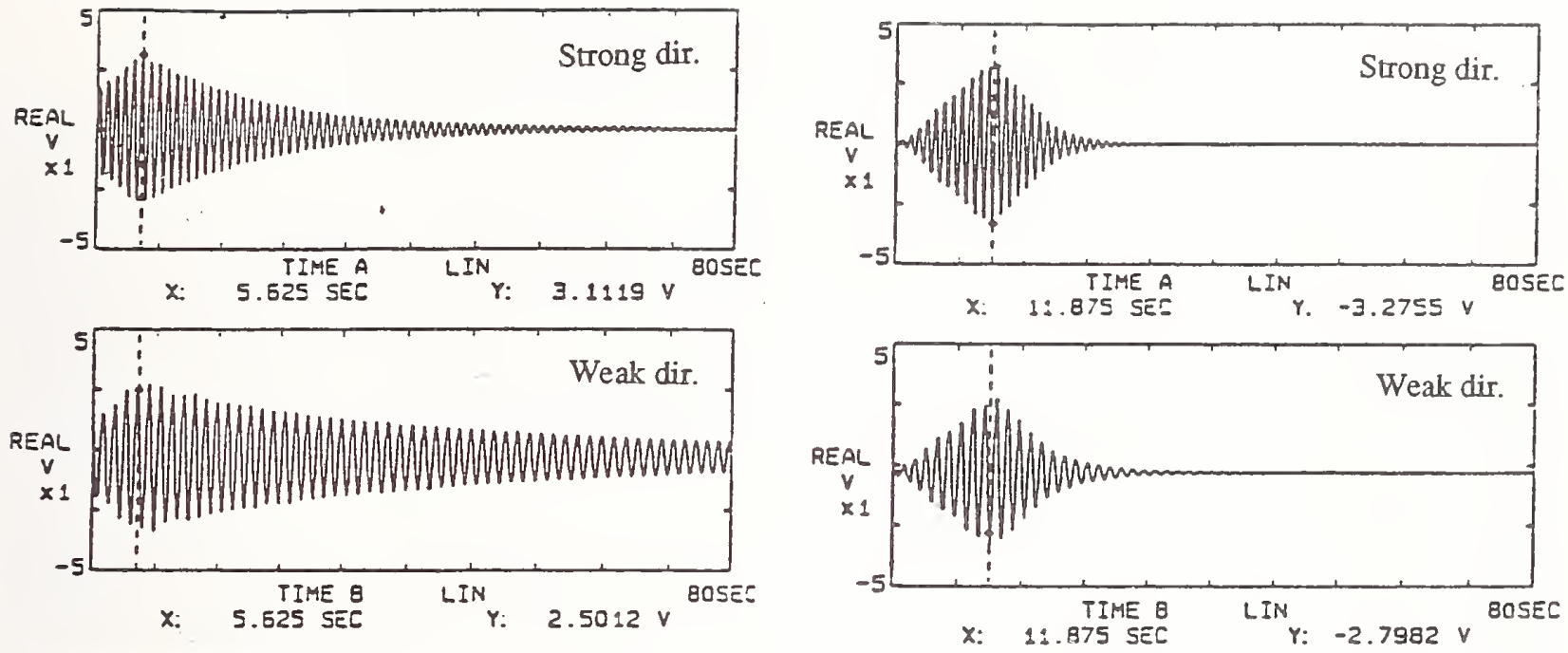

(a) Uncontrolled Free Vibration

(b) Controlled Free Vibration
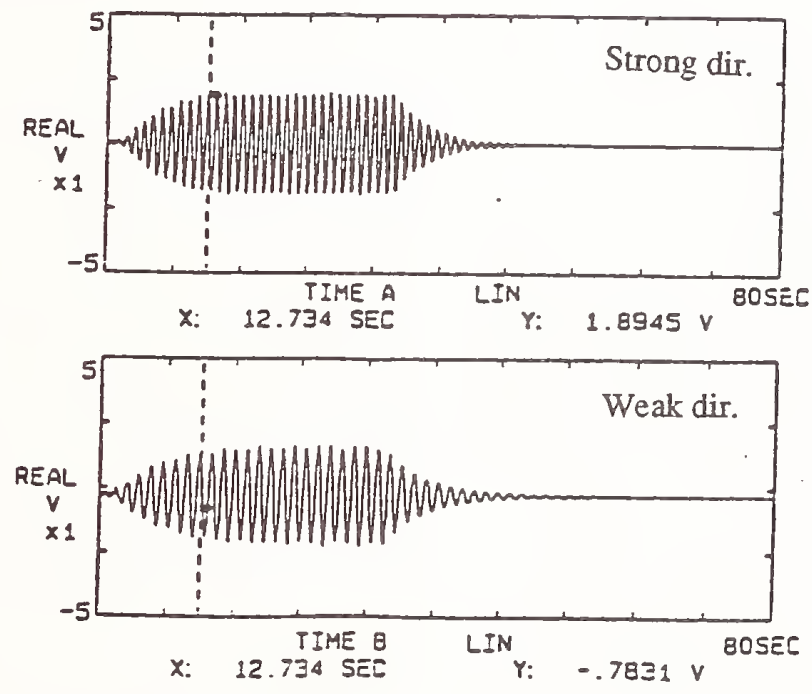

(c) Controlled Forced Vibration

Figure 5. Preliminary Test Results of Full-scale Structure 


\section{Yoshikazu KITAGAWA ${ }^{1}$ and Mitsumasa MIDORIKAWA ${ }^{2}$}

\section{SUMMARY}

A total number of 59 design plans on base-isolated building structures have obtained the required special permissions in Japan by the end of March, 1991. This paper presents the characteristics, present state and safety evaluation guideline of base-isolated building structures.

KEY WORDS: Base-isolated Building Structure, Characteristics of Base-isolated Building Structure, Seismic Safety Evaluation.

\section{INTRODUCTION}

Japan is characteristically subjected to seismic activity, therefore, it is a matter of concern how building structures behave under earthquake conditions. Currently the research focus for a seismic design method has been changed from static analysis to dynamic analysis.

Many studies and proposals concerned with the base isolation system have been carried out. Some of those studies and proposal were realized by actual structures in New Zealand, France, U.S.A., Japan and other countries. Recently, base-isolated building structures have been proposed and enthusiastically put into practice in Japan, although the ball bearing system was proposed by Dr. K. Kito in 1924.

In this paper, characteristics, present state and safety evaluation guideline of base-isolated building structures are briefly presented.

\section{CHARACTERISTICS OF BASE- ISOLATED BUILDING STRUCTURES}

There is a recent technical trend that introduces the base isolation method to diminish the seismic load. The ultimate objective of base-isolated structures is that the structure not be destroyed. In that sense, baseisolation may be said to be method for making aseismic structures. However, its aim of obtaining earthquake resistance by means of reducing the seismic load on the structure makes the base isolation system slightly different from other types of earthquake resistant design methods in that the increased strength and ductility of the structure actually improve its earthquake resistance.

If we assume that ball-bearings can be easily placed between perfectly flat plywood slabs, the resulting structure will possibly have a natural period of unlimited length. This implies a static point so that the structure will not move due to horizontal earthquake ground motions. However, since the structure is actually supported at the points where it touches the ball-bearings, the response force concentrates there. This leads to a supporting point, not allowing a static point to be formed. Since there is no restoring force, there is no guarantee that the structure, after the earthquake ends, will remain its original position. There are several possible means to secure a restoring force, such as the use of both bearings and springs, or roughening the steel surface. With an accompanying restoring force, the resulting structure will possess a longer, but not infinite, natural period.

The base isolation system thus tries to reduce input earthquake ground motion by means of lengthening the overall natural period. Nowadays, laminated rubber bearings composed of thin layers of steel plates and rubber are primarily used. This type of systems is firm against vertical loading and is horizontally flexible ${ }^{1)}$ (see Fig. 1). Energy absorption mechanisms, in use today, include combinations of laminated rubber and various kinds of dampers, (e.g., elasto-plastic, viscoelastic, viscous, friction), laminated rubber containing lead, high-damping laminated rubber, as well as a combination of elastic sliding bearings that use low-friction Teflon and horizontal dampers (see Table 1). In this last case, the overall restoring force characteristics are determined by the friction of the sliding bearings and the restoring force of

1) Dr. Engrg., Director of Production Dept., Building Research Institute, Ministry of Construction.

2) Dr. Engrg., Head of Earthquake Engineering Div. II, IISEE, BRI, MOC. 
the dampers. The natural period of the overall system is able to be adjusted.

Base-isolated building structures have two goals: first, to reduce transmitted earthquake motion by means of lengthening the overall natural period; second, to absorb the earthquake ground motion energy during severe earthquakes by the use of various types of dampers (see Fig. 2). As a result, the baseisolated building structure itself behaves as a rigid body at time of an earthquake. Also, since it forms a so-called "non-vibration space", it does not suffer any story drift as do other structures which are directly lined to the ground (see Fig. 3). This has the effect not only of reducing input earthquake ground motion to the structure during an earthquake, but also of increasing added effect to the structure.

The base isolation system is beneficial to buildings that require a more variety of possible construction sites and/or improved safety and so on. Such building might include museums, art galleries, socially and culturally important buildings containing motion sensitive equipment, such as built-in sophisticated computer network systems, hospitals with expensive medical facilities and equipment, medical-care centers, hotels and condominiums needing a variety of facades, low- and medium-rise apartment buildings containing personal property as well as energy-related buildings such as nuclear power stations.

\section{PRESENT STATE OF BASE-ISOLATED BUILDING STRUCTURES}

Currently, construction of base-isolated building structures in Japan requires the special permission from the Minister of Construction to fulfill Article 38 of the Building Standard Law. The reason is that the base isolation system is a new technology where the design standards and specifications are not yet fully documented.

The first step in the building process requires that the design be examined by the Base Isolation Research Committee (Chairman: Prof. M. Izumi, Univ. of Tohoku ) in the Building Center of Japan. This committee specializes in examining design criteria and specific base isolation system mechanisms to determine whether or not the base-isolated building structure has attained a safety level as a total system. The committee then states the necessary recommendations for compliance.
The next step in the process is to have the planned structure examined by the Baseisolated Building Structure Appraisal Committee (Chairman: Prof. Y. Inoue, Univ. of Osaka). The planned structure is inspected from technical point of view as to its structural strength, safety, the durability and maintenance of the base isolation device. In the case where the planned structure is equipped with a similar base isolation device previously examined by the Base Isolation Research Committee, the Base-isolated Building Structure Appraisal Committee examines only the base isolation system in question.

By the end of March, 1991, a total number of 59 structure design plans have obtained the required special permissions. Construction companies have rapidly been putting these plans into practice. Experiments, earthquake observations and various types of analysis have been carried out on such baseisolated building structures. The results have been presented at a conference sponsored by the Architectural Institute of Japan, at the World Conference on Earthquake Engineering as well as other presentations.

Fig. 4 and Table 2 show an example of design procedures of base-isolated buildings, and an example of design criteria on earthquake response of a base-isolated building structure, respectively.

\section{SAFETY EVALUATION GUIDELINE FOR BASE-ISOLATED BUILDING} STRUCTURES

The Base Isolation Safety Evaluation Committee (Chairman: Prof. H. Aoyama, Univ. of Tokyo) established by the Building Center of Japan proposed the safety evaluation guideline for base-isolated building structures 3) in 1989.

This guideline applies to a base-isolated building structure that is constructed on either hard or intermediate soil and with a height less than 45 meters. However, application of part of this guideline may be waived for a baseisolated building structure which was designed in accordance with special investigations. This guideline requires that target performances in six areas be carried out in the following areas: (1) overall seismic safety; (2) overall wind safety; (3) overall safety in architectural details and equipment design; (4) overall durability of isolation devices; (5) overall fire resistance of isolation devices; and (6) overall construction and maintenance of the isolation devices. 
Base-isolated building structures are classified based on their response to level-2 earthquake ground motions ${ }^{2}$ ) (see Table 3 ). A level-2 earthquake ground motion corresponds to a probable maximum earthquake event currently defined as earthquake ground motion at a ground velocity of $50 \mathrm{~cm} / \mathrm{sec}$ in the Tokyo area. Buildings in each category are reviewed with accordance to safety consideration. The notation $\mathrm{A}^{+}, \mathrm{A}^{-}, \mathrm{B}^{+}, \mathrm{B}^{-}$and $\mathrm{C}$ in Table 2 correspond to the safety evaluation levels: a level $\mathrm{A}^{+}$design is considered to be the most conservative design, hence inherently safe, whereas a level $C$ design is the least conservative. Differences between these safety evaluation levels result in requiring which safety evaluation items be addressed. The required items may include, but are not limited to, the following: architectural design, soil condition, structural design, isolation devices, earthquake response analysis, analytical model, natural period, earthquake ground motions, evaluation for level-2 earthquake ground motions, and/or evaluation of safety margin. A level $\mathrm{A}^{+}$design will require the least number of items, while a level $\mathrm{C}$ design will require the most.

Article 83 of the Building Standard Law specifies the combination loads used in determining a design load acting on a baseisolated building structure with the exception of an earthquake load. This guideline specifies the calculation method for the earthquake load case.

First, an earthquake load acting on the superstructure is to be calculated using the following relationship.

where

$$
\mathrm{C}_{\mathrm{i}}=\alpha \cdot \mathrm{Z} \cdot \mathrm{B}_{\mathrm{B}} \mathrm{A}_{\mathrm{i} \cdot \mathrm{B}} \mathrm{C}_{0}
$$

$\mathrm{C}_{\mathrm{i}}=$ design story shear coefficient of the superstructure;

$\alpha=$ isolation characteristics factor reflecting the base isolation effect;

$\mathrm{Z}=$ seismic zone factor;

${ }_{\mathrm{B}} \mathrm{A}_{\mathrm{i}}=$ distribution factor of story shear force coefficient along the superstructure $\left(\mathrm{B}_{1}\right.$ $=1$ at the lowest story of the superstructure); and

${ }_{\mathrm{B}} \mathrm{C}_{0}=$ standard shear coefficient to be taken equal to 0.2 .

Second, an earthquake load acting on the substructure is the sum of earthquake load acting on the superstructure as determined by Eq. (1) and the earthquake load acting on each part of the substructure. The latter is determined by the procedure with the exception when isolation devices are installed in an intermediate story.

Lastly, for the case when isolating devices are installed in an intermediate story an earthquake load is determined by an appropriate analysis that accounts for the effect of response amplification of the substructure to both the isolation devices and superstructure as well as the transfer of the earthquake load from the superstructure to substructure.

The effect of base isolation is best reflected by an appropriate response analysis of the structure to earthquake-type base excitation. The coefficients $\alpha$ and $\mathrm{B}_{\mathrm{i}}$ are, thus, to be determined by the preliminary response analysis to level-1 earthquake ground motions. This level corresponds to an once-in-a-lifetime earthquake event defined as a maximum ground velocity of $25 \mathrm{~cm} / \mathrm{sec}$ in the Tokyo area.

In general, a base-isolated building structure must be shown to respond to two levels of earthquake ground motions ${ }^{2)}$ for target performance in earthquake resistance. First, during a level-1 earthquake, the superstructure must remain in the elastic range, and the isolation devices must remain within stable deformation (see Fig. 5). Also, during a level-2 earthquake, the superstructure remains within a general yield of the stories (or within a permissible ductility factor), and isolation devices must remain within a performanceinsured deformation.

The degree of safety allowance must be investigated for all base-isolated building structures except for a level A+ design in either case where the superstructure is expected to absorb energy by inelastic deformation, or where the isolating devices undergo deformations larger than stable deformation. Confirmation of the safety allowance is necessary as the level-2 earthquake response analysis does not necessarily cover all the possible unfavorable conditions. These include uncertainty in the input earthquake waveform, the analysis method and the analytical model. Particularly important is the uncertainty in stiffness evaluation of laminated rubber bearings, variation due to manufacturing conditions, hardening or softening in the large deformation range, and eccentricity. Also important is the evaluation of load variation due to earthquake ground motion. Laminated rubber bearings are currently designed in such a way that no tension would be allowed even in case of a leve1-2 earthquake. However, in the 
confirmation of safety allowance, performance of isolating devices beyond this limit is investigated.

\section{CONCLUDING REMARKS}

This paper has presented a brief outline of: (1) characteristics of base-isolated building structures; (2) present state of base-isolated building structures; and (3) safety evaluation guideline for base-isolated building structures.

When the guideline is finally approved and in effect, a relatively conventional and conservative base-isolation design can be reviewed directly by the Safety Evaluation Committee. The state of a base-isolation system is still in its development stage, and a general social consensus for seismic safety of this kind of structure as a new technical trend is yet to be developed.

\section{REFERENCES}

1) "Report on Durability and Reliability of Laminated Rubber Bearings for Base-isolated Structures", the Society of Rubber Industry, Japan, 1988 (in Japanese).

2) High-rise Building Structure Appraisal Committee, "Earthquake Motions of Highrise Building for Dynamic Analysis", the Building Letter, No. 203, the Building Center of Japan, June, 1986, pp. 49-50 (in Japanese).

3 ) "Report on New Building Construction Technology-No. 2, Safety Evaluation Guideline for Base-isolated Building Structures", the Building Center of Japan, 1989 (in Japanese). 
Table 1 Classification of Isolating Devices ${ }^{3)}$

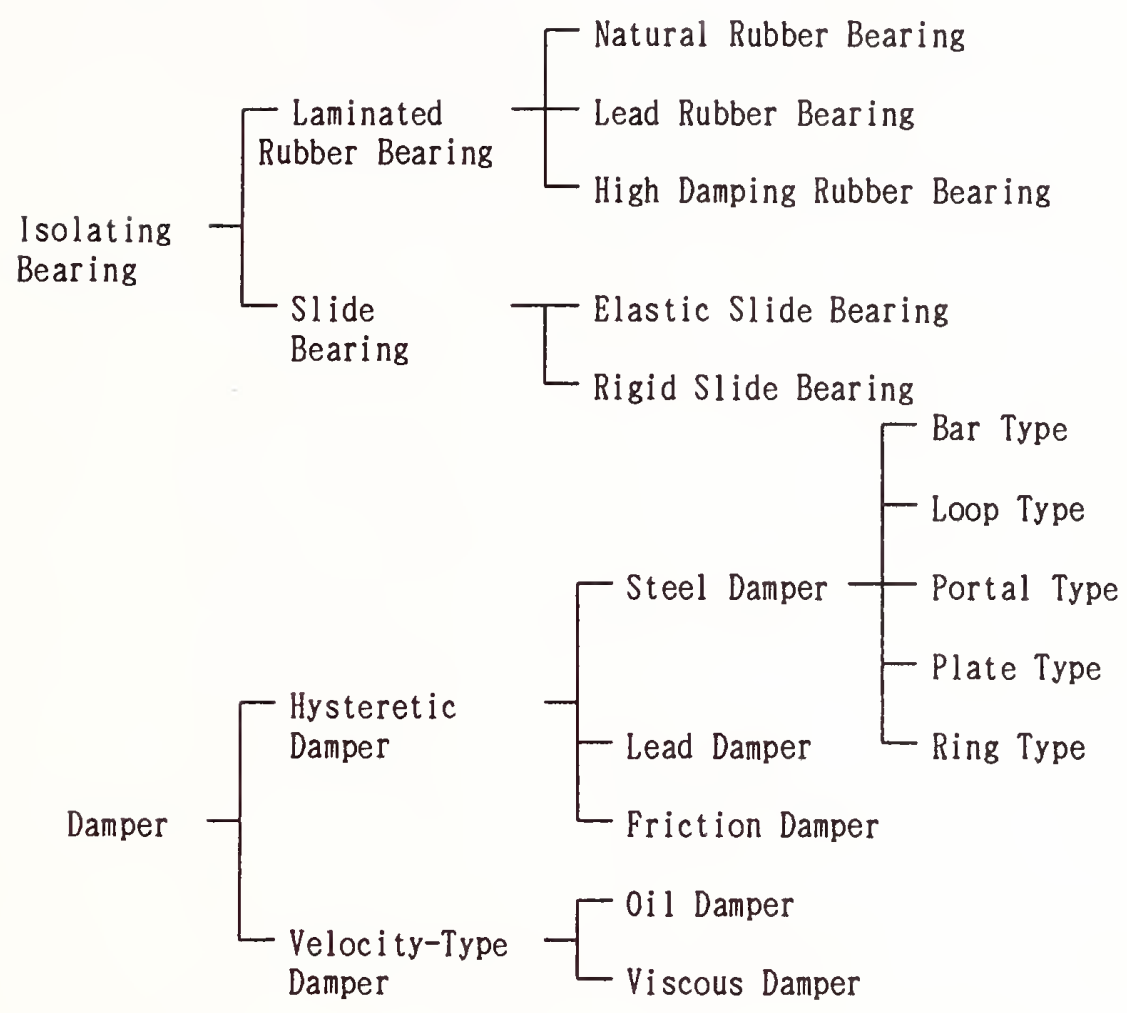

Table 2 Example of Seismic Response Criteria

\begin{tabular}{|c|c|c|}
\hline \multirow{2}{*}{$\begin{array}{c}\text { Ear thquake } \\
\text { Level }\end{array}$} & \multicolumn{2}{|c|}{ Seismic Performance } \\
\hline & Superstructure & Laminated Rubber Bearing \\
\hline $\begin{array}{c}1 \\
(25 \mathrm{~cm} / \mathrm{s})\end{array}$ & $\begin{array}{l}\text { Not exceeding } \\
\text { Al lowable Stress }\end{array}$ & $\begin{array}{l}\text { Less than } 100 \% \text { of Shear } \\
\text { Strain }\end{array}$ \\
\hline $\begin{array}{c}2 \\
(50 \mathrm{~cm} / \mathrm{s})\end{array}$ & $\begin{array}{l}\text { Not exceeding } \\
\text { Initial Yield } \\
\text { Strength }\end{array}$ & $\begin{array}{l}\text { Less than } 200 \% \text { of Shear } \\
\text { Strain }\end{array}$ \\
\hline $\begin{array}{l}\text { Earthquake for } \\
\text { Confirmation } \\
\text { of Safety } \\
\text { Allowance } \\
(50 \sim 75 \mathrm{~cm} / \mathrm{s})\end{array}$ & $\begin{array}{l}\text { Not exceeding } \\
\text { General Yield } \\
\text { Strength }\end{array}$ & $\begin{array}{l}\text { Less than } 300 \% \text { of Shear } \\
\text { Strain }\end{array}$ \\
\hline
\end{tabular}


Table 3 Classification of Base-Isolated Building under Level 2 Earthquake ${ }^{3)}$

\begin{tabular}{|l|c|c|}
\hline \multicolumn{1}{|c|}{$\begin{array}{c}\text { Charcteristics of } \\
\text { Isolating } \\
\text { Characteristics Device } \\
\text { of Superstructure }\end{array}$} & $\begin{array}{c}\text { B-I } \\
\text { Within Stable } \\
\text { Deformation }\end{array}$ & $\begin{array}{c}\text { B-I I } \\
\text { Within Performance- } \\
\text { insured Deformation }\end{array}$ \\
\hline $\begin{array}{l}\text { S-I Elastic Range } \\
\text { In Elast }\end{array}$ & $\mathrm{A}^{+}$ & $\mathrm{B}^{+}$ \\
\hline $\begin{array}{l}\text { S-II } \\
\text { Within General Yield of }\end{array}$ & $\mathrm{A}^{-}$ & $\mathrm{B}^{-}$ \\
\hline $\begin{array}{l}\text { S-III } \\
\text { Within Story Mechanism }\end{array}$ & $\mathrm{C}$ & $\mathrm{C}$ \\
\hline
\end{tabular}




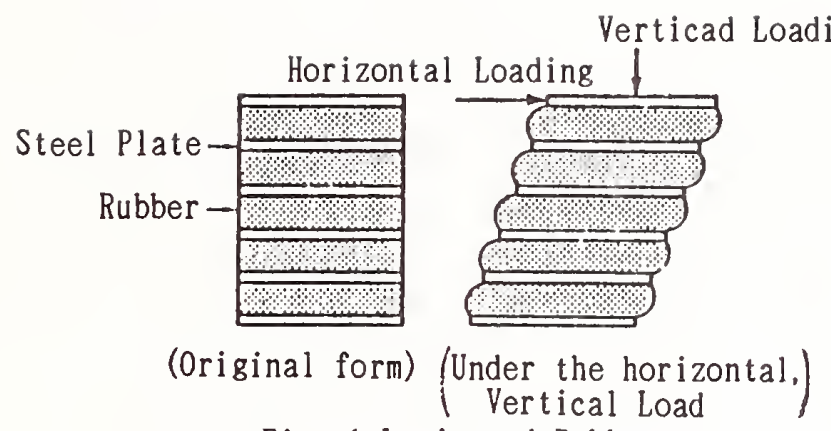

Fig. 1 Laminated Rubber
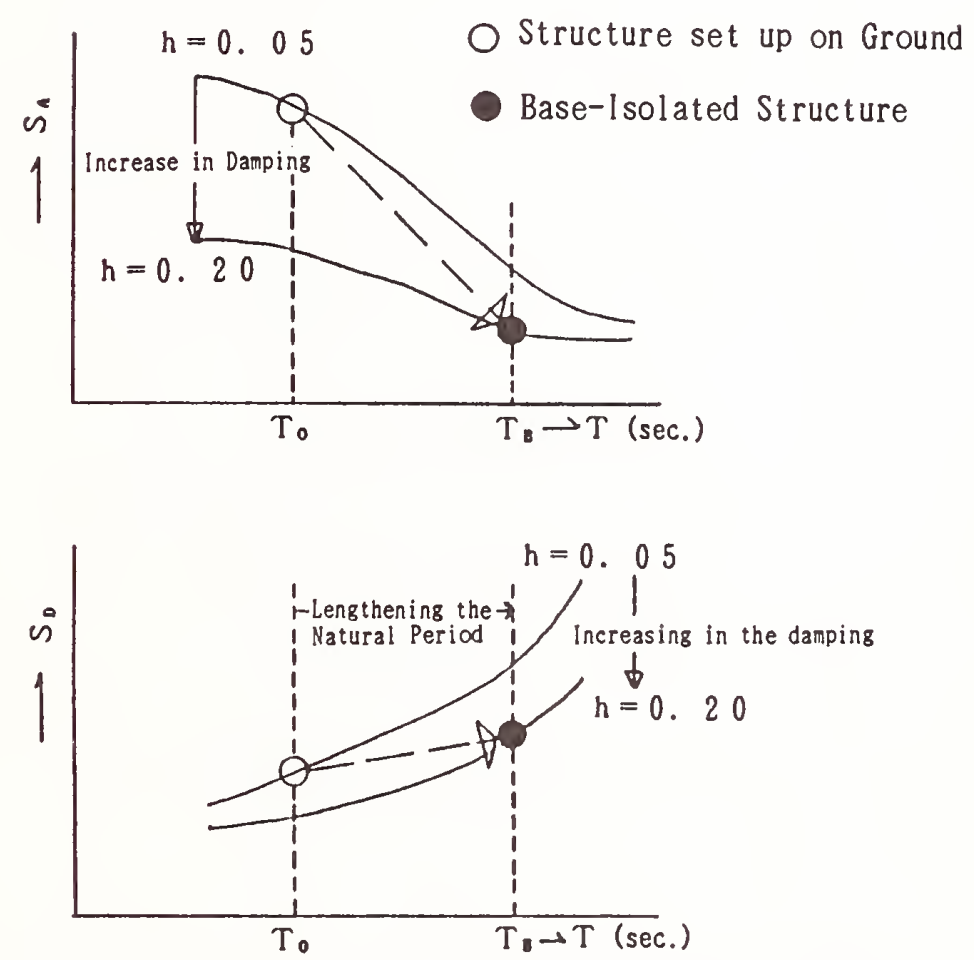

Fig. 2 Schematic Characteristics of Base-lsolated Structure

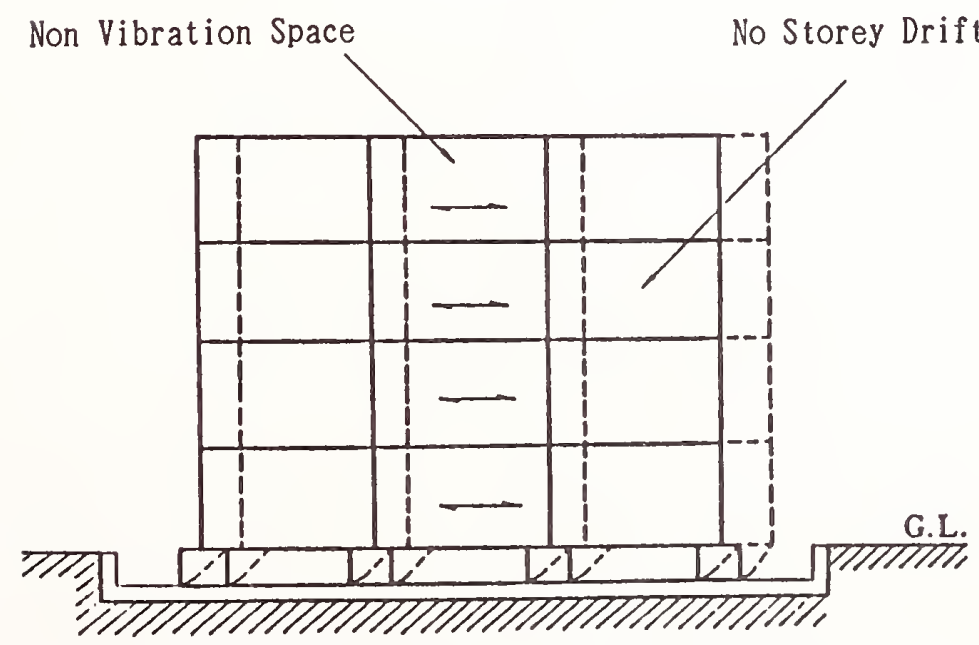

Fig. 3 Dynamic Behavior of Base-Isolated Structure 


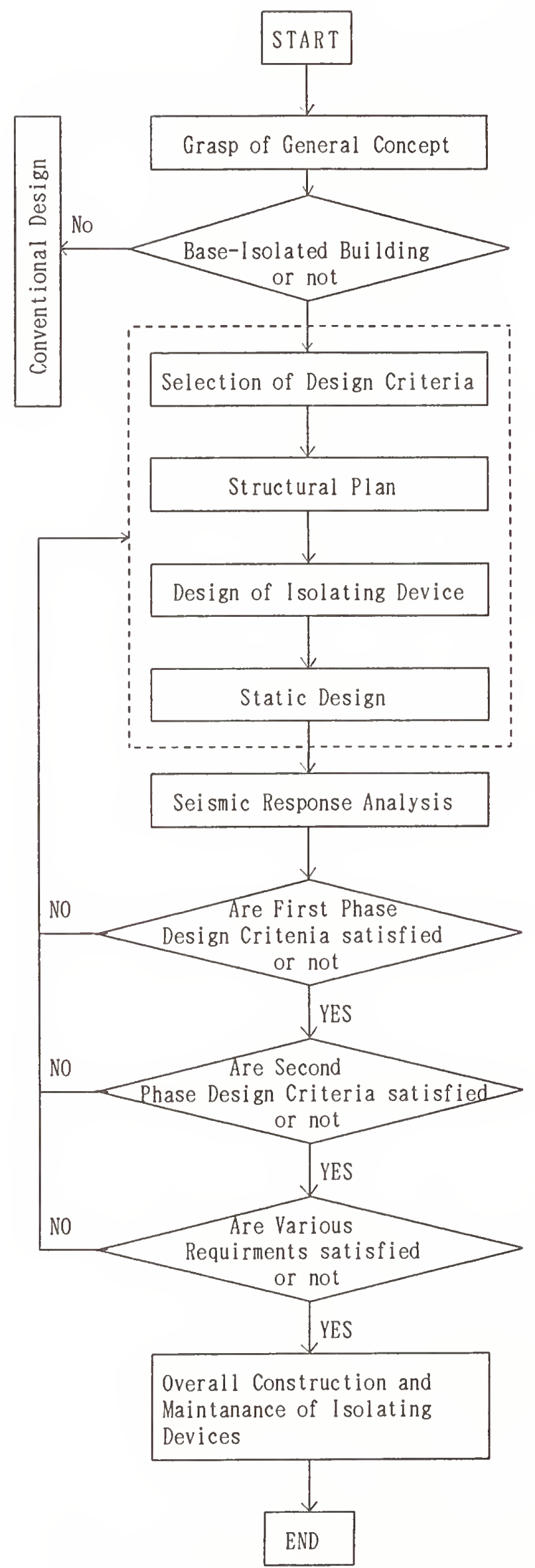

Fig. 4 Flowchart of Design Procedure 


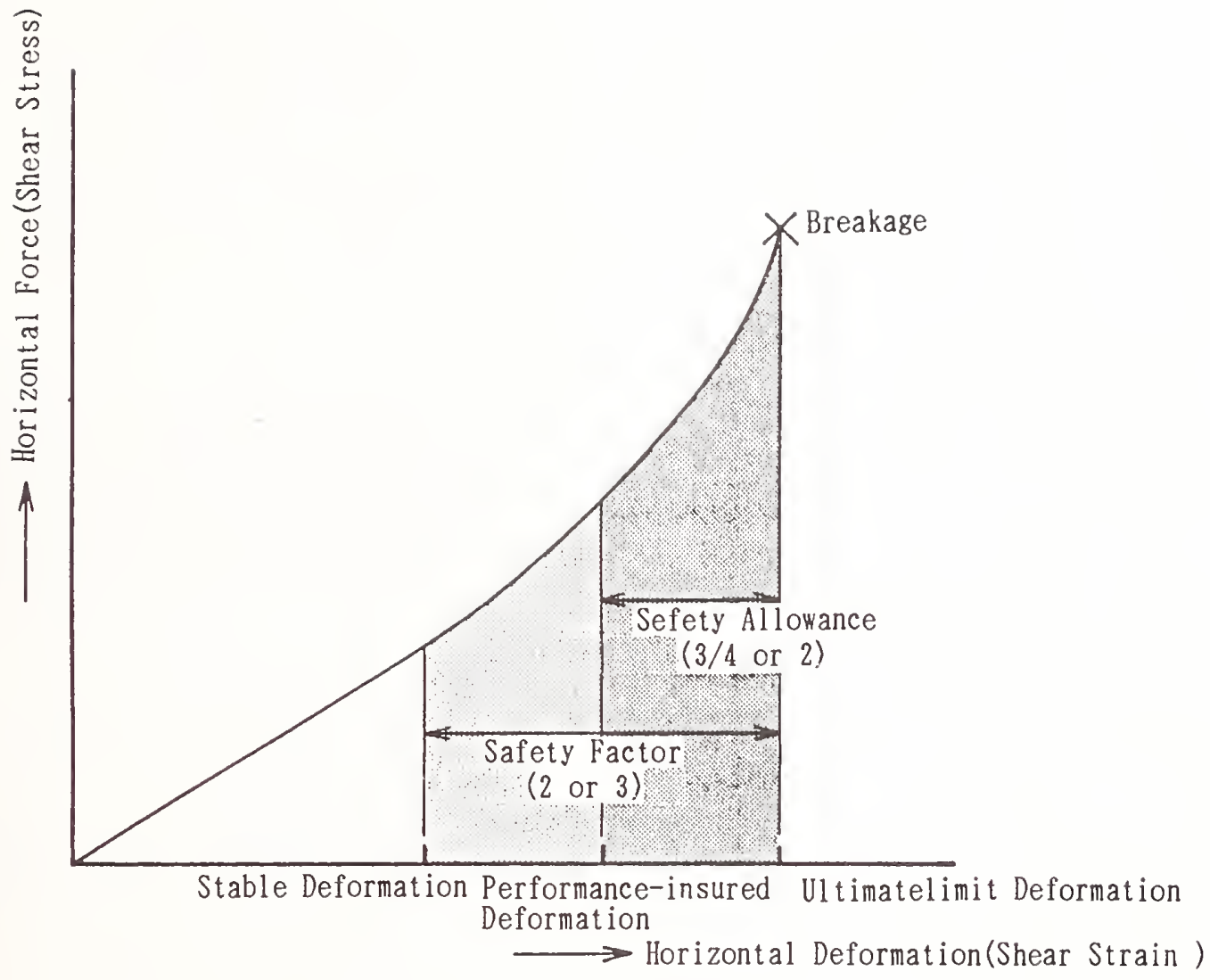

Fig. 5 Schematic Restoring Force Characteristics of Laminated Rubber Bearing ${ }^{3)}$ 


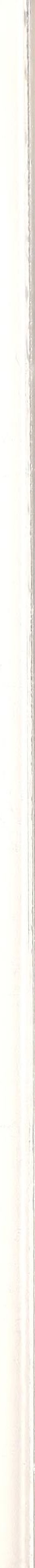




\title{
Dynamic Modeling of Soil-Structure Systems for Control Applications
}

\author{
H. A. Smith* and R. I. Borja*
}

\begin{abstract}
Much attention has been focused recently on the use of actively controlled structural systems in seismic zones. However, the majority of the models utilized in this research are highly simplified representations of the structural and foundation system, and usually do not consider model nonlinearities or complexities such as soil-structure interaction.
\end{abstract}

This paper presents and discusses a modeling technique for studying the effects of soil-structure interaction (SSI) on the active control of seismically excited structures. Instantaneous optimal control algorithms are used to formulate a system of equations applicable to both linear and nonlinear SSI systems. The resulting control equations of motion are solved in the time domain using a direct integration scheme which can be combined with Newton-Raphson iteration for nonlinear systems

This soil-structure interaction (SSI) model developed for use in this study is represented using a coupled finite element (FE) - boundary element (BE) formulation which has the capability to resolve fundamental difficulties such as radiation boundary conditions, nonproportional damping, and hysteretic behavior effectively. The foundation of the building is assumed to behave as a rigid body with both translational and rotational degrees-of-freedom.

KEYWORDS: active control; nonlinear; soilstructure interaction; earthquake; time-domain

\section{INTRODUCTION}

In recent years, considerable research efforts have been placed on the application of active control systems to structures in seismic zones. Many of these structures exhibit inelastic or nonlinear response which aids in the dissipation of energy but causes damage and unserviceability when excessive. Active control is used to ensure that these structures do not undergo extensive and prolonged deformations which could result in destruction.

Various control algorithms and systems, such as the active tendon control systems and active tuned mass dampers, have been investigated for tall structures undergoing earthquake excitations. However, most of the methods studied thus far have involved rigidbased structural models and rarely are the issues of nonlinear behavior and soil-structure interaction effects addressed.

Accurate representation of soil-structure interaction (SSI) effects is a crucial part of earthquake engineering analyses. To date, little work has been done to study the influence of SSI effects on the effectiveness of control algorithms. The properties of the underlying soil can significantly influence structural behavior and consequently alter the performance of a control algorithm formulated with the assumption of a rigid structural base. In this study, a nonlinear SSI model is developed for use with an instantaneous optimal control algorithm.

The purpose of the research is to determine how soilstructure interaction effects influence the active control of buildings subjected to strong ground motion. In Section 2, an overview of the previous work on nonlinear optimal control theory is given. Section 3 formulates the equations governing optimal control of the linear and nonlinear systems, and Section 4 describes the SSI model developed for use with the control algorithm. A summary of the work is given in Section 5.

\section{OVERVIEW OF ACTIVE CONTROL FOR STRUCTURES WITH RIGID FOUNDATIONS}

\subsection{General Theory}

For a linear, actively controlled one-dimensional structure represented using an $N$ degree-of-freedom finite element model, the equation of motion takes the form:

$$
M \ddot{y}(t)+C \dot{y}(t)+K y(t)=H u(t)+F_{E}(t)
$$

where $\mathbf{M}, \mathbf{C}$, and $\mathbf{K}$, are the system mass, damping, and stiffness matrices respectively; $y(t)$ is the vector

* Department of Civil Engineering, Stanford University, Stanford, California USA 94305-4020 
of system response; $\mathbf{H}$ is the matrix relating the locations of the control actuators to the system degrees-of-freedom; $\mathbf{u}(\mathrm{t})$ is the vector of control forces; and $F_{E}(t)$ is the vector representing the external excitation. Equation 1 can be transformed from a set of $N$ equations of motions into a set of $2 N$ state equations in the form:

$$
\dot{\mathrm{z}}(\mathrm{t})=\mathbf{A z}(\mathrm{t})+\mathbb{B} \mathrm{u}(\mathrm{t})+\mathrm{WF}_{\mathbf{E}}(\mathrm{t})
$$

where $\mathrm{z}(\mathrm{t})$ is the state vector; $\mathbf{A}$ is the system matrix; $\mathbf{B}$ is the matrix specifying the locations of the control actuators; and W is the matrix specifying the locations of the applied external forces.

Control algorithms for linear systems are well developed and extensively studied. Optimal control algorithms are based on the minimization of a quadratic performance index whose objective is to maintain the desired system state while minimizing the control effort. For a linear system, this performance index takes the form:

$$
J=\int_{0}^{t_{t}}\left[z(t)^{T} Q z(t)+u(t)^{T} R u(t)\right] d t
$$

where $\mathbf{Q}$ and $\mathbf{R}$ are the weighting matrices dictating the relative importance between the response state of the system, $\mathrm{z}(\mathrm{t})$, and the control forces, $\mathrm{u}(\mathrm{t})$, and $\mathrm{t}_{\mathrm{f}}$ is the duration of the earthquake.

In 1987, Yang et al. [Ref. 14] showed that the optimal control theory based on Eq. 3 is not applicable to seismically excited systems because the time-history of the excitation is not known a priori. As an alternative, they introduced instantaneous optimal control algorithms which are derived by minimizing a time-dependent quadratic performance index at every time step. This instantaneous performance function takes the form:

$$
J=\left[z(t)^{T} \mathbf{Q z}(t)+u(t)^{T} \mathbf{R u}(t)\right]
$$

These instantaneous optimal control algorithms were derived for open-loop, closed-loop and closed-openloop control systems. Yang concluded that all three instantaneous control algorithms yield identical results in an ideal control environment.

The equation of motion governing the response of an actively controlled system undergoing inelastic or nonlinear deformations takes the form:

$$
M \ddot{y}(t)+F_{I}(t)=H u(t)+W F_{E}(t)
$$

The internal force, $\mathbf{F}_{\mathrm{I}}$, is a function of $\mathbf{y}(\mathrm{t})$ and $\dot{y}(t)$ [Ref. 2] and is found from the expression:

$$
F_{\mathbf{I}}(t)=\int_{\text {Volume }} \widetilde{B}^{\mathbf{T}} \sigma d \mathbf{V}
$$

where $\widetilde{\mathbb{B}}$ is the matrix relating strains to displacements and $\sigma$ is the vector of internal stresses. Methodologies for the control of nonlinear systems have been studied less extensively than active control of linear systems. The remainder of this section presents the present state-of-the-art in active control research for systems behaving nonlinearly.

\subsection{Review of Control Algorithms for Nonlinear Structures}

In 1981, Masri et al. [Ref. 13] presented a method which utilized portable gas pulse generators to actively control structural response. This control algorithm continuously monitors the system state and applies a series of force pulses when a specified threshold value is exceeded. The determination of the pulse magnitude is based on a performance criteria which is linearly dependent on the deterministic component of the structure's response. Both linear and nonlinear MDoF systems subject to deterministic or stochastic response can be analyzed with this optimum pulse control method. Masri et al. [Ref. 8] later developed an on-line control method also using pulse generators. This methodology, applicable to linear and nonlinear systems, determines the pulse magnitude based on the instantaneous magnitude of the structural velocity.

A non-optimal active control algorithm for inelastic (bilinear) SDoF systems was developed by Reinhorn et al. [Ref. 10, 11]. This closed-loop algorithm is based on a reformulated version of the Newmark-beta time integration scheme in conjunction with the Newton-Raphson method. Here the active control mechanism is triggered when nonlinear response exceeds a prescribed limit which would render the system unserviceable. Like the previous work of Masri et al., this methodology also utilizes a pulse control system.

Abdel-Rohman and Nayfeh [Ref. 1] used a combination active/passive control system to control nonlinear oscillations of a single-span bridge. A truss tendon is used to provide both the passive control (increasing stiffness and shifting frequencies away from resonance) and active control (increasing damping to limit peak amplitudes). The magnitude of the active control force is proportional to the bridge velocity at midspan. 
In a follow-up to his earlier work, Yang et al. [Ref. 15] proposed the use of the instantaneous control algorithms for nonlinear systems with bilinear elastic-plastic characteristics. The time-dependent stiffness and damping terms of the equation of motion are approximated using influence coefficients representing the tangent stiffness and damping matrices. A solution to the resulting set of nonlinear equations is found using the Wilson- $\theta$ numerical integration scheme. This methodology is successfully proven using examples with both active and hybrid (active/passive) control systems. Yang proposes combining an adaptive control algorithm with an instantaneous control algorithm to account for system degradation in the control process for nonlinear systems.

In 1988, Kamat [Ref, 6] developed a control algorithm for flexible spacecraft with both geometric and material nonlinearities. This method is based on an extension of the Davidon-Fletcher-Powell algorithm for multi-variable function minimization previously studied by Tripathi and Narendra [Ref. 13]. The Newmark-beta average acceleration scheme is used to integrate the nonlinear equations and a globally convergent Newton-Raphson method is used to solve the resulting nonlinear algebraic equations.

Nagurka and Yen [Ref. 9] convert the optimal control problem to an algebraic nonlinear programming problem using a Fourier series approximation of each generalized coordinate. This method generates near optimal trajectories of nonlinear dynamic systems represented by deterministic, lumped-parameter models.

Nonlinear optimal control for Duffing oscillators was studied by Suhardjo, et al. [Ref. 12]. Duffing systems primarily occur in systems with large deflections exhibiting geometric nonlinearities. Here the nonlinear optimal regulator problem is examined and represented using indicial tensor notation and the resulting control methodology is used to study the Duffing systems.

Though all the previously discussed research addresses active control algorithms for structures behaving nonlinearly or inelastically, none of the work specifically discusses the issue of soil-structure interaction. For this reason, the following section formulates the instantaneous optimal control algorithm [Ref. 23] developed specifically for application with nonlinear soil-structure systems.

\section{AN OPTIMAL CONTROL THEORY FOR NONLINEAR SOIL-STRUCTURE SYSTEMS}

\subsection{Control Theory for Nonlinear Systems}

In this study we formulate a control theory for nonlinear soil-structure systems as a constrained minimization problem. As previously presented, a time-dependent quadratic objective function $J(t)$ for instantaneous optimal control in the context of Yang et al. [Ref. 14] is assumed.

We seek to minimize the performance index at $\mathrm{t}=$ $t_{n+1}$,

$$
J\left(t_{n+1}\right)=\mathbf{z}\left(t_{n+1}\right)^{T} \mathbf{Q} z\left(t_{n+1}\right)+\mathbf{u}\left(t_{n+1}\right)^{T} \mathbf{R} \mathbf{u}\left(t_{n+1}\right)
$$

subject to the constraint (i.e. the equation of motion at $\mathrm{t}=\mathrm{t}_{\mathrm{n}+1}$ as stated by Eq. 5 )

$$
M \ddot{y}\left(t_{n+1}\right)+F_{I}\left(t_{n+1}\right)=H u\left(t_{n+1}\right)+F_{E}\left(t_{n+1}\right)
$$

For convenience we write the performance index of Eq. 7 explicitly in terms of the individual elements of the state vector $z\left(t_{n+1}\right)$. Since $J(t)$ is a quadratic function, the performance index can also be written in the following form:

$$
\begin{gathered}
J\left(t_{n+1}\right)=y\left(t_{n+1}\right)^{T} Q_{1} \mathbf{y}\left(t_{n+1}\right)+2 y\left(t_{n+1}\right)^{T} Q_{2} \dot{y}\left(t_{n+1}\right) \\
+\dot{y}\left(t_{n+1}\right)^{T} Q_{3} \dot{y}\left(t_{n+1}\right)+\mathbf{u}\left(t_{n+1}\right)^{T} \mathbf{R u}\left(t_{n+1}\right)
\end{gathered}
$$

where the weighting matrix $\mathbf{Q}$ is written in partitioned form as

$$
\mathbf{Q}=\left[\begin{array}{ll}
\mathbf{Q}_{1} & \mathbf{Q}_{2} \\
\mathbf{Q}_{2}^{\mathrm{T}} & \mathbf{Q}_{3}
\end{array}\right]
$$

Note that the minimization of $J(t)$ is performed instantaneously at each time station, as discussed by Yang [Ref. 14]. Equations 7 through 9 represent a general instantaneous optimal control algorithm applicable to both linear and nonlinear soil-structure systems.

Equation 8 represents a numerical integration of the hyperbolic dynamic equation of motion in time. In practice, time-stepping of a second-order ODE may be performed effectively using either the Newmark method or any of its variants.

One can establish the equivalence of the control algorithm given by Eqs. 7 and 8 with the nonlinear control algorithms proposed by Yang et al. [Ref. 15] by applying the Taylor series expansion of the nonlinear constraint (Eq. 8) about the current time 
station $\mathrm{t}_{\mathrm{n}}$. Upon ignoring the second-order terms and setting $\mathbf{F}_{\mathbf{E}}\left(\mathrm{t}_{\mathrm{n}+1}\right)=-\mathbf{M} \mathbf{v} \ddot{\mathbf{x}}_{\mathrm{g}}(\mathrm{t})$, the expansion takes the form

$$
\begin{aligned}
& M\left[\ddot{y}\left(t_{n}\right)+\Delta \ddot{y}\right]+F_{I}\left(t_{n}\right)+C^{*}\left(t_{n}\right) \Delta \dot{y} \\
+ & K^{*}\left(t_{n}\right) \Delta y=-M v \ddot{x}_{g}\left(t_{n+1}\right)+H u\left(t_{n+1}\right)
\end{aligned}
$$

where $C^{*}\left(t_{n}\right)$ and $K^{*}\left(t_{n}\right)$ represent the tangent damping and stiffness matrices at $t_{n}$. These matrices can be represented as

$$
\begin{aligned}
& \mathrm{C}^{*}\left(\mathrm{t}_{\mathrm{n}}\right)=\partial \mathrm{F}_{\mathbf{I}}\left(\mathrm{t}_{\mathrm{n}}\right) / \partial \dot{\mathbf{y}}\left(\mathrm{t}_{\mathrm{n}}\right) \\
& \mathbf{K}^{*}\left(\mathrm{t}_{\mathrm{n}}\right)=\partial \mathrm{F}_{\mathbf{I}}\left(\mathrm{t}_{\mathrm{n}}\right) / \partial \mathbf{y}\left(\mathrm{t}_{\mathrm{n}}\right)
\end{aligned}
$$

and are the respective gradients of $\mathbf{F}_{\mathrm{I}}$ evaluated at time station $\mathrm{t}_{\mathrm{n}}$. By letting

$$
\begin{gathered}
-M \ddot{x}_{g}\left(t_{n+1}\right)+H u\left(t_{n+1}\right) \\
=-M v\left[\ddot{\mathbf{x}}_{g}\left(t_{n}\right)+\Delta \ddot{x}_{g}\right]+\mathbf{H}\left[\mathbf{u}\left(t_{n}\right)+\Delta u\right]
\end{gathered}
$$

and substituting into Eq. 11, the incremental timestepping algorithm of Yang et al. is obtained where

$$
\begin{gathered}
\mathbf{M}\left[\ddot{\mathbf{y}}\left(\mathrm{t}_{\mathrm{n}}\right)+\Delta \ddot{\mathbf{y}}\right]+\mathbb{F}_{\mathbf{I}}\left(\mathrm{t}_{\mathrm{n}}\right) \\
+\mathbf{C}^{*}\left(\mathrm{t}_{\mathrm{n}}\right) \Delta \dot{\mathbf{y}}+\mathbf{K}^{*}\left(\mathrm{t}_{\mathrm{n}}\right) \Delta \mathbf{y} \\
=-\mathbf{M} \mathbf{v}\left[\ddot{\mathbf{x}}_{\mathrm{g}}\left(\mathrm{t}_{\mathrm{n}}\right)+\Delta \ddot{\mathbf{x}}_{\mathrm{g}}\right]+\mathbf{H}\left[\mathbf{u}\left(\mathrm{t}_{\mathrm{n}}\right)+\Delta \mathbf{u}\right]
\end{gathered}
$$

Clearly, Eqs. 8 and 14 are equivalent for the linear case. For the nonlinear case, the equivalence of the two algorithms can be established in the limit as the time step vanishes. Owing to the explicit form of Eq. 14, however, numerical stability problems could seriously afflict the Yang et al. algorithm in the nonlinear regime, particularly when the time step is large. Furthermore, without a sound iterative strategy, the Yang et al. algorithm could fail to detect the onset of initial yielding or initial elastic unloading in elasto-plastic materials, which could be crucial to the accuracy of the control algorithm.

Equation 8 is a generalized equation of motion and includes effects of soil-structure interaction provided that the equation of motion is imposed over a region which includes not only the structure but also the foundation and the supporting medium. Thus, energy dissipation due to radiation damping, which has no counterpart in a rigidly supported structure, becomes part of the constraint equation.

\subsection{General Solution Algorithm}

Let $\lambda\left(t_{n+1}\right)$ represent an $N$-dimensional vector of Lagrange multipliers for optimal control at time instant $\mathrm{t}_{\mathrm{n}+1}$, and let the Hamiltonian function $H$ be defined by

$$
\begin{gathered}
H=\mathbf{y}\left(t_{n+1}\right)^{\mathrm{T}} \mathbf{Q}_{1} \mathbf{y}\left(\mathrm{t}_{\mathrm{n}+1}\right)+2 \mathbf{y}\left(\mathrm{t}_{\mathrm{n}+1}\right)^{\mathrm{T}} \mathbf{Q}_{2} \dot{\mathbf{y}}\left(\mathrm{t}_{\mathrm{n}+1}\right) \\
+\dot{\mathbf{y}}\left(\mathrm{t}_{\mathrm{n}+1}\right)^{\mathrm{T}} \mathbf{Q}_{3} \dot{\mathbf{y}}\left(\mathrm{t}_{\mathrm{n}+1}\right)+\mathbf{u}\left(\mathrm{t}_{\mathrm{n}+1}\right)^{\mathrm{T}} \mathbf{R} \mathbf{u}\left(\mathrm{t}_{\mathrm{n}+1}\right) \\
+\lambda\left(\mathrm{t}_{\mathrm{n}+1}\right)^{\mathrm{T}}\left[\mathbf{M} \ddot{\mathbf{y}}\left(\mathrm{t}_{\mathrm{n}+1}\right)+\mathbf{F}_{\mathbf{I}}\left(\mathrm{t}_{\mathrm{n}+1}\right)\right. \\
\left.-\mathbf{H u}\left(\mathrm{t}_{\mathrm{n}+1}\right)-\mathbf{F}_{\mathbf{E}}\left(\mathrm{t}_{\mathrm{n}+1}\right)\right]
\end{gathered}
$$

Together with the equations that characterize a particular time-stepping algorithm we view the Hamiltonian as a function of the control forces $\mathbf{u}\left(t_{n+1}\right)$, the Lagrange multipliers $\lambda\left(t_{n+1}\right)$ and, the displacement vector $\mathbf{y}\left(t_{n+1}\right)$ (note that $\dot{\mathbf{y}}\left(t_{n+1}\right)$ and $\ddot{\mathbf{y}}\left(t_{n+1}\right)$ can be determined once $\mathbf{y}\left(t_{n+1}\right)$ is computed). The necessary conditions for minimizing the performance index as defined in Eq. 9 subject to the constraint imposed by the equation of motion are

$$
\frac{\partial H}{\partial y\left(t_{n+1}\right)}=0 ; \frac{\partial H}{\partial u\left(t_{n+1}\right)}=0 ; \frac{\partial H}{\partial \lambda\left(t_{n+1}\right)}=0
$$

Introducing the following $(N \times N)$ gradient arrays where $D$ represents the total derivative:

$$
\begin{gathered}
\Gamma\left(\mathrm{t}_{\mathrm{n}+1}\right)=\frac{D \ddot{\mathbf{y}}\left(\mathrm{t}_{\mathrm{n}+1}\right)}{D \mathbf{y}\left(\mathrm{t}_{\mathrm{n}+1}\right)} ; \quad \Lambda\left(\mathrm{t}_{\mathrm{n}+1}\right)=\frac{D \dot{\mathbf{y}}\left(\mathrm{t}_{\mathrm{n}+1}\right)}{D \mathbf{y}\left(\mathrm{t}_{\mathrm{n}+1}\right)} \\
\mathcal{X}\left(\mathrm{t}_{\mathrm{n}+1}\right)=\frac{D \mathbf{F}_{\mathbf{I}}\left(\mathrm{t}_{\mathrm{n}+1}\right)}{D \mathbf{y}\left(\mathrm{t}_{\mathrm{n}+1}\right)}
\end{gathered}
$$

and expanding Eq. 15, we obtain the following three matrix equations:

$$
\begin{aligned}
& \frac{\partial H}{\partial y\left(t_{n+1}\right)}=2 Q_{1} y\left(t_{n+1}\right)+2 Q_{2} \dot{y}\left(t_{n+1}\right) \\
& +2 \Lambda\left(t_{n+1}\right)^{T} Q_{2} y\left(t_{n+1}\right)+2 \Lambda\left(t_{n+1}\right)^{T} Q_{3} \dot{y}\left(t_{n+1}\right) \\
& +\left[M \Gamma\left(t_{n+1}\right)+2\left(t_{n+1}\right)\right]^{T} \lambda\left(t_{n+1}\right)=0 \\
& \frac{\partial H}{\partial u\left(t_{n+1}\right)}=2 \mathbf{R u}\left(t_{n+1}\right)-H^{T} \lambda\left(t_{n+1}\right)=0 \\
& \frac{\partial H}{\partial \lambda\left(t_{n+1}\right)}=\mathbf{M} \ddot{y}\left(t_{n+1}\right)+F_{I}\left(t_{n+1}\right)-H u\left(t_{n+1}\right) \\
& -F_{E}\left(t_{n+1}\right)=0
\end{aligned}
$$

By solving Eqs. $18 \mathrm{a}, 18 \mathrm{~b}$, and $18 \mathrm{c}$ simultaneously, we obtain the instantaneous values of the vectors $\mathbf{u}\left(t_{n+1}\right), \mathbf{y}\left(t_{n+1}\right)$, and $\lambda\left(t_{n+1}\right)$. 
Note that $\Gamma\left(t_{n+1}\right)$ and $\Lambda\left(t_{n+1}\right)$ are constant gradient arrays, i.e., their elements are constant scalar functions of the integration parameters for a particular time-stepping algorithm. For the linear case $\mathcal{K}\left(t_{n+1}\right)$ is also a constant gradient array; however, $\mathcal{X}\left(t_{n+1}\right)$ is a time-dependent function for the nonlinear systems. It is observed from Eq. 17 that for linear elastic undamped systems, $\mathcal{K}\left(\mathrm{t}_{\mathrm{n}+1}\right)=\mathbf{K}$ and for linearly elastic damped systems, $\mathfrak{X}\left(t_{n+1}\right)=\mathbf{K}+\mathbf{C} \Lambda\left(t_{n+1}\right)$.

\subsection{Linear Optimal Control}

Equations $18 \mathrm{a}, 18 \mathrm{~b}$, and $18 \mathrm{c}$ can be simplified for the linear case by first writing Eq. 18a in a form suitable for evaluation of the Lagrange multipliers $\lambda\left(t_{n+1}\right)$ where

$$
\lambda\left(t_{n+1}\right)=2 \mathbf{U} \dot{\mathbf{y}}\left(t_{n+1}\right)+2 \mathbf{V} \mathbf{y}\left(t_{n+1}\right)
$$

with (assuming symmetric $\mathbf{M}$ and $\mathbf{K}$ )

$$
\begin{aligned}
& \mathbf{U}=-\left[\Gamma\left(\mathrm{t}_{n+1}\right)^{\mathrm{T}} \mathbf{M}+\mathcal{K}\left(\mathrm{t}_{n+1}\right)\right]^{-1}\left[\mathbf{Q}_{2}+\Lambda\left(\mathrm{t}_{\mathrm{n}+1}\right)^{\mathrm{T}} \mathbf{Q}_{3}\right] \\
& \mathbf{V}=-\left[\Gamma\left(\mathrm{t}_{\mathrm{n}+1}\right)^{\mathrm{T}} \mathbf{M}+\mathcal{K}\left(\mathrm{t}_{\mathrm{n}+1}\right)\right]^{-1}\left[\mathbf{Q}_{1}+\Lambda\left(\mathrm{t}_{\mathrm{n}+1}\right)^{\mathrm{T}} \mathbf{Q}_{2}\right]
\end{aligned}
$$

Substituting Eq. 19 in Eq. 18b and solving for $\mathbf{u}\left(t_{n+1}\right)$,

$$
\mathbf{u}\left(\mathrm{t}_{\mathrm{n}+1}\right)=\mathbf{R}^{-1} \mathbf{H}^{\mathrm{T}}\left[\mathbf{U} \dot{\mathbf{y}}\left(\mathrm{t}_{\mathrm{n}+1}\right)+\mathbf{V} \mathbf{y}\left(\mathrm{t}_{\mathrm{n}+1}\right)\right]
$$

The final recurrence equation is obtained by substituting Eq. 20 into Eq. 18c where

$$
\begin{gathered}
\mathbf{M} \ddot{\mathbf{y}}\left(\mathrm{t}_{\mathrm{n}+1}\right)+\mathbf{C} \dot{\mathbf{y}}\left(\mathrm{t}_{\mathrm{n}+1}\right)+\mathbf{K y}\left(\mathrm{t}_{\mathrm{n}+1}\right)-\mathbf{F}_{\mathbf{E}}\left(\mathrm{t}_{\mathrm{n}+1}\right) \\
-\mathbf{H R}^{-1} \mathbf{H}^{\mathrm{T}}\left[\mathbf{U} \dot{\mathbf{y}}\left(\mathrm{t}_{\mathrm{n}+1}\right)+\mathbf{V} \mathbf{y}\left(\mathrm{t}_{\mathrm{n}+1}\right)\right]=0
\end{gathered}
$$

Together with a given time-stepping algorithm (e.g., the Newmark method), Eq. 21 is a linear system of equations that can be solved in a straight forward manner in time.

\subsection{Nonlinear Optimal Control}

Nonlinearities require that the optimal control problem be solved by iteration. Here, Eq. 21 is a nonlinear function of $y\left(t_{n+1}\right)$. An efficient algorithm for solving a system of nonlinear equations is by Newton iteration. Equation 21 is put in the residual form

$$
\begin{gathered}
\mathbf{M} \ddot{\mathbf{y}}\left(\mathrm{t}_{\mathrm{n}+1}\right)+\mathbf{F}_{\mathbf{I}}\left(\mathrm{t}_{\mathrm{n}+1}\right)-\mathbf{F}_{\mathbf{E}}\left(\mathrm{t}_{\mathrm{n}+1}\right) \\
-\mathbf{H} \mathbf{R}^{-1} \mathbf{H}^{\mathrm{T}}\left[\mathbf{U} \dot{\mathbf{y}}\left(\mathrm{t}_{\mathrm{n}+1}\right)+\mathbf{V} \mathbf{y}\left(\mathrm{t}_{\mathrm{n}+1}\right)\right]=\mathbf{r}
\end{gathered}
$$

where $\mathbf{r}$ is an $\mathrm{N}$-dimensional vector function of $\mathbf{y}\left(t_{n+1}\right)$. A vector $\mathbf{y}\left(t_{n+1}\right)$ is sought such that $\mathbf{r}=\mathbf{0}$. The purpose of Newton's method is to iterate over the function

$$
\begin{gathered}
\mathbf{r}^{\prime}\left\{\mathbf{y}\left(\mathrm{t}_{\mathrm{n}+1}\right)_{k}\right\} \Delta \mathbf{y}=\mathbf{r}\left\{\mathbf{y}\left(\mathrm{t}_{\mathrm{n}+1}\right)_{k}\right\} \\
\text { where } \mathbf{y}\left(\mathrm{t}_{\mathrm{n}+1}\right)_{k+1} \leftarrow\left[\mathbf{y}\left(\mathrm{t}_{\mathrm{n}+1}\right)_{k}-\Delta \mathbf{y}\right]
\end{gathered}
$$

(where the subscript $k$ in Eq. 23 represents an iteration counter) until $\|\mathbf{r}\|$ becomes negligible. In practice, the error tolerance represented by the symbol $\|\mathbf{r}\|$ is taken as the Euclidean norm.

A major impediment to an efficient solution of Eq. 22 by Newton iteration is the dependence of the matrices on the (as yet unknown) tangent stiffness matrix $\mathcal{K}\left(t_{n+1}\right)$. An alternative iteration strategy that does not use this unknown tangent stiffness is provided by the so-called modified Newton iteration, which requires the evaluation of an initial tangent operator only; however, the convergence of this iteration is generally very slow. Another possible approach is to take an approximate linearization of the left-hand side of Eq. 23 and define the tangent operator as

$$
\begin{gathered}
\mathbf{r}^{\prime}\left\{\mathbf{y}\left(\mathrm{t}_{\mathrm{n}+1}\right)_{k}\right\}=\mathbf{M} \Gamma\left(\mathrm{t}_{\mathrm{n}+1}\right)+\mathcal{Z}\left(\mathrm{t}_{\mathrm{n}+1}\right) \\
-\mathbf{H R}^{-1} \mathbf{H}^{\mathrm{T}}\left[\mathbf{U} \Lambda\left(\mathrm{t}_{\mathrm{n}+1}\right)+\mathrm{V}\right]
\end{gathered}
$$

where the matrices $\Gamma\left(t_{n+1}\right)$ and $\Lambda\left(t_{n+1}\right)$ are assumed fixed in the linearization. The convergence performance of a Newton-like algorithm based on the approximate tangent operator given by Eq. 24 is presently under investigation.

\section{APPLICATION OF CONTROL ALGORITHM TO SOIL-STRUCTURE SYSTEM}

\subsection{Overview of SSI Model}

The equations formulated and discussed in the previous section are applicable to both linear and nonlinear SSI systems. In this section the importance of incorporating SSI effects in earthquake engineering models is discussed. The SSI model developed specifically for use with the preceding control algorithm is then presented.

When a structure is subjected to earthquake forces, the structure's response is modified considerably by the dynamic deformations of the underlying soil. Accurate representation of soil-structure interaction is a crucial part of earthquake engineering analyses. A 
large number of soil-structure models exist of varying degrees of complexity. The choice of the most appropriate model for a particular analysis is based on the building-foundation system of interest, the desired level of accuracy, and experienced "engineering judgment."

A conventional first step in analyzing the dynamic response of actively controlled $\mathrm{MDoF}$ structures subjected to seismic excitation is to input a onedimensional earthquake ground acceleration at the base of the structure. While this approach may be appropriate for structures supported on a rigid base (such as bedrock), it is not realistic for structures that rest on soft soils where interaction between the soil and structure could dominate the building response. For these cases, it is particularly important that the influence of SSI on actively controlled systems be carefully evaluated.

In the present study, the actively controlled structure is considered as part of a larger system which includes the foundation and the supporting medium. Analysis of a larger system allows modeling of radiation damping and the rocking motion at the base which could otherwise dominate the building response and consequently alter the effectiveness of the control algorithm.

The SSI model proposed for use with the previously outlined control algorithm is shown in Figure 1. The total domain, $\Omega$ is divided into a finite interior part, $\Omega^{1}$, and an unbounded exterior part, $\Omega^{\mathrm{E}}$. Nonlinearities are allowed to take place in $\Omega^{\mathrm{I}}$, but not in $\Omega^{\mathrm{E}}$ where the response is assumed to be strictly linear. Between the two subdomains is a nonreflecting boundary $X_{b}$ that serves to absorb all scattered waves emanating from $\Omega^{\mathrm{I}}$ during seismic excitation. The non-reflecting boundary is not necessarily regular; the only requirement is that it defines the boundary between the linear and the noninear regions. The finite element method is used to solve the numerical problem in $\Omega^{1}$ while the boundary element technique is employed in $\Omega^{\mathrm{E}}$. Thus, a typical mesh consists of mixed finite and boundary elements as shown in Figure 1.

Seismic loads are input directly on the non-reflecting boundary in the form of free-field excitation, following Gutierrez and Chopra [Ref. 5] and Bielak and Christiano [Ref. 3]. Here, the free-field response is substracted from the total response resulting in a composite problem which is solved for the total field in $\Omega^{\mathrm{I}}$ and a scatter field in $\Omega^{\mathrm{E}}$. Material nonlinearities are treated in the finite element formulation using a bilinear constitutive model for the structure and classical elasto-plastic and elastoviscoplastic constitutive models with isotropic and kinematic hardening for soils [Ref. 4]. Timeintegration in $\Omega^{I}$ is done using Newmark's fully implicit scheme, while in $\Omega^{\mathrm{E}}$ time-marching is done by numerical evaluation of the convolution integrals in the time domain. The composite FE-BE system is then solved simultaneously by Newton-Raphson iteration,

\subsection{Some Notes on the Application of Control Theory to SSI Problems}

In analyzing soil-structure interaction problems for control applications, we need to redefine the state vector $\mathrm{z}(\mathrm{t})$. Restricting our structural model to the case where the base of the foundation is assumed rigid, the state vector can be defined in terms of the nodal velocities $\dot{y}(t)$ and displacements $y(t)$ of the structure relative to the motion of the rigid base. If rocking of the base is considered, then the relative motion may be taken with respect to the rigid-body configuration of the structure compatible with the rotational motion of the rigid base. Hence, in principle, the performance index can be uniquely defined.

Note that the translational and rocking movements of the base are themselves unknown in a typical soilstructure problem. Thus, the forcing function $\mathbf{F}_{\mathbf{E}}(\mathrm{t})$ generally differs from the source-point inertia force,

- Mv $\ddot{\mathbf{x}}_{\mathrm{g}}(\mathrm{t})$. However, using the method of Bielak and Christiano [Ref. 3] for prescribing the seismic input through a soil-structure interface, it is always possible to write the equation of motion for the soilstructure system in such a way that the external force is driven by the free-field motion. In that case, an instantaneous control theory can phrased such that the performance index is minimized at each time step depending on the instantaneous motion of the free field.

The control algorithms and SSI model proposed herein are currently being implemented. Parametric studies are being made which quantify the influence of nonlinear soil-structure behavior on control theory. Consideration of system nonlinearities and analysis of the combined FE-BE soil-structure model in the timedomain allows accurate representation of fundamental difficulties associated with SSI analysis.

\section{SUMMARY}

Despite the extensive work done recently in active control of seismically excited structures, little research has directly addressed the issue of the effects of soil-structure interaction. The structural response can be significantly affected by the properties of the underlying soil, which typically are not considered in 
conventional control applications based on rigidfoundation systems. This paper formulates and presents an optimal control algorithm for actively controlled soil-structure systems. The purpose of this study is to determine the effects of SSI models on the effectiveness of control algorithms.

An instantaneous control algorithm is formulated which is applicable to both linear and nonlinear soilstructure interaction systems. The equation governing the control of a nonlinear soil-structure system subjected to strong ground motion are formulated as a constrained minimization problem, and a time-dependent performance index is presented. A solution to the resulting equation is achieved by incorporating a direct integration scheme with the Newton-Raphson technique.

The SSI model proposed for use with this control algorithm is based on a boundary element (BE) finite element (FE) formulation, and is capable of overcoming the fundamental difficulties typically associated with soil-structure interaction analysis such as radiation boundary conditions. The foundation of the structure is assume to behave as a rigid body with the ability to translate and rotate. Hence, the state vector $\mathbf{z}(\mathrm{t})$ in the control algorithm and performance index represents the relative motion taken with respect to the rigid-body configuration considering the rocking motion of the foundation.

Studies are underway which fully implement the control model and algorithms presented in this paper. Results from these studies are expected to quantify the influence of soil-structure behavior on the effectiveness of active control algorithms for seismically excited systems.

\section{ACKNOWLEDGMENT}

Funding for this research was provided by a grant from the National Science Foundation under Contract No. BCS-9058316, Presidential Young Investigator Award.

\section{REFERENCES}

1. Abdel-Rohman, M. and Nayfeh, A.H. (1987). "Active Control of Nonlinear Oscillations in Bridges." Journal of Engineering Mechanics, Vol. 113, pp. 335-348.

2. Bathe, K..J. (1982). Finite Element Procedures in Engineering Analysis. Prentice-Hall, New Jersey.
3. Bielak, J. and Christiano, P. (1984). "On the Effective Seismic Input for Nonlinear SoilStructure Interaction Systems." Earthquake Engineering and Structural Dynamics, Fol. 12, pp. 107-119.

4. Borja, R.I. (1991). "Modeling the Monotonic anc Cyclic Viscoplastic Soil Behavior." Proceedings: Second International Conference on Recent Advances in Geotechnical Earthquake Engineering and Soil Dynamics, University of Missouri-Rolla, Vol.1, pp. 37-40.

5. Gutierrez, J.A. and Chopra, A.K. (1978). "A Substructure Method for Earthquake Analysis of Structures Including Structure-Soil Interaction." Earthquake Engineering and Structural Dynamics, Vol. 6, pp. 51-69.

6. Kamat, M.P. (1988). "Active Control of Structures in Nonlinear Response." Journal of Aerospace Engineering, Vol. 1, pp. 52-62.

7. Masri, S. F., Bekey, G. A., and Caughey, T. K. (1981). "Optimum Pulse Control of Flexible." Journal of Applied Mechanics, Vol. 48, pp. 619626.

8. Masri, S.F., Bekey, G.A., and Caughey, T.K. (1982). "On-line Control of Nonlinear Flexible Structures." Journal of Applied Mechanics, Vol. 49 , pp. $877-884$

9. Nagurka. M.L. and Yen V. (1990). "FourierBased Optimal Control of Nonlinear Dynamic Systems." Journal of Dynamic Systems, Measurement, and Control, Vol. 112, pp. 17-26.

10. Reinhorn, A.M., Manolis, G.D., and Wen, C.Y., (1985). "An On-line Control Algorithm for Inelastic Structures." Second International Symposium on Control, University of Waterloo, Ontario, Canada, pp. 564-579.

11. Reinhorn, A.M., Manolis, G.D., and Wen, C.Y., (1987). "Active Control of Inelastic Structures." Journal of Engineering Mechanics, Vol. 113, pp. 315-333.

12. Suhardjo, J., Spencer, B.F., and Sain, M.K., (1990). "Nonlinear Optimal Control of a Duffing System." submitted to International Journal of Nonlinear Mechanics. 
13. Tripathi. S.S. and Narendra, K.S. (1970). "Optimization Using Conjugate Gradient Methods." IEEE Trans. Automatic Control. IEEE, New York, New York, pp. 268-270.

14. Yang, J.N. and Akbarpour, A. (1987). "New Optimal Control Algorithms for Structural Control." Journal of Engineering Mechanics, Vol. 113, pp. 1369-1386.
15. Yang, J.N., Long, F.X., and Wong, D. (1988). "Optimal Control of Nonlinear Structures." Journal of Applied Mechanics, Vol. 55, pp. 931938.

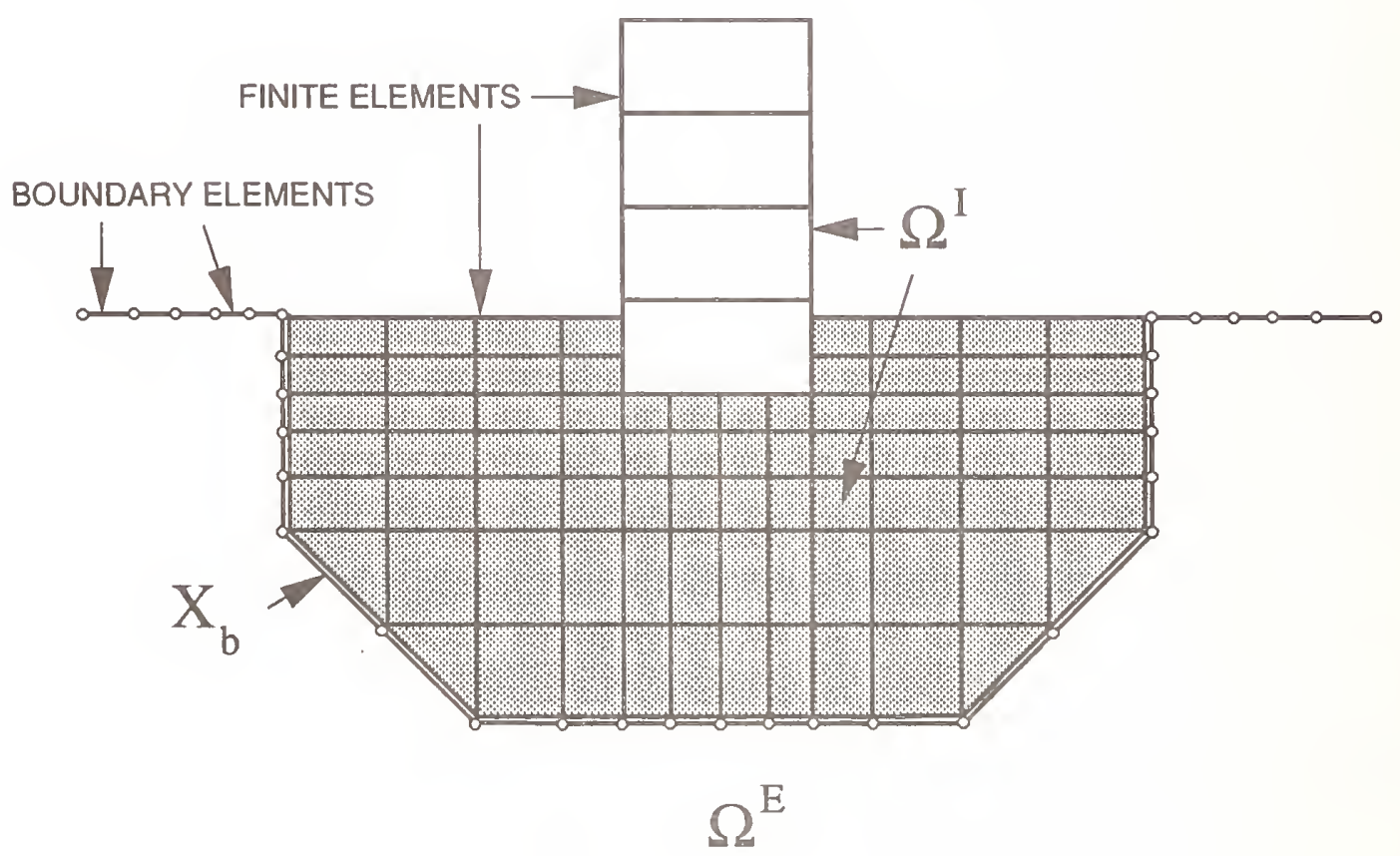

Figure 1: Problem domains and boundaries. 


\title{
Current Research Efforts in Japan for Passive and Active Control of Highway Bridges Against Earthquake
}

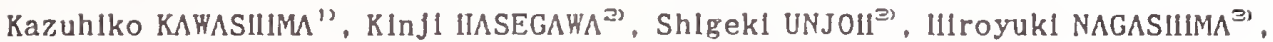 \\ and HIdeyuki SHIMIZU
}

\section{$\triangle$ ABSTRACT}

Thls paper presents current research activitles on passlve, active and hybrid control for application to brldge structures conducted at the Public Works Research Institute.

KET TORDS : Highway Bridges, Menshin Systems, Active Control, liybrid Control

\section{INTRODUCTION}

Menshin systems (Base-isolation), which is belng Introduced for appllcation to hlghway bridges In Japan" ${ }^{\prime 2), ~ I s ~ t o ~ r e d u c e ~ e a r t h q u a k e ~}$ response of highway brldges by "Passlve Means". on the other hand, active control Is to control It by "Actlve Means." Since external energy supply requlred to reduce the bridge response to satisfactory level is signiflcant during a significant earthquake in the active control. It is still in a laboratory. Therefore, "Hybrid" control. which is a combination of advantages of passive and active control, Is promising for reducing the earthquake response of structures with small amount of external energy. The development of hybrld control for Improving the selsmic safety of highway bridges, whlch can not be achleved by extending current selsmlc design method, Is expected ".

A serles of researches, and developments on passive, active and hybrid control for highway brldges have been made at the Public Works Research Institute since 1987. This paper brlefly presents current research actlvitles on passlve, active and hybrid control for application to bridge structures conducted at the Public Works Research Institute.

\section{DEVELOPMENT OF MENSIIIN STSTEMS}

\section{2-1 Jolnt Research Program on MenshIn Systens \\ for IIIghway Bridgcs}

For studylng the application of the menshin systems (passlve control) to the selsmic design of highway bridges, a committee chalred by Professor Tsuneo Katayama, UnIversity of Tokyo, was formulated through 1986 to 1989 at the Technology Research Center for Natlonal Land Development. Three programs were studled in the committee, 1.e., 1) a survey of menshin devices which can be used for highway bridges, 2) a study on the key points of the design of menshin highway bridges, and 3) deslgns of menshin highway bridges. $\Lambda$ s the final accomplisiment of the study, "Guldellnes for
Design of Menshin Brldges (draft)" was published In $1989^{3)}$.

Based on the study above, the three-year Jolnt research program on the menshin systems for hlghway brldges is now underway between Public Works Research Institute and twenty elght prlvate flrms since the year of 1989. The goal of the program is to develop the menshin design method and the new menshin devlces for highway bridges in order to Improve the selsmic performance of new and existing bridges with less cost by the menshin systems. Fig. 1 shows the research 1 tens of the program, whlch are outllned in the follows ${ }^{4)}$.

\section{2-2 Development of New Menshin Devices}

A lot of base isolation devices which are similar to the menshin device have been ever developed for bullding structures. llowever, the menshin devices for highway bridges have to be more compact and more weather-proof than the devices for bullding structures since the menshin devices would be installed at narrow and exposed crests of bridge columns. The new menshln devices should be developed exclusively for menshin highway brldges to be effectively constructed In Japan.

The following ten new devices in the six types are now belng developed under the research program.

1) HIgh Damplng Rubber Bearing----- 4 devices

2) Sllding Frlction Damper-.---.--- 2 devices

3) Steel Damper -------------------- 1 device

4) Roller Menshin Bearing -.------- 1 device

5) Link Bearing ------------------- 1 device

6) Viscous Damper -...-.-.-.--- 1 device

All developed menshin devlces but the link bearing were tested by the loading experiment system of PWRI under the same loading conditions to verlfy their performance. In the tests, the cyclic lateral force was given to the devices by the actuator under the constant axlal force, which is equlvalent to the dead load of the superstructure, as shown in Photo 1. Since the performance of some devices could be affected by the temperature, the tests were conducted in the room shown in Photo 2, where the temperature was kept at $20^{\circ} \mathrm{C}$.

1) llead of Earthquake Englneering Division, Earthquake Disaster Prevention Department, Public Works Research Instltute, MInlstry of Construction. Tsukuba Science City, 305 Japan

2) Senlor Research Englneer, ditto

3) Research Englneer, ditto

4) Assistant Research Englneer, ditto 
FIg.2 shows the lateral force vs. dlsplacement hysteresls loops of a hlgh damping rubber bearing and a sliding friction damper. It Is sald that the damping effect of every tested devlces is satisfactory for highway bridges and the dynamic character is also stable with the smooth hysteresis loop.

The standard of the test procedure for menshin devices are belng speclfied under the research program in order to certify the other devlces whlch would be developed for highway brldges in future. There are two main ltems in the procedure, one of whlch is related to the performance as a support such as the check of the vertical stlffness, and the other is related to the dynamic horlzontal performance as a menshin device such as the check of the stabllity under the repeated cycllc lateral loading, the check of the dependency on the loading velocity or frequency, the check of the dependency on the axlal force, the check of the dependency on the lateral loading direction and the check of the dependency on the temperature. The test condition for each item and the evaluation of the test result have been formulated. The slze and shape of the speclmens, the loadling test apparatus and the loading process wlll be standardized.

\section{2-3 Devclopment of Expanslon Joints and}

\section{Restraincrs for Menshin Bridges}

The knock-off mechanism and the finger expansion Joint which is distingulshed from the regular finger joints by the transverse movement, are being developed under the research program. The restralner which consists of the steel bar installed in the crest of the substructure and the steel casing wlth the high damping rubber inside installed under the superstructure, is also being developed.

The knock-off mechanism is lllustrated in FIg. $3^{5)}$. If the excesslve displacement of the gIrder toward the abutment were brought by earthquakes, the apron of the slab would colllde with the top portion of the abutment. Since the portion is not actually flxed to the abutment Itself. It would be squeezed into the backflll behind the abutment to ease the Impact Induced by the collision.

The mechanlsm was tested as shown in Fig.4, In whlch the top portion was pressed back into the backfill by the actuator. in order to observe the situation of the squeeze and the damage of the backf111, and measure the resistant force of the backfl1 $1^{\circ}$. Photos 3 and 4 show the speclmen and the sltuation after the test, respectlvely. Fig.5 shows the lateral force vs. displacement curve of the mechanism. It Is seen that the Impact force could be mitigated and the extensive displacement of the girder would be controlled by the mechanlsm.

\section{2-4 Derclopwent of Menshin Design Method}

Flg.6 lllustrates the flow of the menshin design method, in which tile two levels of the design earthquake loading are considered as limited states. The lower level, Level 1, Is equivalent to the design seismic force of the selsmic coefficlent method regulated in the Deslgn Speclflcations of IIIghway Bridges - Part $\mathrm{V}$ Selsmic Deslgn. This represents the selsmlc force for moderate earthquakes which are supposed to take place wlth higher probabillty. The hlgher level, Level 2, Is equlvalent to the design selsmlc force of the check of the bearing capacity of the relnforced concrete columns for the lateral force regulated in the specification, for larger earthquakes, such as Kanto earthquake In 1923, whlch are supposed to take place rarely ${ }^{7}$. The deslgn procedure will be formulated, belng based on the flow.

\section{2-5 Applleatlon of Menshin Deslgn}

Since expanslon Jolnts make annoying nolse and are vulnerable to the trafflc load. continuous bridges tend to be constructed recently with the demand of lowering the number of Jolnts. Therefore, one target of the menshin systems is to construct continuous bridges. The multi-span continuous bridge with the girder length more than $1 \mathrm{~km}$, which is called in the research program as a super multi-span continuous bridge, Is highlighted as a cruclal research item. It was concluded that the super multi-span continuous bridge with 26 spans as shown In Fig.7 could be constructed with the menshin system.

Existing slmple glrders would be connected one another in order to also decrease expanslon Joints between adjacent simple glrders. Since the Inertla force of the girder transmitted to each substructure mlght be varled by the connecting. the strengthening of some substructures would be required due to the lack of the bearlng capaclty. It was deduced that the distribution of the inertia force could be Intentionally adjusted with proportion to the capacity of each substructure, by the replacement of the exlsting ordlnary flxed or movable bearings with the menshln devices. The construction method and the structural detall of the connecting and the replacement will be examined under the research program.

\section{2-6 Draft Manual for Menshin Design of Ilghway \\ Bridges}

The program w111 be accompllshed In March, 1992. The draft manual of the menshln design method, the contents of which are shown in the follows. Is to be composed as the frults of the research program.

\section{Chapter 1 INTRODUCTION}

\section{1.l Purpose of Manual}


1.2 Application of Manual

1.3 Definltions of Terms

Chapter 2 BASIC CONCEPTS

2.1 Purpose of Menshin Design

2.2 Earthquake Levels and LImIted States

2.3 Selsmlc Design Force of Menshin Design

2.4 Design Method and Criterlon of Safety Check

2.5 Baslc Flow Charts of Menshin Design

2.6 Appllcation of MenshIn Design

Chapter 3 DESIGN AND CIIECK OF SUPERSTRUCTURE

Chapter 4 DESIGN AND CHECK OF SUBSTRUCTURE

4.1 General

4.2 DesIgn Acceleration for

Substructure

Chapter 5 DESIGN METHOD OF MENSIIN DEVICES

5. 1 Baslc Concept of Deslgn

5.2 Design Acceleration for Menshin Devlces

5.3 Rubber Bearlng

5.4 Lead Rubber Bearing

5.5 IIIgh Damplng Rubber Bearing

5. 6 Steel Damper

5.7 Frlction Damper

5.8 Vlscous Damper

Chapter 6 CIIECK OF MENSIIIN BRIDGES BY DYNAMIC ANALYSIS

6.1 General

6.2 Input Motion of Dynamlc Analysis

6.3 Dynamic Analysis Method

6.4 Safety Check by Dynamic Analysis

Chapter 7 STRUCTURAL DETAILS OF MENSIIN BRIDGES

7. 1 General

7.2 Restralners

7.3 Structural Detalls of Menshin Devices

7.4 Structural Detalls of Expansion Jolnts

Chapter 8 CERTIFICATION TESTS OF MENSIIIN DEVICES

8.1 General

8.2 Dynamlc Loading Test

8.3 Statlc Loading Test

8.4 Ultimate State Test

Chapter 9 RETROFITTING BY MENSIIIN DESIGN

9.1 General

9.2 Appllcation of Menshln Design for Retrofitting

9.3 Deslgn Method of MenshIn Devlces for Retrofitting

\subsection{Construction of Menshin Devices for Retrofitting \\ 9.5 Structural Detalls of Retrofitting}

Appendix I References for Design Appendix II Deslgn Examples

\section{CONSTRUCTION OF MENSIIIN IIIGITWAT BRIDGES}

\section{3-1 Pllot Construction of Mensh In Mighway Bridges}

Five pllot menshin hlghway bridges as shown In Table 1 are under construction with the supervision of Minlstry of Construction. in order to verlfy the performance of the menshin system. One of them, Mlyagawa Bridge in Shlzuoka-ken, was completed and opened for the publlc trafflc in March 15, 1991 as the flrst menshln hlghway brldge In Japan.

\section{3-2 Migagawa Bridge}

- Flrst Menshin Highway Brldge-

1) Outllne of Mlyagawa Brldge

The Mlyagawa bridge located at Ilaruno-machl, Shu-tl-gun, Shlzuoka-ken, is a three-span continuous steel plate girder bridge with the total length of $105.8 \mathrm{~m}$ and the width of $10.5 \mathrm{~m}$ as shown In Flg.8, whlch spans over the Ketagawa river as a bridge of the natlonal hlghway No. $362^{\text {’ }}$. The rubber bearings with the lead plug inserted at the center shown In Photo 5. whlch were developed In New Zealand and are usually designated as lead rubber bearlngs (0) 11). were used as the menshin devlces. Although the lead rubber bearing is orlginally movable to any lateral direction, the restrainers were Installed to prevent the bearlng from the transverse movement so that the menshin system works only in longltudinal direction.

2)Menshin Design

The brldge was deslgned in accordance with the Deslgn Speclflcatlons of llighway Bridges. Table 2 summarlzes the natural perlod, the design horizontal acceleration and the design relative displacement of the bearing for both the selsmic coefficlent method and the check of the bearing capacity of the relnforced concrete columns for the lateral force. The deslgn acceleration Is $0.2 \mathrm{~g}$ with the natural perlod of $0.76 \mathrm{sec}$ in the selsmlc coefflclent method. It is $0.54 \mathrm{~g}$ with the natural perlod of $1.01 \mathrm{sec}$ in the check of the bearing capaclty, when energy dissipation effect of the base-Isolated devices Is taken Into account. llowever, since the bridge Is one of the flrst menshin bridges In Japan. the damplng effect of the devices was not taken Into account in the check of the bearing capacity. Therefore, the design acceleration of $0.7 \mathrm{~g}$ which was obtained by assuming that the energy disslpation of the devlces is zero, was used In the check of the bearing capaclty. 
Since the menshin system triggers off the larger displacement of the superstructure relative to the substructure than the ordinary bridges, the sufficient gap should be kept between the abutment and the girder, and at the expansion Jolnt. On the other hand, the larger gap at the expanslon jolnt would bring the vulnerabllity to the traffic load. Therefore, the following concept was adopted that the gap between the abutment and the girder should be decided as the girder would not collide to the abutment when It is subject to earthquakes for the check of the bearing capacity, and the gap at the expansion joint should be made equivalent to the relative displacement developed at the expansion joint by earthquakes of the seismlc coefficlent method. It was followed that the gaps between the abutment and the girder were $150 \mathrm{~mm}$ and the gaps at the expansion Jolnts were $50 \mathrm{~mm}$.

3) Flcld Vibration Test

The free vibration tests were conducted under the joint research program between the Earthquake Englneering DIvision of PWRI and the Shizuoka-ken government prlor the opening in order to verify the effect of the menshin system. The three hydraullc static Jacks owned by the Research Institute of Japan IIIghway Public Corporation Fere placed between the temporary steel frames assembled under the glrder and the A2 abutment as shown in Photo 6. The force capaclty of each jack is $150 \mathrm{tf}$ and the maximum stroke Is $150 \mathrm{~mm}$. The force created by the jack can be released more rapldly than the regular static Jack to develop the free vibration. The girder was forced by the jack to move agalnst the abutment in the longitudinal direction to a certain displacement. The maximum displacement was decided as $8 \mathrm{~cm}$ so that the total force of the jacks should not exceed the capacity of the abutment.

The accelerations on the girder at each substructure ( 8 points), the accelerations on the crests of the substructures ( 8 polnts) and the displacement of the girder relative to each substructure ( 8 points) were recorded during the free vibration tests.

Fig.9 shows the relative displacement of the girder on the $\wedge 2$ abutment when the force of the Jack was released at $8 \mathrm{~cm}$. It is observed in the figure that the free vibration of the glrder was developed In $0.75 \mathrm{sec}$ after the release and the girder came nearly to a stop at 4 sec, remalning the resldual displacement of $5.4 \mathrm{~cm}$ by the plastlc reslstant force of the lead plug.

FIg.10(a) shows the general model for the lateral load vs. displacement relation of the lead rubber bearing. Since the load conslsts of the linear restoring force of the rubber and the plastic restorlng force of the lead plug. the relation can be expressed as a comblnation of the linear spring model and the friction model shown in Figs.10(b) and (c), respectlvely. The natural perlod and the damping effect was analyzed with a simple single degree of freedom oscllation system as shown In FIg.11, which is a model for the glrder and the lead rubber bearings.

The spring constant and the friction force necessary for the analysis were obtalned from the result of the loading tests, which had measured the lateral load vs. displacement relation of the lead rubber bearing prior to the construction, as $2.351 \mathrm{tf} / \mathrm{m}$ and $173.8 \mathrm{tf}$, respectively. The result of the analysis is also shown with a dotted line in the Fig.9.

The analysis evaluates the test very well in the flrst $0.75 \mathrm{sec}$ after the release. It can be derlved that the dynamic performance of the menshin bridge could be assessed with the parameters obtalned from the loadlng test of the bearing Itself. The gradual decrease of the relative displacement after $0.75 \mathrm{sec}$ observed In the test. could have to do with the creep of the lead plug.

The traffic vibration tests were also conducted by running the trucks under the jolnt research program between the structure Division of PWRI and the Shlzuoka-ken government. No unusual vlbration due to the menshin system was monitored around the bearing.

The long-term measurement of the resldual relative displacement after the release at $8 \mathrm{~cm}$ wlll be done since the end of a serles of tests. The displacement was recovered to $0.9 \mathrm{~cm}$ at about one month later. It is sald that the residual displacement of the bearing cause no practical problem.

At the Mlyagawa bridge, the strong motlon observation Is now being made by the Shlzuoka-ken government and Ground Vibration Division of PWRI.

\section{ACTIVE CONTROL FOR SEISMTC RESPONSE OF IIGITAY BRIDGES}

\section{4-1 Introduction}

Applicabllity of an Active Mass Damper (refers as AMD In the following) for controlling earthquake response of highway bridges was Investigated by using a single-degree-of freedom model and reported in the last jolnt meeting. The results showed that a great deal of external energy is required in order to control earthquake response In appropriate level by means of AMD. The mass and/or stroke required are excessively large, and It seems not practical to control selsmlc response of bridge structures agalnst a significant earthquake (2) 13). Hence, it is of great Importance to develop hybrid control by comblnation of passive and active means. '3)

Development of hybrid control technology 
was Inltated at the Publlc Works Research Instltute slnce 1989. Prellminary study on control of selsmlc response of hlghway brldges using multiple AMDs, whlch is basis for hybrld control is presented here.

The cooperative research program is bcing executed as a U.S.-Japan cooperative research program through the the Panel on Hind and Selsmlc Effects, UJNR. The program is belng conducted at the Publlc Works Research Instltute in Japan side, and at the Natlonal Institute for Standards and Technology, and at National Center for Earthquake Engineering Research'4) with supports of National Sclcnce Foundation in U.S. side. Major subjects of the program. In Japan side includes investigations on (1) passive control method and (2) active control method for application to hybrid control as well as (3) optimum hybrid control whlch comblnes them approprlately.

\section{4-2 IIghway Brldge Analyzed and Analytical \\ Conditions}

For studylng where is the best point for control and effect of multiple control by means of AMD, the transverse response of three-span continuous glrder bridge with length of $150 \mathrm{~m}$ as shown in Fig.12 is analyzed. The brldge is modeled as a two-dimenslonal spring-mass model. Fundamental natural frcquency is $1.6711 \mathrm{z}$, and this is a first flexural mode of the deck. The flrst mode is most predomlnant in the transverse response of the bridge.

For controlling the deck response by means of one AMD, the welght of a driving mass is assumed as l80tf, which corresponds to about $1 / 10$ of the deck welght $(1,950$ tf). Control by means of two AMDs was also studied, In which two AMDs were assumed to be Installed on the glrder at the $\mathrm{P}_{1}$ and $\mathrm{P}_{2}$ plers, respectively. Three cases are analyzed, that is, thelr welghts are assumed to be lootf each, 90tf each, and $120 \mathrm{tf}$ and 60tf (180tf in total). The spring coefflclents, which supports driving masses, are assumed so that fundamental natural frequency of the mass of AMD be $1 / 4$ of fundamental natural frequency of the bridge analyzed. structural damping ratlo of the brldge is assumed as 5\%. A standard ground acceleration. which is speclfled in "Part $V$ Selsmic Deslgn ${ }^{n a)}$ " of the "Deslgn Speclfications for Highway Brldges", Is used as an input motlon.

Control algorlthm of AMD follows the classlcal optimum feedback control method. The control force driving the mass of AMD is assumed as a linear comblnation of the values proportional to displacement and veloclty of the structure and AMD. Proportlonal coefflclents are called as control gain, and the optlmum galn obtalned by solving Rlccattl's Algebralc Equation ${ }^{101} 10$ is used.

\section{4-3 Erfect of Controllung Polnt by NMD}

In order to Investigate an optlmum control polnt, the earthquake rcsponse analyses are conducted. AMD is assumed to be placed at the soine polnts on the glrder. Flg.13 shows peak response displacement and peak response acceleration of the glrder. It Is more effectlve in reduclng selsmic response of the girder when the AMD is Installed near the center of the girder. Comparing with uncontrolled one, peak displacement of the glrder decreases to $1 / 4$ and peak acceleration decreases to about half. On the other hand, effectlveness is smaller when AMD Is placed near the abutments. For example. when $A M D$ is placed on $A$ butment $A_{2}$, although the response dlsplacement becomes smaller by $15 \%$ than uncontrolled one, displacement response near the ends of glrder becomes larger by about 13 times the uncontrolled displacement.

Therefore, it is more effective to Install AMD at the point where the mode value of predominant mode shape is largest.

\section{4-4 Erfect of Multiple Control}

In order to Investigate effectiveness of multiple control, the earthquake response is analyzed, in whlch AMDs are assumed to be Installed on the $P_{1}$ and $P_{2}$ plers. Flg. 14 shows peak displacement and peak acceleration of the glrder controlled at the two polnts. Results controlled by only one AMD Is also shown In Flg.14 for comparlson. Two-polnt control makes posslble to decrease the selsmlc response of girder more signiflcantly than the control by only one AMD. Effectiveness of control of the response and control force requlred by AMDs with the welght of masses of 180 tf is almost same as those of $90 \mathrm{tf}$ both. Effect of the welght of drlving masses appears only in stroke lengths of driving masses. The strokes of drlving mass when the welght of driving masses is $90 \mathrm{tf}$ both Is twice those when the welght is $180 \mathrm{tf}$. Therefore, the welght of driving masses affects the stroke lengths of drlving masses, but does not affect the effectiveness of control. The simllar results can be obtalned when the welght of drlving masses are 60tf and $120 \mathrm{tf}$ each.

\section{4-5 Concluding Remarks up to the Present}

1) It is most effective that the AMD is Installed at the polnt where the mode shape value of a predominant mode is largest for controlling the selsmlc response of continuous girder brldges.

2) Two-point control using AMDs is more effective than one-point control in reducing the displacement response and acceleration response of the glrder. Since multiple control makes It posslble to control the deck response agalnst any mode shapes, it is requlred to further Investigate the effect of the multiple-polnt control in detall. 


\section{DEVELOPMLNT OF A VARIABLE DAMPER}

\subsection{Basic Concept of $\Lambda$ Varlable Damper for Ilghway Bridgcs}

The varlable damper is basically a viscous damper and the viscous damping force is varlable depending on the response of structures (hIghway brldges) as shown In Fig.15. For Instance, the damping coefficlent of the damper Is larger during the vibration within a small amplitude and the damper has the same function as a flxed bearing support against braking load of vehlcles. It Is, however, movable agalnst the load with low veloclty, such as elongation of glrder by temperature change. Once an earthquake occurs and amplltude of vibration of glrder becomes larger up to a certaln level, the damping coefficlent of damper decreases so that energy dissipation be optimum and Inertia force to the substructure be adjusted approprlately. Furthermore, when the vibratlonal amplltude becomes excesslve, the damping coefflclent Increases gradually in order to suppress the amplitude and so that the damper have a functlon as a stopper. Therefore, the varlable damper has the advantages of an usual vlscous damper-stopper, a passlve energy disslpator and a stopper with a shock absorber. The required external energy by the varlable damper for altering the damping coefflcient is greatly smaller than usual actlve control devices because the width of the orlflce of the damper can be changeable with a small amount of energy'.

\section{2 Earthquake Response Analysis of Mult1- \\ Degrec-of-Frecdon Systen with Varlable \\ Dampers}

The equations of motion for a linear multl-degree-of-freedom model wlth the varlable dampers may be written as

$$
\underline{M} \underline{x}+(\underline{C}+\underline{C} \underline{v}) \underline{x}+\underline{K} \underline{x}=-\underline{M} X_{0}
$$

In whlch $\underline{M}$. $\underline{\mathrm{C}}$ and $\underline{\mathrm{K}}$ represent mass, damping and stiffness matrices of the structure. respectlvely. $\underline{x}$ and $x_{0}$ denote displacement vector and ground displacement, respectlvely. $C_{v}$ denotes a damplng matrlx of the varlable dampers and Is glven by a functlon of relative displacement and relative veloclty between the nodes where the varlable dampers are installed. Since C. Is time-varylng. Eq.(1) has to be solved by a direct Integration method. According to the Newmark $\beta$ method, veloclty and displacement are assumed as

$$
\begin{aligned}
& \mathrm{x}_{1}=\mathrm{x}_{1-1}+(1-\alpha) \Delta \mathrm{t} \cdot \mathrm{x}_{1-1}+\alpha \cdot \Delta \mathrm{t} \cdot \mathrm{x}_{1} \\
& \mathrm{x}_{1}=\mathrm{x}_{1-1}+\Delta \mathrm{t} \cdot \mathrm{x}_{1-1}+(1 / 2-\beta)(\Delta \mathrm{t})^{2} \cdot \mathrm{x}_{1-1} \\
&+\beta(\Delta \mathrm{t})^{2} \cdot \mathrm{x}_{1-1}
\end{aligned}
$$

In which $\alpha$ and $\beta$ are parameters of the Newmark $\beta$ method and If a constant acceleration method is assumed $\alpha$ and $\beta$ have to be taken 0.5 and 0.25 , respectively.

Using the above analytlcal method, a computer program, named as "VDAM", whlch can analyse earthquake response of multl-degreeof-freedom system with the varlable dampers was developed.

\section{5-3 Ulghway Brldge Analyzed and Analytical \\ Conditions}

In order to Investigate effectlveness of the varlable damper, a simple span girder bridge, as shown In Flg.16. with a span length of $30 \mathrm{~m}$ is analysed in the longltudinal direction. The model brldge has elastic Isolator and the varlable dampers are assumed to be Installed between the superstructure and the top of substructure. The spring constant of elastic Isolator is defined so that a fundamental natural perlod of the bridge be 1 second.

Fourteen cases In total are analysed as shown In Figs.17 and 18. In Case 1 the varlable damper is not Installed, In Cases 2 and 3 the damping coefficlent of the damper is in dependent of displacement and/or veloclty. The damplng coefflclents of Cases 2 and 3 are glven so that damping ratio of critical be $5 \%$ (Case 2) and $100 \%$ (Case 3 ). In Cases 4 and 5 , the damping coefficlent is dependent on relative displacement as shown In Fig.17. Peak relative displacement d., Is defined as a peak relative displacement computed In Case 2 and It was assumed as $19.4 \mathrm{~cm}$. In Cases 6 and 7, the damplng coefficlent is dependent on relatlve veloclty as shown in Flg.17. Peak veloclty $v_{\text {. }}$ Is defined as a peak value $(113 \mathrm{~cm} / \mathrm{s})$ computed In Case 2. Case 8 Is a combination of Cases 4 and 6 and the damping coefflclent of the damper Is dependent on relative displacement and relative veloclty.

A ground motion acceleration whlch was modlfled so that the response spectra matches with the target spectra is used as an Input ground acceleration. The acceleration response spectrum, which is speclfled in "Part V Selsmic Deslgn" of the "Deslgn Speclflcatlons for IIIghway Brldges", for the check of bearing capacity of relnforced concrete plers, is assumed as the target spectra.

Damplng ratlo of crltical of a model brldge Is assumed $2 \%$ as a modal damplng.

\section{5-4 Effectiveness of Varlable Dampers on \\ Earthquake Response of IIIghway Brldges}

Table 3 shows the peak response of girder and the varlable damper. where the peak values of displacement, veloclty and acceleration of the glrder and dampling force, relative displacement and relative velocity of the damper are presented. Flgs.19 and 20 compare tIme hlstorles of displacement and acceleration 
of the glrder and damping force of the varlable damper between Case 1 (wlthout the varlable damper), Case 5 (dlsplacement dependent) and Case 7 (veloclty dependent).

According to these results, the following remarks may be polnted out:

1) If the damping coefficlent is dependent on relative displacement of the damper, it is effective to set larger damping coefficient around zero displacement (Case 5). The peak damplng force in Case 5 becomes $58.2 \times 2$ tf whlch corresponds to 48.2 \% of the welght of the deck (241.5tf). The damplng force of $96.4 \mathrm{tf}$ makes reduction of acceleration of glrder to $566 \mathrm{gal} / 1300 \mathrm{gal}=43.5 \%$, and relatlve displacement of the gIrder to $13.25 \mathrm{~cm} / 33.04 \mathrm{~cm}=$ 40.1\% comparlng with Case 1 in whlch the varlable damper is not installed.

2) The damping force required to control the response up to the same level is smaller in displacement dependent dampers (cases 4 and 5) than In veloclty dependent dampers (cases 6 and 7). Thls is because pulse-type large damplng forces are requlred In the velocity dependent dampers. Large damplng coefflclent at the time when large veloclty is developed causes large damping force. On the other hand, slnce the damping force is dispersed as time large damplng forces are not required in the displacement dependent dampers.

3) The time history displacement shows that the varlable dampers operate satisfactorlly as a stopper whlch also has a function as a shock absorber without an Impact response.

\section{5-5 Development of $\wedge$ Pl]ot Model of the Varlable Damper}

Photos 7 - 9 show a pllot model of the varlable damper developed. The model is deslgned so that the damplng force be varlable within $20 \mathrm{kgf}$ to $200 \mathrm{kgf}$, maxlmum relative displacement of damper plston be $\pm 5 \mathrm{~cm}$, and the welght be about $40 \mathrm{kgf}$. The varlable damper conslsts of an usual viscous damper and a control system. Damplng characterlstics of the varlable damper is now belng studled. Model experlments are planed.

\section{5-6 Concluding Remarks up to the Present}

1) In the displacement dependent dampers, it is effective to set larger damping coefficlent around zero displacement.

2) The damping force requlred to control the response up to the same level is smaller in the displacement dependent dampers than in the veloclty dependent dampers.

3) The time history response shows that the varlable dampers operate satisfactorlly as a stopper whlch also has a function as a shock absorber without an Impact response.

4) The pllot model of the varlable damper was developed. Experimental study on the characterlstics and control method of the varlable damper is belng studled.

5) The varlable damper seems to be near a practical use.

\section{CONCLUSIONS}

Thls paper brlefly presents current research and development activitles on passlve, active and hybrid control for application to brldges structures conducted at Publlc Works Research Instltute. 1t Is thought that these technologles may become very important In future for constructing super-multiple continuous glrder brldges, long-span bridges, bridges with high-rlse plers, and bridges in urban area with strlct land use restrictlons.

\section{RFFERENCES}

1) Kawashima, K. : Development and Future Scope of Selsmic Isolation of structures, - A Revlew -, Proc. of Japan Soclety of Clvil Englneers, structural Eng./Earthquake Eng., Vol.398/ I $-10,1988$

2) Buckle, 1. : Development and Appllcatlon of Base Isolation and Passlve Energy Disslpation - A World Revlew -, Proc. of $\Lambda$ Seminar and Workshop on Base lsolation and Passlve Energy Disslpatlon, pp.153 174, San Franclsco, U.S.A., March 1986.

3) Guldelines for Deslgn of Base-Isolated Highway Bridges, Final Report of A Commlttee for Study of Appllcatlon of Base Isolation to Selsmic Deslgn of Mlghway Brldges (Chalrman : Professor T. Katayama), Technology Research for Natlonal Land Development. March 1989

4) Publlc Works Research Instltute : Report of Jolnt Research between PWRI and 28 Prlvate Firms on Development of Menshin Systems for Hilghway Bridges, Technlcal Report of Cooperative Research, No.44 and No.60, March 1990 and March 1991. Publlc Works Research Institute

5) Chapman, H. E. and KIrkcaldle, D. K. : Selsmlc Deslgn of Base lsolated BrIdges Incorporating Mechanlcal Energy DIsslpators, Translt New Zealand's 1990 Brldge DesIgn and Research SemInar, Chrlstchurch. New Zealand, November 1990

6) Goto, Y., KlkuchI, Y. and M. Kurolwa : Investlgation on a Knock-off Devlce as an Expanslon Jolnt for Menshin Bridges. Proceedings of the 46 th Annual Meeting of Japan Soclety of Clvll Englneers, October 1991

7) Japan Road Assoclatlon : Part V Selsmlc Deslgn of the Deslgn Speclflcations for Highway Brldges, February 1990

8) 1wasakI, T., Kawashima, K. and Hasegawa, K. : New Selsmlc Deslgn Speclflcations for Road Bridge in Japan, 22nd Jolnt Mecting 
U.S.-Japan Panel on Wind and Selsmlc Effects, U.J.N.R., NIST, Galthersburg, May 1990

9) Matsuo, Y., 0-1shl, A., Hara, K. and Yamashita, M. : Design and Construction of Mlyagawa Brldge, - Flrst Menshin Brldge In Japan -. Brldge and Foundation. Vol.91. No.2, ppl5-21, February 1991

10) Taylor, R. G., and Roblson, T. H. : Highstraln Test on Lead Rubber Bearlngs for Earthquake Loadings, Bull. of the New Zealand Natlonal Soclety for Earthquake EngIneer, Vol.17, No.2, pp90-105, June 1984

11) Bulling, I. J. and KIrkcaldle, D. K. : Base Isolation of Bridges in New Zealand. Proc. of New Zealand-Japan Horkshop on Base Isolation of Highway BrIdges, Hellington, New Zealand, November 1987

12) KawashIma, K., Hasegawa, K. and Yoshlda, T. : Actlve Control of Selsmic Response of Structure by Means of Mass Damper. Civll Englneering Journal, Vol.31-5, May 1989

13) Taguchl, J., Iwasakl, T., AdachI, Y., Sasakl, Y. and KawashIma, K. : U.S.-Japan Cooperatlve Research Program on Hybrid Control of Selsmlc Response of Bridge Structures, 22nd Jolnt Meeting. U.S.-Japan Panel on Wind and Selsmic Effects, U.J.N.R., NIST, Galthersburg, May 1990

14)Feng, Q. and Shlnozuka, M. : Use of A Varlable Damper for llybrid Control of Bridge Response Under Earthquake, U.S. National Workshop on Structural Control Research. Unlversity of Southern Callfornia, CA., U.S.A., October 1990

15) Ito, M. : Automatlc Control, Shokodo Publlshing Co., February 1983

16) Kalman. R. E. : Contrlbutlons to the Theory of Optimal Control. Proc. 1959 Mexlco City Conference on DIfferentlal Equations, Mexico City, 1960, pp102-199 
Table 1 Pllot Program for Construction of Menshln Highway Bridges

\begin{tabular}{|c|c|c|c|}
\hline Owner & Name of Bridge & Type of Superstructure & Total Length \\
\hline Hokkaido developing Bureau & On-netoh Bridge & Steel Girder & $456 \mathrm{~m}$ \\
\hline $\begin{array}{c}\text { Tohoku Regional Construction } \\
\text { Bureau, MOC }\end{array}$ & Nagakigawa Bridge & Steel Girder & $97 \mathrm{~m}$ \\
\hline Iwate-ken & Maruki Bridge & Prestressed Concrete & $92 \mathrm{~m}$ \\
\hline Tochigi-ken & Daiichi Karasuyama Bridge & Prestressed Concrete & $250 \mathrm{~m}$ \\
\hline Shizuoka-ken & Miyagawa Bridge & Steel Girder & $110 \mathrm{~m}$ \\
\hline
\end{tabular}

Table 2 Natural Perlod, Design Acceleration and Design Relative Displacement

\begin{tabular}{|c|c|c|c|c|c|}
\hline Design Method & Item & A1 & P1 & P2 & A2 \\
\hline \multirow{4}{*}{$\begin{array}{c}\text { Seismic } \\
\text { Coefficient } \\
\text { Method }\end{array}$} & Natural Periọd (sec) & \multicolumn{4}{|c|}{0.764} \\
\cline { 2 - 6 } & Design Acceleration (g) & \multicolumn{4}{|c|}{0.20} \\
\cline { 2 - 6 } & $\begin{array}{c}\text { Design Relative } \\
\text { Displacement (mn) }\end{array}$ & 28.2 & 21.8 & 20.2 & 28.0 \\
\hline \multirow{2}{*}{$\begin{array}{c}\text { Check of } \\
\text { Bearing } \\
\text { Capacity }\end{array}$} & Natural Period (sec) & \multicolumn{4}{|c|}{1.01} \\
\cline { 2 - 6 } & Design Acceleration (g) & \multicolumn{4}{|c|}{0.54} \\
\cline { 2 - 6 } & $\begin{array}{c}\text { Design Relative } \\
\text { Displacement (mm) }\end{array}$ & 133 & 109 & 105 & 130 \\
\hline
\end{tabular}


Table 3 Peak Response of Deck and Varlable Damper

(a) Full Control

\begin{tabular}{|c|c|c|c|c|c|c|c|c|}
\hline \multirow{2}{*}{\multicolumn{2}{|c|}{ Analytical Cases }} & \multicolumn{3}{|c|}{ Deck } & \multicolumn{4}{|c|}{ Variable Damper } \\
\hline & & \multirow{2}{*}{$\begin{array}{c}\begin{array}{c}\text { Displace- } \\
\text { ment } \\
(\mathrm{cm})\end{array} \\
33.04 \\
\end{array}$} & \multirow{2}{*}{$\begin{array}{c}\begin{array}{c}\text { Velocity } \\
(\mathrm{cm} / \mathrm{sec})\end{array} \\
189.0 \\
\end{array}$} & \multirow{2}{*}{$\begin{array}{c}\begin{array}{c}\text { Acele- } \\
\text { ration } \\
\left(\mathrm{cm} / \mathrm{sec}^{2}\right)\end{array} \\
1300\end{array}$} & \multirow{2}{*}{$\begin{array}{c}\text { Damping } \\
\text { Force } \\
(\mathrm{t} f)\end{array}$} & \multirow{2}{*}{$\begin{array}{c}\text { Relative } \\
\begin{array}{c}\text { Displace- } \\
\text { ment }(\mathrm{cm})\end{array} \\
-\end{array}$} & \multirow{2}{*}{$\begin{array}{c}\text { Relative } \\
\text { Velocity } \\
(\mathrm{cm} / \mathrm{sec})\end{array}$} & \multirow{2}{*}{$\begin{array}{c}\begin{array}{c}\text { Total } \\
\text { Energy } \\
\text { Absorption } \\
(\mathrm{t} f \cdot \mathrm{m})\end{array} \\
- \\
\end{array}$} \\
\hline 1 & No Control & & & & & & & \\
\hline 2 & $\begin{array}{c}\text { Constant } \\
\text { Damping } \\
\left(h_{1}=0.05\right)\end{array}$ & 25.63 & 148.7 & 1012 & 8.8 & 19.41 & 113.1 & 65.41 \\
\hline 3 & $\begin{array}{c}\text { Constant } \\
\text { Damping } \\
\left(\mathrm{h}_{2}=1.0\right) \\
\end{array}$ & 7.97 & 45.1 & 481 & 47.1 & 5.73 & 30.4 & 81.51 \\
\hline 4 & $\begin{array}{l}\text { Displacement } \\
\text { Dependent } \\
\text { Damping }\end{array}$ & 23.33 & 140.7 & 1043 & 39.2 & 17.32 & 142.2 & 70.70 \\
\hline 5 & $\begin{array}{c}\text { Displacement } \\
\text { Dependent } \\
\text { Damping }\end{array}$ & 13.25 & 84.8 & 566 & 58.8 & 10.18 & 123.6 & 93.62 \\
\hline 6 & $\begin{array}{l}\text { Velocity } \\
\text { Dependent } \\
\text { Damping }\end{array}$ & 21.10 & 131.3 & 1117 & 140.3 & 16.05 & 169.4 & 78.41 \\
\hline 7 & $\begin{array}{l}\text { Velocity } \\
\text { Dependent } \\
\text { Damping }\end{array}$ & 20.35 & 126.7 & 1029 & 109.8 & 15.44 & 147.4 & 76.38 \\
\hline 8 & $\begin{array}{c}\text { Displacement } \\
\text { and Velocity } \\
\text { Dependent } \\
\text { Damping }\end{array}$ & 20.96 & 122.7 & 1136 & 129.3 & 15.72 & 168.1 & 80.52 \\
\hline
\end{tabular}

(b) Partial Control

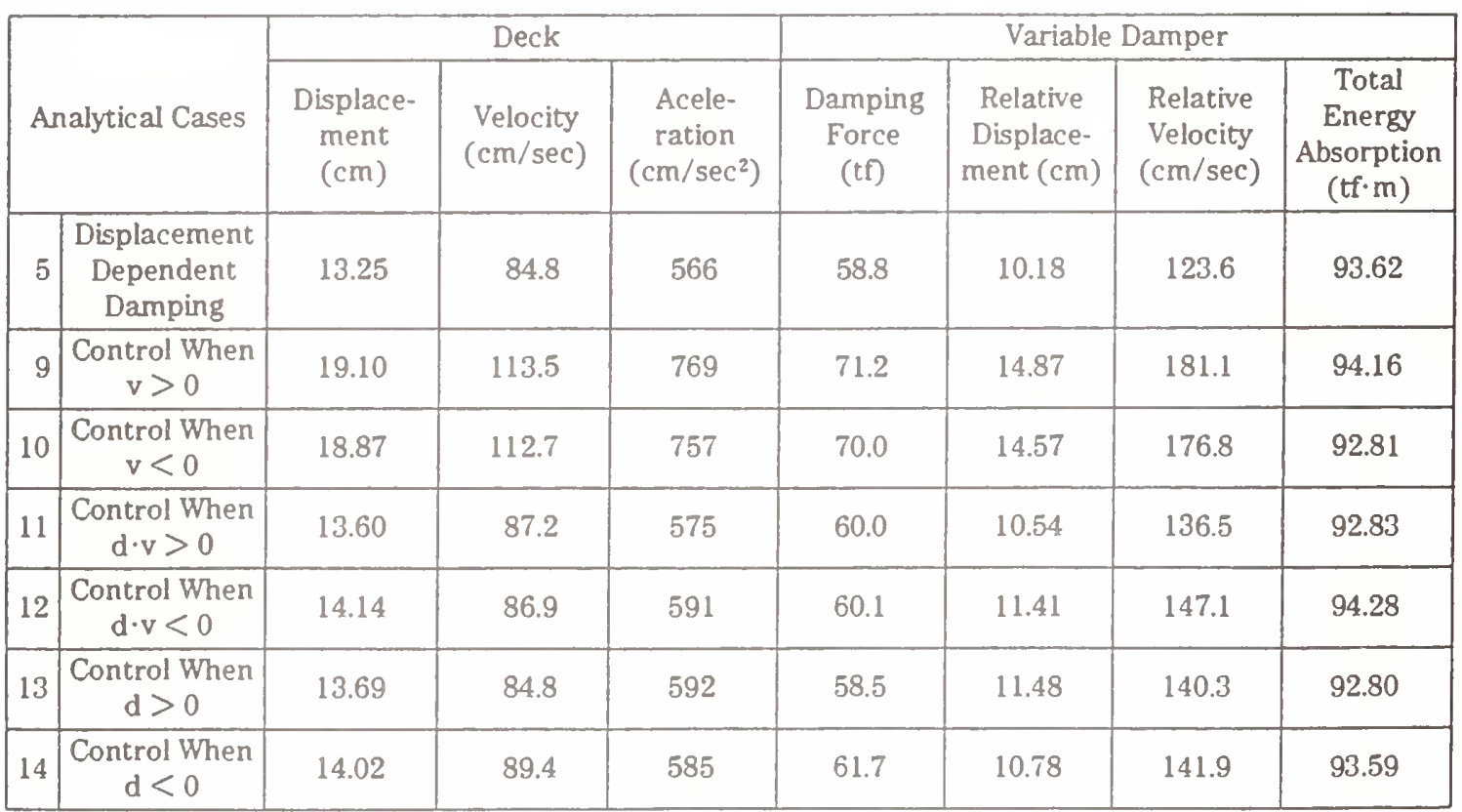




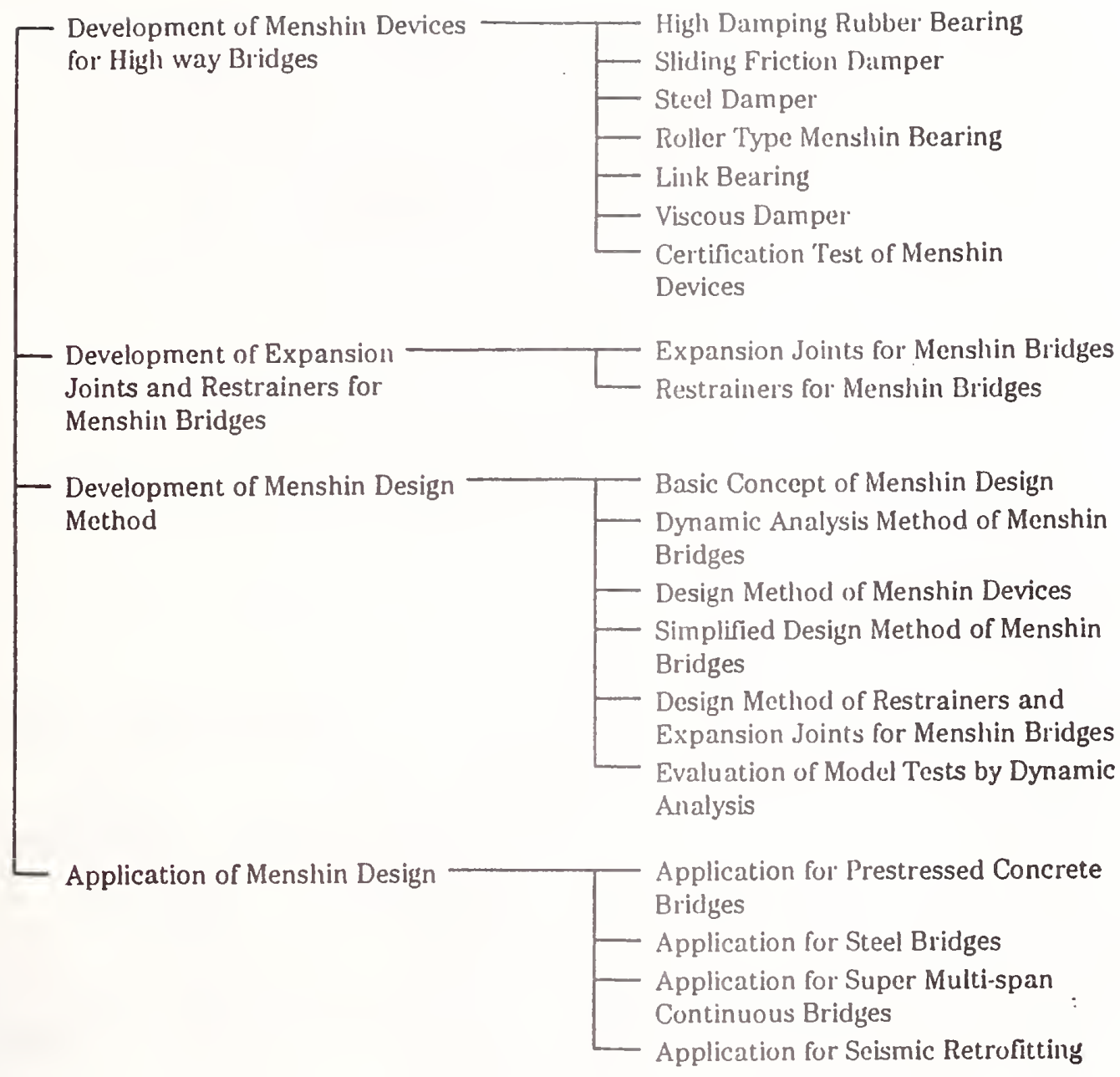

Fig.1 Research Items of Joint Research Program

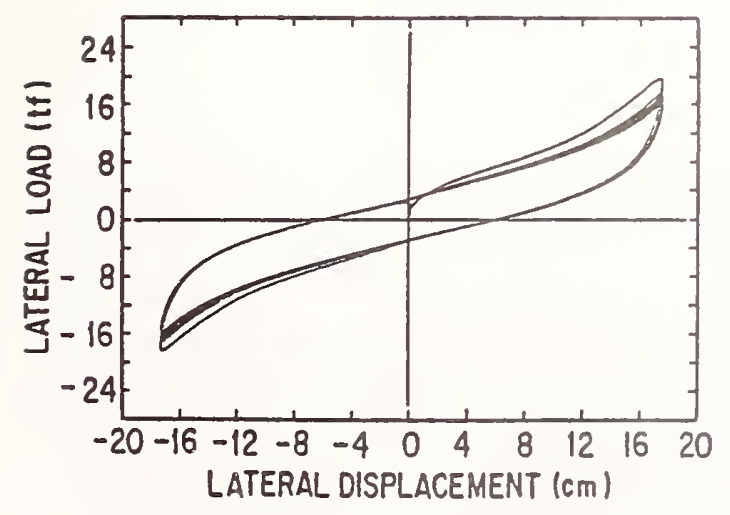

(a) High Damping Rubber Bearing

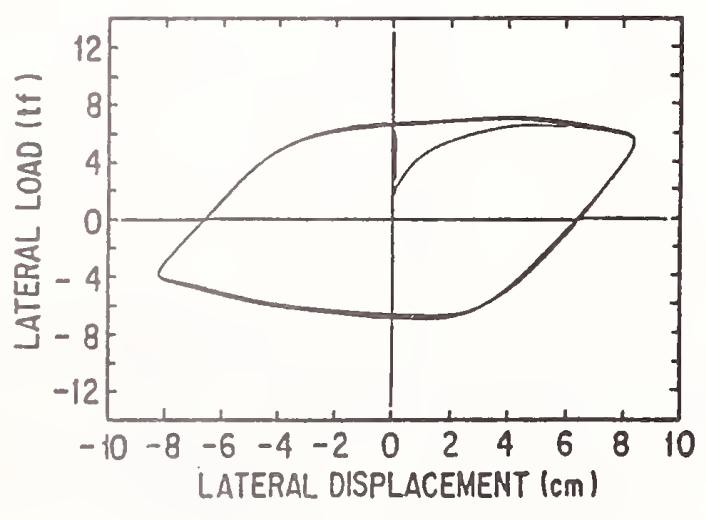

(b) Sllding Friction Damper

Flg.2 Lateral Load vs. Displacement Hiysteresis Loop 


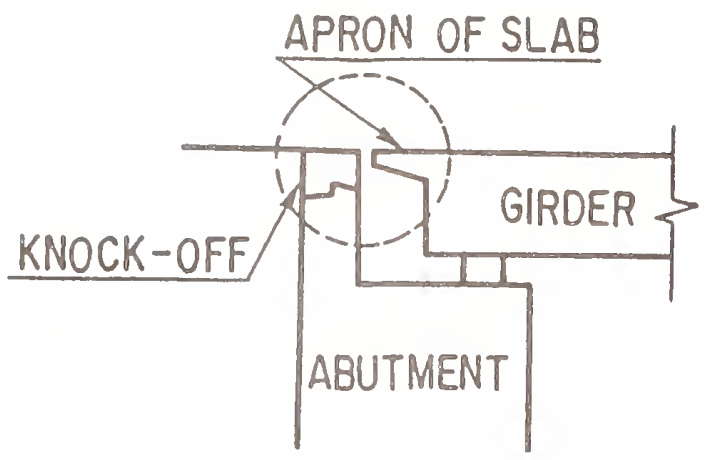

Fig.3 Knock-off MechanIsm

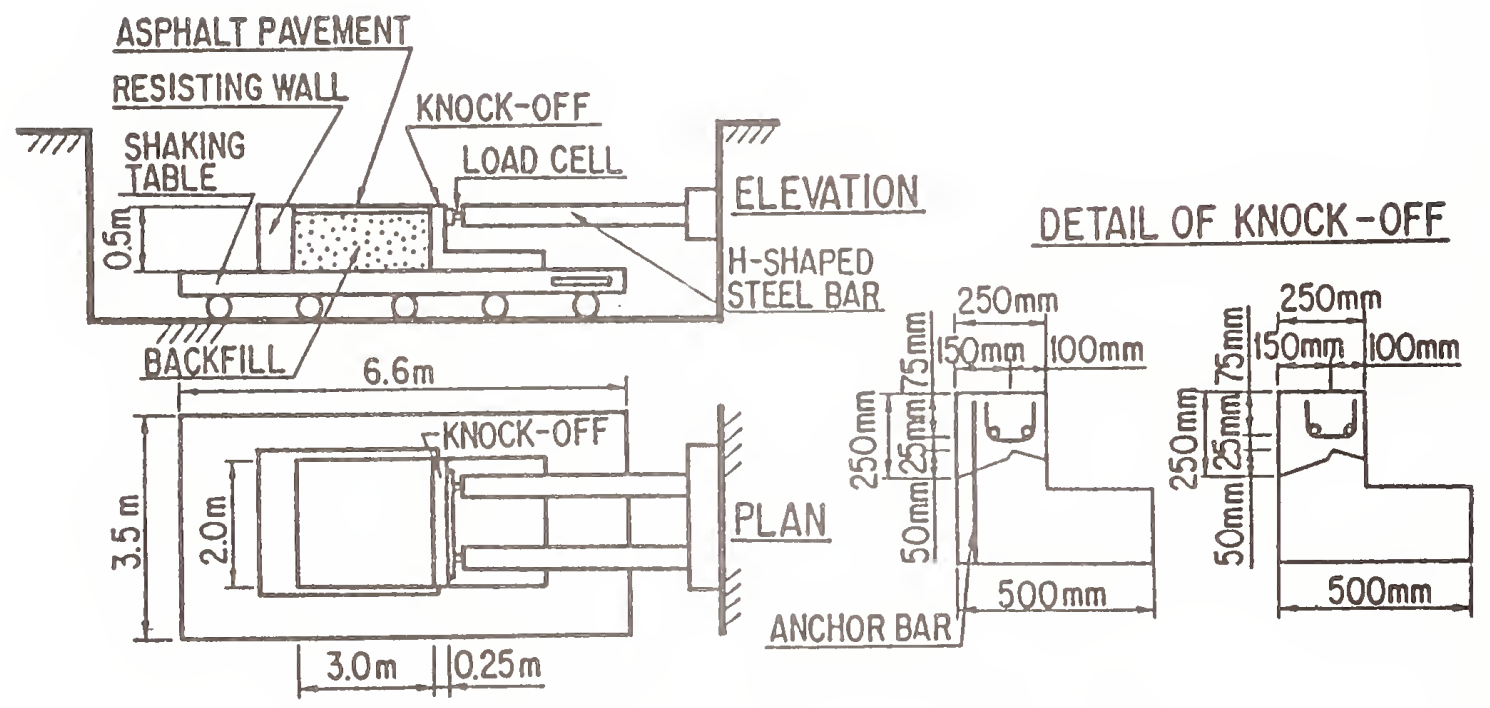

Fig.4 Experiment of Knock-off Mechanism ${ }^{\text {o) }}$

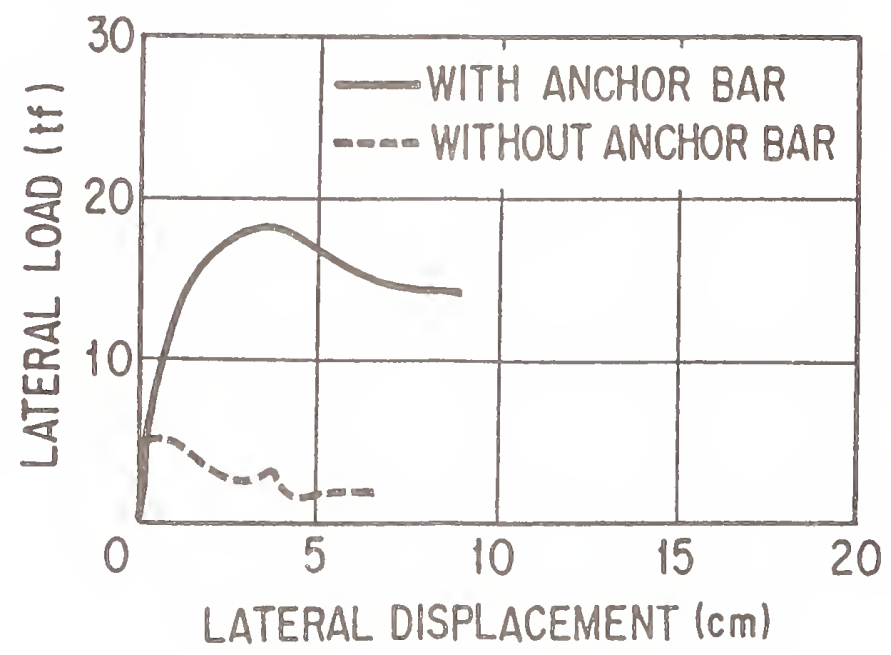

Flg.5 Lateral Load vs. Displacement Relation of Knock-off Mechanism ${ }^{6}$ 


\begin{tabular}{|c|c|c|c|}
\hline [Item] & [Object] & [Analysis Method] & [Design Force Level] \\
\hline $\begin{array}{l}\text { Assumption of } \\
\text { Initial Dimension }\end{array}$ & Substructure & Static Analysis & Level 1 \\
\hline \multirow{3}{*}{ Design } & & & \\
\hline & Menshin Device & \multirow{2}{*}{ Static Analysis } & Level 2 \\
\hline & Substructure & & Level 1 \\
\hline \multirow{3}{*}{ Check } & \multirow{3}{*}{$\begin{array}{c}\text { Menshin Device } \\
\text { Substrcture }\end{array}$} & Static Analysis & Level 2 \\
\hline & & \multirow{2}{*}{ Dynamic Analysis } & Level 1 \\
\hline & & & Level 2 \\
\hline \multirow{3}{*}{ Structural Detail } & & & \\
\hline & \multicolumn{2}{|c|}{ Expansion Joint } & (Level 2) \\
\hline & \multicolumn{2}{|c|}{ Restrainer } & (Level 3) \\
\hline
\end{tabular}

Fig.6 Baslc Flow Chart of Menshin Design

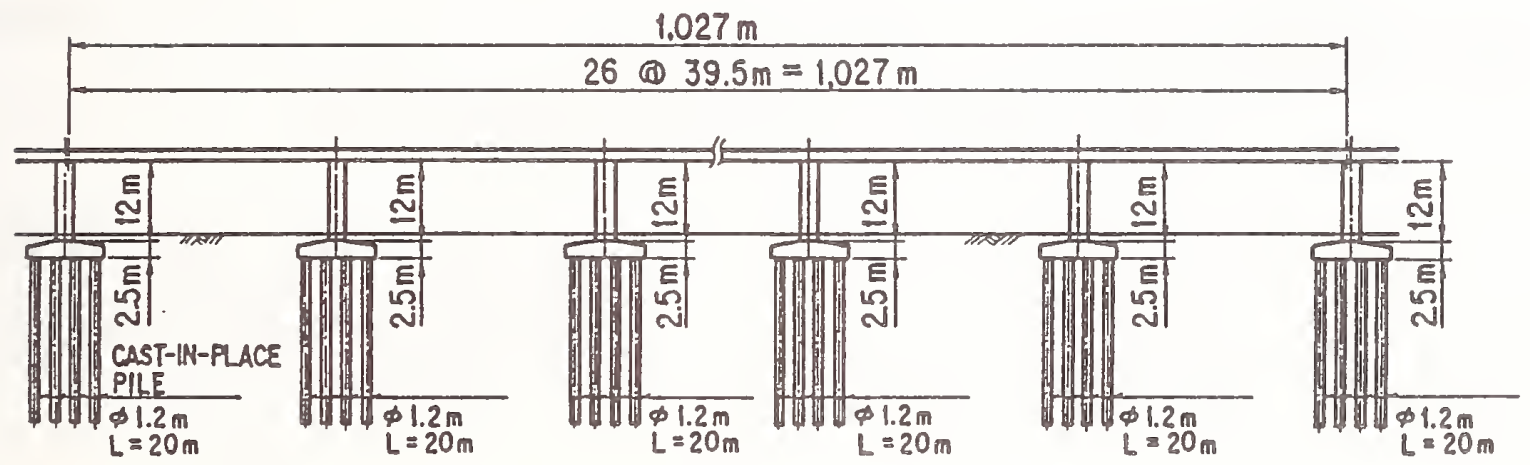

Fig.7 Super Multi-span Continuous Bridge

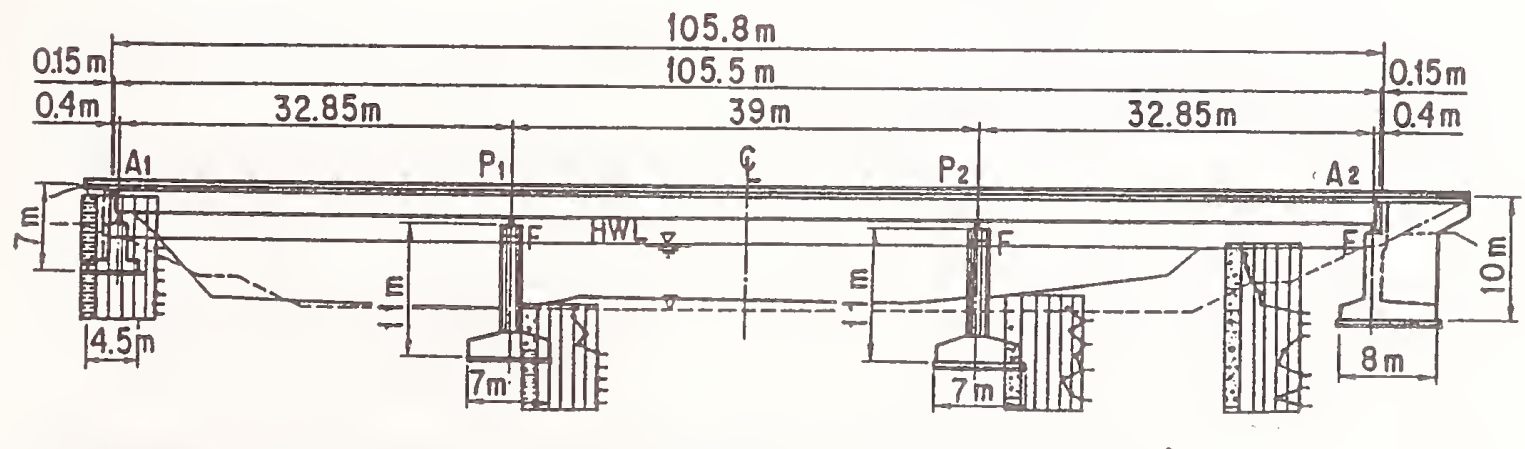

Fig. 8 Miyagawa Bridge 


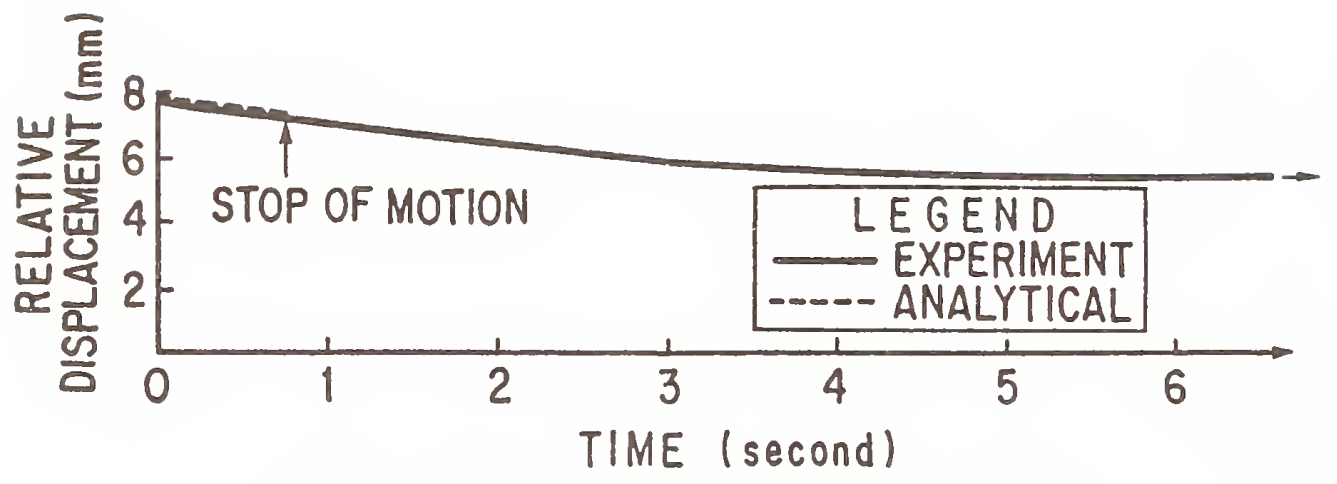

Flg.9 Relative Displacement after Release

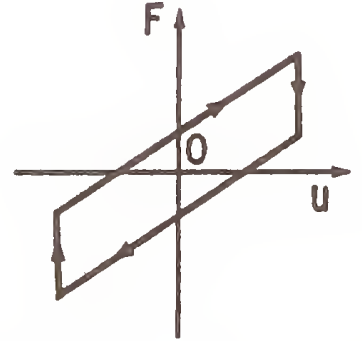

(a) Lateral Load $\nabla s$ Lateral DIsplacement Relation of LRB

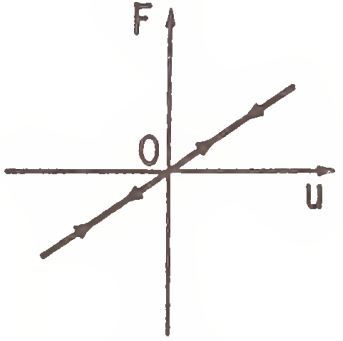

(b) Elastlc Spring

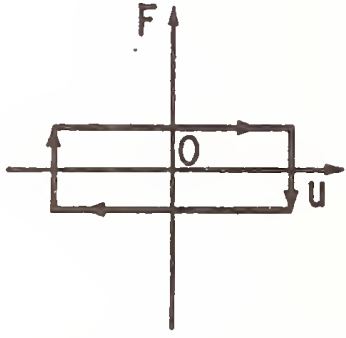

(c) Frlction Force

Flg.10 Load rs. Displacement Relation of LRB

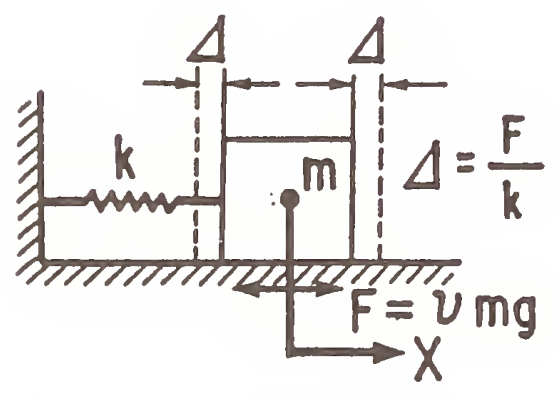

Fig.11 Single Degree of Freedom

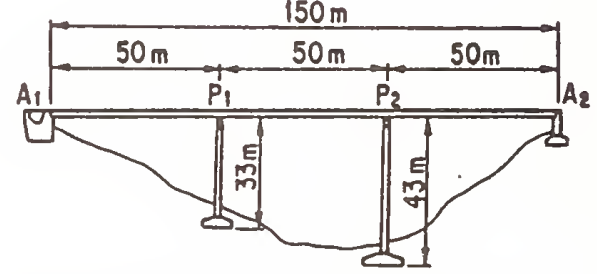

(a) HIghway Brldge Analyzed

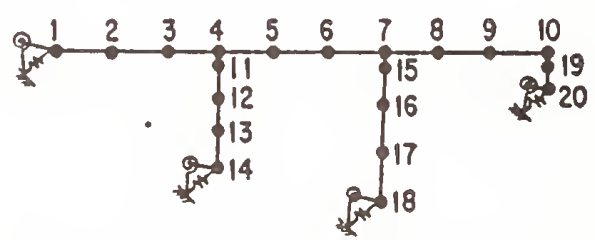

(b) Analytical Ideallzation

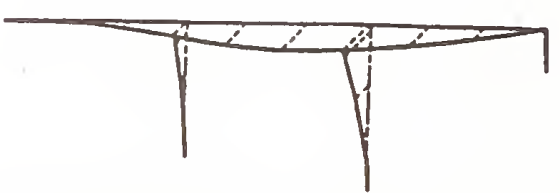

(c) Fundamental Natural Mode. of Vibration $\left(f_{1}=1.67 \mathrm{~Hz}\right)$

Fig.12 Highway Brldge Analyzed and Analytical Idealization 

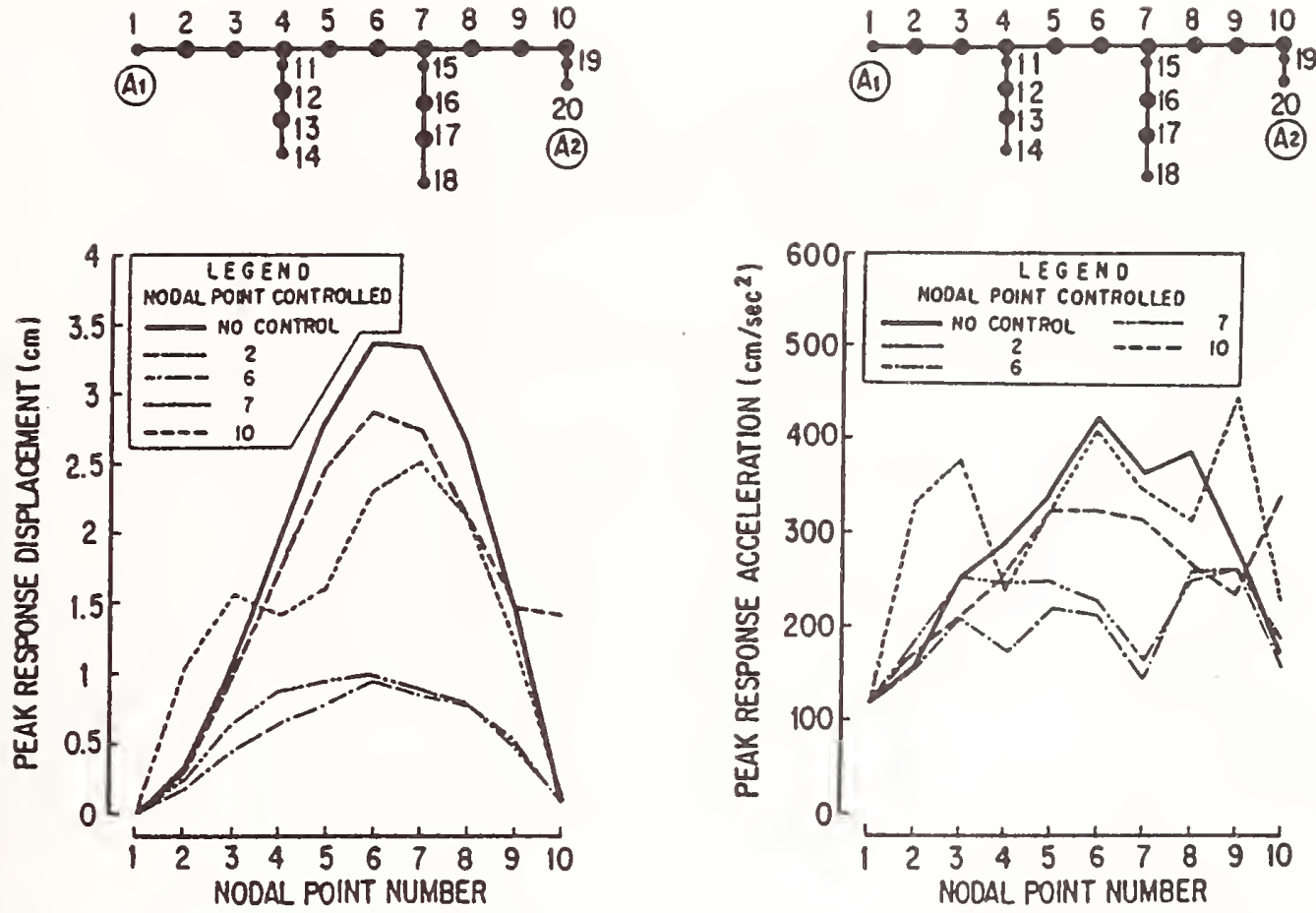

(a) Peak Response Displacement

(b) Peak Response Acceleration

Fig.13 Effect of Controlling Polnt by AMD

AMO 1 AMO 2
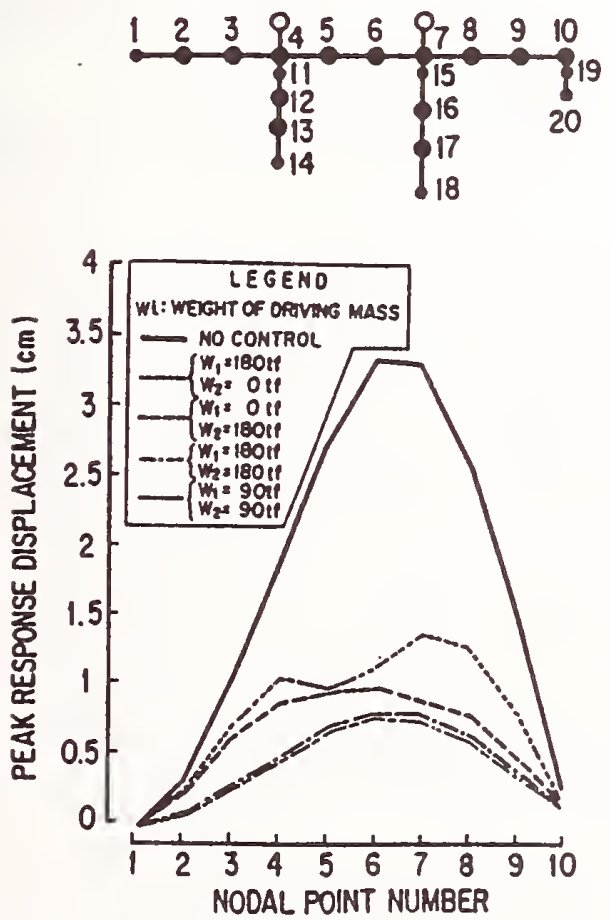

(a) Peak Response Displacement
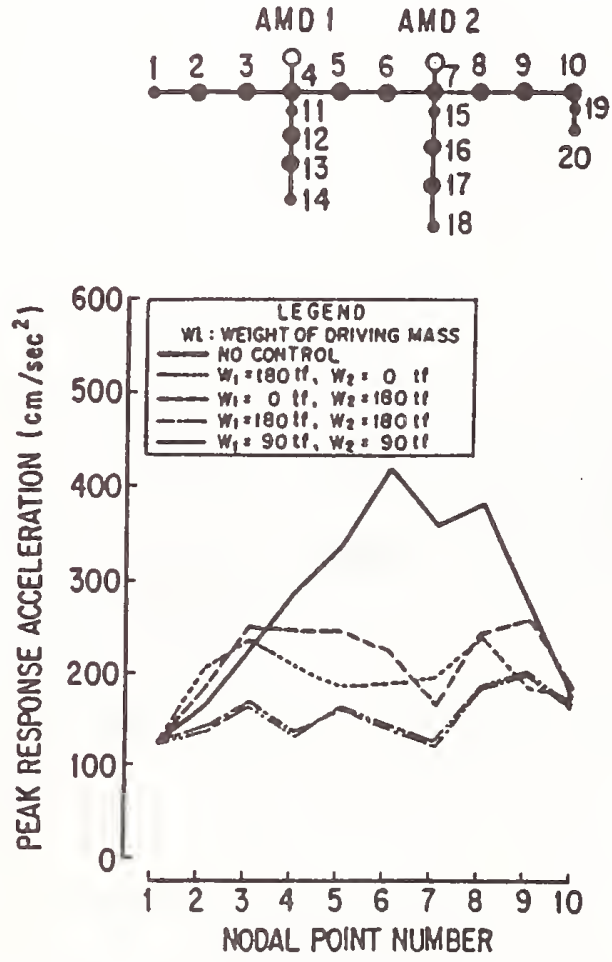

(b) Peak Response Acceleration

Flg.14 Effect of Multiple Control by AMDs 


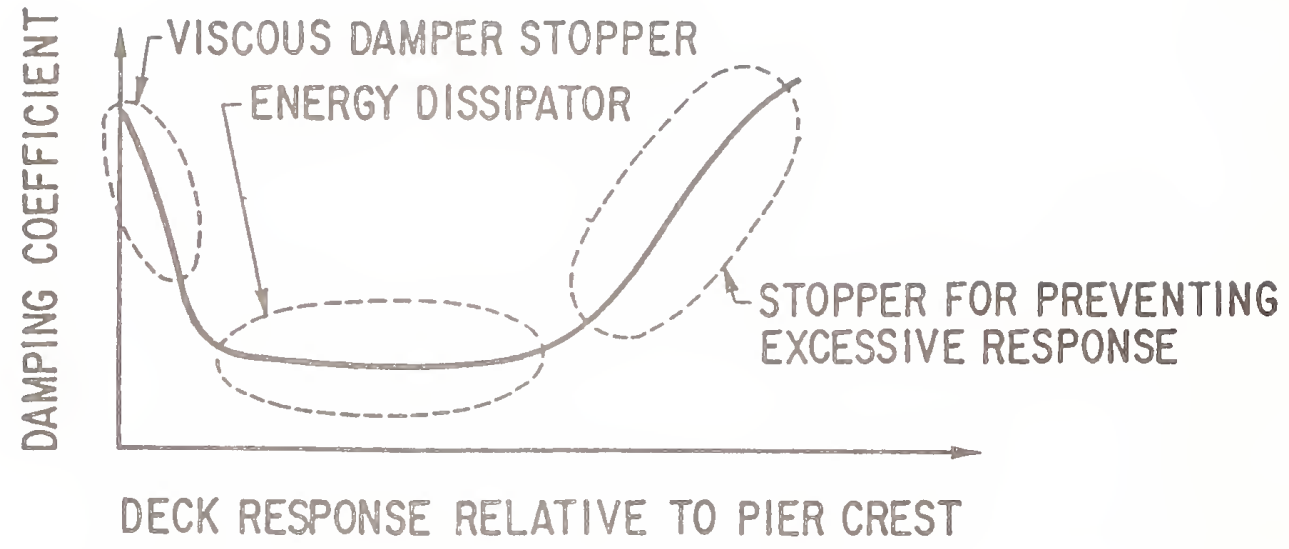

Fig.15 Baslc Concept of Varlable Dampers
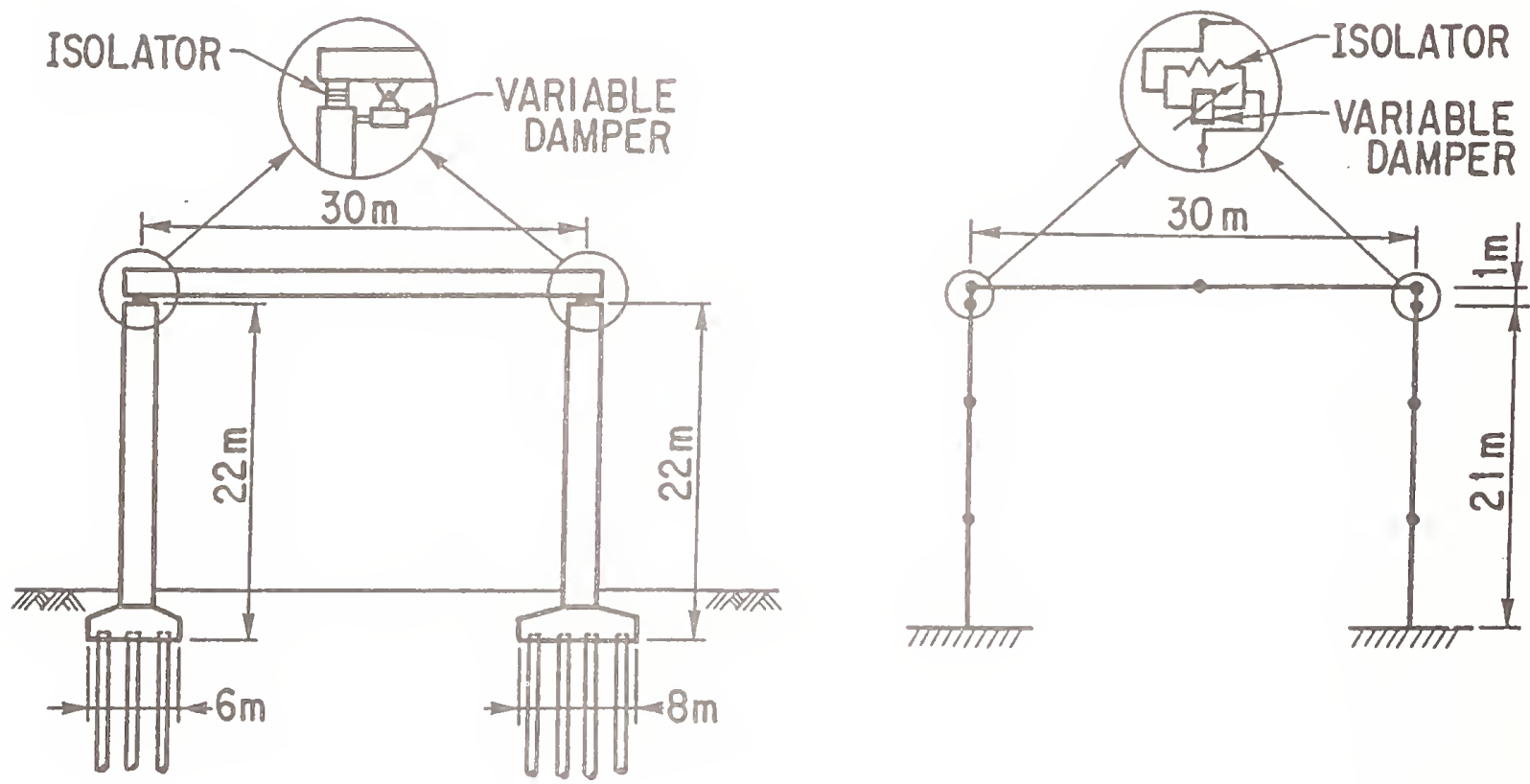

Fig.16 Highway Bridge Analyzed and Analytical Ideallzation 

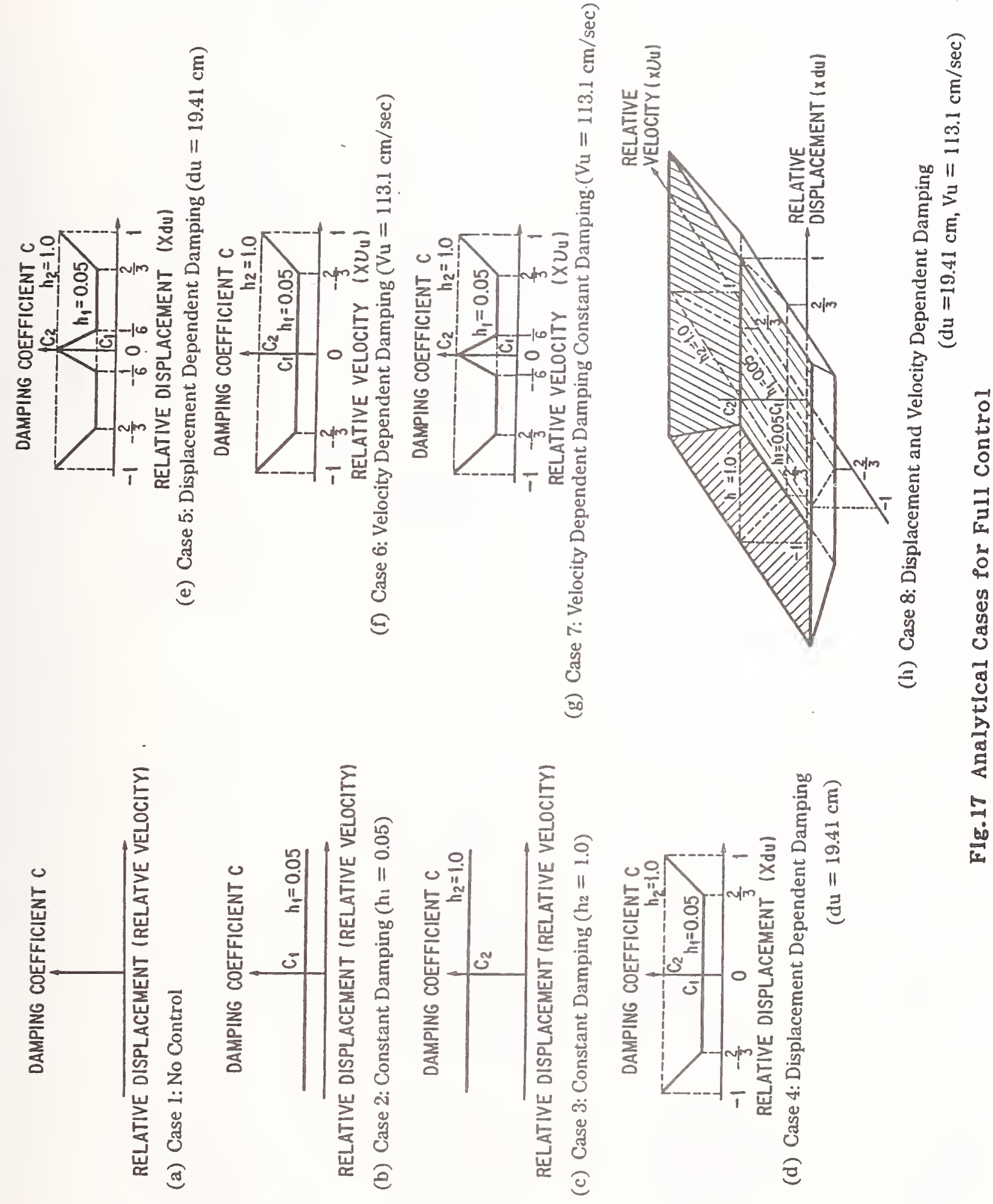

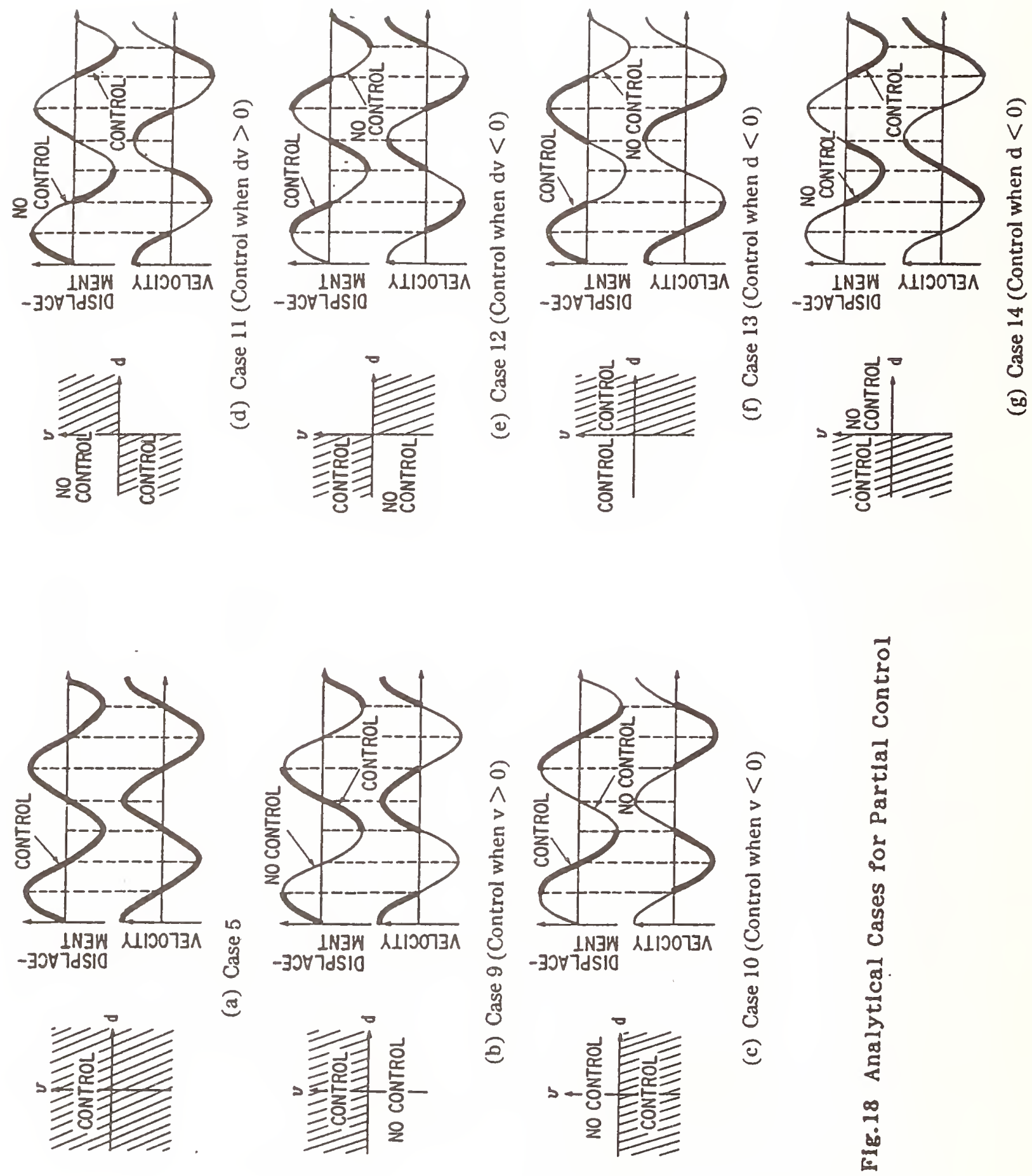

204 

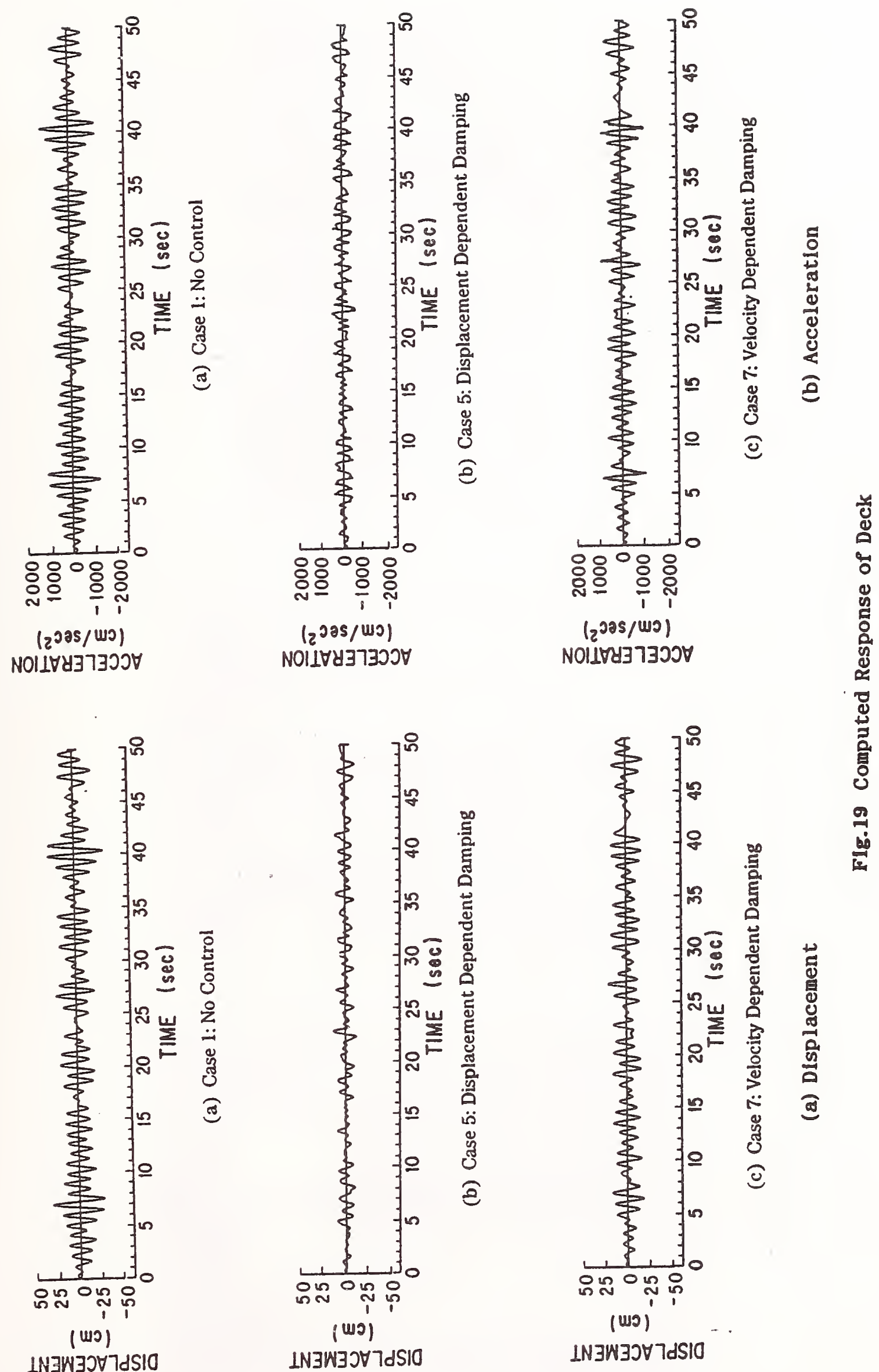


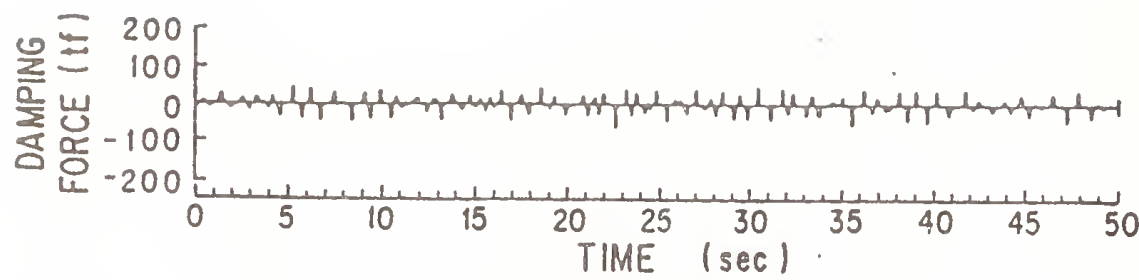

(a) Case 5: Displacement Dependent Damping

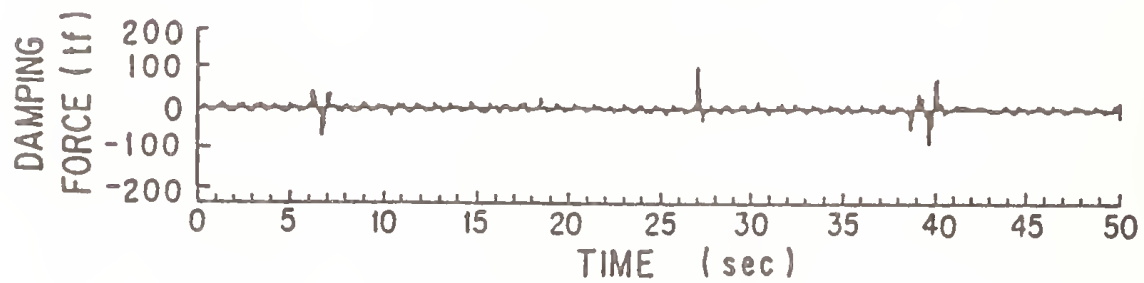

(b) Case 7: Velocity Dependent Damping

(1) Damping Force

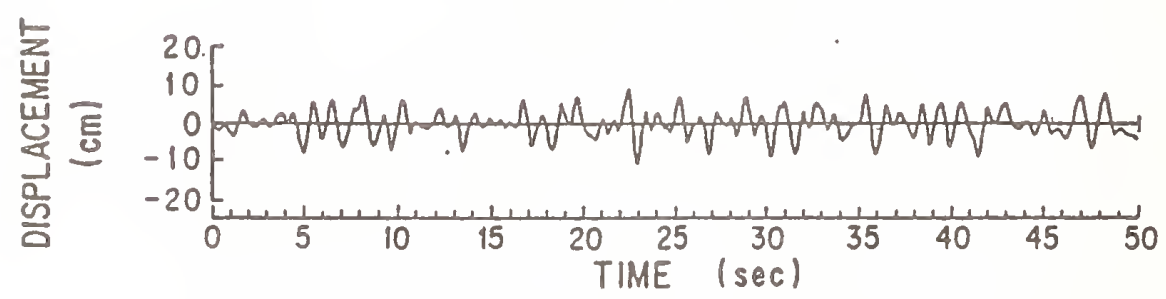

(a) Case 5: Displacement Dependent Damping

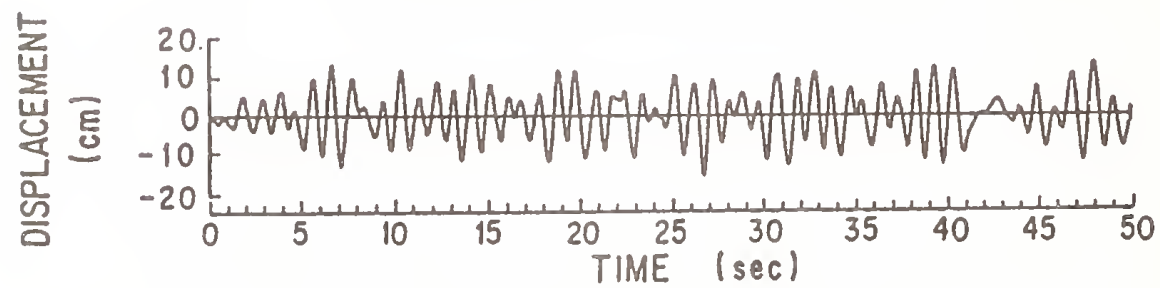

(b) Case 7: Velocity Dependent Damping

(2) Displacement

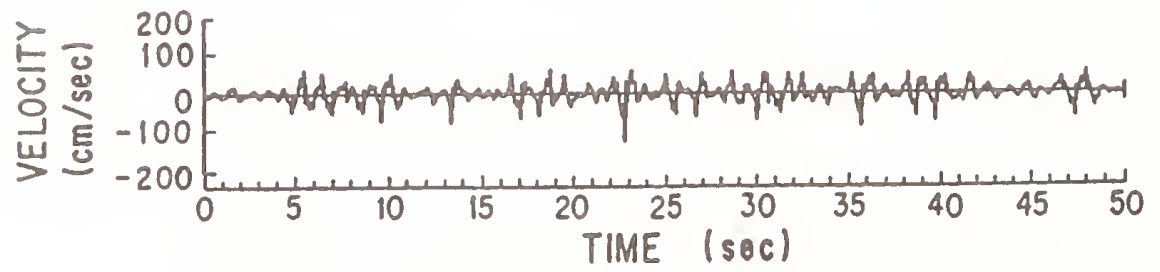

(a) Case 6: Displacement Dependent Damping

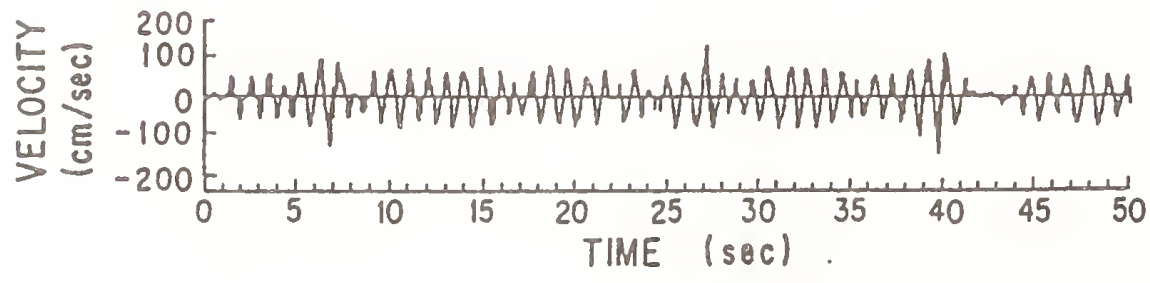

(b) Case 7: Velocity Dependent Damping

(3) Velocity

Fig.20 Computed Response of Varlable Dampers 


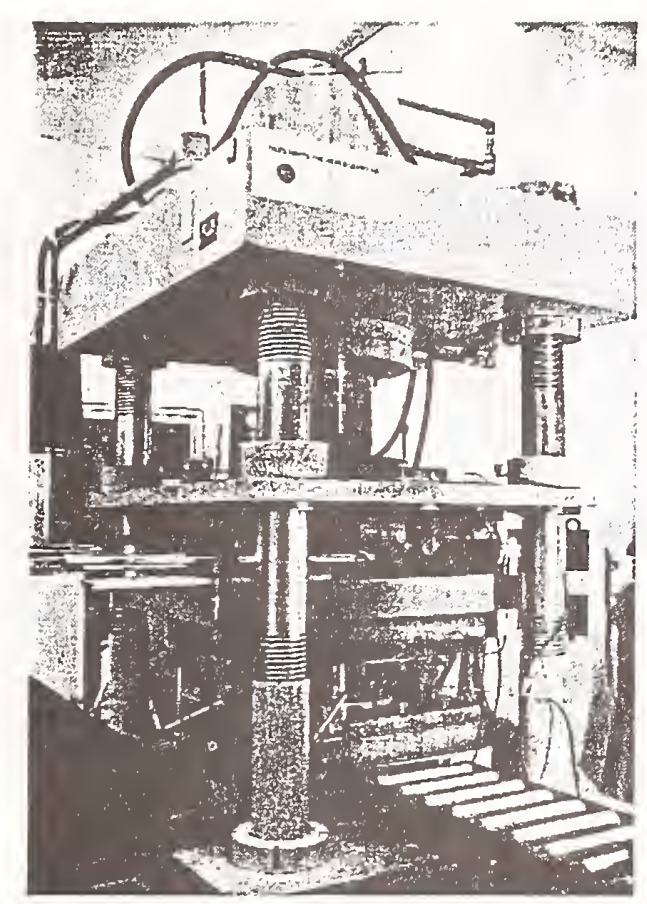

Photo 1 Loading Experlment System for Menshin Devlces

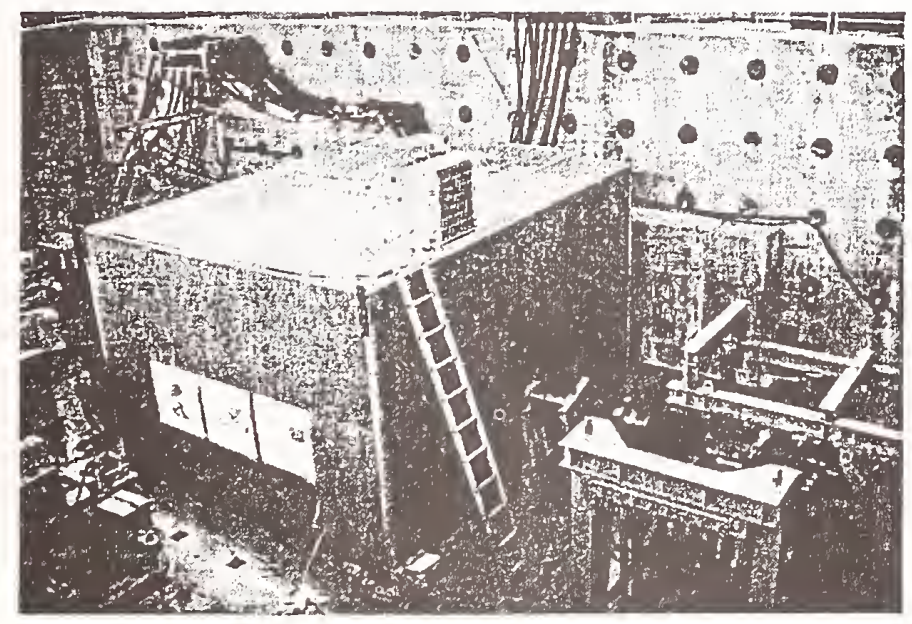

Photo 2 Constant Temperature Room for Test of MenshIn Devlces

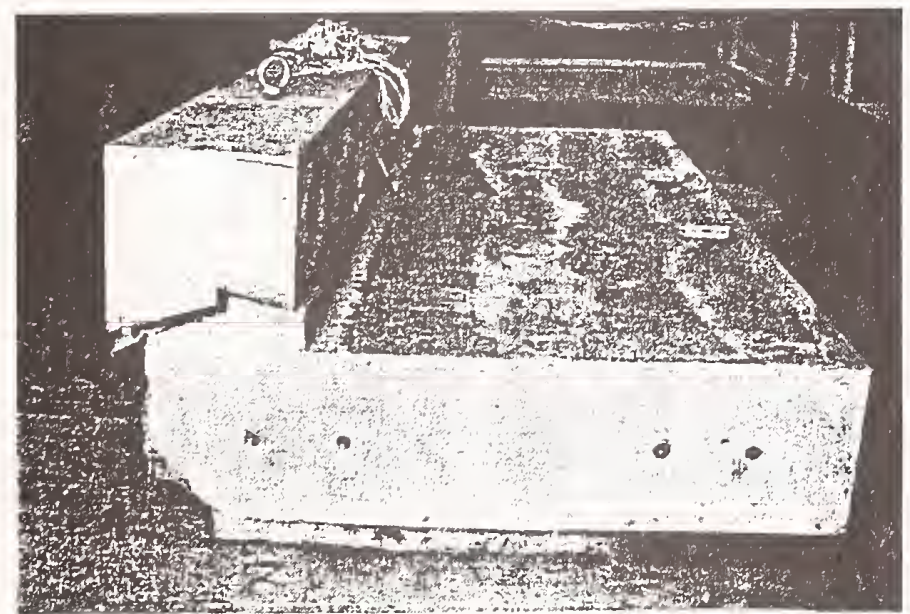

Photo 3 Model of Knock-off Mechanism ${ }^{(3)}$ 


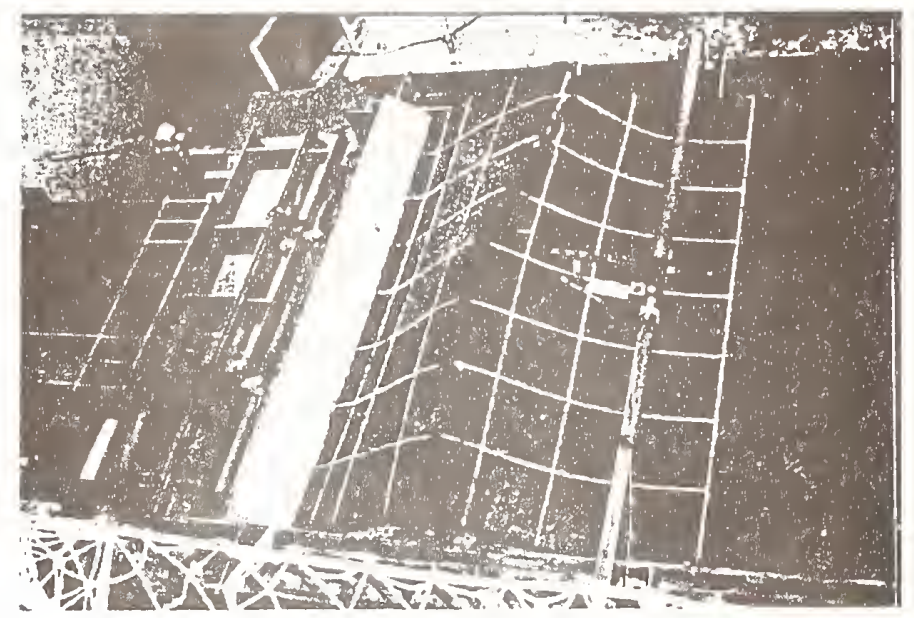

Photo 4 situation after Test ${ }^{(1}$

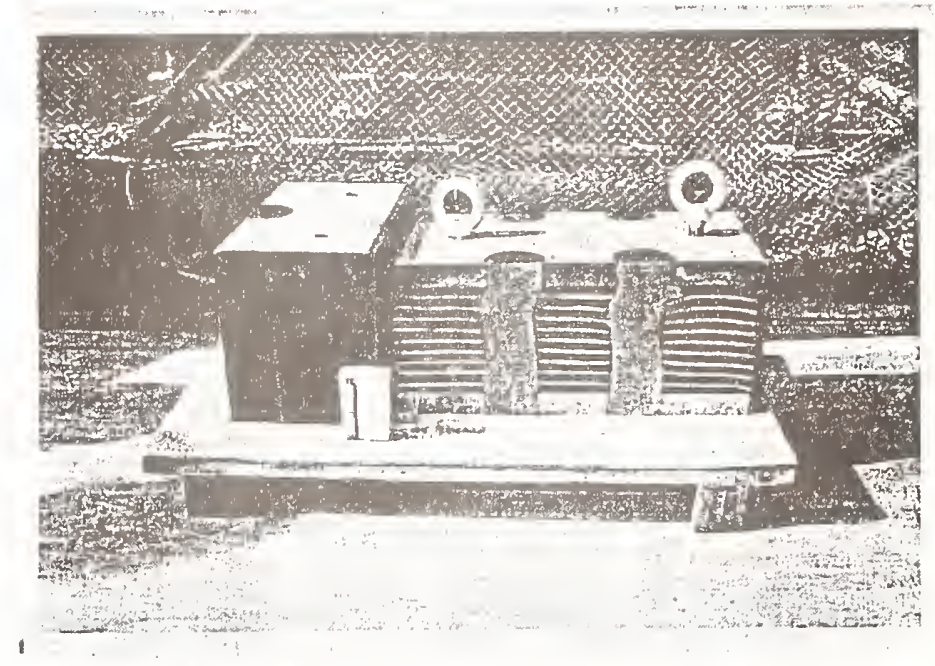

Photo 5 Lead Rubber Bearing

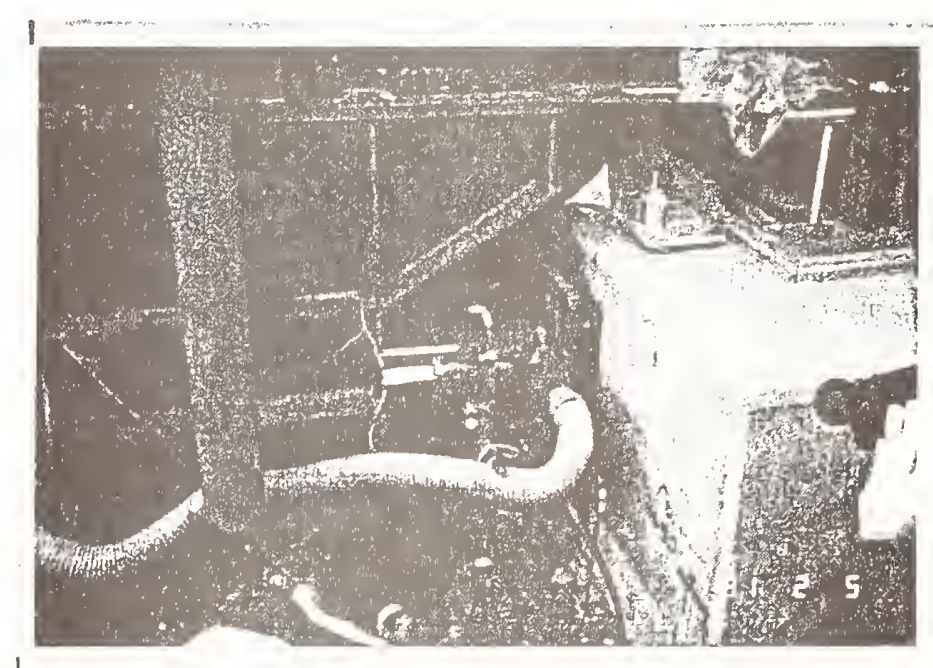

Photo 6 Hydraulic Static Jack 


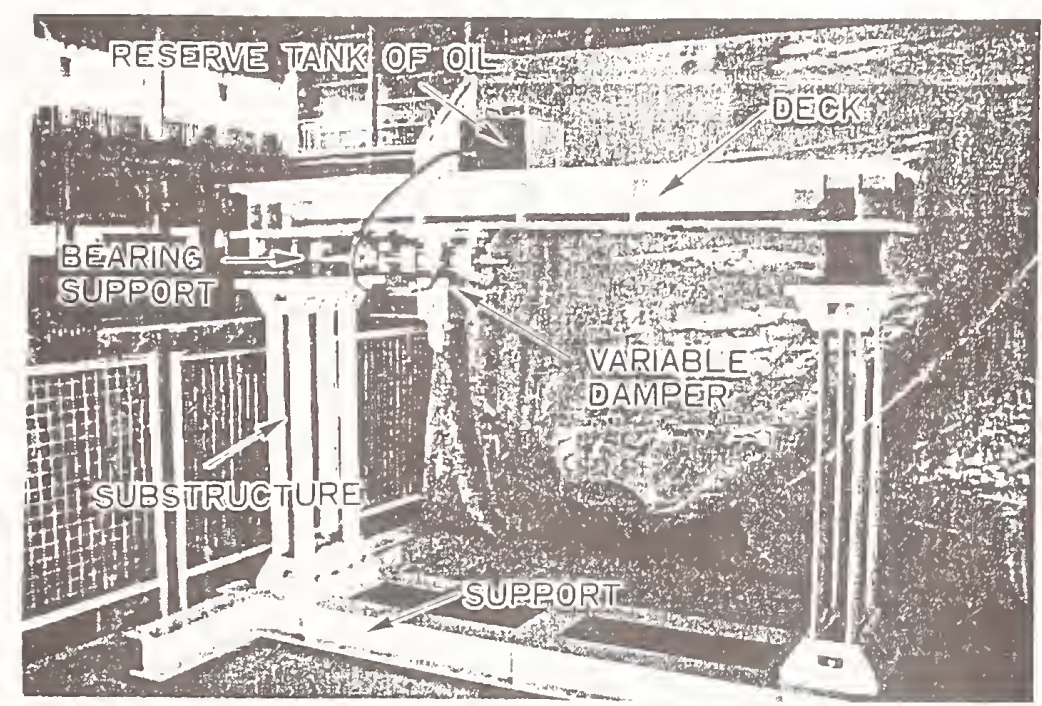

Photo 7 Bridge Model with Varlable Damper

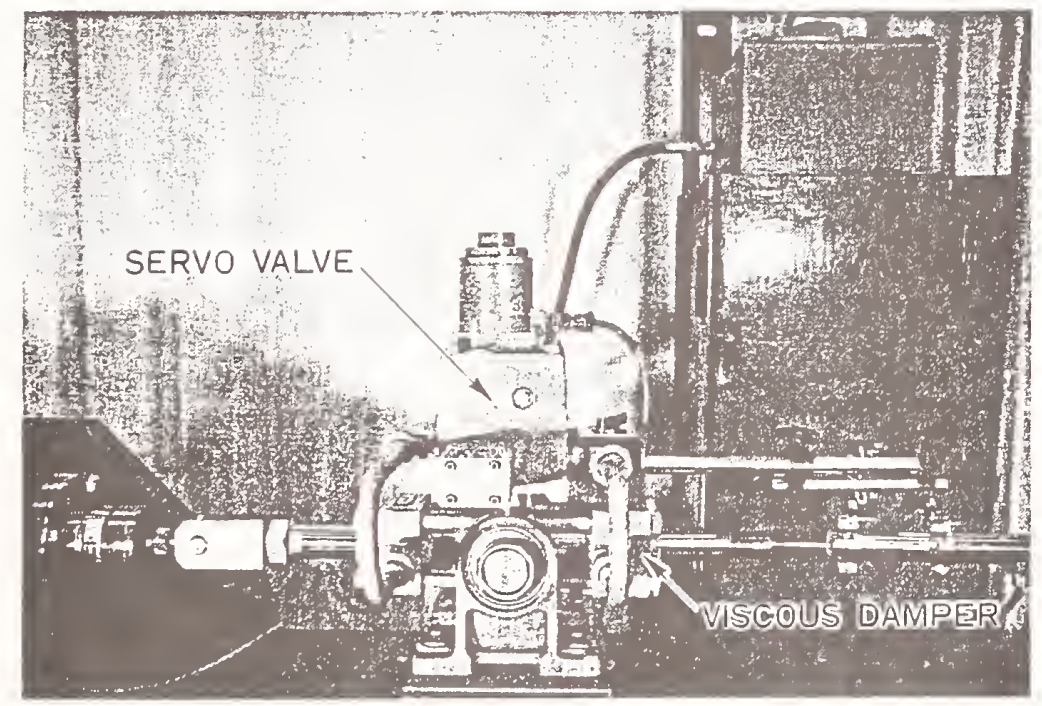

Photo 8 Variable Damper

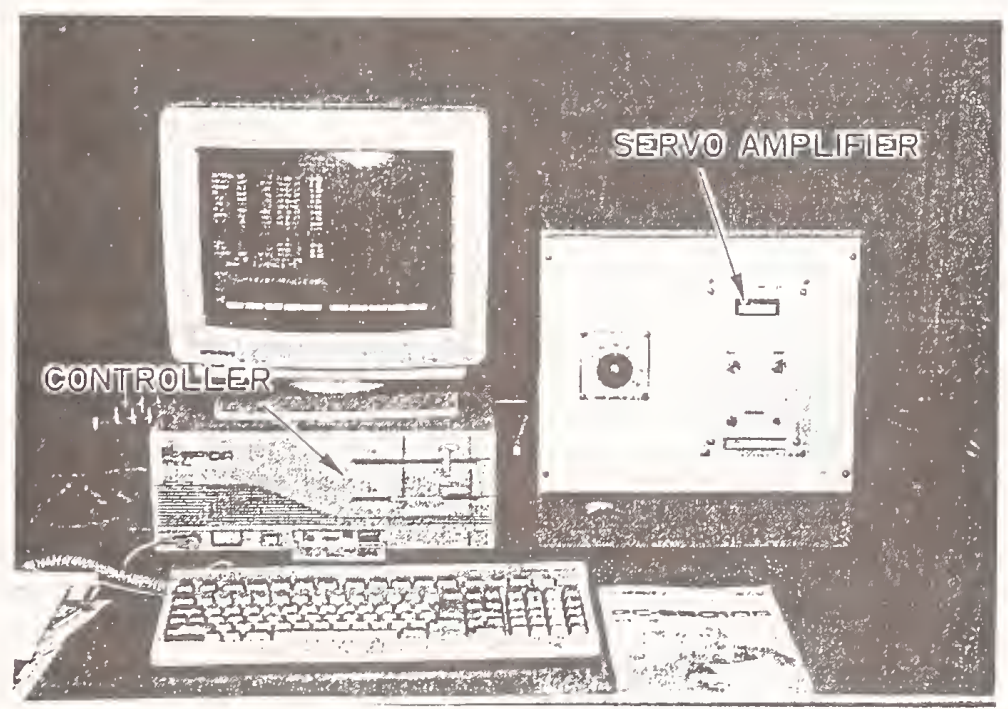

Photo 9 Control System for Variable Damper 


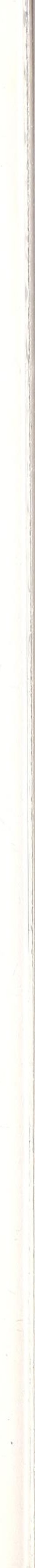




\section{ABSTRACT}

This paper assesses the current status of control technology and its potential application to structural safety against seismic, wind and other dynamics loads. An intensive effort underway to develop a national research program is described. Research needs and important problems remaining from both the technological and practical standpoints are suggested.

\section{INTRODUCTION}

Bridges, buildings and other structures have traditionally relied on their strength and ability to dissipate energy through engineering design to resist dynamic forces such as strong seismic events, extreme winds, ocean waves, and heavy traffic or machine loads. In recent years, however, the use of passive and/or active systems to control and reduce structural and architectural damage caused by earthquakes, winds, and other environmental loads has become an area of considerable research interest. New provisions dealing with seismic isolators have been included in the 1991 edition of the UBC which will enhance the practice. Historically there have been a number of successful applications of control concepts where the objectives, limits and criteria for the controller are essentially established by the specific design requirements. However, the pace of practical application in a global sense and technological advancements in the field of intelligent materials and control systems for civil structural design and construction, have been falling short of expectations. Control technologies as required for such civil structural applications clearly need further development and enhancement through use of advanced sensors, computers, and actuators to (a) detect changes in the system internal state and environment, (b) monitor quantitative models of system performance by means of multiple sensor inputs, and (c) generate real time actions to modify or alter system behavior, performance, and operation due to earthquake, extreme winds, and other natural or man-made hazard uncertainties.
In connection with passive systems, much research has been accomplished in specific areas related to base isolation techniques and a variety of mechanical energy dissipators such as structural bracing systems, friction dampers, viscoelastic dampers, and other mechanical devices. In the area of active systems, active mass dampers, variable stiffness devices and active bracing or tendon systems represent some of the devices being developed, tested, or installed both in the laboratory and, in certain cases, in prototype fullscale structures. Recently, the combined use of active and passive systems, which are often referred to as hybrid systems, have been suggested for some specific structural applications.

\section{DYNAMIC CONTROL AND INTELLIGENCE}

An active or hybrid controlled structure can be viewed under the general context of "intelligent structures" or "intelligent materials". The intelligence can be programmed or built into the structure by material composition and processing, real-time measurement and monitoring of dynamic response, detection of microfracture, yielding, or other failure, or conditioning through computerized servo system to adapt in a controlled manner to external forces or other stimulus. In a general sense, a "controlled" structure usually contains, through ingenious engineering design, its own sensors, data acquisition and reduction, actuators, computational/control, and feedback capabilities.

It appears that such technologies, when sufficiently developed and broadly implemented, possess an excellent potential to impact the safety design and construction of new structures in the future. Furthermore, the dynamic control and intelligence technology also offers a viable, alternative solution to the nation's enormous

\footnotetext{
* Engineering Directorate

National Science Foundation

Washington, D.C. 20550
} 
problems in the rehabilitation of existing structures which are deficient in their seismic, wind, or other resistant capacities.

It is generally agreed that dynamic control and intelligence technology holds considerable promises in the design applications of civil engineering structures, new and existing. By its interdisciplinary nature, such technology also has the potential impact to the future development of a diverse field of scientific or technical subjects, such as material science, vibration, biotechnology, neural network, and new devices.

To forge ahead in the development and practical implementation of structural control technology, a coordinated research program covering these diverse but interconnected subjects is needed and should be developed. This paper describes the development process of such a program by the National Science Foundation (NSF) and presents the results of the current technology assessment and future research needs in this field of emerging importance.

\section{RESEARCH PROGRAM DEVELOPMENT}

Over the last few years, intensive development efforts have been made for the purpose of charting a long-term national research agenda on structural control. An important capstone of such an agenda is to foster, on a coordinated basis, multidisciplinary research and development of passive, active and hybrid control technology for application to structures and nonstructural building systems under dynamic loads. Collaborative efforts among researchers in interdisciplinary areas involving academics, industrial experts and professional practitioners are considered extremely essential.

The development effort, which is expected to lead to an official announcement of research initiative by NSF, can be described by the following series of technical events that have taken place to date:

(1) In 1989, a U.S. Panel on Structural Control Research was established under the auspices of NSF. The Panel has the responsibility of:

(a) Facilitating the transmission of information concerning state-of-the-art developments in the field.

(b) Identifying and prioritizing needed research and development.

(c) Developing preliminary plans for analytical and experimental advancement in the field.

(d) Developing plans for the performance of fullscale testing and demonstration.

The Panel's organization consists of an Executive Committee with Professor George W. Housner as its chairman, and seven (7) Working Groups in: (1) Analytical Methods, (2) Experimental Methods, (3) Building Applications, (4) NonBuilding Applications, (5) Interdisciplinary Approaches, (6) International Coordination, and (7) Information Dissemination. In the meantime, a Japanese counterpart panel on Seismic Control Research was also established by the Science Council of Japan and Dr. T. Kobori is the chairman of the Japanese Panel. Both the U.S. and Japan panels have been working closely in the development of a joint US-Japan research agenda in the areas of active and hybrid control.

(2) On July 23 to 26,1990 , an International Workshop on Intelligent Structures was held in Taipei, Taiwan. The emphasis of the workshop was on the development, application, and modification of active/hybrid control theories, and through innovative materials processing and system concepts, to achieve designed intelligence of civil engineering structures. Three major theme areas for the technical program of the workshop were established: (a) Sensing and monitoring techniques, (b) Structural control, and (c) Intelligent systems (Chong, Liu and Li, 1990).

(3) On October 15 and 16, 1990, a workshop was held at the Electrical Power Research Institute (EPRI) under the joint auspices of NSF and EPRI. The objective of this workshop is to evaluate the status of and research needs in the area of Intelligent Control Systems (Shoureshi and Wormley, 1990). The technical program was structured on four technical areas: (a) General theoretical foundations assessment, (b) Knowledge-based systems, (c) Application related research, and (d) Software/hardware requirements.

(4) On October 25 and 26, 1990, the U.S. Panel on Structural Control Research organized and held the "U.S. National Workshop on 
Structural Control Research" at the University of Southern California, Los Angeles. The workshop identified four specific areas related to earthquake safety for technical discussions. They are: (a) Analytical research, (b) Experimental research, (c) Building applications, and (d) Non-building applications. Proceedings of the Workshop is in press and will be available by the Summer of 1991 (Housner and Masri, in press).

(5) On February 25 and 26, 1991, NSF held another Workshop on "Sensors and Signal Processing for Structural Control" in Washington, D.C. This Workshop focused on assessing the current state of knowledge and technology concerning sensors and measurement techniques, signal processing, actuator mechanics as they applied to structural control (Roberts and $\mathrm{Li}$, in press).

\section{PROBLEMS AND RESEARCH NEEDS}

From the intensive investigations conducted under the special meetings and workshops as described above, a clear picture of the current state of structural control technology is now emerging.

While considerable progress is being made in research and development of passive and active structural control systems both in the U.S. and abroad, a number of important technological as well as practical issues of cross-disciplinary nature need to be addressed in order to forge close ties between research and practice and to accelerate the process of implementation. Such issues by their disciplinary nature include:

- Determination of quantitative parameters of the input forcing functions as well as structural response parameters that could be measured and incorporated in the control algorithms;

- Development of high-tech sensors as well as effective use of conventional sensing devices currently available for sensing and measuring the desired forcing and response parameters which would minimize the time-delay and spillover problems;

- Investigation of actuator mechanics which allow the desired real-time actions to be generated reliably within practical power supply limitations for safety or for comfort control according to the established performance specifications through system design and integration;

- Use of, or use through modifications of, existing control concepts, theories, and systems developed or applied in other fields such as aerospace, navigation, mechanical or electric systems to civil engineering structures;

- Development of new materials and sensors which possess their own intelligence;

- Development of effective signal processing techniques and algorithms for instantaneous, feedback/feedforward, adaptive, or optimum on-line control operation;

- Development of advanced computer technology and systems incorporating artificial intelligence, fuzzy logic, and/or neural networks for specific structural control application;

- Reduction and control of chaotic vibrations in mechanical and transportation systems;

- Development of innovative structural, architectural and nonstructural systems which are amenable to the application of structural control;

- Modelling and robustness of structural control under uncertainties; and

- Reconciliation of the conventional concepts of structural safety and controlled safety.

It is with such a background that a coordinated national research initiative in this emerging area of significant application potential is being formulated. This initiative is designed to facilitate and accelerate research and development in structural control. Through this effort a solid technological base is expected to be established which will make possible for broad, practical implementation of structural control systems to safeguard structural and nonstructural systems against unpredictable natural hazard events. 
The fundamental objectives of the program initiative under development are identified as:

- encourage innovations in passive, active, and hybrid control systems.

- advance sensor and actuator technology and signal processing techniques and their applications.

- develop intelligent robots, other devices and computer systems for structural safety.

- develop innovative systems for energy absorption, added damping, and variable stiffness.

- study the robustness and system reliability of control systems.

- develop guidelines, standards and practical approaches and techniques for design, fabrication and field installation.

- investigate emerging technology subjects in innovative structural systems, and smart materials, sensors, and devices for detection, sensing, monitoring, and diagnosis.

In line with the above objectives, the following key research problems are identified:

- New materials.

- Performance evaluation, analytical and experimental verification.

- Standardized test procedures and performance criteria.

- Integrated structural and architectural systems design techniques and standards.

- Control algorithm development, robustness, and reliability, adaptivity, and optimization.

- Sensors, actuators and monitoring system development and optimal deployment.

- Advanced computer technology incorporating artificial intelligence, neural network, fuzzy logic, etc. for on-line targeting, detection, monitoring, diagnosis, and control.

- Intelligent robots and devices.

- Modelling, signal processing, and computer simulations.

- Practical methods and techniques for design, manufacturing, fabrication, and implementation.

- Laboratory and field experiments of systems and devices under actual or simulated dynamic excitations.

- Design and demonstration projects of control systems as applied to new or existing structures.

- Innovations in base isolation, energy dissipation devices, and other passive techniques.

In some of the research areas identified above, collaboration among researchers, practicing engineers, and manufacturers is necessary. Results obtained from such a coordinated research effort are expected to generate new knowledge, techniques, and a better understanding of the working principles as well as practical limitations inherent in these control systems so that conditions of applicability and design limits of each class of systems can be established and evaluated. It should be emphasized again that the ultimate goal of this multi-year research effort under planning is to bring about technological advances so that control technology can be realistically implemented in a timely fashion to provide safety resistance to protect structures such as buildings, bridges, tunnels, and other critical lifeline systems against earthquakes, winds, and other natural or manmade hazard environments.

\section{SUMMARY AND CONCLUDING REMARKS}

Over the last two decades, considerable progress has been made to improve structural safety through research in structural, earthquake, and wind engineering. The possibility of applying control systems to mitigate the structural damage against earthquakes and winds opens up a wide range of challenging research opportunities for multidisciplinary investigators in the field. Further, such challenges can be undertaken most effectively by engineering professionals through international research cooperation. In this spirit, the mechanisms which might be provided by the International Decade for Natural Disaster Reduction (IDNDR) program can efficiently serve as a launching pad for the research projects as identified. The UJNR Panel on Seismic and Wind Effects, and the US Panel on Structural Control Research and its counterpart Japanese panel are all expected to play a pivotal role in the advancement of control technology and to lead us toward a safer and more economical future for civil engineering construction. 


\section{REFERENCES}

1. Chong, K.P., Liu, S.C., and Li, J.C., Editors, Intelligent Structures (1990). Elsevier Applied Science, London and New York, 460 pp.

2. Housner, G.W. and Masri, S., Editors, Proceedings of U.S. National Workshop on Structural Control Research (in Press).

3. Roberts, R., and Li, W.P., Editors, Proceedings of Workshop on Sensors and Signal Processing for Structural Control (in Press).

4. Shoureshi, R. and Wormley, D., Editors, Proceedings of Workshop on Research Needs in Intelligent Control Systems (1990). NSF/EPRI. 


\author{
Chikahiro Minowa 4 , Nobuyuki Ogawa 2 , Tadashi Mikoshiba ${ }^{5}$,
Kei ichi Ohtani 3 , Norio Oyagil
}

\section{SUMMARY}

The large scale shaking table of Mational Research Institute for Earth Science and Disaster Prevention, was improved in 1988. By this improvement work, the shaking table performances have been enhanced. Just after this mechanical effort, the reinforcement work of the shaking table foundation was conducted. During the reinforcements, the change of dynamic characteristics of large-scale shaking table founda$t$ ion were measured at the various work stages to extract the dynamic interaction effects. By the reinforcements, the foundation weight was increased about 3000 tons. The old one was of about 8700 tons, and the new one has 11700 tons approximately. This paper presents the measurement data and describes the vibration control system for shaking table foundation which was proposed during the planning of this reinforcements.

KEY WORD: Shaking Table Foundation, Vibration Test, Soll-Structure Interaction, Vibration Control

\section{INTRODUCTION}

Many studies to verify experimentally the effects of dynamic interaction between soil and foundation have been carried out in recent years. Host of the dynamic tests, however, have been conducted using comparatively small scale foundation models. It is preferable to use foundations as large as possible in order to minimize the effects of the local irregularities of soil properties which inherently exist in actual soil.

Valuable experimental results for both dynamic soil-structure interaction and dynamic characteristics of the surrounding soil have been presented by making use of the large scale shaking table foundation of National Research Institute for Earth Science and Disaster Prevention. In 1988, the limit performance of this shaking table was improved. The maximum displacement has been enlarged to $44 \mathrm{~cm} p-p$ from old amplitude $6 \mathrm{~cm} p-p$. also the maximum velocity has been magnified to $75 \mathrm{~cm} / \mathrm{sec}$. Reinforcement works of the foundation began just after the improvement. The drives of this shaking table have been possible during the reinforcement works. In course of the reinforcement works, the embedment conditions, the configuration and the weight of the foundation have been changed. At various stages of the reinforcement works, the excitation tests of the foundation have been performed by driving the shaking table. The change of dynamic charac- teristics of the foundation and the surrounding so il at each stages of the work has been measured. The one of objective of this study is to measure the change of dynamic characteristics of the foundation and to extract the interaction effects from the observed results.

In the planning of the reinforcements, vibration control methods for the shak ing table foundation. which already exists, were discussed. The methods are described in this paper.

\section{OUTLINES OF SHAKING TABLE FOUNDATION, EXPERIMENT AND MEASUREMENT}

The foundation is made of reinforced concrete with base area of $39 \mathrm{~m} \times 25 \mathrm{~m}$ and embedded in the soil by $8.2 \mathrm{~m}$ as shown in Fig. 1. Soil profiles are shown in Table 1. In the reinforcement works, concrete mass of about $1,200 \mathrm{~m}^{3}$ was cast between the buttresses of both sides of the foundation as indicated by black pointed area of Fig. 1 . The weight of foundation itself increased from 8700 tons to 11700 tons after the reinforcement works.

Figs. 2(a) to ( $f$ ) show the six states of the foundation when the excitation tests were performed. The first stage corresponds to the state before the reinforcement works; the second to the state when the surrounding soil was removed: the third to the state when the concrete was cast; the fourth and the fifth to the states when the sides of the foundation were half and fully backfilled, respectively; and the sixth to the state when sheet piles were take out. The backfill soil is loose and the shear wave velocity of the soll is estimated to be about $50 \mathrm{~m} / \mathrm{sec}$. The dynamic response of the foundation during the excitation tests have been measured by displacement meters, accelerometers and ear.thpressure gages. Fig. 3 shows the location of accelerometers and the displacement meters( T= 1sec, $\zeta=70 \%$ ) set on the foundation and the surrounding soil.

1 Director, Disaster Prevention Division, National Research Institute for Earth Science and Disaster Prevention, Science and Technology Agency

2 Head, Earthquake Engineering Laboratory, ditto 3 Head, Earthquake and Volcanic Disaster Prevention Section, ditto

4 Senior Researcher, ditto

5 Research Member. Earthquake Engineering Laboratory, ditto 
3. DYNAMIC CHARACTERISTICS OF SHAKING TABLE FOUNDATION

By comparing the experimental results of six stages of the foundation shown in Fig. 2, the effects of various factors on the dynamic characteristics of foundation can be extracted. It should be noted that all of the comparison are made for the results observed at the measurement points of foundation.

\subsection{Effect of Constraint of Soil}

Figs. 4(a) and (b) show the comparison of the horizontal and vertical frequency-response curves for the first and the second experiments. These results are normalized by unit excitation force. The difference of these curves can be considered to be the effect of constraint of soil at the sides of the foundation. It is clear from these results that the constraint of soil at the sides of the foundation deceases the horizontal and vertical responses wich is caused accompanied by the rocking motion of the foundation. It is also noticed that the constraint of soil deceases remarkably the resonant frequency of the rocking motion.

\subsection{Effect of Added Concrete Mass}

Figs. 5(a) and (b) show the comparison of the horizontal and vertical frequency-response curves for the second and third experiments. The difference of these curves may be interpreted as the effects of the added concrete masses. The foundation weight of the third state is about $30 \%$ larger than the second state. It is noticed that the effects of added concrete masses appear only on vertical response of foundation. As being expected, it is also seen that the added masses decrease remarkably the resonant frequency of the rocking motion.

The effect of added masses may also be seen by comparing the first and sixth experiments, whose results are shown in Figs. 6(a) and (b). A slight shift of the resonant frequency of the rocking motion is also noticed from Fig. $6(\mathrm{~b})$. The ma in reason that the effect of added masses is less than the cases shown in Fig. 5 is that the increase of mass the sixth state is only $8 \%$ larger than the first state.

\subsection{Effect of Embedment Depth}

In Figs. $7(a)$ and (b), the frequency-response curves for the third, fourth and fifth experiments are shown simultaneously. From these results, it can be seen that with increase of the embedment depth the horizontal and rocking responses of the foundation tend to decrease. It should be noted that the embedment effects appear only around 4 to $6 \mathrm{~Hz}$ for the hor izontal response but are more pronounced for the rocking response.

\subsection{Effect of Sheet Piles}

The sixth experiment was performed soon after the sheet piles were taken out. Figs. 8(a) and (b) show the comparison of the frequency-response curves for the fifth and sixth experiments. The difference of these two curves may be interpreted as the effects of the sheet piles. Since the difference is very small, it can be said that the effect of the sheet piles is negligible.

\subsection{Deformation of Foundation}

It has been generally pointed out from the theoretical studies that the deformation of foundation become remarkable with increase of frequencies (Iguchi and Luco 1982). Perhaps, one of most interesting subjects is to observe the deformation of the foundation experimentally. Figs. 9(a) to (c) show the deformation curves of the foundation during a half cycle of harmonic vibrations for $f=6,8$ and $10 \mathrm{~Hz}$ of the fifth experiments. The deformation curves are drawn by using the observed results of accelerometers shown in Fig. 3. These results indicate that for higher frequencies more than $f=8 \mathrm{~Hz}$, the foundation may not be considered to be rigid as far as this foundation is concerned.

\section{DYNAMIC CHARACTERISTICS OF SURROUNDING SOIL}

By comparing the experimental results of six stages of the surrounding soil, the effects of various factors on the dynamic characteristics of the surrounding soil may be extracted.

\subsection{Effects of Constraint Soil}

Two resonance curves on the points of $35 \mathrm{~m}$ and $100 \mathrm{~m}$ are shown in Figs. 10 (a) and (b). The 35m measure point near to the foundation displayed the distinct differences between first and second stage. The curve of second stage gave small amplitudes in comparison with the first stage. However. The $100 \mathrm{~m}$ measure point far from the foundation wouldn't include such a remarkable differences.

\subsection{Effect of Embedment Depth}

The resonance curves of the $35 \mathrm{~m}$ measure point in third, fourth and fifth stages are shown in Fig. 11. The embedment effects to surrounding soil responses might be conflicting to foundation responses. The increase of embedment depth decreased the foundation responses, but increased the surrounding soil responses.

\subsection{Effect of Sheet Piles}

Figs. 12(a) and (b) show the comparison of the $35 \mathrm{~m}$ point frequency-response curves for the $\mathrm{f}$ if th and sixth experiments. The difference of these two curves may be interpreted as the effects of the sheet piles. Since the slight differences are recognized.

\section{VIBRATION CONTROL METHOD FOR A SHAKING TABLE FOUNDATION}

Several methods can be imaged, in order to decrease the uncomfortable vibrations of shak ing table foundations. It is generally said that the weight of shaking table foundation needs 100 times its power, so as to take good performances and decrease surrounding soil vibrations. 
Recently, in constructions of new shaking table systems, it can be possible to empioy the effective floating foundation which is supported by air springs on rigid foundations. The floating foundations have been used in many shaking table laboratories in Japan. For the shaking table in operation, however, it may be impossible to set a floating foundation so as to decrease the uncomfortable vibration. In the planning of reinforcement works of the large scale shaking table foundation, vibration control methods for shaking table foundation were discussed in addition to the mass increase methods for foundation. Severe uncomfortable vibrations of foundations take places in sinusoidal shaking table motions. If dynamic dampers will set on the existing foundation, the uncomfortable vibrations would be decreased much more than the mass increase methods. The dynamic dampers for shaking table foundat ion have to work effectively in the frequency range between $3 \mathrm{~Hz}$ and $10 \mathrm{~Hz}$. Therefore, the dynamic damper makes resonances to shaking table motions all over its wide frequency range. In this reason, the spring rigidity of dynamic dampers have to be variable. As the springs with variable rigidities, air springs and hydraulic actuators will be proposed. The high pressured air springs give high frequency resonance. As for the hydraulic actuators, the stroke end position of piston gives high frequency resonance, and the neutral position gives low frequency resonance. If the dynamic damper mass of 600 tons will be used, 1000 a ir springs of $30 \mathrm{~cm}$ diameter would be necessary. or hydraulic actuator of $3 \mathrm{~m}$ stroke and section area $1000 \mathrm{~cm}^{2}$ would be necessary. Figs. 13 and 14 show the images of air spring and hydraulic dynamic damper installed in large scale shaking table foundation of MRIESDP. Fig. 15 is calculation example of dynamic damper effects. Unfortunately, this vibration control methods have not been adopted to reinforcement works.

\section{CONCLUSION}

(1) The constraint of the side soil of foundation has effect mainly on rocking response of embedded foundation.

(2) Added mass of foundation tends to increase the horizontal displacement in lower frequency regions and changes the resonance characteristics of the rocking motion.

(3) Deformation of the foundation becomes remarkable for higher frequencies more than $10 \mathrm{~Hz}$. (4)Even when the backfill soil loose, the embedment effects may appear on the dynamic response of the foundation.

(5) In order to decrease the uncomfortable vibration much more, the vibration control methods must be used for the existing shaking table systems.

\section{ACKNOWLEDGMENT}

The Authors wish to thank Dr. Iguchi, Professor of Tokyo Science University, for his precious helps to our research. And we express the appreciation to Dr. Edward A. Kausel, Professor of M.I.T for his precious advice to our experiments.

\section{REFERENCES}

Iguchi, M. , Minowa, C., Wakui, E. (1991) ,Change of Dynamic Interaction Characteristics Between Soil and Large-Scale Shaking Table Foundation During Reinforcement Works, SMiRT 11 (in Submitted)

Minowa, C., Ogawa, N., Otani, K., Oyagi, N., (1991). Responses of Large-scale Shaking Table Foundation During Improvement Works, Review of Disaster Prevention No. 151. National Research Institute for Earth Science and Disaster Prevention (in Japanese)

Iguchi, M. and Luco, J. E. (1982), Vibration of Flexible Plate on Visco-elastic Medium, Jngng Mech. Div., ASCE, Vol. 108, No. EM6, PP 1103-1120. 


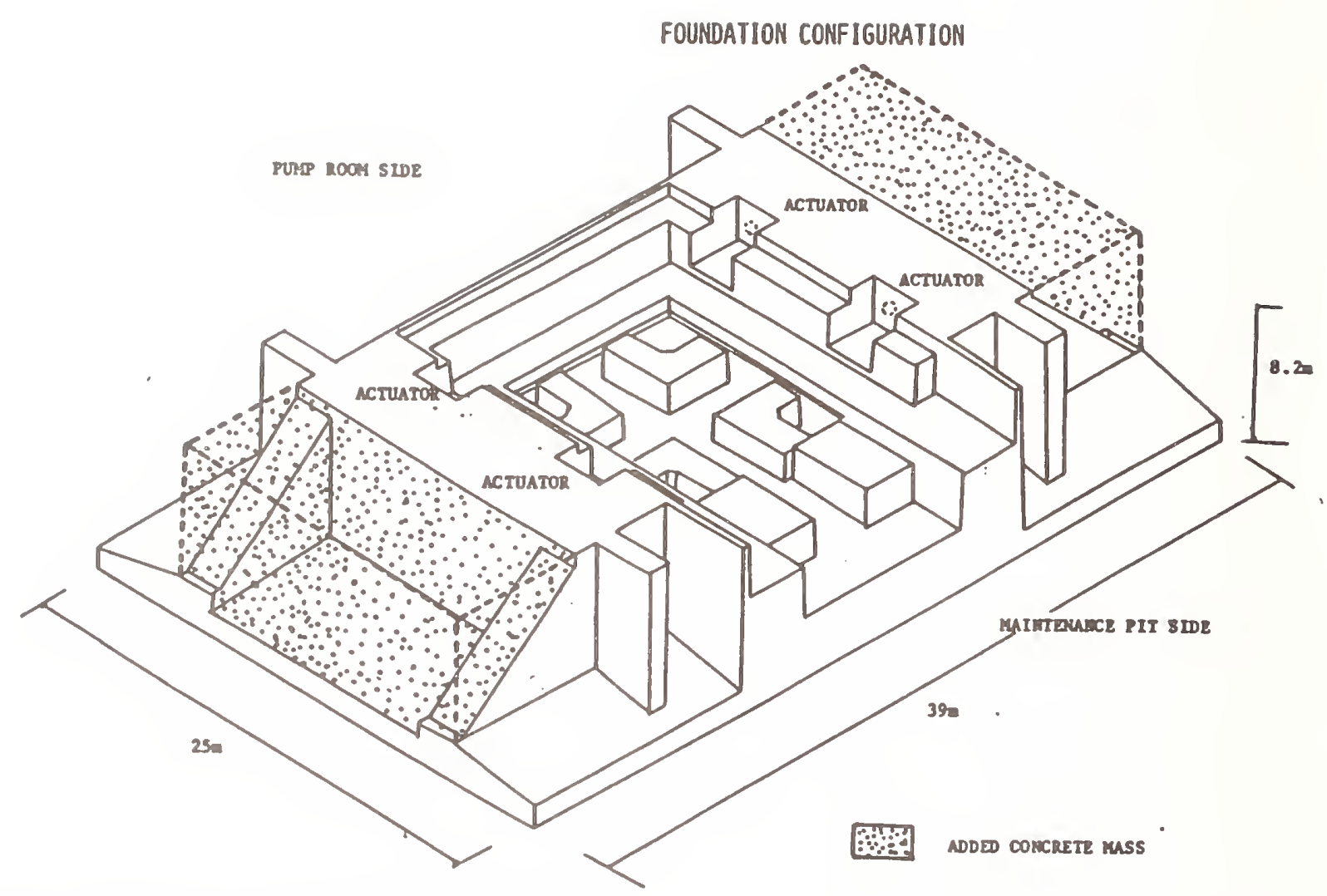

Fig. 1 outline of Shaking Table Foundation

Table 1 Soil Profile

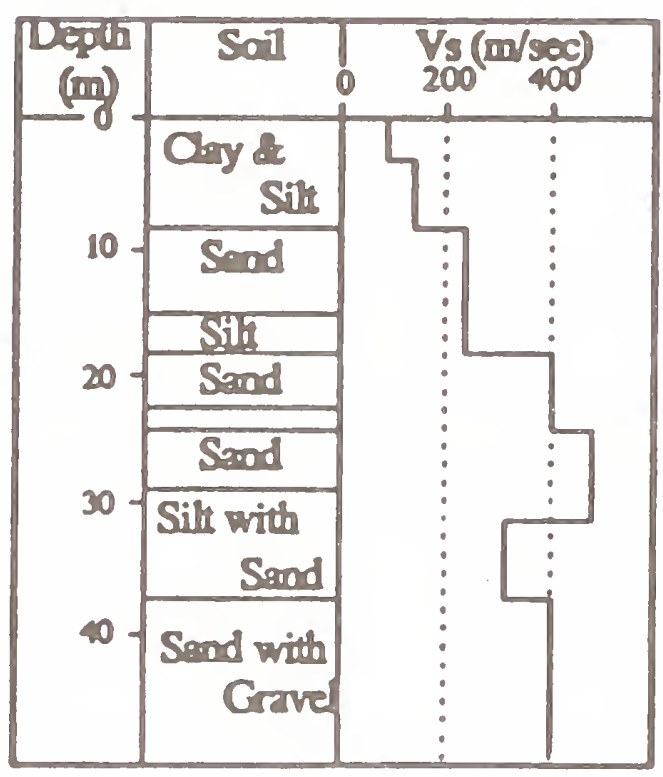

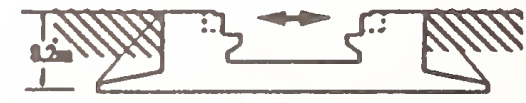

(n) Pirnt Experimoct

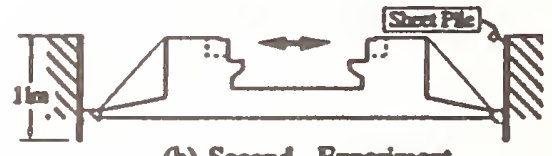

(b) Second Experiment

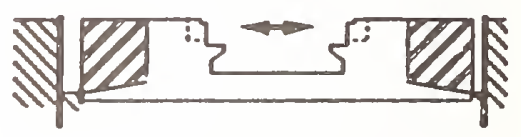

(c) Third Bepperiment
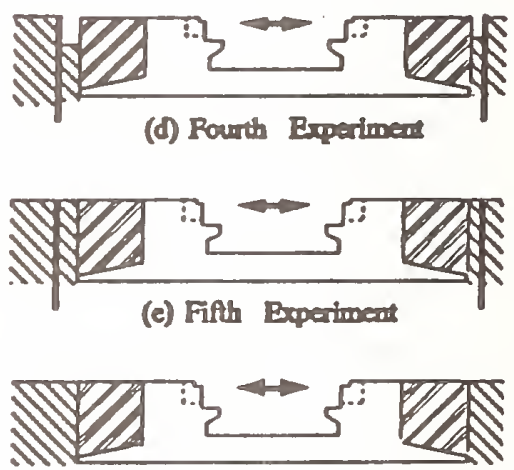

(I) Sitth Bxperiment

Fig. 2 Stages of Reinforcewe Horks 


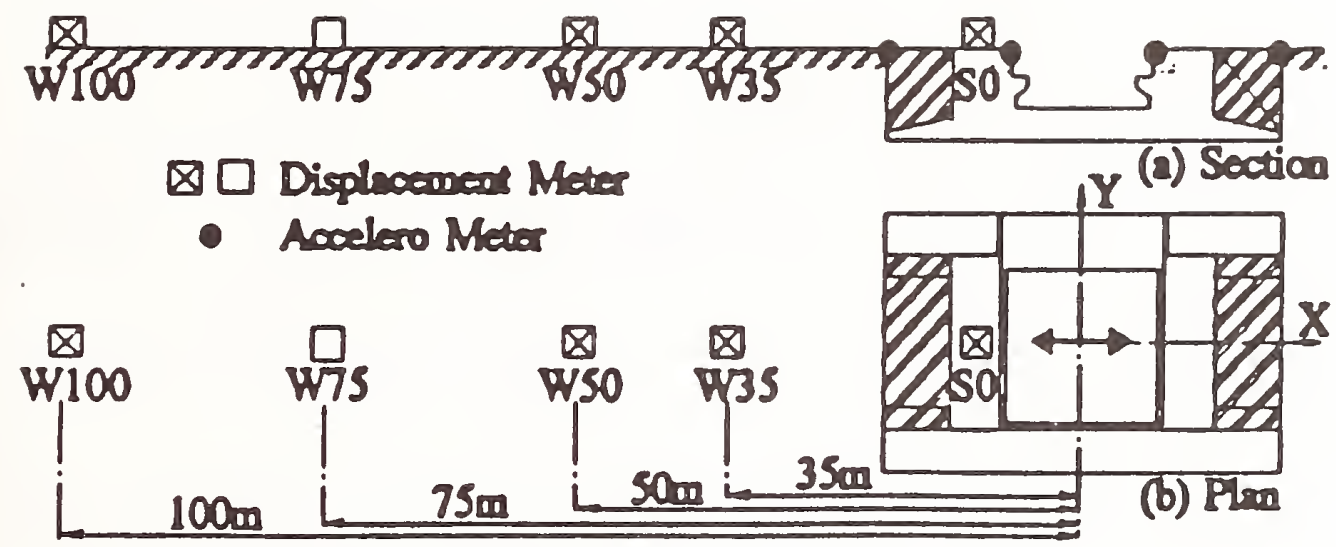

Fig. 3 Location of Sensor

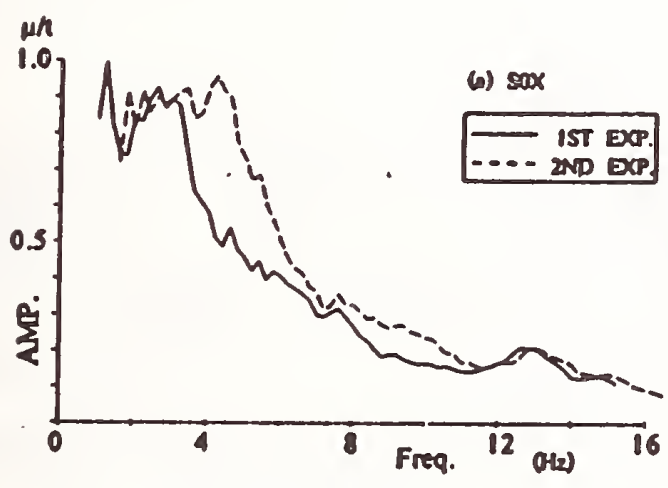

(a) Horizontal

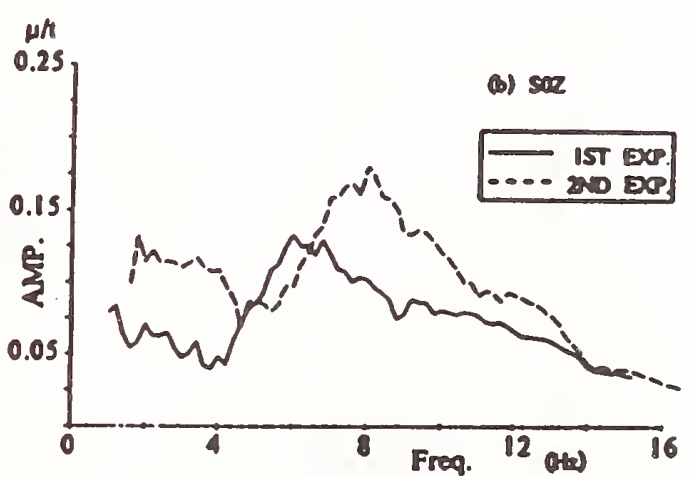

(b) Vertical

Fig. 4 Effect of Constraint of side Soil

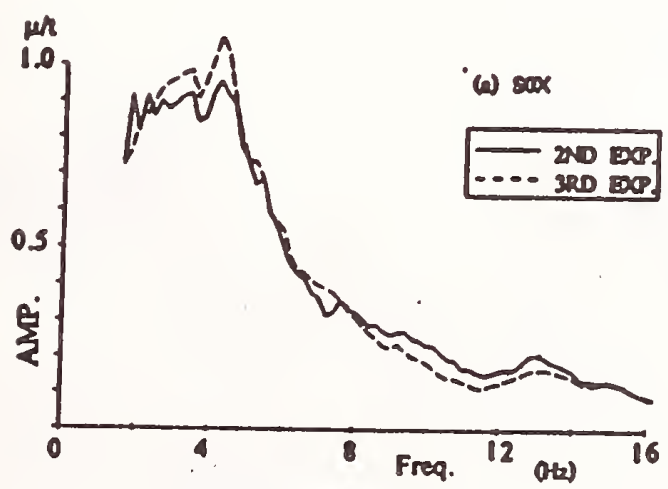

(a) Horizontal

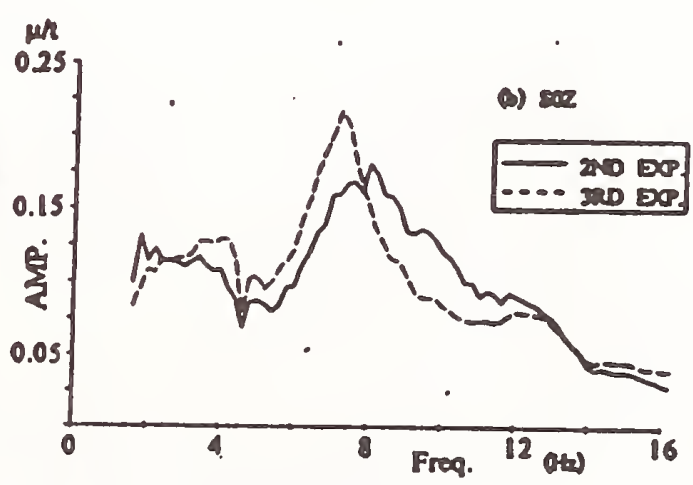

(b) Vertical

Fig. 5 Effect of Added Concrete Mass (Comparison of 2nd and 3rd Stage) 


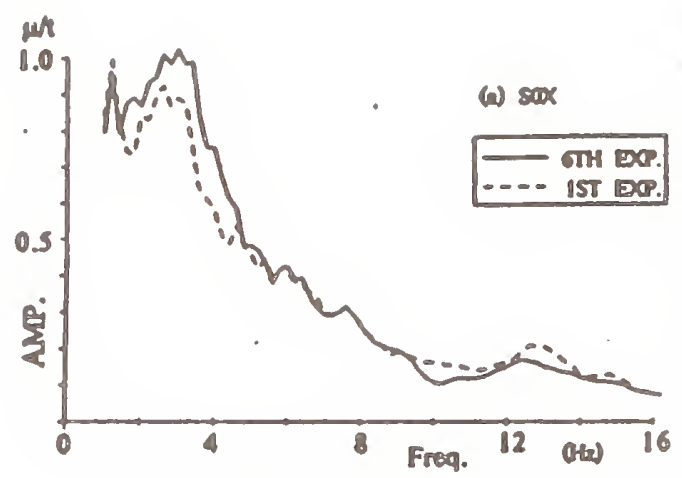

(a) Horizontal

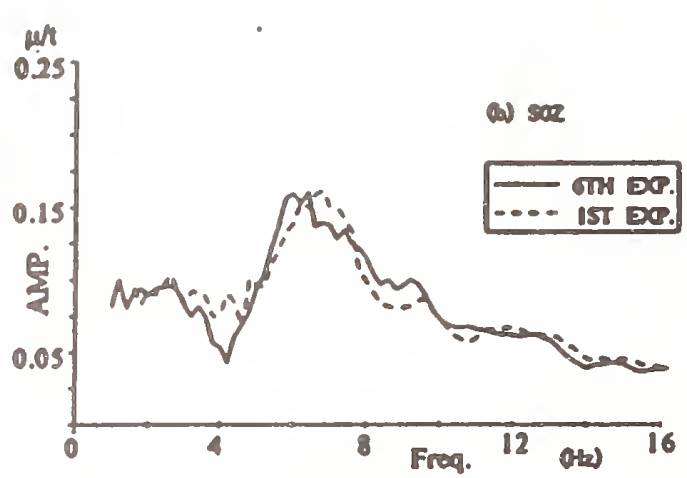

(b) Vertical

Fig. 6 Effect of Added Concrete Mass (Comparison of 1st and 6th Stage)

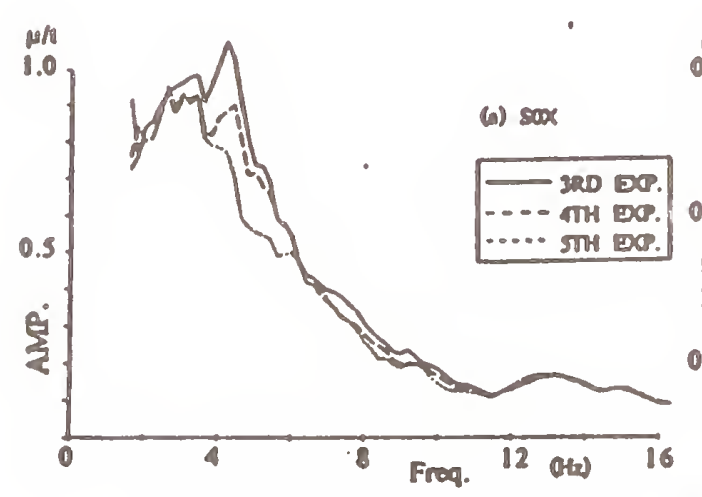

(a) Horizontal

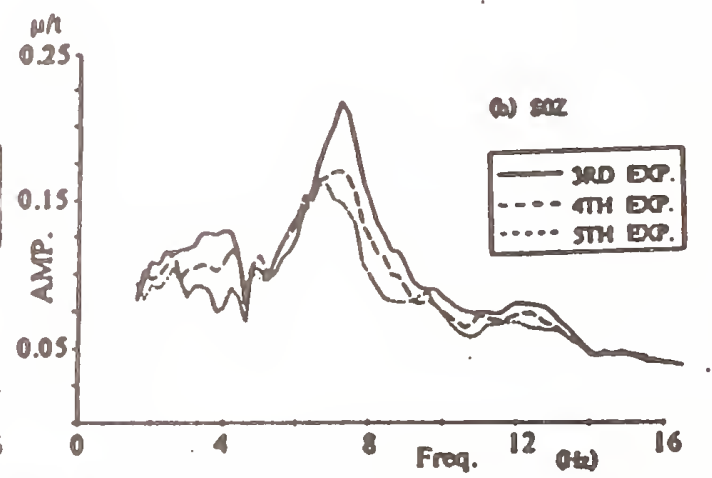

(b) Vertical

Fig. 7 Effect of Embedment Depth

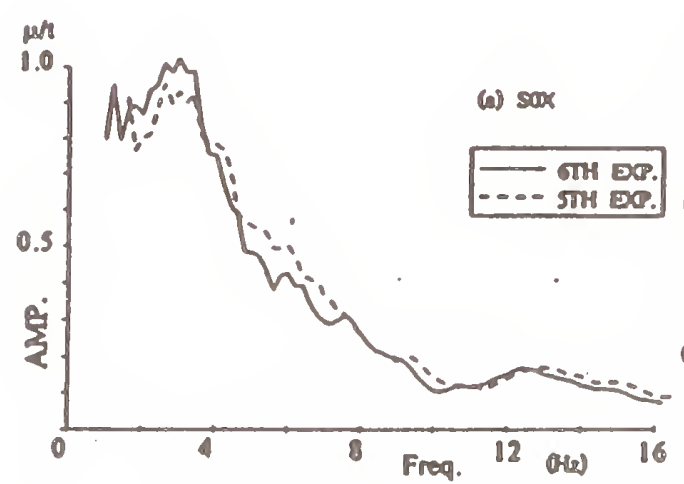

(a) Horizontal

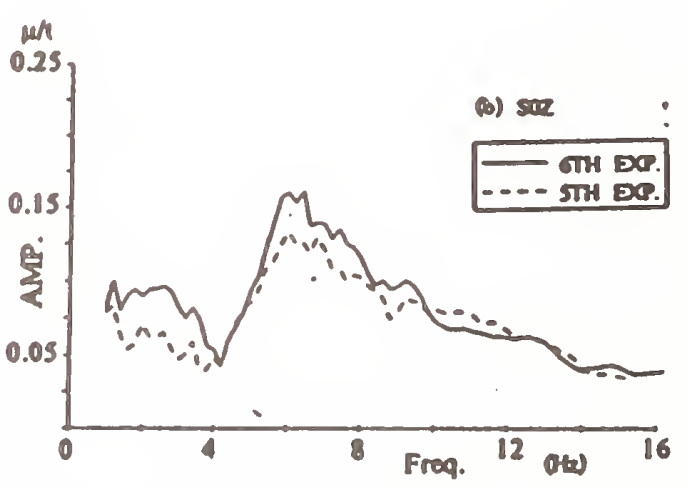

(b) Vertical

Fig. 8 Effect of Sheet Plles 

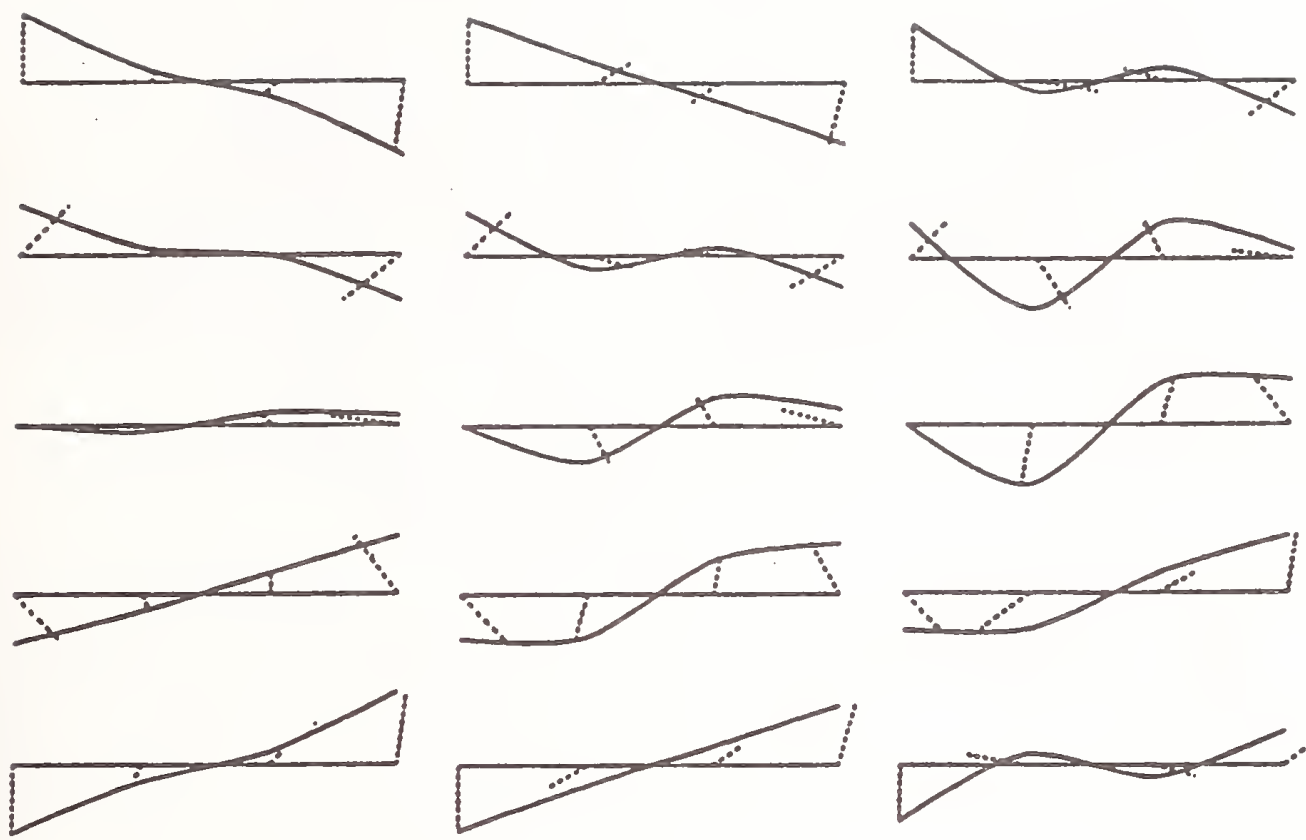

(a) $6 \mathrm{~Hz}$

(b) $8 \mathrm{~Hz}$

(c) $10 \mathrm{~Hz}$

Fig. 9 Deformation Curves of Foundation During a Half Cycle of Vibration (5th Stage)

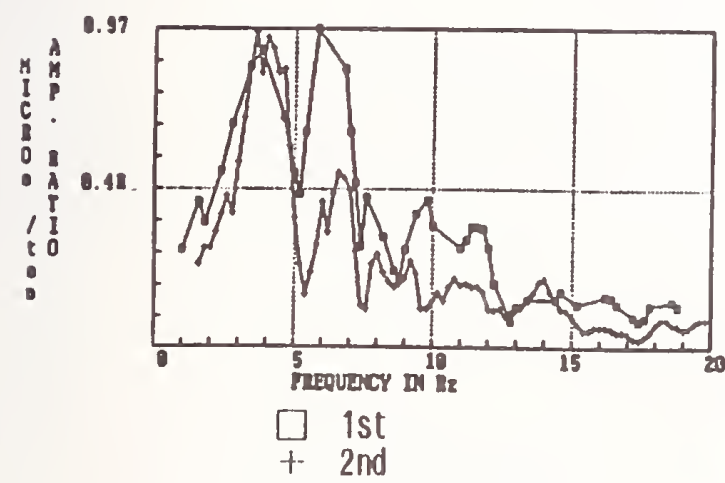

(a) H35m Horizontal

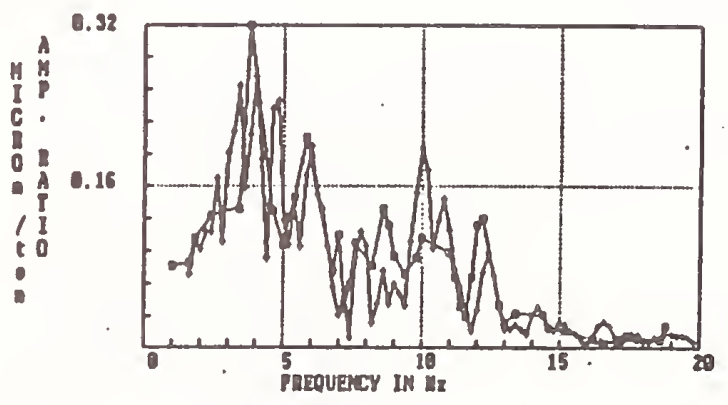

$\square$ 1st

$+2 \mathrm{nd}$

(b) H100 Horizontal

Fig. 10 Comparison of 1 st and 2nd Stage

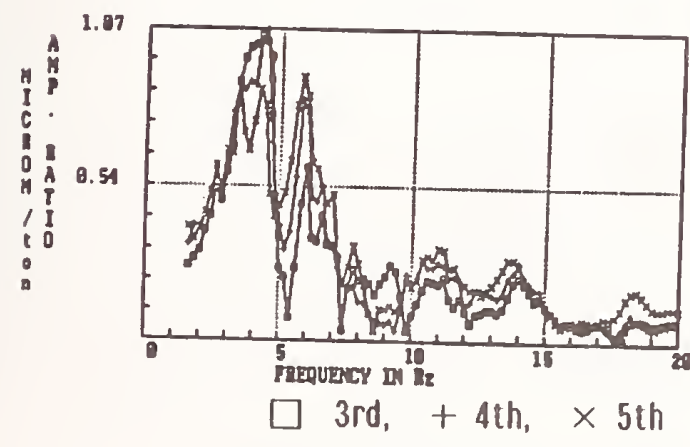

(a) H35m Horizontal

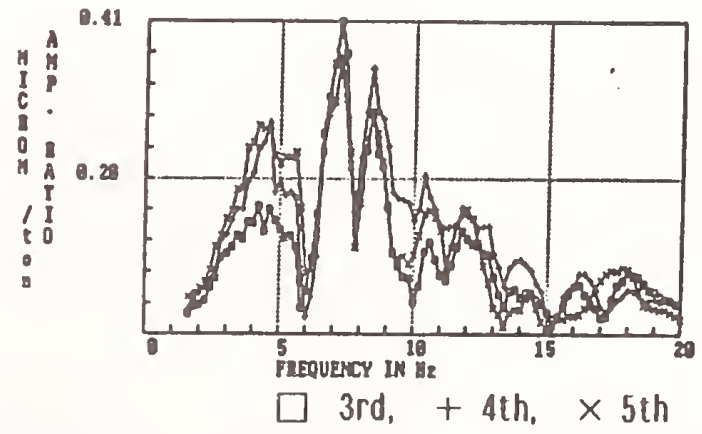

(b) $\mathbf{H 3 5}$ Vertical

Fig. 12 Comparison of 2 nd, 3 rd and 4 th 


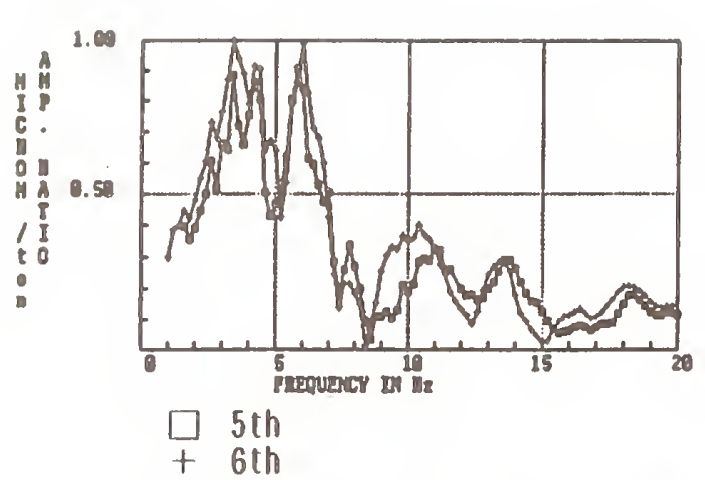

(a) H35m Horizontal

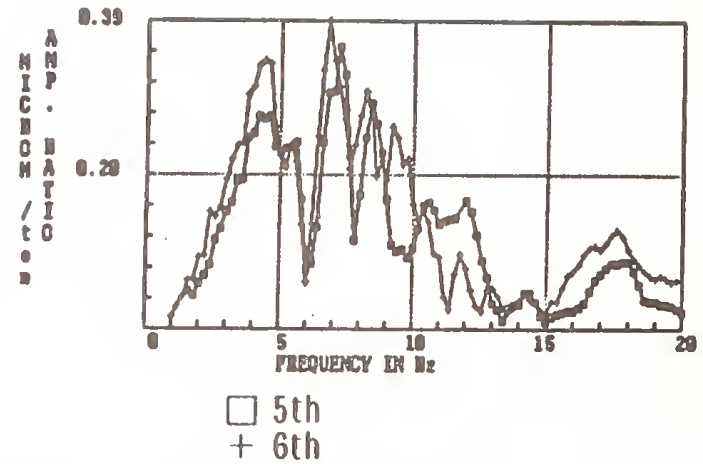

(b) H35 Vertical

Fig. 12 Comparison of 5 th and 6 th
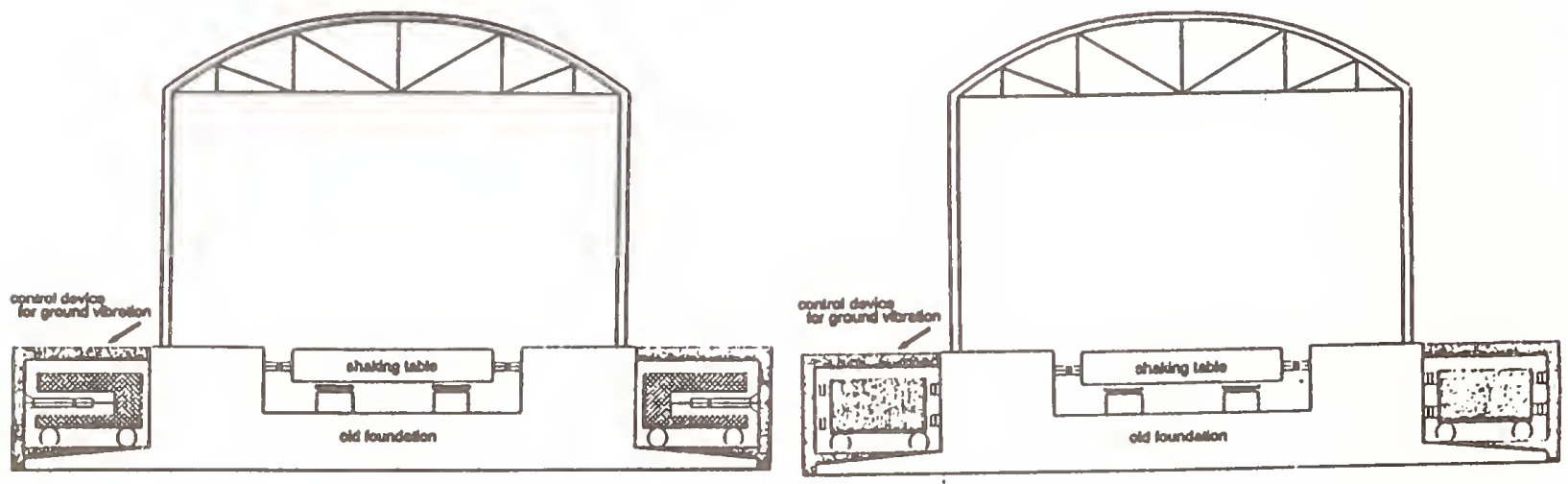

Dynamle dampers consisted of hydraullc cyllnders

Fig. 13 Image of Vibration Control by Hydraul ic Actuators
Dynamic dampers consisted of air springs

Fig. 14 Image of Vibration Control by Air Springs

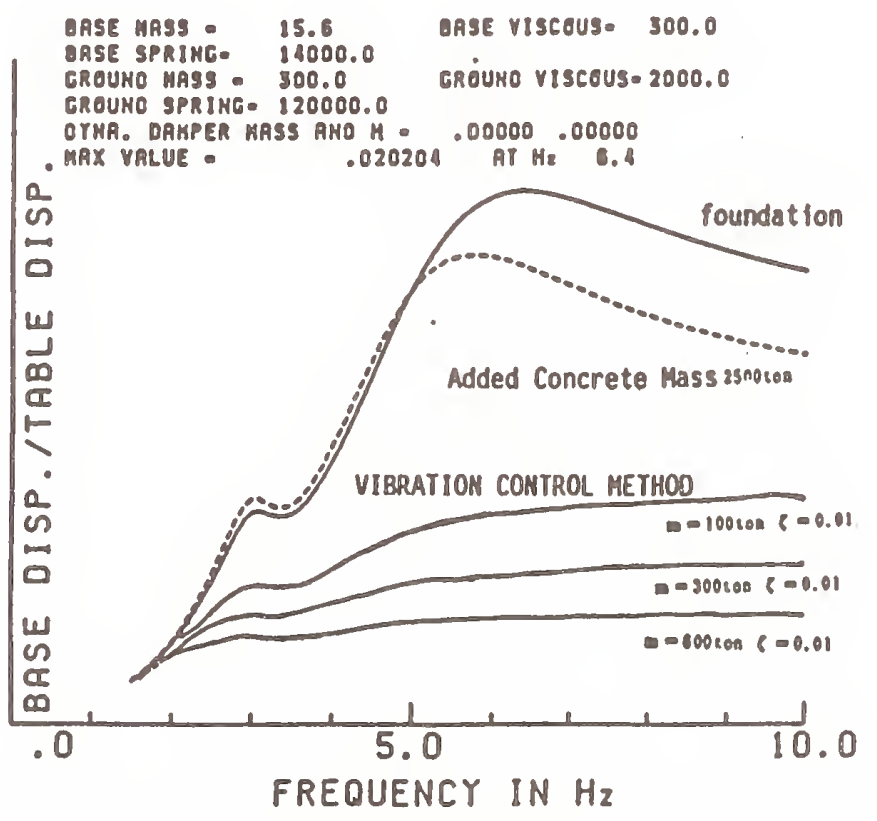

Fig. 15 Calculated Foundation Responses with Vibration Control System 


\title{
Safety and Economic Benefits Realized From Upgrading \\ the Lawrence Berkeley Laboratory
}

\author{
by \\ 1Donald G. Eagling \\ 2James R. Hill
}

\section{ABSTRACT}

The Lawrence Berkeley Laboratory (LBL) initiated a comprehensive seismic safety program following the 1971 San Fernando Earthquake. Since then, 34 buildings have been strengthened, and emergency recovery facilities improved significantly.

The 7.1M Loma Prieta Earthquake, centered 65 miles south of Berkeley, produced $12 \% \mathrm{~g}$ acceleration at LBL compared to $65 \% \mathrm{~g}$ near the epicenter. It caused only non-structural damage at LBL, because those buildings susceptible to structural damage from minor ground shaking had been strengthened. For example, two of LBL's major laboratory buildings would have sustained diagonal tension cracking in brittle reinforced concrete bearing wall window piers if they had not been buttressed to prevent damaging deflections. After the earthquake, it would have been mandatory to evacuate these two buildings and find 130,000 square feet of laboratory space to lease for 350 people. It would have then taken two years before these buildings could be strengthened and reoccupied. Research would have been disrupted over one year and the U.S. Department of Energy would have suffered a loss over $\$ 30$ million if these two buildings had not been upgraded.

Including other facilities that would have suffered structural damage, upgrading LBL saved over $\$ 50$ million at a cost of less than $\$ 4$ million expended since 1971.
KEYWORDS: seismic safety; Loma Prieta; cost savings.

\section{INTRODUCTION}

The Lawrence Berkeley Laboratory is a multiprogram research facility operated by the University of California for the U.S. Department of Energy (DOE). It is located in the San Francisco Bay Area on the hills above the University of California at Berkeley (UCB). The LBL site encompasses 130 acres including 80 buildings and has a population of 4,000 . As can be seen in Figure 1, the seismically active Hayward Fault passes at the foot of the hill near the Laboratory's main entrance. LBL buildings are shown in the foreground of Figure 2 above the UCB Campus. The San Andreas Fault lies about 15 miles west across the bay just beyond the Golden Gate Bridge on the horizon.

In 1971, following the destructive San Fernando Earthquake in Southern California, LBL initiated a comprehensive review of its facilities and operations to improve earthquake safety. Since then, as shown in Figure 3, 34 buildings have been

${ }^{1}$ Retired Plant Manager, University of California, Lawrence Berkeley Laboratory

2Manager, Natural Phenomena Mitigation Programs, U.S. Department of Energy 
strengthened. Active and potential landslide areas have been stabilized, life lines have been hardened, non-structural hazards have been mitigated and emergency recovery facilities have been upgraded and augmented in preparation for a great earthquake.

As shown in Figure 4, the Loma Prieta Earthquake, magnitude 7.1 , occurred on a 25-mile segment of the San Andreas Fault about 65 miles south of the LBL site. Ground acceleration at LBL was only $12 \% \mathrm{~g}$ as compared to $65 \%$ near the epicenter and $25 \%$ on soft sediments near the bay a few miles west of LBL where a portion of the Cypress Street viaduct collapsed. The Loma Prieta Earthquake caused only nonstructural damage at LBL, because those buildings which would have been susceptible to structural damage in 1971 from $15 \% \mathrm{~g}$ accelerations had been strengthened by 1989 . The cost to upgrade LBL facilities since 1971 has been less than $\$ 4$ million. If susceptible buildings had not been strengthened, it is estimated that LBL (and DOE) would have suffered financial losses in excess of $\$ 50$ million.

\section{BACKGROUND}

The Loma Prieta Earthquake triggered a backlog of developing concern about liability which had grown with each of the smaller but damaging earthquakes experienced in California during the last decade or so.

Public attitudes about earthquake hazards and the financial risks of liability have changed considerably during this period. Engineers have become more outspoken about building types which are substandard and hazardous to occupants. Owners and managers have in turn become more aware of their corporate and sometimes personal liability for the safety of occupants, particularly when a building is known to be unsafe.
Allowing people to continue to occupy a building after earthquake damage has shown it to be a potential collapse hazard is untenable to most responsible owners. It is a liability they are unwilling to bear. People are also becoming aware of the enormous costs associated with evacuating a damaged building and relocating occupants elsewhere until the building can be repaired and made safe for reoccupancy. Of course, the cost of lengthy disruptions to operations and research is devastaking in iiself.

Examples from the Loma Prieta Earthquake are many. A very large department store in Oakland was out of business for one year following the earthquake. The Oakland City Hall, a high rise building, sustained structural cracking and has not been reoccupied one and a half years later. Several substandard buildings at Stanford University which remain unoccupied will require enormous costs for rehabilitation before they can be reoccupied. None of these buildings collapsed, but the signs of structural damage are obvious and concerns for liability and public safety required their evacuation.

\section{THE LBL EXPERIENCE}

Earthquake shaking at LBL due to the Loma Prieta Earthquake would not have caused the collapse of any substandard buildings even if they had not been strengthened. However, certain buildings would have sustained structural cracking which would have required the evacuation of occupants, repair and strengthening before reoccupation. Prime examples are the two major laboratory buildings (50A and $50 \mathrm{~B}$ ) shown side by side in the center of Figure 5 as they appeared in 1971 before they were strengthened. The two tower elements are seven stories high on the downhill end and four stories on the uphill end. They are reinforced concrete bearing wall structures of identical design. The end walls are shear walls which provide satisfactory resistance in the transverse direction. Lateral resistance in 
the longitudinal direction, provided by reinforced concrete moment connections, was deficient in that deflections necessary to resist earthquake forces would permit structural failure to take place in brittle bearing elements.

Shaking due to the Loma Prieta Earthquake would have caused diagonal tension cracking in brittle reinforced concrete window piers in the sidewalls if these towers had not been buttressed in the longitudinal direction to prevent damaging deflections. Consequently, it would have been necessary to remove the 350 occupants and find 130,000 square feet of laboratory and office space for them to continue research for two years or more until these buildings could be repaired and strengthened for reoccupancy. This would have cost the U.S. Department of Energy an extra $\$ 30$ million and disrupted vital research programs for at least one year.

A brief explanation of the weaknesses inherent in the original design and the measures taken to prevent structural damage follows.

Figure 6 shows one of the towers in 1973 after it was determined that these buildings would suffer catastrophic collapse in a major earthquake and structural damage in minor shaking. Lateral resistance in the longitudinal direction was originally provided by moment connections between the 8-foot wide vertical elements at the end of the window rows and the heavy longitudinal spandrels between horizontal rows of windows. The 14-inch thick side bearing walls, perforated with windows, transmit the vertical load down through the 2-foot wide window piers. The 8-foot wide end piers were heavily reinforced to resist longitudinal bending, but intermediate 2foot wide window piers were only nominally reinforced. In an earthquake, the 8-foot wide end piers could resist the longitudinal load, but would allow the short brittle window piers to deflect enough to crack in diagonal tension. To compound the problem the reinforced concrete beams supporting heavy concrete sunshades were cantilevered out from the brittle window piers. In minor shaking, the piers would develop typical " $X$ " cracking. In heavy shaking they would disintegrate leading to collapse of the towers. Soon after these hazards were identified the sunshades were removed as shown to reduce the risk until the buildings could be strengthened. At that time these buildings were not evacuated. The concern for liability was not as strong in 1971 as it is today.

Figure 7 shows a diagonal tension failure in a non-ductile window pier in the Misawa Commerce High School as a result of the 1968 Tokachi-Oki Earthquake.

As shown in Figure 8 the solution was to install heavy stiff buttresses on either side of the uphill end of each building to limit deflection of the window piers during earthquake shaking. Each buttress was wrapped around the end wall and in-filled into window openings. Extensive bolting into the floor diaphragms and within the periphery of the in-filled windows tied the buttresses to the buildings. By observing the pattern of windows above the buttress, one can tell where windows were in-filled.

Figure 9 shows the two buildings after strengthening was complete. One of the buttresses can be seen at the far left end of the nearest tower. The cost of strengthening these buildings in 1974 was about $\$ 0.5$ million. The cost today would be about $\$ 1.5$ million. Replacement value today is $\$ 60$ million. This expenditure saved $\$ 30$ million in 1989 when the Loma Prieta Earthquake took place and will save many lives in a great earthquake.

\section{CRITERIA FOR UPGRADE}

Structural criteria for strengthening these buildings were based upon a maximum credible earthquake of 7-1/4 magnitude on the nearby Hayward Fault with a peak 
ground acceleration of $75 \% \mathrm{~g}$ for dynamic analysis. Results were checked by static analysis using a minimum base shear of $20 \%$. These criteria are used for all normal LBL buildings, both for new construction and upgrading existing facilities. For essential buildings having emergency recovery facilities or hazardous materials, a static base shear of $28 \% \mathrm{~g}$ is used.

\section{CONCLUSION}

Including other facilities that would have suffered structural damage, upgrading substandard buildings at LBL saved over $\$ 50$ million during the Loma Prieta Earthquake. The total cost to upgrade these buildings since 1971 is $\$ 4$ million. LBL will spend another $\$ 10$ million over the next few years to complete its seismic upgrade program in preparation for the great earthquake that is sure to come. In the meantime, the work accomplished thus far has produced large cost savings for the U.S. Department of Energy.

The LBL experience in the implementation of its seismic upgrading program served as a basis for the development of the "Seismic Safety Guide" (Eagling, 1983) which was prepared for the Office of Nuclear Safety, U.S. Department of Energy. The Seismic Safety Guide provides the managers of facilities with practical guidelines for administering a comprehensive earthquake safety program.

\section{REFERENCE}

1. Eagling, D.G., et al, (1983) "Seismic Safety Guide," LBL-9143, Lawrence Berkeley Laboratory, University of California, Berkeley, California 


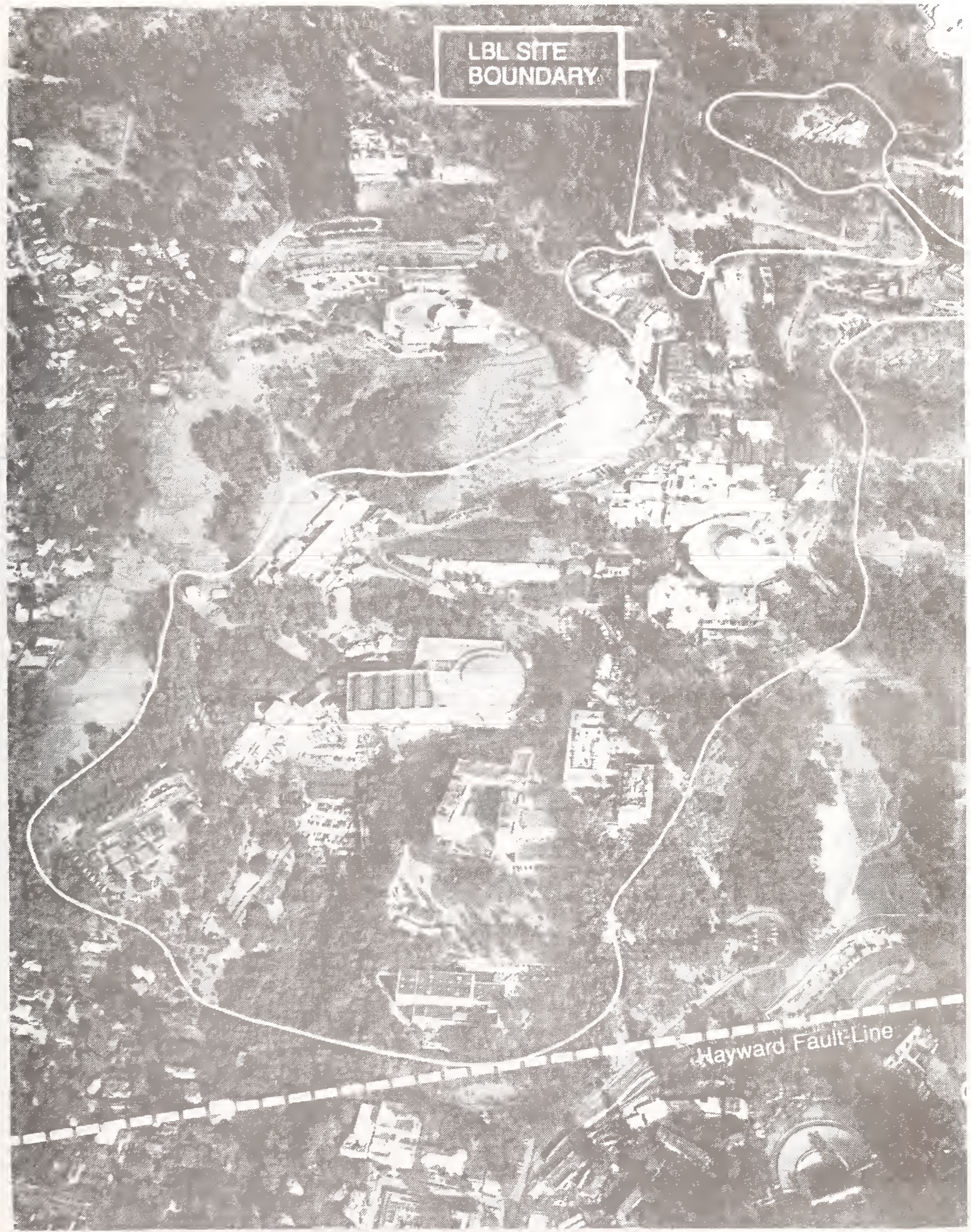

Figure 1. Aerial View of the

Lawrence Berkeley Laboratory (LBL) 


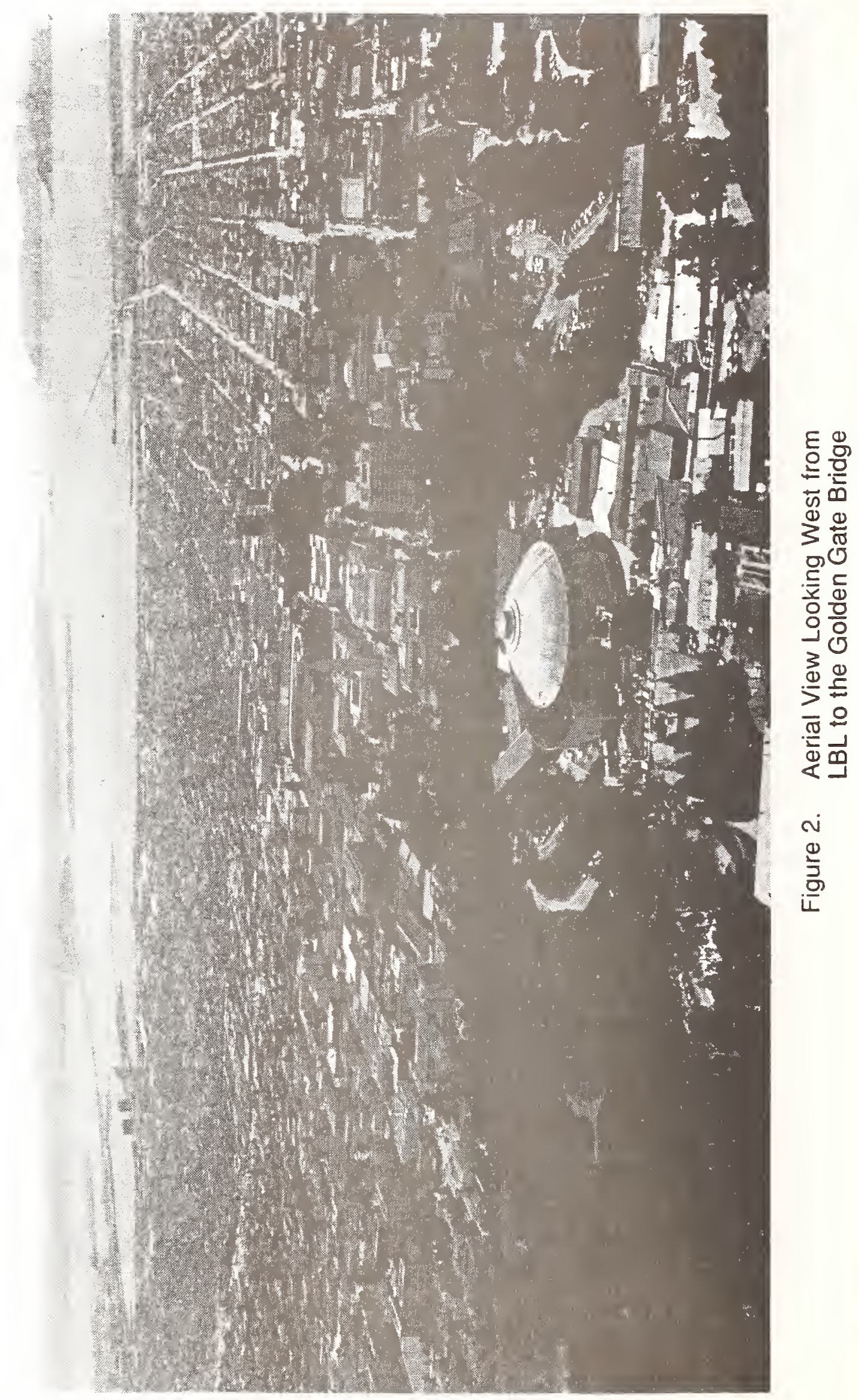




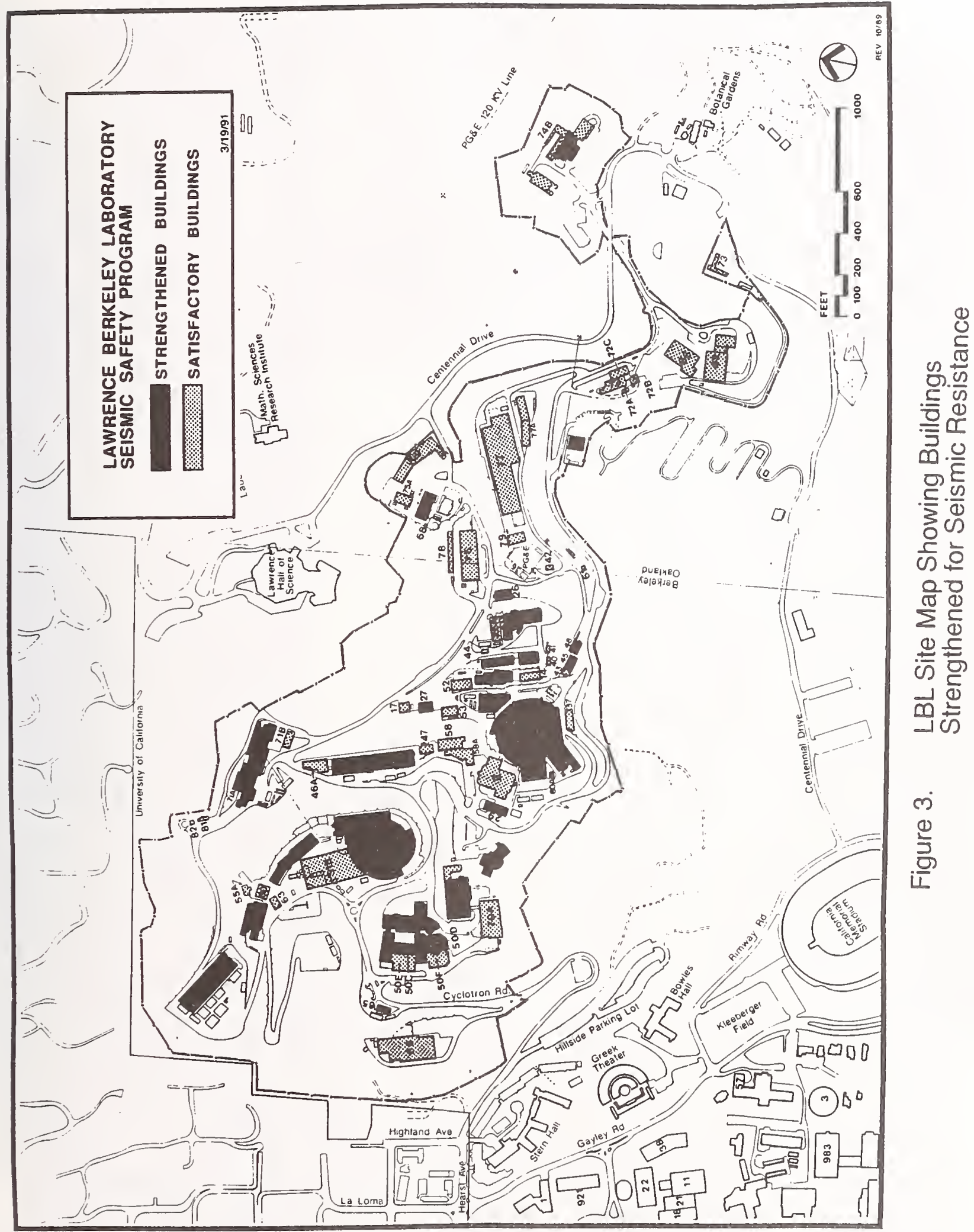




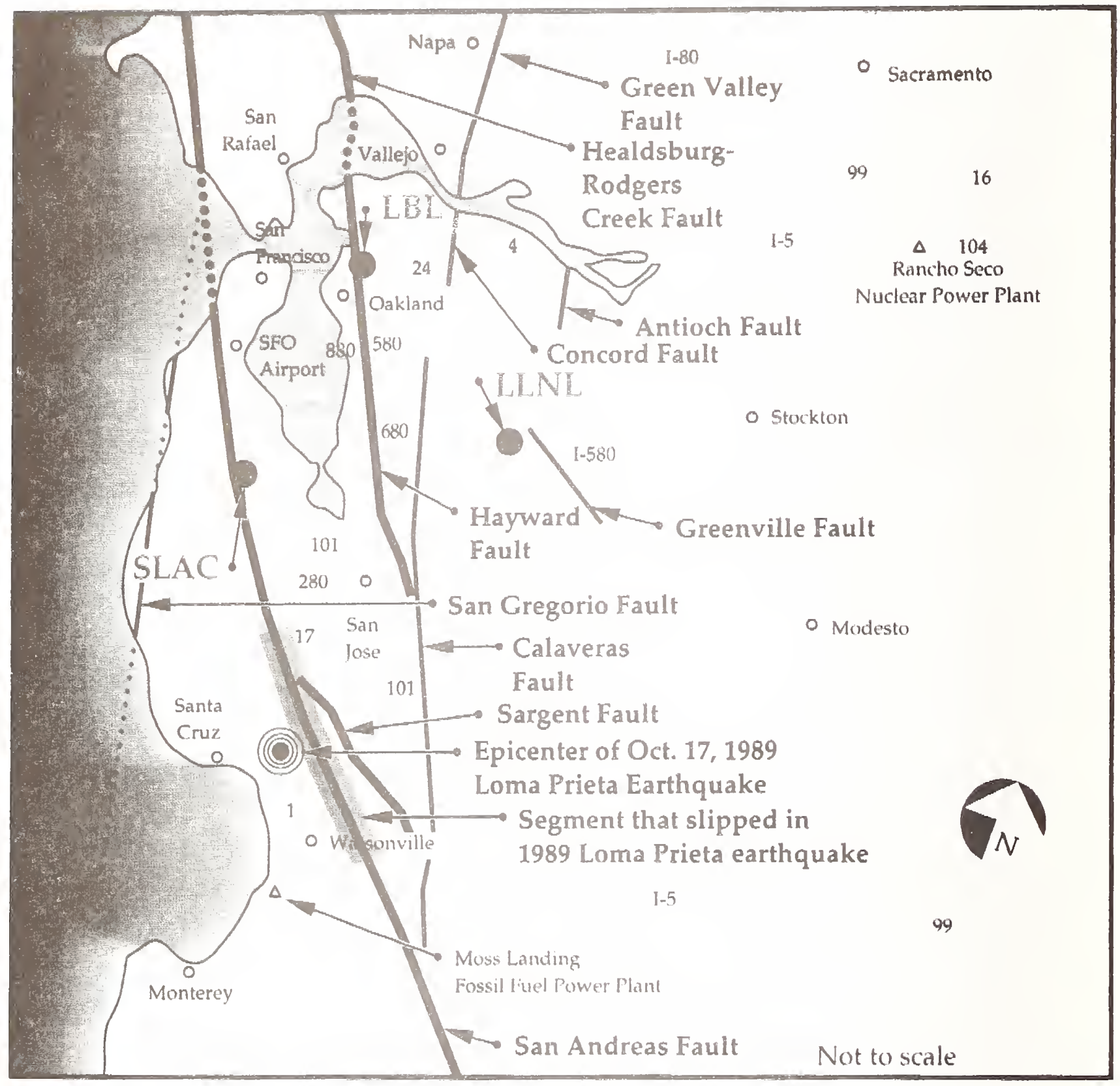

Figure 4. Active Faults

Local to the San Francisco Bay Area 


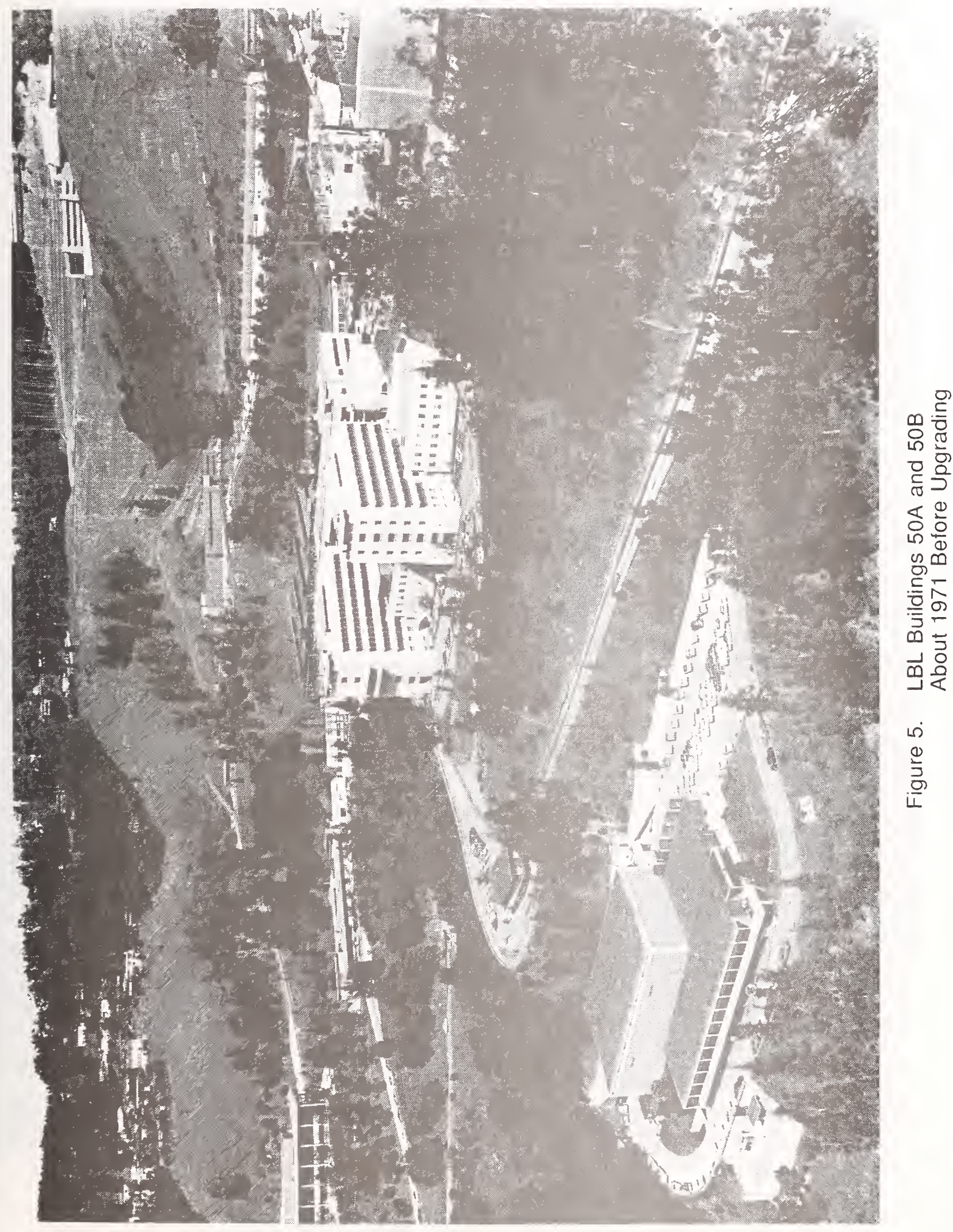




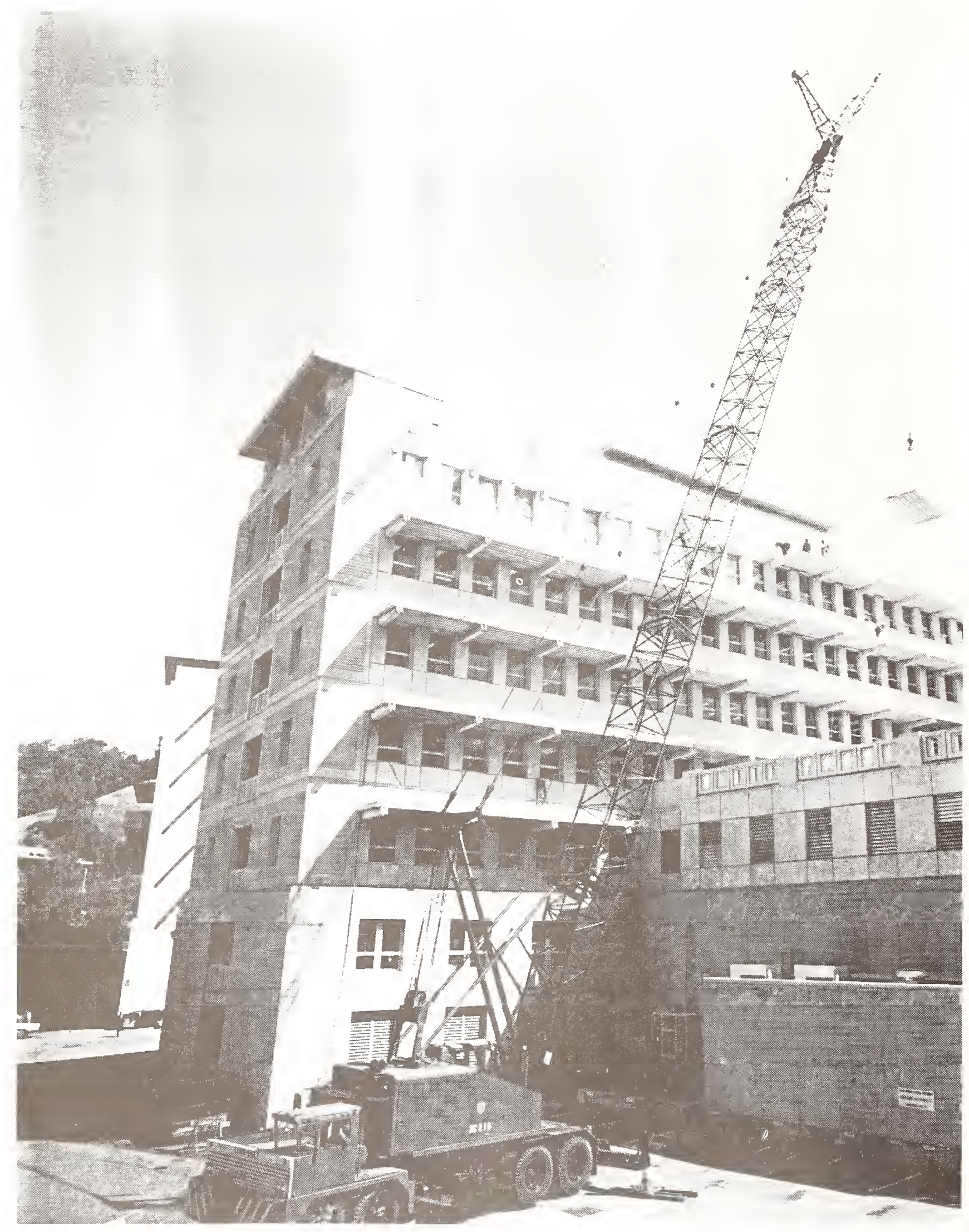

Figure 6. Removal of Concrete Sunshades from Building 50B (About 1972) 


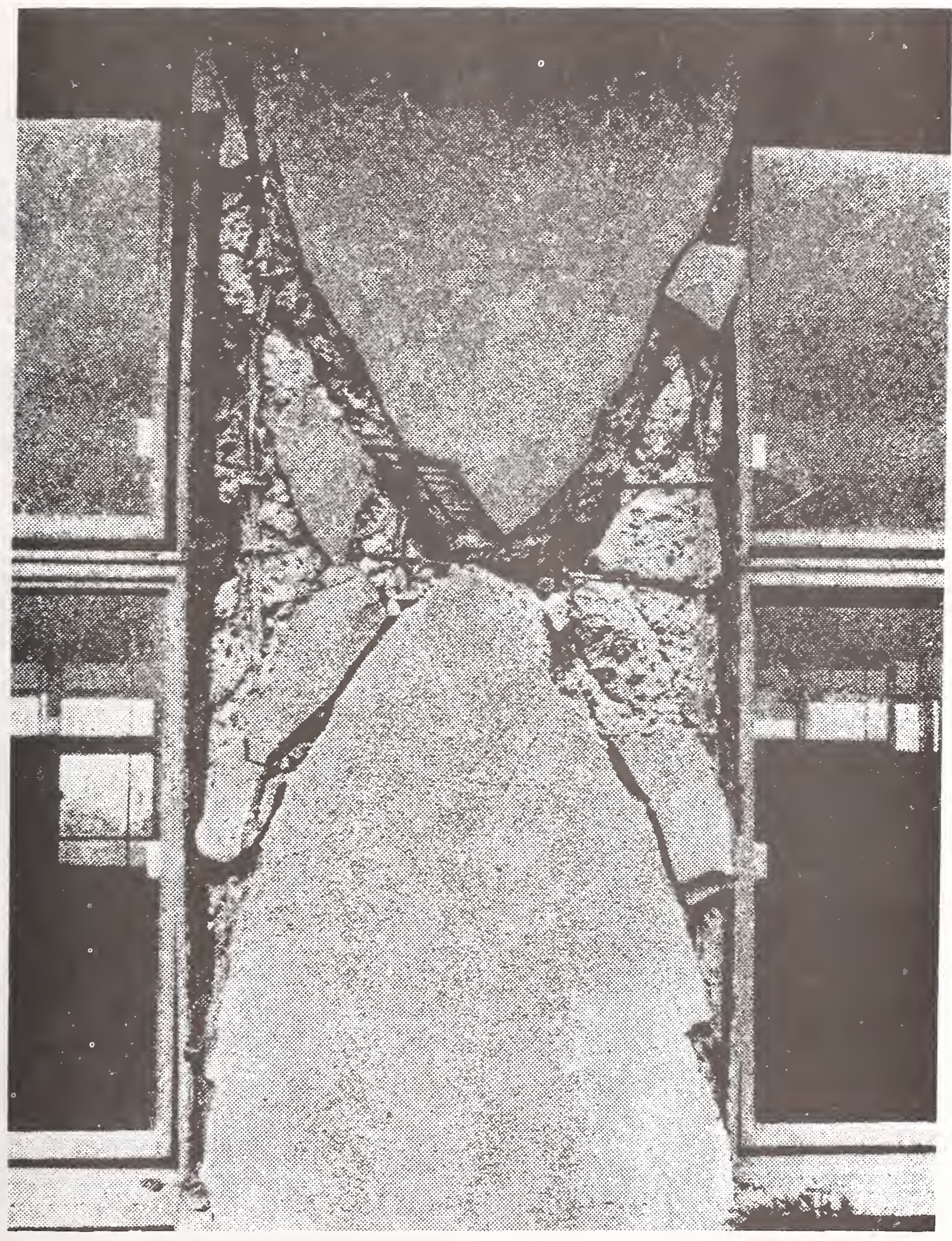

Figure 7. Diagonal Tension Faiłure in Window Pier Misawa Commerce High School Tokachi - Oki Earthquake 1968 


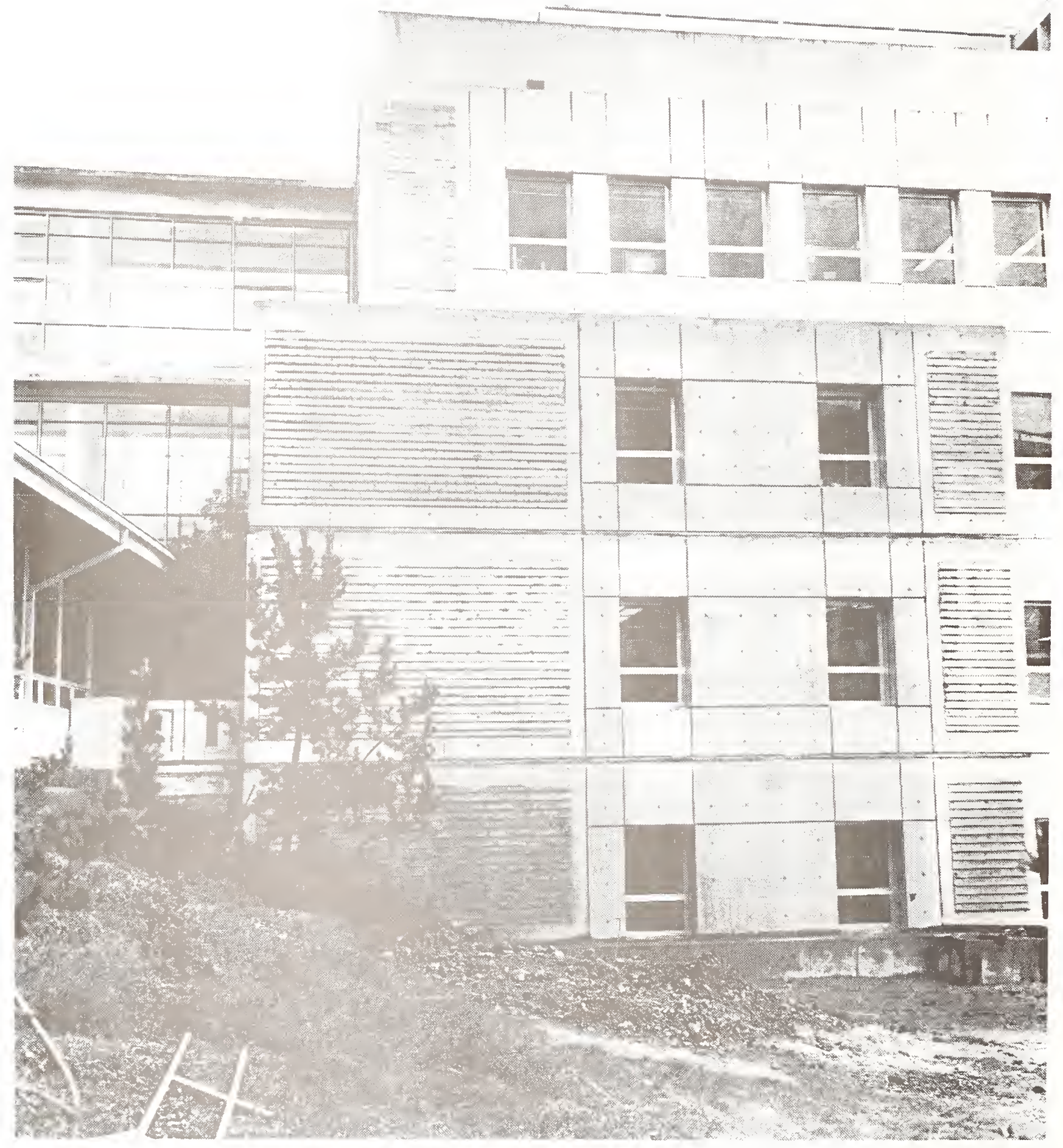

Figure 8. Longitudinal Buttress

Uphill End of Building 50B 


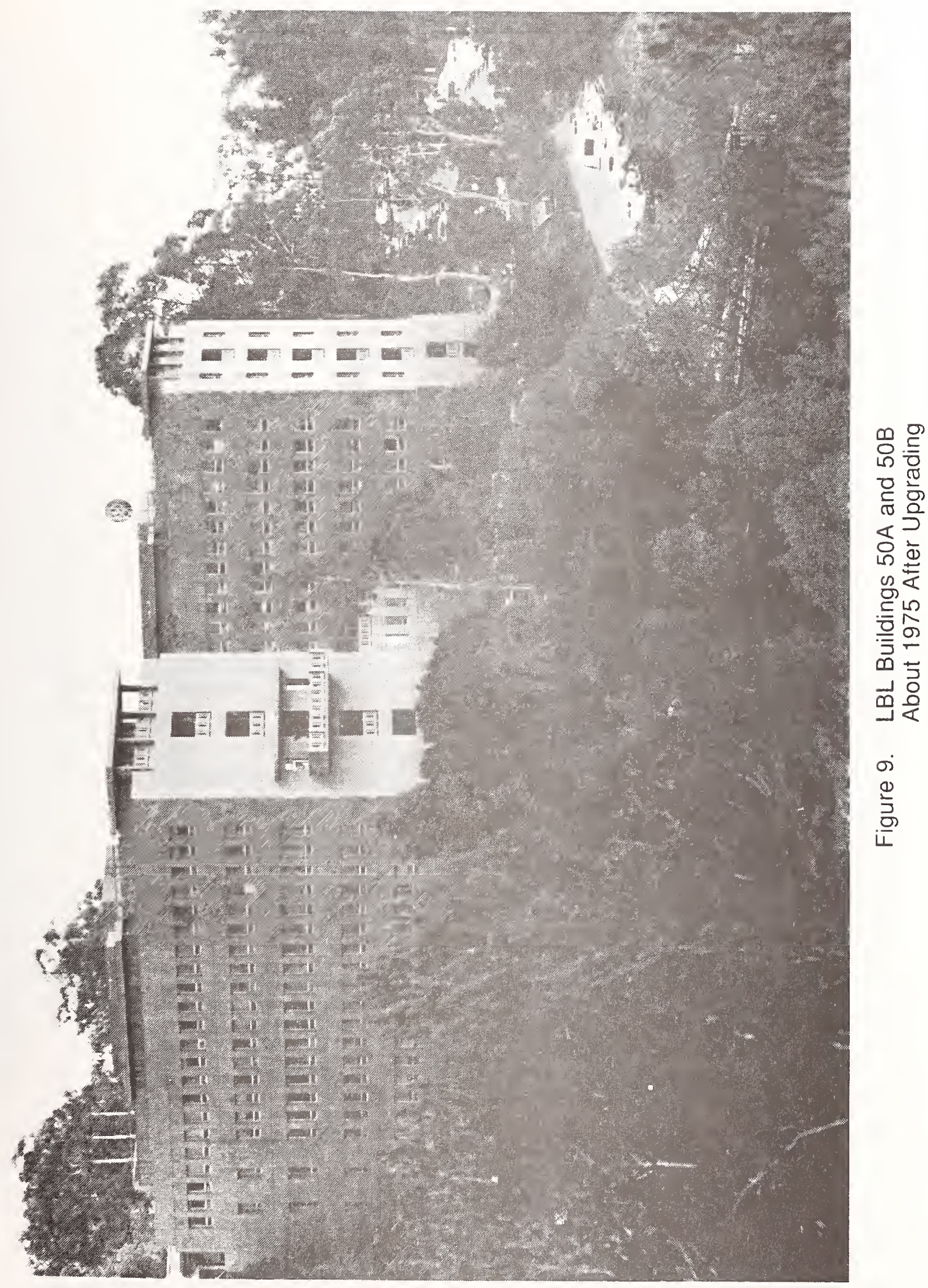




\section{Structural Regulations of Buildings and Development \\ of Technology in Japan}

By

\section{Yuji OHASHI $* 1$}

\section{SUMARY}

This paper presents a outline of structural regulations of the Building Standard Law. which prescribes the basic building restriction of Japan, and relation of building restriction and developement of building technology. showing some examples of new structural technique.

Building regulations in Japan are based on the Building Standard Law. There are a lot of standards in the law. There is a special approval system by the Minister of Construction for new structures which do not comply with the standards to prevent the resririction from becoming too rigid. The system has provided the way for a lot of new building structure to date. Airsupported membrane structure, base isolation structure and response control systems are the latest successful examples of this system.

KEY WORDS: Building Restriction, Structural Regulation. Seismic Design Method, Building Codes, The Building Standard Law. Approval System

\section{OUILINE OF JAPANESE BUILDING RESTRICTION}

1,1 Feature of the land and the buildings of Japan

There have been many disartrous earthquakes in the history of Japan. and every year, the country is attacked by typhoons. These extreme forces of nature have inflicted great damage on building structures, and it has long been a major task of Japanese building technology to find ways of preventing this constant danger.

Traditionary. wood was used to buildings. from the plentiful supplies in the mountains. Houses were constructed with wooden columns and beams, using techniques of disaster prevention developed over years and years of experience.

Most of the urban areas in Japan can be regarded as a continuation of old towns where wooden buildings are densely packed. The urban areas in Japan have been subject to the attacks of a lot of conflagrations in the past.

The cause of conflagrations is not only

\section{Hiroyuki YAMANOUCHI*2}

accidental fires but also the simultaneous outbreak of fires in many places due to a large scale earthquake. The Great Kanto Earthquake (1923) was typical of the latter. with approximately 700,000 buildings being destroyed, and some 140,000 persons dead or missing.

Thus, it is highly necessary that buildings in Japan be able to safely withstand attacks of earthquakes, typhoons and fires. It is the purpose of the building restriction of Japan to safeguard against the danger.

\subsection{Purpose and constitution of the Building Standard Law}

Building Standard Law was enacted in 1950 considering the abovementioned conditions. and since then has been subjected to many revisions in accordance with the advances in technology and the conditions of building disasters that have occurred.

The building standard statute consists of the Building Standard Law, the Building Standard Law Enforcement 0rder as cabinet order, the Building Standard Law Enforcement Regulations as Ministry of Construction Order, and Notifications of Minister of Construction based on these regulations.

The purpose of the statute is to "safeguard the life, health, and properties of the people by providing minimum standards concerning the site, structure, equipment. and use of buildings, and thereby to contribute to the furtherance of the public welfare."

The statute comprises the "general provisions" on procedures for building construction, the "building codes" on standards for safety and sanitation of all buildings in the whole country, and the "zoning codes" on standards for ensuring the safety and appropriate environments in urban areas to be applied to city planning areas based on the City Planning Law, as well as penal provisions.

*1 Senior Research Engineer.

Structural Engineering Department, Building Research Institute, Ministry of Cnstruction Tatehara-1, Tukuba-City, Ibaraki, Japan *2 Dr. Eng. . Director of Structural Dynamics Div. Structural Engineering Dep. BRI 
1.3 Outline of the regulations of the Building Standard Law

1.3.1 General provisions (Procedures for building construction)

(i) Building confirmation

Generally in the case where a building is to be constructed, the building client must submit the construction plan to a building official of the local govarnment, and receive the confirmation of the official as to whether the plan satisfy the regulations of the Building Standard law. If the plan does not meet the regulatons, construction will not be allowed.

There are about 1600 building officials. over 5000 other local officials who concern with building restriction and about 300 local governments throughout Japan. There are about one million building confirmations per year.

(2) Design and supervision by qualified build ing engineers

The design and the supervision of $\mathrm{con}^{-}$ struction works of buildings exceeding a certain scale must be performed by qualified building engineers. The rumber of the building engineers is about 700 thousands since the enforcement of the Building Standard Law. This number includes a lot of dead engineers. The number of active engineers is uncertain. A lot of the engineers work as not the designers of buildings but the supervisers of construction works.

(3) Inspection after the completion of construction

Once a construction work have been completed, the building client must submit a notification of this effect, to the building official. The said building must receive an inspection by the building official, as to whether the building satisfy the regulations. A certificate of inspection is then granted when it is confirmed.

(4) Periodic inspection and periodic report system

The owners of certain buildings such as hospitals, hotels, department stores, theaters, collective dwellings and offices exceeding certain scales, and the owners of escalators and el evators and other building equipments must have regular inspections con cerning the conditions of such buildings and building equipments by a qualified engineer. every 1 to 3 years, and must report the results of inspections to the local government.

1.3.2 Building codes
Building codes stipulate standards for structural safety, fire prevention and sanitation.

1) Standards for structural safety

Regarding structural safety, the codes lay down the standards of detailed structure for each type of structure such as wooden structure, steel structure and reinforced concrete structure, and standard of structural calculation.

In order to ensure the safety of a building, the Building Standard Law Enforcement Order provides that structural calculations must be performed to confirm the safety of large buildings. The range of building for which structural calculations must be done is as follows.

type of construction scale wooden structure $\quad \mathrm{n} \geqq 3$ or $A \geqq 500 \mathrm{~m}^{2}$ others $\quad n \geqq 2$ or $A \geqq 200 \mathrm{~m}^{2}$

(where n: number of stories of the building A:total floor area of the building)

The method of the structural calculation was revised in 1980, and has been in force since June 1, 1981. Adding to the conventional allowable stress design method for elastic range, this new method of structural calculation determines design method considering ultimate stress including the stress within a plastic range. In addition, story drift, rigidity factor and eccentricity factor should be checked to ensure a balanced structural plan.

The Enforcement Order prescribes the loads, the external forces, the allowable stress of building materials necessary for structural calculation, and also the methods of calculation that are necessary for structural safety in accordance with the height and structure of buildings.

Regarding the structural calculation, to confirm structural safety, at least five kinds of loads and external forces must be checked, namely, fixed load, imposed load, snow load, wind force and seismic force.

Values of allowable stress are provided for the common materials such as timber. steel, concrete, etc. Dual allowable stress system is adopted, namely, allowable stress for permanent loads and allowable stress for temporary loads are provided.

Values of allowable stress for permanent loads are half to one third of ultimate stress of materials, values of allowable stress for temporary loads are equivalent to yield level or elastic limit.

The stress generated in each of structu ral members by the combinations of loads and external forces, does not exceed the 
allowable stress.

The purpose of the current seismic design code is that buildings should withstand moderate earthquake motions with almost no damage, and should not collapse nor harm human lives during severe earthquake motions

Regarding seismic design, adding to the allowaole design method, limitations on story drift, rigidity factor, eccentricity factor and ultimate lateral shear strength of each story are provided.

The lateral seismic shear Qi of $i$-th story is determined by

$\mathrm{Qi}=\mathrm{Ci} \mathrm{Wi}$

where $\mathrm{Ci}$ is the lateral seismic shear $\mathrm{co}^{-}$ efficient of the $\mathrm{i}$-th story and $\mathrm{Wi}$ is the weight of the building above the i-th story.

Lateral seismic shear coefficient of the $\mathrm{i}$-th story is given by

$\mathrm{Ci}=\mathrm{Z}$ Rt Ai Co

where $Z$ is the seismic hazard zoning $\mathrm{Co}^{-}$ efficient. Rt is the design spectralcoeffici ent, and $\mathrm{Ai}$ is the lateral shear distribution factor. The standard shear coefficient $\mathrm{Co}_{0}$ is 0.2 for moderate earthquake motions and 1.0 for severe earthquake motions.

For buildings higher than $31 \mathrm{~m}$, or with irregularities exceeding the specified $1 \mathrm{im}^{-}$ its, the calculated ultimate lateral shear strength of each story must not be less than the specified ultimate lateral shear Qun ;

Qun $=$ Ds Fes 0

where Ds is the structural coefficient. Fes is the shape factor, and $Q$ is the shear for severe earthquake motions which is given by Eqs. (1) and (2) letting $C_{0}=1.0$.

The structural coefficient Ds is determined by the energy absorbing capacity of the structure. The shape factor Fes is the product of the factor $\mathrm{Fe}$, which is determined by the excentricity facte $r$ and the factor Fs, which is determined by rigidity of each floor.

2) Approval of the Minister of Construction for new structure and special material

There is a special provision which makes allowance for construction using new structure and materials, in response to progress in constrution technologies and development of new materials. According to this provision. Article 38 of the Building Standard Law. such a building plan requires only special approval by the Minister of Construction, overriding standards of the building codes. The article says as follows.

- The provisions of this Chapter or those of orders or cordinances based thereon shall not apply to buildings using special building materials or methods of construction unanticicipated thereunder, in cases where the Minister of Construction determines that the said building materials or methods of construction are equal or superior to those specified in the said provisions."

Before the approval of the Minister, the safety of the buildings shall be evaluated by the committee of the Building Center of Japan under the supervision of the Minister.

The buildings approved by this system in recent years average about 150 per year.

Super-highrised buildings higher than $60 \mathrm{~m}$ have been approved by this system. To evaluate the safety of such buildings, adding the allowable stress design, dynamic response analyses are taken using records of the ground motions of past earthquakes, where some typical ground motions such as" El Centro" and the ground motions which were recorded near the construction site of the building are used. At this time, The scales of the ground motions are normalized and 2 levels of the ground motions are adopted. Maximum velocity of the ground motions of level 1 is some $25 \mathrm{~cm} / \mathrm{sec}$ and that of level 2 is some $50 \mathrm{~cm} / \mathrm{sec}$. Response from level 1 ground motions shall not exceed elastic limit of the building materials of structural members and that of level 2 ground motions shall be within apt value of ductility factor.

3) 0ther regulations

Outline of other regulations of the Building Standard Law is as follows.

As for fire prevention. the codes stipulate that roofs and external walls of buildings in a specified area be made fire preventive construction. that department stores and other buildings for special use be made fireproof construction, and that fire compartments be created in large scale buildings according to a specified floor space. Standards for emergency facilities, including hallways, staircases, smoke-exhaust equipment, etc. are also stipulated.

To secure sanitation, the codes lay down standards for natural lighting and ventilation of rooms, structure of lavatories. structure of elevators and escalators, etc.

The zoning codes prescribe relationship between sites and roads, land use designated districts, ratio of total floor area to site area, height of a building, restrictions on buildings in fire protection districts, etc.

\section{OUTLINE OF THE HISTORY OF SEISMIC CODE OF BUILDINGS OF JAPAN}

With the end of the Edo Period and the 
Meiji Restoration in 1868. Japan set the course for a modern nation. Abolishing the insulation policy of the Edo Era, the newly established Meiji government carried out various measures to open the country and catch up with western advanced nations. Modern structures such as steel structure and reinfoced concrete structure were introduced from these nations.

With the outbreak of World War I, the Japanese economy made outstanding progress, causing concentration of the population and industries in urban areas and making it necessary to establish urban planning and building regulations in big cities such as Tokyo and 0saka.

In 1919. the City Planning Law and the Urban Building Law was enacted for six major cities. The two laws served as the starting point of modern building regulations in Japan.

The Urban Building Law provided for such systems as building lines regulations and zoning systems. It also stipulated standards for buildings in terms of fireproofness, safety in structural strength. and guarantee of sanitation.

Regarding structural safety, the codes stipulated the standards for detailed structure and structural calculation. As loads, only fixed load and imposed load were provided in regulations of structural calculation.

In accordance with progress in construction technology, and economic and industrial growth, the Urban Building Law underwent several revisions.

In 1923, the Great Kanto Earthquake attacked the Kanto Area, destroying a huge number of buildings. Fires caused by the earthquake burned down wooden houses in the region, killing about 140,000 people.

In reflection on the massive damage, the Urban Building Law set up seismic force and made it obligatory to calculate the seismic strength of building, where seismic coefficient shall be more than 0.1 in 1924. The article says, "Horizontal seismic coefficient shall be more than 0.1 ." That means each building shall be designed and constructed so that it can resist a lateral force of at least $10 \%$ of its weight.

Regulations on safety of buildings in Japanese legislation have since centered on fireproofness and earthquake-proofness.

The lesson of the earthquake demonstrated the great importance of bearing walls in resistance to earthquakes.

There had been only one allowable stress for each material which is about one-third of the yield level of the material.

During the World War II, because of the shortage of construction materials, a dual allowable stress system was introduced into Japan. That is, the stress caused by permanent loads was to be less than the allowable stress for permanent loads, and the stress from temporary loads was to be less than the allowable stresises for temporary loads.

During the World War II, building restriction based on the Urban Building Law were suspended except for some regulations on fire prevention.

After the World War II, the Urban Building Law was restored. In accordance with the enactment of the Constitution of Japan, the Building Standard Law was enforced in 1950. abolishing the Urban Building Law. The application area of the Building Standard Law is the whole nation, not limlted districts as in the Urban Building Law.

Technically speaking, the Building Standard Law was basically the extension of the Urban Building Law. But, regarding structural calculations, the standard was revised, where dual allowable stress system was adopted and seismic coefficient became 0.2 and allowable stress for temporaly load like seismic load regulated about elastic limit of building materials.

Nearly 40 years have passed since the Building Standard Law was enacted in 1950. During the period, Japan has made remarkable progress in economy and building technology. And the Building Standard Law has been revised several times, taking into account progress in building technology and damages to buildings caused by earthquakes.

The Tokachi Earthquake in 1968 showed importance of the ductility as well as strength of structural members. As a result, the structural codes of the Building Standard Law stipulated ductility of buildings with the revision of reinforcement for shearing of pillars of reinforced concrete buildings in 1971 .

During that time, the development of computer technology also promoted structural analysis knowhow. Through computerized seismic analysis, construction technology of super-highrise buildings was developed around 1960, using the earthquake ground motions recorded in the United States.

The construction of super-highrise buildings requires approval of the Minister of Construction based on the regulation of Article 38 of the Building Standard Law and 
evaluation by the committee of the Building Center of Japan before the constructin work of the building. In order to evaluate the safety of the buildings which use special strucure or special materials, the Building Center of Japan was established in 1965 under the supervision of the Minister of Construction.

Against the background of these factors, the Ministry of Construction led the development project for new seismic design method from 1972 to 1977 with a view to thoroughgoing revisions of seismic design method in the Building Standard Law. And in 1981. the drastic revision took effect with dynamic considerations on seismic calculation. For instance, the seismic force, which had been set at more than 0.2 of seismic coefficient, was fixed in accordance with natural periods of buildings. The revision also called for two-stage designing. namely design against the seismic force equivalent to self weight of a building, in addition to the conventional allowable stress design against seismic force of $20 \%$ ofthe self weight of the building. Moreover. retained ultimate lateral shear strength was to be calculated with consideration for ductility of a building, not allowable stress.

Revisions and addition have been made to standards for detailed structure in accordance with progress in structural materials, such as steel products, and development of new structuralforms. including wood frame construction.

\section{BUILDING RESTRICTION AND DEVELOPEMENT OF TECHNOLOGY}

\subsection{Building regulation and technological level}

A lot of technlogical standard s are established in the Building Standard Law. Most of the standards are regulated based on the general technological level and social and economical conditions of the times when the standards are regulated. Also, they reflect the average form and structure of buildings of the time.

Thus, in a rapidly changing society with highly advanced technology, occasionally the standards of the existing building standards cannot deal with the newly developed structure and materials. Some of these buildings do not fit in the formal framework of the existing building regulations.

Sometimes, these existing standards stand in the way in developing these new build- ings. However, there is a special provision, which allows the construction of these buildings that do not satisfy the standards by the approval of the Minister of Construction, as explained in sction 1.3.2 of this paper.

This approval system has covered the construction of these new buildings and has contributed the developement of building technology. Examples of those buildings are super-highrised buildings and pre-fabricated houses, etc.

\subsection{Relation between building restriction} and developement of technology

Here, the writer shows relation between building restriction and developement of technology, using air- supported-membrane structure, base-isolation structure and the structure which adopts response control system as examples.

\subsubsection{Air-supported-membrane structure}

Air-supported-membrane structure usually makes its roof with membrane and makes internal air pressure slightly higher than external air pressure to add the ridigity of the roof.

large-scale air-supported-membrane struc -ture features a lot of special characteristics when compared with conventional structures. The following are some of these characteristics.

1) This type of structure features an extremely large roof with low rigidity. Wind pressure acting on the roof is different from that of usual rectangular medium sized buildings, which have high rigidity.

2) This structure requires a snow-melting system. Snow load on the roof requires higher internal air pressure, which dose not good for usage of the building because the the higher air pressure is, the higher velocity of the air flow at doorways is. Thus, a snow-melting system is required. However, in Japan, we do not have the experiences of such a system.

3) This structure uses membrane, special material.

4) The single huge space created by this structure require s a new concept for the fire prevention and emergency facilities of the building.

5) This structure requires special facilities which sustains internal air pressure. The facilities must be properly operated and well maintained for stability of the structure.

The standards of the Building Standard Law do not anticipate these specific charac- 
teristics of this structure.

These characteristics requires the approval of the Minister of Construction and evaluation of safety by a committee of the Building Center of Japan, before the construction of the building. To this effect, a new concept had to be created for design and evaluation which covers these characteristics.

Around 1980. some major Japanese construction companies began to develop the technology of large-scale air-supported membrane structure like a baseball stadium with roof, studing such existing stadiums in the United States. A special committee was set up in the Building Center of Japan in 1983, based on the agreements among the construction companies, the Building Center of Japan, the Ministry of Construction and exparts. The committee, composed of representatives from these parties. began to work out the standards for evaluation of the safety of the large-scale air-supported membrane structure.

In December 1984, the evaluation standard was made. This work promoted planings of such buildings. The decision to construct the Tokyo Dome, first baseball stadium with roof in Japan, was made. The evaluation standard was used as a guideline for the design of the Tokyo Dome. After the dome was designed, the evaluation committee of the Building Center of Japan made the safety evaluation based on the standard. After that, the Minister of Construction approved the construction of the dome with Article 38 of the Building Standard Law.

Since then, a lot of air-supported membrane structure of medium size have been constructed in Japan.

\subsubsection{Base isolation structure and response control system}

Advances in response analysis technology had given the knowledge that seismic force could be reduced by lengthing the natural period of a building, and research was carried out into how this could be done. Laminated rubber bearing was invented around 1980. The bearing is made of several alternating layers of rubbe $r$ sheets and steel plates and can withstand great forces in a vertical direction. such as the self-weight of the building, while horizontally it is flexible in character. When they are install ed in the foundation of a building, or the columns of its lowest floor, they can support the self-weight of the building and at same time. because of their horizontal flex- ibility, can lengthen the building's natural period. That reduces seismic force. This technique is known as base-isolation. In Japan, it is already beyond the experimental stage and has been introduced gradually into actual construction. Compared with conventional structure it is capable of considerably reducing the effects of seismic force.

Research has also done into other methods of absorbing or controlling the response from an earthquake. One of them is to install a "damper". Dampers can be installed independently in the walls or structural braces, or can he used in combination with laminated rubber bearings as part of a base isolation structure system.

Another technique involves installing a large mass on the roof or top floor of a building. The special characteristics of themass mean that when it is connected through the superstructure of the building to springs and dampers, the vibration caused by external forces such as seismic force is converted to the vibration energy in the mass. The superstructure of the building will then vibrate less violently than it would do without the mass. This kind of system is called 'tuned mass damper".

Structures which use such devices in addition to conventional structural members are known as 'response control structures'. There are already several of them in Japan, and further research is still under way.

The most advanced systems of response control involve sensors and computers. The sensors can measure the intensity of an earthquake motion or a strong wind force, and response vibration of th e building itself. Signals from the sensor are fed into a computer, which calculates and triggers off a "control force " in the building to reduce the response of the building. This kind of system is known as active mass damper" .

In other structures, a computer can calculate to what extent the rigidity of structural braces should be modified, and can alter their rigidity accordingly.

These systems which can reduce the response of structure by using appropriate energy are known as "active response control system '. The research and developement of the systems are now being carried out.

These systems are special ones, and the regulations of the Building Standard Law do not anticipate. Thus, the construction of the building which uses such a system requires approval of the Minister of Construction and evaluation of the committee of 
the Building Center of Japan. It is supposed that it will take long time to evaluate safety of such systems because we do not have the experiences of planings and construction works of the kinds of the systems.

In order to reduce the time of evaluation of the actual construction, prior to the evaluation, special committees which studies model buildings that adopt such systems are sometimes set up base on the requests of the companies which are developing these systems. These comittees are studing basic structural problems of the systems. They contribute to reduce the time of the evaluation of actual construction plans.

4. PRESENT PROBLEMS RELATED TO BUILDING RESTRICTION AND DEVELOPEMENT OF TECHNOLOGY

A lot of buildings which use newly developed technology that dose not comply with the regulations of the Building Standard Law have been constructed by the approval of the Minister of Construction and evaluation of the committee of the Building Center of Japan. The approval and evaluation system based on Article 38 of the Building Standard law contributes the developement of building technology. However, there are some problems in this system and its smooth administration. The following are some of these problems.

1) Technical evaluation requires a lot of time and effort

The evaluation must be conducted carefully to ensure the building safety. Thus, this system requires much time and manpower. This has been pointed out not only by construction companies and structural consultants but also by officials and experts in charge of the evaluation, corresponding to the $i$ ncreasing number of buildings to be evaluated.

2) Intermediate coordination may be required during the technological developement stage.

In general, official evaluation is to be conducted after the completion of the building design. However, a building incorporating extremely new technologies may require coordination between the developer or designer and officials in charge during a technological developement or design stage to promote smooth building developenent. The Building Center of Japan recently started 'technical guidance ' service or setting up of above mentioned special comittee which studies new technique to handle such cases, when necessary, prior to the official evaluation based on the request from the deve1- oper of the technique.

\section{CLOSURE}

Building regulations in Japan are based on the Building Standard Law. There are a lot of standards in the law. There is a special approval system by the Minister of Construction for new structures which do not comply with the standards to prevent the resririction from becoming too rigid. The system has provided the way a lot of new building structure to date. Air-supported membrane structure, base isolation structure and response control systems are the latest successful examples of this system.

This system requires evaluation of the comittee of the Building Center of Japan prior to the approval of the Minister. However, there stil 1 remain some problems to be solved. It is hoped that the system will be simplified to respond to these problems, creating a favorable environment that will promote smooth technological developments while at the same time satisfying the purpose of the building restriction. 


\title{
Seismic Hazard Assessment of Liquefaction Potential \\ at Mormon Island Auxiliary Dam, California, USA
}

by

\author{
David W. Sykora ${ }^{1}$ \\ Joseph P. Koester \\ Mary E. Hynes ${ }^{2}$
}

\section{ABSTRACT}

A seismic hazard analysis was conducted using various combinations of $\mathrm{a}_{\max }$ and earthquake magnitude at a dam site where post-earthquake stability is suspect. Results of the limit equilibrium slope stability analysis using residual strengths and pore pressures were combined with seismic hazard calculations to estimate the likelihood of liquefaction of dredged foundation gravels and consequent failure of the dam-foundation system. The hazard associated with each interval of earthquake magnitude was calculated.

KEYWORDS: Earthquake; Seismic Hazard; Postearthquake Stability

\section{INTRODUCTION}

A seismic stability evaluation of the Mormon Island Auxiliary Dam (MIAD), part of the Folsom Dam and Reservoir Project, located near Sacramento, California, was performed as a cooperative effort between the US Army Engineer Waterways Experiment Station (WES) and the US Army Engineer District, Sacramento (SPK). A location map of the project is shown in Figure 1.

From a Phase I study (Hynes-Griffin et al. 1988), it was determined that the portion of MIAD with shells founded on dredged tailings will not be stable against large-scale internal sliding during and after the design earthquake event. Remedial measures were recommended over this length of the dam. It was concluded from Phase II studies (Wahl et al. 1988) that the segments of MIAD with shells founded on rock or on undredged alluvium will be stable both during and after the design earthquake event, hence, remedial measures in these sections are not required.

Further engineering analysis in the form of limit equilibrium slope stability analyses and seismic hazard assessments were conducted to assist in the decision making process for remedial measures at MIAD. A re-analysis of post-earthquake slope stability, using stratigraphic and cyclic strength data obtained at the site, was conducted to evaluate the slope stability of a representative section of MIAD founded on dredge tailings (gravels) if subjected to the design earthquake or less severe shaking. A seismic hazard assessment (SHA) was performed to determine the risks associated with different combinations of earthquake magnitudes and peak horizontal accelerations causing liquefaction of dredged foundation gravels.

These additional engineering studies were aimed at assessing the potential for occurrence of a damaging earthquake at the site, and provide background analyses from which possible postearthquake embankment configurations could be envisioned. An exhaustive analysis was not conducted because of the short time frame within which the results were applied to the construction of remedial measures. Calculated return periods are considered to be lower-bound values because of the conservatism applied throughout the analysis. The results of the seismic hazard analyses are summarized in this paper.

\section{Project History and Description}

The Folsom Project was designed and built by the Corps of Engineers during the period 1948 to 1956 . Upon completion of the project in

\footnotetext{
${ }^{1}$ Research Civil Engineer, Geotechnical Laboratory, US Army Engineer Waterways Experiment Station, Vicksburg, Mississippi, USA

${ }^{2}$ Supervisory Civil Engineer, Geotechnical Laboratory, US Army Engineer Waterways Experiment Station, Vicksburg, Mississippi, USA
} 
May 1956, ownership of the Folsom Dam and Reservoir was transferred to the US Department of the Interior, Bureau of Reclamation, for operation and maintenance. The Folsom Project is composed of a concrete gravity dam, two adjacent earth-fill wing dams, the earth-fill MIAD, and eight earth-fill saddle dikes. Additional aspects of MIAD, documented in detail by U.S. Army Engineer District, Sacramento (1953 and 1955), are presented below.

MIAD is a zoned embankment dam $4,820 \mathrm{ft}(1,469.1 \mathrm{~m})$ long and $165 \mathrm{ft}(50.3 \mathrm{~m})$ high from core trench to crest at the maximum section. The shells were constructed of dredged tailings gravels. The narrow, central impervious core is a well-compacted clayey mixture founded directly on rock over the entire length of the dam to provide a positive seepage cutoff. Two transition zones, each $12 \mathrm{ft}(3.7 \mathrm{~m})$ wide, flank both the upstream and downstream sides of the core. The transition zones in contact with the core are composed of well-compacted decomposed granite which classifies as a silty sand according to the Unified Soils Classification System (USCS). The second (outer) transition zones are constructed of the fraction of the dredged tailings passing the 2-in. $(5.08 \mathrm{~cm})$ sieve. Typical sections of the dam are shown in Figure 2.

MIAD was constructed across the Blue Ravine, an ancient channel of the American River that is about 1 mile $(1.61 \mathrm{~km})$ wide at the dam site. For about 1,650 ft $(502.9 \mathrm{~m})$ of its width, the Blue Ravine is filled with auriferous, gravelly alluvium of Pleistocene age. The maximum thickness of the channel gravels is about $65 \mathrm{ft}$ $(19.8 \mathrm{~m})$. The gravels have been dredged for their gold content in the deepest portion of the channel, and the tailings were placed back into the partially water-filled channel. The replacement process tended to deposit the tailings in a very loose and random condition. The remaining undisturbed alluvium is crudely stratified and slightly cemented.

\section{POST-EARTHQUAKE SLOPE STABILITY}

\section{Background}

Slope stability studies were performed using the computer program UTEXAS2 (Edris and Wright, 1987). This program may be used to determine limit equilibrium factors of safety against sliding along surfaces prescribed by the user within the soil profile of interest, using one or more of several computational schemes available to the geotechnical engineering community. The scheme selected for this re-analysis calculated factors of safety along circular slip surfaces using Spencer's Method (Spencer, 1967).

Material properties used in UTEXAS2 were derived from the various sources of field and laboratory measurements including pre-construction investigations, construction testing, and recent studies including crosshole and downhole seismic measurements, in-situ density measurements, cyclic triaxial testing, and Becker Hammer Penetration Testing (BPT).

Earthquake-induced shear stresses were computed in the Phase I study using the computer program FLUSH (Lysmer et al. 1973). Zones in the foundation where low factors of safety against liquefaction (high excess pore pressures) were predicted were enlarged slightly to account for lower cyclic strengths indicated by lower $\left(N_{1}\right)_{60}$ values. Strengths were assigned corresponding to residual strength of liquefied soil, $S_{u r}$, for the purposes of post-earthquake stability analysis. The relationship of residual strength to $\left(N_{1}\right)_{60}$ values used in this re-analysis is shown in Figure 3 .

Residual excess pore pressures (expressed by means of a residual excess pore pressure ratio, $R_{u}$ ) induced by earthquake shaking in saturated zones with factors of safety against liquefaction ( $F S_{L}$ ) greater than unity were determined and represented in the manner described by Hynes-Griffin et al. (1988) and Wahl et al. (1988). Average $R_{y}$ values of 0.25 and 0.50 were used in the non-liquefied portions of saturated embankment and foundation gravels, respectively. These values were selected on the basis of upward adjustments to values reported by HynesGriffin et al. (1988) to account-for tower cyclic strengths indicated by the lower $\left(N_{1}\right)_{60}$ values discussed previously. The effect of these earthquake-induced excess pore pressures was modeled as causing a reduction in available frictional strength (by means of a reduced effective angle of internal friction, $\phi^{\prime}$ ) for input to UTEXAS2. An artificially reduced $\phi^{\prime}$ was calculated for nonliquefied materials using the following expression (after Hynes-Griffin, 1987):

$$
\sin \phi^{\prime} R_{\mathrm{y} \neq 0}=\left(1-R_{\mathrm{Z}}\right) \sin \phi_{\mathrm{R}=0}^{\prime}
$$

The zonation of materials and strengths input to UTEXAS2 for slope stability analyses under design pool and earthquake conditions is shown in Figure 4. 
Determination of Foundation Zones Critical to Post-Earthquake Stability

The earthquake acceleration necessary to trigger liquefaction in the free field gravels (average $\left(\left(N_{1}\right)_{60}=7.1\right)$ was estimated for several earthquake magnitudes for level ground conditions using the simplified procedure (Seed and Idriss, 1982). Accelerations estimated by this procedure range from $0.08 \mathrm{~g}$ to $0.10 \mathrm{~g}$ for magnitudes ranging from 6.5 to 5.25 , respectively, but it was found that liquefaction in the free field $\left(\left(N_{1}\right)_{60}\right.$ = 7.1) may not control threshold stability. A residual excess pore pressure ratio, $R_{v}$, of 0.40 was estimated for zones of foundation gravel with average $\left(N_{1}\right)_{60}=13.7$. Vasquez-Herrera and Dobry (1989) found that $R_{u} \leq 0.40$ generally defines stable excess pore pressures in loose, fine sands; this value corresponds to FS of about 1.2 in the foundation gravels at MIAD. Residual excess pore pressure ratios in the remaining saturated, non-liquefied gravels were assigned values between 0.10 and 0.40 for the purpose of evaluating stability with liquefaction restricted to free-field gravels. Excess pore pressure ratios were estimated in the remaining saturated, nonliquefied zones.

Two of the several upstream potential post-earthquake failure surfaces evaluated for the case of liquefaction only in free-field gravels (average $\left(\left(N_{1}\right)_{50}=7.1\right)$ were found to produce a factor of safety against post-earthquake sliding of 1.05 . The factor of safety calculated using UTEXAS2 and material properties associated with the less severe shaking for this particular surface is 1.73 . The results of these efforts indicate that liquefaction of the foundation materials with average $\left(\mathrm{N}_{1}\right)_{60}=13.7$ controls stability with respect to damage to the core of the dam.

Determination of Unsafe Combinations of Acceleration and Magnitude

The principal finding of this re-analysis of post-earthquake slope stability was that deep failure surfaces would not likely develop to the extent of intersecting the core of MIAD unless the zones of dredge tailings in the upstream foundation having an average $\left(N_{1}\right)_{60}=13.7$ were caused to develop residual excess pore pressures about equal to the total overburden stress in situ (that is, and $R_{2}=1.0$, or expressed as 100 percent). It then remained to determine the level of earthquake shaking necessary to induce 100 percent pore pressure response in the $\left(N_{1}\right)_{60}=13.7$ zones.

One-dimensional dynamic response analyses were performed for an idealized column through the upstream slope at the location of the thickest part of these materials (i.e., through the break point between 3:1 and 4.5:1 slopes) using the computer program SHAKE (Schnabel, Lysmer, and Seed 1972) to determine approximate relationships between rock outcrop acceleration and induced shear stresses. The use of SHAKE for this case is expected to yield fairly good, slightly conservative estimates of cyclic shear stresses in the foundation soils. These estimates are somewhat higher than cyclic shear stresses that would result using FLUSH. Stresses calculated using a one-dimensional analysis in the embankment are less accurate for the two-dimensional condition. Cyclic shear strength profiles were developed as a function of $\left(\mathrm{N}_{1}\right)_{60}$ and multiplied by factors to correct for the effects of initial static shear stress on horizontal planes, $K_{\alpha}$, initial effective confining stress, $K_{\sigma}$ (both of these stresses were obtained using FEADAM (Wahl et al. 1988)), and the number of significant cycles based on earthquake magnitude $K_{M}$ using the following relationship (after Seed and Idriss, 1982):

$$
\left(\tau_{\text {cyc }} / \sigma_{o}{ }^{\prime}\right)=\left(N_{1}\right)_{60} / 90 \times K_{M} \times K_{\alpha} \times K_{\sigma}
$$

Figure 5 shows profiles of cyclic strength developed for earthquakes of magnitude 5.25 to 6.5 for the SHAKE idealized column of materials, along with profiles of average cyclic shear stress induced by the design earthquake acceleration history scaled to various (rock outcrop) levels. A shear modulus proportionality constant $\left(K_{2}\right)_{\max }=$ 30 was assigned to foundation-gravels (dredge tailings) to generate the stress profiles. Cyclic shear stresses induced by the design earthquake (predicted using SHAKE) exceed the available cyclic shear strength throughout the foundation gravels in Figure 5 by about 20 percent. It is thus estimated from SHAKE stresses that an increase in cyclic shear strength of about 20 percent would be necessary to avert extensive liquefaction in the gravels with $\left(N_{1}\right)_{60}=13.7$. Figure 6 gives similar relationships for development of 40 percent residual excess pore pressure in the dredge tailings zone with $\left(N_{1}\right)_{60}=13.7$.

A relationship between peak horizontal acceleration, $a_{\max }$, and earthquake magnitude was derived to differentiate between potentially liquefiable and non-liquefiable (unsafe and safe, respectively) conditions for dredge tailings foun- 
dation gravels at MIAD. This relationship, which is specific to a value of $\left(N_{1}\right)_{60}=13.7$ for foundation dredge tailings gravels, is shown in Figure 7. Correspondence between earthquake magnitude and number of equivalent cycles as depicted in the figure is adapted form Seed and Idriss (1982). For the stresses and strength conditions examined in this study, it was determined that rock outcrop accelerations near MIAD of $0.25 \mathrm{~g}$ from a magnitude 6.5 event or $0.37 \mathrm{~g}$ from a magnitude 5.25 event would be required to initiate liquefaction of sufficient extent in the dredge tailings foundation gravels to develop critical failure surfaces passing through the core and potentially leading to loss of the reservoir.

\section{SEISMIC HAZARD ANALYSIS}

The objective of a seismic hazard analysis is to estimate the return period (inverse of hazard) associated with the exceedance of a particular ground motion, usually $a_{\max }$. The probability that a certain level of a site ground motion parameter is exceeded in a specified time interval may be calculated from the analysis results. In addition, for this study, the hazard was estimated for combinations of $\mathrm{a}_{\max }$ and magnitude causing liquefaction of foundation gravels at MIAD.

California and western Nevada comprise the most seismically-active region of the continental United States. In these areas, much emphasis has been placed on recording earthquake-induced ground motions, locating epicenters of earthquakes, deriving distinct source zones, and deriving characteristic parameters, such as those defining attenuation, for various source zones. These efforts greatly benefitted the study of seismic hazard assessment at MIAD.

Several capable faults exist in central California and are summarized in Table 1. The closest capable fault to the Folsom Project is the East Branch of Bear Mountains fault zone, which has been found to be capable of generating a maximum magnitude 6.5 earthquake. The minimum distance between this fault zone and MIAD is $13 \mathrm{~km}$.

\section{Earthquake Source Zones}

Algermissen et al. (1982) proposed the use of numerous seismic source zones in the U.S. to facilitate probabilistic assessment of maximum acceleration in rock. Seismic source zones are selected on the basis of several criteria, including the existence of capable faults, the rate of previ- ous seismic activity, and the controlling type of seismotectonic regime.

The number of seismic zones in California (including near off-shore zones), northern Baja California (Mexico), and western Nevada suggested by Algermissen et al. (1982) is about 60 . Initially, about 50 of these original source zones were considered for this study to determine which zones would significantly affect the seismic hazard assessment. On the basis of this sensitivity analysis, nine of Algermissen's source zones were found to significantly contribute to seismic risk at the site. Only these nine zones were used in the remainder of the study. These nine seismic zones are described below. The locations are shown in Figure 8 , and the recurrence parameters are summarized in Table 2.

A zone delineating the East Branch of the Bear Mountains fault zone (Zone 10), not considered by Algermissen et al. (1982), was included as an option for this study because of its close proximity to MIAD. The computer program RISK (McGuire, 1976) was used for this study and does not allow for true line sources so a thin area source (about $0.7 \mathrm{~km}$ wide) was used to represent this fault zone. The location of this fault zone with respect to source zones, in plan, is shown in Figure 8.

\section{Recurrence Parameters}

Recurrence parameters used for this study were obtained from a national study by Algermissen et al. (1982) and a site-specific study by Tierra Engineering Consultants, Inc. (1983). Algermissen et al. (1982) also presented contour maps of seismic risk for the U.S. based on computer analysis using general,-regional-source parameters. These contour maps were later updated to include the results of more sophisticated analysis and were published by the Federal Emergency Management Agency (Building Seismic Safety Council, 1988). The value of lower bound magnitude, $m_{0}$, is chosen to represent a magnitude cutoff point below which earthquakes are too small to be of engineering interest. A value of $m_{0}=5.0$ is generally recognized to be reasonable for engineering studies and was used for this study.

The annual rate of earthquake occurrence, also called the annual activity rate, is a function of earthquake magnitude and may be determined for each source zone from the historic data by dividing the number of earthquakes that exceed a given magnitude by the length of the observation 
period, $\mathrm{n}$, in years. A complete recurrence relation may be compiled by considering increments of magnitude for the full range of magnitudes possible for the source zone.

Historic reports of earthquakes in the U.S. date back to the fourteenth century (Chiburis, 1977). However, consistent reporting and recording did not occur until the late 1800's and instrument measurements did not begin until the early 1900 's, and then, were only sparsely located. In most cases of reported earthquake activity in central California prior to 1911, only intensities were recorded. Therefore, earthquake magnitudes, $M$, must be estimated from values of Modified Mercalli (epicentral) Intensity, MMI, for a majority of the records. The annual activity rates corresponding to a MMI $\mathrm{V}$ event for all seismic zones used in this study (except Zone 10) were derived from Algermissen et al. (1982). The rate of occurrence for Zone 10 (East Branch of the Bear Mountains fault zone) was reported by Tierra Engineering Consultants, Inc. (1983). The rates of occurrence for all seismic zones are listed in Table 2.

The rate of return corresponding to $m_{0}=5.0$ is a necessary input for RISK. This rate of return may be obtained by relating magnitude and intensity scales of earthquake motions and using published rates of return based on MMI. A correlation between MMI and magnitude, $M$, was determined for this study using seismic data (6809 sets of MMI and M) measured before 1 March 1985 from the western U.S. (west of $105^{\circ}$ W longitude), as contained in the Stanford University data base (Nielsen, 1982). The magnitude at the average plus one sample deviation for Intensity $V$ data is 4.1 .

Algermissen et al. (1982) used a similar relation suggested by Gutenberg and Richter (1942) to relate $\mathrm{M}$ and $\mathrm{MMI}$ :

$$
\mathrm{M}=0.6 \mathrm{MMI}+1.3
$$

A magnitude of 4.3 is obtained for an intensity of $V$ using equation 3 . The seismic risks calculated for this study are lower than those calculated by Algermissen et al. (1982) because a lower value of $m_{0}$ was used, if all other input were equal.

The recurrence rate for earthquake magnitude is assumed to be of the form (Gutenberg and Richter, 1954):

$$
\log [N(M)]=a-b M, \quad M \leq M_{\max }
$$

or

$$
\ln [N(M)]=\alpha-\beta M, \quad M \leq M_{\max }
$$

where

$$
\begin{aligned}
N(M)= & \text { average annual number of } \\
& \text { earthquakes with magnitudes } \\
& \text { greater than or equal to } M ; \\
a, b, \alpha= & \text { parameters determined from } \\
& \text { activity rates for respective } \\
& \text { source zones. }
\end{aligned}
$$
$a, b, \alpha=$ parameters determined from activity rates for respective source zones.

The parameters $\beta$ and $b$ are related by:

$$
\beta=b \ln 10
$$

The values of $\beta$ used in the seismic hazard assessment for this study, obtained from Algermissen et al. (1982) and Tierra Engineering Consultants, Inc. (1983), are listed in Table 2. The magnitude-recurrence relations for these 10 source zones are plotted in Figure 9.

\section{Attenuation Relations}

Relationships proposed by Joyner and Boore (1981) to calculate mean values of peak horizontal acceleration were used for this study. An upper bound value of acceleration of $0.60 \mathrm{~g}$ was applied to these relationships for mean acceleration as suggested by Bolt (1989) for seismic hazard studies. These relationships have been derived from measured data with magnitudes greater than 5.0 in western North America, predominantly in the state of California. The equation proposed to calculate the mean peak horizontal acceleration is:

$$
\begin{aligned}
& \log _{10} a_{\max }= \\
& -1.02+0.249 M-\log _{10} r-0.00255 r
\end{aligned}
$$

where

$$
\begin{aligned}
a_{\max }= & \begin{array}{l}
\text { peak horizontal acceleration } \\
\left(g^{\prime} s\right)
\end{array} \\
M= & \text { magnitude } \\
r= & \left(d^{2}+7.3^{2}\right)^{1 / 2} \quad 5.0 \leq M \leq 7.7 \\
d= & (\text { surface }) \text { distance from source } \\
& \text { to site. }
\end{aligned}
$$


The standard deviation of $\log _{10} a_{\max }$ reported by Joyner and Boore (1981) is 0.220 (0.507 for In $\left.a_{\max }\right)$.

Recent studies by seismologists indicate that thrust faults produce accelerations that are about 20 percent greater than accelerations produced by other types of faulting at a given distance (Bolt, 1989). Reviews of seismologic data for each of the source zones described in Table 2 indicate that thrust faults exist in Zones 2 and 3. In Zone 2, the thrust faults are considered to be inactive and, therefore, were not considered separately for purposes of this study. In Zone 3, however, active thrust faults exist. The modified attenuation relation used for Zone 3 to account for the influence of the type of faulting is:

$$
\begin{gathered}
\log _{10} a_{\max }= \\
-0.941+0.249 M-\log _{10} r-0.00255 r
\end{gathered}
$$

A standard deviation for $\log _{10} a_{\max }$ of 0.220 was assumed. The same cap of $\mathrm{a}_{\max }=0.60 \mathrm{~g}$ was applied to Equation 8. Mean values of $a_{\max }$ from thrust fault zones are not expected to exceed $0.60 \mathrm{~g}$ since the closest point of Zone 3 to MIAD is about $40 \mathrm{~km}$.

\section{Seismic Hazard Calculations and Results}

The computer program RISK was used to calculate the annual probabilities of exceedance given the aforementioned input parameters. The program RISK is based on the theory described by Cornell (1968). A Poisson distribution of events is assumed with the assigned recurrence parameters over each seismic source. The following assumptions are inherent with a Poisson model:

a. The earthquakes are spatially independent.

b. The earthquakes are temporally independent.

c. The probability that two seismic events will take place at the same location at the same time approaches zero.

The probabilities are computed using the combined contributions of sources and a numerical integration method.

The overall study included the calibration of the input data with the results of nation-wide seismic hazard calculations made by others and calculations that followed the profession-wide procedures to calculate the seismic hazard at any given site. The set of calculations presented herein were developed specifically for this study and are reported herein. These hybrid calculations were developed to incorporate information available on critical combinations of earthquake magnitude and peak horizontal acceleration that cause liquefaction for the dredged foundation gravels at MIAD. This latter set of calculations were thought to provide the best values for decision making.

Results of traditional seismic hazard calculations indicate that not all seismic zones used for this study contribute a significant amount to the seismic hazard at MIAD. Rather, only three seismic source zones were determined to make a contribution of 5 percent or greater to the total risk for $a_{\max }=0.25 \mathrm{~g}$ and two seismic source zones contribute 5 percent or greater for $\mathrm{a}_{\max }=$ $0.37 \mathrm{~g}$. These sources zones are: 7,9 , and 10 for $a_{\max }=0.25 \mathrm{~g}$ and 9 and 10 for $a_{\max }=0.37 \mathrm{~g}$. The magnitude and percentage of contributions for each zone are listed in Table 3. Zones 9 and 10 produce 87 and 94 percent, respectively, of the risk at these two levels of acceleration. The East Branch of the Bear Mountains fault zone is the largest contributor to the total seismic risk. The results presented in Table 3 suggest that some of the source zones used for analysis did not contribute any hazard for these two levels of acceleration, including Zone 3 which utilized modified attenuation relationships specific to thrust faulting.

The contributions of different magnitude events were also examined for purposes of this study. The contributions of magnitude intervals of 0.5 were calculated for peak horizontal acceleration of 0.25 and $0.37 \mathrm{~g}$ and are presented in Table 4. Eighty-seven and 94 percent of the contributions for 0.245 and $0.37 \mathrm{~g}$, respectively, come from magnitudes between 5.0 and 6.5. Notice that these numbers correspond to the contributions of Zones 9 and 10 (which have $M_{\max }$ of 6.1 and 6.5, respectively). Therefore, Zones 9 and 10 essentially make the significant contributions to seismic risk between magnitudes of 5.0 and 6.5; the remaining zones make contributions at greater magnitudes. There is relatively little to no contribution for the magnitude range of 6.5 to 7.0 or from Zone 3.

The probability of exceeding a given acceleration alone does not signify a specific risk to liquefaction of the dredged foundation gravels. The results of the seismic hazard and post-earth- 
quake slope stability analyses were combined to estimate the risks for various conditions that will cause initiation of liquefaction of dredged foundation gravels and consequent failure of MIAD. The results presented in Figures 7 and 10 were combined and are presented in Figure 11 and tabulated in Table 5. The annual (total) risk associated with critical combinations of acceleration and magnitude leading to liquefaction of the dredged foundation gravels is approximately 0.0009 (an annual return period of about 1100 years) for magnitudes that could have an impact on the site (greater than 5.0).

The greatest contributions to the seismic hazard causing liquefaction at MIAD come from critical combinations of peak horizontal acceleration for earthquake magnitude intervals greater than 7.0 (corresponding peak accelerations less than $0.21 \mathrm{~g}$ ). The sum of the probabilities of occurrence for magnitudes greater than 7.0 is 6.5 $\times 10^{-4}$. The sum for magnitudes less or equal to 6.5 is $2.5 \times 10^{-4}$. The seismic hazard for the magnitude interval 7.0 to 7.5 comes from Zones 1 (San Andreas Fault zone), 4 (Hayward and Calaveras Faults zone), and 7 (Genoa-Jack Valley and West Walker River Faults zone). The seismic hazard for the magnitude interval from 7.5 to 8.0 comes from Zones 1 and 4 . The seismic hazard for the magnitude interval from 8.0 to 8.5 comes from Zone 1. This finding differs from the conclusion drawn from the traditional seismic hazard analysis.

The Poisson distribution may be used to calculate the probability of exceedance, $P_{e}$, by:

$$
P_{e}=1-e^{-t / T}
$$

where:

$$
\begin{aligned}
& t=\text { time period of interest } \\
& T=\text { return period }(y r s)
\end{aligned}
$$

Using Equation 9 and considering a return period of 1100 years, the annual probability of liquefaction occurring is 0.09 percent.

\section{SUMMARY AND CONCLUSIONS}

Analyses of slope stability for post-earthquake conditions and seismic hazard have been conducted to assist in making decisions regarding remedial measures necessary over portions of MIAD. For the post-earthquake slope stability analysis, accelerations from both the design earthquake and lower magnitude events were used. The seismic hazard analysis used various combinations of $a_{\max }$ and earthquake magnitude to assess the seismic hazard. Results of the two analyses were combined to estimate the likelihood of liquefaction of the dredged foundation gravels and consequent failure of MIAD.

Acceleration levels required to cause liquefaction only in free-field gravels with $\left(N_{1}\right)_{60}=7.1$ were estimated using the Seed-Idriss simplified procedure (Seed and Idriss, 1982, and elsewhere) to range from 0.08 to $0.10 \mathrm{~g}$ for magnitudes ranging from 6.5 to 5.25 , respectively. Onedimensional dynamic response analyses were conducted to determine approximate levels of acceleration required to produce the critical conditions. A range of induced average shear stresses and strength conditions were examined to determine critical combinations of peak acceleration and magnitude. For example, these studies indicated that rock outcrop accelerations near MIAD of $0.25 \mathrm{~g}$ produced by a magnitude 6.5 event ( 8 cycles) or $0.37 \mathrm{~g}$ produced by a magnitude 5.25 event ( 2.5 cycles) would be required to initiate liquefaction of sufficient extent in the dredge tailings foundation gravels to develop critical failure surfaces passing through the core and potentially leading to loss of the reservoir.

The input data used for seismic hazard calculations are primarily from Algermissen et al. (1982) and Joyner and Boore (1981). The computer program RISK by McGuire (1976) was also used. Best estimates of seismic hazard at MIAD from earthquakes with magnitude greater than 5.0 are shown in Figure 10. The annual return periods for the best-estimate relation, including the contribution of all magnitudes, at peak horizontal accelerations of 0.25 and $0.37 \mathrm{~g}$ are 1,500 and 10,500 years, respectively. It was determined, in general, that over three-fourths of the total seismic risk is generated from the Sierran block and the East Branch of the Bear Mountains fault zone and that these same percentages of contribution apply to magnitudes between 5.0 and 6.5 .

The overall risk of experiencing a critical acceleration and magnitude level causing liquefaction of dredged foundation gravels at the site was estimated to be 0.0009 or an annual return period of about 1,100 years. It was determined that the seismic hazard for critical combinations of peak horizontal acceleration and earthquake magnitude originates from three source zones: San Andreas Fault zone, Hayward/Calaveras Fault zone, and Genoa-Jack Valley/West Walker River Fault zone. 
The return periods calculated for this study are considered to be lower bound values. Many conservative estimates were made in the course of this seismic hazard assessment due to the uncertainties associated with many of the input parameters. More sophisticated analyses would require greater effort and time. However, it was known at the initiation of this study that the results would be applicable for only a short duration due to the construction of remedial measures. (The first phase of remedial construction was complete in November 1990, nine months following completion of the seismic hazard study.)

\section{ACKNOWLEDGEMENTS}

The data presented and analyses described, unless otherwise noted, were obtained from research conducted for the US Army Engineer District, Sacramento (SPK), by the US Army Engineer Waterways Experiment Station and reported by Sykora et al. (1990). Permission was granted by the Chief of Engineers to publish this information.

The overall Project Manager was Mr. John Nickell, of the US Army Engineer District, Sacramento. Messrs. Frank K. Chang, Ronald E. Wahl, and Daniel Habeeb, and Dr. Ellis Krinitzsky, WES, provided assistance throughout the study.

\section{REFERENCES}

Algermissen, S. T., Perkins, D. M., Thenhaus, P. C., Hanson, S. L., and Bender, B. L., 1982. "Probabilistic Estimates of Maximum Acceleration and Velocity in Rock in the Contiguous United States," Open File Report 82-1033, US Department of the Interior, Geological Survey, Denver, co.

Bolt, B. A. 1989. "Draft Seismological Report on Seismic Hazard Assessment for Mormon Island Study," Report to US Army Engineer District, Sacramento, Dec. 15.

Building Seismic Safety Council 1988. "Recommended Provisions for the Development of Seismic Regulations for New Buildings," FEMA Reports 95, 96, and 97, (3 Vols.), Federal Emergency Management Agency, National Earthquake Hazards Reduction Program, Washington, D.C.

Chiburis, F. 1978. "Earthquakes of the Northeastern U.S. - 1534 through 1977," Preliminary unpublished report, (cited in Nielsen, 1982).
Cornell, C. A. 1968. "Engineering Seismic Risk Analysis," Bulletin of the Seismological Society of America, Vol 58, No. 5, pp 1503-1606.

Edris, E. V., Jr. and Wright, S. G. 1987. "User's Guide: UTEXAS2 Slope Stability Package, "Technical Report GL-87-1, Vol. 1, US Army Engineer Waterways Experiment Station, Vicksburg, MS.

Gutenberg, B., and Richter, C. F. 1942. "Earthquake Magnitude, Intensity, Energy and Acceleration," Bulletin of the Seismological Society of America, Vol 32, pp 163-191.

Gutenberg, B., and Richter, C. F. 1954. Seismicity of the Earth, 2nd ed., Princeton University Press, Princeton, NJ.

Hynes-Griffin, M. E. 1987. "Seismic Stability Evaluation of Folsom Dam and Reservoir Project, Report 1: Summary Report," Technical Report GL-87-14, US Army Engineer Waterways Experiment Station, Vicksburg, MS.

Hynes-Griffin, M. E., Wahl, R. E., Donaghe, R. T., and Tsuchida, T. 1988. "Seismic Stability Evaluation of Folsom Dam and Reservoir Project, Report 4: Mormon Island Auxiliary Dam - Phase I," Technical Report GL-87-14, US Army Engineer Waterways Experiment Station, Vicksburg, MS.

Joyner, W. B. and Boore, D. M. 1981. "Peak Horizontal Acceleration and Velocity from StrongMotion Records Including Records from the 1979 Imperial Valley, California, Earthquake," Bulletin of the Seismological Society of America, Vol 71, No. 6, pp 2011-2038.

Lysmer, J., Udaka, T., Tsai, C. F., and Seed, H. B. 1973. "FLUSH: A Computer Program for Approximate 3-D Analysis of Soil-Structure Interaction Problems," Report No. EERC 75-30, Earthquake Engineering Research Center, University of California, Berkeley, CA.

McGuire, R. K. 1976. "FORTRAN Computer Program for Seismic Risk Analysis," Open File Report 76-67, US Department of the Interior, Geological Survey, Denver, CO.

Nielsen, R. J. 1982. "Stanford Data Base for Earthquakes in the United States," Report 58, Blume Earthquake Engineering Center, Stanford University, Palo Alto, CA. 
Schnabel, P. B., Lysmer, J., and Seed, H. B. 1972. "SHAKE, A Computer Program for Earthquake Response Analysis of Horizontally Layered Sites," Report EERC 72-12, Earthquake Engineering Research Center, University of California, Berkeley, CA.

Seed, H. B., and Idriss, I. M. 1982. Ground Motions and Soil Liquefaction During Earthquakes, Volume 5 of a series titled: Engineering Monographs on Earthquake Criteria, Structural Design, and Strong Motion Records, Earthquake Engineering Research Institute, Berkeley, California.

Spencer, E. 1967. "A Method of Analysis of the Stability of Embankments Assuming Parallel InterSlice Forces," Geotechnique Vol 17, No. 1, pp 11-26.

Sykora, D., Koester, J., Hynes, M., Fea, T., Gewerth, J., Jorgensen, K., McCune, R., and Treat, R. 1990. "Estimation of Seismic Hazard and Slope Stability Assessment of Mormon Island Auxiliary Dam of Folsom Dam and Reservoir Project" U.S. Army Engineer Waterways Experiment Station, Draft report to U.S. Army Engineer, Sacramento District, Vicksburg, MS, February 1990.

Tierra Engineering Consultants, Inc. 1983. "Geologic and Seismologic Investigations of the Folsom, California Area," Report to US Army Engineer District, Sacramento, Sacramento, CA.

US Army Engineer District, Sacramento 1953. "Foundation Report, American River, California, Mormon Island Auxiliary Dam, Folsom Project." Sacramento, CA.

1955. "Foundation Report, American River, California, Part A: General," Sacramento, CA.

US Department of Interior, Bureau of Reclamation 1977a. "Earthquake Evaluation Studies of the Auburn Dam Area," prepared by Woodward-Clyde Consultants, 8 Vols.

1977b. "Seismic Evaluation of Auburn Damsite: Supplement to Project Geology Report," Vol $20 \mathrm{~F} 6$.

1978. "New Melones Dam Project, California: Geologic and Seismologic Investigations."
Vasquez-Herrera, A. and Dobry, R. 1989. "Reevaluation of the Lower San Fernando Dam, Report 3: The Behavior of Undrained Contractive Sand and Its Effect on Seismic Llquefaction Flow Failures of Earth Structures," Contract Report GL89-2, US Army Engineer Waterways Experiment Station, Vicksburg, MS.

Wahl, R. E., Crawforth, S. G., Hynes, M. E., Comes, G. D., and Yule, D. E. 1988. "Seismic Stability Evaluation of Folsom Dam and Reservoir Project, Report 8: Mormon Island Auxiliary Dam Phase 11," Technical Report GL-87-14, US Army Engineer Waterways Experiment Station, Vicksburg, MS. 
Table 1

Estimated Seismic Characteristics of Capable Faults ${ }^{1}$

(modified from Tierra Engineering Consultants, Inc. , 1983)

\begin{tabular}{|c|c|c|c|c|c|}
\hline $\begin{array}{c}\text { Name of } \\
\text { Fault Zone }\end{array}$ & $\begin{array}{c}\text { Minimum } \\
\text { Distance } \\
\text { To Site }(\mathrm{km}) \\
\end{array}$ & $\begin{array}{l}\text { Type of } \\
\text { Faulting } \\
\end{array}$ & $\begin{array}{l}\text { Maximum } \\
\text { Earthquake } \\
\text { Magnitude }{ }^{2} \\
\end{array}$ & $\begin{array}{c}\text { Approximate } \\
\text { Slip Rate } \\
(\mathrm{cm} / \mathrm{yr})^{3} \\
\end{array}$ & $\begin{array}{l}\text { Most Recent } \\
\text { Displacement } \\
\text { Known } \\
\end{array}$ \\
\hline San Andreas & 170 & strike-slip & 8.5 & $1-2$ & Historic \\
\hline Hayward & 140 & strike-slip & 7.9 & 0.5 & Historic \\
\hline Calaveras & 130 & Strike-slip & 7 & 0.25 & Historic \\
\hline $\begin{array}{l}\text { Genoa Jack } \\
\text { Valley }\end{array}$ & $117+$ & Normal-slip & 7.25 & $0.01 \cdot 0.02$ & Holocene \\
\hline $\begin{array}{l}\text { West Walker } \\
\text { River }\end{array}$ & 142 & Normal-slip & 7.25 & 0.01 & Historic \\
\hline Melones & 27.5 & Normal-slip & 6.5 & $\begin{array}{l}0.0006- \\
0.0001\end{array}$ & $\begin{array}{c}\text { Pleistocene } \\
\pm 100,000\end{array}$ \\
\hline $\begin{array}{l}\text { East Branch } \\
\text { Bear Mtns. }\end{array}$ & 13 & Normal-slip & 6.5 & $\begin{array}{l}0.0006- \\
0.0001\end{array}$ & $\begin{array}{l}\text { Pleistocene } \\
\pm 100,000\end{array}$ \\
\hline
\end{tabular}

1 A capable fault was defined as one that exhibited displacement at or near the ground surface within the past 35,000 years, recurrent movement within the past 500,000 years, exhibits creep movement, and/or exhibits al igned macro-seismicity $(M \leq 3.5)$ determined from instruments.

2 Estimated by Tierra Engineering Consultants, Inc. (1983) based on various studies including: US Department of the Interior, Bureau of Reclamation (1977a, 1977b, and 1978), and others. Modified slightly using data from Algermissen et al. (1982).

3 Slip rates estimated from historic, geomorphic, or geologic evidence.

4 Late Pleistocene displacement may be as old as 500,000 years ago or as young as 10,000 years ago.

Table 2

Description of Seismic Source Zones Used for this Study

\begin{tabular}{|c|c|}
\hline \multicolumn{2}{|c|}{ Source Code } \\
\hline This & Algermissen \\
\hline Study & et al. (1982) \\
\hline 1 & $\mathrm{C} 24$ \\
\hline 2 & C39 \\
\hline 3 & 025 \\
\hline 4 & c38 \\
\hline 5 & 024 \\
\hline 6 & 030 \\
\hline 7 & 029 \\
\hline 8 & 027 \\
\hline 9 & 026 \\
\hline 10 & - \\
\hline
\end{tabular}

Nan Andreas Fault zone
Northern Coast Ranges
Western Great Valley
Hayward \& Calaveras Faul ts
Elk \& Kett leman Hills
Northern Sierra Nevada
Genoa-Jack Valley and
West Walker River Faults
Southern Sierra Nevada
Sierran block
East Branch, Bear Mtns.
fault zone

Recurrence Parameters Algermissen et al. (1982)

Rate

$\frac{\text { at MMI V }}{1.97} \frac{\beta}{0.99} \quad \underline{M}_{\max }$

$\begin{array}{lll}0.358 & 1.0 & -7.9^{-}\end{array}$

$\begin{array}{lll}0.168 & 1.5 & 6.1\end{array}$

$\begin{array}{lll}0.827 & 1.2 & 7.9\end{array}$

$\begin{array}{lll}0.247 & 1.5 & 6.1\end{array}$

$\begin{array}{lll}0.588 & 1.5 & 7.3\end{array}$

$\begin{array}{lll}1.32 & 1.5 & 7.3\end{array}$

$\begin{array}{lll}0.111 & 1.5 & 5.5\end{array}$

$\begin{array}{lll}0.477 & 1.5 & 6.1\end{array}$

$\begin{array}{lll}0.851 * * & 1.96 & 6.5\end{array}$

* Adjusted from 8.5 as per Bolt (1989).

* Rates reported in terms of magnitude. 
Table 3

Contributions of Seismic Zones to Seismic Hazard at Mormon Island Auxiliary Dam

\begin{tabular}{|c|c|c|c|c|}
\hline \multirow[b]{2}{*}{ Source } & \multicolumn{2}{|c|}{$0.25 \mathrm{~g}$} & \multicolumn{2}{|c|}{$0.37 \mathrm{~g}$} \\
\hline & $\begin{array}{l}\text { Annual Rate } \\
\text { (events/yr) }\end{array}$ & $\begin{array}{l}\text { Contribution } \\
\text { to Total Hazard } \\
\text { (percent) } \\
\end{array}$ & $\begin{array}{l}\text { Annual Rate } \\
\text { (events (yr) }\end{array}$ & $\begin{array}{l}\text { Contribution } \\
\text { to Total Hazard } \\
\text { (percent) }\end{array}$ \\
\hline 1 & $1.12 \times 10.5^{-5}$ & 2 & $5.45 \times 10^{-7}$ & 1 \\
\hline 2 & $5.78 \times 10^{-6}$ & 1 & $3.14 \times 10^{-7}$ & $\cdots$ \\
\hline 3 & $1.02 \times 10^{-6}$ & -- & $4.64 \times 10^{-8}$ & $\cdots$ \\
\hline 4 & $2.15 \times 10^{-5}$ & 3 & $1.33 \times 10^{-6}$ & 1 \\
\hline 5 & $4.0 \times 10^{-12}$ & -- & -- & - \\
\hline 6 & $2.84 \times 10^{-6}$ & -- & $1.53 \times 10^{-7}$ & -. \\
\hline 7 & $4.50 \times 10^{-6}$ & 7 & $3.62 \times 10^{-6}$ & 4 \\
\hline 8 & $6.89 \times 10^{-7}$ & - & $2.76 \times 10^{-8}$ & $\cdots$ \\
\hline 9 & $2.77 \times 10^{-4}$ & 42 & $4.77 \times 10^{-5}$ & 50 \\
\hline 10 & $2.91 \times 10^{-4}$ & 45 & $4.14 \times 10^{-5}$ & 44 \\
\hline & & 100 & & 100 \\
\hline
\end{tabular}

Table 4

Distribution of Seismic Hazard Among Earthquake Magnitudes

Range in

Magni tude

$5.0-5.5$

$5.5-6.0$

$6.0-6.5$

$6.5-7.0$

$7.0-7.5$

$7.5-8.0$

$8.0-8.25$

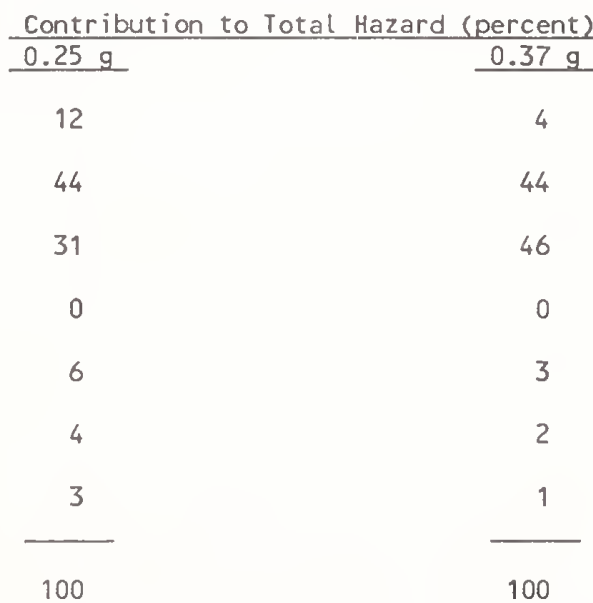


Table 5

Risks Calculated for Various Combinations of Magnitude and Peak Acceleration Causing Liquefaction of Dredged Foundation Gravels, $N_{1} 2_{60}$

\begin{tabular}{|c|c|c|c|c|c|}
\hline $\begin{array}{l}\text { Magni tude } \\
\text { Range } \\
\end{array}$ & $\begin{array}{c}\text { Mean } \\
\text { Magnitude }\end{array}$ & $\begin{array}{c}\text { Number of } \\
\text { Equiv. Cycles }\end{array}$ & $a_{\max }$ & Hazard & $\begin{array}{c}\text { Return } \\
\text { Period(yrs) }\end{array}$ \\
\hline $5.0-5.5$ & 5.25 & 2.5 & 0.37 & 0.000003 & 333,000 \\
\hline $5.5-6.0$ & 5.75 & 4.5 & 0.31 & 0.000094 & 10,600 \\
\hline $6.0-6.5$ & 6.25 & 6.75 & 0.26 & 0.00015 & 6,670 \\
\hline $6.5-7.0$ & 6.75 & 10.0 & 0.22 & - & - \\
\hline $7.0-7.5$ & 7.25 & 13.5 & 0.20 & 0.00012 & 8,300 \\
\hline $7.5-8.0$ & 7.75 & 17.5 & 0.17 & 0.00021 & 4,760 \\
\hline \multirow[t]{2}{*}{8.0} & 8.25 & 23 & 0.16 & 0.00031 & 3,020 \\
\hline & & & Combined: & 0.0009 & 1,100 \\
\hline
\end{tabular}




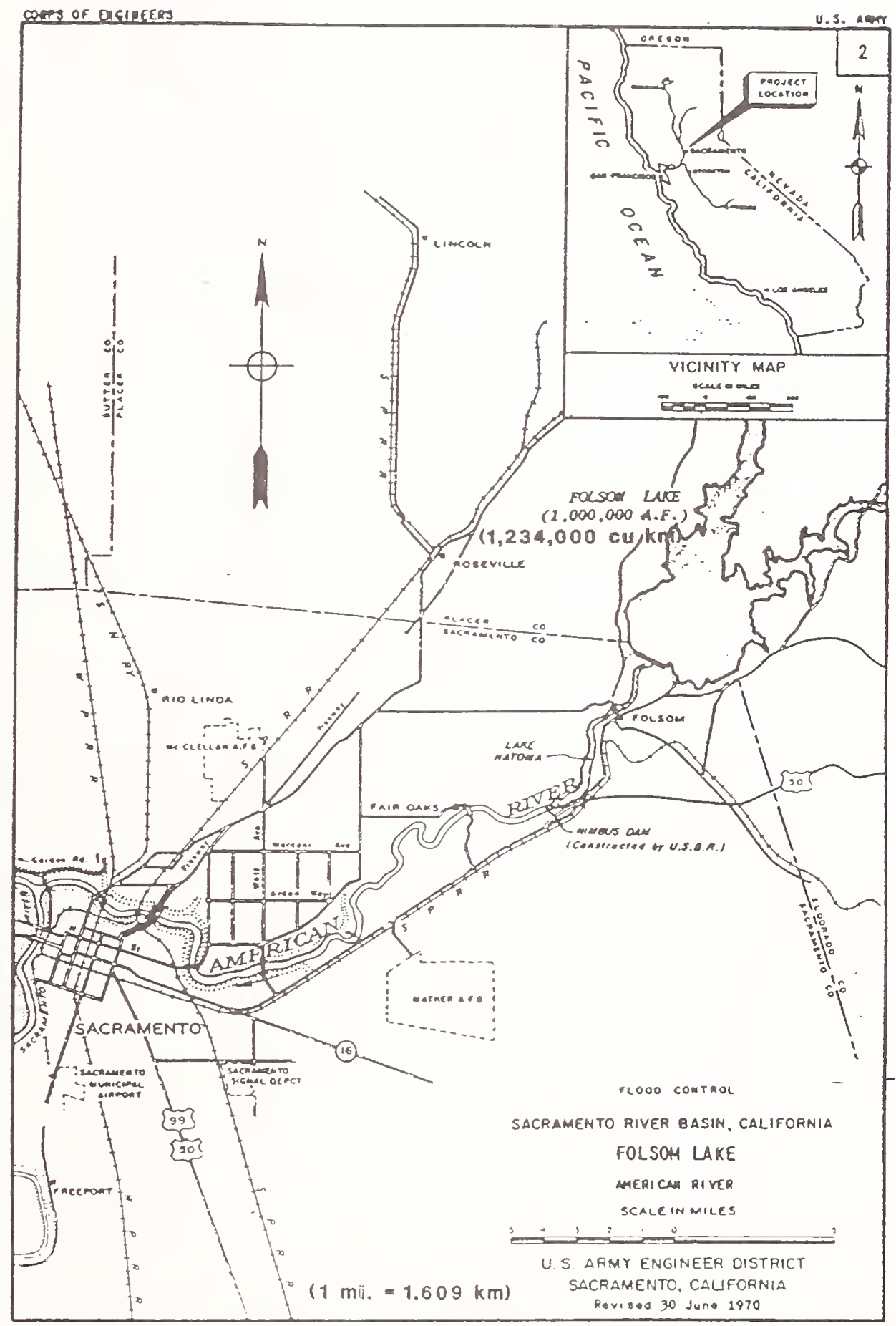

Figure 1. Location of Folsom Dam and Reservoir Project 


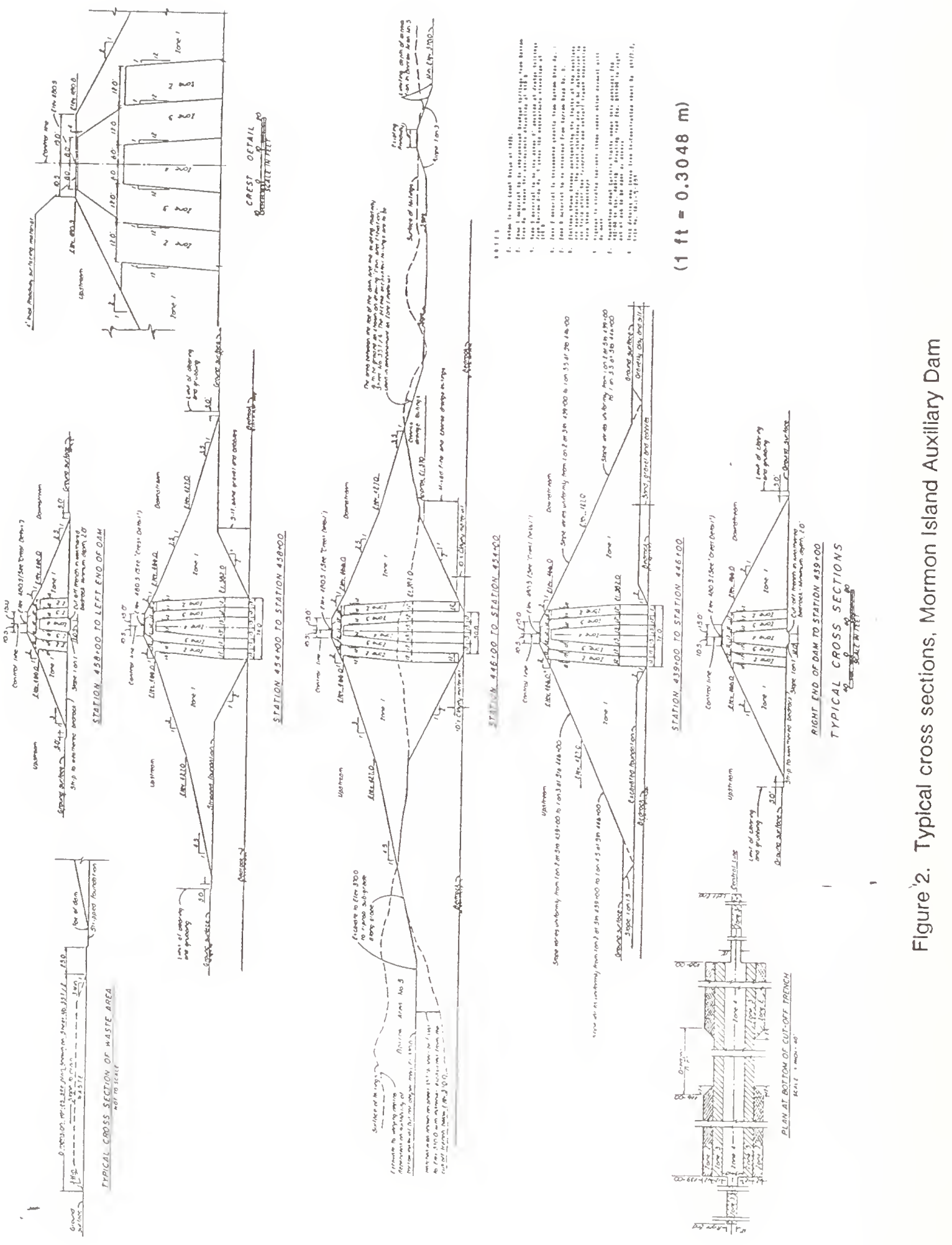




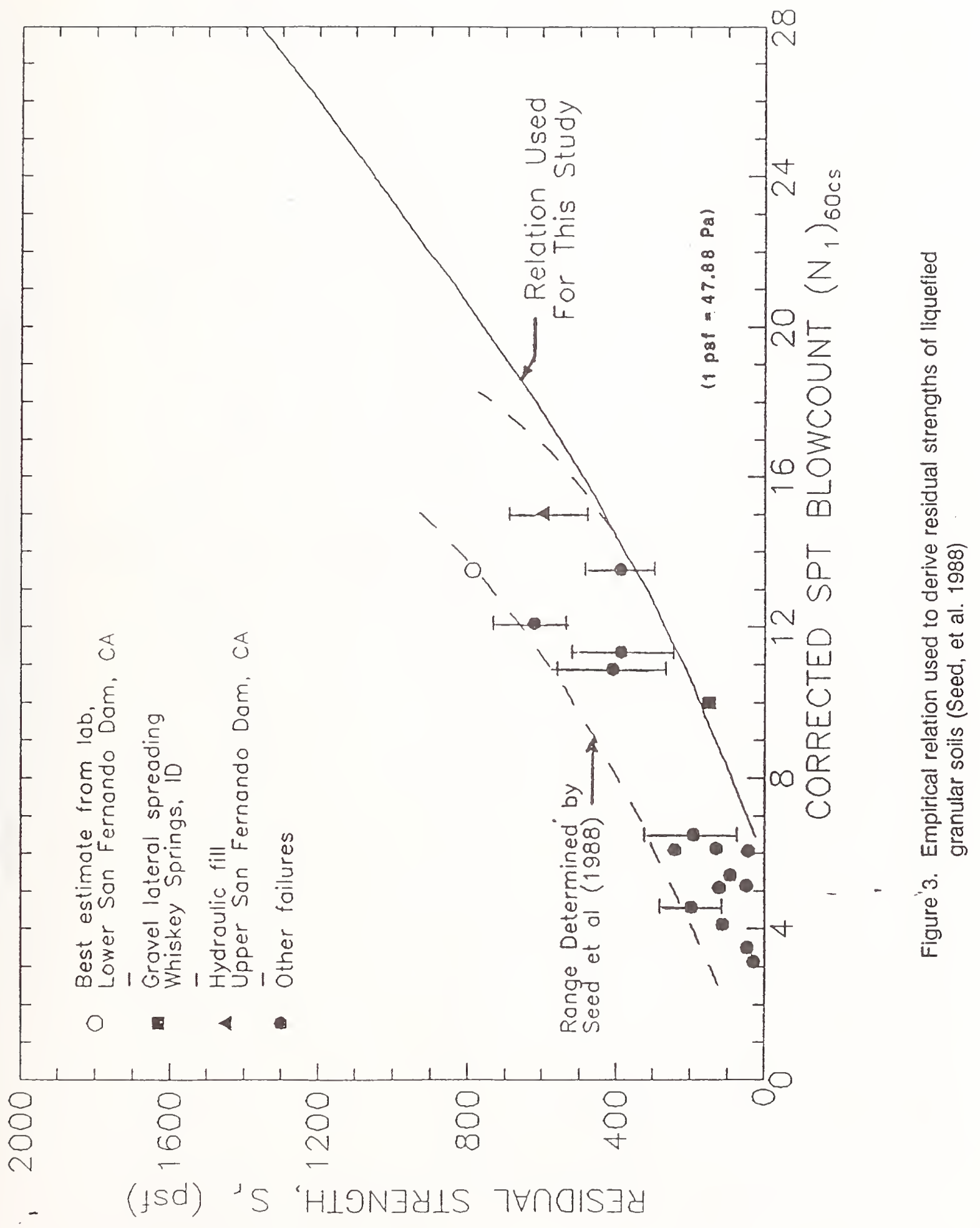



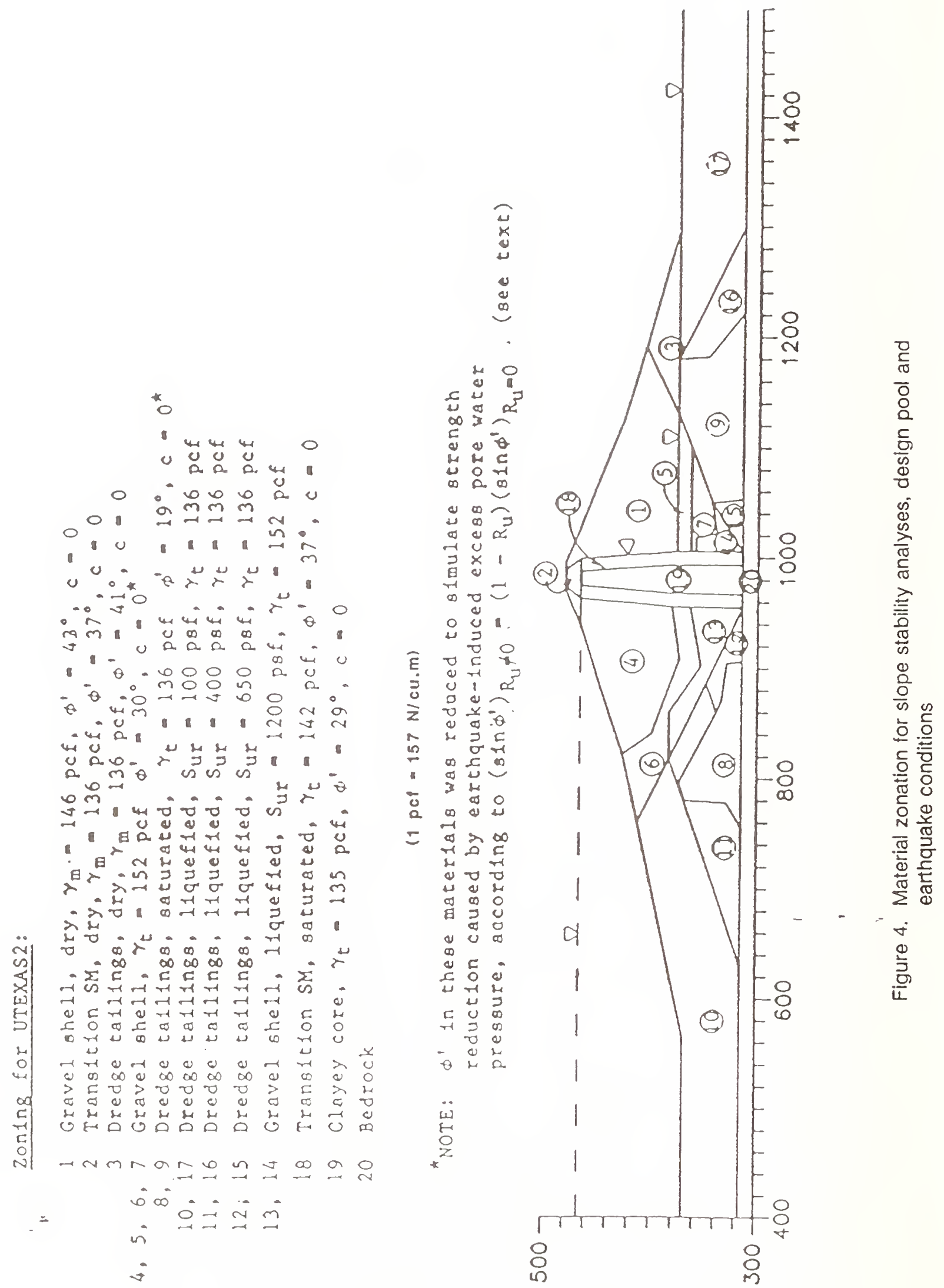


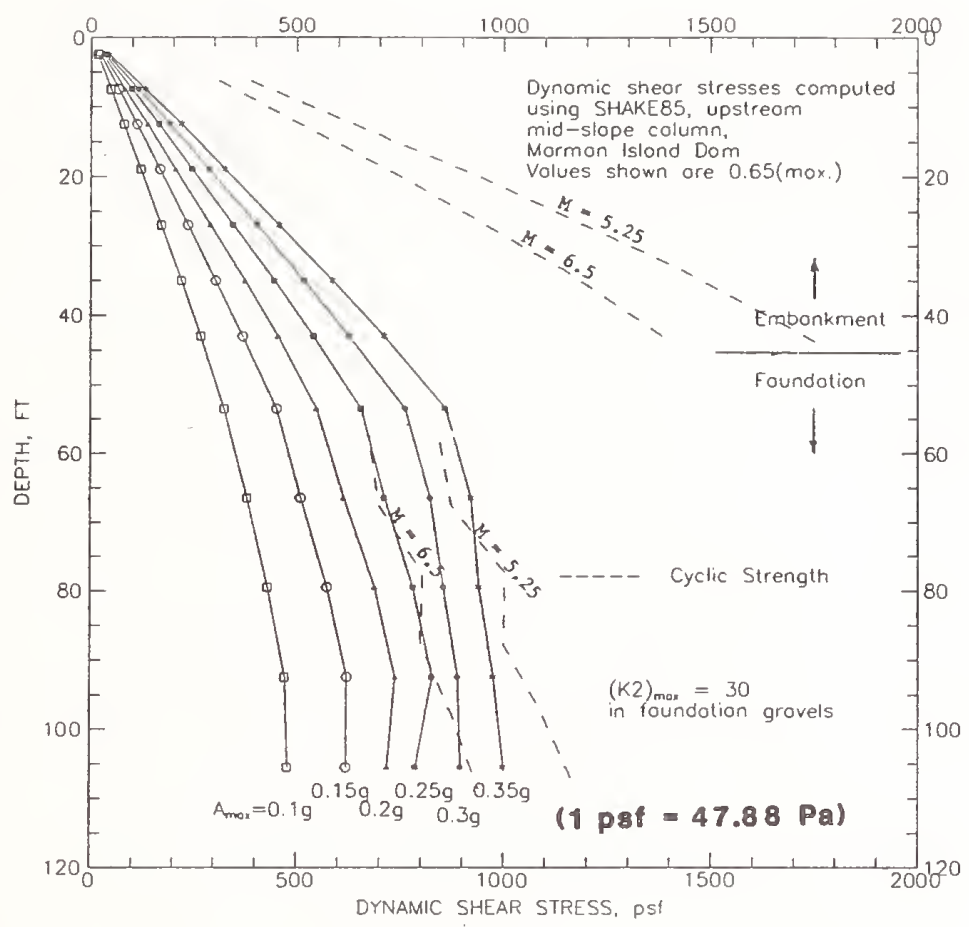

Figure 5. Profiles of average shear stress for upstream, mid-slope column with $\left(K_{2}\right)_{\max }=30$ in foundation gravels, showing cyclic strength profiles for earthquakes ranging in magnitude from 5.25 to 6.5

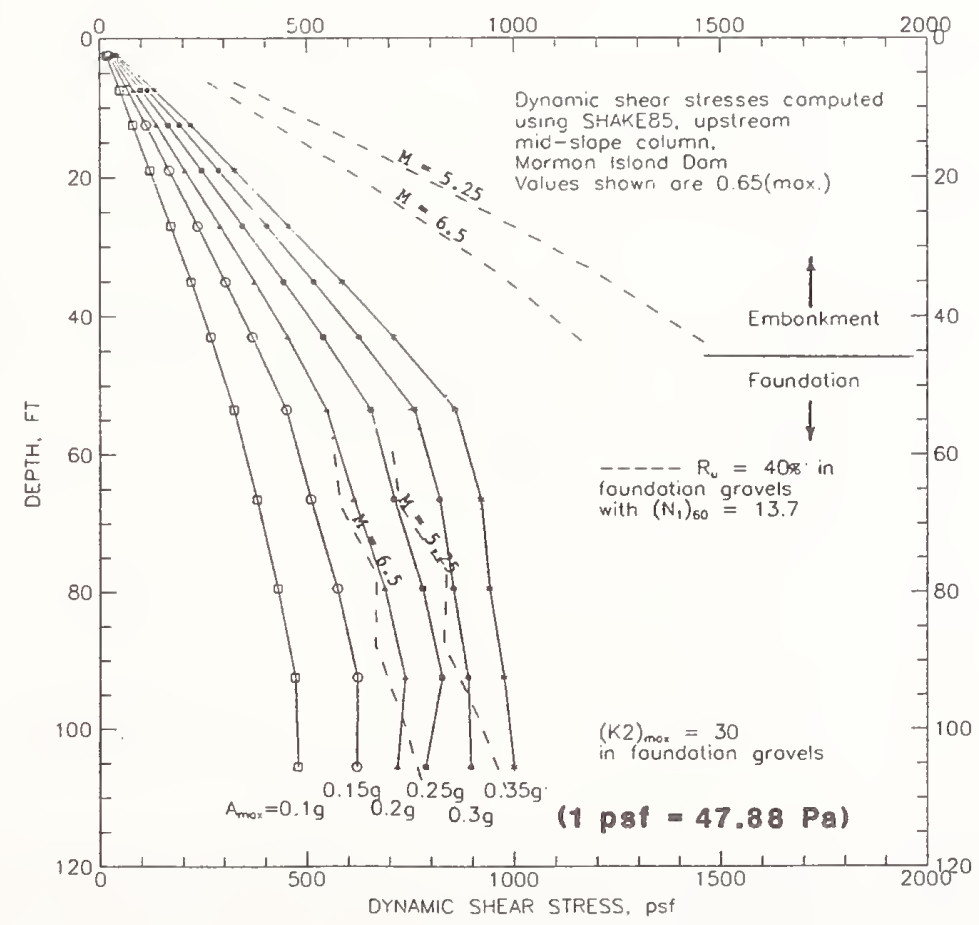

Figure 6. Profiles of average shear stress for upstream, mid-slope column with $\left(K_{2}\right)_{\max }=30$ in foundation gravels, showing cyclic stress profiles required to produce $R_{u}=40$ percent with $\left(N_{1}\right)_{60}=13.7$ for earthquakes ranging in magnitude from 5.25 to 6.5 


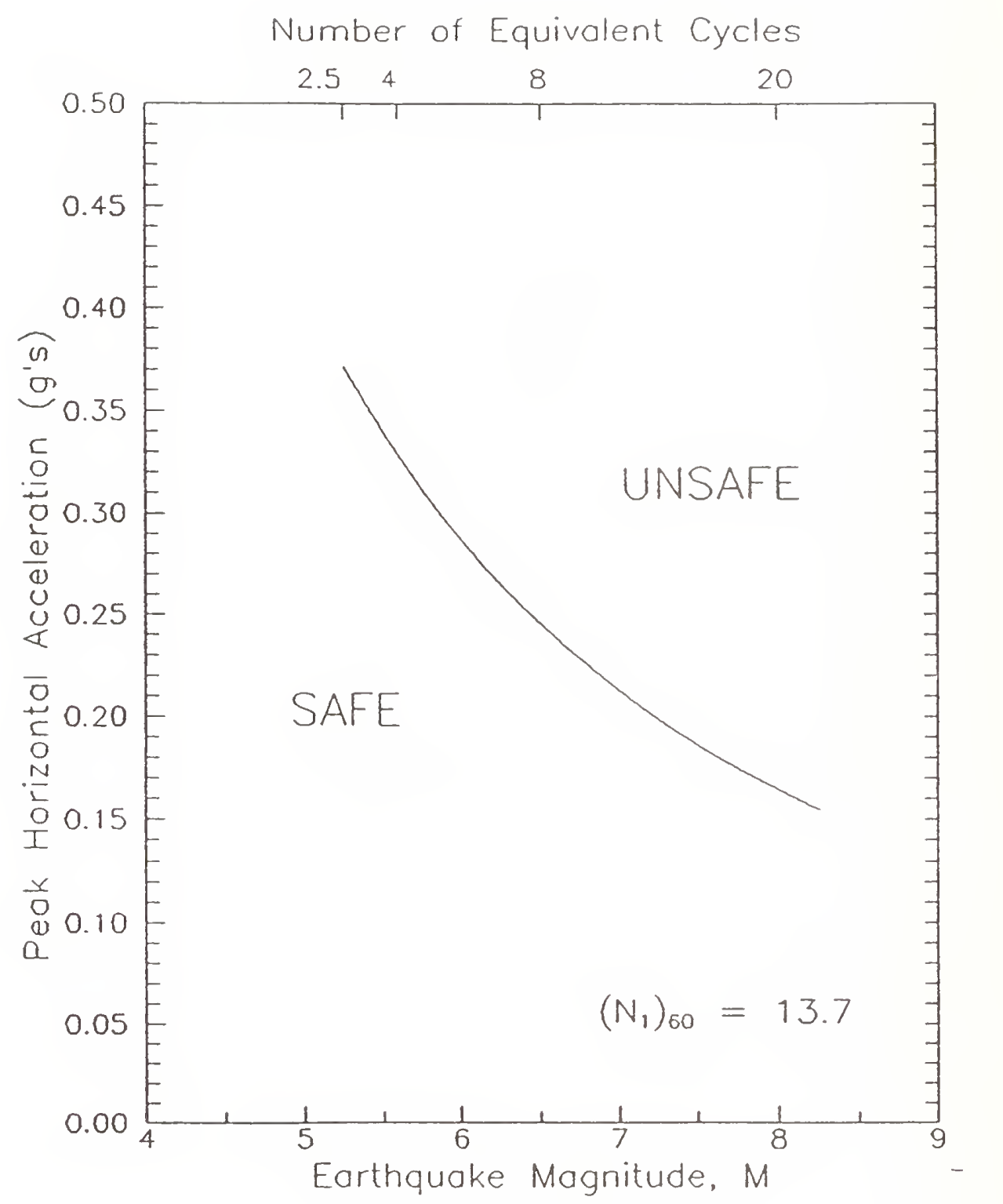

Figure 7. Estimated combinations of $\mathrm{a}_{\max }$ and earthquake magnitude causing liquefaction of dredged foundation gravels for $\left(N_{1}\right)_{60}=13.7$ 


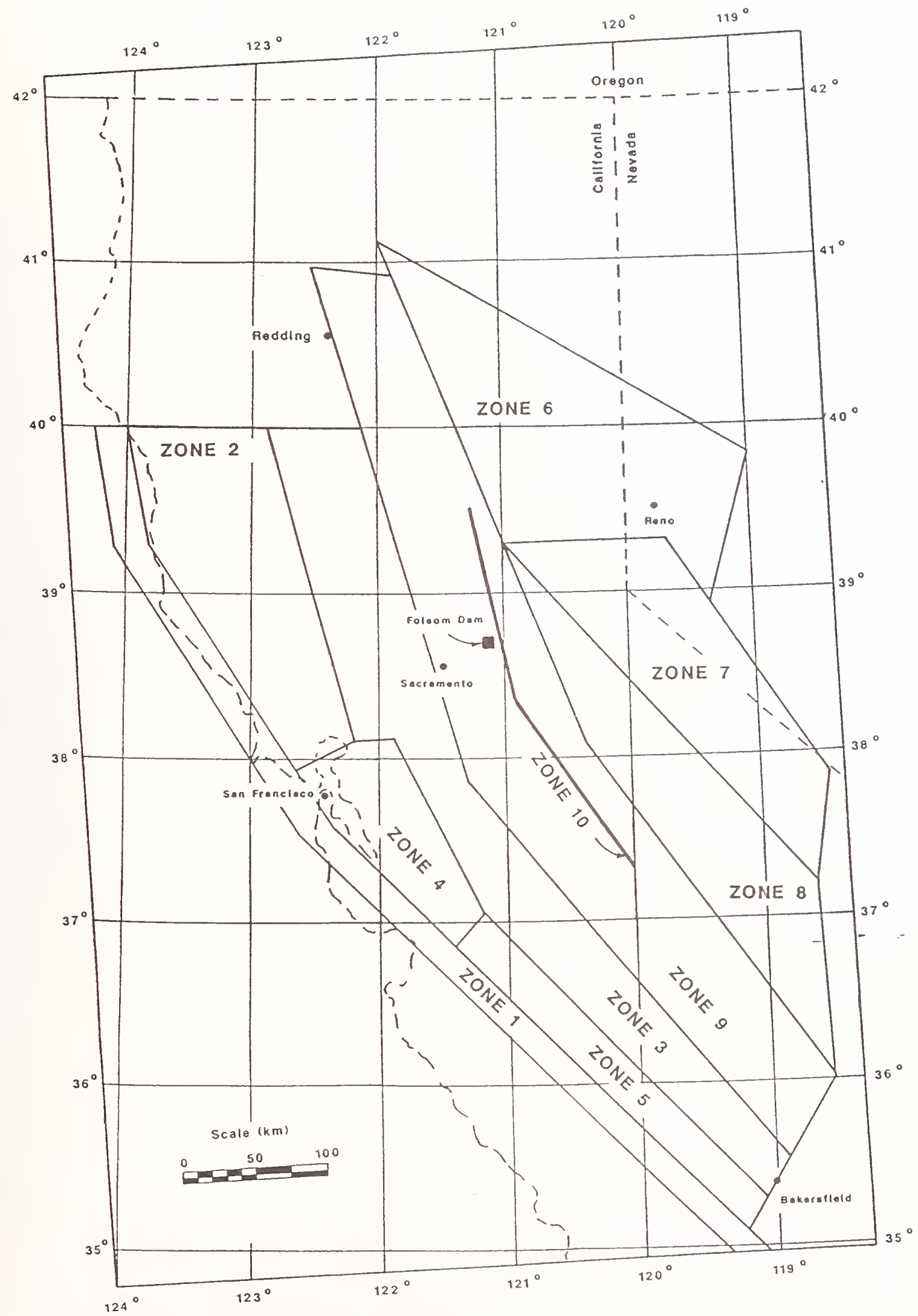

Figure 8. Location of seismic zones used for this study 


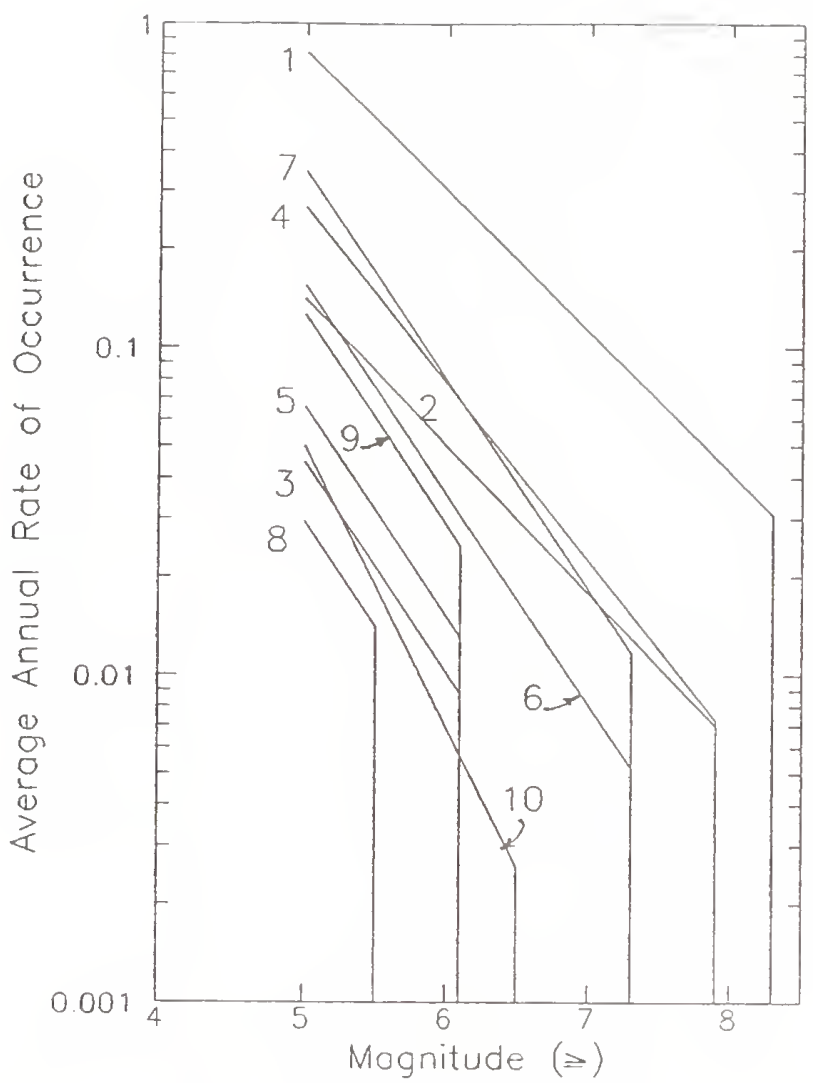

Figure 9. Recurrence relations for seismic source zones used in this study

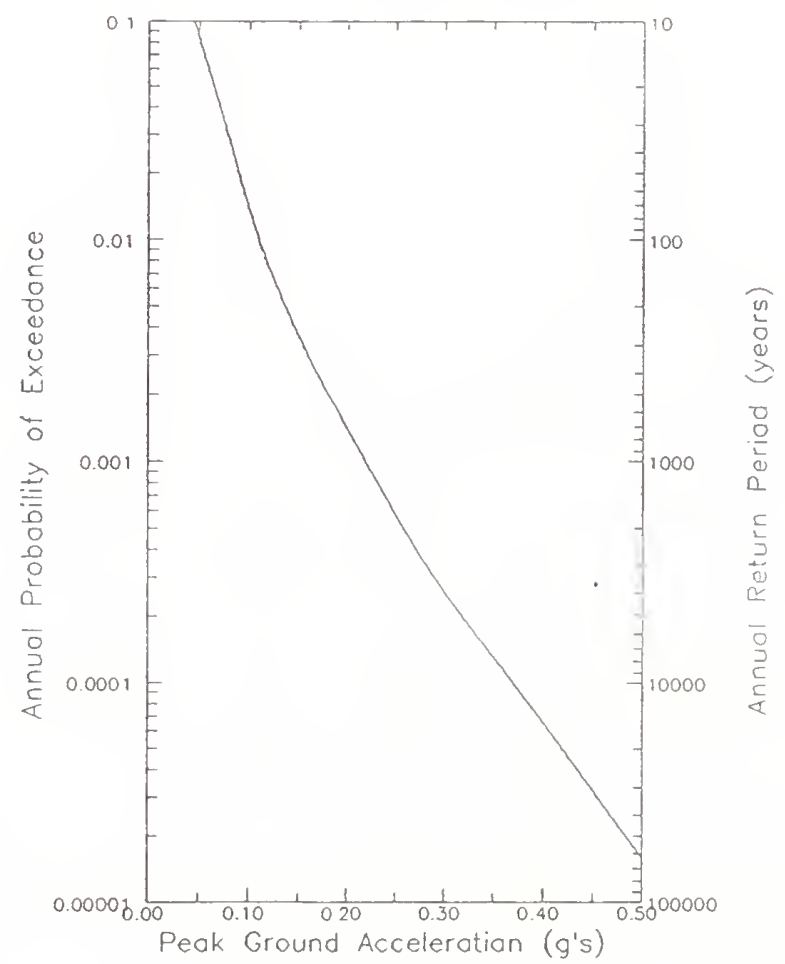

Figure 10. Best estimate of seismic hazard versus peak horizontal acceleration recommended for use in selecting remedial measures 


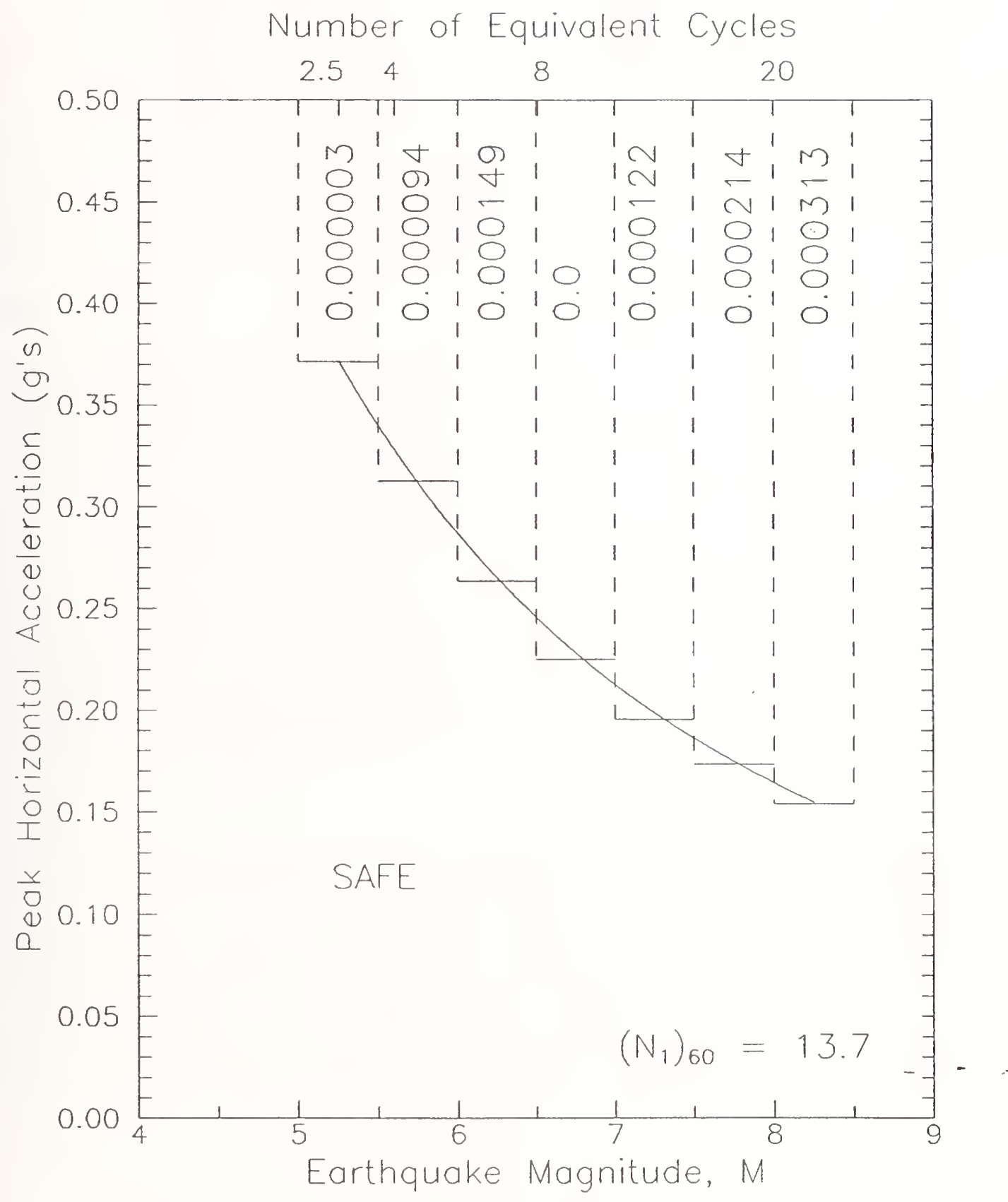

Figure 11. Probabilities of occurrence for different ranges in magnitude at combinations of $\mathrm{a}_{\max }$ and earthquake magnitude causing liquefaction of dredged foundation gravel for $\left(N_{1}\right)_{60}=13.7$ 


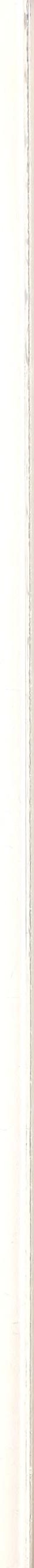




\title{
System Identification of Spirally Reinforced Circular Bridge Columns Subjected to Cyclic Lateral Loading
}

\author{
by \\ William C. Stone ${ }^{1}$ \\ and \\ Andrew W. Taylor ${ }^{2}$
}

\begin{abstract}
Problems relating to present procedures for the design of bridge columns to withstand seismic loads are discussed and a more rational design procedure is proposed. Central to the proposed analysis method is the requirement for an analytical capacity to predict the hysteretic behavior of reinforced concrete bridge columns when subjected to inelastic lateral loads up to and including failure. A three-parameter model with a nonsymmetric trilinear envelope was used in an initial effort to identify relationships between physical column properties and hysteretic model parameters. A digital database of load-displacement histories was established for circular, spirally reinforced bridge column tests. A system identification analysis was performed on each specimen in which the error in predicted cyclic absorbed energy was minimized. Three parameters, comprising a stiffness degrading coefficient, a strength degrading coefficient, and a pinching coefficient, were employed in this study. Subsequent multivariable least squares regression analyses were conducted to correlate the variation of the three failure model parameters with the specimens physical variables as well as cummulative absorbed energy. Conclusions are presented regarding the sensitivity of hysteretic behaviour to certain physical characteristics of circular, spirally reinforced bridge colums.
\end{abstract}

\section{Introduction}

Research on the design of bridge structures to resist seismic loadings has been driven by the inadequate performance of constructed facilities under actual earthquakes. The catastrophic collapse of the I-880 Cypress Freeway, and the significant damage sustained by other elevated highway structures in the Oakland-San Francisco region during the Loma Prieta earthquake of 1989 (Lew, 1990) has given rise to a research project at the National Institute of Standards and Technology (NIST) to develop a rational procedure for the design of ductile bridge columns. This paper describes the fundamental tenets comprising this concept and the results of preliminary work on one phase of the project, that of developing a suitable hysteretic model for the prediction of inelastic dynamic response of ductile bridge columns.

\section{Background}

Before discussing what constitutes a "rational" design procedure, it may prove useful to summarize the current generally accepted design procedure for single, cantilevered bridge columns employed by the California Department of Transportation (Caltrans, 1984), as this represents a more stringent version of the AASHTO (AASHTO, 1978) procedures presently in effect throughout the United States for the design of bridge structures. The Caltrans procedure, presented in Table 1, requires the selection of a maximum expected bedrock acceleration at the bridge site from a seismicity contour map; the selection of a

\footnotetext{
${ }^{1}$ Research Structural Engineer, National Institute of Standards and Technology, Gaithersburg, Maryland

2 Research Structural Engineer, National Institute of Standards and Technology, Gaithersburg, Maryland
} 
response spectrum based on generic soil conditions; and the calculation of the anticipated fundamental period of the structure. The designer then reads a static equivalent lateral design force from the response spectrum and proceeds along the design steps outlined in Table 1. This procedure, while lending itself to a codified standard, suffers from several drawbacks:

- A single peak acceleration value for a regional area ignores important localized phenomena associated with distances from active faults, variations in earthquake magnitudes and their effects on frequency content, and attentuation and frequency shifting with distance from the active faults.

- A sample of representative response spectra for homogeneous soil conditions for a few depth ranges will not necessarily yield a realistic measure of the lateral surface excitation force as experienced by the structure, particularly if the frequency content of the earthquake rock motion is other than assumed in the generation of the generic design charts and if there are multi-layered sedimentary deposits.

- There is no basis for the prediction of the post-earthquake damage status for the structure. Thus, the design codes for lifeline structures presently include arbitrary modifiers to the static equivalent lateral design load based on the level of "importance" of a particular structure. Because of this, there is no ability to perform an effective optimization study which would result in the least-cost design solution to meet a particular survival requirement.

\section{A Rational Design Procedure for Bridge Columns in Seismic Regions}

A more rational approach, described graphically as a computer program flow chart in Fig. 1, to the design of bridge columns is proposed. This approach is based on recent advances in synthetic earthquake generation techniques and the development of reliable models for the prediction of hysteretic behavior in reinforced concrete structures. Because the concept requires the integration of both seismological and structural analysis components, the input data upon which the analyses are based are site specific. Presently there is no national data base from which one might, for example, obtain a set of representative acceleration-time histories for a particular site which might then be used for design. For this reason, it was decided that a demonstration project, using the San Francisco-Oakland Bay area as the example, would be used to limit the scope of the required data base generation. Similarly, because there are many possible variations to superstructure architecture, we have limited the initial scope of this project to the performance and design of circular, spirally reinforced, single cantilevered columns which are monolithically cast with continuous longitudinal reinforcement through the potential plastic hinge regions. These criteria are applicable to a broad number of elevated highway systems presently in use in the State of California.

From a fundamental standpoint there are seven unique, and interdependent, aspects relating to the design of a bridge column that is required to perform in a certain manner when subjected to certain levels of seismic excitation. These are as follows:

- Superstructure and Performance Definition

- Subsurface (Soil Column) Definition

- Bedrock Motion Definition

- Site (Surface) Motion Calculation

- Hysteretic Failure Model Selection

- Inelastic Dynamic Analysis

- Cost Optimization

In considering the first of these, Superstructure and Performance Definition, the engineer would prefer to enter as few pieces of information into a computer program as necessary. In the case of geometry and 
loads, the minimum data required are the height of the column, $L$, and the effective axial load, $P_{\theta}$, from the roadway. In addition the engineer would also like to specify the level of acceptable damage following an earthquake of a given magnitude. It may be appreciated that a bridge column which is required to be totally functional, with no damage at all, following a Magnitude 6.5 earthquake, may in fact demand a more robust design than the same column which would be required to remain marginally standing (and require subsequent demolition) following a Magnitude 7.5 earthquake. Since these criteria will depend on site-specific characteristics, the engineer would also want to provide the computer program with a geographical location (Iongitude and latitude) of the construction site, from which, ultimately, design loadings would be automatically generated. Obviously, this design approach represents a departure from current practices. Its implementation is predicated upon a number of developments taking place and on the integration of what are presently disparate research software into an automated system.

The issue of structural input loadings is addressed in the second through fourth aspects listed above. The seismic excitation function (acceleration-time history) is dependent upon the following parameters, among others:

1. The magnitude of the earthquake.

2. The local tectonics which affect the generation and propagation of seismic waves.

3. The distance from the epicenter to the structure.

4. The underlying soil conditions which exist between the foundation of the structure and bedrock.

Given these parameters the development of an appropriate "design' earthquake loading is a probabalistic process which is presently the subject of considerable research. We envision, ultimately, a national database which would permit the user, by specifying a geographic location for the construction site, to automatically develop a best estimate for the soil column profile from surface to bedrock level; and to automatically generate a suite of design bedrock acceleration-time histories, at varying magnitudes and frequency contents which would be representative of that site. These two pieces of data, combined with existing wave propagation software (e.g. SHAKE, 1990), can be further used to automatically generate surface-level acceleration-time histories which would serve as the input loading for the structural design. Initially, it is clear that the sparsity of available boring logs to bedrock will relegate such automated soil selection procedures to preliminary analyses, pending availability of specific construction site logs. However, with required filing of boring logs to bedrock at all construction sites in seismic regions with a national organization, such as the United States Geological Survey, the completeness of such a soils database would gradually improve to the point where a refined analysis would become unecessary.

Procedures are currently available (e.g. Joyner and Moore, 1988) for the development of synthetic earthquake records at a given site, provided information on local geology and tectonics are available. For any given site, and any given structure, it may be appreciated that a single acceleration-time history, just as with a single equivalent static lateral load, is insufficient for proper analysis. Because some structures may respond more dramatically to a particular segment of a response spectrum, it is important to develop, for each site, a suite of acceleration-time histories which represent, in addition to the entire response spectrum, segments of it. Likewise, because different magnitude earthquakes may initiate from different sources, a separate suite of design acceleration-time histories for each magnitude under consideration must be generated. Given these data, one may then develop a suite of surface-level time histories suitable for subsequent structural analysis. An interactive graphics-driven system which employs the above principals is presently being developed for the Oakland-San Francisco Bay area and will be the subject of a forthcoming paper.

\section{Hysteretic Failure Modets}

The remainder of the proposed design procedure rests upon the ability to analytically predict the dynamic response of the target structure, not just to its elastic limits, but to complete failure. Several computer 
programs presently exist including SAKE (Otani, 1974), SARCF-II (Rodriguez-Gomez, Chung, and Meyer, 1990), and IDARC (Park, Reinhorn, and Kunnath, 1987), among others, which have, to varying degrees, achieved some measure of success in achieving this goal. All are "research codes" and to date are limited to the analysis of two dimensional structural systems. At the heart of these programs are analytical models to idealize the inelastic behavior of reinforced concrete under dynamic or quasi-static loading (EIBorgi, White, and Gergely, 1991). These are generally accomplished with the use of macromodeling schemes in which inelastic action is represented through hysteretic models describing force-deformation characteristics at a cross-section. Such models attempt to capture overall behavior of the structural element based on load-displacement predictive algorithms which are calibrated to experimental data. These latter models, generally referred to as hysteretic failure models, were selected for the project described in this paper because of their ability to be calibrated to experimental data and because the output directly lends itself to the computation of absorbed hysteretic energy and displacement ductility, both of which have been shown to be correlated to a quantifiable measure of the state of damage sustained by the structure following a seismic event (Park, Ang, and Wen, 1984).

Since the mid-1960s research has progressed towards the development of two general hysteretic failure models which can be classified as either "smooth" or "multi-linear," depending on the mathematics of the algorithm employed. State-of-the-art summaries of the various methods can be found in El-Borgi, White and Gergely (1991) and in Park, Reinhorn and Kunnath (1987). In the present study a multi-linear hysteretic model, known as a "Three Parameter Model," based on improvements to the Clough-Takeda Model (Takeda, 1970) by Takayanagi (Takayanagi and Schnobrich, 1977) was employed. This same algorithm is presently used in the program IDARC (Park, Reinhorn, and Kunnath, 1987).

It is common practice to describe the envelope curve of the force-deformation relation of reinforced concrete components by a multi-linear function with three turning points, e.g., cracking, yield, and ultimate strength. The tri-linear approximation to the envelope curve is known as the "skeleton" curve. Procedures have been developed to extract this curve from an equivalent monotonic load-displacement envelope curve that has been fitted to experimental data for columns tested under reversed cyclic loading (Park, Reinhorn, and Kunnath, 1987). A variety of hysteretic properties can be obtained through the combination of the tri-linear skeleton curve and three characteristic parameters, $\alpha, \beta$ and $\gamma$, as will be subsequently described.

The parameter $\alpha$ controls the degradation (softening) in the unloading stiffness that is generally observed in reinforced concrete members as they degrade under reversed cyclic loading. In the three-parameter model, stiffness degradation is introduced by setting a common point on the extrapolated skeleton curve. It is assumed that the unloading lines aim at this point until they reach the displacement-axis, as shown in Fig. 2. The parameter $\alpha$ directly affects the slope of the unloading branches of the load-deflection history and, as can be seen in Fig. 2, indirectly affects the area bounded by the hysteresis loops, which is a measure of the seismic energy absorbed by the structure during any given cycle. As $\alpha$ decreases so does the unloading stiffness.

The parameter $\beta$ determines the rate of strength degradation, as shown in Fig. 3., and is defined as the ratio of the incremental damage sustained by the structural element caused by the increase of the maximum response, $\mathrm{d} \delta_{\mathrm{m}} / \delta_{\mathrm{u}}$, to the normalized incremental hysteretic energy, $\mathrm{dE} /\left(\delta_{\mathrm{u}} \mathrm{P}_{\mathrm{y}}\right)$, as:

$$
\beta=\frac{\frac{d \delta_{m}}{\delta_{u}}}{\frac{d E}{\delta_{w} P_{y}}}=\frac{d \delta_{m}}{\frac{d E}{P_{y}}}
$$


where:

$\delta_{u} \quad=$ Ultimate deformation under monotonic loading; generally defined as the displacement on the descending monotonic failure curve at which point the lateral load has decreased to $80 \%$ of the maximum lateral load.

$P_{y}=$ Yield strength, calculated from the envelope curve.

dE = Incremental hysteretic absorbed energy during the current cycle as shown in Fig. 3.

$\delta_{m}=$ Maximum observed displacement during the present cyclic loading history.

As can be seen from Fig. 3, a value of $\beta$ equal to zero will produce hysteresis loops with no strength degradation, no matter how many subsequent cycles are carried out, provided all other parameters remain the same. Increasing, non-zero values of $\beta$ produce increasingly rapid decay in the maximum load on subsequent cycles.

Pinching behavior, such as illustrated in Fig. 4, may be introduced by lowering the target maximum point (labeled as the Initial Target Point in Fig. 4) to a level of $\gamma \mathrm{P}_{y}$ (labeled as the New Target Point in Fig. 4) along the previous unloading line. A new stiffness is calculated such that the reloading path aims at this new target point until the crack closing point is reached. The stiffness of the reloading path is changed again at this point such that subsequent increases in deformation produce increases in load along a steeper (stiffer) slope which ultimately passes through the initial target point. The introduction of such a pinching parameter leads to a reduction in the cyclic energy absorbed by the structural element. These three parameters, together with the skeleton curve information described above, comprise the variables required for implemention of the hysteretic rule described in Park, Reinhorn, and Kunnath (1987). El-Borgi, White, and Gergely (1991) warn that the proper implementation of this type of model requires calibration of the variables to a specific type of structural element if reliable results are to be obtained. It was for this reason that the initial project scope was restricted to circular, spirally reinforced, single bridge columns. Our first task was thus directed to assembly of a suitable digital database of tests of spirally reinforced, circular concrete bridge columns subjected to reverse cyclic loading with combined axial load. The process of determining the relationship between the hysteretic parameters $\alpha, \beta$, and $\gamma$ and the column geometry and materials is known as system identification. The ability to implement the optimized inelastic dynamic structural analysis described in Fig. 1 is predicated on the ability to reduce such a relationship to a set of closed form equations.

\section{A Proposed Standard for Digital Test Records}

An extensive literature search identified several sources of bridge column test data. Digitized records for 8 column tests were available from Stone and Cheok (1989) and Cheok and Stone (1990); 12 additional records were obtained from Ang, Priestley, and Paulay (1989, 1985, 1981); Mander (1984); Munro, Park, and Priestley (1976); Ng, Priestley, and Park (1978); Priestley and Park (1984); and Zahn (1986). As most of these latter tests were originally conducted using analog recorders a digitizing program was developed at NIST to produce digital load-displacement records from high resolution photographic enlargements from the technical papers. Additional usable data was identified in Lim, McLean, and Henley (1990); McLean and Lim (1990); Petrovski and Ristic (1984); and Wong, Paulay, and Priestley (1990) but this latter data became available too late for inclusion in the analyses reported in this paper. A summary of the available tests and their properties are reported in Table 2. 
One aspect concerning experimental data merits discussion at this point, and that is the matter of "noise", introduced into the load-deflection record either by spurious electronic signals or by mechanical sources such as leaking servo-hydraulic loading apparatus. Inevitably all experimental data is laced with noise to some degree. Furthermore, there exists the issue of how many data points are necessary to effectively capture a single hysteresis loop. For the purposes of analysis, it is desireable to: a) reduce the experimental record to as few digitized points as necessary to accurately capture the load-displacement record; b) eliminate to the best possible degree the influence of noise; c) represent quarter and half cycle hysteresis curves as smooth, continuously differentiable mathematical functions and d) have within each cycle a one data point with precisely zero displacement at the start of each loading cycle. All of these have one ultimate purpose: to reduce computer processing time when performing a system identification analysis, in which several tens of thousands of iterations through the entire data set may be required to arrive at a best fit for the particular parametric model being used. These criteria were achieved in the present study by fitting the initial quarter load cycle, and all subsequent half load cycles with $\mathrm{n}^{\text {th }}$ order polynomial curves. The best fit for the first quarter cycle in almost all cases was achieved through an equation of the form:

$P_{1}(\delta)=C_{0} \delta^{1 / 2}+C_{1} \delta^{3 / 2}+C_{2} \delta^{5 / 2}+C_{3} \delta^{7 / 2}+C_{4} \delta^{9 / 2}+C_{5} \delta^{11 / 2}$

The best fit for all subsequent half cycles was generally achieved through an equation of the form:

$P_{1 . . n}(\delta)=C_{0}+C_{1} \delta+C_{2} \delta^{2}+C_{3} \delta^{3}+C_{4} \delta^{4}+C_{5} \delta^{5}+C_{6} \delta^{6}$

The above fitting was done using a special purpose interactive graphics program, NIDENT 3.0, which was developed on a high performance workstation as part of the present project at NIST. Using NIDENT 3.0, the researcher may experiment with different polynomial fits and visually assess the accuracy of the fit. An initial density of 25 points per half cycle was selected for subsequent regeneration of the loaddeflection hysteresis record using the polynomial regression equation appropriate to each half cycle. Records processed in this manner were then used for system identification analyses as will be described below.

In the process of assembling the digital records of the "raw" data for each column test it became apparent that a specific format would have to be established so that each test could be handled by automated system identification routines being developed at NIST. As there is presently no standard protocol for such data records we propose the format described in Table 4. The substantial problems encountered in developing the digital database used for this paper indicate that it is particularly important that a standard digital record format be defined soon and used throughout the international structural research community in the future. Such a standard, combined with increasingly effective inter-computer communications (e.g. FTP, InterNet, ArpaNet, etc.), would make a much broader range of experimental data available for the refinement of hysteretic failure models for all types of structural components. We feel that such analysis methods represent the vanguard of future seismic-resistant design and as such merit the cooperation of international research laboratories.

\section{System Identification}

The term "System Identification" is generally associated with the experimental acquisition of such dynamic characteristics of a structure as its mode shapes, frequencies, and damping coefficients. In this paper we use the term to refer to the determination of the three parameters $\alpha, \beta$, and $\gamma$, which best characterize the hysteretic behavior of a given test specimen. The system identification procedure used in this study consists of a three dimensional trial and error search with bounded limits on $\alpha, \beta$, and $\gamma$ subject to the constraint of minimizing the error between predicted and experimentally observed differential energy absorption. In equation form, we seek to minimize the function $F$, where $F$ is defined as follows: 


$$
F=\sqrt{\frac{\sum_{i=1}^{n} 0.5\left(\delta_{i+1}-\delta_{i-1}\right)\left(P_{\exp }(i)-P_{\text {theo }}(i)\right)^{2}}{n}}
$$

where:

$\begin{array}{ll}\delta_{i+1} & =\text { displacement of next point in load-displacement record } \\ \delta_{i-1} & =\text { displacement of previous point in load-displacement record } \\ P_{\exp }(i) & =\text { experimentally observed load at current point } \\ P_{\text {theo }}(i) & =\text { predicted load at current displacement, calculated using the multi-linear hysteretic rule and } \\ & \text { the currently selected values of } \alpha, \beta, \text { and } \gamma \\ & =\text { number of data points in the experimental record }\end{array}$

In mathematical terms, the above analysis constitutes an optimization problem. Where smooth, continuously differentiable (tc second order) equations can be used to describe the hysteretic rule, such as are presently employed in the so-called "smooth" hysteresis models (see El-Borgi, White, and Gergeley, 1991, for example), it is possible to make use of procedures such as the Levenberg-Marquardt method (More, 1977), among others. Unfortunately, attempts to integrate a Levenberg-Marquardt solver into NIDENT 3.0 (the NIST graphics-based system identification package) failed with the Three-Parameter model. The reasons for this stem from the fact that the hysteretic rule (see Park, Reinhorn, and Kunnath, 1987 for a detailed presentation) for the Three Parameter model is presently comprised of 15 discrete cases which govern such situations as loading, unloading, re-loading, and pinching. This results in the presence of step-like facets to the function describing the relationship between $\alpha, \beta$, and $\gamma$. Optimization routines such as the Levenberg-Marquardt method base their "next best guess" at the optimum solution by taking exceedingly small steps to obtain estimates of the local first and second derivatives of the function to be optimized. For the Three-Parameter model, this generally results in several iterations until a particular facet is reached. There, considerable variation in a given parameter may not produce any significant change in the predicted load. Once such a situation is encountered most optimization solvers terminate, indicating that they have found the "optimum" solution, even though the fit, as visible in a graphics display, is poor. A solution to this problem was developed for NIDENT 3.0. This consisted of employing the coarse-mesh three dimensional trial and error search for an initial estimate of the parameters $\alpha, \beta$, and $\gamma$. These values were then used to calculate the predicted load-displacement record which was subsequently superimposed graphically, in a different color, on top of the experimental record. Using a high performance graphics workstation it was then possible to interactively adjust any of the three model parameters by means of a dial-box while viewing the results in real time on the graphics screen. This visual-feedback approach proved surprisingly effective in arriving at a "best fit". As a final check, the absorbed energy was calculated for the experimental data model estimates for each cycle and compared in a histogram plot. When the error between the theoretical and experimental sums of the cyclic absorbed energies was reduced to a level of a few percent, the final values of $\alpha, \beta$, and $\gamma$ were recorded.

Examples of the fit between the analytical model and experimental data are shown in Figs 5-9. Several details of these figures bear discussion. The first, as evidenced, for example, in Fig. 8, is that as the column begins to fail, there is a tendency for the predicted loads to overshoot the experimentally observed load at the maximum observed displacements for each cycle. This is an expected consequence of using a tri-linear skeleton curve where the post-yielding stiffness for such a model is defined to' be positive for numeric stability. Secondly, as evidenced in the associated cyclic absorbed energy histograms (see Figs. 5-9), there is a tendency for the predicted absorbed energy to overestimate the experimental data for low values of lateral displacement and to underestimate the experimental data for high displacement ductility. Despite these shortcomings, the Three Parameter model is able to generally predict both overall absorbed 
cyclic energy and displacement ductility to within a few percent error, which was considered acceptable for the puposes of the present project.

\section{Multi-variable Stepwise Regression Analysis}

Given best-fit values of the parameters $\alpha, \beta$, and $\gamma$ for many different column tests, the next objective is to ascertain if there is any correlation between these parameters and the physical properties and dimensions of the test specimens which were modelled. For this objective a stepwise linear regression analysis was conducted. Of the 20 digital test records listed in Table 2 all but three were able to be estimated to within $2 \%$ error in total absorbed energy using the techniques described above. Two specimens represented re-tests of previously loaded specimens and were therefore considered suspect and the third, for reasons yet unknown, proved intractable to accurate solution using the Three-Parameter model. These three specimens were therefore eliminated from the analyses. In addition to the basic specimen properties listed in Table 2, a large series of variable permutations, shown in Table 3, were considered in the regression analyses. The regression analyses were conducted using the commercial software package SAS/STAT (SAS/STAT, 1987) and the results are presented in Table 4. $R^{2}$ (square of the regression correlation coefficient) values of $91 \%, 86 \%$, and $97 \%$ were obtained for the estimates of the parameters $\alpha, \beta$, and $\gamma$, respectively. The regression equations associated with these parameters are given by:

$$
\begin{aligned}
\alpha= & 0.832 \times 10^{1}+0.116 \times 10^{-1} f_{y s}-0.509 \times 10^{2} \frac{f_{c}}{f_{y z}} \\
& +0.430 \times 10^{-6} E_{\text {tot }}-0.665 \times 10^{-1} \delta_{y}+0.572\left(\frac{L}{D}\right) 0.6^{p_{s}}
\end{aligned}
$$

$$
\begin{aligned}
\beta= & 0.189+\frac{P_{c}}{f_{c} A_{g}}\left(13.14 \sqrt{f_{c}}-4.457\right)+\frac{A_{g}}{A_{c}}\left(\frac{f_{c}}{f_{y a}}\right)\left(4.051-30.826 \frac{P_{o}}{f_{c} A_{g}}\right) \\
& -0.00171 \delta_{y}+0.101 \sqrt{f_{g}}\left(\frac{D}{L}\right)+\left(0.356 \rho_{g}-1.306\right)(0.9)^{p_{o}}
\end{aligned}
$$

$$
\begin{aligned}
\gamma= & 0.845+0.00309 \frac{L}{D}+0.0704 \frac{P_{s}}{\sqrt{f_{c}}}\left(\frac{D}{L}\right) \\
& -1.879 \frac{f_{c}}{f_{y s}}+\left(0.0826-0.748 \times 10^{-4} f_{y s}\right) \sqrt{f_{c}}
\end{aligned}
$$

The above relations should not be construed as a reliable basis for seismic design in their present form, given the limited size of the database upon which they were developed. However, from a research standpoint, several useful observations can be drawn which may guide further development of hysteretic failure models.

Stiffness degradation, as defined in Fig. 2 , is heightened by lower values of $\alpha$. It is therefore retarded by high values of spiral reinforcement yield stress, $f_{y s}$; by high concrete strength to spiral reinforcement yield strength, $f$ ' $/ f_{y s}$; by increased initial column flexibility, as inferred by the column aspect ratio, L/D; and by increased amounts of confining reinforcement, $\rho_{s^{\prime}}$. It is of particular note that the total absorbed energy, $E_{\text {lot }}$ enters in this equation. All of the other variables can be derived from material properties and 
geometry. In a compurational analysis it is possible to calculate the cummulative absorbed energy at each point in the time-history. This opens some rather interesting opportunities which may solve the problem of overestimation of cyclic absorbed energy at low displacement ductilities and the underestimation of cyclic absorbed energy at high displacement ductilities. It may be possible, with further research on an expanded test database, to develop a correlation between cummulative cyclic absorbed energy and all the parameters defining a hysteretic model. If such a correlation exists, it may then be possible to answer one of the fundamental questions faced by structural researchers: the quantification of the effects of cyclic load history on the behavior of structures.

Of the three parameters defined above, $\beta$ (strength degradation) appears the least subject to precise definition. Although a relatively high correlation coefficient was achieved, this was at the expense of a significantly higher number of participating terms in the regression equation. This was not altogether unexpected, for Park, Ang, and Wen (1984) had already reported in the derivation of an energy-based failure criterion for reinforced concrete that there existed significant scatter in the data used to define when "failure" actually occurred. The term $\beta$ is the most closely correlated to the state of damage, as previously described, and we therefore anticipated significant scatter. Still, a number of useful observations can be made. Since increased values of $\beta$ correspond to more rapid failure of the column, it may be concluded from a sensitivity analysis of the above equation that higher axial stress levels lead to more rapid failure of a column, as does a lower aspect ratio. This would serve to reiterate the conventional wisdom that highly stressed short columns are at greatest risk in earthquakes. It is also interesting to note that for longitudinal reinforcement ratios of less than about $4 \%$, increasing the confining steel reinforcement serves to improve column performance (see final term in $\beta$ equation).

The third parameter, $\gamma$, influences the pinching behavior in the hysteresis loops. A smaller value of $\gamma$ leads to a more pronounced pinch and, therefore, less energy absorption during any given cycle. Desirable performance would dictate the maintainence of "fat" hysteresis loops. Although a regression equation is presented for $\gamma$, we caution against drawing any behavioral information from it. Only one of the specimens presented in Table 2 exhibited any observable pinching behavior ( $\mathrm{Ng} \mathrm{No}$. 3, shown in Fig. 7 ); all others had $\gamma$ values greater than or equal to 1.0. It may be appreciated from Fig. 4 that values of $\gamma$ in excess of 1.0 result in a re-targeting of the initial target point on the unloading curve; that the results should therefore be insensitive to changes in $\gamma$ beyond 1.0 were verified by means of interactive variation of the parameter using the program NIDENT. It is of some note, however, that all but one specimen exhibited a lack of pinching behavior through failure. Since all of these test specimens were designed in accordance with current Caltrans or New Zealand 3101 criteria, it would appear that these provisions provide for adequate confining reinforcement to prevent significant pinching behavior.

\section{Conclusions}

Within the bounds of the available test data for circular, spirally reinforced concrete bridge columns subjected to cyclic lateral loading, it was found that the Three Parameter model was able to generally predict the observed experimental load-deflection histories, and to produce an estimate of the cummulative absorbed cyclic energy within an error bound of several percent. Preliminary regression equations were developed for the parameters $\alpha, \beta$, and $\gamma$ and explanations were offered to explain the relationship between these parameters and the material and geometric properties of the columns. With only one exception, all columns were able to be accurately modeled with a $\gamma$ value of 1.0 , indicating that the design guidelines utilized for the design of the individual specimens were sufficient to prevent significant pinching hysteretic behavior through failure of the columns. The accuracy of the regression equations can be substantially enhanced through expansion of the available database. To this end a standard format for reporting digital records for tests of reinforced concrete columns subjected to cyclic lateral loading was proposed. 
1. Design the main longitudinal reinforcement for biaxial bending based on AASHTO group loads I-VI and Caltrans seismic loads for group load VII.

2. Determine the probable plastic moment of the column.

3. Design lateral reinforcement for the controlling group load or the lesser of the Caltrans group load VII unreduced earthquake force or the plastic moment, whichever controls.

4. Confinement and shear reinforcement are designed using the AASHTO Code and modifications as specified by Caltrans:

a) Confinement is covered in (8.18.2.2) as modified by Caltrans Code in the plastic hinge zones. Two formulas are used based on the size of the column. In all other locations the confinement equation is (8-62) as defined in the AASHTO Code.

b) Shear strength (8.16.6.1.1) equations (8-46) and (8-47) as defined in the AASHTO Code. Concrete shear strength $(8.16 .6 .11 .4(a)$ is modified by Caltrans in the area of plastic hinging.

c) Reinforcement shear strength (8.16.6.11.4(b)) conforms to AASHTO Code equations (8-53) and (863).

5. Footing design equations conform to the AASHTO Code. Footings are designed for AASHTO group loads I-VII and Caltrans seismic loads for group load VII. 


\begin{tabular}{|c|c|c|c|c|c|c|c|c|c|c|c|c|c|c|c|c|c|c|c|c|}
\hline 梮 & $\cong$ & : & $\begin{array}{c}0 \\
\text { n. }\end{array}$ & $\tilde{\nabla}$ & $\stackrel{\sim}{ \pm}$ & लें & فे & $\overrightarrow{\dot{n}}$ & 它 & 吕 & $\begin{array}{l}0 \\
8 \\
8\end{array}$ & 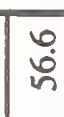 & : & $\stackrel{\infty}{n}$ & $\begin{array}{l}\text { n. } \\
\stackrel{0}{0} \\
0\end{array}$ & 吕 & $\stackrel{m}{n}$ & \begin{tabular}{l|}
$\infty$ \\
0 \\
0
\end{tabular} & 옴 & $\begin{array}{l}0 \\
0 \\
\dot{\infty} \\
\dot{m}\end{array}$ \\
\hline$\triangleleft^{\lambda} \underline{E}$ & 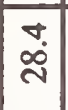 & 冓 & $n$ & $\begin{array}{l}\infty \\
\infty \\
\infty\end{array}$ & స్ & $\underset{\infty}{\infty}$ & $\stackrel{\vec{r}}{\dot{m}}$ & $\stackrel{\Upsilon}{\Xi}$ & 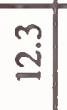 & $\overline{0}$ & 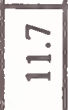 & \% & $\bar{a}$ & $\mid \begin{array}{l}\infty \\
\sim\end{array}$ & $\begin{array}{l}\vec{J} \\
\dot{\Xi}\end{array}$ & ? & $\begin{array}{l}m \\
\infty\end{array}$ & $\stackrel{9}{=}$ & స్త్ & $\tilde{n}$ \\
\hline$a^{2} Z$ & 官 & 亦 & 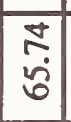 & 管 & 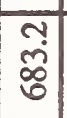 & 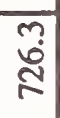 & 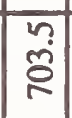 & $\frac{\nabla}{\infty}$ & लें & \begin{tabular}{|l|} 
\\
0 \\
0 \\
0
\end{tabular} & $\frac{N}{\bar{m}}$ & 응 & 水 & 吾 & $\begin{array}{l}\tilde{\infty} \\
\dot{a}\end{array}$ & $\begin{array}{l}2 \\
\text { r. } \\
n\end{array}$ & $\frac{\sigma}{\sigma}$ & 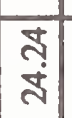 & ఫ్తి & 总 \\
\hline 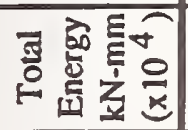 & $\begin{array}{l}\infty \\
a \\
a\end{array} \mid$ & 常 & 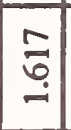 & $\begin{array}{l}0 \\
6 \\
0\end{array}$ & 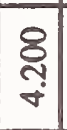 & $\begin{array}{l}\text { స్ } \\
\text { అ్}\end{array}$ & $\mid \begin{array}{l}0 \\
0 \\
0 \\
0\end{array}$ & 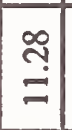 & ఫ్లి & $\begin{array}{c}\tilde{N} \\
\infty \\
i \\
\end{array}$ & 苟 & $\begin{array}{l}\infty \\
\infty \\
i \\
i\end{array}$ & స్ర్ర & $\left|\begin{array}{c}\tilde{\delta} \\
\tilde{m}\end{array}\right|$ & $\frac{\tilde{\sigma}}{\mathfrak{i}}$ & $\left|\begin{array}{l}0 \\
: \\
n \\
n \\
m\end{array}\right|$ & m. & ঙ্ণ & $\stackrel{\Xi}{\Xi}$ & 定 \\
\hline$r$ & ઠิ & క్ర & ڤั. & $\underset{్}{\tilde{\delta}}$ & ธి & ర్ర్ & ర్ & ్ְరి & ర్రి & $\underset{్ ర ీ}{-~}$ & $\underset{乛}{\tilde{\sigma}}$ & ర్ర్త & ơ & క్ర్త్ & క్ & 8 & $\tilde{8}$ & $\underset{8}{8}$ & క్రి & $\stackrel{్}{్}$ \\
\hline$\infty$ & $\begin{array}{l}\mathbf{8} \\
0 \\
\end{array}$ & $\begin{array}{l}\overline{0} \\
\dot{0} \\
\end{array}$ & \begin{tabular}{|l|} 
\\
\hdashline \\
0 \\
\end{tabular} & \begin{tabular}{|c|}
8 \\
0 \\
0
\end{tabular} & $\begin{array}{l}0 \\
0 \\
0 \\
0\end{array}$ & 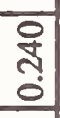 & \begin{tabular}{|c|} 
\\
\\
\\
\end{tabular} & $\begin{array}{l}\overline{8} \\
0 \\
\end{array}$ & $\begin{array}{l}0 \\
0 \\
0\end{array}$ & $\begin{array}{l}\overline{8} \\
0 \\
\end{array}$ & \begin{tabular}{l}
0 \\
\multirow{2}{*}{} \\
0 \\
\end{tabular} & $\begin{array}{l}\overline{8} \\
0\end{array}$ & $\begin{array}{l}\bar{o} \\
0 \\
0\end{array}$ & 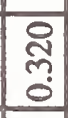 & \begin{tabular}{|l|} 
\\
0 \\
0 \\
\end{tabular} & \begin{tabular}{|l|} 
ণ্ণ \\
\\
\end{tabular} & 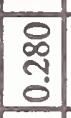 & \begin{tabular}{|l|}
0 \\
0 \\
0 \\
\end{tabular} & \begin{tabular}{|l|} 
\\
\\
0 \\
\end{tabular} & $\begin{array}{l}\text { त् } \\
\text { o }\end{array}$ \\
\hline 8 & $\begin{array}{l}8 \\
\pm \\
\end{array}$ & $\begin{array}{l}8 \\
\dot{I}\end{array}$ & $\begin{array}{l}8 \\
\text { i. }\end{array}$ & $\left|\begin{array}{l}n \\
\infty \\
\infty\end{array}\right|$ & $\begin{array}{l}8 \\
\mathrm{~m} \\
\end{array}$ & \begin{tabular}{l}
0 \\
?ִ \\
\hdashline
\end{tabular} & $\begin{array}{l}8 \\
\dot{0} \\
\end{array}$ & \begin{tabular}{l|}
8 \\
\\
\end{tabular} & $\begin{array}{l}8 \\
\infty \\
\infty\end{array}$ & $\begin{array}{l}8 \\
\pm \\
\end{array}$ & $\begin{array}{l}0 \\
0 \\
0 \\
\end{array}$ & $\begin{array}{l}8 \\
\dot{+}\end{array}$ & $\underset{\mathrm{I}}{\mathrm{I}}$ & $\begin{array}{l}0 \\
0 \\
0 \\
0\end{array}$ & $\begin{array}{l}0 \\
0 \\
0\end{array}$ & $\begin{array}{l} \\
\mathbf{I} \\
\end{array}$ & $\begin{array}{l}0 \\
0 \\
0 \\
\end{array}$ & \begin{tabular}{l|}
8 \\
\\
\end{tabular} & 号 & ถి \\
\hline$a^{0} \mid \sum_{i=}^{\infty}$ & ơ & ఫ్రి & 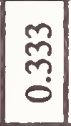 & ஸิ & พ⿳亠े冋ٌ & $\begin{array}{c}\infty \\
\substack{0 \\
0}\end{array}$ & 吾 & $\left|\begin{array}{l}8 \\
0 \\
0\end{array}\right|$ & ఫ్స్రి & $\begin{array}{l}8 \\
0 \\
0\end{array}$ & $\begin{array}{l}0 \\
0 \\
0\end{array}$ & : & 量 & ষ্ণ্ডি & $\frac{8}{0}$ & $\frac{8}{0}$ & ষ্ণ & $\frac{8}{0}$ & : & है \\
\hline $\begin{array}{ll}\ll^{\infty} & E \\
& \dot{g}\end{array}$ & $\overrightarrow{\mathbf{D}}$ & in & $\bar{n}$ & : & $\begin{array}{l}\text { : } \\
\stackrel{\text { aे }}{ }\end{array}$ & $\begin{array}{l}\text { बे } \\
\text { ลे }\end{array}$ & ๙ & $\begin{array}{l}: \\
\text { הิ }\end{array}$ & జ్ల & 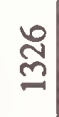 & 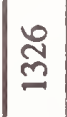 & స్లి & क্ & $\stackrel{\infty}{\sigma}$ & \& & 吕 & 文 & $\stackrel{\infty}{\sigma}$ & ఫ̊ & 弈 \\
\hline 更 & ه্d. & فे & 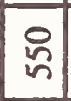 & ฐิ & 官 & 怘 & 必 & $\begin{array}{l}0 \\
6 \\
6\end{array}$ & $:$ & $\Xi$ & $\approx$ & : & ్ㅠ & & స్తి & జ్తి & $\stackrel{\approx}{\approx}$ & đ్ & 品 & 号 \\
\hline & กั. & n. & స్ా & 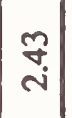 & ָ̊ & $\stackrel{m}{+}$ & $\stackrel{q}{\mathrm{q}}$ & 胥 & $\stackrel{m}{\sim}$ & $\stackrel{?}{i}$ & m & 管 & $\stackrel{g}{-}$ & ga & 9 & $\stackrel{a}{-}$ & 2 & g. & 2 & 2 \\
\hline a. & $\stackrel{\Xi}{\leftrightarrows}$ & ڤ్ & $\begin{array}{l}7 \\
\text { i }\end{array}$ & $\begin{array}{c}\varkappa \\
0 \\
0\end{array}$ & $\cong$ & $\begin{array}{l}8 \\
0 \\
0\end{array}$ & $\begin{array}{l}\overline{0} \\
\dot{i} \\
\end{array}$ & \begin{tabular}{|l|}
$\overrightarrow{0}$ \\
$i$ \\
\end{tabular} & $\begin{array}{l}0 \\
0 \\
\end{array}$ & ?ึ: & 芯 & 8 & $\stackrel{n}{-}$ & 尔 & $\begin{array}{l}8 \\
0 \\
0\end{array}$ & 年 & $\stackrel{?}{-}$ & $\begin{array}{l}0 \\
0 \\
0\end{array}$ & 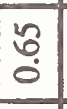 & $\tilde{?}$ \\
\hline 莺 & $\hat{\imath}$ & 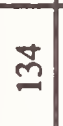 & 2 & సి & స్తి & & ్ㅛ & 워 & : & 8 & 18 & $\underset{8}{8}$ & $\pi$ & $\therefore$ & $n$ & $\approx$ & $\approx$ & $\stackrel{\circ}{n}$ & $\frac{\pi}{a}$ & \\
\hline
\end{tabular}

帚

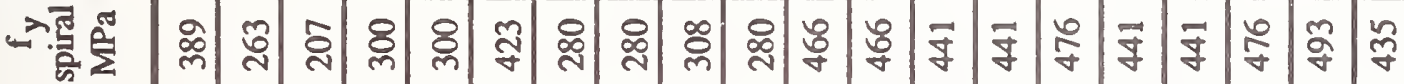

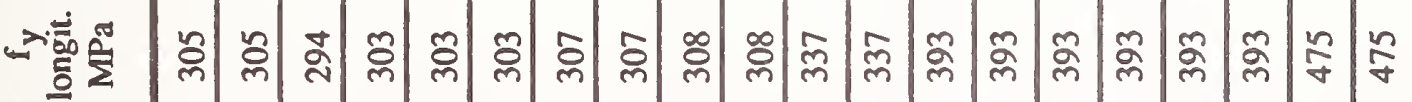

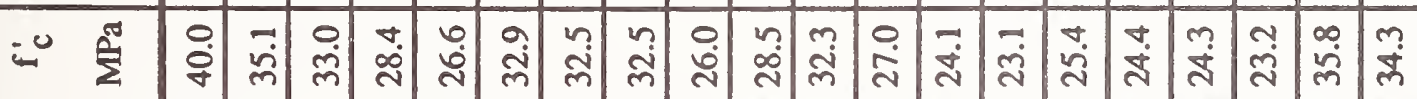

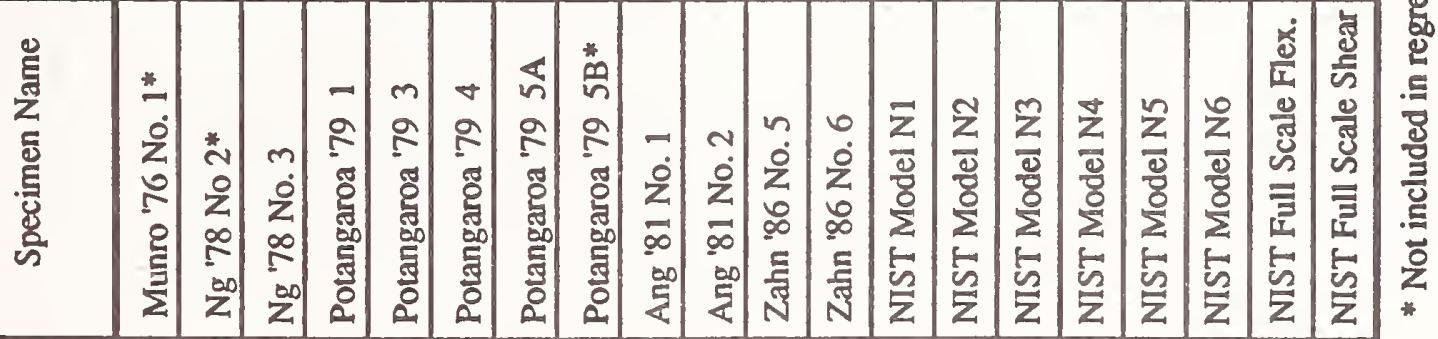




\begin{tabular}{|c|c|c|}
\hline $\begin{array}{l}\text { Regression } \\
\text { Variable }\end{array}$ & Symbol & Definition \\
\hline $\mathrm{X} 22$ & $\frac{\rho_{\mathrm{s}}}{\mathrm{f}_{\mathrm{ya}}}$ & - \\
\hline$X 23$ & $\frac{\rho_{s}}{f_{y a} f_{c}^{\prime}}$ & - \\
\hline $\mathrm{X} 24$ & $E_{\text {tot }}$ & Measured total absorbed energy \\
\hline $\mathrm{X} 25$ & $P_{y}$ & Measured lateral yield load \\
\hline $\mathrm{X} 26$ & $\delta_{y}$ & Measured lateral yield disp. \\
\hline $\mathrm{X} 27$ & $\delta_{\max }$ & $\begin{array}{l}\text { Maximum observed lateral } \\
\text { displacement }\end{array}$ \\
\hline $\mathrm{X} 28$ & $\frac{\delta_{\max }}{\delta_{y}}$ & Ductility ratio \\
\hline $\mathrm{X} 29$ & $\frac{E_{\text {tot }}}{P_{y} \delta_{y}}$ & $\begin{array}{l}\text { Normalized absorbed } \\
\text { energy }\end{array}$ \\
\hline $\mathrm{X} 30$ & $\frac{\mathrm{P}_{\mathrm{e}}}{\sqrt{\mathrm{f}_{\mathrm{c}}^{\prime}} \mathrm{A}_{\mathrm{g}}}$ & - \\
\hline $\mathrm{X} 31$ & $\frac{\mathrm{P}_{\mathrm{e}}}{\sqrt{\mathrm{f}_{\mathrm{c}}^{\prime}} \mathrm{A}_{\mathrm{g}}}\left(\frac{\mathrm{D}}{\mathrm{L}}\right)$ & - \\
\hline $\mathrm{X} 32$ & $\frac{\mathrm{P}_{\mathrm{e}}}{\mathrm{f}_{\mathrm{c}} \mathrm{A}_{\mathrm{g}}}\left(\frac{\mathrm{D}}{\mathrm{L}}\right)$ & - \\
\hline $\mathrm{X} 33$ & $\left(\frac{\mathrm{D}}{\mathrm{L}}\right)$ & Inverse of aspect ratio \\
\hline X34 & $\sqrt{\mathrm{f}_{\mathrm{c}}\left(\frac{\mathrm{D}}{\mathrm{L}}\right)}$ & 一 \\
\hline $\mathrm{X} 35$ & $\sqrt{\mathrm{f}^{\prime} \mathrm{c}}\left(\frac{\mathrm{L}}{\mathrm{D}}\right)$ & - \\
\hline $\mathrm{X} 36$ & $\frac{\rho_{\mathrm{S}}}{\sqrt{\mathrm{f}_{\mathrm{c}}}}\left(\frac{\mathrm{D}}{\mathrm{L}}\right)$ & - \\
\hline $\mathrm{X} 37$ & $\rho_{\mathrm{s}} \sqrt{\mathrm{f}_{\mathrm{c}}}$ & - \\
\hline X38 & $\mathrm{f}_{\mathrm{ys}} \sqrt{\mathrm{f}_{\mathrm{c}}}$ & - \\
\hline$X 39-X 48$ & $\mathrm{~K}^{\rho_{\mathrm{S}}}$ & $\begin{array}{l}\text { Where } \mathrm{K}=0.1,0.2,0.3, \ldots \\
0.7,0.8,0.84,0.9\end{array}$ \\
\hline$X 49-X 58$ & $\left(\frac{L}{D}\right) K^{\rho_{S}}$ & $\begin{array}{l}\text { Where } \mathrm{K}=0.1,0.2 \\
0.3, \ldots 0.7,0.8,0.84,0.9\end{array}$ \\
\hline $\mathrm{X} 59 \cdot \mathrm{X} 68$ & $\rho_{\mathrm{a}} \mathrm{K}^{\rho_{\mathrm{s}}}$ & $\begin{array}{l}\text { Where } \mathrm{K}=0.1,0.2,0.3, \ldots \\
0.7,0.8,0.84,0.9\end{array}$ \\
\hline
\end{tabular}

Table 3 (Part II). Regression variables 


\begin{tabular}{|c|c|c|}
\hline $\begin{array}{l}\text { Regression } \\
\text { Variable } \\
\end{array}$ & Symbol & Definition \\
\hline $\mathrm{X} 1$ & $f_{c}^{\prime}$ & Concrete compressive strength \\
\hline $\mathrm{X} 2$ & $\mathrm{f}_{\mathrm{ya}}$ & $\begin{array}{l}\text { Longitudinal reinforcement } \\
\text { yield stress }\end{array}$ \\
\hline $\mathrm{X} 3$ & $\mathrm{f}_{\mathrm{ys}}$ & $\begin{array}{l}\text { Confining reinforcement yield } \\
\text { stress }\end{array}$ \\
\hline $\mathrm{X} 4$ & $\mathrm{D}$ & Column diameter \\
\hline X5 & L & $\begin{array}{l}\text { Column height or } \\
\text { effective length }\end{array}$ \\
\hline $\mathrm{X} 6$ & $\rho_{s}$ & Confining reinforcement ratio \\
\hline $\mathrm{X7}$ & $\rho_{\mathrm{a}}$ & Longitudinal reinforcement ratio \\
\hline $\mathrm{X8}$ & $\mathrm{Pe}_{\mathrm{e}}$ & Axial load \\
\hline $\mathrm{X9}$ & $\mathrm{Ag}_{\mathrm{g}}$ & Gross cross section area \\
\hline $\mathrm{X} 10$ & $\frac{\mathrm{P}_{\mathrm{e}}}{\mathrm{f}_{\mathrm{c}}^{\prime} \mathrm{A}_{\mathrm{g}}}$ & Normalized axial load \\
\hline $\mathrm{X} 11$ & $A_{c}$ & Effective concrete area \\
\hline $\mathrm{X} 12$ & $\frac{A_{g}}{A_{c}}$ & 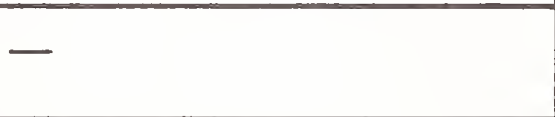 \\
\hline $\mathrm{X} 13$ & $\frac{f_{c}}{f_{y a}}$ & - \\
\hline $\mathrm{X} 14$ & $\frac{A_{g}}{A_{c}}\left(\frac{f_{c}^{\prime}}{f_{y a}}\right)$ & - \\
\hline $\mathrm{X} 15$ & $\frac{A_{g}}{A_{c}}\left(\frac{f^{\prime} c}{f_{y a}}\right)\left(\frac{P_{e}}{f_{c}^{\prime} A_{g}}\right)$ & - \\
\hline$X 16$ & $\overline{\mathrm{L}}$ & Column aspect ratio \\
\hline $\mathrm{X} 17$ & $\frac{f_{c}^{\prime}}{f_{y s}}$ & - \\
\hline $\mathrm{X} 18$ & $\frac{\rho_{\mathrm{s}}}{\rho_{\mathrm{a}}}$ & - \\
\hline $\mathrm{X} 19$ & $\sqrt{f_{c}}$ & - \\
\hline $\mathrm{X} 20$ & $\frac{f_{y a} L}{\sqrt{f_{c}}}$ & - \\
\hline $\mathrm{X} 21$ & $\frac{f_{y s}}{f_{y a}}$ & - \\
\hline
\end{tabular}

Table 3 (Part I). Regression variables. 
Table 4: (Page 1 of 2)

\section{Proposed Standard for Digital Test Records of Reinforced Concrete Columns Subjected to Cyclic Loading with combined Axial Load}

Field FORTRAN
Number Format

Administrative:

$\begin{array}{ll}1 & \text { XX,A10 } \\ 2 & 1 X, A 80 \\ 3 & 1 X, A 80 \\ 4 & 1 X, A 80 \\ 5 & 1 X, A 80 \\ 6 & 1 X, A 80 \\ 7 & 1 X, A 80 \\ 8 & 1 X, A 80 \\ 9 & 1 X, A 80 \\ 10 & 1 X, A 80\end{array}$

Specimen Properties:

11

12

13

14

15

16
1X,E12.6

1X,E12.6

1X,E12.6

1X,E12.6

1X,E12.6

1X,E12.6

1X,E12.6

1X,E12.6

1X,E12.6

1X,E12.6

1X,E12.6

1X,E12.6

1X,E12.6

1X,E12.6

1X,E12.6

$1 X, A 80$

1X,E12.6

1X,E12.6

1X,E12.6

1X,E12.6

1X,E12.6

1X,A80

$1 X, A 80$

1X,E12.6

1X,E12.6

1X,E12.6

1X,E12.6

1X,E12.6

1X,E12.6

1X,E12.6
Description

\author{
Year of Test \\ Test Specimen Name \\ Laboratory Name \\ Laboratory Street Address \\ Laboratory City,State, Country, Zip \\ Laboratory FTP Digital Communications Address (if available) \\ Researchers Name(s) \\ Title of Most Appropriate Report/Paper \\ Reserved for future data/aux. notes \\ Reserved for future data/aux. notes
}

$\begin{array}{ll}f^{\prime}, & \text { Concrete Compressive Strength (MPa) } \\ f_{\text {ya }} & \text { Longitudinal reinforcement yield strength (MPa) } \\ f_{y s} & \text { Confining reinforcement yield strength (MPa) } \\ \text { D } & \text { Column diameter, if Circular (mm) } \\ H & \text { Column depth, in loading direction, if Rectangular }(\mathrm{mm}) \\ \mathrm{W} & \text { Column width, if Rectangular }(\mathrm{mm}) \\ \mathrm{C} & \text { Concrete cover to centerline of confining steel }(\mathrm{mm}) \\ \mathrm{L} & \text { Effective column length }(\mathrm{mm}) \\ \rho_{\mathrm{s}} & \text { Confining steel reinforcement ratio }(\%) \\ \mathrm{s} & \text { Confining steel pitch or spacing }(\mathrm{mm}) \\ \mathrm{ds} & \text { Confining steel bar diameter }(\mathrm{mm}) \\ \mathrm{T} & \text { Confining steel type: Spiral; Hoop; or Rectangular Ties. }\end{array}$

$\rho_{\mathrm{a}} \quad$ Longitudinal steel reinforcement ratio (\%)

dl Longitudinal steel reinforcement bar diameter $(\mathrm{mm})$

$\mathrm{N} \quad$ Number of longitudinal bars

Q Longitudinal splice description (if any)

$\mathrm{P}_{\theta} \quad$ Axial load $(\mathrm{kN})$

$\delta_{\mathrm{cr}} \quad$ Experimentally measured cracking displacement $(\mathrm{mm})$

$\mathrm{P}_{\mathrm{cr}} \quad$ Experimentally measured cracking load $(\mathrm{kN})$

$\delta_{y} \quad$ Experimentally measured yield displacement $(\mathrm{mm})$

$\mathrm{P}_{\mathrm{y}} \quad$ Experimentally measured yield load ( $\mathrm{kN}$ )

Rate of Loading (include units)

P-Delta effects included in load-displacement data? (yes/no)

reserved for future data

reserved for future data

reserved for future data

reserved for future data

reserved for future data

reserved for future data

reserved for future data 
Table 4: (Page 2 of 2)

\section{Proposed Standard for Digital Test Records of Reinforced Concrete Columns Subjected to Cyclic Loading with combined Axial Load}

\section{Field FORTRAN \\ Number Format}

Loading History:

$41 \quad 1 X, 15$

$\begin{array}{ll}42 & \text { XX,E12.6 } \\ 43 & 1 X, E 12.6 \\ 44 & 1 X, E 12.6 \\ 45 & 1 X, E 12.6\end{array}$

$41+n c \quad 1 X, E 12.6$

$42+n c \quad 1 X, E 12.6$
Description

nc Number of cycles in test loading history, including any used in the initial determination of the yield displacement

$\delta_{\max , 1}$ Maximum (positive) displacement for cycle 1

$\delta_{\min , 1}$ Minimum (negative) displacement for cycle 1

$\delta_{\max , 2}$ Maximum (positive) displacement for cycle 2

$\delta_{\min , 2}$ Minimum (negative) displacement for cycle 2

$\delta_{\max , \mathrm{nc}}$

$\delta_{\min , n c}$

Load-Displacement Record:

$\begin{array}{ll}43+n c & 15 \\ 44+n c & 1 X, 2(E 12.6,3 X) \\ 45+n c & 1 X, 2(E 12.6,3 X)\end{array}$

$43+n c \quad 1 X, 2(E 12.6,3 X)$

+ npts npts Number of data points in the load-displacement record $\delta_{1}, P_{1} \quad$ Lateral displacement $(\mathrm{mm})$; Lateral Load $(\mathrm{kN})$ pair $\delta_{2}, P_{2} \quad$ Lateral displacement $(\mathrm{mm})$; Lateral Load $(\mathrm{kN})$ pair

$\delta_{\text {npts }}, P_{\text {npts }}$ Lateral displacement (mm); Lateral Load (kN) pair at final sequential point in the record. 
Table 5: Regression Analysis Coefficients

Regression Analysis for Variable Alpha

R-square $=0.91085245$

\begin{tabular}{lrr} 
Variable & \multicolumn{1}{c}{$\begin{array}{l}\text { Parameter } \\
\text { Estimate }\end{array}$} & \multicolumn{1}{c}{$\begin{array}{l}\text { Standard } \\
\text { Error }\end{array}$} \\
Intercept: & 8.31876014 & 4.89794429 \\
X3 & 0.01160500 & 0.00834998 \\
X17 & -50.93576455 & 24.16746952 \\
X24 & 0.00000043 & 0.00000020 \\
X26 & -0.06646607 & 0.02255637 \\
X54 & 0.57236815 & 0.32174906 \\
\hline
\end{tabular}

Regression Analysis for Variable Beta

R-square $=0.86416021$

\begin{tabular}{lrr} 
Variable & $\begin{array}{l}\text { Parameter } \\
\text { Estimate }\end{array}$ & \multicolumn{1}{l}{$\begin{array}{l}\text { Standard } \\
\text { Error }\end{array}$} \\
& & \\
Intercept: & 0.18964653 & 0.35159550 \\
X10 & -4.45792174 & 2.02667807 \\
X14 & 4.05133212 & 2.06712680 \\
X15 & -30.82632478 & 12.65111662 \\
X26 & -0.00170923 & 0.00062060 \\
X30 & 13.14743204 & 5.32542453 \\
X34 & 0.10056988 & 0.02926639 \\
X48 & -1.30608709 & 0.57406484 \\
X68 & 0.35640403 & 0.11675052
\end{tabular}

Regression Analysis for Variable Gamma

R-square $=0.97634278$

$\begin{array}{lcl}\text { Variable } & \begin{array}{l}\text { Parameter } \\ \text { Estimate }\end{array} & \begin{array}{l}\text { Standard } \\ \text { Error }\end{array} \\ \text { Intercept: } & 0.84494717 & 0.01515021 \\ \text { X16 } & 0.00309135 & 0.00072887 \\ \text { X17 } & -1.87851685 & 0.11806923 \\ \text { X19 } & 0.08262993 & 0.00615182 \\ \text { X36 } & 0.07035537 & 0.01795630 \\ \text { X38 } & -0.00007482 & 0.00000591\end{array}$




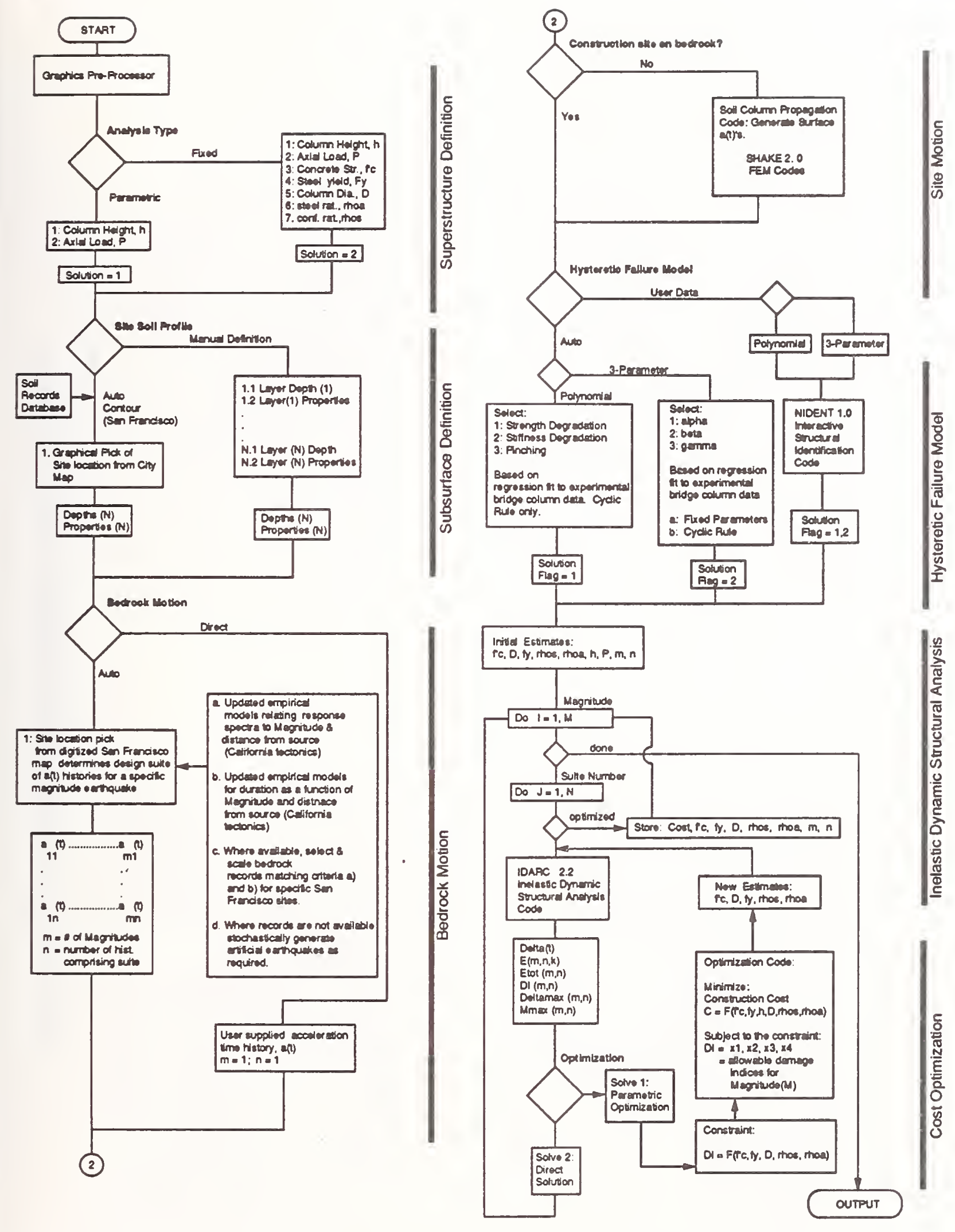

Figure 1. Proposed rational design procedure for bridge substructures in seismic regions. 

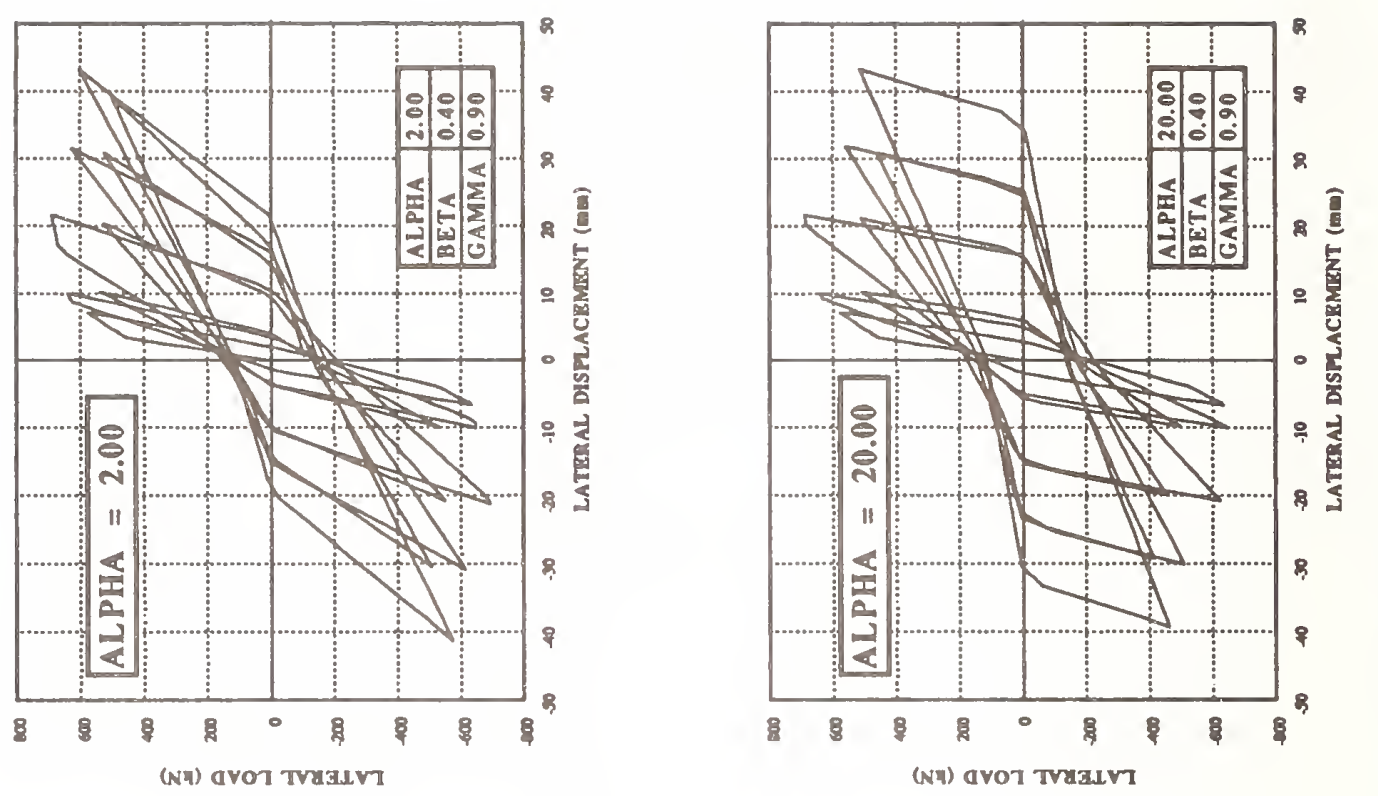

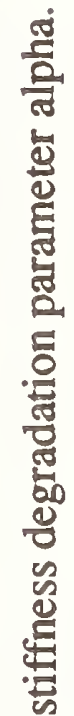
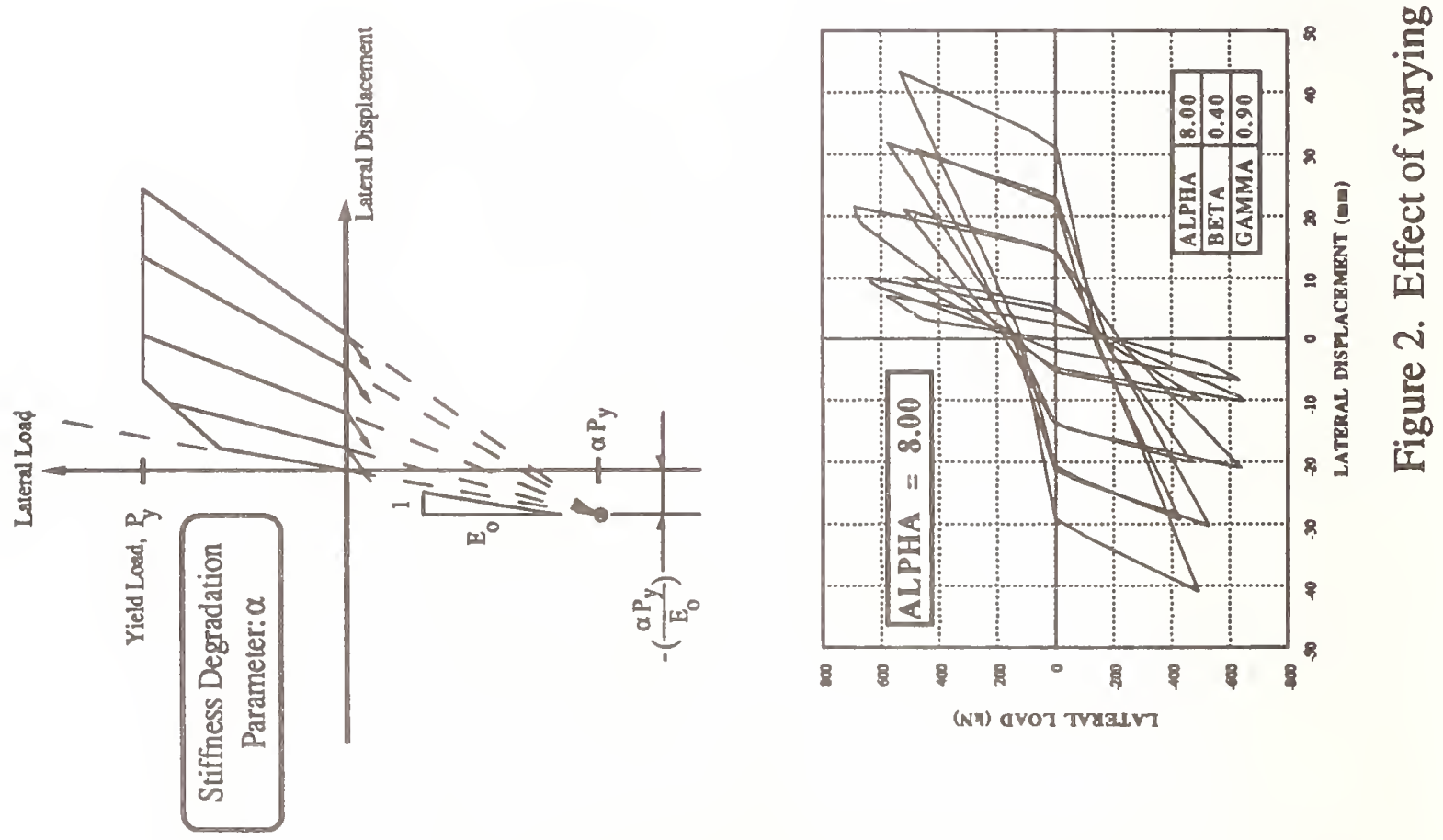

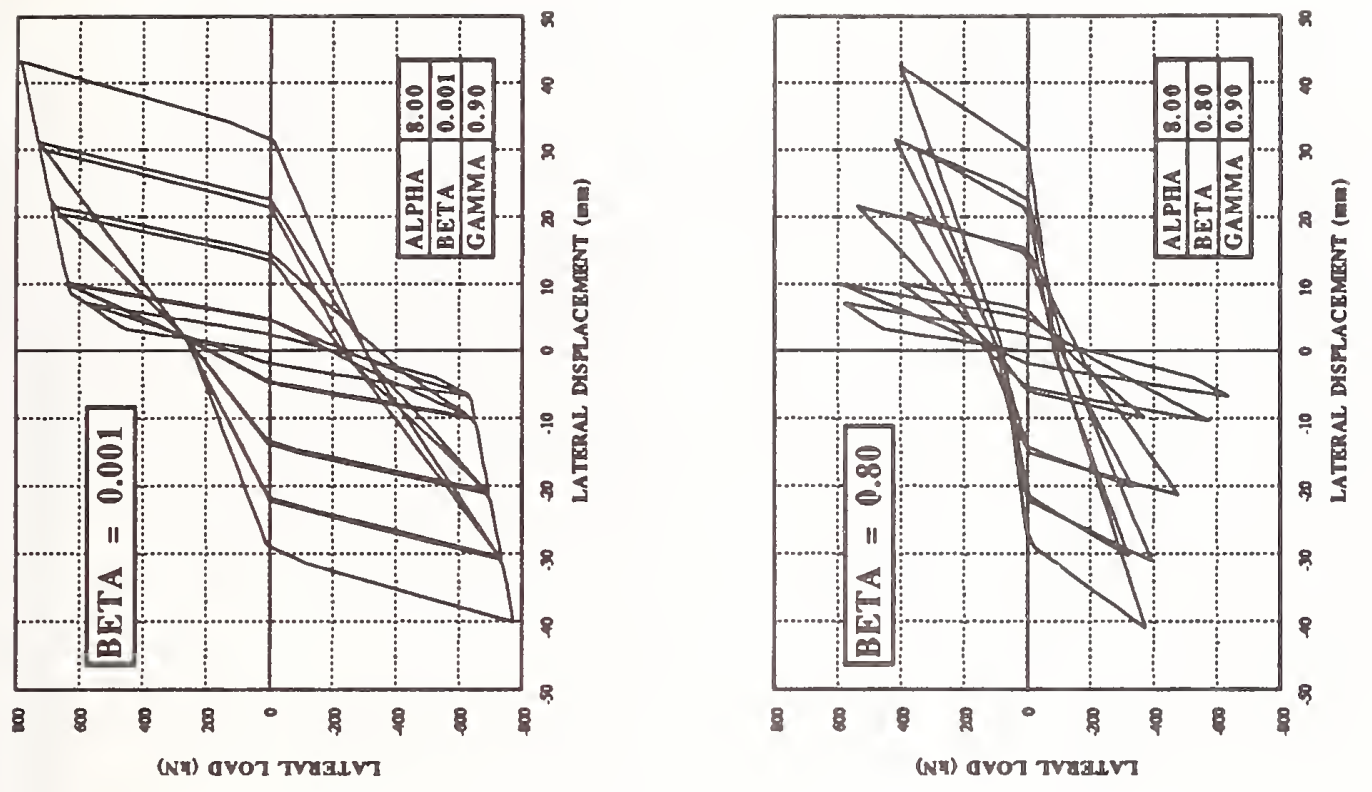

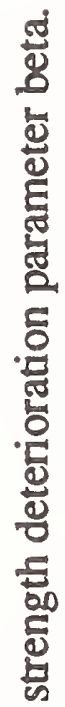
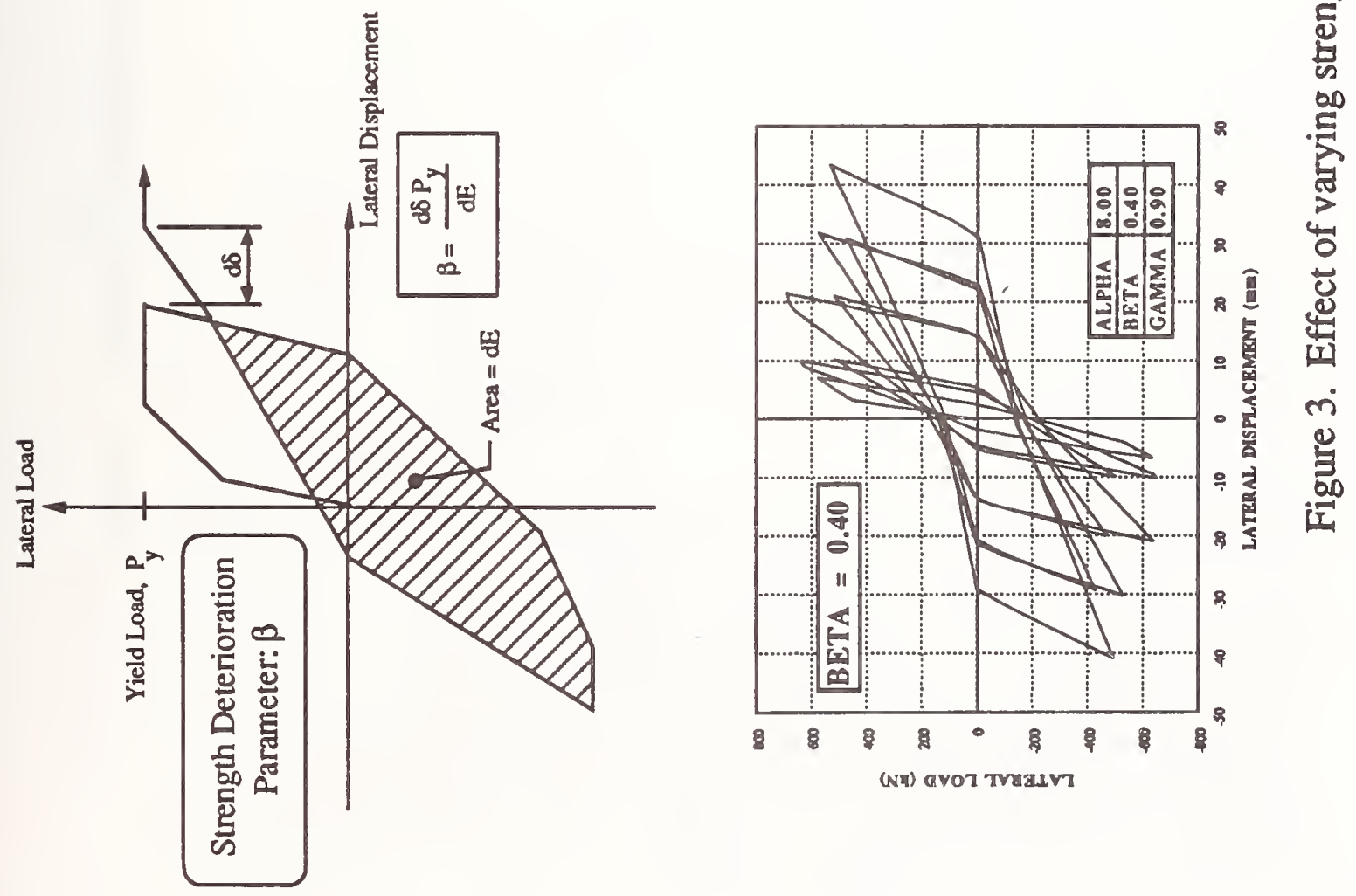

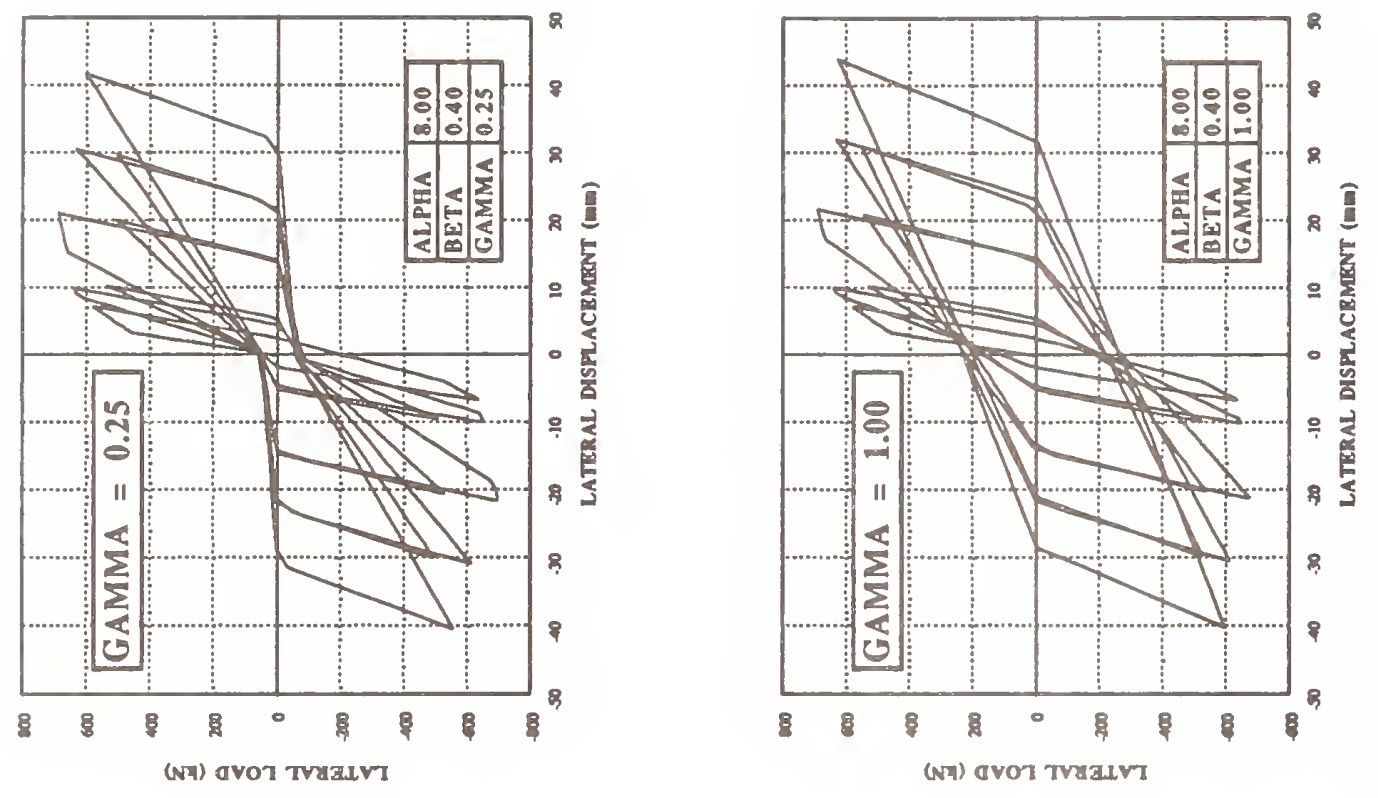

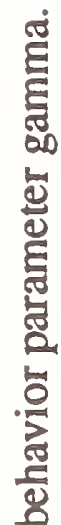

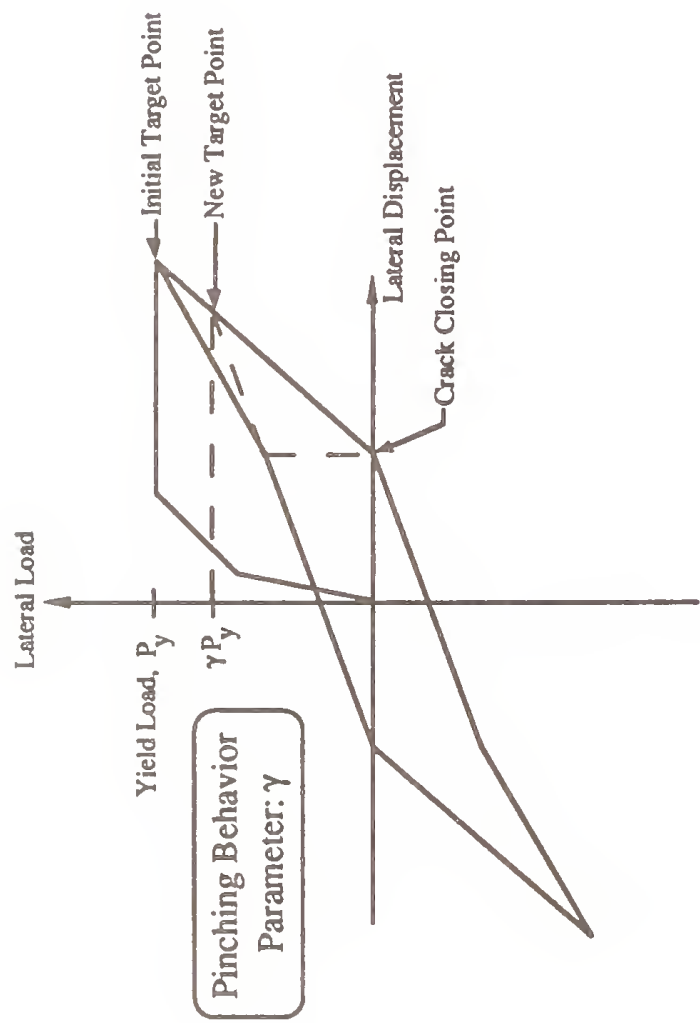

을

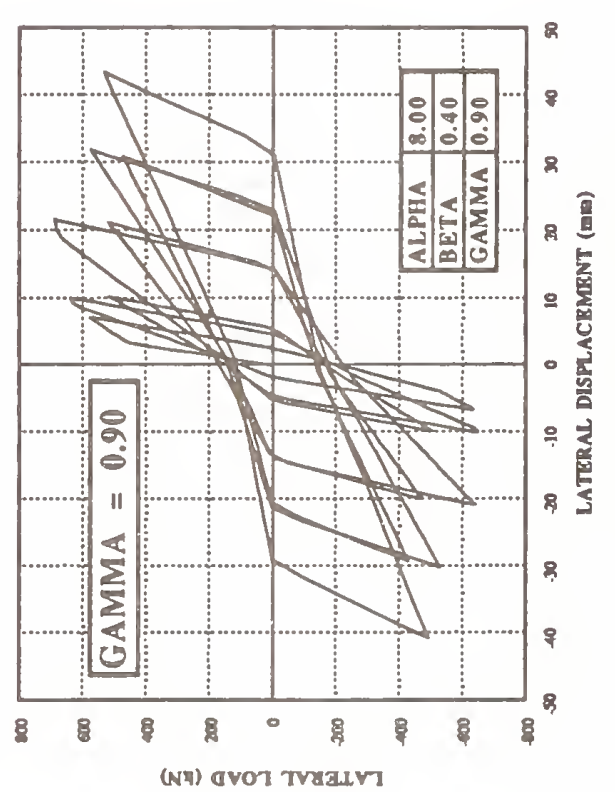

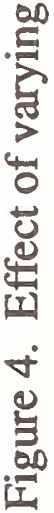




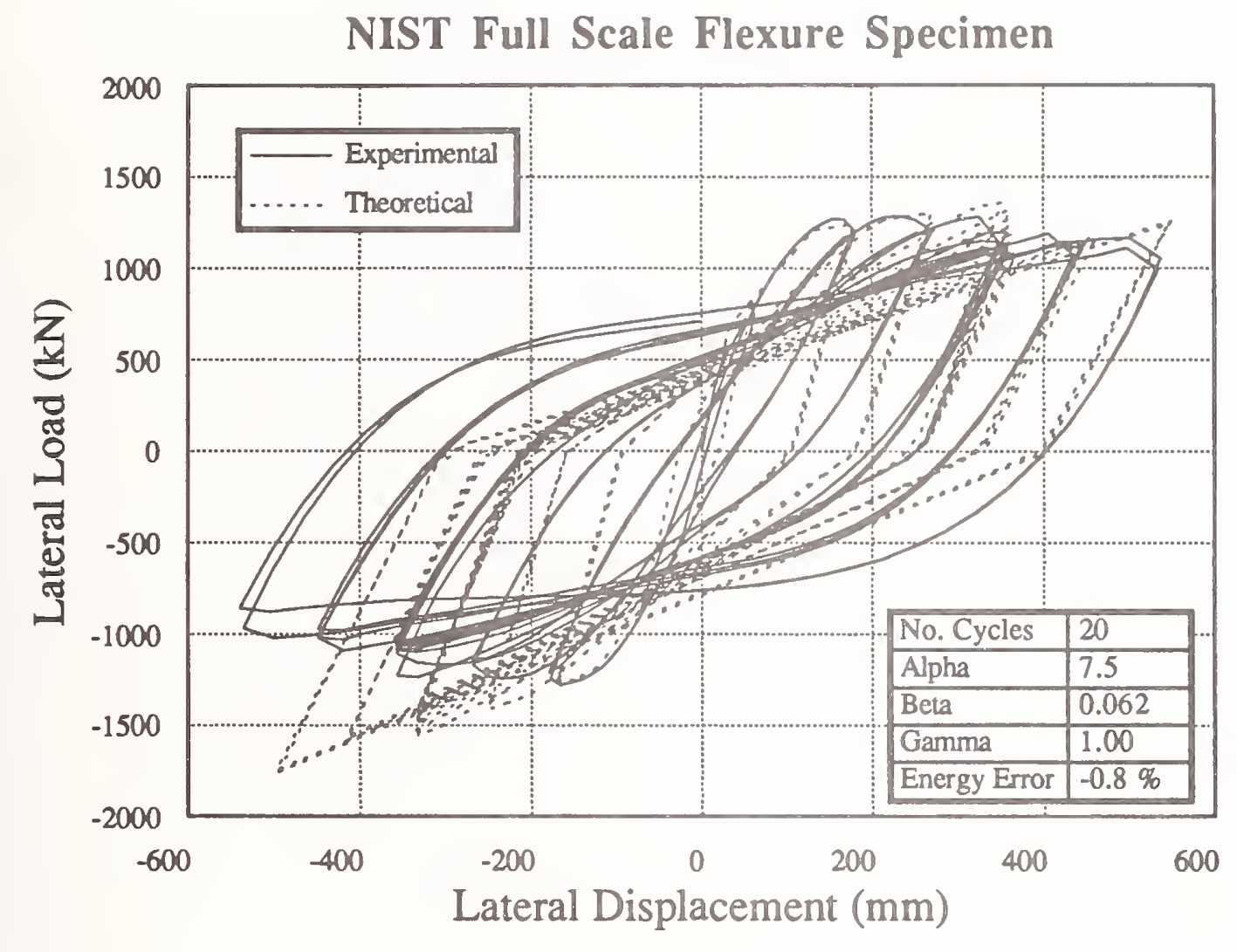

NIST Full Scale Flexure Specimen

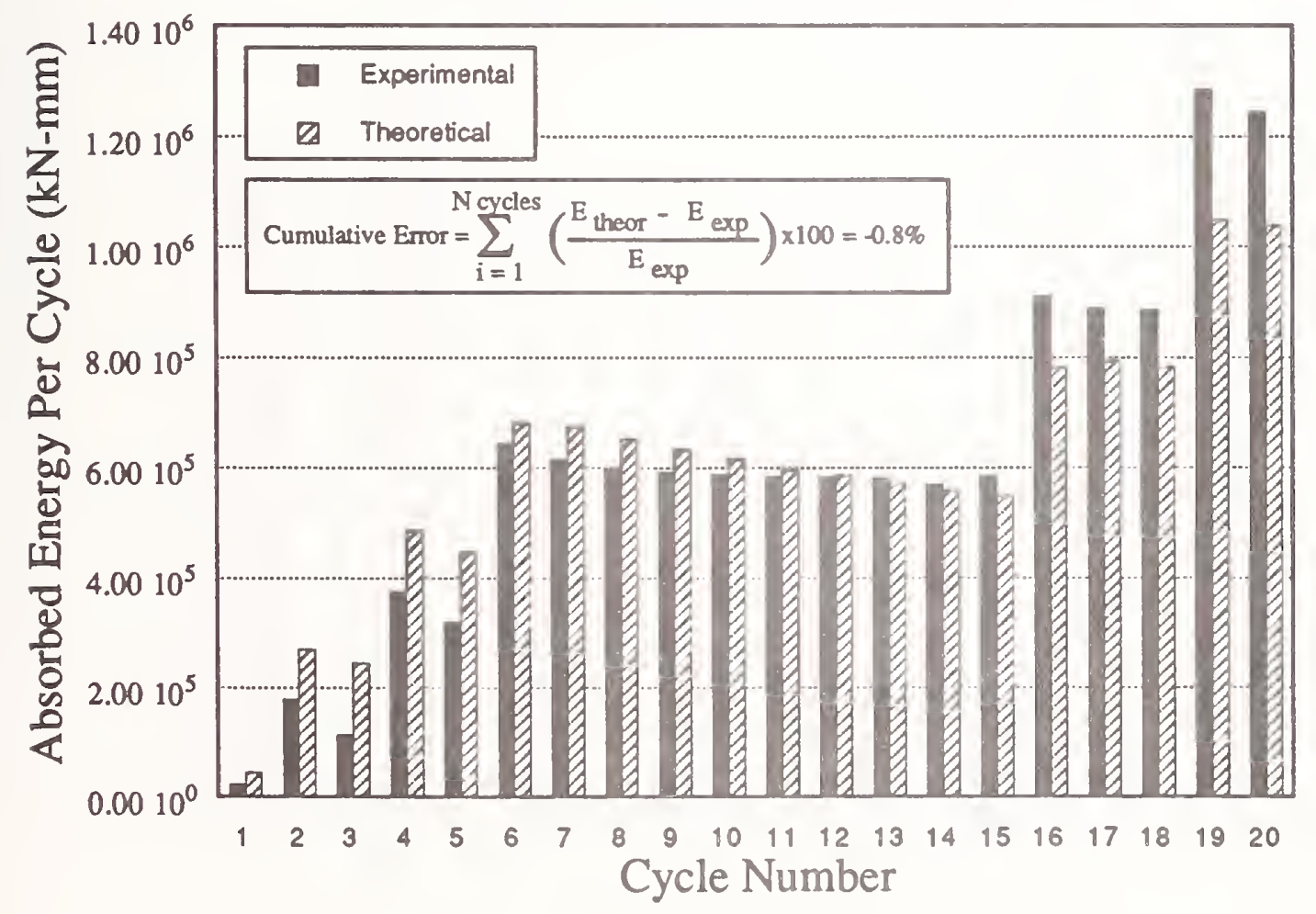

Figure 5. Experimental and analytical results for NIST full scale flexure specimen. 
NIST Model Specimen N1

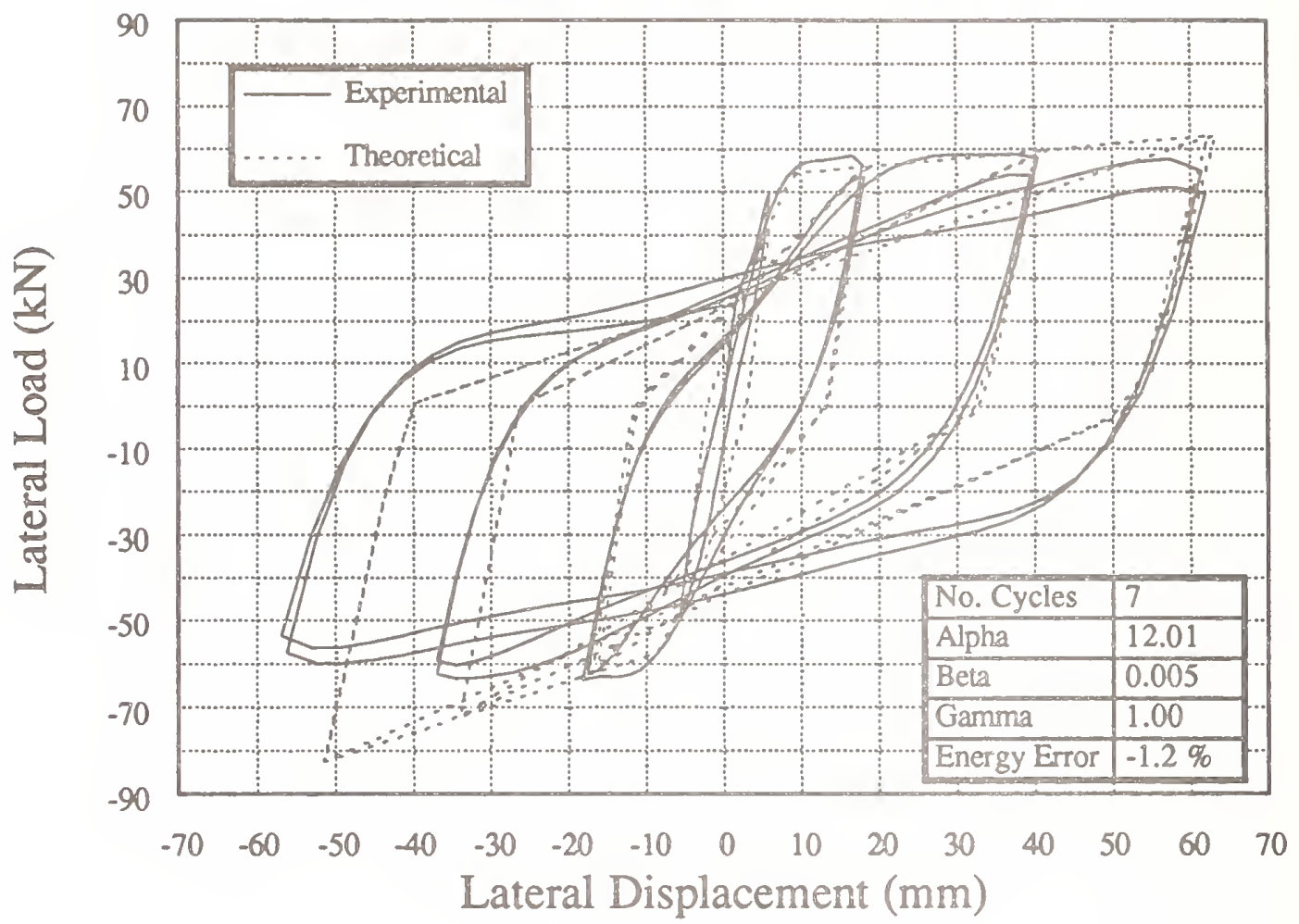

NIST Model Specimen N1

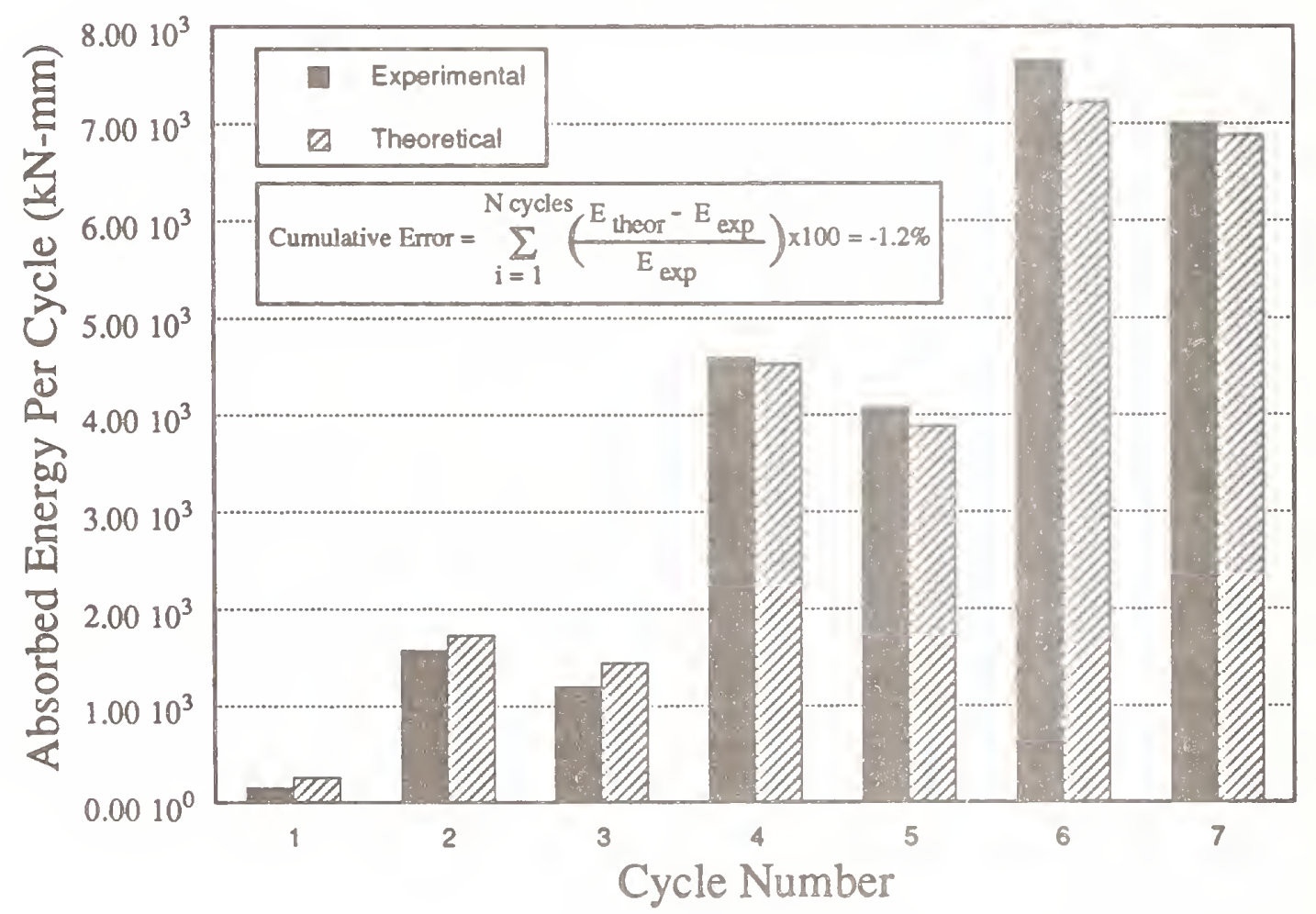

Figure 6. Experimental and analytical results for NIST model specimen N1. 


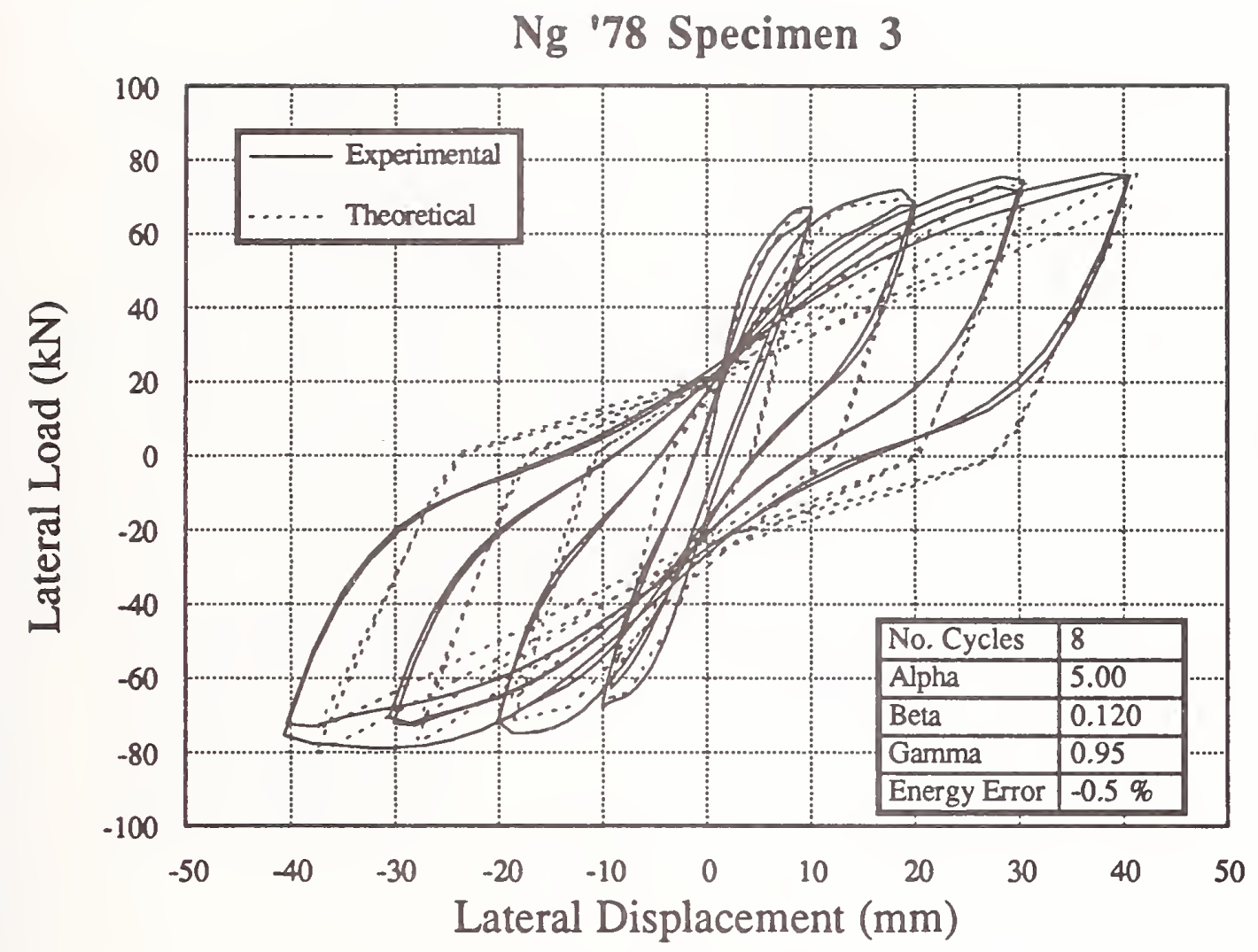

Ng '78 Specimen 3

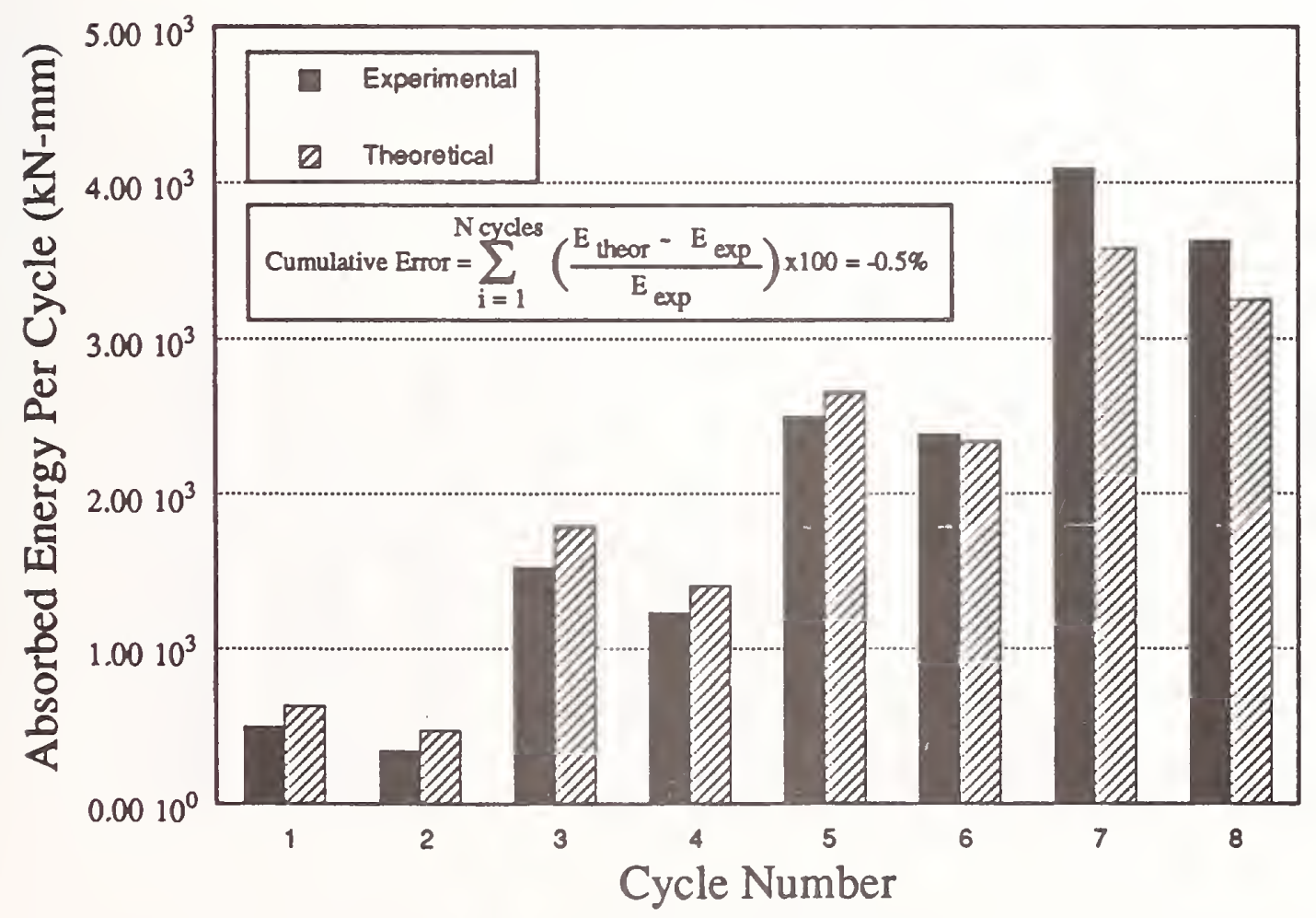

Figure 7. Experimental and analytical results for specimen 3 of $\mathrm{Ng}$. 


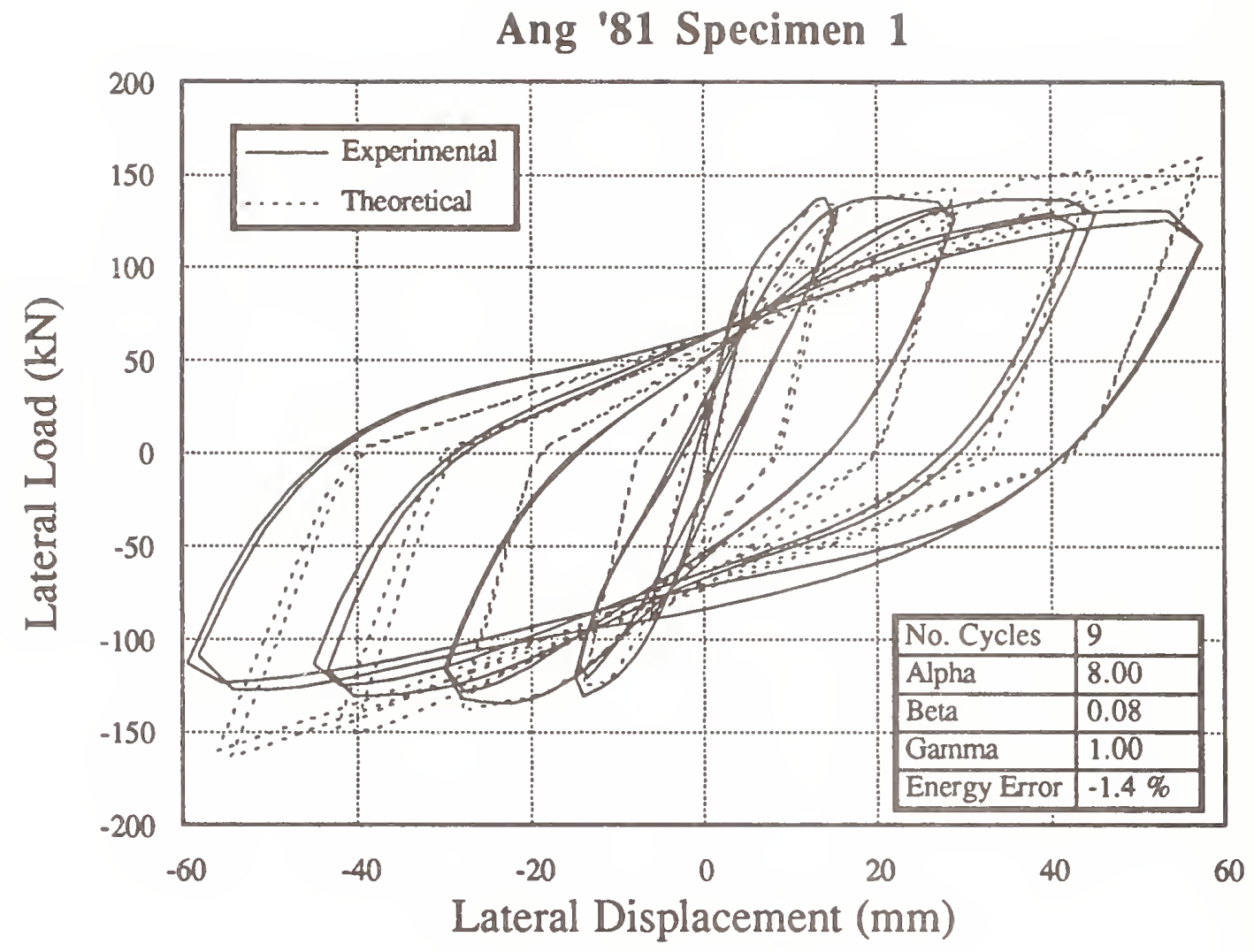

Ang '81 Specimen 1

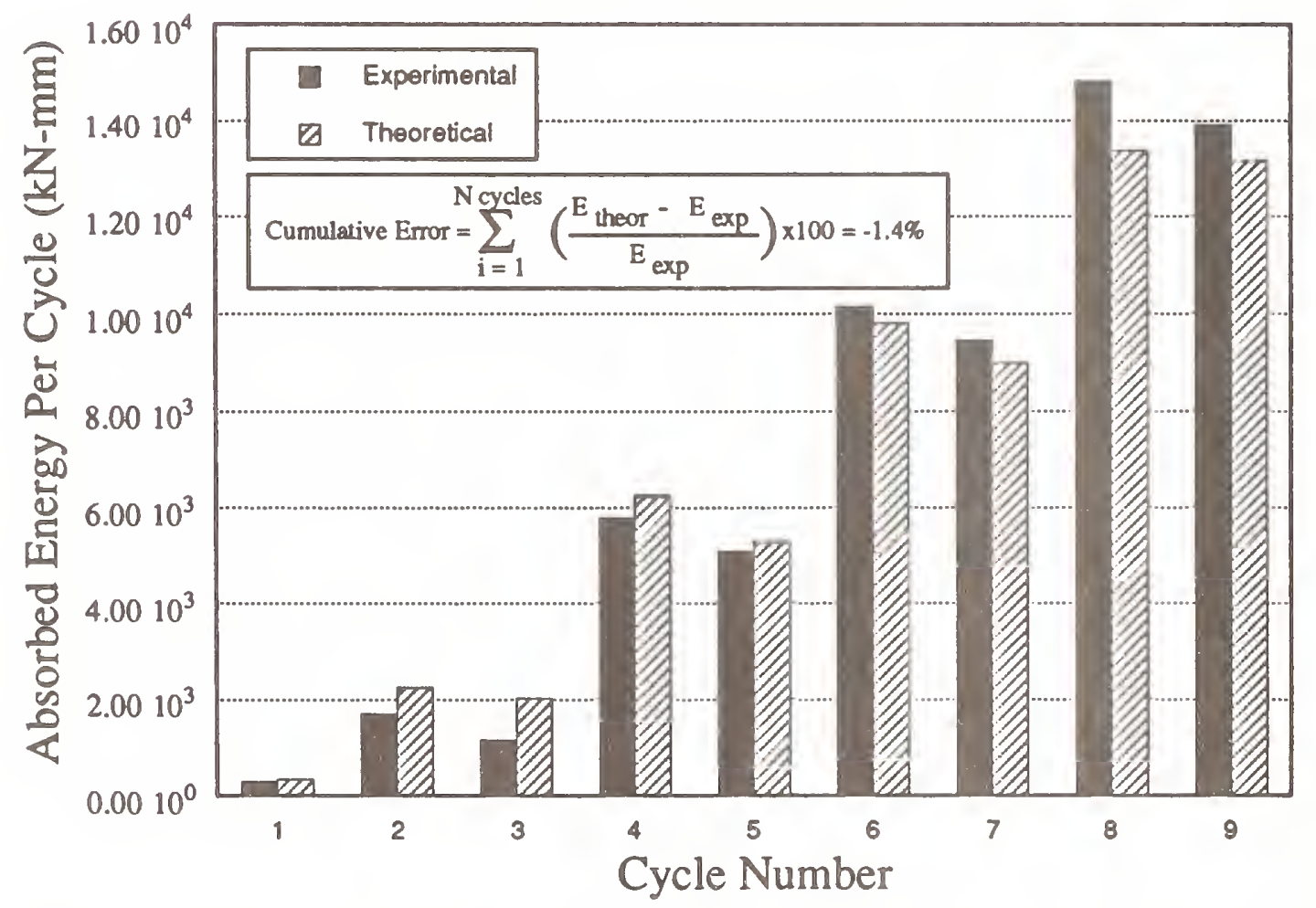

Figure 8. Experimental and analytical results for specimen 1 of Ang. 
Potangaroa '79 Specimen 1

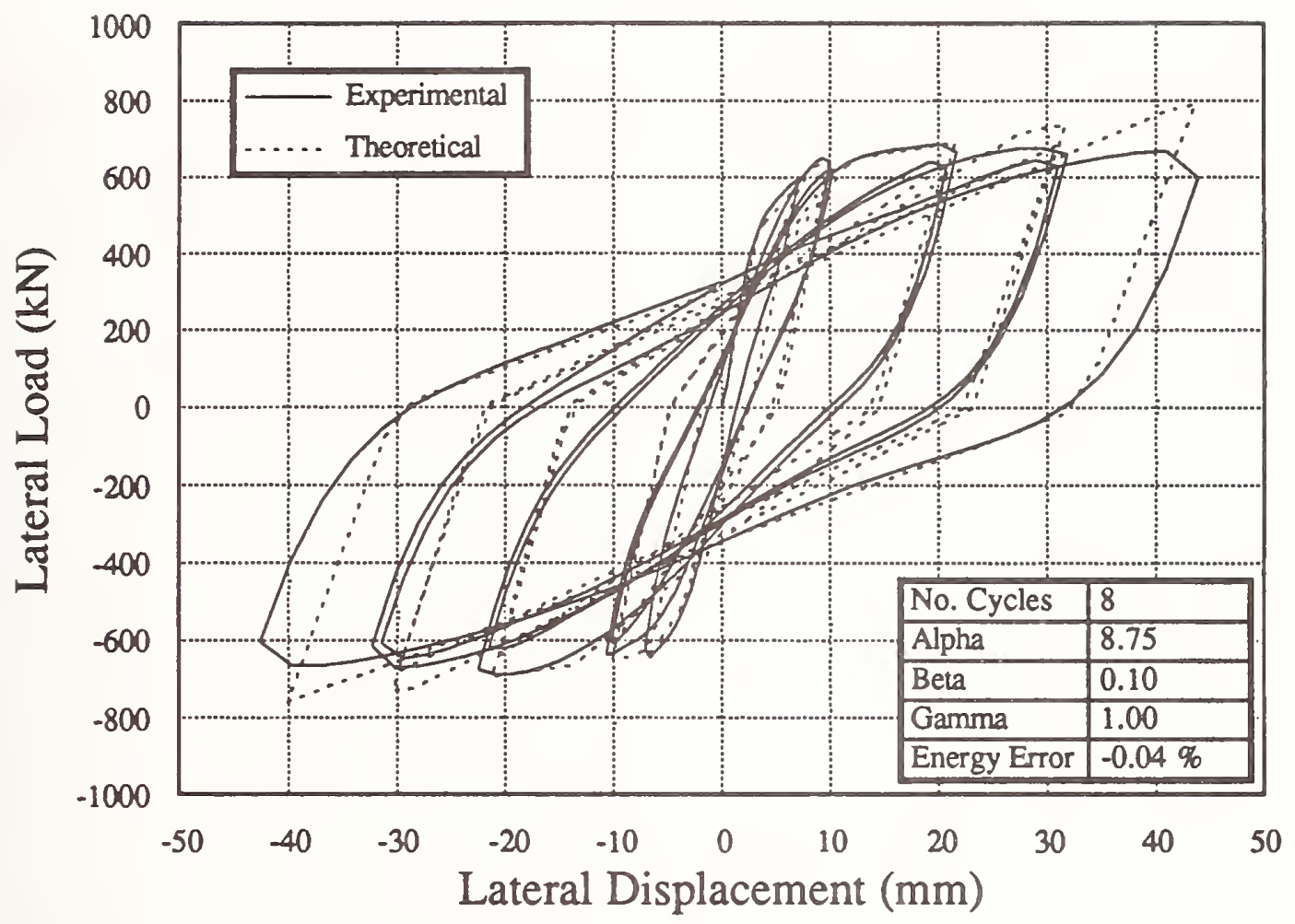

Potangaroa '79 Specimen 1

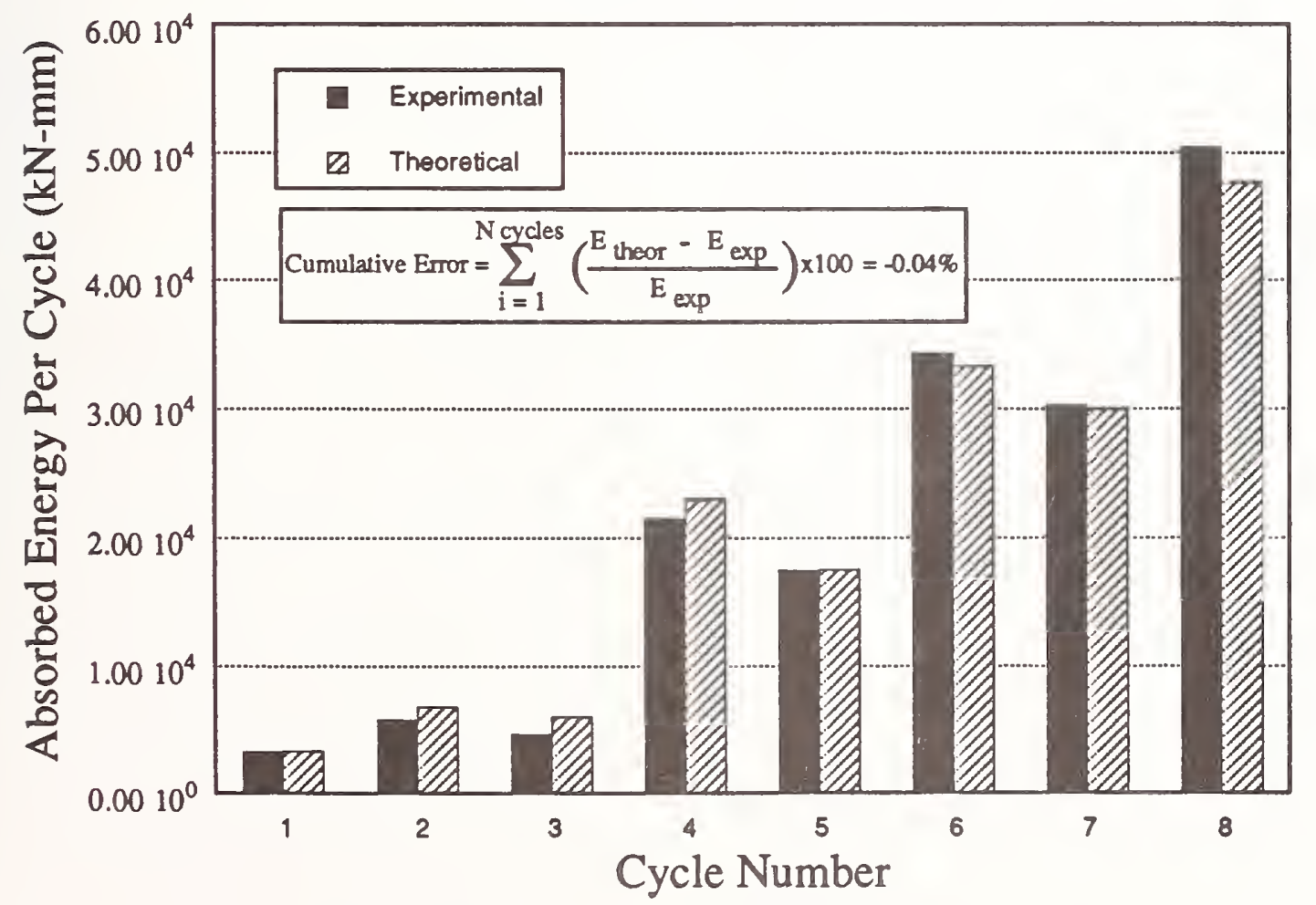

Figure 9. Experimental and analytical results for specimen 1 of Potangaroa. 


\section{Simplified Procedure for Inspecting Earthquake Resistant Potential of Highway Bridges Against Soil Liquefaction}

by

Ken-Ichi Tokida', Jiro Fukui ${ }^{2}$ and Hideo Matsumoto ${ }^{3}$

SUMMARY

Reasonable and simplified procedures are necessary to inspect the earthquake resistant potential of existing highway bridges. Effects due to soll liquefaction during earthquakes are very important problem on the earthquake resistance of bridge foundations and should be considered for the inspection of bridges adequately. Inspections on the earthquake resistant potential of highway bridges have been carried out in Japan since 1971, and the inspection procedure has been improved step by step.

The next inspection of earthquake resistant potential for highway bridges will be conducted in Japan, In 1991. For this inspection, the procedure to inspect the liquefaction-induced damage potentlal of highway bridges has been investigated to improve the former procedure of 1986-inspection. The procedure for the next inspection will be drafted in the near future, referring to the results of the detall investigation shown in this paper.

In this paper, newly investigated procedure for inspecting the liquefaction-induced damage potentlal of highway bridges is presented.

KEY WORDS : Earthquake resistance of bridge foundation, site liquefaction potential, Liquefaction-induced damage potentlal, Procedure for inspection

\section{FOREWORD}

Two kinds of procedures to reduce the earthquake-induced damage of highway bridges can be considered; (1) the earthquake design method for newly-constructing bridges; and (2) the retrofit method for existing ones. The earthquake design methods have been investigated for a long time and applled to the actual design of highway bridges in Japan [ 1 , 2]. On the other hand, the inspections to check the earthquake resistance of existing bridges also have been carried out since 1971 for retrofit of highway bridges.

Table-1 shows the history of procedures for inspecting the earthquake resistant potential of highway bridges In Japan. As shown in this table, soll liquefaction was not inspected directly at the first stage of inspection in 1971 and 1976. However, liquefaction potential of a ground was noted concretely for the first time in the 1979-inspection. Furthermore, in the 1986-inspection, both liquefaction potential of a ground and its effects on bridge foundations were considered. The next inspection for the earthquake resistant potential of highway bridges will be conducted in 1991.

Based on results of the 1986-inspection and lessons from the past earthquakes, the following is necessary to be investigated for establishing the reasonable procedure for the coming inspection.

1) Lack of data for inspection:

For inspecting the liquefaction potential of a ground and the liquefaction-induced damage potential of a bridge suitably, the data related to both ground conditions and structural conditions of highway bridges, especlally, foundation conditions should be surveyed. However, because it is generally difficult to get the data, especially on borings and/or structures related to the bridges constructed long ago, it should be considered how to deal with the bridges without suitable data for inspection. From this point of view, simplified procedures are proposed for the coming inspection with use of data which can be obtained easily in this paper.

2) Reasonable estimation of both liquefaction and its effects on structures:

Not only the occurrence of soil liquefaction but also the effects induced by liquefaction should be considered. From this point of view, two kinds of indexes; (1) the site liquefaction potential; (2) and the liquefaction-induced damage potential are proposed to estimate the scale of liquefaction and damage of highway bridges more quantitatively than the 1986-inspection in this paper.

\section{GROUND LIQUEFACTION POTENTIAL}

\subsection{Indexes of Ground Liquefaction Potential}

As a first stage for inspecting the earthquake resistant potentlal of highway bridges, a ground liquefaction potential defined as the probabillty and/or scale of occurrence of

lHead, Ground Vibration DIvision, Public Works Research Institute, Ministry of Construction. Japan.

2Senlor Researcher, Foundation Division, ditto. 3Researcher, Ground Vibration Division, ditto. 
soll liquefaction at the bridge site should be estimated roughly and/or in detall according to the data obtained. In this paper, indexes for estimating the ground liquefaction potential are proposed as follows :

1) Ground Group and Topographical Group:

Because these indexes can bc got casily comparing with the boring data, they can be applied for inspecting the ground liquefaction potential roughly [see Section 2.3] . 2) Liquefaction Resistance Factor $\left(F_{L}\right)$, Modified Thickness of Liquefiable Layer $\left(H^{*}\right)$ and Site Liquefaction Potentlal ( $\left.I_{P_{L}}\right)$ :

However it needs to get boring data and test results of soll properties to calculate these indexes, they can be applicd for inspecting the ground liquefaction potential in detail [see Section 2.2].

Furthermore, the relation of site liquefaction potential between the objective bridge site and the neighboring site of the bridge is investigated in Section 2.4 .

\subsection{Procedure for Detail Inspection of Ground Liquefaction Potential}

Liquefaction potential as for sandy soll layers can be examined based on the liquefaction resistance factor $F_{L}$ defined by the following equation applied in the "Specification for Highway Bridges" $[1,2]$.

$F_{L}=R / L$

where

$F_{L}$ : Liquefaction resistance factor

$\mathrm{R}$ : Resistance of soll elements to dynamic loads, and $R=R_{1}+R_{2}+R_{3}$

$R_{1}$ : Resistance based on relative density

$R_{2}$ : Resistance based on Dso-values

$\mathrm{R}_{3}$ : Resistance based on fine contents

$R_{1}=0.0882 \sqrt{N} /(\sigma \vee+0.7)$

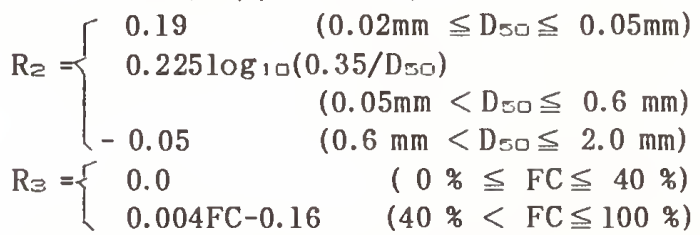

$\mathrm{L}$ : Dynamic load to soll elements

$$
\begin{gathered}
\mathrm{L}=\mathrm{r}_{a} \cdot \mathrm{k}_{s} \cdot\left(\sigma * / \sigma v^{\prime}\right) \\
\mathrm{r}_{a}=1.0-0.015 \mathrm{x} \\
\mathrm{k}_{a}=\mathrm{C}_{\bar{L}} \mathrm{C}_{G} \mathrm{C}_{1} \mathrm{k}_{\square}
\end{gathered}
$$

$\mathrm{N}$ : Blow count by standard penetration test

$D_{50}$ : Mean grain size $(\mathrm{mm})$

FC : Fine contents (\%)

$\mathrm{x}$ :Depth from the actual ground surface $(\mathrm{m})$

$k_{3}$ :Seismic coefficient for evaluating liquefaction

$\mathrm{C}_{\bar{z}}$ : Selsmic zone factor

$\mathrm{C}_{G}$ : Ground condition factor

$\mathrm{C}_{1}$ : Importance factor
$\mathrm{K}_{\square}:$ Standard seismic coefficient $(=0.15)$ $\sigma \vee:$ Total overburden pressure $\left(\mathrm{kgf} / \mathrm{cm}^{2}\right)$

$\sigma \because^{\prime}$ : Effective overburden pressure at the static condition $\left(\mathrm{kgf} / \mathrm{cm}^{\overline{2}}\right)$

Soll layers with the liquefaction resistance factor $F_{L}$ smaller than 1.0 are judged to liquefy during earthquakcs. However $F_{L-}$ value is very suitable to estimate the liquefaction potential of a certain layer at the objective depth, another index is necessary to estimate the liquefaction potential of the whole subsurface ground in stead of $F_{L}-$ value.

In this paper, the following index is proposed as the simplified parameter to represent the ground liquefaction potential.

$$
I_{F L}=\frac{H^{*}}{20}
$$

where

$I_{F L}:$ Site liquefaction potential [ $\left.\leqq 1.25\right]$

$\mathrm{H}^{*}$ : Modified thickness of liquefiable layers, and $\mathrm{H}^{*}=\mathrm{H}_{1}{ }^{*}+\mathrm{Hz}_{2}{ }^{*}$

$$
\mathrm{H}_{1}{ }^{*}=1.5 \mathrm{H}_{\mathrm{FL}}+1.0 \mathrm{H}_{\mathrm{FLz}}+0.5 \mathrm{H}_{\mathrm{FL} 3}
$$$$
\mathrm{Hz}^{*}=1.0 \mathrm{H}_{\mathrm{FL}}+0.5 \mathrm{H}_{\mathrm{FL}} \mathrm{z}
$$

$\mathrm{H}_{\mathrm{t}}{ }^{*}$ : Modifled thickness of liquefiable layer at the depth of 0 to $10 \mathrm{~m}$

$\mathrm{Hz}^{*}$ : Modifled thickness of liquefiable layer at the depth of 10 to $20 \mathrm{~m}$

$H_{F L 1}$ : Total thickness of layers

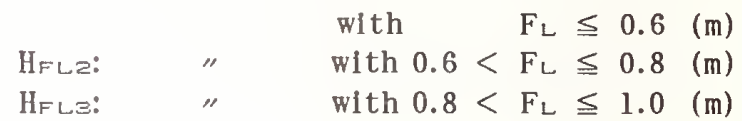

The coefficients in the parameters $\mathrm{H}_{1}{ }^{*}$ and $\mathrm{H}_{2}{ }^{*}$ are decided for convenience sake, by referring the relation in Table-2 [ 1] where bearing capacities of liquefied ground are elther neglected or reduced by reduction factors $D_{E}$ determined in accordance with $F_{L}$-values.

The damages of bridges induced in the past earthquakes in Japan are investigated in view point of the effects of liquefaction and so on. Table-3 shows the typical examples of bridges which can be estimated to be damaged mainly by liquefaction. Site liquefaction potential $\left(I_{F L}\right)$ is calculated with use of boring data at the bridges as shown in Table-3. Furthermore, the damages of bridges related to liquefaction during earthquakes are classified into five levels as shown in Table-4 in this paper. For the bridges in Table-3, the relation between the damage level of bridges and the site lique- faction potential ( $I_{F L}$ ) can be drawn in Fig. 1. The standards on site liquefaction potential can be classified into three groups as follows, considering the damage level of bridges as shown in Table-3.

【 $I_{F L}<0.2 】$ There were not any case of damage related to girder fall induced by 
liquefaction. The scale of liquefaction and its effects on bridges can be assumed to be small. $\quad$............................ (Estimation-1)

【 $0.2 \leqq I_{F L}<0.4 】$ There were cases of damage related to liquefaction. The effects by liquefaction on bridges can be assumed to exist. ........................... (Estimation-2)

【 $0.4 \leqq I_{P L}$ 】 There were cases of girder fall induced by liquefaction. The scale of liquefaction and its effects on bridges can be assumed to be very severe...(Estimation-3)

From the above results, it can be indicated that the index of $I_{P L}$ can be used as one of indexes to estimate the ground liquefaction potential at the bridge site. The IF values of 0.2 and 0.4 can be applled as the boundary to Judge the level of ground liquefaction potential, considering the damage level of bridges.

\subsection{Procedure for Macro-inspection of Ground Liquefaction Potential}

Both ground group and topographical group are selected as the indexes for macroinspection of the ground liquefaction potential, and their effectiveness are investigated in this section.

2.3.1 Ground Group and Site Liquefaction Potential

The ground condition can be classified roughly according to the stiffness and/or amplification characteristics of ground at the bridge site. In this paper, the ground conditions are assumed to be classified into three groups; (1) Ground Group I ; (2) Ground Group II ; and (3) Ground Group $I I$ as shown in Table-5 which shows the classification of ground groups defined in the "Specification for Highway Bridge" $[1,2]$.

Table-6 shows the results investigated on the relation between the ground group and the site liquefaction potential (IPL) at 217 sites of bridges. As shown in Table-6, the sites included in Ground Group I can be assumed as the ones with a low liquefaction potential related to the damage of bridges, considering the Estimation-1 of Section 2.2. In other words, the sites classifled as Ground Group II or III are in danger to have high liquefaction potential related to damage of bridges.

2.3.2 Topographical Group and Site Liquefaction Potential

It is well known that the topographical condition is related to the probability of liquefaction occurrence. In this paper, top- ographical conditions are classifled roughly into three groups, 1.e., A, B and C which are proposed as Table-7 for inspecting the earthquake resistant potential of highway bridges.

Table-8 shows the results investigated on the relation between the topographical group and the site liquefactlon potential ( $I_{F L}$ ) at 332 sites of bridges. As shown in Table-8, the site classified as Topographical Group A can be assumed to have high liquefaction potential related to the damage of bridges. in other words, the sites classified as Ground Group B or $\mathrm{C}$ can be assumed to have low liquefaction potential related to damage of bridges.

\subsection{Liquefaction Potential at Nelghboring Sites}

For dealing with the problem on the lack of boring data at the site of the objective bridge, the relation of liquefaction potential between the bridge site and its neighboring site is investigated with use of the index defined by Eq. (3).

$$
\mathrm{HT}=\mathrm{H}_{1}^{* *}+\mathrm{H}_{2}^{* *}
$$

where

HT : Modified thickness of liquefiable layer (m) $[\leqq 16(2 / 3) \mathrm{m}]$

$$
\begin{aligned}
& \mathrm{H}_{1}{ }^{* *}=1.0 \mathrm{HFL}_{1}+(2 / 3) \mathrm{HFLZ}_{\mathrm{FL}}+(1 / 3) \mathrm{H}_{\mathrm{FLE}} \\
& \mathrm{H}_{2}{ }^{* *}=(2 / 3) \mathrm{HFL}+(1 / 3) \mathrm{HFLZ}_{\mathrm{FL}}
\end{aligned}
$$

$\mathrm{H}_{1}{ }^{* *}$ : Modified thickness of liquefiable layer at the depth of 0 to $10 \mathrm{~m}$

$\mathrm{H}_{2}{ }^{* *}$ : Modified thickness of liquefiable layer at the depth of 10 to $20 \mathrm{~m}$

HFL1, HFL2, HFLs : See Eq. (2)

The coefficients in the parameters $H_{1}{ }^{* *}$ and $\mathrm{H}_{2}{ }^{* *}$ are decided in the same way with the parameters $\mathrm{H}_{1}{ }^{*}$ and $\mathrm{H}_{2}{ }^{*}$ shown in Eq. (2).

For the above investigation, 187 boring data with liquefiable layers are selected within a radius of $750 \mathrm{~m}$ around 10 bridges. The modified thickness of liqueflable layer (HT) of selected sites distributes as shown in Fig. 2. Five items which seem related to liquefaction and their categories are selected to investigate the relations between the boring data of a bridge site and the ones at its neighboring sites as follows.

(Item-1) Difference of above the sea level. Category: $\sim-3 \mathrm{~m} \sim-1 \mathrm{~m} \sim 1 \mathrm{~m} \sim 3 \mathrm{~m} \sim$

(Item-2) Distance. Category: $0 \sim 100 \mathrm{~m} \sim 300 \mathrm{~m} \sim 500 \mathrm{~m} \sim 750 \mathrm{~m}$

(item-3) Difference of ground water level. Category: $\sim-3 \mathrm{~m} \sim-1 \mathrm{~m} \sim 1 \mathrm{~m} \sim 3 \mathrm{~m}$

(Item-4) Difference of ground group. Category: $-1,0,1,2$

(Item-5) Difference of topographical group. Category: $\quad 0,1,2$ 
Fig. 3 shows the distribution of data according to the categories of each items. The regression coefficient and correlation between the difference of modified thickness ( $\Delta \mathrm{HT}$ ) and the above items with each category are calculated with use of type I quantification anaiysls, and the results are summarlzed in Tabic-9. Based on the results of Table-9, however all of correlations are very low, the three correlations on the differences of ground water level, topographical group and ground group are relatively high comparing with other items. Furthermore, as for two items of difference of ground water level and topographical group, the difference of modified thickness ( $\triangle$ IIT) is inclined to increase according to the increase of them.

From the above investigation, the difference of topographicaI group, difference of ground group and difference of ground water level seem to relate to the Ilquefaction potential between two sites, relatively. The guidelines to adopt the boring data at the neighboring site for estimating site liquefaction potential (IpL) of the objective bridge can be proposed as shown in Table-10 for convenlence sake.

\section{LIQUEFACTION-INDUCED DAMAGE POTENTIAL OF BRIDGE}

\subsection{Indexes Related to Damage of Bridge by Liquefaction}

For surveying the indexes related to the liquefaction induced damage of bridge foundations, the following five indexes are selected considering the results of Table-3.

IJ : Supported condition on pier-top.

$l_{F}$ : Foundation type.

$I_{F s}$ : Bearing condition of foundation.

$I_{F L}:$ Site Ilquefaction potential.

Isc : Ground group.

Table-11 shows the categories of each index mentioned above. With use of type I quantification analysis, five cases for analyzing the effects of these indexes to the damage of bridges are conducted by combining them as shown in Table-12. In this analysis. the damage level (see Table-4) of bridge foundations is defined as a dependent varlable and the independent variables are combined with the indexes as shown in Table-12.

Table-13 summarizes the results of category-scores and correlation-coefficients for each case. From these results, it can be seen that the three indexes, i.e., $I_{F}, I_{F} \Xi$ and $I_{H L}$ can explain the damage level of bridge foundations relatively well.
3.2 Simplified Method for Estimatlng Liquefaction-Induced Damage Potential of Highway Bridge

It should be noted that the damage patterns of bridge foundations induced by soll liquefaction is different according to the foundation type as shown in Tablc-14. In other words, it ls desirable to select the suitable indexes to explain the cause of damage induced by liquefactlon. Based on results in Section 3.1 and lessons from the past earthquakes, three indexes, 1.e., P I , P II and P III are proposed in Eqs. (4-1), (4-2) and (4-3), respectively for convenience sake to estimate the liquefaction-induced damage potential of bridge foundations according to the foundation type (see Table-15). For estimating these indexes quantitatively, the weighted points are supposed roughly, considering the scale of effects to damage of bridges.

Abutment:

$\mathrm{PI}=\left(\hat{1}_{C}+1 ;+1_{F}+1_{F E}\right) \times 1_{F L} \times I_{H E} \cdots \cdots(4-1)$

Movable Pier:

$\mathrm{P}$ II $=\left(\mathrm{I}_{C}+\mathrm{I}_{F}+\mathrm{I}_{F S}\right) \times \mathrm{I}_{\mathrm{PL}} \times \mathrm{I}_{G G} \cdots \cdots \cdots(4-2)$

Fixed Pler:

$P$ III $=\left(I_{F}+I_{F S}\right) \times I_{F L}$ where

Ic: Effect of device against fall of a girder

- Continued girder, Fixed girder : 0.0

- Both insurance of $S_{E}$ and installation of stopper/connection : 0.5

- Insurance of $\mathrm{S}_{E}$ or installation of stopper/connection $: 1.0$

- Not insured $: 1.5$

(Note) $\mathrm{S}_{E}$ :Distance between the end of girder and the crest of a substructure.

I. : Effect of girder-support condition on the top of pier/abutment

- Movable bearing : 0.0

- Fixed bearing : 1.0

$l_{F}$ : Effect of foundatlon-type

- Pile, Calsson : 1.0

- Wooden pile, Pile bent : 2.0

$I_{F}:$ : Effect of bearing condition at the bottom of foundation

- Perfect support

$: 1.0$

- Imperfect support

$: 5.0$

- Shallower than liquefied layer : 6.0

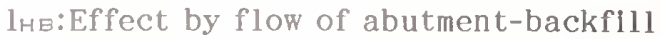

(Represented with lieight of backfill: $H_{B}$ )

- $\mathrm{H}_{\mathrm{\theta}}<5.0 \mathrm{~m}: 1.0$

- $\| l_{B} \geqq 5.0 \mathrm{~m}: 1.2$

lpL:Effect by liquefaction (Site liquefaction potential : IPL)

$\cdot 0.2 \leqq I_{F L}<0.4: 1.0$

$\cdot 0.4 \leqq I_{F L} \quad: 1.5$

(Note)The site with $I_{P L}<0.2$ is omitted because of low liquefaction potential.

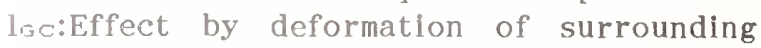
ground (Represented with Ground group) 
- Ground group II : 1.0

- Ground group III : 1.2

3.3 Llquefaction-Induced Damage Potential of Highway Bridge in the Past Earthquakes

The simplifled procedure for estimating $11 q^{-}$ uefaction-Induced damage potential of highway bridge proposed in Section 3.2 are applied to the bridge foundations damaged in the past earthquakes as shown in Table-3. Figs. 4(1), 4(2) and 4(3) show the relations between liquefaction-induced damage potential and damage level for abutment, movable type of pler and flxed type of pler, respectively. Based on these results, the boundary values of Indexes related to the severe damage of bridges, 1.e., with the damage level more than 4 can be estimated as follows.

Abutment:

P I $<6.0$ :Damage Induced by liquefaction can be estimated to be small.

P I $\geqq 6.0:$ Be in danger of severe damage. Detail investigation should be necessary.

\section{Movable Pler:} ....................... (Relation -4$)$

$\mathrm{P}$ II $<6.0$ :Damage induced by liquefaction can be estimated to be small.

P II $\geqq 6.0:$ Be in danger of severe damage. Detall investigation should be necessary.

Fixed Pler:

\section{(Relation-5)}

$\mathrm{P}$ III $<4.5$ :Damage induced by liquefaction can be estimated to be small.

$\mathrm{P}$ III $\geqq 4.5$ :Be in danger of severe damage. Detail investigation should be necessary.

(Relation-6)

4. SIMPLIFIED PROCEDURE FOR ESTIMATING EARTHQUAKE RESISTANT POTENTIAL OF HIGHWAY BRIDGE AGAINST SOIL LIQUEFACTION

From the above investigation and other lessons in the past earthquakes, the simplified procedure for estimating earthquake resistant potential of highway bridge against soll liquefaction can be proposed such as Fig. 5. As shown in this flow-chart, the inspection is classified into four stages as follows.

1) First-stage of Fundamental Inspection:

In this stage, before inspecting the site liquefaction potential and the liquefactioninduced damage potential, the bridges in the following conditions can be excluded.

(1) Bridges designed with use of the specIfications after 1971 in which the effects of liquefaction are considered for earthquake resistant design of bridges.

(2) Bridges whose superstructure can be considered as the types not effected by soil liquefaction severely, for example, Deck Arch Bridge, Rigid-frame Bridge and Culvert Bridge.

2) Second-stage of Site Liquefaction Inspection:

In this stage, the site liquefaction potential is inspected before inspecting the effects of liquefaction on bridges. The inspection flow is divided into two flows according to the existence of boring data at the bridge site. When the boring data is possible to get, the site liquefaction potential can be calculated with use of the index of IPL proposed In Eq. (2). On the other hand, when the data can not be got, the ground liquefaction potential is estimated roughly with use of elther ground group or topographical group of the bridge site based on the results in Section 2.3.

Furthermore, for the bridge site judged as both Ground Groups II and III and Topographlcal Groups A , the boring data at the neighboring site of the bridge site which can be selected by the standard proposed in Table-10 is possible to use to calculate the site liquefaction potential $\left(I_{F L}\right)$. When the site liquefaction potential ( $I_{P L}$ ) is less than 0.2 , the effects of liquefaction is judged to be small by the Relation-1 shown in Section 2.1 and further inspection is not necessary. When the soll data for the index of $I_{F L}$ can not be got at both bridge site and neighboring site, the inspection should progress in the next stage.

(3) Third-stage of Damage Potential Inspectlon:

In this stage, the liquefaction-Induced damage potentlal of P I, P II and P II should be calculated by Eqs. (4-1), (4-2) and (4-3) for the abutment, movable pier and fixed pier, respectively. When the values of P I, P II and $\mathrm{P}$ II are less than the boundary shown in Relations-4, -5 and -6 in section 3.3, the damage induced by soll liquefaction is assumed to be small and further inspection is not necessary.

(4) Four-stage of Detall Stability Inspection:

In this stage, the detail inspection should be conducted to calculate the stability and resistance of foundations by the earthquake resistant design of highway bridge $[1,2]$.

For the unstable bridges for soll liquefaction, the countermeasures for reducing the effects of liquefaction should be selected and designed for planning the retrofit of bridges in the future. 


\section{FUTURE REMARKS}

The results introduced in this paper wlll be referred in the next inspection of earthquake resistant potential for highway bridges conducted in 1991. The further investigation will be carried out after obtalning the results of next inspection to Improve the procedure more reasonably in the future.

\section{ACKNOWLEDGEMENT}

The authors wish to express thelr sincere gratitude to Dr. T. Iwasakl, Dr. Y. Sasakl and Dr. K. Kawashima of Public Works Research Institute (PWRI) for their invaluable comments and to Road Disaster Prevention Section of Road Bureau, Kanto Reglonal Construction Bureau, Metropolltan Government, Kanagawa Prefectural Office, Chlba Prefectural offlce, Yokohama City office, Kawasakl City office, Japan Highway Publlc Corporation and Metropolitan Expressway Publlc Corporation for thelr cooperation of pllot study. The authors also wishes to express thelr gratitude to Dr. S. Uehara and Dr. T. Morohoshl of National Research Institute for Earth Sclence and Disaster Prevention for their allowance to use the boring data-base and to $\mathrm{Mr}$. T. Azuma of Ground Vibration Division for his assistance to prepare the manuscript of this paper.

\section{REFERENCES}

1) Japan Road Assoclation, "Speciflcation for Highway Bridges, Part V. Earthquake Resistant Deslgn", February, 1990 (In Japanese). 2) Iwasaki T., Kawashima K. and Hasegawa K., "New Selsmic Design Speclfications for Road Bridge in Japan", 22nd Jolnt Meeting U.S.Japan Panel on wind and Selsmic Effects, U.J.N.R., Gaithersburg, Maryland, U.S.A., May, 1990 .

3) Toklda K, Fukul J. and Matsumoto H., "Simplified Examination Method on the Stabllity of Bridges Considering the Effects of Soll Liquefaction", International Workshop on Remedial Treatment of Potentially Liquefiable Solls, Task Committee "H" of Panel on Wind and Selsmic Effects, U.J.N.R., Public Works Research Institute, Tsukuba Sclence City. Japan, January, 1991 . 
Table-1 History of Inspection for Earthquake Resistant Potentlal of Highway Bridge Considering Liquefaction Effects in Japan.

\begin{tabular}{|c|c|c|}
\hline \multicolumn{2}{|c|}{ Stage } & Inspection Procedure for Liquefaction \\
\hline 1 & 1971 & $\begin{array}{l}\text { - Views by Site Observation. } \\
\text { - Liquefaction is not considered directly. }\end{array}$ \\
\hline 2 & 1976 & $\begin{array}{l}\text { - Check List for Present Condition and Damage. } \\
\text { - Damage Potential (A, B, C) for Each Check-index. } \\
\text { - Liquefaction is not considered directly. }\end{array}$ \\
\hline 3 & 1979 & $\begin{array}{l}\text { - First-and Second-stage Inspection. } \\
\text { - Ground /Superstructure/Substructure. } \\
\text { - Calculation of Bearing Capacity of Pile (2nd-stage). } \\
\text { - Estimation of Cost for Countermeasure. } \\
\text { - Liquefaction potential of ground is considered. } \\
\text { 1st-stage : Existence of Saturated Sandy Layers (Yes/No). } \\
\text { 2nd-stage: Thickness of Saturated Sandy Layers } \\
\qquad(\sim 1.0 \mathrm{~m} \sim 10.0 \mathrm{~m} \sim) .\end{array}$ \\
\hline 4 & 1986 & $\begin{array}{l}\text { - First-, Second- and Third-stage Inspection. } \\
\text { - Ground /Superstructure/Substructure. } \\
\text { - Calculation of Bearing Capacity of Pile (2nd-stage). } \\
\text { - Estimation of Cost for Countermeasure. } \\
\text { - Liquefaction potential of ground and its effect to foundation } \\
\text { are considered. } \\
\text { 1st-stage : Existence of Saturated Sandy Layers (Yes/NO). } \\
\text { 2nd-stage: Calculate } F_{L} \text { and Thickness (HL) of Layer with } F_{L} \\
\text { less than } 0.6 \text {. } \\
\text { Compare } H_{L} \text { with Depth of Foundation. }\end{array}$ \\
\hline 5 & 1991 & - Inspection Procedure is investigated at present. \\
\hline
\end{tabular}

Table-2 $F_{L} \sim D_{E}$ Relation ${ }^{13.2)}$

\begin{tabular}{|c|c|c|}
\hline$F_{L}$ & Depth, $Z$ (m) & Reduction Factor, $D_{\Sigma}$ \\
\hline$F_{L} \leqq 0.6$ & $Z \leqq 10$ & 0 \\
& $10<Z \leqq 20$ & $1 / 3$ \\
\hline $0.6<F_{L} \leqq 0.8$ & $Z \leqq 10$ & $1 / 3$ \\
& $10<Z \leqq 20$ & $2 / 3$ \\
\hline $0.8<F_{L} \leqq 1.0$ & $Z \leq Z \leqq 20$ & $2 / 3$ \\
& $10<Z$ & 1 \\
\hline $1.0<F_{L}$ & - & 1 \\
\hline
\end{tabular}


Table-3 Damage of Hlghway Bridge and Liquefaction in Japan

\begin{tabular}{|c|c|c|c|c|c|c|c|c|}
\hline \multirow{2}{*}{$\begin{array}{l}\text { Earth- } \\
\text { quake } \\
\text { (EQ) }\end{array}$} & \multirow{2}{*}{$\begin{array}{l}\text { Name of } \\
\text { Hlghway } \\
\text { Bridge }\end{array}$} & \multirow{2}{*}{$\begin{array}{l}\text { Typical Damage of } \\
\text { Bridge Structures }\end{array}$} & \multicolumn{4}{|c|}{ Objective Substructure } & \multirow{2}{*}{$\begin{array}{l}\text { Llquefaction } \\
\text { Phenomena }\end{array}$} & \multirow{2}{*}{$\begin{array}{l}\text { Site } \\
\text { LIQ. Pot. } \\
\text { IPL }\end{array}$} \\
\hline & & & No. & & and its Damage & & & \\
\hline \multirow{16}{*}{$\begin{array}{l}\text { Nligate } \\
\text { EQ }\end{array}$} & \multirow{3}{*}{$\begin{array}{l}\text { Syowa- } \\
\text { Bridge }\end{array}$} & \multirow{3}{*}{$\begin{array}{l}5 \text { simple girders } \\
\text { (P2 7) fell down. } \\
\text { - } 2 \text { piers subsided and } \\
\text { others inclined. } \\
\text { - Pile deformed. etc. }\end{array}$} & 1 & P1 & Settled $(3 \mathrm{~cm})$, Pier-top Disp. $(34 \mathrm{~cm})$ & 4 & \multirow{3}{*}{$\begin{array}{l}\text { Severe } \\
\text { liquefaction } \\
\text { occured. }\end{array}$} & $\theta .57$ \\
\hline & & & 2 & P6 & Subsided in the Rlver. & 5 & & 0.47 \\
\hline & & & 3 & P7 & Settled(9cm). Pler-top Disp. $(7 \mathrm{~cm})$ & 4 & & 0.47 \\
\hline & \multirow{4}{*}{$\begin{array}{l}\text { Higashl- } \\
\text { Kosen } \\
\text { Brldge }\end{array}$} & \multirow{4}{*}{$\begin{array}{l}\text { - } 1 \text { simple girder } \\
\text { (P8 9) lell down. } \\
\text { - Pier subsided and in- } \\
\text { clined. } \\
\text { - Plles deformed. } \\
\text { - Retalning wall abut- } \\
\text { ment subslded. etc. }\end{array}$} & 4 & $A L$ & Slight damage (Unknown In detall) & 2 & \multirow{4}{*}{$\begin{array}{l}\text { Severe } \\
\text { llquefaction } \\
\text { occured. }\end{array}$} & 0.00 \\
\hline & & & 5 & P7 & $m$ & 2 & & 0.06 \\
\hline & & & 6 & P9 & Settled(2.5cm). Pier-top Disp. $(15 \mathrm{~cm})$ & 5 & & $\theta .43$ \\
\hline & & & 7 & AR & Settled $(32 \mathrm{~cm})$, Pier-top Dlsp. $(13 \mathrm{~cm})$ & 4 & & 0.23 \\
\hline & \multirow{3}{*}{$\begin{array}{l}\text { Yachiyo } \\
\text { Bridge }\end{array}$} & \multirow{3}{*}{$\begin{array}{l}\text { - Substructure broke. } \\
\text { - } 1 \text { girder(P2 } \sim \text { ) was } \\
\text { In danger of fall. } \\
\text { - Retalning wall abut- } \\
\text { nent subsided. etc. }\end{array}$} & 8 & $A L$ & Settled $(4 \theta \mathrm{cm})$, incllned 1 th $10.5^{\circ}$ & 4 & \multirow{3}{*}{$\begin{array}{l}\text { Movement of } \\
\text { ground by } \\
\text { llquefaction } \\
\text { occured. }\end{array}$} & 0.34 \\
\hline & & & 9 & $\mathrm{P} 2$ & Pler-body broke. & 5 & & 0.34 \\
\hline & & & 10 & P10 & Up-11ft $(7 \mathrm{~cm})$, Pier-top Dlsp. $(7 \mathrm{~cm})$ & 3 & & 0.13 \\
\hline & \multirow{2}{*}{$\begin{array}{l}\text { Taihel } \\
\text { Bridge }\end{array}$} & \multirow{2}{*}{$\begin{array}{l}\text { - Pler inclined. } \\
\text { - Slightly damaged. }\end{array}$} & 11 & P1 & (Not damaged) & 1 & \multirow{2}{*}{$\begin{array}{l}\text { A few meters } \\
\text { of surface } \\
\text { llquefled. }\end{array}$} & 0.42 \\
\hline & & & 12 & P8 & Pler-top Disp. $(6 \mathrm{~cm})$ & 3 & & 0.17 \\
\hline & \multirow{2}{*}{$\begin{array}{l}\text { Shin- } \\
\text { Matsuhama } \\
\text { Bridge }\end{array}$} & \multirow{2}{*}{$\begin{array}{l}\text { - } 1 \text { girder (P10 11) } \\
\text { fell down. } \\
\text { - Under-construction. }\end{array}$} & 13 & $\mathrm{P} 1$ & (Not damaged) & 1 & $"$ & 0.23 \\
\hline & & & 14 & P7 & Settled $(2 \mathrm{~cm})$, Pler-top Disp. $(2 \theta \mathrm{cm})$ & 4 & 10 m more liq. & 0.78 \\
\hline & \multirow{2}{*}{$\begin{array}{l}\text { Kosudo } \\
\text { Bridge }\end{array}$} & \multirow{2}{*}{$\begin{array}{l}\text { Abutment and pler } \\
\text { subsided. }\end{array}$} & 15 & $\mathrm{P} 1$ & Settled $(75 \mathrm{~cm})$ & 3 & \multirow{2}{*}{ (Unknown) } & 0.17 \\
\hline & & & 16 & AR & Settled $(7 \mathrm{~cm})$ & 3 & & 0.00 \\
\hline \multirow{8}{*}{$\begin{array}{l}\text { Mlyagl- } \\
\text { Ken-0kd } \\
\text { EQ } \\
1978.6 \\
M=7.4\end{array}$} & $\begin{array}{l}\text { Abukuma } \\
\text { Bridge }\end{array}$ & $\begin{array}{l}\text { Crack/peel-off of } \\
\text { pler. Bearlng broke. }\end{array}$ & 17 & P8 & $\begin{array}{l}\text { Pler cracked. } \\
\text { Bearing broke. }\end{array}$ & 3 & $\begin{array}{l}\text { slightly } \\
\text { sand bolled. }\end{array}$ & $\theta .03$ \\
\hline & \multirow{2}{*}{$\begin{array}{l}\text { Yuriage } \\
\text { Bridge }\end{array}$} & \multirow{2}{*}{$\begin{array}{l}\text { Crack of pler/girder } \\
\text { /parapet. } \\
\text { - Joint damaged. }\end{array}$} & 18 & $\mathrm{P} 1$ & Peel-off of pler. Bearing broke. & 3 & Sllght & 0.18 \\
\hline & & & 19 & P6 & Movement of glrder $(6 \mathrm{~cm})$ & 3 & sand boll. & $\theta .00$ \\
\hline & Kaihoku & - Bearing broke. & 20 & P2 & Bearing broke. & 3 & & 0.00 \\
\hline & & - signtiy damaged. & 21 & P4 & Sllghtly damaged. & 2 & Not liquefied. & $\theta . \theta 6$ \\
\hline & & & 22 & AR & Sllghtly damaged. & 2 & & 0.06 \\
\hline & $\begin{array}{l}\text { Eal } \\
\text { Bridge }\end{array}$ & $\begin{array}{l}\text { - Crack/peel-off of } \\
\text { pler }\end{array}$ & 23 & P5 & $\begin{array}{l}\text { Pler cracked. } \\
\text { Movement of girder }(6 \mathrm{~cm})\end{array}$ & 3 & (Unknown) & 0.43 \\
\hline & $\begin{array}{l}\text { Kimazuka } \\
\text { Bridge }\end{array}$ & $\begin{array}{l}\text { - Base of bearing } \\
\text { broke. } \\
\text { - In danger of fall. }\end{array}$ & 24 & P3 & Base of bearing broke. & 3 & Sand boll. & 0.08 \\
\hline Nihon- & Oga & - Pier subsided and in- & 25 & $\mathrm{P} 4$ & Settled(13cm), Pier-top Disp. (23cm) & 3 & (Sand boll. & $\theta . \theta \theta$ \\
\hline Chubu & Bridge & $\begin{array}{l}\text { clined. } \\
\text { Approach settled. }\end{array}$ & 26 & P5 & Settled $(15 \mathrm{~cm})$, Pler-top DIsp. $(26 \mathrm{~cm})$ & 3 & & $\theta . \theta \theta$ \\
\hline EQ & Ryuma & - Abutment cracked. & 27 & $A L$ & Abutment-body cracked. & 4 & Sand boll. & 0.00 \\
\hline 1983.5 & Bridge & $\begin{array}{l}\text { - Bearing broke. } \\
\text { Slightly damaged. }\end{array}$ & 28 & P2 & (Not damaged) & 1 & (Sand boll) & 0.00 \\
\hline & Gomyokoh & - Backflll of abutment & 29 & $\mathrm{AL}$ & Plle-bent cracked. & 3 & Sand boll. & 0.03 \\
\hline & & $\begin{array}{l}\text { Bridge-body was } \\
\text { damaged sligt!y. }\end{array}$ & $3 \theta$ & $\mathrm{AR}$ & Slightly damaged. & 2 & & $\theta . \theta 0$ \\
\hline & Narusawa & - Backfill of abutment & 31 & $A L$ & Sllghtly damaged. & 2 & Sand boll, & $\theta . \theta 0$ \\
\hline & Bridge & $\begin{array}{l}\text { subslded. } \\
\text { Bridge-body was } \\
\text { damaged slightly. }\end{array}$ & 32 & $\mathrm{Pl}$ & Not damaged. & 1 & & 0.00 \\
\hline
\end{tabular}

Note: 〈> shows the unknown or estimated results without actual data. 
Table-4 Classification of Damage Level of Highway Bridge

Related to Liquefaction

\begin{tabular}{|c|c|c|}
\hline $\begin{array}{l}\text { Damage } \\
\text { Level }\end{array}$ & $\begin{array}{l}\text { Liquefaction Related } \\
\text { to Damage of Bridge }\end{array}$ & $\begin{array}{l}\text { Standard to Estimate Damage Level } \\
\text { of Bridge and Countermeasure }\end{array}$ \\
\hline 5 & $\begin{array}{l}\text { Liquefaction is maln factor } \\
\text { and causes severe damag of } \\
\text { bridge. }\end{array}$ & $\begin{array}{l}\text { - Girder is fell down. } \\
\text { - Substructure is broken. } \\
\text { - Countermeasure for liquefaction is } \\
\text { needed preferentially. }\end{array}$ \\
\hline 4 & $\begin{array}{l}\text { Damage of bridge is relatively } \\
\text { severe, and llquefaction is } \\
\text { considered as one of causes. }\end{array}$ & $\begin{array}{l}\text { - Pler-top displacement by subsidence } \\
\text { and/or inclination is more than } 10 \mathrm{~cm} \text {. } \\
\text { - Width of crack is more than } 1 \mathrm{~mm} \text {. } \\
\text { - Countermeasure for both liquefaction } \\
\text { and other cause of damage is needed. }\end{array}$ \\
\hline 3 & $\begin{array}{l}\text { Liquefaction is not directly } \\
\text { related to damage of bridge. }\end{array}$ & $\begin{array}{l}\text { - Pler-top displacement by subsidence } \\
\text { and/or inclination is less than } 10 \mathrm{~cm} \text {. } \\
\text { - Width of crack is less than } 1 \mathrm{~mm} \text {. } \\
\text { - Genaral retrofit and/or repair for } \\
\text { damage is needed. }\end{array}$ \\
\hline 2 & Slightly damaged. & - Slight repalr for damage is needed. \\
\hline 1 & Not damaged. & \\
\hline
\end{tabular}

Note: Damage level for severe damage which was not Induced by llquefactin is considered to be 3 .

Table-5 Classification of Ground Group ", 2)

\begin{tabular}{|c|c|c|}
\hline Group & Characteristic of Ground & TG (s) \\
\hline$I$ & $\begin{array}{l}\text { - Rock, Dlluvial Ground } \\
\text { (FIrin) }\end{array}$ & $\mathrm{TG}<\theta .2$ \\
\hline II & $\begin{array}{l}\text { - Alluplal Ground } \\
\text { (Medium-stiff) }\end{array}$ & $0.2 \leq \mathrm{TG}<0.6$ \\
\hline III & $\begin{array}{l}\text { Soft and Thlck Alluvial } \\
\text { Ground } \\
\text { (Soft) }\end{array}$ & $0.6 \leqq \mathrm{TG}$ \\
\hline
\end{tabular}

- : Characteristic Value of Ground

Table-6 Relation between Ground Group and Site Liquefaction Potential ( $\mathrm{r}_{\mathrm{HL}}$ )

\begin{tabular}{|c|c|c|c|c|c|}
\hline $\begin{array}{c}\text { Ground } \\
\text { Group }\end{array}$ & $\begin{array}{c}\text { WIthout Saturat- } \\
\text { ed Sandy Layer }\end{array}$ & IPL $<0.2$ & $\begin{array}{c}0.2 \leqq \\
I_{P L}<0.4\end{array}$ & $0.4 \leqq I_{P L}$ & Total \\
\hline I & 32 & 7 & 0 & 0 & 39 \\
\hline I & 14 & 75 & 13 & 2 & 104 \\
\hline II & 0 & 34 & 27 & 13 & 74 \\
\hline Total & 46 & 116 & 40 & 15 & 217 \\
\hline
\end{tabular}

\begin{tabular}{|c|l|}
\hline Estimate Suitably & Est. Dangerously \\
\hline Est. Safely & Estimate Suitably \\
\hline
\end{tabular}


$\frac{0}{5}$

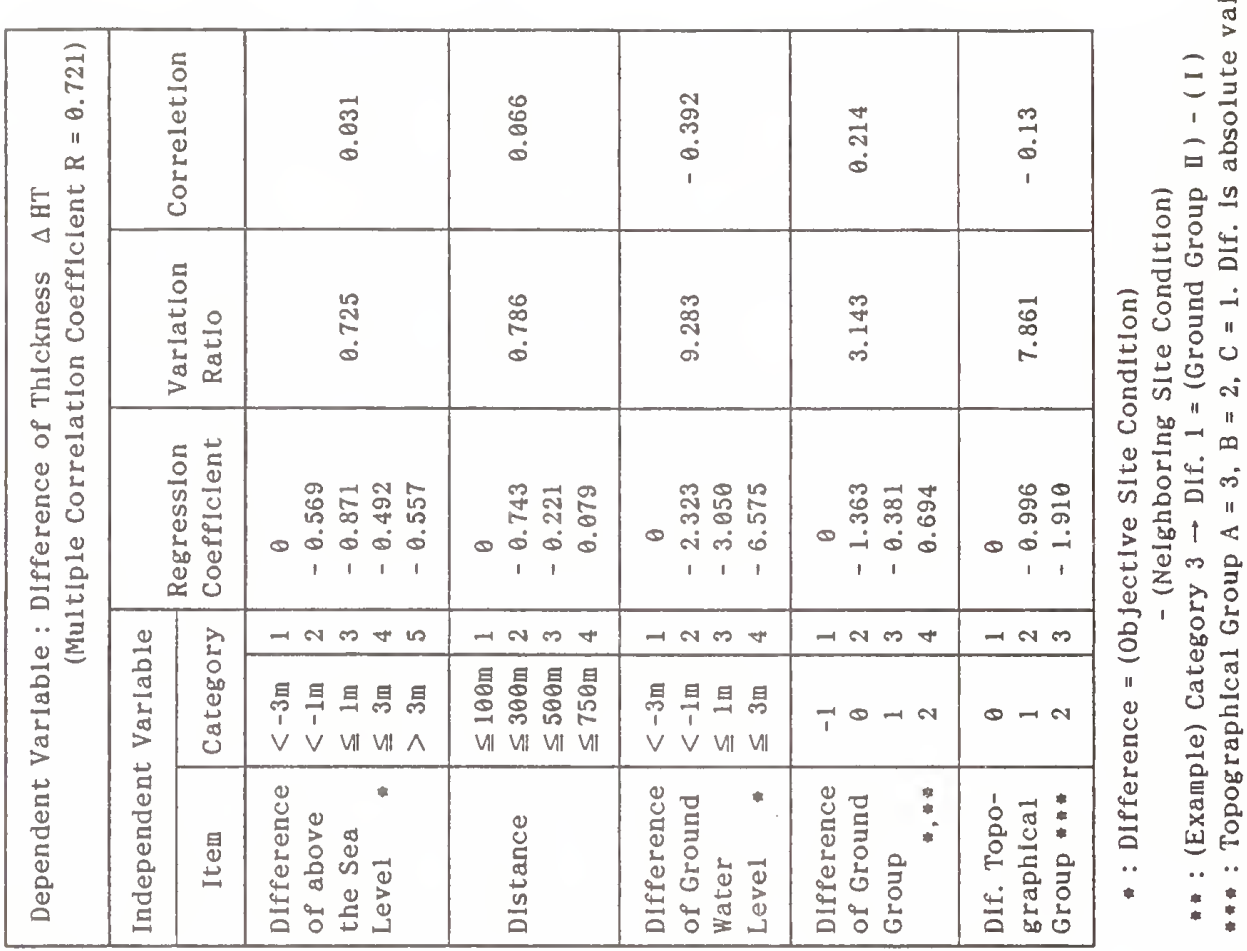
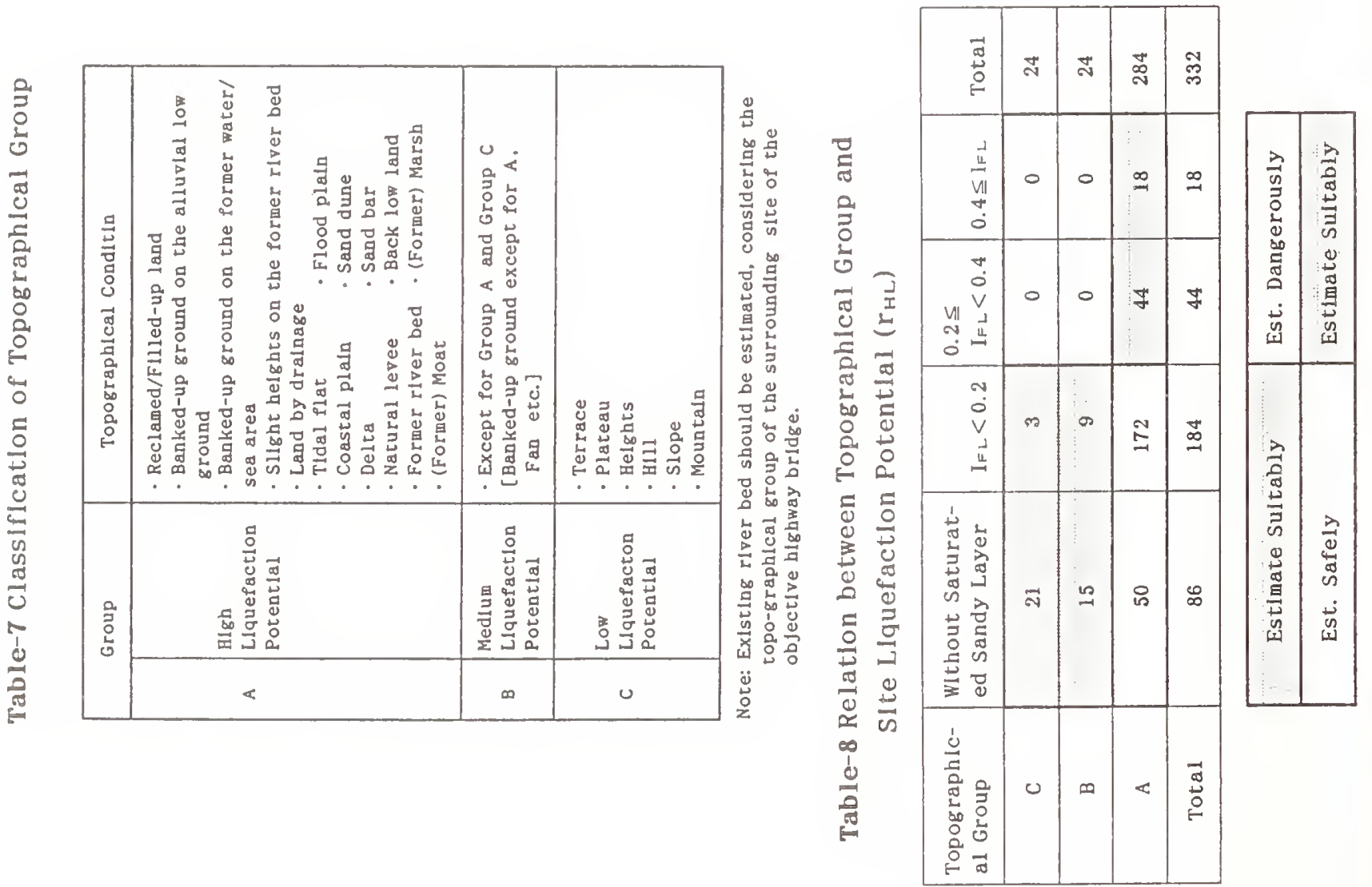

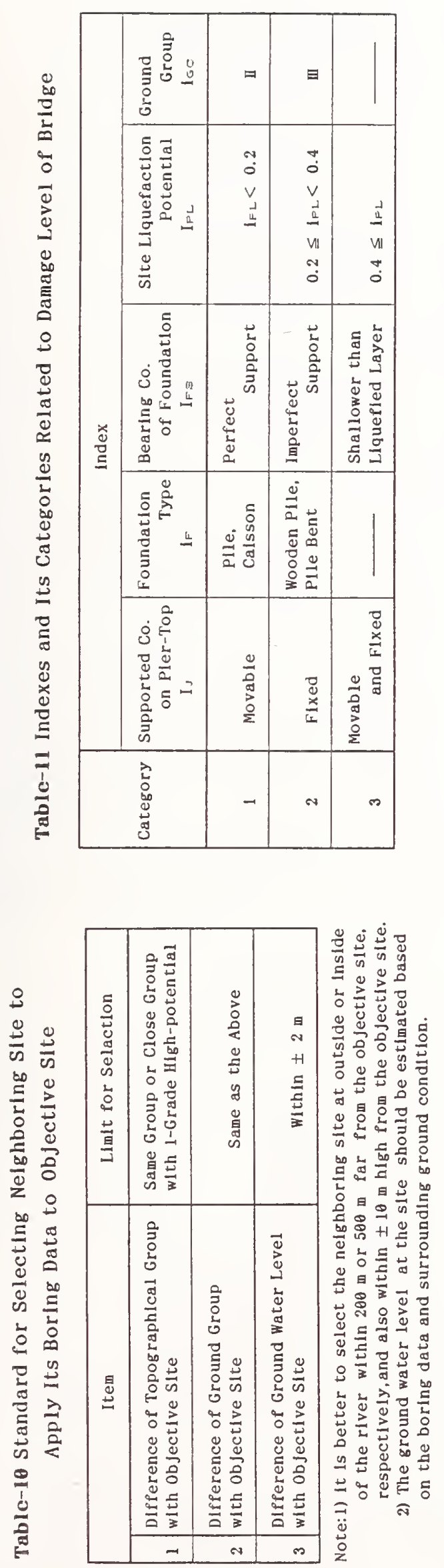
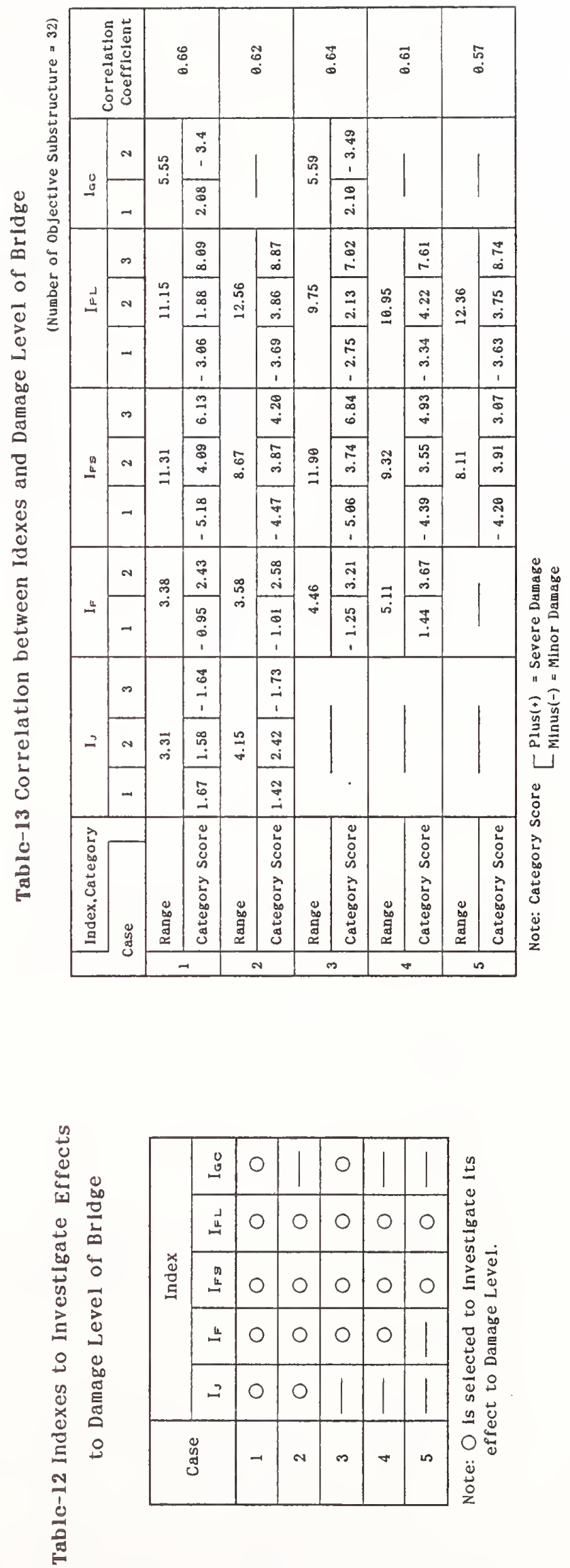
Table-14 Classification of Damage of Foundation Induced by Liquefaction

\begin{tabular}{|l|l|l|}
\hline Abutwent & Movable Pler & \\
\hline & & \\
\hline
\end{tabular}

Table-15 Indexes to Estimate LIquefactionInduced Damage Potential of Highway Bridge

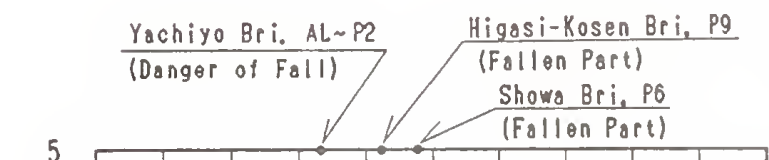

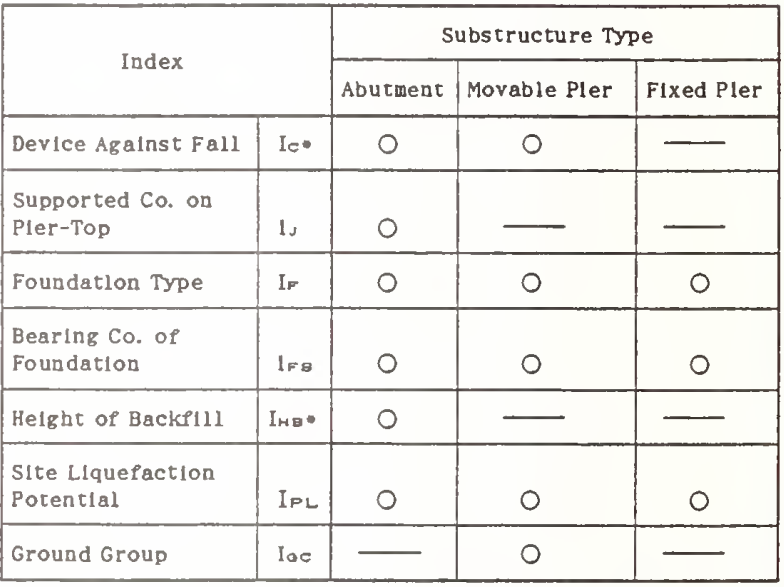

Note: is added Index on Liquefaction-Induced Damage Potentlal.

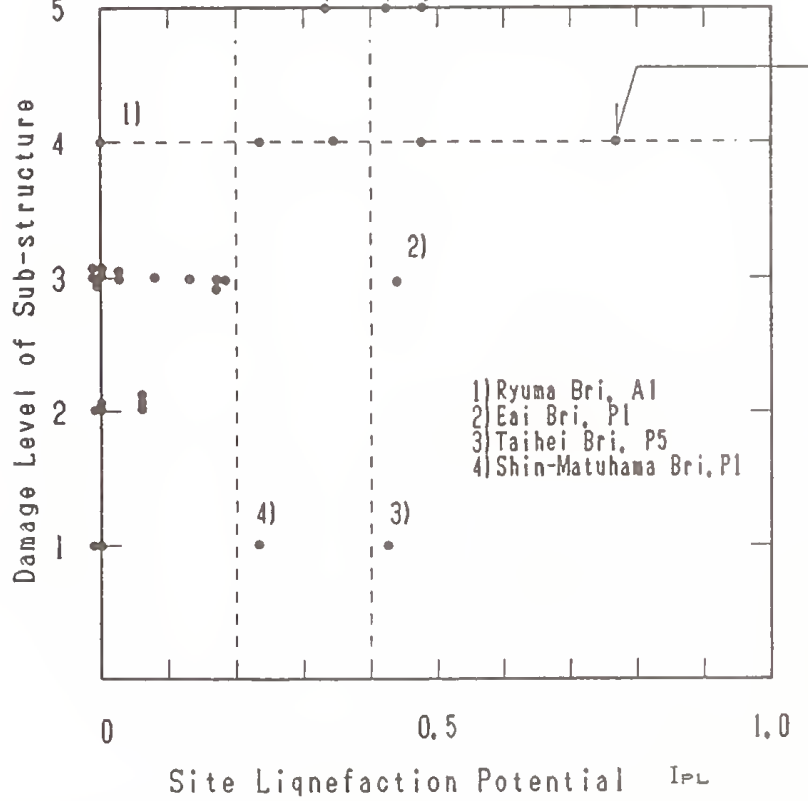

Sin-Matuhama Bri. P7 (Near Fallen Part)

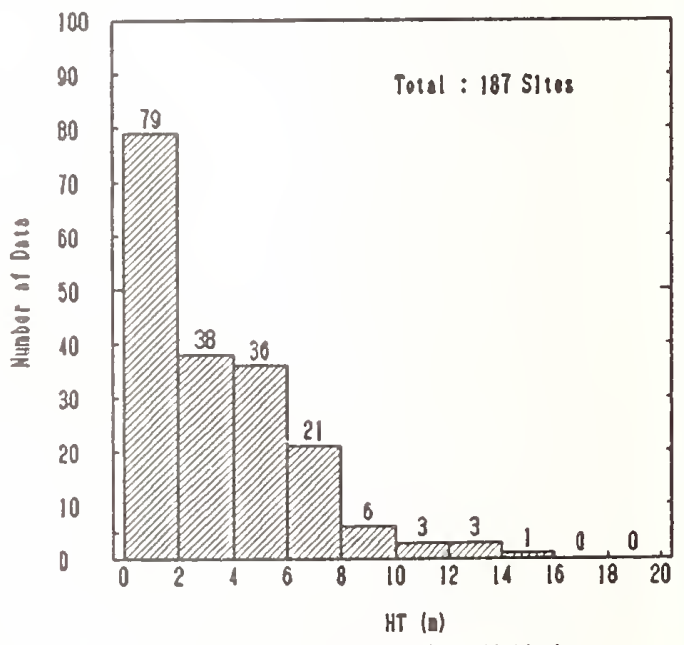
Medilied Thickness of Liguafiall Layor

Fig. 1 Relation between Site Llquefaction Potentlal ( $r_{H L}$ ) and Damage Level of Substructure
Flg. 2 Distribution of Modifled Thickness of Liqueflable Layer (HT) 

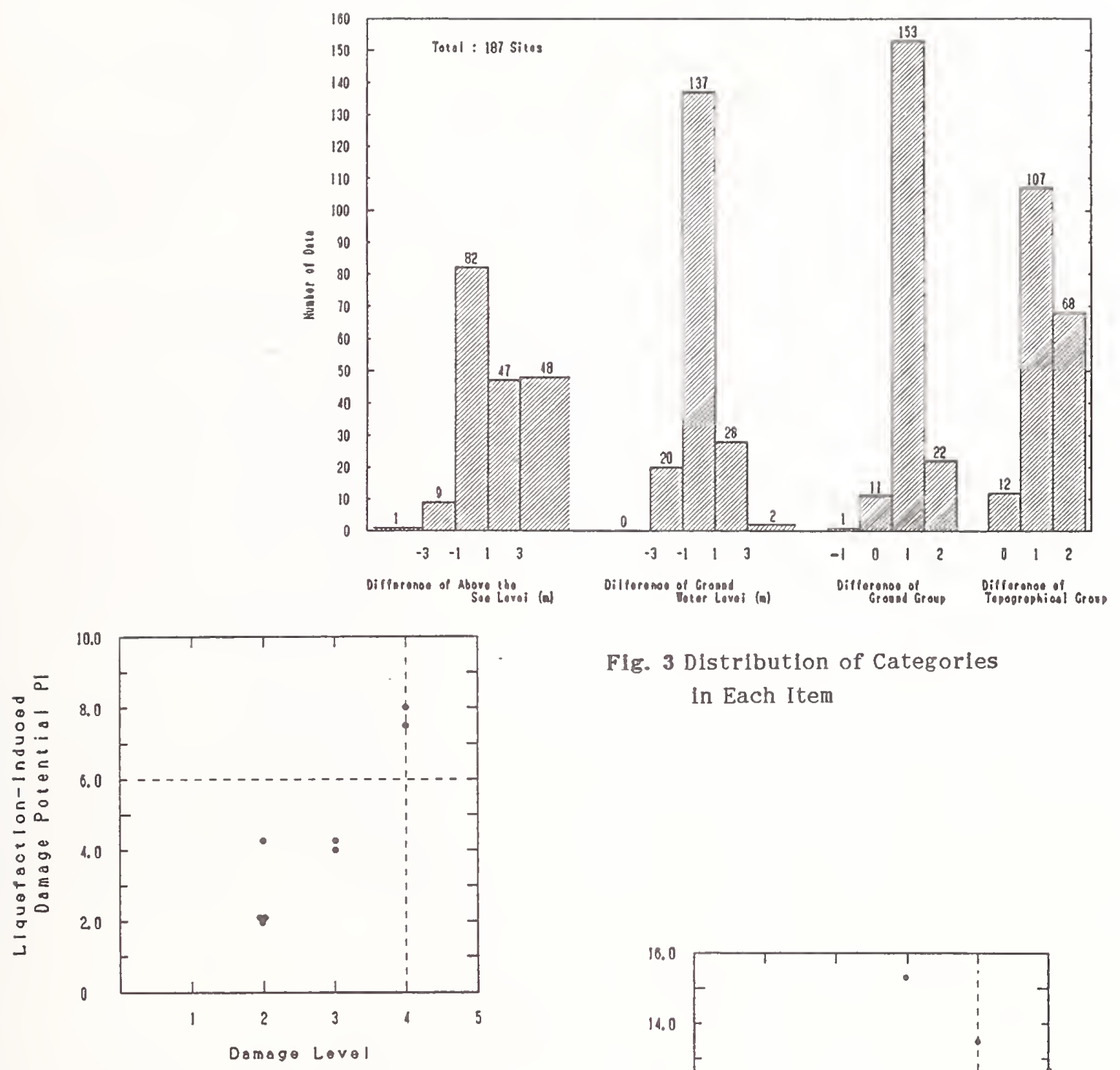

FIg. 3 Distribution of Categories

in Each Item

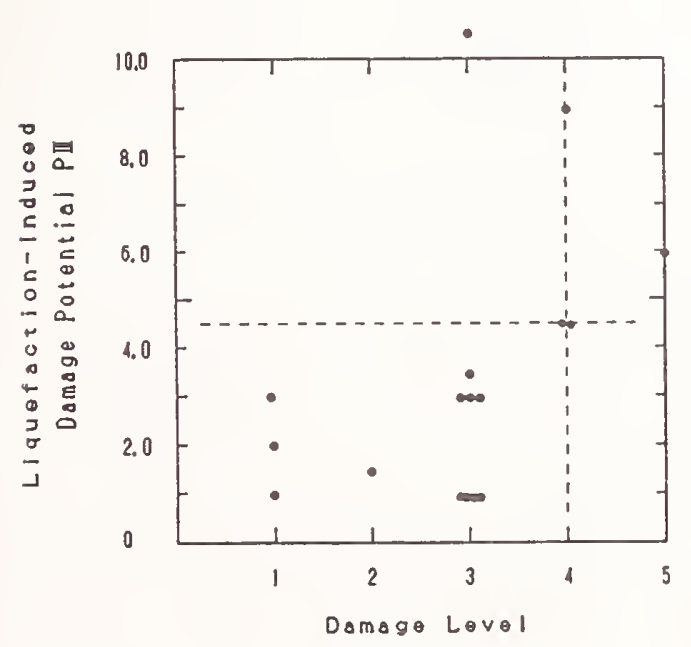

(2) P II for Movable Pler

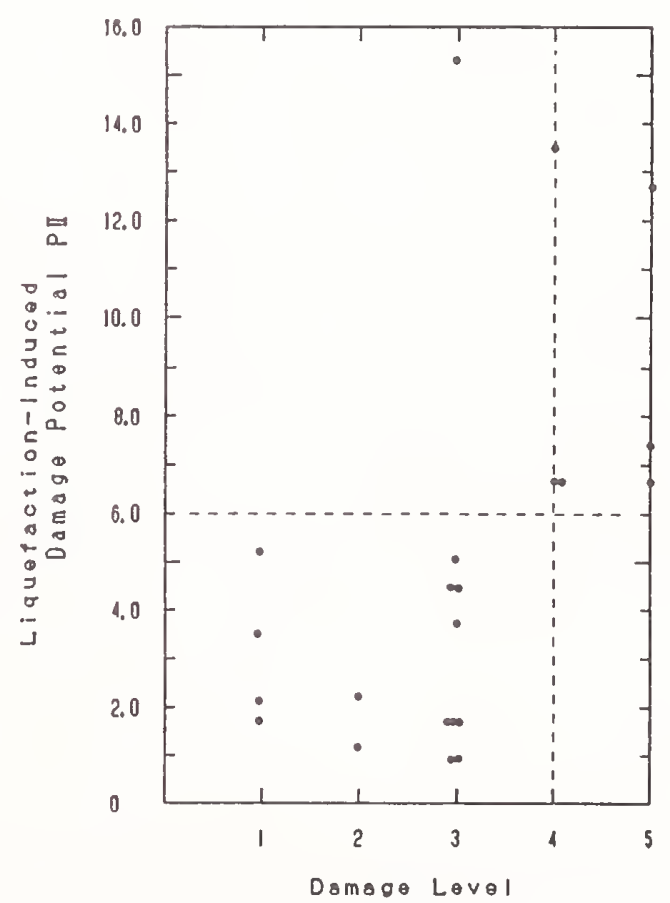

(3) P III for Fixed Pler

Fig. 4 Relation between Damage Level of Substructure and Liquefaction-induced Damage Potential 


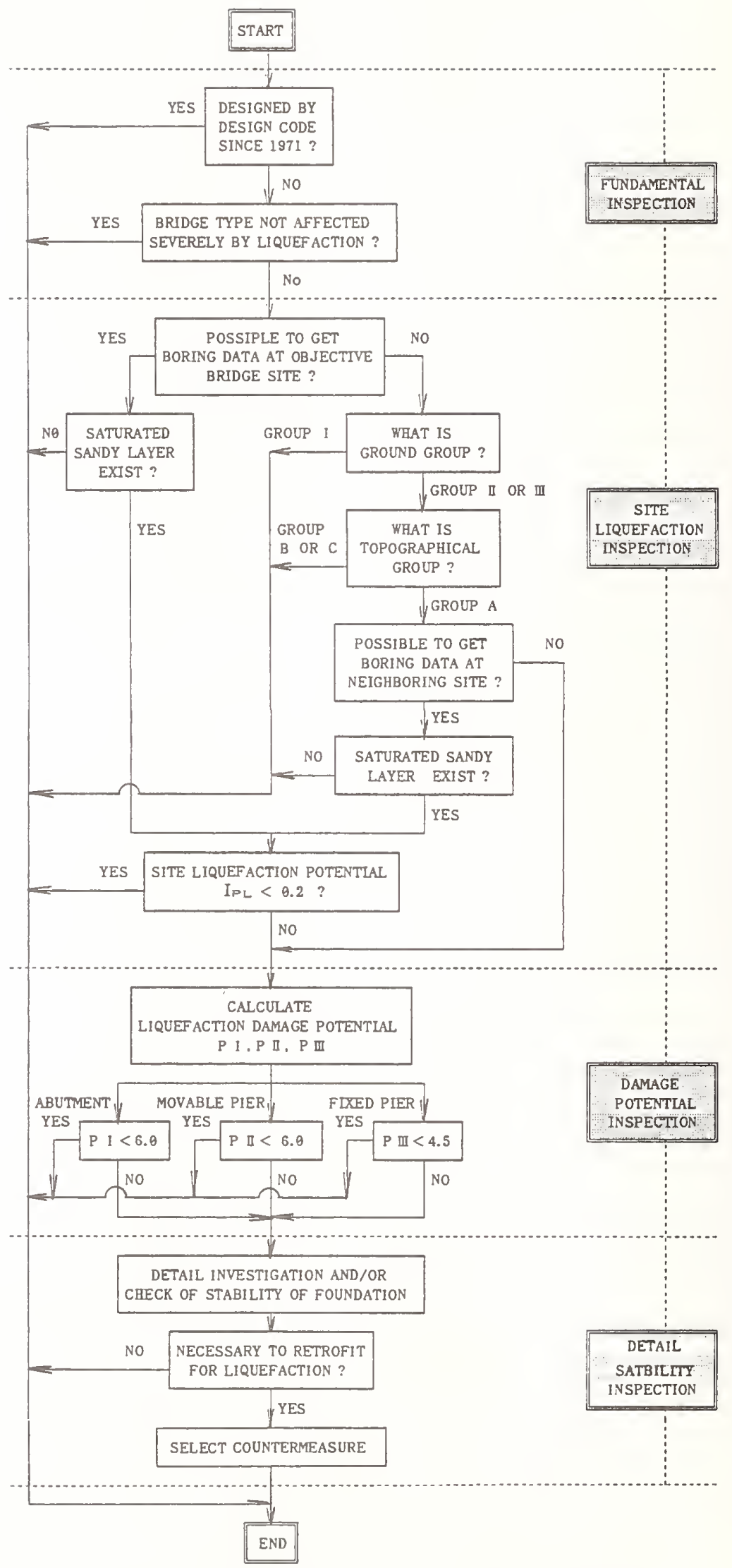

Fig. 5 Example of Flow Chart for Inspecting Earthquake Resistant Potentlal of Highway Bridge Foundation 


\section{Evaluation and Repair of Major Water Resources Structures \\ for Improved Safety and Seismic Stability}

by

\section{Dr. William Roper*}

ABSTRACT: This paper addresses recently developed technology for evaluation and repair of water resources structures for improved safety and seismic stability. It covers selected examples of research conducted under the Repair, Evaluation, Maintenance, and Rehabilitation (REMR) Research Program. The REMR program was a comprehensive six-year effort in which 54 individual studies were conducted. Those studies which can be related to wind and seismic events are discussed under three categories: Monitoring and Inspection of Existing Structures, Remedial Treatments to Improve Safety, and Repair of Damage.

KEYWORDS: Breakwaters; dissimilar armor; foundation assessments; foundation grouting; geophysical methods; jetties; instrumentation automation; liquefiable foundations; liquefiable soils; monitoring structures; nondestructive testing; relief wells; rubble-mound structure toes; underwater inspections; ultrasonic pulse-echo; wave runup and overtopping

\section{INTRODUCTION}

The percentage of the US Army Corps of Engineers' budget devoted to maintenance, repair and rehabilitation of its civil works projects increased throughout the 1980's as the average age of Corps structures increased. About 70 percent of the Corps' hydraulic structures are over 20 years of age; 49 percent are more than 30 years old; and 26 percent were constructed prior to 1940 . Since it generally cost less to rehabilitate a structure than to replace it and budget constraints continued to increase, a major need was for technology to extend the life of existing structures. The Repair, Evaluation, Maintenance and Rehabilitation (REMR) Research Program was initiated in 1984 to meet this need. The overall objective of the program was to identify and develop effective and affordable technology for maintaining and extending the service life of existing Corps civil works structures.
The Corps was one of the first Federal agencies to recognize the need for research to address the nation's deteriorating infrastructure. The REMR Research Program has clearly demonstrated the benefits of research in getting more value for the dollars spent on maintenance and repair activities.

Technology from the REMR Research Program is credited with producing savings in excess of $\$ 70$ million dollars with estimated savings over the next 5 years exceeding $\$ 200$ million for the Corps alone. In addition to dollar savings, the program has resulted in other benefits such as improved safety and reliability, reduced manpower requirements, and improved operational capabilities. These figures represent a significant return on a $\$ 35$ million dollar investment.

REMR was a broad based research program which was broken down into seven problem areas: (1) Concrete and Steel Structures, (2) Geotechnical, (3) Hydraulics, (4) Coastal, (5) Electrical and Mechanical, (6) Environmental Impacts, and (7) Operations Management. A total of 54 individual research studies were conducted over the 6 year life of the program.

Although most of the evaluation, maintenance, repair and rehabilitation efforts at Corps projects are due to normal wear and tear, aggressive environments, and the need for increased capacity, damage from wind and seismic events does pose a significant threat. Several REMR research studies produced technology for evaluation, remedial treatment, and repair efforts related to wind and seismic events. This paper summarizes those studies.

\footnotetext{
* US Army Corps of Engineers, 20 Massachusetts Avenue, NW., Washington, DC 20314-1000
} 


\section{MONITORING AND INSPECTION OF EXISTING STRUCTURES}

The monitoring of existing structures during various loading events can provide advanced warning of impending failure or allow timely actions to be taken which will prevent failure. Once damage has occurred, it is important to thoroughly inspect the damage prior to any repair or rehabilitation effort. The cause and extent of damage must be considered for proper selection of repair or rehabilitation procedures. A summary of the results of REMR studies on inspection and monitoring of existing structures is provided below. The results are applicable to the evaluation of structures subjected to wind and seismic events.

\subsection{Nondestructive Testing}

Nondestructive testing of concrete allows the inspection of larger areas at less costs than coring and provides more information than a visual inspection. A comprehensive REMR technical report describes the available techniques, their applications, advantages, and disadvantages.

A new, improved prototype ultrasonic pulse-echo system was developed for the evaluation of concrete structures where only one surface is accessible. The system uses piezoelectric crystals for both signal generation and detection. The 200-kilohertz two-transducer system has a signal-to-noise ration of 18. The weight and dimensions of the improved system, which has the shortest pulse length on record, works well in making thickness measurements of portland-cement concrete $(<12$ in.) and can indicate the presence of reinforcing steel, voids, and inferior quality concrete both above and below water.

To keep civil works metal structures fully functional and safe, a thorough inspection procedure must be implemented. A guide for the selection of an appropriate test method for metal structures was published. The guide includes information on the theory, applications, advantages, and disadvantages of each nondestructive testing method. Case histories are included which describe how nondestructive testing procedures can enhance inspection routines.

\subsection{Geophysical Techniques}

Existing structures complicate and limit routine application of standard engineering geophysical techniques for foundation assessments. New geophysical methods were developed and standard methods adapted that allow definitive and cost-effective application to existing structures.

Field procedures, data processing methods, and interpretation methods were developed or adapted for high-resolution seismic reflection, groundpenetration radar, microgravity, and self-potential methods. Two field test sites were selected and the methods applied to the assessment of various structure and foundation problems. At the Lockport Approach Dike on the Illinois Waterway, near Joliet, Illinois, a ground-penetrating-radar survey detected possible seepage paths through the dike, verified the location of the concrete core wall, and assessed its condition. At Dike 1, Beaver Dam, Arkansas, a comprehensive foundation assessment was conducted. The geophysical methods applied at Dike 1 succeeded in mapping seepage paths and delineating the complex geology (Figure 1). Based on the results of the geophysical surveys and other geotechnical investigation the rational design of a concrete cutoff wall to eliminate anomalous seepage was possible.

2.3 Evaluation of Damage to Underwater Portions of Coastal Structures

Effectiveness of techniques for inspection and evaluation of underwater damage is limited by the severe conditions encountered in the zone surrounding coastal structures, including high wave energy, strong currents, and low underwater visibility. Current technology and methods for performing inspections were examined, including diver and crane surveys, underwater video, and commercially available side scan and other sonars. Guidance was developed, through testing and experience in actual field conditions, on the selection and use of these techniques. Training was provided to Corps personnel, and the guidance was used in evaluation of underwater parts of Humboldt and Crescent City jetties on the California coast.

Since none of the available technologies is entirely satisfactory, an effort was undertaken to develop an underwater survey system that would be less 
dependent on favorable conditions and provide less subjective results. A prototype system called the Coastal Structure Acoustic Raster Scanner (CSARS) (Figure 2) has been designed, constructed, and improved through field trials. Results, thus far, have been promising.

\subsection{Instrumentation Automation for Concrete Structures}

Automation of instrumentation at existing concrete structures can increase the timeliness and accuracy of data and can reduce man-hour requirements. It can also permit the instruments to be monitored from a remote location or from an off-site office. Information was accumulated on commercially available hardware and software, and guidance was developed on the use of these products for instrumentation automation.

This technology was demonstrated at Beaver Dam near Eureka Springs, Arkansas, where pressure cells, weirs, joint meters, and piezometers were automated. Prior to the automation of the 84 piezometers, a team of field personnel took four hours to read the piezometers which can now be read in less than a minute.

2.5 Continuous Monitoring System for Structural Safety of Large Dams

The normal behavior of a dam needs to be understood so that abnormal behavior can be detected. Precise daily studies of dam motion were not previously feasible because the measurements could not be automated. Under this study, a continuous monitoring system was developed that uses the Navstar Global Positioning System to determine three-dimensional differential movements at up to eight points on a structure. Each position is then compared to an original position to determine the total amount of movement. Accuracies of $+/-5$ millimeters in the three-dimensions are possible. The monitoring and data recording equipment are linked together with telephone lines, R-232 cable, or fiber optic cable. No system operator is required, and real-time structural deformations may be monitored at remote locations such as an off-site office. A prototype system was installed and demonstrated at Dworshak Dam, Idaho from July to September 1989.

\section{REMEDIAL TREATMENTS TO IMPROVE SAFETY}

Improved inspection and analysis techniques now available often point out the need for remedial treatments to existing structures to improve their safety. REMR studies to develop remedial treatments for structures subjected to wind and seismic events are described below.

\subsection{Reducing Wave Runup and Overtopping}

Problems associated with runup and overtopping have occurred on about 20 percent of the Corps' coastal structures. Problems from runup and overtopping range from (1) excessive wave action on the lee side of breakwaters and jetties, (2) flooding and erosion on the backside of seawalls, sea dikes, and bulkheads, to (3) backside subsidence, erosion, and sometimes collapse of revetments.

Mathematical models and flume studies were used to evaluate and rank the hydraulic performance of a number of seawall/revetment configurations. For existing revetments, it was found that an attached low berm fronting a rubble revetment significantly decreases wave runup and overtopping. This technology was used at the Temple Emanuel project on the Chicago waterfront (Figure 3) and resulted in a 12-percent savings over the costs of the traditional high berm revetment.

\subsection{Remedial Treatment of Liquefiable Soils}

Liquefaction of foundation soils can cause catastrophic failure or limit the usefulness of a project. It is now known, through new and improved testing procedures, that many Corps structures are located on liquefiable foundations. Techniques applicable for remedial treatment of the foundations of existing structures were identified, and guidance was provided for their selection and use. Two of the more promising techniques are sand compaction piles and stone columns. The relative costs of these techniques are moderate and they provide (a) vertical support, (b) drains to relieve pore water pressure, and (c) shear resistance in horizontal and inclined directions. Stone columns were used to improve foundations conditions at Steel Creek Dam, Georgia (Figure 4). 


\subsection{Restoration of Relief Wells}

Relief wells, a safety feature when installed at a structure, can become clogged by chemical or biological incrustation allowing uplift pressures to increase beneath the structure. A procedure was developed for restoring the efficiency of these wells using a process called "Blended Chemical High Temperature," or BCHT. The Corps has approximately 5,000 relief wells that must be treated periodically or replaced. The BCHT process will extend the maintenance interval for these wells by at least one year and will result in annual savings of $\$ 500,000$.

An example of additional savings is the relief wells at the New Alton Pumping Station Project in the St. Louis District. Standard cleaning methods failed to bring these wells up to the required 80 percent of original capacity. The BCHT process was demonstrated to be capable of successfully cleaning the wells, thus eliminating the expense of replacement wells. The cost difference between restoration and possible replacement of as many as 60 wells at this site was estimated to be $\$ 1.5$ million.

\section{REPAIR OF DAMAGE}

Several repair techniques and materials were evaluated under REMR and undoubtly many of them can be used to repair damage from wind and seismic events. However, those which would seem to relate more specifically to repair of damage from seismic and wind events are foundation grouting and repair of coastal structures damaged from wave action.

\subsection{Grouting for Foundation Repair and Rehabilitation}

Foundation grouting has long been an accepted procedure for improving foundation conditions. The objective of this effort was to evaluate and develop modern methods of foundation grouting to improve quality control and reduce costs. Several products were developed under this effort including a comprehensive technical report on consolidation grouting of rock masses.

A computerized grout control and monitoring system was developed under a joint effort with the Bureau of Reclamation. The use of this system is expected to substantially reduce the number of changed condition claims by grouting contractors.

A method to evaluate rock properties prior and subsequent to grout injection was developed. A drill rig instrumented with a drilling parameter recorder (Figure 5) is used to predict groutability, and an acoustic emissions monitoring system is used for mapping grout location. Test grouting on this method was conducted at Little Dell Dam, Utah.

\subsection{Rehabilitation of Rubble-Mound Structure Toes}

Many breakwater failures have been attributed to failure of the toes of these structures. No firm guidance existed to aid Corps personnel in designing the berms and most design work was carried out using limited local field experience with past successes and failures.

A series of two-dimensional and three-dimensional breakwater stability physical model experiments was developed and conducted to address the sizing of toe berm and toe buttressing stone in breaking wave environments. The two-dimensional tests focused on sizing of toe stone on rubble-mound structure trunks exposed to 90 -degree wave attack, i.e. wave orthogonals perpendicular to structure crest. Toe berm armor stone sizing for oblique wave attack on rubble-mound structure heads and trunks was examined in the three-dimensional model tests. Guidance for sizing toe berm armor stone was developed for a range of wave and still-water level conditions. Guidance for sizing of toe buttressing stone was addressed for a limited set of incident wave conditions on structure trunks. Use of this new guidance should eliminate wave induced toe berm failures and result in significant dollar savings for the Corps.

\subsection{Use of Dissimilar Armor for Repair and Rehabilitation}

Model test have shown that overlays of concrete units such as dolosse and tribars over stone require larger sizes than if the structure were originally designed for those particular units. Thus, the design guidance for new structures is inappropriate for use in the design of repairs and rehabilitations involving dissimilar armor. 
Stability tests were conducted of dolos overlays on stone-armored, dolos-armored, and tribar-armored breakwater and jetty trunks subjected to breaking waves. Tests were also conducted on tribar overlays of stone-armored breakwater and jetty trunks and dolos overlays of stone-armored breakwater heads subjected to breaking waves. The results from these tests can be used to design appropriately sized armor units for repair and rehabilitation of breakwaters and jetties.

\subsection{Sealing of Permeable Breakwaters and Jetties}

Rubble-mound breakwaters and jetties are intended to protect harbors and navigation channels from excessive wave energy and to prevent shoaling of channels and boat mooring areas by littoral material. The cores of many such Corps coastal structures have deteriorated and become permeable to such an extent that they do not serve, or only partially serve, their original intended function.

A cost-effective alternative to traditional methods of rubble-mound structure sealing (i.e. dismantling to rebuild core sections, chinking layers along surface, additional armoring layers, etc.) was determined to be drilling and grouting (sealing) a vertical barrier curtain along the center line of the structure from the bottom to approximately mean higher high water (Figure 6).

Sealing permeable breakwaters or jetties should be approached from the standpoint of preventing wave or sand movement through the structure and not from the requirement of imparting structural stability or strength. In planning a sealing operation, a quantitative determination must be made of the wave energy or sand passing through the structure to ascertain economic benefits.

\section{INTRODUCTION TO REMR-II PROGRAM}

The successes of the REMR Program, the high demand for its products, and the opportunity for similar successes on other REMR type problems were the justification for getting approval for a follow-on effort (REMR-II). REMR-II was initiated this fiscal year (FY91) and is proposed as a 7-year, \$35-million effort. It will address new and different needs which have been identified by Corps field personnel. REMR-II will concentrate on problems and areas which have the potential for large payoffs and widespread applications. Much of the technology that will be produced will have applications outside the Corps to other types of infrastructures. A significant effort will be devoted to the coordination and sharing of this technology with other federal agencies, state and local govermments, and the private sector.

\section{CONCLUSIONS}

The U.S. Army Corps of Engineers was one of the first Federal agencies to recognize the need for research to address the nation's deteriorating infrastructure. The REMR Research Program was implemented to address that need and has clearly demonstrated the benefits of research in getting more value for the dollars spent on maintenance and repair activities.

The REMR Research Program was a very broad based program with 54 individual research studies. Several of these studies are applicable to the evaluation, remedial treatment, and repair of structures subjected to wind and seismic events, as summarized in the above text.

\section{REFERENCES}

1. O'Neil, E. 1989 (Apr). "Instrumentation Automation for Concrete Structures, Report 4, Demonstration of Instrumentation Automation Techniques at Beaver Dam, Eureka Springs, Arkansas," Technical Report REMR-CS-5, U.S. Army Engineer Waterways Experiment Station, Vicksburg, MS.

2. Thornton, H.T. Jr., and Alexander, A.M. 1987 (Dec). "Development of Nondestructive Testing Systems for In Situ Evaluation of Concrete Structures," Technical Report REMR-CS-10, U.S. Army Engineer Waterways Experiment Station, Vicksburg, MS.

3. Kisters, F. and Kearney, F. 1991 (Jan). "Evaluation of Civil Works Metal Structures," Technical Report REMR-CS-31, U.S. Army Construction Engineering Research Laboratory, Champaign, IL.

4. Barksdale, R.D. 1987 (Nov). "State of the Art for Design and Construction of Sand Compaction Piles," Technical Report REMR-GT-4, U.S. 
Army Engineer Waterways Experiment Station, Vicksburg, MS.

5. Wilt, M.J. and Butler, D.K. 1990 (Mar). "Geotechnical Applications of the Self Potential (SP) Method Report 4, Numerical Modeling of Spanomalius: Documentation of Program SPPC and Applications," Technical Report

REMR-GT-6, U.S. Army Engineer Waterways Experiment Station, Vicksburg, MS.

6. Barksdale, R.D. 1987 (Dec). "Applications of the State of the Art of Stone Columns-Liquefaction, Local Bearing Failure, and Example Calculations," Technical Report REMR-GT-7, U.S. Army Engineer Waterways Experiment Station, Vicksburg, MS.

7. Dickinson, R.M. 1988 (Jul). "Review of Consolidation Grouting of Rock Masses and Methods for Evaluation," Technical Report REMR-GT-8, U.S. Army Engineer Waterways Experiment Station, Vicksburg, MS.

8. Dobecki, T.L., Mueller, T.L., and Savage, M.B. 1989 (Jul). "High Resolution Seismic Reflection Investigations at Beaver Dam, Arkansas," Technical Report REMR-GT-10, U.S. Army Engineer Waterways Experiment Station, Vicksburg, MS.

9. Carver, R.D. 1989 (Jan). "Prototype Experience with the Use of Dissimilar Armor for Repair and Rehabilitation of Rubble-Mound Coastal Structures," Technical Report REMR-CO-2,U.S. Army Engineer Waterways Experiment Station, Vicksburg, MS.

10. Carver, R.D. and Wright, B.J. 1988 (Feb). "Stability of Dolos and Tribar Overlays for Rehabilitation of Stone-Armored RubbleMound Breakwater and Jetty Trunks Subjected to Breaking Waves," Technical Report

REMR-CO-4, U.S. Army Engineer Waterways Experiment Station, Vicksburg, MS.

11. Carver, R.D. and Wright, B.J. 1988 (Jun). "Stability of Dolos Overlays for Rehabilitation of Dolos-Armored Rubble-Mound Breakwater and Jetty Trunks Subjected to Breaking Waves," Technical Report REMR-CO-5, U.S. Army Engineer Waterways Experiment Station,
Vicksburg, MS.

12. Carver, R.D. and Wright, B.J. 1988 (Aug). "Stability of Dolos Overlays for Rehabilitation of Tribar-Armored Rubble-Mound Breakwater and Jetty Trunks Subjected to Breaking Waves," Technical Report REMR-CO-6, U.S. Army Engineer Waterways Experiment Station, Vicksburg, MS.

13. Ahrens, J.P. 1988 (Oct). "Methods to Reduce Wave Runup and Overtopping of Existing Structures," Technical Report REMR-CO-7, U.S. Army Engineer Waterways Experiment Station, Vicksburg, MS.

14. Simpson, D.P. 1989 (Apr). "State-of-the-Art Procedures for Sealing Coastal Structures with Grouts and Concretes," Technical Report REMR-CO-8, U.S. Army Engineer Waterways Experiment Station, Vicksburg, MS.

15. Carver, R.D. 1989 (May). "Stability of Dolos Overlays for Rehabilitation of Stone-Armored Rubble-Mound Breakwater Heads Subjected to Breaking Waves," Technical Report REMR-CO-9, U.S. Army Engineer Waterways Experiment Station, Vicksburg, MS.

16. Kucharski, W. and Clausner, J.E. 1990 (Feb). "Underwater Inspection of Coastal Structures Using Commercially Available Sonars, Technical Report REMR-CO-11, U.S. Army Engineer Waterways Experiment Station, Vicksburg, MS.

17. Markle, D.G. 1989 (Sep). "Stability of Toe Berm Armor Stone and Toe Buttressing Stone on Rubble-Mound Breakwaters and Jetties," Technical Report REMR-CO-12, U.S. Army Engineer Waterways Experiment Station, Vicksburg, MS.

18. Rosati, J.D. and Denes, T.A. 1990 (Oct). "Field Evaluation of Port Everglades, Florida, Rehabilitation of South Jetty by Void Sealing," Technical Report REMR-CO-15, U.S. Army Engineer Waterways Experiment Station, Vicksburg, MS. 


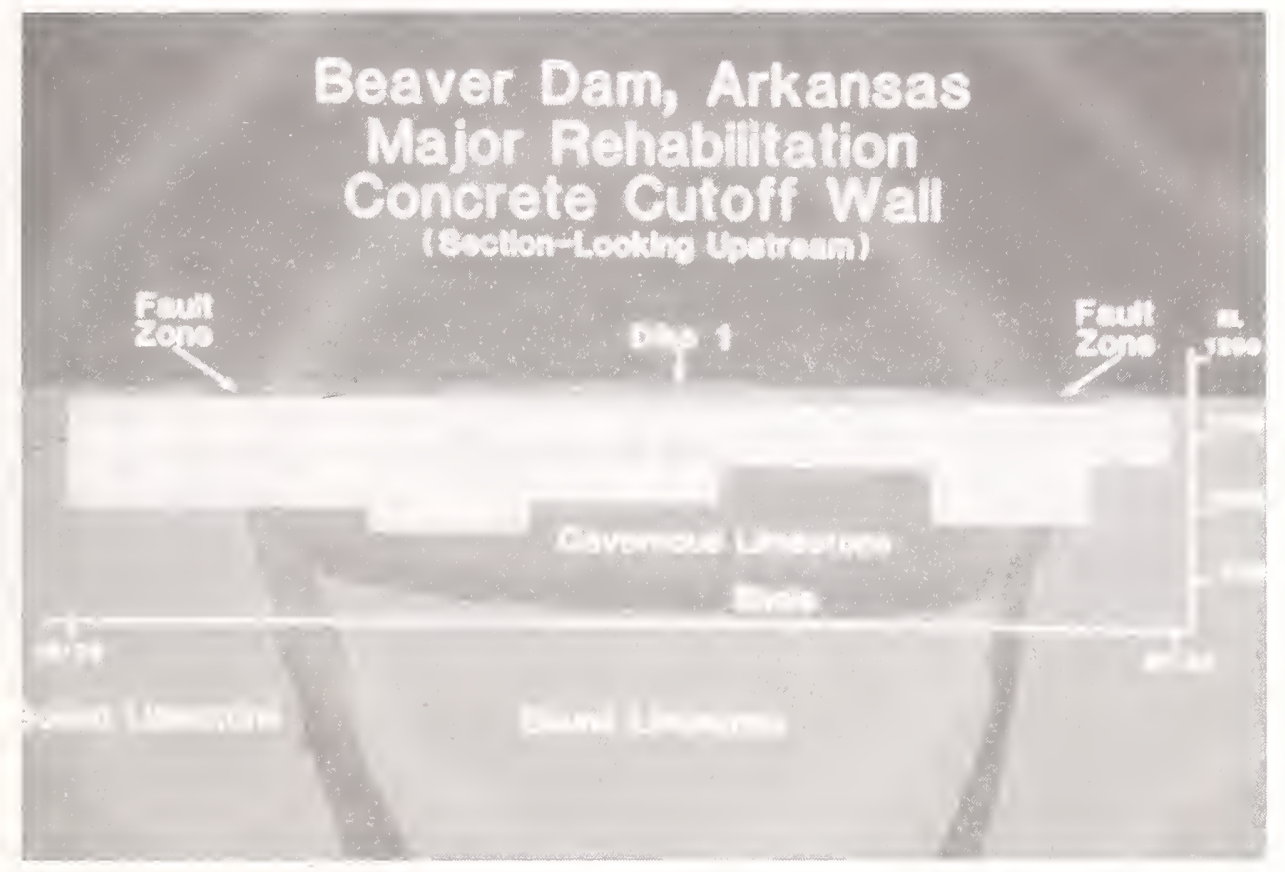

Figure 1. Results from geophysical studies were used to design a concrete cutoff wall at Beaver Dam, Arkansas.

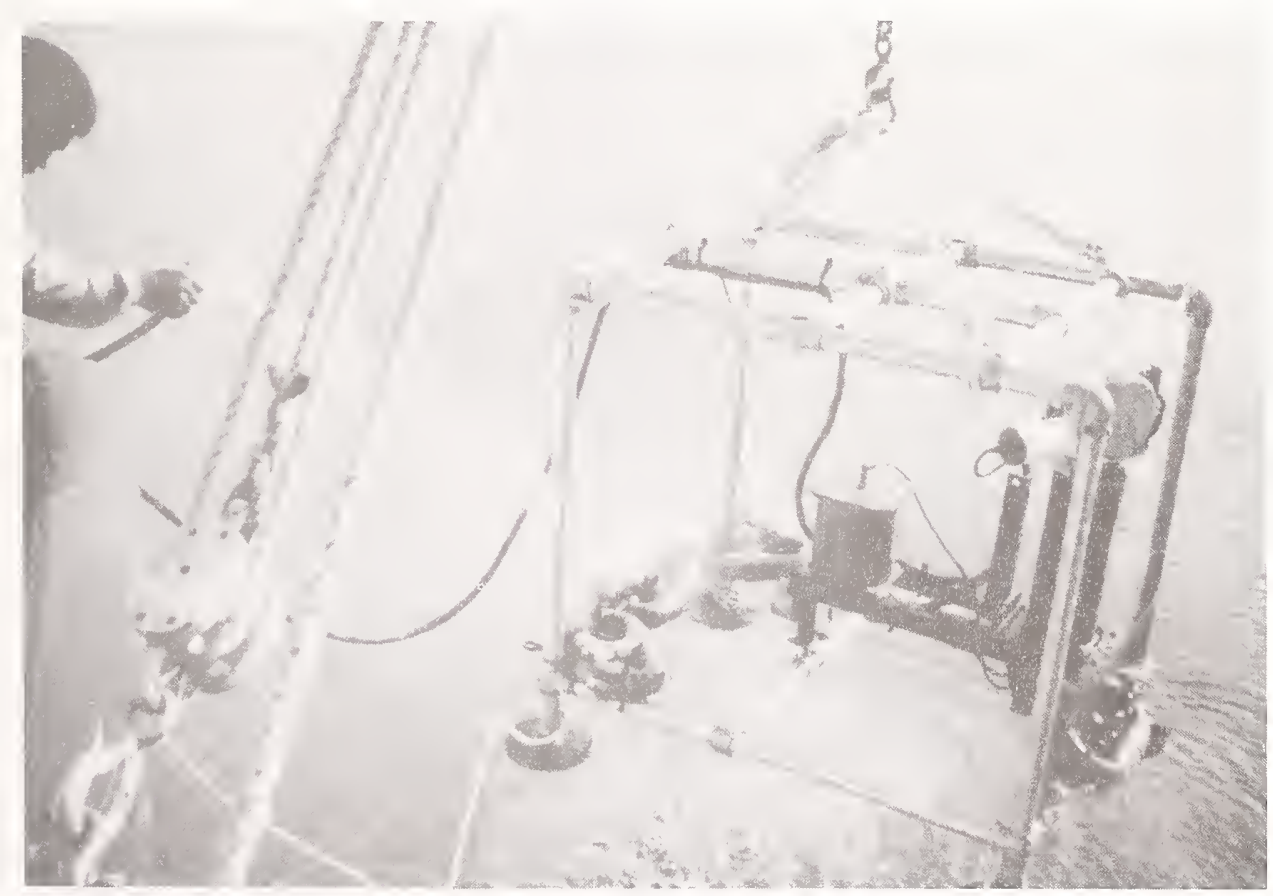

Figure 2. The Coastal Structure Acoustic Raster Scanner is raised from its underwater surveying position. 


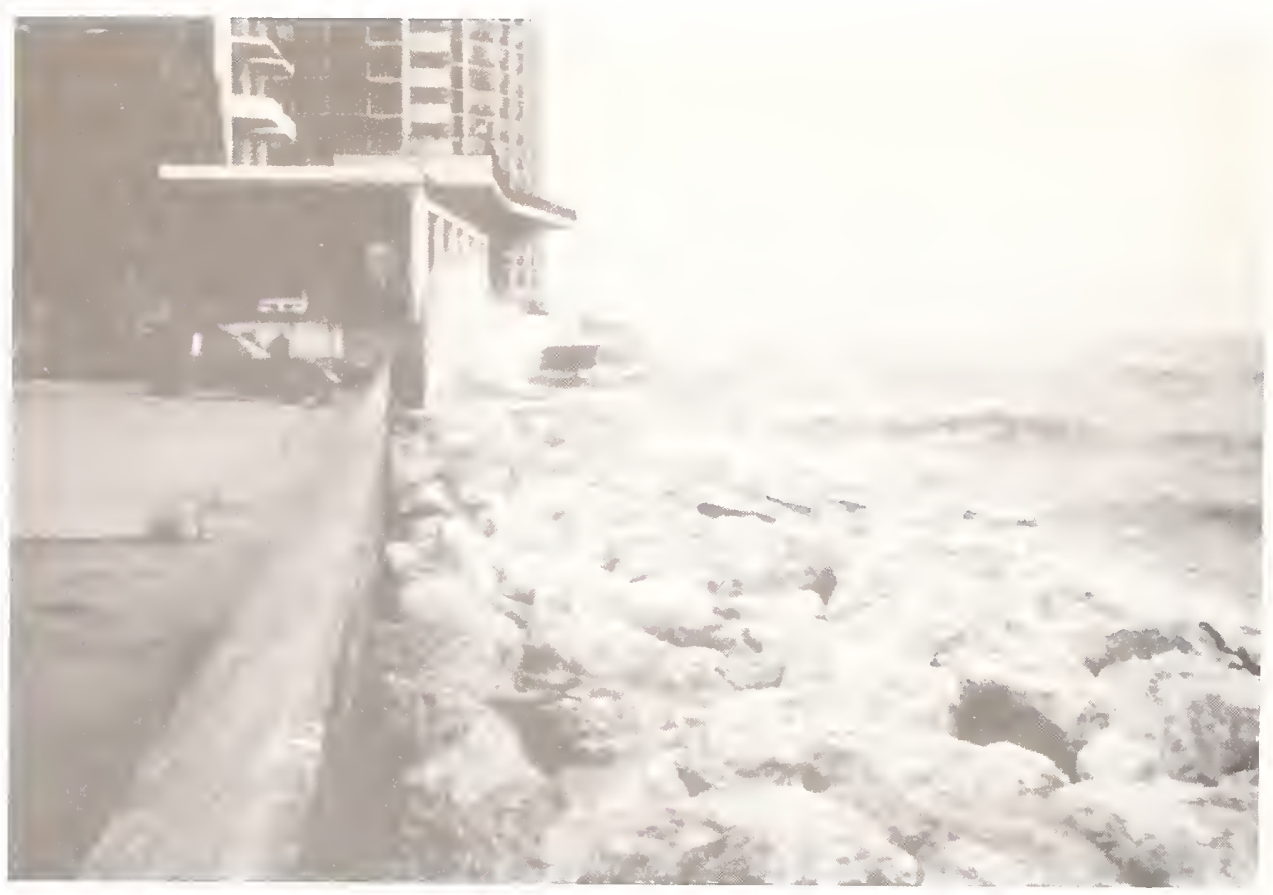

Figure 3. Low berm revetment installed at Temple Emanuel to decrease wave runup and overtopping.

Figure 4. Equipment used to install stone columns to improve foundation conditions.

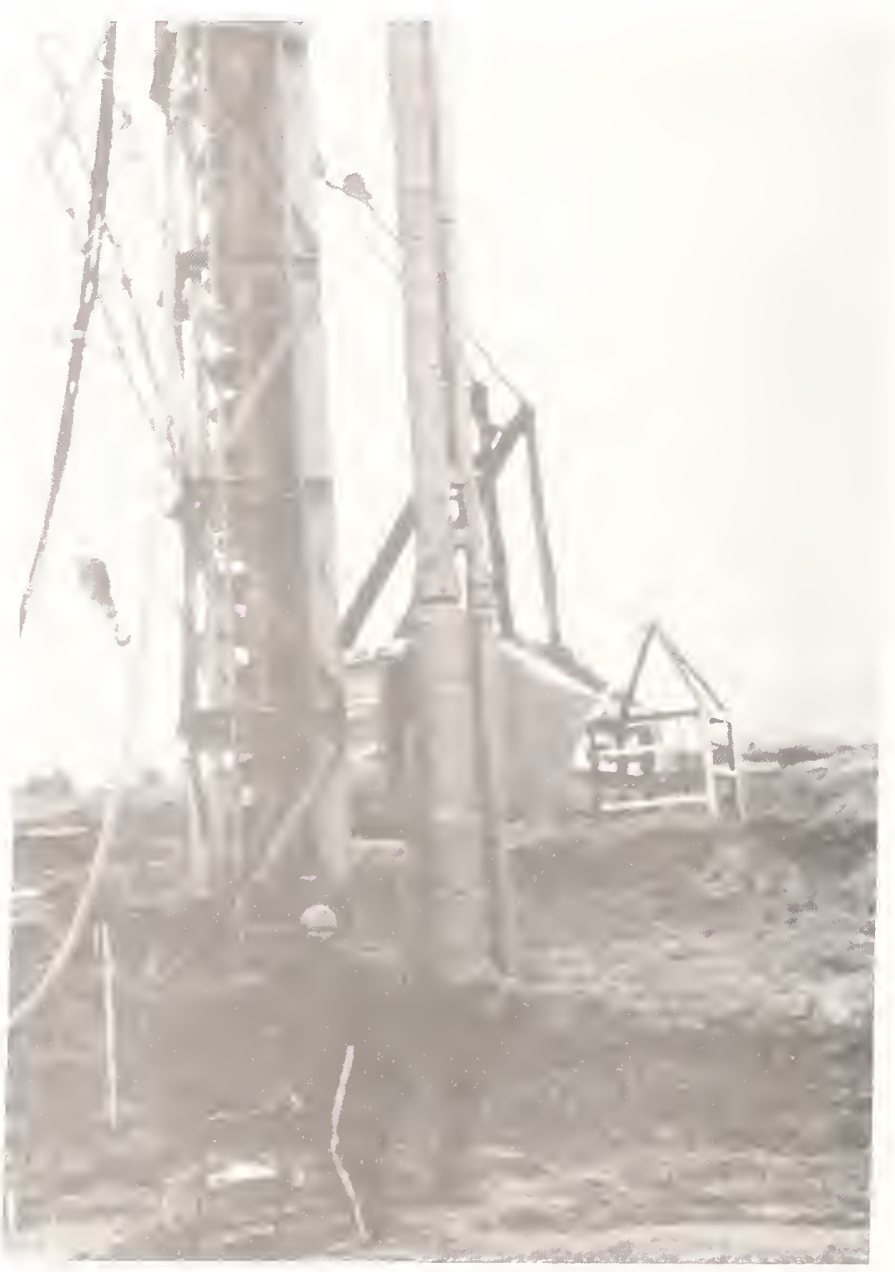


Figure 5. Drill rig

instrumented with "Drilling

Parameter Recorder."
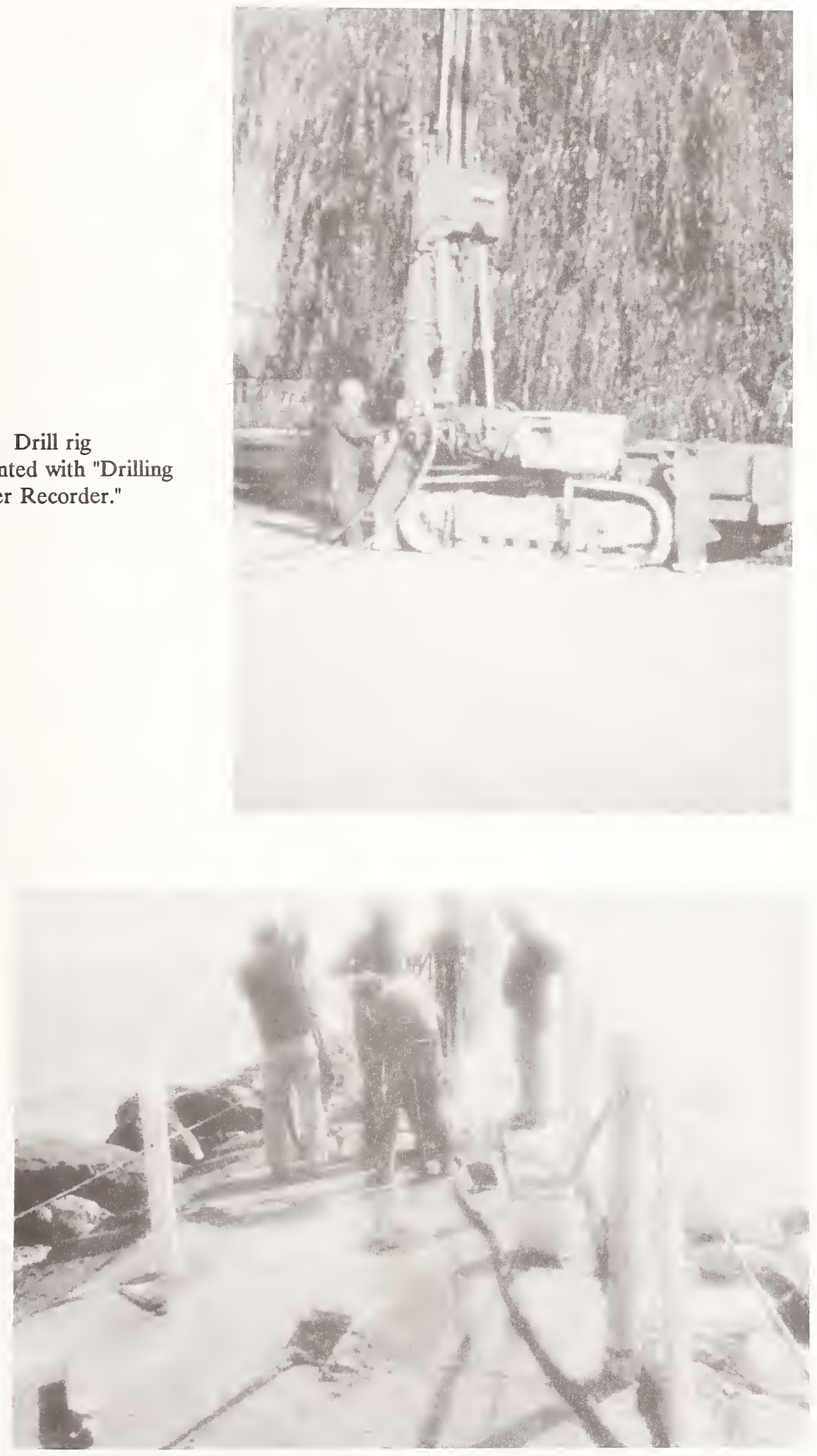

Figure 6. Sealing of the south jetty at Port Everglades, Florida. 


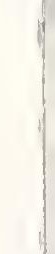




\section{Shaking Table Tests for Hydrodynamic Pressure Acting on Double Cylindrical Caisson Type Breakwater in the Deep Sea}

By

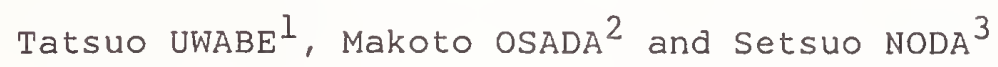

SUMMARY

Shaking table tests were conducted to investigate characteristics of hydrodynamic pressure acting on a double cylindrical caisson. This caisson is composed of a permeable outer cylinder whose upper part has many openings and an impermeable inner cylinder.

The size of caisson model made of acrylic boards was $50 \mathrm{~cm}$ in height and $50 \mathrm{~cm}$ in diameter. The openings of outer cylinder were made within the $20 \mathrm{~cm}$ limits below the top of the model. Opening ratio of $10 \%, 25 \%$ and $100 \%$ were used. These models were called as a permeable type. The model, that has a permeable half circle in front of cylinder and an impermeable half circle in rear side, was made and called as a wave dissipating type. In the experiments, hydrodynamic pressures were measured under the conditions of single cylinder type and cylindric wall type.

In case without opening, the resultant force of hydrodynamic pressure acting on the cylindric wall measured here was almost equal to the value of Westergaard's formula for the wall whose width was the same as the diameter of outer cylinder.

In case with openings, the resultant force of hydrodynamic pressure on the permeable type model with $25 \%$ opening was about 0.7 times of that on the model without opening. The ratio of resultant force on the wave dissipating type model with $25 \%$ opening to that on the model without opening was above 0.9 .

KEY WORDS: Double Cylindrical Caisson, Hydrodynamic Pressure, Opening, Shaking Table Test.

\section{INTRODUCTION}

As offshore and waterfront development is strongly required recently, many large structures have been constructed in deep sea area for port and airport facilities. Because in this area, most of the grounds are very weak and large hydrodynamic pressure acts on these structures, they are supposed to be easily damaged by an earthquake. So we have to investigate the dynamic stability of these structures during earthquake.

Since the breakwater is constructed on deeper seabed ground as compare to other port facilities, it is necessary to go ahead with development of a deep-sea breakwater. In Japan, a composite type of breakwater that consists of a rubble mound and concrete caissons is constructed in general. The cost of the rubble mound of breakwater in deep sea strongly increases. To reduce this cost, it is needed to introduce a large size type of caisson. The double cylindrical caisson discussed in this study is one of them. This caisson is composed of a permeable outer cylinder whose upper part has many openings and impermeable inner cylinder. Wave that permeate through outer cylinder is dissipated in the wave chamber that is formed by outer and inner cylinders.

Generally a design section of the breakwater is determined by wave forces. But the hydrodynamic pressure during earthquake that become large with the increase of the water depth is a main external force for design of the deep-sea breakwater. In the current design standard of port and harbour facilities, the hydrodynamic pressure is given by the Westergaard's formula for a vertical wall, and is given by Zangar's formula for an inclined wall 1 . Uwabe, Noda, Chiba and Higaki ${ }^{2}$ reported that the hydrodynaric pressure on the rectangular caisson is calculated by the Westergaard's formula when the breakwater doesn't show large response. On the other hand, many studies for hydrodynamic pressure on a cylinder have been carried out to design of a footing of bridge. Sakurai ${ }^{3}$ presented general solution of hydrodynamic pressure on a long cylinder, which is derived from the equations of motion considering the flexural osciliation of the cylinder. Goto and Toki ${ }^{4}$ reported the solution of three dimensional hydrodynamic pressure using Euler's equation and velocity potential that is derived from wave equation. But these studies were carried out for the single cylinder, and characteristics of hydrodynamic pressure on a cylindrical caisson with openings were not analyzed in the past studies. Also it is necessary to calculate the hydrodynamic pressure acting on a cylindric wall when this cylindrical caisson is adapted to a composite type breakwater. But there is no description about calculation

1 Dr. Eng., Chief of Earthquake Disaster Prevention Laboratory, Structural Engineering Division, Port and Harbour Research Institute, Ministry of Transport, 3-1-1 Nagase, Yokosuka, Japan.

2 Member of Earthquake Disaster Prevention Laboratory, ditto

3 Dr. Eng., Director, Structural Engineering Division, ditto 
method of this pressure in the current design standard. Therefore, shaking table tests were conducted to investigate the characteristics of hydrodynamic pressure on the double cylindrical caisson.

\section{MODEL OF DOUBLE CYLINDRICAL CAISSON}

2.1 Outline of Double Cylindrical Caisson Figure l shows an outline of double cylindrical caisson type breakwater. This type of caisson has many advantages as follows;

(1) Necessary volume for stability is effectively given.

(2) Costs of materials are cut down.

(3) Surface area of the structure is small.

(4) Various permeable ratio is chosen.

This structure is composed of double vertical cylinders. The upper part of outer cylinder above an intermediate floor slab has many openings. Waves that permeate through these openings are dissipated in the wave chamber that is formed by the intermediate floor slab, and the inner and outer cylinders. An opening ratio of outer cylinder is defined as the ratio of the total area of openings to the upper part area of outer cylinder. On the other hand, the inner cylinder and the lower part of the outer cylinder are impermeable. Inside them, concrete and sand are filled.

\section{2 Model}

Caisson models for shaking table tests were made of acrylic boards. For these experiments, we used a measuring model and two dummy models. Figure 2 shows the outline of these models. The size of the model was $50 \mathrm{~cm}$ in height and $50 \mathrm{~cm}$ in diameter. The diameter of the inner cylinder is $30 \mathrm{~cm}$. On the top of the model there is a cover to link both cylinders and at the bottom of the model there is an acrylic square board to connect to load cells. Sixty four openings whose shape was rectangular were made around the outer cylinder within $20 \mathrm{~cm}$ limit below the top of the model. The opening ratios of model were $0,10,25$ and $100 \%$. The opening ratio of $0 \%$ means that there is no opening on the outer cylinder. The opening ratio of $100 \%$ means that there is no outer cylinder above the intermediate floor slab. In this study, these models were called as a permeable type. Besides these, the model that had a permeable half circle in front of cylinder and an impermeable half circle in rear side was made and called as a wave dissipating type. Therefore, we used four permeable type models (opening ratio: 0, 10 , $25,100 \%$, and three wave dissipating type models (opening ratio: 10, 25, 100\%).

\section{MODEL TESTS}

3.1 Outline of Model Tests
The contents of model tests are as follows;

(1) In case without opening

a) Single cylinder type model

b) Cylindric wall type model

c) Dotted line set type model

(Space between models: $0.5,4.0 \mathrm{~cm}$ )

(2) In case with openings

a) Single cylinder type model

(opening ratio: 10, 25, 100\%)

b) Cylindric wall type model

(opening ratio: 10, 25, 100\%)

The tests of single cylinder type model mean that only the measuring model was set in a container on the shaking table, while the tests of cylindric wall type model mean that the dumm models were set in contact with the measuring model. The tests of dotted line set type model were only conducted using $0 \%$ opening models. In this case, the dumm models were set leaving a space from the measuring model, then relation between the characteristic of hydrodynamic pressure and the distance of space was investigated.

\section{2 Measuring items}

Response accelerations and hydrodynamic pressures on the model were measured. The hydrodynamic pressure was measured by water pressure gauges that were set on the surface of the model. Distribution and resultant force of the hydrodynamic pressure on the model were given by these measured values. However in case with openings, it was difficult to measure the hydrodynamic pressure on openings. Therefore the resuitant force of the hydrodynamic pressure was measured by four load cells set under the model.

Figure $3(a)$ shows an array configuration of accelerometers, water pressure gauges and load cells in case without opening. Because the model was symmetrical with the direction of excitation, the water pressure gauges were deployed in six rows and three columns on a quarter area of the outer cylinder. Angles from the direction of excitation of each column were 0,34 and 67.5 degree. The response acceleration of the model was measured by six accelerometers. Five accelerometers were set in a row inside the outer cylinder and another accelerometer was put on the top of the model.

Figure $3(b)$ shows an array configuration of instruments on the model with openings. Seven water pressure gauges were used to measure distribution of the hydrodynamic pressure on the inner cylinder. Three of them were set in a column on 0 degree from the direction of excitation and others were set in a row around the half part of the inner cylinder. Positions of the water pressure gauges and the accelerometers set on lower part of the outer cylinder were same to those of the case without opening. In case of the wave dissipating type, a permeable half 
circle was set on a side on which the water pressure gauges were set.

3.3 Setring of Model

Two kinds of shaking table that were of electromagnetic type and an underwater shaking table were used for the present study. The underwater shaking table was developed for large structures constructed in deep sea area ${ }^{5}$. Since the shaking table is set on the bottom of the large water tank, it can reproduce the seabed ground during earthquake.

In model tests using electromagnetic type shaking table, a container whose size was 3 m long, 1.5m wide and 1.2m high was set on the shaking table. Figure 4 shows the location of the models. The load cells were set in a steel box and the measuring model was put on them. Crushed stones were poured around the steel box so that the level of the bottom of the model was same to that of the surface of them. The dummy models were set on rectangular steel plates that were put on the crushed stones. In order to fix the model to the container during shaking, the dummy models were connected to a cross beam at the top of the container. In case using the load cells, it was necessary that the measuring model didn't touch the dummy models and the steel box during shaking. Therefore, little spaces were inserted between them. As the effect of this, it was expected that the hydrodynamic pressure on the model decreases in compare with a case without a space. However, we judged that it was possible to estimate the correlation between the hydrodynamic pressure and the opening ratio from the results of test using load cells.

Besides the tests described above, the model tests in which the models were directly set on the bottom of the container were conducted to get rid of effects of the load cells and the crushed stones.

The underwater shaking table was used for the dotted line type model tests. Figure 5 shows the outline of these tests. The single cylinder type model tests and the cylindric wall type model tests were carried out using the underwater shaking table to compare with the results of the tests using container. Input motion used for the experiments was of sinusoidal wave form that was of $5 \mathrm{~Hz}$ and of locycles. Maximum accelerations of the input motion were 50,100 and $200 \mathrm{Gal}$. Table 1 shows the whole test conditions mentioned above.

\section{RESUIT OF MODEL TEST}

\subsection{Distributions of Accelerations}

Distributions of peak values of response accelerations obtained from time histories are shown in Fig.6. Figure 6(a) shows results of cases that the models were directly set on the bottom of the container. It is easy to recognize that the response acceleration of the top of the model(Al) is almost same to that of the bottom of the model(A5). Figure $6(\mathrm{~b})$ shows the results of the case using load cells. In this case, the response acceleration of Al is a little larger than that of A5. This tendency was more obvious in single cylinder type than in cylindric wall type, and was more obvious in impermeable type than in permeable type. But the ratio of acceleration at Al to that at A5 is no more than 1.1 in maximum. Therefore, it was also judged that the models were almost shaken as a rigid body in case with load cells.

\subsection{Distributions of Hydrodynamic Pressure}

Distribution of the hydrodynamic pressure on the model, which was set on the bottom of the container, is described here. Peak values of second and third half waves were chosen from time histories for analysis (called as p). As mentioned earlier, the model was shaken as a rigid body so that a mean value of accelerations measured each accelerometer was used here as a response acceleration of the model. A ratio of this response acceleration to the gravity acceleration was named a seismic intensity (called as $k$ ). Since a relation between $\mathrm{p}$ and $\mathrm{k}$ was almost liner, we used a mean value of $\mathrm{p} / \mathrm{k}$ for following discussion.

\subsubsection{Distribution of Hydrodynamic Pressure (without opening)}

Figures $7(a)$ and(b) show vertical distributions of the hydrodynamic pressure on the model in case of the single cylinder type and of the cylindric wall type respectively. The hydrodynamic pressure on the cylindric wall is larger than that on the single cylinder. Figure 8 shows horizontal distributions of the hydrodynamic pressure on the model at the height of $17 \mathrm{~cm}$ from the bottom of the model. It is easy to recognize in this figure that though the hydrodynamic pressure become small with increase of the angle from the direction of excitation in the single cylinder type, that become large in the cylindric wall type. The hydrodynamic pressures measured in the dotted line type are between them. These facts suggest that the hydrodynamic pressure concentrates near contact point of cylinders in case of the cylindric wall type, and when a little space is set between them, the hydrodynamic pressure is rapidly decreased.

\subsubsection{Resultant Force of Hydrodynamic Pressure (without opening)}

Figure 9 shows vertical distributions of resultant force of the hydrodynamic pressure on the model that are approximately calculated using the horizontal distributions at each level. Distributions of the Gotod 
Toki's formula and the Westergaard's formula are also shown in Fig.9. The distribution of the Westergaard's formula ${ }^{6}$ is obtained for the wall whose width is the same as the diameter of the outer cylinder. The distribution in case of the single cylinder type agrees with that of the GotodToki's formula, and the distribution in case of the cylindric wall type is almost same to that of the Westergaard's formula. Therefore, it is considered that the resultant force of the hydrodynamic pressure on the cylindric wall is given by the Westergaard's formula. Distributions in case of the dotted line type lie between those in case of the cylindric wall type and in case of the single cylinder type.

Whole resultant force of the hydrodynamic pressure was approximately obtained by calculating the areas formed by each distribution. The results of calculations are shown in Table 2. The resultant force in case of dotted line type with $4.0 \mathrm{~cm}$ space, which is equal to $8 \%$ of the diameter, is 0.67 times of that in case of the cylindric wall type. As described earlier, this result suggests the hydrodynamic pressure is decreased by inserting a little space between caissons.

\subsubsection{Distribution of Hydrodynamic Pressure (with openings)}

Figure $10(a)$ shows vertical distributions of hydrodynamic pressure in case of the single cylinder type with openings. The values above $31.5 \mathrm{~cm}$ were measured by the water pressure gauges on the inner cylinder. Though the hydrodynamic pressures measured at Wla-W3a show large value with increase of the opening ratio, the values at W4-W6 decrease. In particular, the value at W4 considerably decrease. From these results, it seems that the hydrodynamic pressure on the lower part of the outer cylinder was decreased with decrease of hydrodynamic pressure on the upper part effected by the openings. On the other hand, it is estimated that the hydrodynamic pressure on the inner cylinder shows large value with increase of the opening ratio. Figure $10(\mathrm{~b})$ shows vertical distributions in case of the wave dissipating type. Differences between the hydrodynamic pressures of each opening ratio are small as compare with those of the permeable type.

Figures $11(a)$ and (b) show horizontal distributions of the hydrodynamic pressure on the lower part of the outer cylinder in case of the permeable, and the wave dissipating type. It is obvious that the hydrodynamic pressure decrease with increase of the opening ratio. Figure 12 shows the comparison of the distributions of hydrodynamic pressure between the permeable and the wave dissipating type. Though the hydrodynamic pressure in the wave dissipating type is larger than that in the permeable type as expected, the differences of the values at W4-W6 are very small. These characteristics of the single cylinder type as described above were observed similarly in the cylindric wall type.

Figures 13(a) and(b) show horizontal distributions of the hydrodynamic pressure on the inner cylinder in case of the permeable type and the wave dissipating type. In case of the permeable type, values at $W 4 a$ and $W 6 a$, and at W3a and $W 7$ a are symmetrical about W5a respectively. Absolute values of each water pressure gauge increase according to the opening ratio. In case of the wave dissipating type, however, signs of the hydrodynamic pressures are same at each point and the absolute values of them increase as increase of the angle. Also the hydrodynamic pressures measured at W5a, W6a and W7a increase with decrease of the opening ratio. In the cylindric wall type, though the hydrodynamic pressure was larger than that in the single cylinder type, same characteristics were also obtained.

\subsection{Relation between Resultant Force and Opening Ratio}

The resultant force of the hydrodynamic pressure was estimated from measured values of load cells. They contained inertial forces of the model, load cells and water inside the model. In the experiments, therefore, the model was shaken in case without water and in case with water, and the inertial forces of the model and the load cells given by subtracting the measured values without water from those with water, and the inertial force of water inside the model was removed from measured value of load cells to obtain the resultant force of the hydrodynamic pressure. In this process, however, the water in the wave chamber was regarded as hydrodynamic pressure in case with opening, and was regarded as inertial force in case without opening. Therefore, the inertial force inside the wave chamber was added to the hydrodynamic pressure on the model without opening when the resultant force on the model without opening was compared with those on the models with openings.

Peak values of the second and third waves of time histories measured by load cells were chosen as measured values of the load cells in the same way as the hydrodynamic pressure (called as f). Figure 14 shows relation between the accelerations and the values of the load cells. Straight lines in Fig.14 shows mean values of $f / k$ used for this analysis.

Figure 15 shows relations of the resultant forces of the hydrodynamic pressure and the opening ratio. The vertical axis shows the ratio of resultant force in case with openings to that in case without opening. As 
mentioned above, the resultant force in case without opening contains the inertial force of the water inside the wave chamber. In case of the permeable type of single cylinder, the ratio of resultant force with $10 \%$ opening is $72 \%$ and that with $100 \%$ opening is $62 \%$. In case of the permeable type of cylindric wall, as similar to these results, the ratio of resultant force with $10 \%$ opening is $78 \%$ and that with $100 \%$ opening is $66 \%$. On the other hand, the ratio of resultant force in case of the wave dissipating type shows little decrease with increase of the opening ratio.

5. CONCLUSION

Shaking table tests were conducted to investigate characteristics of the hydrodynamic pressure acting on the double cylindrical caisson. The following conclusions are obtained.

(1) The resultant force of hydrodynamic pressure on the cylindric wall was almost equal to the value of the Westergaard's formula for the wall whose width is same as the diameter of the cylinder.

(2) The hydrodynamic pressure on the cylindric wall concentrates near the contact points of cylinders. This pressure concentration is relaxed by slightly separating them each other.

(3) In case of the permeable type, the hydrodynamic pressure on the lower part of the outer cylinder tends to decrease with increase of the opening ratio. In particular, the pressure near the openings considerably decreases. In contrast with this, the hydrodynamic pressure on the inner cylinder tends to increase with increase of the opening ratio. These characteristics were also observed in case of the wave dissipating type.
(4) In case of the permeable type, the horizontal distribution of the hydrodynamic pressures on the inner cylinder is almost symmetrical with zero. But in case of the wave dissipating type, the sign of the hydrodynamic pressure around inner cylinder is same all at once and the absolute value of it increases as the angle increases. Also, the absolute value of it increases as decrease of opening ratio for the angle above 45 degree.

(5) The resultant force of hydrodynamic pressure on the permeable type model with $25 \%$ opening is 0.7 times of that on the model without opening. The ratio of resultant force on the wave dissipating type model with $25 \%$ opening to that on the model without opening is above 0.9 .

\section{REFERENCE}

1) Japan port and harbour association: Technical standards for port and harbour facilities, March 1989.

2) UWABE, T., NODA, S., CHIBA, S. and HIGAKI, S.: Coupled Hydrodynamic Response Characteristics and Water Pressures of Large Composite Breakwaters, Report of the Port and Harbour Research Institute, Vol. 20, No. 4, December 1981.

3) SAKURAI, A.: Vibration of Pier constructed in the Water, Civil Engineering, Vol.16, No.6, 1961 .

4) GOTO, H., TOKI, K.: Fundamental Studies on Vibration Characteristics and Aseismic Design of Submerged Bridge Piers, Proc. of JSCE, No.100, 1963

5) NODA, S., KURATA, E. and OSADA, M.: Development of Underwater Shaking Table, Proc. of the 20th Earthquake Engineering Conference, 1989.

6) Westergaard, H.M.: Water Pressures on Dams during Earthquakes, Trans. ASCE98, 1933, pp. 418-434.

Table 1 Test conditions

\begin{tabular}{|l|l|}
\hline Type of Model & $\begin{array}{l}\text { Single Cylinder Type } \\
\text { Cylindric Wa1l Type } \\
\text { Dotted Line Type } \\
\text { (Space between Models : 0.5,4.0cm) }\end{array}$ \\
\hline Opening Ratio & $0,10,25,100 \%$ \\
\hline Type of Caisson & Permeable, Wave Dissipating \\
\hline Measuring Item & Hydrodynamic Pres., Acceleration \\
\hline $\begin{array}{l}\text { Measuring Method of } \\
\text { Hydrodynamic Pres. }\end{array}$ & $\begin{array}{l}\text { Water Pres. Gauge } \\
\text { Water Pres. Gauge + Load Cell }\end{array}$ \\
\hline Input Motion & Sinusoida1 Motion (5Hz, 10Waves) \\
\hline Max. Acceleration & $50,100,200$ Gal \\
\hline
\end{tabular}


Table 2 Measured and theoretical resultant forces of hydrodynamic pressure

\begin{tabular}{|c|c|c|c|c|c|c|}
\hline & \multicolumn{4}{|c|}{ Measured Values } & \multicolumn{2}{c|}{ Theoretical Values } \\
\cline { 2 - 6 } & \multirow{2}{*}{ Wall Type } & \multicolumn{2}{|c|}{ Dotted Line Type } & \multirow{2}{*}{ Single Type } & \multirow{2}{*}{ Hestergard } & \multirow{2}{*}{ Goto\& Toki } \\
\cline { 2 - 6 } & $0.5 \mathrm{~cm}$ & $4.0 \mathrm{~cm}$ & & 138.6 & 55.8 \\
\hline $\begin{array}{c}\text { Resultant } \\
\text { Force (kgf) }\end{array}$ & 133.1 & 113.6 & 89.5 & 57.3 & 1.04 & 0.419 \\
\hline Ratio & 1 & 0.853 & 0.672 & 0.431 & 194 \\
\hline
\end{tabular}

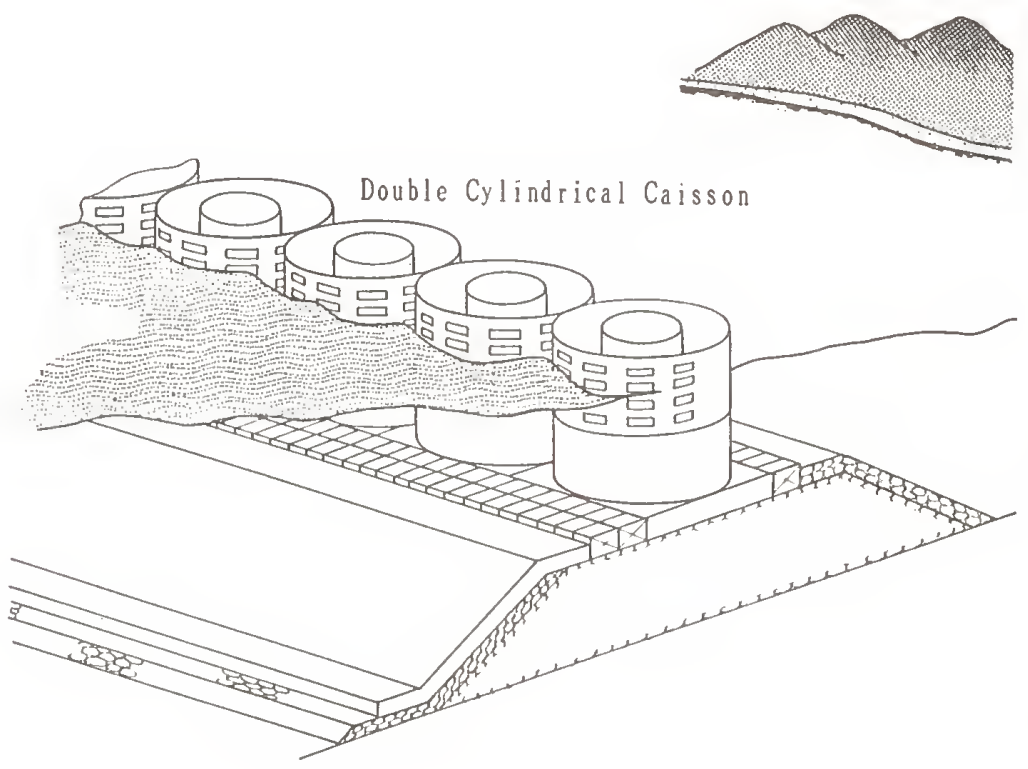

Fig. l outline of double cylindrical caisson type breakwater

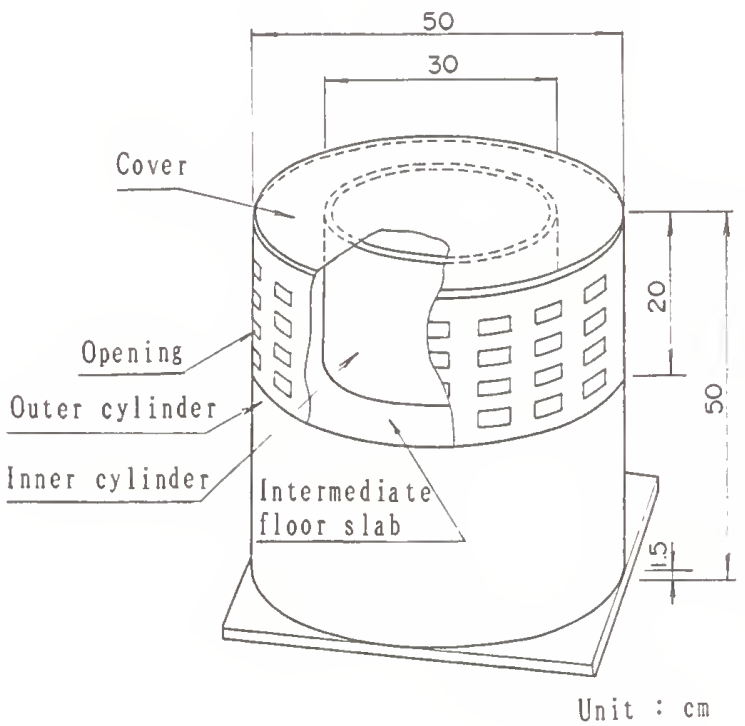

Fig. 2 Model of double cylindrical caisson 


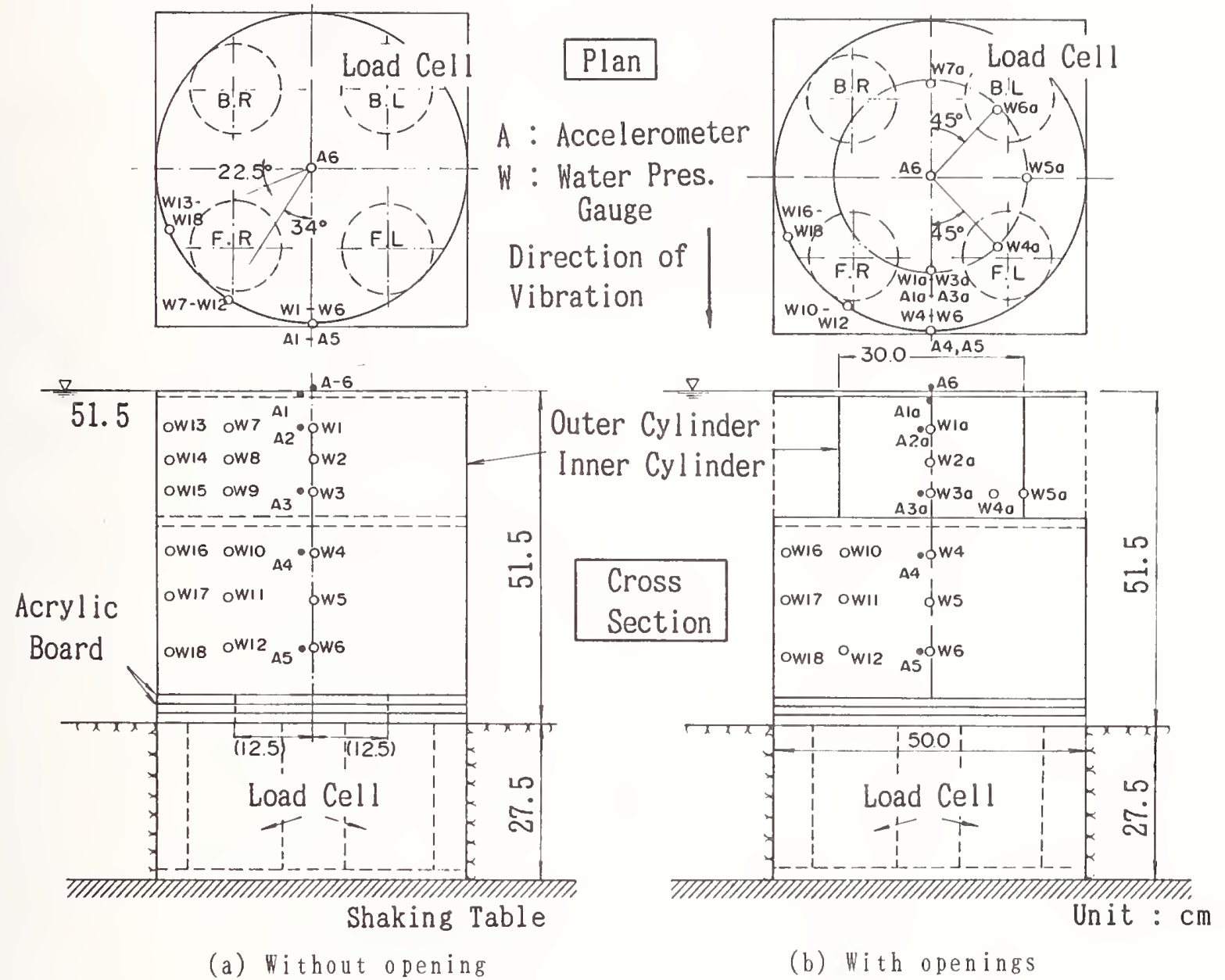

Fig. 3 Locations of pickups

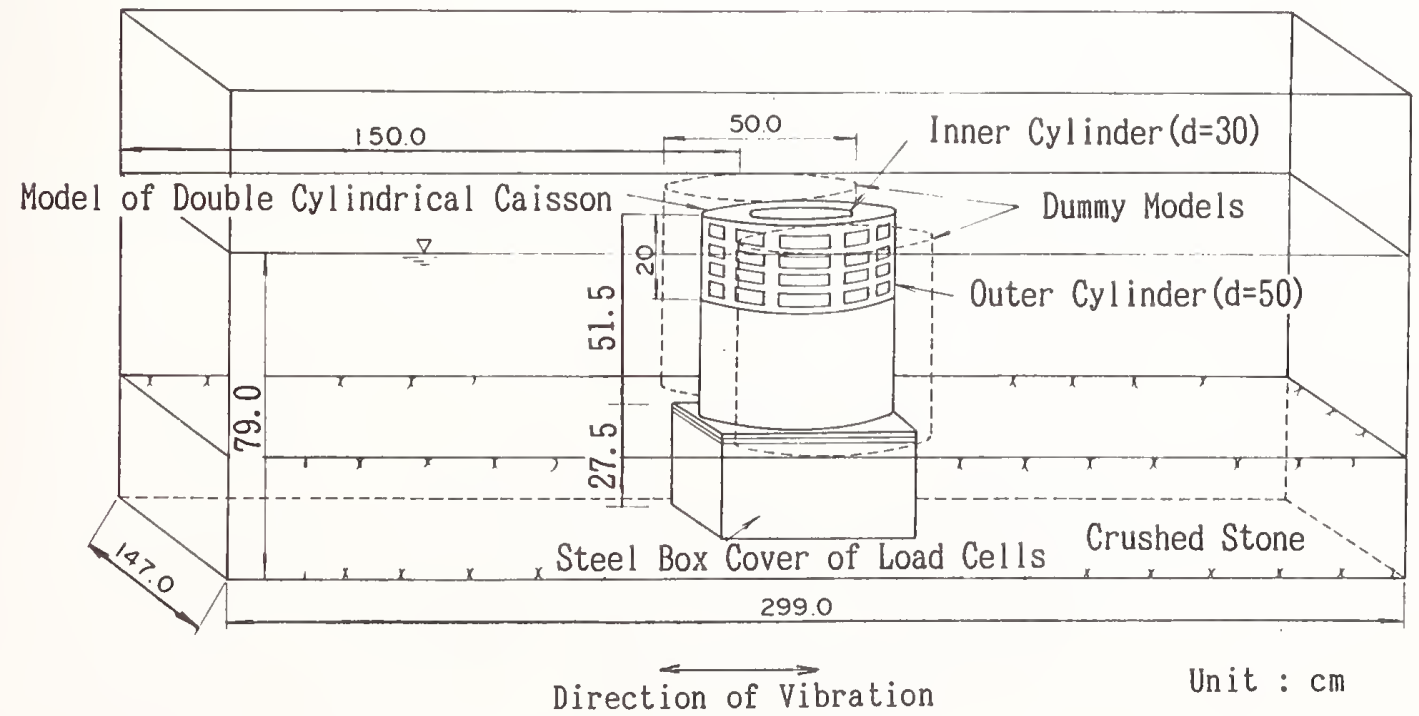

Fig. 4 Setup of model 


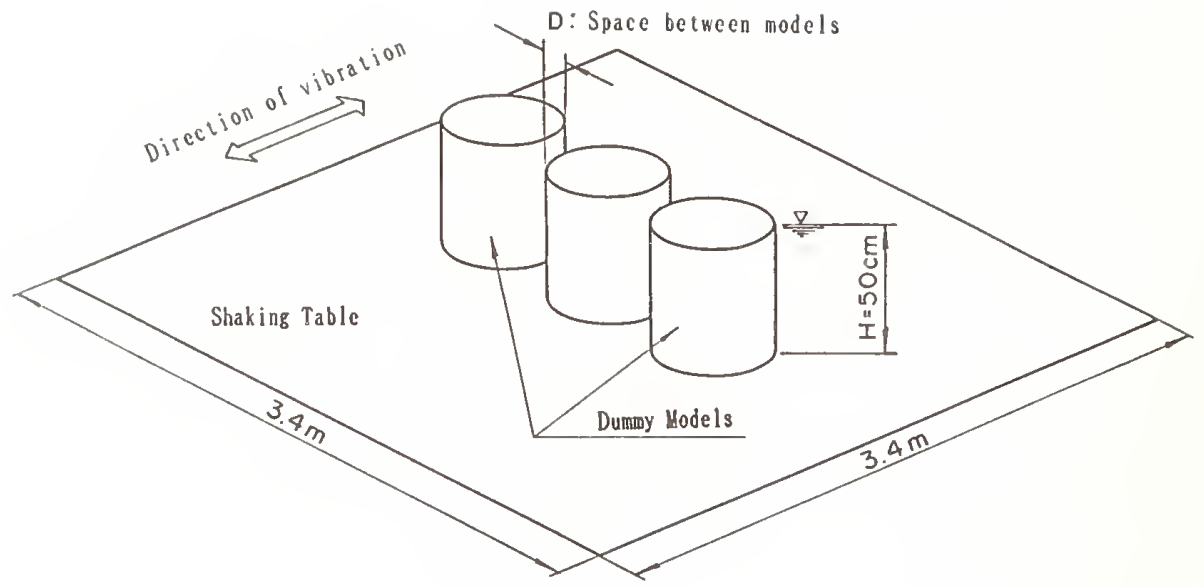

Fig. 5 Setup of dotted line type test
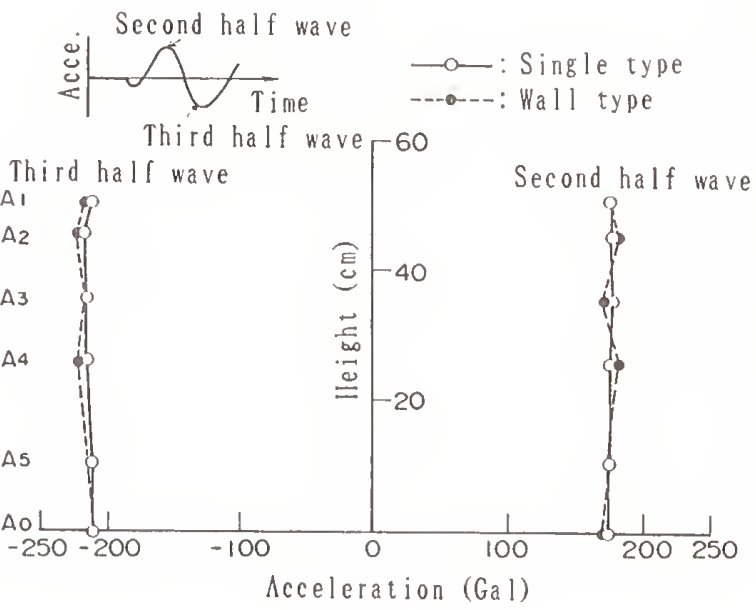

(a) Direct setting on container

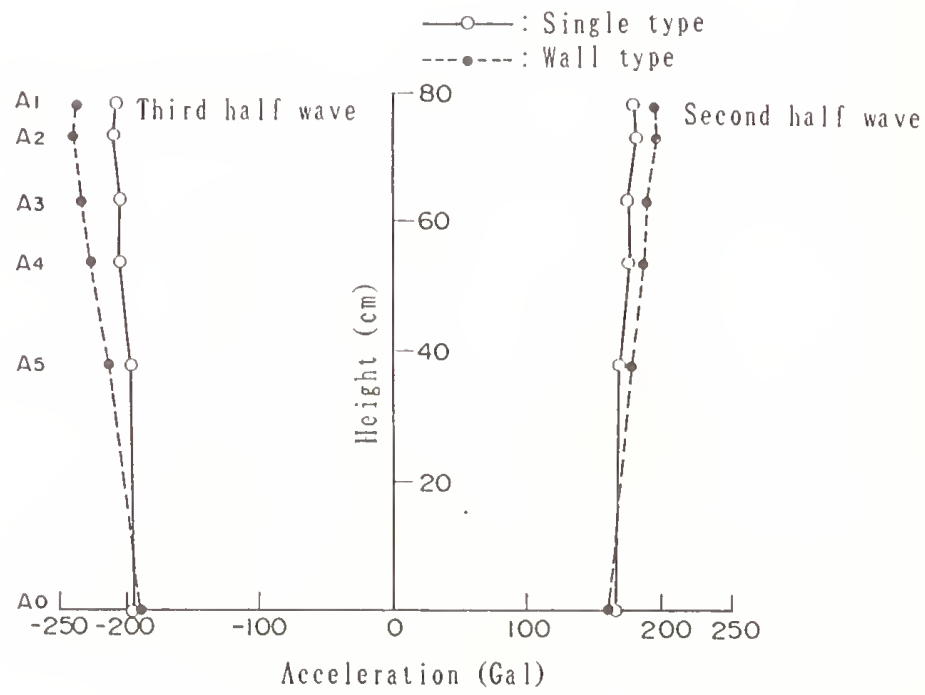

(b) With load cells

Fig. 6 Vertical distributions of acceleration ( $0 \%$ type) 


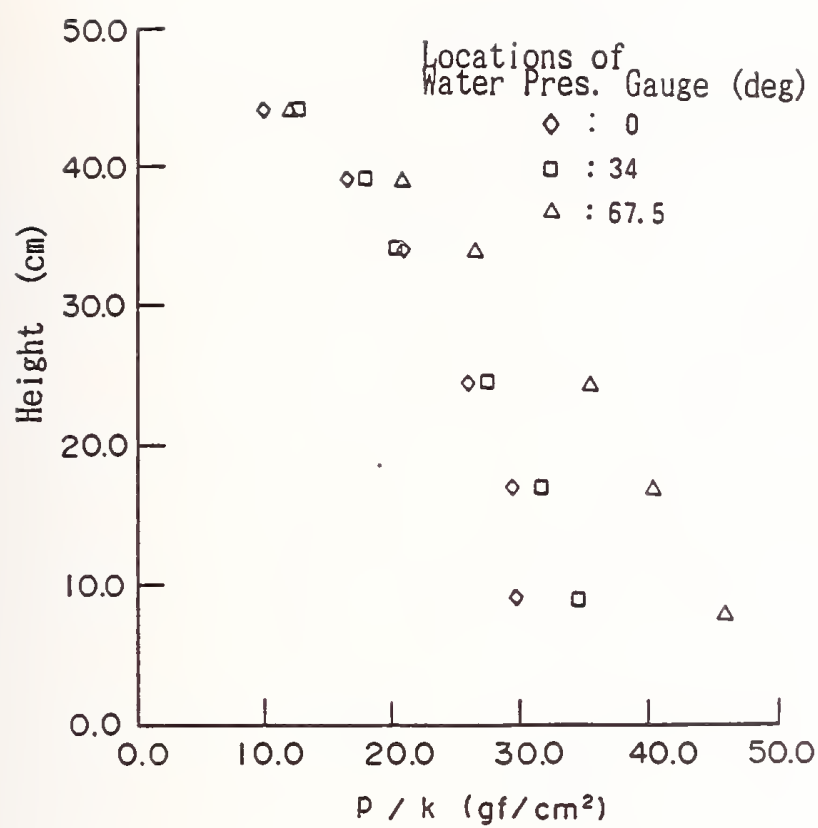

(a) Wall type

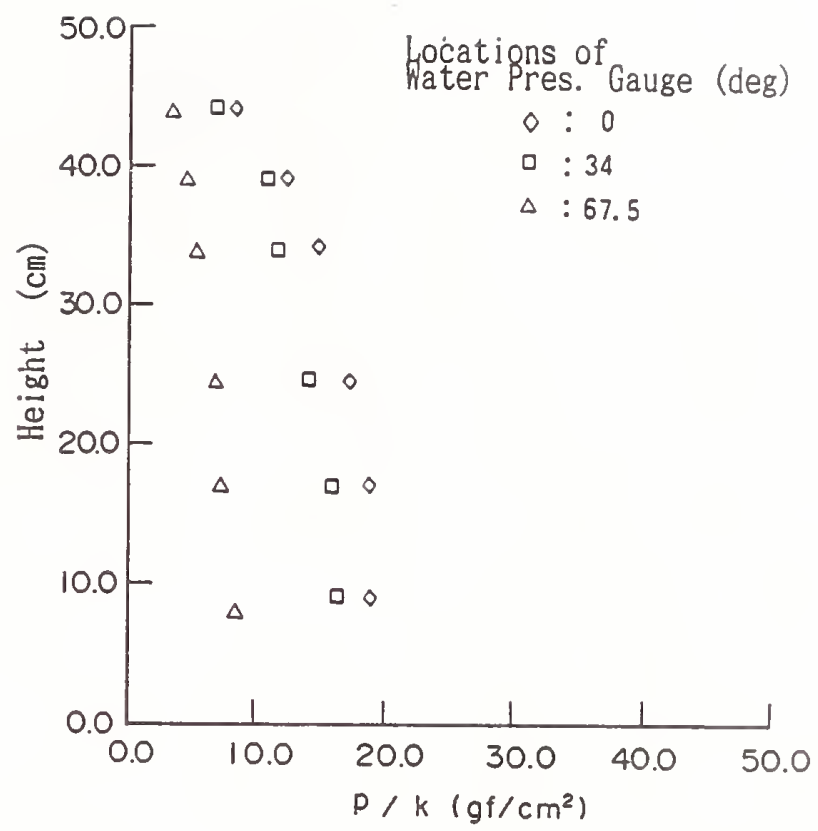

(b) Single type

Fig. 7 Vertical distributions of hydrodynamic pressure ( $0 \%$ opening)

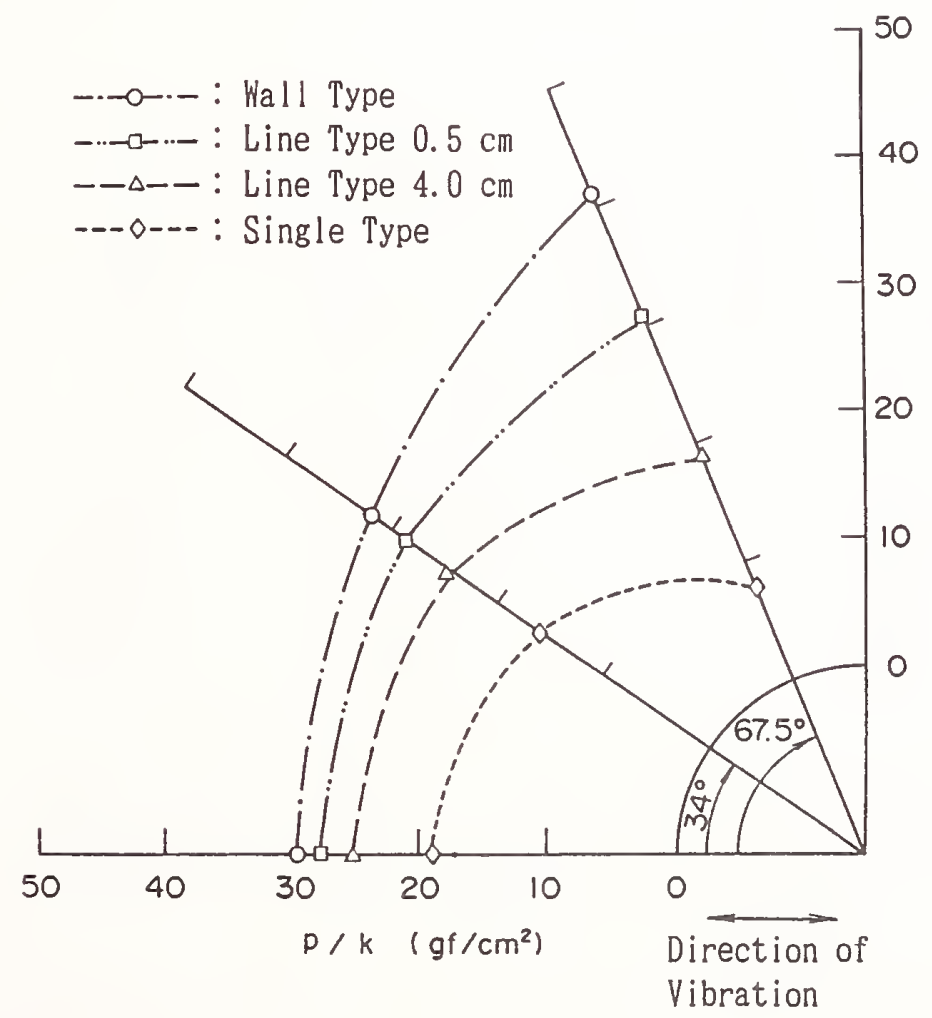

Fig. 8 Horizontal distributions of hydrodynamic pressure ( $17 \mathrm{~cm}$ height) 


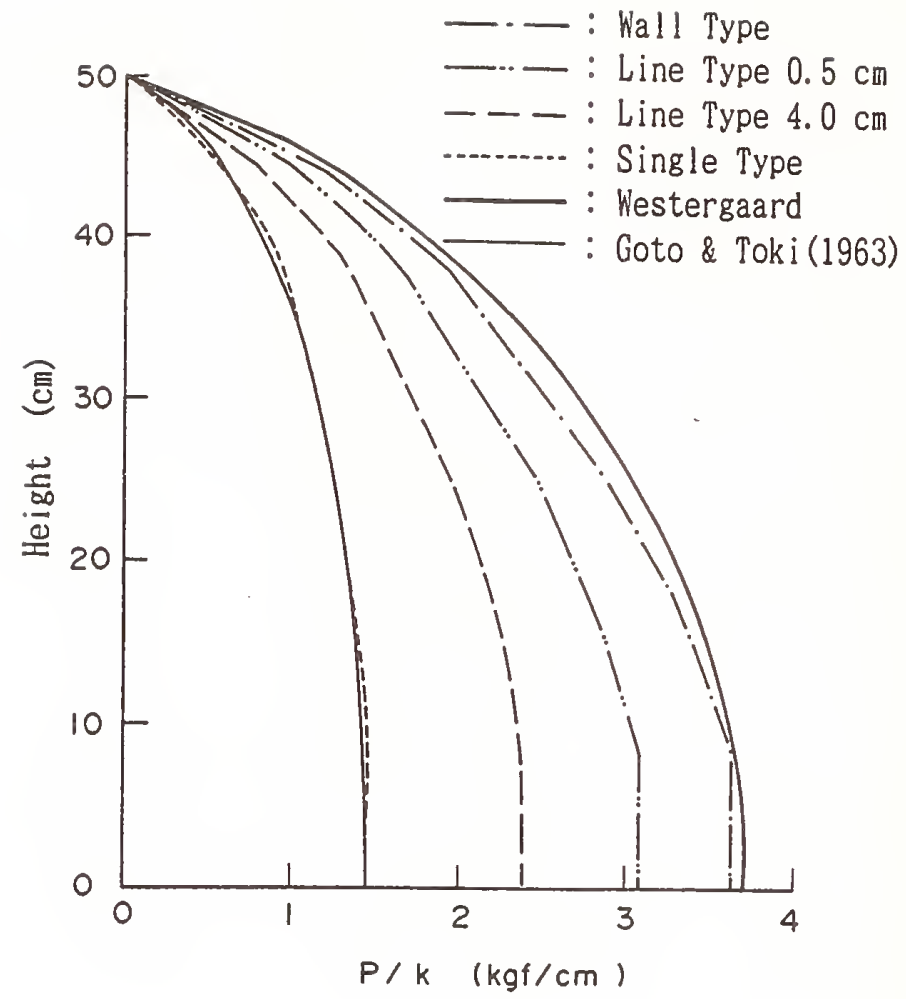

Fig. 9 Measured and theoretical values
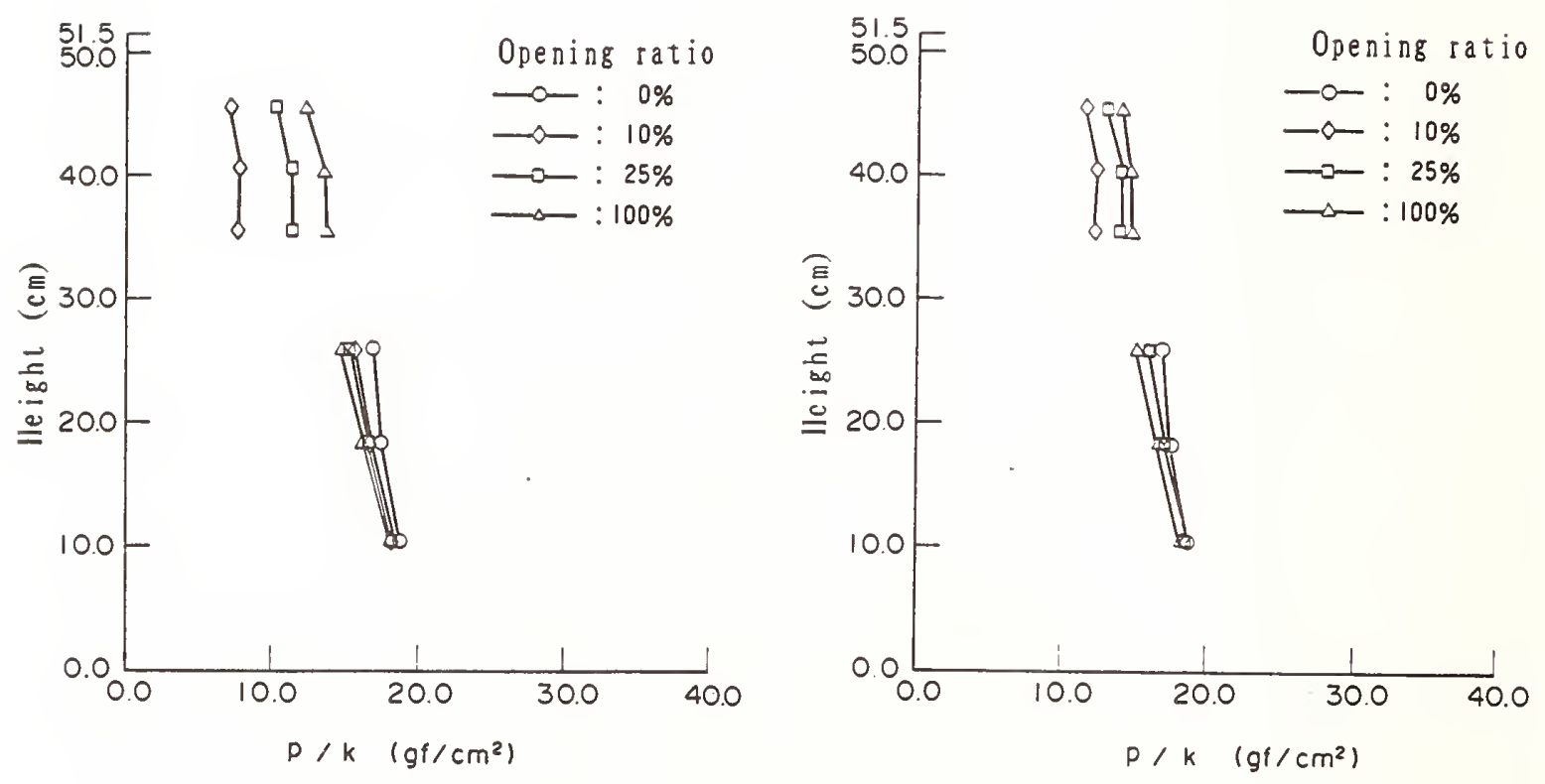

(a) Permeable type

(b) Wave dissipating type

Fig. 10 Vertical distributions of hydrodynamic pressure (single type) 


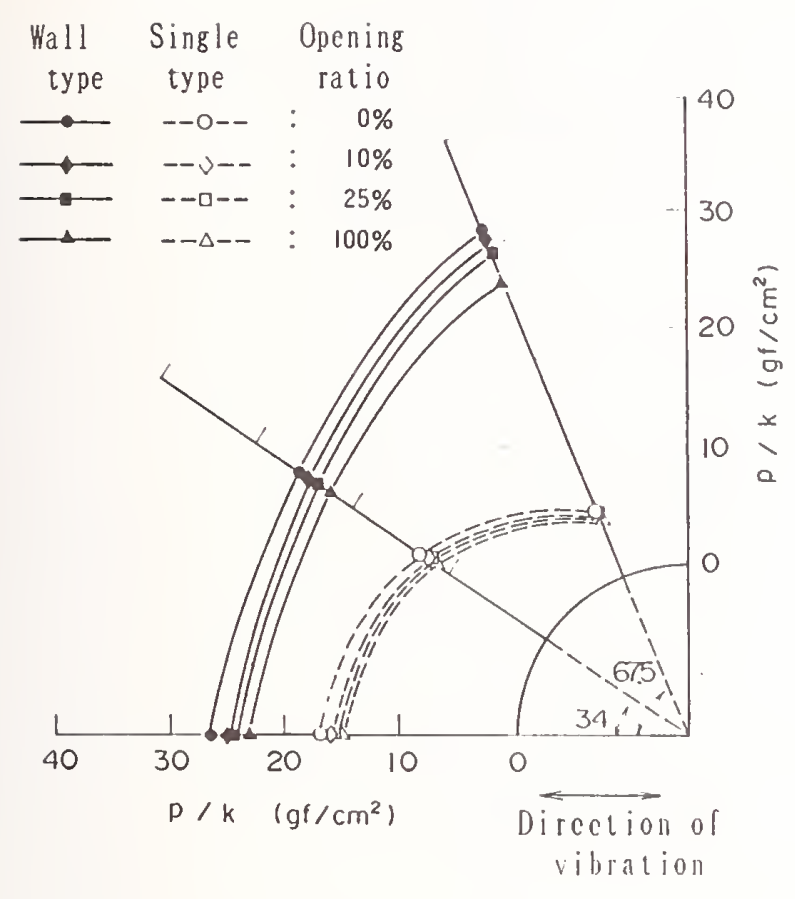

(a) Permeable type

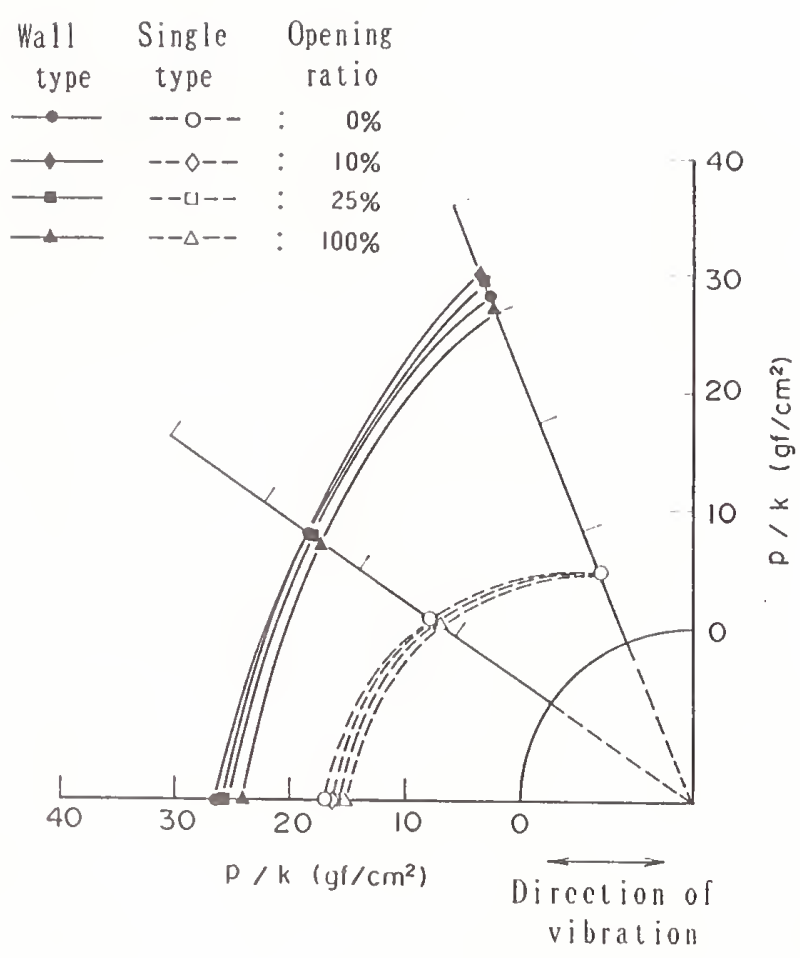

(b) Wave dissipating type

Fig. 11 Horizontal distributions of hydrodynamic pressure $(26 \mathrm{~cm}$ height)

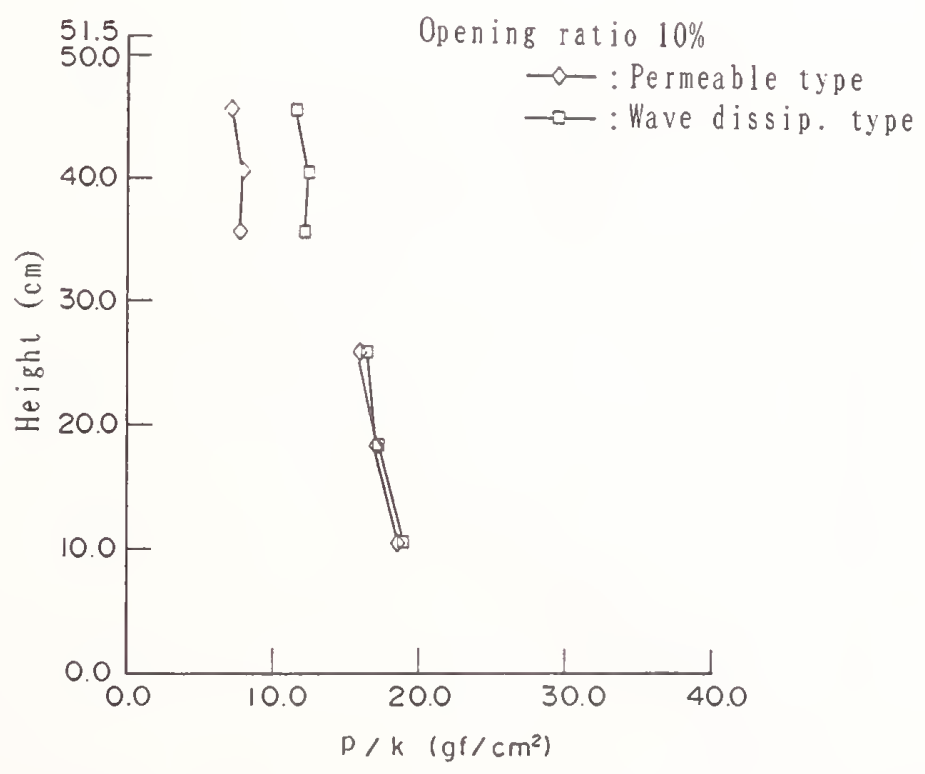

Fig. 12 Hydrodynamic pres. of permeable and wave dissipating type (10\% opening) 


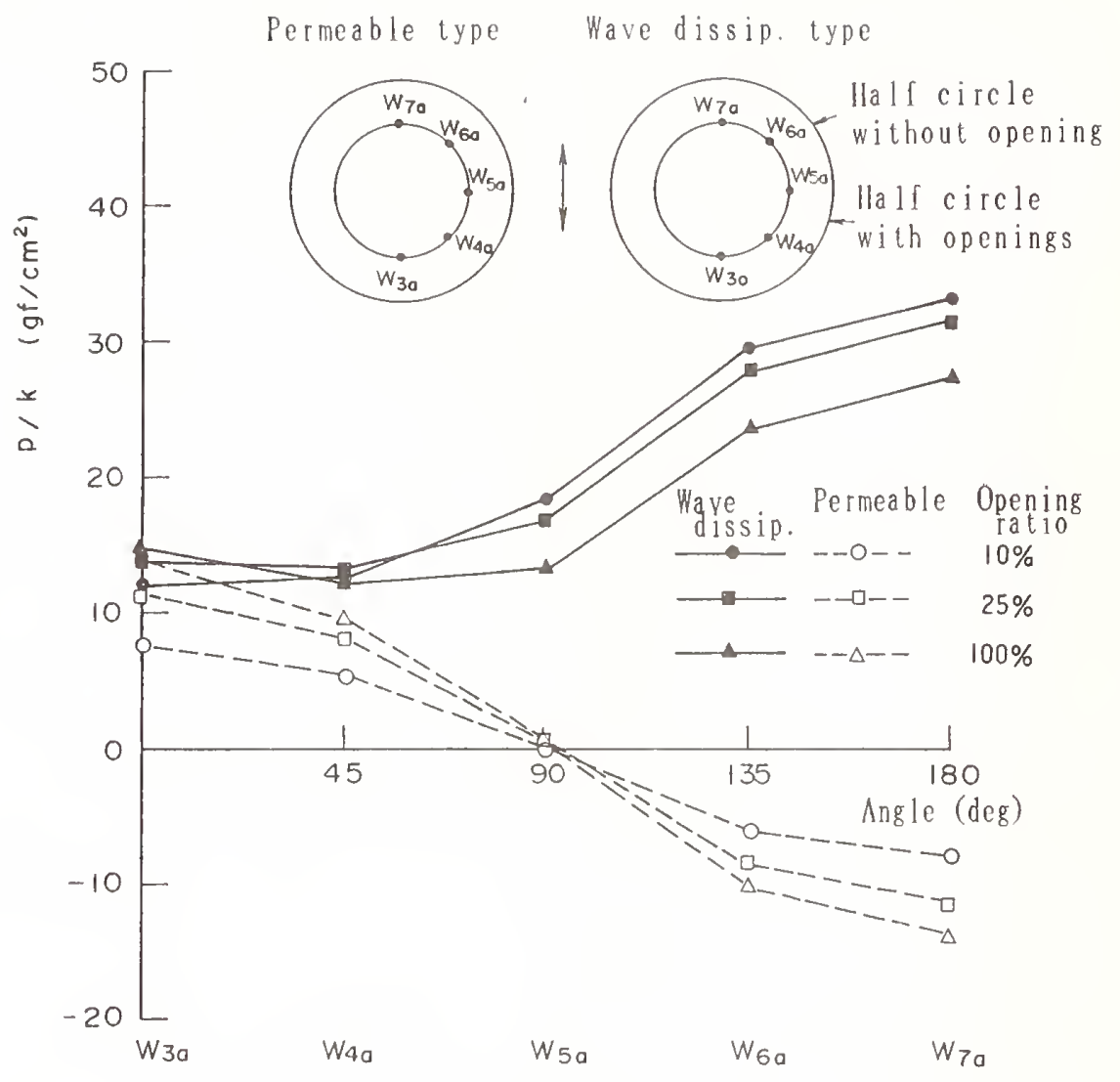

Fig. 13 Horizontal distributions of hydrodynamic pres. on inner cylinder (single type)

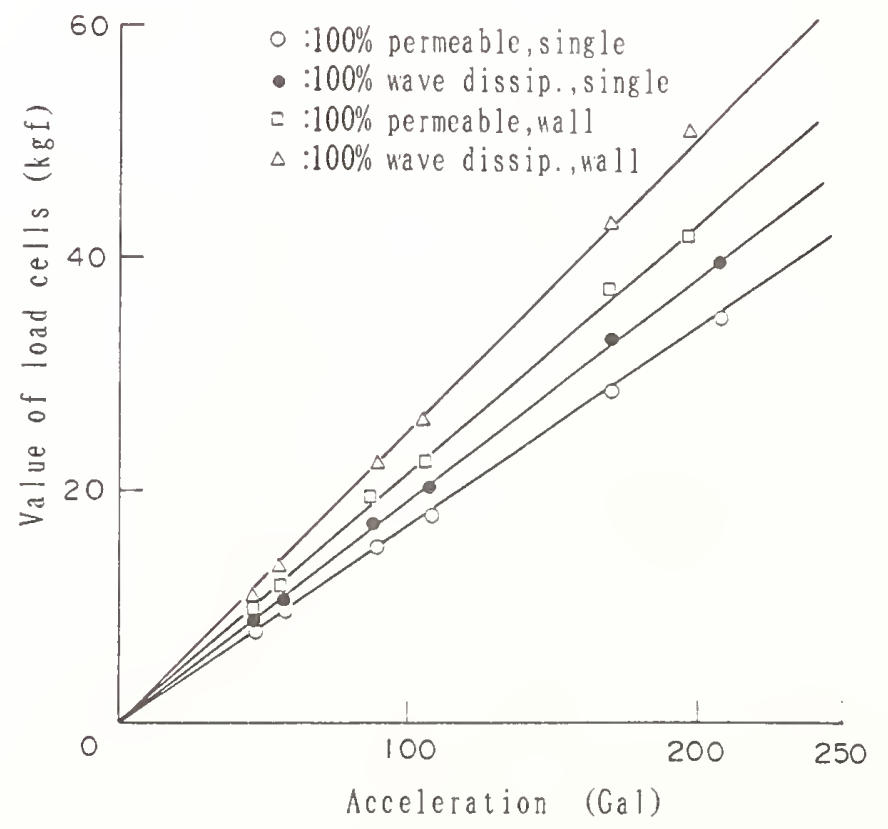

Fig. 14 Mesured values of load cell 


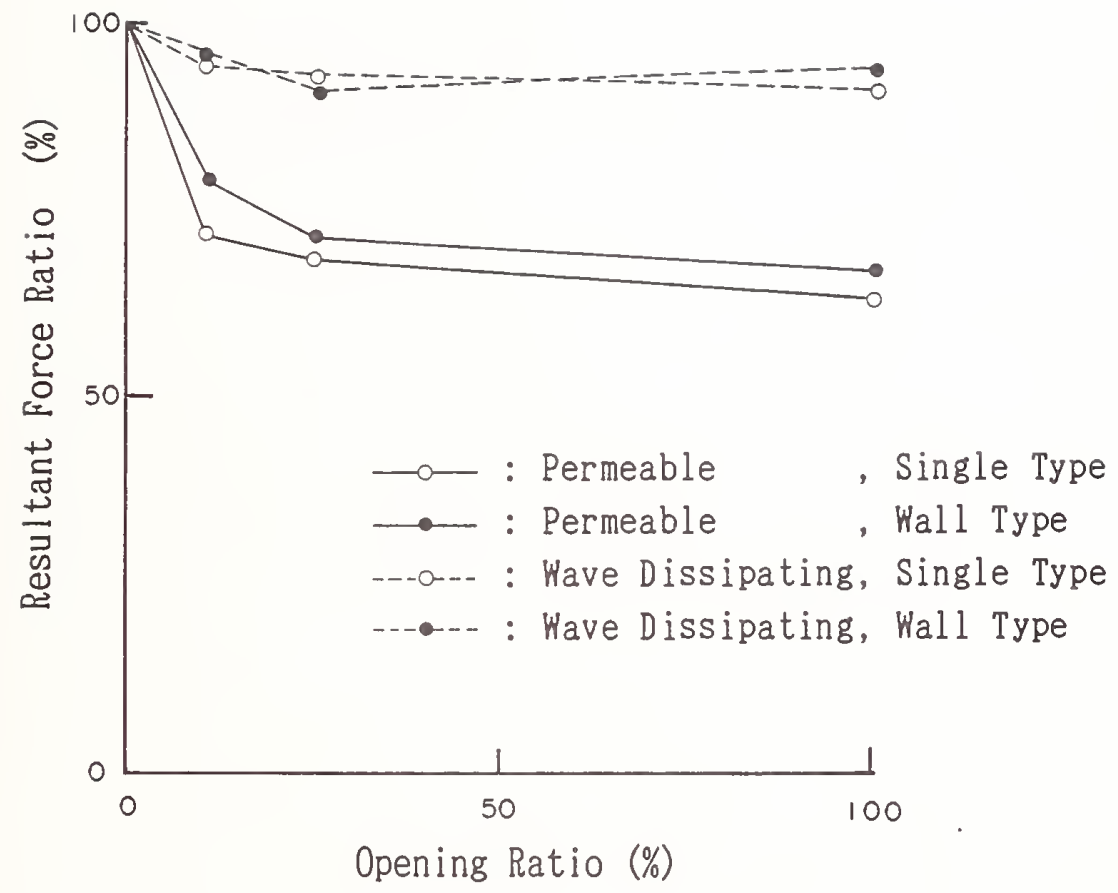

Fig. 15 Hydrodynamic pres, versus opening ratio 


\section{Theme III}

\section{Storm Surge and Tsunamis}




\section{ABSTRACT}

Subaerial and submarine landslide-generated tsunamis constitute a class of tsunamis which, although they have caused at least 58,000 fatalities in the last four hundred years, are inadequately studied and generally fall outside current warning and mitigation systems. This is because their effects, although potentially disastrous, are local with little available response time once they are generated. They are most common in areas of glaciation, volcanic activity, submarine canyons, and reservoirs. While warning and mitigation activities are difficult for this class of tsunamis, there are monitoring and other actions that can be taken on a site by site basis. The definition of a tsunami is expanded to include all impulsively-generated traveling gravitational water waves whose velocities are a function of the water depth.

KEYWORDS: Landslides, Natural Disasters, Natural Hazards, Tsunamis, Water Waves.

\section{INTRODUCTION}

Most tsunamis, including almost all of those which cause damage beyond their source regions, are caused by tectonic displacements associated with earthquakes. The effect of these can be mitigated to a degree by warning systems, particularly in regions beyond the immediate source area. However, there are also tsunamis caused by a variety of mechanisms associated with volcanoes, landslides and other phenomena which are significant hazards and, in general, are inadequately treated by research and mitigation efforts. This paper will examine subaerial and submarine landslide-generated tsunamis including those triggered by earthquakes or volcanic activity and other indirect causes.

\subsection{Frequency and Distribution of Occurrence}

Landslide-generated tsunamis causing fatalities have occurred more than 25 times since 1596 and occur in many places worldwide. They have caused about 58,000 fatalities including about 1500 in the 20th Century.

Figure 1 shows the location of the known fatal landslide tsunamis. It also shows the four types of environments most common for landslide tsunamis: areas of glaciation, areas of recent volcanic activity, submarine canyons, and reservoirs.

Table 1 lists these tsunamis. This list understates the problem since it is not always clear when landslides are the cause of a tsunami during complex earthquake or volcanic sequences.

\subsection{Definition}

Since some of the waves discussed here may seem to be different from what is usually meant by the term "tsunami" the following definition for "tsunami" is used:

A tsunami is an impulsively generated, traveling gravitational water wave which has a velocity (v) proportional to the square root of the depth (d) and where

$$
\mathrm{V}=\sqrt{\mathrm{gd}}
$$

if the depth is great in comparison to the wave amplitudes.

This definition uniquely identifies a single geophysical phenomena eliminating seiches

${ }^{1}$ University of Colorado CIRES, Boulder, CO 80309

${ }^{2}$ NOAA National Geophysical Data Center, Boulder, CO 80302 
which are standing waves, storm surges, and various other waves. As a practical matter seiches generated by tsunamis are usually included as part of the tsunami phenomena. The original Japanese use of the term and earlier European use included storm waves and surges, but these two are two distinct phenomena. Also in much current western literature many events here called tsunamis are called "water waves," an unnecessary and vague term.

\subsection{Causes}

The basic cause of landslide tsunamis is the failure of over-steepened deposits or slopes above or below the water surface. Once unstable conditions have been created the failure can be triggered by any of several agents such as earthquakes, volcanic activity, rain (which increases the mass and reduces the friction), and continued deposition or progressive failure from creep. Once the slide material has been released, the resulting wave depends on the kinetic energy in the slide, the volume and geometry of the body of water, and possibly other factors. On impact of subaerial landslides on water, both a surge or splash and a tsunami are generated. The surge such as the famous 524 $m$ runup associated with the Lituya Bay event is not part of the tsunami as defined here since its velocity is kinetically-generated rather than gravitation in nature. Its velocity does not depend on the depth of the body of water. The displacement of the water surface does create a true tsunami.

Submarine landslides are less well understood. They often generate turbidity currents but may also be rotational. Turbidity currents as inferred by broken submarine cables may or may not be sufficient evidence of the generation of small tsunamis not otherwise observed. Submarine landslides associated with submarine canyons may be due to the purging of sediments from coastal sources or sediments transported along the coasts by currents or they may be part of the process of creating and expanding the canyons laterally or headword. Surprisingly, perhaps, large river deltas do not seem to be sources of submarine slump tsunamis. None have been reported from the great deltas of the Mississippi, Nile, Amazon or other large river deltas. This may be due to the better sorting and finer grain size of these deposits.

\subsection{Environments}

Landslide tsunamis are associated with four principal environmental regimes as follows:

\section{Glacial}

a) over-steepened fjord walls, i.e., Lituya Bay, Alaska 1958; Tafjord, Norway, 1934

b) glacial outwash deposits, i.e., Gulf of Alaska 1964

c) glacial ice, hanging glaciers and calving, i.e., Disenchantment Bay, Alaska, 1905.

II. Volcanic

a) Failure of pyroclastic deposits on volcanic slopes, i.e., Shimabara, Japan, 1792.

b) Collapse of lava flows upon reaching the sea, i.e., Hawaii, 1919

c) Collapses accompanying eruptions, i.e., St. Augustine, Alaska 1883.

d) Collapses of the volcanic edifice produced by earthquakes at the site, i.e., Hokkaido, Japan, 1741.

III. Submarine Canyons, i.e., Grand Banks, Newfoundland, 1929; French Riveria 1979.

IV. Reservoirs, i.e., Vaiont Dam, Italy 1963; Roosevelt Lake, Washington 1949-51.

Reservoirs are a particular problem. These are typically built in steep valleys which may show signs of landsliding before the reservoir was constructed. In addition, the reservoir, may raise the water table, create microclimates of enhanced rainfall or snow, and create the possibility of inducing earthquakes due to crustal loading. Their construction also creates the possibility for landslide-induced surges and tsunamis which can cause damage upstream, transverse to the slide, and downstream overtopping of the dam. Downstream of the dam, flooding may occur from the breaking of the dam or its overtopping but these are floods and do not meet the tsunami definition criteria. 


\subsection{Warnings and Mitigation}

The problems associated with the warnings and mitigation of the landslide tsunami hazard are more difficult than for those due to earthquakes. As can be seen in the following examples, the effects are generally limited to a few kilometers or a few tens of kilometers which means that the time for evasive action is limited to a few minutes. The hazard for each potential landslide tsunami must be evaluated. Depending on the population at risk and the potential time available once a slide has been initiated, various schemes involving monitoring, slope stabilization, and land use may be employed. Most mass failures are detectable well before the failure, and sometimes years earlier. A history of such failures in the area or in similar areas indicates a need for evaluation of the risk. Research can be done to delineate the risk through modeling, both physical and numerical. Surveys can be made of slope stability and rates of deposition, particularly for offshore areas.

\subsection{CASE HISTORIES}

The rest of this study will illustrate the problem with several case histories selected to show some of the features of this hazard.

\subsection{Glacier Related Sources}

\subsubsection{Oversteepened Fjord Walls}

2.1.1.1 Lituya Bay. Lituya Bay is a Tshaped glacially carved fjord approximately $13 \mathrm{~km}$ long, the top being two inlets with glaciers lying in the Fairweather fault plane. On July 10, 1958 a magnitude 7.9 earthquake set in motion at least six landslide-induced tsunamis including one in Lituya Bay. A 30 million $\mathrm{m}^{3}$ slide was released from 200-1000 $m$ above Gilbert Inlet down slopes of about $40^{\circ}$ on the east side of the inlet (Miller, 1960). The impact of the slide on the water sent a surge across the inlet to the opposite point of land, clearing the forest to a height of $524 \mathrm{~m}$. The resulting tsunami swept down Lituya Bay destroying two of three fishing boats, killing two people about three minutes after the wave was first seen. It was 30 to
50 meters high near the middle of the bay. Figure 2 shows the configuration of Lituya Bay and the maximum inundation level. Lituya Bay has been the location of repeated landslide tsunamis including one in 1936 which appears to have been induced by excessive rainfall, and others documented by tree ring dates of new growth areas, although the exact site and nature of these earlier tsunamis have not be exactly determined.

2.1.1.2 Norwegian Fjords. About 210 people have been killed by tsunamis generated by rockfalls and landslides in Norwegian fjords and glacial lakes of Langfjord, Loen Lake, and Tafjord. The tsunamis have had heights of 5 to $15 \mathrm{~m}$ with surges to $70 \mathrm{~m}$ on opposite shores. Earthquakes are not a factor. (Miller, 1960)

At Tafjord, Norway, on April 7, 1934, about one million $\mathrm{m}^{3}$ of rock fell from a maximum height of $730 \mathrm{~m}$ from a $45^{\circ}$ slope along a $229 \mathrm{~m}$ front. Tafjord has a maximum depth of $213 \mathrm{~m}$. The tsunami was about $12 \mathrm{~m}$ high at opposite ends of the fjord and $1 \mathrm{~m}$ at Nordal about $50 \mathrm{~km}$ away. Figure 3 shows the location of the slide and runup heights. The tsunami is believed to have been triggered by melting and freezing of water in the fracture (as such rockfalls are most common in the spring and fall). The beginning of such failure may be detectable several years in advance. (Peck, 1978)

\subsubsection{Glaciation Outwash Deposits}

2.1.2.1 Prince William Sound. A magnitude 8.6 earthquake on March 28, 1964, generated a major tectonic tsunami observed around the Pacific Basin and triggered many local tsunamis mostly from submarine landslides from glacial outwash sediments. Almost 80\% of the tsunami-caused fatalities in Alaska and most of the damage was due to these local landslide tsunamis. In Seward, Alaska, a section of the waterfront $1070 \mathrm{~m}$ long and 91 meters wide slid into the bay. The material was water-soaked alluvium with an offshore slope of $30^{\circ}$ to $35^{\circ}$. A nine meter wave returned in about two minutes. Eight separate local tsunamis caused a total of 71- 
82 fatalities with waves up to $30 \mathrm{~m}$. The fatalities could have been much higher but this is a sparsely inhabited region. (Cox and Pararas-Carayannis, 1976)

\subsubsection{Glacial Ice}

2.1.3.1 Fallen Glacier. A glacier in a hanging valley in Disenchantment Bay, Alaska, apparently suddenly surged out of its valley and fell $305 \mathrm{~m}$ down a $16^{\circ}$ slope into Disenchantment Bay without an obvious trigger. The ice fall generated waves $37 \mathrm{~m}$ high as far as four $\mathrm{km}$ away. Indian legends report that several hanging glaciers had surged in a similar manner in earlier times. Collapse of glacier tongues can also generate large local tsunamis. (Tarr, 1912)

\subsection{Volcano-Related Forms}

\subsubsection{Pyroclastic Deposit Failure}

2.2.1.1 Shimabara, Japan. In 1792 of a 535 million $\mathrm{m}^{3}$ portion of Unzen Volcano collapsed. The collapsed area was located some $4 \mathrm{~km}$ from vents which had been active a month or two earlier. The collapse and resulting landslide was probably caused by a strong swarm of volcanic earthquakes or an explosion. The landslide-generated waves reached a height of about $10 \mathrm{~m}$ and caused devastation for a distance of $77 \mathrm{~km}$ along the Shimabara peninsula. Fifteen thousand people were killed or disappeared without a trace and 6,200 houses were destroyed. (Soloviev and Go, 1974)

\subsubsection{Lava Flows into the Sea}

2.2.2.1 Mauna Loa, Hawaii. On October 2, 1919, an eruption of Mauna Loa produced a stream of lava which reached the sea near Alika on September 30 creating unusual waves and boiling water and creating a delta. Many tourists were attracted to the sight. The submarine extension of the flow became unstable in the marine environment and collapsed creating a $4.3 \mathrm{~m}$ wave which caused minor damage and swept several people out to sea. They were all rescued. (Cox and Morgan, 1977)

\subsubsection{Collapse Accompanying Eruption}

2.2.3.1 St. Augustine I., Alaska. An explosion on October 6,1883, of the summit of the St. Augustine volcano generated a debris avalanche and tsunami which nearly destroyed the community of English Bay, 85 $\mathrm{km}$ to the east. A wave 7.6 to $9.1 \mathrm{~m}$ high reached the community about 25 minutes after the explosion. Fortunately, the wave arrived at ebb tide. The tidal range here is $4.3 \mathrm{~m}$, so only minor damage occurred. Figure 4 shows the location of the slide area on the volcano and the location of English Bay relative to the volcano. (Kienle et al., 1987)

\subsection{Submarine Canyons}

2.3.1 Grand Banks Earthquake. A magnitude 7.2 earthquake on November 18, 1929, was associated with a massive slide down the Laurentian Channel at the Cabot Trench. Hasegawa and Kanamori (1987) believe the volume of the material, $550 \times 10^{6}$ $\mathrm{m}^{3}$, is sufficient to account for the observed earthquake. The resulting tsunami may have been $15 \mathrm{~m}$ on the Newfoundland coast where 26 lives were lost. The earthquake and tsunami occurred at the time an abnormally high tide was expected and while a gale storm was in progress. Twenty-eight cable breaks occurred from the turbidity currents. The landslide could have been triggered by a small earthquake or perhaps was related to the storm. (Keith, 1930, Smith, 1968)

2.3.2 French Rivera. Two waves approximately $3 \mathrm{~m}$ high struck a $30 \mathrm{~km}$ stretch of the French Riviera Coast from the Italian border to Antibes, France including the shore at Monaco and Nice on October 16, 1979. The waves caused considerable damage and 10 deaths. Evidence suggests that the waves were caused by the failure of a ground fill intended to extend an airport runway or by two much larger submarine slides that apparently occurred on the continental slope, perhaps triggered by the landfill slide. Turbidity currents continued beyond the slides and cut submarine cables at 80 and $100 \mathrm{~km}$ offshore of Nice. Figure 5 shows the location of the canyon, slide and affected community. 


\subsection{Reservoirs}

2.4.1 Vaiont, Italy. The Vaiont Dam in Italy, the second highest dam in the world at $265.5 \mathrm{~m}$, was completed in the fall of 1960 . On October 9, 1963 the worst dam disaster in history occurred when 240 million $\mathrm{m}^{3}$ of Mount Toc slid into the reservoir completely filling it over a length of $1.8 \mathrm{~km}$ and a depth $150 \mathrm{~m}$ above the original reservoir level. The surge wave overtopped the dam by 100 $\mathrm{m}$ and was still $70 \mathrm{~m}$ high downstream at the entrance to the canyon. The engineers had been aware of the slope instability since June and several days prior to the disaster realized that the affected area was larger than originally thought. They had begun to try to lower the water level in the reservoir and had thought about evacuating the downstream communities. It had been raining heavily in August and September hampering the effort to lower the reservoir, and was raining hard when the landslide occurred. This, the largest flood disaster ever, killed about 2000 people. (Muiller, 1964: Kiersch, 1965) Figure 6 shows the location of the slide and the affected communities.

Less well reported was a tsunami which traveled upstream demolishing homes and struck the town of San Martino with full force. There were 158 fatalities in Casso and Erto. The toe of the slide was under the level of the reservoir; the ground water level had risen due to the impoundment. Geologically the area was unstable with steep slopes due to earlier glacial action and recent river erosion. The bedding planes dipped steeply toward the river valley. (Quarentilli, 1979)

2.4.2 Franklin D. Roosevelt Lake. Between April 8, 1944, and August 19, 1953, eleven landslides occurred in terrace scarps underlain by bedded unconsolidated deposits in the Reed Terrace area near Kettle Falls, Columbia River Valley, Washington. Narrow segments of the scarp on slopes averaging about $23^{\circ}$ suddenly gave way and slid into Franklin D. Roosevelt Lake. Debris came down from a maximum height of $63.6 \mathrm{~m}$ above water. Waves were generated by at least 11 different slides; the largest wave rose to a maximum height of $19.7 \mathrm{~m}$ on the opposite shore and was observed $10 \mathrm{~km}$ up the lake where boats and barges broke loose from the dock. Observed velocity of one series of waves was about $75 \mathrm{~km}$ per hour. (Miller, 1960)

\section{CONCLUSION}

1. The term "tsunami" should be broad enough to include waves which meet the following criteria: spontaneous generation, traveling gravitational water waves with velocities defined as a function of the water depth. This definition includes landslidegenerated "water waves" not previously classified as tsunamis although physically there is no difference once the waves have been generated.

2. Landslide-generated waves are most common in four environments: glacial and glaciated area, areas of volcanic activity, submarine canyons, and reservoirs. Locally they can be disastrous and collectively they are a significant hazard.

3. Since the hazard is limited in area and in available response time, special warning and mitigation efforts tailored to the individual site are needed.

\section{REFERENCES}

1. Berminghausen, W.H. (1968). "Tsunamis and Seismic Seiches Reported from the Western North and South Atlantic and the Coastal Waters of Northwestern Europe," Informal Report, Naval Oceanographic Office, Washington, D.C. 20390,48 p.

2. Cox, Doak C. and Joseph Morgan. (1977). Local Tsunamis and Possible Local Tsunamis in Hawaiian Islands, HIG-77-14, Hawaiian Institute of Geophysics, $118 \mathrm{p}$.

3. Cox, Doak C. and George PararasCarayannis. (1976) Catalog of Tsunamis in Alaska, SE-1, United States Department of Commerce, National Oceanic and Atmosspheric Administration, $43 \mathrm{p}$.

4. Dall, W. H. (1883). United States Coast and Geodetic Survey Pacific Coast Pilot, Part I. p. 202-204. 
5. Hasegawa, H.S. and H. Kanamori. (1987). "Source Mechanism of the Magnitude 7.2 Grand Banks Earthquake of November 1929: Double Couple or Submarine Landslide?" Bulletin of the Seismological Society of America, Vol. 77, No. 6, p. 1984-2004.

6. Heck, N.H. (1947). "List of Seismic Sea Waves," Bulletin of the Seismological Society of America, Vol. 37, No. 4, p. 269-286.

7. Johnston, J.H.L. (1930). The AcadianNewfoundland Earthquake of November 18, 1929. Proceedings of the Transactions, Nova Scotia Institute of Science, Halifax, Nova Scotia, Vol. 17, p. 223-237.

8. Kiersch, George A. (1965). "The Vaiont Reservoir Disaster," Geologic Hazards, Mineral Information Services, State of California, Sacramento, p. 129-138.

9. Keith, Arthur. (1930). "The Grand Banks Earthquake," Earthquake Notes, Eastern Section of the Seismological Society of America, Vol. 2, No. 2, p. 1-5.

10. Kienle, Jurgen, Zygmunt Kowalik, and T.S. Murty. (1987). "Tsunamis Generated by Eruptions from Mount St. Augustine Volcano, Alaska," Science, Vo1. 236, p. 1442-1447.

11. Miller, Don J. (1960). Giant Waves in Lituya Bay, Alaska, United States Geological Survey Professional Paper 354-C, United States Government Printing Office, Washington, D.C., 83 p.

12. Müller, Leopold. (1964). The Rock Slide in the Vaiont Valley," Felsmechanik und Ingenieur Geologie, (Rock Mechanics and Engineering Geology) Springer Verial Wien, Vol. 2, p. 148-212.

13. Peck, Ralph B. (1978). "Laurits Bjerrum: Contributions to Mechanics of Rockslides," Chapter 3 in Voight, Barry (ed.) Rockslides and Avalanches, Elsevier Scientific Publishing Co, Amsterdam, Vol. 1, 833 p.

14. Quarentilli, E.L. (1979). "The Vaiont Dam Overflow: A Case Study of Extra Community Responses in Massive Disasters," Disasters, Vol. 3, No. 2., p. 199-212.

15. Smith, W.E.T. (1968). Earthquakes of Eastern Canada and Adjacent Areas, 1928-1959, Publications of the Dominion Observatory, Ottawa, $121 \mathrm{p}$.

16. Soloviev, S.L. and Ch.N. Go. (1975). A Catalogue of Tsunamis of the Eastern Shore of the Pacific Ocean, Academy of Sciences of the USSR, "Nauka" Publishing House, Moscow, 204 p. (Translation by Canada Institute for Scientific and Technical Information, National Research Council, Ottawa, $285 \mathrm{p}$.

17. Soloviev, S.L. and Ch.N. Go. (1974). A Catalogue of Tsunamis on the Western Shore of the Pacific Ocean. Academy of Sciences of the USSR, "Nauka" Publishing House, Moscow, 310 p. Translation by Canada Institute for Scientific and Technical Information, National Research Council, Ottawa, 439 p.

18. Spaeth, M.G. and S.C. Berkman. (1972). "Tsunami of March 28, 1964, as Recorded at Tide Stations and the Seismic Sea Wave Warning System," in The Great Alaska Earthquake of 1964, Oceanography and Coastal Engineering, National Academy of Sciences, p. 38-110.

19. Tarr, R.S. (1909). The Yakutat Bay Region, Alaska: Physiography and Glacial Geology, United States Geological Survey Professional Paper 64, pt. 1, 144 p.

20. Tarr, R.S. and L. Martin, (1912). The Earthquakes at Yakutat Bay, Alaska, in September 1899. United States Geological Survey Professional Paper 69, 135 p. 


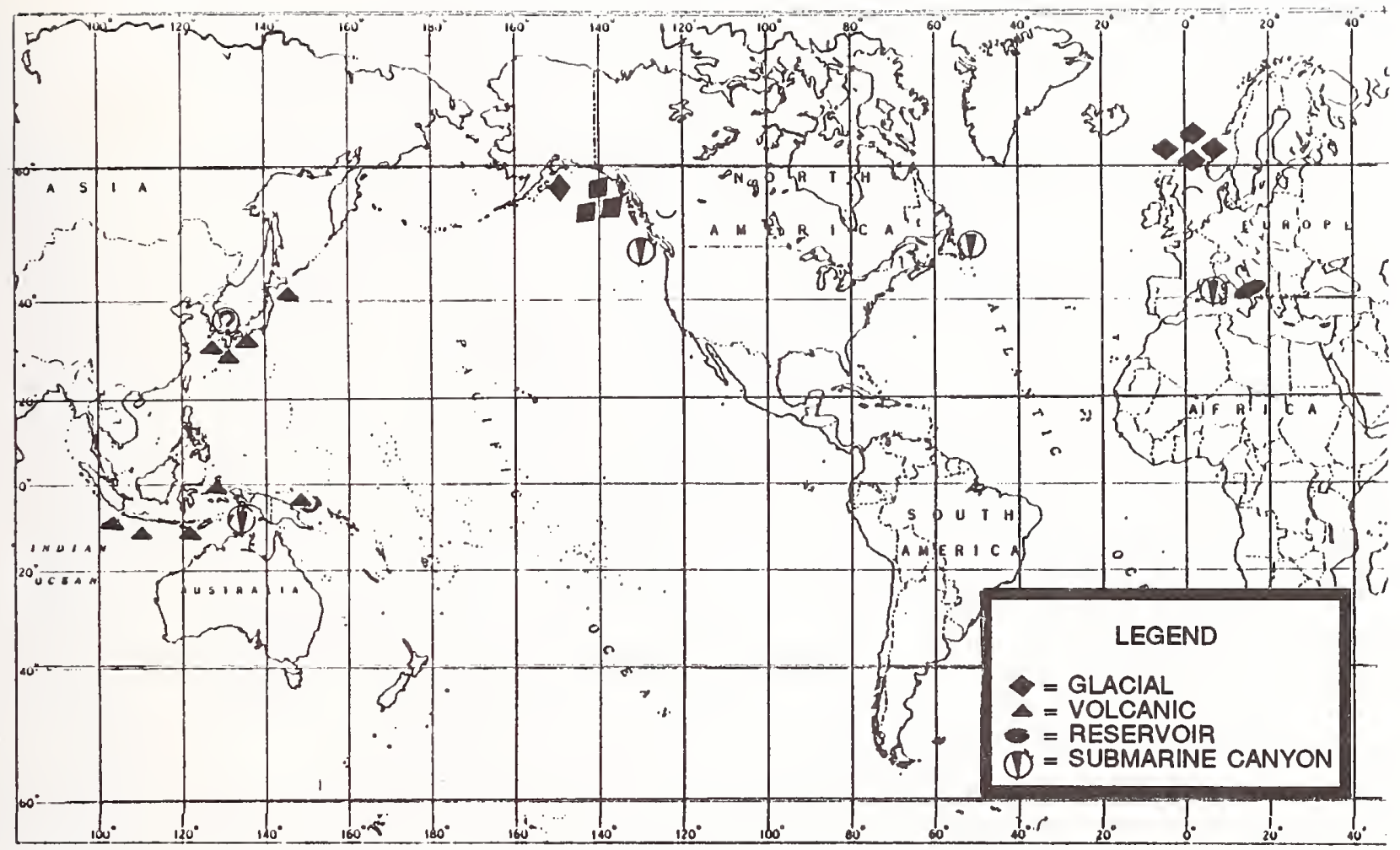

Figure 1. Locations of landslide-generated tsunamis.

Table 1.--IDENTIFIED LANDSLIDE-GENERATED TSUNAMIS CAUSING FATALITIES

\begin{tabular}{|c|c|c|c|c|c|}
\hline DATE & LOCATION & $\begin{array}{l}\text { MAX RUNUP } \\
\text { (SURGE) } \\
(\mathrm{m})\end{array}$ & SETTING* & DAMAGE & FATALITIES \\
\hline 15960904 & SEIKAIDO, JAPAN & 5.0 & V? & ISLAND SUN & 708 \\
\hline 15970910 & BEPPU BAY, JAPAN & 2.0 & v? & SOME & 40 \\
\hline 17000401 & KYUSHU, JAPAN & 2.0 & $?$ & 300 HOUSE & 1000 \\
\hline 17410829 & HOKKAIDO, JAPAN & 90.0 & $\mathrm{v}$ & 800 HOUSES & 1600 \\
\hline 17560222 & LANGFJORD, NORWAY & 40.0 & G & BUILDING \& BOATS DESTROYED & 32 \\
\hline 17920521 & SHIMABARA, JAPAN & 11.0 & $\mathrm{~V}$ & 6200 HOUSES & 15030 \\
\hline 18151122 & JAWA (JAVA), INDONESIA & 3.6 & $\mathrm{v}$ & SOME & 1200 \\
\hline 18530000 & LTUYA BAY, AK & 37.0 & G & SOME & MANY \\
\hline 18710302 & N. MOLUCCA Is. & 25.0 & $\mathrm{~V}$ & MUCH DAMAGE & 277 \\
\hline 18830827 & JAVA SEA & 35.0 & V & TOWNS DESTROYED & 36000 \\
\hline $1888 \quad 03 \quad 13$ & BISMARCK SEA & 60.0 & $\mathrm{v}$ & VILLAGES DESTROYED & MANY \\
\hline 18990910 & S.E. ALASKA & $(60.0$ & G & VILLAGE DESTROYED & SOME \\
\hline 19050115 & LOEN LAKE, NORWAY & $(40.0)$ & G & BUILDINGS \& BOATS DESTROYED & 61 \\
\hline 19280804 & FLORES SEA & 10.0 & $\mathrm{~V}$ & SHIPS SUNK & 128 \\
\hline 19291118 & GRAND BANKS, NFLND. & 4.6 & SC & CABLES BROKEN & 28 \\
\hline 19340407 & TAFJORD, NORWAY & $(62.0)$ & $\mathbf{G}$ & EXTENSIVE & 44 \\
\hline 19360921 & LOEN LAKE, NORWAY & $(70.0)$ & G & EXTENSIVE & 73 \\
\hline 19460623 & B. C., CANADA & 30.0 & SC? & CABLES BROKEN & \\
\hline 19580710 & S. ALASKA & $(525.0)$ & $G$ & 2 BOATS SUNK & \\
\hline 19631009 & VAIONT, ITALY & $(240.0)$ & $\mathbf{R}$ & SOME & $159^{\prime}$ \\
\hline 19640328 & GULF OF ALASKA & 67.0 & G & MUCH DESTRUCTION & $71-82$ \\
\hline 19710318 & CHUNGAR, PERU & $(30.0)$ & G & CAMP DESTROYED & 500 \\
\hline 19790718 & LOMBLEN I., INDONESIA & 10.0 & SC? & 4 VILLAGES & 540 \\
\hline 19791016 & FRENCH RIVIERA & 3.0 & SC & CONSIDERABLE & 10 \\
\hline
\end{tabular}

DEATH TOTAL APPROXIMATELY 58,000

*KEY: $G=$ GLACIAL AREA, $V=$ VOLCANIC AREA, SC = SUBMARINE CANYON, $R=$ RESERVOIR

'Number due to tsunamis of total of about 2000 killed in the flood. 


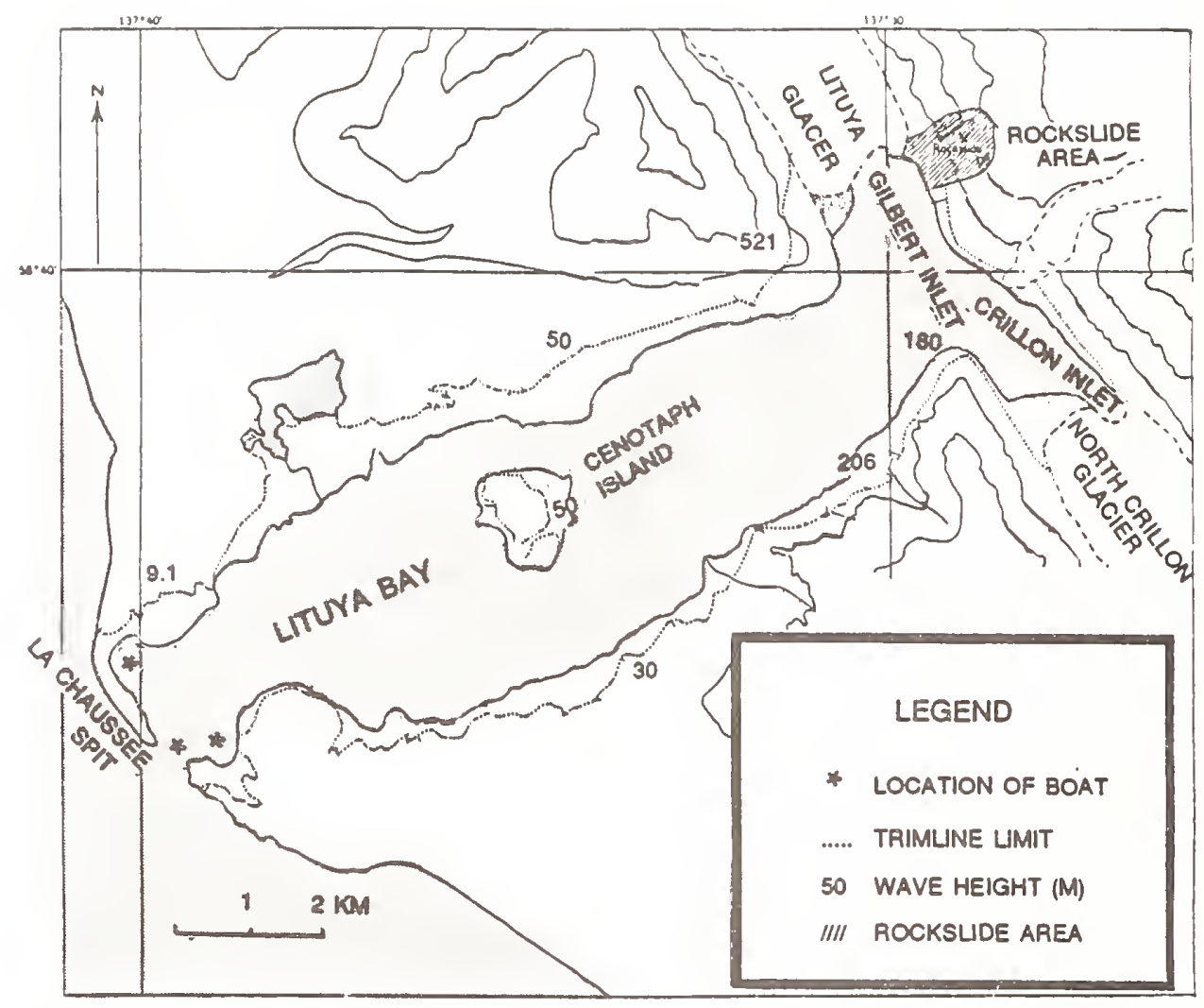

Figure 2. Map of Lituya Bay showing setting, location of boats, and trimline caused by the 1958 tsunami.

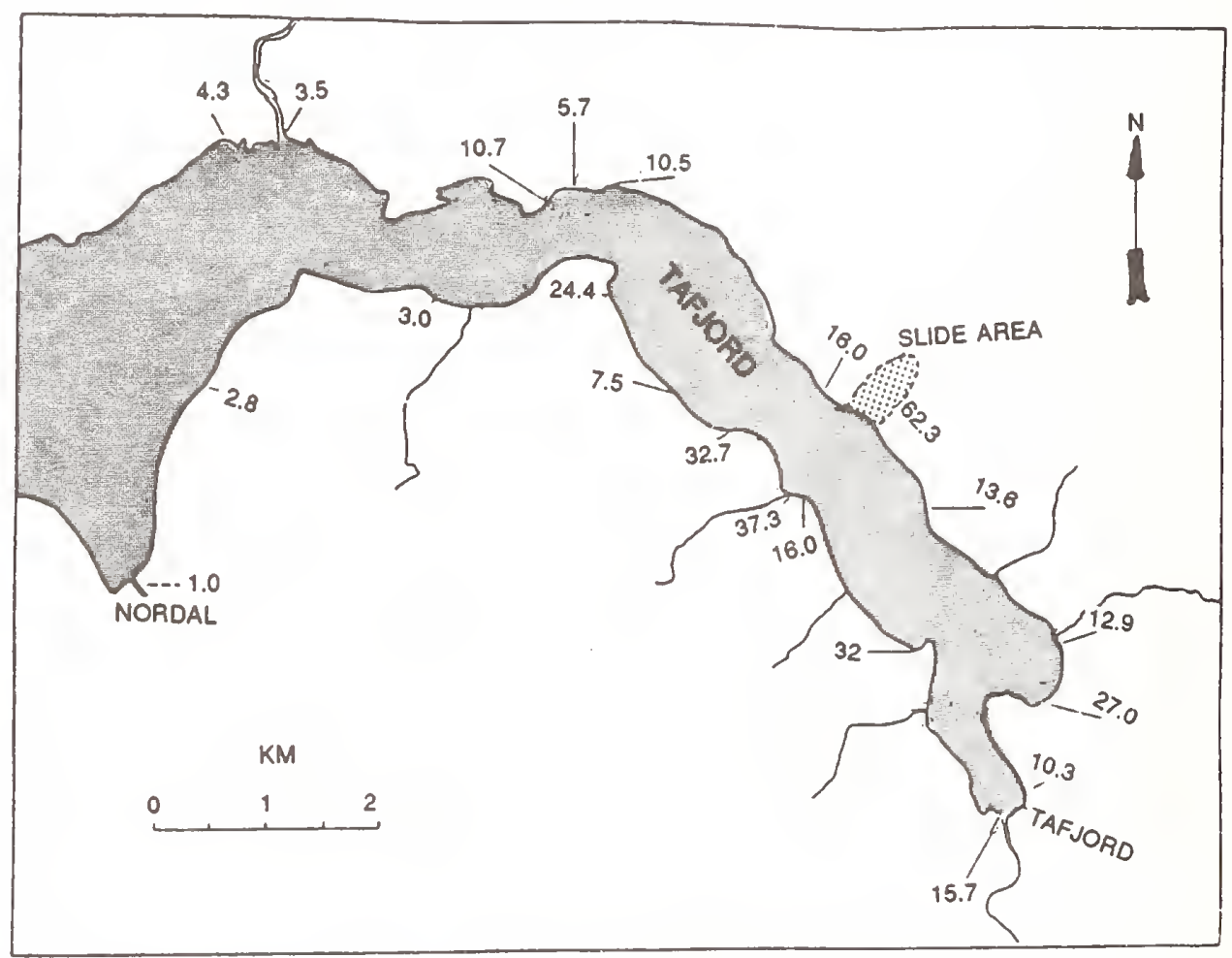

Figure 3. Tafjord showing wave heights in meters produced by the rock slide of 1934. 

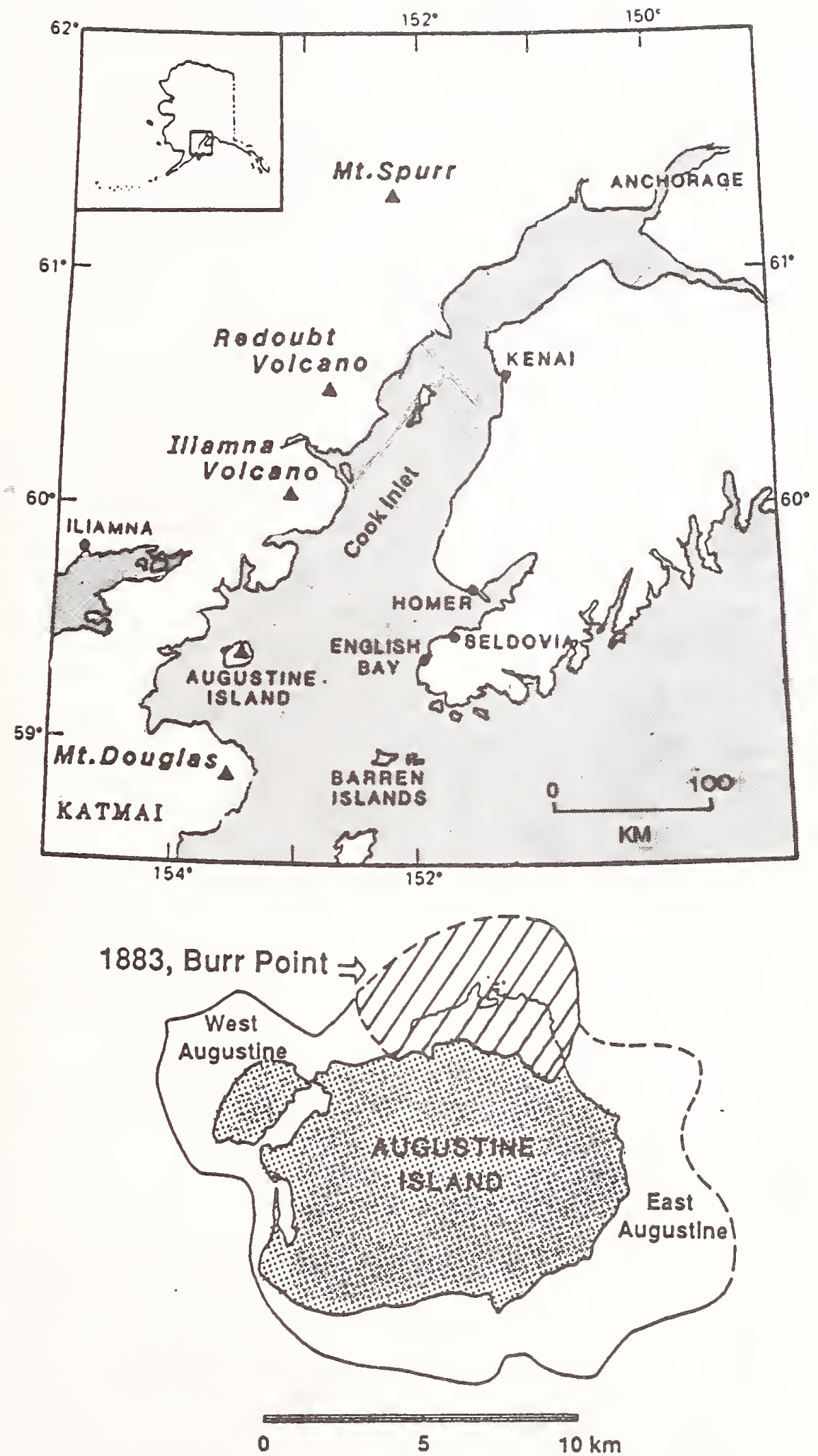

Figure 4. Map showing the location of the slide area on the St. Augustine volcano and the location of English Bay relative to the volcano. 


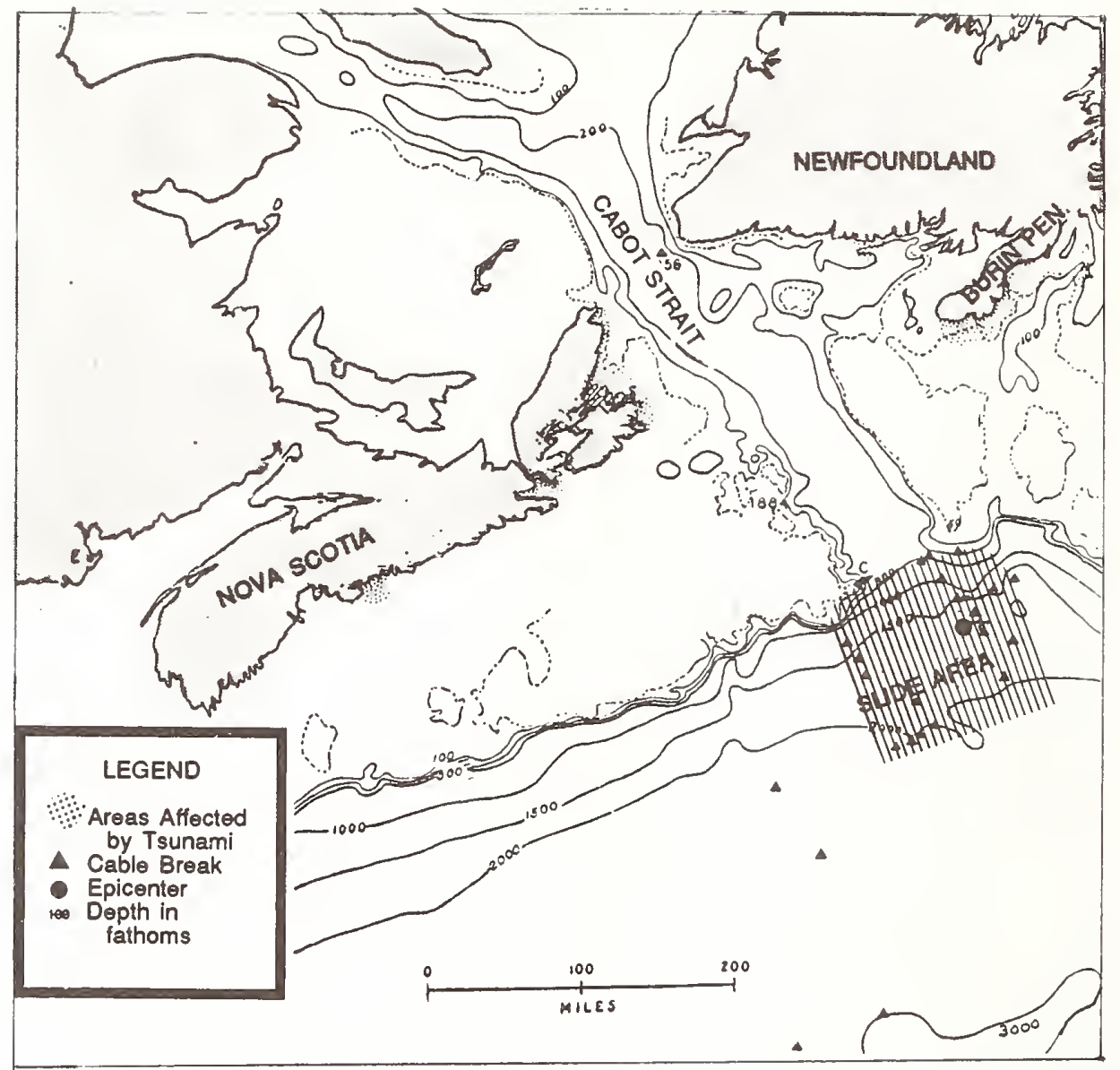

Figure 5. Location of the Grand Banks slide, cable breaks, and areas affected by the tsunami.

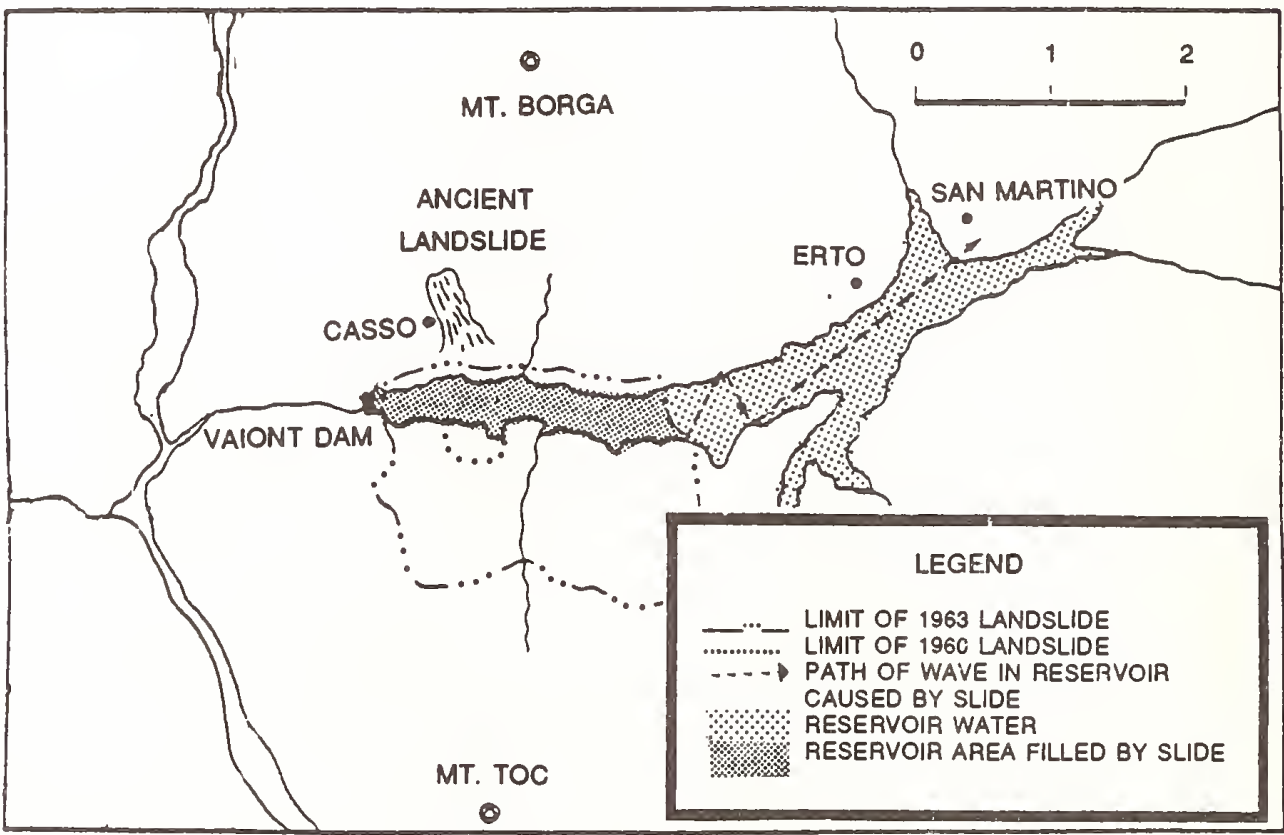

Figure 6. Vaiont Reservoir slide showing slide area and communities affected by the wave. 


\title{
A Study on the Effect of Tsunami Breakwater by Numerical Simulation
}

\author{
Chlakl GOTO" and Xatsutoshi Tanimoto ${ }^{21}$
}

\section{Abstract}

In order to estimate the tsunami reduction effects of bay-mouth breakwater, the numerical simulation assuming the 1960 Chllean Earthquake Tsunami vas carried out upon the ofunato bay In Sanriku Coast.

Through the comparison of the numerlcal results vith and vithout bay-mouth breakrater. it vas concluded that the bay-mouth breakwater vas able to reduce the tsunaml height to half order.

Key Words : Tsunami, Numerical Slmulatlon, Baymouth Breakwater. Tsunaml Reductlon Effect.

\section{Introduct lon}

The Sanriku coast had been attacked by tsuna i many times. In the recent 100 years. Meiji Great Sanriku Tsunami occured in 1896. Syouva great Sanriku Tsunaml In 1933 and Chllean Earthquake Tsunaml in 1960 caused serious damage to Sanrlku Coast. The 1896 and 1933 Great

Sanriku Tsunami vere the huge tsunami and run-up on the land more than 30 meters hight. The 1960 Chilean Earthquake tsunaml propagated on the Paclfic ocean from South Amerlca.

As a tsunaml defence vork, bay-mouth breakvater vith 736 weters long vas constructed In Ofunato Bay In 1968. When $1 \mathrm{t}$ yas planed and examinated, the hydraullc model experlments or theoretical analysls vere carried out. Hovever. the problems of scale effect and Inltial tsunam vave proflle remalned to be unsolved. It vas caused by that the ablllty of computer vas not enough and the Investlgatlon on tsunal vas not fully developed.

Then, In thls paper, the tsunal reductlon effects of bay-mouth breakrater vas examined by use of recent developed technlque of tsunaml

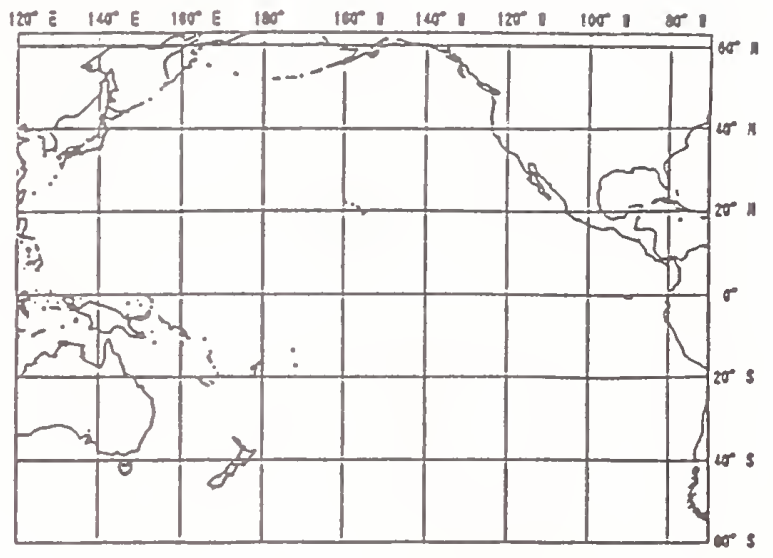

Flgure 1 Computational region of trans-oceanlc propagation

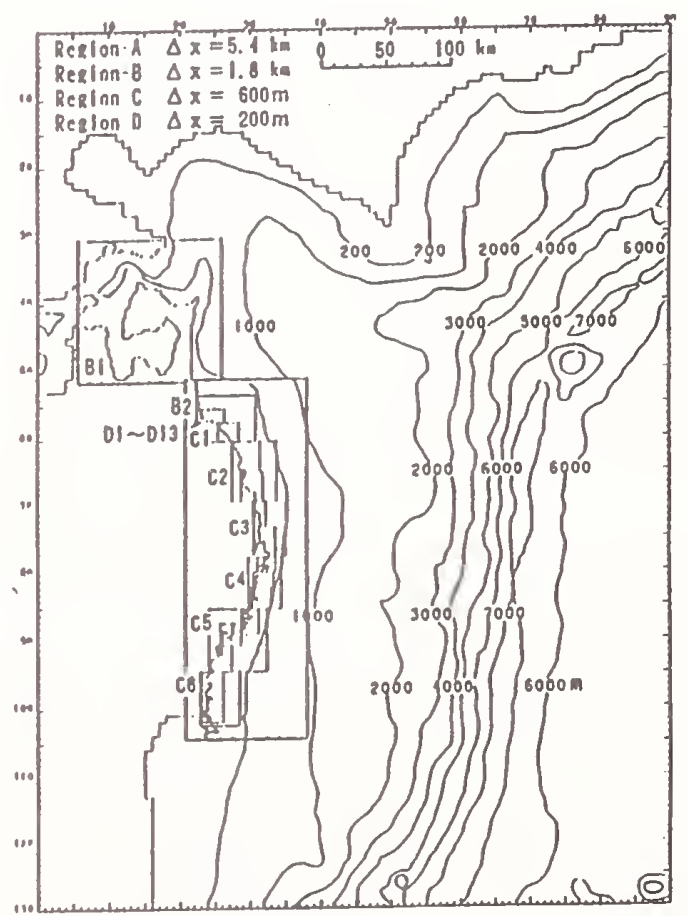

Figure 2 Compuatlonal region near Sanriku Coast

1) Cheif, Ocean Energy Utllizatlon Lab, PHRI

2) Directer. Hydraullc Engineerlng Div..PHRI 
numerical simuiation.

\section{Isunami Numerical Sigulabion}

\section{1 Computational Region}

The numerical simulation are carried out for the Chilean Earthquake tsunami occured in 1960. The simuiation is divided into two part: transoceanlc propagation and near Sanriku Coast propagation of tsunaml.

The computatlonai reglon of trans-oceanic propagation is shown in Fig. 1. The region inciudes ail over the Pacific Ocean surrounded by Far Eastern Asla. Australla, North America and South America, which extends from 60 degrees south to 60 degrees north in latitude and from 120 degrees east to 170 degrees west in longitude. The computational grid size was 10 glnutes in latltude and 10 minutes longitude (about 111 kllometers near the equator).

The computational region near Sanriku Coast is shown in Fig.2. The region is extended from the Nemuro Penlnsula in Hokkaldo to the coast of Miyagi Prefecture and include the area from 36 degrees and 20 minutes to 43 degrees in north latllude and from 139 degrees and 40 minutes to 145 degrees and 20 minutes in east longitude. This area is further divided into slx subregions. The grid size in the deepest area is set 5,400 m, and is made small in shallor sea area up to 1.800m, 600m, 200m, 100m, and 50 m.

\section{2 Governing Equatlons of Tsunami in Deep Sea}

in the probiem of tsunaml generated in Japanese coast, the computational area considered is about $100 \mathrm{~km}$ widh and $100 \mathrm{~km}$ length, thus the Carteslan coordinates system is used usually. However, in thls problem, the tsunami is generated in Chlle, propagates over 10.000km and attacks Japan, thus the sphericai coordinates system wust be employed. Moreover. because the Corloils force and dispersion effect could not be negiected in the tsunami propagation in deep sea. The ilnear Boussinesq theory must,be used for the governing equations of numerical simuiation.

The earth is considered as the sphere with the radius $R$. the latitude and longitude coordlnates are denoted by $(\lambda, \psi)$ and discharge flux in each direction by $(M, N)$. The governing equations' of tsunaml on trans-oceanic propagation are expressed as follows:

$$
\begin{aligned}
& \frac{\partial \dot{\partial}}{\partial t}+\frac{1}{R \cos \lambda}\left[\frac{\partial}{\partial \lambda}(M \cos \lambda)+\frac{\partial N}{\partial \psi}\right]=0 \\
& \frac{\partial M}{\partial t}+\frac{R h}{R} \frac{\partial n}{\partial \lambda}=-f N+\frac{1}{R} \frac{\partial}{\partial \lambda}\left[\frac{h^{3}}{3} F_{3}\right] \\
& \frac{\partial N}{\partial t}+\frac{R h}{R \cos \lambda} \frac{\partial \eta}{\partial \psi}=f M+\frac{1}{R \cos \lambda} \frac{\partial}{\partial t}\left[\frac{h^{3}}{3} F_{3}\right] \\
& \quad F_{3}=\frac{1}{R \cos \lambda}\left[\frac{\partial^{2}}{\partial t \partial x}(u \cos \lambda)+\frac{\partial^{2} v}{\partial t \partial y}\right]
\end{aligned}
$$

\section{3 Governing Equations near Sanriku Coast}

In the computation near Sanriku Coast, two types of tsunaml theories in the plane coordinates are used.

The following nonilnear long wave theory (shallow water theory) with the noniinear term and the friction term are used for the computation near the coastai region whlch contains the runup on a dry land.

$$
\begin{aligned}
& \frac{\partial D}{\partial t}+\frac{\partial M}{\partial x}+\frac{\partial N}{\partial y}=0 \\
& \frac{\partial y}{\partial t}+\frac{\partial}{\partial x}\left[\frac{\mu^{2}}{h+r_{1}}\right]+\frac{\partial}{\partial y}\left[\frac{M N}{h+r_{1}}\right]+g\left(h+r_{1}\right) \frac{\partial r}{\partial x} \\
& +\frac{8 n^{2}}{D^{7 / 3}} M Q=0 \\
& \frac{\partial N}{\partial t}+\frac{\partial}{\partial y}\left[\frac{H^{2}}{h+r_{1}}\right]+\frac{\partial}{\partial x}\left[\frac{\mu N}{h+r_{1}}\right]+g(h+r) \frac{\partial u}{\partial y} \\
& +\frac{8 n^{2}}{D^{7}-3} N Q=0
\end{aligned}
$$

where $(x, y)$ denotes the speclaî coordinates. t the time coordinate. " the elevation of tsunami surface from the stlll vater level, h the stili vater depth, \& the gravltational acceleration. $n$ the Manning's roughness parameter, (M.N) the discharge flux in the $(x, y)$ direction, and

$$
Q=\left(M^{2}+N^{2}\right)^{1 / 2} \text {. }
$$


The shallow water theory stated above Is used for the tsunaml simulations near the coastal

line. On the other hand, in the sea area with large depth. the easier equations can be employed. Because the assumption of small amplitude holds. nonllnear term In the shallow vater theory can be neglected. Horeover, the bottom frlction nay not have a large influence on vave wation. Thus, In the coastal area except in the viclnity of coastal line, the following the linear long vave theory can be used.

$$
\begin{aligned}
& \frac{\partial u}{\partial t}+\frac{\partial H}{\partial x}+\frac{\partial N}{\partial y}=0 \\
& \frac{\partial M}{\partial t}+g h \frac{\partial v}{\partial x}=0 \\
& \frac{\partial N}{\partial t}+8 h \frac{\partial \nu}{\partial y}=0
\end{aligned}
$$

\section{4 The Initial and Boundary Conditions}

As the Initial conditlon of tsunaml numerlcal simulation, the vertical component of deformation of sea bottom estimated by the earthquake dislocation model is given to the vave surface profile.

When the strain acermulated in the earth reaches the limit. the dlslocation is generated and the crust of both side slip suddenly. This phenomenon is the dislocation motion which generates the earthquake. When the dislocatlon motion happens below the sea bottom, the upheaval and subsldence of sea bottom occurs and tsunaml is generated.

The dislocation motion can be descrlbed by the easy fault model. The distrlbution of vertical displacement of the sea bottom near the fault can be calculated by the method of Mansinha and Smylle ${ }^{\prime \gamma}$ uslng the glven fault parameters. The vertlcal dlsplacement obtalned is added to the vater surface and used for the initial conditlon of tsunatl.

For the boundary condltion of runup. the wethod of Irasakl and $\mathrm{Mano}^{3}$ I Is used, In whlch the topography near the vave tlp is consldered to be like stairs. When the vater elevation at the sea slde grid point is higher than the ground elevation at the land side grid point. the difference of both elevations is used for the total depth in the computation.

\section{Isunami Reduction Effect}

\subsection{Reproducibility of Numerlcal Slmulation}

The numerlcal simulation results of Chilean Earthquake Tsunaml In ofunato bay are shown in Flg. 3. Flgure shors the distribution of maximum vater elevatlon by contour llnes and the values at some grld polnts. The values denotes the computed tsunami helght In meters and the values In ( ) denote the measured tsunaml helghts.

Flgure \& shows the comparlsons between the computed and measured tsunaml helght. Aldat proposed the parameters $K$ and $K$ deflned by the following equatlons.

$$
\begin{aligned}
& \log K=(1 / n) \sum \log K i \\
& \log \pi=\left[(1 / n) \sum(\log K i)^{2}-(\log K)^{2}\right]^{1 / 2}
\end{aligned}
$$

where KI denotes the ratio of the computed value and the measured one at point 1 , K the mean ratio of the computed and the measured one, and $x$ the scattering (corresponds to the standard deviatlon In logarlthmic values).

In thls computation, $K=0.94$ and $k=1.19$. Thus it is concluded that the computed results agree vlth the measured values vell. Hovever, the computation seems underestimatlng where the runup helght Is large and overestimatlng where the runup helght is swall. The area where the runup helght is large is the inner bay. therefore, it Is thought that the effect of resonance does not appear sufflclently because the characteristic of perlod of Incldent tsunaml Is small different from the actual one. As regards the large measured values In the bay center and bay mouth. there are the probleas of the accuracy of measurement and that the highest tsunami trace 


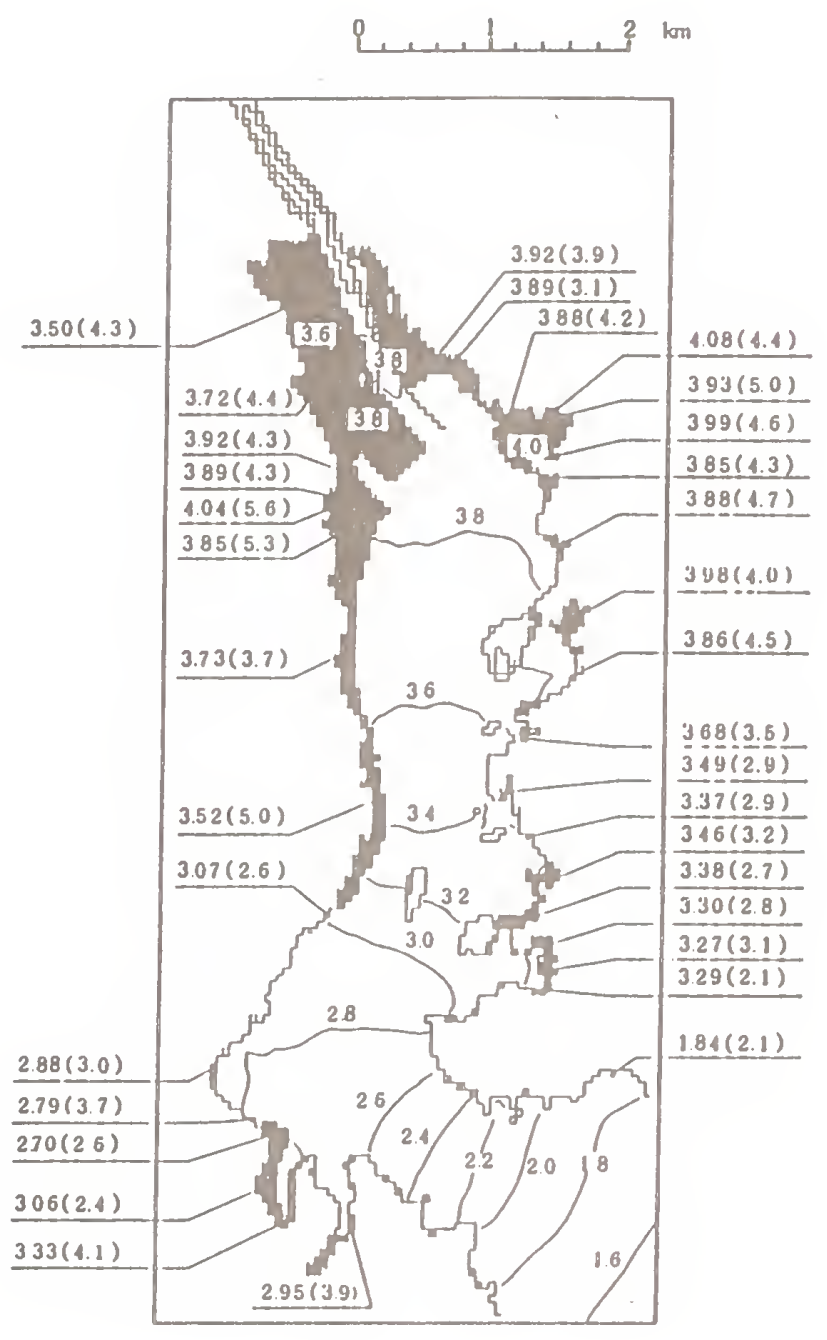

Figure 3 Maximum tsnami heights

(Without breakwater)

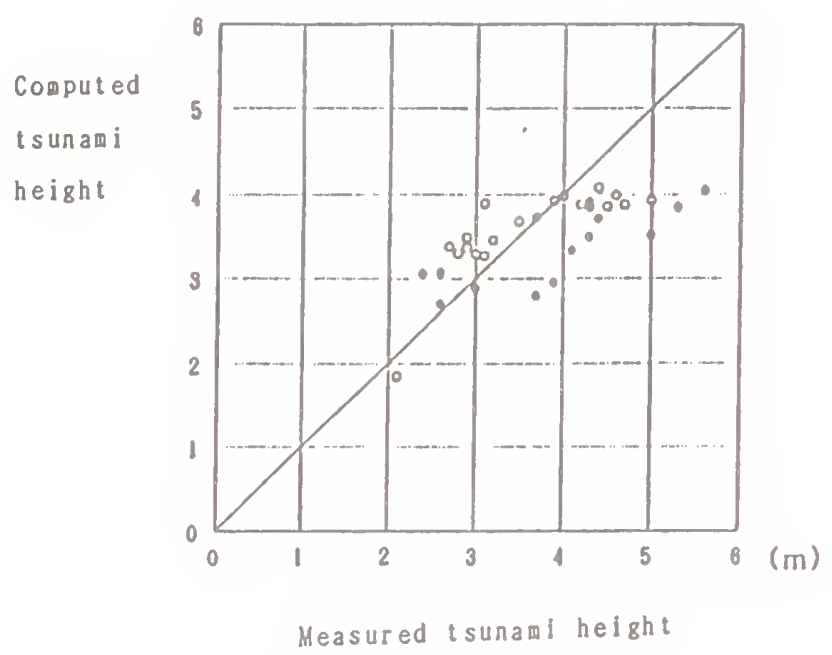

Figure 4 Comparison betveen numerical and measured data

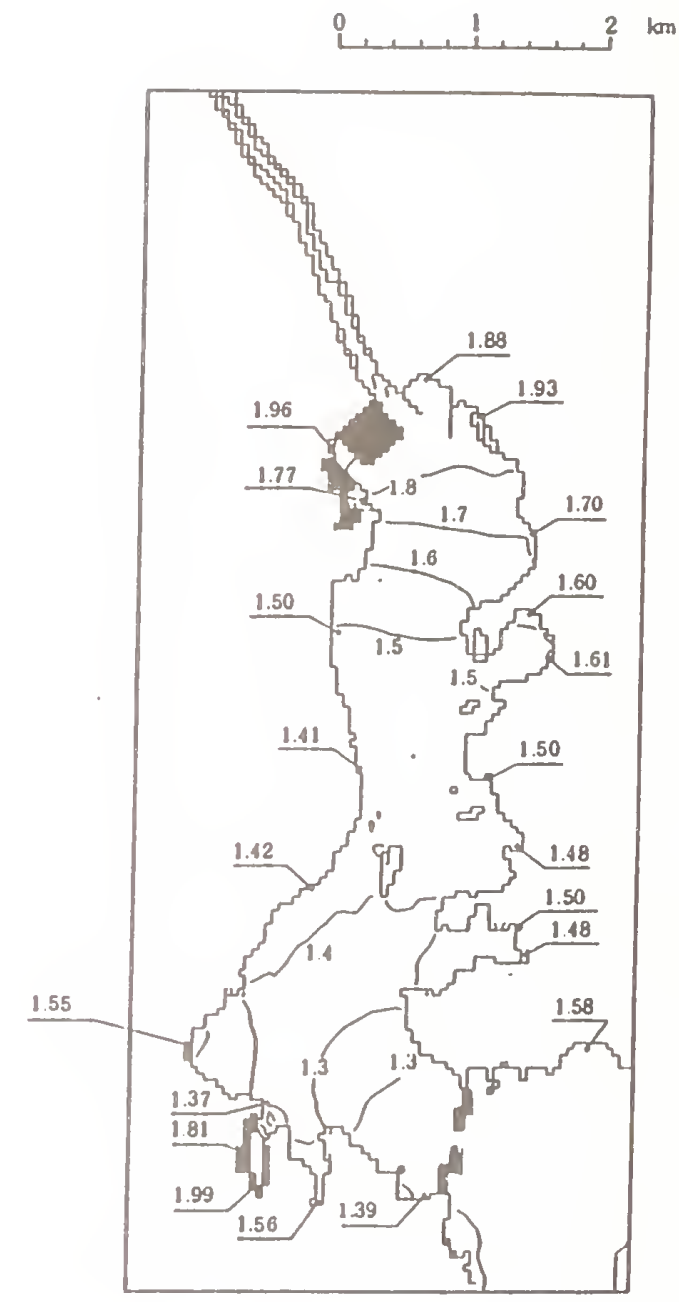

Figure 5 Maximum tsnami heights

(vith breakvater)

tend to be measured as the tsurami runup beight. Moreover, because the computed value is the averaged one in 50 meters grid, it is possible that the local movement of tsunami can not be reproduced.

\section{2 Effects of Bay-mouth Breakwater}

Figure 5 shors the computation resuits of the case in which the contemporary topography with the bay-mouth breakwater is used.

When the prediction and the reproduction computations are compared to estimate the effect of bay-mouth breakvater. the parameters $A$ and $a$ are introduced, which are sigiliar to Eqs. (11). 
(12) and are calculated froa the ratio of tsunai helght vith and whout breakuater.

The bay-wouth breakvater reduced the tsunami heights in the bay to half order $(A=0.47$. $a=1.12$ ). the raximum tsunami height becomes? weters. Inundation area are restricted to the iov ground area. for example. the Chayamae dorn tovn. reclalued land and Hosoura In Ofunato fishlng Port.

\section{Conciusions}

From the tsunami numerical sloulations, the tsunami heights are analyzed, and the reproducibility of computation and the effect of bay-mouth breakvater are considered. The aajor conclusions are as follows:

(1) The tsunawi numerlcal simulation glves good resuits vith the acceptable error $10 \%$.

(2) The bay-mouth breakrater is able to reduce the tsunami heights by half in the Chllian Earthequake Tsunami.

\section{References}

1) Goto, C. : A study on numerical simulation for trans-oceanic propagation of tsunaml. PHRI rept.. (To be published).

2) Mansinha,L. and D.E.Smylle: The displacement flelds of lnclined faults; Bull. Selsm. Soc. At.. vol.61. No.5. pp. 1433-1440. . 19.71.

3) Irasaki. T and A. Mano : Numerical simulation of two dimenslonal runup on land in the Eulerian descriptlon. Conf. of Coastal Eng. in Japan. Yol 26. pp70-74.1979.

4) Aida, 1. : Reliablllty of a Tsunami Source Hodel derived froa Fault Paraweters; J. Physics of Earth, vol.26. pp.57-73., 1978. 


\section{Theme IV}

\section{Joint Cooperative Research Program}





\section{The U.S.-PRESSS Program}

\section{M.J. Nigel Priestley}

\section{General}

Precast Seismic Structural Systems have been chosen by the U.S. and Japan as the topic for the 4th phase of the U.J.N.R. Panel on Wind and Seismic Effects Large Scale Testing Program. U.S. funding for an initial three year program was approved by the National Science Foundation in May 1990, and the project has proceeded very rapidly from that time.

\section{Research Emphasis}

The U.S.-PRESSS project aims (1) to develop comprehensive and rational design recommendations based on fundamental and basic research data which will emphasize the viability of precast concrete construction in seismic zones, and (2) to develop new materials, concepts and technologies for precast concrete construction in seismic zones.

This second aim also indicates the emphasis and direction of the U.S.-PRESSS research project. It is felt that the greatest challenge and promise for precast structural systems in seismic zones is to develop new and innovative technology appropriate to the construction constraints. The approach of designing precast structures to emulate monolithic reinforced concrete structures has already been established by earlier experiments and design studies, and is felt to require less research effort. Further, it is doubtful if emulation of monolithic reinforced concrete structures is economically viable for precast systems in the United States.

\section{Research Projects}

The following proiects are currently funded in Phase I of U.S.-PRESSS. It will be seen that the emphasis is on design studies and analytical development. Experimental research is currently being carried out in an associated study at National Institute for Standards and Technology, but will also be the focus of a second phase of the U.S.-PRESSS project, expected to start in 1992.

Project 1.1 - Concept Development: Development of new concepts for precast concrete construction for seismic zones focus on innovative structural solutions and the incorporation of advanced technology to ensure relevance for the needs of the 21 st century. A series of seminars involving practicing designers, precasters and contractors has already been held to promote discussion and development of new concepts. Conclusions from these seminars will be available shortly. From these preliminary studies, a selection of systems which have been established as economically and technically viable will be chosen for further experimental and analytical study. 
Project 1.3 - PRESSS Connection-Classification and Modeling: An important task for future analytical and design studies is the development of a classification scheme for generic PRESSS buildings based on connection type and function. This involves a thorough review of existing research and design information, and original work to predict the characteristics of innovative and currently untested connections. There is considerable cooperation with the Japanese-PRESSS group in this area, and also with Project 1.1, since it has been found that strong interaction between Projects 1.1 and 1.3 is essential to the success of both studies.

Project 1.4 - PRESSS Analytical Platform Development: The special needs of dynamic inelastic analyses of PRESSS are being met by developing advanced anaiytical programs based on the DRAIN-2D architecture. Both 2-D and 3-D versions, based on fiber constitutive models, and capable of reproducing the deformation characteristics of precast connections are being developed. These programs will be used in analytical studies to predict structural response in the different seismic zones of the U.S.

Project 1.6 - PRESSS Preliminary Design Recommendations: Current seismic design codes for precast concrete structures are being reviewed, and design philosophy for the final design recommendations formulated. Prescriptive design requirements for 'strong-joint' (i.e., monolithic reinforced concrete emulation) are being based on existing information, and those for ductile joints are being based on the results of Projects 1.1, 1.3 and 1.4. The format of the recommendations is expected to be strongly influenced by structural reliability theory.

Project 1.7 - PRESSS Coordination: This project provides the umbrella under which the separate projects listed above are interrelated. Regular coordination meetings involving the entire PRESSS research team are held twice a year, and are attended by researchers working in allied fields not specifically funded in the PRESSS project. The coordination between U.S. and Japanese research teams is also an extremely important part of this project. The U.S. team is desirous of having closer interaction between the U.S. and Japanese teams than has been possible in previous U.J.N.R. joint studies. As a means toward closer cooperation, both teams have have agreed on a standard 'test-bed' building, to enable different design philosophies and details to be compared. Commitments have been made toward producing joint documents on design recommendations and connection classification.

The first U.S.-Japan Joint PRESSS meeting, held in San Diego in November/December 1991, was extremely productive and effective in terms of cooperative effort. 


\section{Summary}

Although the U.S.-PRESSS project has only been in operation for 12 months, it is already producing useful information in the form of preliminary reports on structural concepts, connection classification, and a draft version of the analytical platform. Cooperation with the Japanese team has been effective and rewarding.

Although the scope of Phase I of the U.S.-PRESSS program is comparatively modest, it is expanding by association with the NIST experimental program and with the ATLSS building systems program. It is expected that further experimental projects will be added to U.S. PRESSS early in 1992. 


\section{U.S.-Japan Cooperative Research Program Precast Seismic Structural System}

by

Shin Okamoto, Shinsuke Nakata, Takashi Kaminosono

Hitoshi Shiohara and Mizuo Inukai

\section{Part 1 Design Trial of 15 story Precast Reinforced Concrete Buildings}

\section{Introduction}

In 1990, Japan side did three cases of trial design of 15 -story precast concrete structures using current Japanese building codes and design requirements. Here one of three design trials is introduced as case 1 .

Case I consists of moment-resisting concrete frames without structural walls. The dimensions are $30 \mathrm{~m} \times 60 \mathrm{~m}$ in plan ( $6 \mathrm{~m} \times 10 \mathrm{~m}$ in bay size), $57 \mathrm{~m}$ in height ( $3.8 \mathrm{~m}$ in story height).

Common designed conditions are as follows:

(1) no-basement, but with sufficiently rigid footing beam

(2) seismic zone factor $=1.0$

(3) medium grade ground (soil period $\mathrm{Tc}=0.6$ second).

The precast elements in the designed buildings are used for columns, beams, semi-finished slabs and spandrels.

This building is designed in a manner the same as a monolithic structure, because the precast elements are connected rigidly with in-situ concrete. Therefore, the design is based on "AIJ Standards for structural calculation of reinforced concrete structures" and related standards. The strength of concrete is $360 \mathrm{~kg} / \mathrm{cm} 2$, the uppermost value allowed in the standards.

High-rise precast concrete buildings in Japan have a short history. The precast concrete structure was introduced to Japan more than 30 years ago; only a few precast concrete buildings were constructed as compared with other types of construction. A major reason may be that ductile frame buildings such as steel frame or steelframed reinforced concrete are preferred in $\mathrm{Ja}$ pan attacked frequently by earthquakes; and the ductile performance of precast concrete construction has not been clearly understood.

Another factor is that the construction cost of precast concrete structures is higher than cast-insitu reinforced concrete structures. Accordingly, precast concrete structures which are assembled by their units have not been used positively up to this time.

With a rapid development of experimental research on joint performance and joint construction methods to assure acceptable performance, not only high-rise reinforced concrete structures but also high-rise precast concrete structures have been constructed in the last several years. Furthermore, the lack of labor power caused the development of construction of precast concrete structure:

Through the study of the three buildings on precast concrete, we believe that the designed buildings satisfy the requirements in serviceability and aseismic performance, and contribute to reduction of construction term, building cost. Outline of designed building, material design concept and precast joint system are here mentioned.

Fig. 1 shows the joint concept of precast members integration. In the beam-column joint region, longitudinal reinforcements of columns and beams are exposed from these members and are casted in rigid body by post casted concrete.

Detailed section of column and beam are shown in Fig.2. Hatched parts show the precast concrete in this figure. Fig. 3 shows the detailed arrangement of reinforcements in corner column. The longitudinal reinforcement of beams are anchored in the beam column joint with 90 degree hooks.

Fig. 4 illustrates the procedure of construction set up of precast members. In the step 1, precast columns are jointed at column base through sleeve joints. Step 2 shows the setting beam members from both directions. In step 3, half-precast slabs are installed and top reinforcements of slab are arranged. Step 4 indicates pouring cast-in-situ

Building Research Institute ,MOC 
concrete at slab surface, beam top and beamcolumn joint. Size of designed column section is $1 \mathrm{~m}$ by $1 \mathrm{~m}$ at lower stories, and $85 \mathrm{~cm}$ by 90 $\mathrm{cm}$ in lower beams.

Table 1 shows the defined condition of criteria for "ductile" members. In columns, the limitation of axial force ratio, shear span ratio and longitudinal reinforcement ratio are defined. In beams, applied shear stress ratio is limited. According to the a check of this criteria to this design example, this building is estimated as ductile structure.

\section{Results of Structural Analysis}

Fig. 6 shows calculated skeleton curves of horizontal force - story drift relationship in each story. Using this mathematical model, elastoplastic frame analysis showed around $2.0 \mathrm{~cm}$ story drift in each story due to design shear force $(C B=0.168)$. And due to 60 percent higher design shear force, responsed story drift reached to hinge mechanism in each story. Fig. 7 is the results of dynamic response analysis to four input earthquakes. Upper two graphs are in the case of $25 \mathrm{~cm} / \mathrm{sec}$ max. velocity input. Lowers are in case of $50 \mathrm{~cm} / \mathrm{sec}$ input. The results of responsed story drift due to $25 \mathrm{~cm} / \mathrm{sec}$ input, show $1.53 \mathrm{~cm}$ max. story drift. In case of 50 kine input, the max. response show due to Hachinohe Earthquake and its responsed shear force is almost same as that of failure mechanism of structure. This means that the designed building is enough safe to big earthquake.

\section{Conclusion}

In this report, an example of three design trials are introduced and discussed its seismic safety based on the existing Japanese seismic design criteria. In order to develop more grade of design freedom, it is recommended that prestressed concrete system should be much more used. Through this project results from US side and Japan side, Japanese seismic design standard and design manual of precast joints are to be established and next year this designed building will be discussed its seismic safety based on these new research products. 
1-1 outline of Butlding

1) Plan Logitudinal Direction:

10 (a) $6.00 \mathrm{~m}=60.00 \mathrm{~m}$

Transverse Direction:

3 (a) $10.00 \mathrm{~m}=30.00 \mathrm{~m}$

2) Elevation

Total Bullding Height $57 \mathrm{~m}$

story Height

$3.8 \mathrm{~m}$

3) Number of Stories

15 (No-basement)

4) Type of Structure

Precast reinforced concrete frame

External wall

precast concrete panel cladding

Internal wall

Board (fireproof board) partition walls

5) Usage Office

1-2 Materials

1) Concrete

- Preçast Concrete Normal Concrete FC= $360 \mathrm{~kg} / \mathrm{cm}^{2}$

For Column, Beam and Slab

- In situ concrete

Normal Concrete

$E C=360 \mathrm{~kg} / \mathrm{cm}^{2}$

- Precast wall panel

Light Weight Concrete $\quad E C=300 \mathrm{~kg} / \mathrm{cm}^{2}$

2) Reinforcement

- Column and Beam

Deformed bar

SD 40

$$
\Sigma Y=40,000 \mathrm{~kg} / \mathrm{cm}^{2}
$$

For Hoop, stirrup

High strength deformed bar

fy $\geq 13,000 \mathrm{~kg} / \mathrm{cm}^{2}$

- Secondary beam and Slab

Deformed bar

SD 35 SD 30

For stirrup

Deformed bar

SD 30 


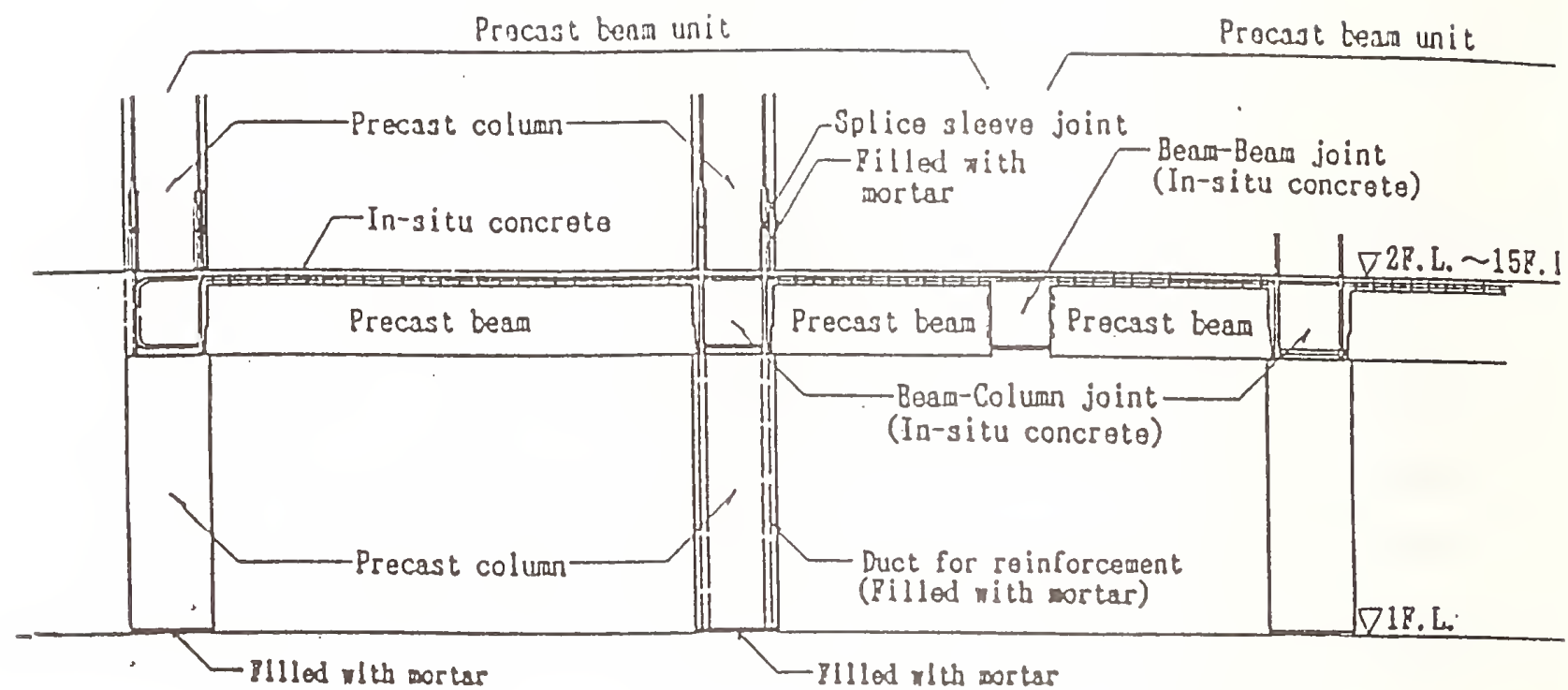

X DIRECTIOII PRAME

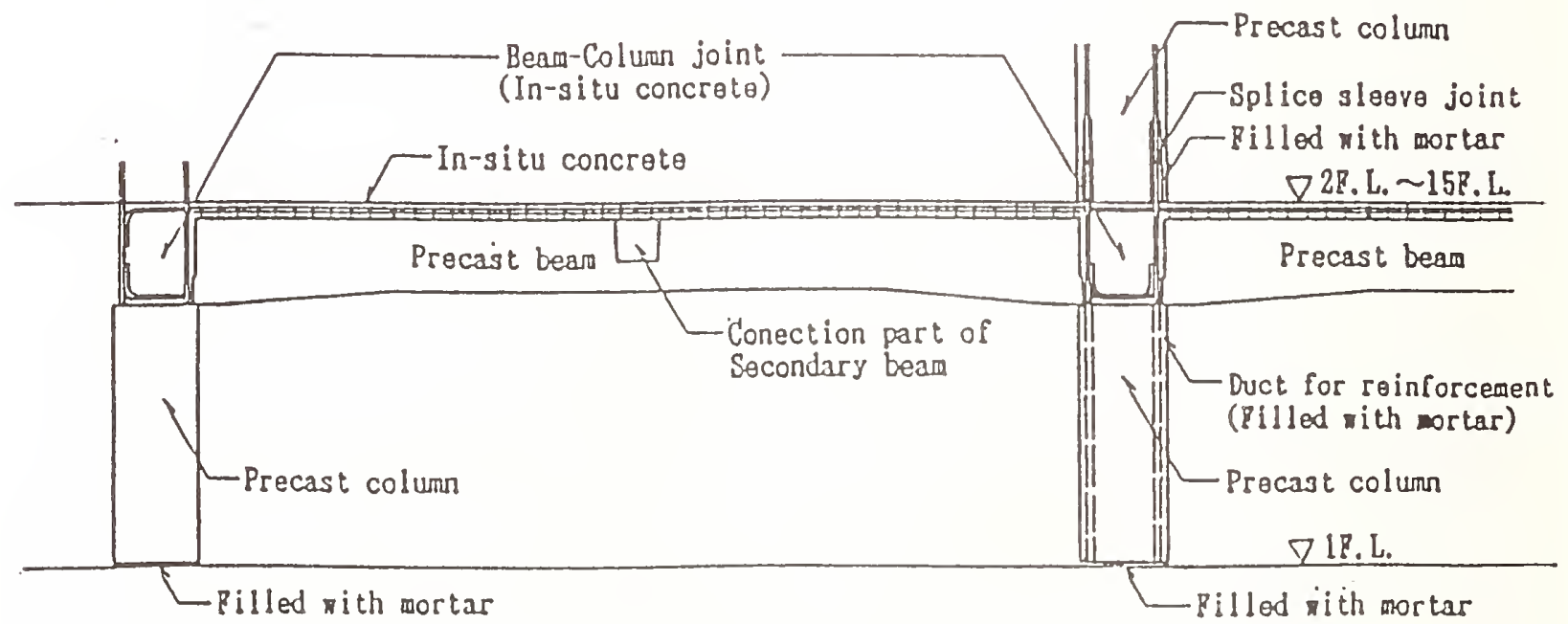

I DIRECTIOH BRAMR

Fig.l Frame Details 


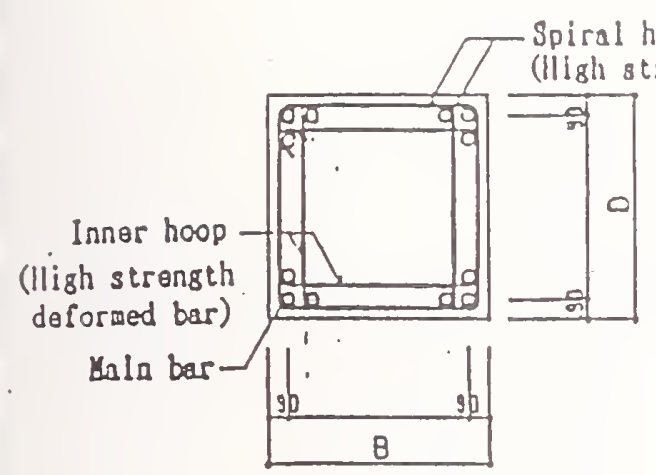

Beara Details

$X$ direction beam

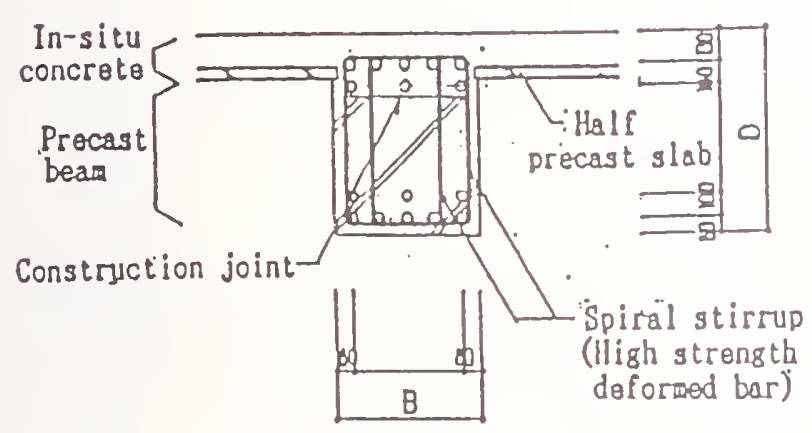

Anchorare of main reinforcements of beara

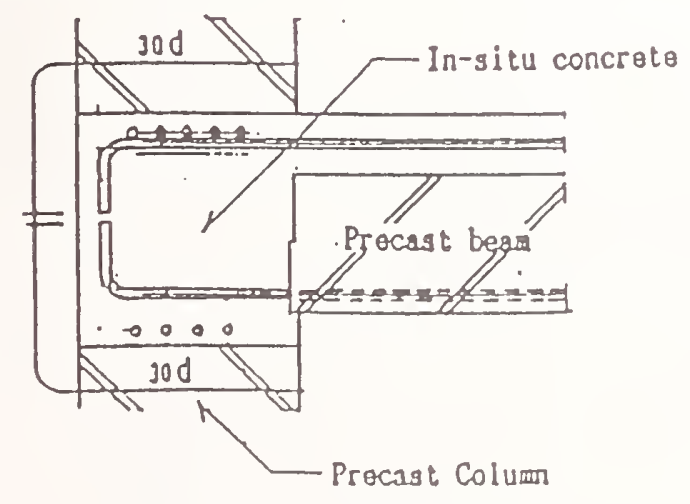

Y direction beam

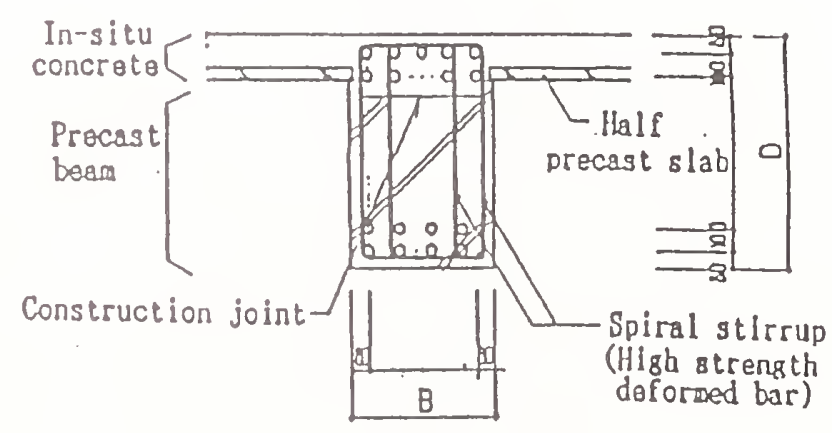

Beam-Bear joint

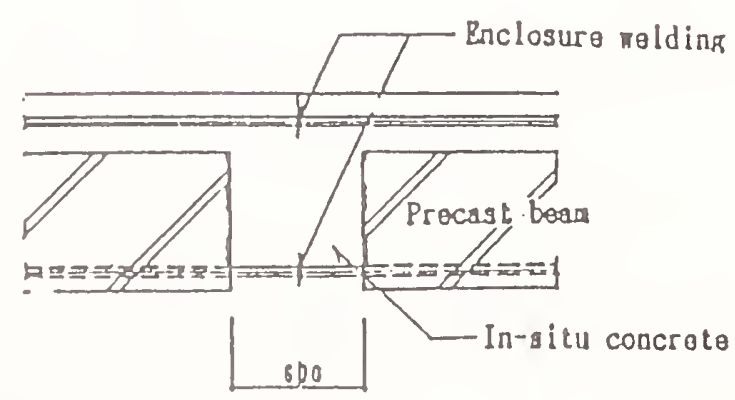

Fig.2 Details of Columns and Beams 
Detail of Cornar beara-culumn joint

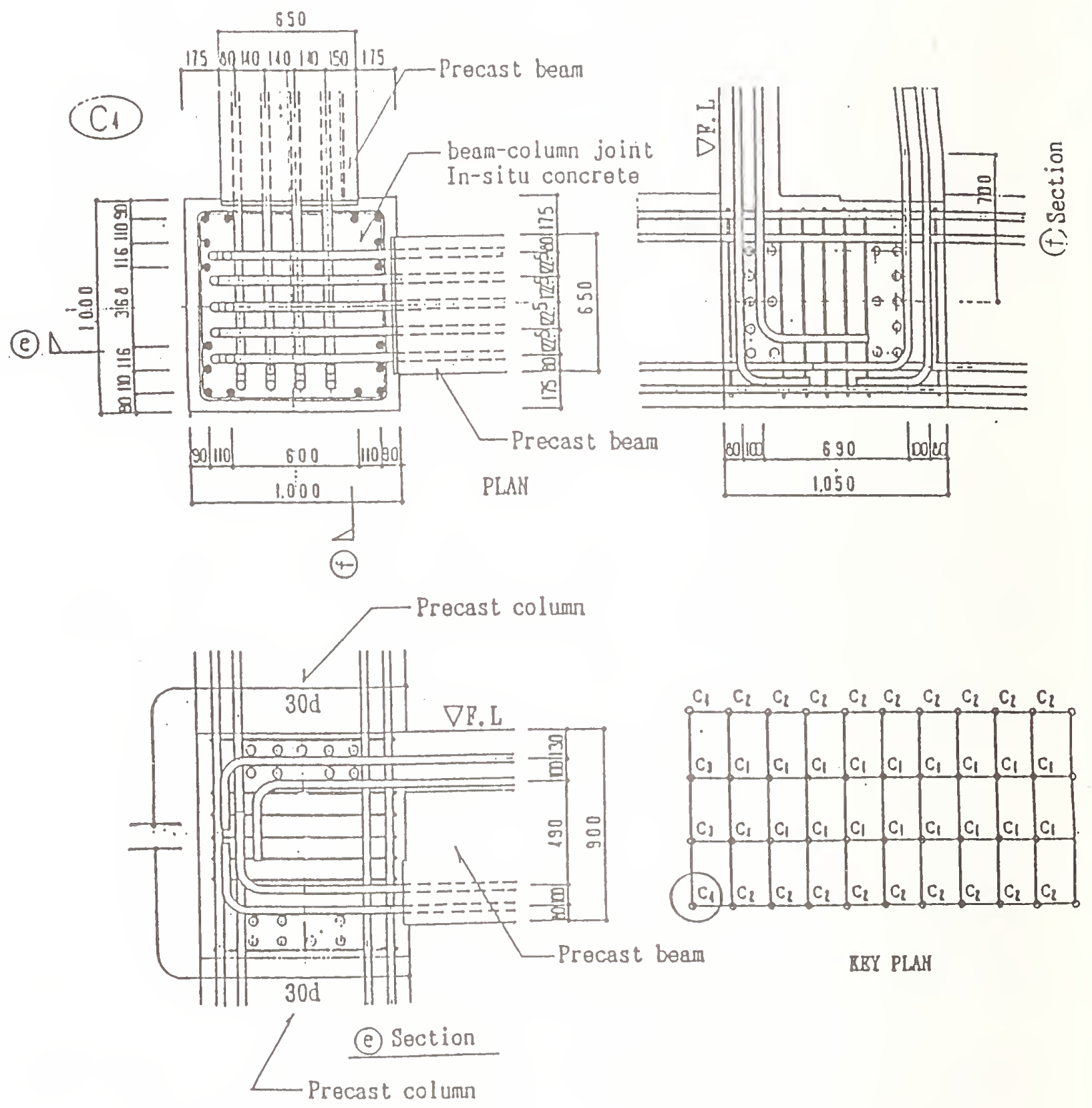

Fig.3 Detail of Corner Beam Joint 


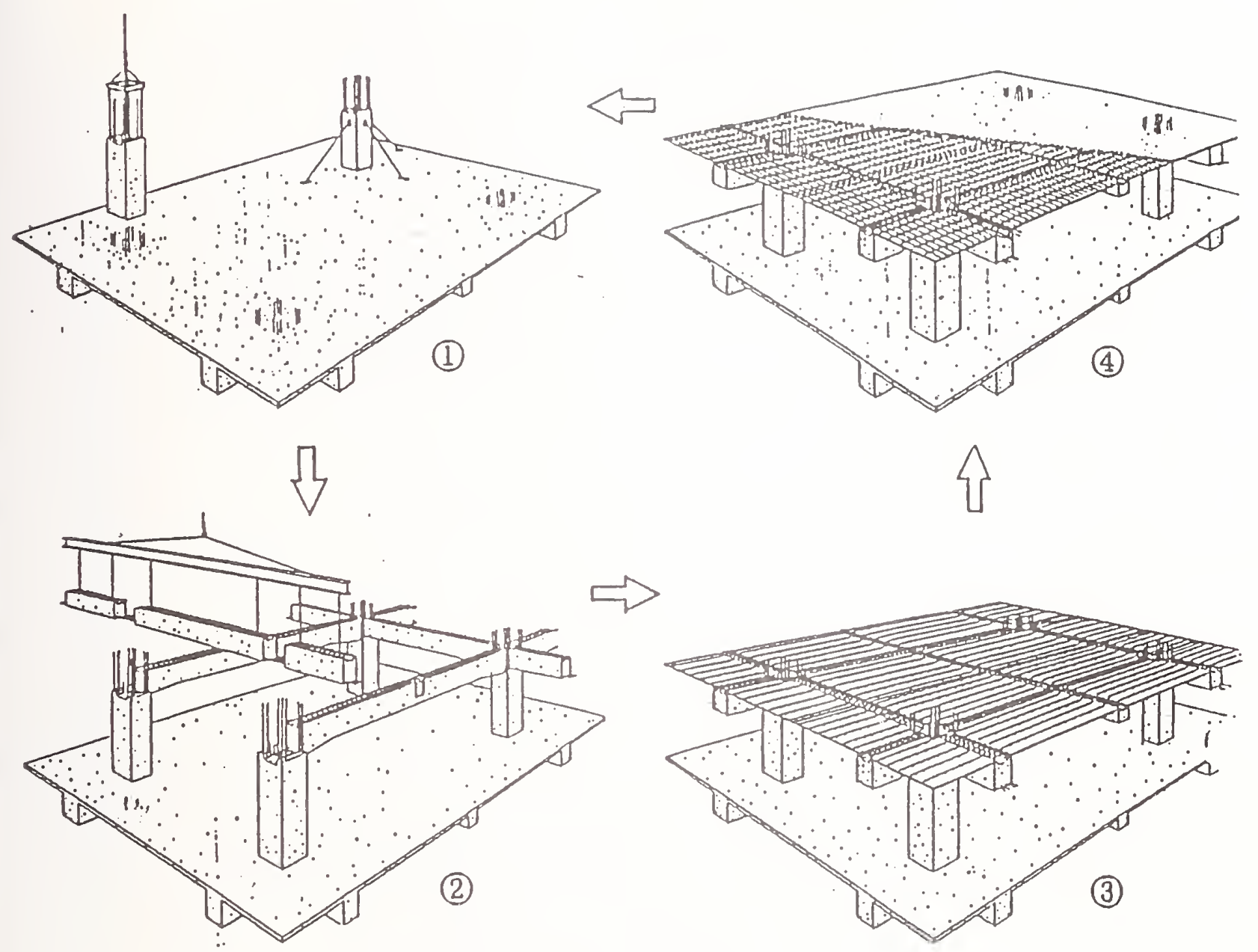

(1) Setting precast concrete Column

(2) Setting precast concrete beam and half precast concrete slab

(3) Arrangement of beam reinforcement, floor slab reinforcement, beam-column joint reinforcement

(4) Placing concrete into beam-column joint, on the half precast beam, and on the hulf precast slab 
Table 1 Required Condition for Ductile Members

For Column

\begin{tabular}{|c|c|c|c|}
\hline leas. & $\begin{array}{l}\text { Limliation of } \\
\text { RAIIK A }\end{array}$ & Desloned value & Evaluatlon \\
\hline Collapse mode & $\begin{array}{l}\text { Should be } \\
\text { flexural yielding }\end{array}$ & $\begin{array}{l}\text { Ali columas are } \\
\text { flexural yieldiag }\end{array}$ & A \\
\hline \multirow{2}{*}{$\begin{array}{l}\text { Axlal stress at } \\
\text { Collapse gectanlsa }\end{array}$} & \multirow{2}{*}{$60 / F_{C} \leqq 0.35$} & $\begin{array}{rrrr} & A & 9847^{t} & (91 x) \\
x \text {-direction } & B & 491^{t} & (4.6 x) \\
& C & 474^{t} & (1.4 x)\end{array}$ & .1 \\
\hline & & 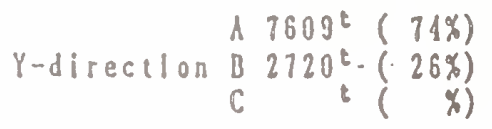 & $\Lambda$ \\
\hline $\begin{array}{l}\text { Shear span ratlo of } \\
\text { lst story columas } \\
\text { foralag biages }\end{array}$ & $2 H / Q \cdot D \geqq 2.5$ & more $\operatorname{than} 3.97$ & $A$ \\
\hline $\begin{array}{l}\text { Relaforcemeat ratlo } \\
\text { lor beadiar momeat }\end{array}$ & $R_{t} \leqq 0.8 \%$ & $0.54 \%$ to $0.80 \%$ & $A$ \\
\hline $\begin{array}{l}\text { Heansbear stress } \\
\text { at collapse } \\
\text { mechanlsm }\end{array}$ & $\tau u / F_{C} \leq 0.1$ & less than 0.099 & - 1 \\
\hline
\end{tabular}

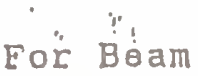

\begin{tabular}{|c|c|c|c|}
\hline $\begin{array}{c}\text { Items } \\
. .\end{array}$ & $\begin{array}{l}\text { LIOllatlon of } \\
\text { RAHK A }\end{array}$ & Deslgned value & Evalualloo \\
\hline Collapse mode & $\begin{array}{l}\text { Should be } \\
\text { flexural yielding }\end{array}$ & $\begin{array}{l}\text { All bear are } \\
\text { llexural yielding }\end{array}$ & $A$ \\
\hline $\begin{array}{l}\text { Hean shear stress } \\
\text { at collapse } \\
\text { mechanlsm }\end{array}$ & $\mathrm{u} / \mathrm{F}_{\mathrm{C}} \leqq 0.15$ & less than 0.091 & $\Lambda$ \\
\hline
\end{tabular}

"RANk $h^{\circ}$ can be Judged to this frame from syathetic evaluation above mentloned. 


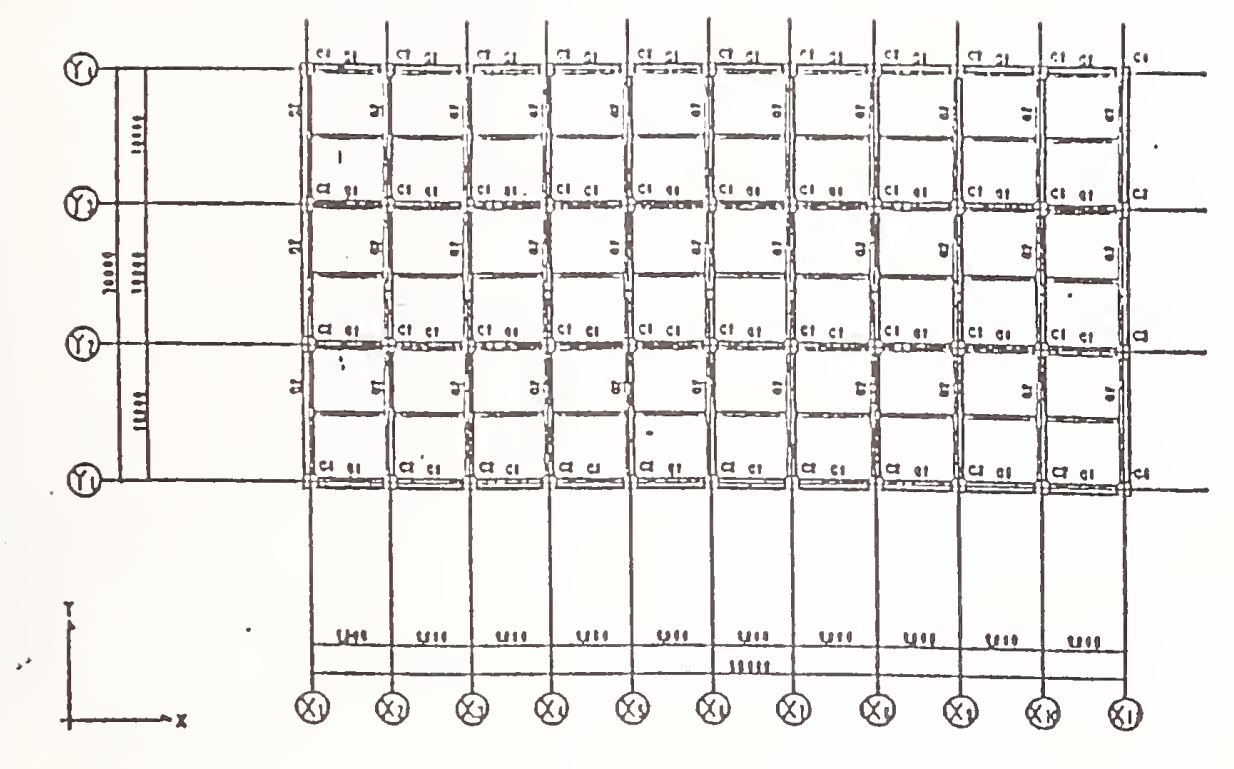

Typlcal floor plan

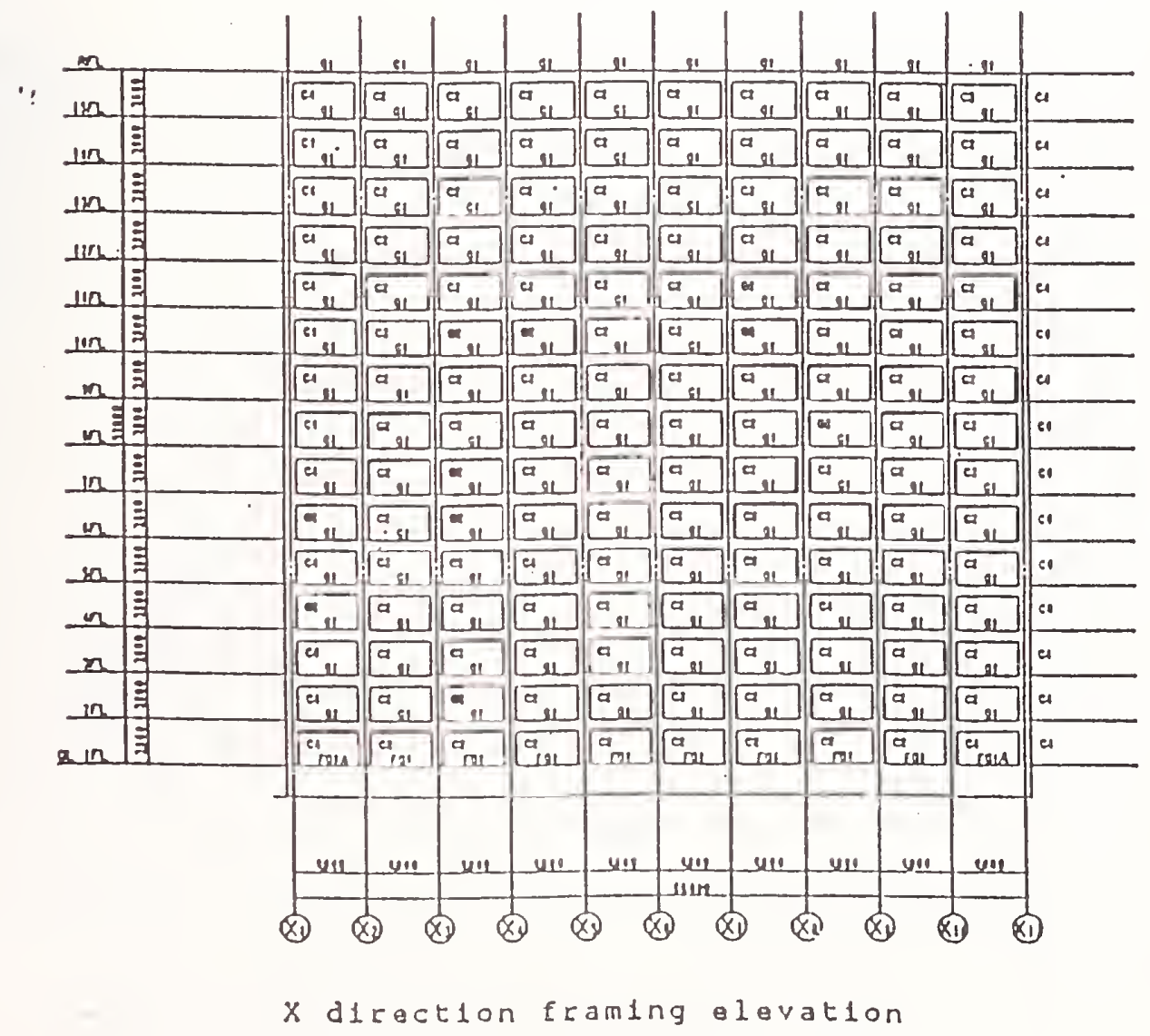

Fig.5 Plan and Elevation of Designed Building 
Story numbre

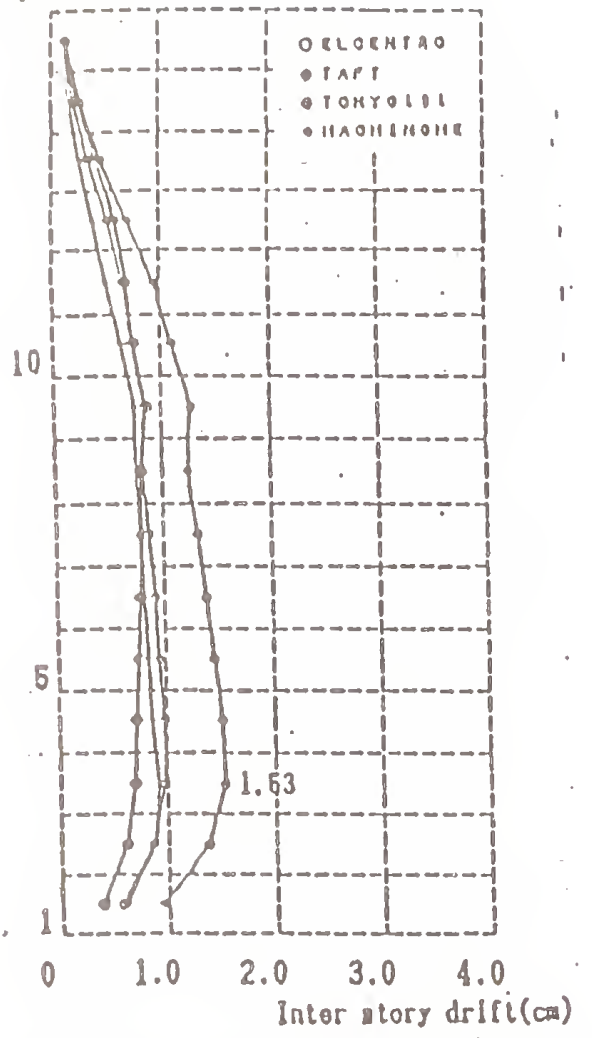

Maximum Response Inter Story Drift slory nualur

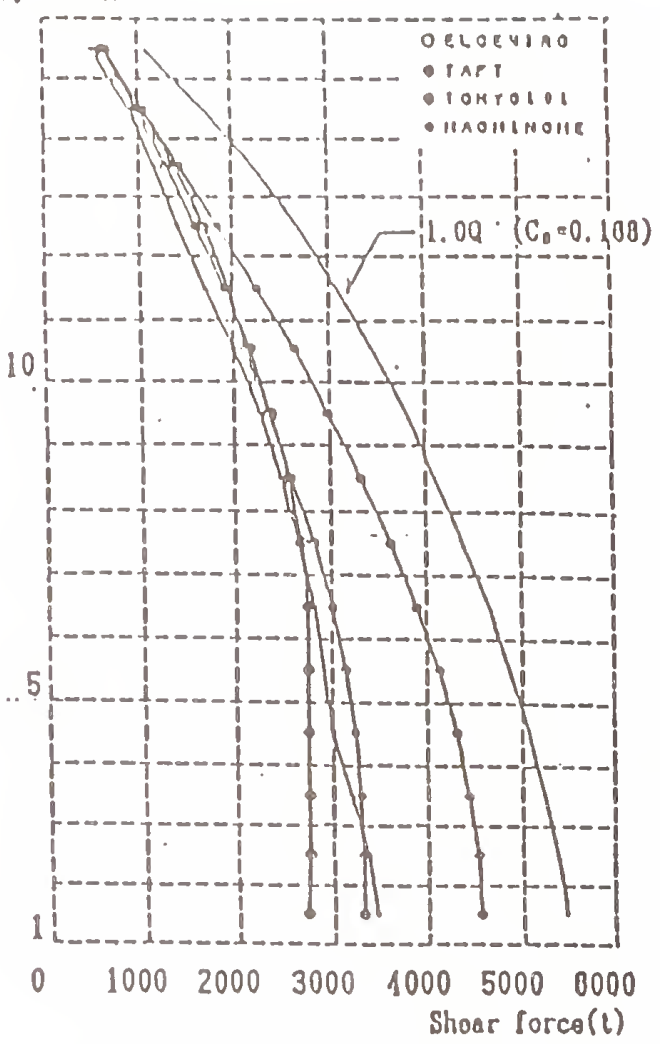
$X$ Direction $(25 \mathrm{~cm} / \mathrm{sec})$

Story numbor

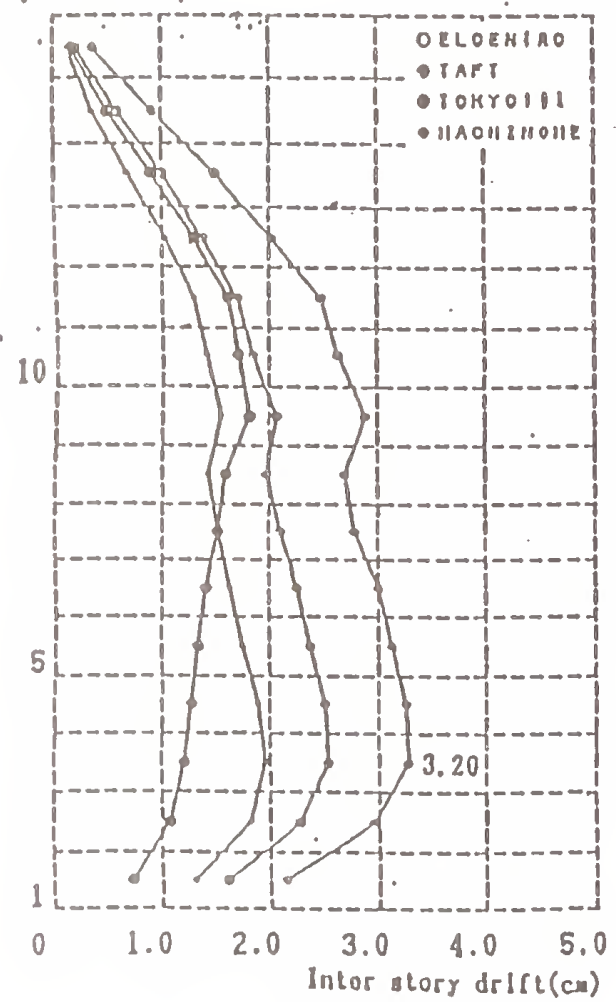

Slory numbor

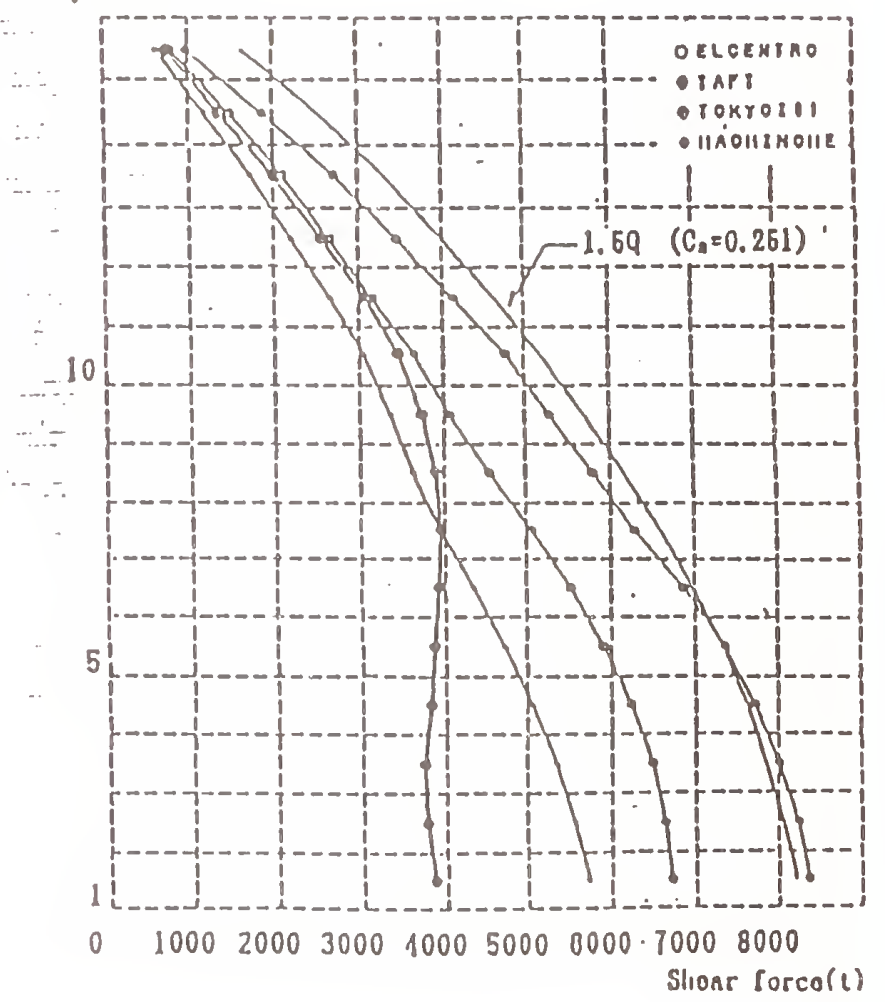

Haximum Mesponse Inter Story Drift $X$ Direction $(50 \mathrm{~cm} / \mathrm{sec})$

Haximum Respoliso Shoar Porce

Fig.6 Skclcton Curve of Eacli Story and Results of Frame Analysis 


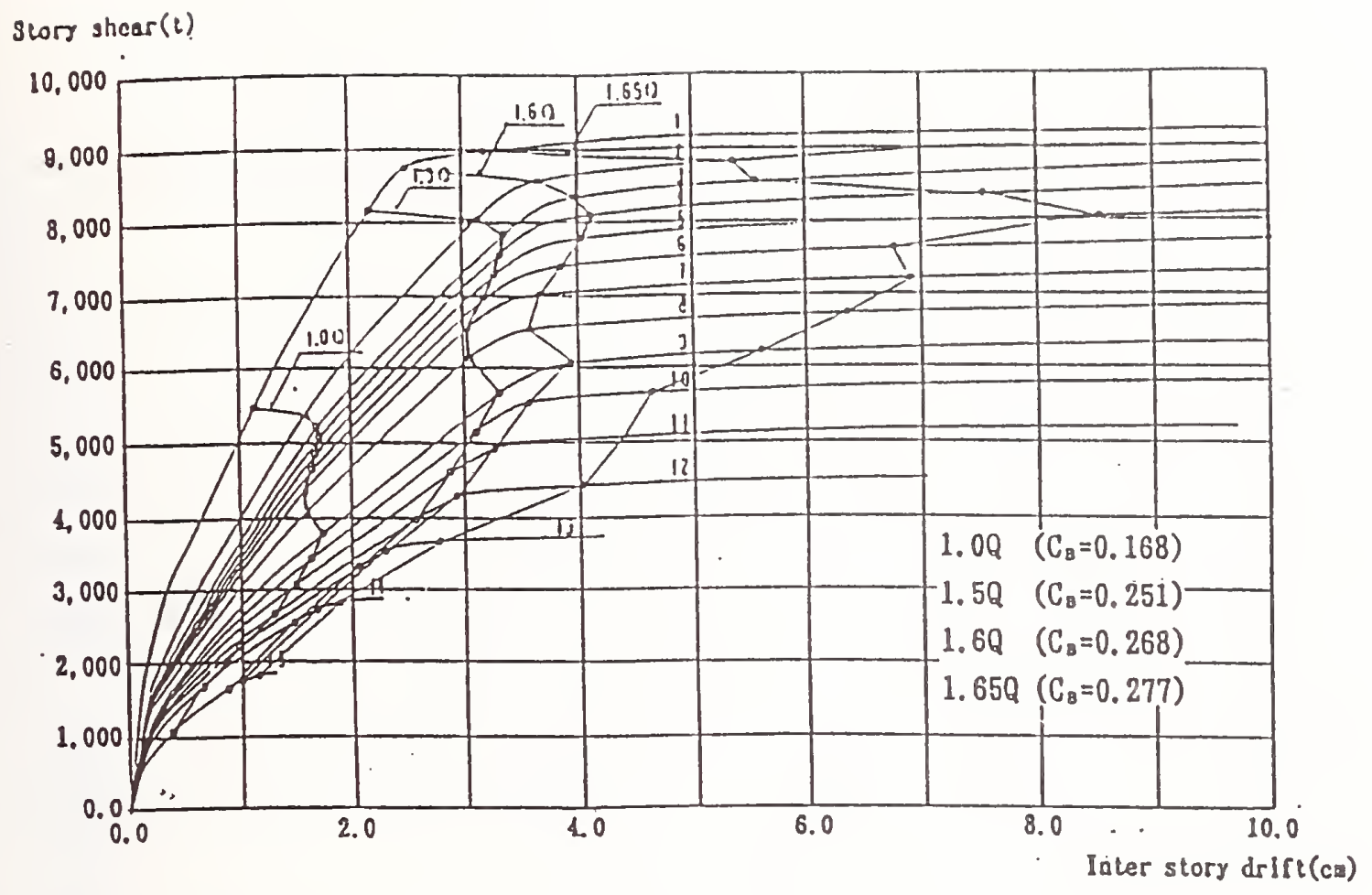

Story shear-Inter story drift reration $x$ Direction

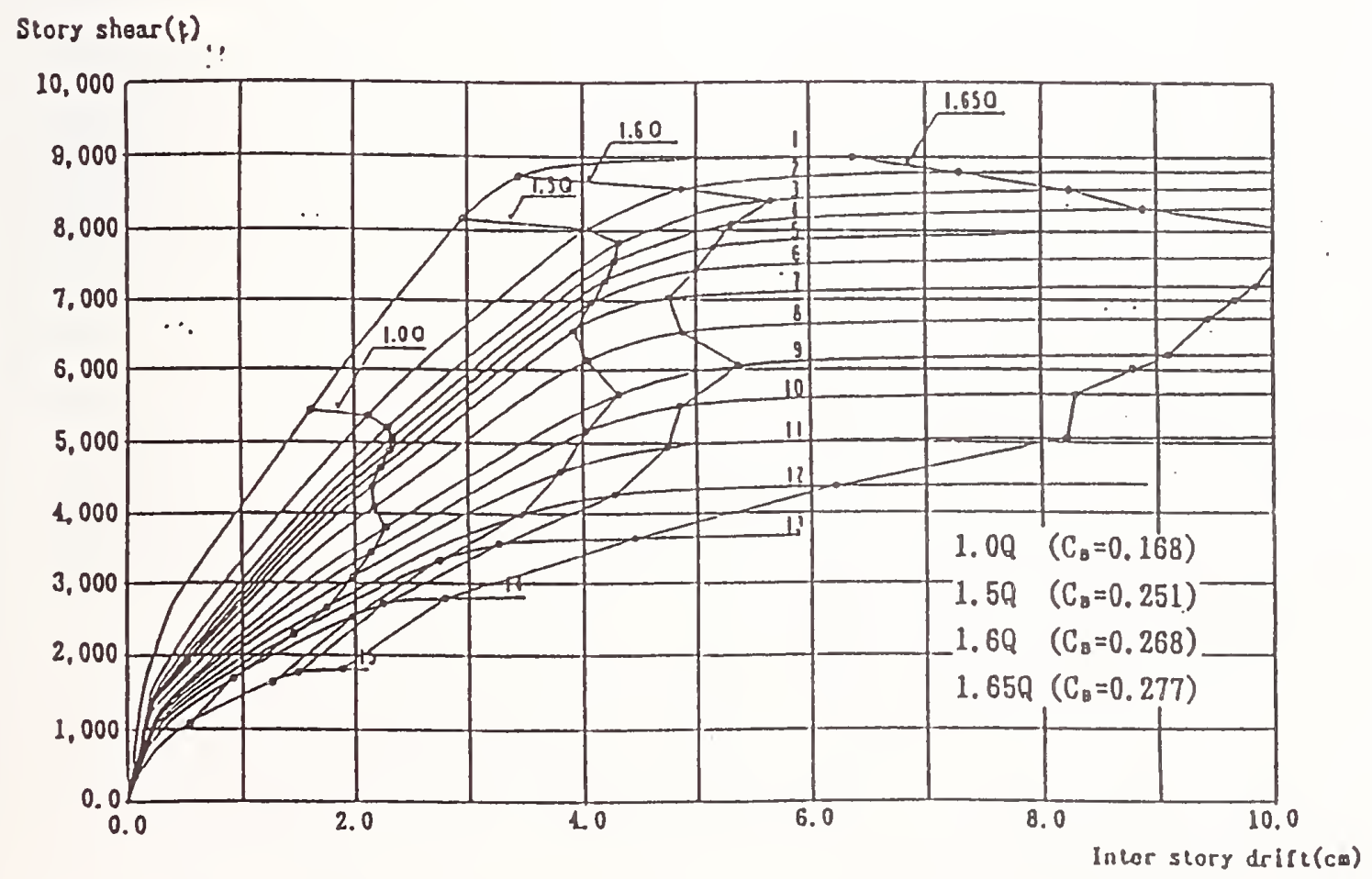

Story shear-Inter story drift reration $Y$ Diroction

Fig.7 Results of Dynamic Response Analysis 


\section{Part 2-1}

\section{Tensile Tests of Lap-Spliced Joint Precast Concrete Panel Connections}

\subsection{Introduction}

Tensile force occurring in connections of precast concrete frame-wall structure, such as (1) wall panel to boundary column connections, (2) wall panel to boundary beam connections, and (3) slabto-slab connections are often designed to be transmitted at joint by lapped deformed bar which are embedded in site-cast concrete. Many researchers have reported the behavior of these joints under shear stress, although reports on the tensile behavior are limited. Thus, the provisions in castin-place concrete building codes are used to design of lapped-spliced joint to tensile force. It is aimed to develop lapped-spliced joint in which the site assembly may be simplified and necessary site work may reduced and in which satisfactory performance may be assured.

In this paper, results of 17 panels tensile tests are reported and tensile behavior for the details which include (1) the type of splice (2) lap lengtl of splice, (3) space between splice reinforcement, (4) shape of splice reinforcement, and (5) reinforcement ratio, are discussed.

\subsection{Test Program}

\subsubsection{Specimens}

The specimens tested were seventeen full-scale precast concrete flat panels. Their dimensions are 500 $\mathrm{mm}$ in width $\times 1,000 \mathrm{~mm}$ in length and 100 or 120 $\mathrm{mm}$ in thickness.

Figure 1 shows the loading apparatus and the shape of the specimens. The specimens are connected at the center. The four different types of lap joint tested are shown in Fig. 2. They include

- straight lap splice joint (straight lap joint),

- loop shaped lap splice joint (loop splice joint),

- straight lap splice which laid on precast concrete panel which embedded in topping collcrete (topping concrete lap joinl), and a

- splice reinforcement in between full-precast segments(precast segment lap joint).
The test variables are

- panel thickness $t(100 \mathrm{~mm}$ or $120 \mathrm{~mm})$,

- lap length $\ell$ (10d, $20 d, 30 d$, where $d$ the nominal cross sectional area of deformed bar),

- spacing of lapped bar $s$ (60 $\mathrm{mm}$ or $30 \mathrm{~mm})$,

- the presence or absence of supplemental reinforcement, which is laid transverse to reinforcement in loop in case of a loop shaped splice joint only,

as well as four different lap details.

Seventeen specimens and the material properties are listed in Table 1. SD30 grade steel were used for the splice reinforcing bars. Normal weight concrete was used and the compressive strength of concrete of site-cast concrete was $384 \mathrm{kgf} / \mathrm{cm}^{2}$.

All of the specimens were placed horizontally and concrete was cast on it to form an integrated unit. The concrete was left for 15 to 22 days before casting. No preparation on concrete joint was carried out except topping concrete lap joint. The interface of precast concrete and topping concrete was brushed. veneer panel was used for the form for side edges of segment lap splice joint.

\subsection{Loading and Measurement}

The specimens were loaded with increasing monotonic tensile force until failure occurred. The deformations were measured between two targets on specimen. The targets were anchor bolts embedded in concrete and the distance between them was 600 $\mathrm{mm}$ and the distance is nearly equal to the 6-times of the panel thickness. Average tensile strain was defined here as the ratio of the deformation to the distance between targets $(=600 \mathrm{~mm})$. Average tensile stress was defined as the ratio of the total tensile force to the total cross sectional area of splice reinforcement.

\subsection{Test results and Discussions}

Figure 3 show the relation of average tensile strain and average tensile stress. The Ultimate strength 
and the Ultimate. strain at strength are listed in Table 3. Observed failure modes are shown in Fig. 5.

\subsubsection{Straight lap splice joint}

During the tests of the specimens, the lap length of which exceeded $20 d$ ( $d$; nominal diameter of rebar ), yield of the steel and the failure in the zone with no lap joint were observed(specimens \#1, \#2, \#3, \#4). Almost of all deformation are able to be attributed to opening of the crack at the concrete construction joint. The specimens with thickness of $100 \mathrm{~mm}$ and $120 \mathrm{~mm}$ had almost the same strength and ductility. In the case of the specimens which had a lap length of $10 d$, tensile yield of the steel was observed. The average strain was almost 1$2 \%$, before sudden rupture at the splice occurred and the strength suddenly dropped off (specimen \#5, \#6).

The tensile stiff ness was almost equal to the stiffness of the reinforcing steel by themselves. The opening of the crack at concrete interface may reduce the stiff ness. The different spacing of lapped reinforcing bars seemed to have little effect on their strength and ductility.

\subsubsection{Loop splice joint}

The specimen \#7 and \#8 had a splice length of $10 d$ and had transverse reinforcement placed inside the loop. The splice reinforcement yield observed and attained to maximum strength at average strain of $1.0-1.3 \%$. It sustained strength and a gradual failure observed. In the case of the specimens which had a shorter splice length of $5 d$ showed gradual failure at cast-in-place concrete before the reinforcement yielded, while it had a transverse reinforcement inside of the loop bar (specimen \#10). The specimens without transverse reinforcement showed brittle rupture at average strain of $0.05 \%$, before yielding of the reinforcement (specimens \#9, \#11).

\subsubsection{Topping concrete splice joint.}

In the case of specimen which hasl a splice lengtl of more than $20 d$ showed yielding of the reinforcement and a gradual failure at the section occurred at the point where the truss reinforcement a was terminated (specimen \#12 \#13). In the case of a $10 \mathrm{~d}$ splice length, just after the yielding of the reinforcement, a sudden failure and reduction of strength was observed at the splice joint. The stiffness before yield was generally higher than for the other types of splice joint due to the tensile force transmitted by concrete of cast-in-place panel.

\subsubsection{Precast segment lap joint}

When the stress in reinforcement exceeded $51-71$ $\%$ of the yield strength, shear slip at the construction joint between precast concrete panel and castin-place concrete occurred, and a sudden reduction of strength was observed. Bond failure along the surface of splice reinforcement was not observed. (specimen \#15 \#16 \#17).

\subsection{Concluding Remark}

Tensile tests of the spliced joints with embedded cast-in-place concrete were carried out. Monotonically increasing tensile force were applied. Splice reinforcement was SD30 grade steel and the compressive strength of concrete was $384 \mathrm{kgf} / \mathrm{cm}^{2}$. From the test result, the following conclusions are made.

1. Straight lap longer than $20 d$; where $d$ the nominal diameter of the bar, show excellent behavior. The maximum average strain exceed $3 \%$. When the lap joint length was $10 d$, yield strength of the steel attained but after that sudden failure occurred.

2. Loop-shape splice joint showed better performance than straight lap splice joint with lap length $10 \mathrm{~d}$, if transverse reinforcement is added. Without transverse reinforcement, brittle failure occurred at average strain of 0.05 $\%$.

3. Straight lap splice joint in topping concrete show excellent behavior similar to straight lap splice joint. In addition, higher stiffnesses were obtained compared with straight lap splice joint.

4. The lap splice joint in precast segments showed brittle failure before the yield strength was reached. Failure at the construction joint between the precast concrete and cast-in-place concrete were observed. 
Table 1: List of Specimens (cont'd)

\begin{tabular}{|c|c|c|c|c|}
\hline No. & Type of Splice & $\begin{array}{l}\text { Thickness } \\
t(\mathrm{~mm})\end{array}$ & $\begin{array}{l}\text { Lap Length } \\
\ell(\mathrm{mm})\end{array}$ & $\begin{array}{l}\text { Spacing } \\
t(\mathrm{~mm})\end{array}$ \\
\hline \# I & \multirow{6}{*}{ D13 Straight Lap Splice } & 100 & $30 d$ & 60 \\
\hline$\# 2$ & & 120 & $30 d$ & 60 \\
\hline \#3 & & 100 & $20 d$ & 60 \\
\hline$\# 4$ & & 100 & $20 d$ & 30 \\
\hline \#5 & & 100 & $10 d$ & 60 \\
\hline \#6 & & 100 & $10 d$ & 30 \\
\hline$\# 7$ & \multirow{5}{*}{ D10 Loop-Shape } & 100 & $10 d^{\circ}$ & - \\
\hline \#8 & & 120 & $10 d^{\bullet}$ & - \\
\hline$\# 9$ & & 100 & $10 d$ & - \\
\hline$\# 10$ & & 100 & $5 d^{\circ}$ & - \\
\hline \#11 & & 100 & $5 d$ & - \\
\hline$\# 12$ & \multirow{3}{*}{ D10 Topping.Concrele } & 120 & $30 d$ & - \\
\hline$\# 13$ & & 120 & $20 d$ & - \\
\hline \#14 & & 120 & $10 d$ & - \\
\hline \#15 & \multirow{3}{*}{ D13 Precast Segment } & 100 & $30 d$ & - \\
\hline \#16 & & 100 & $20 d$ & - \\
\hline \#17 & & 100 & $10 d$ & - \\
\hline
\end{tabular}

- : with tranaverse reinforcement in loop

Table 2: List of Specimens

\begin{tabular}{|c|c|c|c|c|c|}
\hline \multirow[b]{2}{*}{ No. } & \multicolumn{2}{|c|}{$\begin{array}{c}\text { Concrele Compressive } \\
\text { Strength }\end{array}$} & \multicolumn{2}{|c|}{$\begin{array}{l}\text { Steel Tensile } \\
\text { Strength }\end{array}$} & \multirow{2}{*}{$\begin{array}{c}\text { Splice Reinforcement } \\
\text { Ratio } \\
\%\end{array}$} \\
\hline & $\begin{array}{l}\text { Pre-Cast } \\
\mathrm{kg} t / \mathrm{cm}^{2}\end{array}$ & $\begin{array}{c}\text { Cast-in-Place } \\
\mathrm{kg} t / \mathrm{cm}^{2}\end{array}$ & $\begin{array}{c}\text { Yield } \\
\mathrm{kg} / / \mathrm{cm}^{2}\end{array}$ & $\begin{array}{l}\text { Ultimale } \\
\mathrm{kg} / / \mathrm{cm}^{2}\end{array}$ & \\
\hline \#1 & 155 & \multirow{6}{*}{384} & \multirow{6}{*}{3489} & \multirow{6}{*}{5082} & 1.01 \\
\hline \#2 & 455 & & & & 0.81 \\
\hline \#3 & 171 & & & & 1.01 \\
\hline$\# 4$ & 455 & & & & 1.01 \\
\hline$\# 5$ & 159 & & & & 1.01 \\
\hline$\# 6$ & 474 & & & & 1.01 \\
\hline$\# 7$ & 457 & \multirow{5}{*}{384} & \multirow{5}{*}{3890} & \multirow{5}{*}{5787} & 0.86 \\
\hline \#8 & 474 & & & & 0.71 \\
\hline$\# 9$ & 480 & & & & 0.86 \\
\hline \#10 & 474 & & & & 0.86 \\
\hline \#11 & 459 & & & & 0.86 \\
\hline$\# 12$ & 459 & \multirow{3}{*}{384} & \multirow{3}{*}{3890} & \multirow{3}{*}{5787} & \multirow{3}{*}{0.71} \\
\hline \#13 & 457 & & & & \\
\hline \#11 & 180 & & & & \\
\hline$\# 15$ & 180 & \multirow{3}{*}{384} & \multirow{3}{*}{3897} & \multirow{3}{*}{5704} & \multirow{3}{*}{0.40} \\
\hline \#16 & 480 & & & & \\
\hline \#17 & 480 & & & & \\
\hline
\end{tabular}

Table 3: Test Results

\begin{tabular}{|c|c|c|c|c|}
\hline No. & $\begin{array}{c}\text { Ultimate } \\
\text { Tensile Load } \\
\text { tont }\end{array}$ & $\begin{array}{c}\text { Average Strain al } \\
\text { Ultimale Load } \\
\mathrm{mm} / \mathrm{mm}\end{array}$ & $\frac{\text { Ultimale Stress }}{\text { Yield Stress }}$ & Failure Mode"• \\
\hline$\# 1$ & 21.4 & 0.0255 & 1.21 & A \\
\hline$\# 2$ & $>23.6^{\circ}$ & $>0.0343$ & 1.33 & A \\
\hline \#3 & $>22.2^{\circ}$ & $>0.0178$ & 1.25 & A \\
\hline \#4 & $>24.7^{\circ}$ & $>0.0329$ & 1.40 & A \\
\hline \#5 & 20.6 & 0.0198 & 1.16 & $\mathrm{C}$ \\
\hline \#6 & 18.4 & 0.0069 & 1.04 & $\mathrm{C}$ \\
\hline$\# 7$ & 17.3 & 0.0096 & 1.04 & $\bar{B}$ \\
\hline \#8 & 19.1 & 0.0130 & 1.15 & B \\
\hline \#9 & 10.8 & 0.0011 & 0.65 & D \\
\hline$\# 10$ & 9.5 & 0.0178 & 0.57 & C \\
\hline$\# 11$ & 6.3 & 0.0006 & 0.38 & D \\
\hline$\# 12$ & 23.1 & 0.0215 & 1.38 & $\bar{A}$ \\
\hline$\# 13$ & 19.1 & 0.0040 & 1.11 & A \\
\hline$\# 11$ & 15.6 & 0.0013 & 0.94 & $\mathrm{C}$ \\
\hline$\# 15$ & 5.5 & 0.0010 & 0.71 & $E$ \\
\hline$\# 16$ & 4.9 & 0.0008 & 0.63 & $\mathrm{E}$ \\
\hline \#17 & 1.0 & 0.0000 & 0.51 & $\mathbf{E}$ \\
\hline
\end{tabular}

- Ultimate Strength rere not altailled during icsts

- see Fig. 5 


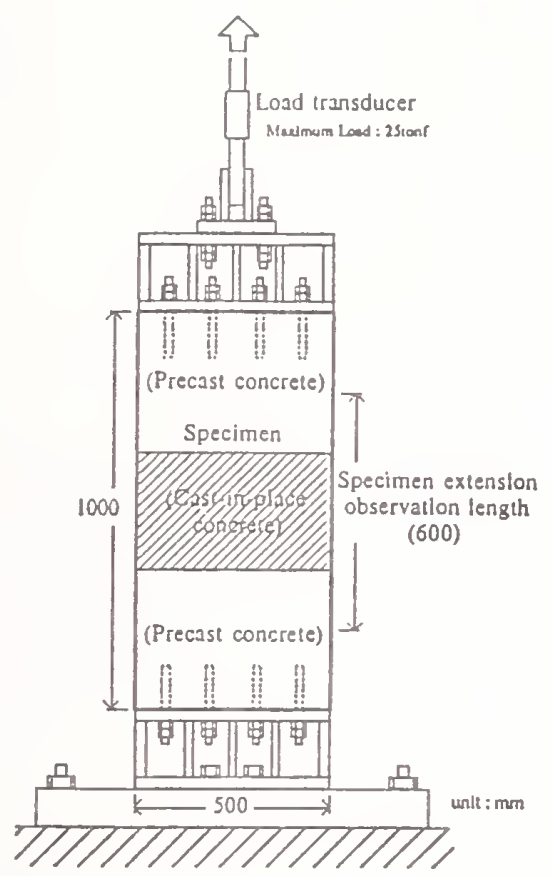

Figure 1: Specimen and Loading Apparatus

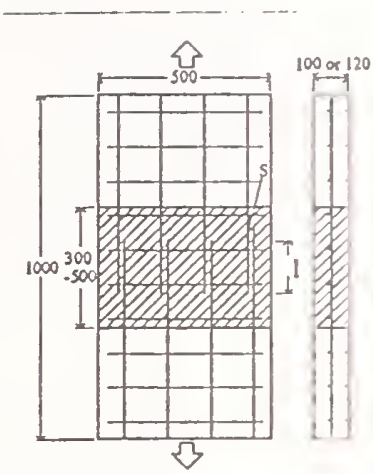

(a) Straight Lap Spliced Joint

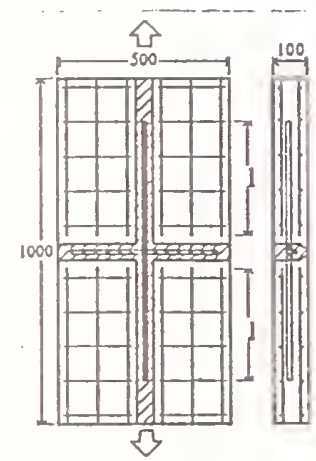

(d) Precast Segment Joint

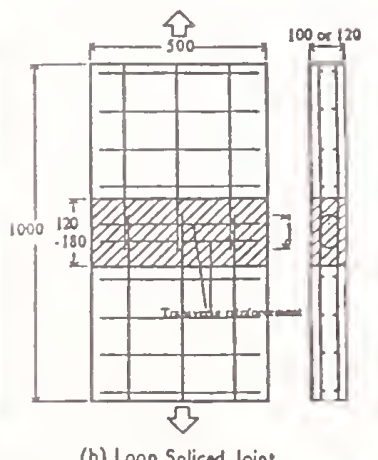

(b) Loop Spliced Joint

(c) Topping Concrete Lap Spliced Joint unh : mo

Figure 2: Details of Splice Joint 


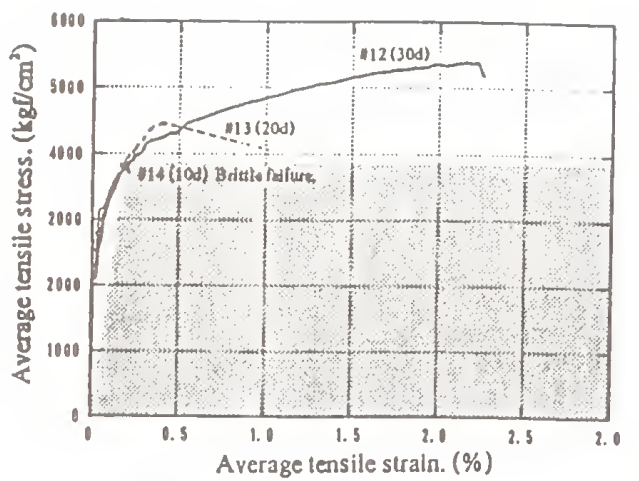

(c) Topping Concrete Lap Spliced Joint

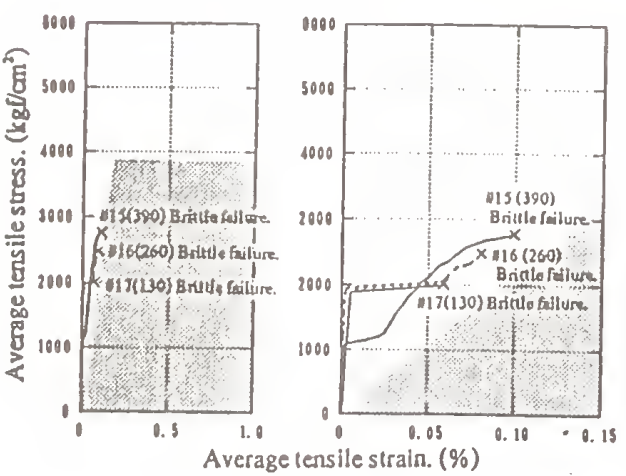

(d) Precast Segment Joint

(Note: - Splice ralnforceing bar yield. $\times$ Failure.

影 Stress-Sirain relation of reinforclng bas only.)

Figure 3: Average strain vs. Average Stress Relations (cont'd)

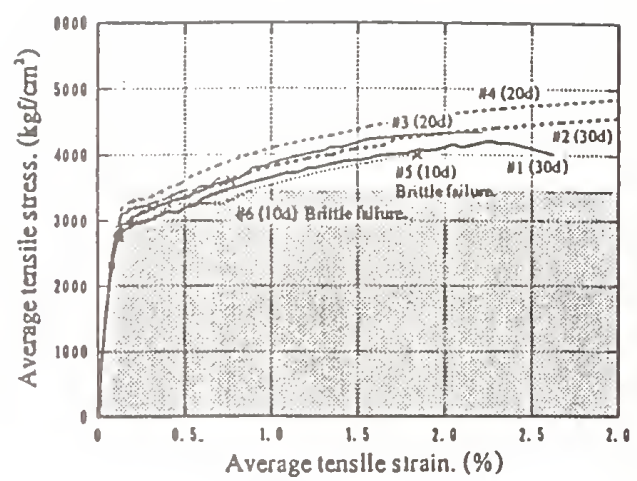

(a) Straight Lap Spliced Joint

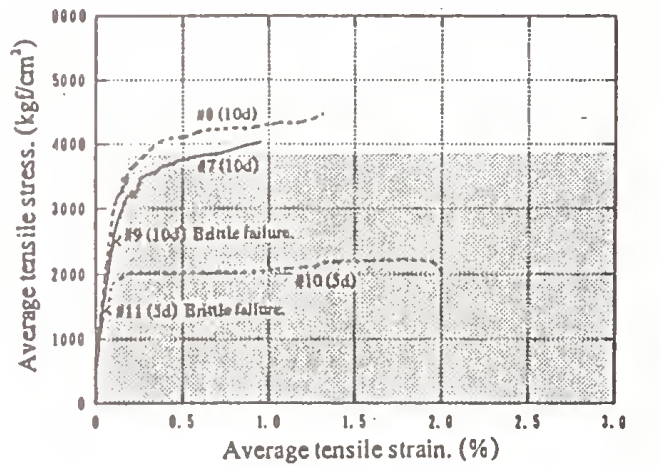

(b) Loop Spliced Joint

(Nole: - Spllce rainforceing bar yield. $\times$ Failure. Siress-Sirain relation of reinforeting bar only.)

Figure 4: Average Strain vs. Average Stress Relations (cont'd) 
A

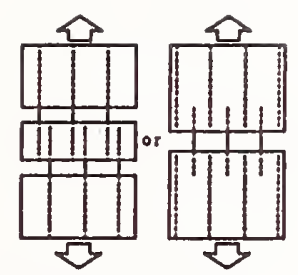

A : Gradual failure after yleld

due to opening at construction jolnt.

$(\# 1, \# 2, \# 3, \# 4, \# 12, \# 13)$

B

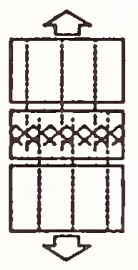

B : Gradual fallure after yleld

due to concrete fracture near spllced bar.

$(\# 7, \# 8)$

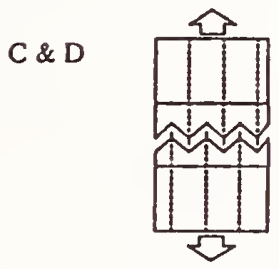

C : Brittle failure after yleld due to fracture near spliced jolnt.

$(\# 5, \# 6, \# 10, \# 14)$

D : Brittle Failure befor yleld

due to fracture near spliced jolnt. $(\# 9, \# 11)$

E

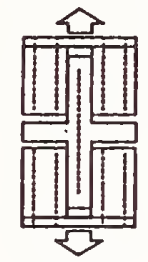

E : Brittie failure due to slide

along construction joint between segments. (\#15,\#16,\#17)

Figure 5: Failure Modes 


\section{Part 2-2 \\ Strength of Concrete Interface Subjected to Compression and Shear}

\subsection{Introduction}

In precast concrete buildings, site-cast concrete connections require cast-in-place concrete for their completion. In the site-cast connection, the interface between precast concrete and cast-in-place concrete have an important role in force transfer.

The majority of existing data about shear transfer has been obtained from tests of push-off specimens which have splice reinforcement across interface, but without a clamping force on the interface. Building code requirements for vertical joint or horizontal joint of a wall-panel construction reflects these test results and study.

At the connection of line element such as beam and column, the shear should be transferred by aggregate interlock under high bending moment, such as in flexure hinge section. Paticulary, in the member with a small shear-to-span-ratio, shear force is smaller than the normal compressive force. In this condition of stress, the interface does not cause any slip and behaves as a monolithic constructed concrete with a crack. This kind of concrete interface should be regarded to be equal to monolithic with respect to the shear transfer by concrete. But, less data is available on slip beliavior of an interface and the failure mode with high clamping force.

This paper reports tests of concrete interfaces. The purpose is to find conditions, at which interface behaves monolithically. Deformation at the interface and the failure mode are also discussed.

\subsection{Test Program}

\subsubsection{Variables}

This is a simple direct shear test to examine concrete interface between the precast and cast-inplace concrete. Table 1 lists the specimeus. Number of specimens is 46 in total. The two variables of the tests are listed as follow:

1. Five different interfaces are tested. The interfaces are chosen considering the possibility of usage in practice, which does not necessary reflect the current practice in precast concrete member manufacturing.

2. The inclination of the loading direction to interface $\theta$. This is chosen to find the angle at which the specimen behave equal to monolithic one.

The five different surface conditions of precast concrete are shown in Fig. 1. The characteristics of these surface conditions are briefly explained as follows;

- Type A specimens have no interface because they are monolithically constructed and intended to be used as control specimens.

- Type B specimens have concrete interface without any intentional preparation. Thus the surface was as smooth as the steel form surface.

- Type C specimens have a concrete interface intentionally roughened by brush before precast concrete hardened. 'The depth of roughened surface was estimated to be $1-2 \mathrm{~mm}$.

- Type D specimens have concrete interface shot-brusted with small steel balls. This operation was intended to be done until the aggregate become visible. But due to the limitation of ability of machine, the obtained roughness was estimated to be $1 \mathrm{~mm}$.

- Type E specimens have a concrete interface with small shear keys. The size of the shear keys were $2.8 \mathrm{~mm}$ height with section of triangular section and which were set by $9 \mathrm{~mm}$ spacing.

- Type F specimens had a castelerated concrete interface. The dimensions of casteleration were $10.0 \mathrm{~mm}$ height and the width was about 35 $\mathrm{mm}$. The spacing was $60 \mathrm{~mm}$.

\subsubsection{Shape of specimen, materials}

Figure 2 shows the shape of specimens. All 46 specimens have the same shape and dimensions, $20 \times 20 \times 10 \mathrm{~cm}$. They have no internal reinforcement. On four sides, shear keys with spacing of 20 $\mathrm{mm}$ were made, in order to prevent non-uniform stress causing irregular failure of specimen. Normal weight concrete with compressive strength of 213-294 $\mathrm{kgf} / \mathrm{cm}^{2}$ was used. The maximum aggregate size was specified to be $20 \mathrm{~mm}$. Table 2 lists 
the concrete compressive strength. Cast-in-place concrete was placed to make the direction of the interface vertical to horizontal plane.

\subsubsection{Loading}

Figure 3 shows a loading rig. The loading rig was set between the parallel loading plates of the hydraulic universal testing machine, the capacity of which is 200 tonf. Monotonically static increasing compressive load was applied to the specimen, maintaining the constant angle between the collcrete interface and loading direction. The value of $\tan \theta$ of the angle was 0.4 to 2.5 .

In order to prevent from irregular failure due to uneven stress by bending moment, the rotational freedom of the loading plates was fixed. To release confinement of interface after large slip at interface, a set of slide bearing was inserted between the loading rig and the base plate.

White gypsum capping was used to get uniform stress transfer between specimen and $10 \mathrm{~mm}$ thich steel L-shape loading plates, the surface of which had the same shape as the shear key on specimen sides. The gypsum capping was also intended to keep the opposite sides of specimen parallel. Tests were carried out without initial cracks at interface.

\subsubsection{Measurement}

Applied load and the deformation near the interfaces were measured. Assuming the shear stress along the interface $\tau$ and clamping stress norinal to interface $\sigma_{n}$ is uniformly distributed, the following equations are obtained from the equilibrium of internal stress and applied force.

$$
\begin{aligned}
\tau & =\frac{P}{A} \sin \theta \\
\sigma_{n} & =\frac{P}{A} \cos \theta
\end{aligned}
$$

where, $P$ : the applied load, $\theta$ : the angle from loading direction to the normal line to interface, $T$ : shear stress along the interface, $\sigma_{n}$ Hormal stress acting on interface, $A$ : area of interface.

By increasing the compressive strength of the concrete, the ultimate shear stress of the specimen also increases. Thus, for the purpose of coinparing the ultimate shear stress of specimen, the ratio of the shear stress to compressive strength of concrete referred to as the normalized shear stress is used. In the case that the strength of the precast concrete is different from that of the cast-in-place concrete, the mean value was used to normalize the shear stress.
Translational displacement along the interface and at $90^{\circ}$ to the interface were measured with four crack displacement transducers, which were attached to the both surfaces of the concrete with adhesive. The distance between measurement targets of each crack displacement transducer was $60 \mathrm{~mm}$ in common.

\subsubsection{Test procedure}

More than two specimens were tested with the same test variables. Some specimens show irregular failure patterns, for example, the value of strain mear sured on opposite side of specimen were significantly different, and the failure modes differ on two sides. The reason of irregular failure may be attributed to errors in the capping procedure. In this case, the irregular data was discarded and another specimen was tested. The actual number of specimens loaded was 63 and the 17 specimens failed irregularly, ( $27 \%$ of total number of specimens) the data of which were discarded. Thus, the tests of only 46 specimens are reported here.

The specimens with small $\tan \theta$ value were tested first, By increasing the $\tan \theta$, the dominant failure pattern changed from crushing of concrete to translational displacement along interface. Once change of failure mode occurred, further tests with specimen with larger $\tan \theta$ values was not $\operatorname{conducted.}$

\subsection{Test Result and Discussion}

Here the (1) ultimate Shear Stress, (2) shear stresstranslational displacement relation, and (3) failure criterion of the interfaces are reported and discussed.

\subsubsection{Ultimate shear stress}

The ultimate shear stress ol different types of in terface are compared with that of monolithic one in Fig. 4. The horizontal axis represents the normalized sliear stress defined in equation (1) and the vertical axis represents the $\tan \theta$. The values of tan 0 at which the specimens showed almost equal or greater strength were $0.6,0.8,1.00,1.00$ and 1.25 for Type B, C, D, E, and F, respectively.

The provision for shear-friction in the ACI code [1] specify an effective friction coefficient 0.6 to concrete to concrete and 1.0 for intentionally roughened concrete interfaces respectively. If the effective shear friction coefficient in the ACI code is used, the interfaces are expected to have higher strength than monolithic concrete interface. 


\subsubsection{Translational displacement - sliear stress relation}

The shear stress vs. translational displacement along interfaces are shown in Figures 5 to 7 . The translational displacement is the mean value of four displacements, obtained with iour crack displacement transducers. The elastic stiffness of the interfaces showed good correlation with that of monolithic concrete, except that the Type B specimen with unroughened interfaces show low stiffness. As the value of $\tan \theta$ decreased, the elastic stiffness deceased. The ultimate shear stress was attained at the translational displacement of $0.1-0.25 \mathrm{~mm}$. The stiffness of interface and the translational displacement at maximum shear stress of Type $F$ interface was variable but was generally larger than that of monolithic specimen and specimen with Type E interface.

\subsubsection{Failure criterion of interfaces}

The ultimate shear stress divided by the concrete strength $\tau / f_{c}^{\prime}$, and normal stress $\sigma_{c} / f_{c}^{\prime}$ are plotted in Figures 8 to 12, and compared with the yield surface of monolithic concrete.

Type A Monolithically constructed specimens of Type A construction, showed compressive railure, when $\tan \theta$ was in the range of $0.4-1.67$. In this case, diagonal sliding was occurred after the ultimate load was reached. The specimen with a value of $\tan \theta$ of 2.5 showed failure along the plane corresponding to interface.

The plot marks show good correlation to the arc of Mohr's stress circle, which had principal stresses of zero and $1.25 f_{c}^{\prime}$, (where, $f_{c}^{\prime}$ is the compressive strength of a concrete cylinder ( 10 $\mathrm{cm}$ dia. $\times 20 \mathrm{~cm})$ )

Type B In the case of the interface Type B, at which no roughening was carried ont, no failure along interface was observed, with the values of $\tan \theta$ of 0.4 and 0.6 . The sprecimen ivith a value $\tan \theta$ of 0.8 , showed sudden slip and brittle failure at a shear stress of $25 \%$ - 35) $\%$ of ultimate shear stress of monolithic specimen.

Type C The interface of Type C, which had a brushed interface, showed no failure along the interface when value of $\tan \theta$ from 0.4 to 1.0 . The specimen with $\tan \theta=1.25$, showed a sudden slip and reduction of restoring force just after attaining to maximum load. The maximmm load exceeded that carried by a monolithic specimen. From the failure surface observed, the cast-in-place concrete was scratched off by precast concrete.

Type D The shotbrust roughened interface of about $1 \mathrm{~mm}$ depth, was used in Type D. The specimen of with $\tan \theta$ values of $0.4-0.6$ showed no failure along the interfaces. The specimen with $\tan \theta$ values of 0.8 , showed sud. den failure after it attained its maximum load. The maximum load was larger than that of the Type A specimen. The failure plane seemed to have been made by scratching of the cast-inplace concrete by precast concrete like that of Type C.

Type E The interface Type $E$ had small shear keys. In this type, specimens with $\tan \theta$ from 0.4 to 0.8 showed no failure along interface. The maximum strength of specimens in which $\tan \theta$ equaled 1.0 exceeded the strength of the monolithic specimen. One of them showed a sudden failure along the interface after maximum strength was reached, the other specimen showed different failure mode and the strength rapidly decreased. The maximum strength of the specimens with $\tan \theta$ of 1.25 exceeded the strength of the monolithic one. After attained to the maximum strength, sudden failure along interface occurred. The cast-in-place concrete seemed to be scratched of by the shear key of the precast concrete.

Type $\mathrm{F}$ The Type F interface has a casteleration. No failure along the interface were observed in the specimens with $\tan \theta$ value of $0.4-1.25$. During the loading of the specimens with $\tan \theta$ values of 1.67 , sudden reduction of load occurred at a strength of $70 \%$ of the monolithic specimen strength. Failure of cast-inplace concrete along the lines which connect the peaks of the casteleration of precast concrete was observed.

\subsubsection{Discussion}

The values of $\tan \theta$ at which the failure mode change from crushing of concrete to failure along interface are listed in Table 4. From these test results, it was found that by increasing the roughness of the interface, the ability to transmit skew compressive force increases. It is also seen that the specimen with higher shear strength than the monolithic specimens did not necessary showed the same failure mode as monolithic specimens. 


\subsection{Conclusion}

Forty three specimens were subjected to compression and shear. Testing was were carried out in order to examine the performance of the concrete interface between the cast-in-place concrete and the precast concrete. The conclusions are given below.

1. When the angel $\theta$ from the direction of loading to the normal line to interface was small, No failure along the interface occurred and both sides of the concrete acted as one unit. The maximum strength was greater or equal to that of monolithic specimens. By increasing the angle $\theta$, the failure mode changed to the failure along the interface which was always accom. panied by sudden reduction of restoring force. Therefore, if the angle $\theta$ is smaller than a particular value (which depends on the type of interface) the interface of precast concrete and the cast-in-place concrete beliave as one.

2. The angle at which the failure mode clianged from failure other than interface to the failure at interface, varied according to type of interface. The $\tan \theta$ for interface without roughening was $0.6-0.8$. As increasing the depth of roughing, The $\tan \theta$ increase up to $0.8-1.67$. In case of monolithic concrete, the value $\tan \theta$ was more than 1.67 .

3. The translational displacement at the maximum shear stress was estimated to be 0.1 $0.25 \mathrm{~mm}$. Whether or not an interface was used, did not affect the elastic stiffuess before. the maximum strength. The stifness of an interface without any roughening was lower than other interfaces.

\section{References}

[1] ACI Committee 318. Building Code Require. ments for Reinforced Concrete (ACI $31 \mathcal{S} .89$ ) and Commenlary (ACI 318R.8.9). American Concrete Insitute, Detroit, Michigan, 1989. 
Table 1: List of Specimens

\begin{tabular}{|c|c||c|c|c|c|c|c|c|c|}
\hline Type & \multirow{2}{*}{$\begin{array}{c}\text { In terface } \\
\text { Condition }\end{array}$} & \multicolumn{7}{|c|}{$\tan \theta$} & Total No. \\
\hline \hline A & Monolithic & 2 & 1 & & & & & & 12 \\
\hline B & $\begin{array}{c}\text { Concrete to } \\
\text { Concrete }\end{array}$ & 1 & 2 & 2 & & & & & 5 \\
\hline C & $\begin{array}{c}\text { Concrete to Roughened } \\
\text { Concrete with brush }\end{array}$ & 2 & & 2 & 1 & 2 & & & 7 \\
\hline D & $\begin{array}{c}\text { Concrete to } \\
\text { Shotbrusted Concrete }\end{array}$ & 2 & 2 & 2 & & & & & 6 \\
\hline E & $\begin{array}{c}\text { Concrete to Concrete } \\
\text { with Small Shear Keys }\end{array}$ & 2 & & 2 & 2 & 2 & & & 8 \\
\hline F & $\begin{array}{c}\text { Concrete to Concrete } \\
\text { with Casteleration }\end{array}$ & 2 & & 2 & & 2 & 2 & & 8 \\
\hline
\end{tabular}

where, $\theta$ : angle (see Fig. 3)

Table 2: Concrete Compressive Strength

\begin{tabular}{|c|c|c|c|}
\hline \multirow[b]{2}{*}{ Type } & \multicolumn{3}{|c|}{ Concrete Compressive Strength in $\mathrm{kgl} / \mathrm{cm}^{2}$} \\
\hline & $\begin{array}{l}\text { Precast } \\
\text { Concrete }\end{array}$ & $\begin{array}{c}\text { Cast-in-Place } \\
\text { Concrete }\end{array}$ & $\begin{array}{l}\text { Average } \\
\text { Strength }\end{array}$ \\
\hline A & - & $213-248$ & - \\
\hline $\bar{B}$ & 270 & 245 & 258 \\
\hline C & 226 & 251 & 239 \\
\hline $\mathrm{D}$ & 248 & 242 & 245 \\
\hline $\mathbf{E}$ & 224 & 204 & 214 \\
\hline $\mathbf{F}$ & 213 & 291 & 252 \\
\hline
\end{tabular}

Table 3: Observed Failure Modes

\begin{tabular}{|c|c||c|c|c|c|c|c|c|}
\hline Type & \multicolumn{1}{|c||}{$\begin{array}{c}\text { Interface } \\
\text { Condition }\end{array}$} & 0.4 & 0.6 & 0.8 & 1.0 & 1.25 & 1.67 & 2.5 \\
\hline \hline A & Monolithic & CC & C & CC & CC & C & CC & SS \\
\hline $\mathrm{B}$ & $\begin{array}{c}\text { Concrete to } \\
\text { Concrete }\end{array}$ & C & CC & SS & & & & \\
\hline $\mathrm{C}$ & $\begin{array}{c}\text { Concrete to Roughened } \\
\text { Concrete with brush }\end{array}$ & CC & & CC & C & SS & & \\
\hline D & $\begin{array}{c}\text { Concrete to } \\
\text { Shotbrusted Concrete }\end{array}$ & CC & CC & SS & & & & \\
\hline E & $\begin{array}{c}\text { Con crete to Concrete } \\
\text { with Small Shear Keys }\end{array}$ & CC & & CC & CS & SS & & \\
\hline F & $\begin{array}{c}\text { Concrete to Concrete } \\
\text { with Casteleration }\end{array}$ & CC & & CC & & CC & SS & \\
\hline
\end{tabular}

where, C: Crushing of Concrete, S : Sliding along interface and

$\theta$ : angle (see Figure 3)

Table 4: $\tan \theta$ at which the failure mode change from crusling of concrete to slide failure along interface

\begin{tabular}{|c|c|c|}
\hline Type & Interface Condition & $\tan \theta$ \\
\hline A & Monolithic & $1.67-2.5$ \\
\hline B & Concrete to Concrete & $0.6-0.8$ \\
\hline C & Concrete to Brnshed Concrete & $1.0-1.25$ \\
\hline D & Concrete to Shotbrusted Concrete & $0.6-0.8$ \\
\hline E & Concrete to Concrete with small shear keys & 1.0 \\
\hline F & Concrete to Concrete with Casteleration & $1.25-1.67$ \\
\hline
\end{tabular}




\begin{tabular}{|c|c|c|} 
Cast-In-Place $\quad 200$ & \\
\hline
\end{tabular}

(a) Type B Concrete to Unroughened Concrete

$\mid$\begin{tabular}{|c|} 
Cast-In-Place \\
\hline Precast
\end{tabular}

(b) Type C Concrete to Roughened Concrete with brush

\begin{tabular}{|c|} 
Cast-In-Place \\
\hline Precast
\end{tabular}

(c) Type D Concrete to Shotbrusted Concrete

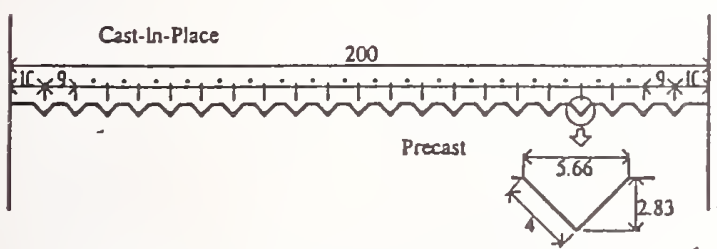

(d) Type E Concrete to Concrete with Small Shear Keys

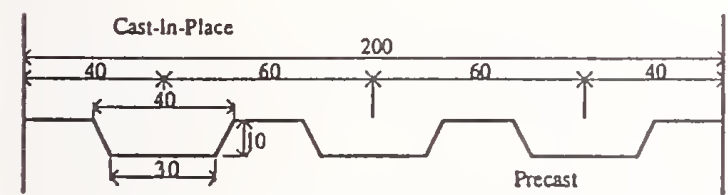

(e) Type F Concrete to Concrete with Casteleration

unit : mm

Figure 1: Configuration of Interfaces of Specimens
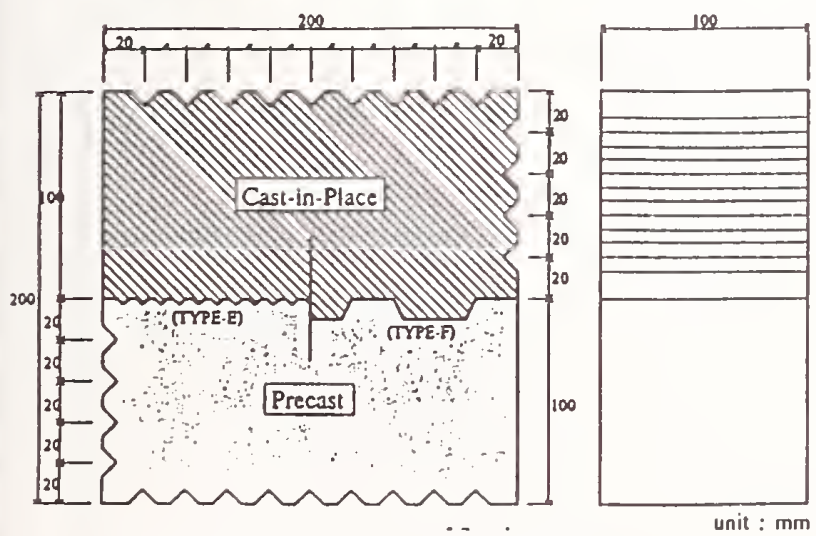

Figure 2: Geometry of Specimens

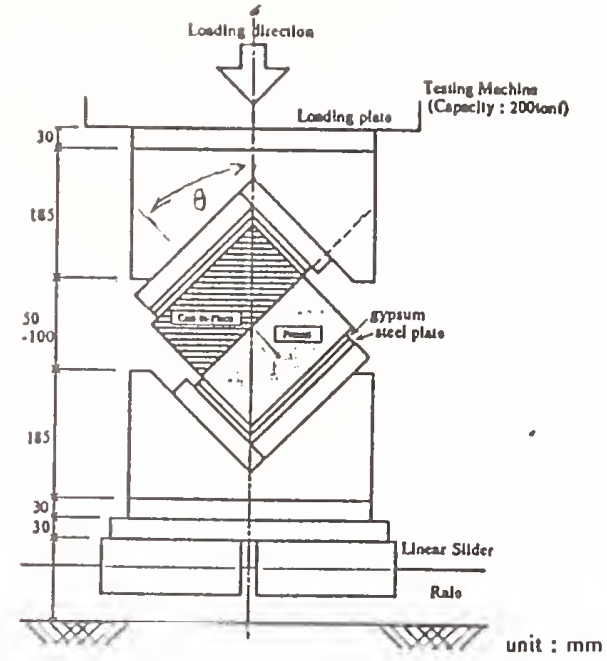

Figure 3: Loading Method
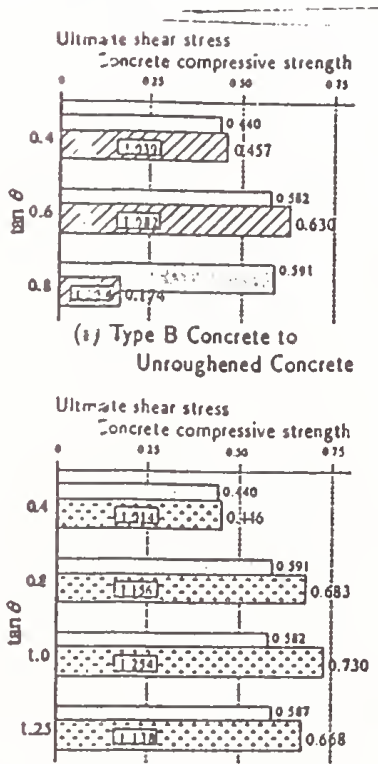

(b) Type C Concrete to

Roughened Concrele with brush

Ul:rite sheat stress

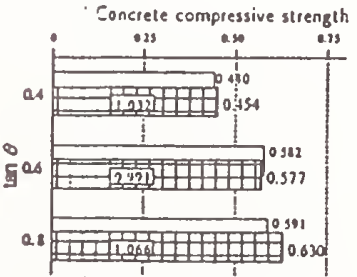

(c) Type D Conciete to Shorbrusted Concrete

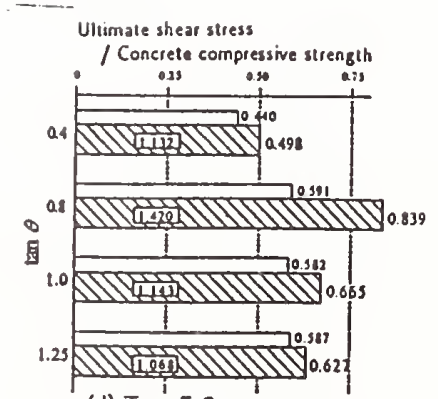

(d) Type E Concrete to

Concrete with Small Shear Keys

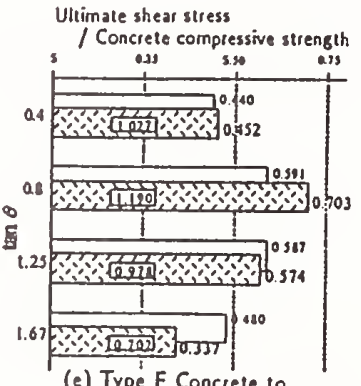

(e) Typé F Conciete to

Concrete with Casteleration

$\square$ Trpe'A Mandiuk

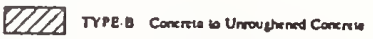

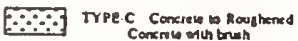

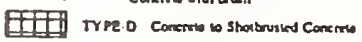

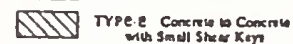

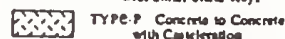

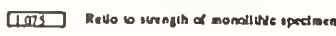

Figure 4: Comparison of Ultimate Slear Stress 


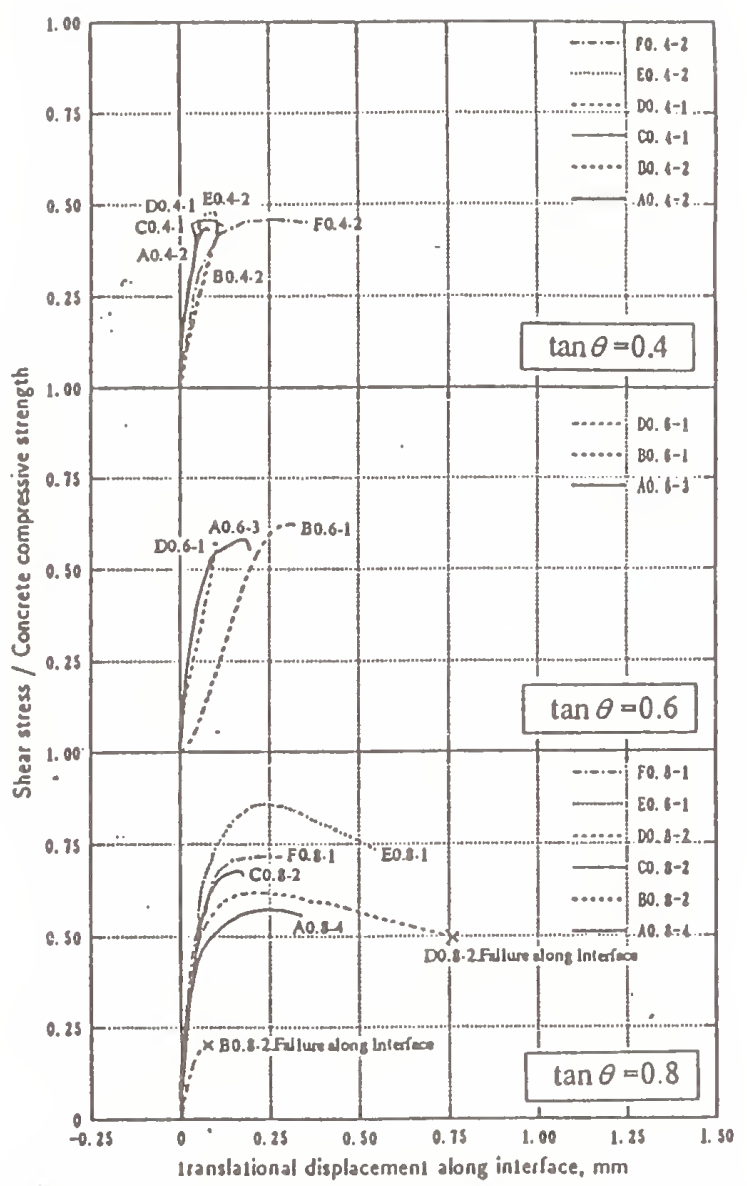

Figure 5: Translational Displacement along Concrete Interface vs. Shear Stress Relation (Cont'd)

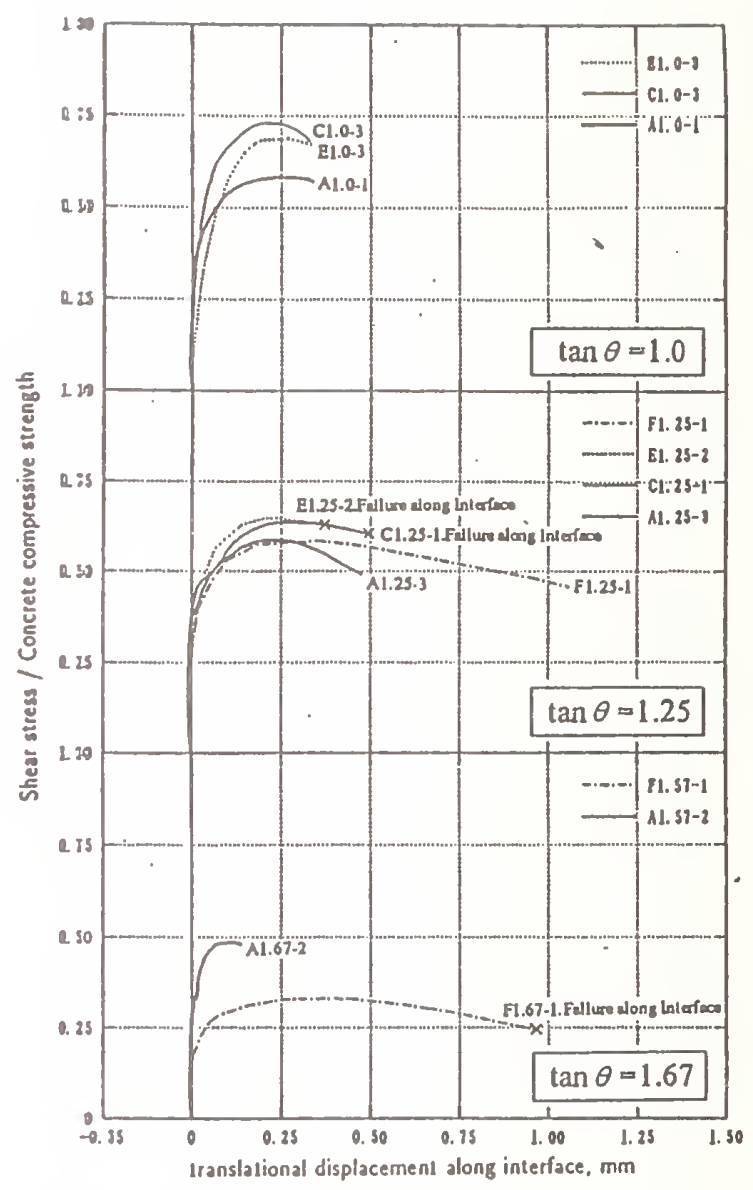

Figure 6: Translational Displacement along Concrete Interface vs. Shear Stress Relation (Cont'd)

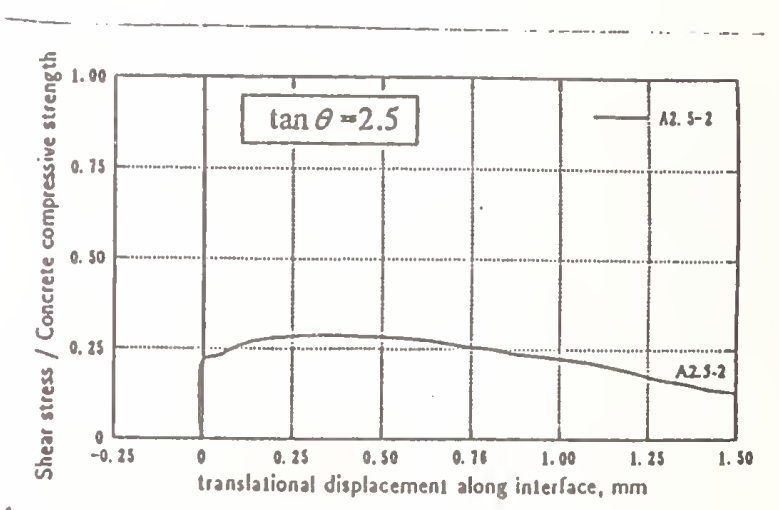

Figure 7: Translational Displacement along Concrete Interface vs. Shear Stress Relation 


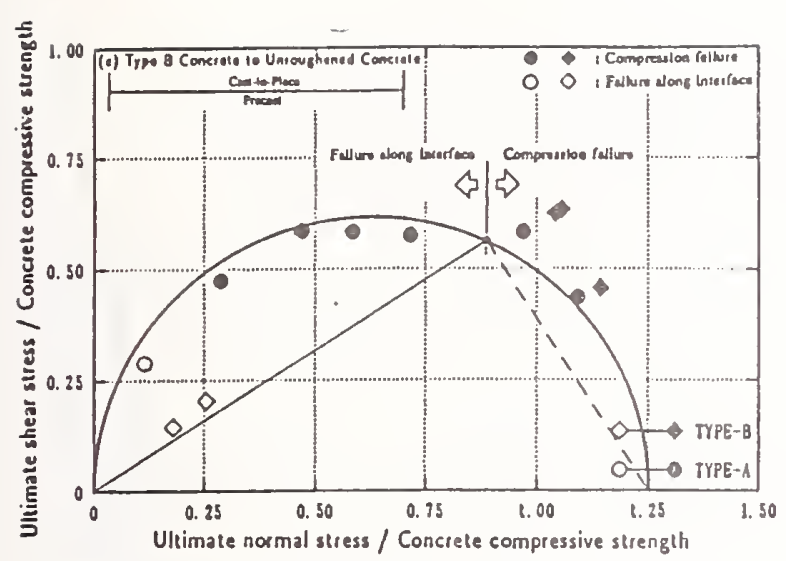

Figure 8: Failure Criterion of Type B Concrete to Concrete unroughened

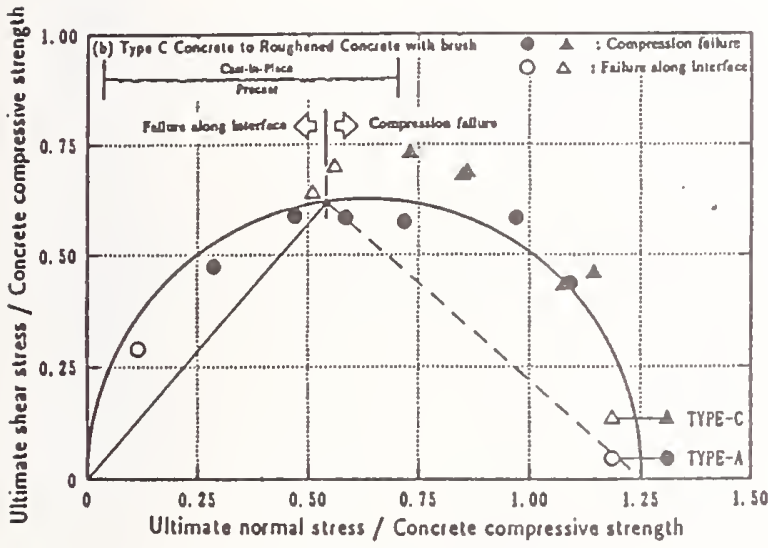

Figure 9: Failure Criterion of Type C Concrete to Roughened Concrete with Brush

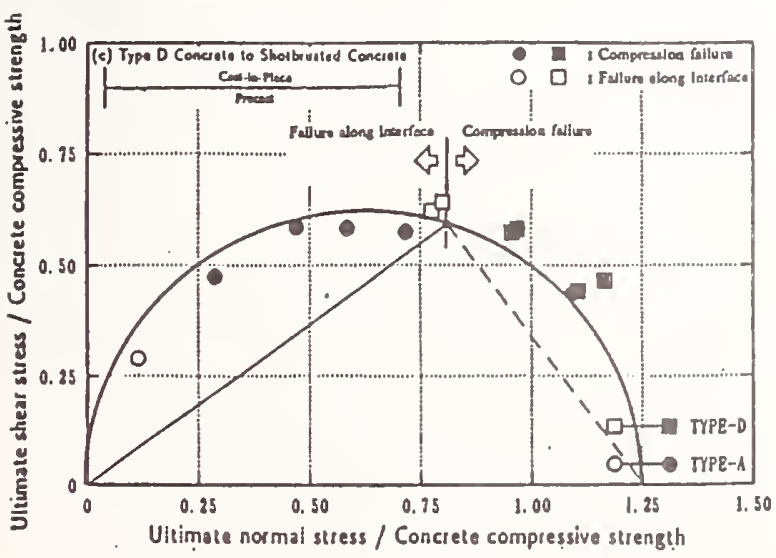

Figure 10: Failure Criterion of Type D Concrete to Shotbrusted Concrete

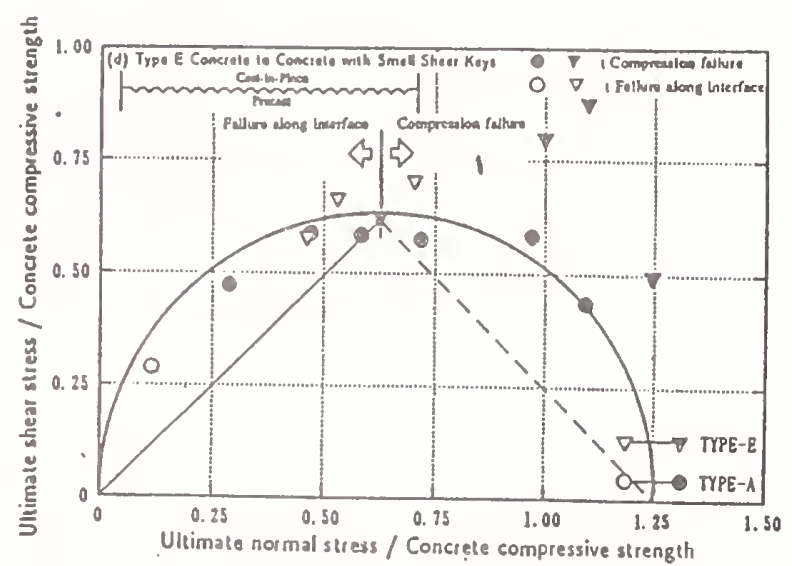

Figure 11: Failure Criterion of Type E Concrete to Concrete with small Shear Keys

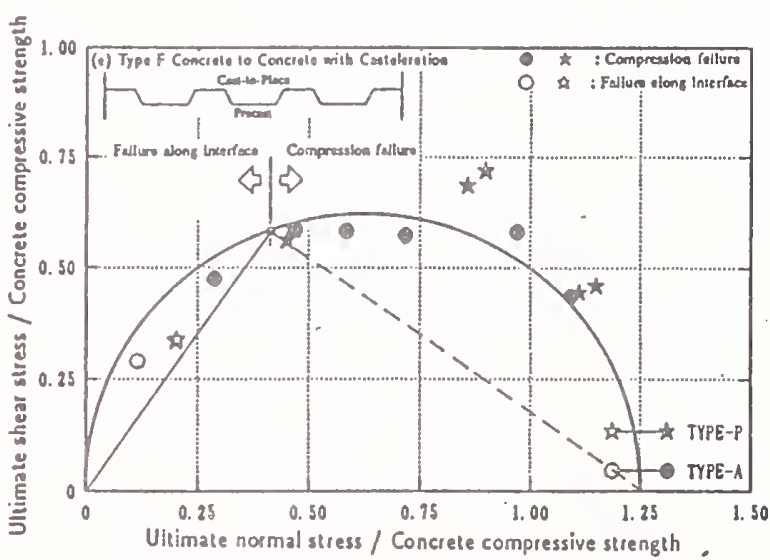

Figure 12: Failure Criterion of Type F Concrete to Concrete with Casteleration 
Japan-U.S. Cooperative Research Program PRESSS, Part 3

Experimental Study on Shear Walls of High-Rise

Precast Reinforced-Concrete Frame Buildings.

by

Shinsuke Nakata, Takashi Kaminosono, Hitoshi Shiohara, and Mizuo Inukai

\section{ABSTRACT}

We make an experimental study on two lower three-storied shear walls of fifteen-storied precast reinforced concrete frame building. We have not yet made criteria about high-rise precast reinforced concrete frame building. This experimental study will be a fundamental data which may be useful for making the criteria. In this experiment, we put an attention on the vertical joints of the shear walls, in order to discuss why and how the vertical joints are destroyed and what effects on the shear walls this destroying happens. So we get the results of destroying and not destroying of vertical joints on first floor.

At the results, it is clear that at the shear wall which vertical joints are destroyed its strength easily decrease and at the shear wall which vertical joints are not destroyed its strength keep itself until joint translation angle is 1/100. When the horizontal load marks the maximum load, the displacement of both shear walls concentrates on the first floor, and after that, the rotation angle and story drift angle decreases on over second floor.

Therefore we recognize that it is useless for seismic system to design the vertical joints which is destroyed under earthquake.

\section{KEY WORDS}

1) precast. 2) frame. 3)shear wall. 4)cotter-bar in vertical joint. 
Japan-U.S. Cooperative Research Program PRESSS, Part 3

Experimental Study on Shear Walls

of High-Rise Precast Reinforced-Concrete Frame Buildings.

by

ShInsuke Nakata"1, Takashi Kaninosono ${ }^{2}$, Hitoshi Shiohara ${ }^{3}$, and Mizuo Inukal 4

\section{ABSTRACT}

We made an experimental study on two lower three-storled shear walls of fifteenstorled precast reinforced concrete frame bulldings. We put an attention especlally on vertical jolnts between column and shear wall which is supposed to effect on strengths of bulldings.

\section{DESIGN Of TEST SPECIMENS}

The specimens are two shear walls, that is three-storled, one-third scale, 3 meters span, 1.17 meters helght on each floor. The specimens are made of columns, beams, shear walls, slabs, a foundation, and a loading-beam (FIg. 1). The precast members of the specimen are columns and shear walls with beam (Fig.l, white parts), and the cast-in-place members of it are slabs, a part of beams, vertical folnts, and so on (Fig.l, gray parts). The slze of members are as follows; column section: $300 \times 300 \mathrm{~mm}$, beam section: $300 \times 230 \mathrm{~mm}$, wall thlckness: 100 $\mathrm{mm}$, slab thlckness:100mm. The speclmen has vertical joints and horlzontal joints. The vertical jolnts are reinforced concrete $150 \mathrm{~mm}$ wide, 230 or $100 \mathrm{~mm}$ thick, between cast-in-place column and beam, or precast column and shear wall, respectively. They include shear-cotters(100x100mm section, $20 \mathrm{~mm}$ thick, 45 degrees) and maybe cotterbars. The horlzontal jolnts have two types; one is spllce-sleeves-and- mortartype which is $10 \mathrm{~mm}$ thick between shear wall and slab, or column and slab, and the other is cotter-bars-type between beam and slab. In order to discuss why vertical jolnts fall, we decide the parameters of test specimens as the existence of cotterbars and vertical-bars area of shear wall in the horizontal joint on first floor.

The specimen PCWALLl has no cotter-bars and all vertical-bars of shear wall in the horizontal jolnts on first floor, and the specimen PCWALL2 has cotter-bars and three vertical-bars in each side of shear wall on first floor. We show the data of test specimen in Table 1, the bar arrangement of test specimen in Fig.2, the section detall of column in Fig.3, the detall of vertical joint in Fig.4, and the material propertles in Table 2.

3. TEST SETUP and LOADING HISTORY

We show test set-up equipment in Fig.5. We put the specimen on reaction floor. four actuators upon the specimen for axial force loading, two actuators on reaction wall for horlzontal force loading. This test setup is called a cantllever loading. The specimens are subjected to cyclic load history.

During cyclic loading, the specimen PCWALLl is subject to the axial force (2l0tonf) and the top moment which keeps the inflection point 7 -meters high. The specimen PCWALL2 is subject to the axlal force (l00tonf). The inflection point of PCWALL2 is 4.2-meters high.

The cyclic load history is as follows; one positive-negative cycle at lateral force $(=20$ tonf which is below bending crack strength), one cycle at joint translation angle $(R=1 / 2000,1 / 1600 \mathrm{rad}$.$) , two$ cycles at $\mathrm{R}=1 / 800,1 / 400,1 / 200,1 / 100$ (rad.), and then, for specimen PCWALLl, two cycles at $R=1 / 50$, or, for specimen PCWALL2, three cycles at $\cdot R=1 / 67$ (rad.)and the deflection for fallure.

During loading, we sample the data of bending deformation in column and shear wall, folnt sllp and opening displacement at horizontal and vertical joints, and steel straln of column-main-bar, wallvertical-bar, beam-main-bar, and cotterbar.

- 1 Head Research Associate, Bullding Research Institute (BRI). I Tatehara, Tsukuba City, IbarakI-Pref., Japan

- 2 Chief Research Assoclate, BRI.

- 3 Research Associate, BRI.

- 4 Research Associate, BRI. 


\section{RESULTS}

The crack configuration in Fig.6 and lateral load - displacement relationshlp in Flg.7 are shown. About specimen PCWALLl, bending-crack is found at $R=1 / 1600$ (rad.), bending yleld happens at about $R=1 / 250$, and specimen strength decrease largely at $R=1 / 50$ because of shear-sllp- fallure at precast shear wall on flrst floor. The bending yleld is caused by tenslle-ylelding of column-maln-bars in tensile-sidecolumn on first floor and wall- vertical bars In quarter-tenslle-side - wall from first to thlrd floor. It is unexpected that there is no fallure in vertical joints in spite of no cotter bars.

About specimen PCWALL2, bending-crack is found at $R=1 / 1600$ (rad.), bending yleld

happens at about $R=1 / 270$, and specimen strength decrease largely at $R=1 / 67$ because of vertical-jolnts-fallure on first floor. The bending yleld is caused by tenslle-ylelding of column-main-bars in tenslle-side-column on first floor. The result is that the vertical-joints-fallure is cause by the decrease of axlal force, the lnflection polnt helght, and the wallhorlzontal-bar area on first floor.

\section{1 COMPARISON OF TEST RESULTS} with CALCULATED RESULTS about STRENGTHS.

Table 3 is the comparison of test with calculated results about bending-crack, bending-yleld, and maximum strength of specimens. The equatlons for calculations are below Table 3. About bending-yleld and maximum strength, calculated results follow test results perfectly, but about bending-crack strength, calculated result is greater than test. It is because we declde the bending-crack-happening as the time when we can see a crack at precast members ignoring horizontal joints.

\section{2 OVERALL DISPLACEMENT}

Fig.8 shows the overall displacement of specimens at $R=1 / 400,1 / 200,1 / 100,1 / 50$ or $1 / 67$ (rad.), and maximum $R$ (Jolnt translation angle). We describe the displacements by ten times multiplying. In Fig.8, we can find that the overall displacements follow the bending-displacement-type from first to third floor untll smaller displacement, and the horizontal displacement concentrates on first floor at maximum $R$ whlle the story drift displacements on 2 nd and $3 r d$ floor decrease.

Fig.10 shows rotation angle - story drift angle relationshlp. It is clear that the relationship of each floor is linear untll $\mathrm{R}=1 / 50$ (rad.) In PCWALLl, or $1 / 67$ in PCWALL2, and the displacement concentration on flrst floor is caused by the rapid Increase of story drift angle on first floor and decrease of rotation angle.

\section{3 DISCUSSION about DISPLACE- MRENT CONCENTRATION}

Flg.ll shows the lateral load - opening or slip of vertical and horizontal joints relationshlp. Flg.9 shows the sampling place of these data. Both of jolnt opening displacement and sllp is tend to Increase at positive loading (column tensile). In specimen PCWALLl, the joint sllp is about 7 -millmeters at $R=1 / 50$ (rad.), and in specimen PCWALL2, it is about 14 mlllimeters at $\mathrm{R}=1 / 67$ (rad.). After that, In PCWALL1 the precast wall on first floor is mainly deformed whlle negative loading (column compressive), and In PCWALL2 the vertical jolnts fallure is caused by rupture of wall-vertical-bars, Increase of jolnt-sllp displacement at first floor wall, and compressive fallure of columns whlle positive loading (column tenslle).

\section{CONCLUSIONS}

1. The specimen PCWALLl (without cotter bar): fallure mode is shear-slip of precast shear wall and hysteresis characteristic is bending type including lager hysteresis energy within about $R=1 / 100$. There is no fallure at joints.

2. The specimen PCWALL2 (with cotter bar): fallure mode is vertical-jolnts when joint translation angle is $1 / 67$. The displacements concentrate on flrst floor.

3. The horlzontal displacement concentrates on first floor because of shear fallure or horizontal joint slip displacement of first floor wall whlle the rotation angle and story drift angle from second to thlrd floor decrease.

4. The vertical jolnt fallure on first floor is caused by the Increase of horlzontal folnt slip of shear wall. 
5. The equations for calculated results properly follow the test results even if precast concrete shear wall.

\section{REFERENCES}

1. Y.Suenaga, T.Goto, Y.Sonobe, "Gulde for Design and Prefabrication of Precast Reinforced Concrete Structures", 1986, Architectural Institute of Japan.

2. S.Mochizuki, E.Makitani, T.Shinto,"Behavlors and Design Method on Vertical Joint of Wall Panel Precast Concrete Structures", 1989, Architectural Institute of Japan.

3. K.Ogura, H.Aoyama, H.Tomosawa, "Standard for Structural Calculation of Reinforced Concrete Structures", 1988, Architectural Institute of Japan. 
Table 1 Section SIze of Specimen

\begin{tabular}{|c|c|c|c|c|}
\hline Member & \multicolumn{4}{|c|}{ Sect 1 on $S \mid z e$} \\
\hline \multirow{3}{*}{$\begin{array}{c}C \circ 1 \text { um n } \\
\left(\mathrm{PCa}^{2}\right)\end{array}$} & Section & $300 \times 300$ (min) & & \\
\hline & Main bar & $12-D 13$ & Maln bar ratlo & $1.69 \%$ \\
\hline & lloop & D6840 & Hoop ratlo & $1.07 \%$ \\
\hline \multirow{3}{*}{$\begin{array}{r}\text { B e a m } \\
\quad\left(\mathrm{PC}_{3}\right)\end{array}$} & Section & $230 \times 300$ (mm) & & \\
\hline & Main bar & $12-D 13$ & Maln bar ratlo & $2.21 \times$ \\
\hline & Stirrup & $D 6840$ & Stirrup ratio & $0.348 \times$ \\
\hline \multirow{3}{*}{$\begin{array}{r}W a \perp 1 \\
\left(P C_{a}\right)\end{array}$} & Length & $2400 \quad(\mathrm{~mm})$ & & \\
\hline & Height & $856 \quad(\mathrm{~mm})$ & Wall bar & D100100 \\
\hline & Thickness? & $100 \quad(\mathrm{~mm})$ & Wall bar ratlo & $0.71 \%$ \\
\hline \multirow{3}{*}{$\begin{array}{c}S \perp \text { a b } \\
\text { (Cast-in-place) }\end{array}$} & Length & $4000 \quad(\mathrm{~mm})$ & & \\
\hline & Fidth & $1000 \quad$ (ms) & Slab bar & $6 \phi 950$ mesh \\
\hline & Thickness! & (mm) & Slab bar ratio & $0.560 \%$ \\
\hline
\end{tabular}

Table 2 Results of Material Test unlt:kg/ $\mathrm{cm}^{2}$

a) Tensil Strength of Bar

\begin{tabular}{|c|c|c|c|}
\hline \multirow{2}{*}{ Type } & \multirow{2}{*}{ Name } & \multicolumn{2}{|c|}{ Strength } \\
\cline { 3 - 4 } & & Yeilld & Rupture \\
\hline \multirow{3}{*}{ PCa } & D 6 & 3560 & 5060 \\
\cline { 2 - 4 } & D10 & 3950 & 5810 \\
\hline \multirow{3}{*}{ Cast-in-place } & D13 & 4030 & 5950 \\
\hline & D 6 & 3690 & 5260 \\
\hline & D13 & 3650 & 5140 \\
\hline
\end{tabular}

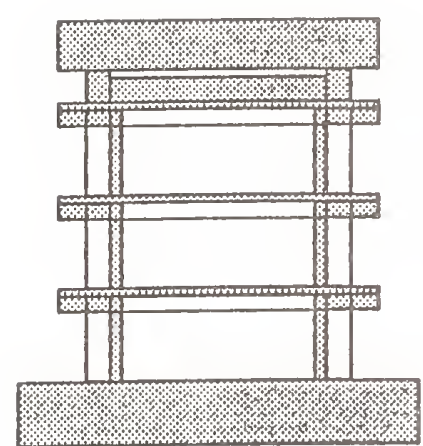

Elevation 1

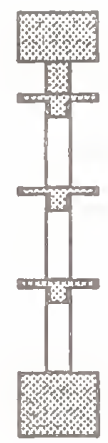

Elevation 2 notes $\square: P C a$, , cast-in-place

Fig. 1 Specimen

Fig. 3 Section Detail of Column

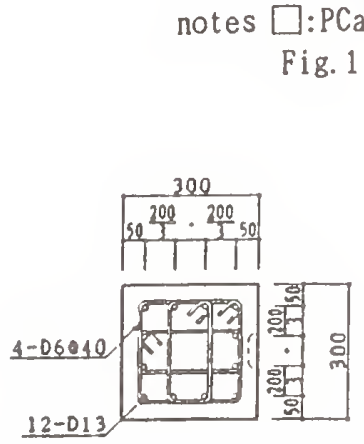

b) Compressive Strength of Concrete

\begin{tabular}{|c|c|c|c|c|}
\hline \multicolumn{2}{|c|}{ Type } & $\begin{array}{l}\text { Ist } \\
\text { Story }\end{array}$ & $\begin{array}{l}\text { 2nd } \\
\text { Story }\end{array}$ & $\begin{array}{l}\text { 3rd } \\
\text { Story }\end{array}$ \\
\hline \multirow{2}{*}{ PCa } & PCHALL1 & 505 & 515 & 507 \\
\cline { 2 - 5 } & PCHALL2 & 526 & 522 & 526 \\
\hline Cast-in-place & 555 & 505 & 617 \\
\hline \multicolumn{2}{|c|}{ Mortar } & 646 & 680 & 691 \\
\hline \multicolumn{2}{|c|}{ Grout } & 691 & 691 & 691 \\
\hline
\end{tabular}

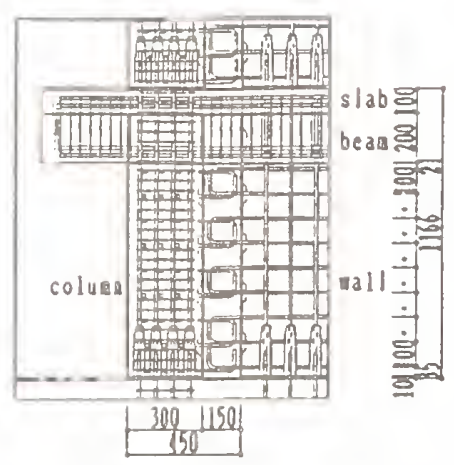

Fig. Detail of Vertical Joint

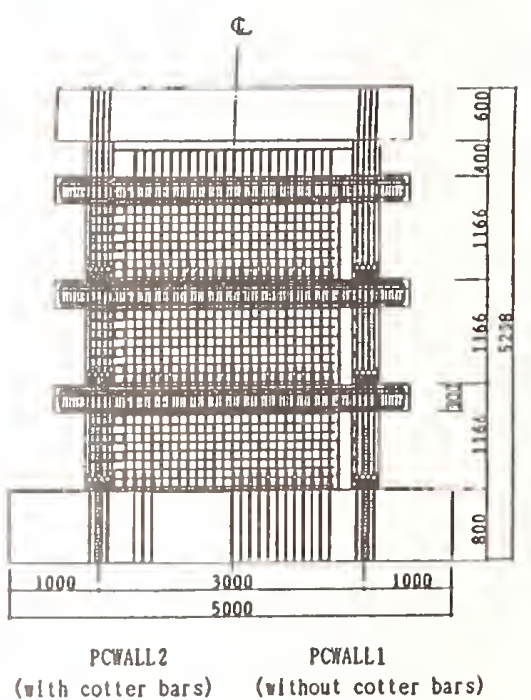

Fig. 2 Bar Arrangement 

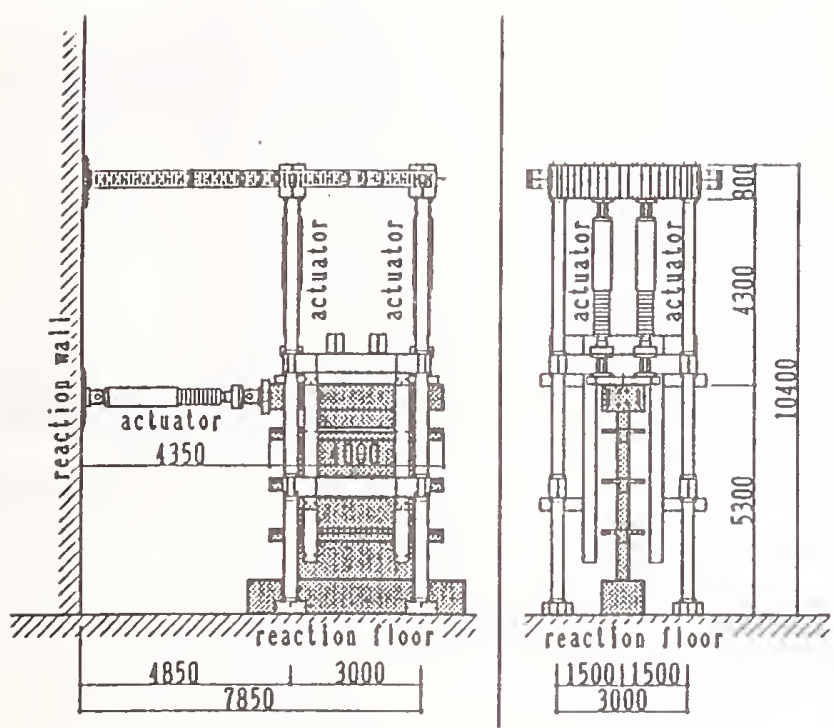

Fig. 5 Set-up Equipment

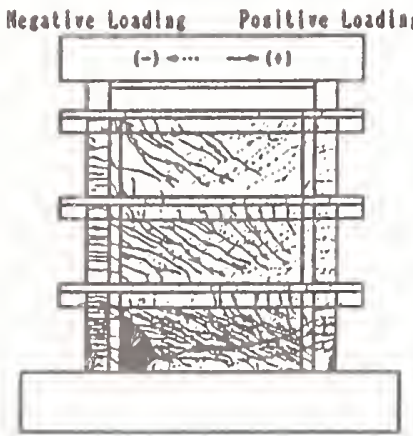

a) Specimen PCHALL1

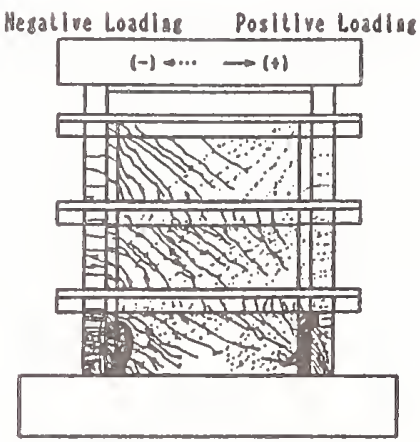

b) Specimen PCWALL2

Fig. 6 Crack Configuration

Table 3 Comparlson of the Test Results Ith Calculated Results

\begin{tabular}{|c|c|c|c|c|c|c|c|}
\hline \multirow{2}{*}{\multicolumn{2}{|c|}{$\frac{\text { Speclmen }}{\text { Strength }}$}} & \multicolumn{3}{|c|}{ PCWALL 1} & \multicolumn{3}{|c|}{ PCWALL 2} \\
\hline & & Bendling Crack & Yelld & Maxi aum & Bending Crack & Yelld & Maxlaum \\
\hline \multicolumn{2}{|c|}{ Test results (tonf) } & 40.2 & 84.8 & 100.8 & 53.5 & 93.4 & 104.3 \\
\hline \multirow{2}{*}{$\begin{array}{l}\text { Calculated } \\
\text { Results } \\
\text { (tonf) }\end{array}$} & Howent (tonf $\cdot a)$ & 212.3 & 558.9 & 617.4 & 161.5 & 358.7 & 362.6 \\
\hline & Shear (tonf) & 30.3 & 79.8 & 88,2 & 38. 0 & 84.5 & 85.4 \\
\hline \multicolumn{2}{|c|}{ Test Results/Shear } & 1. 33 & 1. 06 & 1. 14 & 1. 41 & 1. 11 & 1. 22 \\
\hline
\end{tabular}

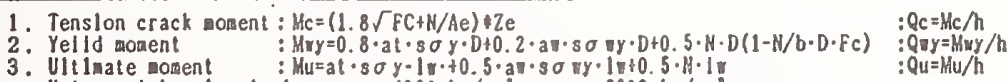

Values olth caluculation : $\$ \sigma y=4000 \mathrm{~kg} / \mathrm{cm}^{3} \cdot \$ \sigma \quad y=3900 \mathrm{~kg} / \mathrm{cm}^{2}$

PCHALL1:Fc=502 ke/ca" $\mathrm{H}=226.0$ ton : $h=700.0 \mathrm{~cm}$

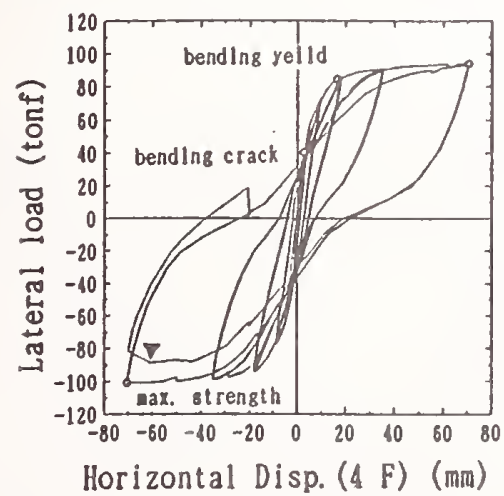

$\nabla$ :faliure of shear silp

a) Specimen PCHALL1

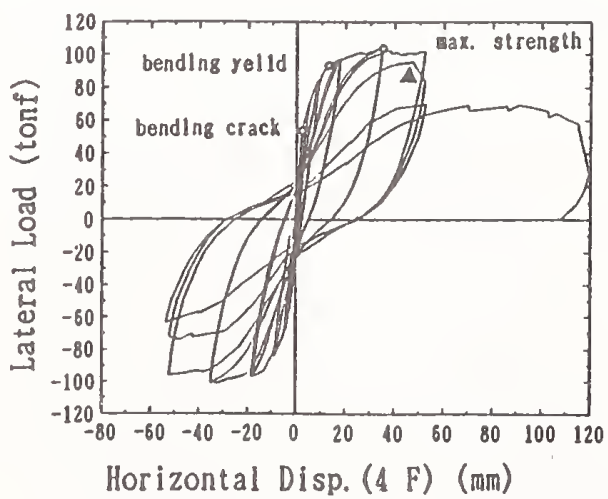

$\Delta$ : faliure of vertical jolnt

b) Specimen PCHALL2

Fig. 7 Lateral Load - Displacement Relationship 


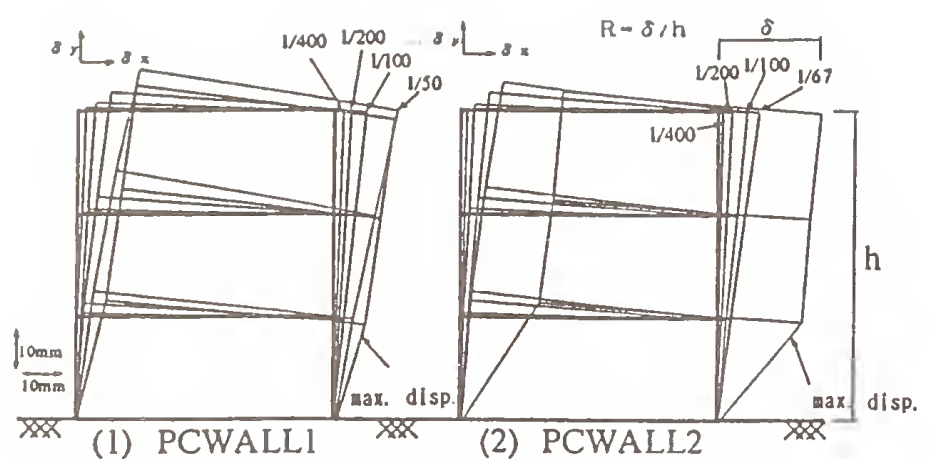

Fig. 8 Overall Displacement

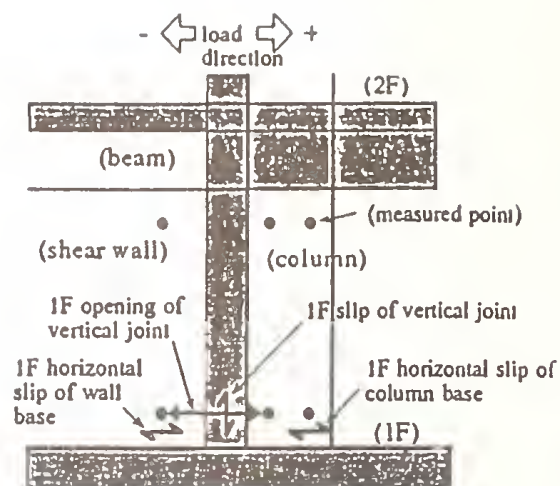

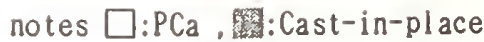

Fig. 9 Measured Points of Opening and Slip
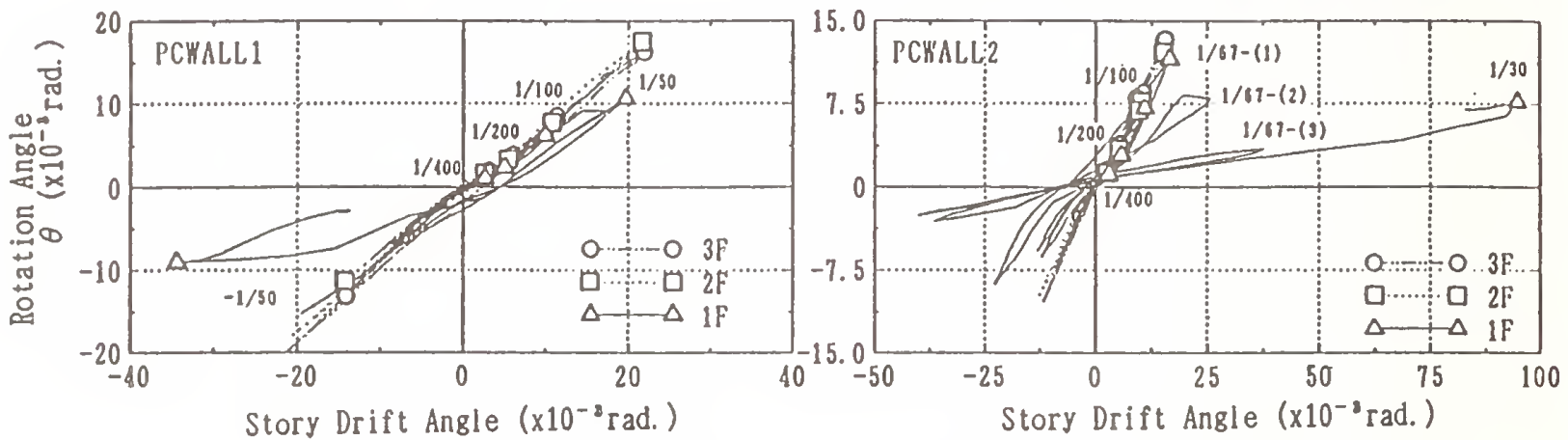

Fig. 10 Rotation Angle - Story Drift Angle Relationship
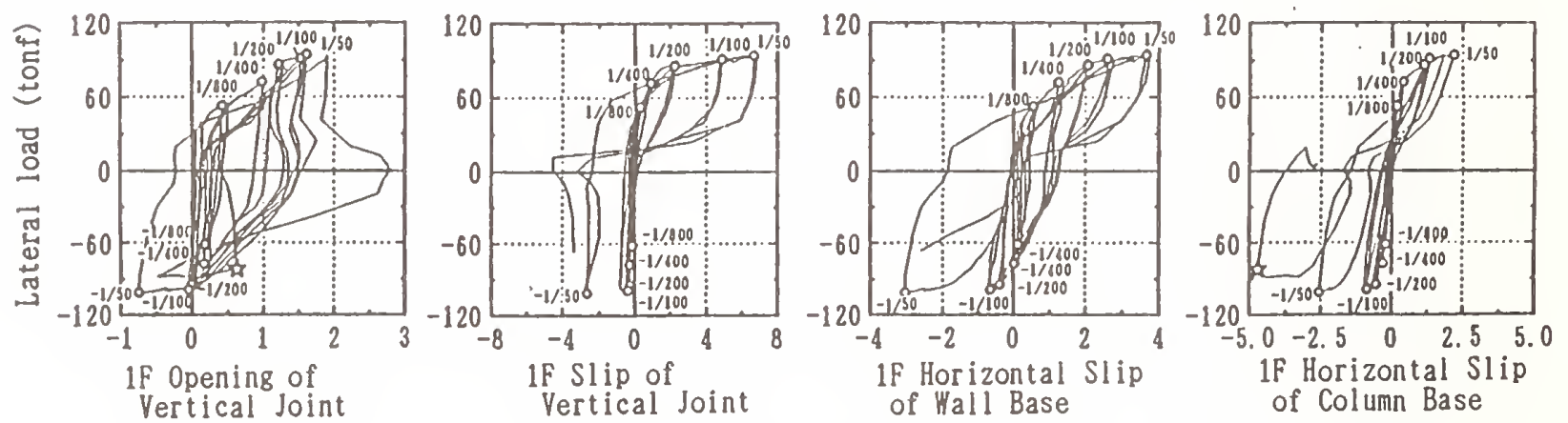

a) Specimen PCHALL1
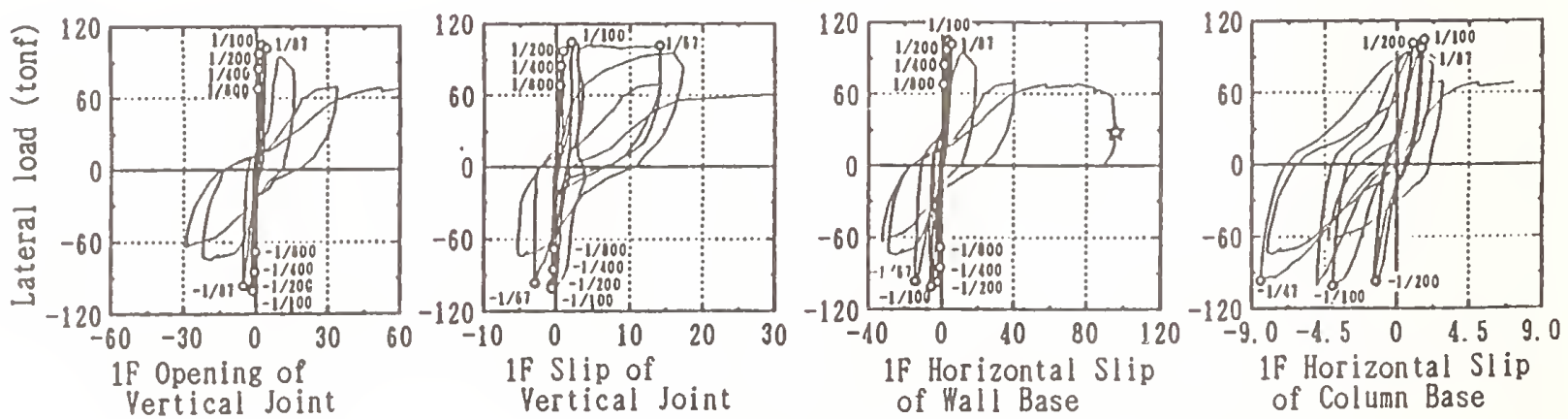

b) Specimen PCHALL2

(㧒 max. disp.)

(mm)

Fig. 11 Lateral Load - Joint Opening.Slip Relationship (1F) 


\section{Theme V}

\section{Joint Performance of Nonstructural Systems}





\section{ABSTRACT}

The October 17, 1989 Loma Prieta earthquake in Northern California produced a few new findings concerning the behavior of nonstructural components, while in most respects the earthquake confirmed past conclusions. The psychological impact of the earthquake, however, was more historic than the technical nonstructural lessons learned: Expectations have been raised, at least in California, as to the level of seismic performance, including the performance of nonstructural items. These higher expectations on the part of the public must be balanced against the increased cost of higher levels of protection. Some nonstructural features, such as elevators and various hazardous materials components, are likely candidates for improvements, while past practice will proceed unchanged for most items.

KEYWORDS: contents; equipment; nonstructural components.

\section{INTRODUCTION}

A variety of nonstructural earthquake damage, as well as good performance or lack of damage, occurred in the Loma Prieta earthquake. None of the 63 earthquake fatalities was caused by nonstructural damage, as shown in Table 1. However, this optimistic fact should be cited in conjunction with another fact: the earthquake's ground motion only peripherally affected the heart of the urbanized portion of the region, causing only a moderate level of shaking. Even many deficient or vulnerable nonstructural items escaped damage. Judgement must be used in interpreting earthquake casualty statistics: There is sometimes a tendency for the latest earthquake's figures to be quickly seized and used to prove a particular theory or to support a certain policy prescription. Some kinds of straightforward engineering solutions, such as anchoring relatively rigid pieces of equipment or cabinets, appear to need no revision. Future changes in practice will be more focused on more complicated nonstructural components that did not fare as well as most designers and clients would like, such as elevators and hazardous materials components.

\section{LOMA PRIETA NONSTRUCTURAL DAMAGE}

A summary of nonstructural damage in this earthquake is provided in Ding and Arnold et al. (1990) and discussed by Soong (1990) and by many of the authors of papers in the Applied Technology Council ATC-29 proceedings (Bruce, 1991 in progress). One convenient means of pulling together the variety of effects is to group them by building occupancy. Using this approach, some of the more interesting and significant kinds of damage are seen to have occurred in medical, manufacturing, and laboratory settings, rather than residential, school, or office buildings. Ubiquitous types of nonstructural items such as suspended ceilings or light fixtures suffered damage where not designed in accordance with then current (1985 or 1988 edition) Uniform Building Code provisions, and in the case of some ceilings there was perhaps damage even where those provisions were met. However, damage to the more specialized kinds of nonstructural features in medical, manufacturing, and laboratory buildings was more notable.

The prime case of medical facility damage was the Watsonville Community Hospital.

\footnotetext{
* The Reitherman Company, Half Moon Bay, CA 94019
} 
Though no strong motion instrumentation was at the site, it probably experienced shaking of about the intensity measured at the Corralitos station $(0.47$ g PGA vertical, 0.64 g horizontal) or the Watsonville Pacific Bell building (0.66 PGA vertical, $0.39 \mathrm{~g}$ horizontal). These peaks are at least double the typical values for the more urbanized portion of the region around San Francisco Bay. Damage to nonstructural items at the Hospital comprised a long list, as reported by Angell (1990): fallen and spilled pharmaceuticals and chemicals, (including a dangerous hazardous material incident); malfunctioning radiology processor (no Xray service); spilled files and leaning, overturned, or jammed file shelving (only ad hoc patient tracking, billing, reference to medical histories, etc.); lab equipment thrown to floor (no "high tech" support services available); broken water pipe (3 inches of water in the key Central Supply area within 10 minutes); broken gas line (one of the danger signs that almost led to complete evacuation); large exterior oxygen tank tipped 20 degrees (adjacent to 30,000 gallon propane tank, causing another situation that almost triggered complete evacuation); toppled refrigerators (no food service); main doors jammed (usual access had to be bypassed); damaged elevators (manual transportation of patients from the area of the building that was evacuated--the Critical Care Unit on the top or fourth floor); one of two diesel motor-generators displaced off its mounts, disabling itself and causing a fuel outage to the other unit (concurrently with a 26-hour utility company service outage); paramedic base station radio damaged and not repaired until two days later (while telephone service was sporadic after an initial complete outage). Some of the above, such as the generator damage, should have been prevented by the use of currently required California Hospital Act building code requirements. Other examples, however, such as spilled chemicals and perhaps elevator damage, seem to be problems that current standards do not completely solve.

The case of this hospital--one of the smaller of the 112 acute care hospitals in the region but the most severely shaken (California Association of Hospitals and Health
Systems, 1990)--illustrates the range of effects possible, and also indicates the distinction between damage that can cause injuries vis-a-vis damage that can interrupt an essential service. The near collapse of the oxygen tank represents both types of risk, the damage to the generators was only a functional loss problem, while the extensive amount of glass (window and contents) damage in the building was primarily a safety threat.

At one large high-technology research and manufacturing facility with numerous labs, a similar long list of nonstructural damage pertains, though at a lesser scale. This complex of buildings was near to sites where the recorded ground motion reached a peak of 0.3 to $0.4 \mathrm{~g}$ acceleration. Damage included: toppled compressed gas cylinders, spills of hazardous materials in labs, broken glassware, overturned file cabinets; asbestos ceiling material was released, small computers fell, equipment on wheels rolled and hindered exiting, some light fixtures fell, and several chilled water lines broke and caused water damage.

A commonality between the public hospital and the private research and manufacturing facility is that loss of function proved to be-in retrospect, from the point of view of tenants or owners--intolerable. In both the hospital and lab facilities, extensive remedial measures have been implemented after the earthquake, totalling between one and two million dollars for nonstructural work in the case of the company and $\$ 42$ million in the case of the hospital to demolish the existing facility and construct a new one The drastic solution in the case of the hospital was necessitated by structural and soils failure problems with the building, but the result will be a new facility with greatly enhanced nonstructural protection since it will be built under 1990s California Hospital Act criteria which exceed ordinary UBC requirements.

\section{CURRENT EFFORTS}

Some of the current efforts to deal with the observed performance of nonstructural components in the Loma Prieta earthquake are educational in nature, rather than only a 
matter of engineering. Many, perhaps most building owners and users assumed the building code was providing them with extensive nonstructural protection, while in fact the aims of the Uniform Building Code's seismic regulations, as stated by the Structural Engineers Association of California (1990), are rather modest. Protection against functional losses, such as flooding from an occasional broken pipe that causes a building to be shut down for repairs, isn't promised. There are even many nonstructural items that may cause serious injury--tall file cabinets or chemicals on shelves for example--that are not within the scope of the building code, and are outside the process by which drawings are produced to guide the construction of a building under the regulations of a building department. The efforts to better educate clients so that they can either knowingly accept the risk of codeminimum design or select a higher (and costlier) level, are not coordinated but are rather the efforts of individual consultants or building code personnel. A standardized and quotable explanation, with specific mention of nonstructural components that are included within the scope of the building code and their intended performance levels, would be a useful addition to chapter one of the UBC. More sophisticated clients, such as some facilities managers of larger companies or agencies, knowledgeably discuss the subject with their designers, but this is still unusual. Short of a definitive public opinion survey there is no way of determining what the general public or typical building owner/occupant expectation of nonstructural seismic performance is, but among earthquake engineers it is commonly stated that the public expects to receive more than the code intends to deliver. The following three facts add up to a communication problem:

1. The public commonly uses the term "earthquake proof;"

2. Earthquake engineers know that codeminimum designs will experience extensive nonstructural (and structural) damage in large earthquakes;

3. Most buildings are designed to a codeminimum level (and many fall beneath that level with respect to nonstructural components--water heaters have often been installed without seismic restraint in recent construction in California, for example).

The solution, if there were to be excellent communication between earthquake engineers and the public over this issue, would not be simply to universally raise minimum requirements to ensure very high levels of performance. Once the public found out the cost of that extra protection, they would not be willing to pay for the extra benefit. The solution, if communication were better, would probably be a matter of selective voluntary use of higher standards for projects where the client needs and can afford higher protection (e.g., the labs of the corporation in the above example), and a slight improvement in the mandatory minimum requirements for all buildings based on better technical seismic protection techniques.

The State of California is now pursuing improvements in nonstructural performance with respect to schools and hospitals, the two types of buildings for which the State preempts local jurisdictions in the enforcement of building regulations.

The Office of the State Architect, which controls the building permit process for schools in California, has been continually updating its nonstructural regulations since the 1950s for new construction and is now also looking into the issue of the retrofit of schools up to a current level of seismic protection. The California Seismic Safety Commission is currently investigating the cost and implications of a statewide survey of nonstructural hazards in schools. The Berkeley Unified School District commissioned a nonstructural seismic survey of its schools after the Loma Prieta earthquake (Reitherman and Kustu, 1990), including prioritized hazard rankings, cost estimates, and other necessary guidance to decide how to proceed. The same District accomplished a structural seismic safety study of its schools by SOH \& Associates along with a disaster planning effort by Emergency Management Group.

If the structural, nonstructural, and emergency preparedness needs found in Berkeley are projected statewide, including 
desirable improvements as well as bare minimum estimated needs, the potential cost would be enormous. With regard to nonstructural retrofitting, the only feasible approach is to narrow down the scope of evaluations to potential damage that is truly unacceptable, beginning (and perhaps ending, for most schools) with items that would cause serious injury. In the Berkeley Unified School District nonstructural study, approximately half the estimated nonstructural life safety retrofit cost was attributable to items in the highest of three hazard categories, which is a common finding: Half the cost can be eliminated if only the most serious life safety threats are tackled. In many buildings, narrowing down the scope results in a nonstructural life safety retrofit cost of fifty cents or a dollar per square foot, instead of a figure several times higher if more conservative life safety criteria are used. Extending the objectives to include protection of property value and essential functions has an even greater associated cost increase factor than extra conservatism in the life safety evaluation process.

With regard to hospitals, the Office of Statewide Health Planning and Development has commissioned a study of elevator performance at medical facilities in the Loma Prieta earthquake. Like suspended ceiling systems, elevators are a nonstructural system that, even if constructed up to current California requirements, don't seem to yet provide acceptable performance. In both cases, the systems have many elements, thus complicating earthquake solutions, and the construction industry developed the basic product designs prior to the evolution of seismic regulations. Some of the more reliable or easiel engineering solutions interfere with the usual way these systems are installed or built, or increase cost significantly. Solutions must involve improvements in the products manufactured by the construction industry, not just individually engineered retrofit or new installation designs.

Staehlin (1990) reported that fifty elevators in hospitals required repairs as a result of the Loma Prieta earthquake, and Schiff (1990) catalogued several areas of concern with regard to elevator safety and post-earthquake functionality. Many tenants or owners in buildings other than hospitals also concluded after the earthquake that the performance of their elevators was unsatisfactory, and it is likely that improved elevator design requirements will be one result of the earthquake for both market and regulatory reasons.

The Association of Bay Area Governments (1990) has completed a National Science Foundation sponsored study of hazardous materials incidents caused by the earthquake, (there were over 150) and this is another area where some specific changes are likely to be soon implemented. The topic of hazardous materials and earthquakes includes a wide variety of nonstructural items--compressed gas cylinders, fume hoods and ventilation systems, piping, lab chemical bottles, etc. Some of these items, such as compressed gas cylinders, are most likely to be regulated by a building operation safety code, such as the Uniform Fire Code in the case of California jurisdictions. There has been interest on the part of the fire service and fire protection engineering community responsible for developing the UFC in incorporating earthquake engineering rules, and so it is a matter of developing workable (predominantly prescriptive rather than analytical) provisions. Hazardous material piping issues have been studied by Kircher and Loshkari (1990), and the applicable avenue for incorporation of improved performance may lie in the revision of piping standards such as those of the American Society of Mechanical Engineering. Unlike some of the other nonstructural problem areas like ceilings or light fixtures, the hazardous material piping problem will get worse rather than better unless future practice considerably improves: Current practice often neglects earthquakes, and combined with the fact that large amounts of such nonstructural components are being installed every year, the level of vulnerability will increase.

\section{CONCLUSIONS}

The Loma Prieta earthquake was of greater structural or geological significance than for its nonstructural lessons, but there were still 
some noteworthy effects within the scope of this paper's topic:

1. Psychological effects: Building tenants and owners, on the one hand, and earthquake engineers and building code personnel on the other, are dealing with the disparity between perceived protection and actual protection, and between the performance expected by the earthquake engineering community and by the general public.

2. Technical developments: Elevators and hazardous materials are two areas where the development of improved design solutions will probably be quickly reflected in revisions to models codes and standards. With regard to most nonstructural components, the earthquake validates current approaches and emphasizes the need for effective implementation of existing criteria.

\section{REFERENCES}

1. Ding, Day, Christopher Amold, et al. (1990). "Architecture, Building Contents, and Building Systems," in Lee Benuska, ed., Loma Prieta Earthquake Reconnaissance Report, Earthquake Engineering Research Institute.

2. Soong, T.T., 1990. "Seismic Performance of Nonstructural Elements During The Loma Prieta Earthquake," in Noel Raufaste, ed., Wind and Seismic Effects: Proceedings of the 22nd Joint Meeting of the U.S.-Japan Cooperative Program in Natural Resources Panel on Wind and Seismic Effects, National Institute of Standards and Technology.

3. Robert Bruce, ed., 1991 in progress. Seismic Design and Performance of Equipment and Nonstructural Elements in Buildings and Industrial Structures. Applied Technology Council.

4. Angell, Lisa, 1990. "Earthquake '89 Summary Report: Facilities Problems." Hospital Council of Central and Northern California course on Earthquake Hazard Reduction and Emergency Planning for Hospitals.
5. California Association of Hospitals and Health Systems, 1990. "Hospital Earthquake Preparedness: Issues for Action: A Report on the Loma Prieta Earthquake."

6. Structural Engineers Association of California, 1990. Recommended Lateral Force Requirements and Commentary.

7. Reitherman, Robert and Onder Kustu, 1990. Nonstructural Seismic Hazard Survey for the Berkeley Unified School District. The Reitherman Company, for the Berkeley Unified School District.

8. Staehlin, William, 1990. Personal communication to Anshel Schiff in Lee Benuska, ed., Loma Prieta Earthquake Reconnaissance Report. Earthquake Engineering Research Institute.

9. Schiff, Anshel, 1990. "Performance of Elevators," in Lee Benuska, ed., Loma Prieta Earthquake Reconnaissance $\underline{\text { Report }}$ Earthquake Engineering Research Institute.

10. Association of Bay Area Governments, 1990. Hazardous Materials Problems in Earthquakes: A Guide to Their Mitigation. 
Table 1. Loma Prieta Earthquake Fatalities

\begin{tabular}{|l|r|}
\hline CAUSE OF DEATH / COUNTY & NUMBER \\
\hline Collapse of Cypress "doubledecker" freeway / Alameda & 41 \\
Unreinforced masonry building damage/ San Francisco & 5 \\
Unreinforced masonry building damage/ Santa Cruz \& Monterey & 4 \\
Dwelling collapse / San Francisco & 3 \\
Fall on stairway / San Francisco & 2 \\
Fall from tower / Santa Clara \& Monterey & 2 \\
Landslide on coastal highway / Santa Cruz & 1 \\
Smoke inhalation from natural gas caused fire / San Francisco & 1 \\
Gunshot wound to civilian while directing traffic / San Francisco & 1 \\
Motor vehicle accident, collapsed span of Bay Bridge / San Francisco & 1 \\
Motor vehicle accident with horse on highway / Santa Cruz & 1 \\
Carbon monoxide inhalation from emergency generator / Alameda & 1 \\
\hline TOTAL & 63 \\
\hline
\end{tabular}

source: "Earthquake-Associated Deaths - California," Morbidity and Mortality Weekly Report. Vol. 38, No. 45, November 17, 1989, Centers for Disease Control. 


\title{
State-of-the-Art Report on Seismic Design of Building Equipment and Nonstructural Components in Japan
}

\author{
By \\ Masaya HIROSAWA ${ }^{1}$, Hatsukazu MIZUNO ${ }^{2}$, and Mitsumasa MIDORIKAWA ${ }^{3}$
}

SUMMARY

Recently in Japan, in the event of an earthquake, more investigations have been made into damage to building equipment, furniture and nonstructural components such as interior and exterior finishing and nonstructural walls rather than structural members, and there have been not a few reports on the analysis of such damage. Accompanied by this trend, seismic design guidelines for nonstructural components have been prepared under the supervision of the administrative organizations concerned and some of the guidelines have been used for actual construction.

In this paper, we will survey damage to these nonstructural components and members used for construction and introduce various related guidelines which have recently been prepared to reveal their goals and other principal contents.

KEY WORDS: Earthquake Resistance, Building Equipment, Nonstructural Component, Seismic Guideline, Confirmation, State-of-the-Art

\section{NNTRODUCTION}

Recently, earthquake hitting cities with many medium- and high-rise buildings have inflicted great damage to nonstructural components. For example, windows and water storage tanks at the roof are broken, interior and exterior finishing come off, and indoor furniture is tumbled. Also, as for reinforced concrete buildings, what is called nonstructural walls have often caused a brittle failure of structural columns, and have displaced doorway sashes to stop the inhabitants from going in and out. Like collapsing buildings, such breakage is in most cases very dangerous because it causes building inhabitants and passers by to be injured or killed as well as significantly decreasing the functions of the buildings which are expected to work in case of a disaster.

Table 1.1 shows damage to equipment machines and so on in the recent severe earthquakes in Japan. Also, Table 1.2 shows the history of various seismic guidelines related to equipment machines and so on. As seen in these tables, in the 1978 Miyagiken-oki Earthquake which inflicted great damage mainly to Sendai, the most populous city in the Tohoku region, major damage was done to large computers, many water storage tanks at the roof, and a lot of other interior and exterior finishing and equipment machines. Based on this experience, the Ministry of Construction and other organizations concerned started to prepare seismic regulations concerning main nonstructural components for construction and equipment machines, while as seen in Table 1.3, some related industries tried to meet the challenge by having a private organization (for example, the Reinforced Plastic Association) prepare related technical guidelines. That was the time when work was under way to sweepingly revise the existing seismic regulations conceming buildings based on the results of the five-year national research \& development program. Therefore, preparation of new regulations on equipment machines followed the example of this revisional work.

In 1980, laws and orders concerning the seismic design methods for building structures saw a sweeping revision for the first time in thirty years. In the revised version, the goal of seismic safety was to allow buildings to survive without collapse such a severe earthquake motion that they might possibly encounter only once in their lives. For that purpose, it was stipulated that ultimate strength should be designed by using 1.0 as an elastic response shear force coefficient.

The revised laws and orders (Enforcement Order of the Building Standard Law) stipulated that in light of the damage to nonstructural components in 1978, chimneys and water tanks extruding from the roof (Article 39-2) and water-supply and drainage and other piping facilities (Article 129-2) should be safe in the event of earthquakes. After this performance provisions were set, the Building Center of Japan published in 1982 under the supervision of the Ministry of Construction "Guideline for Seismic Design and Construction of Building Equipment" 3 ), provisions covering concrete seismic design methods for the overall building equipment. Although these provisions cover earthquake forces and displacements to be considered, structural design methods, and recommended details, which are noted in Section 2.2, the targeted seismic safety is a little smaller than that for structures. Moreover, the 1983 revision of "Technical Guideline and Commentary for Water Supply and Drainage Equipment" 1') involved the addition of seismic countermeasures, which followed the above guidelines. The Ministry of Construction notified each building officials that these guidelines should be used for reference in designing.

On the other hand, immediately after the 1978 Miyagiken-oki Earthquake, the Architectural Institute of Japan established a committee, which then began

1) Dr. Engrg., Deputy Director General, Building Research Institute, Ministry of Construction.

2) Ms. Engrg., Head of Large Scale Structure Testing Div., Production Dept., BRI, MOC.

3) Dr. Engrg., Head of Earthquake Engineering. Div. II, IISEE, BRI, MOC. 
investigating the seismic safety of nonstructural components for construction such as various interior and exterior finishing. In 1985, the results of the investigation were published as "Guideline and Commentary for Scismic Design and Guideline for Seismic Design and Construction" 4). As previously stated, these guidelines were mainly intended for nonstructural components such as interior and exterior finishing but are not often used for actual designs now partly because the 1975 version of laws and orders do not contain any provisions for nonstructural components.

For government buildings which are often used as disaster prevention bases in the event of a disaster, the Government Building Division, the Ministry of Construction had had its own regulations based on the buildings important factors, but in 1987, it prepared a seismic design guideline chiefly intended for interior and exterior finishing 5). This technical guideline, whose details are noted in Section 2.3, is now used to design many government buildings.

On top of the above examples, another building element which is likely to suffer from earthquakes is reinforced concrete nonstructural walls in reinforced concrete buildings. Despite repeated experiments since the 1968 Tokachi-oki Earthquake where many related disasters were observed, there has been no coordinated technical guideline available yet. Also, there is something to be modified in the particular sections of the Japanese Industrial Standard which provide for design seismic forces and other matters for various vending machines, which are often installed in the middle floors of the building these days. In addition, dedicated investigations have been made into the access flooring system which is used to install computers.

Seismic guidelines on these nonstructural walls, vending machines, and free access flooring systems are covered in Section 2.5.

In addition to the several nonstructural structures stated above, chimneys and reinforced concrete block fences are examples of building belongings which have often sustained damage from earthquakes and are provided with well-coordinated technical guidelines, and equipment piping for nuclear power plant facilities is a nonstructural element which is scrupulously designed to resist great seismic forces. On the contrary, nonstructural components for buildings with a base isolation system or with an active seismic response control system are a typical example for which no seismic technical guidelines have ever been considered. This report does not refer to these matters for want of space.

Chapter 2 of this report gives the outline of the typical guidelines which are used for actual design. Moreover, Chapter 3 describes the seismic design for several equipment machines covered by these guidelines. This chapter is divided into several sections each of which refers to design seismic forces or other major items of those guidelines.

\section{OUTLINE OF TYPICAL TECHNICAL GUIDELINES}

\subsection{Qutline}

Each of the following sections covers the guidelines listed below as typical seismic guidelines for several building nonstructural components and outlines their contents.

a) Guideline for Seismic Design and Construction of Building Equipment (Building Center of Japan, revised in 1984) 3), 3)

b) Guideline for Seismic Design of Building Nonstructural Components (Public Buildings Association, 1987) 5 )

c) Technical Guideline and Commentary for Water Supply and Drainage Equipment -1983 version (Building Center of Japan, 1983) ${ }^{1 \text { ) }}$

Similarly, Section 2.5 outlines seismic guidelines for reinforced concrete nonstructural walls, and vending machines and free access flooring systems installed inside and outside the building as examples for which several guidelines have been made but still have much to be modified.

\subsection{Guideline for Seismic Design of Building Equipment (Building Center of Japan, 1984) ${ }^{3}$ ). 3')}

\subsubsection{Background}

The Building Center of Japan, a juridical foundation supervised by the Ministry of Construction, compiled this guideline in 1982. Damage to nonstructural components and building equipment during the 1978 Miyagiken-oki Earthquake motivated intensive studies on seismic performance of them. The Enforcement Order, Revised Building Standard Law b) executed in 1981 includes specifications on seismic safety of water tanks, chimneys, etc. extruding from roofs, piping equipment and elevators.

Notification No. 1101 of the Ministry of Construction, $1981^{c}$ ) specifies lateral design seismic forces of water tanks, chimneys, etc. extruding from roofs. The lateral shear force, $P$, for water tanks, etc. extruding from roofs shall be determined from the following formula:

$$
\mathrm{P}=\mathrm{k} \cdot \mathrm{W}
$$

where,

$\mathrm{P}=$ lateral design seismic force acting on water tanks, etc.;

$\mathrm{k}=$ design seismic force coefficient of water tanks, etc. which shall be determined by multiplying a value more than 1.0 by a value of seismic zone factor $Z$;

$\mathrm{Z}=$ seismic zone factor specified in article 88 , Enforcement Order, Building Standard Law. The Minister of Construction specifies a value within a range between 1.0 and 0.7 according to the extent of earthquake damage, seismic activity and other seismic characteristics based on the record of earthquake in the region concerned; and,

$\mathrm{W}=$ sum of dead loads of water tanks, etc. and supporting parts of structure, and live loads of water tanks, etc. (unit: kgf).

The lateral design seismic force on water tanks, etc. can be reduced to a half of that mentioned above, if some countermeasures of preventing damage and harm 
to human lives due to lateral movement and toppling of water tanks, etc. during earthquakes are effectively done.

The guideline conforms to the Enforcement Order, Building Standard Law and Notification No. 1101 of the Ministry of Construction, 1981 mentioned above, and includes knowledge of some studies, new countermeasures from practical viewpoint and some design examples. The scope of the guideline is:

(1) Installation of building equipment in buildings of more than three stories and their heights not taller than 60 meters. Seismic performance of equipment itself is supposed to be confirmed by equipment manufacturers; and

(2) Installation of equipment lighter than $100 \mathrm{kgf}$ is excluded, if equipment is installed on carefully treated surface of structure in a way specified by equipment manufacturers.

The guideline adopted two types of design seismic force on equipment; One is the force specified in the local seismic coefficient method, another the force specified in the modified seismic coefficient method. Both includes acceleration amplification effects with stories of building, and the latter explicitly considers acceleration amplification effects of equipment.

\subsubsection{Seismic Force I}

Lateral design seismic forces to equipment installation are the followings and act on the center of the gravity in principle:

$$
\begin{aligned}
& F_{H}=K_{H} \bullet W \\
& K_{H}=Z \bullet K_{S}
\end{aligned}
$$

where,

$F_{H}=$ lateral design seismic force;

$\mathrm{K}_{\mathrm{S}}=$ standard design seismic force coefficient

(Table 2.1); and

$$
Z=\text { seismic zone factor. }
$$

If vertical seismic forces are considered, the vertical design seismic force is given as follows:

$$
\begin{aligned}
& F_{V}=K_{V} \bullet W \\
& K_{V}=K_{H} / 2
\end{aligned}
$$

where,

$F_{V}=$ vertical design seismic force; and

$\mathrm{KV}=$ vertical design seismic force coefficient.

If a tank with free water surface is considered, W of the above expression is substituted for $\mathrm{W}_{0}$.

$$
\mathrm{w}_{0}=\alpha_{\mathrm{T}} \cdot \mathrm{W}
$$

$\alpha_{\mathrm{T}}$ is prepared in figures for cylinder and ball tanks, and in formula for rectangular, cylinder and ball tanks. Namely the lateral design seismic force to a water tank is given as follows:

$$
\mathrm{F}_{\mathrm{H}}=\mathrm{K}_{\mathrm{H}} \bullet \mathrm{W}_{0}=\mathrm{Z} \bullet \mathrm{K}_{\mathrm{S}} \bullet \alpha_{\mathrm{T}} \bullet \mathrm{W}
$$

The force acts at the following height, $h_{0 g}$, from the bottom:

where,

$$
h_{0 g}=\beta T \cdot h
$$

$\mathrm{h}=$ equivalent height of a water tank (unit: $\mathrm{cm}$ ); (1) full height for steel tanks and the like; and (2) height of the center of overflow pipe for a fiber-reinforced plastics tank. In a case of hopper-type overflow, the height shall be the sum of height of water surface and radius of overflow pipe; and
$\beta_{\mathrm{T}}=$ ratio of force-acting height $\mathrm{h}_{0 \mathrm{~g}}$ and equivalent height h. Figures and formula are prepared.

Liquid tanks with free surface shall be designed in a similar way as water tanks.

\subsubsection{Seismic Force II}

Lateral seismic forces to equipment installation

are:

where,

$$
\begin{aligned}
& \mathrm{F}_{\mathrm{H}}=\mathrm{K}_{\mathrm{H}} \bullet \mathrm{W} \\
& \mathrm{K}_{\mathrm{H}}=\mathrm{Z} \bullet \mathrm{I} \cdot \mathrm{K}_{1} \bullet \mathrm{K}_{2} \bullet \mathrm{k}_{0}
\end{aligned}
$$

$\mathrm{K}_{\mathrm{H}}$ = lateral design seismic force coefficient;

$\mathrm{W}=$ weight of a nonstructural component or equipment (unit: kgf);

$\mathrm{Z}=$ seismic zone factor $(0.7 \sim 1.0)$;

$I=$ importance reduction factor $(1.0,2 / 3)$;

$\mathrm{K}_{1}=$ floor response amplification factor of a building (1 10/3);

$\mathrm{K}_{2}=$ response amplification factor of a nonstructural component or equipment $(1.0 \sim 1.5 \sim 2.0)$; and

$\mathrm{k}_{0}=$ standard design seismic force coefficient

If vertical seismic forces are considered, the vertical design seismic force coefficient $\mathrm{K}_{\mathrm{V}}$ is given as:

(1) supported on a vibration-reduction apparatus;

$\mathrm{K}_{\mathrm{V}}=\mathrm{K}_{\mathrm{H}} / 2$

(2) fixed with base, floor, etc. by anchor bolts, etc.;

$\mathrm{K}_{\mathrm{V}}=\mathrm{K}_{\mathrm{H}} /\left(2 \mathrm{~K}_{2}\right)$

Importance reduction factor I is given as shown in Table 2.2:

(1) important equipment $I=1.0$; and

(2) general equipment $I=2 / 3$.

Building amplification factor $\mathrm{K}_{1}$ is given as shown in Fig. 2.1:

$$
\begin{aligned}
\mathrm{K}_{1} & =\mathrm{A}_{\mathrm{B}} & & ; \text { penthouse } \\
& =1+\left(\mathrm{A}_{\mathrm{B}}-1\right) \bullet h / \mathrm{H} & & ; \text { general floors } \\
& =1 & & ; \text { basement and first floor }
\end{aligned}
$$

where,

$\mathrm{H}=$ height from ground level; and

$\mathrm{h}=$ height of equipment-installed floor (unit: $\mathrm{m}$ ).

$A_{B}$ means response amplification at the roof, and is given as follows:

$$
\begin{array}{rlrl}
A_{\mathrm{B}} & =10 / 3 & & ; \mathrm{T}_{\mathrm{T}}<0.6 \\
& =10 / 3-2 / 3\left(\mathrm{~T}_{\mathrm{T}}-1\right) & ; 0.6 \leq \mathrm{T}_{\mathrm{T}}<1.2 \\
& =3.2 / \mathrm{T}_{\mathrm{T}} & & ; 1.2 \leq \mathrm{T}_{\mathrm{T}}
\end{array}
$$

Fundamental natural period $\mathrm{T}_{\mathrm{T}}(\mathrm{sec})$ is evaluated as follows:

$$
\mathrm{T}_{\mathrm{T}}=(0.02+0.01 \alpha) \cdot \mathrm{H}
$$

The coefficient $\alpha$ is the ratio of the total height of steel construction stories to the entire height of a building. If all stories over the ground level are of steel construction, $\alpha=1$. If all stories are of reinforced concrete or of steel and reinforced concrete composite construction, $\alpha=0$. follows:

Equipment amplification factor $\mathrm{K}_{2}$ is given as

(1) fundamental natural frequency $f_{m}(\mathrm{~Hz})$ is unknown, $\mathrm{K}_{2}=2$; and

(2) fundamental natural frequency $f_{m}$ is known, 
1) in a case of $f_{m} \leq 15, K_{2}$ is given for the ratio $\mathrm{fb}_{\mathrm{b}} / \mathrm{f}_{\mathrm{m}}$ in Fig. 2.2. In a case of important equipment, a value of $\mathrm{I} \cdot \mathrm{K}_{1} \bullet \mathrm{K}_{2} \bullet \mathrm{k}_{0}$ shall not be less than 0.6 , and in a case of general equipment, shall not be less than 0.4.

2 ) in a case of $f_{m}>15, K_{2}=1$.

2.3 Guideline for Seismic Design of Building Nonstructural Comoonents (Public Buildings Association, 19872 ${ }^{5 \text { ) }}$

The contents of the guideline are the following: Chapter 1. General

1.1 Purpose

1.2 Scope

1.3 Target of Safety

Chapter 2. Seismic Design

2.1 Inspection for Seismic Safety of

Nonstructural Components

2.2 Deformation Capacity against Story Drifts and Nonstructural Components

2.3 Inspection for Strength Capacity of

Nonstructural Components

2.4 Inspection for Overturning Possibility of

Nonstructural Components

Chapter 3. Design of Details

3.1 Principles of Detail Design

3.2 Exierior walls and their Finishing

3.4 Ceiling and Floor Materials

3.5 Opening Members such as Windows and Doors

3.6 Furniture and Equipment

3.7 Computers and Associated Equipment

\subsubsection{General}

The purpose of this guideline is to provide minimum standards for use in nonstructural component design and inspection for the seismic resistant capacity of nonstructural components mainly in government buildings to maintain the seismic safety of total building systems in a major earthquake.

The guideline applies to all nonstructural components in buildings not taller than 60 meters. Nonstructural components include all members except for structural members, equipment, chimneys, parapets, exterior stairs, and miscellaneous structures, such as: a) exterior walls and their finishing; b) exterior fixture; c) partition walls and interior materials including interior doors; d) ceiling and floor materials; e) furniture and equipment; and f) computers and associated equipment.

The target of safety is as follows:

(1) In inspecting the safety of the earthquake resistant capacity of a government building, the target of the seismic performance in a major earthquake is decided by taking into consideration the functions to be performed and the location conditions;

(2) Activity section rooms in a government building to be used as disaster prevention bases in a major earthquake shall possess the seismic resistant capacity to perform their functions after a disaster;

(3) The target of seismic resistant capacity of nonstructural components, as shown in Table 2.3, is the following: a) Ordinary government buildings shall be guaranteed to be safeguard against loss of life and secondary disasters; and

b) Activity section rooms in a government building to be used as disaster prevention bases in a major earthquake shall be secured their functions in addition to the condition mentioned above; and

(4) In the seismic design of nonstructural components, the target of seismic resistant capacity shall be classified into two groups, exterior and interior, in a building:

a) All exterior parts of a building shall be guaranteed not to fall down due to break; and

b) The interior parts of a building shall be designed by distinguishing the activity section rooms from the others.

\subsubsection{Seismic Design}

Nonstructural components shall be designed to possess the seismic resistant capacity against expected story drifts and seismic forces in a major earthquake.

The following inspections are required in the seismic design of nonstructural components:

a) Inspection for the deformation capacity against story drifts;

b) Inspection for the strength capacity against seismic forces; and

c) Inspection for the possibility of overturning and sliding.

All of above inspections are not always required depending on conditions such as characteristics of nonstructural components, fixing positions, and fixing types. Fig. 2.3 shows the general flow of the seismic design of nonstructural components.

In the inspection for the strength capacity of nonstructural components, the procedures are in the following:

(1) Nonstructural components and their joints, if necessary, are designed to resist the design seismic forces determined from the calculations;

(2) The design seismic forces for a nonstructural component shall be calculated considering the floor response amplification of the building concerned, the response amplification of the nonstructural component itself, the seismic zone factor, and the importance factor; (3) The design seismic forces may be assumed to act noncurrently in the following direction: a)horizontal (inplane); b)horizontal (out-of-plane); and c)vertical directions; and

(4) In the design of nonstructural component joints, the maximum working stresses shall not exceed the allowable stresses of material under temporary loads.

The design seismic forces for a nonstructural component is determined according to the "Overall Design Standard for Earthquake Resistant Capacity of Government Buildings" prepared by the Ministry of Construction, which includes seismic: a) forces based on the modified seismic force coefficient; b) forces based on the local seismic force coefficient; and c) forces determined from the rigorous analysis procedure.

According to the modified seismic force coefficient, the lateral design seismic force, $F_{H}$, shall be determined from the following formula: 


$$
\begin{aligned}
& F_{H}=K_{H} \cdot W \\
& K_{H}=\mathrm{Z} \cdot I \bullet K_{1} \bullet K_{2} \bullet k_{0}
\end{aligned}
$$

where,

$\mathrm{K}_{\mathrm{H}}$ = lateral design seismic force coefficient;

$\mathrm{W}=$ weight of a nonstructural component or equipment (unit: $\mathrm{kgf}$ );

$Z=$ seismic $z$ one factor $(0.7 \sim 1.0)$;

$I=$ importance reduction factor $(1.0,2 / 3)$;

$\mathrm{K}_{1}=$ floor response amplification factor of $\mathrm{a}$ building (1 10/3);

$\mathrm{K}_{2}=$ response amplification factor of a nonstructural component or equipment (1.0 1.5 2.0); and

(0.3).

$\mathrm{k}_{0}=$ standard design seismic force coefficient

The vertical design seismic force, $F_{V}$, shall be determined by the following formula:

$$
\mathrm{FV}=\mathrm{KV} \cdot \mathrm{W}
$$

where, $\left(=\mathrm{K}_{\mathrm{H}} / 2\right)$.

$\mathrm{KV}_{\mathrm{V}}=$ vertical design seismic force coefficient

In the formula (2.17), the value of $\mathrm{I} \bullet \mathrm{K}_{1} \bullet \mathrm{K}_{2} \bullet \mathrm{k}_{0}$ shall be not less than 0.6 and 0.3 for the important and ordinary nonstructural components, respectively.

\subsubsection{Design of Details}

In the design of nonstructural components, the details shall be examined by properly grasping their individual characteristics and their fixing conditions on the building.

The detail design of nonstructural components depends on their fixing conditions which can be classified into three groups such as surface, line, and point joints.

The seismic effects on nonstructural components depend on the fixing conditions mentioned above. The nonstructural components such as exterior tiles and mortar with surface joint are dominated by the effects of story drifts. The inspection for the strength capacity against seismic forces is required for the nonstructural components such as ceiling with point joint. The inspection for both deformation and strength capacity is required under certain circumstances for nonstructural components with line joint.

2.4 Technical Guideline and Commentary for Water Supoly and Drainage Equipment (1983 version) ${ }^{1}$ )

\subsubsection{Outline}

Based on the 1970 revision of the laws and orders, technical guidelines for building water supply and drainage equipment were published as "Technical Guideline and Commentary for Water Supply and Drainage Equipment", but this first edition had no regulations on seismic design. Later, the 1980's revised version stipulated that safety in the event of earthquakes should be considered for storage tanks, piping, and equipment, resulting in the 1982 seismic design guideline ${ }^{3}$ ) intended for the whole equipment. The guideline covers water supply and drainage equipment and piping.

This guideline is extensively used for actual design partly thanks to the administrative guidance d). Thus, when the guideline $1^{1}$ ) was revised in 1983, the related part of the above equipment guideline was added to it as a new section. Since then, the seismic regulations of the guideline have been almost the same as the technical guideline ${ }^{3)}, 3^{\prime}$ ) shown in Section 2.2 . Here, we focus on piping and outline its related guidelines, which are not covered in Section 2.2.

\subsubsection{Scope}

This guideline mainly covers equipment such as water storage and supply tanks, and water supply and drainage pipes. Also, as for seismic design, it refers to a) design seismic force, b) seismic measures at the base of equipment, and c) seismic measures for piping.

\subsubsection{Seismic Measures for Piping Principles}

Piping sometimes suffers damage due to the deformation of buildings forced by earthquakes and excessive vibrations of the piping itself. To avoid such damage, the seismic force working on the middle floor piping is considered as a horizontal force equal to $60 \%$ of the dead weight of the piping and the allowable stress design method is applied for the working stress generated at each element by this horizontal force. In addition, if the story drift angle $R_{D}$ caused by the seismic force is not to be particularly considered, use $R_{D}=1 / 200$ and appropriate expansion joints. To be specific, seismic support intervals for the piping, the cross section of the support members, and required erection anchors are determined to meet the above conditions.

\section{Piping through Expansion Joint of Buildings}

For piping though the expansion joint of buildings, the relative displacement $\delta_{D}$ of both buildings shall be defined as follows. Flexible joints to be provided (expressly illustrated) must resist the following displacement:

$$
\delta_{D}=2 R_{D} h
$$

Here, $\mathrm{h}$ is the height from the ground to where the piping runs.

\section{Connections between Equipment and Piping}

Basically, the equipment shall be fixed, and the piping shall be supported by sliding supports and the like so that it will not be subjected to excessive displacement. Then, flexible joints are used to connect them (illustrated).

\section{Horizontal Piping}

Horizontal piping is given seismic supports at an interval appropriate to impede excessive displacement in the axially perpendicular direction on the occasion of earthquakes. On the assumption that fixed-type or supporting-type seismic supports are used, a convenient table shows various kinds of piping, how to actually support them and to select the cross section of the 
supporting members and required anchors according to the intervals of the seismic supports.

\section{Vertical Piping}

Vertical piping is given seismic supports to hamper excessive displacement in the axially perpendicular direction in time of earthquakes and to flexibly resist the story drift of the building. Like the case of horizontal piping, a convenient table is given to be utilized for design.

\subsection{Seismic Guidelines for Other Nonstructural components}

\subsubsection{Guidelines for Reinforced Concrete Nonstructural Walls \\ (1) Outline \\ In the 1968 Tokachi-oki Earthquake, two to four} story reinforced concrete school buildings particularly sustained heavy damage. Most damage was caused by the nonstructural and hanging walls (These are known generically as secondary walls. Refer to Fig. 2.4) installed in the reinforced concrete frames without making any calculations for these elements. These walls shortened the clear height of the structural columns, increasing stiffness to concentrate stresses, and in turn causing brittle shear failures in many columns.

Since then, secondary wall-caused damage to reinforced concrete buildings has been observed in many earthquakes at home and overseas, amounting to one of the important specific challenges which must be overcome to minimize seismic damage. Though many experimental investigations have been made since the 1968 Tokachi-oki Earthquake to produce certain results, there have not yet been any measures commonly applicable to a variety of reinforced concrete structures. The current specific measures for such secondary walls are as follows:

a) as for ultimate strength design methods where ideal seismic behaviors are pursued, secondary walls are used in such ideal forms as perfect slits 7);

b) as for general reinforced concrete structures, a method of making the thickness of secondary walls, $t$, small enough for the column width, $b,(t / b<1 / 6$ and $t<10 \mathrm{~cm})$ is illustrated in the seismic technical guideline ${ }^{2-8)}$; and c) as for thick-walled frame structures which have substantial stiffness and strength, recommended standard secondary walls are detailed 6 ).

The above third problem will be detailed below.

(2) Secondary Walls in Guideline for Structural Design of High-rise Walled Frame Structures Outline

Intended for six to eleven story apartment houses (now applicable to as fifteen story buildings), these structures contain a frame structure composed of flat rectangular-sectional wall columns in the longitudinal direction and a shear wall structure with surrounding wall columns in the span direction (refer to Fig. 2.5). It is necessary to specify how to treat secondary structures because they are mainly built in the longitudinal direction but are essential as partitioning walls or exterior walls which are needed for apartment houses to work properly. The superstructure in the longitudinal direction is a frame structure and a failure mechanism is assumed to be a total failure mechanism which is ductile enough to develop yielding hinges at the end of the beams and the wall base in time of severe earthquakes. However, since the structure has extremely high elastic rigidity and a short fundamental natural period of approximately $0.012 \mathrm{~h}$ (h: height of a building), the required horizontal bearing capacity is defined as 0.35 or more in terms of yielding base shear coefficient to obtain a response deflection of $1 / 100$ or less in terms of drift angle.

\section{Recommended Details of Secondary Walls}

It is recommended that anything but wall columns used for structural members should be considered as secondary walls, and that secondary walls should have a thickness of $12 \mathrm{~cm}$ or so, and out of four sides in contact with the structure, at least two should be notched into slits because they do not have any adverse effects on superstructure behaviors on the occasion of earthquakes (Fig. 2.6). Incidentally, it was revealed that in the failure experiments on semi-full and full-scaled structural frames with secondary walls complying with these details, the secondary walls ruptured before developing major displacement and the subject structure showed the expected inelastic deformation capacity.

\subsubsection{Seismic Measures for Vending Machines (1) Outline}

At present in Japan, there are various vending machines installed on the street or in the building and the variety is on the increase. Some of them are for bottled drinks and so heavy that they can probably damage as if they should be tumbled. Thus, by listing design forces, the Japan Industrial Standard (JISB-8562, 1985) recommended that before installing vending machines, not only impact by human bodies and wind forces but also seismic forces should be investigated to obtain required strength capacity.

\section{(2) Design Seismic Forces and Their Problems}

It is stipulated that for a vending machine of weight $W$ (its height of gravitational center is $h$ ), a $0.4 \mathrm{~W}$ horizontal force and a $0.4 \mathrm{~W} \cdot \mathrm{h}$ overturning moment on the installation surface should be considered to enable the machine to resist seismic forces. There is no provision, however, on the location of installations or the allowable strength capacity of anchor bolts.

Therefore, this JIS can be applied even to the case where the machines are installed in the middle floors of the building. In that case, what is called floor responses should be considered to increase design stresses, which has not yet been covered by this JIS.

\subsubsection{Free Access Floors in Computer Room}

The design and construction of free access floors in a computer room are specified in guidelines of Refs. 
5 and 4. The lateral design seismic forces are determined basically by the formula (2.16).

The design target of each guideline is the following:

(1) Guideline of Ref. 5 (Public Building Association, 1987)

Free access floors in a computer room shall resist the lateral seismic design forces, due to a major earthquake, without brittle failure or collapse to secure the ways of refuge. This guideline applies to the computer rooms of ordinary use except for those to be used in a major earthquake.

In the design of supports for free access floors, the maximum working stresses shall not exceed the allowable stresses of material against lateral design seismic forces, and principally the strength capacity shall be confirmed by an experiment.

(2) Guideline of Ref. 4 (Architectural Institute of Japan, 1985)

The extent of damage in nonstructural components is divided into five ranks according to the amount of damage, the necessity for repair and exchange, the fall down, and/or the deterioration of important functions.

The allowable limit of damage due to a moderate or major earthquake, as the design target of nonstructural components against story drifts, shall be provided by one of five ranks according to the importance of a building, the type of nonstructural components, the effects on refuge, and so on.

In the design, the maximum working stresses shall not exceed the allowable stresses of material against lateral design seismic forces.

3. COMPARISON OF SEISMIC DESIGN METHODS IN RELATED TECHNICAL GUIDELINES

\subsection{Outline}

In this chapter, we refer to the design seismic forces, design methods for each element, and other matters covered by the above guidelines for several nonstructural components, while making a comparison with design methods for building structures. In addition, we outline the seismic safety levels aimed at by each guideline, the actual conditions of nonstructural component design, and the confirmation methods.

\subsection{Principles of Seismic Design}

The lateral design seismic force coefficient, $\mathrm{gk}$, of equipment and nonstructural components is generally given by the following formula:

where,

$$
\mathrm{gk}=\mathrm{Z} \cdot \mathrm{g} \mathrm{K} \cdot \mathrm{g} \mathrm{k}_{\mathrm{O}}
$$

$\mathrm{gk}=$ lateral design seismic force coefficient;

$\mathrm{Z}=$ seismic zone factor $(0.7 \sim 1.0)$;

${ }_{\mathrm{g}} \mathrm{K}=$ factor due to floor response amplification of a building, response amplification of a nonstructural component, importance, and so on; and $\mathrm{g}_{\mathrm{O}}=$ standard design seismic force coefficient
The value of $\mathrm{g}_{0}$ is 0.2 in Refs. 3, 3' and 5. The value of $\mathrm{gK}_{\mathrm{g}} \mathrm{gk}_{0}$ for important equipment and nonstructural components is increased by 1.5 times that for general oncs. These values are determined by expecting a major earthquake of maximum ground acceleration of $0.2 \sim 0.3 \mathrm{~g}$ (g: acceleration of gravity), which is a smaller level of maximum ground acceleration for the seismic design of building structures.

The value of ${ }_{\mathrm{g}} \mathrm{K}$ is $2 \sim 10$ in Refs. 3 and 3', and 1.5 10 in Ref. 5.

The allowable stress design is basically required for equipment and nonstructural components against the lateral design seismic forces determined by the formula (3.1), while the ultimate strength design is principally required for building structures.

The formula (3.1) is compared in detail with each guideline in the following section.

\subsection{Design Seismic Forces and Deformation capacity}

Table 3.1 summarizes two typical guidelines for the seismic design of equipment and nonstructural components. The table includes the seismic structural design of example buildings ( $31 \mathrm{~m}<$ height $\leq 60 \mathrm{~m}$ ) for reference.

Design seismic forces to building equipment and nonstructural components are given based on a seismic force coefficient. This is derived from specification of local seismic coefficient to water tanks, chimneys, etc. extruding from roofs specified in Notification No. 1101 of the Ministry of Construction, 1981, Building Standard Law. The design seismic force coefficient of building equipment and nonstructural components is determined by the local seismic coefficient method or by the modified seismic coefficient method. Both includes acceleration amplification effects with stories of a building, and the latter includes explicitly those effects of equipment. An importance factor is also a parameter of seismic force coefficient. Building owners and structural designers can determine whether specific building equipment and nonstructural components are general or important.

Representative seismic coefficient values of general building equipment and nonstructural components at the first floor level are compared in Table 3.1 with a representative base shear coefficient value of buildings higher than 31 meters and not taller than 60 meters. The seismic zone factor $Z$ is assumed 1.0, and the structural characteristics factor $R_{t}$ is also assumed 1.0 in building base shear determination. The design seismic force coefficient is 0.4 in the local seismic coefficient method, and 0.2 in the modified seismic coefficient method. These values are equivalent to a design base shear coefficient of 0.2 for the first phase design or for possible several modcrate earthquake ground motions during building lifetime. The design of members are based on allowable stresses for temporary loads in both building equipment and nonstructural components, and building structures. In addition, the structural design requires a check of ultimate strength of 
an overall structure against a design base shear coefficient of 1.0. This check is on the basis of possible one major earthquake ground motion during building lifetime.

The seismic design of building equipment and nonstructural components requires a deformation capacity check in addition to a stress check. Buildings are designed for moderate earthquake ground motions so that story drift angles are less than $1 / 200$. Vertical pipes of buildings are designed so that the pipes can deform to 1/200 story drift angles without damage. Pipes through expansion joints are designed so that the pipes can deform to maximum relative displacements among two structures in possible reverse phases. The guidelines include several detail examples to secure enough deformation capacity.

The seismic design of building equipment and nonstructural components for major earthquake ground motions (Ref. 5) assumes the following story drift angles of three types of buildings: a) Steel Structure more than $1 / 100$ story drift angles; b) Reinforced Concrete Structure, and Steel/Reinforced Concrete Composite Structure with comparatively a few walls less than 1/100 story drift angles; and c) Low-rise and Medium-rise Reinforced Concrete Structure, and Steel/Reinforced Concrete Composite Structure with comparatively many walls - less than $1 / 200$ story drift angles. Story drift angles in building structures during a major earthquake are evaluated from those for moderate earthquake ground motions in the presented formulae of Ref. 5. As the first step of the seismic design of building equipment and nonstructural components, the maximum story drift angle of a structure shall be estimated and evaluated. Then, the prospected damage of building equipment and nonstructural components shall be compared with that of a building structure, and suitable ones shall be selected.

\subsection{Seismic Design Methods for Equipment Machine. Piping Bodies, and Their Supporting Members}

\section{(1) Outline}

Metallic materials are often used for various water tanks, boilers, equipment machines, storage boxes and piping bodies. Lately, FRP (fiber reinforced plastics) has sometimes been used for storage tanks. Also, steel angle members are used as material for supporting frames used to support piping against the structure. In designing each member such as a machine body by one of these materials, the allowable stress design is often used to control working stresses generated in each member by the design force noted in Section 3.3.

\section{(2) Stress Analysis of Each Member}

A working stress generated in each member is approximately in elastic calculated on the basis of the elastic stiffness of each material.

\section{(3) Allowable Stress of Each Member}

The Enforcement Order, Building Standard Law stipulates that the dead weight of each machine and the weight of its contents should be defined as permanent loads and these weights plus seismic forces as temporary loads. In case of the materials covered by JIS, it lists allowable stresses for separate loads. As seen in Table 3.2 , the temporary allowable stress of metallic material is the standardized yield point strength of that material. Incidentally, in normal cases, the standardized yield point strength is approximately $1 / 1.1$ to $1 / 1.3$ and never below the actual yield point strength of the material although it depends on the type of steel material. The $0.2 \%$ offset point strength is used for steel materials which have opaque yield points. Moreover, the order stipulates that allowable stresses of adhesives and the like which do not have any standards should be determined by making experiments on it and then setting appropriate safety factors on the results.

\section{(4) Confirmation of Strength Capacity of Each Member}

In terms of the strength capacity, the safety of various equipment machine bodies is usually confirmed by checking to see if the working stress of each member obtained as stated above is not over the temporary allowable stress. Never available are those design methods which use the ultimate strength and expect the effects of inelastic deformation capacity as in building superstructures.

\subsection{Allowable Stress of Anchors}

\section{(1) Outline}

What is called post-installed anchors are often used to attach equipment to reinforced concrete buildings or floor slabs. In the seismic actions for equipment and piping covered in this report, such anchors are used in the following cases and play an important roll:

a) installing equipment machines or vending machines on the floor slabs;

b) attaching seismic supporting member of piping to walls; and

c) attaching prefabricated precast exterior panels.

Therefore, some related technical guidelines provide for the allowable strength capacity of the postinstalled anchors. But there are still many problems unsolved because of the variety of the products on the market.

\section{(2) Design Methods of Anchors}

Like the equipment machine bodies noted in Section 3.4, the allowable stress design method is used to design anchors, so it is necessary to set the allowable strength capacity for anchors.

\section{(3) Temporary Strength Capacity of Anchors}

Since anchors are ordinarily subjected to tensile forces, shear forces, and/or their combined forces when used to attach equipment machines, temporary strength capacities are set for those working stresses as follows:

Tensile bearing capacity. Ta

$$
\mathrm{Ta}=\Phi_{1} \bullet \operatorname{Min}\left(\mathrm{Ta}_{1}, \mathrm{Ta}_{2}, \mathrm{Ta}_{3}\right)
$$


where,

$\mathrm{Ta}_{1}=$ strength capacity which is caused by the tensile yield of anchor and depends on their sectional area, $a_{A}$, and yield point stress, $\sigma_{y}$;

$\mathrm{Ta}_{2}=$ strength capacity which is caused by the cone-type failure of concrete and depends on the anchors' embedded length, $l_{\mathrm{A}}$ and concrete strength, $\mathrm{Fc}$;

$\mathrm{Ta}_{3}=$ strength capacity caused by the bond failure of the connecting plane between adhesive and concrete when adhesive anchors are used; and

$\Phi_{1}=$ strength reduction coefficient which represents the safety factor of the material.

\section{Shear capacity, $\mathrm{Oa}$}

$\mathrm{Qa}=\Phi_{2} \bullet \operatorname{Min}\left(\mathrm{Qa}_{1}, \mathrm{Qa}_{2}\right)$

where,

$\mathrm{Qa}_{1}=$ bearing strength which is caused by the shear failure of anchor bodies and depends on $\mathrm{a}_{\mathrm{A}}$ and $\mathrm{a}_{\mathrm{A}}$ and $\sigma_{\mathrm{y} ;}$ and

$\mathrm{Qa}_{2}=$ strength capacity which is caused by the failure of concrete and is usually represented by a function of Fc, Ec (elastic modulus for concrete) and a A .

Safety with anchors subjected to combined stresses

(Q, T) shall be considered by using charts based on the following expression or other similar alternatives.

$$
(\mathrm{Q} / \mathrm{Q} a)^{\mathrm{n}}+(\mathrm{T} / \mathrm{Ta})^{\mathrm{n}} \leq 1
$$

Ordinarily, the value of 1 or 2 is used for $n$.

\section{(4) Problems with Anchors}

As stated above, anchors play an important role in the seismic design of nonstructural components but there are many problems unsolved, including those under investigation:

a) There is no standard for industrial products manufactures, while many products are on the market; b) Few research materials are available in terms of the effects of dynamic cyclic loading and creep phenomena on strength capacities or load-deflection relationships;

c) There are few data on time-dependent durability or fire proof abilities;

d) Few date are available in terms of how base concrete conditions and construction preciseness work on the anchors; and

e) There are few date on limit conditions for combined stresses.

\subsection{Structural Details for Seismic} countermeasures

\section{(1) Outline}

Since actions based on structural calculations cannot cover the whole sphere of aseismicity improvement for building equipment, structural details to be adopted are often illustrated and recommended specifically. Among such structural details, many have been developed to cope with horizontal deformations occurring in time of earthquakes, while some are related to the strength capacity. These structural details are divided in several major categories below.
(2) Structural Details for Seismic Deformations

The structural details are mainly related to piping joints, the formation and joining of interior and exterior finishing, structural strength capacity, and other matters. a) Many of the structural details for piping joints are to control deformations occurring in time of earthquakes. For example, as for piping through expansion joint members as shown in Section 2.4, the detail describes how to install flexible pipe joints or flexible joints in a manner that they will not be damaged by deformations of possible intensity. Also it describes how to use flexible joints where the piping enters the building from outside so as to control uncalculated deformations which are possible to occur vertically and horizontally.

b) The structural details related to the formation and joining of various interior and exterior finishing ${ }^{1)}$ contain typical details about fasteners for precast curtain walls (fixed or sliding type), dry-type partition walls in steel buildings (flexible type), glazing compounds of glass windows (clearance with frame members), and seismic doors and ceilings (flexible enough to resist inplane deformations).

c) The structural details for strength capacity include details about reinforced concrete nonstructural walls stated in Section 2.4 (1) and convenient tables for selecting appropriate seismic support members for piping (see Section 2.3), as well as the detailed figures of structural joints for the supporting frames of equipment machines (showing the shape of gusset plates for the end of braces and the position of rivet holes). They are used to omit calculations for the strength capacity except the cases of secondary walls.

\subsection{Equipment Machine Design and Confirmation}

Today in Japan, licensed building engineers are responsible for the seismic designing of building structures based on the related laws and orders b), whereas building officials at the supervising authorities are in charge of structural calculations and structural drawings based on those calculations. On the other hand, although building equipment and piping under control of laws are similarly confirmed, there is no large control or building confirmation for various interior and exterior finishing. Partly due to this, except the cases of official buildings, aseismicity has not necessarily inspected for nonstructural components. Also, building confirmation for building equipment is not as scrupulous as that for strength capacity.

\section{CONCLUDING REMARKS}

We reported above on the guidelines, and related actual design and confirmation regarding the seismic design for building equipment and other nonstructural components or members. As stated, there are not a few problems as some guidelines have much to be coordinated or improved. These guidelines are established by several committees of leamed and experienced people, affiliated with the Ministry of Construction, and the Ministry of International Trade 
and Industry. Researchers at the Building Research

Institute commit themselves to almost all these

committees and offer them technical information so as

to maintain consistency among the guidelines.

Table 1.1 Examples of Recent Earthquake Damage to Bullding Equipaents, Nonstructural Elements. etc.

\begin{tabular}{|c|c|c|}
\hline Year & Earthquako & Contents of Typlcal Danage \\
\hline 1964 & Mllgata Erq. & $\begin{array}{l}\text { Danage to sever plpe and floatlng-up of septle tanks } \\
\text { due to llquld-factlon of sand layer }\end{array}$ \\
\hline 1965 & Shlzuoka Erq. & Damage to $\operatorname{lnd}$ in glass \\
\hline 1968 & Tokach!-ok! Erq. & Breakage of roof chtraney and Independent chlaney \\
\hline 1978 & $\begin{array}{l}\text { lzuohshløa-klnkal } \\
\text { Erq. }\end{array}$ & $\begin{array}{l}\text { Damage to ater and gass supply, electrle facllitles } \\
\text { due to landslide, damage to redical factlltles }\end{array}$ \\
\hline O 1978 & Mlyaglken-okl Erq. & $\begin{array}{l}\text { Damage to blg computers, roof vater tanks, plolng. } \\
\text { ducts, gass facllltles, flre facllltles and many } \\
\text { other nonstructural elements }\end{array}$ \\
\hline 1983 & NIhonkal-chubu Erq. & Outdoor underground plolng. septle tanks and oll tanks \\
\hline 1987 & Chlbaken-Tohookl Erq. & Sllding anf falling down of aany roof tlles \\
\hline
\end{tabular}

Table 1.2 Progress to Establishaent of Aselsule Design Code and Regulatlons Regarding Nonstructural Bullding Elements

\begin{tabular}{|c|c|c|c|c|c|}
\hline \multirow{2}{*}{ Year-Month } & \multirow{2}{*}{$\begin{array}{l}\text { ileas. Code and Culdelline "I } \\
\text { Mark in () shows the refferenco } \\
\text { nuabor in this report }\end{array}$} & \multicolumn{4}{|c|}{ ltems related "lth Equipaent etc. } \\
\hline & & $\begin{array}{l}\text { Prthquale } \\
\text { Danage }\end{array}$ & $\begin{array}{l}\text { Code or } \\
\text { Order }\end{array}$ & $\begin{array}{l}\text { Technical } \\
\text { Guldellne }\end{array}$ & $\begin{array}{l}\text { Siructural } \\
\text { Regulstion }\end{array}$ \\
\hline 1976.3 & $\begin{array}{l}\text { End of the natlonat project on nev } \\
\text { asolsale design wethod (a) }\end{array}$ & & & & 0 \\
\hline 1978. & $\begin{array}{l}\text { t.G. for water supply and dralnage } \\
\text { equipaent } \\
\text { (1): Vithout aselswic regulattons }{ }^{-2}\end{array}$ & & & $\mathrm{O}^{-8}$ & \\
\hline 1978.8 & Mlyaglken-ok! Earthquake & $0^{-3}$ & & & \\
\hline $1980 \sim$ & $\begin{array}{l}\text { Hany technical suldellnes by private } \\
\text { assoclatlons }(2.1 \sim 2.7)\end{array}$ & & & $\mathrm{O}$ & \\
\hline 1980 & $\begin{array}{l}\text { Lerge revilaton of the Bullding } \\
\text { Standard } L \text { as (b) }\end{array}$ & & 0 & & \\
\hline 1981.1 & $\begin{array}{l}\text { T. G. For struefural ealeulation } \\
\text { basing the roylsed code }(2.8)\end{array}$ & & & & 0 \\
\hline 1981.8 & $\begin{array}{l}\text { Notlfleation Mo. } 1101 \text { by MOC on the } \\
\text { revlsend code "b* }(\text { (c) }\end{array}$ & & 0 & & \\
\hline 1982.1 & $\begin{array}{l}\text { t. G. for bullding equipments basing } \\
\text { on } e^{-(3)}\end{array}$ & & & $\mathbf{0}$ & \\
\hline 1982.2 & $\begin{array}{l}\text { Diractor s Nont!fleation Ho. } 32 \text { by } \\
\text { MoC recomendine to apply t. } 6 .{ }^{\circ} \text { (d) }\end{array}$ & & $\mathrm{O}$ & & \\
\hline 1983.2 & $\begin{array}{l}\text { Revilition of }(1)-\left(1^{\circ}\right) \text { : Addition of } \\
\text { aselsale regulations }\end{array}$ & & & 0 & \\
\hline 1983.5 & Nihonka1-chubu Earthquake & 0 & & & \\
\hline 1984.9 & Reviaton of $(3) \rightarrow\left(3^{\circ}\right)$ & & & 0 & \\
\hline 1985.11 & $\begin{array}{l}\text { T. G. for sselsnic design of } \\
\text { nonstructural olewents by A1f (4) }\end{array}$ & & & 0 & \\
\hline 1987.2 & $\begin{array}{l}\text { T. G. Por aselsale design of } \\
\text { nonstructural olenents by G.B.S ( } \$ \text { ) }\end{array}$ & & & 0 & \\
\hline 1987.10 & $\begin{array}{l}\text { T. C. Cor nediun-high rised wall } \\
\text { irame construction by BC) (b) }\end{array}$ & . & & & 0 \\
\hline 1988.10 & $\begin{array}{l}\text { T. G. for reinforced concrete } \\
\text { bulidings based on vilinate strength } \\
\text { concept by All (7) }\end{array}$ & & & & 0 \\
\hline
\end{tabular}

Hote : 1) See note of table 1.3 concerning on the lark AIJ. G.B.S. and AtJ.

13) Mark $O$ mean the lten has prtaary importance. 
Tabio I. I (a) Typlcal Aselsale Guldellines for Architectural Monstructural Eleaents Equipaent etc. . and the Main Contents

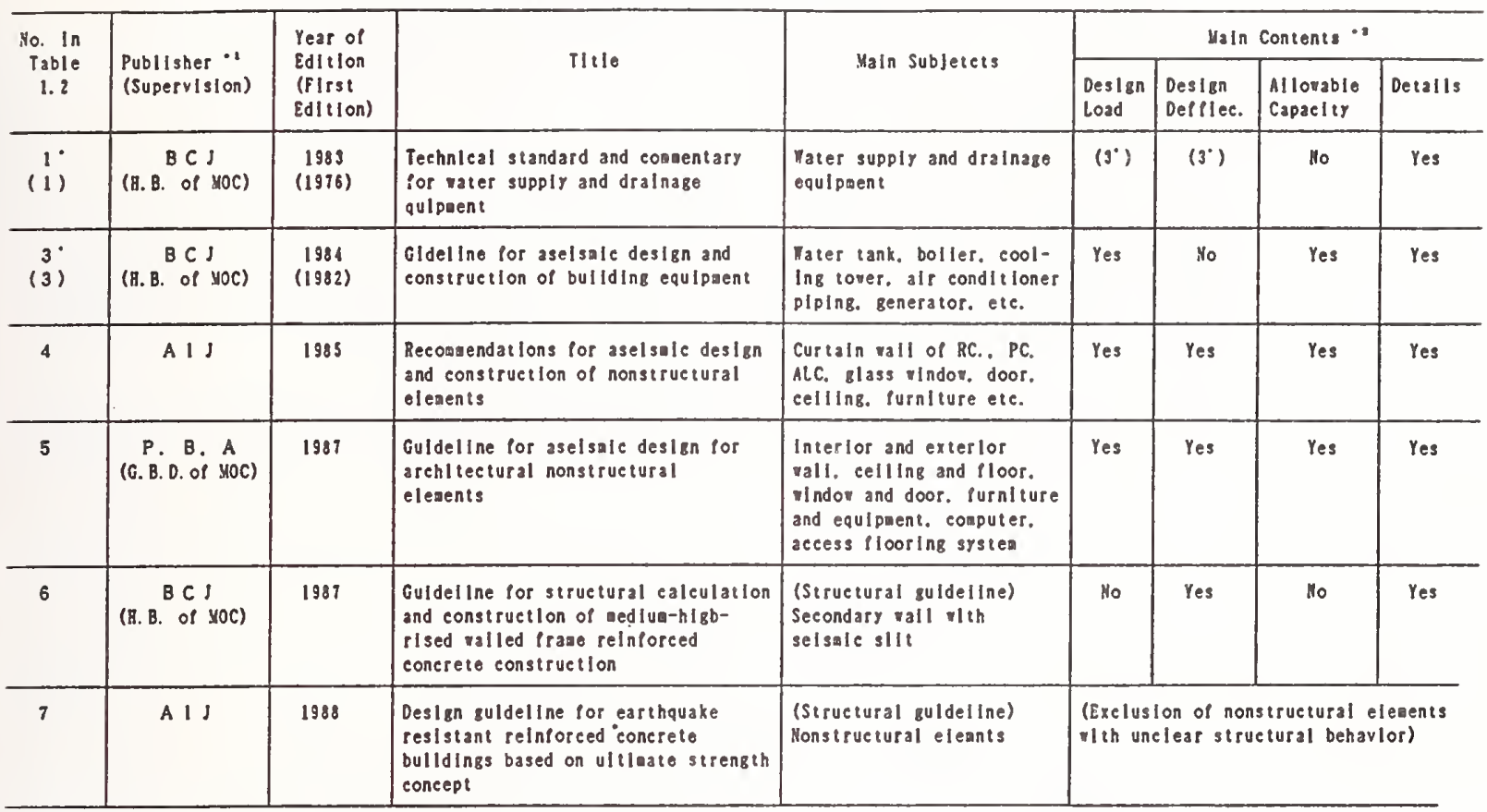

Note 11 8CJ : Bullding Center of Japan. Als: Arebltectural Instltute of Japan. P. 8. A. : Pubrle Building Assoclatlon B. B. or G.8.D. of HOC : Housing 8ureau or Goveraaent Bullding Division of Minlstry of Construetion

\$2 Yes or Ho wean tbe suldellne contains or does not contaln regulatlon related vlth the Itea. respectively (3') aeans the guldellne applles the zuldellne Io. ${ }^{\prime}$ correspondingly related with the Itea.

Table 1.s (b) Technical Guldelines related Vith Bullding Equlpments etc. Prepalred by Private Sectors and Reffered at Compllat lon of the Guldellne (3) (Except 2.8)

\begin{tabular}{|c|c|c|c|}
\hline $\begin{array}{l}\text { Ho. in } \\
\text { Table } 1.2\end{array}$ & Title of Guldelline & $\begin{array}{l}\text { Year of } \\
\text { Edition }\end{array}$ & Publisher \\
\hline 2. 1 & $\begin{array}{l}\text { Guldeline for aselsale design and } \\
\text { construetion of buliding equipaents }\end{array}$ & 1980 & Bullding Center of Sapan \\
\hline 2. 2 & $\begin{array}{l}\text { Guldelline for aselsale design of } \\
\text { englne generator equipaents }\end{array}$ & 1981 & $\begin{array}{l}\text { Mippon Engine Generator } \\
\text { Assoclation }\end{array}$ \\
\hline 2. 3 & $\begin{array}{l}\text { Guldeline for aselsale design of } \\
\text { buliding equipaents (Draft) } \\
\text {. }\end{array}$ & 1981 & $\begin{array}{l}\text { The Soclety of lleating. Alr } \\
\text { Condlitioning and Sanitary } \\
\text { Engineering of Japan }\end{array}$ \\
\hline 2. 4 & $\begin{array}{l}\text { Data book for aselsale deslign of } \\
\text { bullding equipaents }\end{array}$ & 1980 & $\begin{array}{l}\text { Bullding Bureau of Japan } \\
\text { Telephon and Telegraph Pubile } \\
\text { Corporatlon }\end{array}$ \\
\hline 2. 5 & $\begin{array}{l}\text { Aselsale deslgn standard for FRP vater } \\
\text { tank (Draft) } \\
\text { Structural calculation acthod for FRP } \\
\text { vater tank }\end{array}$ & $\begin{array}{l}1980 \\
1981\end{array}$ & $\begin{array}{l}\text { The Japan Relnforced Plastles } \\
\text { Assoclation }\end{array}$ \\
\hline 2. 6 & $\begin{array}{l}\text { Manual for aseisale design and } \\
\text { construction of bullding electrieal } \\
\text { equipaents }\end{array}$ & 1983 & $\begin{array}{l}\text { Japan Electrical Construction } \\
\text { Association }\end{array}$ \\
\hline 2. 7 & $\begin{array}{l}\text { Guldeline for aselsale design and } \\
\text { construction of copper plping for } \\
\text { bullding equipaents }\end{array}$ & 1984 & $\begin{array}{l}\text { Japan Copper Developsent } \\
\text { Assoclation }\end{array}$ \\
\hline 2.8 & $\begin{array}{l}\text { Guideline for structural calculation } \\
\text { and comentary basing on nev aselsale } \\
\text { code }\end{array}$ & 1981 & Bullding Center of Japan \\
\hline
\end{tabular}


Table 2.l Standard Selsmlc Coefficlent K,

\begin{tabular}{|l|c|c|}
\hline & Important equipment & General equipment \\
\hline $\begin{array}{l}\text { The highest floor. } \\
\text { roof and penthouse }\end{array}$ & $\begin{array}{l}1.5 \\
0\end{array}$ & 1.0 \\
\hline $\begin{array}{l}\text { The second floor and } \\
\text { floors higher than the } \\
\text { second floor }\end{array}$ & $\begin{array}{l}1.0 \\
\text { se }\end{array}$ & 0.6 \\
\hline $\begin{array}{l}\text { Basement floor and the } \\
\text { flrst floor }\end{array}$ & 0.6 & 0.4 \\
\hline
\end{tabular}

NOTE Values in parentheses means selsulc lateral coefflclents of Important equlpment with vibration isolator apparatus.

Table 2.2 Importance Reduction Factor I

\begin{tabular}{|l|c|c|}
\hline & $\begin{array}{l}\text { Important } \\
\text { Bullding Equlpment }\end{array}$ & $\begin{array}{l}\text { Gencral } \\
\text { Bullding Equlpment }\end{array}$ \\
\hline $\begin{array}{l}\text { Importance } \\
\text { Reductlon } \\
\text { Factor 1 }\end{array}$ & 1.0 & $2 / 3$ \\
\hline
\end{tabular}

Table 2.3 Targots of Selsmle Safety of Nonstructural Components

\begin{tabular}{|c|c|c|c|}
\hline$\cdot$ & \multicolumn{2}{|c|}{$\begin{array}{l}\text { Target of selsinlc safety of } \\
\text { nonstructural components }\end{array}$} & Requlred capaclty \\
\hline $\begin{array}{l}\text { Class A } \\
\text { Bulldings aimed to } \\
\text { functlon as dlsaster } \\
\text { prevention bases }\end{array}$ & $\begin{array}{l}\text { Safeguard of the } \\
\text { human llfe } \\
\text { Guarantee of the } \\
\text { functlons requlred } \\
\text { In dlsaster pre- } \\
\text { ventlon bases }\end{array}$ & $\begin{array}{l}\text { Exterior of the bullding } \\
\text { (all parts) } \\
\text { Interlor of the bullding } \\
\text { (all spaces besldes the } \\
\text { actlvlty sectlons) } \\
\text { lnterlor of the bullding } \\
\text { (actlvlty sectlons and } \\
\text { the llke) }\end{array}$ & $\begin{array}{l}\text { - No fall due to break } \\
\text { - No break or collapse } \\
\text { due to brlttleness } \\
\text { - Damages, If any. } \\
\text { should be local ones } \\
\text { llilted to members. } \\
\text { jolnts, etc. }\end{array}$ \\
\hline $\begin{array}{l}\text { Class B } \\
\text { Government bulldings } \\
\text { requlred for the } \\
\text { sake of refuge and } \\
\text { first aid }\end{array}$ & $\begin{array}{l}\text { Safeguard of the } \\
\text { human llfe } \\
\text { Guarantee of the } \\
\text { functlons required } \\
\text { In disaster pre- } \\
\text { ventlon bases }\end{array}$ & $\begin{array}{l}\text { Exterior of the bullding } \\
\text { (all parts) } \\
\text { Interlor of the bulldling } \\
\text { (practlcally the } \\
\text { lotallty) }\end{array}$ & $\begin{array}{l}\text { - No fall due to break } \\
\text { - Danages, If any. } \\
\text { should be local ones } \\
\text { llitted to members. } \\
\text { jolnts and the llke }\end{array}$ \\
\hline $\begin{array}{l}\text { Class } \mathrm{C} \\
\text { Ordinary government } \\
\text { bulldings }\end{array}$ & $\begin{array}{l}\text { Safeguard of the } \\
\text { human } 11 \mathrm{fe}\end{array}$ & $\begin{array}{l}\text { Exterlor of the bullding } \\
\text { (all parts) } \\
\text { Interlor of the building } \\
\text { (all parts) }\end{array}$ & $\begin{array}{l}\text { - No fall due to break } \\
\text { - No break or collapse } \\
\text { due to brittleness }\end{array}$ \\
\hline $\begin{array}{l}\text { Class D } \\
\text { Bulldlngs storlng or } \\
\text { handllng dangerous } \\
\text { waterlals }\end{array}$ & DIIIO & $\begin{array}{l}\text { Exterlor of the building } \\
\text { Interlor of the building } \\
\text { (all parts) }\end{array}$ & - DItto \\
\hline
\end{tabular}




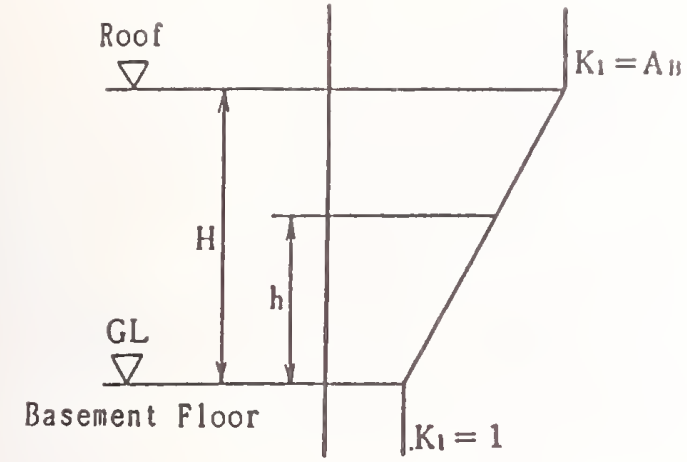

Fig. 2.1 Building Amplification Factor $K_{1}$

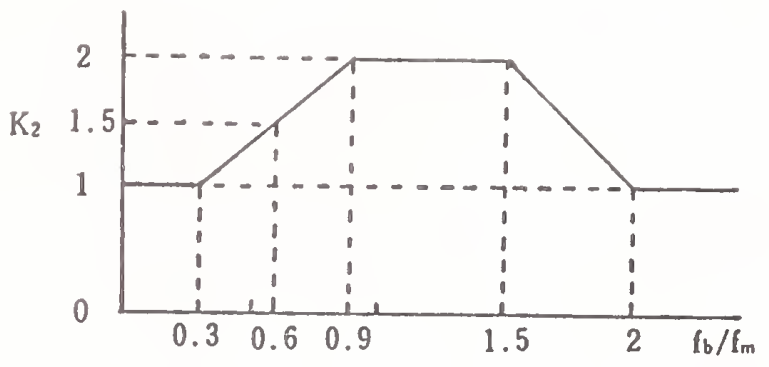

Fig. 2.2 Equipment Amplification Factor $\mathrm{K}_{2}$ ( $\mathrm{f} . \leqq 15)$

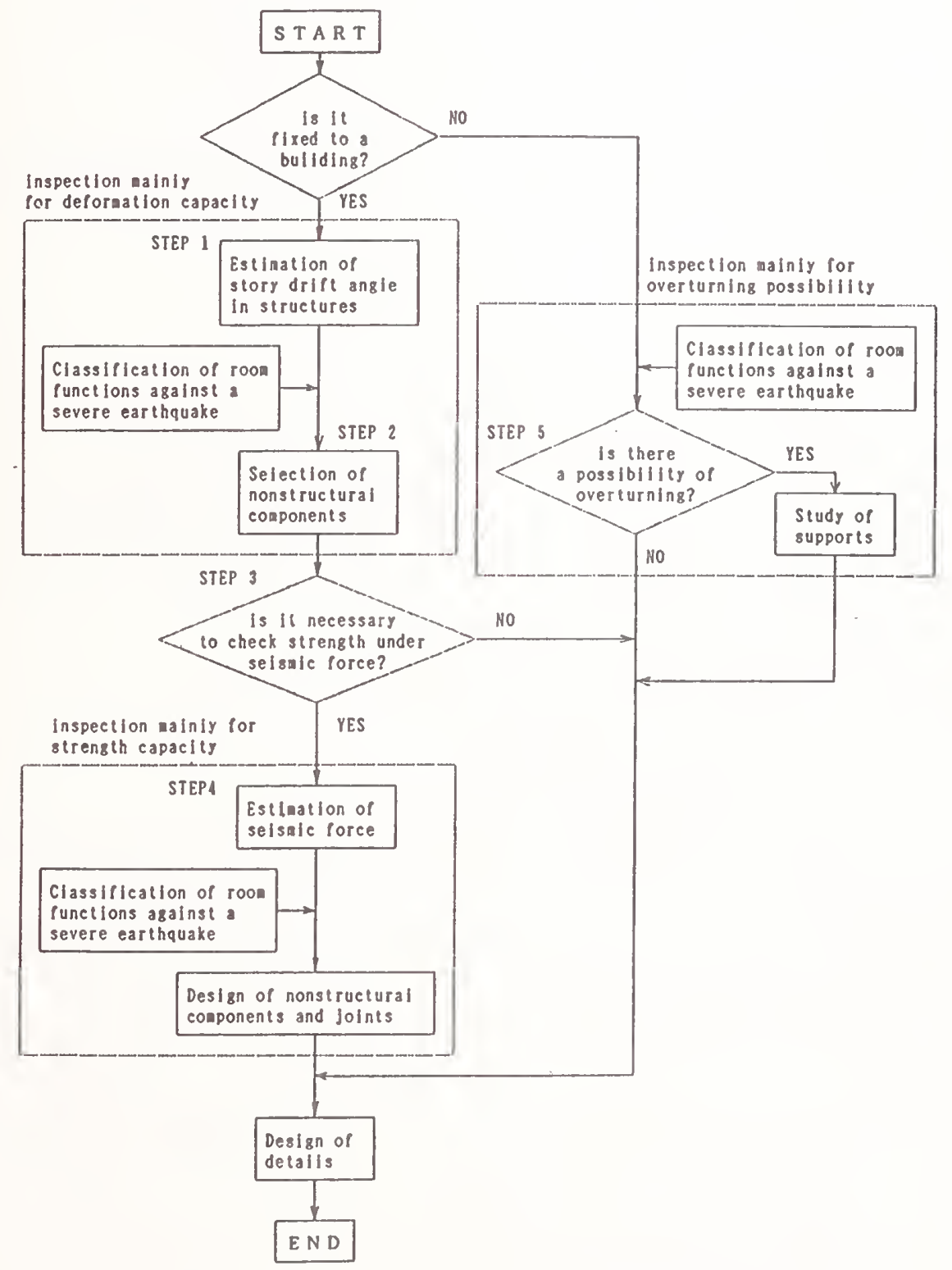

Fig. 2.3 Generai Fioz of Selsaic Design of Nonstructurai Coaponents 


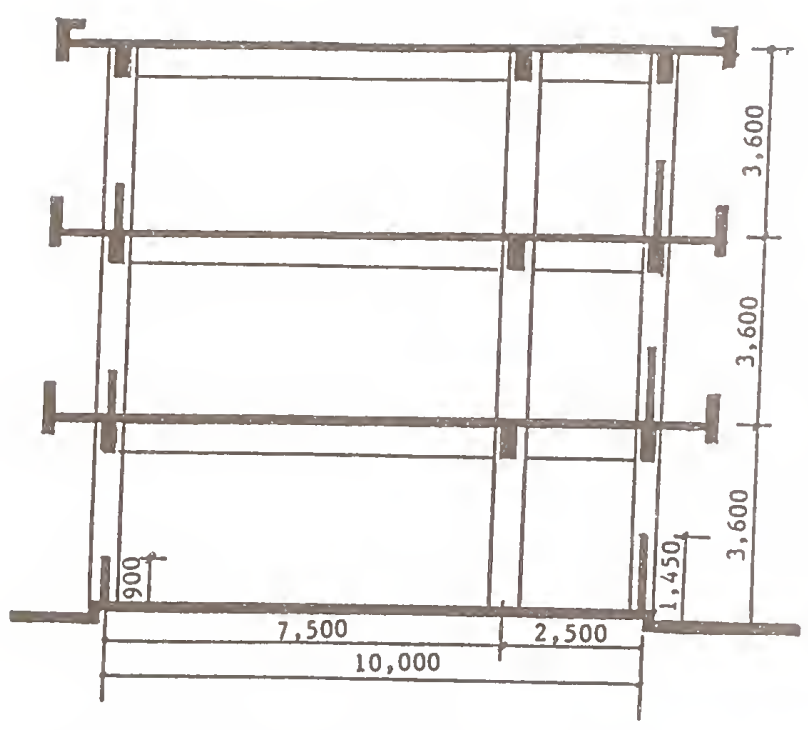

Fig. 2.4 Cross Section in Span Direction of Typical Japanese School Buildine

(Usually. columins In the outer frames are 1th nonstructural spandrel wall llke thls flgure)

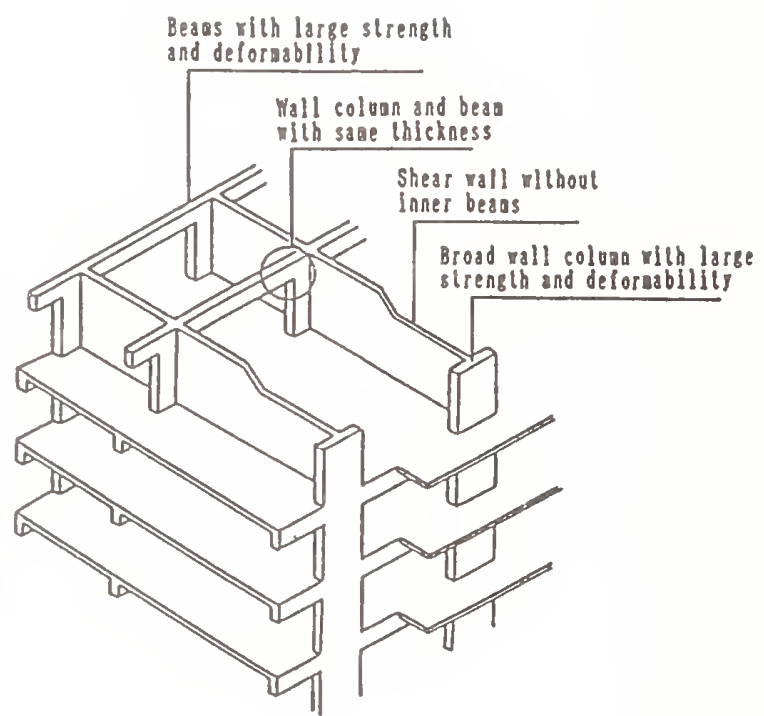

Fig. 2.5 Outline of Structural System of the $R / C$. Frame Structure wi th Wall Column

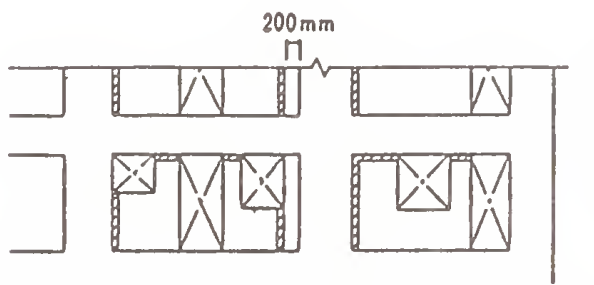

a) Arrangement of Structural Slit

(Case A : one side and top of n.s. walls)

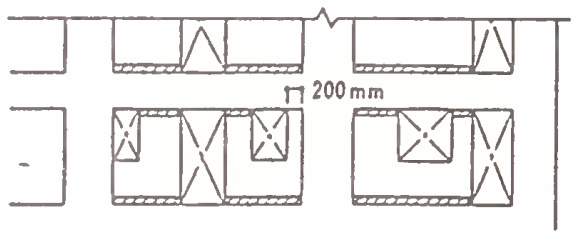

b) The Same

(Case B : top and bottom of n.s. walls)

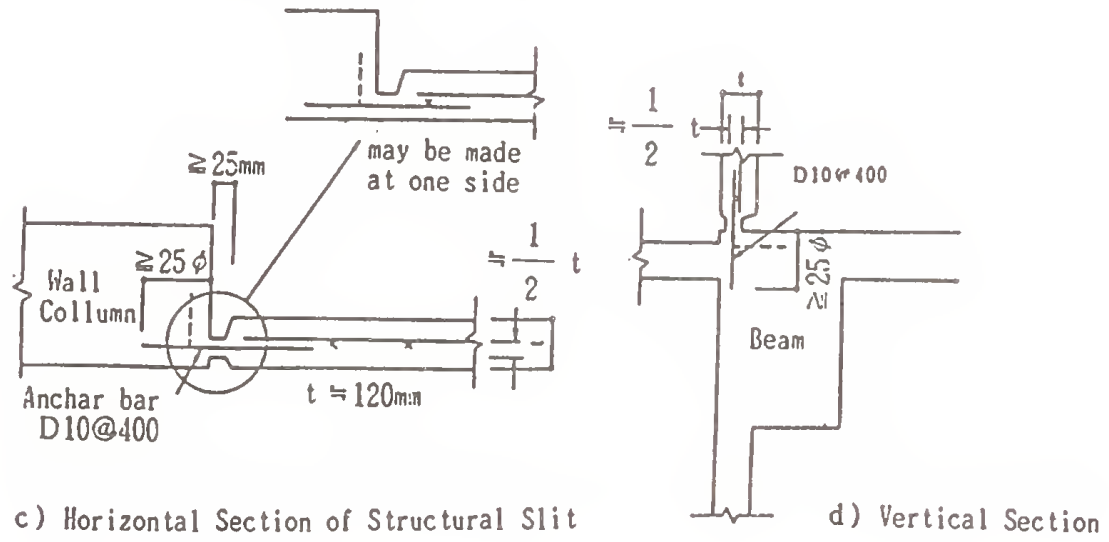

Fig. 2.6 Treatment of Non-structural Walls in HFW Construction" 
TABLE 3. I SEISMIC DESIGN METHODS OF BUILDING EQUIPMENT. HONSTRUCTURAL EQUIPMENT AND BUILDIHG STRUCTURES

\begin{tabular}{|c|c|c|c|c|}
\hline $\begin{array}{l}\text { MAME OF GUIDE- } \\
\text { LINE or CODE } \\
\text { lleAs }\end{array}$ & \multicolumn{2}{|c|}{$\begin{array}{l}\text { GUIDELINE OH SEISMIC DESIGN OF BUILDING } \\
\text { EQUIPMENT (1982) }\end{array}$} & $\begin{array}{l}\text { GUIDELIHE OF NONSTRUCTURAL } \\
\text { COMPOHENTS OF BUILDIMG (1987) }\end{array}$ & $\begin{array}{l}\text { BUILDIHO STRUCTURE } \\
\text { ( BUILDING STANDARD LAII) } \\
\text { (for Reference) }\end{array}$ \\
\hline Objects & \multicolumn{2}{|c|}{$\begin{array}{l}\text { Selsnle Deslgn on Installatlon of } \\
\text { Bullding Equipaent }\end{array}$} & $\begin{array}{l}\text { Sclsale Design of Nonstruetural } \\
\text { Components In Bullding }\end{array}$ & Selsule Deslgn of Bulldings \\
\hline Seope & \multicolumn{2}{|c|}{$\begin{array}{l}\text { (1) Equlpaent Installatlon in bulldings } \\
\text { on wore than three atorles, and vith } \\
\text { bullding hel ght lover than } 60 \text { meters. } \\
\text { (2) Installatlon of equlpnent } 1 \text { ghter } \\
\text { than } 100 \mathrm{~kg} \text { is excluded. }\end{array}$} & $\begin{array}{l}\text { (1) Governental and publle bulldings } \\
\text { lover than } 60 \text { aeters } \\
\text { (2) All nonstructural components } \\
\text { other than bullding structure. } \\
\text { bullding equlpaent. chlmneys. } \\
\text { paraphets. }\end{array}$ & $\begin{array}{l}\text { (an example) } \\
\text { Bulldings hlgher than } 31 \\
\text { weters and lover than } 60 \\
\text { weters }\end{array}$ \\
\hline Deslgn Method & $\begin{array}{l}\text { Local Selsale } \\
\text { Coefflelent Method }\end{array}$ & $\begin{array}{l}\text { Modifled Selsale } \\
\text { Cocfilelent Method }\end{array}$ & $\begin{array}{l}\text { One of the folloring the aethods } \\
\text { (1) Modifled selsalc coefflelent } \\
\text { method } \\
\text { (2) Local selsale coefficlent method } \\
\text { (3) Rlgorous calleulatlon } \\
\text { (Earthquake response analysls) } \\
\text { Hodlfled selsale coefflelent method } \\
\text { seeas to be recomanded. }\end{array}$ & $\begin{array}{l}\text { Equlvalent Lateral Force } \\
\text { Method (story ahcar } \\
\text { coefflclent aothod) } \\
\text { (Local aclanle coefflelent } \\
\text { nethod for vater tanks. } \\
\text { chlaneys, otc. protruding } \\
\text { (ron roofa. and underground } \\
\text { (basenent) atructures) }\end{array}$ \\
\hline $\begin{array}{l}\text { Deslgn Selsnle } \\
\text { Force }\end{array}$ & $\begin{array}{l}F_{n}=\pi n \cdot \pi \\
R_{n}=Z \cdot R_{3} \\
\text { vhere } \\
Z=\text { Solsale Zone } \\
\text { Coefflelent } \\
R_{3} \text { - Local Selsale } \\
\text { Coefflelent } \\
(0.1,0.6 .1 .0 \\
(1.3), 1.5 .(2.0))\end{array}$ & 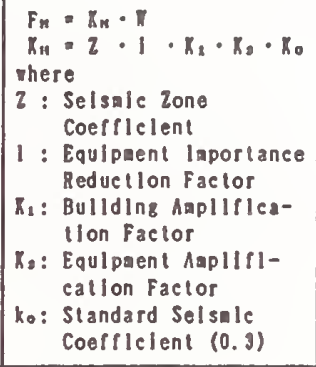 & $\begin{array}{l}\text { Modifled selsile coefflelent nethod } \\
\text { is the same as left. }\end{array}$ & 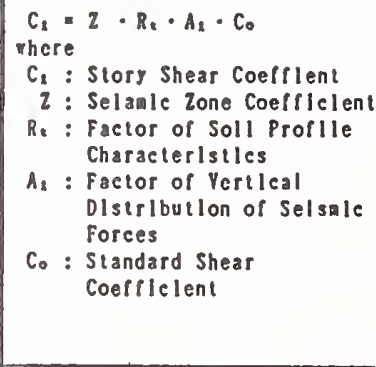 \\
\hline $\begin{array}{l}\text { Selsale Zone } \\
\text { Coefflelent }\end{array}$ & $Z=\underset{l}{0.7,0.8 .0 .9}$ & The sane as left. & The aame as left. & The ane as left. \\
\hline $\begin{array}{l}\text { Selsale Coeffl- } \\
\text { clent of General } \\
\text { Equlprent at } \\
\text { Flrst Floor and } \\
\text { Baseaent or } \\
\text { Base Shear Coef. } \\
\text { of Bullding }\end{array}$ & $\begin{array}{l}\text { 0. A } \\
\text { (Lateral Selsale } \\
\text { Coef. of General } \\
\text { Equlpaent at Flist } \\
\text { Floor and Basement } \\
\text { [ }[2=1]\end{array}$ & $\begin{array}{l}0.2 \\
\text { (Lateral Selsalc Coef. } \\
\text { of Ceneral Equlpaent at } \\
\text { Flrst Floor and Basenent } \\
\text { ) }\left[2=K_{2}=R_{0}=1, \quad I=2 / 3, k_{0}=\right. \\
0.3]\end{array}$ & The sare as left. & $\begin{array}{c}\text { Base Shear Coef. } C_{1} \\
C_{1} \geq 0.2 \text { for Moderate Eq. } \\
\text { Ground Motlons } \\
C_{1} \geq 1.0 \text { for Major Eq. } \\
\text { Ground Motlons } \\
\text { (Check of Villaate Strength) } \\
{\left[Z=A_{2}=R_{2}=1\right]}\end{array}$ \\
\hline $\begin{array}{l}\text { Bullding } \\
\text { laportance } \\
\text { Factor }\end{array}$ & & & $\begin{array}{l}\text { Governaental and publle bulldings } \\
\text { are classifled Into three categorl- } \\
\text { es on the basis of requlred selswle } \\
\text { performance: The lovest correspondes } \\
\text { the level of Bldg. Stan. Lav. Tho } \\
\text { helghest is selsalc perforaance of } \\
\text { disaster rellef and rehabllliatlon } \\
\text { bases after ajor earthquakes. } \\
\text { specifle performance is not shown. }\end{array}$ & 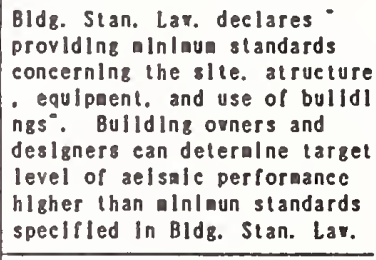 \\
\hline $\begin{array}{l}\text { Bullding } \\
\text { Aaplifleatlon } \\
\text { Factor } \\
\qquad \mathrm{K}_{1}\end{array}$ & $\begin{array}{l}\text { Mot explicllty con } \\
\text { sldered. But local } \\
\text { selsale coefa. are } \\
\text { glven for three } \\
\text { locatlon types of } \\
\text { storles. }\end{array}$ & $k_{1}=i=10 / 3$ & The same as left. & $\begin{array}{l}\text { A factor } A_{1} \text { of the above sels- } \\
\text { alc force Includes accelera- } \\
\text { llon anplifleatlon effects } \\
\text { vith estlated fundanental } \\
\text { perlod of bullding. }\end{array}$ \\
\hline $\begin{array}{l}\text { Equlpment } \\
\text { laportanco } \\
\text { Reduction } \\
\text { Factor } \\
\qquad 1\end{array}$ & $\begin{array}{l}\text { Local selsale coef } \\
\text { s. are glven for } \\
\text { general eqlpment } \\
\text { and Important } \\
\text { equlpaent. Blds. } \\
\text { ovners and atr. de } \\
\text { al gners can select } \\
\text { the value. }\end{array}$ & $\begin{array}{l}1-2 / 3-1.0 \\
\text { Bullding orners and str. } \\
\text { deslgners can deteralne } \\
\text { laportance and select } \\
\text { the value. }\end{array}$ & The same as left. & \\
\hline
\end{tabular}


TABLE 3. I SEISHIC DESIGN METHODS OF BUILDING EQUIPMENT. MONSTRUCTURAL EQUIPMENT AND BUILDING STRUCTURES (Continued)

\begin{tabular}{|c|c|c|c|}
\hline $\begin{array}{l}\text { Equipaent / } \\
\text { Coaponents } \\
\text { Aaplification } \\
\text { Factor } \\
\quad \mathrm{K}\end{array}$ & $K=1-$ & $\begin{array}{l}\text { The same as left In principie. } \\
\text { Speciflc values of the factor are } \\
\text { given sop' nonstructural components } \\
\text { (Joints of PC pancl. elc.. celling. } \\
\text { furniture). }\end{array}$ & \\
\hline $\begin{array}{l}\text { Range of Design } \\
\text { Selsaic } \\
\text { Coefficlent } \mathrm{K}_{n}\end{array}$ & $K_{\text {\% }}=0.14-2$ & The same as let 8. & $\begin{array}{l}\text { Deslgn seisnic forces are weh } \\
\text { affected by the above coefs. } \\
\text { and tactors. }\end{array}$ \\
\hline $\begin{array}{l}\text { Selsalc Design } \\
\text { of Equignent / } \\
\text { Components }\end{array}$ & $\begin{array}{l}\text { Selsalc perforaance of equipaent itself is } \\
\text { supposed to be confliemed by anutacturers. }\end{array}$ & $\begin{array}{l}\text { Selswic deslgn procedures of soae } \\
\text { nonstructural components (exterlor } \\
\text { rall. partlon all. celling. lloor. } \\
\text { (ree access floor. furnlture, conpu- } \\
\text { ter. etc.) are presented. }\end{array}$ & $\begin{array}{l}\text { Hotlfication. Hotlfication } \\
\text { Order and reguiatlon spedify } \\
\text { lateral selsmic force of vater } \\
\text { tanks, chimeys. cte. protru- } \\
\text { ding from roofs. }\end{array}$ \\
\hline $\begin{array}{l}\text { Deformablifty of } \\
\text { Equlpaent / } \\
\text { Components }\end{array}$ & $\begin{array}{l}\text { Ho coanents for equipaent in general. } \\
\text { Yertlcal plpes shall bo subjected to story } \\
\text { drift of } 1 / 200 \text { radian of storg helght in } \\
\text { principle. Plpes through expansion joints } \\
\text { shall be subjected to possibie aaxiaua } \\
\text { relative displacement among tro struetures. } \\
\text { Several datall exanples of piping at expanti } \\
\text { on joints and service connectlons to bidg. } \\
\text { to absorb possible displacements. }\end{array}$ & 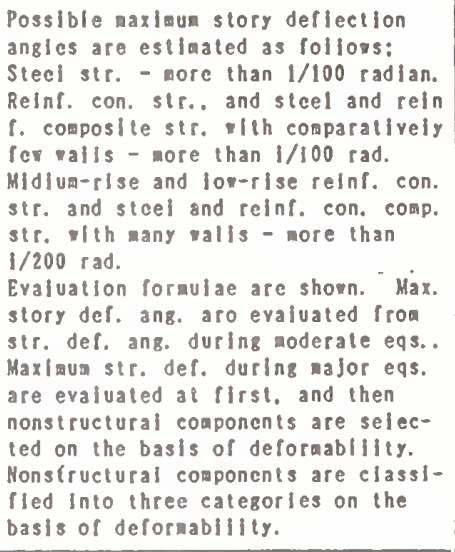 & $\begin{array}{l}\text { Story deflection angles lor } \\
\text { moderate earthquakes } \\
\text { : not more than } 1 / 200 \text { rad. } \\
\text { : not more than } 1 / 120 \text { rad. In } \\
\text { cases here such deformations } \\
\text { of structure of a specifle } \\
\text { buliding is not likely to lead } \\
\text { considerabie danage of any } \\
\text { part of the sald buliding. }\end{array}$ \\
\hline $\begin{array}{l}\text { Cross Section } \\
\text { Design of } \\
\text { Heabers of } \\
\text { Equipnent / } \\
\text { Components/Bidg }\end{array}$ & Allowabie Unit Stress for Teaporarily Load & The save as left. & $\begin{array}{l}\text { for Moderate Eqs. : Allowable } \\
\text { Unit Stress for Temp. Load } \\
\text { for Major Eqs. (Checking of } \\
\text { Uitlate Capaclty basing on } \\
\text { the ductllity of the str.) }\end{array}$ \\
\hline
\end{tabular}

Table 3.2 Example of Allowable Stress for Steel"

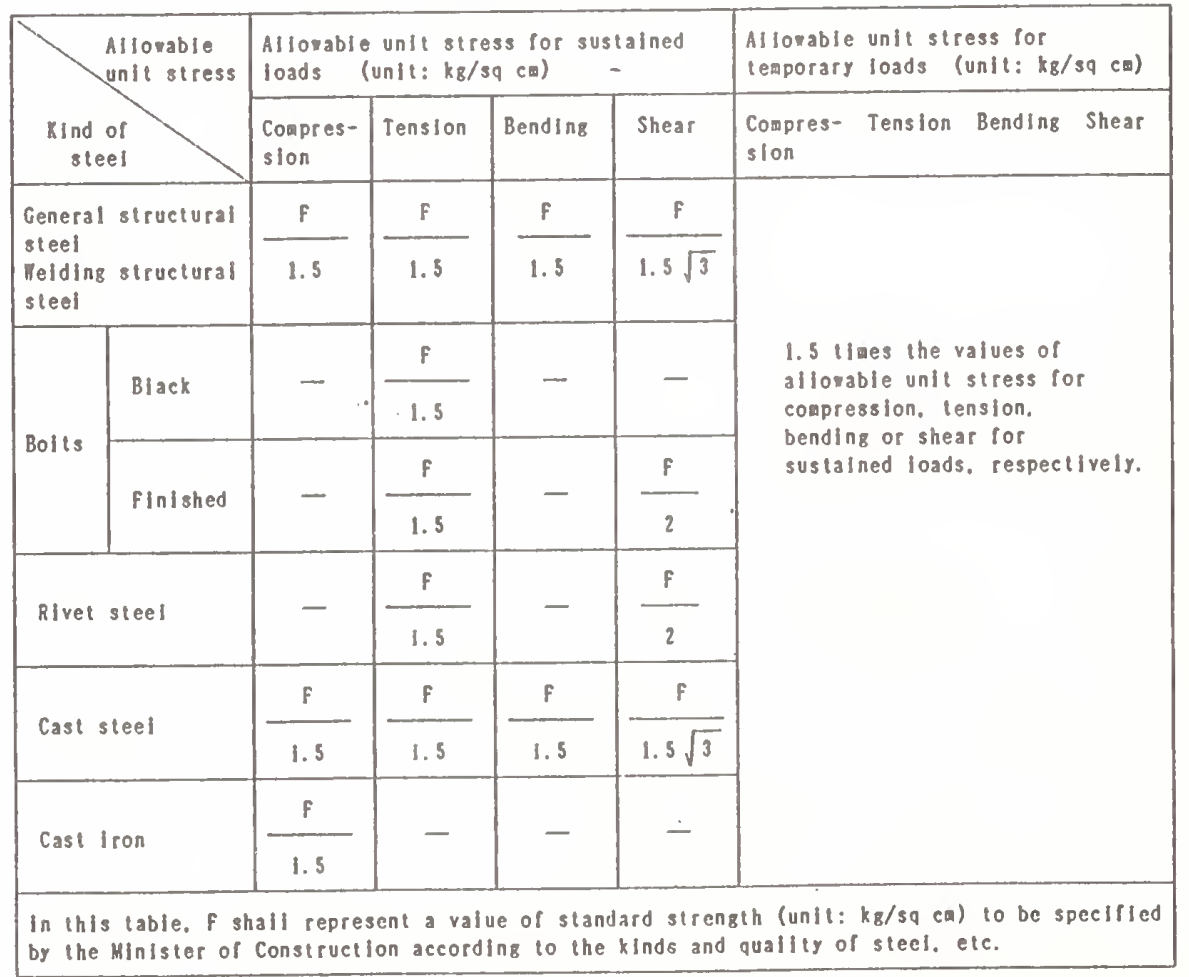




\section{Theme VI}

\section{International Decade for Natural Disaster Reduction}




\section{ABSTRACT}

The Loma Prieta earthquake provides a wealth of information on the seismic response of a wide variety of structures located in a large metropolitan area. Soil amplification of motions at sites distant from the epicenter contributed significantly to the damage developed during the earthquake. Because of the large shaken area, the earthquake provides much useful information on earthquake resistant design and preparedness planning. Structural damages resulting from the earthquake are reviewed herein with emphasis on buildings and bridges. Implications for modern design and retrofit methods are highlighted. Emphasis is placed on the need to carefully consider soil conditions, to treat a structure as a system rather than as an assemblage of independent elements, to explicitly define performance expectations, and to increase efforts to retrofit older seismically hazardous structures.

KEYWORDS: buildings; bridges; damage; earthquakes; retrofit; seismic resistant design.

\section{INTRODUCTION}

The Loma Prieta earthquake of October 17, 1989 has proven to be one of the most costly natural disasters in American history. Probably the most vivid examples of structural damages from the period immediately following the earthquake were the catastrophic collapse of the Cypress Street viaduct on Interstate 880 in Oakland, the partial collapse of a section of the San Francisco - Oakland Bay Bridge, and the distress to numerous buildings in San Francisco's Marina district. As additional data was gathered during the days and weeks following the earthquake, it became abundantly clear that damages were far more extensive than originally suspected.

In total more than 18,000 dwellings and several thousand other structures were significantly damaged by the earthquake. Nearly a thousand of these were destroyed by the earthquake itself and 500 more have been demolished since the earth- quake. Numerous buildings and bridges stand empty today as studies continue to determine the technical and economic feasibility of restoring their structural integrity.

Particularly severe damages were observed the epicentral region. The older downtown regions of Santa Cruz, Watsonville and Los Gatos (Fig. 1) were hard hit as were individual homes in the Santa Cruz mountain. Today, several square blocks in Watsonville and Santa Cruz have been demolished and stand vacant as silent reminders of the devastation caused by this earthquake. Highway and building structures were also damaged in localized regions throughout the greater San Francisco Bay Area. Significant damages were also observed in lifeline facilities (water pipelines and treatment plants, in particular), telecommunication facilities, and in the architectural and mechanical components and contents of buildings.

The total cost of the physical damages to structures is estimated by the Federal Emergency Management Agency (FEMA) to be in excess of $\$ 6.7$ billion. However, the total cost of the earthquake, considering the loss in immediate and long term business revenue, damage to contents and inventories, medical and workman's compensation claims, and reallocation of resources, is likely several times this amount.

The human toll of the earthquake was also substantial. Sixty seven fatalities resulted from the earthquake and more than 3,700 injuries were reported. While these numbers are large, they are no where as large as might have been expected considering severity of structural damage. The low number of casualties is attributable in part to the fact that on the day of the earthquake many people had gone home early to watch the baseball World Series.

\footnotetext{
*Professor of Civil Engineering, University of California, Berkeley, CA 94720
} 
For example, based on the number of vehicles expected on the Cypress Viaduct on a normal workday, estimates of fatalities made just after the earthquake exceeded 700 , substantially greater than the 42 deaths that actually occurred. This is indeed fortunate, but it is clear that had the earthquake occurred under more normal circumstances, casualties in this and other structures would likely have been far greater.

In addition, the number of damaged and destroyed dwellings resulted in more than 10,000 displaced persons. Finding adequate food and shelter for these individuals contributed significantly to the recovery efforts. Fortuitously, the weather was good and, with a few important exceptions, the transportation infrastructure remained intact permitting relief supplies to be delivered to the needy.

The Loma Prieta earthquake is the first major seismic event to strike a major metropolitan area in the U.S. in nearly 20 years. As such, it provides the earthquake engineering profession with a unique opportunity to assess structural design and retrofit methods. As the earthquake affected an area where even larger earthquakes are expected, an examination of the damages will provide particularly valuable indications of future damage trends. Because the levels of motion was not unusually severe, and because many different common structural types and soil conditions were excited, the earthquake also provides planners and engineers in other parts of the world with many valuable lessons.

In this paper, the overall nature of structural damages observed during the Loma Prieta earthquake are reviewed. After making some overall comments on the apparent severity and distribution of the damages, information regarding the specific types of structural damages observed is presented. Due to space limitations, emphasis is placed on building structures and bridges. Finally, the implications of these damages to the design of structures in seismically hazardous areas are offered.

Additional detailed information on the damages can be found in the References.

\section{SEVERITY AND DISTRIBUTION OF DAMAGES}

Ground motions were recorded at 131 sites and in 46 buildings during the earthquake. Correlation of this information with observed damage will provide a focus for research for many years to come. However, several important observations regarding the distribution and severity of structural damage can already be made.

First, ground motions recorded in the epicentral region were quite severe, ranging up to $64 \%$ of gravity. Motions greater that 30 to 40 percent of gravity were detected over a very wide area. Since these levels of motion approach those considered in the design of new structures, one might expect to see in these areas some significant damage to engineered structures, especially to older ones designed to lower force levels. However, damage in these areas with few exceptions concentrated in older unreinforced masonry and wooden structures.

Older types of engineered structures with known seismic vulnerabilities (such as non-ductile reinforced concrete buildings, tilt-up structures, precast buildings, etc.) generally survived the motions in the epicentral region without serious damage. While the precise reasons for this unexpectedly good behavior are under study by many at the moment, this anomaly reconfirms the limitations of peak ground acceleration as sole reliable index of earthquake damage potential. In this case, the recorded motions in the epicentral region ranged from 6 to 15 seconds, depending on the record and the method used to determine duration. This duration is short for this magnitude event. In addition, surface displacements induced by the shaking were also relatively small in comparison with those developed during other more typical and damaging earthquakes of this magnitude.

Comparison of the motion and damage data obtained for this and other earthquakes will provide very important insight into the factors that influence damage in structures. Until the outcomes of such studies are known, it is prudent to acknowledge that the Loma Prieta earthquake did not generate particularly damaging motions in the epicentral region and that it may not be conservative to extrapolate damages occurring in this region to other parts of the Bay Area or the world where earthquakes with greater damage potential might occur. 
Damage was quite serious to a wide variety of structural types in some areas outside the epicentral region. In particular, regions of San Francisco, Oakland and other areas as far as 80 to $100 \mathrm{~km}$. from the epicenter suffered significant damages. Peak ground accelerations recorded on firm soil at these distances were generally around $10 \%$ of gravity or less. However, most of the structures damaged in these areas were concentrated around the San Francisco Bay on man made land overlying bay mud or on soft, deep soil deposits. In these areas motions were recorded with peak accelerations ranging between 20 and $30 \%$ of gravity. Nonetheless, duration of shaking was relatively short, generally less than $6 \mathrm{sec}$., at these sites.

Attenuation of peak ground acceleration at distance was substantially less severe than might be expected on the basis previous west coast earthquakes. Whether this discrepancy relates to special features of the fault mechanism and resulting directivity for the Loma Prieta earthquake or unusual, high amplification of the earthquake waves by the soft bay mud requires additional study. Regardless, the large inventories of older, seismically vulnerable, structures located over these soils resulted in substantial numbers of damaged structures. Soil effects clearly had a dominant influence on the unusual severity and distribution of damages throughout the Bay Area.

Nonetheless, serious damage still concentrated in only the most vulnerable of structures since motions still were generally significantly below current design levels. On the other hand, the damage observed possibly provides a reasonable indication of the damages that might develop over a wider area if a large local earthquake occurred in the Bay Area. In this case, peak accelerations would approach those that developed only on soft soil during the Loma Prieta earthquake. These damages also may provide a useful indication of the nature of damages that might occur in other areas of the world where similar soft soil conditions exist. The 1989 Loma Prieta and 1985 Mexico earthquakes clearly point out the potential vulnerability of urban areas overlying soft deep soil deposit, even for distant earthquakes. This should have major implications for the Pacific Northwest, the central mid-west and many locations on the eastern seaboard of the U.S. and elsewhere in the world where similar conditions exist.
Significant damages also occurred to new and older buildings in the Palo Alto area. This region was relatively close to the epicenter and had large stocks of buildings. Ground motions ranging between 30 and 40 percent of gravity were recorded. Several new concrete and steel buildings suffered damaged as did older reinforced concrete, wood and masonry structures.

Thus, it appears that structural damage is highly dependent on the nature of the building inventories present in the shaken area, the types of soil conditions and the specific characteristics of the motions generated by the fault rupture and that arrive at the site. While efforts aimed at microzonation must continue, this sensitivity makes it from a practical perspective all the more important to design structures in accordance with the basic lessons learned from past earthquakes.

These past earthquakes have suggested the desirability of designing simple structures that are inherently insensitive to the uncertainties associated the input motions and soil conditions. Thus, emphasis should be placed on avoiding systems with limited redundancy or that tend to concentrate damage in a few locations, on providing details capable of large inelastic deformations, on selecting structural systems that are able to limit deformations to reasonable levels, and on attaching nonstructural components in such a manner that they do not adversely influence structural response and are not extensively damaged by the structural deformations.

The damages produced by the Loma Prieta earthquake must be reviewed to determine the continued soundness of these past lessons. In the following sections, the performance of a variety of structures will be reviewed with this in mind.

\section{DAMAGE TO BRIDGE STRUCTURES}

More than 1500 bridges exist in the area affected by the Loma Prieta earthquake. Eighty of these suffered some relatively minor damage during the earthquake, ten required shoring (though traffic continued to flow over them during repair) and another ten were closed due to the severity of the damage. Three bridges suffered collapse of one or more spans. These were the double deck Cypress Street Viaduct, the truss section of the San Francisco - Oakland Bay Bridge and the Struve Slough bridge west of Watsonville. The collapsed span on the Bay Bridge was replaced within about 
a month. The Cypress Street Viaduct has been demolished, and six other double deck viaducts in and near San Francisco remain closed a year and a half after the earthquake awaiting the results of engineering studies to determine whether they can be economically retrofit. The Struve Slough bridge was removed and rebuilt within a few months using modern design practices.

Virtually all of the bridges in the area had undergone the Phase I retrofit program, initiated by the California Department of Transportation (Caltrans) following the 1971 San Fernando earthquake. These retrofits consisted of installing cable restrainers at bridge expansion joints which are intended to prevent bridge deck members from sliding from their seats. These retrofits proved to be generally quite effective during the earthquake. In addition, at the time of the earthquake severa! bridges in the Bay Area, including the double deck Interstate 480 Embarcadero viaduct, were under design review for Phase II retrofits. The focus of this new retrofit effort was on tall single column bents that failed catastrophically during the 1971 San Fernando event.

\section{DAMAGE TO STEEL BRIDGES}

A number of long span steel bridges are used in the Bay Area to cross the bay and to span over the Sacramento River. Damage was reported to three of these: the San Francisco - Oakland Bay Bridge on Interstate 80, the San Mateo - Hayward Bridge on Highway 92 and the Carquinez Bridge where Interstate 80 crosses the Sacramento River at Carquinez Straits.

The portion of the San Francisco - Oakland Bay Bridge east of Yerba Buena Island consists of a double level freeway supported on truss spans. A large steel tower (numbered E9) is provided near the center of this segment of the bridge. This tower resists longitudinal loads from a single 506-ft. span to the west and two 290-ft. spans to the east. The two concrete roadways extend across the tower on sets of $50-\mathrm{ft}$. long, simply supported steel beams running parallel to the bridge's longitudinal axis. Each of these beams was bolted to a seat angle on the east, but the seat was allowed to slide freely at the west end. During the earthquake the beams slid from the free end with the west end of the upper deck resting on the lower one (Figs. 3 and 4). The lower deck was also unseated and came to rest several feet lower on an electrical transformer housing and the tower braces.

In addition, the bottom chords of the trusses were attached to the tower by means of twenty 1-in. diameter bolts. During the earthquake the bolts in the connection on the east side of the tower sheared completely and the bearing plate moved approximately 5-10 inches to the east. This was the proximate cause of the roadway beams slipping from their seats.

Additional damage to the eastern portions of the bridge were also identified. These damages ranged from spalling of concrete in support piers to shifting of bearing plates and breakage of anchor bolts.

The bridge was repaired by jacking the eastern segments back into place and providing new roadway beams and supports. The support seats were constructed about 50\% longer than in he original design. A more extensive study is currently under way by Prof. A. Astaneh and his colleagues at the University of California, Berkeley and by Caltrans to assess more reliable long term retrofits.

The San Mateo - Hayward Bridge is a steel orthotopic box girder bridge with a main span of $750-\mathrm{ft}$. During the earthquake one of the bearing assembles on an approach pier shifted. The cap screw used to retain the 5-1/2-inch diameter bearing pin stripped off. The upper portion of the bearing assembly shifted with respect to the lower potion by about 2-3/4 inches. The bridge was jacked back into position and repaired without interruption of traffic.

The Carquinez Bridge consists of a pair of steel cantilever truss spans. Bearings supporting steel plate girder on the approach to the bridge reportedly tipped over. These were repaired by jacking the girders up and re-setting the girders. In addition, the piers supporting the truss spans shifted in some locations as much at 2-inches.

The closure of the San Francisco - Oakland Bay Bridge and the damage to the other bridges crossing the bay clearly indicated how vital these vehicular arteries were to transport within the Bay Area. The Governor of the State of California has since signed a proclamation mandating that such critical bridge structures be designed to remain operable following a major earthquake. This is a significant departure from the emphasis usually 
placed on life safety in the design of such structures.

\section{DAMAGE TO REINFORCED CONCRETE BRIDGES}

The most spectacular damage to reinforced concrete bridges was the catastrophic collapse of nearly a mile long portion of the upper deck of the Cypress Street viaduct located in west Oakland on poor soil reclaimed from the bay (Fig. 5). This structure was designed in the early 1950's and construction was completed in 1957. The death toll from this collapse was 42 , though as mentioned earlier a thousand casualties or more might have been expected had the earthquake occurred during congested rush hour traffic.

A variety of factors contributed to the failure of this structure. These include the amplification of the ground motions due to the soft soil conditions in the vicinity, traveling wave effects, and variable soil conditions. The structure was also built at a time when earthquake resistant design procedures were not highly developed. Thus, while the bridge appears to have been conservatively designed relative to the structural requirements in force at the time of its construction, it has a number of major deficiencies with respect to current construction practices.

This bridge represented in many respects a substantial advance in the state of the art at the time it was built. Not only did it have two levels, it was one of the first major bridge structures in the U.S. to employ post-tensioning and large diameter reinforcing bars. In most cases the structural system incorporated a significant number of flexural hinges in order simplify the future addition of access ramps, to reduce secondary forces resulting from deformations associated with post-tensioning and foundation settlement, to reduce computational effort and to control moments that could be transferred to the foundations. This resulted in a structure that was nearly statically determinant. In addition, detailing did not incorporate features needed to impart ductility to the elements (shear reinforcement sufficient to develop the flexural capacity of members, confinement of potential plastic hinge regions and inadequate development length on reinforcement), and joints were neither confined nor designed to resist the shear forces associated with realistic lateral loadings. Details of a typical transverse bent are shown in (Fig. 6). In addition, in the longitudinal direction, frame action depended on the bending forces developed in the decks being transferred to the columns by torsional forces developed by shear friction. A relatively massive and brittle structure resulted.

Detailed studies by Nims et al (1989) and others have indicated that any of a number of structural deficiencies could have triggered the collapse. The lack of redundancy (needed to redistribute forces in the event of the failure of an element) and the brittle details utilized made the final catastrophic outcome a certainty, regardless of the actual trigger of the failure and details of the seismic input.

The dominant features of the typical collapse mechanism are shown in (Fig. 7). Shear cracks in the pedestal supporting the hinged upper level columns were able to extend downward into the joint region following the projection of downward bending hooks on the end of the transverse girder's (cap's) top level reinforcement. The lack of shear reinforcement in the joint allowed this inclined crack to act like a slide, with the resultant pancake collapse of the upper level.

The sudden and catastrophic nature of this failure mechanism was demonstrated convincingly during the demolition of the viaduct. A wrecking ball was used to initiate failure in a single column. Almost immediately progressive collapse occurred throughout the upper level not only extending transversely across the roadway, but also longitudinally for six bays to the end of the remaining standing portion of the viaduct (Fig. 8). Clearly, such brittle structures are not compatible with earthquake resistant design.

Upon construction of the Cypress Street viaduct a series of six other double deck viaducts were designed and constructed in the San Francisco Bay Area. All of these suffered damages during the earthquake. Each suffered characteristic distress in the lower joint regions similar to that developed in the Cypress Street structure. An example of this is the Southern Freeway portion of Interstate 280 located near the southern border of San Francisco (Fig. 9).

A bent in a curved connector structure between Interstates 880 and 980 near the Cypress viaduct also suffered damage. A knee joint extending transversely from the side of the deck developed severe shear cracks and a \#18 bar fractured at the hook (Fig. 10). The apparently inadequate shear 
capacity of such joints is of concern, since the structure was only about two years old at the time of the earthquake. Similar damages were seen on several older single level viaducts (e.g., where Interstate 280 crosses Mission Creek). Improved design criteria and retrofit procedures for such knee joints are under investigation by Caltrans.

Two short bridges crossed over Struve Slough near Watsonville. These consisted of multiple, skewed T-beam spans supported on monolithic pile bents. During the earthquake the supporting piles failed in shear, resulting in the deck of one of the bridges collapsing and the piles punching up through the deck.

\section{RETROFIT TESTS OF CYPRESS VIADUCT}

The need for rapid retrofit of the damaged double deck freeways in the San Francisco area led to a series of field tests on undamaged portions of the Cypress Street viaduct. These tests consisted of forced vibration studies to determine the dynamic characteristics of the structure and static lateral load tests in the transverse direction to determine force and deformation capacities. Tests were performed on a relatively unmodified segment of the structure, as well as on the same segment after it was retrofit. The three bents used in the tests are shown in (Fig. 11). The results of these tests have been reported by Moehle and Mahin (1990).

Tests on the original structure indicate that the upper column pedestal and the adjacent lower joint developed cracking characteristic of the damage leading to the failure of the structure

(Fig. 7) at a displacement of about 3/4-in.

$(191 \mathrm{~mm})$ at the upper deck level. The total lateral load of 1400 kips (635t) applied to the three bents corresponds to an equivalent base shear coefficient of about 0.32 assuming a 2:1 distribution of loads to the upper and lower deck levels. A simple elastic time history analysis of the test structure has shown that it would have required a base shear coefficient at least $61 \%$ larger to have remained elastic for a ground motion recorded nearby. The working stress base shear coefficient utilized in the original design was 0.06 .

Three different types of retrofits for the lower joints were investigated. In addition, upper and lower bent caps (girders) were externally posttensioned to help compensate for inadequate bar development lengths, and to provide increased strength and confinement in the joints. Most of the columns were reinforced in shear by adding exterior post-tensioning.

The retrofits were able to maintain the vertical load integrity of the test structure. However, significant damage was observed. In particular, the critical failure zone moved away from the lower joint to the upper joints, which began to fail and disintegrate during the tests. Diagonal cracks in the upper joints began at displacements at the upper deck level of less than 1-in (254 mm). In addition,the non-retrofit columns began to fail in shear at an upper deck level displacement of about 1.5-in. (381 mm) and an equivalent base shear coefficient of about 0.61 .

After strengthening the shear damaged columns, the structure was again cycled and lateral displacements of 9.8 -in. $(0.25 \mathrm{~m})$ were achieved at its top along with equivalent base shear coefficients of 0.91 . These values are about 13 and 3 times greater, respectively, than the values that could have been developed by the original structure (Fig. 12).

One of the bents had heavy steel wide flange sections post-tensioned vertically along the face of the columns like splints. During the tests composite action could not be maintained and the relatively long lengths of unbounded post-tensioning steel used resulted in large cracks and spalling in the lower joints and in gaps between the steel and the concrete (loss of confinement) over large portions of the columns and joints.

Another bent had inclined rock anchors grouted in the lower joints. This bonded reinforcement proved effective in resisting perpendicularly oriented shear cracks. However, towards the end of the tests spalling and flexural cracking and joint shear cracking had begun. The continued integrity of this retrofit scheme under these conditions was not fully addressed.

The third retrofit consisted of a heavy steel collar placed around the pedestal and the base of the upper level column. This collar was post-tensioned to the sides of the lower joint. During the test the collar was observed to rotate about the lower joint and, upon its removal following the tests, fully developed sets of inclined cracks were observed in the joint along with much pulverized concrete. 
These tests indicate the effectiveness of retrofitting existing bridge structures. However, they point out the need to consider a structure as a system and not to simply fix the damaged or over-stressed portions. The limitations of the tests must also be recognized. Loading of the test structure was halted when the test site had to be vacated. However, the structure was not believed safe to continue testing at that time. The deformation history imposed may not be conservative for the most severe ground motions expected in the Bay Area. In addition, no attempt was made to retrofit or test the structure in the longitudinal direction and this mode of behavior must be carefully considered.

\section{DAMAGE TO WOODEN BUILDINGS}

As indicated previously nearly 20,000 dwelling units were damaged during the Loma Prieta earthquake and 10,000 individuals were forced to relocate as a result. A majority of these displaced people lived in wood frame houses and apartments. Many homes located in the Santa Cruz mountains, in the immediate epicentral region, were damaged. Damages ranged from fallen chimneys and porches to partial or complete collapse. Many wood frame buildings in the hardest hit areas were overwhelmed by the seismically induced inertia forces. Sadly, the majority of the damage occurred in older wood frame buildings where the structures were simply not connected to their foundations. During the earthquake, as they have in innumerable past earthquakes, the structures simply shifted off their foundation with resultant vertical dislocation (Fig. 13).

Another common type of failure that was observed related wood frame dwellings built upon short pony or cripple walls. These short walls provided a two to four foot (0.6 to $1.2 \mathrm{~m}$ ) tall access space that was used for storage, ventilation and to accommodate sloped sites. In many older buildings the framing between the ground floor and the foundation consisted of vertical studs and horizontal siding. Even though diagonal braces were provided in the upper levels to resist lateral loads, braces were typically omitted from the pony walls. In addition, the horizontal siding covering these walls in most cases had badly deteriorated and effectively provided little or no lateral resistance (Fig. 14). The failure of these short support walls resulted in large vertical and lateral displacements of the supported structures (Fig. 15).
The unfortunate aspect of both of these forms of damage is that simple and economical retrofit procedures, if implemented prior to the earthquake, could have prevented or significantly reduced the severity of the observed damages. Repair following the earthquake was generally extremely expensive not only as a result of the required structural repairs, but because of wide spread damages to architectural, electrical and mechanical features. Pre-earthquake retrofits to these walls and foundations were seen to be effective in several instances in Santa Cruz and elsewhere.

Another form of damage to wooden structures was observed in the Marina District in San Francisco. This area was constructed on loose, fine sandy hydraulic fill. During the earthquake the area exhibited evidence of significant liquefaction with localized sand boils, lateral spreading, slumping and heaving of sidewalks and roadways.

Many wood buildings were damaged or collapsed in this area. However, a detailed inspection of the damages indicates that the collapses were concentrated in three or four story apartment buildings (Fig, 16) located at the corners of blocks (or where a structure was not sandwiched between two ther adjacent buildings with little or no separation). These older apartment buildings were generally constructed with relatively massive apartment floors supported over a level of garages (Fig. 17). The bottom level thus was largely open to allow for multiple garage door openings. Typically, parking stalls were several cars deep and often extended out though the back of the building to provide for even more parking. This situation resulted in a soft first story. Lateral load resistance was provided by horizontal wood sheathing (often covered by brick veneer) placed over only a few walls. This sheathing was observed to have decayed severely in many cases during the life of the structure.

The amplified seismic motions in the Marina District resulted in the collapse of the lower level of these corner apartment buildings in many cases. It is significant to note that these types of apartment complexes are quit common throughout San Francisco. Some apparently identical buildings located only a few blocks away from the heavily damaged area, but on firmer ground, remained virtually undamaged following the earthquake. 
Nonetheless, the potential hazard posed by these structures during future more severe earthquakes should be carefully investigated.

Initial suppositions regarding to the causes of the severe structural damage in the Marina District focused on the observed soil liquefaction. However, structures did not collapse or suffer substantial damage even in the most heavily afflicted area, if the lateral load resisting system was continuous over the height of the building. Another remarkable feature was the limited damage to residential homes located along the middle of a block. These structures typically were two or three stories tall, with adjacent structures having the same floor elevations and virtually no separation. As noted in during other recent earthquakes, such structures seem (at least initially) to buttress one another and suffer only limited damage. More extensive damage occurred in buildings located at the corners of blocks. Where liquefaction occurred near or under a structure, vertical differential settlements of a few inches were observed with resultant structural and especially architectural damage.

Similar damages were also observed in other areas of San Francisco, notably in the Mission Creek area located south of Market Street. The distribution of this damage is similar to that following the great 1906 San Francisco earthquake.

\section{DAMAGE TO UNREINFORCED MASONRY BUILDINGS}

The older downtown areas of many well established cities in California were built of unreinforced masonry. These commercial areas suffered significant damages in Watsonville, Santa Cruz, Oakland and San Francisco. However, damage appears to be strongly influenced by local soil conditions and the intensity of ground motions. This can be seen in Table 1 where the approximate numbers of unreinforced masonry (URM) buildings vacated following the earthquake are compared with the total stocks in various cities. Cities are listed in order of decreasing epicentral distance.
Table 1. Damage Statistics for URM Buildings*

\begin{tabular}{|c|c|c|}
\hline City & Approx. Number & $\begin{array}{l}\text { Number } \\
\text { Vacated }\end{array}$ \\
\hline \multicolumn{3}{|c|}{ 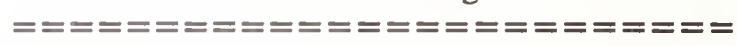 } \\
\hline Berkeley & 400 & 5 \\
\hline San Francisco & 2000 & 252 \\
\hline Oakland & 2000 & 400 \\
\hline \multicolumn{3}{|l|}{ South San } \\
\hline Francisco & 42 & 2 \\
\hline San Mateo & 28 & 1 \\
\hline Salinas & 96 & 16 \\
\hline Hollister & 17 & 14 \\
\hline Palo Alto & 49 & 0 \\
\hline Mountain View & 20 & 6 \\
\hline Gilroy & 41 & 2 \\
\hline San Jose & 230 & 3 \\
\hline Los Gatos & 29 & 11 \\
\hline Santa Cruz & 46 & 36 \\
\hline
\end{tabular}

$==\mathrm{=}=\mathrm{=}=\mathrm{=}=\mathrm{=}=\mathrm{=}=\mathrm{=}=\mathrm{=}=\mathrm{=}=\mathrm{=}=$

*Adapted from Benuska (1990)

Only limited damage was detected in Gilroy, for instance, even though motions in excess of 50 percent of gravity were recorded in the vicinity of several unreinforced masonry structures. In other cities damage only concentrated in certain areas, with severe damage in some areas and virtually none in others. While soil conditions play an important role in this distribution, the precise interrelationships between the various factors influencing damage in this class of hazardous structure need careful study.

The most prevalent form of damage to URM structures was the collapse or dislocation of parapets. In most of these cases the masonry was tied to the floor diaphragm by means of steel anchors. The short extension of the wall above the roof fell from many buildings, even where only moderate ground motions occurred far from the epicentral region.

A particularly devastating form of damage resulted when the walls were not tied to the floor diaphragms. In many cases the walls failed outof-plane, falling into the street (Fig. 18). In several notable cases the walls fell from upper floors of a building onto the roof of a lower adjacent structure (Fig. 19). The damage to the lower building resulted in two deaths in two separate buildings in Santa Cruz. In another instance, five casualties resulted when a wall collapsed onto the sidewalk area in front of an 
unreinforced masonry structure. For the level of shaking encountered, moderate amounts of tie reinforcement appeared effective in limiting this type of damage.

In some cases in-plane shear failures of brick walls was observed (Fig. 20). In some cases this distress resulted in local collapse of wall panels. In other buildings wide spread, inclined cracks developed, stepping along weak mortar joints. In many cases buildings with moderate cracking have been left un-repaired with continued occupancy or the cracks have been simply repaired with epoxy injection to insure water tightness.

Brick and stone architectural veneers fell from many buildings. Typical metal inserts embedded in the mortar joints proved insufficient when the attachment nails pulled from the wood framing. The framing under the veneer had deteriorated badly in many of these cases. In other cases the veneers were dislodged as a result of hammering against adjacent structures.

\section{DAMAGE TO REINFORCED CONCRETE STRUCTURES}

While non-ductile concrete frames have performed poorly in past earthquakes, few of these types of buildings were located in areas subject to severe ground shakings during the Loma Prieta earthquake. In some cases severe shear cracks were observed in columns. However, the buildings in question (for example, along Mission Street near Third Street in San Francisco) were located midblock with no space separating them from the adjacent structures. It is expected that the adjacent structures provided the required lateral resistance in these cases.

In Watsonville, where peak accelerations of $39 \% \mathrm{~g}$ were recorded, an old five story reinforced concrete frame structure appeared to suffer mainly architectural damage. The building had a number of broad shear walls which apparently accounted for its good behavior in spite of the severe motions recorded in the area.

Damage was observed in a number of newer reinforced concrete structures. For example, a mechanical penthouse, containing a water tank, fell from the top of a reinforced concrete multistory hotel in Burlingame. Across the street another hotel, build less than 16 months prior to the earthquake, suffered significant damages to its shear walls in the lower levels and to its diaphragms near the shear walls. Both of these hotels were constructed on fill over bay mud. Motions at the nearby San Francisco International Airport were up to $33 \% \mathrm{~g}$.

A ten story moment frame constructed in San Jose of lightweight concrete suffered severe spalling damages in several locations and architectural damages in spite of ground motions in the area less than $11 \%$ g. lightweight concrete shear walls in a 15 story telecommunications building (Fig. 21) in Oakland suffered severe cracking, spalling and splitting in the lower story. This building was designed as a dual system with steel frames proportioned to carry $25 \%$ of the lateral forces along with the gravity loads.

Damage also occurred in reinforced concrete buildings used as hospitals and schools. The seven story tower of the Peralta Hospital, built in Oakland in 1927, was severely damaged and has been demolished following the earthquake. The Palo Alto Veterans Administration Hospital suffered serious damage, including shear cracking to the columns in two of six buildings. The four buildings without damage had been previously retrofit. A number of reinforced concrete buildings on the Stanford University campus, including the School of Business Administration, the Library and some residence halls suffered moderate cracking. The John O'Connell High School in San Francisco suffered serious structural cracking to its frame-wall system.

\section{DAMAGE TO STEEL BUILDINGS}

Damage to steel buildings was typically less obvious than that to masonry or concrete structures. However, there were several reports of buckled braces in several buildings along the San Francisco Peninsula near San Mateo and Palo Alto. In most cases these could be fixed within a few days. In other cases substantial effort was needed to find damage in buildings where large amounts of architectural distress suggested the presence of structural damage. Evidence of panel zone buckling, gusset plate yielding and buckling, and column buckling were found in several buildings. 


\section{DAMAGE TO RETROFIT STRUCTURES}

The engineering profession has known for many years of the seismic vulnerability of many types of structural systems and has attempted to retrofit many of these structures. The Loma Prieta earthquake provides an opportunity to assess the efficacy of the procedures used.

A good example of the effectiveness of retrofits is the performance of a four story reinforced concrete telecommunications building in Watsonville. This building had been be upgraded by infilling windows and adding shear walls. During the earthquake accelerations were recorded up to $1.24 \mathrm{~g}$ at the roof without the building suffering any significant structural damage. Another example is the retrofit reinforced concrete structures at the Veterans Administration Hospital in Palo Alio. As mentioned previously, these suffered little damage in comparison to the non-retrofit units.

On the other hand, there is ample evidence that some retronit schemes did not work as well. This is attributable to the lack of any performance standards for retrofit work, any code to set load and detailing requirements, and virtually no research on the effectiveness of many types of retrofit procedures used in practice.

One example of this situation is a 6 story reinforced concrete building constructed in San Francisco at 150 Fourth Street during the early 1980's (Fig. 22). During change of ownership a few years after it was built a number of seismic deficiencies were identified. These were remedied on the basis of protection of the life safety of the occupants by adding steel braces and shear walls. Following the earthquake, connections in the steel braces were observed to buckle (Fig. 23), the attachments of the braces to the concrete frames had slipped (in some cases due to faulty installation of anchor bolts), extensive cracking occurred in the shear walls, and initiation of punching shear failures in a few column to flat plate connections. The building has been since repaired (Fig. 24) to restore the capacity that existed prior to the earthquake.

Another example, is the Hotel Oakland in Oakland. This is a steel frame building with extensive masonry infill panels. In retrofitting this structure new lateral load resisting elements were added and the exterior masonry elements were positively attached to the building to prevent large panels from falling into the street. As result of the earthquake nearly all of the masonry piers in the building developed distinctive $\mathrm{x}$-shaped shear cracks. In addition, at a few locations masonry elements were dislodged from the building and fell to the street (Fig. 25). This building apparently preserved life safety as intended, but extensive and expensive repairs were required to restore the building fully to service.

Most of the focus of retrofit work has logically been on unreinforced masonry buildings. In a recent study by Conrad (1990) 400 of San Francisco's more than 2000 URM buildings were inspected and 69 were identified as having been retrofit to some degree. This would indicate that only about $3 \%$ of the city's URM buildings have been retrofit. Most of the retrofits had been implemented through the introduction of steel braces. Retrofit structures tended to be found in clusters where a local community was being redeveloped. The report found that $54 \%$ of the retrofit buildings suffered no damage, but no comparison with the performance with adjacent non-retrofit structures was offered. Light damage was observed in $22 \%$ of the retrofit structures and moderate damage was seen in another $20 \%$. Heavy damage was seen in three buildings (3\%).

One of these structures (259 Front Street) was located at the corner of a block and it was heavily braced along two street sides (Fig. 26). The added braces at the street level buckled out of plane significantly (Fig. 27), but no damage was actually found in the masonry portions of this four story building. The second structure (1051-1075 Battery Street) was also braced but the mortar in the existing masonry walls was apparently so poor that random sections of the exterior wall fell from the building. Another building (located at the corner of Sixth and Bluxome Streets) had apparentiy been partially retrofit by addition of wall anchors. Five people were killed as the upper level wall on one side of the structure fell onto the sidewalk and street. This damage may have been initiated by pounding with an adjacent building. In all of these cases it is clear that the lack of a consistent, systems approach to the design of the retrofits had a detrimental effect and that a new class of potentially hazardous buildings (i.e., the inadequately retrofit structure) needs to be investigated. 


\section{DAMAGE DUE TO HAMMERING OF ADJACENT BUILDINGS}

Another important observation from the Loma Prieta earthquake is that many buildings suffered damage due to pounding. The separation of many buildings was insufficient to avoid collision of the upper stories. A wide range of damage resulted, from local spalling of veneers near the impact point through cracking of vertical supporting members to failure (though not collapse) of columns. Field inspections have identified several hundred cases where pounding contributed to the observed damage. In many instances it was apparent that a few more cycles of impact could have caused the failure of the structures involved (Fig. 28). In many of the severely damaged unreinforced masonry structures evidence suggests that pounding was a contributor to the damage.

In one instrumented building in Oakland (at the intersection of 17th and Harrison Streets) the records show clear evidence of pounding at one corner of the building. The steel moment frame building (with reinforced masonry walls along the property lines) was separated from the adjacent unreinforced masonry storefront by about an inch (25 mm). However, no significant damage was observed in either building as a result of the pounding.

Damage due during the 1985 Mexico and other earthquakes suggests that pounding is a serious problem that needs to be addressed by the engineering profession. A number of investigators are currently studying this problem as it relates to the Loma Prieta earthquake.

\section{LOSS OF FUNCTIONALITY}

An important observation regarding damage to structures during the Loma Prieta earthquake has been the public's reaction. Most structures performed generally in conformance with the design professions expectations. New structures and most engineered structures did not collapse, and life safety was protected, even in regions of severe shaking. However, these motions were not the most severe or damaging that might be expected in the Bay Area. Nonetheless, the public reaction to these damages was generally that they were excessive.

There was much nonstructural damage to partitions, ceilings, cladding and contents (Fig. 29) in structures with little or no structural damage. This damage not only contributed a significant life safety threat in many cases, it disrupted the functionality of the structures and added substantially to repair costs. One ten story building in Oakland reportedly had \$6 million in water damages due to the breakage of a fire sprinkler line.

Structural damages were repaired quickly in many cases, but in other cases considerable delays were encountered as owners await financing or as technical difficulties are encountered. In many cases the resulting repairs were cosmetic or intended to simply restore a structure to its pre-quake condition.

Large institutional owners or ones with significant capital investments have increasingly developed heightened awareness of the need to control damage. In addition to consideration of life safety for a structure's occupants, they have become concerned over institutional life safety. For example, Stanford University has developed much more stringent criteria since the earthquake for retrofitting their seismically hazardous buildings. Having had to relocate several departments and instructional and research facilities following the earthquake, they now stipulate that buildings should be designed or retrofit to permit repairs to be made within a few days or weeks of the earthquake (depending on the occupancy of the building). Other institutions that cannot similarly just pick up and move have come to similar conclusions. Similarly, the Governor's proclamation also indicates that California state buildings should be built or retrofit so that they would remain operable following a major earthquake. This is a major departure relative to the conventional design of buildings.

\section{IMPLICATIONS FOR EARTHQUAKE RESISTANT DESIGN}

Few new lessons have been developed as a result of the Loma Prieta earthquake. However, as the first major urban earthquake in the U.S. in nearly two decades, the earthquake stands as a compelling reminder of many important past lessons. We have again seen the vulnerability of several major classes of buildings designed in earlier eras when our knowledge of earthquake resistance was not fully developed. The damages to numerous unreinforced concrete buildings, wood dwellings with inadequate foundation attachments, soft story 
structures (e.g., Marina District apartment houses) and non-ductile concrete frames (e.g., double deck viaducts) are reminders of well-known past lessons.

Similarly, the important effects of soil liquefaction and site amplification have been seen in many past earthquakes, such as the 1985 Mexico, 1967 Venezuela and 1964 Nigatta, Japan earthquakes. The Loma Prieta earthquake indicates that these soft soil sites should be carefully considered in design as they will be sensitive not only to close earthquakes, but also to any number of earthquakes generated on other relatively distant faults.

The special need to have a safe and dependable transportation system has been again demonstrated. It has been seen that certain structures may be more critical than others, and greater levels of conservatism should be considered to assure their operability even following a major earthquake.

At the same time some past phenomena were not seen. However, the Loma Prieta earthquake appears to be an unusual earthquake in many respects and its motion in the epicentral region appears not to be as damaging as other typical earthquakes in the western U.S. Thus, the good behavior of some types of structures during this earthquake should not lead to complacency in implementing their retrofit.

The damages provide a clear warning to the Bay Area and to other seismically active areas of the world to increase preparedness activities. In particular, the substantial hazard posed by our older seismically vulnerable structures must be remedied. This can only be done through reliable evaluation and retrofit criteria developed and validated on the basis of laboratory research and quantitative investigations of the seismic performance of buildings during earthquakes.

The earthquake has shown a greater value being placed by the public, government and corporate entities on reducing economic as well as life hazards. Control of damage during earthquakes need not involve great expense, but additional attention to the selection of the structural system and to detailing of nonstructural components. Additional research is needed to provide a reliable design basis for such considerations.
Finally, it must be recalled that the timing and location of the Loma Prieta earthquake were fortuitous. The epicenter was in a sparsely populated region relatively far from urban centers. It also occurred at a time when many people were away from the most vulnerable structures. This set of favorable circumstances can not be expected to occur for all future earthquakes.

\section{ACKNOWLEDGMENTS}

Many of the research observations made in this paper were made possible by the generous research support provided by the National Science Foundation and the California Department of Transportation. In addition, the author would like to thank his many colleagues, especially Jack Moehle, Hasan Astaneh and Roy Stephen, for sharing their observations with him. The findings and conclusions of this paper, however, must be blamed solely on the author alone.

\section{REFERENCES}

Astaneh, H. et al (1989), "Preliminary Report on the Seismological and Engineering Aspects of the October 17, 1989 Santa Cruz Loma Prieta) Earthquake, "Report No. UCB/EERC-89/14, Earthquake Engineering Research Center, Univ. of California, Berkeley, October.

Benuska, Lee, Editor (1990), "Loma Prieta Earthquake Reconnaissance Report," Earthquake Spectra, EERI, Supplement to Vol. 6, May.

Conrad, J. (1990), "Performance Evaluation of Strengthened Unreinforced Masonry Structures Following the October 17, 198 Loma Prieta Earthquake," Graduate Student Report, Dept. of Civil Engineering, Univ. of California, Berkeley, May.

Dames and Moore (1990), A Special Report on the Oct. 17, 1989 Loma Prieta Earthquake, Los Angeles, CA, January.

EQE Engineering (1989), Oct. 17, 1989 Loma Prieta Earthquake: A Quick Look Report, San Francisco, CA, November. 
The Governor's Board of Inquiry on the 1989 loma Prieta Earthquake (1990), "Competing Against Time," Report to Governor George Deukmejian, Housner, G.W., Board Chairman, Thiel, C.C., Editor, May.

Nims, D.K. et al (1989), " Collapse of the Cypress Street Viaduct as a Result of the Loma Prieta Earthquake, "Report No. UCB/EERC. 89/16, Earthquake Engineering Research Center, University of California, Berkeley, November.

Seed, R.B. et al (1990), "Preliminary report on the Geotechnical Aspects of the October 17, 1989 Loma Prieta Earthquake," Report No. UCB/EERC90/05, Earthquake Engineering Research Center, Univ. of Calif., Berkeley, April. 


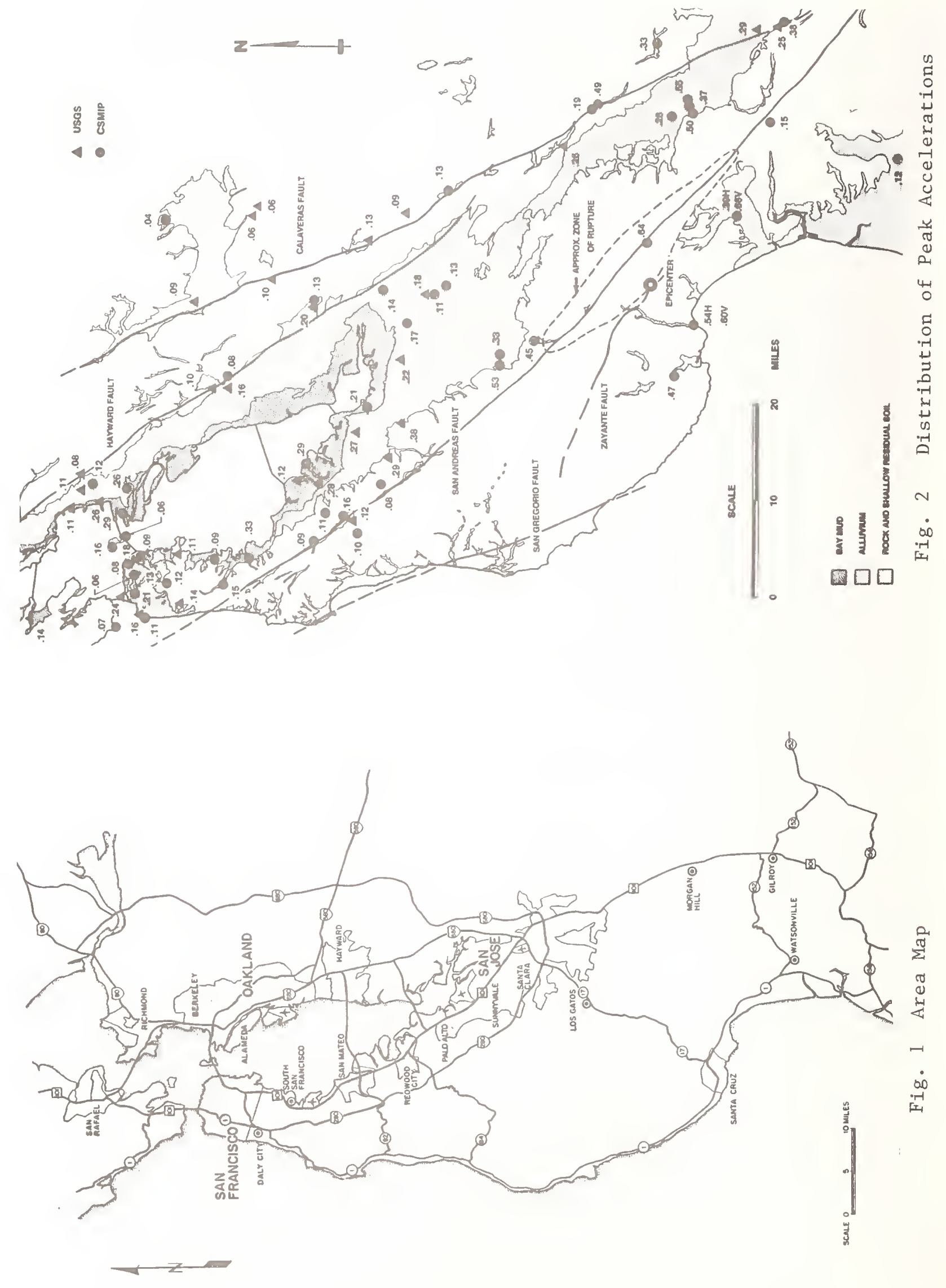



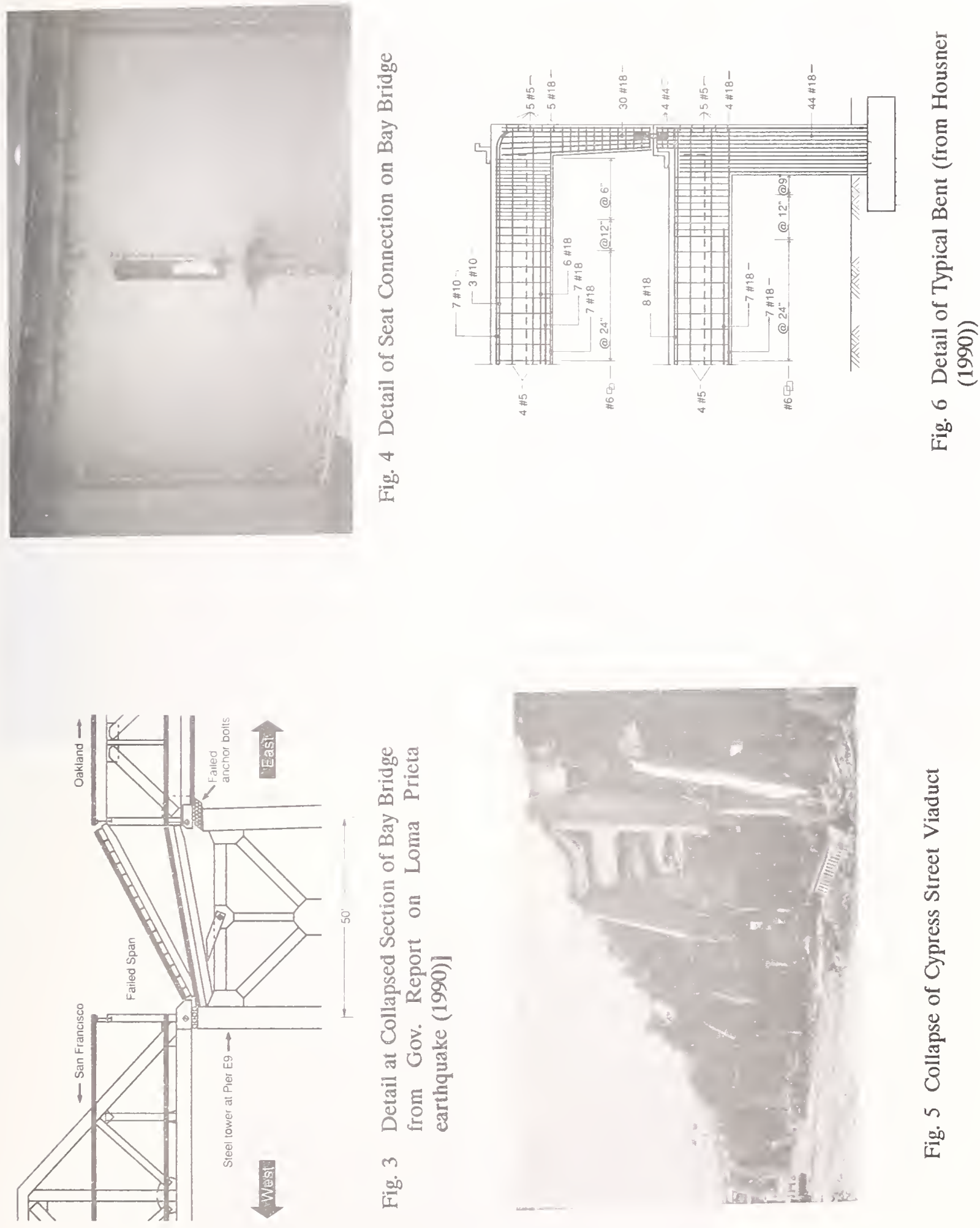

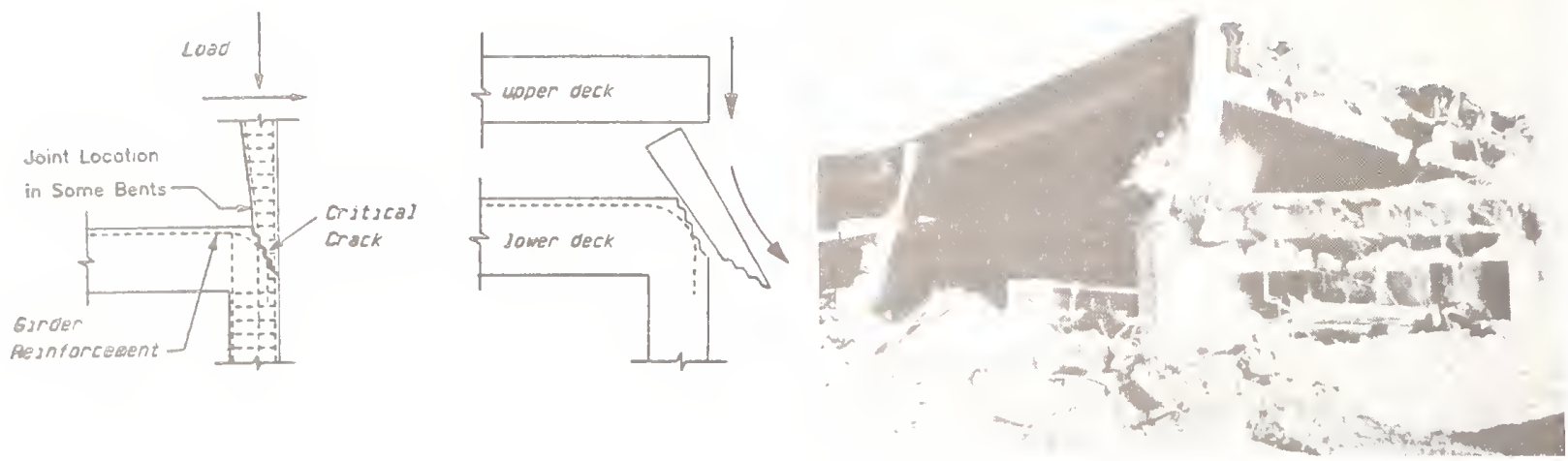

Fig. 7 Postulated Failure Mode

Fig. 8 Failure Mode Observed during Demolition
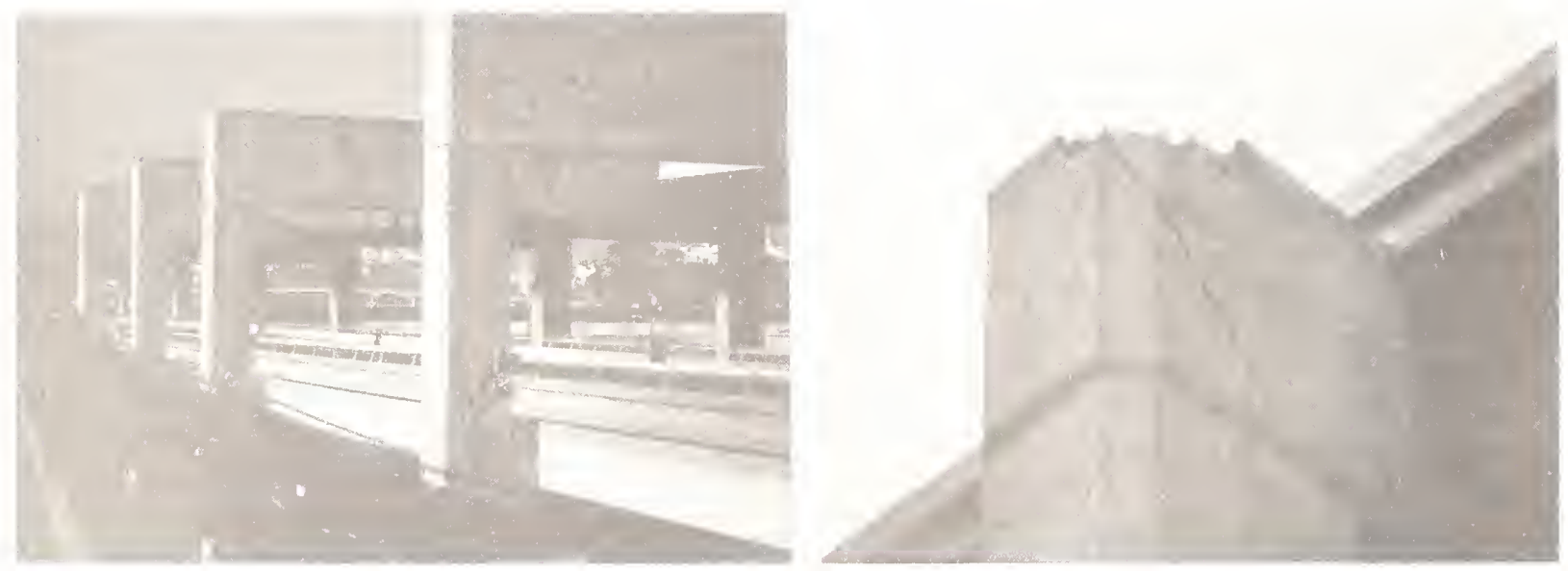

Fig. 9 Damage to Southern Freeway

Fig. 10 Damaged Knee Joint in New Freeway

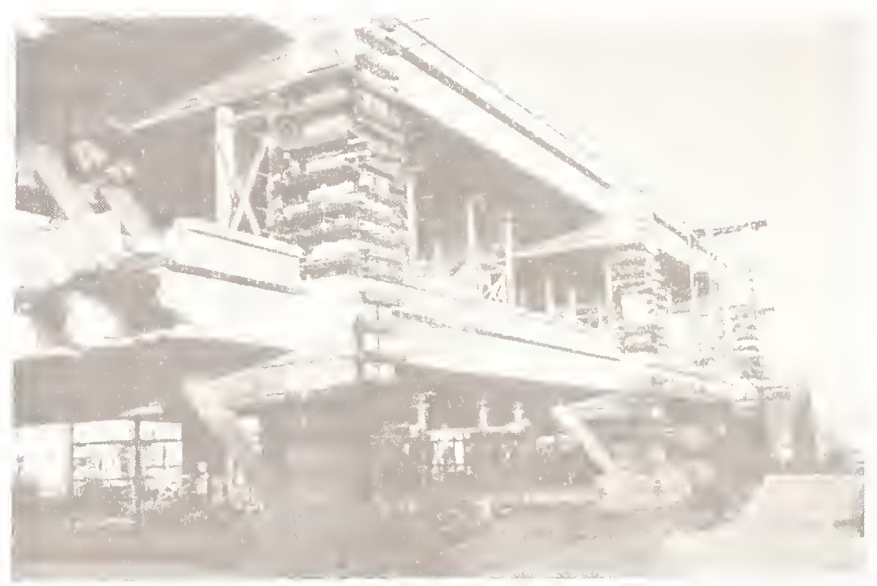

Fig. 11 Cypress Street Test Structure 

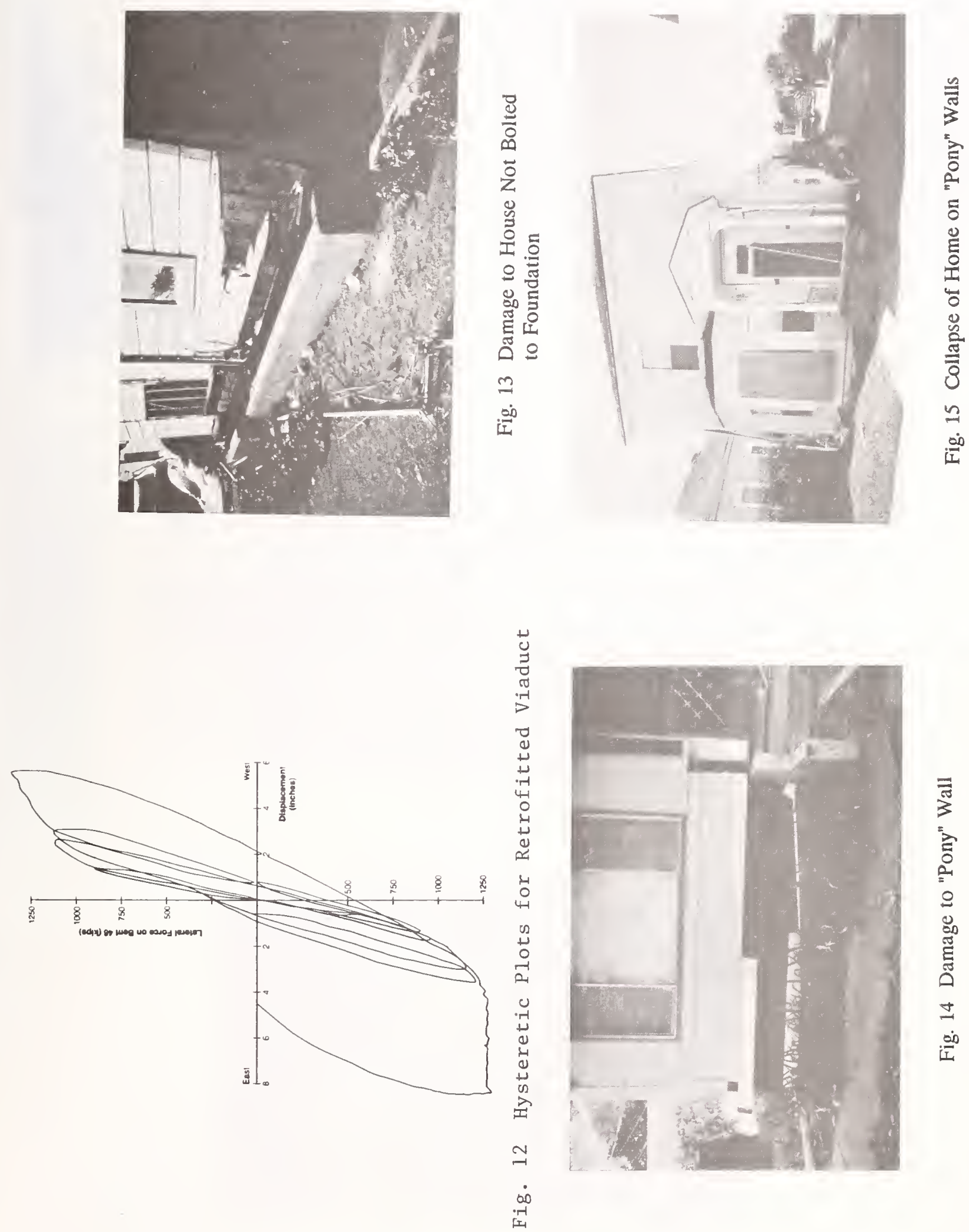


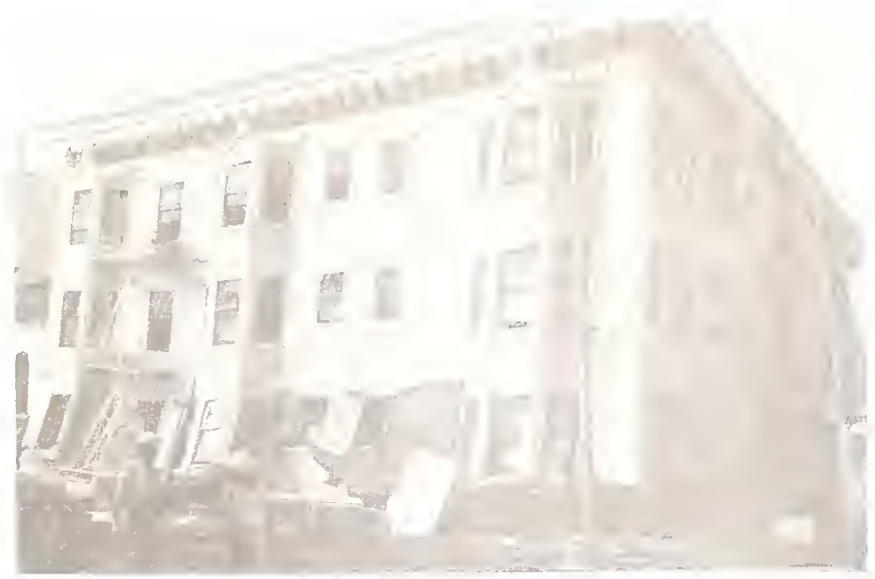

Fig. 16 Collapse of Apartment in Marina District

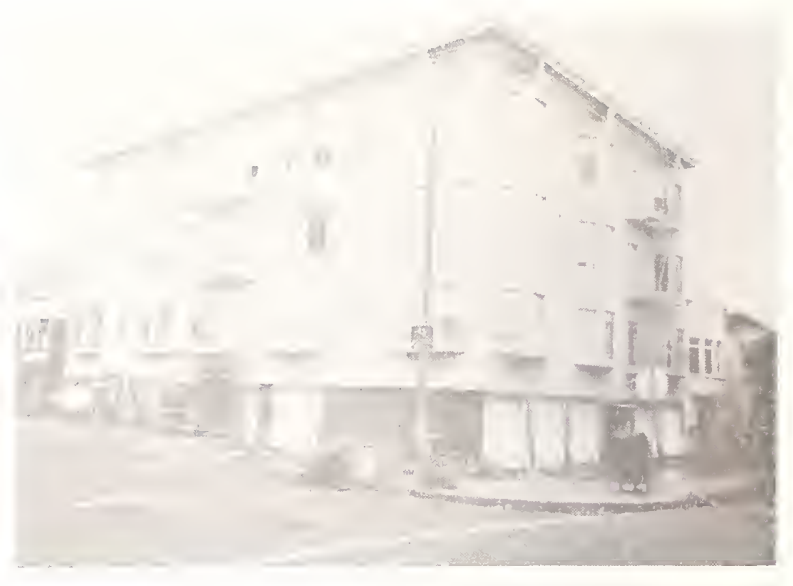

Fig. 17 Typical Marina District Apartment

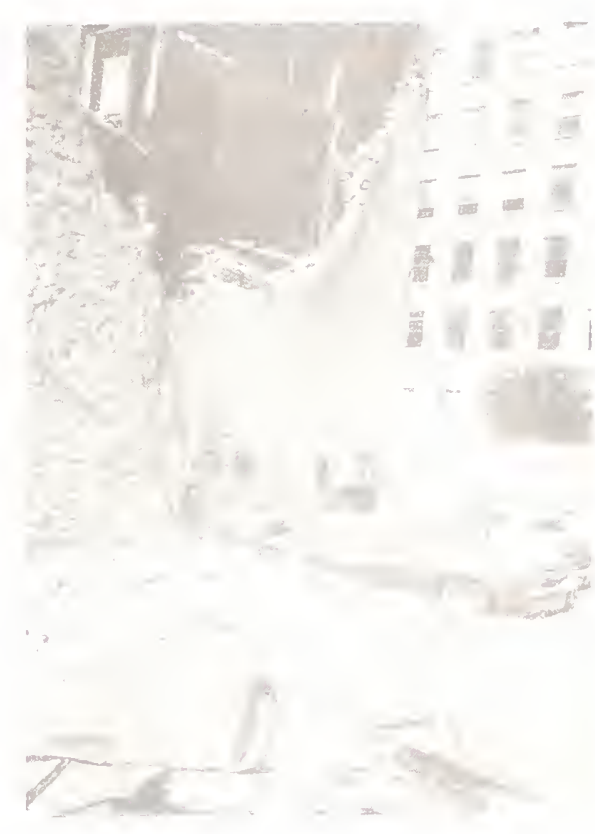

Fig. 18 Out-of-Plane Faitere of Masonry Wall

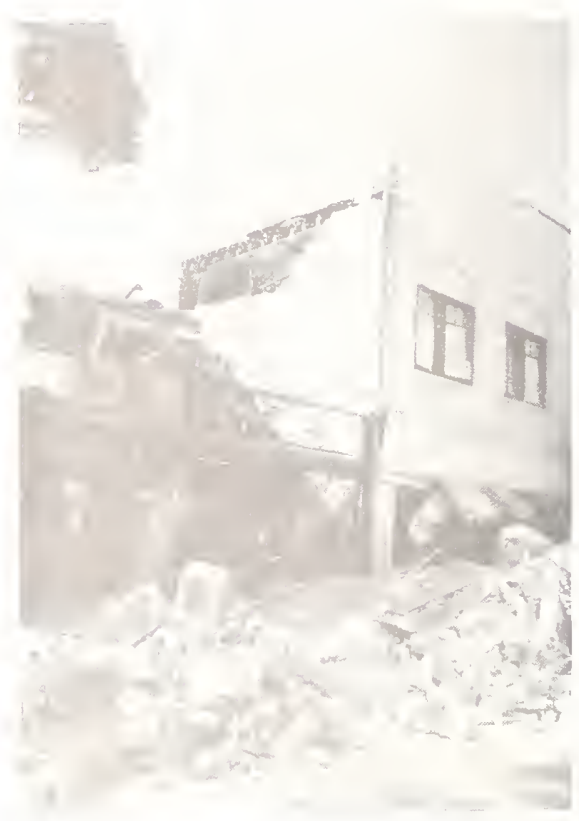

Collapse of Masonry Wall Onto Adjacent Roof

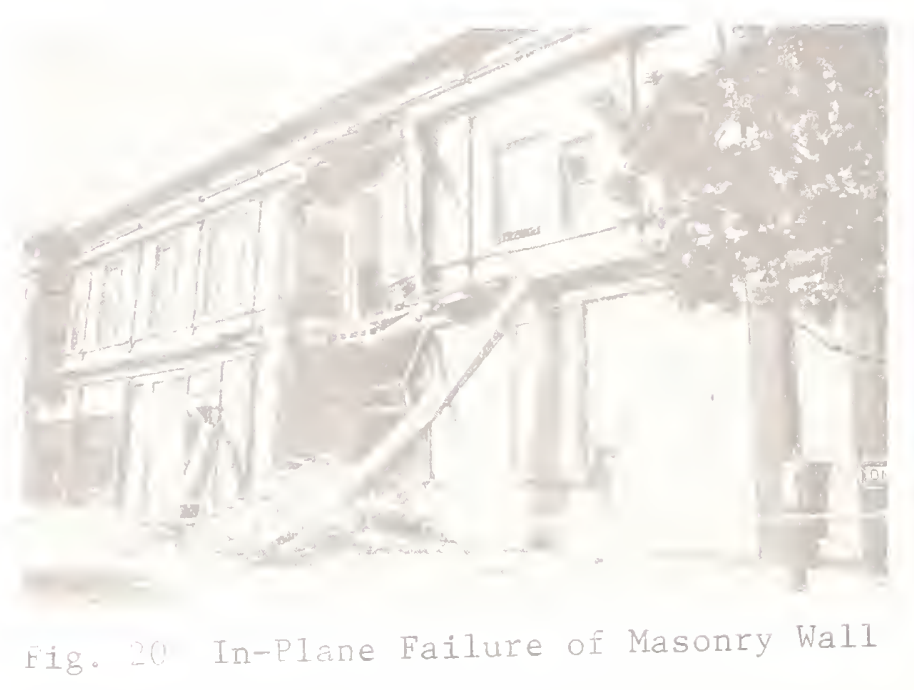




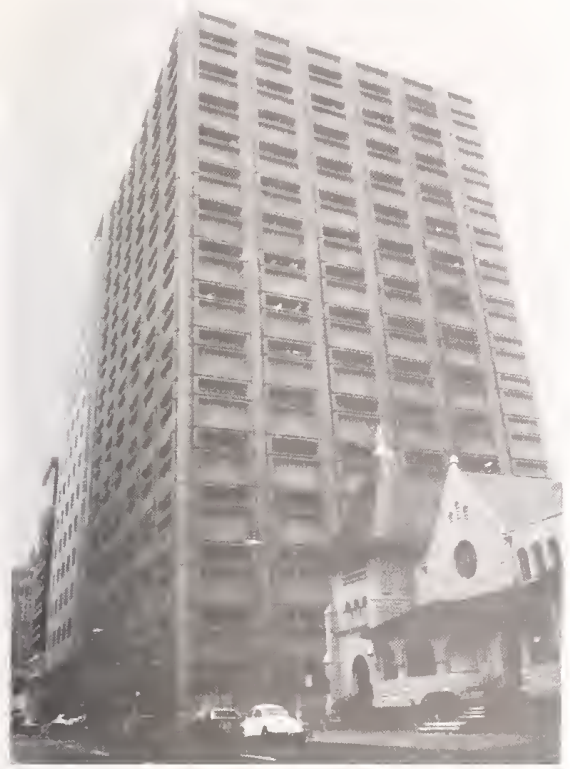

Fig. 21 Lightweight Concrete Shear Walls Failed At Base of Building

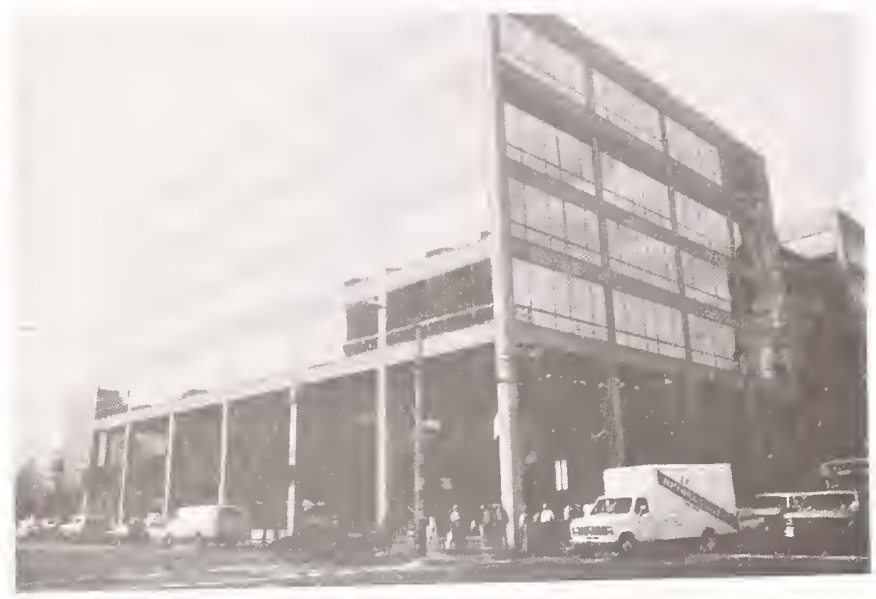

Fig. 22 Retrofit of New Reinforced Concrete Building

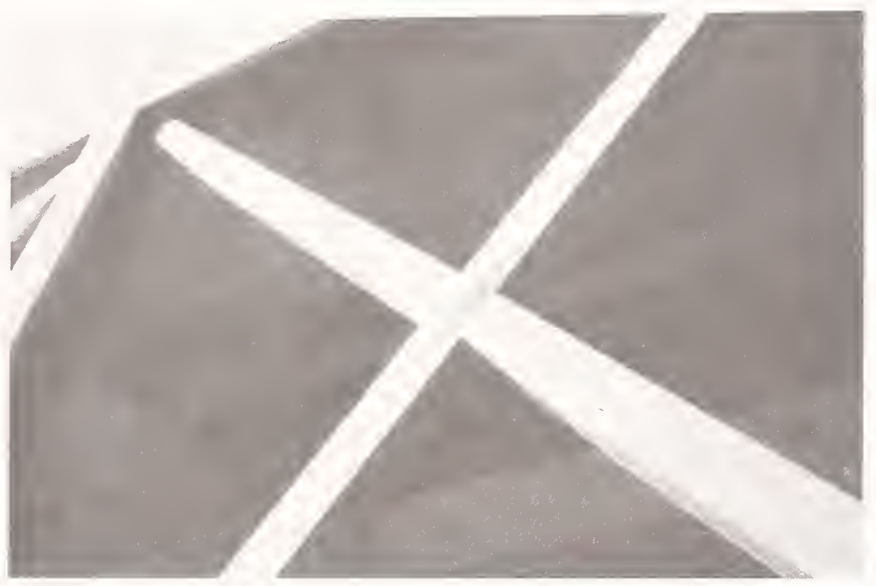

Fig. 23 Buckled Brace Intersection

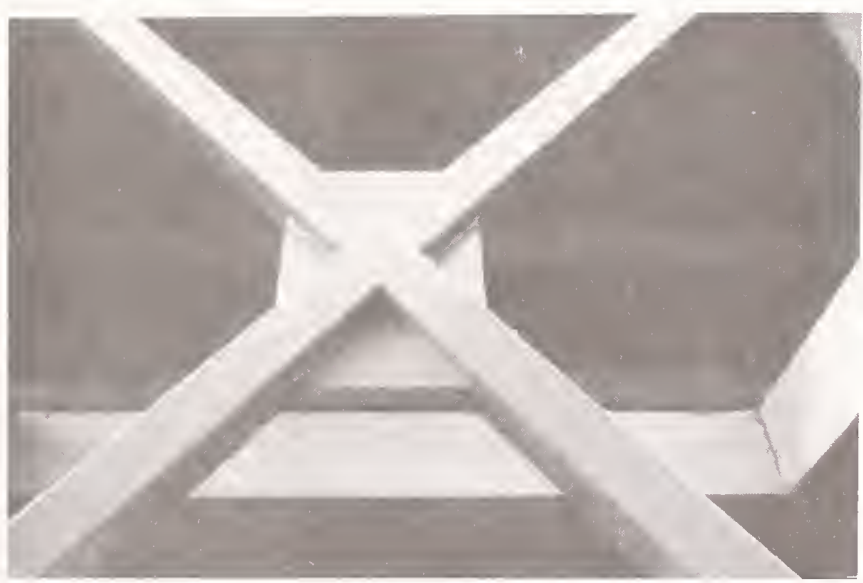

Fig. 24 Repair of Damaged Intersection 


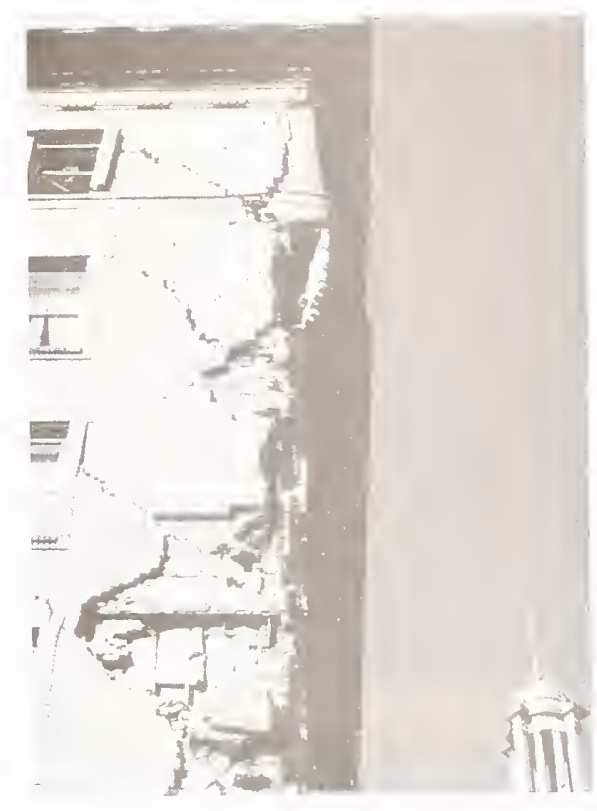

Fig. 25 Damage to Retrofit Steel Frame Building with Masonry Infilled Walls

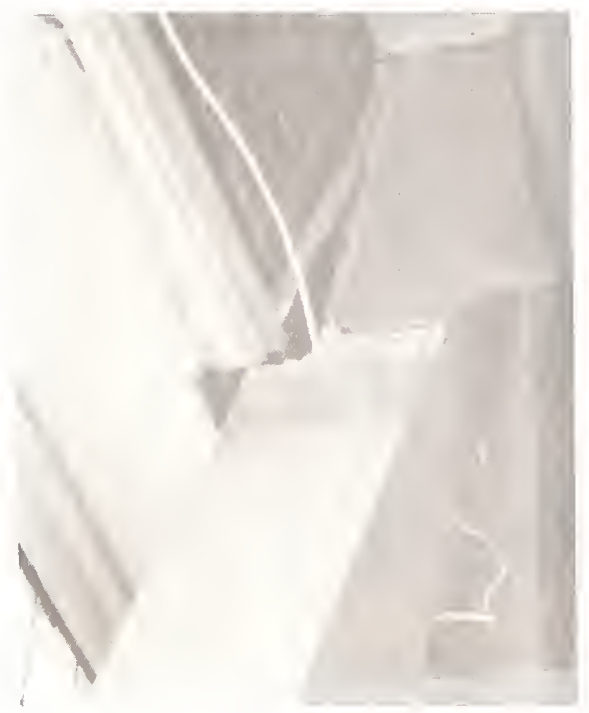

Fig. 27 Buckled Brace in URM Building

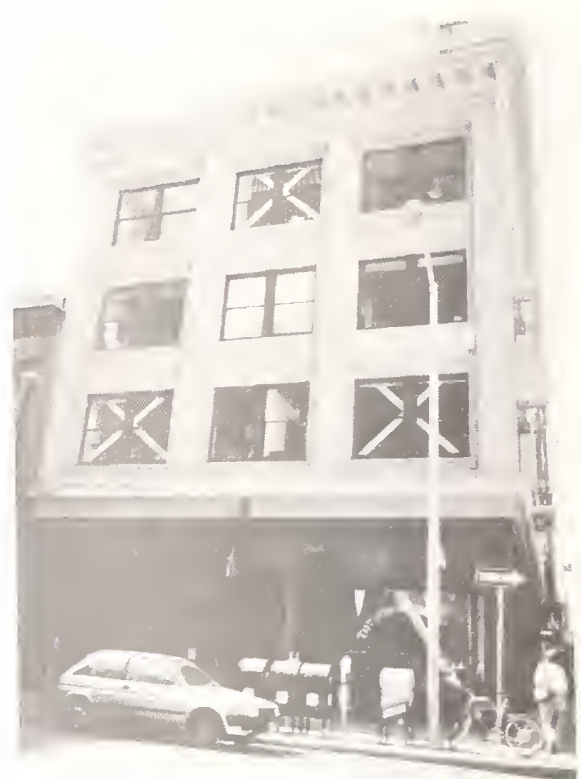

Fig. 26 Retrofit URM Building with Steel Braces

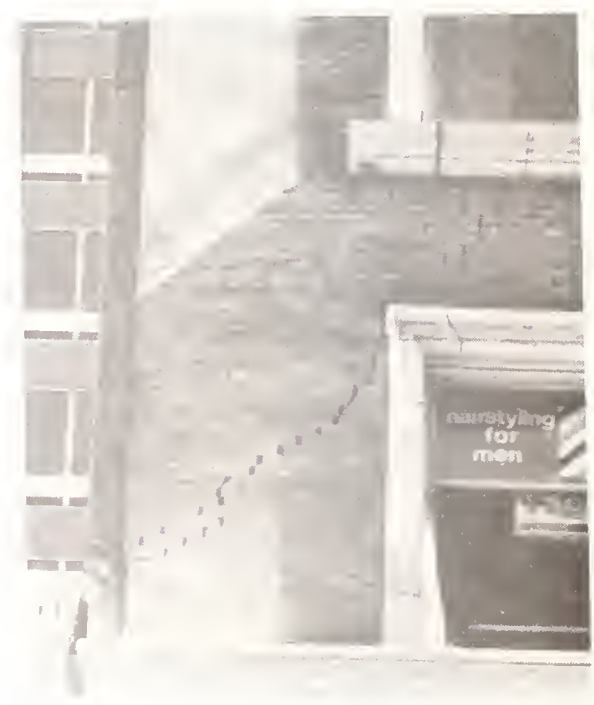

Fig. 28 Pounding Damage

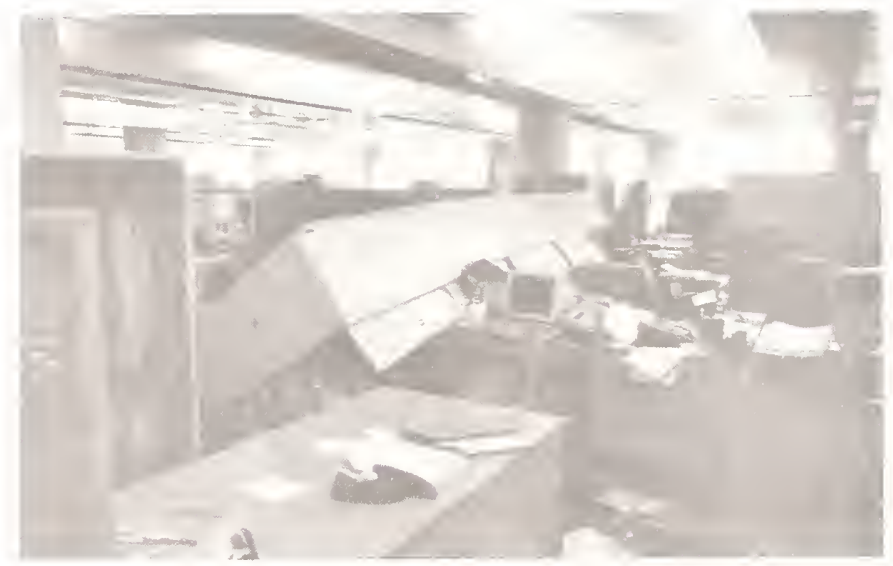

Fig. 29 Damage to Building Contents 
Damages and Lessons Learned From Hurricane Hugo

by

Peter R. Sparks*

\section{ABSTRACT}

Wind and surge conditions in Hurricane Hugo are reviewed and their relationship to the extent and nature of damage is discussed. It is shown that in areas where the gust wind speed exceeded $50 \mathrm{~m} / \mathrm{s}$, $10 \%-20 \%$ of the buildings were destroyed or seriously damaged. At $40 \mathrm{~m} / \mathrm{s}$ the figure was about $6 \%$ and at $30 \mathrm{~m} / \mathrm{s}$ only $1 \%$ were seriously damaged. Surge damage, although locally severe, only accounted for about $10 \%$ of the overall damage.

In general damage was related to the local conditions not to the relative severity. Thus the wind damage in Charleston, where the wind conditions had a recurrence interval of 50 years, was similar to that in Sumter where the same wind speed had a recurrence interval of more than 200 years. It is suggested that this was due to the fact that more than $95 \%$ of structural systems and 99\% of building enclosures had been selected without direct reference to design wind conditions which had been based on appropriate recurrence intervals. For recently constructed buildings design flood levels did have a bearing on the structural form.

Certain types of buildings and components performed very poorly, primarily mobile homes, unreinforced masonry buildings, older single family dwellings close to the ocean and some newer ones with masonry foundations, most roofing materials and some wall cladding components.

The severe disruption of the electricity supply system, beginning when the wind reached about $30 \mathrm{~m} / \mathrm{s}$, and its effect on the community is discussed and contrasted with the much better performance of the telephone system.

It is concluded that the extensive damage resulted in general not from unprecidented wind and surge conditions, but from the failure to use available knowledge on wind and surge effects in the selection of building and utility systems.

KEYWORDS: buildings; damage; Hurricane Hugo; storm tides; tropical cyclones; utilities.

\section{INTRODUCTION}

By the time Hurricane Hugo crossed the coast of South Carolina just after midnight on September 22, 1989, it had already caused over $\$ 2$ billion worth of damage in the Caribbean. In its passage through the states of North and South Carolina it caused further damage estimated to be nearly $\$ 7$ billion, making it the most expensive storm in the United States history.

* Department of Civil Engineering, Clemson University, Clemson, SC 29634-0911 
At landfall Hugo had a central pressure of $934 \mathrm{mb}$ and an eye about $50 \mathrm{~km}$ in diameter. Winds circulated in a counterclockwise direction about the eye, but the high forward speed produced a highly asymmetric wind field, increasing speeds to the right of the track and reducing them to the left. The highest winds and worst storm surge occurred where the northeastern part of the eye-wall crossed the coast about $35 \mathrm{~km}$ northeast of the city of Charleston at Bulls Bay. The high forward speed $(13 \mathrm{~m} / \mathrm{s}-18 \mathrm{~m} / \mathrm{s})$ and a track almost normal to the coast resulted in very unusual wind conditions in the interior of South Carolina and the western part of North Carolina.

\section{WIND CONDITIONS}

A number of anemometers measured wind conditions during the passage of Hugo. Unfortunately only one of these did so under standard meteorological conditions and no anemometers survived in the area of highest winds.

Figure 1 shows the probable maximum gust wind speeds at a height of $10 \mathrm{~m}$ in the most exposed locations, based on corrected observations in Charleston, Myrtle Beach, Beaufort, Sumter, Camden, Florence, Charlotte, and Hickory plus the use of a theoretical wind field model.

\section{STORM TIDES}

Continuous records of water level were obtained near the Customs House in Charleston and at Winyah Bay near Georgetown. Additional still water levels were obtained by surveys of tide marks along the coast.

In the Charleston area tides ranged from $3 \mathrm{~m}$ above mean sea level in Charleston Harbor to $4.5 \mathrm{~m}$ at the north end of the Isle of Palms. At the south end of Bulls Bay the tide reached $6 \mathrm{~m}$ and at the north end of the bay, in the fishing village of McLellanville, it was $4.2 \mathrm{~m}$ to $4.8 \mathrm{~m}$. In the resort areas along the northern coast, including Myrtle Beach, tides were $3 \mathrm{~m}$ to $4 \mathrm{~m}$ above mean sea level. The normal tidal range is less than $2 \mathrm{~m}$ and much of the occupied land is only $2.5 \mathrm{~m}$ to $4 \mathrm{~m}$ above mean sea level.

In the areas that experienced the eye of the storm, Charleston, Folly Beach, Sullivans Island and the Isle of Palms, the offshore winds before the eye held the surge back until the winds dropped as the eye passed. The water level then rose rapidly, remained up while the trailing eyewall passed and then dropped as the winds subsided.

To the northeast of the eye the surge rose more steadily, reaching its peak at about the time of the highest winds. The surge began to drop as the winds diminished and moved around to the south.

To the southwest of the eye the offshore winds suppressed the surge and little flooding was experienced.

\section{SEVERITY OF THE STORM}

Based on its central pressure, Hugo was the 10th most intense storm to strike the United States this century, being about the same strength as the 1926 storm 
in Miami and Hurricane Hazel which struck the Carolinas in 1954. The hurricane produced the highest storm tide recorded on the Atlantic coast this century, but a similar tide was recorded at Savannah Beach near the South Carolina-Georgia border in 1893 and higher tides might have been experienced in the Charleston area in the storm of 1752. However, in the southern part of Bulls Bay the tide was a very rare event which would be expected to be exceeded on average only once in over 500 years. In McLellanville the mean recurrence interval was about 300 years and at the northern end of the Isle of Palms about 200 years. On Sullivans Island, in Charleston, and along most of the northern coast the mean recurrence interval was approximately 100 years and about 80 years at Folly Beach.

In the Charleston area the winds had a mean recurrence interval of about 50 years, but similar conditions had not been experienced since 1911. They had however also been experienced in 1893, since records began in 1879 . Based on the description of damage, the wind conditions in Hugo were almost certainly exceeded in 1752 and possibly in a number of other storms in the 300 year history of the city.

In the Bulls Bay area the wind conditions probably had a mean recurrence interval of about 100 years, possibly as high as 200 years. It was about 60 years in McLellanville and less than 20 years in the Myrtle Beach area.

The combination of an intense storm and high forward motion produced rare wind conditions in the interior of South Carolina and in the Charlotte area of North Carolina. At Sumter, $150 \mathrm{~km}$ from the coast, the mean recurrence interval was probably between 200 and 300 years. The very gusty wind conditions in Charlotte, $300 \mathrm{~km}$ from the point of landfall, may have had a recurrence interval more than 100 years.

\section{BUILDING PERFORMANCE}

Since the early 1960s engineers have recommended that buildings and other structures be designed for conditions with a mean recurrence interval of 50 to 100 years. Well designed structures usually incorporate factors of safety, so serious structural damage should not be expected in conditions with a mean recurrence interval less than 500-1000 years. Such conditions existed only for surge action in Bulls Bay and probably did not exist anywhere for wind action. Nevertheless the damage was widespread. The extent of damage appeared to be related to the local conditions, not the relative severity of those conditions, nor was damage confined to buildings constructed before appropriate design criteria were available. In retrospect this was not surprising.

Most of the damage occurred in South Carolina where the building stock consists of approximately $75 \%$ wood-framed single-family dwellings, $15 \%$ mobile homes, and about $10 \%$ other types of buildings. These other types, however comprise about $35 \%$ of the value of construction. 
Single-family dwellings are usually constructed on traditional lines, sometimes influenced by prescriptive building code requirements. These requirements generally do not adequately reflect the need to resist wind and water effects.

Since 1976 mobile homes have been constructed to Federal Government standards. The wind loading requirements in these are much lower than those generally set for conventional construction and reflect a very poor understanding of wind effects on buildings.

In South Carolina buildings over $450 \mathrm{~m}^{2}$ or three or more stories in height must be designed by a registered architect or engineer. Even these buildings often contain components selected on the basis of empirical design procedures and product data which do not adequately consider the effects of wind (or surge).

Under these circumstances it is unlikely that, of all of the buildings affected by Hurricane Hugo more than 5\% had structural systems designed to resist appropriate wind and surge loads. Probably less than $1 \%$ of the buildings had roofing and cladding systems specifically designed for appropriate wind conditions. Design wind speeds based on recurrence intervals therefore had very little bearing on the wind resistance of most buildings.

Design flood levels had more of a bearing on coastal construction because the availability of insurance through the government-run
National Flood Insurance Program was tied to satisfying floor elevation requirements based on the 100 year flood level. Unfortunately the flood maps were not very accurate and buildings were often constructed without consideration of the forces generated by the storm surge and the associated wind loads.

Table 1 gives the insured losses for buildings and their contents. The number of insurance claims for each type of building is in almost exactly the same proportion as its relative contribution to the building stock and the amount of damage is in the same proportion as its relative value. Although the flood damage was widely reported and many buildings were destroyed, flood losses were only about $10 \%$ of the total property losses and accounted for only $4 \%$ of the insurance claims.

Table 2 gives the Red Cross estimate of the number of housing units damaged. This was made shortly after the storm, subsequently insurance claims were made on nearly 3 times as many properties as were initially observed to be damaged. Ultimately claims were made on $30 \%$ of buildings in South Carolina but only $3 \%$ were seriously damaged or destroyed. The vast majority of damage was due to relatively minor wind damage followed by extensive rain damage.

The distribution of damage was closely related to gust wind speeds, the proportion of mobile homes, and, for surge damage, proximity to the ocean. In some rural areas where $20 \%-30 \%$ of the population 
lives in mobile homes, $70 \%-80 \%$ of the buildings completely destroyed were of that type.

On the islands near Charleston and on the shores of Bulls Bay nearly all buildings experienced some wind or surge damage and in some coastal communities nearly $50 \%$ of the ocean-front buildings were completely destroyed.

In counties where the wind gusted to more than $50 \mathrm{~m} / \mathrm{s}$ at least $80 \%$ of the buildings experienced some damage and 10\%-20\% were destroyed or experienced extensive damage. Damage rates diminished as the wind speed dropped. At $40 \mathrm{~m} / \mathrm{s}$ about $6 \%$ of buildings were destroyed or seriously damaged. At $30 \mathrm{~m} / \mathrm{s}$ less than $1 \%$ received significant damage.

\subsection{Detailed Survey of Wind Damage}

Wind damage to buildings and other structures was observed along the South Carolina coast from Edisto Beach $55 \mathrm{~km}$ southwest of Charleston, to the North Carolina border and inland to beyond Charlotte. Damage to roof coverings, wall cladding, and signs occurred where the local gust wind speed exceeded $30 \mathrm{~m} / \mathrm{s}$. Major structural damage, including loss of roof structure, collapse of singlestory masonry buildings, complete destruction of mobile homes, and extensive damage to older preengineered metal buildings and wood-framed construction, took place where the gust wind speed exceeded $50 \mathrm{~m} / \mathrm{s}$. However, damage was dependent on the upwind terrain and shelter. In sheltered locations even old woodframe houses remained completely undamaged where the gust wind speed in open country exceeded $55 \mathrm{~m} / \mathrm{s}$.

South Carolina is a heavily forested state. The trees provided significant protection from the wind and undoubtedly reduced the amount of damage to buildings. However pine trees apparently began to fall as the wind speed approached $30 \mathrm{~m} / \mathrm{s}$ and many buildings, although protected from the wind by the trees, subsequently suffered damage from them.

In the Bulls Bay area, where few trees were left standing, the exposure of buildings would have changed significantly during the course of the storm.

Two other factors greatly reduced the wind damage. Firstly, the densely populated islands of Folly Beach, Sullivans Island and the Isle of Palms experienced the eye of the storm. This meant that the strongest winds would have come from the north to northeasterly direction and south to southwesterly direction i.e. along or obliquely to the shore. Many ocean-front buildings would therefore have received shelter from neighboring buildings. Secondly, the strongest winds in the storm affected the most lightly populated area of the coast, occupied primarily by a wildlife refuge. In this area all settlement is landward of the Intracoastal Waterway in forested areas. Had the storm hit $30 \mathrm{~km}$ to the southeast, Charleston and the adjacent islands would have experienced onshore winds producing wind loads on oceanfront properties perhaps double 
those actually experienced. Had the storm hit $80 \mathrm{~km}$ to the northwest all of the buildings on the densely populated northern coast would also have experienced wind loads more than twice those actually experienced.

\subsubsection{Single Family Dwellings}

In general these performed reasonably well, probably more as a result of shelter than any other factor. Major structural failures resulted from loss of roofs, shear failures and foundation failures.

Failures of roof structures were relatively rare, probably due to the use of metal anchors to attach roofs to walls in exposed coastal locations. However, in the highest wind areas, failures occurred even where anchors had been used, particularly after window damage. A typical roof failure which led to a general collapse is shown in Figure 2.

Failure to provide bracing led to some shear failures in two story buildings. The traditional bracing techniques proved to be insufficient, especially in buildings with few interior cross-walls and large openings in exterior walls.

In most coastal flood-prone areas buildings are elevated on wood or prestressed concrete piles. On the South Carolina coast many buildings had been constructed on concrete block piers. The local building code had permitted unreinforced masonry piers to have a height to width ratio of 10 , if filled with concrete. Piers meeting this requirement failed, as did those that were lightly reinforced (Figure
3). In meeting the elevation requirements for flood insurance, the very large forces applied to the piers by the wind acting on the building had apparently been overlooked.

Many single family dwellings lost shingles. These apparently minor wind failures resulted in significant rain damage, often magnifying the initial damage by a factor or 10 . Repeated on an enormous scale, this contributed significantly to the total cost of the storm.

In some areas wind and surge damage to single-family dwellings was difficult to differentiate, particularly in older buildings built on grade or newer buildings meeting the flood insurance elevation requirements, but subjected to surge in excess of the design level, as in the northern part of the Isle of Palms and in Bulls Bay. In some instances wind debris was transported by the surge making the nature of the wind failure difficult to determine.

\subsubsection{Mobile Homes}

As mentioned earlier these buildings had a failure rate far higher than other classes of structures. Their vulnerability was recognized and the Governor of South Carolina ordered the evacuation of all mobile homes in the coastal region prior to the arrival of Hugo. This probably saved many lives.

Structural collapse of mobile homes was often sudden and complete, either by overturning or by the separation of the superstructure from the chasis. A typical example 
is shown in Figure 4. In general the more stable "double-wide" homes, formed by joining two "single-wide" units together, performed better than "singlewide" homes.

\subsubsection{Multi-Family Wood-Framed Construction}

Several of these professionally designed buildings in exposed locations suffered extensive roof failures, often precipitated by window damage. In some of these buildings metal anchors had been used to secure the roof. Whether or not these had been selected after a structural analysis is not known, but consideration of internal pressure would not have been required by the building code and the uplift loads could have exceeded the design value after the failure of windward windows.

\subsubsection{Masonry Walled Buildings}

Failures of unreinforced masonry buildings were observed over a wind area (Figure 5). The instability of these buildings has been documented in several past hurricane investigations, but the form of construction is still permitted by many local building codes.

\subsubsection{Pre-Engineered Metal Buildings}

A number of these buildings located in exposed locations suffered serious damage (Figure 6). Being light and very efficiently designed, these structures were very sensitive to the under-specification of wind loads in earlier building codes. Buildings designed to increased requirements in recent years appeared to have performed much better.

\subsubsection{Steel and Concrete Framed Buildings}

As observed in other hurricanes, the frames of buildings designed by structural engineers to meet the wind loading requirements in the building code preformed well. The wall cladding, roof system, and roof covering, often selected without reference to the wind-load requirements, performed very poorly.

An exterior wall system which had been employed extensively in the area used gypsum board attached to metal studs. The gypsum board was covered with insulation and stucco. Based on published data on the ability of such systems to resist wind suction, these systems should not have been used on any building over $10 \mathrm{~m}$ high located on the South Carolina coast. Nevertheless, this system had been used extensively on medical facilities, educational buildings, condominiums, office buildings, and hotels. Failures were found on the coast as far north as the North Carolina border where the actual wind speeds were less than half of the design value. Several buildings in the Charleston area, including hospitals and other critical facilities, were seriously damaged (Figure 7). Window systems also failed due to positive pressure and suction, giving rise to extensive internal rain damage.

Failures of flat-roof coverings, both build-up-roofs and single-ply systems, sometimes coupled with 
the roof-deck failures, were also to be found along the South Carolina coast as far as the North Carolina border and inland as far as Charlotte. These failures, which included schools used as emergency shelters, hospitals, and other critical facilities, resulted in extensive rain damage to the interior structure and contents of the buildings. A limited survey of insurance data indicated that the rain damage in multi-story buildings was often 20 to 30 times the actual wind damage to the structure and multi-million dollar claims occurred in areas where the storm had a recurrence interval of less than 20 years.

The local building code, in use when most of these buildings were designed, underestimated the uplift loads on the edges of roofs. The design loads were almost certainly exceeded in many places in Hugo. In some cases the shortcomings in the building code may have led to the selection of an adequate system, but in many cases the system was probably chosen on the basis of cost rather than winduplift resistance.

\subsection{Detailed Survey of Surge Damage}

Storm surge damage was observed along $240 \mathrm{~km}$ of coastline from Folly Beach near the entrance to Charleston Harbor to Cape Fear $50 \mathrm{~km}$ beyond the North CarolinaSouth Carolina border. Shallow still water flooding of sheltered lowlying buildings occurred throughout the area, including the older parts of the city of Charleston. The worst structural damage resulted from wave and current action along the beachfront and the unprotected shoreline of Bulls Bay.

\subsubsection{Single Family Dwellings}

Many older buildings built on grade or on low piers floated off their foundations. Those that were better anchored or heavier experienced damage from rising water or, if near the ocean, extensive damage by wave action (Figure 8).

As mentioned in the survey of wind damage, many oceanfront houses had been elevated on slender unreinforced or lightly reinforced masonry piers. These were supported on shallow concrete footings, some less than $0.5 \mathrm{~m}$ below grade. In addition to lacking resistance to wind forces transferred to them by the supported building, many piers became unstable when erosion exceeded the embedment depth. Several hundred oceanfront buildings of this type collapsed and many more were damaged. Other buildings had been supported on cast-in-place concrete columns. Many of these were also underdesigned, poorly constructed and lacked proper embedment. They also performed poorly (Figure 9) as did wood piles that had very short embedments, some as little as $1 \mathrm{~m}$. Buildings constructed on wood or prestressed concrete piles, embedded at least $3 \mathrm{~m}$, generally performed well, although in some cases buildings were damaged when the wave height exceeded the lowest floor elevation. 
Wave and current action extended farther inland than predicted by the flood insurance maps. Some foundations, particularly solid masonry walls, had therefore been selected on the assumption that they would be subjected only to still water flooding. These foundations performed poorly when subjected to a combination of wind, wave, and current action.

\subsubsection{Other Buildings}

Ocean-front condominiums, hotels and other commercial buildings had usually been supported on piled foundations, but the first floor of many of these buildings had not been elevated above the 100 year design flood level and wave damage was quite common.

When the bearing walls were perpendicular to the shoreline the first floor rooms were gutted by the waves, but the upper floors remained stable and undamaged. In the few cases where the bearing walls were parallel to the shoreline the first story bearing wall failed and parts of the two or three floors above collapsed.

Some buildings had used slab-ongrade floors at the lowest level which were independent of the piled foundation supporting the rest of the building. Even small amounts of erosion under these slabs caused their collapse.

Many sea walls, bulk heads and retaining walls failed, leading to the destruction of almost all oceanfront swimming pools in the Myrtle Beach area.

\section{PERFORMANCE OF UTILITIES}

The electric utility companies had constructed transmission and distribution systems which were very vulnerable to wind damage. The decision to use wood poles for high voltage transmission systems and overhead local distribution systems was probably made on economic grounds. Although interruption of power supply is common in the region in severe thunderstorms and had been experienced in earlier hurricanes, the extreme vulnerability of the system had not been appreciated by the utility companies nor their customers. It had certainly not been appreciated that loss of electric power for an extended period of time would have such an effect on the basic essentials of life - the ability to obtain food and water and the provision of wastewater facilities.

Approximately 1.5 million people living in areas where the wind speed exceeded $30 \mathrm{~m} / \mathrm{s}$ lost electric power. The utility companies made tremendous efforts to restore power, but the extent of the damage was so great that in many cases the system could not be repaired, but had to be rebuilt, usually to the previously existing standards. Eight days after the storm only $23 \%$ of the customers in the Charleston area had power and in some rural areas it was two to three weeks before power was restored.

The telephone companies had attempted to reduce the vulnerability of their systems by burying cables. In most areas there was very little interruption of 
telephone service. Other forms of communication, including television and radio broadcasts and even two way radio communications of emergency services, were seriously affected by loss of electric power and the collapse of transmission towers.

\section{CONCLUSIONS AND LESSONS LEARNED}

Hurricane Hugo taught South Carolina and the nation some very expensive lessons. The potential for disaster had been recognized but the political and economic systems made it difficult to remedy the situation. It is worth examining what went wrong.

The state had chosen a laissez-faire system of building control. The power to adopt and the responsibility for enforcement of building codes had been delegated to local jurisdictions. This resulted in considerable variation in the quality of control, from some of the best in the country to no control at all.

The model building code adopted showed a very poor understanding of the wind and surge effects on structures and permitted forms of construction in wood and masonry which were inconsistent with the loading requirements. Lacking proper deemed-to-comply documents, the performance requirements of the code were unenforceable for non-engineered structures. Using the permitted forms of construction in the code led to structural systems unsuitable for a hurricane, tornado, and earthquake prone area such as South Carolina.
In poor rural areas mobile homes were the only affordable form of housing for many people. These homes were built to inadequate standards and when delivered to site were often not properly anchored.

Despite the fact that cladding failures can pose a threat to public safety and even compromise the structural integrity of a building, cladding systems had been specified by those without adequate training in structural design. The professional licensing laws had permitted this.

In recent years owners had often been unwilling to pay for adequate professional inspection during construction. The quality of construction had suffered. Compounded by poor building code requirements, the use of inappropriate design professionals and inadequate material testing standards, this had led to cladding systems and, in some cases, structural systems with very low wind resistance.

The insurance industry had been willing to insure property with little regard for its wind resistance. Premiums were often based on the building's fire resistance. Thus there was little or no incentive for the owner to improve wind resistance in order to meet insurance requirements.

The electric utility companies had been permitted to construct transmission and distribution systems which were very vulnerable to damage by a hurricane. The public was unaware of how fragile 
the system was or how dependent they were on a continuous supply of electricity.

Finally, there was the lack of experience. For 30 years prior to Hugo, during which time the hurricane-prone areas of the state expanded rapidly, no major hurricanes hit the South Carolina coast.

From an engineering standpoint the dominating lesson is clear and the solution is straightforward. Design and construction practices must reflect the loads which are known to occur in conditions with reasonable recurrence intervals. The prospects for achieving this and correcting past mistakes are not good.

The building stock changes slowly and the fragmented building control system in the United States is ill-equipped to impose improved construction standards. Based on the success of the National Flood Insurance Program, the best prospect for improved construction is by insurance industry action. That industry certainly learned its lesson in Hugo when it paid out the equivalent of all property insurance premiums collected in South Carolina in the last 5 years.

Not all lessons learned were concerned with what went wrong. Properly designed buildings performed well and the telephone service was a fine example of what can be achieved with good planning. Perhaps the most valuable lesson learned was that modern technology can be used very effectively to monitor storms and warn coastal residents of impending danger.

In 1893 a storm of similar strength to Hugo drowned 1000-2000 people in South Carolina. Prior to Hugo's landfall over 250,000 people were evacuated from the coastal area. Only a handful of people were killed, none by drowning in their homes. It is a poor reflection on the construction industry that many evacuees returned to buildings that were in considerably worse condition than their counterparts after the 1893 storm.

\section{ACKNOWLEDGEMENTS}

This study of the effects of Hurricane Hugo was made possible by grants from the National Science Foundation, South Carolina Sea Grant Consortium, South Commission on Higher Education, the Federal Emergency Management Agency and Clemson University. This support is gratefully acknowledged. 
Table 1. Insured Damage to Buildings and Contents in South Carolina

Number of Claims

Total Amount

(\$ million)

Wind

Conventional dwellings

$287456(74 \%)$

$1423(55 \%)$

Mobile homes

$57808(15 \%)$

$172(7 \%)$

Commercial property

$41282(11 \%)$

$997(38 \%)$

Total wind damage

386546

2592

Flood

All types

15739

320

Table 2. Number of Dwelling Units Destroyed or Damaged in South Carolina

\begin{tabular}{lrrrr}
\hline & Destroyed & $\begin{array}{c}\text { Major } \\
\text { Damage }\end{array}$ & $\begin{array}{r}\text { Minor * } \\
\text { Damage }\end{array}$ & Total \\
\hline Single family dwellings & 3783 & 18146 & 57698 & 79627 \\
Apartments & 313 & 2647 & 8948 & 11908 \\
Mobile homes & 5200 & 5976 & 9063 & 20239 \\
Total & 9296 & 26769 & 75709 & 111774 \\
& & & & \\
\hline
\end{tabular}

Externally observable damage only, excludes damage to outbuildings, fences, decks, porches etc. 


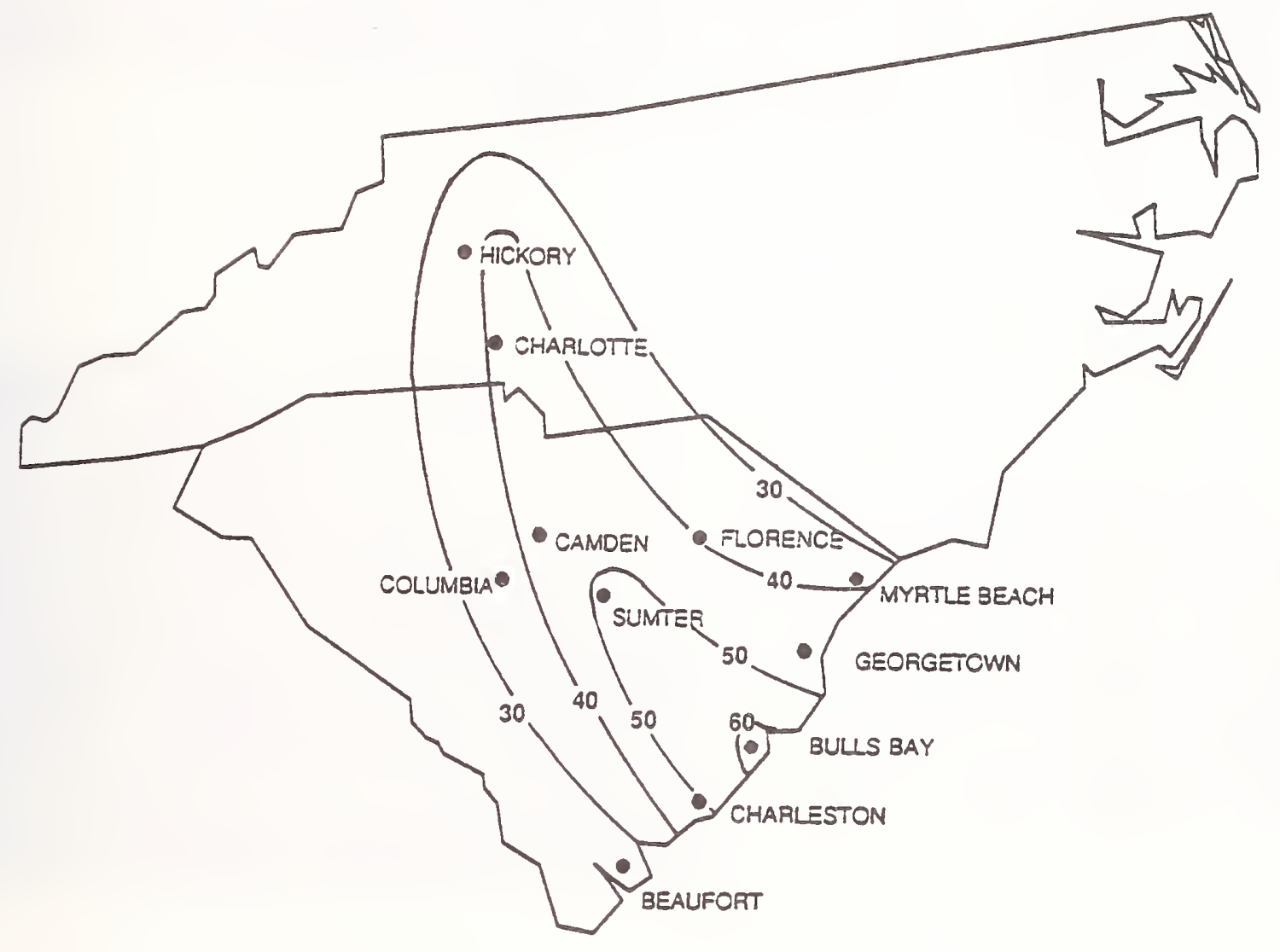

Figure 1. Probable Maximum Gust Wind Speeds (m/s) 


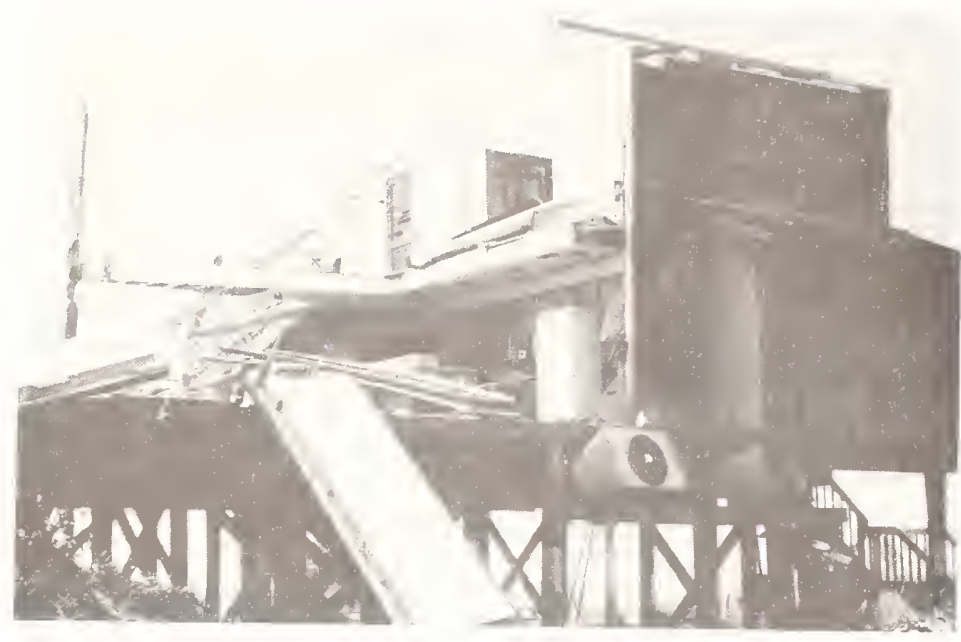

Figure 2. Wood-Framed House, Folly Beach

Figure 3. Masonry Pier Failure by Wind Action, Isle of Palms
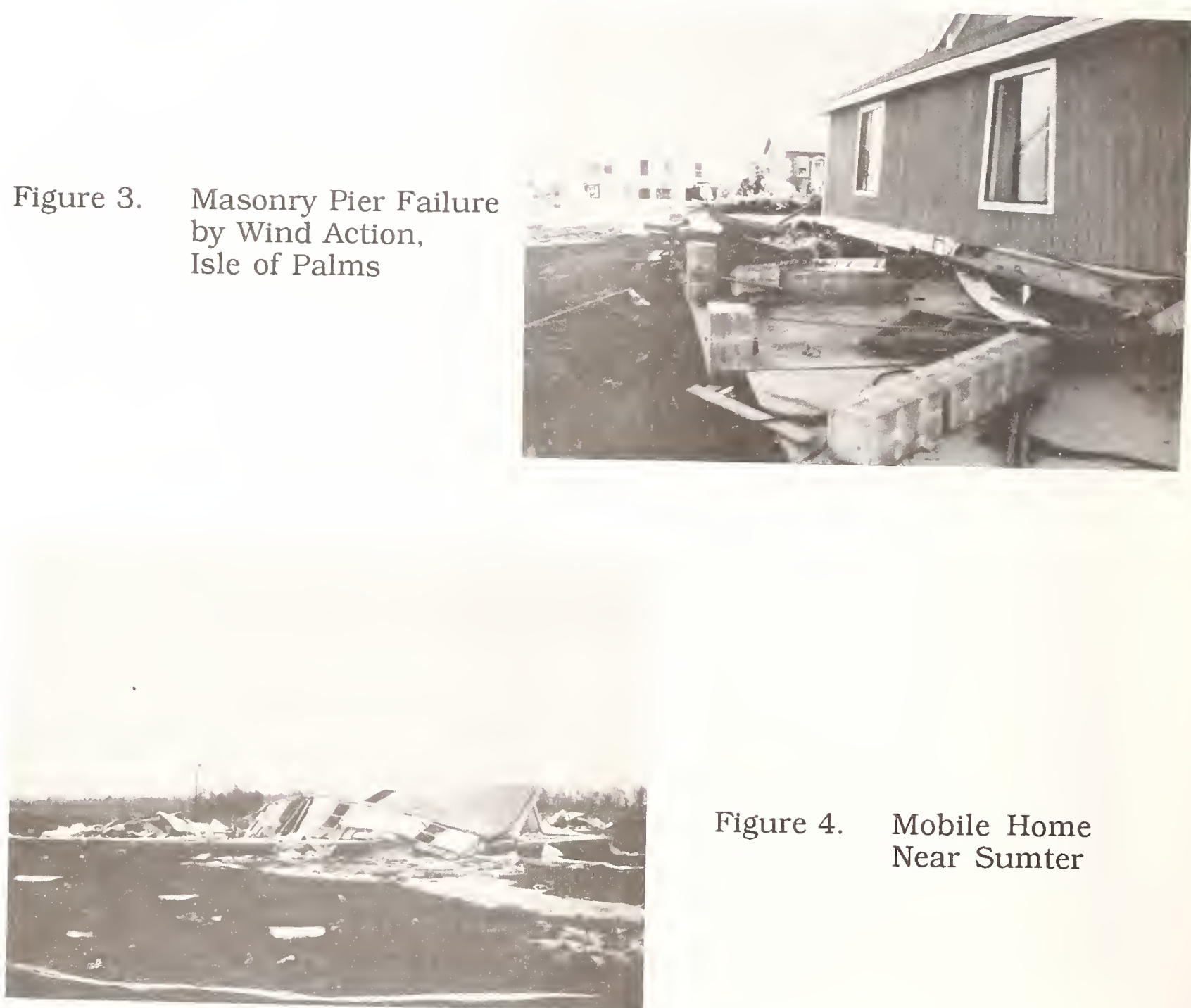

Figure 4. Mobile Home Near Sumter 


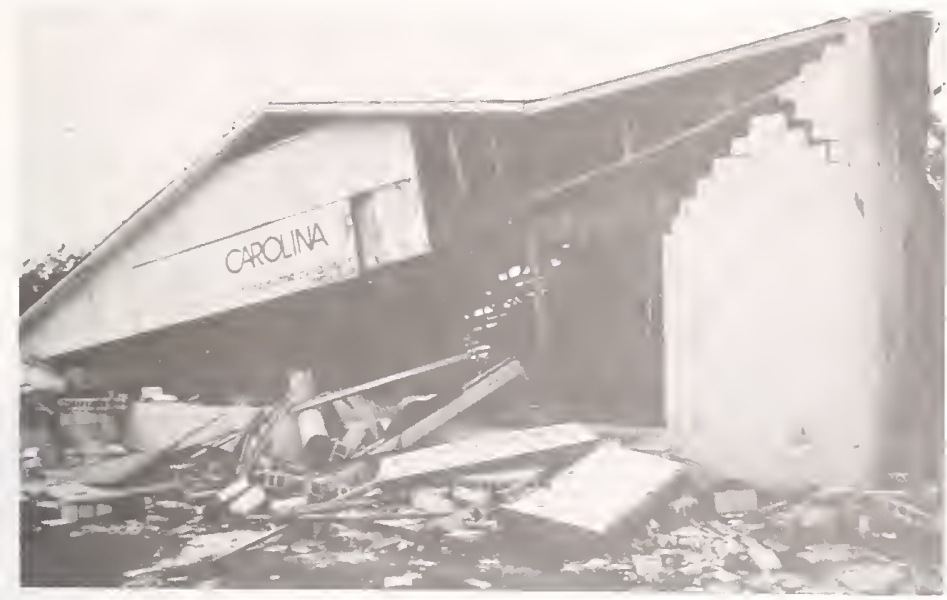

Figure 5. Unreinforced Masonry Building, Charleston

Figure 6. Pre-Engineered Metal Building, Charleston
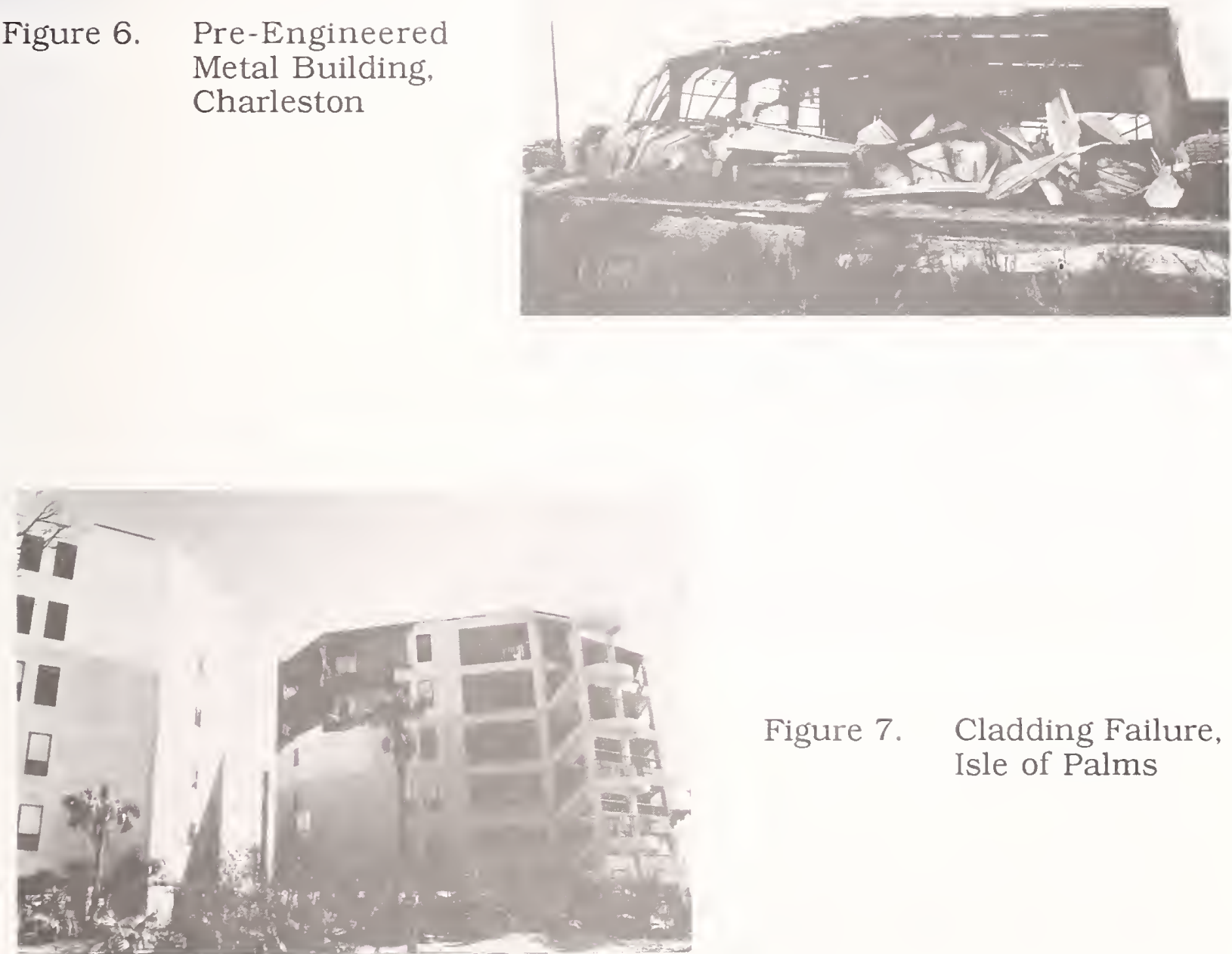

Figure 7. Cladding Failure, Isle of Palms 
Figure 8. Wave Damage to Masonry Building Near Myrtle Beach
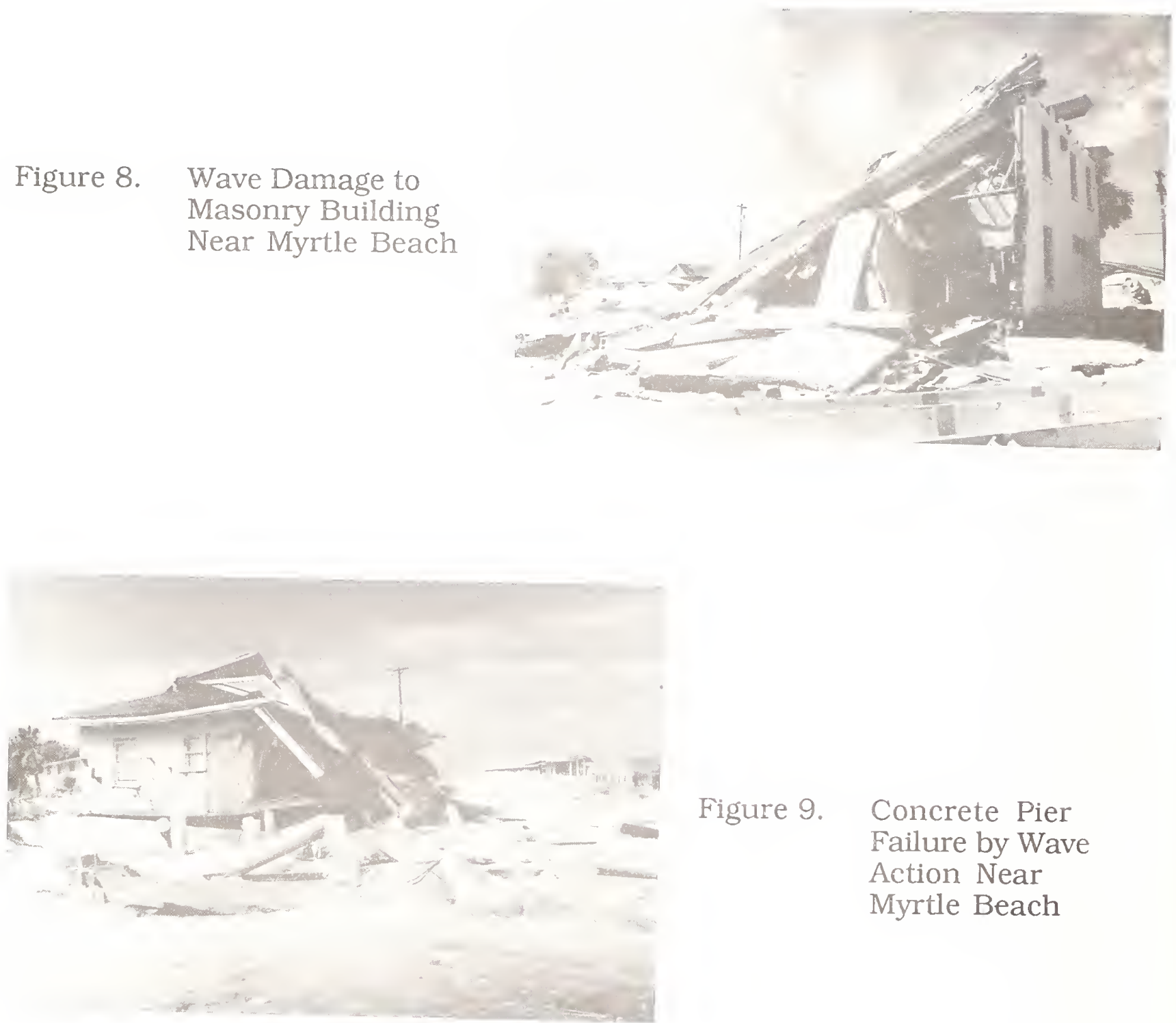

Figure 9. Concrete Pier Failure by Wave Action Near Myrtle Beach 


\title{
United States Federal Agency Programs in Disaster Countermeasures
}

\section{By}

\author{
Paul F. Krumpe \\ Office of U.S. Foreign Disaster Assistance \\ Agency for International Development \\ Department of State \\ Washington, D.C. 20523 \\ and \\ Kenneth F. Sullivan \\ Earthquakes and Natural Hazards Division \\ Federal Emergency Management Agency \\ Washington, D.C. 20472
}

\section{INTRODUCTION}

The purpose of this paper is to present an overview of the roles and responsibilities of U.S. Federal Agencies and the major programs they are conducting which involve mitigating the impacts of natural and man-made or technological hazards on vulnerable populations, economic investment and critical facilities both in the United States and abroad. The United States through its many Federal Agencies, state and local governments is committed to protecting its people, businesses, communities and economic resource base in the face of disaster.

According to the U.S. National Academy of Sciences, Advisory Committee on the International Decade for Natural Disaster Reduction, as many as 70 million people in 39 states face significant risk from earthquakes and secondary hazards such as landslides. It is estimated that more than $\$ 100$ billion in total economic losses could occur from a single major California earthquake. Billions of dollars in damage could occur from a devastating hurricane such as Agnes in 1972 or Hugo in 1989 which we know resulted in $\$ 9$ billion in losses, including 8,800 square miles of downed timber. The U.S. experiences some 900 tornadoes annually; wildfires destroy hundreds of thousands of acreage each year and volcanoes are a constant threat. The eruption of Mount St. Helens in 1980 caused over $\$ 1$ billion in damage. Recent estimates indicate landslides cause $\$ 1$ to $\$ 2$ billion in economic losses each year with flood disasters ( $\$ 1$ billion annual loss) and drought impacts ( $\$ 40$ billion estimated loss in 1988 alone) causing recurring intermittent losses.

The Office of U.S. Foreign Disaster Assistance, Agency for International Development, estimates that more than 3 million people have died and more than 900 million have been seriously affected worldwide by disaster during the past 22 years. Property damage and economic losses are believed to exceed $\$ 75$ billion during the same period, although data collected over the years remains imprecise.

The magnitude of destruction and human loss both physical, social, and economic is dramatic when viewed on a global scale and at the national level. Governments have, in several instances, failed following significant disasters and their impacts. We, in the United States, recognize that we live in a disaster-prone world and nation and have determined to take concerted action to mitigate these negative impacts now and in the future.

\section{DISASTER REDUCTION PROGRAMS OF THE U.S. GOVERNMENT}

Within the 14 cabinet level departments of the federal government and more than 70 independent agencies, there are thousands of bureaus and offices dealing with various aspects of hazard reduction either at the personal, local, state, federal or global scale. Billions of dollars are expended annually to monitor, regulate, control, document and respond to the many facets of natural and technological hazards as they affect the American people both in the public and private 
sectors. The nature of our government is to protect its citizens, as well as to provide humanitarian assistance to those in need abroad. The lead U.S. domestic agency responsible for disaster management and civil defense is the Federal Emergency Management Agency (FEMA). The Agency for International Development's (A.I.D.) Office of U.S. Foreign Disaster Assistance (OFDA) coordinates U.S. international disaster assistance to host countries abroad. Both FEMA and OFDA work closely with other federal agencies to ensure effective and timely implementation of disaster countermeasures as mandated by legislated laws and regulations at all levels of government. The federal departments and their many agencies have specific missions and programs designed to prevent, mitigate, prepare for, respond to, rehabilitate or otherwise ameliorate the impacts of disaster.

The Lead Role of the Federal Emergency Management Agency (FEMA) in Earthquake Hazards Reduction

Under the 1980 amendments of the U.S. Earthquake Hazards Reduction Act, the Federal Emergency Management Agency (FEMA) was assigned the leadership role for the National Earthquake Hazards Reduction Program (NEHRP). FEMA's leadership responsibilities include a range of activities that focus on planning and coordinating the work of the NEHRP, and broadening its scope of participation and effect.

The purpose of the National Earthquake Hazards Reduction Program is to reduce the risk to lives and property. This is accomplished through a comprehensive, multi-agency program of scientific research, mitigation, preparedness and response planning and public education. FEMA, as the lead agency, has the statutory responsibility to plan, coordinate and recommend goals, priorities and budgets for earthquake activities among the principal agencies authorized under the Earthquake Hazards Reduction Act of 1977, as amended. The agencies include the United States Geological Survey, the National Science Foundation and the National Institute for Standards and Testing. to:

The primary activities of the program are

(1) develop improved seismic design and construction practices for adoption by Federal agencies, State and local governments and the private sector;

(2) provide financial and technical assistance to State and local governments to implement comprehensive earthquake hazard reduction programs;

(3) develop public education and awareness programs and

(4) plan for and coordinate an adequate Federal capability to respond to a catastrophic earthquake.

FEMA's Role in Managing Other Natural and Technological Hazards and Emergency Response

FEMA's natural and technological hazards programs include the following elements: (1) National Earthquake Hazards Reduction, (2) Hurricane Preparedness, (3) Dam Safety, (4) Radiological Emergency Preparedness, (5) Hazardous Materials and (5) Chemical Stockpile Emergency Preparedness Program.

The goal of the Hurricane Preparedness Program is to reduce the loss of life and property damage from hurricanes in high-risk populations and to develop State Hurricane Evacuation Plans. FEMA, as the chair of the Interagency Coordinating Committee on Hurricanes, coordinates ongoing hurricane-related planning and mitigation activities of the U.S. Army Corps of Engineers, the National Weather Service, the National Hurricane Center and the Office of Ocean and Coastal Resource Management.

The objective of the Dam Safety Program is to enhance the safety of the Nation's dams, thereby protecting lives and property. FEMA exercises dual responsibilities through its Dam Safety Program to (1) coordinate Federal dam safety activities and (2) coordinate and implement activities designed to encourage States to implement strong dam safety programs.

The mission of the Hazardous Materials Program is to provide technical and financial assistance to State and local governments. In addition, FEMA coordinates and cooperates with the private sector in developing, implementing and evaluating hazardous materials emergency 
preparedness programs for State and local governments. The mission is accomplished through five separate functional elements--planning, training, exercising, information exchange and intergovernmental coordination/cooperation. FEMA develops and distributes planning and preparedness guidance to State and local governments in cooperation with the 13 member agencies of the National Response Team. Hazardous materials training courses and course materials are developed and financial assistance is provided to State and local governments.

As a result of a Presidential Directive in 1979, FEMA was assigned the lead Federal role for radiological emergency planning and response. Under FEMA's Radiological Emergency Preparedness Program, the goal is to enhance integrated emergency planning and response for all types of peacetime radiological emergencies by the State, local and Federal governments. The primary emphasis is directed to planning and preparedness for commercial nuclear power plants, nuclear fuel cycle and material license holders, Department of Defense and Department of Energy facilities and transportation accidents. Key activities pertaining to offsite radiological emergency planning and preparedness include evaluation of emergency response and utility plans, review of public emergency information materials, review and testing of utility alert and notification systems, periodic exercises to test emergency response plans and periodic program activities such as drills, plan updates and public meetings.

FEMA, more than any other Federal agency, provides the financial and technical assistance to State and local governments to prepare for, respond to, and recover from natural disasters. This is done through the Civil Defense Program, which provides a system of survival capabilities to protect life and property from natural hazards through the construction of emergency operation centers, warning systems, and training of State and local emergency managers. Other relevant FEMA programs assisting natural hazard reduction efforts of State and local governments are (1) The national Flood Insurance Program, which makes flood insurance backed by the U.S. Government available to communities that have agreed to adopt and enforce floodplain management ordinances to reduce future flood losses through wise utilization of their floodplains; and (2) The Fire Prevention and
Control Programs of the U.S. Fire Administration, which provides training and grants that support the efforts of State and local governments to reduce the number of fires nationwide and the loss of life and property from fire.

The Role of the Department of the Interior's U.S. Geological Survey (U.S.G.S.) in Geophysical Hazards Countermeasures In the United States

A principal goal of the National Earthquake Hazards Reduction Program is to identify, evaluate, and characterize accurately the seismic hazard in areas subject to high or moderate seismic risk. The U.S. Geological Survey (USGS) is the principal agency responsible for addressing this goal. There are two primary program objectives: to determine the tectonic and geologic framework and earthquake potential of the various earthquake-prone (or seismogenic) zones in the United States through detailed seismological and geological studies; and, as these zones are defined and their seismic potential quantified, the hazards and risks to the population, structures, and lifelines must be identified, evaluated, and documented. Decisions made by various governmental and private sector entities regarding construction practices, land use planning, and disaster preparedness should be based on accurate and complete assessments from work under this program element.

The USGS also conducts earthquake engineering research focused on strong groundmotion data collection, processing and analysis, maintains centers for seismological data collection and dissemination and leads the nation's earthquake prediction research programs in prediction methodology and experiments; theoretical, laboratory and fault zone studies; and induced seismology research.

The USGS currently is managing several projects focusing on earthquake hazards in the Eastern United States. These include: studies of the structure of the crust in earthquake prone areas, examination of faults, calculation of horizontal stresses over large areas, modeling of the local amplification of shaking due to earthquakes, and earthquake monitoring networks. The Parkfield Earthquake Prediction experiment on the San Andreas fault in central California is now fully operational and being monitored in real time. The use of high-precision geodetic surveying across large 
distances of the Earth's surface now allows scientists to monitor minute changes in the dimensions of the Earth's crust in earthquake-prone regions. This information provides a more accurate assessment of where and how stresses are accumulating in the crust.

In earthquake engineering research the USGS in cooperation with other agencies is conducting laboratory simulation of earthquake strong ground motions which promises to increase dramatically our ability to learn about the effect of damaging earthquakes on engineered structures. Research on spatial variation of strong ground motion is helping to illuminate the patterns of local damage during earthquakes. Understanding this variability is prerequisite to controlling it by means of protective measures or appropriately conservative seismic design.

The USGS is at the forefront of producing and deploying arrays of new digital seismographs in the U.S. and elsewhere in the world. The southern Quebec Earthquake of November 25, 1988, was a real-time test of the Earthquake Early Alert Service.

Understanding earthquake risk is fundamental to disaster planning and mitigation policy and implementation of countermeasures. Despite the Loma Prieta Earthquake, the risk of a damaging earthquake in the San Francisco Bay region still confronts nearly 6 million people. A new study, released in July 1990 by the USGS, says that there is approximately a 70 percent chance of another earthquake equal to or larger than Loma Prieta int he next 30 years, meaning that the earthquake is twice as likely to happen as not. The same report examined individual segments of Bay Area faults and gave probabilities of major earthquakes on each of those segments during the next 30 years. It is important to recognize that there are various potential sources for the next big earthquake, and that these sources are much closer to heavily populated areas than the Loma Prieta event, hence the potential for loss is greater.

USGS Technical Support For International Activities in Geophysical Hazards Reduction

Since 1983 the U.S. Geological Survey (USGS) has worked closely with the Agency for International Development's Office of US Foreign Disaster Assistance (AID/OFDA) in support of geophysical hazards reduction programs in the less developed countries (LDCs).

These programs have produced results that have placed AID/OFDA and the USGS in a highly visible role as leaders in reducing the impact of natural disasters. In addition to cooperating with OFDA in crisis responses such as the catastrophic eruption of Ruiz Volcano (Colombia), the toxic gas emissions of Lake Nyos (Cameroon), and the earthquake devastation in Armenia (USSR), the USGS provides ongoing technical assistance in OFDA's prevention, mitigation and preparedness activities.

In 1984 the USGS and OFDA sponsored a Geologic and Hazards Training Program in Denver which has proven to be a milestone in the technology transfer of earthquake countermeasures information to the LDCs. The purpose was to develop hazard mitigation expertise in order to save lives and reduce economic losses in countries where geologic and hydrologic hazards are prevalent. Forty-two international participants from 28 disaster-prone countries attended. The proceedings volume $(1,112 \mathrm{pp}$.), has been used extensively by other organizations as a text for subsequent hazards training courses.

In 1988 the USGS completed a series of detailed earthquake conditional probability maps and reports which cover the Circum-Pacific region and show comparative earthquake and tsunami potential for zones in the U.S., Central and South America, Southeast Asia, Japan and Alaska.

The Volcano Monitoring and Research Project in Indonesia has been a cooperative AID/Jakarta-funded five-year volcanology program between the Volcanological Survey of Indonesia and the USGS. At the conclusion the agreement was renewed by AID/OFDA. The purpose of the program was to provide the on-site consultant services of an eminent advisory volcanologist, who, with a number of USGS scientists and technicians, prepared a national volcano hazards assessment of Indonesia and trained the Indonesians so that they could respond to volcanic crises. This work included upgrading the volcano monitoring networks and providing transfer of technology and expertise in volcanology.

In 1986, as an outgrowth of the USGS's Volcano Crisis Assistance Team (VCAT) and as a result of the Ruiz Volcano disaster in Colombia, a 
5-year program was set up between the USGS and AID/OFDA. This cooperative program, equally funded by the USGS and OFDA, has established the U.S. capability of providing rapid, efficient and cost-effective volcano emergency response, initially in Latin America and also worldwide. VDAP provides on-site monitoring by a technicallyqualified volcano crisis assistance team, ongoing mapping and analyses of volcano hazards, preparation of data on the threat information to facilitate evacuation planning, an equipment cache, and training. To date VDAP has responded to volcanic threats in Colombia, Costa Rica, Guatemala, Ecuador, and Peru.

The U.S. Geological Survey is currently implementing the Worldwide Earthquake Risk Management Program (WWERM) as a one-year interagency cooperative pilot program (1990-91) with OFDA. Subsequent activities will depend on co-funding commitments from other donors and organizations. The objective of WWERM is to develop an action plan and conduct the one-year pilot program in each of three earthquake-prone target regions to demonstrate the utility, importance, feasibility and need for uniform global earthquake hazard mapping and risk assessment/management in preparation for a program linked to the International Decade for Natural Disaster Reduction. In each of the pilot project's four target countries (Morocco, Peru, Chile and Indonesia) the USGS, in cooperation with host country experts, will prepare probability earthquake ground motion maps and preliminary estimates of expected physical losses within the "built environment" as a basis for risk management, life saving preparedness planning, and the development of mitigation strategies.

The Department of Commerce's National Institute of Standards and Technology (NIST) Improving Seismic Design And Construction Guidelines

The role of the National Institute of Standards and Technology (NIST) in the NEHRP is to conduct research and provide technical support for the development and application of improved seismic design and construction practices. The research conducted by NIST is driven by two general objectives: to make new construction safe and economical with respect to earthquake hazards and to mitigate potential earthquake hazards in existing facilities. Thus, laboratory and analytical studies are conducted to provide technical information needed for improving building codes and standards pertaining to new construction, and to develop new criteria regarding the repair and strengthening of existing structures.

Several years ago, NIST initiated a multiyear research program to develop technical data on the behavior of connections between beams and columns to provide a basis for a rational seismic design method for precast beam-column connections. Inelastic deformations are concentrated in the connections, which are smaller and weaker than the precast elements being connected. Thus, the connections are often the weak links in the structure, and their strengthening is essential as an earthquake countermeasure. NIST is also developing other strengthening techniques which are aimed at improving lateral strength and ductility and are being applied to deficient structures. A set of design guidelines for assessing the overall capacity of strengthened reinforced concrete frame structures is being developed. A prerequisite to the establishment of such guidelines is knowledge of the interaction between existing structural members and strengthening elements and of the behavior of the anchoring elements used to join the structural members.

The National Science Foundation's (NSF) Responsibility For Upgrading Experimental Research Laboratories in Earthquake Mitigation

Experimental research in earthquake engineering is conducted at many laboratories located at universities across the United States. These laboratories vary from very large multipurpose facilities to small specialized facilities. NSF is continually providing resources to upgrade and expand the capabilities and instrumentation at these facilities. At the present time, several major facilities exist that conduct research sponsored by the NSF. These include The University of California (Berkeley and San Diego), University of Colorado, Cornell University, University of Illinois, State University of New York at Buffalo, University of Texas at Austin, Lehigh 'Jniversity and The University of Michigan.

Additionally the NSF has been at the forefront of supporting information dissemination centers and clearing houses in natural hazards. A number of these include: the National Information Service for Earthquake Engineering (NISEE) at the University of California, Berkeley, and the 
California Institute of Technology, which conducts comprehensive earthquake engineering dissemination programs; the National Information Service of the National Center for Earthquake Engineering Research (NCEER) at the State University of New York at Buffalo; and the Natural Hazards Information Center at the University of Colorado, a major clearinghouse for social science and policy information in the hazards field.

The information the NSF disseminates reaches a diverse audience that includes engineers, architects, building officials, planners, government officials, and researchers. Numerous channels of communication are employed to inform users about the results of countermeasures research from projects supported by the NSF in disciplines such as engineering, the social sciences, architecture, and planning.

The Role of the Department of Commerce's National Oceanic and Atmospheric Administration (NOAA) In Mitigating the Impacts of Floods, Severe Storms and Tsumamis In the United States and Abroad

The primary mission of the National Weather Service (NWS) is the protection of life and property and the enhancement of the national economy. Hence, the basic functions of NWS are the provision of forecasts and warnings of severe weather, flooding, hurricanes, and tsunami events; the collection, exchange, and distribution of meteorological, hydrologic, climatic, and oceanographic data and information; and the preparation of hydrometeorological guidance and core forecast information. The NWS is the single "official" voice when issuing warnings for lifethreatening situations and is the source of a common national hydrometeorological information base. The national information base forms an infrastructure on which the private sector can build and grow.

Accurate and timely weather and river forecast and warning systems are vital to the safety and well-being of the Nation's population. Weather and water resources forecasting harnesses modern advances in information to increase the productivity of American industry, thereby contributing to economic growth.

The National Weather Service (1) collects and exchanges hydrometeorological data and information on a national and international basis; (2) issues warnings and forecasts of severe weather, floods, hurricanes and tsunami events which adversely affect life and property; (3) issues weather, river and water resources forecasts and related guidance materials used to form a common national hydrometeorological information base for the general public, private sector, aviation, marine, forestry, agricultural, navigation, power interests, land and water resources management agencies and emergency managers at all levels of government; (4) provides climatological summaries, quality controls for observed and collected data; and (5) other services such as global, national or general regional atmospheric models.

The National Weather Service (NWS) is charged with responsibility for the Tsunami Warning Service and for the preparation and distribution of Watches and Warnings of tsunamis that may threaten lives and/or property in and around the Pacific Ocean. The NWS operates and administers the Pacific Tsunami Warning Center (PTWC) and the Alaska Tsunami Warning Center (ATWC). The PTWC functions as the National Tsunami Warning Center responsible for providing tsunami warning services for all coastal States and other U.S. interests throughout the Pacific. The PTWC also provides regional warning services for Hawaii; the ATWC provides regional warning services for Alaska, British Columbia, Washington, Oregon, and California. The PTWC is the International Operational Center for the Tsunami Warning System in the Pacific.

The relationship between earthquake size and historic tsunami generation is being studied by the PTWC on an area-by-area basis to determine the influence of regional and local tectonics and submarine geology on the generation of tsunamis. These studies are providing the basis for a better evaluation of the present warning thresholds and operational procedures.

The PTWC continues to work closely with Hawaii Civil Defense in coordinating and supporting State legislation for enhancement of tsunami mitigation measures for the State of Hawaii. The State Legislature approved funding for the installation of nine additional tide gauges within the Hawaiian Islands, equipped with digital data access via a computer telephone query. Each of the County Civil Defense Agencies, as well as the State Emergency Operating Center, will have 
microcomputers capable of automatically interrogating and plotting sea level data from any station using software developed at the PTWC. Telefax units are also being installed to provide a graphics communication link between the PTWC and all Civil Defense Agencies.

The National Geophysical Data Center (NGDC) located in Colorado acquires, processes, and analyzes technical data on earthquake hazards, and disseminates the data in many usable formats to Federal agencies, private industry, academia, and the public.

The NGDC Pacific Tsunami Data Base includes more that 1,600 events since 49 B.C. and more than 5,100 locations where tsunamis were observed. Times of generating earthquakes, tsunami arrival times, travel times, first motion of the wave, and periods have been added to the data base. The data base has been designed for use on IBM-compatible personal computers.

The Department of Energy (DOE) Program in Environment, Safety and Health For Mitigating Technological, Earthquake and Other Hazards

The Department of Energy (DOE) plays a major role in the National Earthquake Hazard Reduction Program (NEHRP) and is committed to supporting the program through the Department's environmental, safety, and health obligations. The support has been forthcoming from all levels of the Department, especially from the operations offices and power administrations that serve as NEHRP contacts. The Department's representatives have participated in NEHRP activities of the Interagency Committee on Seismic Safety in Construction and the Subcommittee on Federal Earthquake Response Planning.

In April 1989, the Department issued DOE Order 6430.1A, General Design Criteria, which specifies the use of design basis earthquake levels for nuclear processing facilities and other hazardous operations based on probabilistic hazard curves. The DOE Order requires the use of the Design and Evaluation Guidelines for DOE Facilities Subjected to Natural Phenomena Hazards. This was re-issued as an interim report in 1989, and its methodology is based on the approach used in the Uniform Building Code UBC (1988 Edition) and the U.S. Army's Seismic Design Guidelines for Essential
Building. DOE's Office of Safety Appraisals is sponsoring workshops on the use of the guidelines.

The Department of Energy (DOE) continues to strengthen the awareness and broaden the involvement of its program offices, field organizations, and energy contractors in the National Earthquake Hazards Reduction Program (NEHRP). The following major organizational units of DOE are involved in natural phenomena hazard mitigation programs: 1) Management and Administration; 2) Defense Programs, 3) Energy Research, 4) Environment, Safety and Health, 5) Fossil Energy, 6) International Affairs and Energy Emergencies, 7) Nuclear Energy, 8) Civilian Radioactive Waste Management, 9) Power Marketing Administrations, 1) Operations Offices and 11) Energy Technology Centers throughout the U.S.

These organizations are responsible for implementing the requirements of Departmental Orders, including specified consensus standards (e.g., seismic requirements of the Uniform Building Code (UBC) and the Seismic Design Guidelines for Federal Agencies).

Department of Defense (DOD) Activities in Civil Works, Research and Education for Disaster Reduction and International Humanitarian Response

The work of the U.S. Army Corps of Engineers (CE) military and civil works programs and activities in earthquake, tsunami and flooding countermeasures conducted by the U.S. Navy are important contributions to the protection of critical coastal facilities worldwide.

The Loma Prieta Earthquake demonstrated the need for an increased effort in the area of structural evaluation of existing structures and methods of retrofitting. This has set the stage for research work on base isolation and elastic damping systems. A large percentage of essential military installations are located in areas of high seismic activity, and therefore should be able to function during and after a seismic event. Many of these facilities are constructed of masonry units and are vulnerable to seismic damage.

The Corps of Engineers continues to develop and improve its seismic design and 
construction requirements, using the latest seismic design provisions and innovative design concepts for water resource type structures. A new geotechnical seismic design manual applying the latest findings of research for the practical design of shallow and deep foundations, retaining walls, buried structures, slopes, and embankment dams is in preparation. The manual, developed with the U.S. Naval Civil Engineering Laboratory, provides geotechnical design guidance for waterfront structures. In addition, structural engineering guidance is being prepared for the seismic design of concrete towers required for the intake of outlet works for dams.

The U.S. Navy Facilities Engineering Command continues to investigate naval shore facilities located in areas of high seismic risk. The program is approximately 85 percent completed and will ultimately involve 95 Navy activities. Areas of vulnerability to potential liquefaction, tsunami flooding, and landslides have been identified, and widespread deficiencies are being addressed. Approximately 14,500 structures have been screened, approximately 1,600 structures analyzed, and 650 found to be seriously vulnerable. For the structures identified as hazardous, nonstructural components as well as the lateral force resisting system were evaluated. In areas where site hazards are identified, they are shown on planning documents, and new construction restricted or adapted to provide protection.

Bureau of Reclamation Earthquake and Flood Hazards Reduction Applications Research And Implementation

The Bureau of Reclamation (Reclamation) earthquake hazards reduction activities basically involve seismic analyses and the designs or modifications of embankment and concrete dams and large structures. These seismic analyses require a variety of state-of-the-art technical studies, including regional and local seismotectonic investigations, microseismic monitoring, subsurface drilling and trenching explorations, materials sampling and testing programs, and various types and levels of dynamic analyses, including risk-based analyses. The studies include the installation of field instrumentation and the development of a wide latitude of seismically related programs. Reclamation also conducts research related to earthquake effects on materials and structures. Projects underway in Fiscal Year 1990 include centrifugal modeling of embankment dam cracking and soil strength and deformation following liquefaction.

The Bureau of Reclamation is the lead technical agency in the Department of the Interior's Safety of Dams Program and is involved in seismic issues throughout the contiguous 48 States and Alaska. There are, at present, 385 dams in Interior's Safety of Dams Program. Of these, 269 are Reclamation, 52 are Bureau of Indian Affairs (BIA), 29 are Fish and Wildlife Service (FWS), 26 are National Park Service (NPS), and 9 are Bureau of Land Management (BLM). This Bureau has identified about 70 dams that may require modifications for safety reasons; however, most of these safety issues are not associated with earthquakes.

Within the Bureau of Reclamation, a major program is continuing to evaluate the safety of existing dams and foundations of new dams in highly seismic areas. Dams or dam foundations that are suspected of being liquefiable are first evaluated using in situ field testing and simplified empirical methods. Techniques for determining in situ void ratio and the steady state of deformation are used in the evaluation of liquefaction potential on projects for which the simplified empirical methods do not give a definitive result.

The Role of the Department of Transportation In Protecting Critical Facilities and Lifelines In the U.S.

While the Department of Transportation (DOT) is emphasizing seismic safety in new construction, its long term objectives are to develop prioritized courses of action involving mitigation or retrofit programs for existing buildings and lifelines in high risk areas, and to promote long term research into ways to increase seismic resistance for both new and existing structures. DOT also expects that this seismic safety program will have the added benefit of reducing loss and disruption risk from other natural and man-made hazards affecting transportation systems.

A goal of DOT's hazards reduction program is to achieve earthquake resistance commensurate with the seismic risk for that region for new structures and lifelines. All agencies of the Department of Transportation (DOT) are encouraged to identify cost-effective, low expense activities for quick enhancement of their present 
programs. In this regard, procedures are being established for a future review of the vulnerability of existing DOT facilities in areas of higher seismic activity.

Another goal calls for the review of DOT Orders that govern leasing of space, with adherence to local building codes on seismic safety as an evaluation factor in renting building space. Agencies are also encouraged to continue building a seismic knowledge base and sponsoring low cost research. Underlying these objectives is the Departmental policy to develop awareness and information programs for all its constituencies and employees on the need for increasing seismic resistance for the Nation's transportation system.

The 1971 San Fernando earthquake was a major turning point in the development of seismic design criteria for bridges in the United States. The earthquake started a chain of events which led to the American Association of State Highway and Transportation Officials (AASHTO) adopting, in 1983, a set of guidelines prepared by Federal Highway Administration (FHWA) to establish design and construction provisions for bridges to minimize their susceptibility to damage from earthquakes. DOT is also concerned with the additional effects of dynamic earthquake-induced ground shaking on the behavior of structures and on soils underlying ports and harbors, as well as tsunamic threat.

The Department of Veterans Affairs (VA) Hospitals and Medical Facilities Protection Against Disasters

The Department of Veterans Affairs (VA) develops plans and strategies for the provision of emergency health care services to veteran beneficiaries in Veterans Administration medical facilities, to active duty personnel and where possible to civilians in communities affected by national security emergencies. The VA works closely with other USG agencies to apply applicable building codes and construction techniques to protect its facilities and equipment against natural disasters. The VA also assists The Department of Health and Human Services (HHS) in developing national plans to mobilize the health care industry and medical resources during times of national emergency.

The Department of Veterans Affairs (VA) seismic strengthening program strives to ensure the safety of patients and staff through the seismic strengthening or replacement of all essential substandard buildings in seismic-risk areas. Since the inception of the program in 1971, approximately 120 buildings have been strengthened, are being strengthened, or are presently in the design stage of a construction project for strengthening. The seismic structural strengthening program has made significant progress toward achieving its objective, although much more remains to be done.

The Loma Prieta Earthquake prompted the VA to reexamine its seismic correction program. A comprehensive study of VA requirements in this areas has been completed. There is an increased priority for projects that address seismic deficiencies. The seismic correction program has been instrumental in proposing funds for seismic projects; \$5.9 million for design of seismic correction at Long Beach Medical Center was budgeted for Fiscal Year 1990, with construction funding of $\$ 67.2$ million planned for Fiscal Year 1991. Design funding of $\$ 15.3$ million for seismic corrections at the Martinez Medical Center is planned for Fiscal Year 1991, with construction funding of $\$ 157.8$ million planned for future fiscal years.

Commensurate with a recent VA study, the development of future budgets will continue to give high priority to projects at medical centers requiring seismic correction, including future projects at Memphis, Albuquerque, American Lake, and Manlo Park. The Loma Prieta Earthquake significantly damaged the VA medical center in Palo Alto, California, and necessitated an emergency response by the VA. The VA has been provided $\$ 54$ million in emergency funds for medical supplies and staff equipment, temporary bed and support space, seismic upgrading, and the design and site preparation for a replacement facility. The total project cost of the replacement facility is $\$ 252$ million.

Also included in VA earthquake hazard mitigation efforts is a wide range of programs initiated to: (1) Anchor major mechanical and electrical equipment to prevent dislodging or disruption during an earthquake. (2) Install an emergency radio network to provide direct communication between any of the VA facilities in the United States; (3) Provide emergency utility services, especially water and electrical power, in all VA medical centers; and (4) Install special 
earthquake provisions for equipment, furniture, and supplies to assure the operation of VA medical centers in the postearthquake period.

Nuclear Regulatory Commission (NRC) Seismic Countermeasures for Civilian Nuclear Electric Power Plants

Under its congressional mandate to regulate commercial production and use of nuclear materials, the Nuclear Regulatory Commission (NRC) conducts a variety of regulatory activities and manages a strong research program to support its regulatory operations. NRC-supported research encompasses the areas of seismicity, tectonics, and stress/strain measurements. These studies provide a scientific basis for regulating the activities of the nuclear industry and improving the safety of nuclear plants and waste disposal facilities. NRC-supported research programs in these areas contribute to the efforts of the National Earthquake Hazards Reduction Program (NEHRP).

Since 1980, the NRC has sponsored analytical and experimental research on low-rise reinforced concrete shear walls, buildings, and building segments. The research is focused on answering certain structural concerns related to (1) the adequacy of criteria currently used in design and analysis, and (2) the ability of existing nuclear power plants to withstand earthquakes greater than considered in the original design.

While the adequacy of nuclear plant equipment to withstand earthquakes has been a continuing consideration, only the more recent plants have used a rigorous testing program to qualify their equipment for design level earthquakes. The resistance to earthquakes larger than design levels has not been documented. An extensive NRC and industry effort nearing completion has used both the collection of earthquake experience data from non-nuclear facilities and the synthesis of existing nuclear equipment qualification test data to form a program to reevaluate the seismic activity.

The studies performed have shown that, on a generic basis, much of the equipment used in nuclear plants is inherently seismically-rugged if properly anchored and not subjected to damaging interactions (e.g., the collapse of un-reinforced masonry walls onto equipment). In general, it has been found that the seismic strength evaluation of electrical equipment is the most critical for operating nuclear plants.

In recent years, both industry and the NRC have been concerned with the appropriateness of NRC's piping design rules for seismic and other dynamic loads. An over-design of piping for dynamic inertial loadings can produce negative effects from thermal expansion and the relative displacement of piping and points and can reduce its overall reliability.

Both the NRC and the Electric Power Research Institute (EPRI) have sponsored programs to evaluate the earthquake experience of piping in heavy industrial facilities. The basic conclusion of these programs is that welded above-ground piping, designed according to the more relaxed criteria of the non-nuclear Industry, performs very well during large earthquakes.

Environmental Protection Agency (EPA) Natural and Technological Hazards Abatement

The Environmental Protection Agency (EPA) works to prevent and respond to hazardous materials releases and related incidents that are caused by natural disasters. Building on EPA's existing statutory response activities under the National Oil and Hazardous Substances Pollution Contingency Plan, EPA provides managerial and technical leadership to State and local governments requesting assistance with hazardous materials releases, damage to hazardous materials containers, fires involving hazardous materials, stabilizing leaks and spills to protect public safety and the environment, and related incidents caused by natural disasters. EPA also conducts environmental research contributing to our understanding of natural hazards. The Environmental Monitoring and Assessment Program (EMAP) provides statistically determined baselines on ecosystem status from which to measure and understand impacts of disasters. Research is also conducted to determine the environmental and ecological impacts of genetically engineered biological agents and to assess the cumulative loss of wetlands on the frequency and severity of floods.

The Role of the U.S. Department of Agriculture (USDA) in Mitigating Drought, Flood, Fire and Landslide Impacts

The United States Department of Agriculture's Office of International Cooperation 
and Development (USDA/OICD) is coordinating a Famine Mitigation Project for Africa under a Resource Support Service Agreement (RSSA) with OFDA for an initial two year period. It is widely acknowledged by emergency experts that much can be done to mitigate the effects of a famine situation prior to its onset. The intent of this activity is to identify, test under actual field conditions, and develop standard implementation models for a limited number of interventions that can dramatically reduce the impact of famines prior to their onset, and to reduce the recovery period after the conclusion of a famine. The major areas that will be investigated under this activity include Early Warning Systems and Rapid Assessment, Seeds and Tools, Livestock Preservation, Water Resources, Cash for Work, and Conflict Modifications. Expert teams will be formed to design and field test these interventions in Sudan, Ethiopia, Somalia, Angola, and Mozambique. Following implementation and evaluation of the selected interventions, the teams will develop generic guidelines so that these activities may be implemented wherever they are necessary and appropriate. Finally, workshops will be conducted for famine response personnel in the United States and in East and Southern Africa to provide an overview of the tested activities and to develop practical plans for their use during future famine situations.

The Early Warning and Rapid Assessment team will examine current Early Warning Systems and options for OFDA, develop methods and survey instruments for establishing deviations from norms, and identify indicators for determining appropriate intervention measures for at-risk populations. The Seeds and Tools team will identify agricultural baselines and identify appropriate seed varieties, tools and methods that could be employed prior to famine onset. This team will also examine agronomic and horticultural packages and seed bank activities as well as traditional crops and practices. The Livestock team will identify and test activities to maintain livestock through famine situations. The Water Resource team will identify interventions that can be implemented at regional and local levels to maintain a reliable, safe water supply. Although Food for Work activities have been extensively employed and examined in the past, the Cash for Work team will identify direct cash transfer opportunities and how they may be employed to support and strengthen the agricultural, livestock and water resources activities to be tested by the other teams. The Conflict Modifications Team will identify the barriers to working in and applying the above interventions under conflict situations.

Additionally, the USDA, U.S. Forest Service conducts both domestic and international drought, flood, fire and landslide impacts programs which focus on disaster preparedness (primarily emergency planning, wildfire prevention, and wildland fuel modification) and wildfire suppression. The USDA also conducts research examining ecosystem processes; people/structure/hazard interactions; vegetation management and biological controls: climate/weather/hazard linkages, and post-hazard recovery.

The Soil Conservation Service of the USDA aids local communities sponsoring projects to reduce flood and drought hazards; provides assistance for emergency intervention and recovery; education and awareness; drought prediction and warning; community mitigation planning; and research on the relationships between soil moisture regimes and agricultural productivity.

The U.S. Forest Service's Disaster Assistance Support Program (DASP) was established in 1985 to increase cooperative efforts between OFDA and the U.S. Department of Agriculture (USDA).

The primary goal of DASP is to assist OFDA in disaster prevention, preparedness, and emergency response, mainly to developing nations of Africa, Latin America and the Caribbean, and Asia and the Pacific regions. The Forest Service is thus able to:

(1) Provide technical support in disaster prevention;

(2) Develop and implement programs for training disaster management personnel from OFDA, United States embassies and USAID missions, and from host countries;

(3) Develop and use a computerized roster system for identifying technical experts and disaster management specialists;

(4) Plan and coordinate workshops, conferences, reports, and publications that promote effective disaster prevention, preparedness, and management; and 
(5) Mobilize disaster management specialists, equipment, and supplies to disasters.

DASP works with OFDA to strengthen the ability of countries to cope with disasters by helping them improve their own disaster preparedness and response capabilities. DASP has provided the following assistance to countries around the world through its support to OFDA:

(1) Landslide hazard training and assessments in Asia, Latin America, and the Caribbean;

(2) Development and implementation of disaster management training courses and simulation exercises;

(3) Sponsorship of workshops and conferences;

(4) Locust control operations in Africa;

(5) Wildfire assessments and technical assistance in Latin America;

(6) Operation of water purification systems at disaster sites;

(7) Production of operations manuals and guidebooks for disaster management;

(8) Shipment of fire suppression supplies and equipment; and

(9) Supply of communications personnel and equipment.

U.S. Public Health Service (PHS), Centers for Disease Comtrol (CDC), Epidemiological Surveillance and Emergency Management

The Centers for Disease Control, International Health Program Office in Atlanta, Georgia provides epidemiological technical assistance internationally in natural and man-made emergency situations. The CDC organizes and maintains a resource center (including a library and data base of consultants) to support CDC-wide organizational activities and objectives. $\mathrm{CDC}$ assists international organizations and their respective constituents in preparedness activities leading to more effective provision of assistance in emergency situations, and provides technical assistance internationally to U.S. government agencies and multilateral organizations involved in refugee health care.

In 1989, eighty-six members of CDC staff participated in forty-three emergency response missions and developed for the World Health Organization (WHO), a distribution network for rapid assessments for nine types of emergencies. In 1990, CDC, WHO and AID are designing and implementing a project to develop the surveillance and response capabilities of African countries lying within the meningitis belt. CDC has also developed a briefing package for use by consultants in emergency and non-emergency situations. This package includes such information as communications procedures, cultural sensitivity guidelines, and instructions for shipping supplies and samples to the U.S. They are also conducting retrospective evaluations of recent emergency responses to determine most appropriate and effective response procedures.

Agency for International Development (A.I.D.), Office of U.S. Foreign Disaster Assistance (OFDA) Program in Disaster Prevention, Mitigation and Preparedness In The Developing World

A.I.D., through the Office of U.S. Foreign Disaster Assistance (OFDA), is responsible for providing emergency relief assistance to foreign nations affected by natural or man-made disasters and for providing other assistance in disaster prevention, mitigation, and preparedness. This program has been structured to (1) concentrate OFDA relief resources on those activities which save the greatest number of lives; (2) concentrate OFDA mitigation and preparedness resources on those activities which save the greatest number of lives and protect the economic infrastructure of developing countries; (3) reorient OFDA's approach to disasters by integrating development concepts into relief, rehabilitation, prevention, mitigation and preparedness activities; and (4) encourage other U.S. Government departments, private industry, international institutions and A.I.D. regional bureaus to integrate disaster preparedness and relief principles into their projects.

The ultimate goal of this program is to save lives and reduce human suffering in disaster-prone countries. A.I.D. recognizes that property loss and subsequent economic and social disruptions associated with disasters are major deterrents to 
A.I.D.'s and the developing countries' goals of fostering economic growth and sustaining the viability of development assistance programs. OFDA currently works with the Agency's regional bureaus to reduce the threat posed by natural hazards to development.

A.I.D.'s strategy addresses the principal goal of saving the greatest number of lives by (1) responding with relief goods and services during disasters in foreign countries, and (2) preparing for and reducing the likelihood of economic impacts and loss of life prior to the occurrence of disasters. The two main components of this strategy are as follows: (1) U.S. Government Emergency Relief Coordination. Through the use of all appropriate U.S. Government resources and cooperation with private sector resources, A.I.D. seeks to alleviate suffering and reduce the number of deaths in the aftermath of disaster by providing efficient and rapid responses to requests for emergency relief and to enhance recovery through rehabilitation programs, and (2) Prevention, Mitigation, and Preparedness. A.I.D. seeks to apply multidisciplinary approaches in the fields of disaster prevention, mitigation and preparedness to reduce the impacts of disasters.

The program in disaster prevention, mitigation and preparedness (PMP) stimulates new and dynamic approaches to reduce the impacts of disasters on potential victims in target countries. The goal is to save lives. Through pre-disaster action, OFDA assists vulnerable countries in reducing the economic and social impacts caused by disasters. The PMP program provides support to applicants from the public and private sectors, institutions, universities and agencies. Groups implementing activities are encouraged to provide matching support to ensure the transfer of findings and results. The following illustrate areas of concentration which may constitute the multi-year disaster PMP program: (1) private sector activities; (2) famine; (3) hydrometeorological events; (4) geophysical conditions; (5) medical and health concerns; (6) environmental and technological disasters; (7) A.I.D. mission program support; and (8) project design, analysis, and evaluation. The A.I.D. PMP program will support the U.S. and international goals established for the U.N. International Decade for Natural Disaster Reduction.

The program will provide the analytic, technical, economic and social expertise necessary to support A.I.D. policy and program interventions to reduce the impacts of disasters on development. Sustainability will be assured by not funding projects where the host government commitment is inadequate. Activities will contribute to sustaining economic development by reducing the vulnerability of the work force and economic assets to disasters.

This program supports A.I.D. efforts to provide more effective humanitarian assistance to those who potentially would suffer from natural and man-made disasters and to intervene on their behalf prior to the occurrence of disaster. The program will also help to protect private sector investment and economic development worldwide.

Principal beneficiaries will be the potential victims of disasters in the developing countries and officials in public and private sector organizations who have disaster PMP, relief, rehabilitation and reconstruction responsibilities.

Major outputs of this program are: hazard-specific technical assistance and training in selected countries based on strategic planning; (2) building host country institutional capacity to manage disasters and monitor hazards; and (3) reduction of disaster potential through protection of infrastructure, mitigation of impacts, and helping host governments plan for, prepare and, where possible, prevent disasters.

\section{U.S. FEDERAL PROGRAM STRATEGY FOR THE DECADE OF THE 1990'S}

The U.S. Federal Program for reducing the impacts of natural disasters in the decade of the 1990 's focuses on reducing fatalities, human suffering, environmental damage and economic losses by coordinating programmatic resources to resolve priority hazard-related issues and integrate and enhance planning and response capabilities from the Federal to the local levels. Integration of extensive interdisciplinary expertise, various missions of the Federal agencies and State and local governments, and existing components of private sector disaster reduction efforts is key to the successful reduction of hazards during this decade. The federal program strategy seeks to integrate mitigation measures across hazards by applying common tools for pre-disaster interventions, 
examining causal relationships, geographic and spatial similarities and other factors leading to successful forecasting and implementation of appropriate risk reduction measures prior to event occurrence. The strategy for the 1990's will better define acceptable risks by hazard type and location and will increase public awareness as to those practical countermeasures which can be taken to reduce personal and community economic, social and physical impacts. The Federal Subcommittee on Natural Disaster Reduction of the Committee on Earth and Environmental Sciences of The President's Office of Science and Technology Policy (OSTP) has recently completed a draft report. This report will help establish the U.S. national strategy for disaster reduction in the 1990's. At the same time, these activities are complemented by current program planning by the National Research Council's U.S. National Committee on the Decade. Their report with a recommended plan of action, will be available in late June, 1991.

\section{Sources}

Advisory Committee on the International Decade for Natural Hazard Reduction, 1987. Confronting Natural Disasters: An International Decade for Natural Hazard Reduction. National Academy Press, Washington, D.C., 60 p.

Advisory Committee on the International Decade for Natural Hazard Reduction, 1989. Reducing Disasters' Toll: The United States Decade for Natural Disaster Reduction. National Academy Press, Washington, D.C.

Committee on Earth and Environmental Sciences, 1991. Hazard-Proofing the Nation: Strategy to Reduce Natural Disasters (In Draft) Federal Subcommittee on Natural Disaster Reduction. Washington, D.C. $48 \mathrm{pp}$.

Federal Emergency Management Agency, 1987. Plan for Federal Response to a Catastrophic Earthquake. FEMA, Washington, D.C.

Federal Emergency Management Agency (FEMA) 1990. Report to the U.S.
Congress - National Earthquake

Hazards Reduction Program:

Fiscal Year 1989 Activities.

Washington, D.C. FEMA.

Federal Emergency Management Agency, 1991. Principal Threats Facing Communities and Local Emergency Management Coordinator. A Report to the U.S. Senate Committee on Appropriations. 115 pp.

Federal Emergency Management Agency (FEMA) 1991. Report to the U.S. Congress National Earthquake Hazards Reduction Program: Fiscal Year 1990 Activities. Washington, D.C. FEMA.

Hennig, Leaura M. 1990. The Natural Hazards Data Resources Directory. Natural Hazards Research and Applications Information Center and U.S. Dept of Commerce, National Geophysical Data Center, Boulder, Colorado. 247 pp.

Krumpe, Paul F. 1990. Office of U.S. Foreign Disaster Assistance (OFDA) 1990 Program in Disaster Prevention, Mitigation and Preparedness. A.I.D. Washington, D.C. 9 pp.

National Oceanic and Atmospheric Administration. 1991. Policy Statement on the Weather Service/ Private Sector Roles. DOC/NOAA. Federal Register Vol. 56 No. 13. Washington, D.C.

U.S. Public Health Service. 1987. Disaster Response Guides. PHS Office of Emergency Preparedness. Rockville, Md. 


\section{Manuscripts Authored for Panel Meeting but Not Presented Orally}


1 


\section{Boundary Layer Wind Tunnell Study on Full Aeroelastic Long Span Bridge Model}

by

Kolch1 YOKOYAMA") Tomok1 KANAZAKI ${ }^{23}$ and Masahiko YASUDA ${ }^{3)}$

\begin{abstract}
In order to carry out plnal verification of aeroelastic safety of the Akashi Kalkyo(stralt) Bridge, which has a main span of $1,990 m$ and two side spans of $960 \mathrm{~m}$ and a truss stiffening girder, its full aeroelastic bridge model wind tunnel testings were planned and are now in progress. A geometrical model scale of $1 / 100$ was selected and primary dimensions to be required for the test section of wind tunnel were determined; width 41 m, helght $4 \mathrm{~m}$ and length $30 \mathrm{~m}$. This paper presents some discussions related to this large boundary layer wind tunnel pacility and Ideas of modeling for the bridge.
\end{abstract}

Keypords: wind, design, pull model, suspension bridge. wind tunnel

\section{Introduction}

The Akashl Kalkyo Bridge, which rill connect the Honshu(main island) to the Amajl Island, Is now under construction. As the bridge is a very long span suspension bridge whose main span length is far beyond that of the current porld longest suspension bridge, it is one of the most important themes to secure the wind resistant safety of the bridge. Therefore. It is necessary to verify the safety more accurately not only by evaluating from the ordinary wind tunnel tests using a sectional model but also by carrying out wind tunnel tests using an aeroelastic full bridge model whose shape and elasticity should be as simllar as possible. Fig.l shows the general view of the Akashl Kalkyo Bridge.

This paper summarizes conclusions of the study concerning the large boundary layer wind tunnel pacllity and a full aeroelastic model of the Akashi Kalkyo Bridge.

\section{Purpose of the Full Aeroelastic Bridge Model Mind Tunnel Test}

The purposes of the full aeroelastic bridge model wind tunnel test are classifled as follows;
1) Verification of Aerodynamic Stability

As the fundamental naturai frequency of long span suspension bridges such as the Akashl Kalkyo Bridge is very low, flutter characteristics of those bridges are very sensitive to slight change of member arrangement and to the difference in test conditions. Therefore, It is necessary to verify the aerodynamic safety more precisely by full model wind tunnel tests.

\section{2) Estimation of wind Load}

Main members of the stiffening truss of the Akashl Kalkyo Bridge are decided by static wind load. In the static design with wind load, gust response of drag, lift and moment are considered but these are all estimated by theoretical formulas. If the accuracy of those formulas is verifled quantitatively by means of observing three dimensional behavior of the full model in a simulated turbulent wind, more rational design for wind load will be possible.

3) Verification of the Ordinary find Tunnel Testing Method

Not only in Japan but also in other countries. wind-induced vibration of a long span bridge has mainly been predicted by Find tunnel tests in smooth flow using a sectional model. However, in truth, wind is changing in time and in space. The structure also has three dimensional spread that can not be expressed by the sectional model. Therefore, it should be quite important to study three dimensional effects of wind and the structure by carrying out large scale full model wind tunnel test in order to understand accuracy

1) Head, Structure Division. Structure and Bridge Department. Public Torks Research Institute. Ministry of Construction

2) Senior Researcher, ditto

3) Head, First Design Division, Design Department. Honshu-Shikoku Bridge Authority 
and limit of the current ordinary wind tunnel testing method quantitatively.

As described above, the maln purposes of full aeroelastic bridge model wind tunnel tests are to verify the safety of the Akashl Kalkyo Bridge to strong wind, to establish rational wind resistant design method and to Improve current wind tunnel testing method.

3. Construction of the Large Boundary Layer Wind Tunnel Facility

\subsection{Required Characteristics of the find Tunnel}

At first, the model scale of $1 / 100$ was decided considering not to fall to simulate the characteristics of the bridge and to make $1 \mathrm{t}$ as small as possible. Then the width $41 \mathrm{~m}$ and helght $4 \mathrm{~m}$ of the test section were decided to put whole the model in 1 t. The length of the test section $30 \mathrm{~m}$ were selected considering to generate boundary layer turbulent flow.

The maximum wind speed $12 \mathrm{~m} / \mathrm{s}$ was almed at considering the Froude number similarity and loss of energy due to generating turbulence.

The properties of smooth flow were aimed at as follows;

a) Turbulence Intensity

; less than $1 \%$

b) Mean Wind Speed Distribution . ; less than $3 \%$

\subsection{Pllot Mind Tunnel Test}

In order to determine the structural conflguration of the 1 ind tunnel and the bullding which satisfy the required properties economically, a pllot wind tunnel test was carried out. Its scale was $1 / 16$. The pilot wind tunnel is shown in Photo 1. The facts understood by this test mere as follows:

1) Speclfications of the contraction nozzle :

a) Contraction ratio 2 can satisfy the required flow propertles.

b) Two steel screens are enough for the requlred propertles.

c) One of steel screens is to be installed at the entrance of the bell-mouth.

2) Bullding :

a) The minimum length of 75 is required.

b) The minimum height of $19.5 \mathrm{~m}$ is required.

c) The celling can be gade 2 m lower at the side of the lower reach.

3) Others :

a) Corner-vanes at the entrance are very efficient and those at the exit are not.

b) The flow is little affected by the inside trusses supporting the celling of bullding.

c) The flow is little muddled by the streamline-section posts of corner-vanes.

\subsection{Final Plan of the find Tunnel}

The general layout of the wind tunnel facllity selected as a final plan is shown in Fig.2. Improved points after the pllot wind tunnel test considering the usage are as follows;

a) Three test sections are prepared: smooth flow test at upstream side, turbulent flow test at downstream side and different wind direction test at the center.

b) Sensor rooms are arranged at both sides of the test section.

c) Size and number of fans are selected as $1.8 \mathrm{~m}$ in diameter and 36 respectively.

d) Wind speeds are controlled by rotation cycles of $\mathrm{f}$ ans.

This wind tunnel facillty had been completed on the end of Feb. 1991 at the site of the Public Works Research Institute of Ministry of Construction. Flow properties were measured Just after completion of the wind tunnel and the results are quite satisfactory.

4. Modeling of Full Aeroelastic Long-span Suspension Bridge

\subsection{Required Characteristics of Aeroelast1c Model}

In time of carrying out the full model wind tunnel tests for the Akashi Kaikyo Bridge to verify aerodynamic stability and gust response considering three dimensional effects of wind and the structure, it is considered that the most important subject is to realize a good simllarity of the model. In modeling of a full suspension bridge, following attention should be pald generally;

a) to satisfy the simllarity of shape, mass distribution and stiffness distribution of the structure at the same time

b) to reduce the damping of model as small as possible

On the other hand, larger scale w11l cause hlgher costs of the model as well as the wind tunnel facllity. Through a lot of studies on modeling, it was found possible to make a full aeroelastic model of the 
Akashi Kalkyo Bridge with a geometrical scale of 1/100, having a pretty satisfactory performance except minor points in geometrical and mechanlcal simllarity. For example, mass and stiffness of the girder, which actually are not unlform, are almost uniformly distributed to the bridge axis. However, it is conflrmed by some analytical studies that those relaxation of similarity requirement would give little effects on aerodynamic characteristics of the bridge.

\subsection{Modeling of St1ffening Truss Girder}

In order to reallze three dimensional aeroelastlc behavior of the truss model, the similarity of geometrical shape as well as stiffness of vertical, lateral and torslonal directions is really important. From a lot of sectional model wind tunnel studies repeated so far, it is quite clear that the cross section shape of the stiffening girder causes a lot of effects on flutter characteristics. Therefore, in modeling of the stiffening truss girder, at flrst, attention was pald to realizing the similarity of the stiffness without providing a kind of stlffening splne at the center of cross section.

Two types of the truss model mere studied. One is the rigld block model connected by springs, and the other is the wholly elastic model in which four stiffening bars are used as maln cords. As for the Iatter, it was found difficult to support deck glrders separated at each panel in a row. It is needless to say that misalignment in the deck girders affects flutter characteristics of the bridge very much.

Consequently, the rigld block model was adopted. In the model, the truss glrder is composed of rigld blocks of every four truss panels to simulate the aerodynamic characteristics of the actual truss girder, and springs installed between blocks representing the aechanical characteristics. In this modeling, it was important and also really hard to design the spring. Based on the prelimlnary study on the characteristics of those springs. $V$-shape springs were finally selected. The outline of the model is shown in Fig. 3 and Photo 2.

Actually, the problems were still to be worked out in how to ofnitulze effects of springs and clearances between the blocks on the flutter characterlstics, and how to design such rigid blocks as expected. As for the former problem, it is confirmed that there are few effects of $V$-shape springs by sectional model gind tunnel test. And for the latter, it is solved by using light new moterial of carbon flber plate for the truss members.

The detalled modeling of the truss girder is one of reaso., \& a geometrical scale was determined as $1 / 100$.

\subsection{Modeling of Tower}

The model of tower is composed of a prame of stiffening bars installed inside and exterfor mooden forms similar to the geometrical shape of actual structure. According to the analysis on the actual brldge, the effect of towers on total behavior in static as well as dynamic responses can not be 1 gnored. Homever, it is really hard to realize all the simllar stiffness only by scalling down actual structure. So 1t pas preliminarlly studled to check the effect of stiffness of tower columns, diagonal and lateral members on static deformation as well as osclilation behavior of the tower, and also the effect of stiffness of towers on the behavior of girder.

From the results of the study, 1t was found that the stiffness of bridge axial and torsional directions would be easily slmulated by choosing an appropriate section of stiffening bars. Simulation of stiffness transversal to the bridge axis was not easy, but was confirmed by replacing the effect of actual diagonal members to those of lateral members by cutting at their cross points.

However, it was also found that small error in torsional deflection of the girder would be inevitable because it is very hard to simulate the axial stiffness of tower columns.

Fig. 4 shows a prame of stiffening bars of the tower model. The level of similarity was checked by analyzing natural frequencles and static deflection on the total bridge structure. The results were almost satisfactory.

\subsection{Modelling of Cable}

As for the modeling of the cable, the mass, drag force on it and axlal stiffness should be slmulated, especially considering the effect of difference in Reynolds number on drag force similarity of circular cable section. In this sense, 1 t is out of the question to model them by using only one k1nd of uniform wire. Therefore, the design was made by using a unifora wire similar to only axlal stlffness and welght pleces similar to mass and drag force arranged at a certain interval. The dimension and arranging pitch of weight pieces were determined after the decision of the mass similarity requirement. The preliminary study was finally checked by measuring the drag force with wind tunnel test and the 
damping for the extended cable.

Aerodynamic Interference between a stiffening girder and cables close to it near the center of maln span is another problem to be considered. A preliminary wind tunnel test was carried out with a sectional model of two cables and a girder comblned. Judging from the results, weight pleces. which are simllar to only shape and not to drag force, are to be attached in a certain position near the center so that there is no wrong effect of cables on aerodynamic characteristics of the girder. Fig. 4 and 5 show the modeling of cables.

\subsection{Condition of Connection}

Connections of each element such as end links, tower links, cable anchors, tower bases etc. Were carefully designed so as to reallze the same functions as those of the actual bridge and a small structural damping on the total model system.

The completed full model of the Akashl Kalkyo Bridge Is shown In Photo 3.

\section{Concluding Remarks}

This paper describes the circumstances of studying on a large wind tunnel pacllity and a full aeroelastic model of the Akashi Kalkyo Bridge.

Main subjects of this study are summarized as follows;

1) Construction of the large boundary wind tunnel

2) Modeling of a stiffening truss without a stiffening spine

3) Consideration on aerodynamic interaction between stiffening truss and cables

After finlshing the tests for the Akashl Kalkyo Bridge, thls facllity will also be used for full model wind tunnel tests of the Kurushima Bridges, three suspension bridges with center spans of $600 \mathrm{~m}, 1.020 \mathrm{~m}$ and $1.030 \mathrm{~m}$ of stiffening boxes, and the Tatara Brldge, the world longest cable-stayed brldge with a center span of $890 \mathrm{~m}$. Through these tests, it is expected that wind resistant design of long span bridges wlll make further progress. 


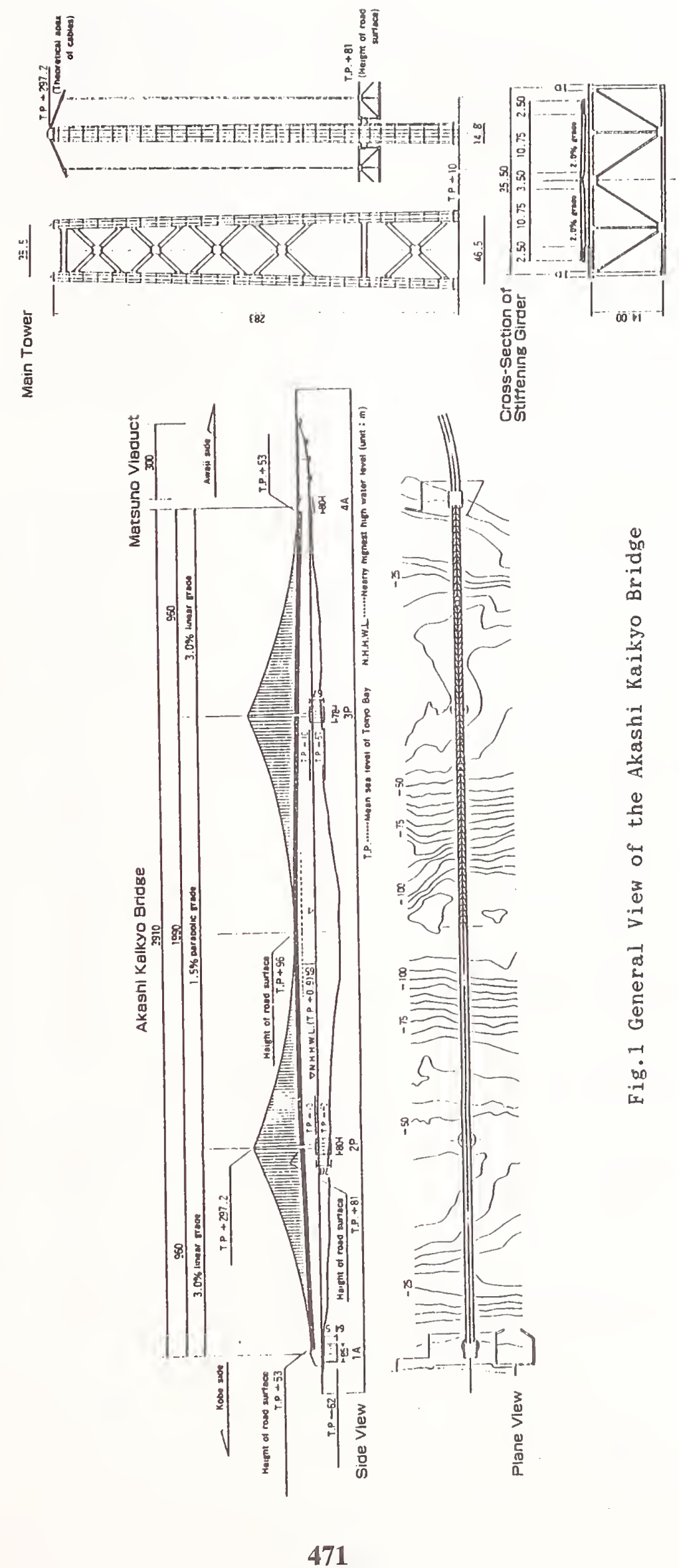



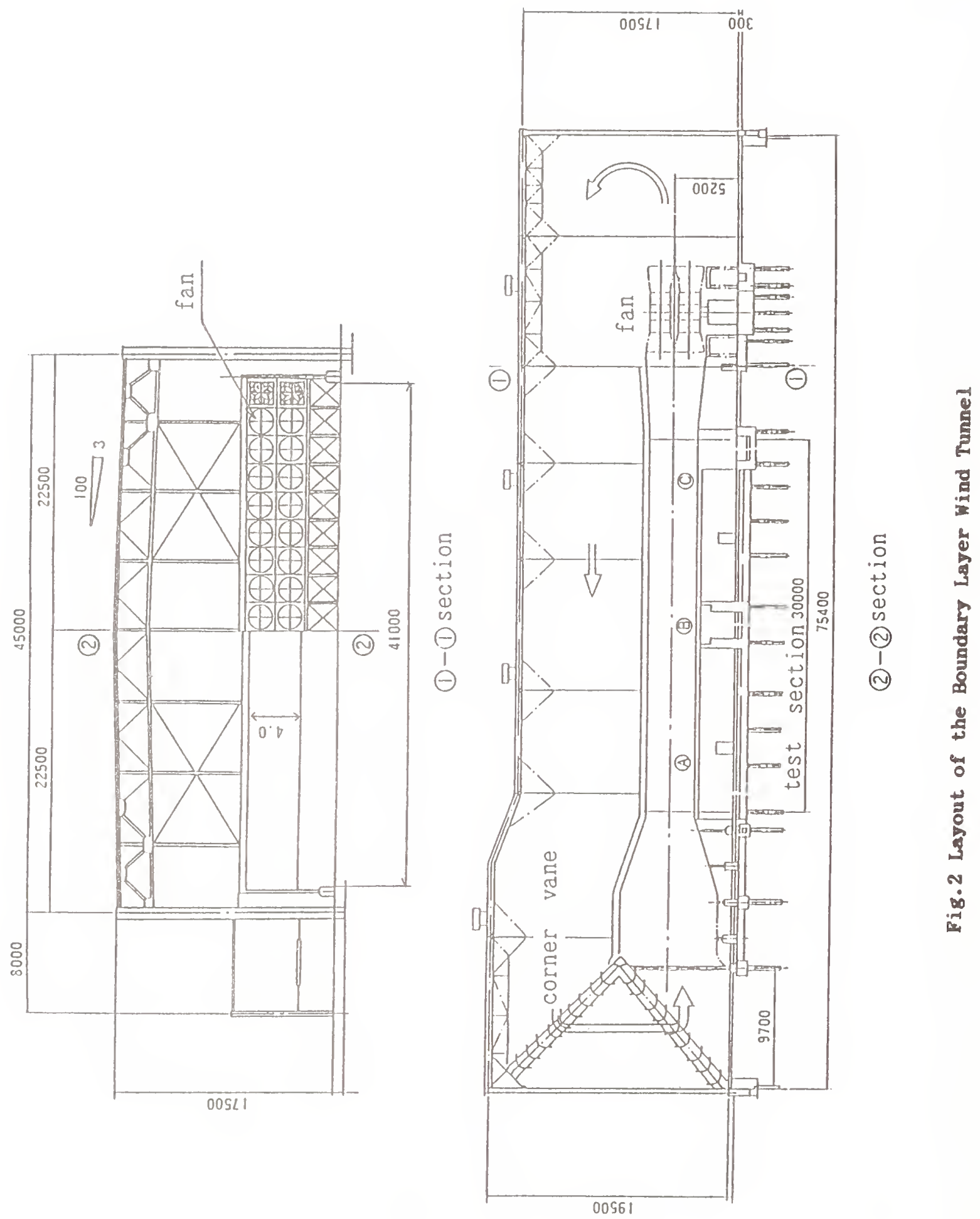


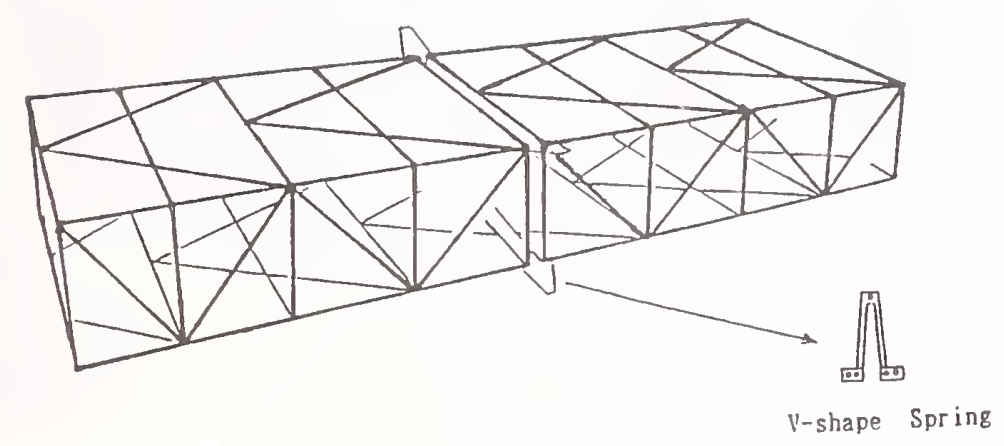

Fig.3 Idea of Stiffening Truss Model
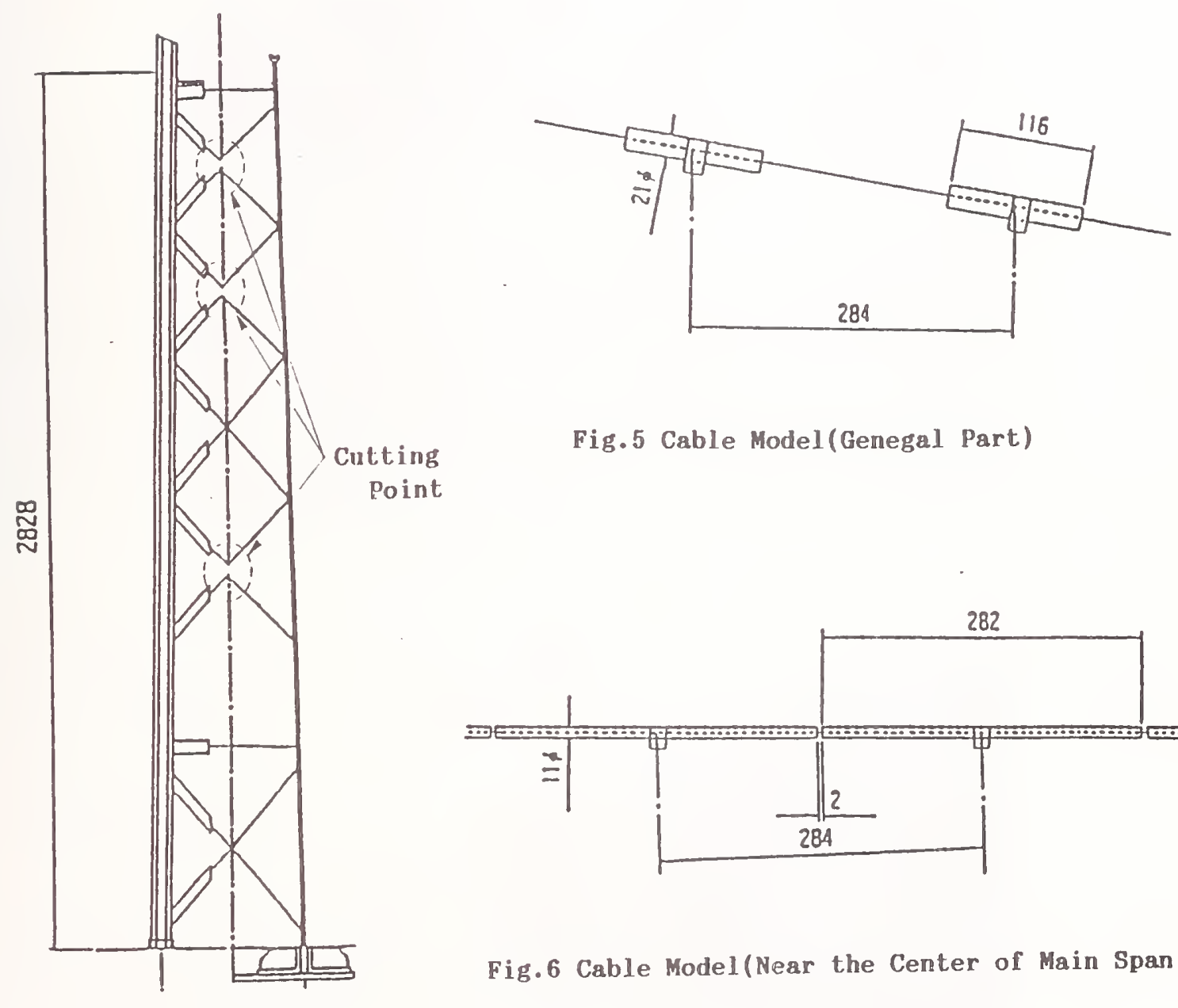

Fig.5 Cable Model(Genegal Part)

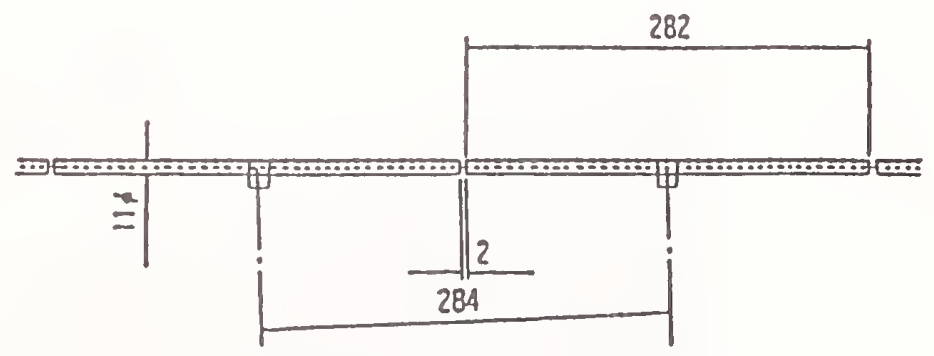

Fig. 6 Cable Model(Near the Center of Main Span)

Fig.4 Tower Model 


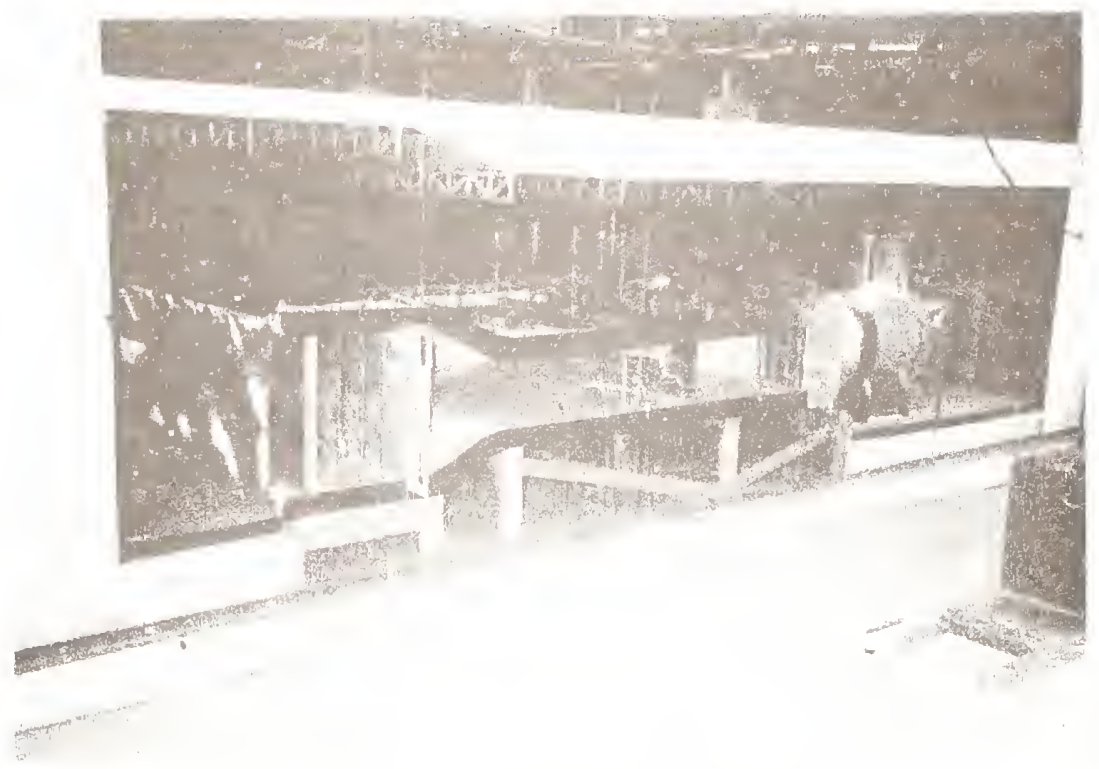

Photo 1 Pilot Wind Tunnel Test

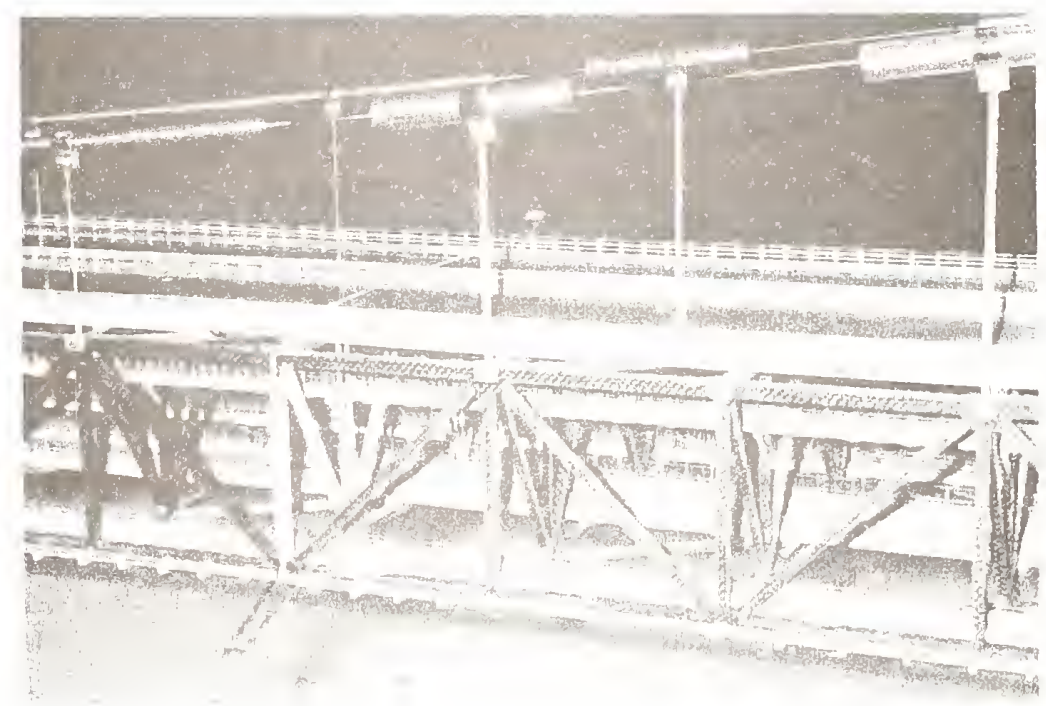

Photo 2 Stiffening Truss Model

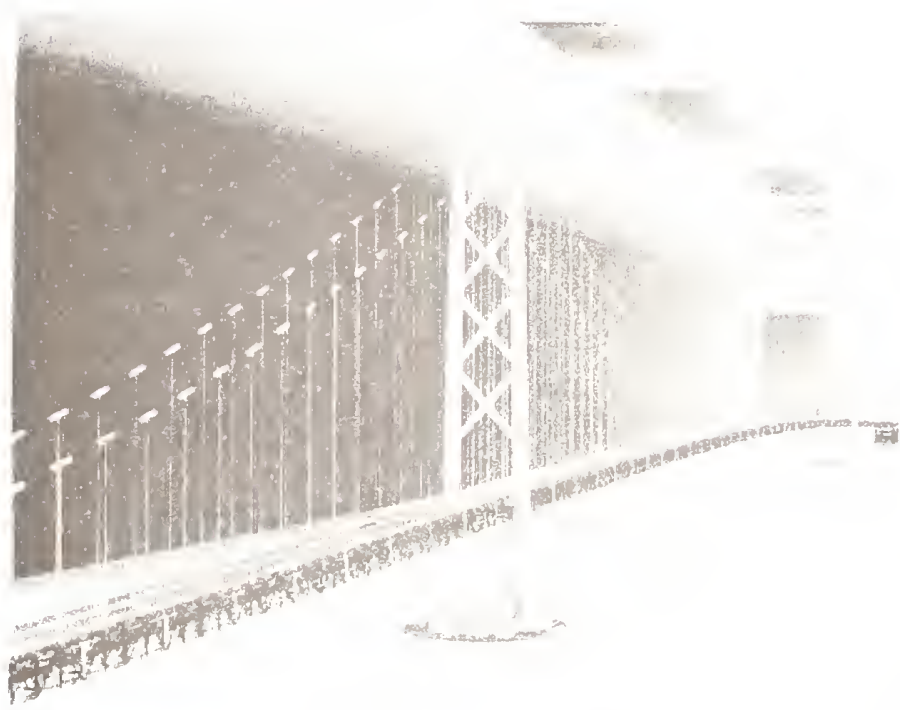

Photo 3 Full Model 


\section{Comparison of Responses of a Select Number of Buildings \\ to the 10/17/1989 Loma Prieta (California) Earthquake \\ and Low-Level Amplitude Test Results}

\section{by \\ M. Çelebi ${ }^{1}$, L. T. Phan ${ }^{2}$ and R. D. Marshall ${ }^{2}$}

\section{ABSTRACT}

This paper summarizes dynamic characteristics of five buildings within the San Francisco Bay area. The dynamic characteristics are extracted from the October 17, 1989 Loma Prieta earthquake response records and from ambient tests conducted in November 1990. Dynamic characteristics determined for two of the five buildings prior to the Loma Prieta earthquake are also included for comparison. The results are to be used to draw conclusions related to the validity of small amplitude tests in assessing the dynamic characteristics of buildings and other structures. The preliminary results show, in some cases, that low-level tests are useful and, in other cases, they show considerable differences with those determined from strong-motion response records.

KEYWORDS: vibration; testing; strongmotion; earthquakes; buildings; damping; frequency; period.

\section{INTRODUCTION}

This paper provides a summary, progress to date and preliminary results of a project that aims to study the dynamic characteristics of

${ }^{1}$ U.S. Geological Survey, 345 Middlefield Road Menlo Park, CA 94025 USA

${ }^{2}$ Building and Fire Research Laboratory National Institute of Standards and Technology Gaithersburg, Maryland 20899 USA a select number of buildings in the San Francisco Bay area. The identified characteristics from the recorded responses of the subject buildings to the Loma Prieta earthquake of October 17, $1989\left(M_{s}=7.1\right)$ and those from recent ambient vibration tests are compared. None of the buildings studied in this project suffered visible damage during the Loma Prieta earthquake (LPE). For some buildings, arailable results from small amplitude tests performed prior to the LPE are also used for comparison. The main objective of the project is to study the validity of small amplitude tests in assessing the dynamic characteristics of buildings and other structures.

\section{2. $A P P R O A C H$}

The steps to be taken during the course of the project are as follows:

1. Select a feasible number of buildings in the San Fransisco Bay area from which recorded response data are/will be available. The buildings selected are representative of different designs and construction materials and yet form a basis to protide a representative inventory of structures and data, both from strong-motions such as the LPE, and small amplitude data.

2. Perform ambient vibration testing. This step has been carried out using a PC-based data acquisition system. The 
system accommodates 16 data channels, has an input range of $+/-10$ volts and uses a 12-bit A/D converter capable of performing up to 250,000 conversions per second. For this study, each channel was sampled 50 times per second. In execution of this step, in a majority of the cases, permanently-installed forcebalance accelerometers were used as the sensors. This facilitates easy access to various floors of the building, without having to provide temporary cables or sensors and makes it possible to directly compare the results with those from strong-motion excitation. Nominal accelerometer sensitivity is 2.5 volts/g.

3. Analyses of Data. Both the recorded strong-motion responses and the ambient responses are analyzed to identify relevant dynamic characteristics and to provide a basis for comparison of these characteristics. Whenever applicable, studies performed by other investigators will also be used. This step will include detailed time-history analyses.

4. Derivation of Conclusions and Recommendations: This is the last step and ultimate goal of the project which seeks to determine the validity of smallamplitude testing as a means of assessing the dynamic characteristics of buildings and other structures.

\section{SELECTED BUILDINGS}

After considering several candidate structures, five buildings were selected for this study. Significant characteristics of the selected buildings (structural type, foundation type and height), distance from the Loma
Prieta earthquake epicenter, number of channels of strong-motion sensors within the superstructure and the peak accelerations at the ground (or foundation level) and at roof level for the selected buildings are summarized in Table 1. Also indicated in the table is the agency (USGS or CDMG) responsible for the instrumentation in each building and the nominal north-south building orientation. The orientation is important in identifying the direction of recorded motions and resulting evaluations.

\section{SUMMARY OF ANALYSES TO DATE}

To date, processed strong-motion data is available only for three of the five buildings. The analyses and investigations performed on these three structures are summmarized below. General information is provided in those cases where detailed records are not yet available. For some buildings, small amplitude test data and results were available prior to the LPE and these are summarized for each building in Table 2. Also summarized in Table 2 are the results of data-analyses to date.

\subsection{Administration Building (CSUH)}

The instrumentation scheme of the Administration Building of the California State University, Hayward, is seen in Figure 1. This CDMG-instrumented building is square in plan and sits on an 18 " thick $(45.7 \mathrm{~cm})$ mat foundation supported by bearing piles. The 13-story building has a steel moment-frame core and exterior reinforced concrete frame (Shakal and others, 1989). There were no small-amplitude tests conducted prior to LPE. 


\subsubsection{Strong-Motion Data}

Copies of the unprocessed strong-motion acceleration records obtained from this building during LPE are seen in Figure 2. Detailed analyses of these records will be performed when data is available. At present we estimate the period to be approximately 1.1-1.2 seconds determined from the average of several cycles of the top floor records in Figure 2.

\subsubsection{Ambient-Vibration Data}

Figure 3 shows time-histories and amplitude spectra of ambient vibration response of the roof of the building recorded after the LPE. The identified frequencies (periods) are 0.93 $\mathrm{Hz}(1.07 \mathrm{sec})$ in the $\mathrm{N}-\mathrm{S}$ direction and 0.86 $\mathrm{Hz}(1.16 \mathrm{sec})$ in the $\mathrm{EW}$ direction. Note that the ambient vibration data obtained in this study is expressed in microvolts rather than as a percentage of $\mathrm{g}$.

\subsection{Santa Clara County Office Building}

The instrumentation scheme and general dimensions of this building are seen in Figure 4 . The 13-story, moment-resisting steelframe building experienced strong shaking due to other earthquakes that occurred prior to the LPE. Records of the response of this building to the Morgan Hill (1984) earthquake are also available (CDMG, 1985). The building is founded on a concrete mat foundation (Shakal and others, 1989).

\subsubsection{Strong-Motion Data}

The unprocessed copies of the strong-motion acceleration records obtained from this building during LPE are seen in Figure 5. Detailed analyses of these records will be per- formed when data is available. At present we estimate the period (average of several cycles of top floor records in Figure 5) to be approximately 2.4 seconds in both directions.

\subsubsection{Ambient-Vibration Data}

Figure 6 shows time-histories and amplitude spectra of ambient vibrations of the roof of the building recorded after the LPE. The identified periods (frequencies) are $1.92 \mathrm{sec}-$ onds for both NS and EW directions. Other identified frequencies are shown in the figure.

\subsection{San Bruno Office Building}

This 6-story, reinforced-concrete momentresisting framed building is founded on individual spread footings. Overall dimensions and the general instrumentation scheme of the building are shown in Figure 7 (Shakal and others, 1989).

\subsubsection{Strong-Motion Data}

The processed strong-motion accelerations and displacements are shown in Figure 8. For the sake of brevity, we show only preliminary results obtained by systern identification procedures whereby a model is estimated based on observed input-output data (Ljung, 1987 and Mathworks, 1988). The model used in this paper is the ARX model based on the Least Squares method (for single input-single output) and as seen in Figure 9 , provides an excellent match for the accelerations at the roof (output) with the ground floor motion as input. From these analyses, we extract damping values of $7.2 \%$ 
and $4.1 \%$, and periods of 0.85 and 1.02 seconds for the N-S and E-W directions, respectively. As seen in Figure 9, the timehistories of the recorded and calculated motions of the roof and corresponding amplitude spectra are in excellent agreement.

\subsubsection{Ambient-Vibration Data}

Figure 10 shows the time-histories and amplitude spectra of ambient vibration of the roof of the building recorded after the LPE. The periods identified from these records are 0.59 (NS) and 0.71 (EW) seconds. Another significant peak at $1.93 \mathrm{~Hz}(0.52$ seconds $)$ is seen in the EW direction (north end). Damping values are $2.9 \%(\mathrm{NS})$ and $2.3 \%(\mathrm{EW})$.

\subsection{Transamerica Building}

\subsubsection{The Building and Strong-Motion Data}

Figure 11 shows the instrumentation scheme of the Transmerica Building as well as the orientation (in degrees) of the building. Also shown in the figure are the processed accelerations and displacements at different levels. Detailed studies of these records were performed by Çelebi and Şafak (1991) and Safak and Çelebi (1991). According to these studies, the building experiences rocking motion at approximately 0.5 seconds $(2 \mathrm{~Hz})$ and the fundamental translational period (frequency) is 3.57 seconds $(0.28 \mathrm{~Hz})$.

Figure 12 provides results determined from applying system identification techniques as described previously (Ljung, 1987 and Mathworks, 1988). The figure shows recorded motions and spectra and calculated motions and spectra for the 49 th floor corresponding to basemat input motion. In addition to identifying the fundamental frequency at $0.28 \mathrm{~Hz}$, also identified is the $2 \mathrm{~Hz}$ rocking motion frequency apparent for both the output and input motions. This rocking frequency also appears in phase with the spectral analyses using the 49th level horizontal and basemat vertical motions.

\subsubsection{Pre-LPE Tests and Analyses}

Dynamic response characteristics determined from small amplitude (forced and ambient) vibration tests and analyses performed on the Transamerica Building in 1972-73 are summarized by Stephen, Hollings and Bouwkamp (1974) and Kinemetrics (1979). Analysis performed on the structure did not include soil-structure interaction. The fundamental periods (frequencies) determined from these investigations are 2.94 seconds $(0.34$ $\mathrm{Hz}$ ) for both the NS and EW directions. The modal damping percentages are 0.9 and 1.4 respectively. These characteristics are summarized in Table 2.

\subsubsection{Post-LPE Ambient Test}

A 40-second window of recorded ambient vibration data of both the NS and EW direction at 48th floor of the Transamerica Building and corresponding amplitude spectra are shown in Figure 13. The data has been filtered with a Butterworth filter (order 4, at $0.1 \mathrm{~Hz}$ ). The frequencies identified from this analyses are shown in the figure. The $0.34 \mathrm{~Hz}$ frequency is identical with the preLPE identified frequencies from tests and analyses. Also identified is the $2 \mathrm{~Hz}$ frequency but whether it corresponds to the rocking motion is still under investigation. Damping values based on combined mode response are $1.5 \%(\mathrm{NS})$ and $1.9 \%(\mathrm{EW})$. 


\subsection{Pacific Park Plaza Building}

\subsubsection{The Building and Strong-Motion Data}

The instrumentation scheme and recorded acceleration responses at different levels of the 30-story three-winged reinforced concrete moment-resisting frame building as well as the two free-field sites in proximity to the building are shown in Figure 14. Peak values of accelerations at roof and ground level are also provided in Table 1. System identification techniques were applied and the recorded and calculated output acceleration responses at the 30th floor level and corresponding amplitude spectra are shown in Figure 15. Also shown are the input ground level motion records and their amplitude spectra. The identified fundamental frequency (period) is $0.38 \mathrm{~Hz}$ (2.63 seconds) for both NS and EW directions. However, this mode is a torsional-translational mode. One of the striking results of this set of records is that the ground level and free-field records show frequencies that are clearly structural; thus, there is feedback of structural frequencies. Further detailed analyses of these records showing this feature are in Çelebi and Şafak (1990) and Şafak and Çelebi (1990).

\subsubsection{Pre-LPE Tests and Analyses}

Non-destructive testing and analyses of the Pacific Park Plaza Building was performed in 1985 by Stephen, Wilson and Stander (1985). They determined the first mode frequencies (in both directions) and the first torsional frequency to be $0.59 \mathrm{~Hz}$. The difference between this frequency and the $0.38 \mathrm{~Hz}$ frequency determined from strong-motion responses can be attributed to several factors including significant soil-structure interaction during the strong-motion event which possibly did not occur during small amplitude tests. Another possibility is the action of the piles and non-linear behavior of the foundation and sub-strata of the soil during the strong motion event. Yet another possibility is the micro-cracking of the concrete although no visible damage was experienced by the structure.

\subsubsection{Post-LPE Ambient Vibration Tests}

In Figure 16, we show the recorded ambient vibration responses at the center core and the wings of the 30 th floor. Also shown are the amplitude spectra with identified frequencies. These spectra show the first mode (translational-torsional) frequency to be 0.49 $\mathrm{Hz}$. Again, as with the Transamerica Building, we observe that the post-LPE first mode frequency is closer to the pre-LPE frequency than it is to the frequency identified from strong-motions.

\section{DISCUSSION AND CONCLUSIONS}

The recorded strong-motion and ambientmotion data of the five buildings provides a unique opportunity to study the dynamic characteristics of a variety of building structures. In addition, it provides an opportunity to assess the validity of the low-level non-destructive testing procedures of structures-one of the stated objectives of this project. The preliminary results of the postLPE ambient vibration investigation (this study) and those available from strongmotion data and pre-LPE tests and analyses are summarized in Table 2 for easy comparison and are discussed below. The study to date covers preliminary assessments and has not advanced to a stage whereby the significant differences between the characteristics 
determined from low-level amplitude tests and those from strong-motions can be satisfactorily explained. Also a clear statement about the usefulness of low-level tests in assessing vibrational characteristics of structures can not be made at this stage.

- CSUH Administration Building periods from the strong-motion data and post-LPE ambient study are similar.

- Santa Clara County Office Building periods from the strong-motion records and this study differ considerably. The periods identified from ambient test data acquired in the two orthogonal directions of the roof are also quite differentraising the question as to why the building was not excited in a strong translational-torsional mode considering its significant ecccentricity.

- The San Bruno Office Building results from strong-motion and ambient data are not similar. Periods in both directions obtained from strong-motion data are longer than those obtained from ambient tests.

- The pre- and post-LPE Transamerica Building first mode periods are identical but differ from the period determined using the strong-motion records. Furthermore, using the strong-motion records, a rocking mode at $2 \mathrm{~Hz}(0.5 \mathrm{sec}-$ onds) has been identified. The investigation of the $2 \mathrm{~Hz}$ frequency from ambient data is being carried out to see if that is associated with a rocking mode.

- As in the case of the Transamerica Building, there are substantial differences between the periods identified from pre-and post-LPE low level amplitude tests and the strong-motion records of the Pacific Park Plaza Building.

Final conclusions will be made in the future regarding the testing techniques employed in this study and their accuracy in predicting dynamic characteristics of building structures during strong-motion events which is the basis for earthquake resistant design procedures. During the course of this work, we have found system identification techniques to be a very useful tool in assessing the responses from both the strong-motion and ambient tests.

\section{ACKNOWLEDGMENTS}

The authors acknowledge the data provided by CDMG and USGS, as well as the relevant information related to the buildings tested. Dr. M. Huang and Mr. Robert Land of CDMG and Mr. Marion Salsman of USGS provided help in carrying out the testing of the buildings. Carol Sullivan of USGS typed the manuscript.

\section{REFERENCES}

1. Çelebi, M., and Şafak, E. (1991). "Recorded Seismic Response of Pacific Park Plaza (Part I-Data and Preliminary Analysis)." Submitted, ASCE Journal of Structural Division.

2. Çelebi, M., and Şafak, E. (1990). "Recorded Seismic Response of Transamerica Building (Part I-Data and Preliminary Analysis)." Accepted, ASCE Journal of Structural Division (August 1991). 
3. Kinemetrics, Inc. (1979). "Application Note No 5: Transamerica Building Ambient Vibration Survey." September 1979.

4. Ljung, L. (1987). "System Identification: Theory for the User." Prentice-Hall.

5. The MathWorks, Inc. (1988). "User's Guide: System Identification Toolbox for use with Mathlab." South Natick, MA.

6. Maley, R. et. al. (1989). "U.S. Gelogical Survey Strong-motion Records from the Northern California (Loma Prieta) earthquake of October 17, 1989." U.S. Geological Survey Open-file Report $\overline{89-}$ 568, October 1989.

7. Marshall, R. D., Phan, L. T., and Çelebi, M. (1990). "Measurement of Structural Response Characteristics of Full-Scale Buildings: Selection of Structures." U.S. Geological Survey Open-file Report 90-667." March 1991. (Also published as NISTIR 4511, February 1991, Gaithersburg, MD.).

8. CDMG (1985). "Processsed Data from the Strong-Motion Records of the Morgan Hill Earthquake of 24 April, 1984." Report OSMS 85-05. California Department of Conservation, Division of Mines and Geology, Office of Strong Motion Studies, December 1985.

9. Şafak, E., and Çelebi, M. (1991). "Recorded Seismic Response of Pacific Park Plaza (Part II-System Identification)." Submitted, ASCE Journal of Structural Division.

10. Şafak, E., and Çelebi, M. (1990). "Recorded Seismic Response of Transamerica Building (Part II-System Identification)." Accepted, ASCE Journal of Structural Division (August 1991).
11. Shakal, A. F., Huang, M. J., Ventura, C. E., Reichle, M., Ventura, C., Cao, T., Sherburne, R. W., Savage, M., Darragh, R., and Petersen, C. (1989). "CSMIP Strong-Motion Records from the Santa Cruz Mountains (Loma Prieta), California Earthquake of October 17, 1989." Report No. OSM 89-06. November 1989.

12. Stephen, R. M., Hollings, J. P., and Bouwkamp, J. G. (1974). "Dynamic Behavior of A Multi-Story Pyramid Shaped Building." EERC Report 7317. University of California, Berkeley, September 1974.

13. Stephen, R. M., Wilson, E. L., and Stander, N. (1985). "Dynamic Properties of A Thirty-Story Condominium Tower Building." EERC Report 85-03. University of California, Berkeley. April 1985. 
TABLE 1. Characteristics and Loma Prieta Peak Acceleration of Buildings.

\begin{tabular}{|c|c|c|c|c|c|c|c|c|}
\hline \multirow[t]{2}{*}{ Building } & \multirow{2}{*}{$\begin{array}{l}\mathrm{H}^{* *} \\
\mathrm{~m}\end{array}$} & \multirow{2}{*}{$\mathrm{N}_{\mathrm{A}} / \mathrm{N}_{\mathrm{B}} *$} & \multirow[t]{2}{*}{$\begin{array}{l}\mathrm{D}^{* *} \\
\mathrm{~km}\end{array}$} & & \multicolumn{3}{|c|}{$\begin{array}{l}\text { LPE Peak } \\
\text { Accel. }(\mathrm{g})\end{array}$} & \multirow[t]{2}{*}{ Comments } \\
\hline & & & & & & Grnd. & Roof & \\
\hline $\begin{array}{l}\text { (1) Administration } \\
\text { Building (CSUH) } \\
\text { Hayward, CA } \\
\text { (CDMG) } \\
\text { NS }=320^{\circ(* * *)}\end{array}$ & 61 & $13 / 0$ & 70 & 16 & $\begin{array}{l}(\mathrm{NS}) \\
(\mathrm{EW}) \\
(\text { Vert })\end{array}$ & $\begin{array}{l}0.07 \\
0.09 \\
0.05\end{array}$ & $\begin{array}{l}0.15 \\
0.24\end{array}$ & $\begin{array}{l}\text { Steel moment-frame core. } \\
\text { Exterior reinforced concrete } \\
\text { moment-frame. } \\
\text { Concrete shear walls around } \\
\text { elevator shafts to second floor. } \\
\text { (0.4-5 m slab on grade } \\
\text { and bearing piles) }\end{array}$ \\
\hline $\begin{array}{l}\text { (2) Santa Clara Cty. } \\
\text { Office Bldg. } \\
\text { San Jose, CA } \\
\text { (CDMG) } \\
\text { NS }=337^{\circ}\end{array}$ & 57 & $12 / 1$ & 35 & 22 & $\begin{array}{l}(\mathrm{NS}) \\
(\mathrm{EW}) \\
(\text { Vert })\end{array}$ & $\begin{array}{l}0.11 \\
0.10 \\
0.10\end{array}$ & $\begin{array}{l}0.35 \\
0.36\end{array}$ & $\begin{array}{l}\text { Moment-resisting steel frame. } \\
\text { (Concrete mat) }\end{array}$ \\
\hline $\begin{array}{l}\text { (3) Office } \\
\text { Building } \\
\text { San Bruno, CA } \\
\text { (CDMG) } \\
\text { NS }=335^{\circ}\end{array}$ & 24 & $6 / 0$ & 81 & 13 & $\begin{array}{l}(\mathrm{NS}) \\
(\mathrm{EW}) \\
(\text { Vert })\end{array}$ & $\begin{array}{l}0.14 \\
0.12 \\
0.12\end{array}$ & $\begin{array}{l}0.25 \\
0.32\end{array}$ & $\begin{array}{l}\text { Reinforced concrete moment- } \\
\text { resisting frame. } \\
\text { (Individual spread footings) }\end{array}$ \\
\hline $\begin{array}{l}\text { (4) Transamerica Bldg. } \\
\text { San Francisco, CA } \\
\text { (USGS) } \\
\text { NS }=351^{\circ}\end{array}$ & 257 & $60 / 3$ & 97 & 22 & $\begin{array}{l}\text { (NS) } \\
(\mathrm{EW}) \\
\text { (Vert) }\end{array}$ & $\begin{array}{l}0.11 \\
0.12 \\
0.07\end{array}$ & $\begin{array}{l}0.24 \\
0.31\end{array}$ & $\begin{array}{l}\text { Steel frame. } \\
48 \text { th floor is the top used floor } \\
\text { ( } 2.75 \mathrm{~m} \text { thick concrete mat) } \\
\text { (No piles) }\end{array}$ \\
\hline $\begin{array}{l}\text { (5) Pacific Park Plaza } \\
\text { Emeryville, CA } \\
\text { (USGS) } \\
\text { NS }=350^{\circ}\end{array}$ & 95 & $30 / 1$ & 97 & 21 & $\begin{array}{r}(\mathrm{NS}) \\
(\mathrm{EW}) \\
(\text { Vert })\end{array}$ & $\begin{array}{l}0.17 \\
0.21 \\
0.06\end{array}$ & $\begin{array}{l}0.29 \\
0.38\end{array}$ & $\begin{array}{l}\text { Reinforced concrete moment- } \\
\text { resisting frame. } \\
\text { ( } 1.50 \mathrm{~m} \text { thick concrete mat } \\
\text { on friction piles) }\end{array}$ \\
\hline
\end{tabular}

*Note 1: $\mathrm{N}_{\mathrm{A}}=$ no. floors above ground level, $\mathrm{N}_{\mathrm{B}}=$ no. of floors below ground level

** Note 2: $\mathrm{H}=$ height of the building, $\mathrm{D}=$ distance to epicenter, $\mathrm{n}=$ number of channels, .

***Note 3: The orientation of the-nominal NS designated direction of the building. 
TABLE 2. Summary of Identified First Mode Characteristics Periods ( $\mathrm{T}$ in seconds), Frequencies ( $\mathrm{f}$ in $\mathrm{Hz}$ ) and Damping $(\zeta$ ).

\begin{tabular}{|c|c|c|c|c|c|c|c|}
\hline \multirow[t]{2}{*}{ Building } & \multirow[t]{2}{*}{$\begin{array}{l}\text { Nominal } \\
\text { Direction }\end{array}$} & \multicolumn{2}{|c|}{$\begin{array}{c}\text { Pre-LPE } \\
\text { Test \& } \\
\text { Analyses }\end{array}$} & \multicolumn{2}{|c|}{$\begin{array}{l}\text { LPE } \\
\text { Data }\end{array}$} & \multicolumn{2}{|c|}{$\begin{array}{l}\text { Post-LPE } \\
\text { Ambient }\end{array}$} \\
\hline & & $\mathrm{T} /(\mathrm{f})$ & $\zeta(\%)$ & $\mathrm{T} /(\mathrm{f})$ & $\zeta(\%)$ & $\mathrm{T} /(\mathrm{f})$ & $\zeta(\%)=x$ \\
\hline \multirow[t]{2}{*}{$\begin{array}{l}\text { (1) Administrative } \\
\text { Building ( } \mathrm{CSUH})\end{array}$} & NS & & & $\begin{array}{l}1.1 \\
(0.91)\end{array}$ & & $\begin{array}{c}1.07 \\
(0.93)\end{array}$ & 0.7 \\
\hline & EW & & & $\begin{array}{l}1.2 \\
(0.82)\end{array}$ & & $\begin{array}{c}1.16 \\
(0.86)\end{array}$ & 0.8 \\
\hline \multirow{2}{*}{$\begin{array}{l}\text { (2) Santa Clara Cty. } \\
\text { Office Bldg. } \\
\text { San Jose, CA }\end{array}$} & $\mathrm{NS}$ & & & $\begin{array}{l}2.4 \\
(0.42)\end{array}$ & & $\begin{array}{c}1.92 \\
(0.52)\end{array}$ & + \\
\hline & EW & & & $\begin{array}{c}2.4 \\
(0.42)\end{array}$ & & $\begin{array}{c}1.92 \\
(0.52)\end{array}$ & + \\
\hline \multirow{2}{*}{$\begin{array}{l}\text { (3) Commercial Office } \\
\text { Building } \\
\text { San Bruno, } \mathrm{Ca}\end{array}$} & NS & & & $\begin{array}{c}0.85 \\
(1.17)\end{array}$ & 7.2 & $\begin{array}{c}0.59 \\
(1.70)\end{array}$ & 2.9 \\
\hline & EWV & & & $\begin{array}{c}1.02 \\
(0.98)\end{array}$ & 4.1 & $\begin{array}{c}0.71 \\
(1.40)\end{array}$ & 2.3 \\
\hline \multirow[t]{2}{*}{$\begin{array}{l}\text { (4) Transamerica Bldg. } \\
\text { San Francisco, CA }\end{array}$} & NS & $\begin{array}{c}2.94 \\
(0.34)\end{array}$ & 0.9 & $\begin{array}{l}3.6^{*} \\
(0.28)\end{array}$ & 2.1 & $\begin{array}{l}2.9 \\
(0.34)\end{array}$ & 1.5 \\
\hline & EWV & $\begin{array}{c}2.94 \\
(0.34)\end{array}$ & 1.4 & $\begin{array}{c}3.6^{*} \\
(0.28)\end{array}$ & 1.6 & $\begin{array}{c}2.9 \\
(0.34)\end{array}$ & 1.9 \\
\hline \multirow[t]{3}{*}{$\begin{array}{l}\text { (5) Pacific Park Plaza } \\
\text { Emeryville, CA }\end{array}$} & NS & $\begin{array}{l}1.70^{-x} \\
(0.59)\end{array}$ & 2.6 & $\begin{array}{c}2.63 \\
(0.38)\end{array}$ & 11.6 & $\begin{array}{c}2.04 \\
(0.49)\end{array}$ & 0.4 \\
\hline & EW & $\begin{array}{l}1.70 \\
(0.59)\end{array}$ & 2.6 & $\begin{array}{c}2.63 \\
(0.38)\end{array}$ & 15.5 & $\begin{array}{c}2.04 \\
(0.49)\end{array}$ & 1.0 \\
\hline & Torsion & $\begin{array}{l}1.70 \\
0.59\end{array}$ & 3.8 & $\begin{array}{c}2.63 \\
(0.38)\end{array}$ & & & \\
\hline
\end{tabular}

* A significant rocking mode is identified at 0.5 seconds.

$\approx$ This is torsional-translational mode.

**xIdentified by spectral analyses.

+Unidentifiable due to noisy signal. 
Hayward - 13-story School Offico Bldg.

(CSMap Station No.68364)

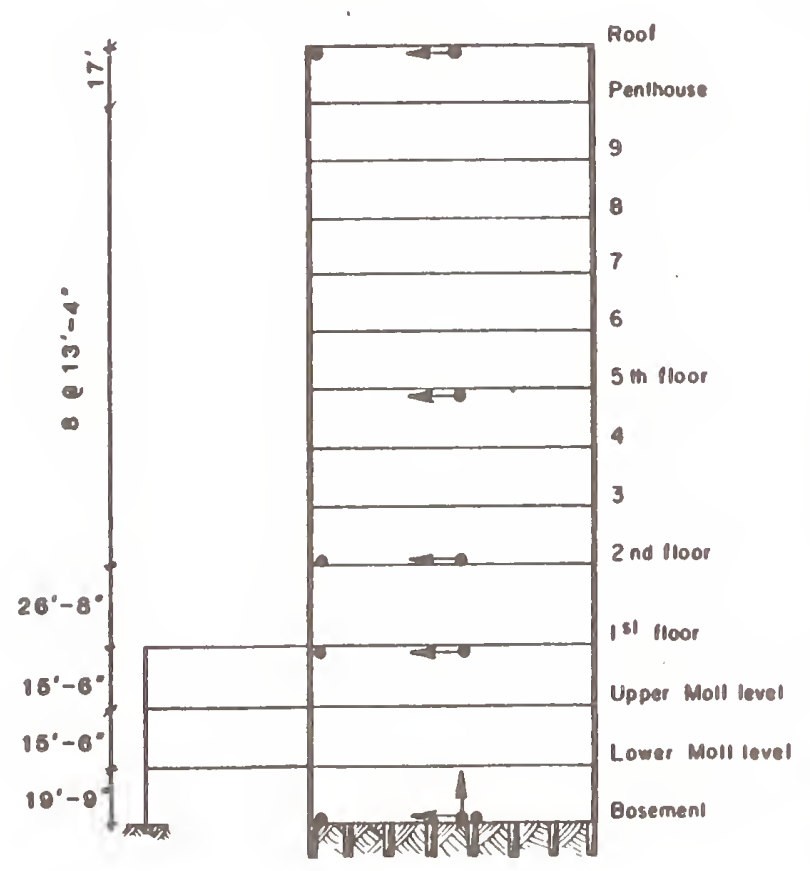

E/W Elovation
SENSOR LOCATIONS

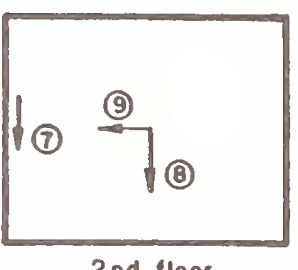

2nd floor

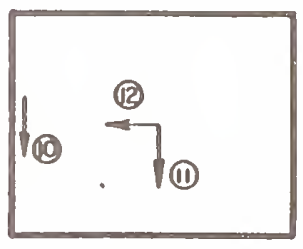

Ist floor

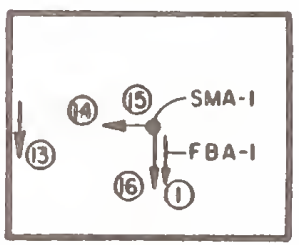

Basement
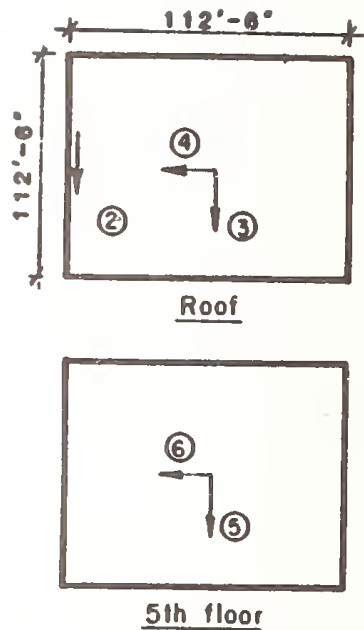

$N_{\text {rel }}$
$V$

Note: $1 \mathrm{ft} \cdot 0.3048 \mathrm{~m}$

Siructure Pelerence Orientation: $N=320^{\circ}$

Figure 1. General instrumentation scheme of Administration Building, California State University (CSUH), Hayward. Figure is adopted from Shakal and others (1989). 
Hoyeord - 13-story School Office Bldg

(CSMIP siotion 58354)

Record 58354-C0188-69291.02

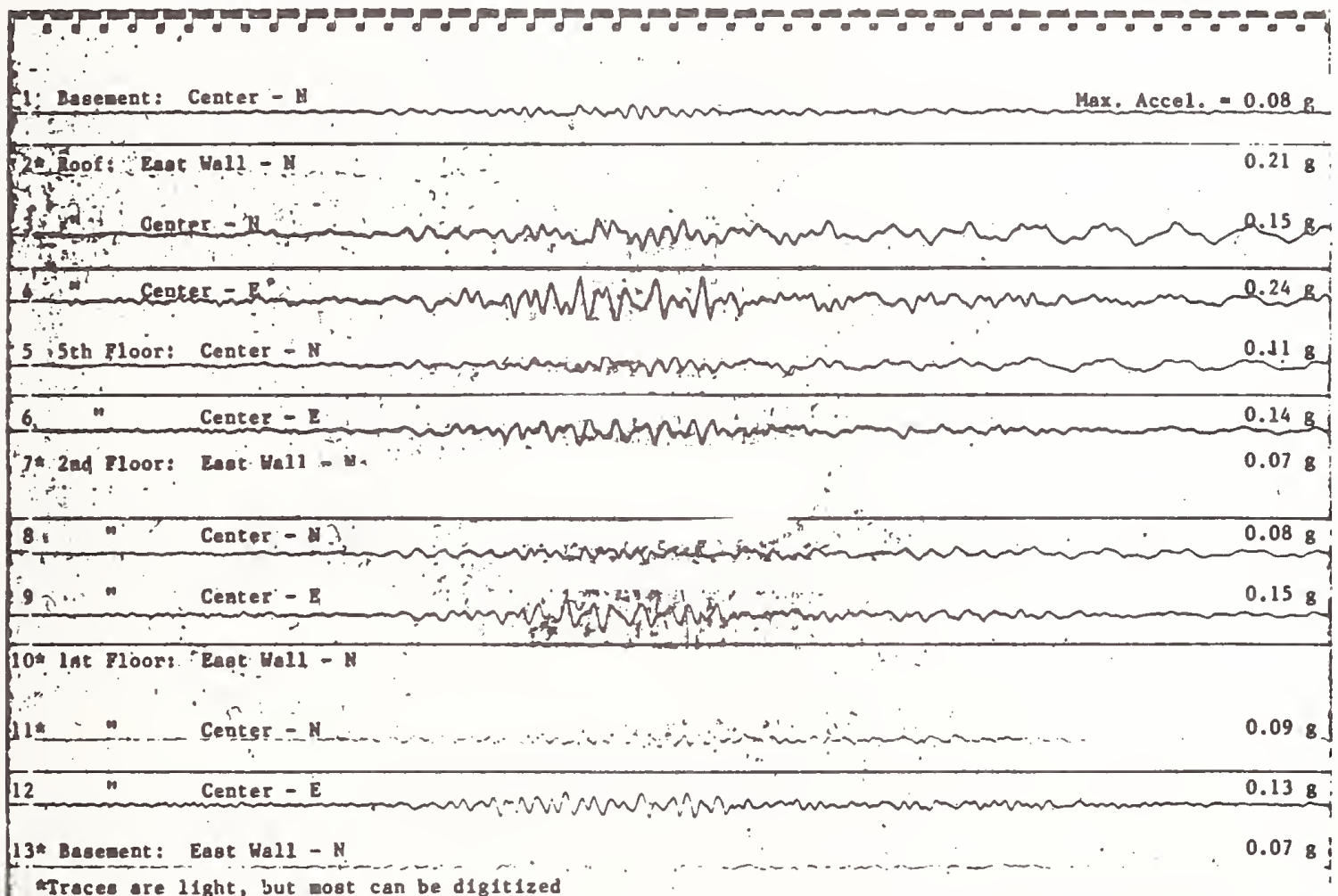

mrace are 11ght, but most can be dig1tized

14 Basement: Center - E

Max. Accel. $=0.098$

150 Center - Up 0.058

16 Center $-\mathrm{N}$

Structure Reference Orientation: $N=320^{\circ}$

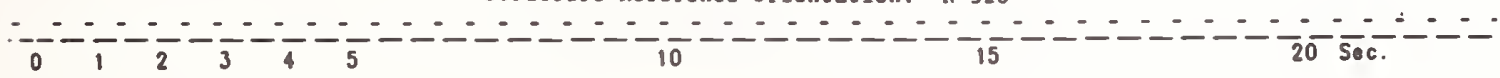

Figure 2. Unprocessed copies of the film records of the accelerations recorded at the CSUH Administration Building (Figure is adopted from Shakal and others, 1989). 

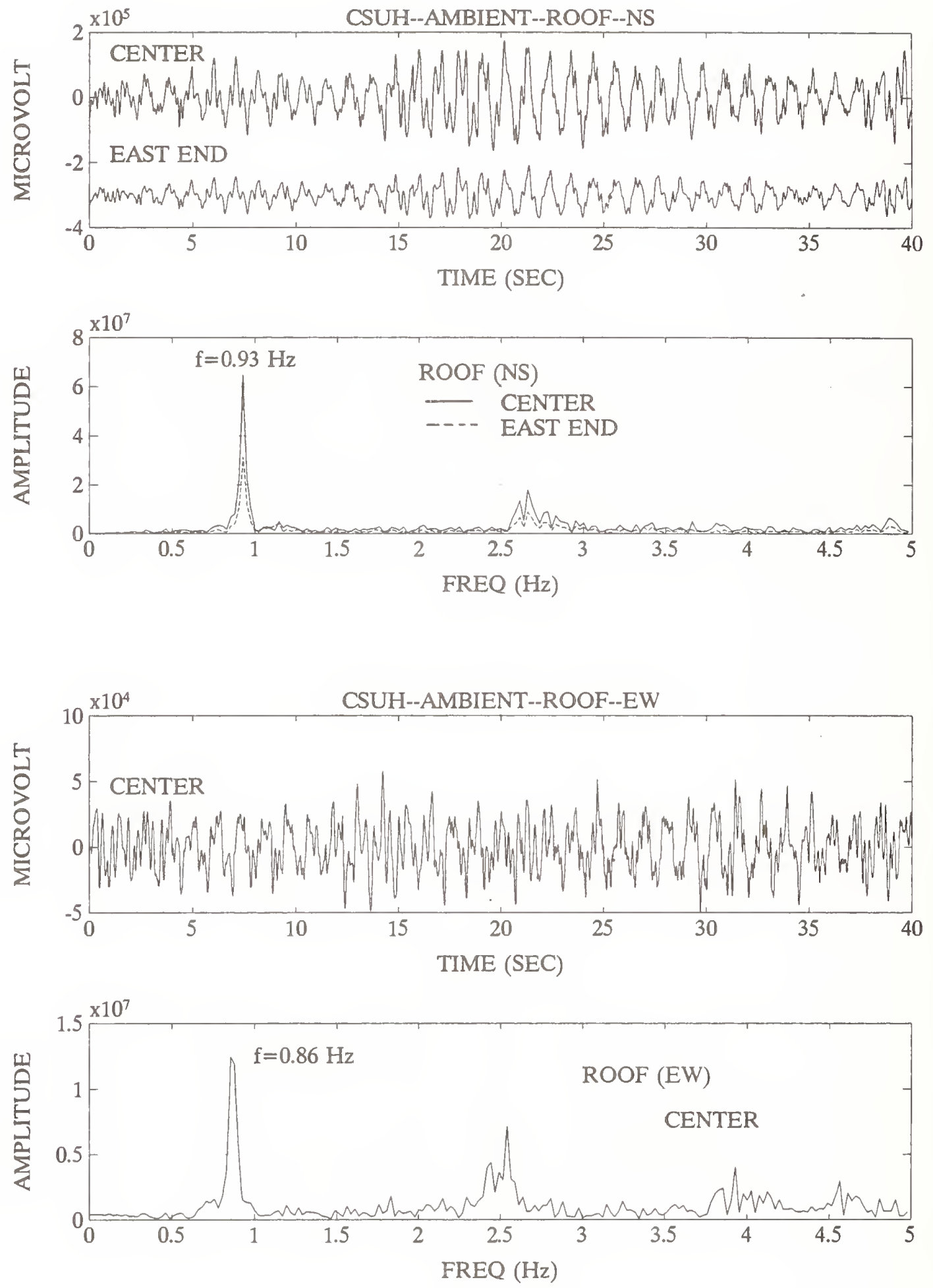

Figure 3. Ambient vibration response of the roof (NS and EW directions) of CSUH Administration Building and corresponding Fourier amplitude spectra 


\section{San Jose - 13-story Government Offlce Bidg. (CSMIP station No. 67367 ) \\ SENSOR LOCATIONS}

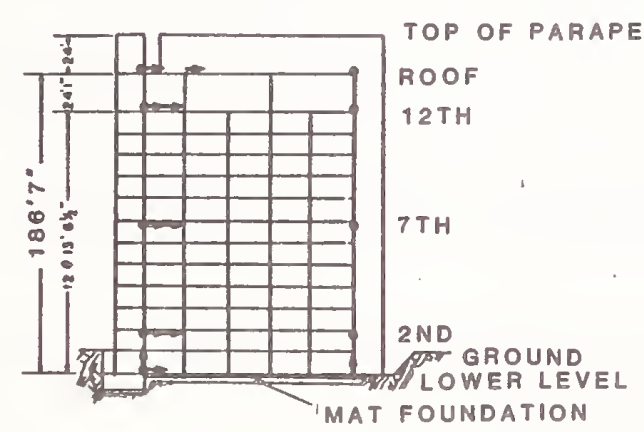

E-W SECTION

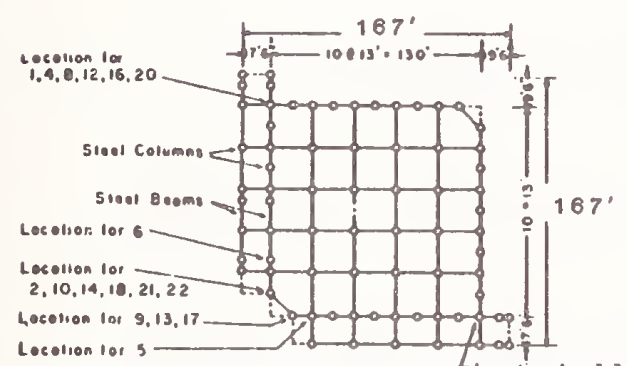

TYPICAL FLOOA PLAN
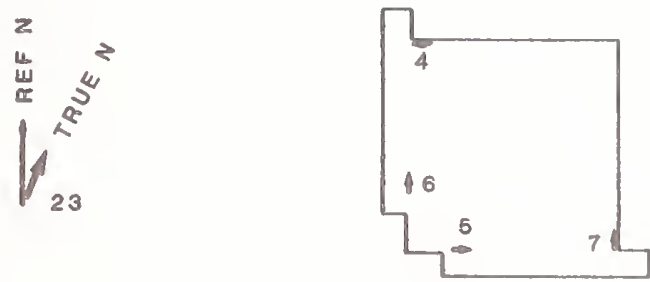

ROOF PLAN

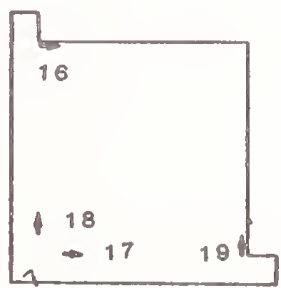

2ND FLOOA PLAN

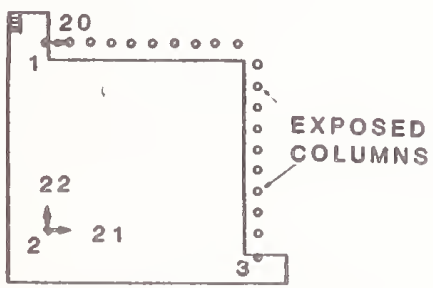

LOWER LEVEL PLAN

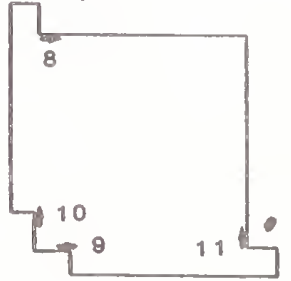

12 TH FLOOR PLAN

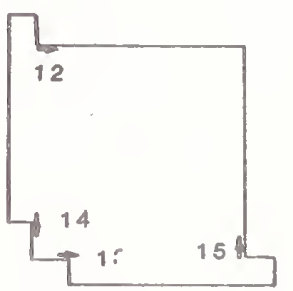

7TH FLOOR PLAN

Note: $1 \mathrm{ft} 0.3048 \mathrm{~m}$.

Figure 4. General instrumentation scheme of 13-story Santa Clara County Government Office Building, San Jose. Figure is adopted from Shakal and others (1989). 
Son dose - ijatory Govermant offico Bidg

(CSAP sielie 57357)

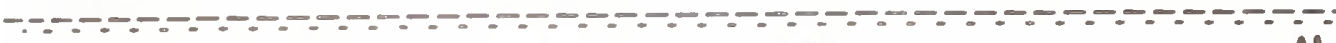

1 Lover Lovel: Coroer - Up

Channo 1. 1. 22, 0.22 secondo

SH Corner - ip

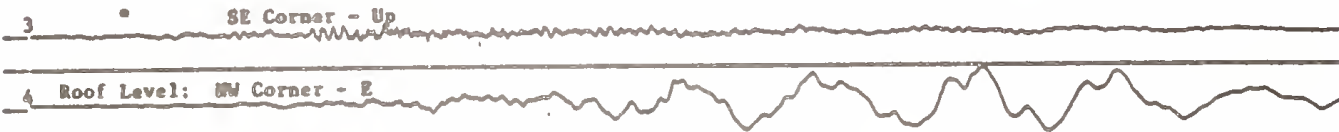

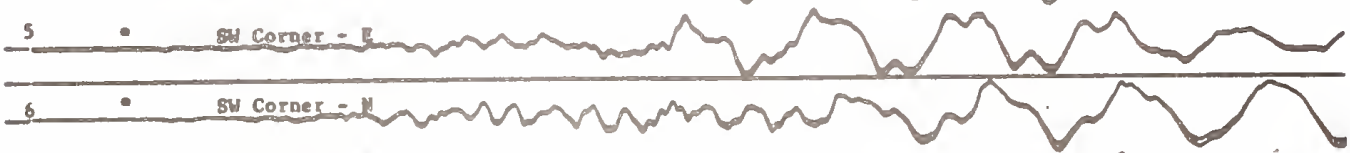

$3 \quad \mathrm{secorner-1}$

12th Ploors W Corwer- E

SW Corner-S Corner - E

11_ SE Coraer -

12 Ith Ploor: $\mathrm{MH}$ Corner -

$13 \mathrm{Ten}$ Y100\%: $\mathrm{WW}$ Corner -

14. is corner- -

15 SE Corner -

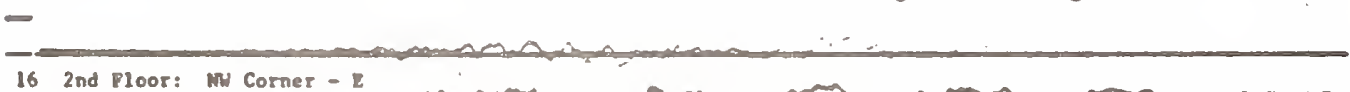

16 2nd Ploor: IN Corner-2

$17 \quad$ SW Cormer - I

18 SW Cordor $-\mathrm{N}$

20 Lover Level: He Corser - 2

21 84 Corner - E

SH Corser $-\mathrm{N}$

8iructure Reference orlentetion: $10337^{\circ}$

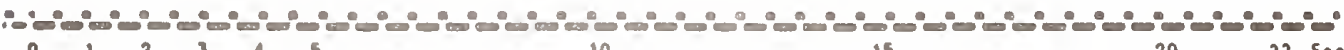

Figure 5. Unprocessed copies of the film records of the accelerations recorded at the 13-story Santa Clara County Government Office Building, San Jose. Figure is adopted from Shakal and others, 1989. 

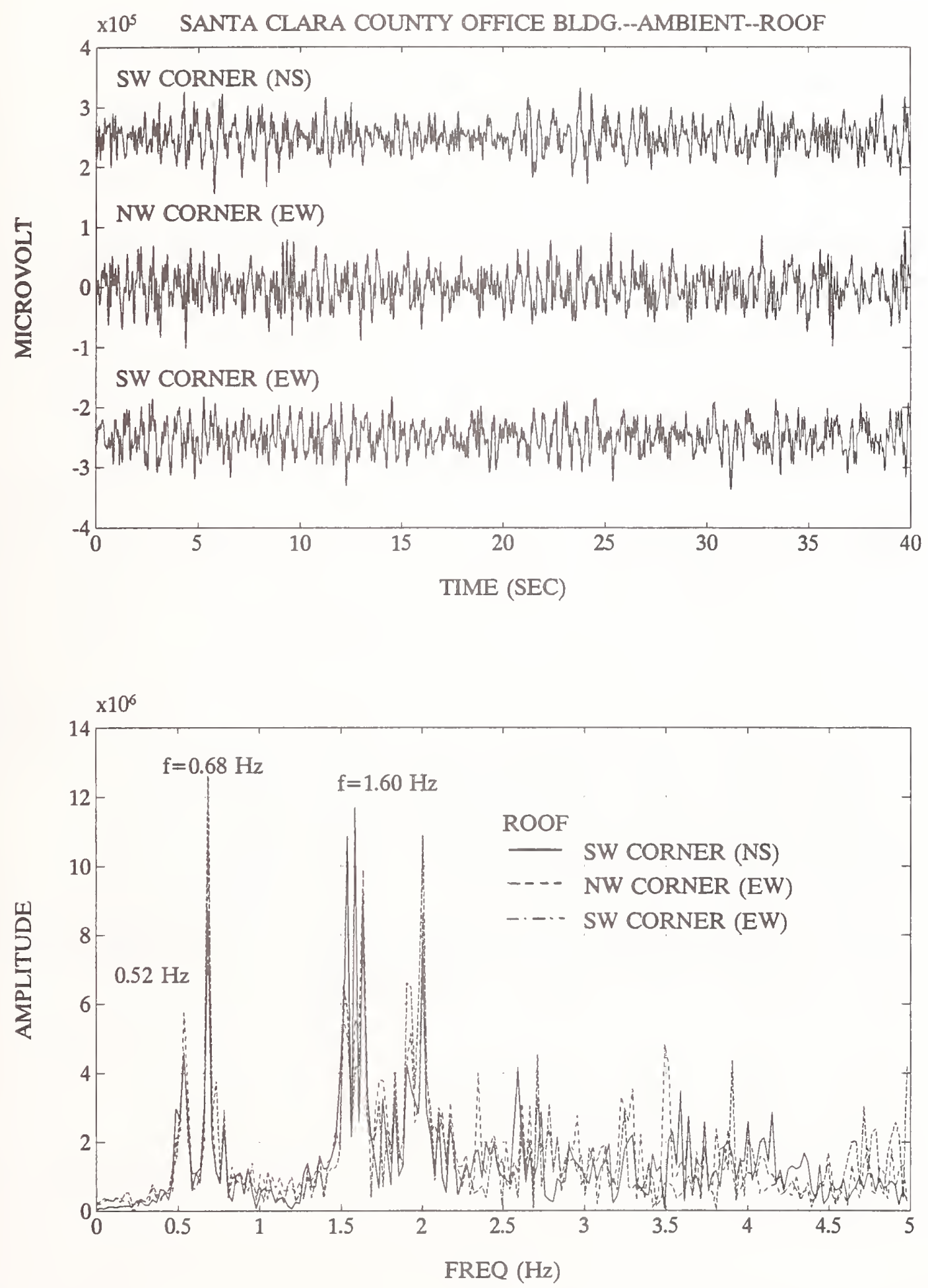

Figure 6. Ambient vibration response of the roof (NS and EW directions) of the Santa Clara County Government Office Building, San Jose, and corresponding Fourier amplitude spectra. 


\section{San Bruno - 6-story Office Bidg.}
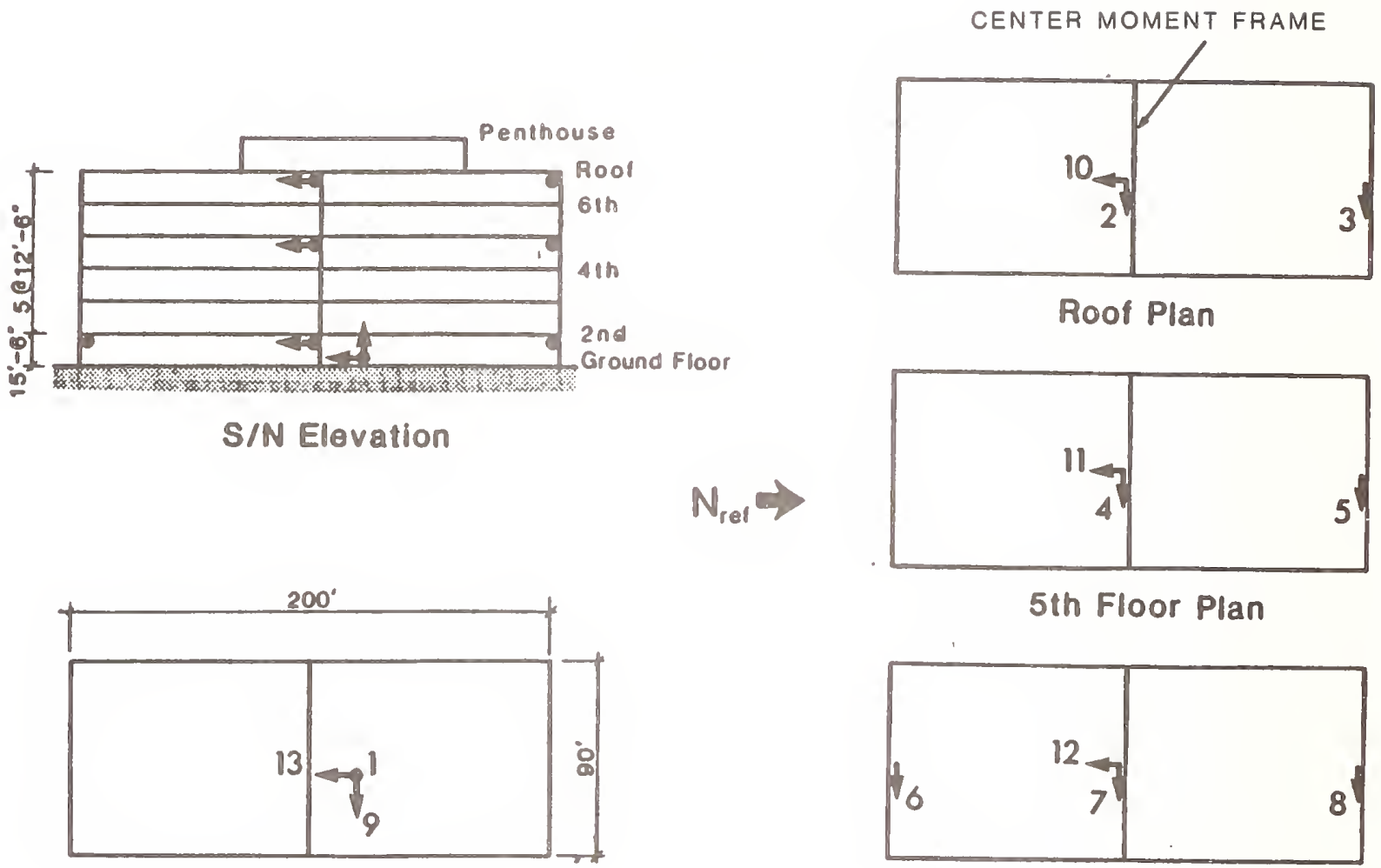

5th Floor Plan

Ground Level Plan Note: $1 \mathrm{ft} 0.3048 \mathrm{~m}$.

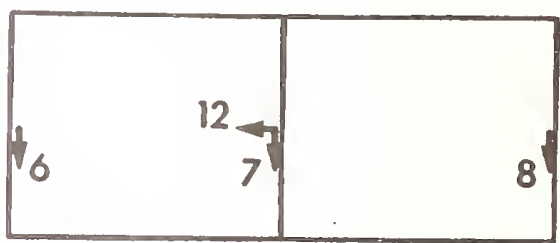

2nd Floor Plan

Figure 7. General instrumentation scheme of the 6-story Office Building in San Bruno. Figure is adopted from Shakal and others (1989). 

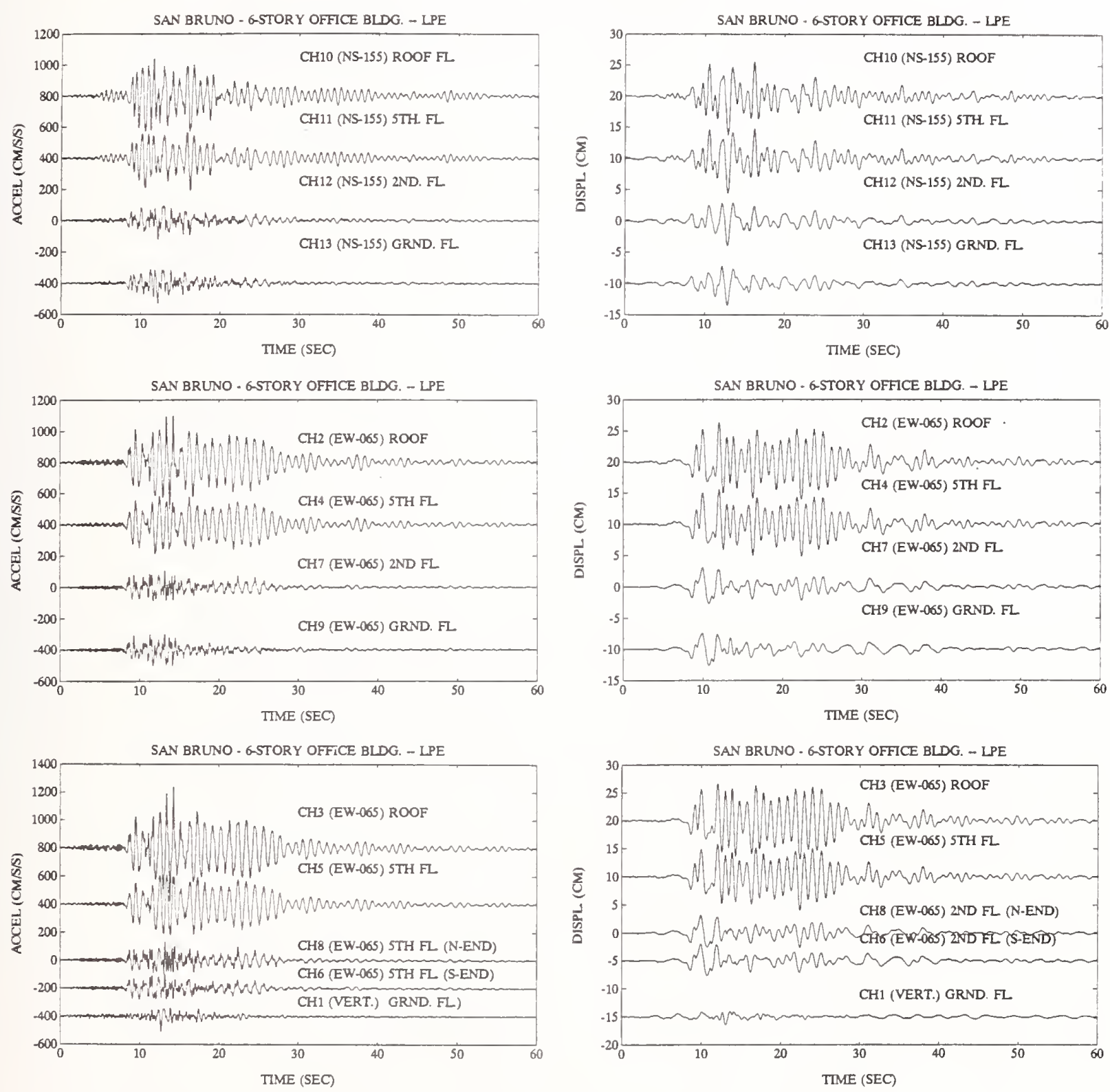

Figure 8. Processed strong-motion accelerations and displacements at different levels of the 6-story Office Building in San Bruno (LPE data). 

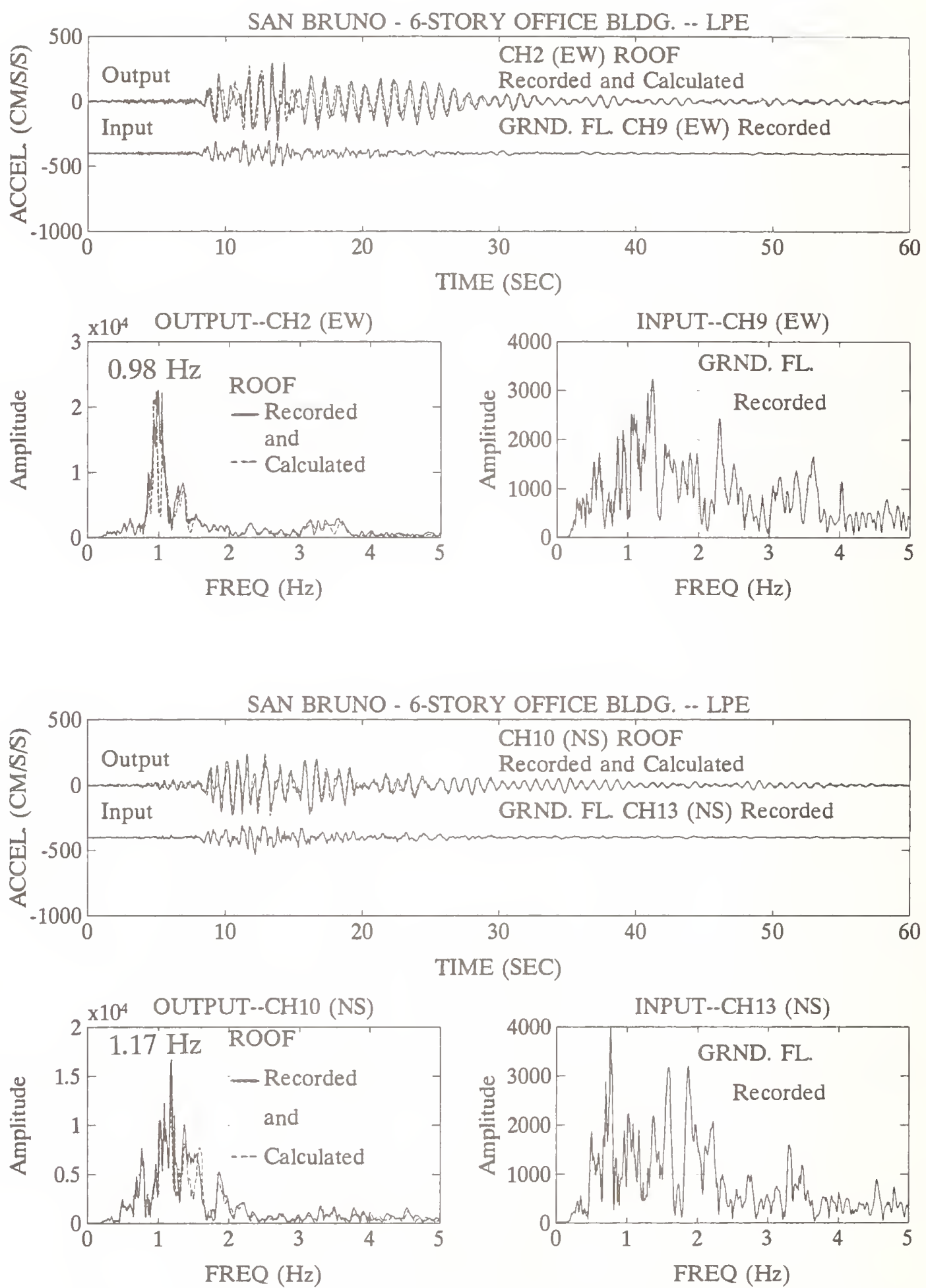

Figure 9. Recorded and Calculated (by system identification) Roof Level Accelerations and Fourier Amplitude Spectra for San Bruno Office Building with Ground Level Motions as Input. 

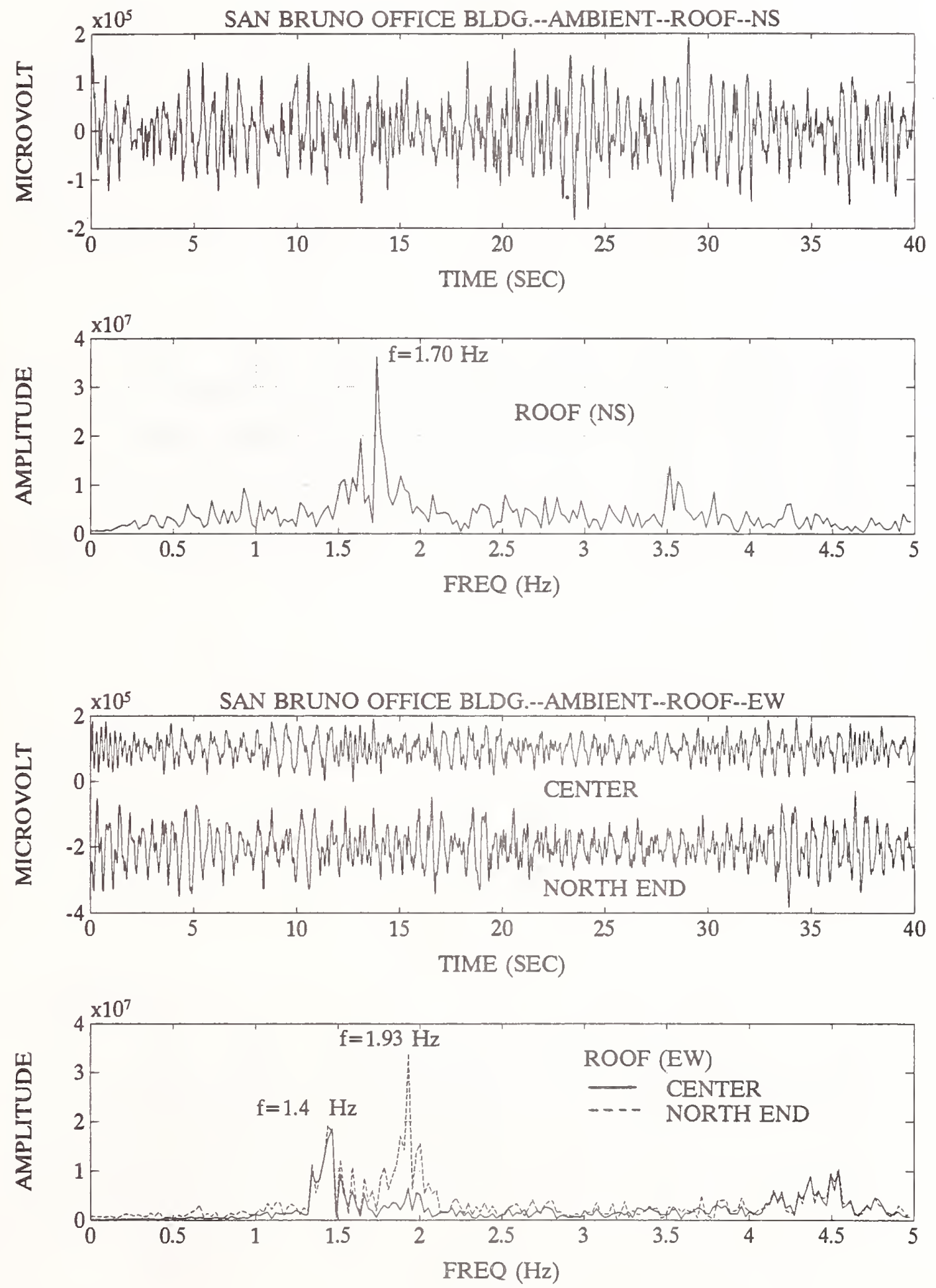

Figure 10. Ambient vibration response of the roof of the San Bruno Office Building (NS and EW directions) and corresponding Fourier amplitude spectra. 

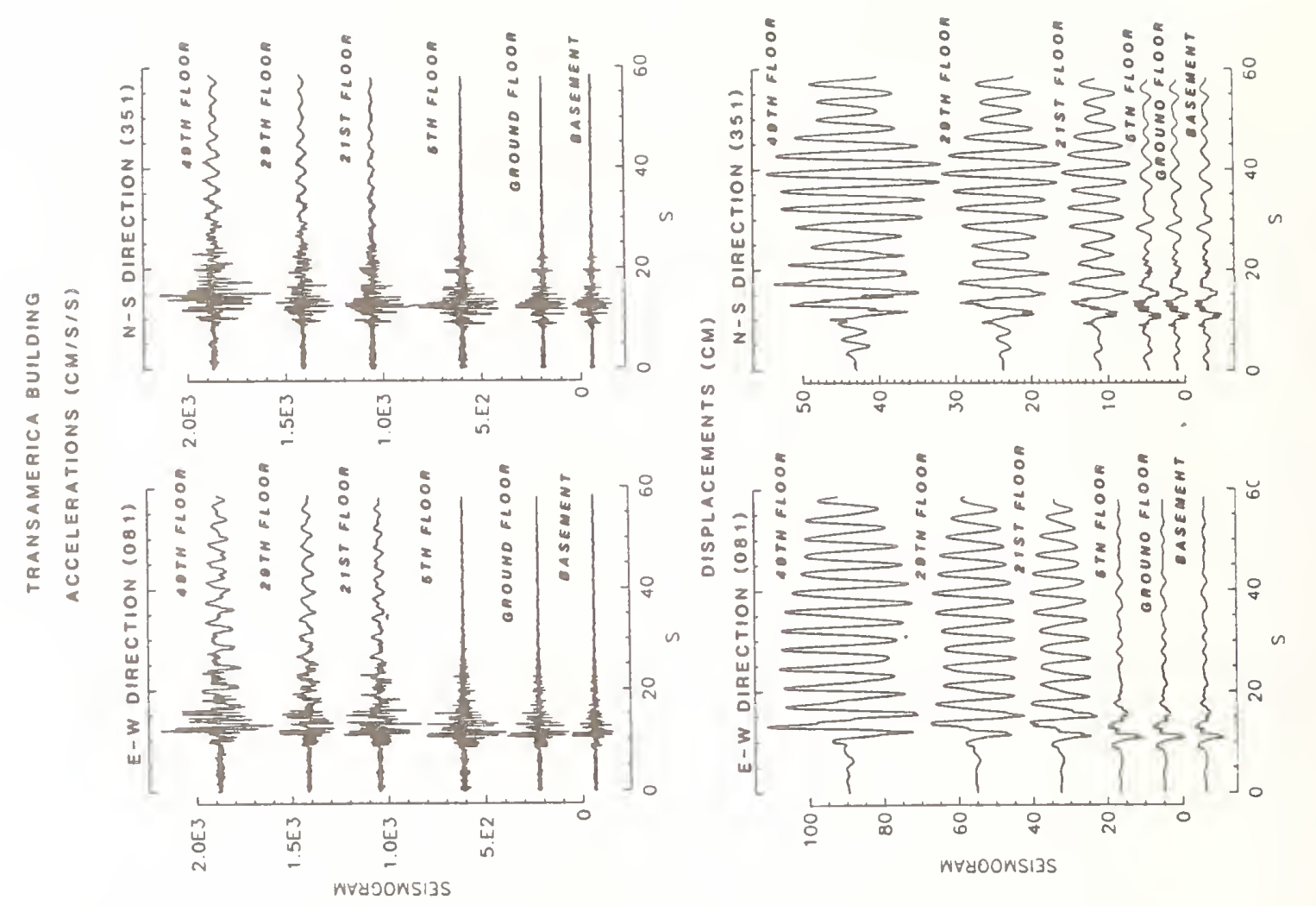

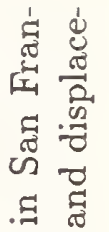

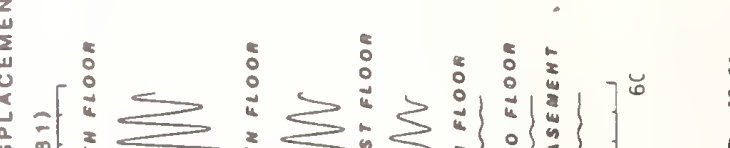

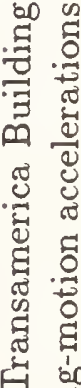

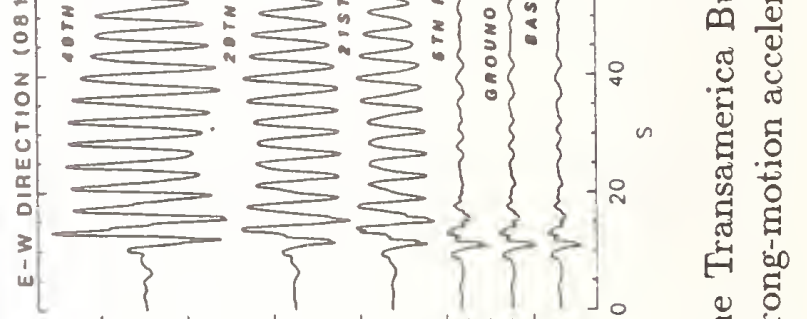

,

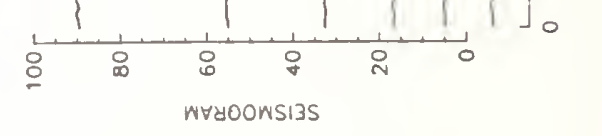

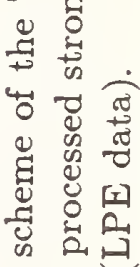

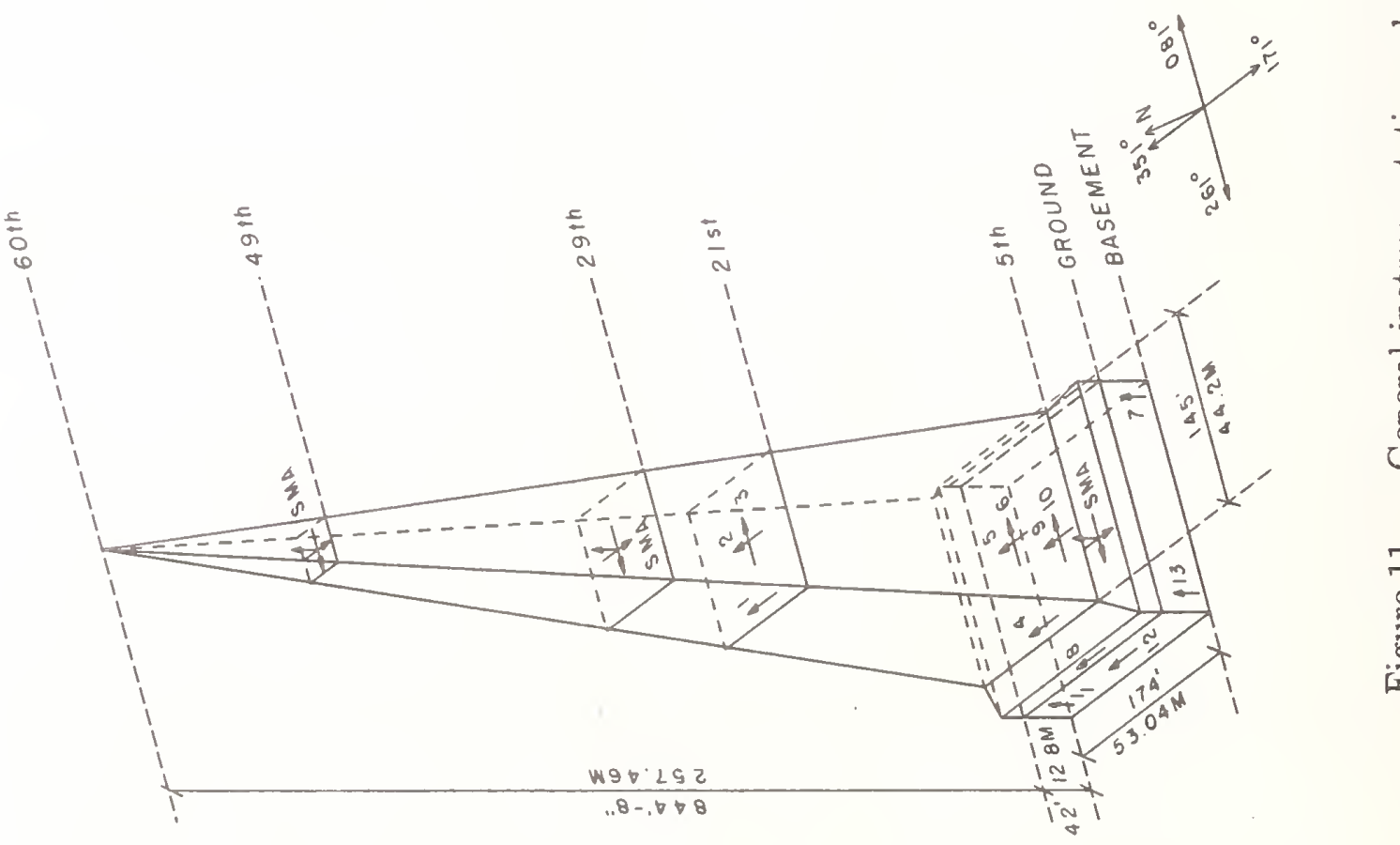



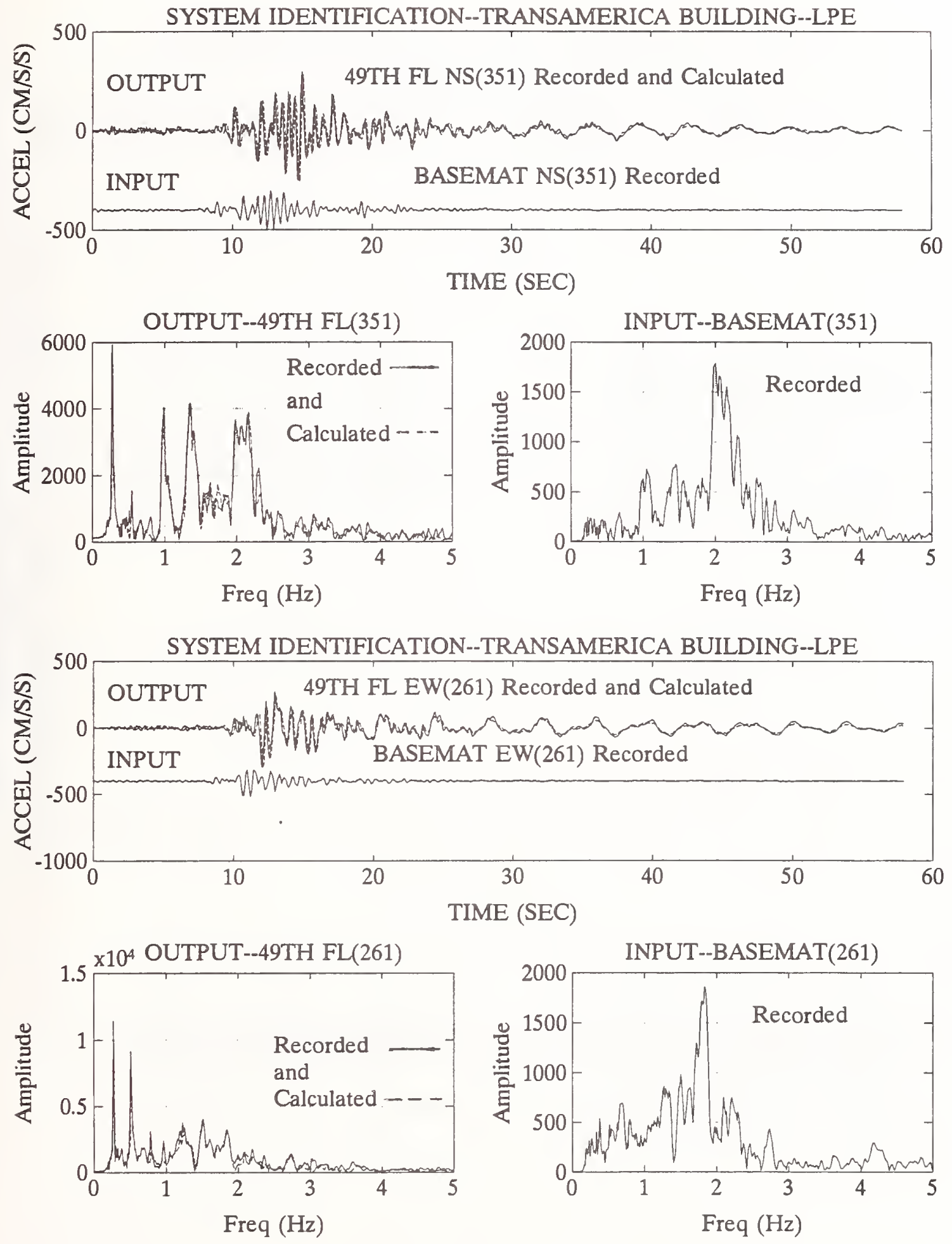

Figure 12. Recorded and Calculated (by system identification) 49th Floor Accelerations and Fourier Amplitude Spectra with Basemat Motions as Input 

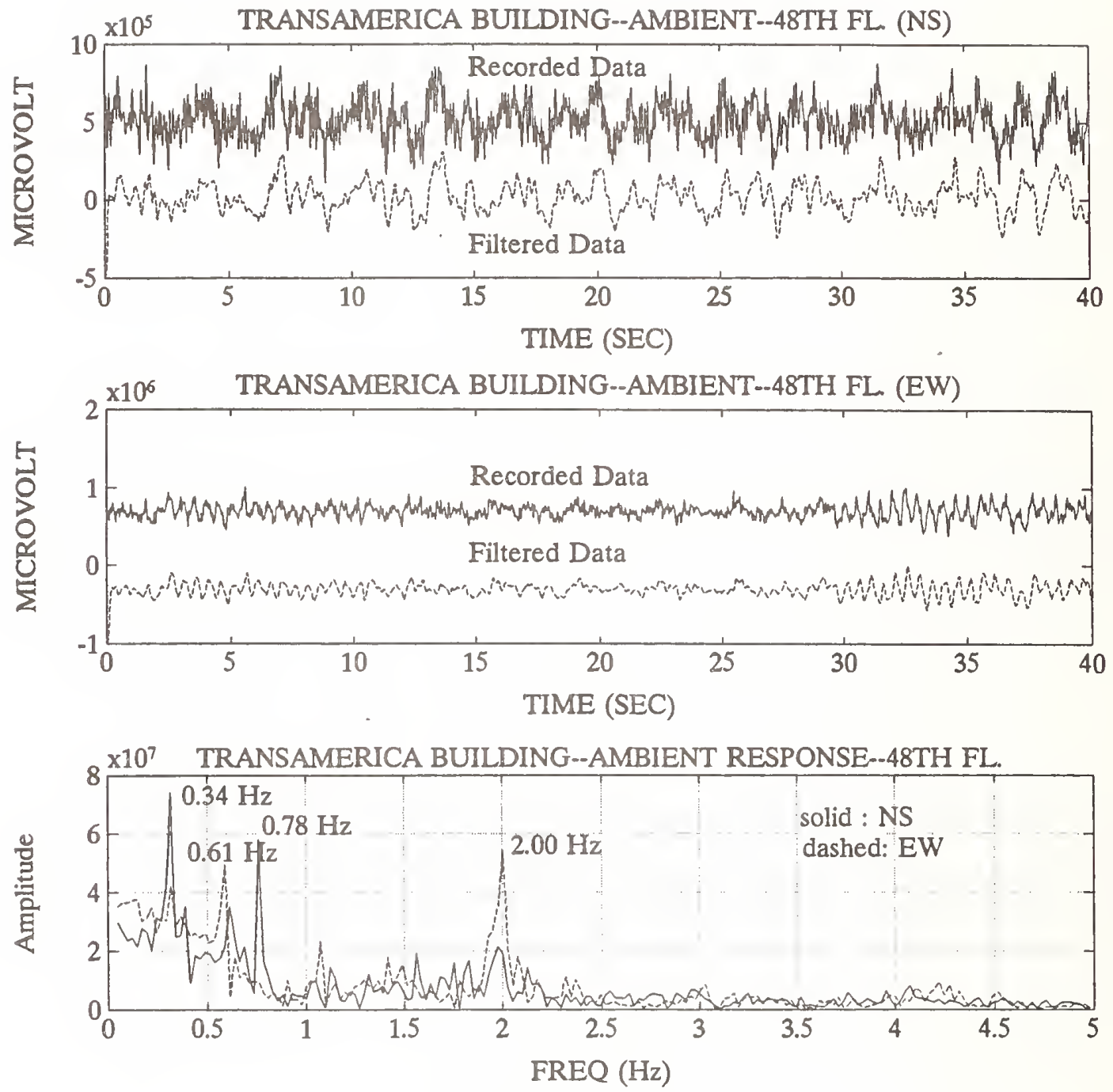

Figure 13. Ambient vibration response of the 48th floor of the Transamerica Building (NS and EW directions) and corresponding Fourier amplitude spectra. 


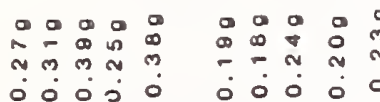

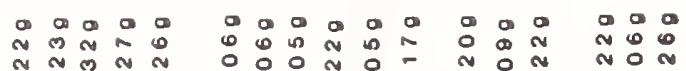

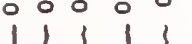

jo o.

i 000 : 0

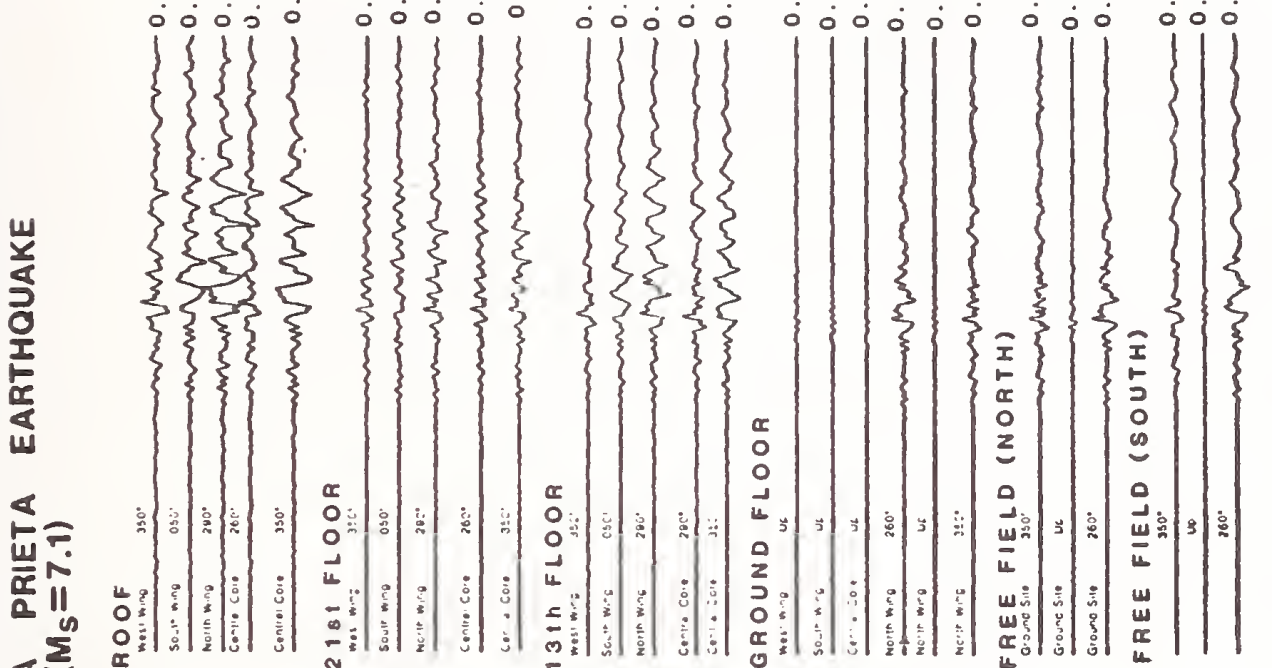

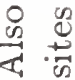

\{\}\{\}

$\{3 \leq\}$

N㐫

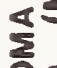

옹ำ

눙
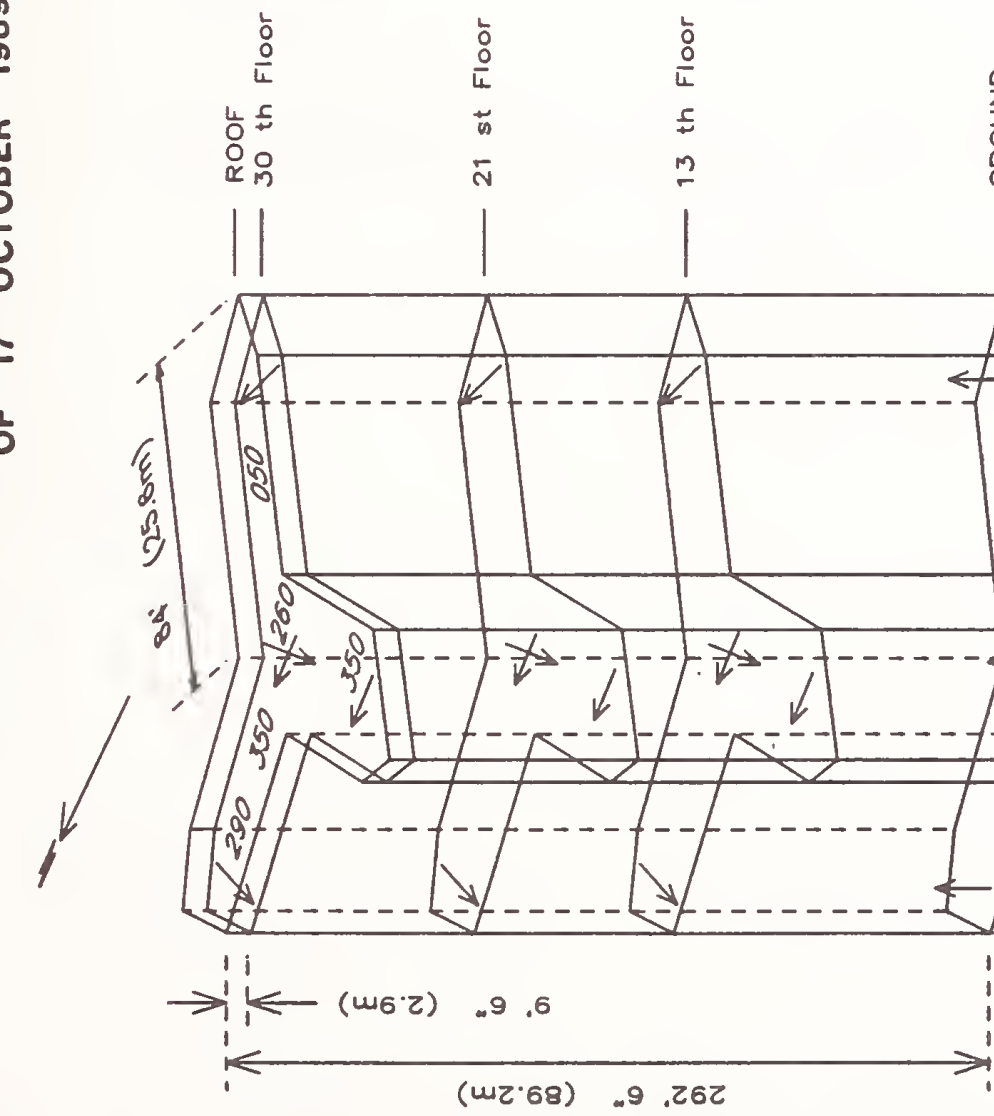

혼

出

年

$\frac{\circ}{\circ}$

$\frac{\circ}{4}$

U.

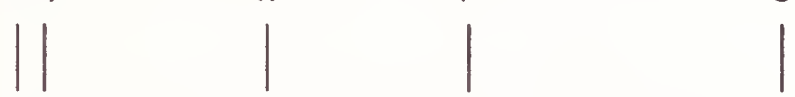

ర

1

8
0
0
0

点 

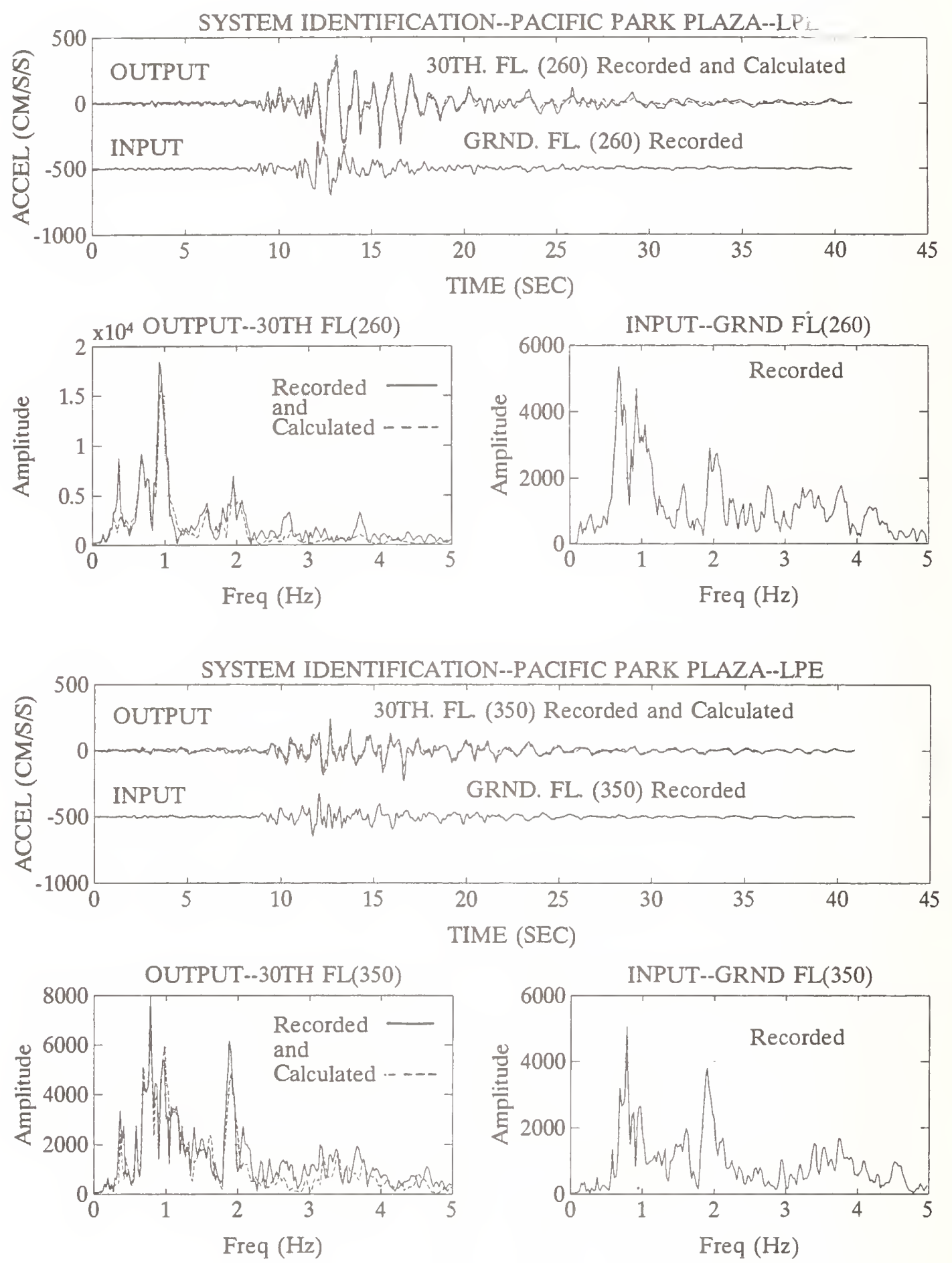

Figure 15. Recorded and Calculated (by system identification) 30th Floor Center Core Accelerations of Pacific Park Plaza Building and corresponding Fourier Amplitude Spectra with Ground Motions as Input 

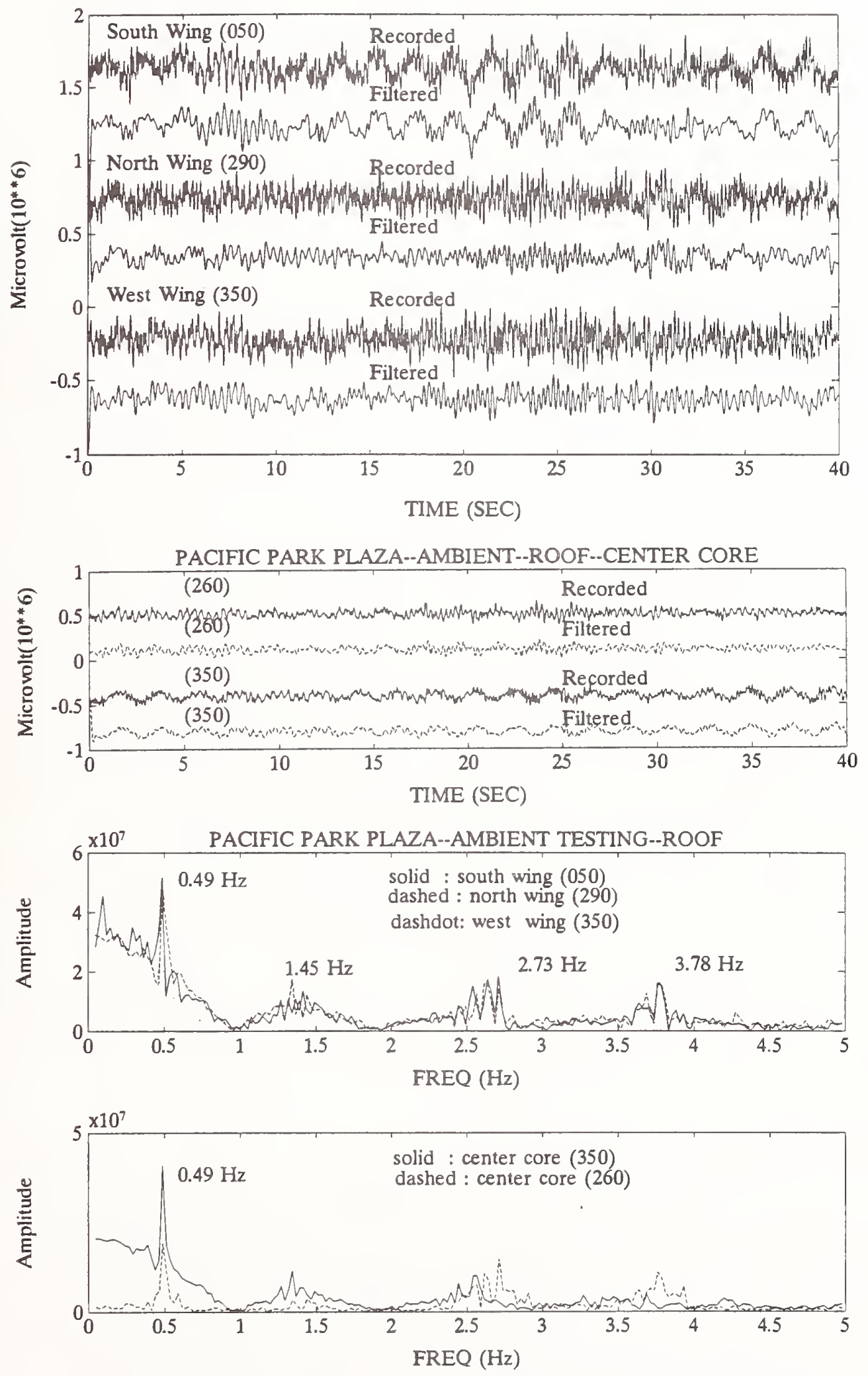

Figure 16. Ambient vibration response of the 30th floor center core of Pacific Park Plaza Building (NS and EW directions) and corresponding Fourier amplitude spectra. 


\title{
Evaluation of Penetration Resistance for Liquifaction Assessment at Jackson Lake Dam
}

\author{
by \\ Jeffrey A. Farrar and Nario Yasuda ${ }^{*}$
}

\section{ABSTRACT}

The authors performed a statistical analysis on a large amount of Standard Penetration Resistance Test (SPT) data collected as part of dynamic compaction construction control at Jackson Lake Dam. Jackson Lake Dam was modified by the Bureau of Reclamation to increase seismic stability. Modifications included treatment of the foundation with dynamic compaction to increase resistance to liquefaction. Dynamic compaction was accomplished in two stages. SPT was used to evaluate effectiveness with over 300 SPT borings performed. Engineers performed initial evaluations were performed by direct comparisons among adjacent boreholes. In this report the SPT data are evaluated in statistical fashion to provide further insight into penetration testing and construction by dynamic compaction. Analysis is presented on depth of treatment, effect of compaction phase, improvement by soil type, effect of differing energy in SPT, influence of gravels in evaluation of SPT, and increase in liquefaction resistance in potentially liquefiable soils. Further analyses should be performed to evaluate overburden pressure correction factors, clean sand equivalent adjustments, and effectiveness of wick drains.

KEYWORDS: penetration resistance testing; standard penetration test; liquefaction resistance; dynamic compaction.

\section{INTRODUCTION}

Jackson Lake Dam located in northwestern Wyoming, was constructed in several stages from 1906 to 1916. The dam is comprised of a short southern embankment, concrete spillway and outlet works structure founded on a bedrock ledge, and a northern embankment approximately $4,300 \mathrm{ft}$. long founded on fluviolacustrine sediments. The dam was investigated starting in 1975 as part of the Bureau of Reclamation's
Safety of Dams program. The north embankment and foundation were found to be susceptible to earthquake-induced liquefaction. The design earthquake was of Richter magnitude 7.5 at an epicentral distance of 4 miles. Reclamation undertook modifications of the dam from 1986 to 1988 to increase seismic stability. Modifications included removal of the northern embankment and foundation treatment consisting of deep dynamic compaction and reinforcement with mixed-in-place soil cement columns. A detailed overview of the foundation treatments was reported by Farrar et al., (1990).

The purpose of this report is to present analyses of penetration resistance data collected during the dynamic compaction program. A preliminary report on evaluation of dynamic compaction was presented by von Thun (1988). These preliminary analyses were based on a direct comparison of neighboring drill holes. In this report, all data were evaluated in a statistical manner to provide further insight into the effectiveness of dynamic compaction and the use of the standard penetration test for liquefaction resistance evaluations.

\section{DYNAMIC COMPACTION PROGRAM}

Dynamic compaction was used to improve the foundation beneath the central portions of the dam as illustrated on figure 1. The concept of block treatments was applied, using deeper treatments of a honeycombed pattern of interconnecting soil cement columns under the toe of the dam. This allowed for

* Civil Engineer, Materials Engineering Branch, Research and Laboratory Services Division, Bureau of Reclamation, Denver, Colorado, USA, 80225.

** Research Engineer, Filltype Dam Division, Dam Department, Public Works Research Institute, Ministry of Construction, Tsukuba, Japan, 305. 
significant savings in foundation costs.

The dynamic compaction program consisted of dropping a 30-ton weight from a height of $100 \mathrm{ft}$. The drop grid, illustrated in figure 2, had primary impact points spaced on $40 \mathrm{ft}$. centers with 20 drops at each impact point. The treatment was then completed with 15 secondary and 10 tertiary drops with 40 and $20 \mathrm{ft}$. closure spacings. A final "ironing" phase was applied to the complete construction surface using a 30 ton weight dropped from a height of $40 \mathrm{ft}$. The final ironing phase was only applied to the downstream portion of the foundation downstream of centerline since the working pad was excavated upstream of centerline for embankment placement.

Several design and construction features assisted in the dynamic compaction program. Drainage trenches were excavated around the perimeter of the dynamic compaction working surface. These trenches were helpful in lowering the ground water. Typical horizontal spacing between trenches was $300 \mathrm{ft}$. Finegrained soil was excavated to a depth of $7 \mathrm{ft}$. and silty gravel backfill was replaced to provide a stable working surface. This excavation and backfill was performed in almost all of the treatment areas. Foundation investigations revealed numerous layers of lake deposits separating cohesionless soils. In areas where lake deposits would delay dissipation of excess pore pressures, wick drains were installed. von Thun (1988) analyzed wick drains using the direct comparison approach and found they greatly improved effectiveness of treatment. Approximately 45 percent of the $750,000-\mathrm{ft}^{2}$ area of dynamic compaction was treated with wick drains.

Dynamic compaction treatment areas were divided into sectors as shown on figure 3. Construction was performed in two stages as shown on the figure. Since the construction was performed in two stages, there were significant differences in construction and monitoring methods to be considered. The Stage I contractor used modified Manitowac cranes with a single part line to drop the weight. The Stage II contractor used a lattice boom crane specifically designed for dynamic compaction. The significant difference among the contractors was the greater amount of repair time required by the Stage I contractor which influenced continuity of treatment. As will be shown later, a greater level of treatment was realized in Stage II. This increased improvement may be also due to more extensive use of wick drains in Stage II.

\section{MONITORING PROGRAM}

Principal methods for evaluating improvement in dynamic compaction were SPT and piezometers. A considerable amount of additional testing was performed to evaluate improvement. Cone penetration testing was initially performed in Stage I construction but the program was greatly reduced after it became evident that the presence of gravel layers slowed testing. Foundation shear wave velocity was measured by both cross hole and surface wave methods. There was also a study using several inplace test methods to evaluate the increases in horizontal stresses from dynamic compaction. Interpretation of specialized testing was complicated by complex layering of the foundation. As a result of complex stratigraphy, simple penetration tests provided the measure of improvement.

Monitoring of Stage II was performed by drilling 168 SPT drill holes before and after compaction. For Stage II monitoring 153 SPT drill holes were drilled. SPT holes were located in regular patterns of 50- to $80-\mathrm{ft}$. spacings. Samples were taken at $2.5 \mathrm{ft}$. intervals to depths of $35-$ to $50-\mathrm{ft}$. Drilling was performed by contractors. SPT testing was accomplished generally within 1 to 2 weeks after completion of the dynamic compaction phase to be studied. Reclamation drilled an additional 25 SPT holes approximately 9 months after dynamic compaction to evaluate aging effects. These drill holes are not included in statistical evaluations presented in this paper. A typical layout of SPT drilling performed in sector $\mathrm{N}$ is shown on figure 4.

Different philosophies were applied to the SPT monitoring program in the two stages of construction. There was an equal amount of pre- and postcompaction SPT drill holes. In Stage I, SPT's were performed after specific phases of compaction. At a single location where soil conditions were critical there were two and sometimes three post-compaction SPT borings. In other noncritical locations there were no post-compaction borings. In Stage II, each precompaction boring was matched with a postcompaction boring drilled after the final phase of compaction. As a result of these differences, the Stage I data are useful to evaluate improvement by phase of compaction. 
There were very significant procedural differences in SPT among Stage I and II contractors. The Stage I SPT was performed using safety hammers by the rope and cathead (pulley) method. Stage I drill holes were advanced using tricone rotary rock bits and drilling mud. A pump bypass line was used to maintain fluid level in Stage I holes during the removal of rockbit. Casing was rarely required in Stage I. The Stage II contractor performed SPT using a CME (Central Mine Equipment Company) automatic hammer. The hammer lift is accomplished with a hydraulically driven chain and cam mechanism to lift and drop the hammer. Stage II holes were advanced with the casing advancer which is a rotary casing advanced by circulation of drill mud. With the casing advancer system, the casing was left inplace during SPT resulting in less disturbance from fluctuating fluid levels in the drill hole. During SPT testing, a 50-blow limit was typically observed. With the use of the automatic hammer in Stage II, there was a greater tendency to continue testing in high blow count material and blow counts in excess of 50 were obtained.

The most significant difference in between Stage I and II SPT testing was the energy delivered to the sampler. Seed et al. (1984) have shown the significance of SPT with regard to liquefaction analysis. In an effort to measure energy, Reclamation performed energy measurements in accordance with ASTM (American Society for Testing and Materials) test designation D4633 (1986). A Binary Instruments Model 102 calibrator with piezoelectric load cell was used to check SPT energy. The measurements were difficult due to premature integration times believed to be caused by the large NW drill rods used. Data for the Stage I contractor were initially collected using an incorrect rod area factor. Only 10 series of tests of approximately 200 blows of data were collected for both the Stage I and II contractors. The best estimate of drill rod energy ratio, $\mathrm{ER}_{\mathrm{i}}$, was 73 and 97 percent for Stage I and II contractors, respectively.

The measured energy delivered by the Stage I contractor appears high since he used a jointed hammer and rod connection with consistently soft worn rope to drop the hammer. Prior to the discovery of the rod area correction, energy corrections to SPT $\mathrm{N}$ values in this report were performed using conservative assumptions of 40 and 80 percent $E_{R_{i}}$ for Stage I and II contractors, respectively. These values of energy were also used in this report for calculation of $N_{160}$ values. Details of the energy measurements are being reported in a thesis by Farrar (1991).

For statistical analyses, data were collected and input on a spreadsheet program Lotus $123^{\mathrm{TM}}$. Data were entered at field offices under the direction of project geologist Karl Wirkus. For each SPT test, particle size analysis (gradation) and moisture content tests were performed to identify soil type. The soil sample was classified according to the Unified Soil Classification System (USCS). Recovery, which is expressed as the ratio sample length to drive length, was also input to evaluate sample quality. An example of the data base is shown on table 1. Four spreadsheets were developed, representing pre- and postcompaction data for Stage I and II construction. Over 4,000 SPT tests make up the database. Analysis and verification of this data was undertaken by Mr. Yasuda. A more comprehensive draft report by is available from Reclamation. This database is available for further study by request.

Caution should be used in grouping of soil types based on gradation analysis from the SPT test. In many cases there is low recovery of soil, resulting in a soil classification which is not representative of the material tested. Also, the gradation could be a mixture of layers and may not represent the dominant layer affecting the $\mathrm{N}$ value. Occurrence of no recovery may often represent liquefied sands. In many cases the sample size is below that required by recognized testing procedures for a representative gradation.

It is important to note that the frequency distribution analysis represents the number of occurrences less than or equal to the value shown on the graphs. Most frequency distribution (histogram) graphs plot $\mathrm{N}$ values in increments of five blows. An apparent arithmatic mean from distribution bars will plot to the right (larger value) of the true mean value. Therefore, the true arithmatic mean is generally five blows less than depicted on the graphs.

\section{SUMMARY OF IMPROVEMENTS}

\subsection{Improvement by Soil Type}

A summary of improvement in raw $\mathrm{N}$ value by soil type is shown on table 1. Several significant findings can be seen in this table. Predominant soil types present in the foundation include those with USCS 
groupings of Poorly Graded Gravels (GP), Poorly Graded Sands (SP-SM), Silty Sands (SM), and Silts (ML). Frequency distribution graphs of the precompaction raw $\mathrm{N}$ value for these major soil groupings are shown on Figures 5 through 12. We have found no explanation for the differences in frequency distribution between Stages I and II. The data for Stage I appear log-normally distributed. This may be attributed to thicker layers of gravels encountered in Stage I.

A summary of gross improvement by soil type is taken as the percentage of the increase in mean values before and after compaction. The amount of improvement for Stage I appears to be less than Stage II, but the data from Stage I include primary and secondary phases of compaction. Since the data for Stage I include interphase testing, it does not represent final improvement. Improvement is significant for all soil types.

The most significant data trends in table 1 are the differences in mean values from Stage I and II construction. The primary difference is due to the energy delivered in SPT by the Stage I and II contractors. The data provide a unique opportunity to investigate the theorem of $N$ value inverse proportionality to energy delivered. From this data we can determine if the theorem holds true, regardless of soil type.

\subsection{Energy Effect on SPT Data}

To evaluate the inverse proportionality of $\mathrm{N}$ value with energy, the ratio of pre-compaction Stage I to Stage II data is plotted by soil type on figure 13. This graph shows the ratio of raw $N$ values ranges from 48 to 57 percent for the most predominant soils present. The ratio did not seem to correlate with particle size or permeability inferred by USCS symbol. The differences in mean values vary little by soil type. These findings indicate that the inverse proportionality holds regardless of soil type. Extreme values outside this range were checked and found to be caused by low sample population.

It is assumed that the ratio of precompaction raw $\mathrm{N}$ values represents the ratios of mean energy delivered by the two drilling contractors. This assumption would appear valid if geologic conditions remain constant. The ratio of approximately 50 percent does not agree with the measured energies mentioned in section 3 .
Part of the reason for this disagreement may be due to the differences in drill hole advancement techniques. The ratio does confirm the assumed energies based on engineering judgement $\left(\mathrm{ER}_{\mathrm{i}}=40\right.$ and 80 percent $)$. It is clearly evident that the different energies are significant to interpretation of ground improvement.

\subsection{Improvement by Phase of Dynamic Compaction}

Data from Stage I allow the best opportunity for evaluating the improvement by phase of the dynamic compaction program. Figures 14 through 16 show the mean raw $\mathrm{N}$ values tabulated at $5 \mathrm{ft}$. depth increments for different phases of compaction. The data show that while a significant increase in penetration resistance is obtained from the primary and secondary impacts, there is still additional benefit from tertiary and quaternary impacts. Improvement in silts (ML) is more pronounced from later phases of compaction which is related to lower permeability of the fine grained soil. Effect of compaction phase is also illustrated in figure 17 where all Stage I data are evaluated.

\subsection{Effective Depth of Improvement}

The determination of average raw $\mathrm{N}$ values versus depth aids in ready evaluation of effective depth of treatment. Figures 14 through 16 show that effective depth of treatment is approximately $40 \mathrm{ft}$. for Stage I. Effective depth of improvement both for Stages I and II is summarized by averaging all penetration data on figures 17 and 18. It is not clear from figure 18 if the depth of treatment for Stage II is greater. SPT testing was generally stopped at $40 \mathrm{ft}$ during Stage II testing. Examination of figure 19 for Stage II silty sands (SM) shows some indication that effective depth is also in the vicinity of $40 \mathrm{ft}$.

Comparison of figures 17 and 18 indicates that there was a significantly larger occurrence of gravels in Stage I with higher penetration resistance.

\section{EVALUATION OF LIQUEFACTION RESISTANCE}

\subsection{Computation of Normalized SPT N value}

To evaluate liquefaction resistance, we computed the $N_{160}$ value as proposed by Seed et al. (1984). To adjust for energy differences between Stages I and II, 
drill rod energy ratios of 40 percent for Stage I and 80 percent for Stage II were first applied. Future studies should be performed using different energy ratio assumptions. This initial assumption of energy seemed to produce a good match of mean $\mathrm{N}$ values with each stage.

SPT $\mathrm{N}$ values at depths less than $10 \mathrm{ft}$ were multiplied by a factor of 0.75 to account for incomplete energy transmission in short drill rod sections. For calculation of overburden stress, the ground water was assumed to be at the base $(7 \mathrm{ft})$ of the dynamic compaction working surface. The wet unit weight of the silty gravel (GM) working surface backfill was assumed to be $104 \mathrm{lb}_{\mathrm{f}} / \mathrm{ft}^{3}$. This assumption is unreliable for the gravels whose wet unit weights can reach $140 \mathrm{lb}_{\mathrm{f}} / \mathrm{ft}^{3}$ and future studies should use higher weights. The saturated unit weight of the foundation soils could vary from 115 to $145 \mathrm{lb}_{\mathrm{f}} / \mathrm{ft}^{3}$. In this analysis we assumed a saturated unit weight of foundation soils of $125 \mathrm{lb}_{\mathrm{f}} / \mathrm{ft}^{3}$.

Overburden pressure correction of the SPT N value to the 1 ton $/ \mathrm{ft}^{2}$ stress level was performed using the following equations.

and

$$
\mathrm{N}_{160}=\mathrm{C}_{\mathrm{n}} * \mathrm{~N}_{60}
$$

$$
\mathrm{C}_{\mathrm{n}}=\sigma^{\prime \mathrm{n}}
$$

where;

$$
\begin{aligned}
& \mathrm{n}=-0.5 \\
& \sigma^{\prime}=\text { effective vertical stress in ton } / \mathrm{ft}^{2}
\end{aligned}
$$

Chamber tests on coarse and fine sands have shown that the factor, $C_{n}$, varies with particle diameter. Chamber tests also show that penetration resistance in coarser sands is larger than that for finer sands at an equivalent density. In this analysis, we only used a constant $C_{n}$ factor. Future studies could be performed to evaluate the data with $C_{n}$ as a function of mean particle diameter, $\mathrm{D}_{50}$. This correction factor may not be too significant since a majority of data is taken near the 1-ton $/ \mathrm{ft}^{2}$ stress level which corresponds with a depth range of approximately 20 to $30 \mathrm{ft}$.

\subsection{Improvement by Soil Type}

Figures 20 and 21 were developed to reflect the improvement in mean $\mathrm{N}_{160}$ for all soil types. It should be noted that the $\mathrm{N}_{160}$ method proposed by Seed et al. (1985) is only applicable to sands. These figures allow for examination of improvements to all soil types. All soils exhibit significant increases in penetration resistance. Data for Stage II gravels show larger increases than those for Stage I.

\subsection{Improvement in Sands}

Figures 22 through 25 illustrate the improvement in clean sands (SP, SP-SM) and silty sands (SM). The frequency distributions are shown before and after compaction for both Stages I and II. All of the diagrams show a reduction in the lower $\mathrm{N}_{160}$ values. For clean sands, there was a reduction in the number of test occurrences after compaction. There were more low $\mathrm{N}$ values in SM sands in Stage II data.

In the method proposed by Seed et al. (1985), the limiting $N_{160}$ value for clean sands for magnitude 7.5 earthquakes is approximately 20 to $25 . \mathrm{N}_{160}$ values greater than 25 should not exhibit initial liquefaction. An approximate correction in $\mathrm{N}_{160}$ for silty sands (SM) is approximately 7.5 blows. Figures 22 through 25 show that the soils have practically no liquefaction potential after compaction. The data also demonstrate that improvement goals should be specified in a statistical manner.

\subsection{Effects of Gravels}

The presence of gravels presents a difficulty in evaluating liquefaction resistance. Figures 22 to 25 show a large number of data with high $\mathrm{N}_{160}$ values prior to compaction. If gravels are present in the test interval, the $\mathrm{N}$ values of sands may be increased greatly. At first impression it would seem that the data would indicate that most soils are resistant to liquefaction. However, it is well known that coarse particles present in significant percentages will result in higher penetration resistance values.

Figures 26 and 27 were developed to evaluate if removing samples recovered with appreciable gravel contents ( $>5$ percent) would result in a more reasonable distribution of data. These graphs were developed for Stage II construction. Examination of these figures reveals that although the number of high blow count tests occurrences is significantly reduced, the distribution of high $\mathrm{N}_{160}$ values remains. The figures do show a significant reduction in the occurrence of low $\mathrm{N}_{160}$ values for loose sands. Possibly gravel can also be present in the bottom of the sample interval and is not recovered. 
Figures 28 and 29 were developed to illustrate the dependence of $\mathrm{N}_{160}$ on mean particle diameter, $\mathrm{D}_{50}$. Hydrometer tests were not performed on the SPT soil samples so fine-grained soils were not evaluated. The data serve to illustrate the extreme variability of $\mathrm{N}$ value at any mean particle diameter. This variability is caused by many factors including geologic variability and sample recovery. Although there is considerable scatter, a trend of decrease in $\mathrm{N}_{160}$ with decrease in particle diameter, $\mathrm{D}_{50}$ is evident.

Of all the attempts to evaluate liquefiable sands none were completely successful in reducing the effects of gravels on penetration resistance. Recently it has been recognized that given the correct conditions gravel may be liquefiable. The conventional SPT is not appropriate for evaluation of these materials. One approach to separating data by geologic classification was presented by Wirkus (Farrar et al., 1990). SPT soil samples were grouped into three geologic groups: Qfg (any soil containing more than 5 percent gravel), Qfc (fine-grained soils according to USCS group symbol), and Qfs (sandy soils with less than 5 percent gravels). Figure 30 illustrates improvement by depth for these three groupings for Stage II construction. The improvement for sands shows reasonable conformance with ranges in penetration resistance for liquefiable sands without the influence of gravels.

\subsection{Importance of No Recovery Tests.}

For evaluation of liquefaction resistance, penetration resistance tests may be the most important when no sample recovery was possible . Lack of recovery may be caused by very loose clean sands which liquefy during testing. These same sands have the highest susceptibility to earthquake induced liquefaction. No recovery may also be caused by very coarse gravel obstructing the barrel. To examine this effect, we took all $\mathrm{N}_{160}$ values of less than 50 blows. Figure 31 shows the occurrence of no recovery $\mathrm{N}_{160}$ values for Stage II. There is a significant reduction in no recovery after compaction.

\subsection{Clean Sand Equivalent Offset}

Recently, there has been an attempt to evaluate post earthquake residual strength from penetration resistance data (Seed, 1987). A proposed correction in $\mathrm{N}_{160}$ to account for increased fines content was proposed. This correction allows for evaluation of an equivalent clean sand $\mathrm{N}_{160}$ value for soils containing fines contents of up to 75 percent.

We investigated this offset in $\mathrm{N}_{160}$ values to see if the offset may be influenced by increased density and horizontal stresses induced by dynamic compaction. Figure 32 shows a comparison of the values recommended by Seed (1987) and the values obtained from both stages of compaction before and after treatment. First it can be seen that the factors proposed by Seed are extremely conservative and could possibly result in a preponderance of low equivalent $\mathrm{N}$ values in dirty sands. Part of the differences between Seed's values and our data may be caused by the higher $N$ values resulting from the gravels. It is interesting to note that at approximately 35 percent fines, our data show an equivalent offset of 7.5 blows, which was proposed by several groups including Seed for correcting $\mathrm{N}$ values for silty sands.

The clean sand equivalent offset increased significantly after treatment in Stage II. This trend was not apparent in Stage I data but intermediate treatment phase data are included. The results do point to the dependence of the offset on density and horizontal stress level. Further study should be performed to analyze the data using overburden pressure corrections which are dependent on particle size.

\section{CONCLUSIONS}

Reclamation performed over 4,000 SPT tests both before and after a dynamic compaction ground improvement program at Jackson Lake Dam. Improvements were performed to increase the resistance of foundation soils to liquefaction. These data were analyzed to provide additional insight into the use of penetration testing for assessment of liquefaction potential. Construction was performed in two stages with each stage using differing construction and penetration testing methods. Important conclusions are as follows;

- The data serve to illustrate that at any given site there will be extreme variability in penetration resistance in any given soil type due to natural deposition conditions. This variability may also be due to particle size effects. After dynamic compaction, there is also variability. Evaluations of improvement of improvement should be performed in a statistical manner. Contract specifications for improvement should also be expressed in a statistical manner. 
- Penetration resistance data were significantly affected by energy delivery. Drilling contractors used two different drilling and SPT testing methods. Adjustments to raw $\mathrm{N}$ values were required to accurately evaluate liquefaction resistance.

The effective depth of improvement was approximately $40 \mathrm{ft}$.

- Penetration resistance was increased by dynamic compaction for almost all soil types.

- Liquefaction resistance was evaluated by using the $\mathrm{N}_{160}$ method proposed by Seed et al. (1984). After dynamic compaction, there were very few occurrences of $\mathrm{N}_{160}$ values less than 20 to 25 blows/ft.

- The frequent occurrence of gravels had a large influence on the penetration resistance data. Data for sands can be more accurately evaluated by omitting SPT samples where coarse particles are encountered.

- The offset in penetration resistance caused by fines content was evaluated. The offset in mean $\mathrm{N}$ value was investigated to see if it was a function of compactive effort or resulting density range of the soils. The offsets were much larger than the conservative values proposed by Seed (1987). Some of the data indicate this offset was a function of density range.

\subsection{Areas of Future Study}

The database of SPT data from Jackson Lake Dam is available for additional study. Additional studies varying the overburden stress correction factor, energy corrections, and corrections for particle size effects could be performed. Such analyses would provide further insight into use of penetration resistance for evaluating ground improvement.

\section{REFERENCES}

1. Farrar, J.A., Wirkus, K.E., McClain, J., (1990), "Foundation Treatment for the Jackson Lake Dam Modification," Proceedings of the U.S. Committee on Large Dams, New Orleans, LA., March 14.

2. von Thun, J.L., (1988), "Preliminary Results of Dynamic Compaction Stage I and Stage II Treatment of Jackson Lake Dam Foundation," USCOLD News, March.

3. Seed, H.B., Tokimatsu, K., Harder, L.F., and R. M. Chung, (1984), "Influence of SPT Procedures in Soil Liquefaction Resistance Evaluations," Report No. UCB/EERC/84/15, Earthquake Engineering Research Center, University of California at Berkeley, October, $50 \mathrm{pp}$.

4. American Society for Testing and Materials, (1986), "Standard Test Method for Stress Wave Energy Measurement for Dynamic Penetrometer Systems," Annual Book of Standards, Volume 4.08, ASTM, Philadelphia.

5. Farrar, J.A., (1991), "Field Energy Measurements of Standard Penetration Testing," Thesis, University of Colorado at Denver, In preparation.

6. Seed, H.B., (1987), "Design Problems in Soil Liquefaction," Journal of Geotechnical Engineering, ASCE, Vol. 113, No. 8, August 


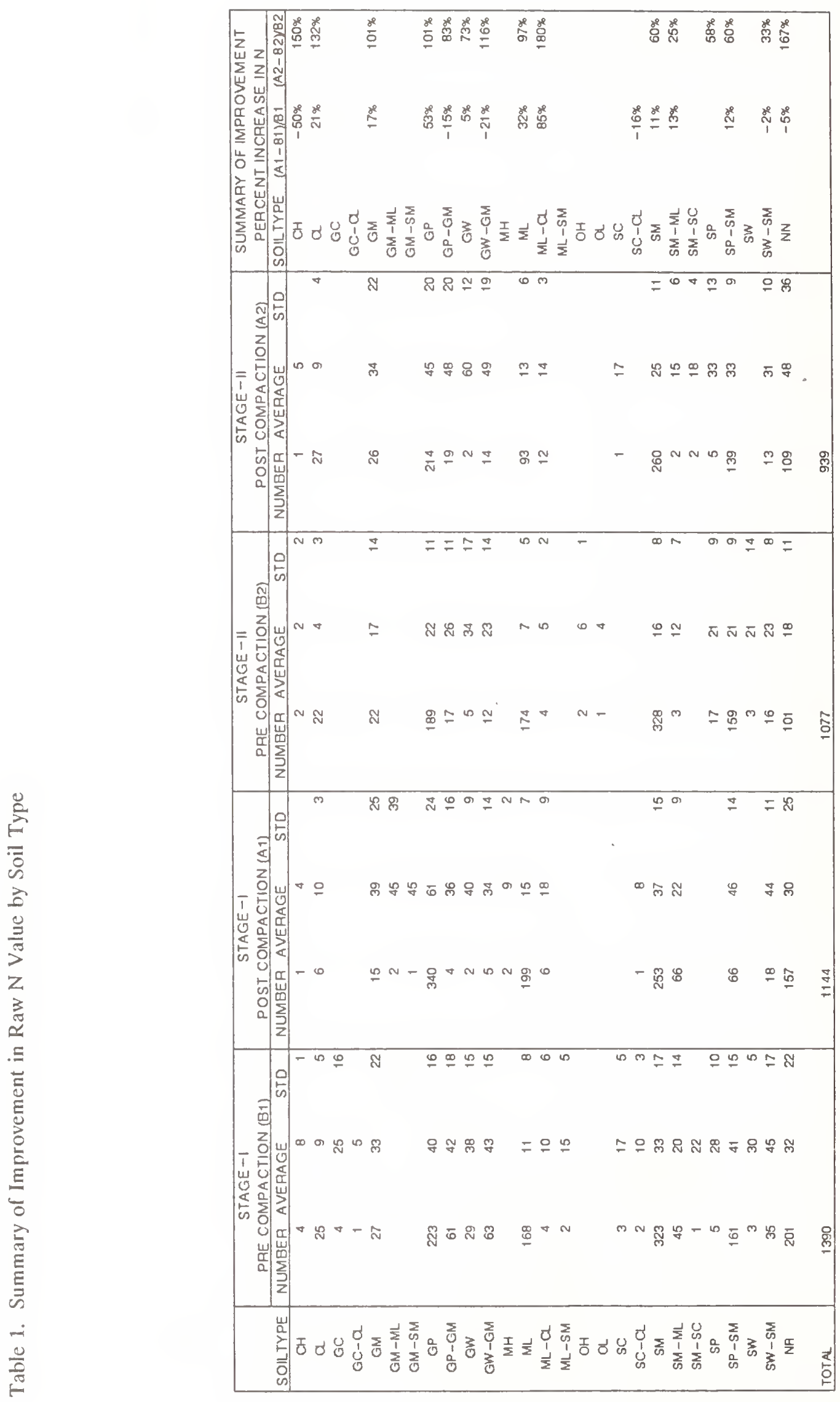


Table 2. Example of SPT Spreadsheet Data - Pre-compaction Stage I

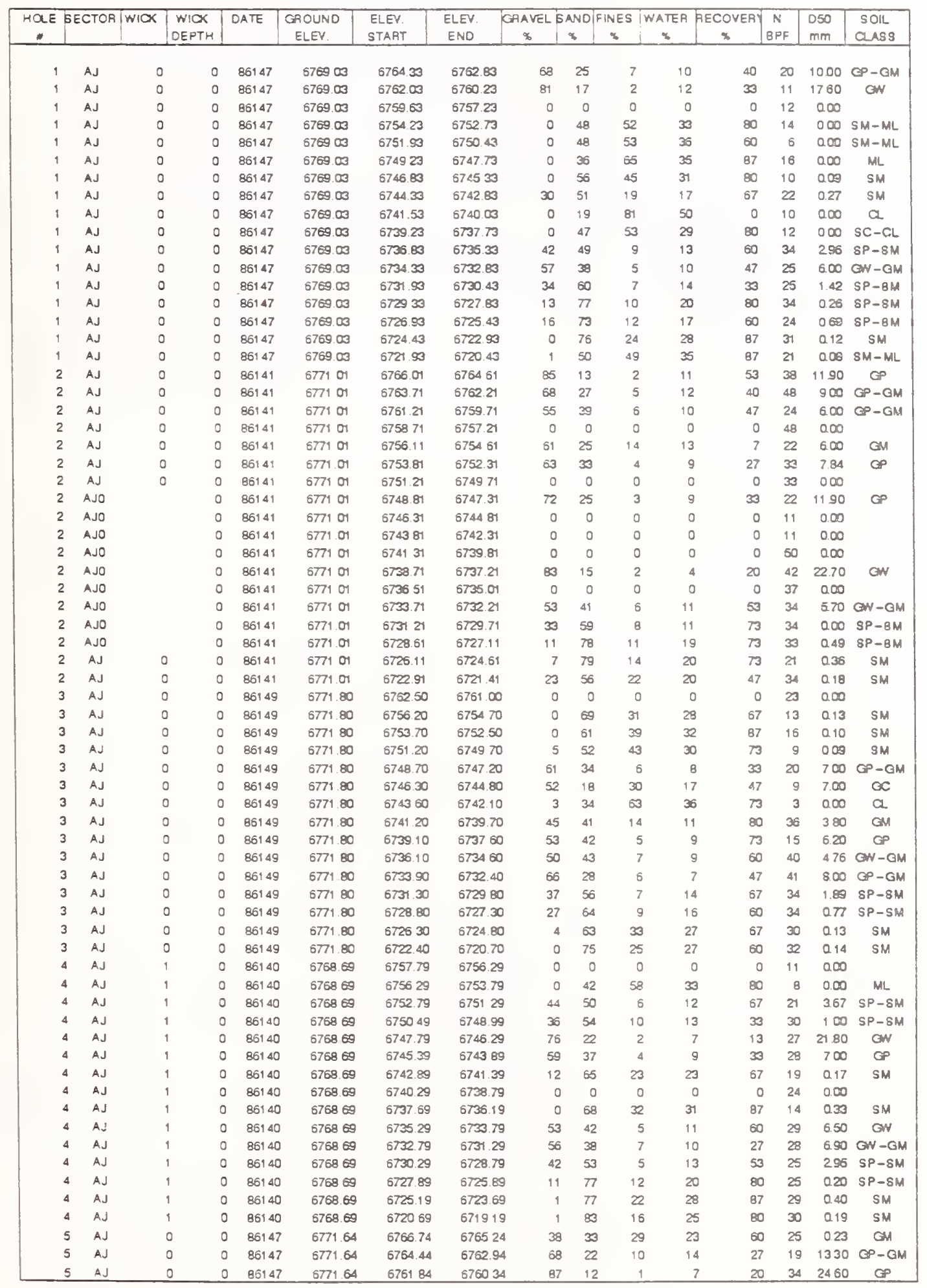




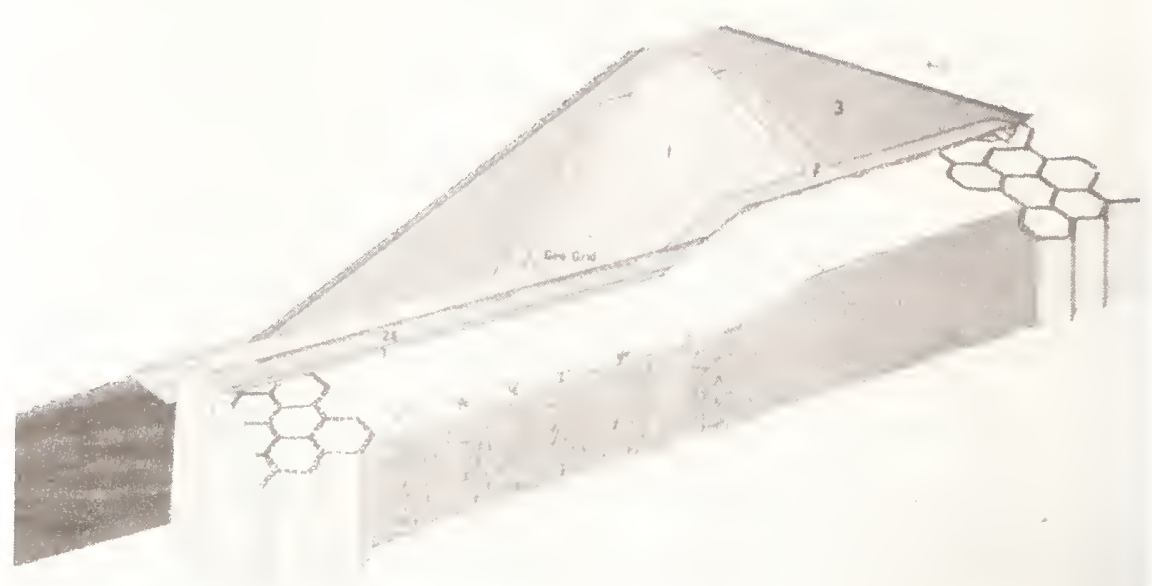

Figure 1. Cross Section of Jackson Lake Dam as Constructed

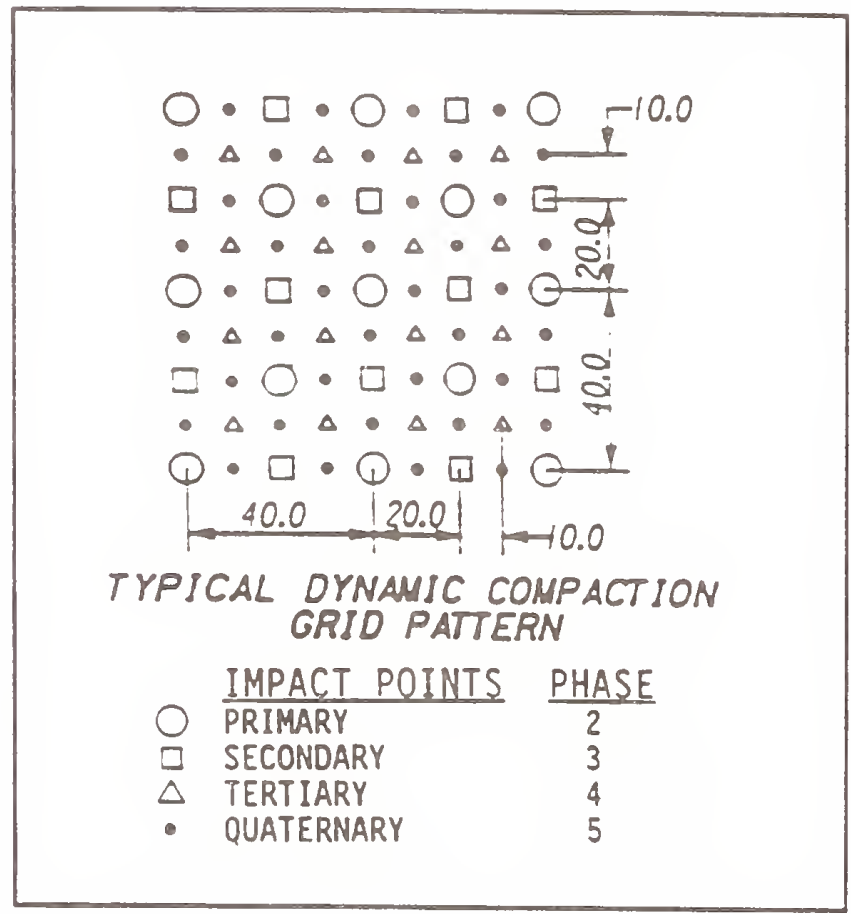

Figure 2. Dynamic Compaction Drop Pattern (Spacing Shown in feet) 


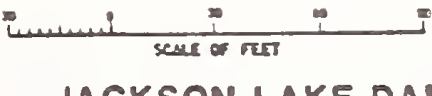

JACKSON LAKE DAM MODIFICATION

STAGE I

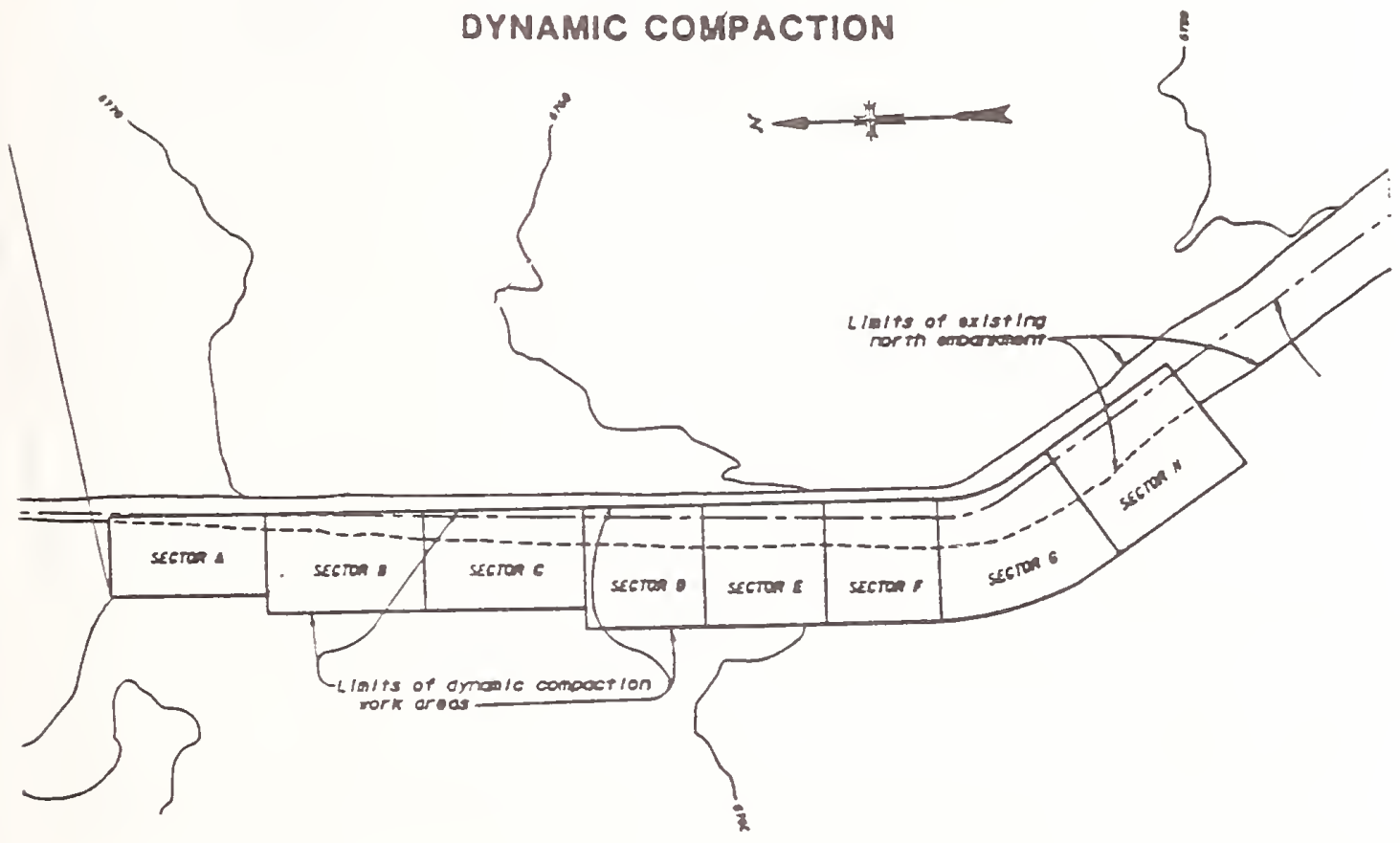

JACKSON LAKE DAM MODIFICATION

STAGE \|

DYNAMIC COMPACTION

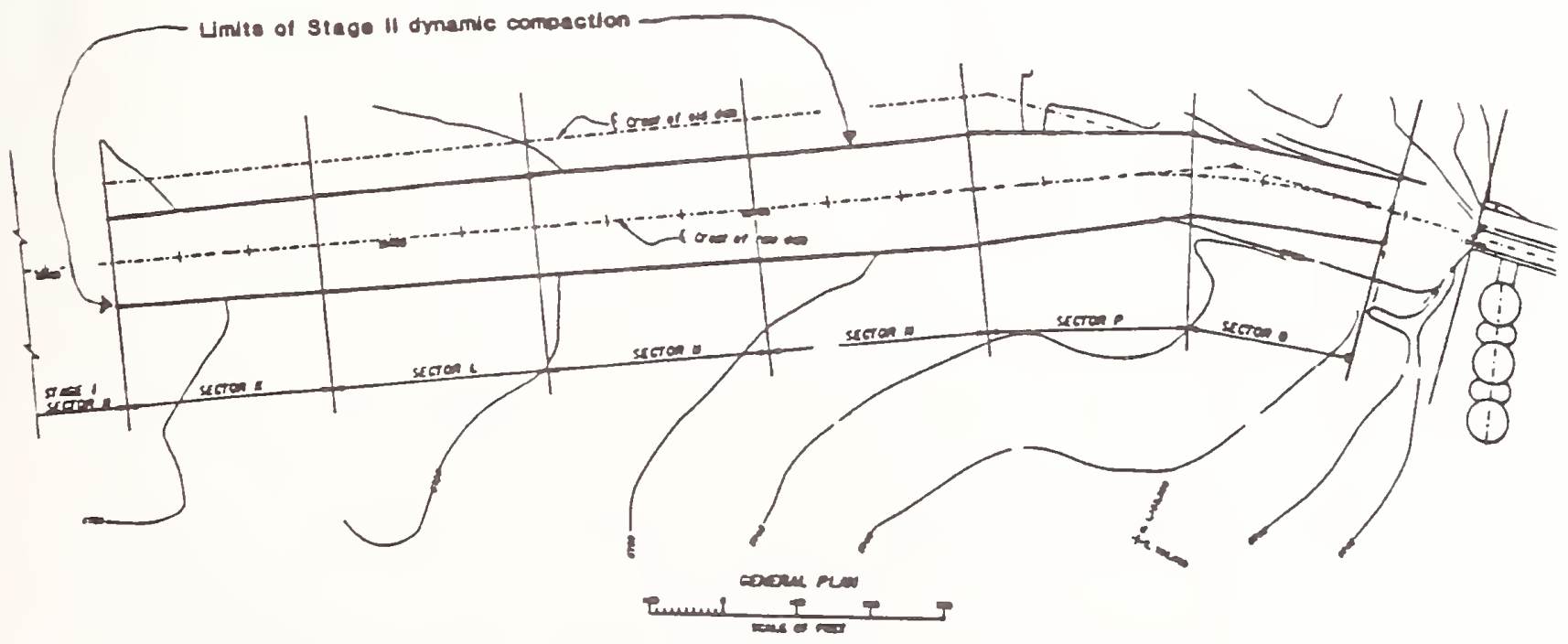

Figure 3. Plan of Stage I and Stage II - Jackson Lake Dam Modification 

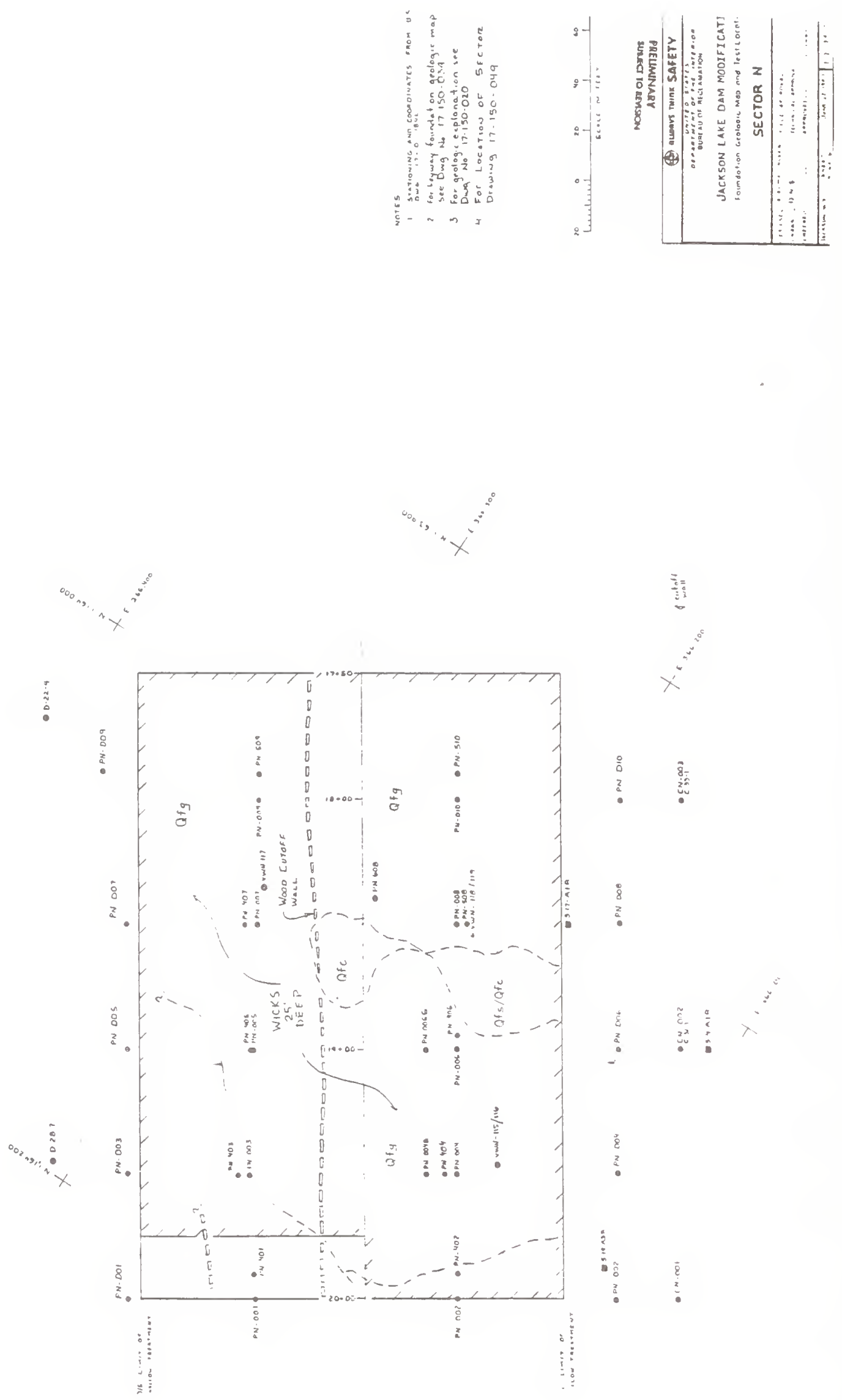

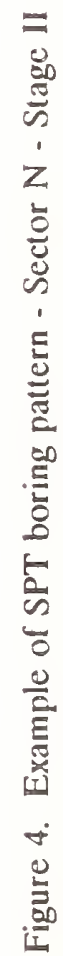


PRESTAGE-I GP

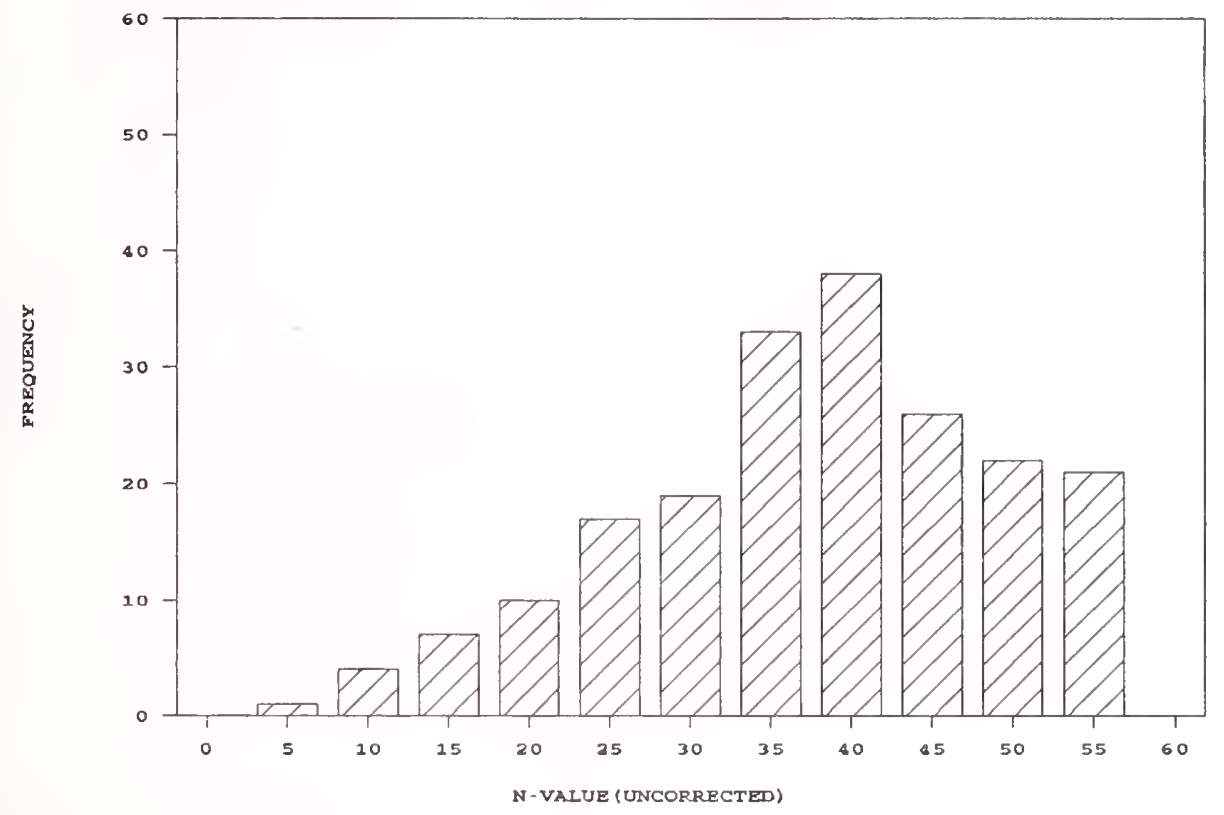

Figure 5. Histogram of raw $\mathrm{N}$ value of GP, precompaction, Stage I

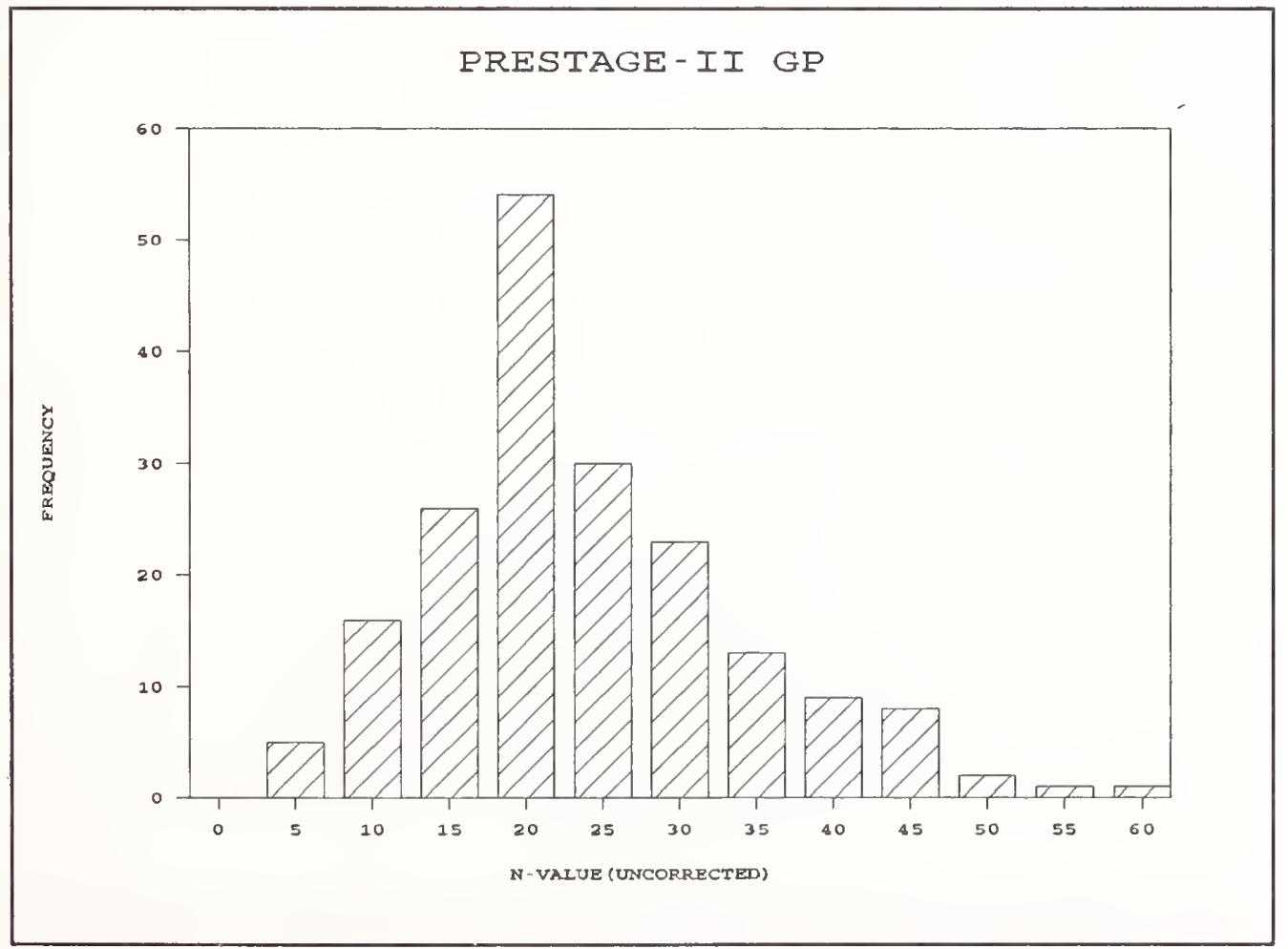

Figure 6. Histogram of raw $\mathrm{N}$ value of GP, precompaction, Stage II 
PRESTAGE-I SP-SM

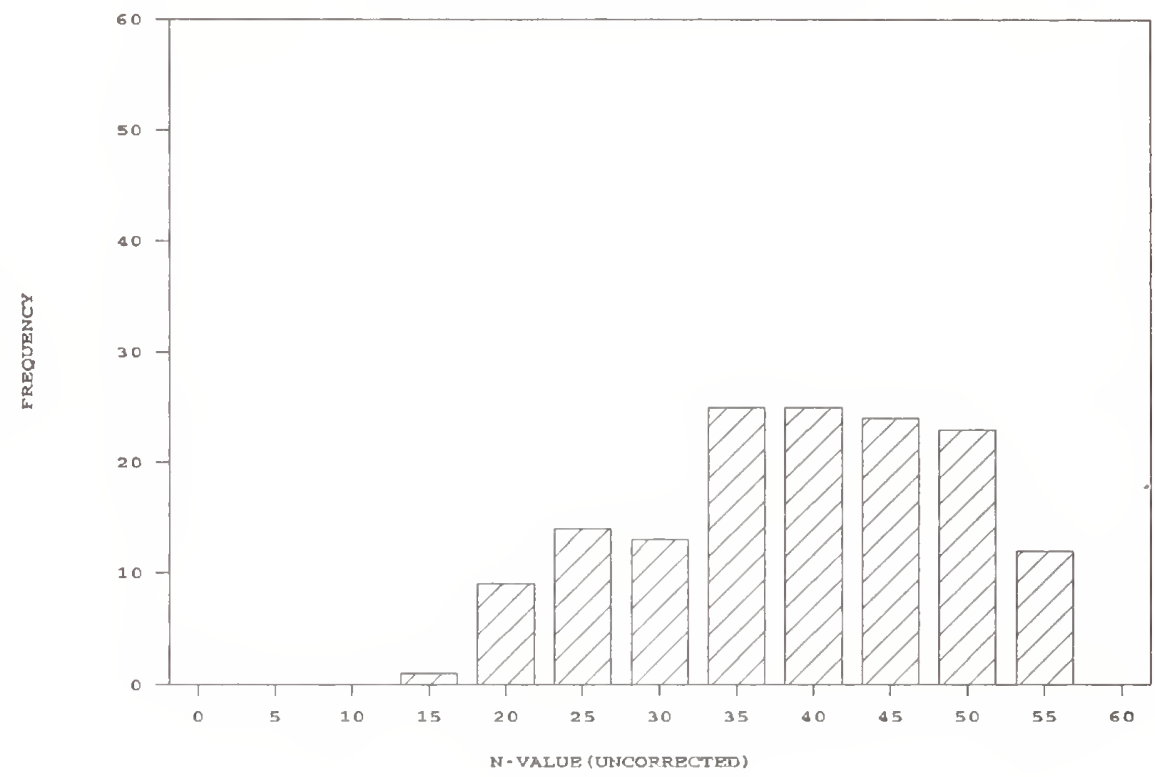

Figure 7. Histogram of raw $\mathrm{N}$ value of SP-SM, precompaction, Stage I

PRESTAGE-II SP-SM

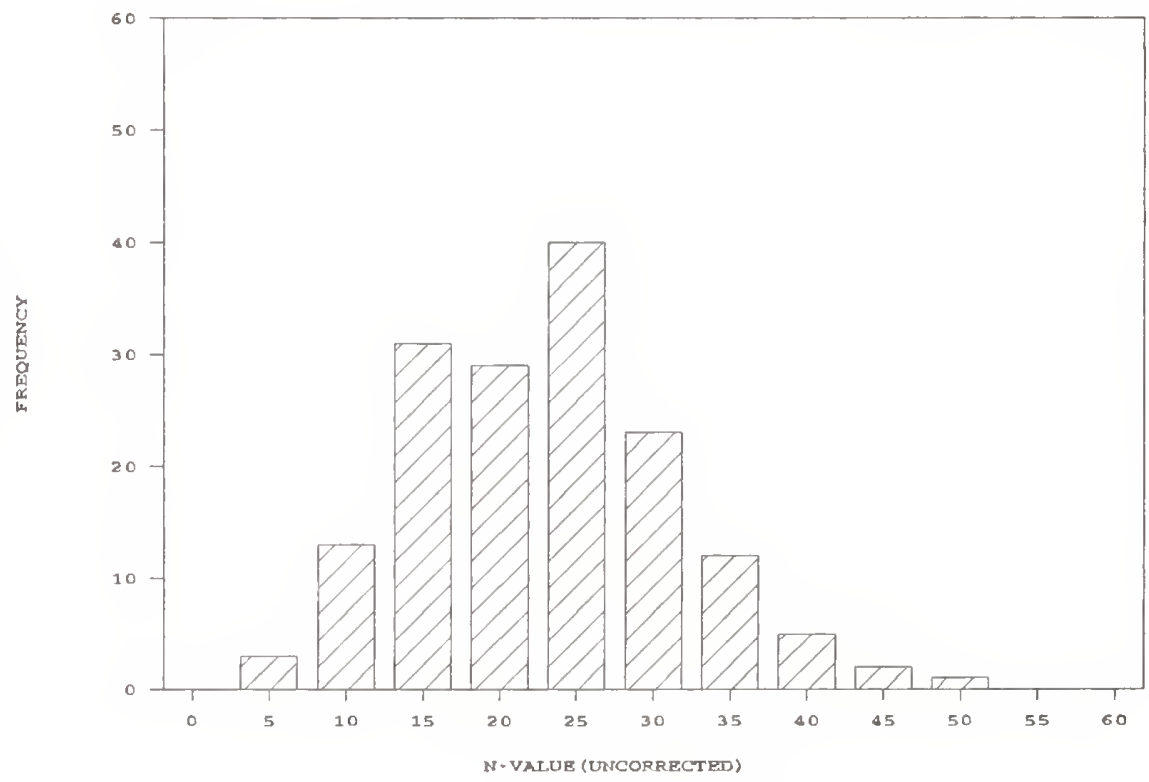

Figure 8. Histogram of raw N value of SP-SM, precompaction, Stage II 


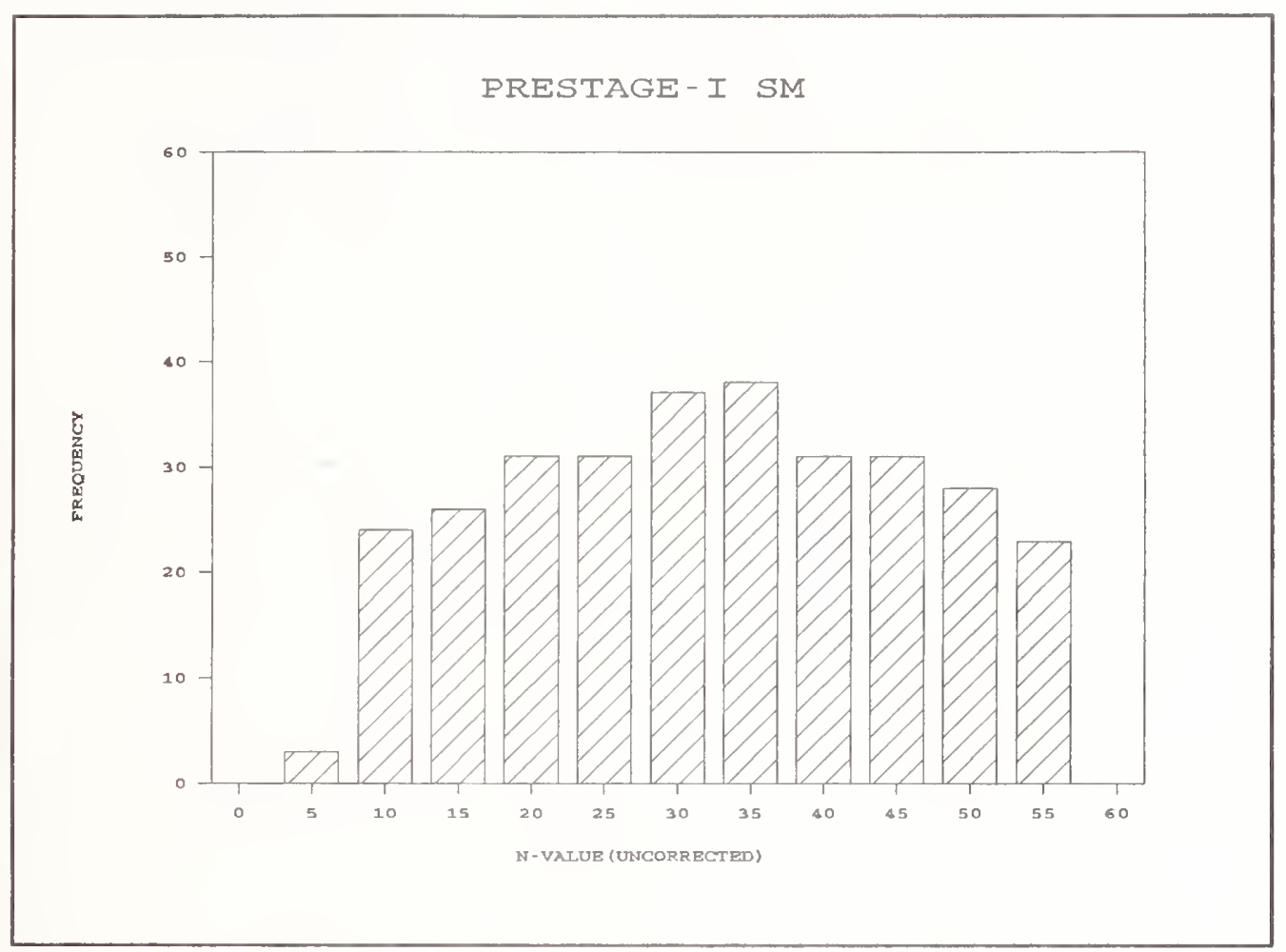

Figure 9. Histogram of raw $\mathrm{N}$ value of SM, precompaction, Stage I

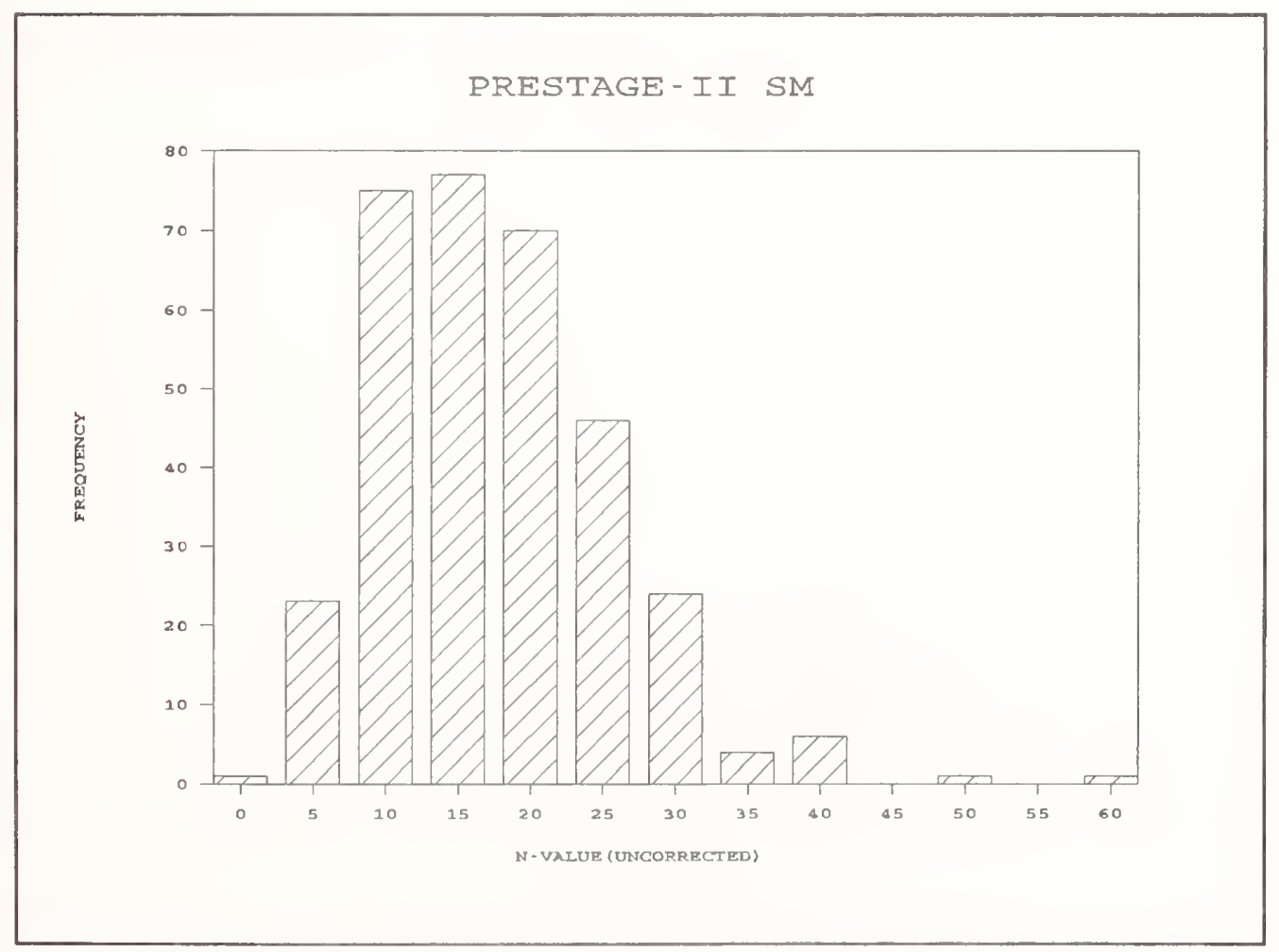

Figure 10. Histogram of raw $\mathrm{N}$ value of SM, precompaction, Stage II 
PRESTAGE - I ML

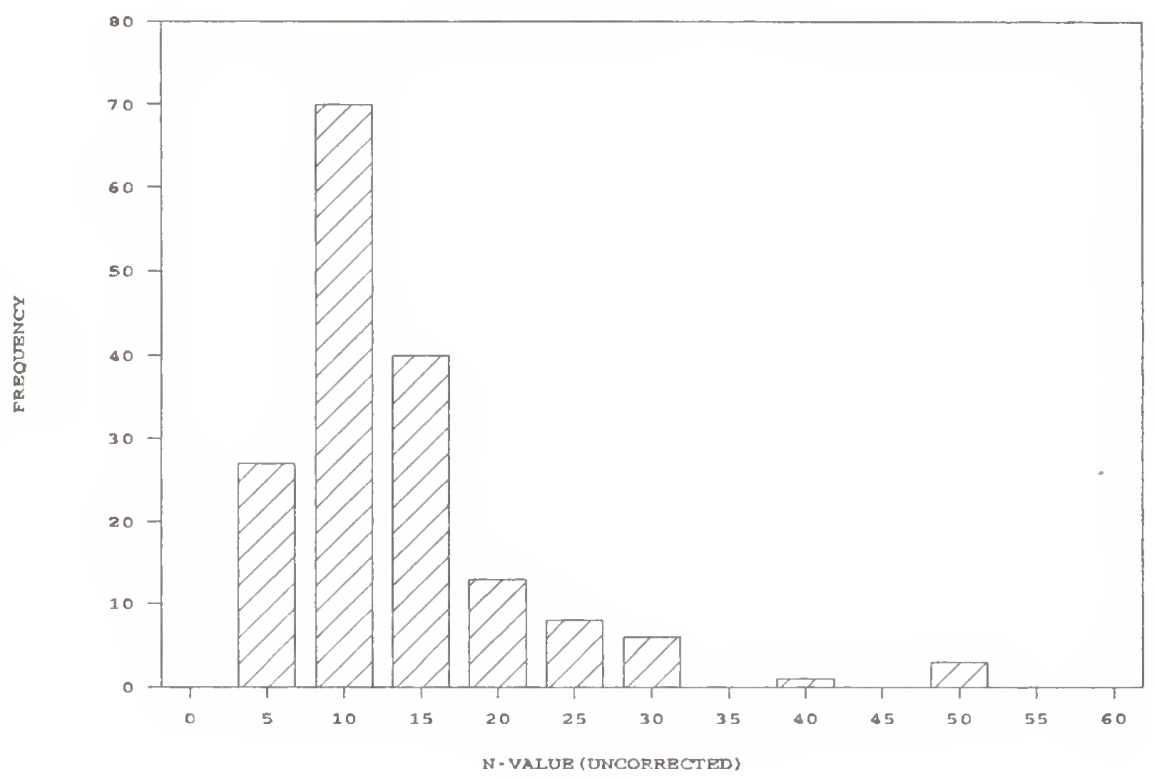

Figure 11. Histogram of raw $\mathrm{N}$ value of $\mathrm{ML}$, precompaction, Stage I

PRESTAGE-II ML

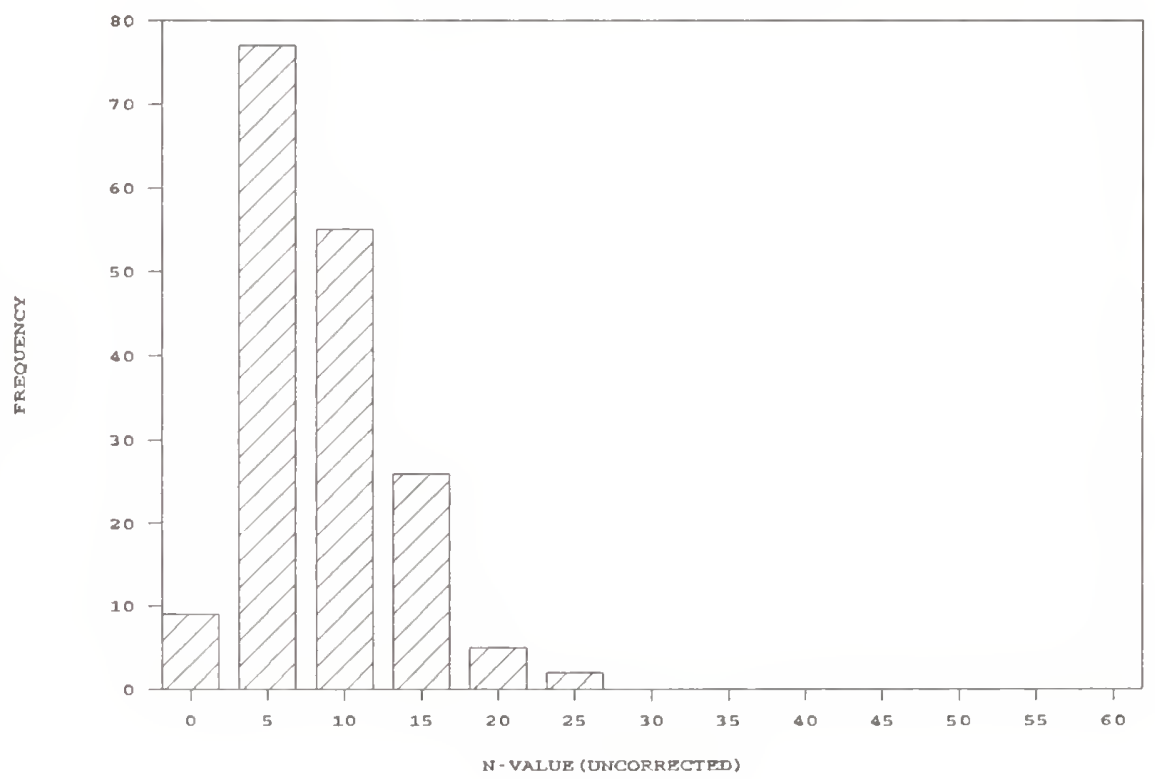

Figure 12. Histogram of raw $\mathrm{N}$ value of $\mathrm{ML}$, precompaction, Stage II 


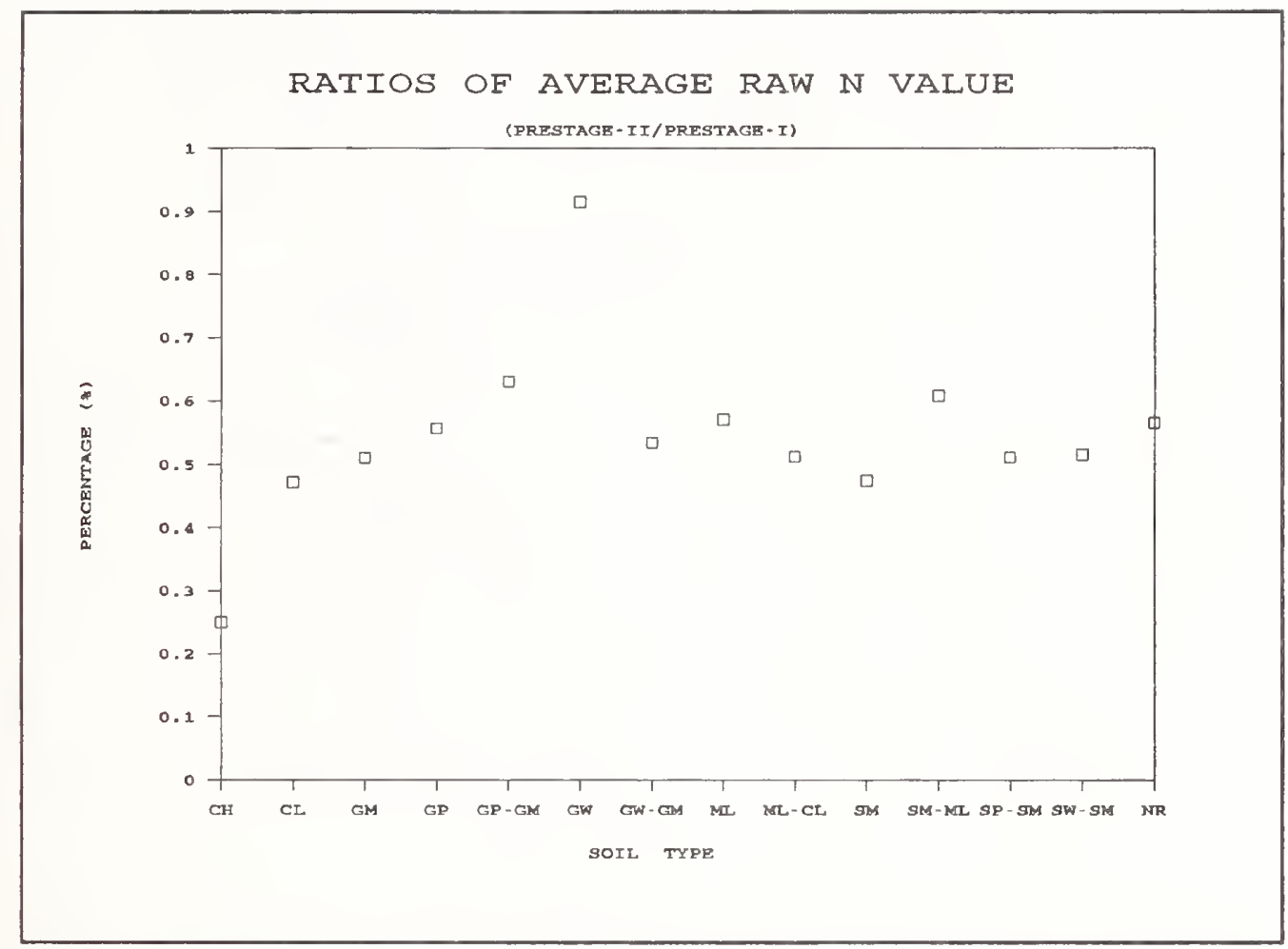

Figure 13. Ratio of average raw $\mathrm{N}$ value of Stage I and II by soil type, precompaction

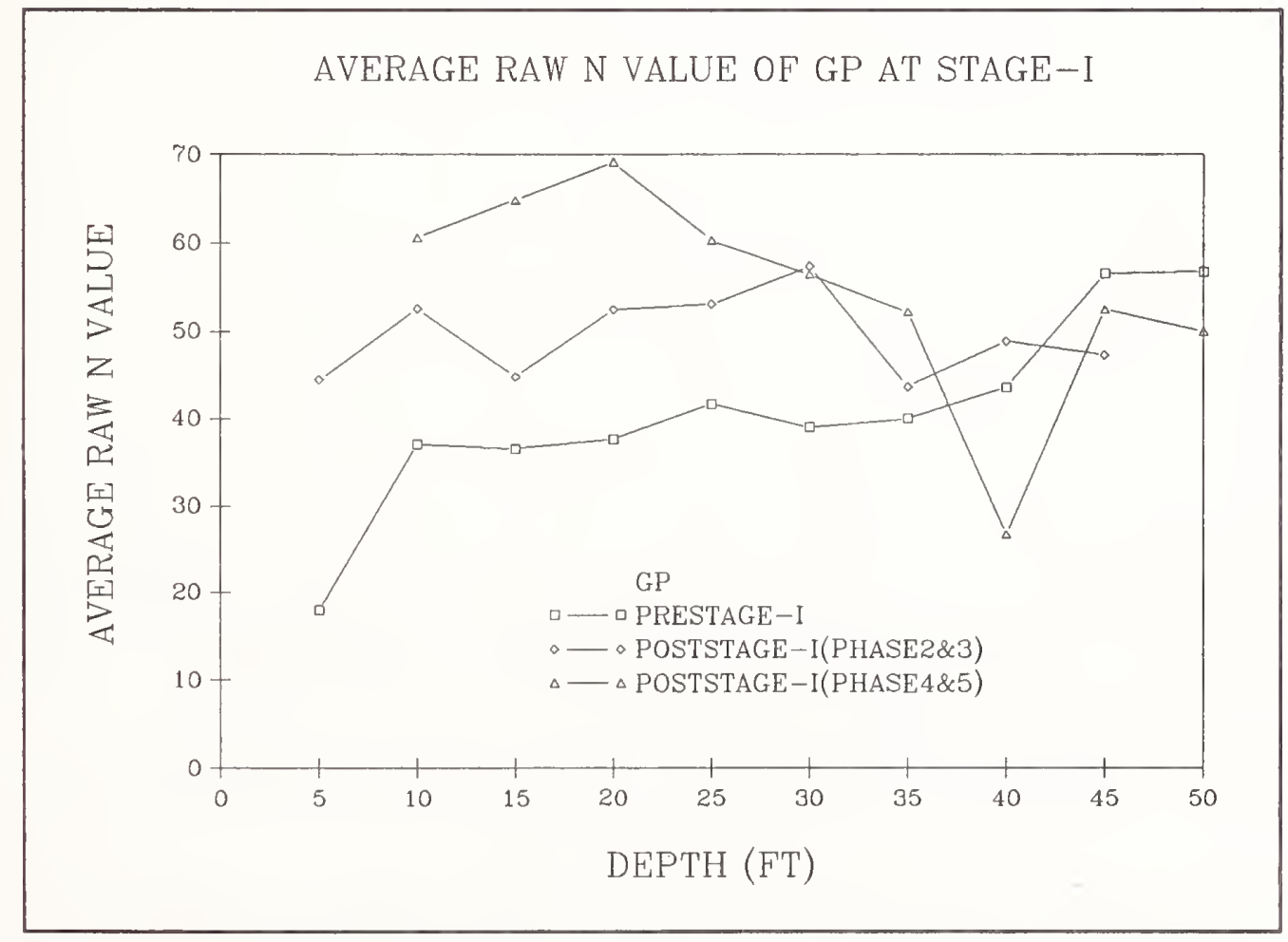

Figure 14. Average raw $\mathrm{N}$ value versus depth, GP soil, Stage I 
AVERAGE RAW N VALUE OF SM AT STAGE-I

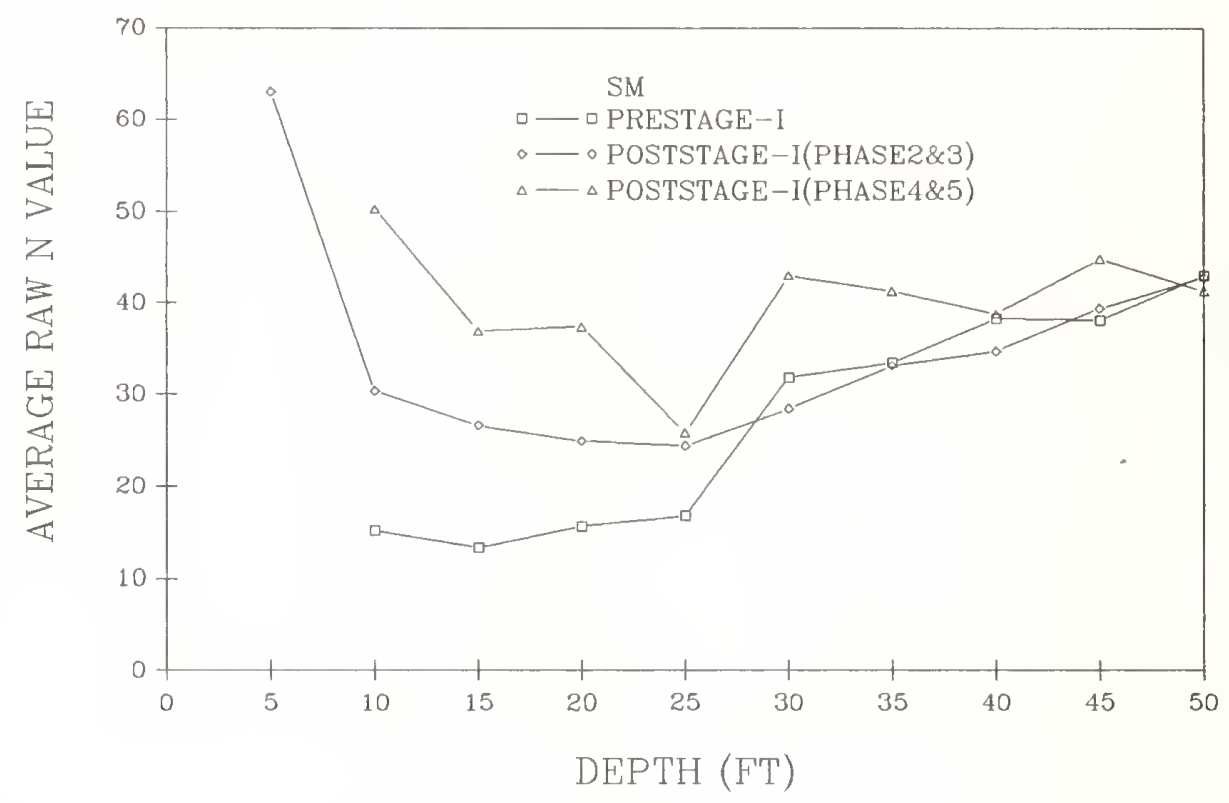

Figure 15. Average raw N value versus depth, SM soil, Stage I

AVERAGE RAW N VALUE OF ML AT STAGE-I

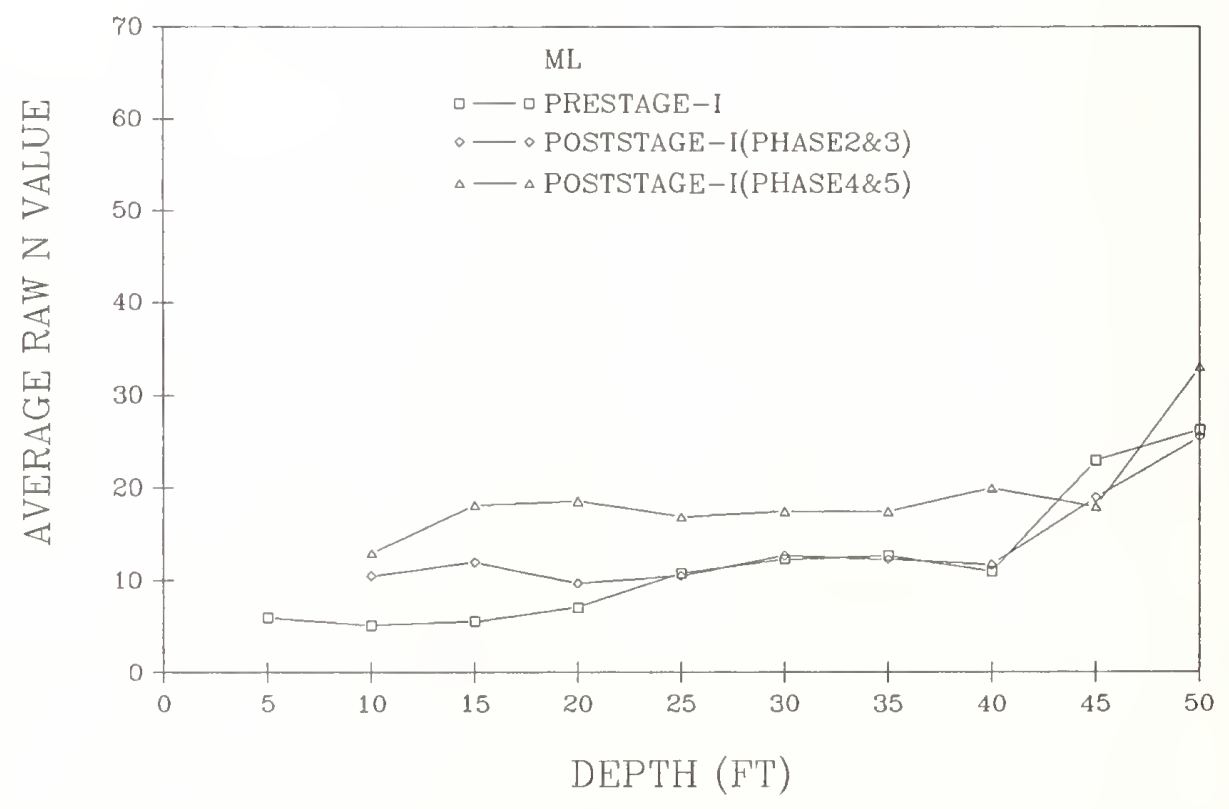

Figure 16. Average raw $\mathrm{N}$ value versus depth, ML soil, Stage I 


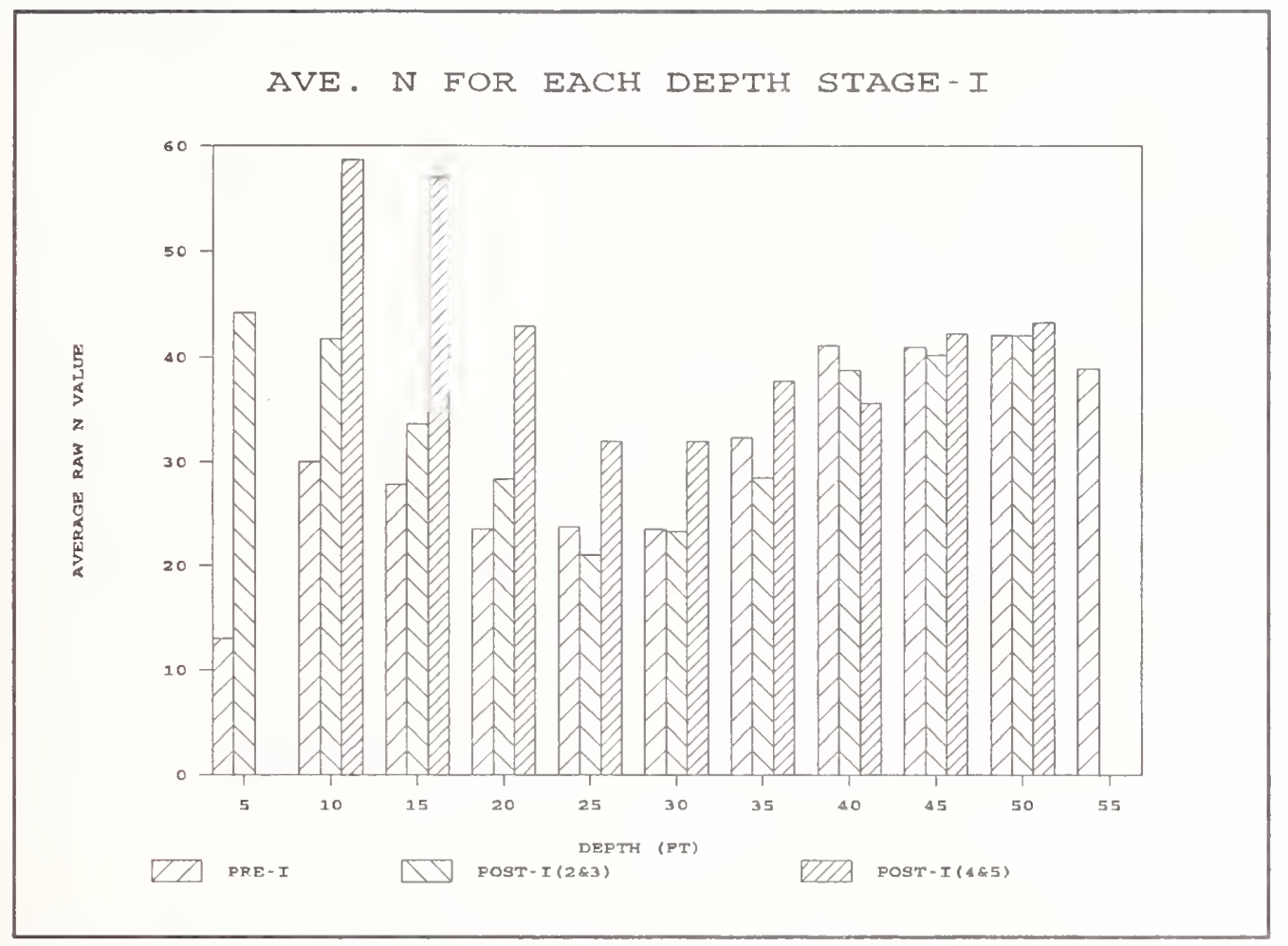

Figure 17. Average raw $\mathrm{N}$ value of all data versus depth, Stage I

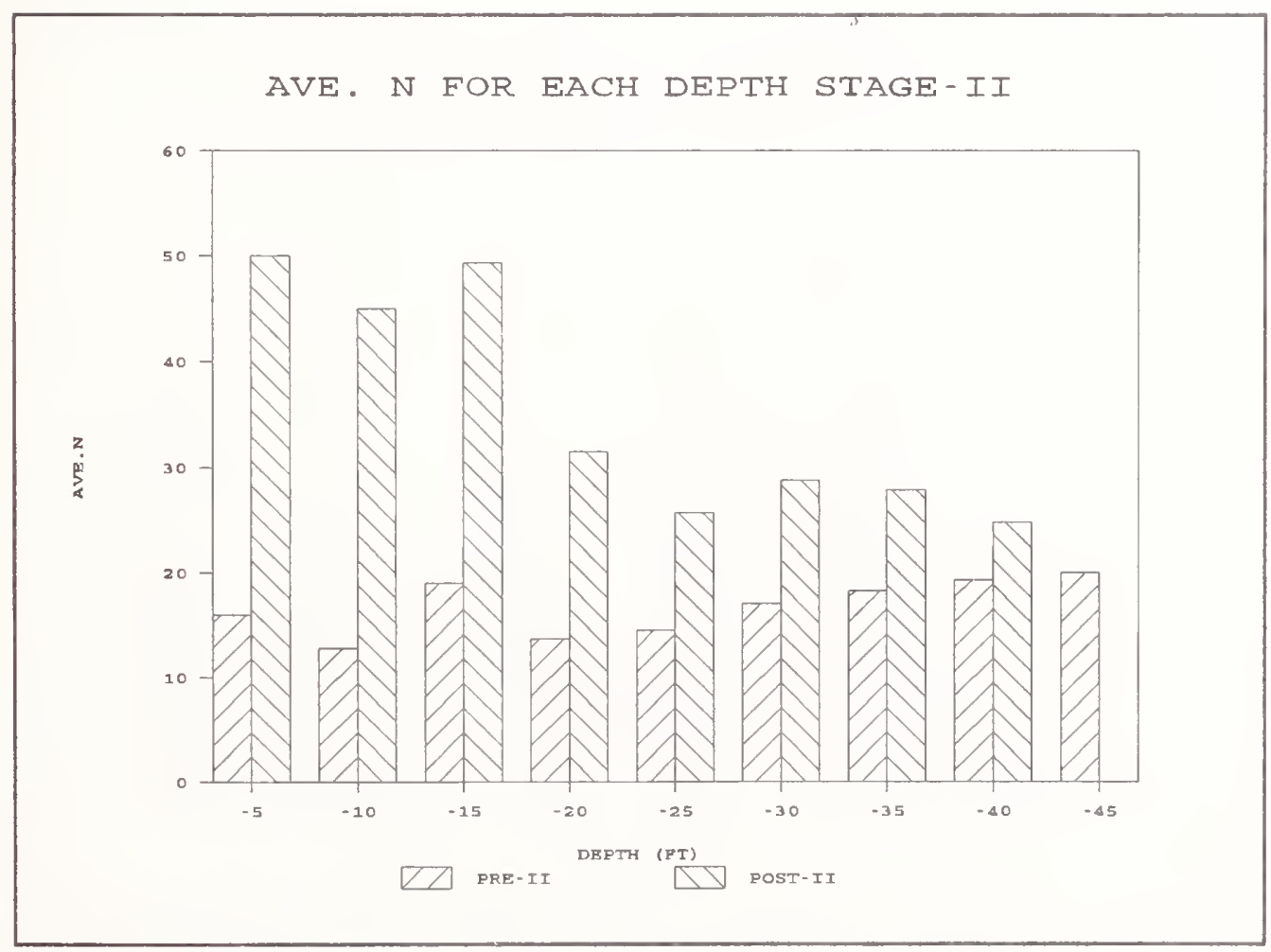

Figure 18. Average raw $\mathrm{N}$ value of all data versus depth, Stage II 


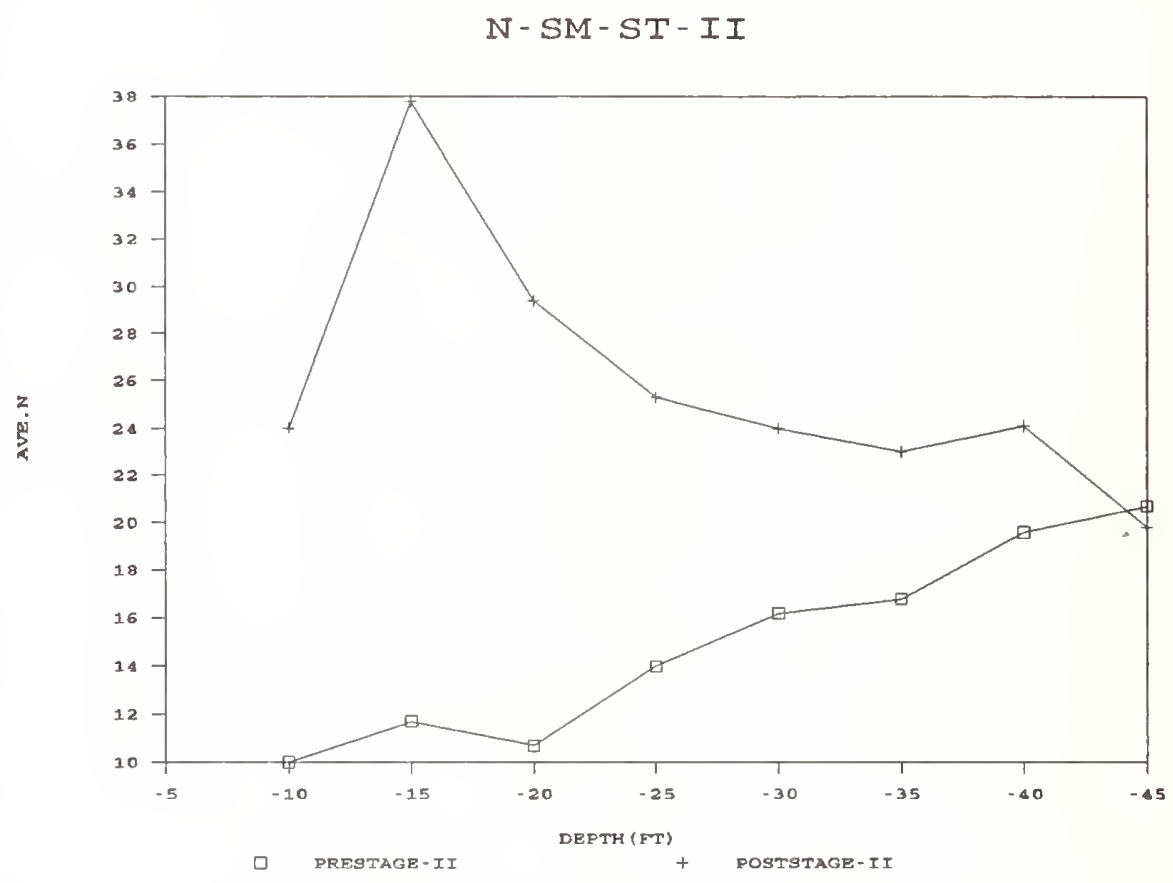

Figure 19. Average raw $\mathrm{N}$ value versus depth, SM soil, Stage II

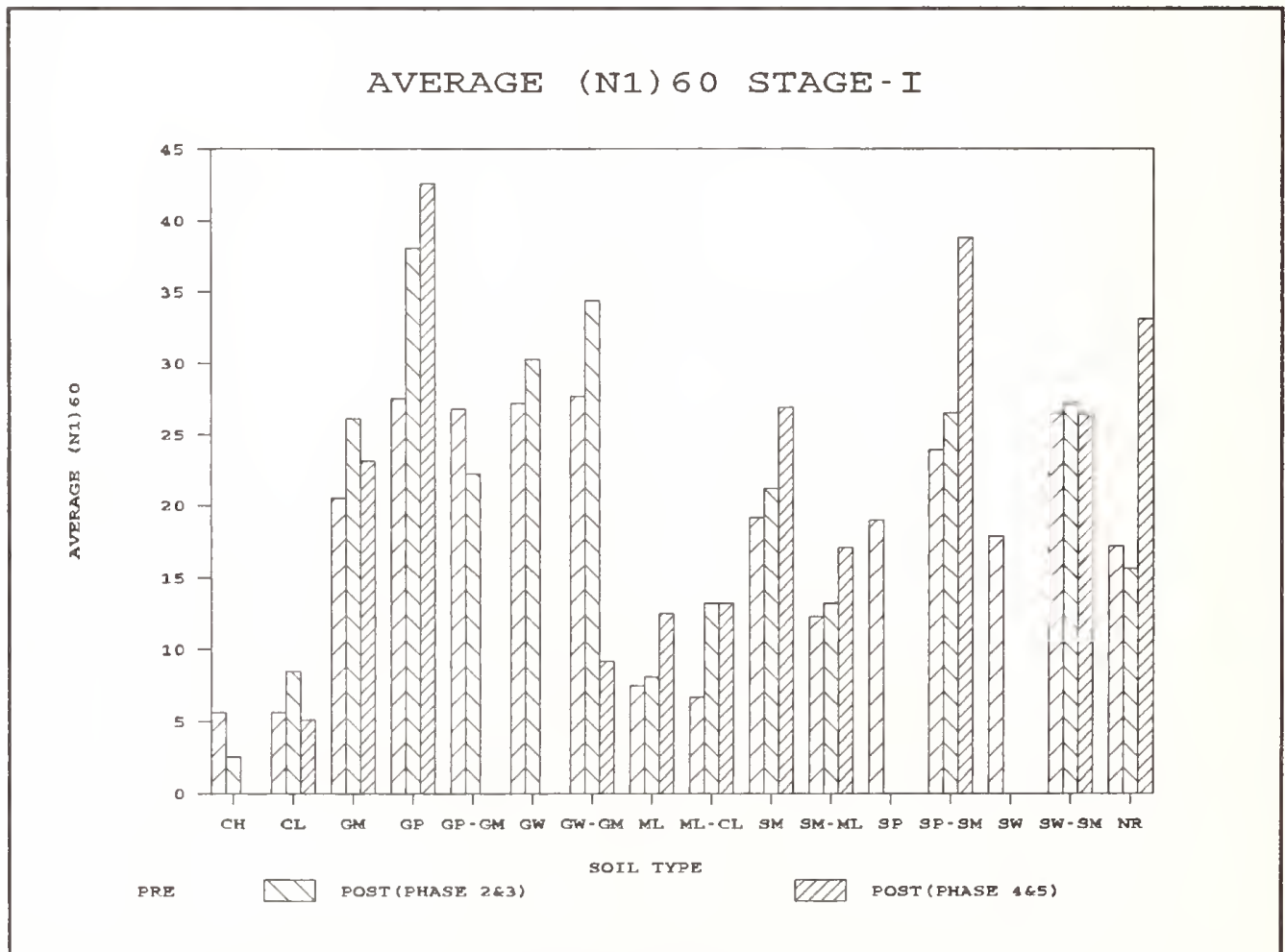

Figure 20. Average $\mathrm{N}_{160}$ value for soil types, Stage I 
(N1) 60 (STAGE-II)

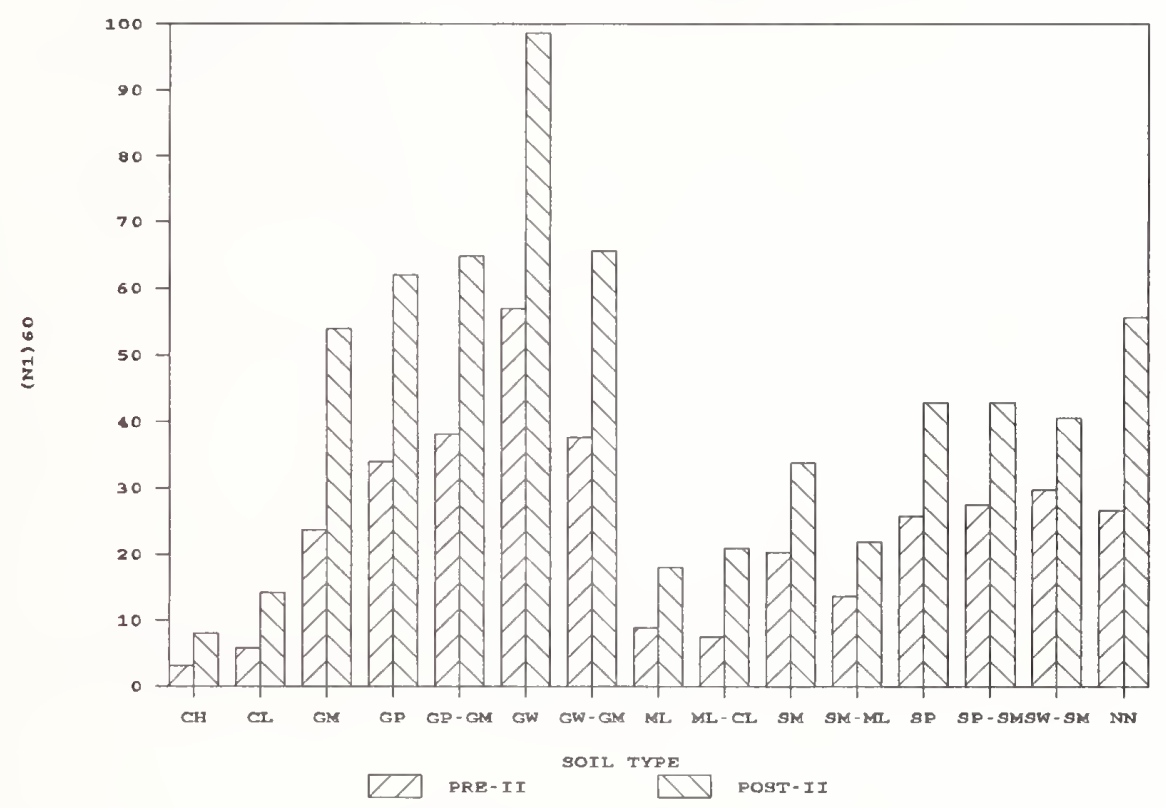

Figure 21. Average $\mathrm{N}_{160}$ value for soil types, Stage II

COMPARISON OF HISTOGRAMS OF (N1)6O VALUE, SP, SP-SM STAGE-I BEFORE AND AFTER DYNAMIC COMPACTION

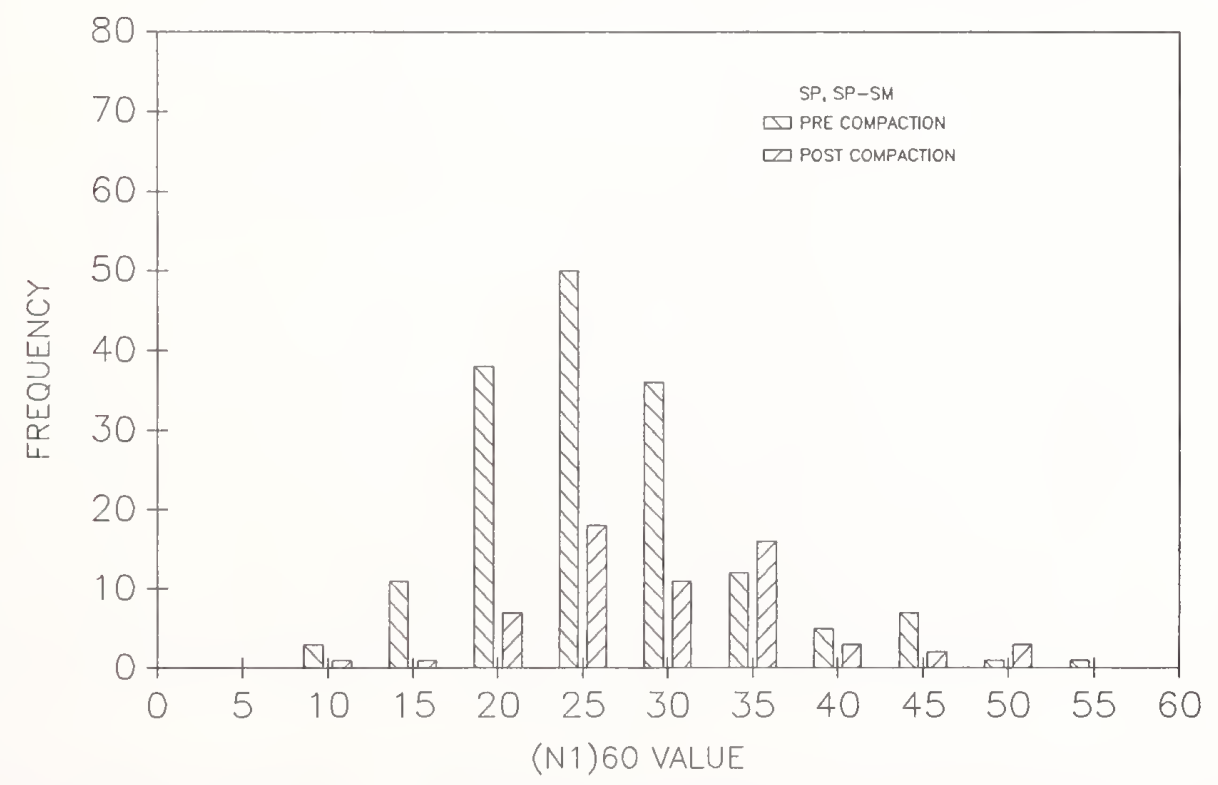

Figure 22. Distribution of $\mathrm{N}_{160}$ values of SP and SP-SM sands, Stage I 
COMPARISON OF HISTOGRAMS OF (N1)60 VALUE, SP, SP-SM STAGE-II BEFORE AND AFTER DYNAMIC COMPACTION

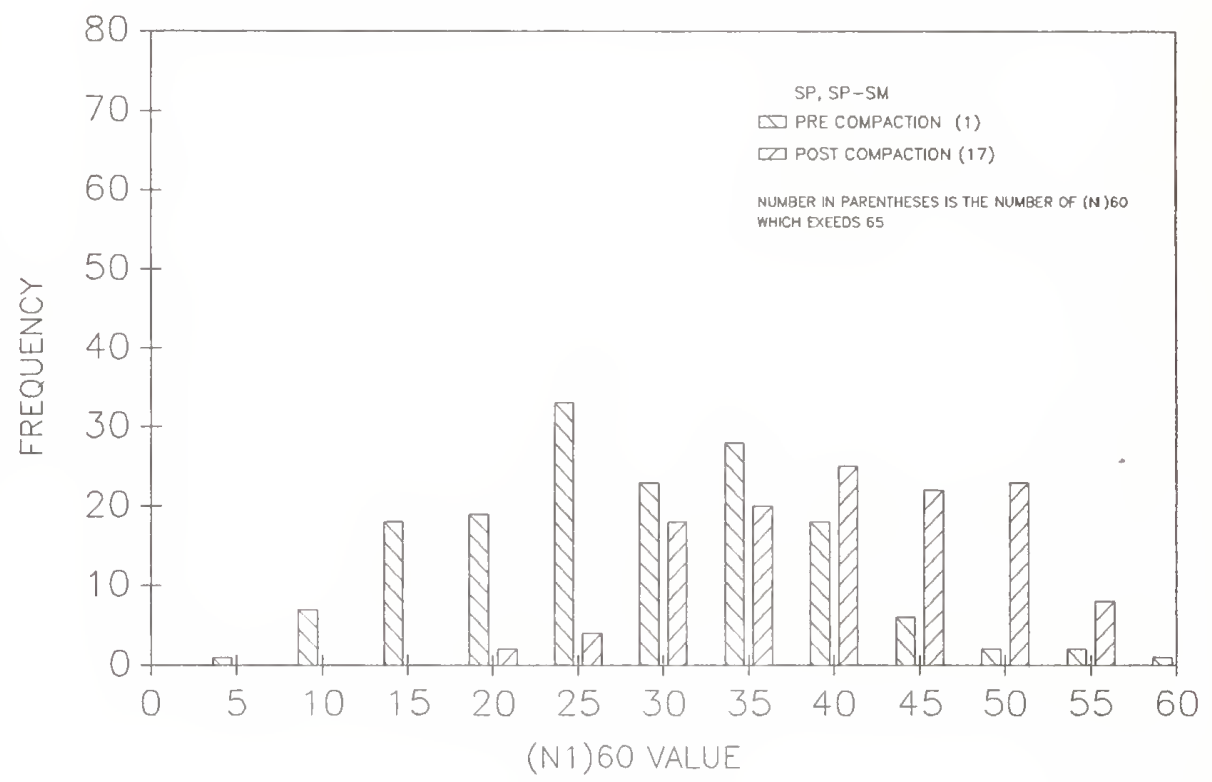

Figure 23. Distribution of $\mathrm{N}_{160}$ values of SP and SP-SM sands, Stage II

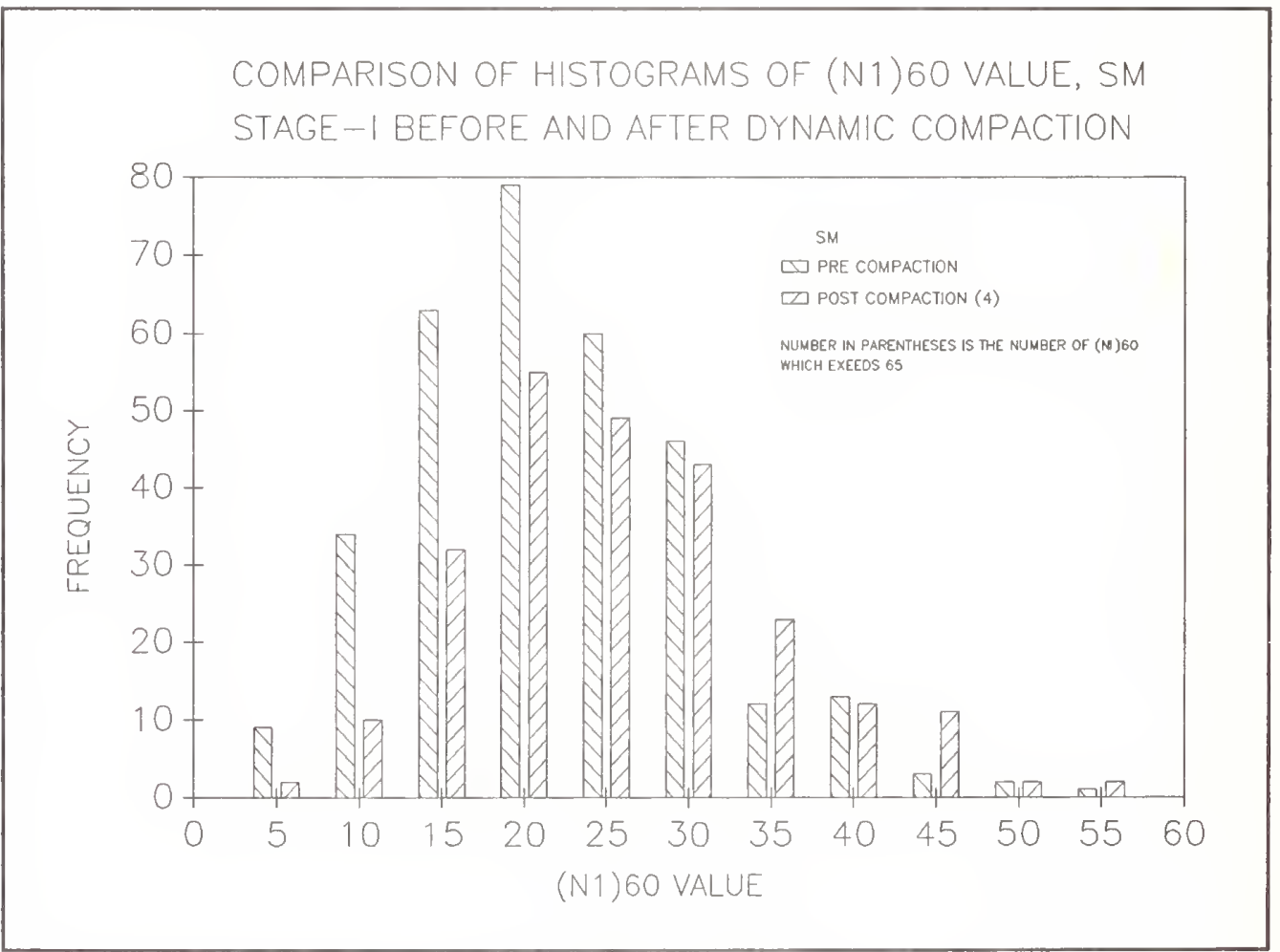

Figure 24. Distribution of $\mathrm{N}_{160}$ values of SM sands, Stage I 


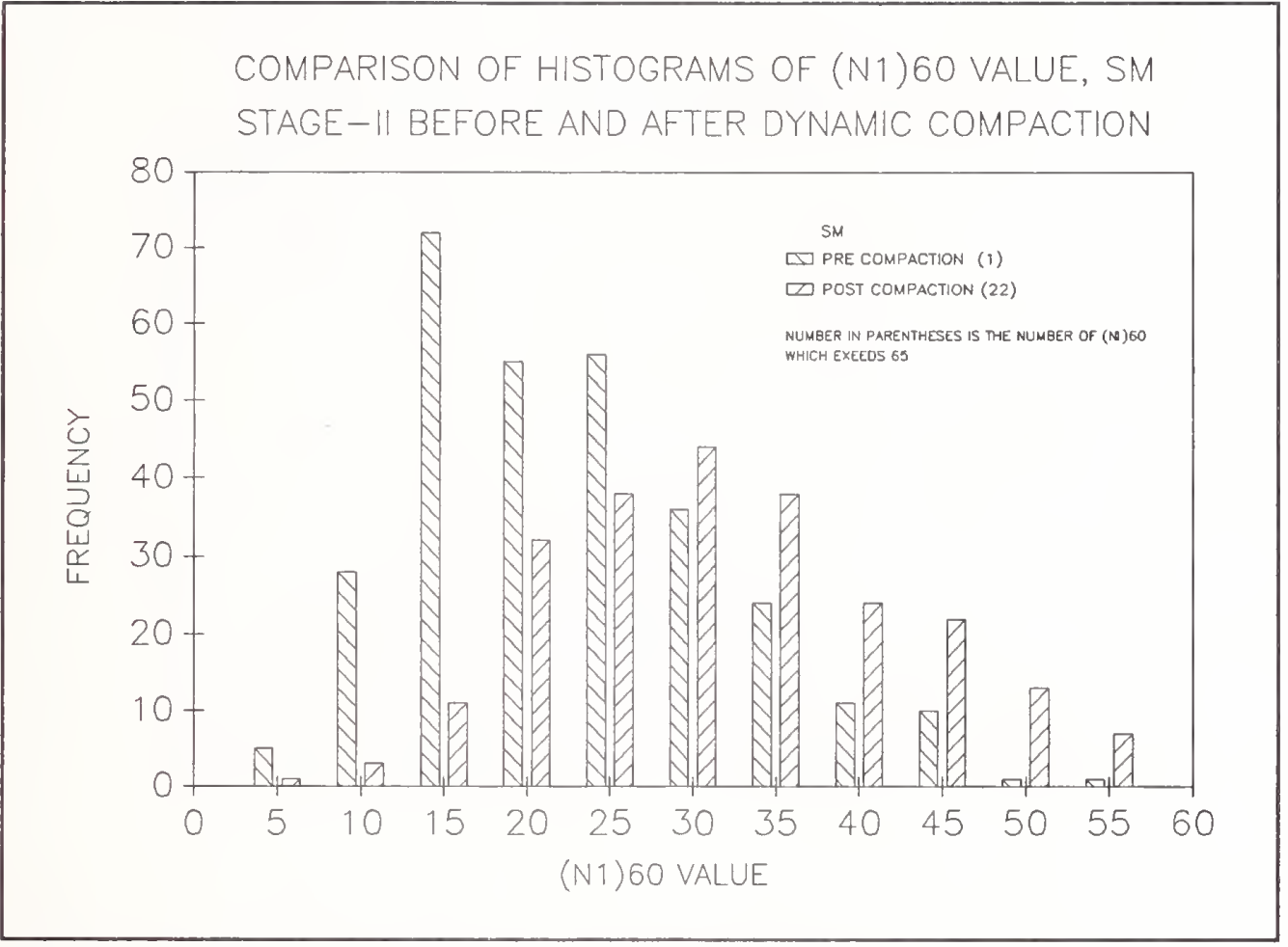

Figure 25. Distribution of $\mathrm{N}_{160}$ values of SM sands, Stage II

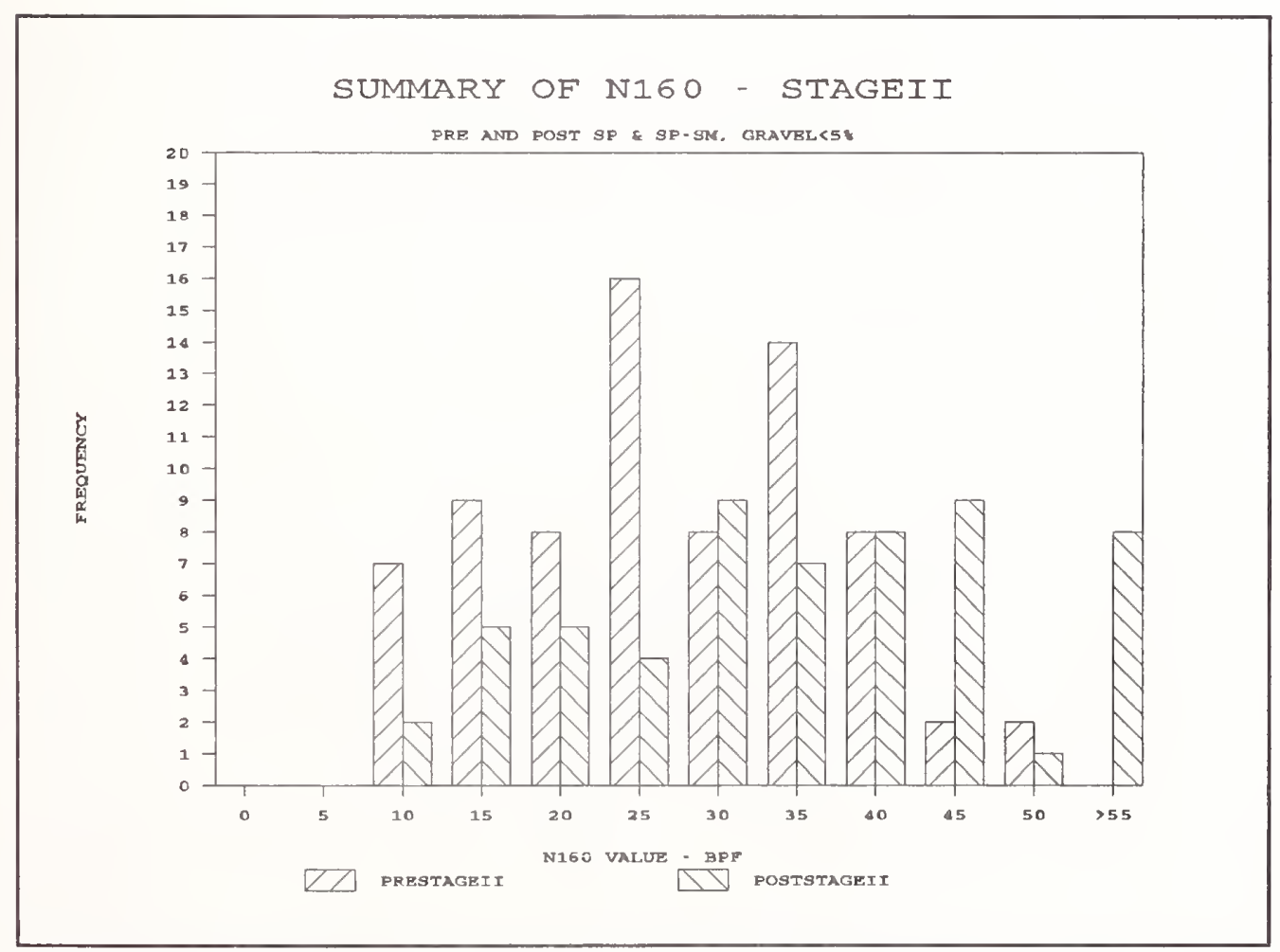

Figure 26. Distribution of $\mathrm{N}_{160}$ values for SP and SP-SM sands with gravel content less than 5 percent, Stage II 


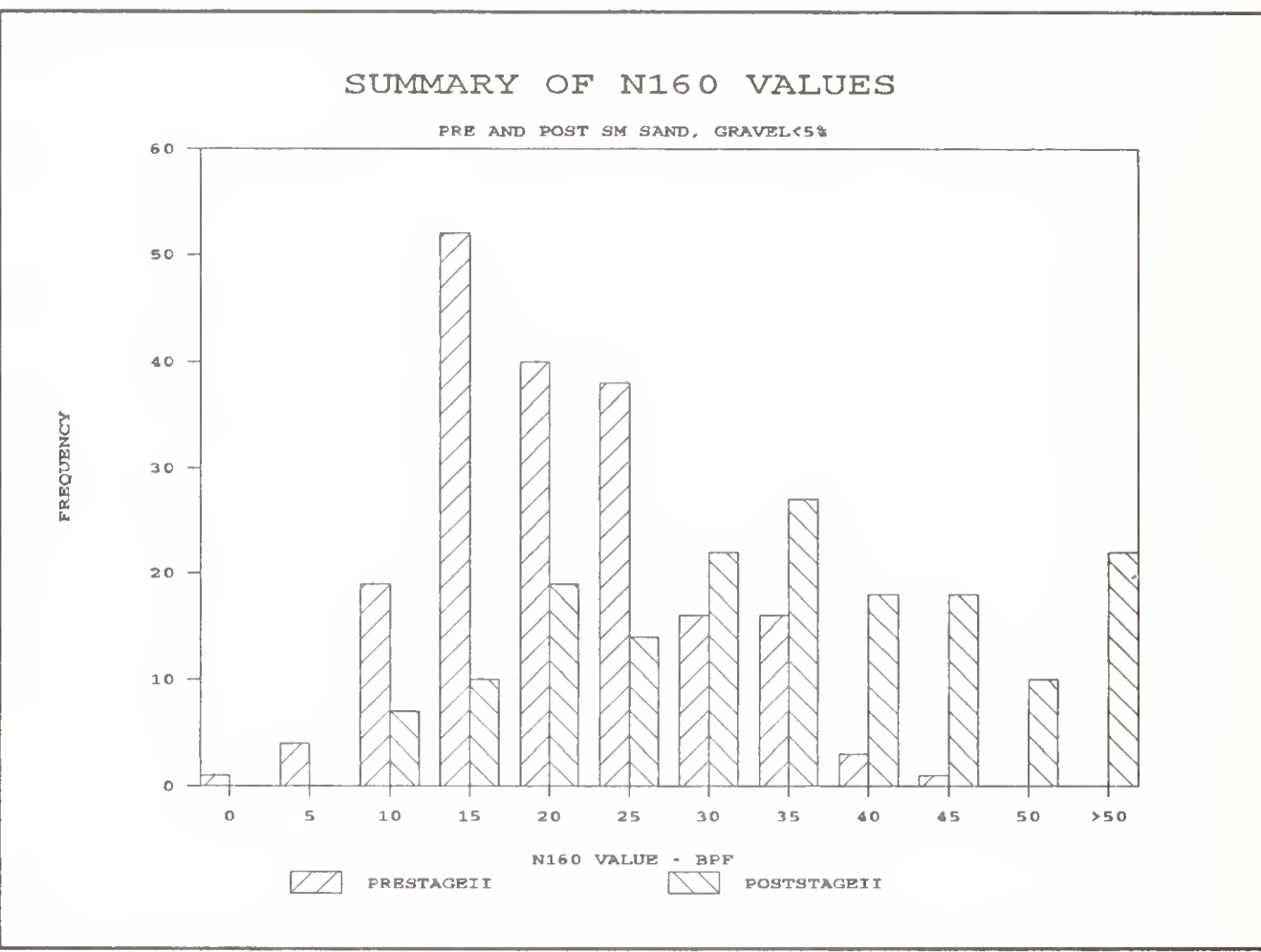

Figure 27. Distribution of $\mathrm{N}_{160}$ values for $\mathrm{SM}$ sands with gravel content less than 5 percent, Stage II

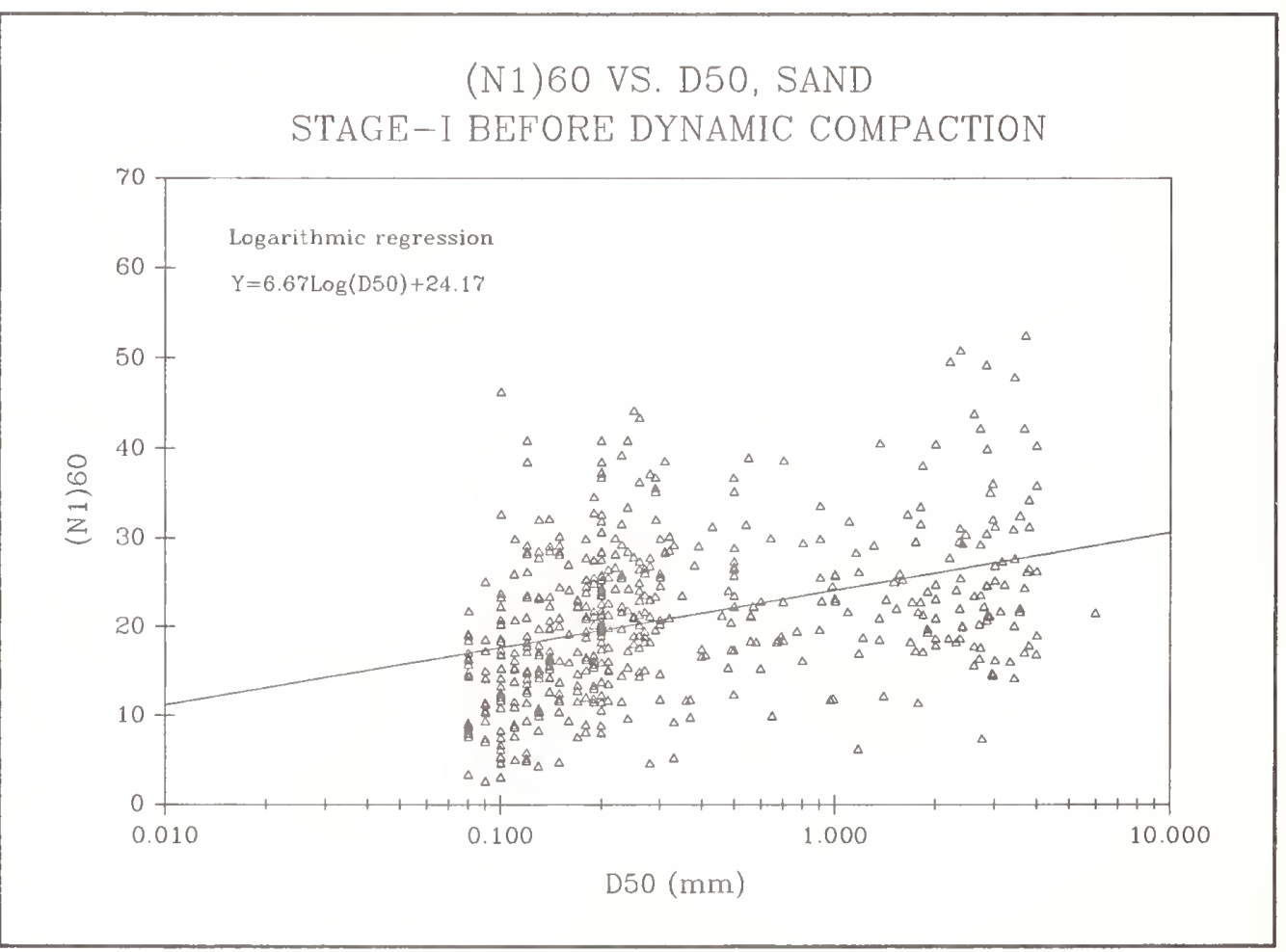

Figure 28. $\mathrm{N}_{160}$ values versus $\mathrm{D}_{50}$ for sands, Pre-compaction, Stage I. 


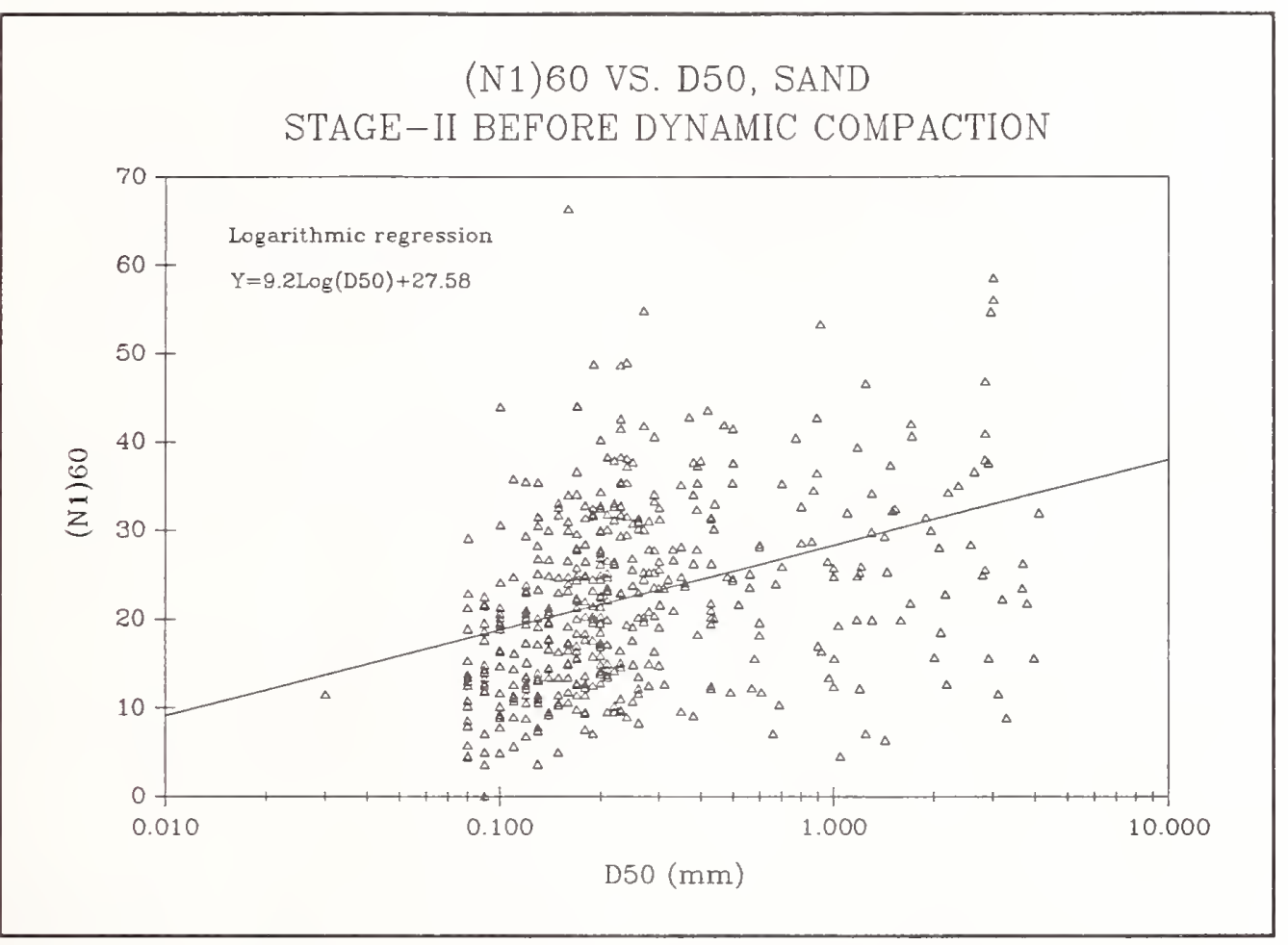

Figure 29. $\mathrm{N}_{160}$ values versus $\mathrm{D}_{50}$ for sands, Pre-compaction, Stage II.

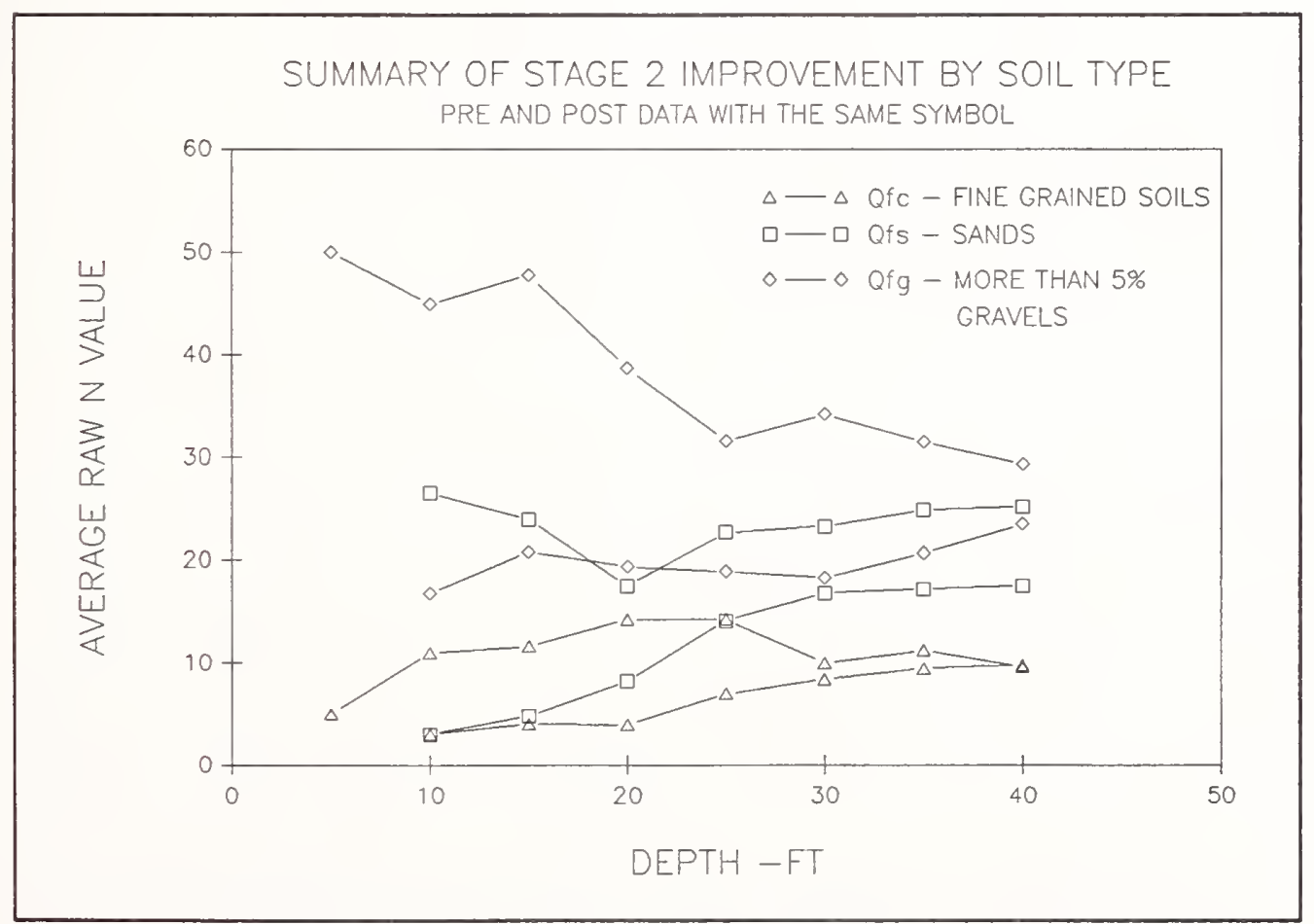

Figure 30. Stage II soil improvement by geologic grouping. 


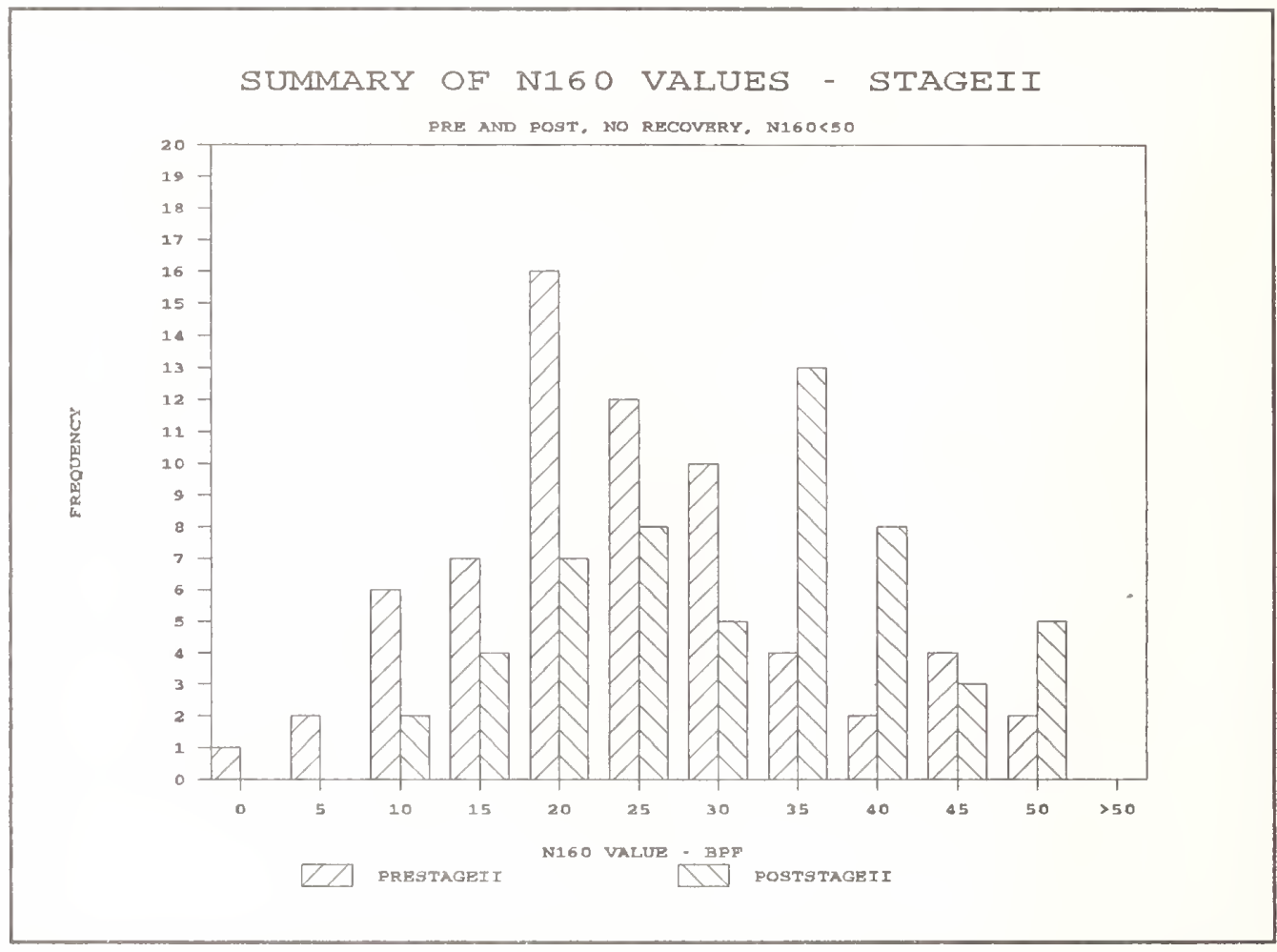

Figure 31. Distribution of $\mathrm{N}_{160}$ values of No Recovery, Stage II.

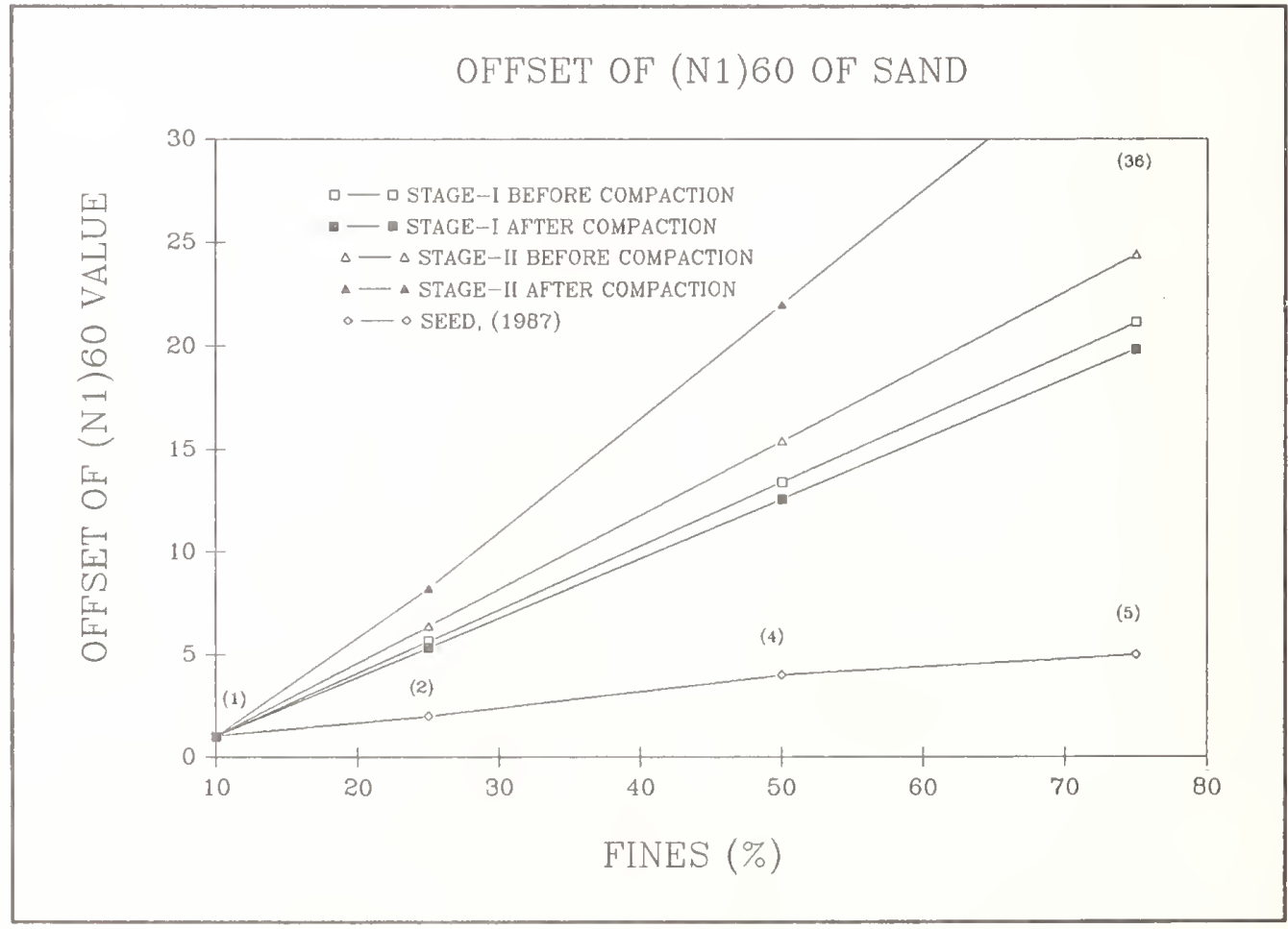

Figure 32. Offset of $\mathrm{N}_{160}$ values versus fines content. 
Yukitake SHIOI*1, Michio OKAHARA*2, Jiro FUKUI*3, Syoji TAKAGI*4

[Abstract]

In this report, torsional resistance of a multi-column foundation to eccentric horizontal load is reviewed. To rsional resistance characteristics were clarified by means of loading tests at fields and in laboratories.

[Key words]

Multi-column foundation, Eccentric load, Torsional resistance, Inclined pile, Field test, Model test

\section{Introduction}

The multi-column foundation method is economical and easy to execute when foundations are to be installed in the sea or in a lake with considerable water depth. (Fig. 1) However, when the free length of a pile is long due to the deep water. the displacement of a slab caused by horizonta]. forces is large. Therefore, it becomes necessary to install quite a few piles to keep the displacement within allowable tolerances. It was previously reported that the use of inclined piles in combination with vertical piles is very effective in solving this problem, in the report on "Vibration characteristics of multicolumn foundation with inclined piles during earthquakes" at the 12th UJNR joint meeting. (Fig. 2) In that report, the analysis was made on the premise that horizontal forces work on the center of a slab. However, on actual foundation, earthquake forces change moment by moment and the horizontal forces do not always work on the center of a slab. There are cases where an eccentric load exists as a result of a ship collision, or where the center load is changed into an eccentric load due to the ground slope or lack of uniformity of pile lengths and or pile spacing. There are very few examples in which analysis or experiments were made on these eccentric loads.

In this paper we introduce equations for calculating torsional resistance to an eccentric load and load sharing for multi-column foundations, results at a full size model test, and the results of a comparison between the small-sized model test values using acrylic model and the analysis values.

2. Torsional resistance and load sharing of multi-column foundations

Fig. 3 shows the two different relationships between a torsional moment and the rotating angle of a slab and between a torsional moment and the rotating angle of the whole multi-column group on the ground surface, when the torsional moment works at a slab of the multi-column foundation. When the displacement is small, these relationships are linear. It is generally considered that torsional resistance of a multicolumn foundation consists of two resisting moments. One is the sum of the torsional resisting moments $\mathrm{M}_{\mathrm{r}_{\mathrm{i}}}$ of individual piles. The other is the sum of the values obtained through multiplying horizontal resistance at a pile head $H_{r i}$ by the distance from the center of a slab $\ell_{i}$.

In this case, theoretical solutions of torsional resistance and horizontal resistance are given and their sharing ratios in the torsional moment are determined.

* 1 Chief, Design Department, TransTokyo Bay Highway Corporation. (Fomer Chief of Structure and Bridge Department,P.W.R.I., Ministry of construction)

*2 Head, Foundation Engineering Division, Structure and Bridge Department, P.W.R.I., Ministry of Construction

* 3 Senior Research Engineer, Foundation Engineering Division, Structure and Bridge Department, P.W.R.I., Ministry of Construction

* 4 Chief, Investigation Section, Kagoshima National Highway Construction Office, Ministry of Construction 
(1) Theoretical solution of torsional resistance.

Under the conditions that a pile with a free length $h$ penetrates into elastic ground and a pile head receives a torsional moment $M_{0}$ (Fig. $3)$, then if the rotating angle of a pile at the depth $x$ is $\phi_{x}$, the shear ground reaction force, $\tau_{x}$ of, the pile surface can be expressed by the following equation.

$$
\tau_{\mathrm{x}}=\mathrm{D} / 2 \cdot \phi_{\mathrm{x}} \cdot \mathrm{k}_{\mathrm{s}}
$$

Here,

$\tau_{\mathrm{x}}$ : shear ground reaction force between a pile and the ground $\left(t f / \mathrm{m}^{2}\right)$ $D$ : diameter of a pile (m)

$k_{s}$ : coefficient of the shear ground reaction force of the ground ( $t f / m^{3}$ )

From the balance of the $d x$ section in Fig. 3,

$$
\frac{d M_{x}}{d x}=-\frac{\pi}{2} D^{2} \cdot \tau_{x}
$$

Here,

$\mathrm{M}_{\mathrm{x}}$ : torsional resisting moment $(t f \cdot m)$ at the depth $x$.

The following equation is obtained from the relationship between the rotating angle $\phi_{\mathrm{x}}$ and strain $\theta_{\mathrm{x}}$.

$$
\frac{d \phi x}{d x}=\theta_{x}=\frac{-M_{x}}{G I p}
$$

Here,

G:coefficient of shear elasticity of a pile $\left(t \mathrm{f} / \mathrm{m}^{2}\right)$

Ip:pole moment of a pile $\left(\mathrm{m}^{4}\right)$

The following differential equation can be derived from (equations 1-3).

$$
\frac{\mathrm{d}^{2} \phi \mathrm{x}}{\mathrm{dx} \mathrm{x}^{2}}=\varepsilon^{2} \phi \mathrm{x}
$$

$\varepsilon=\left(\pi D^{3} k_{s} / 4 G I p\right)^{1 / 2}$

By solving the equation 4 the following is obtained: Here,

$$
\phi_{\mathrm{x}}=\phi_{\mathrm{o}} \exp (-\varepsilon \mathrm{x})
$$

$\phi_{0}$ :rotating angle at the ground surface

When (6) is differentiated and $x$ equals 0 , equation 7 is obtained.

$$
\theta_{\mathrm{o}}=-\varepsilon \phi \text { 。 }
$$

Torsional moment $M_{0}$ at a pile head is expressed as follows.

$$
M_{0}=-\theta \text { oIp }
$$

From equation 7 and 8 the rotating angle $\phi$ o at ground surface can be obtained as follows.

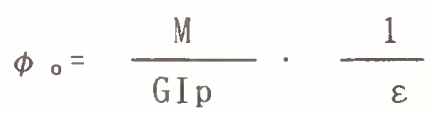

When $1 / \varepsilon$ equals $\ell$ o(Refer to Fig. 4), $l_{\text {o }}$ indicates a depth of a virtual fixed point to torsion.

From the above, torsional resistance $M_{p t}$ of one pile can be expressed as in (10) by using the rotating angle $\phi^{*}$ of a footing.

$$
\begin{aligned}
& M_{p_{i}}=G I_{p} \theta_{0}=G I_{p} \cdot \frac{\phi^{*}}{h+\ell_{0}} \\
& =G I_{p} \frac{\varepsilon}{1+\varepsilon h} \cdot \phi^{*}
\end{aligned}
$$

Here,

$$
\text { h: free length of a pile (m) }
$$

Equation 10 indicates that torsional resistance of a pile becomes smaller as the free length becomes longer. Applying these equations to the case of an inclined pile shows that component of cosine of an inclined angle $\theta$ becomes effective. However, when torsional resistance in the axial direction of an inclined pile is taken into consideration, there is no significant difference when 10 is applied to the resistance of all piles.

\section{(2) Theoretical solution of horizontal resistance}

A horizontal spring constant at the pile head of a pile with a free length $h$, which penetrates elastic ground is expressed with the following equation:

$$
\begin{gathered}
\mathbf{K}_{1}=\frac{12 E I \beta^{3}}{(1+\beta \mathrm{h})^{3}+2} \\
\beta=(\mathrm{kD} / 4 \mathrm{EI})^{1 / 4}
\end{gathered}
$$

Here,

$\mathrm{K}_{1}$ :spring constant of a pile for horizontal displacement ( $t f / m$ )

EI:flexural rigidity of a pile (tf.m)

$\mathrm{h}$ : free length of a pile (m)

$\mathrm{k}$ : coefficient of horizontal subgrade reaction $\left(t \mathrm{f} / \mathrm{m}^{3}\right)$

$\mathrm{D}$ : diameter of a pile (m) 
When the rotating angle of the footing is $\phi^{*}$, the horizontal force $\mathrm{H}_{\mathrm{i}}$ of a pile head can be obtained from the following equation.

$$
\mathrm{H}_{\mathrm{i}}=\mathrm{K}_{1} \cdot \ell_{\mathrm{i}} \cdot \phi^{*}
$$

Here,

$\ell_{i}$ :distance from the rotating central axis to pile (i)(m)

In the case where there are vertical piles only, resisting moment by the horizontal resisting force is expressed as follows.

$$
\sum H_{i} l_{i}=\sum H_{i} l_{i}^{2} \phi^{*}
$$

In the case where there are inclined piles, since the axial force of a inclined pile resist a torsional moment, equation 14 applies. In this case an inclined angle $\beta$ of a slab to a horizontal surface due to the torsional moment is neglected.

$\sum H_{i} l_{i}=\sum H_{i} l_{i}^{2} \phi^{*}\left(\cos ^{2} \theta \sin ^{2} \quad \alpha_{i}\right.$ $\left.+\cos ^{2} \alpha_{i}\right)+\sum k_{v} l_{i}^{2} \phi^{*} \sin ^{2} \theta \sin ^{2} \alpha_{i}$

Here,

$$
\mathrm{K}_{\mathrm{v}} \text { :spring constant at a pile for }
$$
axial direction ( $t f / m$ )

$\theta$ :inclined angle of a pile

$\alpha_{\text {i }}$ : angle between the inclination direction of an inclined pile and the central direction of a slab (Refer to Fig. 5)

The equations above indicate that $\mathrm{K}_{1}$ rapidly decreases with an increase in free length $h$. Thus a multi-column foundation with long free length is easily affected by a torsional moment. However, when there are inclined piles, the longer the free length becomes, the more effective the inclined piles become for both torsional moments and horizontal loads. Among the various inclined piles, possible piles at the corner or at the edge are most effective as equation 14 shows. Inclined piles in the central part, however, have the same properties as those of vertical piles for resisting a torsional moment.

\section{(3) Sharing ratio}

Sharing of resistance to a torsional moment which works on a multi-column foundation is determined as follows.

$$
\begin{aligned}
& \mu_{\mathrm{H}}=\sum \mathrm{H}_{\mathrm{p}_{\mathrm{i}}} \ell_{\mathrm{i}} / \mathrm{M} \\
& \mu_{\mathrm{M}}=\sum \mathrm{M}_{\mathrm{p}} / \mathrm{M}
\end{aligned}
$$

Here,

$$
\begin{gathered}
\mu_{\mathrm{H}} \text { : sharaing ratio by the horizontal } \\
\text { resisting force of piles }
\end{gathered}
$$

$\mu_{\mathrm{m}}$ :sharing ratio by the torsional resistance of piles

$\mathrm{H}_{\mathrm{p}_{\mathrm{i}}}$ :horizontal resistance of one pile

$\ell_{i}$ :distance from a slab center to a pile head

M:torsional moment working on a multi-column foundation

$\mathrm{M}_{p_{i}}$ : torsional resistance of one pile When the relations $I_{p}=2 I$ and $M_{p i}=\sum$ $\mathrm{M}_{\mathrm{p}} / \mathrm{n}$ are substituted into (15) and (16) after eliminating $\phi^{*}$ from the relationship among (equaiton $10 \sim$ 13), (17) and (18) can be obtained. These are applicable only to vertical piles.

$$
\begin{aligned}
& \mu_{\mathbf{M}}=\sum M_{p_{i}} / M \\
& =\frac{1+\frac{6 \sum\left(\ell_{i} / h\right)^{2}}{n} \cdot \frac{E}{G} \cdot\left[\frac{1}{\varepsilon h}+1\right] \frac{\beta^{3} h^{3}}{(1+\beta h)^{3}+2}}{2 n \cdot G I+\sum \ell_{i}^{2}\left[h+\frac{1}{\varepsilon}\right] K_{l}}
\end{aligned}
$$

$\mu_{\mathrm{H}}=1-\mu_{\mathrm{M}}$

When inclined piles are used, the equations change to (19) and (20).

$\mu_{\text {м }}=2 n \cdot G I /\left[2 n \cdot G I+\sum \ell_{i}{ }^{2}(h+1 / \varepsilon)\left\{K_{1}\right.\right.$ $\left(\cos ^{2} \theta \sin ^{2} \alpha_{i}+\cos ^{2} \alpha_{i}\right)+k_{v} \sin ^{2} \theta$ $\left.\left.\sin ^{2} \alpha_{i}\right\}\right]$

$\mu_{\mathrm{H}}=1-\mu_{\mathrm{M}}=\sum \ell_{\mathrm{i}}{ }^{2}(\mathrm{~h}+1 / \varepsilon)\left\{\mathrm{K}_{1}\left(\cos ^{2}\right.\right.$ $\left.\theta \sin ^{2} \alpha_{i}+\cos ^{2} \alpha_{i}\right)+k_{v} \sin ^{2} \theta \sin ^{2}$ $\left.\alpha_{\mathrm{i}}\right\} /\left[2 \mathrm{n} \cdot \mathrm{GI}+\sum \ell_{\mathrm{i}}{ }^{2}(\mathrm{~h}+1 / \varepsilon)\left\{\mathrm{K}_{\mathrm{l}}\left(\cos ^{2} \theta\right.\right.\right.$ $\left.\left.\left.\sin ^{2} \alpha_{i}+\cos ^{2} \alpha_{i}\right)+k_{v} \sin ^{2} \theta \sin ^{2} \alpha_{i}\right\}\right]$

$$
\begin{aligned}
& \text { Here, } \\
& \ell_{i} \text { :distance from a slab center } \\
& \text { to a pile (m) } \\
& \mathrm{h} \text { : free length of a pile (m) } \\
& \mathrm{n} \text { : number of piles } \\
& \text { E:Young's modulus of pile } \\
& \text { materials ( } t f / \mathrm{m}^{2} \text { ) } \\
& \text { G:shear elastic coefficient of } \\
& \beta=(\mathrm{kD} / 4 \mathrm{EI})^{1 / 4}
\end{aligned}
$$

$\mathrm{k}$ :horizontal coefficient of subgrade reaction

D:diameter of a pile(m)

$K_{1}$ :spring constant in the perpendicular direction of a pile axis $(t f / m)$

$$
\mathrm{K}_{1}=\frac{12 \operatorname{EI} \beta^{3}}{(1+\beta \mathrm{h})^{3}+2}
$$


$\mathrm{K}_{\mathrm{v}}$ : spring constant in the pile axial direction ( $\mathrm{t} / \mathrm{m}$ )

Equations 17 through 20 show that when $\mathrm{K}_{1}, \mathrm{~K}_{\mathrm{v}}$ and values are determined, the sharing ratio of torsional moment by the horizontal resisting force and that by the torsional resistance of piles can be determined from the dimensions of a multi-column foundation.

\section{Field Test Results}

While a multi-column foundation is said to be a structural system easily affected by torsional moment, it also can be referred to as a ductile structural system because torsional resistance largely depends on the horizontal spring constant or coefficient of shear subgrade reaction, although the torsional resistance is affected by the free length of a pile as analyzed in the earlier section.

Eccentric horizontal load tests shown in Fig. 6 were conducted with full- sized foundation models in order to examine foundation movement, stress distribution, load sharing, etc. when torsional force was applied. The maximum load was set to be 60tf. The loads on the foundation models $P_{1}$ and $P_{2}$ became a reaction force to each other. The measurement was conducted mainly at $\mathrm{P}_{2}$.

Fig. 7 shows load-(rotational displacement )-time chart resulting from torsional load at a slab of $\mathrm{P}_{2}$. The amount of displacement is the average of horizontal displacemants measured by two dial gauges on the diagonal line at the model. The two dial gauges showed almost the same values. Because horizontal displacement of the central pile of the foundation was small (maximum 0.2mm), we concluded that the horizontal load acted almost purely as a torsional moment.

According to Fig.7, displacement shows an almost straight line relationship and residual displacement is small. Therefore, as long as the load is less than 60tf, we conducted that $P_{2}$ movement is within the range of elasticity. A load of $60 t f$ was tested on $\mathrm{P}_{2}$ which corresponds to an allowable horizontal bearing capacity of 69tf. Displacement on the ground surface was about $5 \mathrm{~mm}$ at the corner pile which is affected most by torsional moment. However. it was about $8 \mathrm{~mm}$ in an axial center loading test. We assume that the difference is caused by the torsional resistance of the piles which worked effect ively to decrease the horizontal load on the piles.

Next, torsional angle $\phi *$ was determined by dividing the displacement by the distance from the slab center to the measuring point. Also, the rotating angle $\phi$ ' was determined by dividing the ground surface displacement of a pile by the distance from the slab center to the pile center. The relationship between the torsional moment and the torsional angle $\phi^{*}$ and between the torsional moment and rotating angle, $\phi$ ', are shown in Fig. 3. The figure indicates that the ratio of the rotational angle, $\phi$ ', to the torsional angle, $\phi^{*}$, is about $60 \%$. Therefore, torsional rotation of a slab forces a horizontal displacement of a pile on the groundsurface to take place. As a result, horizontal resistance of the ground acts as a torsional resistance moment.

The relationship between the two different angles of torsion, $\phi^{*}$, corresponding to torsional moments of $P_{1}$ and $P_{2}$ respectively is shown in Fig. 8. When a torsional spring constant is defined as the ratio, torsional moment to the angle of torsion, the torsional constant gradually decreases as the angle of torsion becomes larger. However, since its decrease is small, a fixed number can represent torsional spring constants for an extensive range of of an angle of torsion.

The torsional resistance moment was calculated from the shear stress of a pile body. The horizontal resistance moment was calculated from multiplyingthe pile head horizontal force $\mathrm{H}_{\mathrm{i}}$ by the distance from a slab center, $\ell_{i}$ and pile head horizontal force $\mathrm{H}_{\mathrm{i}}$ was calculated from the bending moment of a pile. These results for each pile is shown in Table 1 .

Table-1 shows that the sharing ratio of torsional resistance of a pile is about 60 \% and it increases 
slightly with an increase in load. We believe it increases because torsional effects gradually reach the lower parts of the piles and increase, shear resistance on the pile surface due to horizontal resistance in the ground.

The test results above can be summarized as follows:

i) Displacement movement caused by loads up to 60tf, which is close to the allowable horizontal bearing capacity, is within the range of elasticity as seen in Model $\mathrm{P}_{2}$.

ii) The ratio of the torsional resistance of a pile alone to the torsional moment of the whole model is about $60 \%$. The torsional resistance of a pile is effective in decreasing the amount of displacement. Although the sharing ratio increases with an increase in load, the amount is small.

iii) Rotation of a slab has a nearly completely linear relationship with displacement of the ground surface. Since its torsional spring constant does not respond sensitively to an increase in displacement, it is possible to set a fixed number as a representative constant for a certain range of displacement.

iv) From these test results, it was shown that a multi-column foundation is a tenacious structural system with a desirable response to an eccentric load. It also can be inferred that the larger the diameter of a pile, the larger its resistance will be and that the shorter the free length of a pile, the smaller its displacement in rotation will be.

\section{Small-sized model test}

\section{(1)Outline of tests}

Most of the loading test of multicolumn foundations have been conducted on models with vertical piles only. In this study, loading tests were performed on one model with vertical piles and on two other other models with inclined piles in addition to vertical piles for comparison.

As shown in Fig.9, three types of models of multi-column foundations were used. Each had 28 piles consisting of 4 lines and 7 rows.

Model 1. a multi-column foundation composed of vertical piles only.

Model 2. a multi-column foundation with inclined piles in the bridge axial direction (a short side) only

Model 3. a multi-column foundation with inclined piles in the

perpendicular direction to the bridge axis (a long side) only

Acrylic resin was used as a material because it is easy to build uniform models with it. From the tensile test results the Young's $E=290 \mathrm{~N} / \mathrm{cm}^{2}$, and Poisson's ratio $=0.356$ were determined. The linear relationship between stress and strain was also confirmed.

It was difficult to make the elastic ground model appropriate for the acryic pile model. Therefore, the diameter of the acrylic resin part corresponding to a pile in the ground was adjusted such that the displacement (deflection) and inclined angle (angle of deflection) were nearly equal to those values in the full-scale test. Diameter of a free length pile is $30 \mathrm{~mm}$, but diameter of a pile in the ground should be $50 \mathrm{~mm}$ based on our calculations. On the models, the lower end of a pile in the ground was fastened.

Dimension and form were made as small as a 1/100 scale. After careful study, we found it difficult to make an exact acrylic model of a typical foundation. Therefore, we focused on determining structural characteristics.

Loading was executed as follows. (Refer to Fig. 10)

(i)eccentric loading in the bridge axial direction $\mathrm{HI}$

(ii)eccentric loading in the bridge axis H3

Measurement was concentrated on one rectangular section $(1 / 4$ of the whole area) out of the four rectangular sections made by axes of the bridge axial direction and that of perpendicular direction to the bridge axis.

\section{(2) Test Results}

In the tests, two series loadings were carried out on three different types of models. However, in this report, only the results of loading test in the $\mathrm{X}$ direction are shown as 
figures. Other test results, at the standard loading level, are shown in tables.

In order to compare test results and calculations, the following calculation methods were adopted.

- The composite structure model (SHELL) - a structure analysis model wiht a slab as a shell and a pile as a solid beam element

- The solid frame model(3FRAME)a solid frame structure analysis (three dimension) model with a slab as a plane framework and pile as a bar member connected to a node of frame

Fig. 11 and Fig. 12 show the horizontal displacement and the torsional angle caused by a horizontal load with an eccentricity of 220mm in the bridge axial direction ( $\mathrm{x}$ direction) of a slab. Fig. 11 shows displacement on the central axis (the $x$ axis) of a slab of three different models. Of the two methods tested, SHELL was used as a standard method. Fig. 12 shows the torsional angles of slabs of three models in radians. Horizontal displacement and the resulting torsional angle are shown in Table.2when horizontal eccentric loading as much as 200kgf acted in the $X$ direction and the $Y$ direction. If there were two different values found at $H=200 \mathrm{kgf}$, the average was taken. Section force of a pile caused by a horizontal eccentric load of $\mathrm{H}=200 \mathrm{kgf}$ is shown in Table. 3. Table 4 shows the estimated section force caused by the torsional moment. This force is estimated by subtracting the section force obtained in the separately conducted horizontal axis load test from the section force obtained in the horizontal eccentric load test.

\section{(3) Review}

Fig. 11 and 12 show that the horizontal displacement of a slab in the $x$ direction and the torsional deformation respectively have a linear relationship with an increase in load. Scattering of the test values and analysis values, other than those of the torsional angle in the $Y$ direction, was relatively small; within 20응

Table 2 shows that horizontal displacement of a slab center by eccentric loading has the same results as axial horizontal loading (Table 4). Displacement is half as much because the load is half as much.Torsional moment in the $Y$ direction is half of that in the $x$ direction. However, inclined piles in model 2 resist torsional moment well, both in the $\mathrm{x}$ direction and the $Y$ direction judging from torsional angles. This is due to the effect of the arm length in the direction from a torsional center to the piles. Though inclined piles in model 3 are effective for countering the effect of eccentric loading in the $Y$ direction, they are not as effective for loading in the $x$ direction. The results above indicate that the eccentric load in the horizontal direction can be analyzed as an axial loading in the horizontal direction anda torsional moment. Table 3 shows the torsional effect from a horizontal eccentric load on a pile section. Though there are differences between the test values and analytical values, there is the same tendency. Torsional moment in the $\mathrm{x}$ direction is twice as much as that in the $Y$ direction. Bending moment decreases by 20-30\% when there are inclined piles in thex direction (in plane). With inclined piles in the perpendicular direction to the load (out plane), a decrease in the moment by about $10 \%$ was obtained in our the analysis The decrease in the bending moment in the $Y$ direction is not as remarkable as that in the $\mathrm{x}$ direction. However, a decrease of 10-20\% was observed in Model 3. Bending moment in the direction perpendicular to a load works in the both $X$ and $Y$ direction, which becomes a resisting force against torsional moment on a slab. Some test values of axial force are abnormal. However, the difference between test values and analytical values is relatively small. This indicates that axial force in the inclined piles becomes remarkably large.

\section{Summary}

The characteristics of torsional resistance of a multi-column foundation against eccentric load in the horizontal direction which is said to be a weak point of this 
foundation was clarified through theoretical reviews and load tests in the field and the laboratory. The results of the reviews and the tests are as follows.

(1) The resisting moment to a torsional moment caused by an eccentric horizontal load can be treated as the sum of the total amount of torsional resistances of unit piles and the total amount of the moment obtained from multiplying the horizontal resistance of a pile by the distance from the slab center.

(2) When the angle of torsion is very small, the resisting moment and the angle of torsion have an almost linear relationship and the angle of torsion of a slab and the angle of torsion of pile groups of a multi-column foundation on the ground surface have a directly proportional relationship.

(3) The theoretical equations for the two resisting moments were obtained, which made it possible to calculate a sharing ratio of the two different moments. These equations can be applied to a foundation which has inclined piles in combination with vertical piles.

(4) From these equations it was shown that though a multi-column foundation is less resistant to a torsional moment as the free length becomes longer, the foundation can be strengthened by installing inclined piles.

(5) As a result of the field test (pure torsional loading test), it was found that multi-column foundations have structural characteristics of ductile resistance to a torsion.

(6) The share of torsional resistance in a pile unit in the torsional resistance of the whole foundation is equal to the moment resulting from multiplying the horizontal resistance by the arm length and is nearly directly proportional. This shows that the larger the pile diameter is and the shorter the free iength is, the larger the torsional resistance will be.
(7) If the torsional spring constant is de fined as the ratio of the angle of torsion to the torsional moment, a fixed number can represent the constants, because it is not sensitive to displacement.

(8) Also in the acrylic model tests (eccentric horizontal load test), both horizontal displacement (central axis displacement) and torsional displacement (horizontal rotational angle) have a linear relationship with load. These displacement agree with the analysis values.

(9) Eccentric horizontal load can be treated by being analyzed as a horizontal force and a torsional moment. In this case, horizontal displacement agrees with the values obtained in the horizontal axial loadingtest.

(10)Inclined piles effectively resist to rsional moment. Inclined piles become more effective as the arm length from the central axis becomes longer.

(11)With vertical piles and inclined piles, bending moment caused by an eccentric horizontal load occurs in two directions; the loading direction and the direction perpendicular to it, which acts as torsional resistance.

From these results, the mechanism of resistance of multi-column foundation to an eccentric horizontal load was made clear and calculations can be made for various designs.

Finally, we would like to express our profound gratitude to those who supported and helped us in the process of this study. 


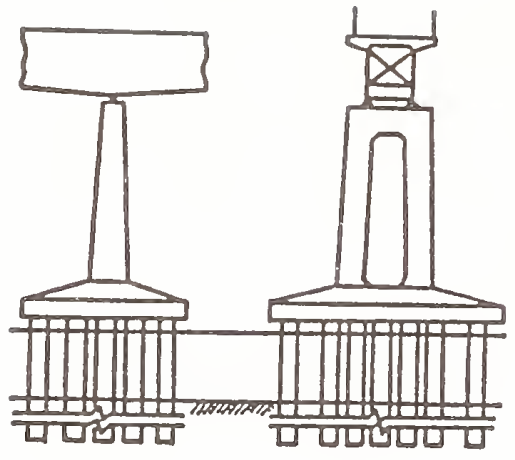

Fig. 1 Multi column foundation
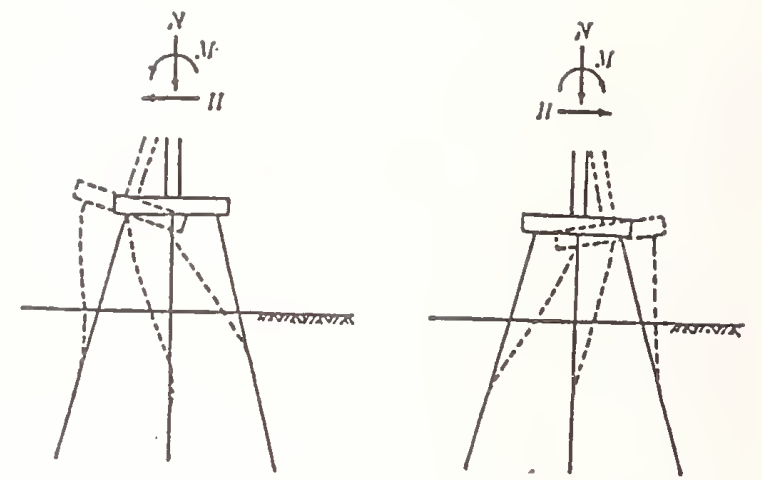

Fig. 2 Behavior of multi column foundation with inclined piles

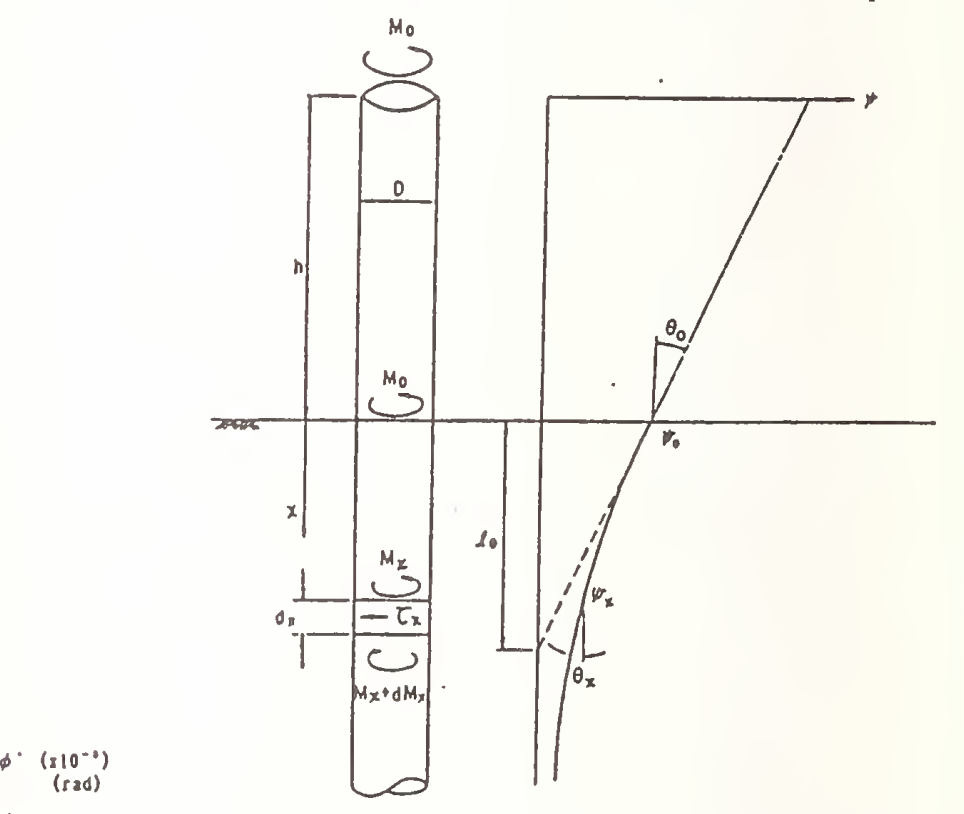

Fig. 4 Deformation of pile by torsion
Fig. 3 Torsional load and deformation

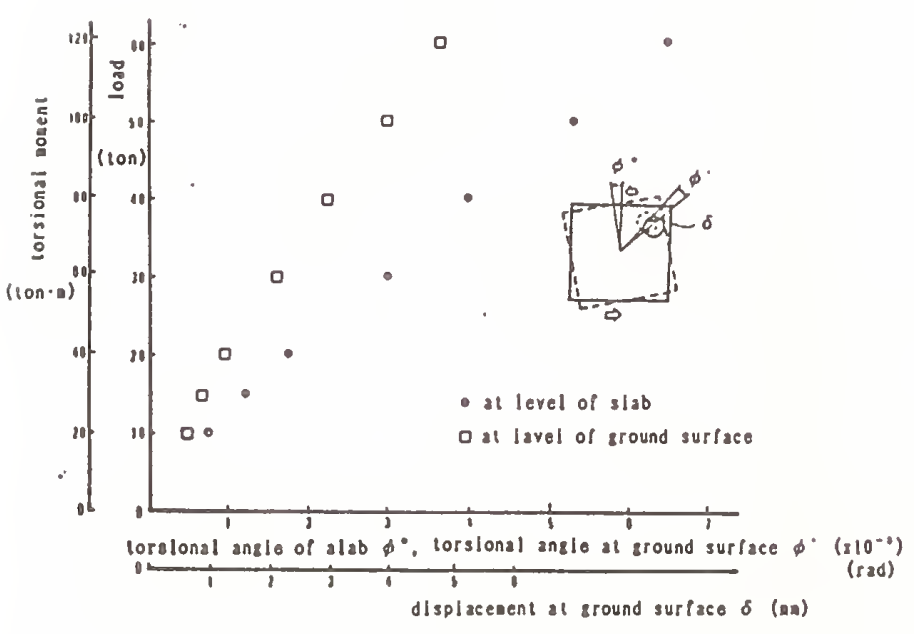

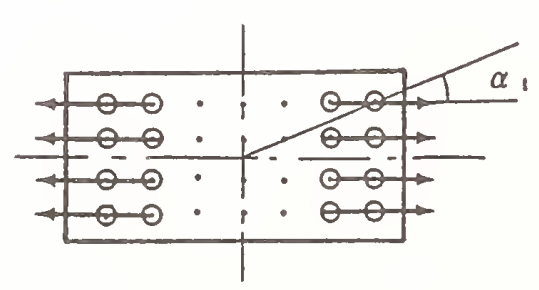

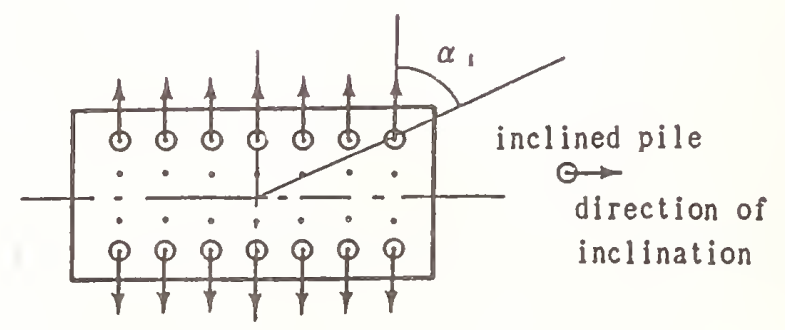

Fig. 5 Direction of inclined pile and angle of pile position 

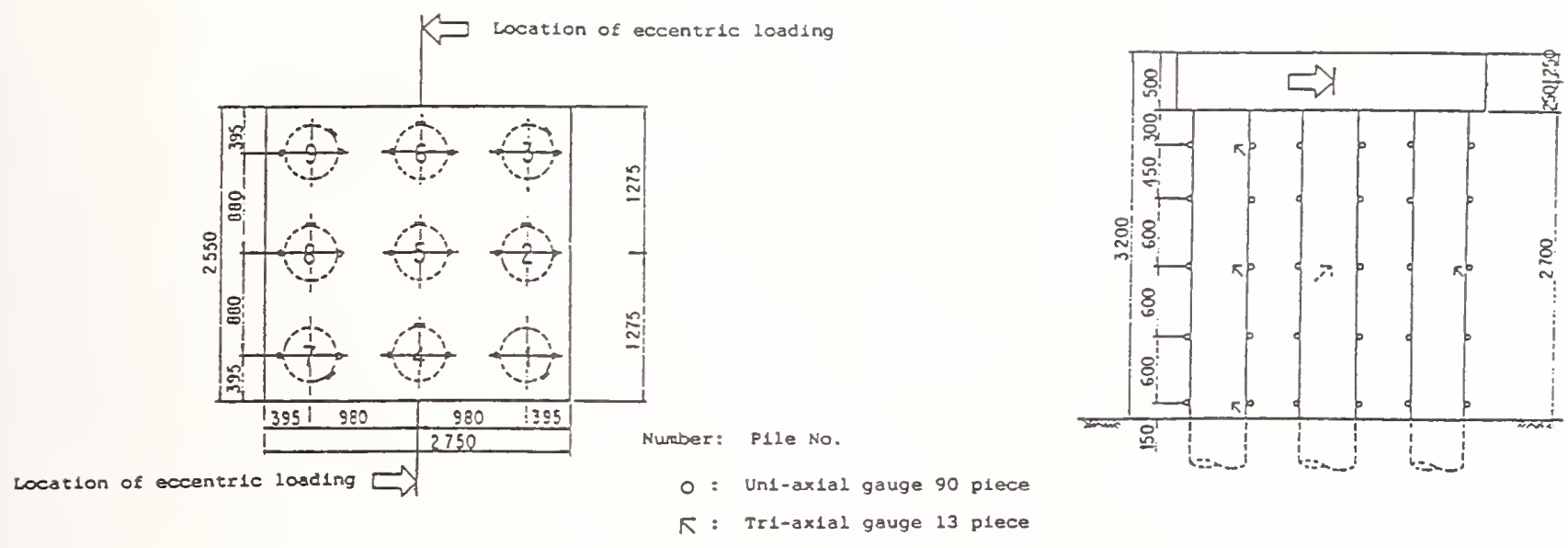

Fig. 6 Location of Gauge

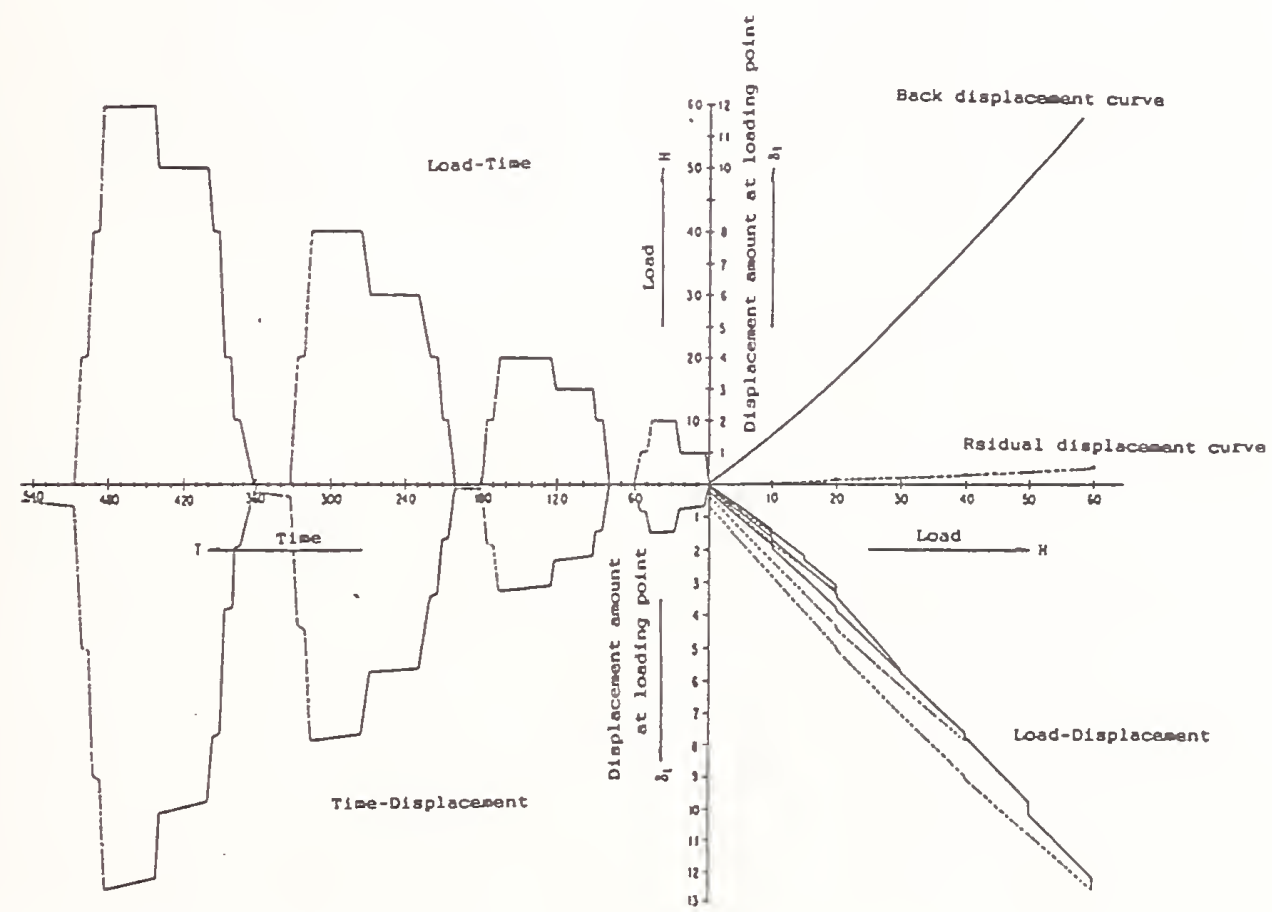

Fig. 7 Eccentric Horizontal Load Test (Load-Displacement-Time chart) 


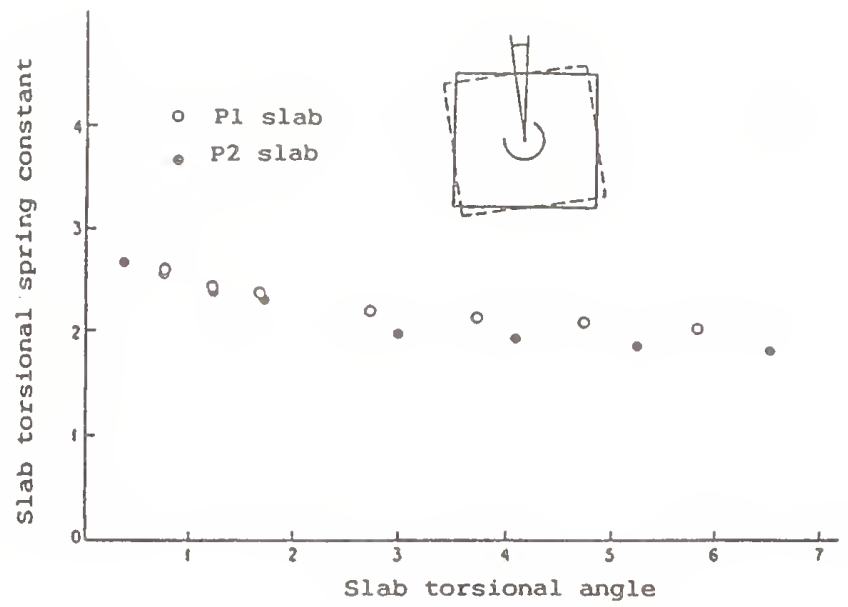

Fig. 8 Slab Torsional Spring Constant-Torsional Angle

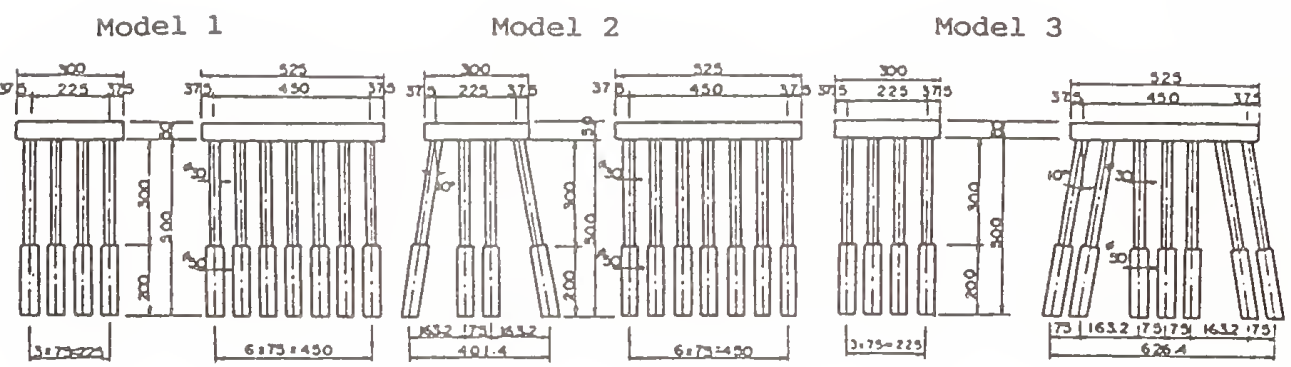

Fig. 9 Side view of Models

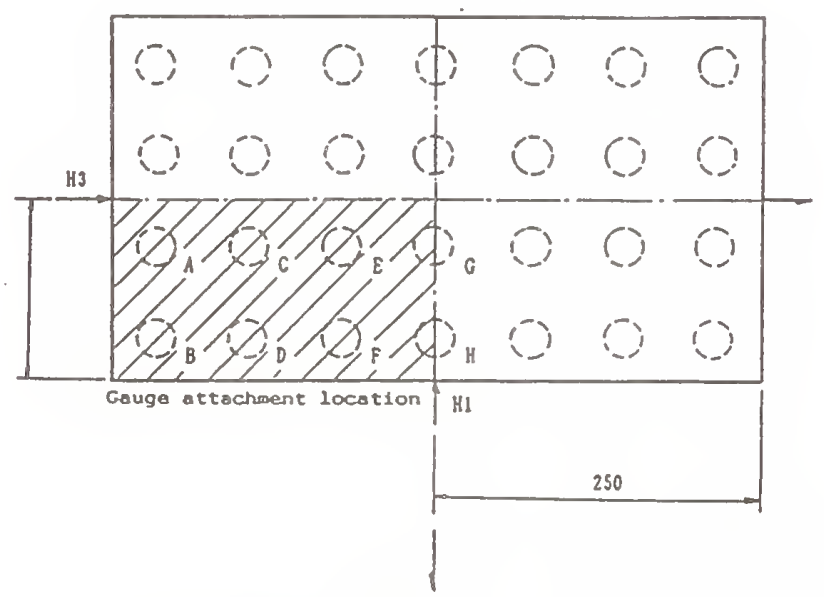

H1: Horlzontol axis in the $x$ direction (losding in two direc

tions of $x$ direction)

H3: Horlizontal axis in the $y$ drection (loading in two direc

rions of $Y$ dilection)

Fig. 10 Loading Location 
* MODEl I X Horizontal eccentricity

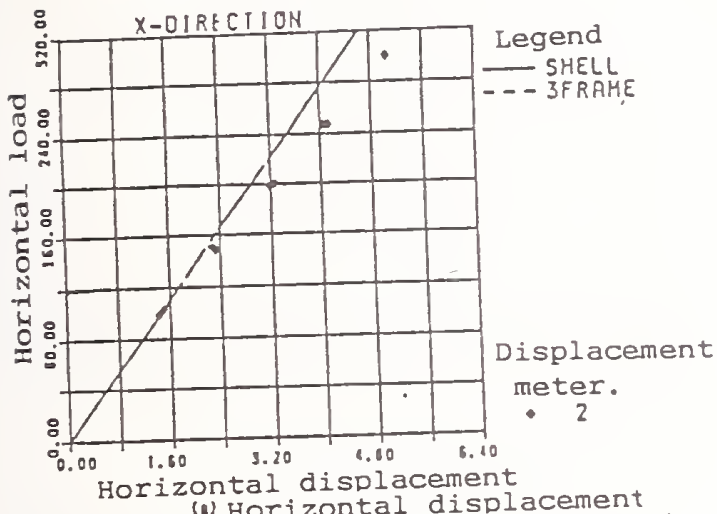

* MOUFl $2 X$ Horizontal eccentricity

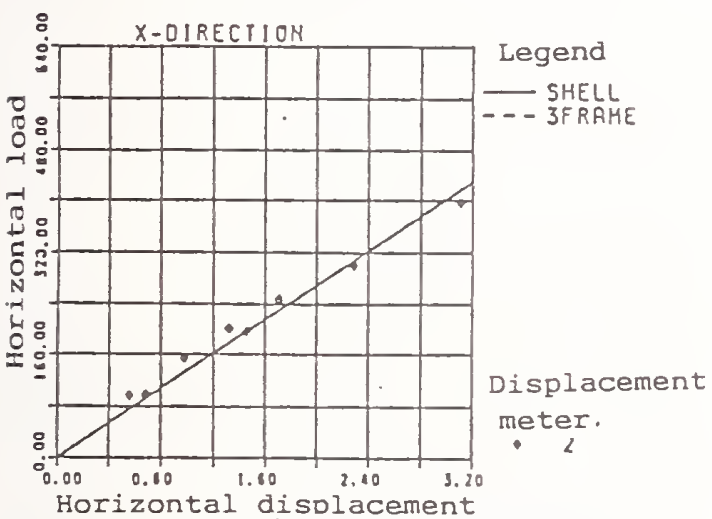

(e) Horizontal displacement

* MODEl 3 X horizontal eccentricity

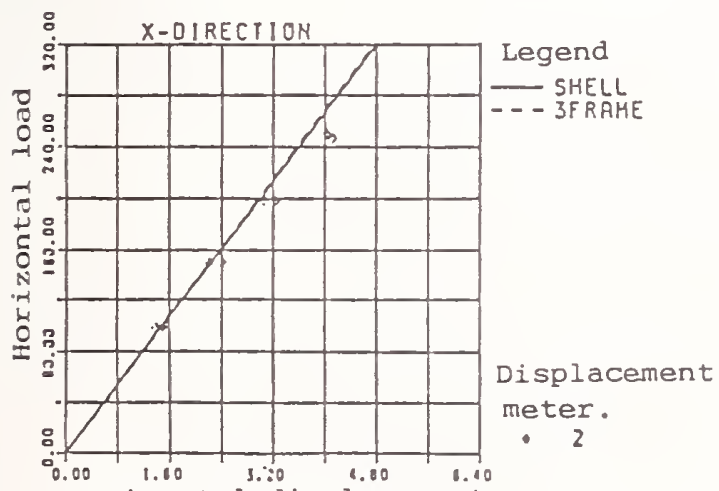

Horizontal displacement

(b) Horizontal displacemnt
* MODEL \& $\times$ Horizontal eccentricity

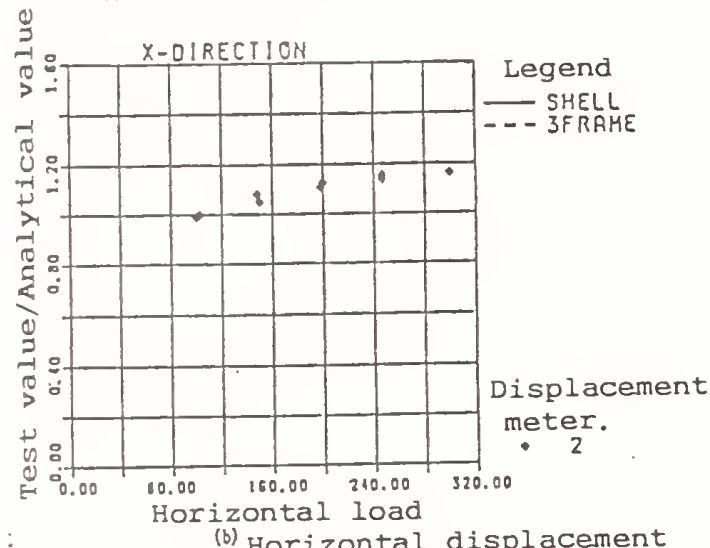

* MODEl $2 \times$ Horizontal eccentricity

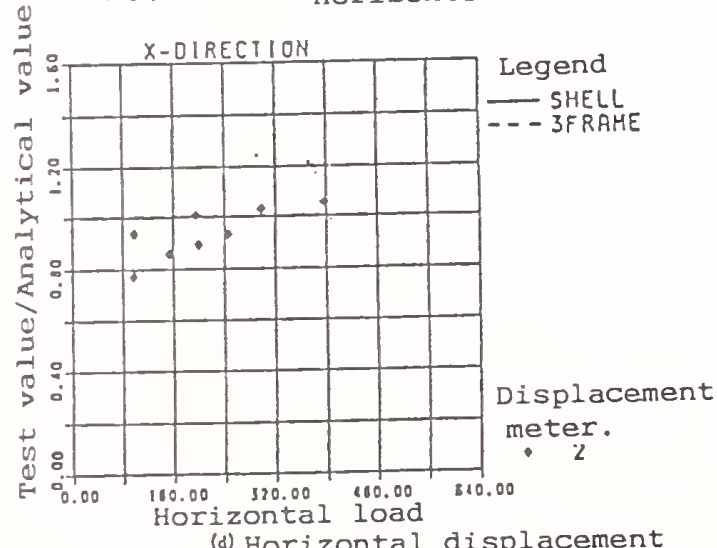

(d) Horizontal displacement

* model $3 x$ horizontal eccentricity

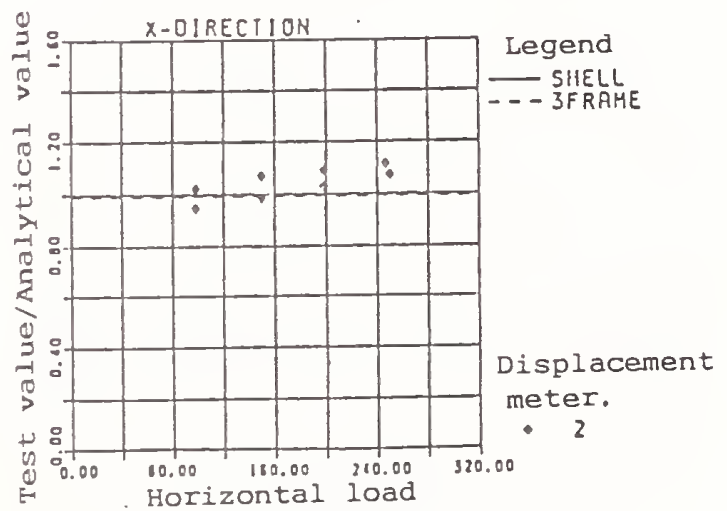

(1) Horizontal displacemnt

Fig. 11 Horizontal Displacement of a Slab by a Horizontal

Eccentric Load (In the $X$ direction) 
* MODEL 1 X. Horizontal eccentricity

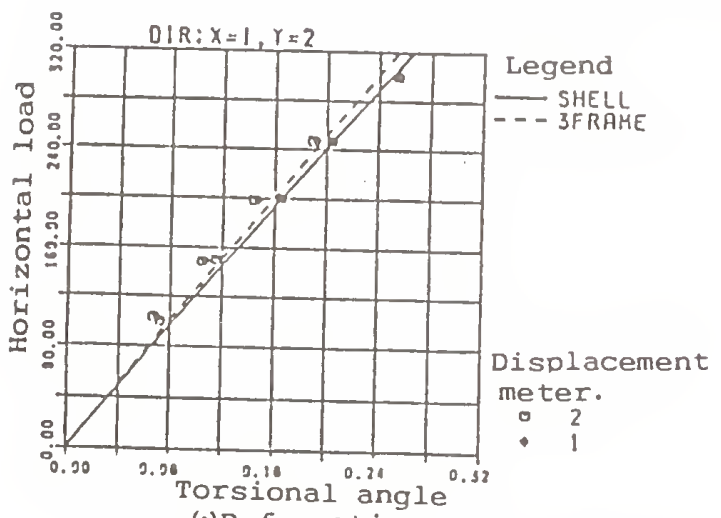

* MODEL 2 Horizontal eccentricity

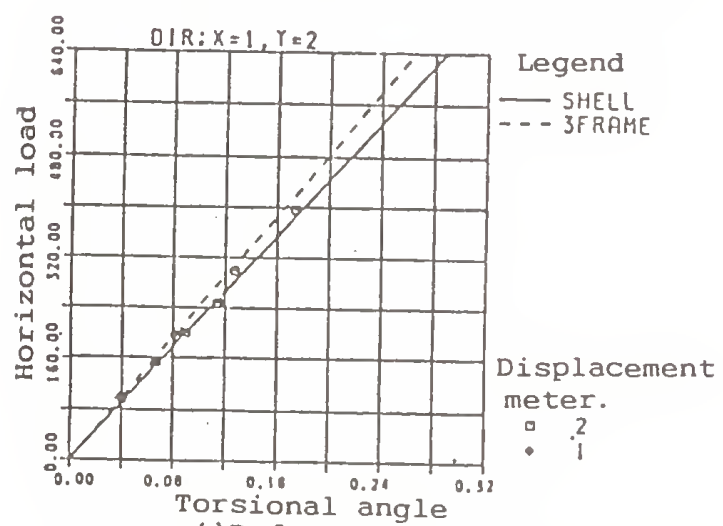

(c) Deformation

* mODEl 3 X Horizontal eccentricity

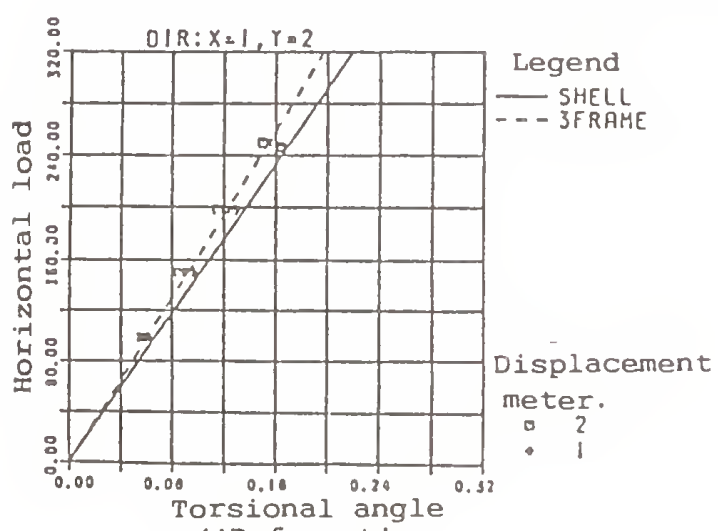

(o) Deformation

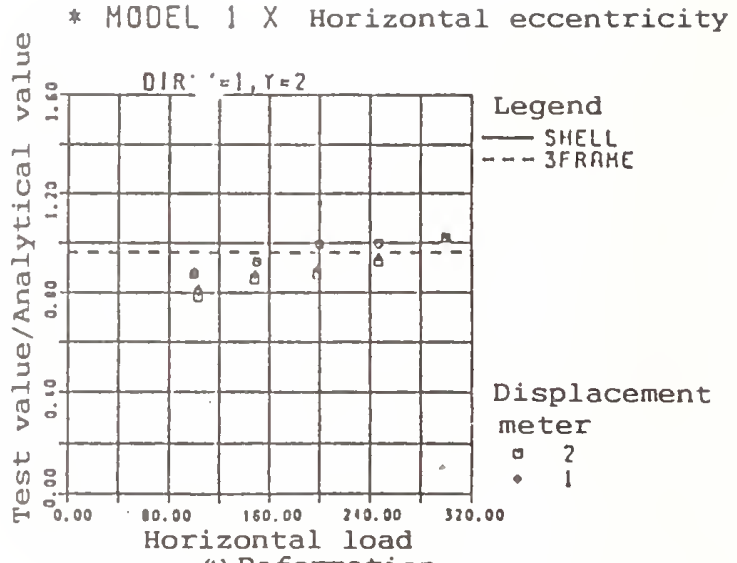

(b) Deformation

* MODEl 2 X Horizontal eccentricity

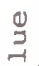

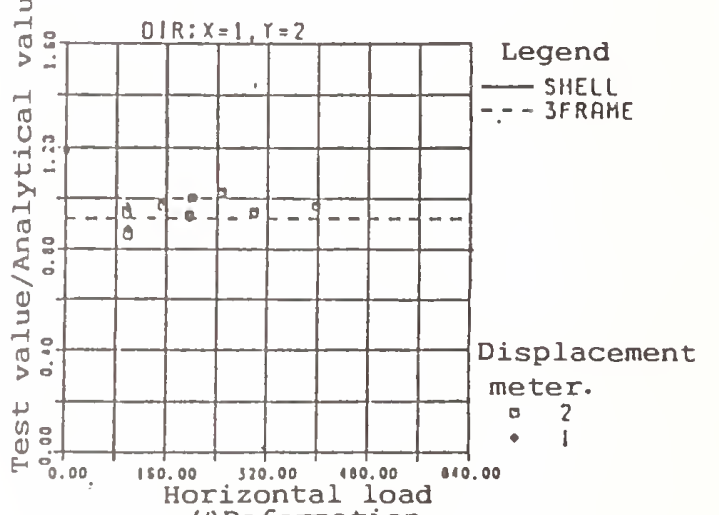

* MODEL $3 \times$ Horizontal eccentricity

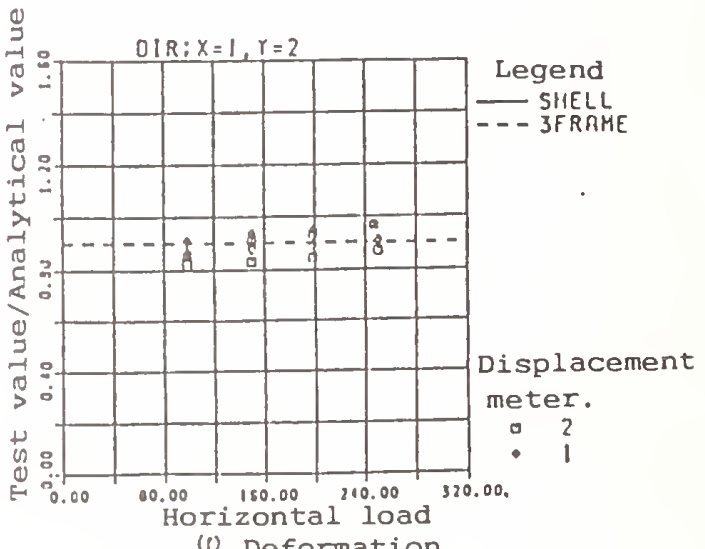

(b) Deformation

Fig. 12 Torsional Deformation of a slab by a Horizontal

Eccentric Load (In the $X$ direction) 
Table 1. Sharing Ratio of Resisting Moments

\begin{tabular}{|c|c|c|c|c|c|c|c|c|c|c|c|c|c|c|c|}
\hline \multirow{3}{*}{$\begin{array}{l}\text { Load } \\
\text { (t) }\end{array}$} & \multirow{3}{*}{$\begin{array}{l}\text { Torsional } \\
\text { moment } \\
\text { load } \\
(t . m)\end{array}$} & \multicolumn{3}{|c|}{$\begin{array}{l}\text { Toralonal resiating moment of a plle } \\
\left(\sum M_{1}\right)\end{array}$} & \multicolumn{11}{|c|}{ Horlzontal resisting moment of plles $\left(H_{p_{1}} \cdot Q_{1}\right)$} \\
\hline & & \multirow{2}{*}{$\begin{array}{l}\text { - Resiling } \\
\text { moment per } \\
\text { one plle } \\
(t \cdot m)\end{array}$} & \multirow{2}{*}{$\begin{array}{l}\text { Torslonal } \\
\text { resiating } \\
\text { moment of } \\
\text { of all piles } \\
(\mathrm{t} \cdot \mathrm{m})\end{array}$} & \multirow{2}{*}{$\begin{array}{l}\text { Sharing } \\
\text { ratio H m } \\
\text { (1) }\end{array}$} & \multicolumn{9}{|c|}{ * Horizontal moment of each pile $(t \cdot m)$} & \multirow{2}{*}{$\begin{array}{l}\text { Horizontal } \\
\text { resisting } \\
\text { moment of } \\
\text { all plles } \\
(\mathrm{t} \cdot \mathrm{m})\end{array}$} & \multirow{2}{*}{$\begin{array}{l}\text { Sharing } \\
\text { ratio } \\
\mu \times(1)\end{array}$} \\
\hline & & & & & 1 & 2 & 3 & 4 & 5 & 6 & 7 & 8 & 9 & & \\
\hline 20 & 39.5 & 2.554 & 22.99 & 61.5 & 2.09 & 1.32 & 2.87 & 0.91 & 0 & 1.19 & 1.79 & 1.32 & 2.93 & 14.42 & 38.5 \\
\hline 40 & 79 & 5.552 & 49.97 & 62.8 & 4.99 & 2.73 & 4.95 & 2.18 & 0 & 2.23 & 4.47 & 2.73 & 5.33 & 29.61 & 37.2 \\
\hline 60 & 118.5 & 8.282 & 75.54 & 62.6 & 7.42 & 4.09 & 7.82 & 3.15 & 0 & 3.26 & 6.78 & 4.09 & 7.96 & 44.57 & 37.4 \\
\hline
\end{tabular}

Table 2. Deflection of Slab by Horizontal Eccentric Load H=200kgf

\begin{tabular}{|c|c|c|c|c|c|c|}
\hline & Direction & Location & kind & Model 1 & Model 2 & Model 3 \\
\hline \multirow{4}{*}{$\begin{array}{l}\text { Horlzontal } \\
\text { displacement } \\
\text { of axis ( } \mathrm{mm})\end{array}$} & \multirow{2}{*}{$x$ direction } & \multirow{2}{*}{$\begin{array}{l}\text { Eccentricity } \\
220 \mathrm{~mm}\end{array}$} & Test & 3.2 & 1.4 & 3.2 \\
\hline & & & Analysis & 2.90 & 1.49 & 3.00 \\
\hline & \multirow{2}{*}{$Y$ direction } & Eccentricity & Test & 3.2 & 3.3 & 1.8 \\
\hline & & $110 \mathrm{~mm}$ & Analysis & 2.86 & 2.95 & 1.58 \\
\hline \multirow{4}{*}{$\begin{array}{l}\text { Angle of } \\
\text { torsion } \\
\times 10^{-2} \\
\text { (rad) }\end{array}$} & \multirow{2}{*}{$x$ direction } & \multirow{2}{*}{$\begin{array}{l}\text { Eccentricity } \\
220 \mathrm{~mm}\end{array}$} & Test & 1.60 & 0.90 & 1.25 \\
\hline & & & Analysis & 1.66 & 0.91 & 1.38 \\
\hline & \multirow{2}{*}{$Y$ direction } & \multirow{2}{*}{$\begin{array}{l}\text { Eccentricity } \\
110 \mathrm{~mm}\end{array}$} & Test & 0.65 & 0.50 & 0.50 \\
\hline & & & Analysis & 0.83 & 0.45 & 0.69 \\
\hline
\end{tabular}

Remark: Analytical values are the SHELL values. 
Table 3. Section Force by Horizontal Eccentric Load H=200kgf

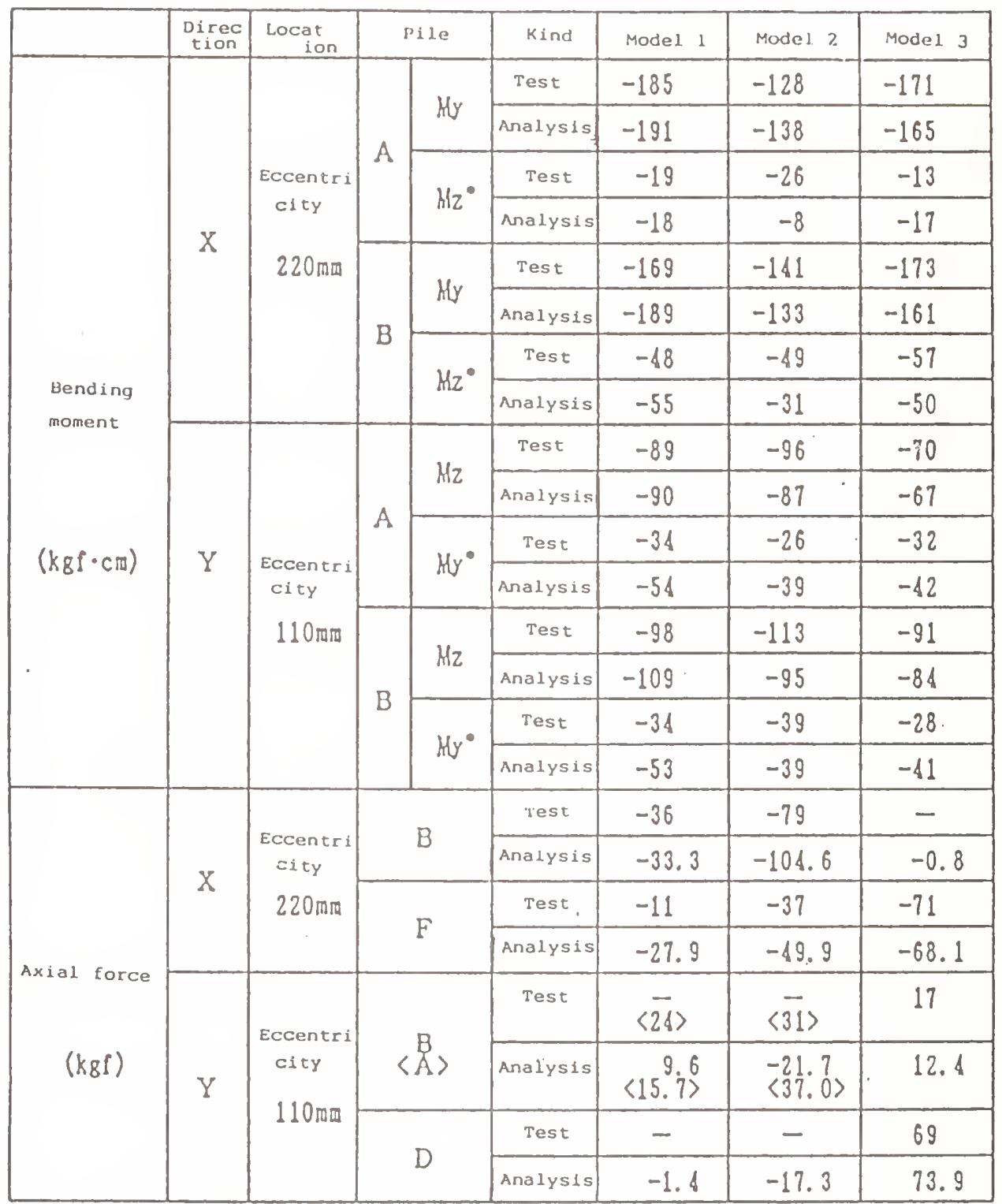

Remark) Analytical values are SHELL values.

Bending moment with * is the moment in the perpendic ular direction to the load.

Table 4. Horizontal Displacement at Slab by $\mathrm{H}=400 \mathrm{kgf}$

\begin{tabular}{|c|c|c|c|c|c|}
\hline Direction & Location & kind & Model 1 & Model 2 & Model 3 \\
\hline \multirow{2}{*}{ X direction } & Eccentricity & Test & 6.2 & 3.0 & 6.2 \\
\cline { 3 - 6 } & & Analysis & 5.81 & 2.99 & 6.02 \\
\hline \multirow{2}{*}{ Y direciton } & \multirow{2}{*}{ Eccentricity } & Test & 6.8 & 6.8 & 3.5 \\
\cline { 3 - 6 } & & Analysis & 5.72 & 5.90 & 3.33 \\
\hline
\end{tabular}

Remark: Analytical values are SHELL values. 


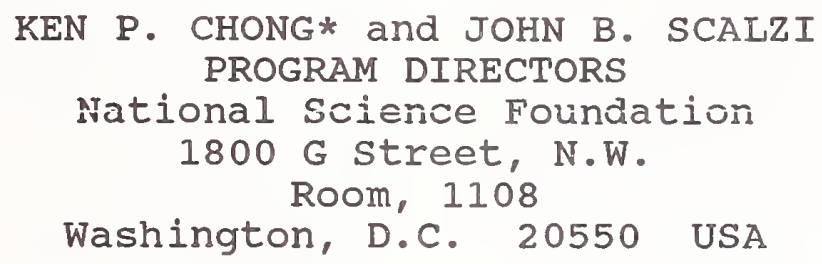

\section{ABSTRACT}

Due to environmental, man-made and natural hazards. infrastructure of public works in the world is deteriorating. Nondestructive evaluation (NDE) is essential for condition assessment for repair, retrofit, rehabilitation, and replacement (if needed) to insure the public safety. In this paper an overview of nondestructive evaluation projects, including a new initiative and four new awards on Quantitative NDE for large structural systems, is presented.

KEYWORDS: Non-destructive evaluation; structures, condition assessment

\section{INTRODUCTION}

The world invests about US $\$ 1,430$ billion annually in the

Note: Part of this paper is
taken from "Overview of Nondestructive Evaluation Projects and Initiative at "NSF by K. P. Chong, J. B. Scalzi and $O$. W. Dillon in Intelligent Structures, Elsevier, London, 1990.

*to present paper. construction of structures, including: buildings (residential, commercial, industrial, etc.), civil works, and utilities, such as

highways, water and sewer structures, railroads, and transmission lines. construction is the largest industry in the world amounting to $10 \%$ of the world's gross domestic product.

Structures are generally the $m \circ s t e x p$ e $n s i v e$ investments/assets in any country. In addition structures have long service life compared with any other kinds of commercial product, and are rarely replaceable once they are erected. Yet the feedback and controls

on the "state of health" of structures are practically nonexistent (compared with say the much less costly automobiles). Nondestructive evaluation is an essential part of this feedback and monitoring system for infrastructures.

During the past several years, many reports have been published concerning the sad state of deterioration of the nation's public works, such as bridges, roadways, water and sewer systems, ports,

harbors, airports, and buildings of all types. According to the 1988 National 
Research Council Report on "Building for Tomorrow" estimates of public infrastructure amounted to \$409 trillion in

1984, and growing rapidly. The U.S. Interstate system, built in the 1950's needs repair, so do most of the state and county secondary roads. Some $42 \%$ of all U.S. highway bridges are inaủequãte and half of school buildings are 50 years or older. In the U. S. alone, recent bridge collapses include:

- Mianus River Bridge Connecticut, 1986, 3 deaths

- Schoharie Creek - New York, 1987, 10 deaths

- Hatchie River - Tennessee, 1989,8 deaths

- Miamis Town River - Ohio, 1989,2 deaths

According to David Aschauer (Chief Economist of U.S. Federal Reserve Bank Chicago), a 1\% increase in public capital causes 1/3\% rise in productivity. From 1971 to 1985 U.S. productivity growth fell 1.2\%, out of which $1 \%$ was attributed to neglect of the infrastructure. If the present infrastructure deterioration continues, the Department of Transportation estimates that the U.S. economy will miss out on:

\section{- $3.2 \%$ growth in GNP \\ - 5.9\% disposable income \\ ○ $2.2 \%$ employment \\ - $2.7 \%$ productivity}

The infrastructure ages and deteriorates with time. The deterioration is mostly a result of aging of the materials, excessive use, overloading, climatic conditions, lack of sufficient maintenance, and difficulties encountered in proper inspection methods. All of these factors contribute to the obsolescence of the structural system as a whole. Ảs a result, repair, retrofit, rehabilitation, and replacement become necessary to insure the safety of the public.

\section{THE PROBLEM}

In order to evaluate the safety of a structure, it is essential to determine the remaining strength of the total system by a performance analysis based upon the strength and inspection data of the materials and the structural system.

A visual inspection process will provide data with respect to the external physical condition of the material such as the degree of corrosion and general deterioration. By past experience and judgement an engineer will evaluate the remaining life of the material and the contribution to the safety of the structure.

Strength determinations may be made by sampling the material and testing it in a laboratory. However, this method destroys some of the structure which subsequently must then be repaired. The repair is usually noticeable and disruptive, as a result, many engineers would prefer a nondestructive technique. 
THE SOLUTION

Although there are many techniques for nondestructive evaluation (NDE) currently available for metals which are used in defense and manufactured products, there are only a few which are available for the construction materials such as wood, concrete, masonry, and steel. These current methods for construction materials are not very reliable and in some instances they can only be used on a comparative qualitative basis. Instruments specifically designed for construction materials and with greater accuracy than those currently available are required in order to quantitatively evaluate the safety of the structure and to estimate its remaining life adequately.

\section{NSF ACTIVITY IN NDE}

The NSF Division of Mechanical and structural systems is encouraging basic research to investigate the requirements to develop suitable instruments for nondestructive evaluation of strength properties and other physical conditions for construction materials. The Program Directors in the Division are encouraging multidisciplinary activities involving electrical, mechanical, chemical, computer, electronic and structural engineers, as suitable for the project to perform group or team efforts in the research projects. Unfortunately, this "encouragement" should not be interpreted as large sums of new money for this approach. Rather this is our personal assessment with which all of us agree.

NSF is also encouraging close cooperation and active participation by the industries involved in the manufacture of nondestructive equipment and/or instrumentation. By joint efforts viable products can result which will be of great help to engineers responsible for the safety and longevity evaluation of structural systems.

As a source of information on the type of questions which the engineering community would like to have answered by the use of nondestructive evaluation techniques, NSF supported two workshops to outline specific needs of the profession. One was held in February, 1988, at the University of Southern California, Los Angeles, and the Proceedings are titled, "Nondestructive Evaluation for Performance of Civil structures." The contact person is Dr. Sami F. Masri. The other workshop was held in June, 1989, at the National Institute of standards and Technology, at Gaithersburg, Maryland, titled International Workshop on Sensors and Measurement Techniques for Assessing structural Performance," organized by Dr. Richard D. Marshall and his associates.

\section{CENTERS AND OTHER NDE ACTIVITIES}

In addition to NDE research done at MIT, Illinois, Cornell, West Virginia, Virginia Tech, New Jersey Institute of Technology, Georgia Tech, etc., the following centers concentrate on various aspects of NDE. 
I. Johns Hopkins Center for NDE (R. Green)

- Heavy on experiment

- Advanced sensors

- Artificial intelligence

- Life cycle management include fracture, fatigue

- Measurement science for

microelectronics

- Process control

The closest project to large structural system is the infrared television for wall thinning of buried pipelines.

II. Iowa state center for NDE (D. Thompson)

- NSF Industry/University CRC

- Modeling efforts emphasized

- Advanced ultrasonic NDE

- Advanced electromagnetic NDE

- $\mathrm{x}=\mathrm{nay}$ \& thermal NDE imaging

- NDE for materials properties

- NDE for advanced composites

- Ultrasonic stress

measurement

III. National Institute of Standards and Technology

- Transducer standards

- Pulse-echo testing of

concrete

- Automated manufacturing

- Metals, plastics, ceramics, paints, etc.

IV. NASA - Langley NDE center (J. Heyman)

- Space structures

- Aging aircrafts

- Imbedded sensors

- smart structures

\section{NSF INITIATIVE}

Believing that "an ounce of prevention is better than a pound of cure," and that NSF should play a leading role in addition to be acting as a catalyst in the "Quantitative Nondestructive Evaluation for Large structural systems" in civil engineering, a NSF initiative was issued in April 1990. The deadline for receipt of

proposals was set at June 1, 1990. The initiative was sponsored by the following four programs, totalling \$1M, over a two year period. Program directors involved are Iisted below.

Dr. John B. Scalzi - structures and Large systems

Dr. Ken P. Chong - structures and Building systems

Dr. Oscar Dillon - Solid Mechanics

Dr. Thomas zimmie Geotechnical, Geomechanics

Academic and research institutions in the United states with engineering, research and educational programs were invited to submit proposals. The contents of the proposal must clearly relate to the research topics described in the Programs of the Division of Mechanical and structural systems of the National science Foundation.

Projects were encouraged to be multidisciplinary in nature involving investigators from one or more departments at a single institution or from several institutions wherever the required expertise may be locatea. It was envisioned that projects may include researchers from the following engineering and science disciplines: structural, 
mechanical, material science, electrical, geotechnical, computer science, chemical or chemistry, electronic and others as appropriated. A team or group effort was strongly encouraged to achieve the desired result and final product of research. Contributions of all the participants must be combined into a single integrated proposal which conformed to the usual requirements and Iimitations of a proposal length. Each researcher must have a scope of work which contributes to the entire project.

Industry collaboration is highly desirable and may be in the form of participating personnel, loan of equipment, gifts, supplies of various kinds, and/or financial contributions. The academic institution must be the prime research management organization.

A panel of experts have been convened to evaluate the proposals on a competitive basis. The investigators and the synergistic benefits derived, as well as how these interactions are to be organized and performed, are examined.

SPECIFIC TOPICS OF THE NSF INITIATIVE

Research efforts are to be directed toward increasing fundamental knowledge of quantitative nondestructive evaluation of construction materials and their application to large structural systems of wood, concrete, masonry and steel. The data developed for equipment may be for the material properties alone or for the fabricated forms as total systems. Some data may be used to determine how each system or material deteriorates with time and excessive loads. The data and prototype resulting from the research should be of such a nature that the resulting equipment may be useful for practitioners, and can be produced as a viable portable and economical commercial product.

SUGGESTED RESEARCH TOPICS OF INTEREST

The following topics of interest were published in the NSF Initiative.

- Determination of wood properties - above and below ground

- Determination of concrete properties - above and below ground

- Determination of masonry properties

- Determination of steel safety remaining as a result of corrosion

- Determination of initial cracking in steel and concrete, including welds and rebars due to fatigue, design faults

$$
\text { fabrication, or }
$$

- Rate of deterioration in steel or concrete

- Early warning of impending failure

- General inspection of the 
degree of deterioration in steel, concrete, masonry, soil retaining systems and wood

- Determination of the effective length of piles of wood, steel, or concrete, and the amount of erosion or scour in foundations

- Methodology for predicting the remaining safe life of large structural systems

FROJECTS SUTPEORTED BY THE INITIATIVE

The recently awarded projects are briefly described below. The projects are in four basic areas of interest to the structures, Solid Mechanics, Geomechanics, and Building systems programs of the National Science Foundation.

1. Fiber optic sensors for Strength Evaluation and Early Warning of Impending Failure in Structural components; Dr. Edward G. Nawy, Mohamad H. Maher - Rutgers University, The state University of New Jersey

The objective of this research is to dovelop and verify by experimentation the optical fiber strain and stress sensor systems for on-line, accurate, and real time monitoring of critical components of structural systems under service load conditions. The application of these sensor systems will permit easier inspection of structures for impending failures.

A series of experiments are to be undertaken on scale models of reinforced and prestressed concrete structural beams, rolled structural steel sections, and beam to column connections.

2. Nondestructive Methods of Assessing Damage in Reinforced Concrete structures: Drs. Kenneth H. Stokoe, Jose M. Roesset and James O. Jirsa University of Texas-Austin

The objective of this research is to study nondestructive methods based on the propagation and attenuation of stress waves for evaluating (1) the degree of damage to structural and foundation elements, (2) the location and extent of that damage, and (3) the extent and quality of repair. One of the key thrusts of this research will be the integrated study of both body and surface stress waves. The technigues to be used will be selected in terms of the type of structural elements and their accessibility for use of nondestructive test equipment. The rapidiy-developing technique based on surface wave measurements will be used where there is access to an exposed surface of the structural element which has dimensions similar in magnitude to the depth of the element veing investigated. The spectral Analysis of-Surface-Waves (SASW) method will be used.

3. Micromagnetic surface studies of Materials for Nondestructive Evaluation, Dr. David Jiles - Iowa state University,

Dr. W. A. Theiner - University of Saarland, Federal Republic of Germany

This project is a joint 
research effort into the use of magnetic surface studies for nondestructive evaluation between the center for NDE at Iowa state University and the Fraunhofer Institute for Zerstorungfreie Prufverfahren (NDT) at the University of Saarland in west Germany. The objective of the research is to identify alternating current magnetic measurements which can be made on the surfaces of constructional steel components to evaluate their mechanical condition. Such methods, in which the penetration of the magnetic field is restricted to the surface, will be useful for determining the mechanical state of the surface as a result of shot peening, grinding, surface hardening and residual surface stress. It is aiso known that in fatigue failure, the fatigue crack initiates at the surface and then propagates into the bulk of the material. Monitoring of the surface condition is therefore critical in identifying the onset of failure in the material as a whole.

4. Fundamentals of Embedded optical Fibers In structural Concrete; Drs. K. S. Kim, T. F. Morse - Brown University

The thrust of this project will be to combine the knowledge and expertise of faculty members from solid mechanics, materials science, civil engineering, and optical sensing to obtain a more quantitative description of the response of structural concrete to external loads. By embedding optical fibers in a concrete structure during the fabrication process, it is possible to sense, through a variety of techniques, the local internal state of the structure. This research will aid in the prediction of the behavior of such materials, will point toward directions for the improvement of structural concrete, and can be applied to the retrofitting of existing structures with novel sensors.

\section{NSF SUPPORTED WORKSHOP ON NDE}

- "NDE for performance of Civil structures," Sam Masri (USC), $2 / 88$.

- "International Workshop on Sensors and Measurement

Techniques for Assessing Structural Performance"

Richard MarshaII (NIST), 6/89.

- "Colloquium

Monitoring

Infrastructure

on Facility

and for Management"

(Building Research Board/NRC).

- "NDE of Construction Materials and Large

Structural systems," (ColoradoBoulder), $10 / 90$.

- "NSF-ATLSS Workshop on Sensor and Signal Processing for structural control" (NSF), 2/91.

\section{SUMMARY AND CONCLUSION}

An overview of non-destructive evaluation projects at NSF and a discussion on the new ivs initiative and projects on the "Quantitative Nondestructive Evaluation for Large structural systems" are presented. The authors hope that this paper will act as a catalyst, sparking interest and further 
research in quantitative nondestructive evaluation of civil engineering structures. This paper reflects the personal views of the authors, not necessarily those of the National Science Foundation. 


\author{
KEN P. CHONG, SHIH-CHI LIU \\ and HENRY J. LAGORIO \\ PROGRAM DIRECTORS, \\ NATIONAL SCIENCE FOUNDATION \\ WASHINGTON, D.C. 20550 USA
}

ABSTRACT

The U.S. National Science Foundation spends over U.S. \$40 million annually for basic research in civil engineering, covering areas in structures, earthquake engineering, building systems, solid mechanics, geomechanics and environmental engineering. Significant amounts of basic knowledge and technology have been advanced through these research efforts. Concrete engineering, including structures and material aspects, is an important component of civil engineering research. In this paper current and recent research projects and findings are discussed.

Keywords: Concrete structures; high performance concrete; seismic concrete structures; fracture of concrete; micromechanics.

\section{INTRODUCTION}

Structural failures emphasize the need for material research. The short-term solution is to have innovative NDE (nondestructive

evaluation) sensors to evaluate and diagnose the integrity and predict the remaining useful life of various structures. The long term goal should involve creating and designing high-strength, high tech (HSHT) materials with desirable structural properties and reliable performance specifications.

Advanced ceramics and high performance concrete are HSHT materials that have a lot of potential. Among the desirable properties, ceramics is highly resistant to corrosion and heat. However, one of the major drawbacks of such materials is its brittleness, failing suddenly without any warning. Researchers at Michigan and others have tried mixing fiber in ceramics, improving its ductibility, with some degree of success. Others have concentrated on the micro-mechanics, metallurgy, surface chemistry and characterization. High strength concrete is a form of ceramics having compressive strength as high as $40 \mathrm{ksi}$ (about 10 times normal concrete) which would enable future high rise buildings to be built with concrete. One of the major problems with high strength concrete is that the fracture toughness $\left(\mathrm{K}_{l c}\right)$, which is a measure of the energy related to fracture, does not increase proportionally, and needs to be improved for structural performance.

The National Science Foundation, through its engineering programs in Structures, Geomechanics and Building Systems, and the Earthquake Hazard Mitigation programs, in addition to the Engineering Research Centers (e.g. at Lehigh University) and the Science and Technology Centers (NSF Center for Advanced Cement-Based Materials), supported research in concrete materials and structures.

Some of the NSF supported projects are listed below:

* Mathematical Modeling of Concrete Creep and Shrinkage

* Research Needs for Concrete Masonry

* Rehabilitation, Renovation and Reconstruction of Buildings

* High Strength Concrete

* Fiber Reinforced Concrete

* Fracture Toughness

* Micro-mechanics of Concrete

* Shear in Reinforced Concrete 
* Physics and Chemistry of Cement-based Materials

* Behavior of Concrete in Cold Climate

* NDT of Concrete

* Fiber Optics in Concrete

* Continuous Lightly Reinforced Concrete Joist Systems

* Highway Bridges

* Construction Methods

* Automation/Robotics

* Non-Distinctive Evaluation

* Seismic Precast Structures

* Structural Controls

* International Cooperative Initiatives

* Full-Scale Seismic Pseudo Dynamic Testing of Reinforced Concrete Structures

\section{HIGH PERFORMANCE CONCRETE}

More than half of the NSF supported research projects are related to high performance concrete (HPC), which is defined as "Concrete having desired properties and uniformity which cannot be obtained routinely using only conventional constituents and normal mixing, placing, and curing

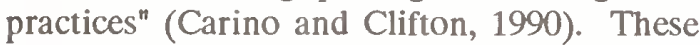
properties include: high strength, high toughness, durability, enhanced workability, freeze-thaw durability, etc. National programs on HPC exist in Japan, Canada, Norway, and France. Generally chemical admixtures or fibers can be added in concrete to achieve certain mechanical properties. Concrete admixtures (Rosenbaum, 1991) include: highrange water reducers (superplasticizers), retarders, accelerators and air-entraining agents. In the United States, W.R. Grace and Master Builders are the two largest suppliers of the concrete admixtures, accounting for about twothirds of the U.S. admixture market. A new development (2) is on extended-set retarders and activators, which indefinitely keeps fresh concrete from setting (until it is mixed with an activator).

Besides the basic concrete research sponsored by the NSF, other federal programs, such as the Strategic Highway Research Program (SHRP), supports HPC and concrete research $(3,4)$.

\section{NSF PROJECTS IN PROGRESS}

The following is a list of examples of ongoing NSF research projects in concrete. Highlights of some of these projects will be presented at the Symposium.

* Bazant (Northwestern) "Nonlinear and Probabilistic Theory for Concrete Creep." The linear modeling of concrete creep with aging has matured, and it is now appropriate to develop a nonlinear theory. This research will establish such a theory, based on micromechanics analysis of the solidification process of portland cement and nonlinearities due to strain-hardening and development of backstress. The model will first be developed for basic creep at constant humidity and temperature, and is then generalized to include the effects of variable humidity and temperature. This model is based on the hypothesis that the rate of bond ruptures (which is the source of creep) depends on the microdiffusion flux of water molecules in cement gel. The model will be extended to include probabilistic aspects of material parameter uncertainty, including correlation of random parameters, and fluctuation of environmental conditions. Random effects of environment are handled by a new sampling scheme based on spectral approximations solutions from diffusion theory. A numerical algorithm for step-by-step integration in time, in finite element programs will also be developed. Creep experiments are to be conducted with a novel large triaxial-torsional testing machine with temperature control. Hollow test cylinders will be subjected to triaxial loading at various temperatures with confining pressure which prevent cracking or simultaneous strain-softening due to drying or temperature change. The results will improve creep predictions for radioactive waste storage, large span bridges, nuclear reactor accidents, concrete shells and tanks, buildings and other concrete structures.

* Brock (Kentucky) "Transient Studies of Dislocation-based Micromechanical Effects in Fracture."

* Buyukozturk (MIT) "A Study of Fracture Behavior in High Strength Concrete." 
* Darwin/McCabe (Kansas) "Improving Development Characteristic of Reinforcing Bars" (Co-sponsored by Civil Engineering Research Foundation).

The purpose of the research is to investigate the shear strength of lightly reinforced concrete flexural members and develop recommendations for modifications in current design provisions. The research includes tests of 21 continuous two-span T-beam and joist systems to identify the effects of flexural and shear reinforcement on shear capacity. Flexural reinforcement ratios of 0.75 and 1.0 percent and levels of shear reinforcement ranging from 0 to $75 \mathrm{psi}$ are included. The T-beams extend earlier work at the University of Kansas, and are aimed at directly addressing the level of safety provided by current shear design provisions for lightly reinforced members. The joists represent typical configurations used in practice.

Efforts during the first year have concentrated on evaluating the shear capacity of continuous lightly reinforced T-beams. Recently a literature survey has been completed, forms have been constructed, and six specimen cross-sections without shear reinforcement have been tested. Of the six sections, only one provided a capacity in excess that predicted by the ACI Building Code. Strengths between 80 and 90 percent of the predicted strength were obtained in the other five cases. If borne out by the next series of tests, these observations will have a major impact on design practice, for they firmly establish for the first time that a wide range of reinforced concrete beams have been designed with a reduced margin of safety for shear. Analytical evaluation will include a comparison of the cracking shears with existing empirical and analytical expressions. The contribution of concrete, shear reinforcement, dowel action, and aggregate interlock to shear strength will be estimated. Fracture mechanics concepts are to be applied to the failure of beams without shear reinforcement and evaluate the applicability of truss models to lightly reinforced members with shear reinforcement.

* Gopalaratnam (Missouri), Shah
(Northwestern), Batson (Clarkson), Criswell (Colorado St.), Ramakrishnam (SDSM\&T) and Wecharatana (NJIT) "Fracture Toughness of Fiber Reinforced Concrete (FRC)"

- study specimen size, loading configuration/rate.

- evaluate currently used toughness and specifications.

- provide basis for the use of strength/toughness data.

- recommend guidelines in specifications.

* Hawkins Kobayashi (Washington) "Mixed Mode Fracture of Concrete."

The objective of the proposed research is to continue prior University of Washington studies on mixed-mode concrete fracture aspects of diagonal tension failure in reinforced concrete members. Specifically, the shear transfer mechanism, which is thought to resist stable crack growth, will be studied using crack-line wedge-loaded, double cantilever beam specimens with short starter cracks and various loading histories which are crack-length dependent. Moire interferometry will be used to measure simultaneously two orthogonal displacement fields from which the crack opening displacement and the slip of stably growing diagonal tension cracks will be determined. Moire data together with the loading data will be used interactively with a finite element code to deduce the crack closure and shear forces in the fracture process zone under mixed mode loading. Mixed mode stable crack growth criterion will be deduced from this hybrid experimental-numerical analysis. The results will be correlated with fractography and profilometer analyses of the fractured surfaces in order to assess the relative micromechanic contributions of the various constituents (hardened cement paste, coarse aggregate and fine aggregate, etc.) to mixed mode concrete fracture.

* Hinze/Holt (Washington) "Expansive Cements"

- mix with water in bore holes, etc.

- use in liu of explosives

- measure expansive stresses

- geomechanics 
* Hover (Cornell) - To construct durable concrete.

- $60 \mathrm{ksi}$ automatic mercury porosimeters were built, have been used in a microsilica-based concrete parking garage.

* Hsu (Houston) "Shear in Reinforced Concrete."

Shear action is an important factor in the failure of reinforced concrete structures. A softened truss model theory has been developed that is capable of predicting the behavior of various types of structures when shear is predominant. The first objective is to generalize the softened truss model theory so that it can be applied to situations where shear (torsion) is combined with axial loads. The second objective is to perform tests on 40 full-size reinforced concrete panels in order to determine the material laws required in the general theory, including the softening law, the constructive law of cracks, and the law governing the contribution of concrete. The research are being carried out in a $\$ 440,000$ panel-testing facility recently completed at the University of Houston. This facility consists of a giant steel frame embedded with 40 jacks of 100-ton capacity each, which can test reinforced concrete panels 55 inches square and up to 16 inches thick. Establishment of a general truss model theory in conjunction with the finite element method will permit one to predict the behavior of a whole range of structures subjected to membrane stresses (walls and shells). A few full-size panels made of high performance concrete are being tested.

* Kangari (Georgia Tech) "Advanced Technologies and Materials in Concrete Slipforming."

* Lee and Chung (SUNY-Buffalo) "Effect of Freezing Cycles on the Mechanical Behavior of Concrete."

- 9 to $12 \mathrm{ksi}$ concrete is planned for year 2. - low cycle

* Li (Michigan) "Fracture Testing Technology for Advanced Ceramic and Cementitious

\section{Matrix Based Composites."}

This project investigates the bridging processes of quasi-brittle materials by means of a unique fracture testing technology developed by the Principal Investigator, with specific focus on high strength concrete, advanced ceramics and their composites (e.g. metglas and polymer fiber reinforced high strength concrete; and silicon carbide reinforced silicon nitride to be manufactured and provided free of cost by Norton Ceramics). The objectives of the proposed work are (1) to refine and extend a testing technique based on sound theoretical principles for testing of non-linear fracture parameters, including the post-cracking forcedisplacement curve; and (2) to develop a data base of accurate fracture parameters for high strength concrete and ceramics which exhibits the development of process zones large enough to invalidate classical linear elastic fracture mechanics treatment.

The test technique requires stable measurement of load versus load point displacement and crack tip opening displacement beyond the peak load. Successful load tracking at this stage requires system stiffness from both the loading frame, loading train and specimen.

* Monteiro (Berkeley) - Micromechanics in Concrete.

* Naaman (Michigan) "High Performance Fiber Reinforced Cement Composites: International Workshop." 6/23-26/91, Stuttgart, Germany (with Reinhardt and German DFG).

* Nanni (Penn State), "Aramid Fiber Reinforced Concrete."

* Nawy/Maher (Rutgers) "Fiber Optic Sensors for Strength Evaluation and Early Warning of Impending Structural Failure."

The main objective of this proposed research is to develop and test optical fiber strain and stress sensor systems for on-line, accurate, and real-time monitoring of critical components of structural systems under service load conditions. 
In this proposed research the combined resources of Rutgers' Civil Engineering Department and those of its center for Fiber Optic Material Research Program (FOMRP) will be devoted for development and implementation of both discrete and continuous optical fiber strain/stress sensors for detection and warning of imminent structural failures for both concrete, and steel structures. In the case of concrete structural components, the sensor system will be evaluated under both embedded (internal) and exposed (external) condition; where the latter is attached to existing structures and the former is embedded in the structure during its construction.

* Ross (New Mexico) "Dynamic Fracture in Quasi-Brittle Materials: An Experimental Study."

* Sansalone/Pratt (Cornell) "Neural Network in Non-Destructive Testing."

- impact-echo develop by Carino and Sansalone.

- automating and simplying impact-echo signal analysis/reduction.

- applicable to HPC.

* Englekirk (Englekirk \& Hart) "Concept Developments for Precast Concrete Structural Systems."

This is a part of the coordinated research program in seismic precast concrete structures. This project will develop structural concepts for using precast concrete in seismic zones of the United States. Due primarily to current building codes and lack of relevant analytical and experimental data, precast concrete is not currently used in U.S. seismic zones.

Initially, several regional research workshops will be held around the country. These will be limited in size to facilitate interaction among the participants who will be invited to represent various contributors to the design/construction industry (including architects, developers, researchers, etc.)

Next, the economic viability as well as structural feasibility of the design concept will be investigated. Design documents will be prepared using the concepts resulting from the workshops. Feedback about economical ways to improve the details proposed from general contractors will be obtained. Potential use of automated processes will also be considered.

The analytical model development and design criterion development projects will require a feedback from design engineers and other industry representatives. The required information to academic researchers and other means will be provided throughout the duration of this project.

* Stanton (Washington) "Connection Classification and Modelling for Precast Seismic Structural Systems."

* Swartz (Kansas State) "Influence of Concrete Constituents on Mode 1 Fracture Characteristics"

Since the processes of initiation and growth of cracks which lead to fracture in concrete must surely be influenced by the various components in the mixture (as well as state of stress, curing conditions, moisture content, etc.), it would be desirable to verify that the proposed testing standards are suitable for a wide range of key mix parameters.

Concomitantly, the influence of different mix parameters on fracture properties including the shape of the crack front and process zone also may be determined.

The successful completion of this work will provide further evidence that fracture mechanics is a viable and useful tool for the characterization of the behavior of cementitious materials subjected to stress and for the development of design formulas for shear strength, bond strength, deflection response and crack width of reinforced concrete structures in which size and brittleness effects can be considered explicitly.

* Keiser (Illinois) "An Experimental Setup to Investigate Dynamic Torsional-Translational Response of Reinforced Concrete."

* Azizinamini (Nebraska) "Design and 
Detailing of Transverse Reinforcements for High Strength Reinforced Concrete Columns Subjected to Seismic Loading."

The development and investigation of high strength reinforced concrete applications comprises a major advance in building planning and design because of its increased capacities. The present state of high strength reinforces concrete design needs indepth study to accurately predict the anticipated performance of its many component parts under dynamic lateral loading such as earthquake loads. High strength reinforced concrete is also a sophisticated and complex building material due to the large number of design and construction constraints which influence its quality, long term behavior, and final stress values. In order to more accurately model its structural response, it is necessary to develop a fundamental data-base of performance standards.

The proposed project is concerned with the development of design and detailing criteria for transverse reinforcement in high rectangular columns with compressive strengths exceeding 15,000 psi. Its objectives are to determine methods to provide sufficient ductility for earthquake-resistant structures. The research plan includes both experimental and analytical studies. At least twelve large-scale column specimens will be tested and be subjected to axial and repeated lateral loads at increasing displacements. From these tests, data will be collected for the analytical documentation of the effects of concrete compressive strength, axial load, and types of transverse reinforcement on the ductility of high strength concrete columns.

* Wood (Illinois) "Experimental Investigation of the Strength Stiffness and Deformation Capacity of Slender Reinforced Concrete Walls."

During the past 20 years, the satisfactory behavior of many reinforced concrete buildings during damaging earthquakes has been attributed to the presence of structural walls. Structural walls provide stiffness to the building systems, and control the drift and damage in the buildings. A critical concern for the design of structural walls in seismic regions has been the specification of reinforcement details to insure ductile response. The performance of buildings in Vina del Mar during the March 1985 Chilean earthquake appears to contradict professional opinion, because the buildings performed well and the reinforcement details were essentially nonexistent.

This research project develops methods for determining the strength, effective stiffness, and deformation capacity of reinforced concrete walls. Walls are used as the primary lateral-load resisting system in many reinforced concrete structures, yet many fundamental concepts have not been verified experimentally.

The experimental phase of the project involves lateral load tests of reinforced concrete walls. Major variables include the geometry of the cross section, amount of web reinforcement, type of loading, and amount of confinement reinforcement. Walls are subjected to static load reversals and dynamic loading.

The analytical phase of the project uses the observed response and the measured response of the experiments to develop a hysteresis model suitable for reproducing nonlinear response in shear and flexure. Methods are developed to determine the strength, likely mode of failure, and effective stiffness of structural walls during the design process.

* Wight (Illinois) "Earthquake Type Loading on R/C Beam-Column Connections: Special Cases of Wide Beams and Eccentric Beams."

* Moehle (Berkeley) "Seismic Resistance and Retrofit of Post-Tensioned Flat-Plate Floors."

The flat-plate floor system is generally recognized as an unsuitable structural system for resisting high-intensity lateral loads. Nevertheless, in regions of high seismicity in the U.S. this structural system is still one of the most widely used systems in multistory buildings braced by stiffer ductile frames of structural walls. Recent research has shown that even in these braced structures the conventionally-reinforced flat plate is 
susceptible to failures if gravity shear stresses on the floor and lateral drifts are not controlled to acceptable values. Performance of the unbonded post-tensioned flat-plate floor in a similar situation is not well known. This research studies the behavior of this structural system.

The research involves design, construction, experimental testing, retrofitting, and analysis of unbonded post-tensioned flat-plate construction subjected to gravity and reversed cyclic lateral loads simulating earthquake effects. Both isolated connections and a three by three bay model floor are studied. Effects of gravity load intensity, lateral load intensity, and retrofitting techniques are the primary variables in the study. The experiments determine the suitability of this structural system to support gravity floor loads when subjected to cyclic lateral drifts typical of those occurring in buildings during intense ground shaking. One of the primary objectives is to establish guidelines for design of this structural system.

* Eberhard/Sozen (Illinois) "Experiments and Analysis to Study the Seismic Response of Reinforced Concrete Frame-Wall Structures with Yielding Columns."

* Hsu (Houston) "Reinforced Concrete Framed Shearwalls in Earthquake."

\section{NSF CENTER FOR ADVANCED} CEMENT-BASED MATERIALS

$\begin{array}{ll}\text { Northwestern (Shah) } & \text { Michigan } \\ \text { Illinois } & \text { NIST }\end{array}$

\section{Areas of Investigation}

* Processing procedures (control of initial/final structure).

* Microstructure (porosity, damage, interfaces)

* Bulk Properties (fracture mech., durability, FRC)

* Modeling (generic, interfacing, simulation, database)

* Design of New Materials (improved properties through material science)

\section{REFERENCES}

1. N.J. Carino and J.R. Clifton, "Outline of a National Plan on High- Concrete: Report on the NIST/ACI Workshop, May 16-18, 1990," NISTIR 4465, National Institute of Standards and Technology, USA, Dec., 1990.

2. D. B. Rosenbaum, "Concrete Admixtures," Engineering News Record, pp. 35-40, Jan. 21, 1991.

3. Strategic Highway Research Program, "Concrete and Structures: Progress and Products Update," National Research Council, USA, Nov., 1989.

4. "Nationally Coordinated Program of Highway Research, Development, and TechnologyAnnual Progress Report FY 1990," FHWA-RD-90-109, Federal Highway Administration, USA.

5. T. Hsu and S. Mau, "International Workshop on Concrete Shear in Earthquake." University of Houston, January 1991. 


$$
\text { . }
$$




\author{
Martin C. Miller ${ }^{1}$, William E. Roper ${ }^{2}$, \\ Leon E. Borgman ${ }^{3}$, and Joannes J. Westerink ${ }^{4}$
}

\section{ABSTRACT}

The historical record of tropical storms at specific sites in the Gulf of Mexico is too short to provide adequate statistics for estimates of extreme waves and water levels for engineering design and project economic evaluation. This paper describes a method that has been applied by the Coastal Engineering Research Center (CERC), U.S. Army Engineer Waterways Experiment Station to expand the available suite of storms and sample the historical storm data set to obtain reliable, statistical parameters of storm effects. Parameters from historical storms were used, along with additional, hypothetical storms, to obtain relationships between the parameters associated with storm characteristics and storm effects of wave height, water level, and shoreline recession. Water level estimates were obtained using a finite element storm surge, tide and current model which was recently developed and tested for the Gulf. This model offers considerable advantages over the finite difference models that were previously used for this purpose. The extreme conditions at the site were obtained using a "bootstrap" statistical technique to reduce the number of storms modeled. The methods described were used to evaluate beach fill design alternatives at Panama City Beach, Florida in the northern Gulf of Mexico.

KEYWORDS: Panama City Beach, Florida; modeling; water levels; storm surge; wave heights; "bootstrap."

\section{INTRODUCTION}

Panama City Beach, Florida is a recreational beach located in the northern Gulf of Mexico along the panhandle of west Florida (Figure 1). The beach is heavily developed over much of its eighteen mile length, with single family homes and condominiums built along the waters' edge. Inlets at each end of the beach provide access to small boat harbors and quiet coastal lagoons. The beach is susceptible to flooding from hurricane related storm surge, which could result in great loss of life and property. Beach and flood protection is considered necessary but the recreational and aesthetic value of the area must also be preserved. An artificial berm is being considered along beach front to protect the region from flooding. In order to determine the economic justification for the project and to effectively design the berm, it is necessary to evaluate the degree of protection it will provide during storms of various magnitude that may impact the site. From the designers standpoint, it is desirable to know the return period of the storm that would be protected against for a selected design. From the economic standpoint, project justification requires that the benefit of the project exceed the cost. This requires an economic model that allows assessment of the damage for an expected flooding level.

1 Chief, Oceanography Branch, Coastal Engineering Research Center, U. S. Army Engineer Waterways Experiment Station, Vicksburg, MS 39180-6199

${ }^{2}$ Assistant Director, Directorate of Research and Development, Civil Works Program, Headquarters, U.S. Army Corps of Engineers, Washington, DC 20314-1000

3 L. E. Borgman, Inc., 2526 Park Avenue, Laramie, WY 82070

4 Assistant Professor, Civil Engineering, University of Notre Dame, Notre Dame, IN 46556-0767 
In the northern Gulf of Mexico, the design storm is the hurricane. These non-frontal storms enter the Gulf of Mexico from the Atlantic (and sometimes the Pacific) during the months of June through November. The months of most frequent occurrence are August through October. During the period from 1871 to 1973 , a total of 281 tropical cyclones entered the Gulf coast of the United States, an average of 2.75 storms per year. These were, by no means, evenly distributed in time or space, however. A detailed analysis of these storms and their characteristics can be found in Ho, et al. (1987) and later publications of the National Oceanic and Atmospheric Administration (NOAA), National Weather Service.

Though records exist of many storms that have occurred throughout the Gulf, the historical occurrence at any specific site is usually insufficient to provide a statistically reliable basis by which to calculate extreme values of waves, water levels, and the resulting shoreline recession for long return periods. Designs of coastal structures and beach fills are often based on the fifty or one-hundred year storm condition. There are virtually no areas where measurements of the desired parameters have been made for that length of time.

Designers must, therefore, rely on numerical models to obtain the necessary statistical data. The spectral wave model, SHALWV, has been developed at CERC and has been used to determine wave conditions in a number of coastal applications including hurricanes (Jensen, et al., 1987; Hughes and Jensen, 1986; Abel, et al., 1989). It will reliably provide a time series of the wave height and period on a grid overlying the area of interest provided the wind distribution for the region is known. The winds are obtained from direct measurement, in the case of more recent storms or they can be calculated using the, well established, Standard Project Hurricane (SPH) model and the relevant parameters of storm path and landfall location, speed of movement, central pressure deficit, maximum wind speed, and radius to maximum winds.

Historical data on the tropical storms and hurricanes that impact the northern Gulf of Mexico have been collected and published since the late 1800's. An archive of storm parameters is maintained by the National Hurricane Center in Miami, Florida. These data can be used to obtain the landfall location, path, central pressure, maximum winds, and (sometimes) radius to maximum winds for storms that impact the site of interest. The time histories of wave conditions and water levels, required for engineering design or project evaluation, are not included in the data and, except on rare occasions during the most recent storms, measurements of these parameters do not exist. Reliable measurements of recession rate are virtually nonexistent.

\section{WATER LEVEL MODEL}

Until quite recently, finite difference models have been used to calculate the water level due to tides and storm surges in coastal areas. These models require that the area of interest be discretized with regular spatial resolution, typically one degree by one degree, or with nested grids of smaller resolution in areas of particular interest. A fully non-linear finite element approach has now been formulated that allows greater flexibility in the representation of complex boundary geometry. This model, developed by Westerink, et al. (1991) and by Luettich, et al. (1991) has been applied to calculate the tide in the entire Gulf of Mexico and has been calibrated to match measured tidal response at twenty tidal stations around the Gulf. A finite element grid was created to cover the entire area (Figure 2) with the particular area of interest for water level calculations along the northern Gulf of Mexico from Mobile Bay to the Florida Bight (Figure $3)$.

The Mobile Bay area is the site of intensive investigations in the Army Corps of Engineers, Dredging Research Program. One of the elements of this $\$ 35 \mathrm{~m}$ dollar, five year program is to determine the potential for resuspension of dredged material disposed of in the nearshore zone, within the potential reach of waves and currents. This has required the determination of the water level during all 
tidal stages and during periods of hurricanes that affect the Gulf, in order to describe the detailed structure of the bottom boundary layer under the combined influence of waves and currents. The second area of interest is the beach berm construction at Panama City Beach, Florida. Though no additional projects are presently planned, the northern Gulf of Mexico is heavily used for business and recreation and it is expected that detailed knowledge of the water level along the coastline will eventually be required.

A grid of triangular elements was constructed over the entire Gulf of Mexico. The density of triangulation was determined in relation with the depth over the different areas investigated and the need for accurate results at selected sites. The grid coverage for Panama City Beach and the adjacent offshore area are shown in Figure 3. Typical grid spacing in the open ocean is about 27 nautical miles $(50 \mathrm{~km})$, while nearshore the spacing was reduced to 6600 yards (2000 meters) for a coastal segment. The smallest grid element was 300 yards (330 meters). The ocean tide was induced at the boundary of the Gulf, i.e. at the Straits of Yucatan and the Straits of Florida, as well as by tidal potential forcing within the interior domain. The input variables include earth rotation and a constant bottom friction term. No additional tuning of the model was performed for the calculation of the tides. Comparison of model and measurements for several tide stations along the Gulf are shown in Figure 4. The tides are shown to be accurately calculated at these stations from Mobile in the west to the Florida Bight in the eastern side of the Gulf.

Once the grid was set up and confirmed for the tides, the model was applied to determine the water level due to hurricane storm surge at Panama City Beach. The finite element approach allows the calculation of storm surge over the entire Gulf using the, well established, tidal boundary conditions at the measurement stations. This has the considerable advantage that the boundary conditions do not have to be tuned for individual storms and, therefore, provides a much greater predictive capacity for the model. The great flexibility of the triangular finite element grids allowed the establishment of the proper resolution of coastal features. If these had not been properly resolved, the storm surge would have been seriously underpredicted.

Water level data have been collected at tidal stations located near the beach, and observations of high water were available for post-storm surveys made by Corps of Engineer personnel and others. The water levels from hurricane Kate (November 19-22, 1985) were simulated and are compared to measurements at locations east and west of the landfall location (Figure 5). Storm track, central pressure deficit and radius to maximum winds were used in the (SPH) model to calculate the wind field over the Gulf of Mexico. These show that the model accurately predicts the surge elevation, particularly on the eastern, or "dangerous" semi-circle, of the storm. The results were only slightly less successful on the western side. This was judged to be a result of the SPH model's inability to accurately represent the changes in wind speed in the transition zone from land to water.

\section{STORM SELECTION}

There are several ways in which reliable statistics for determining storm effects may be obtained. The reconstruction of historical storm activity provide a direct, concrete summary of what is likely to have occurred in the past storms. When studies are concentrated on a particular local site, however, it is unlikely that a sufficient number of storms have occurred over the period of record to provide reliable statistical measures. The population of storms for the last 75 years may show apparently random variation in number of storms and storm intensity that are difficult to ascribe to local climatology. Rather, it seems more likely that future storm activity will possess sufficient sampling variability to fill in the present gaps in the historical data.

There are at least two statistical procedures that can be employed to utilize the general statistics of the historical storm data and analyses, but which allow the future to have realistic variation from the past. (1) The 
storm climatology can be used to establish joint probability laws for the geometric and intensity parameters of the storms, and these can be used with substantial subjective engineering judgement to select typical storms with estimated probabilities of occurrence as input to the engineering studies. (2) The vectors of geometric and intensity parameters can be used in an extension of statistical procedures, known as "bootstrap" techniques to simulate a large population of storm activity (Efron, 1982; Borgman, 1990).

The pure bootstrap method uses random selections from the historical population to compute some statistic of interest which depends on the data set. For example, suppose that $\mathrm{x}_{1}, \mathrm{x}_{2}, \mathrm{x}_{3}, \ldots, \mathrm{x}_{\mathrm{n}}$ are independent observations in the sample taken from some population. It is a simple matter to calculate the 95th percentile of the data. The single sample of data can be used to compute one value of this percentile. If many such samples were available, it would be possible to calculate the 95th percentile for each and to determine the standard deviation. Since only one sample is available, however, it is not possible to calculate the standard deviation.

A surprisingly accurate estimate of the standard deviation can be obtained by repeatedly drawing $\mathrm{n}$ observations from the sample population with replacement. This can be done rapidly in a computer until a large number (say, 10,000) of synthetic samples of $n$ observations are assembled. It has been shown that the standard deviation for the statistic, which was prepared from the synthetic bootstrap samples, is not much different from what would have been obtained if one had taken a large number of independent samples from the original population, calculated the statistic from each of these real samples, and computed the standard deviation (Efron, 1990).

The basic bootstrap procedure does not allow for the occurrence of values outside of the historical data set. This is probabiy satisfactory for relatively large historical data sets when dealing with statistics primarily related to the mean or middle behavior of the data. Most designs are based on the extreme values that exist at the upper tail of the distribution. There may also be "holes" in the data which could be filled by likely future occurrences. It may be necessary to apply some sort of smoothing or interpolation procedure to extend the storm data set to include additional storms. Of course this step must be made with considerable engineering judgement and evaluation of the results as they are generated.

The result of the extended bootstrap procedure is a large population of possible future storm activity. This method provides a population of several thousand storms to which coastal engineering models can be applied to determine the probabilities, bias and standard variation of coastal flood stage, wave conditions, beach recession, or whatever other statistic is of importance to the engineering study. Because of time and money constraints, it is usually only possible to carry out complete model calculations for 30 to 40 storms. Even if computer time is free, the data file manipulation required in the cascade of numerical models applied to achieve the final result makes the simulation of all storms impractical.

\section{APPLICATION TO PANAMA CITY BEACH, FLORIDA}

Tropical storms and hurricane data from the National Hurricane Center indicated that forty-two storms made landfall within seventy-five miles of Panama City Beach since 1886. Of these, fourteen were of hurricane strength at the time they were within that radius. The historical record does not supply enough hurricanes to obtain statistically significant extrapolations to extreme conditions. Though the record shows the storms that actually occurred and provides information on the frequency of occurrence, it does not provide a record of the storms that might have occurred with small random variations in conditions. The relationship between the storm parameters and storm results can be investigated by "inventing" storms to fill in the parameter space. 
The number of hurricanes that were used to determine extreme conditions along Panama City Beach was expanded, first, by path translation in which the track of the storm was shifted parallel to itself in such a way as to make landfall at the same stage of storm development. The path of each historical storm was translated 50 miles to the right and left of the recorded track. The procedure increased the number of storms but did not triple the result since some storms were translated out of the area of influence on the site and others provided near duplicate conditions. Some judgement must be applied at this stage to eliminate duplicate storms and to develop synthetic storms to fill in the parameter space.

The storm selection procedure resulted in approximately fifty storms for which the parameters of maximum wind speed, radius to maximum winds, central pressure deficit, forward speed, and landfall location were known. These parameters were used in the SPH model to obtain the wind field surrounding the storm. The wind field was then used to calculate the time series of wave conditions using the spectral wave model SHALWV. The water level was calculated using the finite element model described above, and the recession of the shoreline determined from the SBEACH model (Larson and Kraus, 1989; Larson, et al., 1990).

Multiple regression equations were developed to determine the relationships between wave height, water level, and shoreline recession as dependent variables and the storm parameters as independent variables. The nearestneighbor, extended bootstrap procedure was then used to select the parameters the storms had and the regression relationship was used to determine the result of the parameters. A very large number of storm sets was bootstrapped in this way to provide guidance for the conditions for return periods of interest.

\section{CONCLUSIONS}

The Corps of Engineers has the responsibility to provide design criteria for coastal protection projects in hurricane prone areas. An innovative statistical approach has been developed to provide the data required for extrapolating historical hurricane storm effects to long return periods. The water levels generated by these hurricanes has been modeled using a finite element model, ADCIRC. This model allows the computation of water level due to hurricane surge over the entire Gulf of Mexico without tuning the boundary conditions to provide a match of the surge elevation at specific locations. These new techniques have been evaluated by the Corps, and have recently been applied to the design of a protective beach fill at Panama City Beach, Florida.

\section{ACKNOWLEDGEMENTS}

The research presented in this paper, unless otherwise noted, was sponsored by the Office of the Chief of Engineers, U.S. Army, and is published by its permission. Panama City Beach studies were conducted for the Mobile District, U. S. Army Corps of Engineers.

\section{REFERENCES}

1. Abel, C E., B. A. Tracey, C. L. Vincent, and R. E. Jensen, "Hurricane Hindcast Methodology and Wave Statistics for Atlantic and Gulf Hurricanes from 1956-1975," Wave Information Studies of US Coastlines, WIS Report No. 19, Coastal Engineering Research Center, US Army Engineer Waterways Experiment Station, Vicksburg, MS., March 1989.

2. Borgman, L. E., "An Algorithm for Optimal Efficiency in Selecting Storms for Finite Element Modeling of Surge, "Contractor Report, Coastal Engineering Research Center, U.S. Army Engineer Waterways Experiment Station, Vicksburg, MS., 18 November 1990.

3. Efron, B., "The Jackknife, The Bootstrap, and Other Resampling Plans," Regional Conference Series in Applied Mathematics, No.38, Society for Industrial and Applied Mathematics, Philadelphia, PA., 1982. 
4. Efron, B., "More Efficient Bootstrap Computations," Journal of the American Statistical Association, 85(409), pp.7989, March 1990.

5. Ho, F. P., J. C. Su, K. L. Hanevich, R. J. Smith, and F. P. Richards, "Hurricane Climatology for the Atlantic and Gulf Coasts of the United States," NOAA Technical Report NWS 38, National Oceanic and Atmospheric Administration, National Weather Service, Washington, DC, April 1987.

6. Hughes, S. A. and R. E. Jensen, "A User's Guide to SHALWV: Numerical Model for Simulation of Shaliow Water Wave Growth, Propagation, and Decay," Instruction Report CERC-86-2, Coastal Engineering Research Center, US Army Engineer Waterways Experiment Station, Vicksburg, MS., June 1986.

7. Jensen, R. E., C. L. Vincent, and C. E. Abel, "A User's Guide to SHALWV: Numerical Model for Simulation of Shallow-Water Wave Growth, Propagation, and Decay; Report 2, SHALWV-Hurricane Wave Modeling and Verification," Instruction Report CERC-86-2, Coastal Engineering Research Center, US Army Engineer Waterways Experiment Station, Vicksburg, MS, June 1983.

8. Larson, M. and N. C. Kraus, "SBEACH: Numerical Model for Simulating StormInduced Beach Change, Report 1, Empirical Foundation and Model Development," Technical Report CERC-89-9, Coastal Engineering Research Center, US Army Engineer Waterways Experiment Station, Vicksburg, MS., July 1989.

9. Larson, M., N. C. Kraus, and

M. R. Byrnes, "SBEACH: Numerical Model for Simulating Storm-Induced Beach Change, Report 2, Numerical Formulation and Model Tests," Technical Report CERC-89-9, Coastal Engineering Research Center, US Army Engineer
Waterways Experiment Station, Vicksburg, MS., May 1990.

10. Luettich, R. A., J. J. Westerink, and N.W. Scheffner, "ADCIRC: An Advanced Three Dimensional Circulation Model for Shelves, Coasts and Estuaries, Report 1: Theory and Methodology of ADCIRC-2DDI and ADCIRC-3DL," Coastal Engineering Research Center, US Army Engineer Waterways Experiment Station, Vicksburg, MS., In Prep.

11. Westerink, J. J., R. A. Luettich, and N.W. Scheffner, "ADCIRC: An Advanced Three Dimensional Circulation Model for Shelves, Coasts and Estuaries, Report 2: ADCIRC-2DDI Users Manual," Coastal Engineering Research Center, US Army Engineer Waterways Experiment Station, Vicksburg, MS., In Prep. 


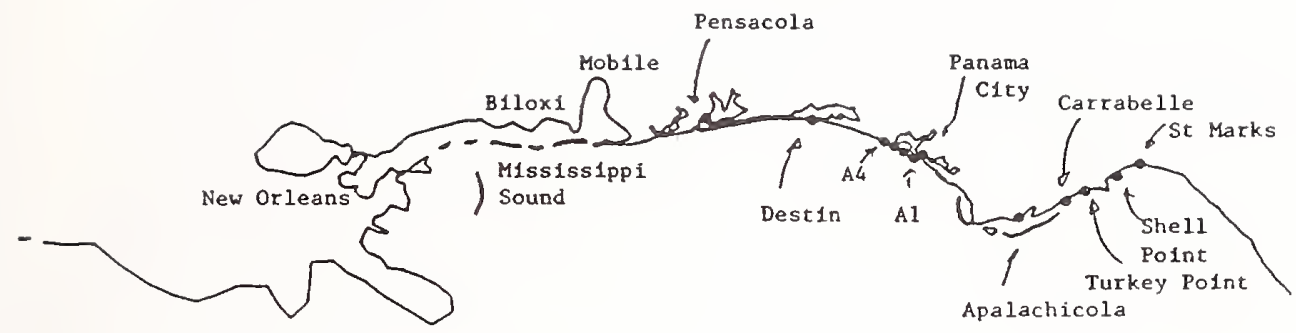

GULF OF MEXICO

Figure 1. Northern Gulf of Mexico from Louisiana to the Florida Bight. 


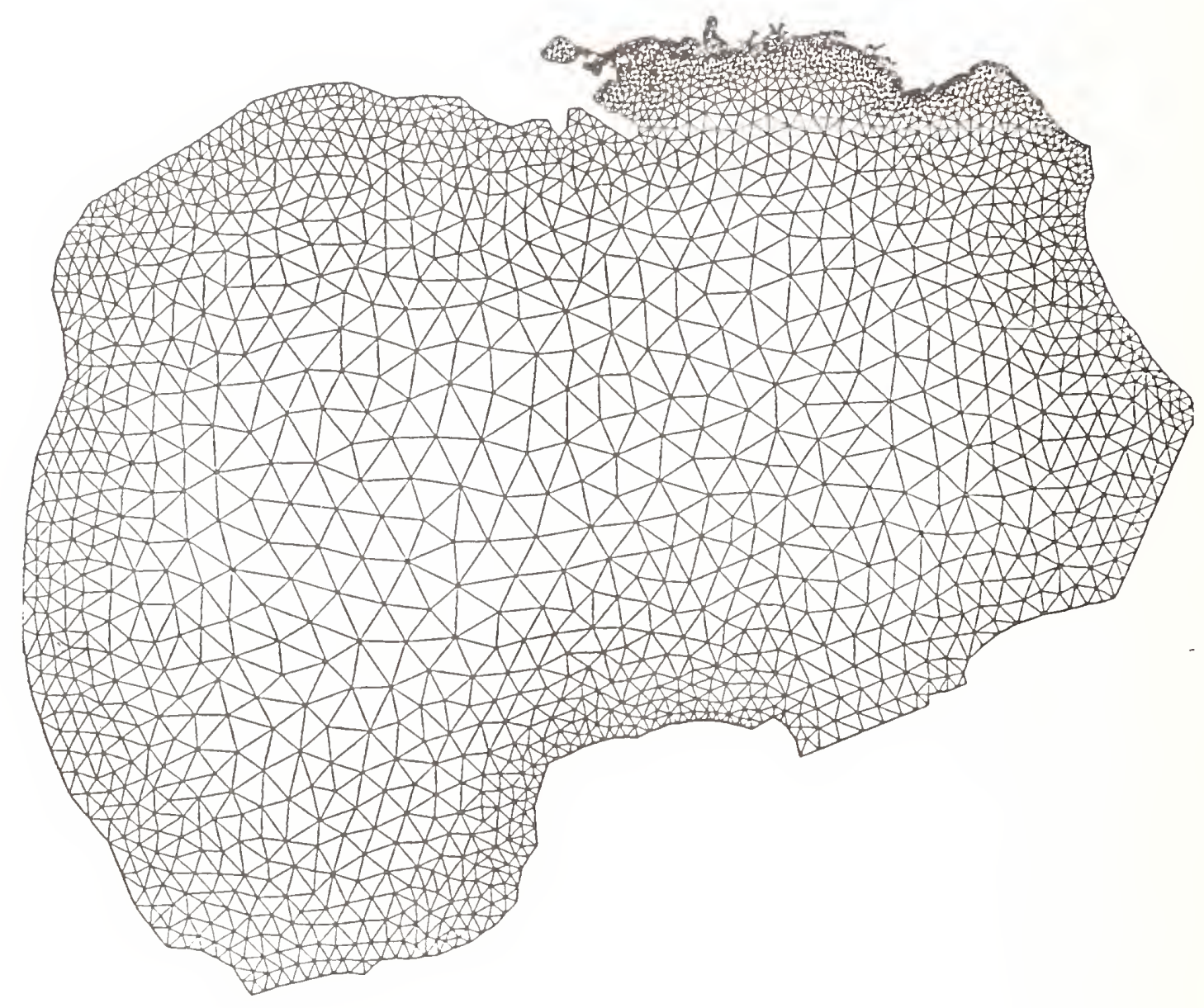

Figure 2. Finite element grid covering the Gulf of Mexico. Grid elements are concentrated in the northeastern Gulf from Mississippi Sound to the Florida Bight. 


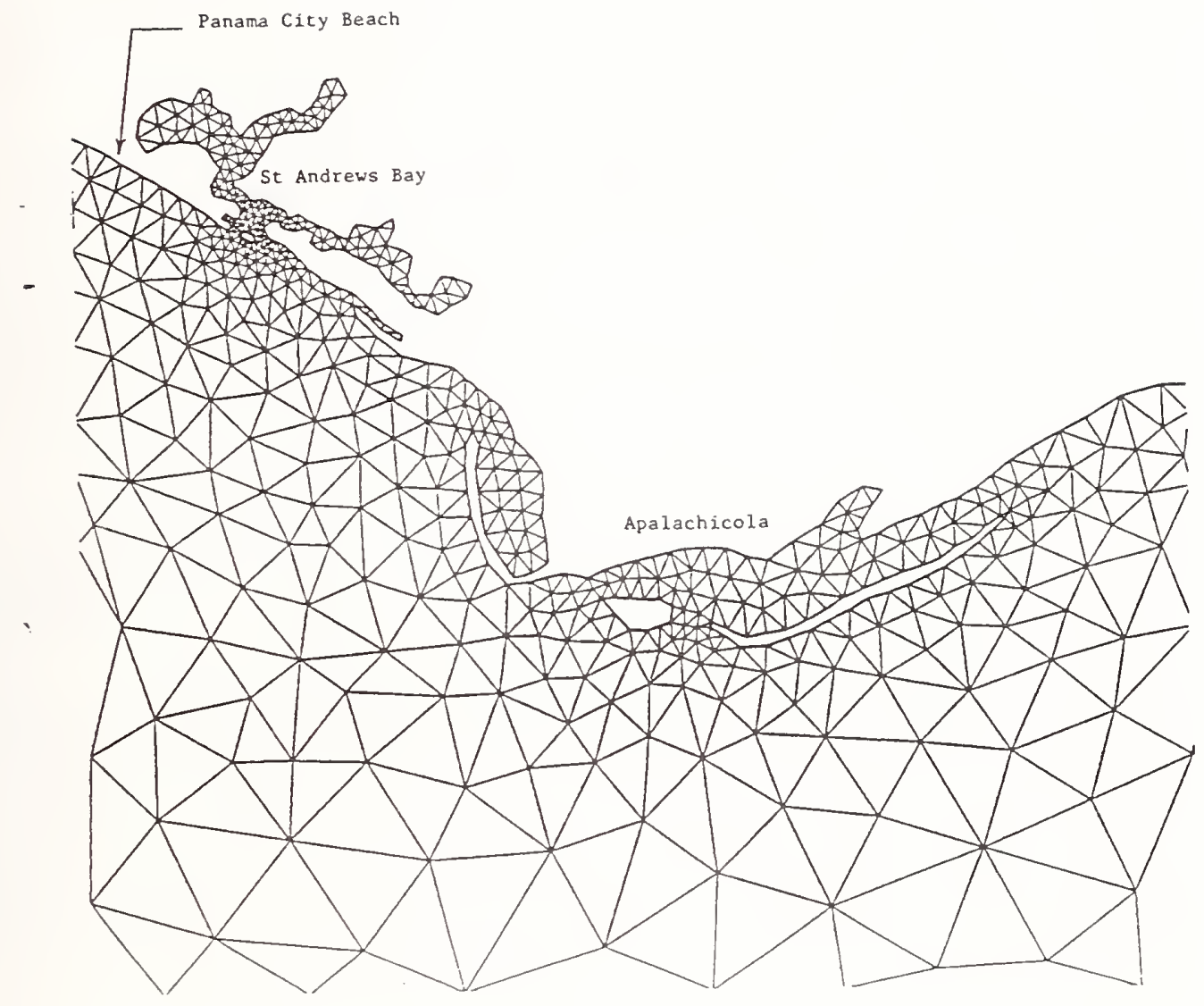

Figure 3. Detail of the finite element grid in the study area near Panama City Beach Florida. 
GULF OF MEXICO. BILOXI

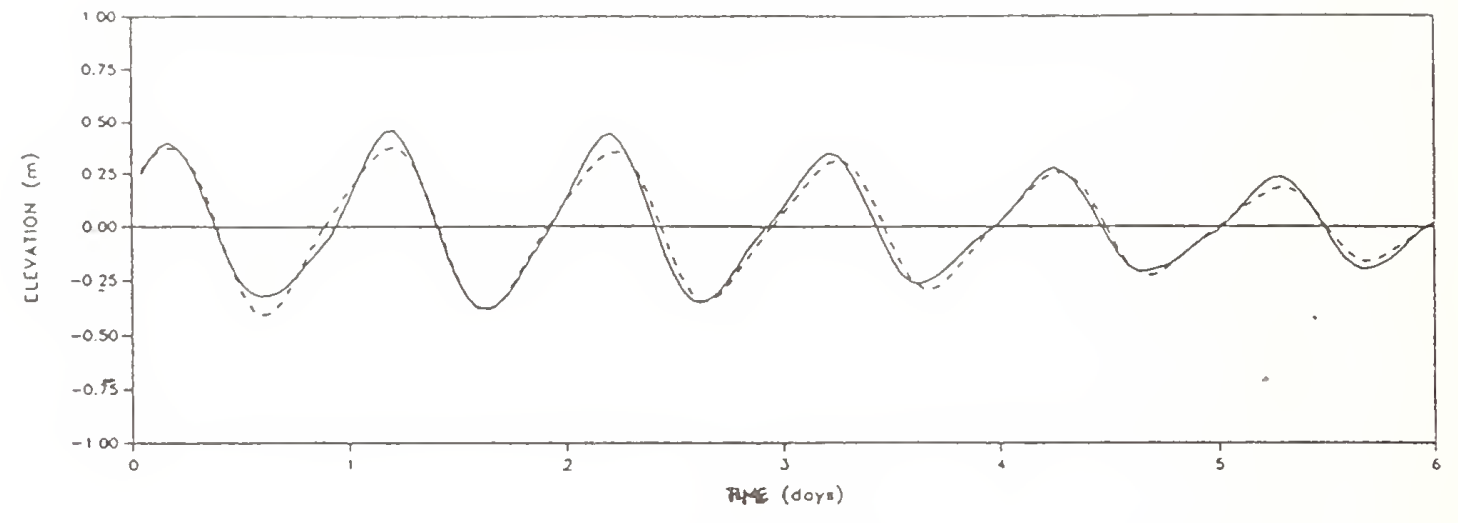

GULF OF MEXICO. CEDAR KEY

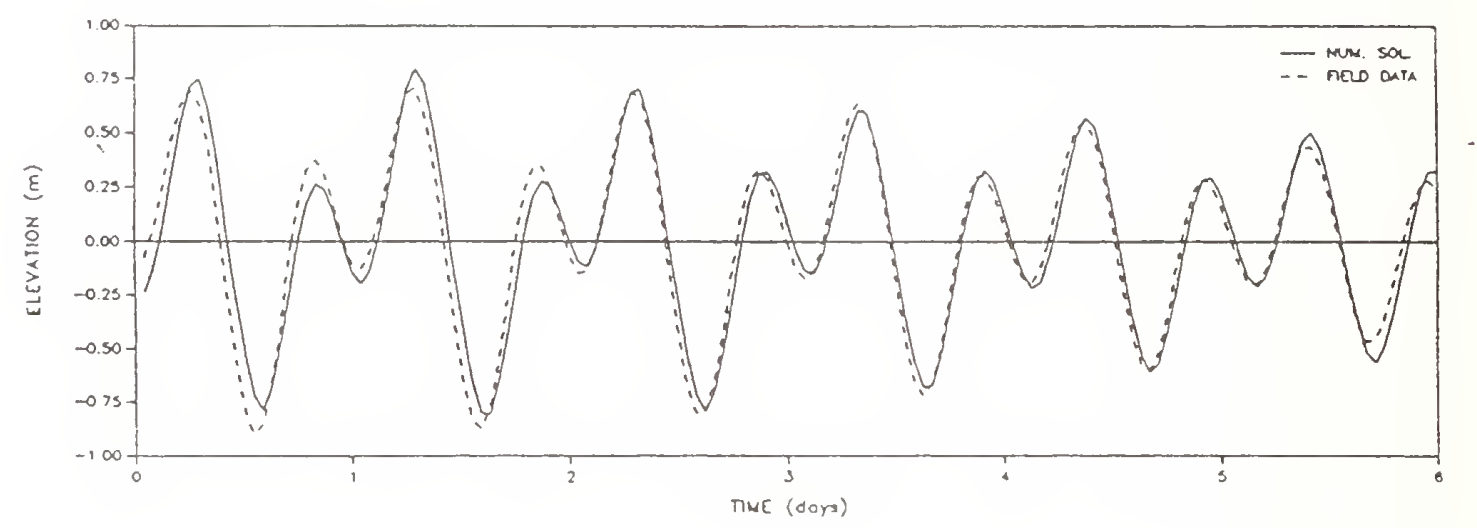

Figure 4. Comparison of the measured tidal signal (dashed line) to the numerical solution (solid line) using the program ADCIRC for tidal stations to the east and west of the study area. 
HURRICANE KATE

PANAMA CITY

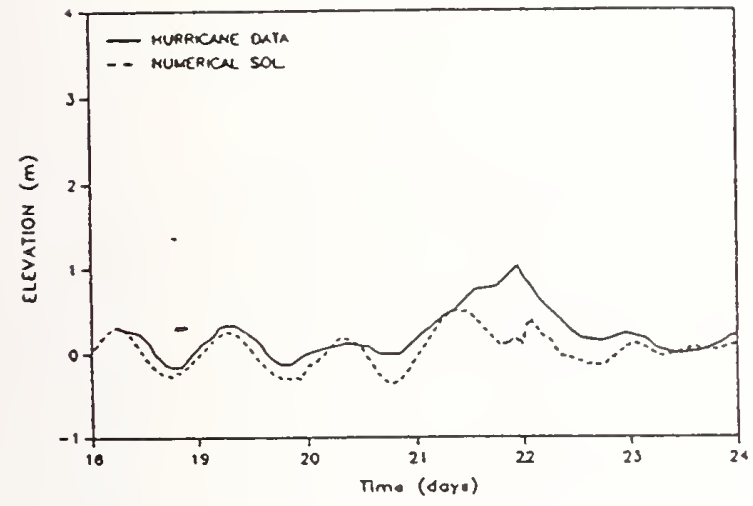

HURRICANE KATE

TURKEY POINT

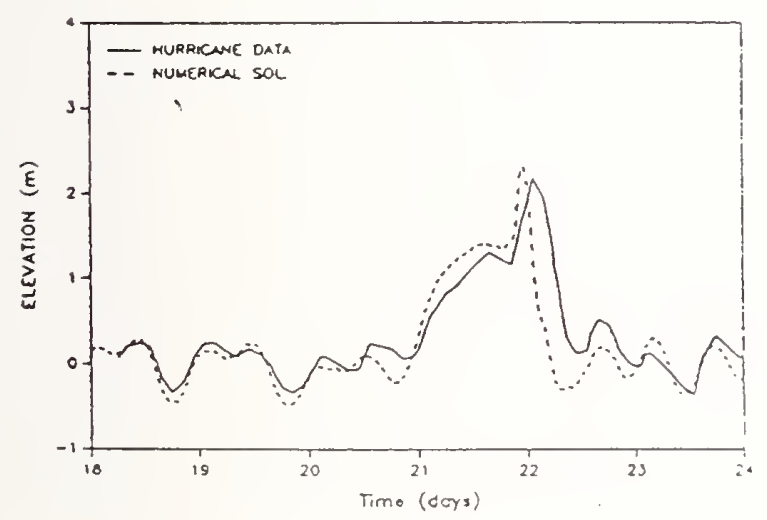

HURRICANE KATE

DESTIN

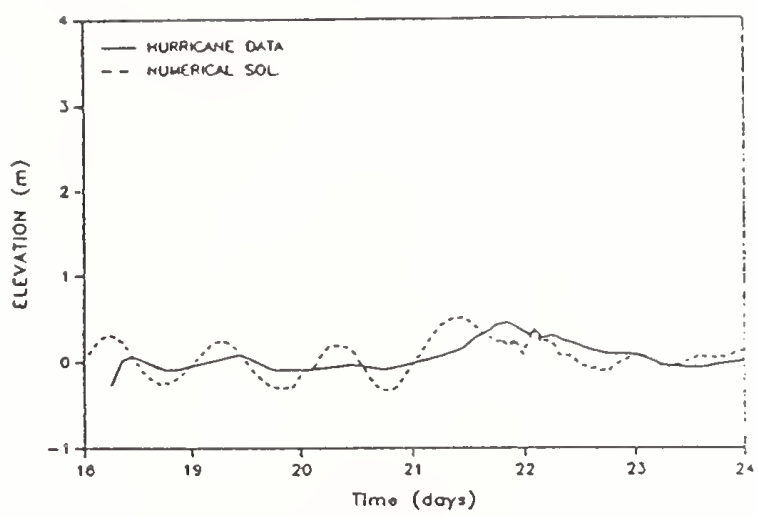

HURRICANE KATE

CARRABELLE

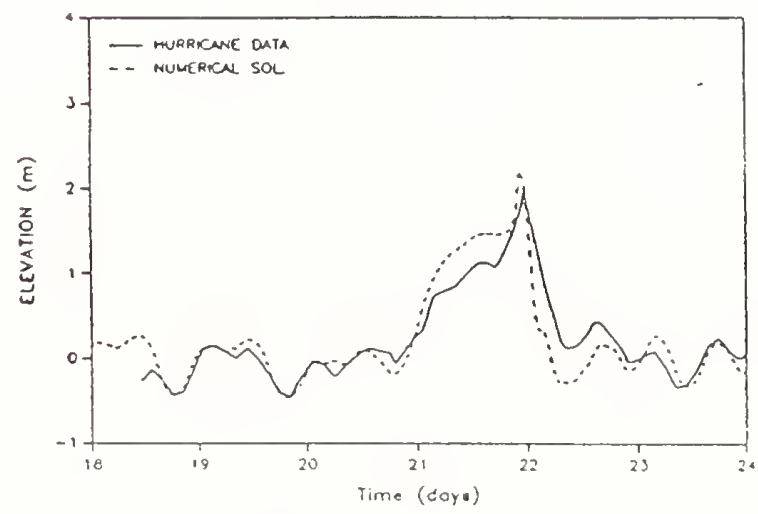

Figure 5. Comparison of the measured (solid line) and computed (dashed line) water level (tide plus surge) during hurricane Kate (18-24 November, 1985). Panama City and Destin are to the west of landfall of the storm center. Turkey Point and Carrabelle are to the east of landfall. 


\section{U.S. Coordinated Program for Masonry Building Research: Sixth Year Status}

by

James L. Noland ${ }^{1}$

\section{ABSTRACT}

The U.S. program, which consists of twenty-eight specific research tasks, is coordinated with a parallel program in Japan. Both are conducted under the auspices of the UJNR Panel on Wind and Seismic Effects. The primary purpose of the U.S. program is to support the development of a limit state design procedure for masonry as well as provide experimental data, analytical methods, etc. Several technical accomplishments have been realized in both modeling and experimental areas. The technology transfer plan includes dissemination of research reports, topical reports and a summary report on the specific research areas as well as by presentations and papers. Design and criteria recommendations will be an extremely important mode of technology transfer and are expected to support limit state design standard development. Current status of the program is presented. Completion is expected by spring 1993.

KEYWORDS: masonry, progress,

structures, technology transfer, UJNR

\section{INTRODOCTION}

The U.S. Coordinated Program for Masonry Building research is an integrated set of 28 specific research tasks being conducted by the U.S. Technical Coordinating Committee for Masonry Research (TCCMAR/US). The U.S. program is coordinated with a parallel program in Japan to exchange information and concepts for the mutual benefit of both countries. Both programs are conducted under the auspices of the United States-Japan
Natural Resources Panel on Wind and Seismic Effects.

\section{PROGRAM OBJECTIVES}

Primary program objectives are:

1) Development of design and criteria recommendations for limit state design of reinforced masonry buildings and components.

2) Development of a consistent experimental database on the behavior of masonry materials, components and systems.

3) Development of analytical nonlinear models for research and design office use for detailed analysis, system analysis, and dynamic loads determination.

4) Improved material and subassemblage experimental procedures for obtaining masonry properties.

5) Improved masonry fabrication procedures and standards.

6) Developing an increased awareness among engineers, architects, code bodies and the public of the capabilities of reinforced masonry in all seismic zones.

7) Interfacing with standards development groups to support development of a consensus limit state standard for masonry.

1 Atkinson-Noland \& Associates, Inc.

2619 Spruce Street

Boulder, CO 80302 


\section{3. $A P P R O A C H$}

With NSF support, the Technical Coordinating Committee for Masonry Research/U.S. (TCCMAR/U.S.) was formed in February 1984. TCCMAR/U.S. was and is comprised of researchers from academic and industrial organizations who have strong backgrounds in research into the properties and characteristics of reinforced masonry materials, structural components and systems, analytical techniques, structural dynamics, building codes, and earthquake engineering. TCCMAR researchers are listed in Table 1. TCCMAR participants defined the research program conducted, the research and will analyze and interpret the results.

The U.S. research plan is a phased stepby-step program of separate, but coordinated research tasks. Emphasis is being placed upon intra-task information exchange and consultations so the experimental and analytical efforts are mutually supportive. The research tasks comprising the coordinated program are listed in Table 2.

The program includes both experimental and analytical research tasks. The experimental and analytical efforts are conducted in parallel with each becoming more complex and sophisticated as knowledge and experience accumulate. The U.S. plan is thus a "building block" approach. The program began in October 1985 and will be completed in the spring of 1993 .

\section{CURRENT STATUS}

As of March 1991, the program is approximately 75 percent complete. Remaining work consists of refining analytical models and programs, further, experimental studies on reinforcing bar bond and splices in grouted masonry, development of masonry material tests compatible with the needs of nonlinear analysis and limit state design, experimental and analytical studies of the behavior of the five story research building, development of limit state design and criteria recommendations and final technology documentation. Research task reports which have been published are listed in Table 3 .

Partial funding for planning and conducting experiments on a five-story full-scale reinforced masonry research building has been arranged. Researchers at the University of California-San Diego will commence detailed planning in mid-April. Specimen construction will begin in August 1991 and testing is expected to begin in the early fall of 1991.

Funding for development of design recommendations and technology documentation is expected by May 1991. Work in that area will begin shortly thereafter.

\section{ACKNOWLEDGEMENS}

Primary funding for the program was and is being provided by the National Science Foundation (U.S.). The U.S. Army Corps of Engineers has provided support for extended studies on reinforcing bar bond and splicing and material tests. The U.S. masonry industry has provided masonry materials and funds for specimen construction. 
TABLE 1

TCCMAR RESEARCHERS

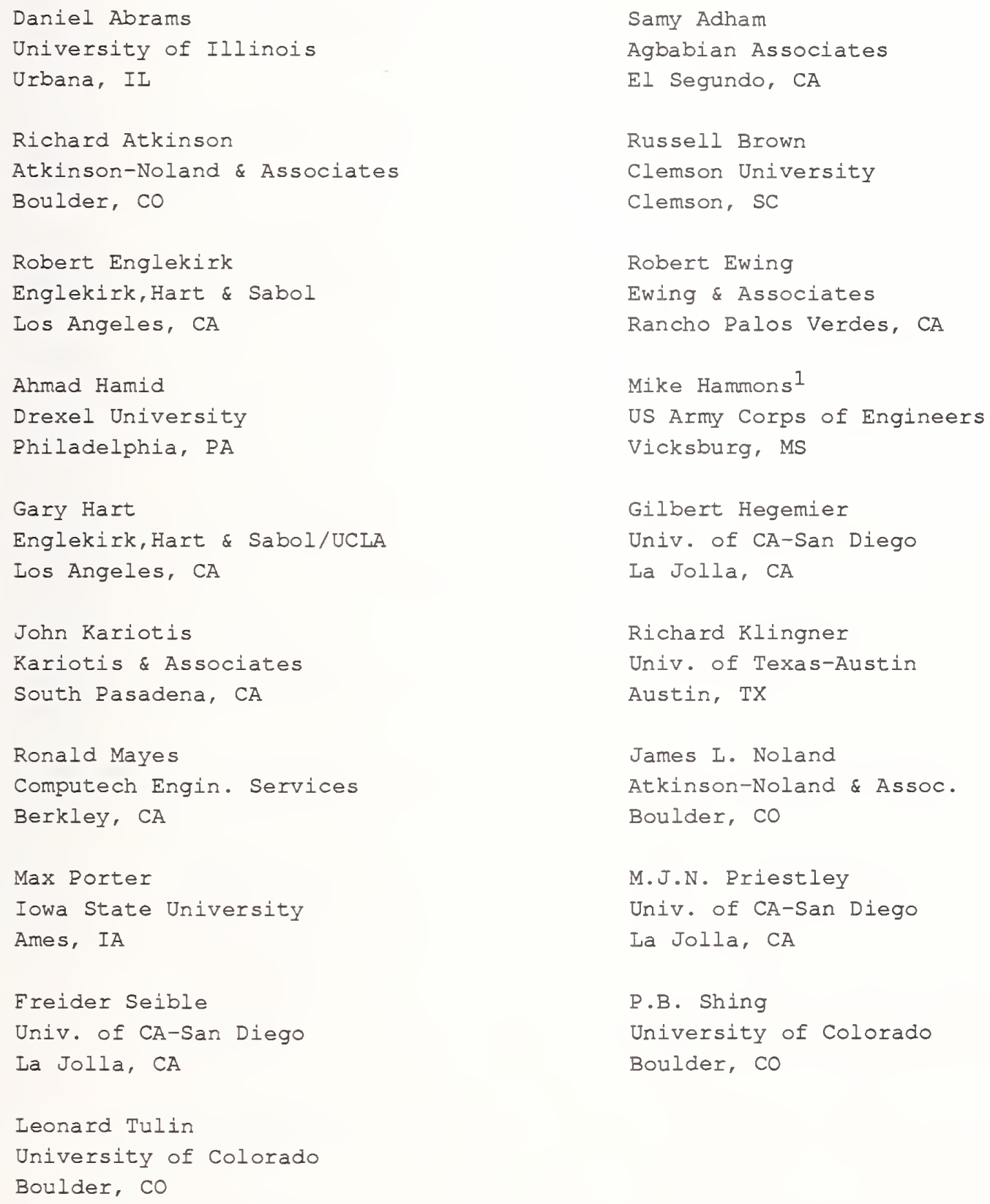

1 New Member 
Grouted Hollow-Unit Clay \& Concrete

R. Atkinson

Masonry in Compression

Grouted Hollow-Unit Concrete Masonry

A. Hamid

Under Combined Compression \& Flexure

R. Brown

Grouted Hollow-Unit Clay Masonry Under

Combined Compression \& Flexure

Masonry Test Methods for Limit State

R. Atkinson

Design

M. Hammons

*Nonlinear Force-Displacement Models of

R. Englekirk

Reinforced Masonry Components \& Systems

*Nonlinear Finite Element Models for

R. Ewing

Analysis of Reinforced Masonry

*Nonlinear Lumped Parameter Models for

J. Kariotis

Dynamic Response Analysis of Reinforced Masonry Systems

Nonlinear Models of Floor Diaphragms

M. Porter

Nonlinear Models of Reinforced Masonry

R. Mayes

Walls Acting Out-of-Plane

Experimental Study of One-Story

B. Shing

Reinforced Masonry Shear Walls

Experimental study of Two-story

R. Klingner

Reinforced Masonry Shear Walls

Experimental Study of Three-Story

G. Hegemier

Reinforced Masonry Shear Walls and

F. Seible

Development of Automated Feed-Back Test Method for Stiff Structures

Experimental Study, Static \& Dynamic,

A. Hamid of Out-of-Plane Behavior of Reinforced

S. Adham

Concrete Masonry Walls

Experimental Study, Static \& Dynamic, of Out-of-Plane Behavior of Reinforced Clay Masonry Walls

${ }^{*}$ Research Tasks to be completed 
Experimental Study, Static \& Dynamic,

N. Priestley

of Flanged Reinforced Masonry Walls

*Analytical Study Based on Prior Tests,

G. Hegemier

of Wall-Floor Intersections

Experimental study (Preliminary) of

L. Tulin

Reinforcing Bar Bond \& Splices in

Grouted Masonry

*Experimental Study (continuation) of

R. Atkinson

Reinforcing Bar Bond and Splices in

M. Hammons

Grouted Masonry

Experimental Study, Static \& Dynamic

D. Abrams

Behavior of Scale Model Three-Story

Reinforced Masonry Buildings

Development of Reliability-Based

G. Hart

Iimit-State Design Methodology for

Masonry Buildings

Development of Reliability Factors for

G. Hart

Masonry Materials, Components, \& Systems

*Design of Five-Story Reinforced Masonry

J. Kariotis

Research Building

*Design and Construction of Large

G. Hegemier

Specimen Research Building

F. Seible

*Experimental Study of Nonlinear

G. Hegemier

Behavior of a Five-Story Building

F. Seible

Under Cyclic Lateral Loads

*Design \& Criteria Recommendation for

J. Noland

Limit State Design and Documentation and

Technology Documentation

*Overall Program Coordination

J. Noland

*Research Tasks to be completed 
Task No.

Author/s - Title

1.1-1:

Atkinson and Kingsley, Comparison of the Behavior of Clay \& Concrete Masonry in Compression, September 1985.

1.2(a)-1: Hamid A.A., Assis, G.F., Harris, H.G., Material Models for Grouted Block Masonry, August 1988

1.2(a)-2: Assis, G.F., Hamid A.A., Harris, H.G., Material Models for Grouted Block Masonry, August 1989

1.2(b)-1: Young, J.M., Brown, R.H., Compressive Stress Distribution of Grouted Hollow Clay Masonry Under Strain Gradient, May 1988

2.1-1: Hart, G. and Basharkhah, M., Slender Wall Structural Engineering Analysis Computer Program (Shwall, Version 1.01), September 1987.

2.1-2: Hart, G. and Basharkhah, M., Shear Wall Structural Engineering Analysis Computer Program (Shwall, Version 1.01). September 1987.

2.1-3: Nakaki, D. \& Hart, G., Uplifting Response of Structures Subjected to Earthquake Motions, August 1987.

2.1-4: Hart, G., Sajjad, N., and Basharkhah, Inelastic Column Analysis Computer Program (INCAP, Version 1.01), March 1988.

2.1-5: Hong, W.K., Hart, G.C., Englekirk, R.E.,Force-Deflection Evaluation and Models for University of Colorado Flexural Walls, December 1989.

2.1-6: Hart, G.C. Jaw, J.W., Low, Y.K., SCM Model for University of Colorado Flexural Walls, December 1989.

2.1-7: Hart, G., Sajjad, N., Basharkhah, M., Inelastic Masonry Flexural Shear Wall Analysis Computer Program, February, 1990.

2.2-1: Ewing, R., El-Mustapha, A., Kariotis, J., FEM/I - A Finite Element Computer Program for the Nonlinear Static Analysis of Reinforced Masonry Building Components, December 1987 (Revised June 1990).

2.3-1: Ewing, R.; Kariotis, J.; El-Mustapha, A., LPM/I, A Computer Program for the Nonlinear, Dynamic Analysis of Lumped Parameter Models, August, 1987.

2.3-2: Kariotis, J., El-Mustapha, A., Ewing, R., Influence of Foundation Model on the Uplifting of Structures, July 1988.

2.3-3: Kariotis, J., Rahman, M., El-Mustapha, A., Investigation of current Seismic Design Provisions for Reinforced Masonry Shear Walls, January 1990 . 
3.1(a)-1: Scrivener, J., Summary of Findings of Cyclic Tests on Masonry Piers, June 1986 .

3.1 (b)-1: Seible, F. and LaRovere, H., Summary of Pseudo Dynamic Testing, February 1987 .

3.1(c)-1: Merryman, K., Leiva, G., Antrobus, N., Klingner, R., In-Plane Seismic Resistance of Two-Story Concrete Masonry Coupled Shear Walls, September 1989.

3.2 (a): Hamid, A., Abboud, B., Farah, M., Hatem, K., Harris, H., Response of Reinforced Block Masonry Walls to Out-of-Plane Static Loads, September 1989.

3.2 (b)-1: Agbabian, M., Adham, S., Masri, S., Avanessian, V. Traina, Out-of-Plane Dynamic Testing of Concrete Masonry Walls, Volumes 1 and 2, July 1989.

4.1-1: Limin, H., Priestley, N., Seismic Behavior of Flanged Masonry Shear Walls, May 1988 .

4.2-1: Hegemier, G. Murakami, H., On the Behavior of Floor-to-Wall Intersections in Concrete Masonry Construction: Part I: Experimental

4.2-2: Hegemier, G., Murakami, H., On the Behavior of Floor-to-Wall Intersections in Concrete Masonry Construction: Part II: Theoretical

5.1-1: Porter, M., Sabri, A., Plank Diaphragm Characteristics, July 1990.

5.2-1: Porter, M., Yeomans, F., Johns, A., Assembly of Existing Diaphragm Data, July 1990.

6.2-1: Scrivener, J., Bond of Reinforcement in Grouted Hollow-Unit Masonry: A State-of-the-Art, June 1986.

6.2-2: Soric, Z. and Tulin, L., Bond Splices in Reinforced Masonry, August 1987.

7.1-1 Paulson, T., Abrams, D., Measured Inelastic Response of Reinforced Masonry Building Structures to Earthquake Motions, October, 1990.

8.1-1: Hart, G., A Limit State Design Method for Reinforced Masonry, June 1988.

9.1-1: Kariotis, J.C., Johnson, A.W., Design of Reinforced Masonry Research Building, September, 1987

9.2-1: Seible, F., Report on Large Structures Testing Facilities in Japan, September 1985 .

9.2.2: Seible, F., Design and Construction of the Charles Lee Powell structural Systems Laboratory, November 1986.

9.2.3: Seible, F., The Japanese Five-Story Full Scale Reinforced Masonry Building Test, January 1988 . 
$11 \cdot 1-1$

TCCMAR, Summary Report:

U.S. Coordinated Program for Masonry Building Research, September 1985 to August 1986.

$11.1-2:$

Status Report:

U.S. Coordinated Program for Masonry Building Research, November 1988 .

1 Task Reports are available through

the Earthquake Engineering Research

Library, Berkeley, CA 
Appendix

Task Committees A-J Reports 



\title{
Summary of Task Committee Workshop Reports
}

\author{
Report of Task Committee on
}

(A) STRONG-MOTION INSTRUMENT ARRAYS AND DATA

Date: $\quad$ May 15, 1991

Place: Public Works Research Institute (Tsukuba Science City)

$\begin{array}{rlr}\text { Attendees: Japan Side }- & \text { S. Noda (Chairman) } & \text { (PHRI) } \\ & \text { K. Ohtani } & \text { (NIED) } \\ & \text { K. Tamura } & \text { (PWRI) } \\ & & \\ \text { U.S. Side - } & \text { A.G. Brady (Chairman) } & \text { (USGS) }\end{array}$

\section{MISSION STATEMENT}

\section{Objective:}

The objective of the Task Committee is to coordinate the provision of strong-motion earthquake data to researchers and to the practicing engineering community. The Task Committee focuses on instrumentation; recording, processing, and analyzing strong-motion data; research to ensure high-quality data dissemination; and analysis of ground motion and structural motion in dynamic response to earthquakes.

\section{Scope of Work}

The $\mathrm{T} / \mathrm{C}$ coordinates strong-motion research, processing strong-motion data, and disseminating information on the recorded behavior of structures. In addition to regular exchange of data and publications, the $\mathrm{T} / \mathrm{C}$ 's technical approach includes:

* Planning and conducting T/C workshops and meetings, held generally in conjunction with UJNR Joint Meetings.

* Conducting related technical sessions at professional society meetings.

* Creating procedures for the dissemination of significant strong-motion digital data with regard for the rights and expectations of (a) the owner, (b) the users of data, and (c) the earthquake engineering community.

* Creating an up-to-date information exchange on computer processing procedures and related research so all users of processed data are aware of valid ranges and practical Iimitations.

* Developing a research program for appropriate instrumentation and dynamic analysis of structures with base isolation or other response-reducing systems, under earthquake excitation.

* Developing a research program using both permanent and temporary arrays and data derived to study site response. 


\section{Accomplishments}

* Catalogs of strong-motion earthquake records observed both in the United States and Japan are being exchanged. U.S. data are published in the "Seismic Engineering Program Report", and the Japanese data are published in "Strong-Motion Earthquake Records in Japan". Digital data is exchanged on tape, floppies, and CDROMs. Many other publications were also exchanged.

* Data tapes on the Loma Prieta earthquake of October 17, 1989, processed by USGS and CDMG, were delivered to Japanese side.

* Disks containing data on the Chiba-Toho-Oki earthquake of December 17, 1987, processed by the National Research Center for Disaster Prevention, were delivered to U.S. side.

* The Japanese Technical Study Team for the Loma Prieta Earthquake visited northern California, USA, between Nov. 16 \& 29, 1989 to study the effects. The team and the U.S. hosts included many panel members.

* Dr. Sasaki visited the U.S. during March 20-29, 1990, visiting U.C. Berkeley, USGS, Stanford, CALTRANS, CDMG; Loma Prieta Earthquake effects in San Francisco, Oakland, and epicentral area; and Washington (AID, NIST, NSF). Panel members hosted throughout; T/C A contacts included A. G. Brady and R. D. Borcherdt, of USGS, and A. G. Franklin of USAEWES.

(Other Panel members included J. Gates, R. Hanson, H.S. Lew and N. Raufaste).

* Mr. Keiichi Tamura of PWRI was a Visiting Scholor at Stanford University for one year ending October 1990 working on strong motion instrument arrays and data.

* Mr. Susumu Iai of PHRI visited California for one month in March 1991 for joint research with California Division of Mines and Geology on recording and processing of strong earthquake motion.

\section{Future Plans}

* The T/C Chairmen will seek funding sources and finalize the planning for a 3rd Workshop on Processing Strong Motion Records in spring of 1992 .

* Coordinate the analysis of records from arrays: downhole 3-D arrays (geophysics and earthquake engineering) and structural arrays (structural engineering).

* The T/C recognizes the efforts of the International Working Group on the Effects of Surface Geology and encourages wider participation by Panel members. 


\section{Information Exchange}

* Will be performed within the domestic community through technical meetings, conferences, seminars, and workshops.

* Will be performed through participation in post-earthquake field investigations with concentration in areas where strong-motion stations have recorded data.

* Will be performed with the counterpart side through T/C workshops; visitor exchanges, seminars, lectures; and participation in annual Joint Panel meetings.

* The most crucial information exchange is rapid description of recovered strong motion (and subsequently, digital strong-motion data on tape or disk) from significant earthquakes.

\section{Impact}

* Most managers who process strong-motion recordings use techniques based, or closely associated with, the work of this $\mathrm{T} / \mathrm{C}$ and its members. Foreign networks fitting this category include:

AUSTRALIA - Australian Seismological Center, Bureau of Mineral Resources, PO Box 378, Canberra ACT 2601.

CANADA - Pacific Geoscience Center, PO Box 6000, Sidney, BC. V8L 4B2.

ITALY - The Italian National Commission for Research and Development on Alternative Energy Sources (ENEA), Rome.

MEXICO - Japan-Mexico Earthquake and Disaster Prevention

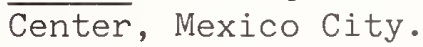

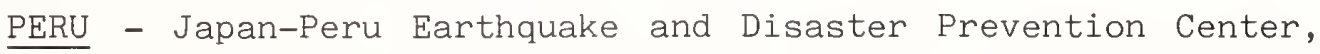
$\overline{\text { Lima. }}$.

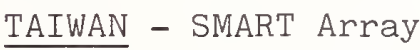

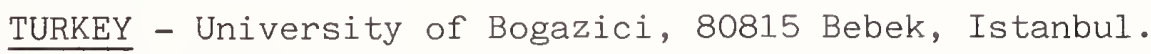

YUGOSLAVIA - Institute of Earthquake Engineering and Engineering Seismology, Skopje.

* Use of seismological and strong-motion data, in convenient form, is facilitated in countries other than where recorded.

* Dissemination of digital data from significant earthquakes, taking into account the conditions of the 3rd paragraph in the Scope of Work, increases the research data base; application of this data in design practice aids in reduction of earthquake hazards. 


\section{Barriers}

* Lack of adequate funding for T/C joint endeavors.

* Establishing joint research efforts and maintaining close interaction between participants are difficult unless visiting research appointments are established. (Funding and staff availability are often barriers). 


\section{Report of Task Committee on}

\section{(B) LARGE-SCALE TESTING PROGRAM}

Date: May 15, 1991

Place: Public Works Research Institute

Tsukuba, Japan

$\begin{array}{rlrl}\text { Attendees: Japan Side - } & \text { K. Ohtani (Chairman) } & & \text { (NIED) } \\ & \text { H. Yamanouchi } & & \text { (BRI) } \\ & \text { S. Nakata } & \text { (BRI) } \\ & \text { Y. Koga } & \text { (PWRI) } \\ \text { U.S. Side - H. S. Lew (Chairman) } & \text { (NIST) }\end{array}$

\section{MISSION STATEMENT}

1. Objective

The objective of the Task Committee is to develop performance data of full-scale dynamic properties of structures to better resist wind and seismic loads through both laboratory testing of prototype structures and field testing of structures in situ. Improved full-scale test data will validate the results of small-scale model tests and substantiate the results of computer analyses of structural behaviour.

\section{Scope of Work}

The Task Committee develops its research agenda in coordination with other appropriate T/Cs, such as T/C's "C" and "D", for full-scale evaluation of buildings, and other structures except bridges.

* Plans and conducts workshops and joint meetings to identify research topics and develops joint research programs.

* Coordinates research projects carried out by various laboratories in the U.S. and Japan. Facilitates publication of research results and implementation of findings in codes and standards.

* Facilitates exchange of research personnel, technical information and available testing facilities.

3. Accomplishments

* The National Science Foundation (NSF) has funded the third phase (5-story structural test) of the U.S.-side research of the U.S.-Japan Coordinated Program for Masonry Building Research. The testing of five-story full-scale masonry structure will be carried out at the University of California, San Diego during 1991-1993.

* The U.S. Technical Coordinating Committee on Masonry Research was held in August 1990. 
* The 6th Joint Technical Coordinating Committee on Masonry Research (JTCCMAR) was held in August 1990 at Seattle, Washington. Progress on individual research projects were presented by principal investigators and future coordination of the Joint Program was discussed.

* The first phase of the U.S.-Japan Joint Technical Coordinating Committee on Precast Seismic Structural systems Program (PRESSS) was held in November 1990 At San Diego, California.

* The Japan PRESSS Research program is continuing at several institutions including BRI, University of Tokyo and Yokohama National University. The Japan TCC Meetings were held during the past fiscal year.

\section{Future Plans}

* The second Joint Technical Coordinating Committee (JTCC) on PRESSS will be held in Japan in October 1991. The U.S. TCC on PRESSS will meet prior to the second JTCC on PRESSS in June 1991.

* In support of International Decade for Natural Disaster Reduction (IDNDR) program, techniques will be explored to disseminate findings of Joint Research Projects carried out under the auspices of $T / C$ "B" to countries with high seismic risks.

* A workshop on Composite, Mixed an Hybrid Structural Systems is being planned to be held in summer of 1992 in the U.S.

* Information exchange of following topics between appropriate U.S. and Japan Organizations will be continued;

a. Application of high strength construction materials, such as concrete and steel, to structures in high seismic zones,

b. Testings of large-scale structures other than buildings and bridges.

5. Information Exchange

* Technical reports and research documentation were exchanged with participating organizations in both countries.

6. Impact

* The results of the past joint research projects on reinforced concrete and steel structures have been published in both U.S. and Japanese technical journals. A number of key findings have been incorporated into U.S. and Japanese building codes and design guidelines.

* As a results of joint research projects, the state of practice and understanding in earthquake engineering has been improved in both countries. The results from the joint program above further stimulated research in both countries.

* Facilitate joint research projects utilizing available testing facilities in both countries. 


\section{Barriers}

* There are no major technical barriers for the attainment of the Task committee mission. However, different building practices and needs require careful planning for effective joint research projects.

* Securing funding to support exchange of research personnel is difficult in both countries. Funding agencies of both countries should be informed about the technical benefits resulting from the joint panel activities and encouraged to participate researcher exchange and joint research programs. 


\title{
First Meeting of the Joint Technical Coordinating Committee on Precast Seismic Structural Systems (PRESSS)
}

\author{
San Diego, USA
}

Nov. 29, 30, Dec.1, 1990

\section{DRAFT RESOLUTIONS}

1. The first meeting of JTCC-PRESSS was held at the University of California San Diego at the Whispering Palms Country Club, San Diego on November 29 and 30, and December 1, 1990. The meeting was attended by 22 researchers and 5 observers from Japan, and 15 researchers and 7 observers from the USA.

2. At the meeting there was a successful exchange of information and ideas between the researchers from both countries on the subjects of precast structural system behavior, behavior of assemblies, testing procedures, analytical modeling methods and seismic design procedures.

3. The need for, and importance of, continuing experimental and analytical research on PRESSS was reaffirmed.

4. The common goal of Japan and USA research efforts is to develop design guidelines for PRESSS.

5. Continued cooperation and interchange of design concepts will be carried out based on the 'test building' concept.

6. The Hachinohe $1968 \mathrm{~N}$-S record amplified to $0.33 \mathrm{~g}$ peak ground acceleration will be used as the base record for comparing dynamic response.

7. The US side will develop at least one shear wall building concept and at least one ductile joint concept and report results of design studies at the next US/Japan meeting.

8. The US side will carry out dynamic inelastic time-history analyses of the test-design buildings and report results at the next US/Japan meeting.

9. The US side will carry out inelastic collapse mechanism analyses of its design buildings and report at the next US/Japan meeting.

10. The Japan side will carry out dynamic inelastic time-history analyses of its Case II and Case III buildings and report at the next US/Japan meeting. 
Page 2

Resolutions

11. The Japan side will carry out collapse analyses and dynamic inelastic time-history analyses of the US frame test building to ensure correct calibration of analysis methods between the two countries.

12. Both sides will investigate correlation between full structural simulations and simplified structural condensation models for dynamic inelastic analyses.

13. Both sides will continue to develop and classify new connection concepts. The US and Japan connection groups will interact and agree on the format for presenting connections for the data base report. Agreement on the format will be reached by May 1, 1991.

14. The completed data base report will be finalized by 1992 .

15. The Japan side has made considerable progress on its new design guidelines. The US side will prepare and present a detailed framework for its recommendations for the 1991 meeting.

16. The two sides will exchange information on test load patterns to simulate seismic response of connections and members and investigate the practicality of adopting a common load pattern for experimental research.

17. The technical communication which has carried out between Japan and US PRESSS teams has been valuable and should be continued. There should be a continuation of the exchange of researchers so as to facilitate dialogue on concepts and design.

18. The next meeting will be held in Japan on October 30, 31st and November 1, 1991. 


\section{REPORT OF TASK COMMITTEE ON \\ (C) REPAIR AND RETROFIT OF EXISTING STRUCTURES}

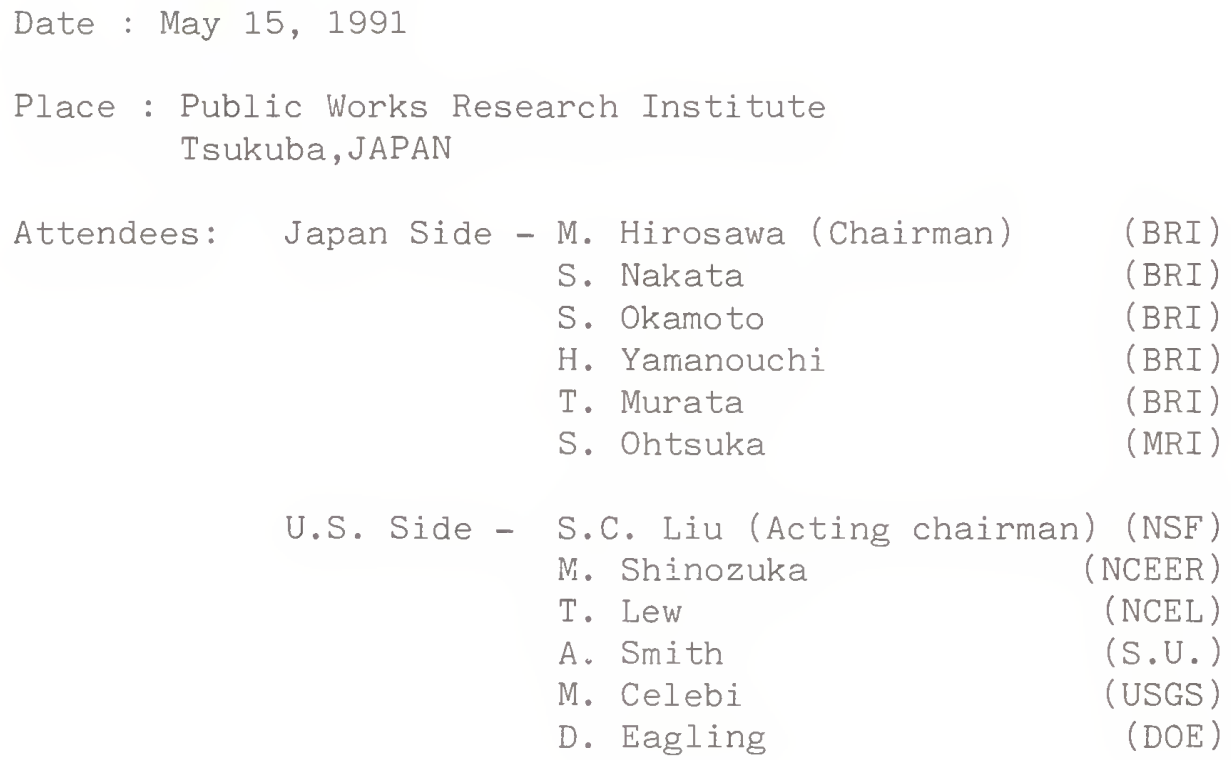

\section{MISSION STATEMENT}

1. Objective

The objectives of the Task Committee are to encourage research and provide technology transfer activities in materials, components, and whole buildings and structural systems related to the repair and retrofit of existing buildings and other structures. The scope will encompass studies related to materials of construction, structural components as well as prototype structural systems.

\section{Scope-of-Work}

The $\mathrm{T} / \mathrm{C}$ work includes information exchanges, planning, and hosting workshops and seminars. Workshops are generally held in conjunction with the annual Panel's meeting. They provide T/C members with an opportunity to review related research and to direct plans for future research, share and implement results. The T/C conducts related technical sessions at professional society's meetings. The T/C studies new materials and methods to accomplish repair and retrofit operations on buildings e.g., fiberglass reinforced plastics, high performance concrete, post-installed anchor bolts, carbon-fibre wire, structural adhesives, and exploits use of automation and robotics for repair and retrofit. Work focuses on coordinating research projects in U.S. and Japan to minimize duplication and to maximize benefits.

\section{Accomplishments}

* Status reports were delivered on recent related NSF initiatives: 
This initiative was issued in June, 1990. The responses from the U.S. research communities were overwhelming. Plans are underway for the second year announcement; interdisciplinary research teams are encouraged. The following four projects were selected for support in the first round:

1. Fiber optic sensors for strength evaluation and early warning of impending failure in structural components.

2. Nondestructive methods in assessing damage to reinforced concrete structures.

3. Micromagnetic surface studies of materials for nondestructive evaluation.

4. Fundamentals of embedded optical fibers in structural concrete.

Details of these four projects and a description of the initiative are included in the proceedings of the 23rd UJNR Joint Meeting in Tsukuba, Japan.

- REPAIR AND REHBILITATION RESEARCH FOR THE SEISMIC RESISTANCE OF STRUCTURES

In early 1990, NSF announced a new 5-year research program that focuses on a coordinated research effort in the seismic repair and rehabilitation of existing structures. The general goals of the program are to : (a) initiate a concentrated effort to integrate the existing body of knowledge on the repair and rehabilitation of buildings, (b) carry out additional research as required to develop practical engineering measures for immediate implementation, and (c) to promote closer ties between research and practice by facilitating transfer of knowledge and techniques through the development of design guidelines applicable to U.S. practice.

During the first year of the research program, FY 1990, NSF funded a total of nine projects.

- Strengthening and repair of nonductile reinforced concrete frames using external steel jackets and plates.

- Seismic retrofit with energy dissipators.

- Evaluation of the strength, stiffness, and ductility of older steel frame structures.

- Experimental evaluation of slab-column frame and the use of the ductile steel.

- Behavior of clay brick and concrete masonry infill walls.

- Repair and rehabilitation research program coordination. 
In addition, cooperation and coordination efforts were initiated with other on-going seismic repair and rehabilitation programs, conducted by the National Center for Earthquake Engineering Research (NCEER), the Earthquake Engineering Research Institute (EERI) through its Existing Building Committee, the Federal Emergency Management Agency (FEMA), the Building and Fire Research Laboratory (NIST), The California Seismic Safety Commission (CSSC), and other organizations. The first coordination meeting of FY 1991 was held in Salt Lake City on February 13, 1991.

* 3-1 day ASCE seminars on Rehabilitation, Planning and Structural Repair of Concrete and Masonry were held in, Oakland, CA (3/90); Boston (4/90); and Washington D.C. (5/90).

* A workshop on Nondestructive Evaluation of Civil Structures and Materials was held in October, 1990, in Boulder, Colorado. 406 pages hardcover proceedings are available from the University of "Colorado, Department of Civil Engineering. Participants came from many disciplines of engineering in academics and industries.

There were five working groups:

- concrete

- masonry

- steel

- timber

- advanced equipment and techniques.

* Proceeding of the Workshop on Evaluation, Repair, and Retrofit of Structures, (NISTIR 4515), held at NIST in May 1990, was published by NIST and distributed at the 23rd UJNR Joint Meeting in Tsukuba, Japan. Copies of the proceedings were distributed also to authors, workshop participants, and other researchers and practicers in the U.S. 22 papers were presented at the NSF sponsored workshop, of which 17 papers were on repair and retrofit of structures. 24 delegates attended, 12 were from the U.S. and 12 from Japan.

* In the U.S., FEMA published ATC 21, A Handbook for Seismic Evaluation of Existing Buildings, and ATC 22 Techniques for Seismically Rehabilitating Existing Buildings. The U.S. Department of Energy and U.S. Postal Service are involved in extensive repair and retrofit projects.

* The Architectural Institute of Japan (AIJ) have revised its Ultimate Strength and Deformation Capacity of Buildings in Seismic Design in December 1990 after 13 years since the first edition. This book contain many recent research results mainly on evaluation method of bearing capacity and ductility of structures and structural members such as foundation structure, reinforced concrete structure, steel framed reinforced concrete structure, steel structure, wooden structure, vessel structure and structure with passive control.

* The Architectural Disaster Prevention Association has revised its Guidelines for Evaluating and Strengthening Existing Reinforced Concrete Buildings in October, 1990 after 13 years since the first edition and the Guidelines for Evaluation of Earthquake Damage and Retrofitting 
Methods of Buildings in March, 1991.

- In the Guideline for Evaluating, a simplified rigorous evaluation method for school buildings vulnerable to earthquake was added as one of appendixes.

- In the Guideline for strengthening, structural calculation method to strengthen existing reinforced concrete buildings by steel panels or steel braces was newly regulated based on recent research results.

* In Japan several prefectures such as Kanagawa prefecture and Shizuoka prefecture where a severe earthquake is anticipated to occur, continue to discuss countermeasures after the earthquake, and in case of Kanagawa prefecture, it will be decided to start to cultivate engineers especially for urgent evaluation of damages applying the guidelines.

* The guidelines were presented to U.S. side at the 23rd UJNR Joint Meeting ; the English version of the guidelines was translated by Dr. M. Ohkubo and will be printed in March, 1992 at UCSD.

4. Future Plans

* A second round of related NSF initiatives are planned for FY 92:

- Quantitative Nondestructive Evaluation for Large Structural Systems

- Repair and Rehabilitation Research for the Seismic Resistance of Structures

* Repair and retrofit of existing structures are being studied in association with a possible federal initiative on adaptation due to the global changes (MARS) program.

* New initiatives are being developed by NSF to focus on central and eastern U.S. existing structures/buildings.

* In support of IDNDR activities, T/C "C" plans to participate in task committee activities related to repair and retrofit of damages due to various disasters.

* A possible workshop is being planned on the Design Approaches and Construction Methods for Repair and Retrofit of Buildings and Structures after 1992. The Workshop will focus on the use of newly developed methods for repair, retrofit and evaluation of buildings/structures.

\section{Information Exchange}

* Publications of the Joint T/C "C" of "D" Workshops on Evaluation Repair and Retrofit of Structures were distributed, to all delegates and will be made available to design professionals through technical presentations at national meetings of professional societies.

* A U.S. Panel (Japanese Technology Evaluation Center Panel) visited 29 sites in Japan in July, 90, to study and exchange information on construction technologies. 
* Published workshop reports and individual research papers; they were exchanged with the U.S. and JAPAN-side members.

* Numerous papers presented at the 23rd UJNR Joint Panel Meeting are of interest to $\mathrm{T} / \mathrm{C}$ "C".

6. Impact

* Contributed to development of U.S. and Japan design criteria for repairing and strengthening reinforced concrete, steel, and other buildings.

* T/C recommendations were incorporated into building codes and professional practices, as illustrated by rehabilitation programs used by the City of Los Angeles to upgrade existing masonry buildings to resist earthquake forces.

* Influenced changes to U.S. and Japan design practices to upgrade existing structures.

\section{Barriers}

* Greater progress needs be made to implement available research results. Additional funding sources need to be identified to support technical activities to support committee missions and to support participate attendance at Joint Panel Meeting workshops. Creative technical information services, including translation of Japanese files, abstracts or entire reports are needed to improve the effectiveness of information exchange. 
Date: May 14, 1991

Place: Public Works Research Institute Tsukuba, JAPAN

$\begin{array}{rlr}\text { Attendees: Japan Side }- & \text { S. Okamoto, Chairman } & \text { (BRI) } \\ & \text { M. Hirosawa } & \text { (BRI) } \\ & \text { S. Nakata } & \text { (BRI) } \\ & \text { H. Yamanouchi } & \text { (BRI) } \\ & \text { T. Murota } & \text { (BRI) } \\ & \text { S. Ohtsuka } & \text { (MRI) } \\ & & \\ & & \text { (NSF) } \\ \text { U.S. Side } & \text { S.C. Liu, Acting chairman } & \text { (NCEL) } \\ & \text { T. Lew } & \text { (NIST) } \\ & \text { H.S. Lew } & \text { (NCEER) } \\ \text { M. Shinozuka } & \text { (DOE) } \\ & \text { D. Eagling } & \text { (USGS) } \\ \text { M. Celebi } & \text { (Stanford) } \\ \text { A. Smith } & \end{array}$

1. Objective

The objectives of this task committee are to develop disaster mitigation policies and programs to improve the capacity of existing structures to resist wind and seismic forces. To provide adequate performance evaluation, each country will coordinate development of condition assessment, screening, and structural analysis methodologies. Structures will be analyzed and instrumented, and then evaluated after disasters.

\section{Scope of Work}

* Develop an inventory of "benchmark" structures that have been analyzed and instrumented to measure wind and seismic responses.

* Develop a uniform system for screening and analyzing wind and seismic resistance capacity of structures in each country.

* Develop sensor technology, instruementation, and "expert" systems to provide condition assessment of existing structures.

* Evaluate masonry and precast concrete buildings, and seismic base isolation systems; include results in each country's catalog of "benchmark" structures for post-disaster performance evaluation

* Conduct workshops at future UJNR Joint Panel Meetings, cooperatively with $\mathrm{T} / \mathrm{C}$ "B" and "C". 


\section{Accomplishments}

* The Proceedings of a Workshop on Evaluation, Repair, and Retrofit of Structures (Joint Task Committee "C" and "D"), held at NIST in May 1990, was published and distributed to the authors, workshop participants, and other researchers and practicers in the U.S.

* The U.S. Side (NIST) conducted the translation and published the Japanese MOC documents on base isolation:

Report of the Expert Committee on Advanced Technology for Building Structures:

Part 1, Damping Structures and Trends of Future
Part 2, Survey Report on Framing of the Guidelines for
\[ \begin{array}{l}\text { Technological Development of Base-Isolation } \\ \text { Systems }\end{array} \]

Status reports on recent U.S. legislation were presented at the 23rd Joint Panel Meeting:

1990 National Affordable Housing Act, Sec. 947 on Seismic Safety Standards. Requires HUD to conduct risk assessments of all HUD-assisted housing, and to develop or adopt aseismic standards in accordance with Executive Order 12699. A first report to Congress is due by May 21, 1992. ".... the Secretary shall consult with the Director of the Federal Emergency Management Agency (FEMA) and may utilize the resources under the National Earthquake Hazards Reduction Program ...."

National Earthquake Hazards Reduction Program Reauthorization Act; Public Law 101-614, Nov.16, 1990. Sec. 8 on Seismic Standards. "The President shall adopt, not later than December 1, 1994, standards for assessing and enhancing the seismic safety of existing buildings constructed for or leased by the Federal Government...." "The President shall ensure the issuance, before February 1, 1993, by all Federal agencies of final regulations required by .... Executive Order numbered 12699, issued January 5, 1990."

Information was exchanged on the activities of each country in the International Decade on Natural Disaster Reduction (IDNDR). Several U.S. Agencies are participating on the Federal Subcommittee on Natural Disaster Reduction (SNDR), under the Committee on Earth and Environmental Sciences (CEES).

A report entitled: Hazard-Proofing the Nation, Strategy to Reduce Natural Disasters was drafted by SNDR, and will be submitted to all Federal Agencies by June 1991. Included in the research and implementation strategies are risk assessment and mitigation programs. When completed, copies will be mailed to the Japanese members. 
* Status reports of several FEMA - ATC projects were discussed, including those on seismic risk assessment of existing structures. The U.S. Dept. of Energy and U.S. Postal Service are actively conducting risk assessment studies, and planning or conducting extensive repair and retrofit projects.

\section{Future Plans}

* Develop a reporting system and data collection form for building inventory and performance standard, and compile a computer data file for exchange between countries. Report at each Joint Panel Meeting. A special subcommittee shall be established to formulate a working plan for "benchmark" structures.

* Continue to encourage participation by private industry, consulting engineering firms, universities, funding agencies and State and local government agencies involved in instrumentation, evaluation, and condition assessment of existing buildings.

* Monitor development of sensor technology and instrumentation of structures for condition assessment, and to measure long-term aging effects on building components.

* Participate in coordination of Joint Panel activities in the International Decade for Natural Disaster Reduction (IDNDR), pertaining to structural performance evaluation.

* A workshop on Structural Performance Evaluation Methodologies will be discussed to be held in the U.S. after 1992. The workshop will place emphasis on a synthesis of current methodologies used in both sides and comparative studies of these methodologies.

\section{Information Exchange}

* Technical documents exchanged, and pertinent Japanese papers delivered at 23rd Joint Panel Meeting.

* Japense side will send to the U.S. T/C Chairman a copy of the Final Revision of "Design Guidelines for Medium Rise Reinforced Masonry Buildings" developed by TCCMAR-Japan. U.S. Side will explore feasibility of translating this manuscript into English. Summary report of the design guidelines was printed in the Pre-Proceedings of "22nd Joint Meeting (3-3 Okamoto).

6. Impact

* Enables the development of revised standards and building code provisions to prevent destruction from high winds and earthquakes. 
* Provides engineers with the capability to conduct condition assessment of existing structures for the purpose of developing cost effective repair, retrofit, strengthening or demolition programs.

* Will increase the confidence level of the public, regulators, policy makers and engineers, to be asured that the majority of major structures will perform adequately to resist high wind and earthquake forces.

7. Barriers

* Difficulty in identifying priorities and inadequate resources to document load carrying capacity of existing buildings subjected to highly probable extreme winds and earthquakes.

* Difficulty in developing probability risk maps for tornadoes, typhoons, and hurricanes.

* Limited resources for instrumenting buildings, for conducting post-disaster evaluations, and for participating in foreign travel for coordinaton of activities. 


\section{Report of Task Committee on}

(E) GROUND MOTION AND SEISMIC DESIGN FORCE

Date: $\quad$ May 14, 1991

Place: $\quad$ Public Works Research Institute

Tsukuba

Japan

Attendees: Japan Side- K. Kawashima (Chairman)

T. Dohi

(PWRI)

Y. Kitagawa

(GSI)

K. Ohtani

(BRI)

T. Uwabe

(NIED)

H. Sugita

(PHRI)

(PWRI)

K. Tamura

(PWRI)

G. A. MacRae

(PWRI)

U.S. Side-

S. T. Algermissen (Chairman)

(USGS)

A. G. Brady

J. R. Hill

MISSION STATEMENT

1. Objectives

The objectives of this Task Committee are to develop techniques and exchange information and experiences on: 1) engineering characterization of ground motion, 2) mapping techniques for displaying ground motion data, 3) microzonation, 4) siting and design applications, and 5) earthquake hazard and risk assessment.

\section{Scope of Work}

Plan and conduct cooperative research, T/C workshops and meetings. These meetings and workshops are generally held in conjunction with the annual Panel Meeting on Wind and Seismic Effects. Activities include:

- Conduct cooperative research programs

- Exchange research personnel

- Exchange information on a timely basis 


\section{Accomplishments}

All final preparations have been made for the workshop "Hazard/Risk Assessment and Design Earthquake Loading" to be held on May 28-29, 1991 at the Public Works Research Institute, Tsukuba, Japan. Fourteen papers have been accepted for presentation.

\section{Future Plan}

1) The workshop "Hazard/Risk Assessment and Design Earthquake Loading" will be held on May 28 and 29, 1991. A study tour will precede the workshop.

1i) Proceedings for the workshop will be published and distributed to the panel members and interested parties.

iil) The Task Committee co-chairmen will develop a system for the exchange of approprlate technical material.

\section{Information Exchange}

Technical reports and research documentation were exchanged with participating organizations in both countrles.

\section{Impact}

Task committee efforts influence the national seismic codes concerning input seismic forces.

\section{Barriers}

Lack of funding for travel to conduct workshops and related meetings has been the principal barrier in the past. 
(F) DISASTER PREVENTION METHODS FOR LIFELINE SYSTEMS

Date: May 15, 1991

Place: Public Works Research Instltute, Tsukuba, Japan

$\begin{array}{cc}\text { Attendees: Japan Side - Y. Sasaki (Chairman) } & \text { (PWRI) } \\ \text { T. Murota } & \text { (BRI) } \\ \text { T. Uwabe } & \text { (PHRI) } \\ \text { K. Tokida } & \text { (PWRI) } \\ \text { H. Sugita (Observer) } & \text { (PWRI) } \\ & \\ \text { U.S. Side - J. Cooper (Acting Chairman) } & \text { (FHWA) } \\ \text { M. Celebi } & \text { (USGS) } \\ \text { J. Hill } & \text { (DOE) } \\ \text { T. Lew } & \text { (NCEL) } \\ \text { D. Eagling } & \text { (LBL) }\end{array}$

MISSION STATEMENT

1. Objective

The objectives of Task Committee "F" are to improve 1) the behavior of lifeline systems during earthquakes and 2) engineering and other seismic countermeasures such as damage estimation techniques and inspection procedures. These technologies provide users with improvements to existing standards of practice for safety and serviceabillty of lifeline systems. Lifeline systems such as gas, oll, water, and sewage pipelines; and power, communication, and transportation systems are cruclal to the survival and health of a city or community. Earthquakes affecting such systems cause severe social and economic disruptions to communities and cause human suffering to the residents.

\section{Scope of Work}

* Plan and conduct $\mathrm{T} / \mathrm{C}$ workshops and meetings; they generally are held in conjunction with the annual UJNR Joint Meeting. The purpose is to exchange the state-of-the-art knowledge and practice, and to identify cooperatively key opportunities for exchange and studies which effectively implement research results.

* Conduct related technical sessions at professional society meetings. 
* Create a research program on a selected lifeline system (similar in concept to the Large-Scale Testing Program). For example, through joint demonstration, produce criteria for emergency design and loss evaluation and on-line monitoring systems for lifeline operation.

* Conduct special activities such as translating, printing, and distributing MOC PWRI's publication Manual for Repair Methods for Civil Engineering Structures Damaged by Earthquake.

* Develop performance standards and a manual on repair, restoration, and retrofit of lifelines.

\section{Accomplishments}

* Researchers from both sides have contributed technical papers on lifeline systems at the 23rd joint panel meeting.

* Researchers from both sides have participated in the post-event field investigations on the collapse and damage of lifeline structures in the San Francisco Bay area following the Loma Prieta earthquake in October 1989. A number of in-depth studies on earthquake behavior, safety, repair and strengthening of the lifeline structures have been undertaken.

* Encourage active perticipation in promoting the goals of IDNDR.

4. Future Plan

* Conduct the 4th Joint Workshop on Earthquake Disaster Prevention for Lifeline Systems on August 19-21, 1991 at Los Angels.

* Encourage the identification of existing specifications used for the seismic design and retrofit of lifeline structures in both countries and encourage the development of criteria for those lifeline structures where insufficient design guidance exists.

* Continue observation of instrumented buried pipes in Parkfield, California, and Chiba, Japan and exchange data.

\section{Information Exchange}

* Domestic community: through technical meetings, conference sessions, seminars, and workshops.

* Between U.S. and Japan: through T/C workshops and annual Joint Panel Meetings. 
* Visits by researchers and participation in technical meetings sponsored by organizations such as NCEER, EERI and ASCE.

* Short-term ( 3 to 12 months) researcher exchanges to participate in on-going lifeline research.

6. Impact

* Contributed to increased field engineers' technical knowledge on repair methods, through seminars with lectures by T/C members using the MOC Manual in nine major cities in Japan, including Tokyo and Osaka; more than two thousand participants attended seminars.

* Contributed to the assessment of design, construction, and operating standards for lifeline earthquake engineering (TCLEE/ASCE) via T/C members participation in the committee work.

\section{Barriers}

* Insufficient funds to conduct annual Task Committee Workshops and to publish proceedings and reports.

* Lack of participation by U.S. Industrial organizations and utilities in research or in implementation of findings due to a reluctance to adopt new technologies and practices. 


\section{TASTR COMMTTTEE REPORT}

(G) Passive, Active, and Hybrid Control Systems

Date : May 151991

Place : Public Works Research Institute, Tsukuba, Japan

Attendees :

$\begin{array}{lll}\text { Japan Side - Y. Kitagawa (Chairman) } & \text { (BRI) } \\ \text { K. Kawashima } & \text { (PWRI) } \\ \text { K. Yokoyama } & \text { (PWRI) } \\ \text { S. Nakata } & \text { (BRI) } \\ \text { H. Yamanouchi } & \text { (BRI) } \\ \text { M. Ozaki } & \text { (Chiba University) } \\ & \text { G. MacRae } & \text { (PWRI) } \\ & & \\ \text { U.S. Side - S. C. Iiu (Chairman) } & \text { (NSF) } \\ & \text { H. S. Lew } & \text { (NIST) } \\ \text { M. Shinozuka } & \text { (NCEER, Buffalo) } \\ \text { H. Allison Smith } & \text { (Stanford University) }\end{array}$

\section{MISSION STATEMENT}

\section{(1) Objective}

The objectives of T/C "G" are to: (1) develop research plans in passive, active, and hybrid control of structures and equipment, (2) implement such control techniques as computerized motion reduction or modification devices/systems in actual design and construction of structural engineering facilities under seismic or wind environments, (3) promote U.S.-Japan cooperation in structural control research. (4) bring together governmental, academic, and industrial participants in joint pursuit of such efforts, and (5) contribute to IDNDR by organizing joint research and other technical activities in structural control on the basis of international cooperation.

\section{(2) Scope of Work}

The UJNR T/C "G" works closely with other organizations to provide the leadership in control research efforts by facilitating the exchange of technical data and information through the established UJNR mechanisms. Work includes:

* Providing technical assistance, consultation and coordination to UJNR affiliated research agencies in the initiation, development, and execution of their programs in structural control research.

* Promoting joint government-university-industry collaborative efforts to facilitate technology transfer and practical implementation.

* Sponsoring and conducting multidisciplinary workshops and 
meetings to identify key areas of research and opportunities for cooperation, and to exchange new knowledge and experience in practice.

Developing promotional and demonstrative activities to stimulate public awareness and interest in this emerging field of research.

Establishing performance standards, design specifications, guidelines and code recommendations for application in new construction as well as retrofit/rehabilitation of existing structures with control systems.

Initiating research in new intelligent materials, high-tech sensors, optimal control systems design, and laboratory and field experiments of prototype and full-scale structures.

\section{Accomplishments}

The U.S. Panel on Structural Control Research interacted actively with its counterpart Japanese Panel in exchanging technical information and developing joint research plans.

An "International Workshop on Intelligent Structures" was held in July 1990 at the Academia Sinica, Taipei, Taiwan. The Workshop was organized by S.C. Liu and K.P. Chong - both UJNR panel members - and J.C. Li of the National Central University in Taiwan, and was well attended by researchers from the U.S., Japan, Korea, Italy, and other countries.

The major theme areas of the Workshop are: (a) Sensing and Monitoring, (b) Structural Control, and (c) Inteligent Systems. The workshop proceedings (460pp. hard bound) was published by Elsevier Applied Sciences (London) including technical contributions in the development, application, and modification of active/hybrid control theories and technologies for civil engineering structures.

A "U.S. National Workshop on Structural Control Research" was held at the University of Southern California, Los Angeles, professors George W. Housner and Sani Masri. UJNR panel members $S$. $C$. Liu and $K$. P. Chong actively participated in the workshop's technical activities. The workshop identified four specificareas related to earthquake safety in it's technical program.

They are: (a) Analytical research, (b) Experimental research, (c) Building applications, and (d) Non-building applications. Proceedings of the workshop is in press and will be available by the summer of 1991.

* Workshop on Sensors on Signal Processing for structural Control was held at NSF, February 25 and 26 1991. Proceedings which include research needs are being distributed by Lehigh University. 


\section{(4) Future Plans}

A "U.S.-Japan Workshop on Passive and Active Control of Bridges Against Earthquakes" sponsored by T/C "G" is scheduled for September 4 and 5, 1991 at NCEER, Buffalo, New York. A study tour to inspect base-isolated bridges across the U.S. will be conducted by participants prior to and following the workshop (workshop co-chairmen: Ian Buckle/NCEER and K. Kawashima/PWRI).

A major multi-year research initiative on "Structural Control Research for Performance, Safety and Hazard Mitigation"is being developed by NSF. The program encourages team research projects and lays out a multidisciplinary research agenda to achieve the following objectives:

- encourage innovations in passive, active, and hybrid controlksystems including the adaptation of existing technology.

- advance sensor and actuator technology and signalprocessing techniques and their appiications.

- develop intelligent. robots, other devices, advanced computer systems and control algorithms for structural safety.

- develop innovative systems for energy absorption, addeddamping, and variable stiffness.

- study, the robustness and system reliability of control systems.

- develop guidelines, standards and practical aevelop guidelines, standaras and practical approachesand techniques for design, fabrication and field installation.

- investigate emerging technology subjects in innovativestructural systems, and smart materials, sensors, anddevices for detection, sensing, monitoring, and diagnosis.

Joint research projects on hybrid control of bridges are beingdeveloped by PWRI, NIST, FHWA, NCEER, and University of California, Irvine.

Joint research projects on active and hybrid control of buildings are being developed by BRI, NCEER and University of California, Irvine.

Develop specific work plans for coming year (1991-1992) and forthe next five years.

In cooperation with T/C "J", continue to support development and implementation of base-isolation technology for bridge 
structure.

\section{(5) Information Exchanges}

Technical materials on structural response and control systems were exchanged.

\section{(6) Impact}

The T/C "G" has stimulated research communities from both sides to initiate multidisciplinary studies and cooperative investigation in structural control.

\section{(7) Barriers}

No technical barriers are identified at the present time. However lack of sufficient financial backing from both sides may present difficulties in achieving the objectives of T/C "G". 
Report of Task Committee on

(H) SOIL BEHAVIOR AND STABILITY DURING EARTHQUAKES

Date: MAY 14, 1991

Place: Public Works Research Institute Tsukuba, Japan

\begin{tabular}{|c|c|}
\hline Attendees: & Japan side - K. Tokida (Chairman) \\
\hline & Y. Koga \\
\hline & S. Sasaki \\
\hline & S. Noda \\
\hline & T. Fujisawa \\
\hline & Y. Yamazaki \\
\hline & Y. Yamaguchi(Observer) \\
\hline
\end{tabular}

U.S. side - A. G. Franklin (Chairman)

(WES)

\section{MISSION STATEMENT}

\section{Objective}

Government agencies with responsibility for public works have the need to assure their seismic safety and to provide economical protection against earthquake hazards. The objective of this Task Committee is to assist in meeting those needs by enhancing the available technology for predicting the dynamic behavior of soils, analyzing dynamic soil-structure interaction, and modifying the earthquake behavior of foundations and earth structures in order to assure their safe performance during earthquakes.

\section{Scope of Work}

* Present technical papers at annual joint panel meetings on technological developments and the state-of-the-art and practice related to soil behavior and stability during earthquakes.

* Exchange information and technical data relating to field performance, research and methods of practice.

* Plan and conduct T/C workshops in coordination with proposed or ongoing cooperative research programs.

* The Task Committee plans and conducts programs of cooperative research, exchange of researchers between U.S. and Japanese research institutions, publication of research results and recommended practice. The benefits realized from available research funds can be amplified by bringing 
greater resources to bear on problems of mutual interest, and by coordinating research tasks to make the best use of the respective strengths of the two sides' research capabilities.

* Exchange visiting researchers using mechanisms provided by formal and informal cooperative research programs. Such exchanges promote technical information exchanges, familiarization with methods of practice on the respective sides, and mutual understanding and cooperative relationships between researchers on the two sides.

\section{Accomplishments}

* U.S. researchers presented 6 papers and Japanese researchers presented 11 papers, on soil behavior and stability during earthquakes, at the 22nd and 23rd joint panel meetings.

$5 / 90,5 / 91$

* Mr. Nario Yasuda of the PWRI completed a one-year guest researcher assignment at the U.S. Bureau of Reclamation doing research in Seismic

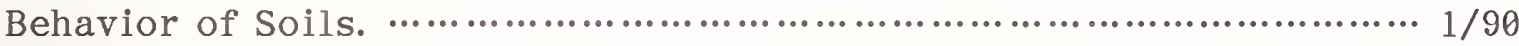

* Dr. Yasushi Sasaki of the PWRI visited sites of damage around the San Francisco Bay Area and the epicentral area of the Loma Prieta Earthquake. He was assisted by several U.S. Panel Members including the T/C (H) U.S. Chairman.

$3 / 90$

* A set of $35 \mathrm{~mm}$ slides showing the effects of the Loma Prieta Earthquake was provided to the Japanese side by the U.S. side. .......................... 3/90

* Dr. Ashok K. Chugh, of the U.S. Bureau of Reclamation, visited the PWRI in March and April 1990, to study the Dynamic Behavior of Rock-Fill Dams. $.4 / 90$

* Mr. Keiichi Tamura of the PWRI completed a one-year visit as a guest researcher at Stanford University working on Seismic Response Characteristics of Ground. $10 / 90$

* Mr. Motoki Kazama of the PHRI completed a one-year visit as a guest researcher at the Scripps Institute of Oceanography working on Effects of Offshore Environments on Seismic Response of Soil Deposits and Pile Foundations. $10 / 90$

* The International Workshop on Remedial Treatment of Potentially Liquefiable Soils was conducted at PWRI in Tsukuba from 22 to 25 January, 1991. The U.S. side was represented by Professor W. D. Liam Finn of the University of British Columbia. Nineteen papers were presented. $\cdots \cdots 1 / 91$

* Mr. Ken-ichi Tokida, the T/C (H) Japan Chairman, visited St. Louis and met Mr. R. H. Ledbetter of the U.S. Army Engineer Waterways Experiment Station and discussed the proceedings of the International Workshop held in January and plans for the next workshop. 
* Proceedings of the International Workshop on Remedial Treatment of Potentially Liquefiable Soils was published and distributed to the members of Task Committee $(\mathrm{H})$ and participants of the Workshop.

* The English language report on the expert team of Japan Disaster Relief Team (JDR) on the earthquake in the Philippines of July 16, 1990, was provided to the U.S. side. $5 / 91$

4. Future Plans:

* Identification of research tasks on preventive measures against soil liquefaction that are of common interest, in accordance with-the results of the planning meeting held at Tsukuba in May 1989. $9 / 91$

* T/C (H) proposes to hold the next U.S.-Japan Workshop on Remedial Treatment of Potentially Liquefiable Soils in conjunction with the 25th annual UJNR meeting.

* T/C (H) has relinquished its responsibility for consideration of marine structures subject to earthquakes and the measurement of sea floor earthquake motions to the new Task Committee $(\mathrm{K})$ on Wind and Earthquake Engineering for Offshore and Coastal Structures, recognized at the 23rd Joint Panel Meeting. $5 / 91$

* T/C (H), at the 22nd Joint Panel Meeting, discussed the need for technological innovation and research to assist in saving lives following natural disasters caused by earthquakes. The principal areas of need were identified as improved technology for locating survivors and the development of new equipment and systems for safe excavation of debris to remove survivors from collapsed structures. T/C (H) recognizes this subject is outside their area of responsibility but feels it is important and should be discussed by the full Joint Panel.

The Task Committee suggests the following options for implementation:

(1) Establish a new Task Committee which will address this topic area and provide the focal point to share experience and research in this area.

(2) Incorporate this topic into another existing $\mathrm{T} / \mathrm{C}$.

$\mathrm{T} / \mathrm{C}(\mathrm{H})$ will continue to explore methods whereby this topic will receive appropriate visibility.

* T/C (H) will support the proposed visit of Mr. Yoshikazu Yamaguchi to the U.S. Army Engineer Waterways Experiment Station as a visiting researcher during 1991 and 1992.

* T/C (H) will support the proposed visit of Mr. Junichi Koseki to the Massachusetts Institute of Technology as a visiting engineer during 1991 and 1992. 


\section{Information Exchange:}

* T/C workshops, exchange of visitors, participation in annual joint panel meetings, and presenting technical papers.

* Exchange of researchers between U.S. and Japanese government laboratories.

* Visits by researchers and participation in technical activities such as post-earthquake field investigations.

* Professional community in the U.S. and Japan, publication of papers in journals, publication of research reports by the respective agencies, participation in professional society meetings and conferences, and workshops.

\section{Impact}

* Through the exchange of researchers and the diffusion of earthquakerelated technical data, experience, and information on methods of practice, the state of technology in geotechnical earthquake engineering has been raised on both sides.

* Through the cooperative research program on in-situ testing of soils which was carried out after the 1983 Nihonkai-Chubu Earthquake, improved and more accurate methods of using in-situ tests for evaluating the liquefaction potential of soils were achieved; these have been in general use in the United States since 1985. The Loma Prieta Earthquake stimulated renewed awareness of the need for further research in soil liquefaction and amplification effects of soft soils.

* Through the workshops on remedial treatment of potentially liquefiable soils held in 1988 and 1991, beneficial information on recent technology were exchanged and contributed to progress future research of both U.S.and Japan- sides.

\section{Barriers}

* Insufficient U.S. and Japan Government funds allocated to adequately address earthquake engineering research.

* Administrative limitations on foreign travel. 
Resolution of the International Workshop

on

the Remedial Treatment of Potentially Liquefiable Soils

\author{
Public Works Research Institute \\ Ministry of Construction \\ 1 Asahi. Tsukuba-shi, Ibaraki-ken 305 \\ Japan
}

January 22-25, 1991

The following resolutions are hereby adopted:

1. The U.S. Panel members of the UJNR Meeting were unable to participate in this particular meeting because of effect of the Gulf War. Consequently, the title of this particular meeting was changed to International Workshop from the Second Workshop of the Task Committee " $H^{\text {" }}$ of the UJNR Meeting which was originally scheduled.

2. About 35 participants from Canada, Philippines and Japan joined this Workshop, discussed and exchanged information eagerly and effectively.

19 papers were presented and discussed according to the workshop program.

Technical visits were made to the sites in and around the Tokyo Bay where the remedial treatment of soil liquefaction and soft ground were conducted.

All the participants to this Workshop recognized that this particular meeting gave a beneficial chance to exchange the current findings and knowledge, which are inevitable to establish a more reliable technology and standards concerning the remedial treatment of the potentially liquefiable soils.

3. Some important findings of the workshop are as follows;

3-1 It is important to recognize what is the liquefied state, in order to find the best solution. There was considerable discussion about the different liquefied states: 1) Near surface liquefaction with upward seepage gradients and very low liquefied strength, and 2) The deformation of soil structures with liquefied zones at their residual strength. This kind of recognition should be reflected in the algorithms of the analyses as well as in the back calculation of the past cases. 
3-2 A sophisticated technical method was presented to estimate the deformation of soil structures such as embankment dams caused by the soil liquefaction. Efforts like this kind of development are expected to refine the current technology in analysis.

3-3 There is a great need to document the performance of treated ground during earthquakes and to compile the information into a data base.

3-4 Further investigations for estimating the effects of liquefaction on bridges and underground structures are required for establishing simplified procedures and reasonable design methods.

3-5 Although various types of remedial treatment methods have been developed and applied in practice, the standards and specifications for selecting reasonable countermeasures against liquefaction and the induced lateral ground displacement have not been established. For establishing the effective countermeasures, the liquefaction phenomena, the degree of liquefaction and its effect need to be investigated further.

3-6 The continuation of information exchange by the Joint Meetings, UJNR and its future Workshops is considered essential, although the U.S. members were unable to participate on this particular occasion. 
Report of Task Committee on

( I) STORM SURGE AND TSUNAMI

Date: $\quad$ May 15, 1991

Place: Public Works Research Institute Tsukuba, Japan

Attendees: Japan Side - T. Uda (Chairman) (PWRI)

K. Tanimoto (PWRI)

S. Ohtsuka (MRI)

M. Okada (MRI)

N. Ohyagi (NIED)

MISSION STATEMENT

U.S. Side - J.F. Lander (Acting Chairman)

(Univ. of Colorado)

W.E. Roper (U.S. Corps)

1. Objective

The objective of this $\mathrm{T} / \mathrm{C}$ is to mitigate damages from storm surges and tsunamis through shared technologies, research, information sharing, and cooperative work. Storm surge and tsunami are hazards capable of inflecting damage of disastrous proportions. Storm surges are associated with hurricanes and typhoons where high winds and the mounding of water under the low barometric pressure of the storm's eye can cause extensive flooding and severe wave action. Tsunamis are predominately caused by underwater earthquakes and, to a lesser extent volcanic activity. Depending on the distance from the source tsunamis arrive within minutes to up to a day after generation.

\section{Scope of Work}

* Exchange results of research on storm surge and tsunami occurrence, generation, propagation, and coastal effects. This includes observations on historical, current, and theoretical tsunamis. Of particular interest is the effort by U.S. and JAPAN to acquire deep ocean tsunami measurements.

* Exchange results and status of anti-storm surge and tsunami activities including analysis of the problem, planning, warning, and engineering approaches.

* Exchange information on planned and ongoing projects relating to storm surge and tsunamis.

* Exchange information on development of technologies such as computer programs to predict travel times, land-fall locations, run-up heights, and wave characteristics and analysis; improved instrumentation, and use of satellite communications for detection and warning.

* Facilitate dissemination through exchange of literature, technical reports at joint meetings, special workshops, joint projects, and direct interaction among participants. 


\section{Accomplishments}

* Exchanged digital bathymetric data with the Japanese side; U.S. side received a computer program to calculate tsunami travel time charts.

* Expanded the number of active U.S. participants with representation from COE, University of Colorado, NOAA, and NSF.

* The U.S. side has compiled detailed information on all tsunamis affecting the U.S. and its possessions. The publication, "United States Tsunamis 1690-1989" has been printed and given to the Japanese side.

* A Second Tsunami Workshop was held on November 5-7, 1990 in Hawaii. Nine members participated from the Japanese side and about 20 from the U.S. side. Site visits were made to Hilo as part of the workshop. Proceedings were published and they were sent all related members.

* NOAA has adopted the travel time program developed by Mr. Okada (MRI/JMA) using NOAA gridded bathymetric data to run on their computers. The first ever computed travel time charts have been prepared for the Caribbean sea using this program developed by Mr. Okada. A copy of the published paper was sent to the Japanese side.

\section{Future Plans}

* Develop exchanges of data and information on activities related to tsunami measurements including deep ocean measurements.

* Explore and promote joint undertakings such as tsunami gauge testing, scientist exchange, satellite communications for tsunami warning, and assistance in contacts within the U.S. and JAPAN .

* The U.S. and Japanese sides agree that there is a need to hold workshops at about 3 year intervals to exchange the latest research and technology relating to various aspects of storm surge and tsunami hazards. A third workshop including both storm surge and tsunamis is being planned for August, 1993 in Japan near the time of the International Union of Geodesy and Geophysics (IUGG) Tsunami Commission Symposium.

* Develop activities and information exchanges to support the International Decade of Natural Disaster Reduction.

\section{Information Exchange}

* Continue exchange of publications, bibliographic data, technical reports, and personal contacts. 


\section{Impact}

* Increased cooperation among scientists and engineers working in these fields.

* Hasten implementation of new modeling and design techniques developed by the U.S. and Japan.

* Facilitated wider dissemination of information and technology to scientists and engineers in both countries.

\section{Barriers}

* Insufficient funding from government and private sector organizations to participate in T/C workshops and the Panel's annual joint meetings.

* The tsunami problem is less severe in the US than in JAPAN which leads to a smaller community of researchers. There are few U.S. researchers focusing on tsunamis at any specific location; thus highlighting the importance of $\mathrm{T} / \mathrm{C}$ periodic meetings and workshops.

* There are different approaches and degree of significance in dealing with problems in the U.S. and JAPAN. For example, in the U.S. much of the hazard is from remote sources which leads the government to emphasize developments of warning and evacuation schemes. In JAPAN the engineering approach is needed because there are more locally generated tsunamis which often do not provide sufficient times for adequate warning and evacuation. This barrier is partially being addressed by inviting U.S. engineers and non-government specialists to participate during the annual meetings. 


\title{
TASK COMMITTEE I
}

\author{
Report of the 2nd UJNR Tsunami Workshop \\ November $5-7,1990$ \\ Honolulu and Hilo, Hawaii
}

\section{Activities}

1. The workshop was held over two days at the East-West Center, University of Hawaii, followed by a one day field trip to Hilo, Hawai .

2. Three topics were addressed

A. Predictions and Observations of Tsunami Behavior in Coastal Waters and on Land.

B. Applications of Numerical Modeling to Improved Travel Time Predictions, Source Region Definition, Inundation, and Run-up Prediction.

C. Protective Measures in Japan and the U.S. With Regard to the Use of Numerical Models and Design Tsunami Concept.

3. Discussions followed each paper and a longer round table discussion followed each topic.

4. Twenty-five papers were presented and about 30 people were in attendance including nine from Japan.

5. On the field trips, briefings were made by Dr. Gordon Burton, Director of the Pacific Tsunami Warning Center at Ewa Beach, Oahu, by the staff of Hawaiian Volcano Observatory and by Mr. Harry Kim, Director of Hawaijan Civil Defense on Hawaij. The participants toured the Kilauea Crater, the Tsunami Memorial and Hilo Bay area, and the site of the destruction of the village of Kalapana by recent volcanic activity.

6. The proceeding have been published and distributed to the participants, task committee member and other involved with the workshop. Additional copies will be available to tsunami researchers world wide on a cost basis. 


\section{Comments}

1. There was much good interaction among the participants. Among the topics stressed for future work were:

a) the importance of having a true wave profile, perhaps from deep ocean sensors both to determine the tsunami source structure and to project for run-up models.

b) The need for observational data from the shore line and on shore areas where the waves have become non-linear.

c) The importance of continuous development of models. simulating harbor effects for specific harbors as a training and planning tool. This includes accurate inundation models, life line protection, tsunami forces on structures and effect of defense measure such as dikes and breakwaters.

d) Quick evaluation of the tsunami potential perhaps using seismic moment is needed for warning purposed as well as a more deliberate evaluation which may involve historical data for planning purposes.

2. Workshops and symposia are useful ways to involve Japanese and U.S. government and academic researchers in the solution of the Task Committee I's mission area in storm surge and tsunami and should be convened at reasonable intervals.

3. Acknowledgment is made to the U.S. National Science Foundation which supported most of the U.S. participants under grant BCS-8908688 and NOAA's National Geophysical Data Center which provided important clerical and other support including the publication of the proceedings.

Takaaki Uda

Public Works Research Institute

Tsukuba, Japan

May 1991 
Date: $\quad$ May 14, 1991

Place: $\quad$ Public Works Research Institute, Ministry of Construction 1-banchi Asahi, Tsukuba-shi, Ibaraki-ken 305, JAPAN

Attendees: Japan Side - M. Fufiwara (Chairman) (PWRI)

M. Okahara (PWRI)

T. Fujitanl (MRI)

K. Nishikawa (PWRI)

Y. Ninomiya (PWRI)

K. Hasegawa (PWRI)

U.S. Side - J.D. Cooper (Chairman) (FHWA)

W.E. Roper (Corps of Eng.)

MISSION STATEMENT

\section{1. $\underline{\text { Objectives }}$}

The objectives of this Task Committee are to plan, promote, and foster research on the behavior of highway bridges when subjected to wind and seismic forces and to disseminate research results and provide specifications and guidelines based on the task committee's finding. Surface transportation systems for movement of goods and people play a vital part of commerce and intercourse between people. Highway bridges are especially influenced by the forces of wind and earthquakes because of their open exposure to those forces.

\section{Scope-of-Work}

The scope of the work is applicable mostly to highway bridges without any limitation on their size and function: such as existing bridge and new bridge designs; whole system of bridges; and/or to single components of a bridge.

The mission is performed through:

Conducting workshops, exchanging researchers, developing methods for design evaluations and test procedures, developing inspection techniques, rehabilitation and mainterance specifications and policies, and performing cooperative research programs and other relevant cooperative administrative activities.

\section{Accomplishments (past 2 years)}

Japanese side hosted an ad hoc $\mathrm{T} / \mathrm{C}(\mathrm{J})$ Retrofit Subcommittee meeting in December 17 to 22, 1990 to discuss and review practical seismic retrofit applications in both countries. Nineteen technical presentations were made by 5 U.S. researchers and 30 Japanese researchers. Technical topics included the 
history of developing retrofit techniques for bridges; damage assessment from the Loma Prieta earthquake; discussion on condition assessment and prioritization of bridges for seismic retrofit; seismic strengthening methods; and research in progress. Site visits were made to view retrofit technology applied to bridges on Tokyo metropolitan expressways.

- United States and Japanese post earthquake investigative teams collaborated to investigate the dumage to transportation systems with emphasis on highway bridges caused by the Loma Prieta Earthquake of October 17, 1989. Technical information was exchanged at the 22nd and 23rd Joint Panel Meetings.

- Conducted coordinated research studies on seismic performance of bridge plers and columns. Details of this work involved determining the performance of reinforced concrete piers and columns subjected to dynamic cyclic loading, performing model tests on the fallure of relnforced concrete plers, testing full and large-scale concrete columns and for the behavior of concrete filled steel tubes.

- Held the seventh bridge workshop in Tsukuba, Japan in 1991, which was followed by site visits of Higashi Kobe bridge, Kansal international airport, and Akashi Kaikyo bridge. Held the sixth bridge workshop in Lake Tahoe Nevada U.S. in 1990, dealing with the determination and evaluation of the performance and strengthening of bridge structures, structural monitoring, repairs, safety and nondestructive evaluation. Special attention was given to the seismic and wind loadings of modern cable-stayed bridges, vibration suppression, base isolation, dynamic control techniques, construction techniques of long span bridges, maintenance of existing bridges and limit state design.

- Both sides presented technical papers at the 22nd and 23rd UJNR Joint Meeting and participated in technical study tours to buildings, bridges, factories construction sites, and instrumented structures.

\section{Future Plans}

- Conduct the 8 th bridge workshop just prior to the 24th Joint Panel meeting in the Chicago Illinois area of the United States.

United States side plans to host a follow-up ad hoc T/C(J) Retrofit Subcommittee meeting to study practical seismic retrofit measures.

- Continue to investigate and exchange technical information on improved seismic retrofit and strengthening procedures for highway bridges based on experimental, analytical, and field studies. This exchange should include information on maintenance of existing bridges.

- Continue experimental research study on the seismic performance of bridge piers and columns, and support emphasis on base isolation of bridges in cooperation with $\mathrm{T} / \mathrm{C}(\mathrm{G})$.

- Develop a coordinated research study on seismic, aeroelastic, and aerodynamic response of cable-supported bridges with emphasis on cable inspection, vibration control and corrosion protection. 
Conduct a coordinated research study to compare the seismic design criteria for bridges in Japan and the U.S. and discuss the method and analysis for bridge column design. Information on application of limit state design method should be exchanged.

Continue a coordinated research study on seismic response control, system identification techniques, and nondestructive evaluation of bridge structures.

- Encourage a coodinated research study on use and performance of structural materials including new materials.

\section{Information Exchange}

- Exchanged technical reports, research program documentation, construction logs, design plans, and assorted photographs and videos, including technical data appropriate for Investigating the Phillppine earthquake of 1990 .

- Mr. Kelichi Tamura who studied at Stanford University, Mr. Kinji Hasegawa who studied at University of California and Mr. Shigeki Unjoh who studied at University of Southern Callfornia, returned to PWRI.

- Mr. Mohsen Sultan, Callfornia Department of Transportation is on a one year exchange with PWRI in Tsukuba.

\section{Impact}

- The free exchange of literature, instrumentation technology, and earthquake response data has led to the advancement in design technology, and development of preliminary retrofit guidelines, and to the callbration and verification of specifications.

Greater uniformity was achieved in wind engineering test procedures and modeling resulting in more efficient solutions to the aerodynamic bridge problem.

- The workshop and study tours in the two countrles have facliltated technology transfer, as an example, in the area of cable protection and vibration suppression of cable-stayed bridges.

A set of priorities for needed research from a more international viewpoint has reduced the conduct of dupllcative research efforts.

\section{Barriers}

There are no major technical barriers to achleve the Task Committee mission. However, financial barriers, especially funding needed to participate in workshops and panel meetings and for conducting actual bridge tests and large scale model tests, continue to limit the effectiveness of the work in this Task Committee's work. 
APPENDIX- 1

RESOLUTION OF THE FIRST U.S.-JAPAN WORKSHOP ON SEISMIC RETROFIT

\title{
BRIDGES
}

\author{
TSUKUBA, JAPAN \\ December 17 and 18,1990
}

The following resolutions are proposed by the organizers of the First U.S.-Japan Workshop on Seismic Retrofit of Bridges to the Task Committee $J$ of UJNR:

1. Both Japanese and U.S. participants gained insight into the need for bridge retrofit methods and technical solutions as a result of the workshop. It is recommended a second workshop on seismic retrofit of bridges be held in one or two years.

2. Considerable progress has been made in implementing retrofit techniques to restrain bridge spans from failures. As a consequence, future research and implementation should be directed into more critical areas, such as substructure stability.

3. Both countries are actively involved in developing retrofit techniques for improving performance of bridge piers. The research being carried out has been complementary rather than duplicative which emphases the value of the current information exchange. Japanese research is directed primarily to problems associated with premature termination of longitudinal reinforcement. U.S. research has been directed toward improving flexural ductility and shear strength of piers. Continuing cooperation and information exchange is recommended in this area.

4. Both sides recognize the importance and difficulty of effective retrofit of bridges on foundations of inadequate strength or stability. Increased efforts to develop and implement effective solutions is urged. 


\section{RESOLUTION OF THE SEVENTH U.S.-JAPAN BRIDGE ENGINEERING WORKSHOP} ANALYSIS, DESIGN, PERFORMANCE AND STRENGTHENING

TSUKUBA, JAPAN

May 8 and 9,1991

The following resolutions are proposed by the organizers of the 7 th U.S. -Japan Bridge Engineering Workshop to the Task Committee J of UJNR:

1. The seventh U.S.-Japan Bridge Engineering Workshop provided valuable exchange of technical information which was beneficial to bridge engineering communities of both countries. 81 participants representing government, academia, industry and private practice presented 32 papers in 10 technical sessions. Main themes included : 1) Seismic Design; 2) Wind Resistant Design; 3) Bridge Construction; 4) Design Methods; and 5) Bridge Maintenance. In view of the importance of cooperative programs on the subject of wind and seismic effects on bridges and on performance, strengthening, structural monitoring, safety, non-destructive evaluation and design innovation of these transportation structures, the continuation of technical cooperation and interaction is considered essential.

2. The Workshop recognizes the importance of continued exchange of personnel, technical information, research data and bridge response data from significant earthquakes and strong winds, and the use of available unique research facilities in both countries and encourages cooperative efforts in mutually agreeable areas of bridge research.

3. The primary purpose of the Workshop is to exchange technical information on a timely basis that is usable by bridge engineering profession. The specific objectives of this Workshop are:

3.1 To ensure a first-hand exchange of information resulting from the unique problems each country is faced with; for example, the development and implementation of limit state or load and resistant factor design methods.

3.2 To stimulate collaborative research work in the important area of bridge engineering for better design, construction, performance, rehabilitations and strengthening of bridge structures in both countries.

3.3 To facilitate the exchange of technical information and ideas and to promote the broadening of viewpoints for those involved. 
4. The Workshop identifies the following technical topics for continued cooperative research programs :

4.1 Dynamic control and seismic isolation of bridge structures including : active, passive and hybrid control, damping augmentation, experimental studies and application to long-span cable-supported bridges.

4.2 System identification techniques for wind and seismic engineering including : data interpretation studies, development of mathematical models, identification of non-linear systems, reduced-order models, computational algorithms and optimum sensor locations.

4.3 Non-destructive evaluation techniques including damage detection by sensor monitoring, expert systems, inspection techniques, structural monitoring, condition assessment for safety, performance evaluation and repair procedures.

4.4 Experimental and analytical studies on the effects of dynamic soil characteristics, including bridge-soil interactions, on the behavior of bridge structures.

\subsection{Retrofitting and strengthening methodologies for bridge structures.}

4.6 Development of design criterla based on limit-state concepts.

5. The Workshop identifies the following technical topic for future cooperative technical programs:

\subsection{Use and performance of structural materials including new materials.}

6. It is anticipated that the interaction among the delegates from the United States and Japan during the round-table discussions and the technical study tour will lead to an enhanced exchange of data and innovative ideas, and will also lead to the establishment of cooperative research efforts, both theoretical and experimental, on bridge engineering. Because of the importance, benefits and potential of these Workshops, it is recommended to conduct the 8 th bridge engineering workshop in Chicago Illinois, just prior to the 24th UJNR joint meeting in the United States, in May 1992. A study-tour will be planned to visit research laboratories and bridge-construction sites. 
1. PUBLICATION OR REPORT NUMBER NIST/SP-820

2. PERFORMING ORGAMIZATION REPORT NUMBER

\section{BIBLIOGRAPHIC DATA SHEET}

3. PUBLICATION DATE

September 1991

4. TITLE AND SUBTITLE

Wind and Seismic Effects--

Proceedings of the 23rd Joint Meeting of the U.S.-Japan Cooperative Program in Natural

Resources Panel on Wind and Seismic Effects

5. AUTHOR(S)

Noel J. Raufaste, Editor

6. PERFORMING ORGANIZATION (IF JOINT OR OTHER THAN NIST, SEE INSTRUCTIONS)

U.S. DEPARTMENT OF COMMERCE

NATIONAL INSTITUTE OF STANDARDS AND TECHNOLOGY

GAITHERSBURG, MD 20899

7. CONTRACT/GRANT NUMBER

8. TYPE OF REPORT AND PERIOD COVERED Fina 1

9. SPONSORING ORGANIZATION NAME AND COMPLETE ADDRESS (STREET, CITY, STATE, ZIP)

Same as Item 非6 above

10. SUPPLEMENTARY NOTES

DOCUMENT DESCRIBES A COMPUTER PROGRAM; SF-185, FIPS SOFTWARE SUMMARY, IS ATTACHED.

11. ABSTRACT (A 200-WORD OR LESS FACTUAL SUMMARY OF MOST SIGNIFICANT INFORMATION. IF DOCUMENT INCLUDES A SIGNIFICANT BIBLIOGRAPHY OR LITERATURE SURVEY, MENTION IT HERE.)

This publication is the proceedings of the $23 \mathrm{rd}$ Joint Meeting of the U.S.-Japan Panel on Wind and Seismic Effects. The meeting was held at the Public Works Research Institute, Tsukuba, Japan, during May 14-17, 1991. The proceedings include the program, list of members, panel resolutions, task committee reports, and 42 technical papers.

The papers were presented under seven themes: (I) - Wind Engineering, (II) - Earthquake Engineering, (III) - Storm Surge and Tsunamis, (IV) - Joint Cooperative Research Program, (V) - Performance of Nonstructural Systems, (VI) - International Decade for Natural Disaster Reduction, and (VII) - Summaries of Task Comnittee Workshop Reports (oral presentations on $1 \mathrm{y}$ ).

12. KEY WORDS (6 TO 12 ENTRIES; ALPHABETICAL ORDER; CAPITALIZE ONLY PROPER NAMES; AND SEPARATE KEY WORDS BY SEMICOLONS) accelerograph; bridges; buildings; concrete; design criteria; disasters; disaster reduction; earthquakes; geotechnical engineering; ground failures; lifelines; liquefaction; masonry; repair and retrofit; risk assessment; seismic; soils; standards; storm surge; structural engineering; tsunamis; and wind loads.

13. AVAILABILITY

$\mathrm{X}$ UNLIMITED

FOR OFFICIAL DISTRIBUTION. DO NOT RELEASE TO NATIONAL TECHNICAL INFORMATION SERVICE (NTIS).

$\mathrm{X}$ ORDER FROM SUPERINTENDENT OF DOCUMENTS, U.S. GOVERNMENT PRINTING OFFICE, WASHINGTON, DC 20402.

X ORDER FROM NATIONAL TECHNICAL INFORMATION SERVICE (NTIS), SPRINGFIELD, VA 22161.

14. NUMBER OF PRINTED PAGES 636 





\section{NIST Technical Publications}

\section{Periodical}

Journal of Research of the National Institute of Standards and Technology-Reports NIST research and development in those disciplines of the physical and engineering sciences in which the Institute is active. These include physics, chemistry, engineering, mathematics, and computer sciences.

Papers cover a broad range of subjects, with major emphasis on measurement methodology and the basic technology underlying standardization. Also included from time to time are survey articles on topics closely related to the Institute's technical and scientific programs. Issued six times a year.

\section{Nonperiodicals}

Monographs-Major contributions to the technical literature on various subjects related to the Institute's scientific and technical activities.

Handbooks-Recommended codes of engineering and industrial practice (including safety codes) developed in cooperation with interested industries, professional organizations, and regulatory bodies.

Special Publications - Include proceedings of conferences sponsored by NIST, NIST annual reports, and other special publications appropriate to this grouping such as wall charts, pocket cards, and bibliographies.

Applied Mathematics Series - Mathematical tables, manuals, and studies of special interest to physicists, engineers, chemists, biologists, mathematicians, computer programmers, and others engaged in scientific and technical work.

National Standard Reference Data Series - Provides quantitative data on the physical and chemical properties of materials, compiled from the world's literature and critically evaluated. Developed under a worldwide program coordinated by NIST under the authority of the National Standard Data Act (Public Law 90-396). NOTE: The Journal of Physical and Chemical Reference Data (JPCRD) is published bi-monthly for NIST by the American Chemical Society (ACS) and the American Institute of Physics (AIP). Subscriptions, reprints, and supplements are available from ACS, 1155 Sixteenth St., NW., Washington, DC 20056.

Building Science Series-Disseminates technical information developed at the Institute on building materials, components, systems, and whole structures. The series presents research results, test methods, and performance criteria related to the structural and environmental functions and the durability and safety characteristics of building elements and systems.

Technical Notes-Studies or reports which are complete in themselves but restrictive in their treatment of a subject. Analogous to monographs but not so comprehensive in scope or definitive in treatment of the subject area. Often serve as a vehicle for final reports of work performed at NIST under the sponsorship of other government agencies.

Voluntary Product Standards - Developed under procedures published by the Department of Commerce in Part 10, Title 15, of the Code of Federal Regulations. The standards establish nationally recognized requirements for products, and provide all concerned interests with a basis for common understanding of the characteristics of the products. NIST administers this program as a supplement to the activities of the private sector standardizing organizations.

Consumer Information Series-Practical information, based on NIST research and experience, covering areas of interest to the consumer. Easily understandable language and illustrations provide useful background knowledge for shopping in today's technological marketplace.

Order the above NIST publications from: Superintendent of Documents, Government Printing Office, Washington, DC 20402.

Order the following NIST publications-FIPS and NISTIRs-from the National Technical Information Service, Springfield, VA 22161.

Federal Information Processing Standards Publications (FIPS PUB)-Publications in this series collectively constitute the Federal Information Processing Standards Register. The Register serves as the official source of information in the Federal Government regarding standards issued by NIST pursuant to the Federal Property and Administrative Services Act of 1949 as amended, Public Law 89-306 (79 Stat. 1127), and as implemented by Executive Order 11717 (38 FR 12315, dated May 11, 1973) and Part 6 of Title 15 CFR (Code of Federal Regulations).

NIST Interagency Reports (NISTIR) - A special series of interim or final reports on work performed by NIST for outside sponsors (both government and non-government). In general, initial distribution is handled by the sponsor; public distribution is by the National Technical Information Service, Springfield, VA 22161, in paper copy or microfiche form. 
